


\section{Marine Biological Laboratory}




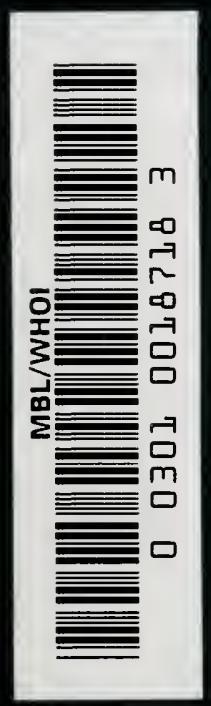



4.7. abot

march 21-1904

St foris- trom a.w.quecley. 



$$
\begin{gathered}
\text { TEXT-BOOK } \\
\text { COMPARATIVE ANATOMY }
\end{gathered}
$$


s. 


\section{TEXT-BOOK}

OF

\section{COMPARATIVE ANATOMY}

BY

DR. ARNOLD LANG

PROFESSOR OF ZOOLOGY IN THE UNIVERSITY OF ZURICH

FORMERLY RITTER PROFESSOR OF PHYLOGENY IN THE UNIVERSITY OF JENA

WIтн

PREFACE TO THE ENGLISH TRANSLATION BY

PROFESSOR DR. ERNST HAECKEL, F.R.S.

DIRECTOR OF THE ZOOLOGICAL IXSTITUTE IN JEXA

TRANSLATED INTO ENGLISH BY

HENRY M. BERNARD, M.A. CaNtab.

AND

MATILDA BERNARD

PART I.

\section{站ondan}

MACMILLAN AND CO.

A ND NEW YOR K

1891 



\section{TRANSLATORS' PREFACE}

Tuis translation of the first volume of Professor Lang's Lehrbuch der Vergleichende Anatomie may be considered as a second edition of the original work. Professor Lang kindly placed at our disposal his notes, collected for the purposes of emendation and expansion, and they have been duly incorporated in the text.

We did not think it necessary to increase the size of the book by the addition of footnotes, either for the addition of new material where it seemed to us that the account might with advantage be fuller, or for calling attention to the opinions of other writers when these did not happen to agree with that expressed in the text. In one case a recent discovery (that of Jawarovski of antennæ in the embryo of Trochosa) lent such sudden and unexpected support to the morphology of the Arachnoidea set forth in the text that attention was called to it in a footnote.

In carrying out our work as translators we have kept as close to the original as the requirements of our own language would allow. How far we have sncceeded must be decided by those who know by experience the difficulty of breaking down the long and weighty German sentences, and of rearranging their contents into readable English. We have endeavoured to steer a middle course between the too free use of periphrases which suits the German style, and the use of single technical terms which better suits the more concise English sentence. The former style has, we think, some advantages over the latter, so long as the multiplicity of words does not obscure the meaning. There can be no doubt that it appeals more directly to the understanding. The object of such a text-book as this is to 
enable an ordinarily intelligent reader to obtain a clear grasp of the facts and of their relation to one another; a knowledge of the technical terms is of secondary importance, and is easily acquired.

We trust that this translation of the work of our friend and (in the case of one of us) former teacher, Professor Lang, will prove as useful to earnest students of biology in the English-speaking world as it has proved to ourselves.

H. \& M. B.

JENA, 1891. 


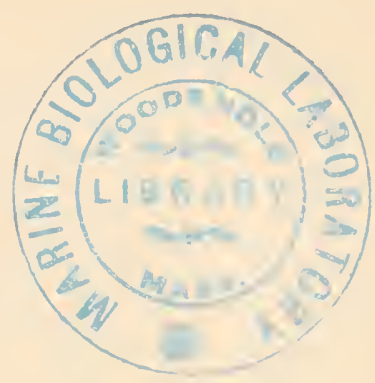

\section{PREFACE BY PROFESSOR ERNST HAECKEL}

THE morphology of the animal borly, which is the subject of the following excellent text-book, has been, during the last forty years, i.e. since the commencement of my academic career, the favourite object of my scientific labours. During these four decades no other sciencè has undergone such profound and striking transformation.

In the years 1852-1856, when I attended in Berlin and Würzburg the masterly anatomical and zoological lectures of Johannes Müller, Albert Kölliker, and Franz Leydig, the study of comparative anatomy and of comparative histology lad been brought into great prominence through Mïller's classical researches in the former, and Leydig's in the latter field.

Oscar Schmidt's text-book of comparative anatomy which resulted from the transcription of Johannes Müller's summer lectures, and passed through eight editions, gives evidence of the stage then reached by that science. Upon this work the present text-book of Professor Arnold Lang is founded, as its ninth edition; the present state and needs of the science, however, compelled the new editor to rewrite the whole book on a much larger scale.

Johannes Müller, the great master in the domains of comparative anatomy and physiology, died in 1858, after having held sway as the leader in these sciences for more than quarter of a century. This very year 1858 saw the simultaneous publication by Charles Darwin and Alfred Wallace of their preliminary sketches of the Theory of Selection. The year after appeared the Origin of Species, which at one stroke ushered in, by means of this theory, a new epoch for the biological sciences. 
The theory of the mutual action and reaction of inheritance and adaptation in the struggle for existence clearly explained the forces at work in the production of biological phenomena. The facts themselves had already been set out in their wonderful array, and comparative anatomy had even arranged them with profound philosophical judgment, but no mechanical explanation of them was forthcoming.

Thomas Huxley in England, and Carl Gegenbaur in Germany, by means of their well-known text-books of comparative anatomy, were the first to succeed in revealing in detail the important transformation which this mechanical explanation of morphological phenomena, by means of the new theory of descent, had brought about in the biological sciences.

It was my happiness during the first twelve years of my occupancy of a University chair in Jena, i.e. from 1861 to 1873 , to have Gegenbaur for my colleague and friend. My own attempts to give the theory of descent its widest application in those sciences which are comprised under the term biology owe much to this stimulating intercourse, and are embodied in my works: Die Generelle Morphologie (1866), Die Natürliche Schöpfungsgeschichte (1868, Sth ed. 1889), and Die Anthropogenie (1874, 4th ed. 1891).

Oscar Schmidt's and Gegenbaur's text-books and my above-named works all issued from the University in the small Thuringian town of Jena, and from the same source has now appeared this text-book of Professor Arnold Lang, formerly my distinguished pupil, and afterwards and till quite recently my helpful colleague. Professor Lang has here successfully carried out the very difficult task of selecting the most important results from the bewildering mass of new material afforded by the extensive researches of the last decades, and of combining them with great judgment. Besides this he has, more than any former writer, utilised the comparative history of development in explaining the structure of the animal body, and has endeavoured always to give the phylogenetic significance of ontogenetic facts. Lastly, he has, by the clear systematic reviews of the various classes and orders which precede the anatomical account of each race, further facilitated the phylogenetic comprehension of complicated morphological problems, his 
wisely chosen and carefully executed illustrations assisting materially in this result.

It is therefore with great pleasure that I commend this book to the English student, in accordance with the wish expressed by my friend Professor Lang and his translators Mr. and Mrs. Bernard, and in the hope that the English translation will promote to as great an extent as the German original the wider study and better comprehension of animal morphology, and will attract new students to this noble science.

\section{ERNST HAECKEL.}

JENA, 1891.

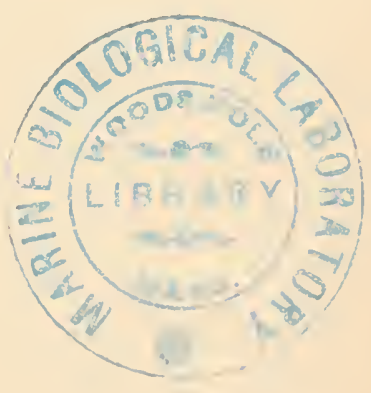





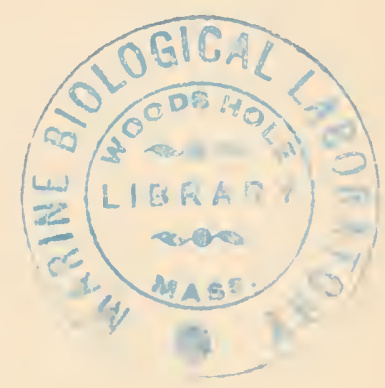

\section{AUTHOR'S PREFACE TO PART ${ }^{1}$}

WHEN requested by the publishers to undertake a new edition of Dr. Oscar Schmidt's Text-book of Comparative Anatomy, I found that this could only be done in one of two ways. Either the revision must be limited to trivial alterations, and to a different choice and a greater number of illustrations, or the book must be entirely re-written. I chose the latter course, which the great advance made in zoological research seemed to render unavoidable. The result is the Text-booti of Comparative Anatomy, the first part of which I now publish.

In compiling the book I have endeavoured to do full justice to the numerous important results of the research of the last decades. I have been less anxious to supply a complete and detailed compendium of Comparative Anatomy than to emphasise those points which it seems to me are deserving of special attention. The present work in many respects exceeds the limits till now usually assigned to text-books of Comparative Anatomy. It contains, separated as far as possible from the portion devoted to the main subject, the elements of Comparative Embryology, which will perhaps not be unwelcome to many students. Following Oscar Schmidt's example, I have prefaced the Comparative Anatomy of the different animal races by short systematic reviews, which may be of use to the student of systematic zoology. The book had also to contain what was necesary for the zoological education of the medical student.

All these parts, not necessarily belonging to the domain of Comparative Anatomy, and also many theoretical discussions, are distinguished from the rest by smaller print.

1 The first part consisted of the first four chapters of this volume. 
I have taken my own course as regards the arrangement and method of treating the material. I must naturally leave it to my fellow-zoologists to decide how far I have succeeded.

I have given special care to the illustration of the book. It contains a large number of illustrations now for the first time accessible to the majority of students; these I have, for the most part, myself adapted to the requirements of the text. I have to thank the practised hand of my pupil, the young scientific artist, Mr. Sokolofsky of Hamburg, for some particularly good illustrations.

I owe my best thanks to my honoured publisher, Mr. Gustav Fischer, for his obliging courtesy.

JENA, 1888. 


\title{
CONTENTS
}

\author{
CHAPTER I
}

THE CELL

Introduction

\section{PROTOZOA}

Systematic Revicw

1. Protoplasm

2. ADAptations for Locomotion

3. Membraxes, Shells, Skeletal Formations

4. Adaptations for Ingestion of Food . . . . . 16

5. Adaptations for Excretiox . . . . . . 17

6. Trichocysts . . . . . . . . . . 17

7. Stigmata (red eye-spots) . . . . . . . 18

S. Nuclei . . . . . . . . . . . 18

9. Reproduction . . . . . . . . . . . . . . . . 18

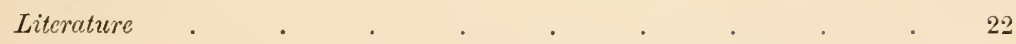

Egg Cells, Sperir Cells, Fertilisation, Sexual Reproduction of the

Metazon . . . . . . . . . . 23

The Aximal EgG

The EGG YolK . . . . . . . . . . . 26

1. Trpes of Telolecithal EgGs . . . . . 27

2. Types of Centrolecithal Eggs . . . $2 S$

The EGg Exvelopes . . . . . . . . . . 28

Male Reproductive Cells, or Spermatozoa . . . . 30

Maturation of the EGg . . . . . . . . . . . 31

Fertilisation $\quad$. $\quad$. . . . . . . 32

Literature . . . . . . . . . . 34

Tissue Cells and Cell Tissue . . . . . . . . . . 34

1. Epithelial Tissue . . . . . . . . 36 
2. Connective Tissue

3. Neuro-muscula and Muscle Tissue . . . . 46

4. Nerive Tissue . . . . . . . . . 50

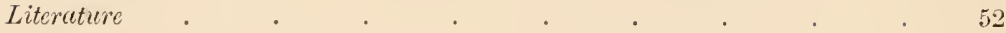

\section{CHAPTER II}

METAZOA

INTRODUCTION

\section{Zoophyta or Colenterata}

Systematic Review

\section{Gastræadæ}

Systematic Revicu

Literature .

Porifera

Systematic Review

Literature

.

\section{Cnidaria}

Systematic Review

1. General .

2. The Body Epitheliun .

3. The Gastro-canal System

4. Musculature . $\quad$. $\quad$. . . . . . . 86

5. Tentacles of the Cxidaria, Margixal Lobes of the Scypiomeduse: 90

6. The Neryous System . . . . . . . . 92

7. The Sensoliy Orgaxs . . . . . . . . . . 94

8. Suppoltixg Organs, Protective Organs, Skeleton . . $\quad 97$

9. Funnel Cavities (Septal Fumnels); Subgenital Cavities, Subgenital Chamber . . . . . . . . . . . . 101

10. The Sexual Orgaxis . . . . . . . . . 101

11. The Stratification of the Cnidaria Body . . . . 103

12. Rernoduction . . . . . . . . . 104

13. Organisation of the Siphonophora . . . . . 108

14. Life-history of the Ciidaria, Alternation of Generations • 115

Literature . . . . . . . . . 117

The fundamental law of Biogenesis-Egg segmentation and the development of the two primary germinal layers of the Metazoa (gastrulation)-The ontogeny of the Cnidaria . . . . . . . . 118

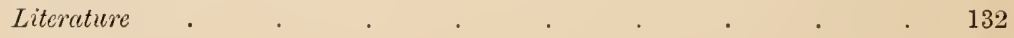




\section{CHAPTER III}

\section{PLATODES}

Systematic Review

1. Geveral Remaris

2. Tine Bony Fori .

3. The Outei: Body Epitheliun

4. The Gastro-caxal System

5. Supportixg Orgass, Passive Orgaxs of Locomotion

6. The Musculature

7. Orgaxs of Adhesion

8. The Nervous Srstem

9. The Sexsory Orgaxs

10. The Body Parexchym.

11. The Excretory or Water-yascular Systea .

12. The Sexula Organs

13. Asexual Reproduction and its Origin-The Organisation of the Cestoda .

14. Ostogent of the Polyclad . . . . . . . 167

15. The Life-history of the Trematoda . . . . . 168

16. The Life-histori of the Cestod . . . . . . . . 171

The Influexce of Parasitisir ox the Structure axd Developmext of

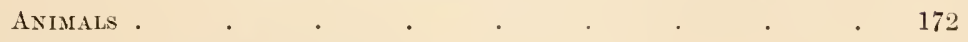

Stromlation and Segmentation . . . . . . . . 175

Literature . . . . . . . . . . . 176

\section{CHAPTER IV}

\section{VERMES}

Systematic Review

1. Form of Body and Outer Organisation

2. The Ixtegumext

3. The Dermo-muscular Tube

4. The Proboscis of the Nemeitina and ACanthocephala • • 197

5. The Intestinal Canal . . . . . . 200
A. The Fore-gut
B. THE MID-GUT
C. The Hind-gut axd the Axus 
6. The Body Cavity, the Musculature which passes traxsversely

7. The Nervous Srsten . . . . . . . 215

8. Sexsory Organs. . . . . . . . . 228

A. Organs of Touch . . . . . . . . 228

B. Eyes . . . . . . . . . . 229

C. Olfactory Organs (Ciliated Organs) . . . . 231

D. Organs of TAste (Cup-shaped Organs) . . . . 233

E. Lateral Organs . . . . . . . . . 233

F. Auditory Organs . . . . . . . . . 234

G. The Lateral Eyes of Polyophthalmus . . . 234

9. Excretory Organs-NePhridi . . . . . . 235

10. Respiratory Oigans . . . . . . . . . 246

11. Blood-vascular System . . . . . 248

12. Genital Organs. . . . . . . . 254

13. Parthenogenesis . . $\quad$. . . . . 266

14. Asexual Reproduction by Gemition and Fission . • . 266

15. Stock Formation . . . . . . 267

16. ONTOGENy OF THE Worms . . . . . . . . 268

Literature . . . . . . . . . 283

\section{CHAPTER V}

\section{ARTHROPODA-ARTICULATA}

First Division-Crustacea

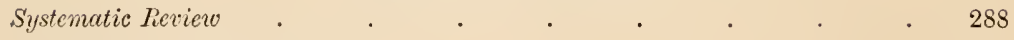

1. Outer Organisation . . . . . . . . 300

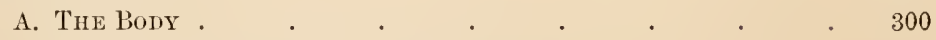

B. The Extremties . . . . . . $\quad$. 307

C. The Respiratory Ohgaxs-Gills . . . . 324

2. The INtegument $\quad$. . . . . . . 330

3. The Musculature . . . . . . . . . 331

4. The Exteric Canal . . . . . . . . . 336

A. The Fore-gut

B. The Mid-gut . . . . . . . . 338

C. The Hind-gut . $\quad$. $\quad$. $\quad$. 341

5. The Nelivous Ststemi . . . . . . . . . 342

6. The Sensory Organs . . . . . . . . . 351

A. Eres . . . . . . . . . . . . 351

B. Other Sensory Organs . . . . . . . 355 
7. The Blood-vascular System axd the Body Cavity . . . 358

8. Excretony Orgaxs (Antennal Glands, Shell Glands) . . . 368

9. The Coxpectire Tissue. . . . . . . 370

10. The Sexual Organs . . . . . . . 370

11. Sexual Dimorphisis . . . . . . . . . 376

12. Hermaphroditish in the Crustacea . . . . 381

13. Parthenogenesis-Cyclic Reproduction . . . . 382

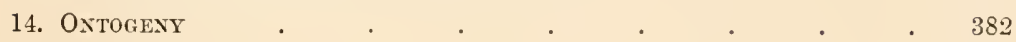

15. Phylogeny

Literature . $\quad . \quad$. $\quad$. $\quad . \quad$. . 411

1. Trilobites . . . . . . . . . 414

2. Gigantostraca . . . . . . . . . 415

3. Hemiaspidæ . . . . . . . . 416

4. Xiphosura . $\quad$. . . . . . . . 417

Literature $\quad$. $\quad$. $\quad$. $\quad$. $\quad$. $\quad$. 421

Second Appexdage to the Crivtacea

Pantapoda

Literature

422

425

\section{CHAPTER VI}

SECOND DIVISION OF THE ARTHROPODA

\section{Tracheata}

Class I. Protracheata

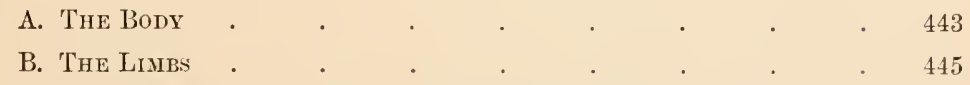

2. The Integument And Glands . . . . . . 458

3. The Musculature . . . . . . . 460

4. The Exteric Canal . . . . . . . . 460

5. The Neryous System . . . . . . . . 464

6. The Sensory Organs . . . . . . . . . . 469
A. Eres .
469
B. Auditory Organs . . . . . . . . . . 471
C. Olfactory and Gustatory Orgaxs . . . . 474 
7. The Ciriculatory Systen

8. Fat Bonies-Luminous Bonies

9. The Respilatory Orgaxs

10. Sound-producing Apparatus .

11. Sexual Organs .

12. Dimorphism-Polymorphism .

13. Develormext AND Life-history

14. PhyLog ENY

Class III. Arachnoidea sive Chelicerota

Systematie Rieview

1. Outer Organisation

A. The Body

B. The Extremities

2. The Nervous Systen

3. The Eyes.

4. Glands opening on the Outer Integunent .

5. The Intestinal Canal .

6. The Blood-vascular System

7. The Respiratory Organs

8. The Sexual Organs

9. Ontogeny

10. Phylogeny

Literature

APpendage to the Arthropoda

\section{Tardigrada}




\section{CHAP'TER I}

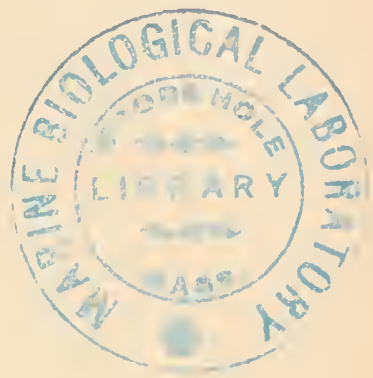

THE CELL

Unicellular animals-The cell as the starting-point in the development of the higher animals (egg and sperm cells) - The cells which compose the bodies of those animals (tissue cells and cell tissue).

\section{INTRODUCTION.}

The starting-point of all organic life and of all organic structure is the cell. The simplest organisms, the lowest animals, are eells. Every higher animal begins individual existence as a cell, and every higher organism appears to be composed of cells which have arisen by multiplication from one cell.

The cell is an organie individual of the first order.

In all cases except that of the lowest organisms the descendants of one cell unite to form communities or states, which then rank as individuals of a higher order.

Every higher organism, every bird, every fish, and so on, is such a cell community. In such a community, the closely united cells share in the common work. Some undertake one function, some another, for which they are specially adapted.

Every cell consists of two essential parts: (1) the Protoplasm, and $(2)$ the Nucleus. The latter may be considered as a special differentiation (specially developed portion) of the protoplasm. Chenically considered protoplasm is a carbon compound as yet not fully understood : it is related to albumen, and is, in life, a stable combination, though subject to variation within very narrow limits. It is viscid and capable of swelling. The nucleus lies within the protoplasm as a chemically and physically differentiated part of it. It is an essential portion of the cell, in whose multiplication it plays an important part. According to some observers, if the nucleus is remored from a cell the latter perishes. If, on the other hand, a nucleus is introduced into an unnucleated piece of protoplasm, certain characteristic phenomena of life otherwise absent appear in it.

VOL. I. 
There are very simple creatures, small masses of protoplasm, in which no nucleus has been found. Should the absence of nuclei in these creatures be established they would rank lower in the scale than cells. To such organisms the name "Cytods" is applied, and Haeckel has united them, as the simplest of all organisms, under the group of Monera.

A frequent though not necessary portion of the cell is the cell integument or cell membrane, a product of secretion, serving for protection or support. Such a membrane can also arise by the hardening and modification of the peripheral layers of the protoplasm itself.

A single cell (a unicellular organism, an egg cell) is in itself from the first capable of all those activities and functions which are contained in the conception of Life. These phenomena of life, though they may not as yet be physically and chemically explained, are certainly not to be referred to the working of any special vital foree peculiar to organisms. There is also no special fundamental substance, no life substance, which can be found in organisms, and with which a special vital force is connected. We have to do here with the same forces and the same substances that we meet with elsewhere in nature.

The life of the cell shows itself in the simplest cases in-

1. Motion.-Protoplasm is contractile. The finest visible portions can change their relative positions. The cell can change its form and its position in space.

2. Irpitability.-The cell responds to external stimuli by such movements.

3. Metabolism.-By means of its life-activity some of the cell substance is used up, decomposed. What has become useless is excreted (excretion). By means of the ingestion of food foreign substances are introduced. These are digestible if, when assimilated by chemical action, they can be changed into ingredients of protoplasm (digestion, assimilation). If, owing to their chemical properties, such a conversion is impossible, they are indigestible, and are expelled out of the body.

4. Growth.-By nourishment more protoplasm can be produced than was formerly present. The cell in consequence increases in sizeit grows.

5. Reproduction. - It may be assumed that the size of an individual cell is limited. If it exceeds these limits of individual size it divides into two cells (reproduction by means of division). Each of the two portions has the same physical and chemical properties as the mother cell (simplest form of inheritanee). The daughter cell by growth attains the size of the mother cell.

As the cell is the starting point both in the animal and in the vegetable kingdoms, it can easily be understood that no sharp line of demarcation between the lower forms in these two kingloms can be establisherl. Haeckel has therefore set up an intermediate kingdom, that of the 


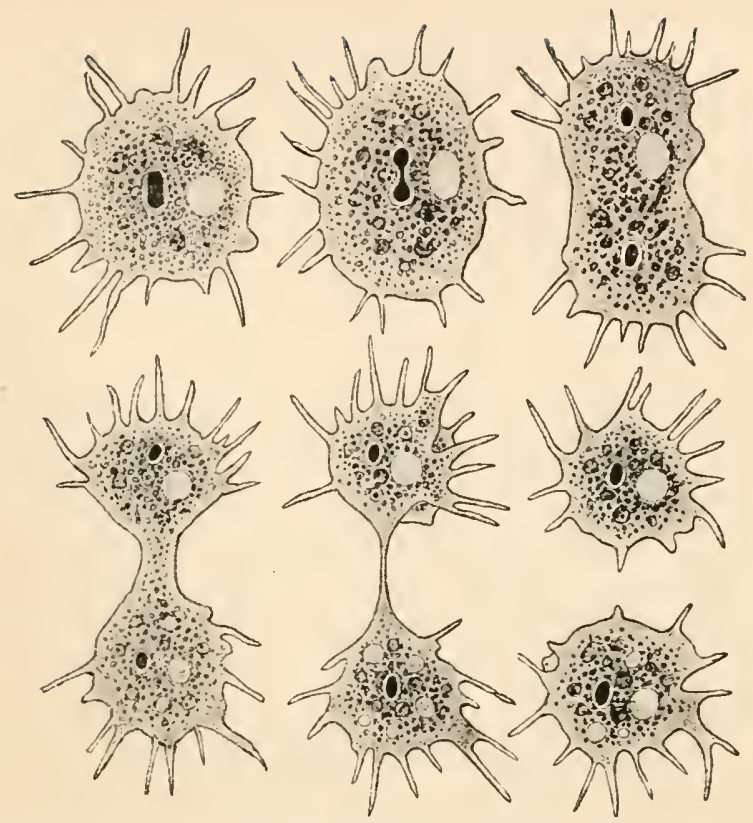

Fic. 1.-Amœba polypodia in the successive stages of division. The light spot is the contractile vacuole, the dark the nucleus (after F. E. Schulze).

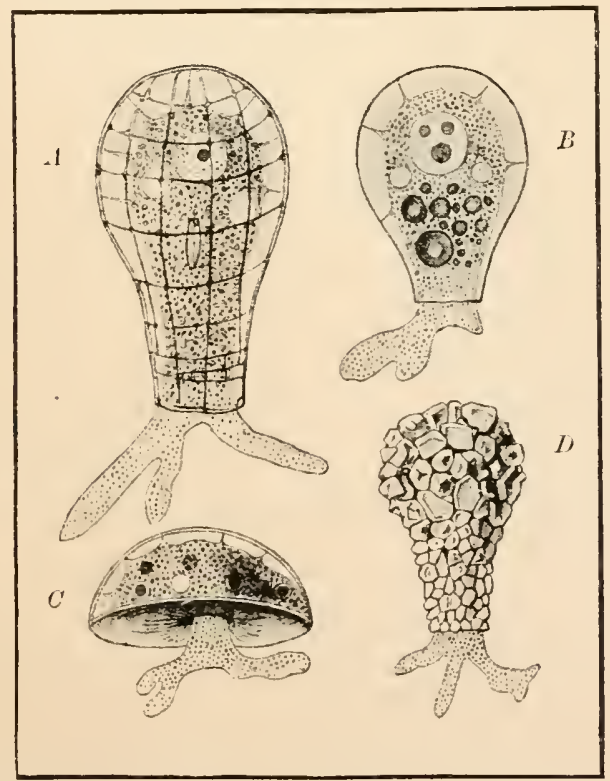

FIf, 2,-A, Quadrula symmetrica, after F. E. Schulze. B, Hyalosphenia lata, after F. E. Schulze. C, Arcella vulgaris, after Hertwig and Lesser. D, Difflugia pyriformis (after Wallich) completed. 
Profistu, consisting of the simplest organisms. But there is also no sharp line of demarcation between the Protista on the one side and animals and plants on the other. Some Protista are, chiefly by their method of nutrition, more nearly related to plants, others to animals. The latter are called Protozoa, in contradistinction to all other animals, which are classed as Metazoa.

\section{THE FIRST RACE OR PHYLUM OF THE ANIMAL KINGDOM.}

\section{PROTOZOA.}

\section{Systematic Review.}

\section{Class I. Monera.}

Simplest organisms. Small masses of protoplasm of varied changing form, in which till now no nuclei have been demonstrated. Locomotion and ingestion of food by means of bhnt (amceboid) or long and fine processes (psendopodia). Reproduction by fission and gemmation. All Mlonera live in water. Protamerer, Myrodiction, Protomyixa.

\section{Class II. Sarcodina.}

Unicellular organisms, with nucleus or nuclei. Locomotion and ingestion of food by means of filose non-vibrating processes of varying length (psendopodia). Reproduction by fission or gemmation.

\section{Sul-Class I. Amœbina.}

Naked or shelled Sarcodina of changing shape. Locomotion and ingestion of food by means of streaming of the body and the formation of processes mostly short and lobate. Contractile racioles generally present. Amobe (Fig. 1), Areolla (Fig. 2, C), Difflugia (Fig. 2, D), Quadrula (Fig. 2, A), Hyalospheniu (Fig. 2, B).

\section{Suh-Class II. Rhizopoda.}

Sarcolina whose protoplasm secretes a very variously-shajed chitinous, generally calcareous, shell, which is at first muiaxial. Locomotion and ingestion of fond hy means of pseudopodia, which freqnently fuse with one another, often in a reticular manner. Contractile vacuoles generally absent.

\section{A. Imperforata.}

Shells of one chamber or more, not perforated by fine pores, bnt having one or two larger apertures throngh which the protoplasm and the pseudopodia pass out. Mitiola (Fig. 3, C), Lituola, Gromia (Fig. 3, A).

\section{B. Perforata.}

Shells of one chamber or more, perforated by fine pores for the passage of the pseuklopodia. Globigerina, Rotalia (Fig. 3, $B$ ). 


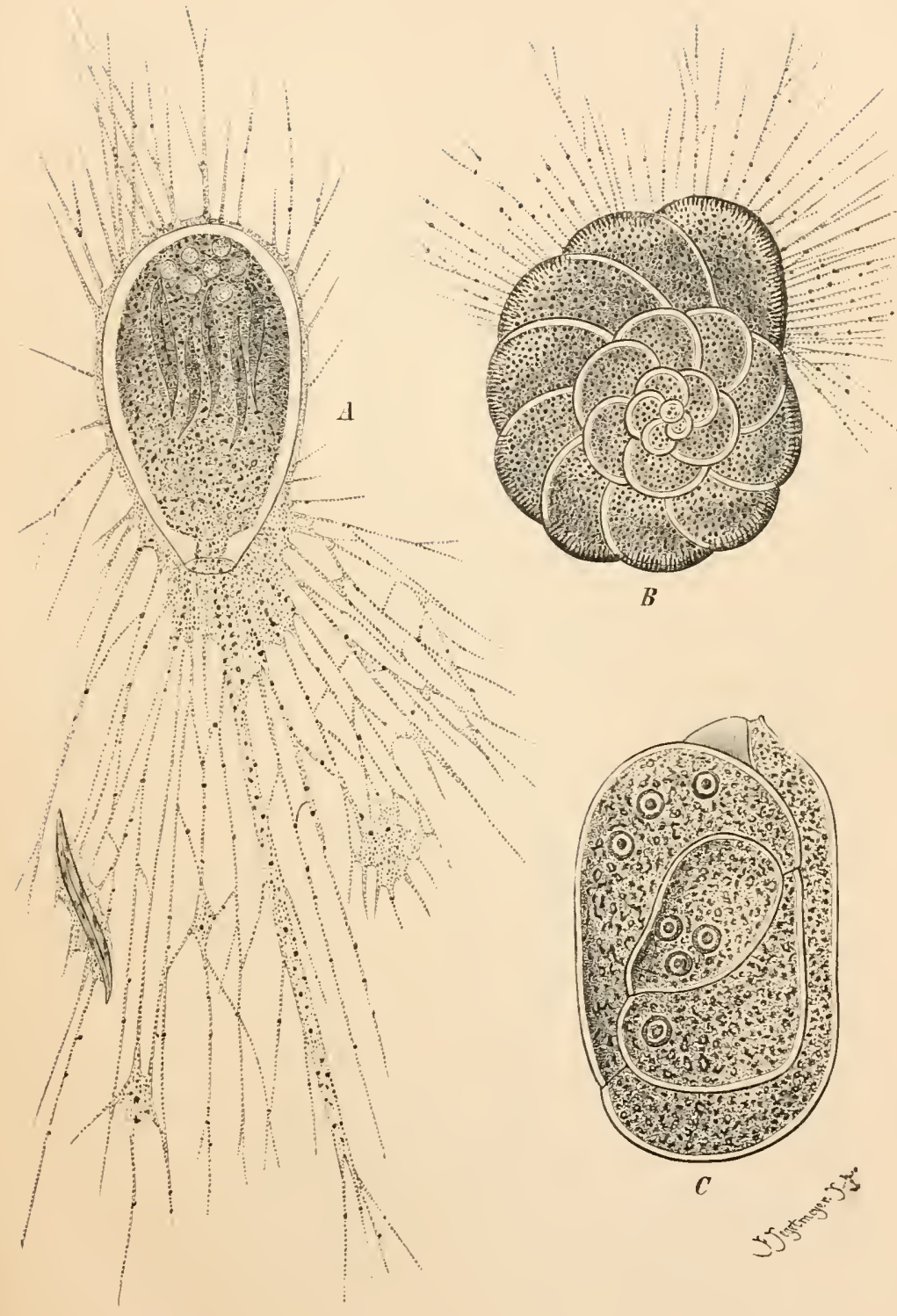

Frg. 3.-A, Gromia oviformis after M. S. Schultze. $\quad B$, Rotalia Freyeri, after M. S. Schultze. C, Miliola (after R. Hertwig) the nuclei in the chambers. 


\section{Sub-Class III. Heliozoa.}

Globular Sarcodina, naked or clothed with a siliceous skeleton, with fine more or less stiff psendopodia radiating on all sides. Contractile vacuoles generally

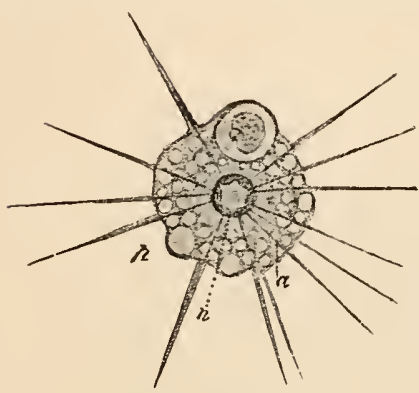

Fig. 4.-Actinophrys sol, after Grenacher. $p$, Pseudopodia ; $n$, nucleus ; $a$, axial filaments of the peudopodia. present in varying numbers. Actinophrys (Fig. 4), Actinosphorium, Acanthocystis, Clathrulina.

\section{Sub-Class IV. Radiolaria.}

Body dirided by an originally splherical or egg-shaped capsular membrane into an outer, and an inner, nucleated portion (outer and inner calsules). The outer capsule consists of protoplasm (without nucleus) and of a gelatinons envelope (calymua). The protoplasm forms a layer round the inner capsule and a network ronud the calymna, these two being connected by means of protoplasmic threads. Fine flexible pseudopodia radiate in all directions from the surface of the calymua. Skeletons of extraordinarily various shapes, of silica or of chitin-like organic substance (acanthin), are seldom wanting. The extra- and intracapsular frotoplasm are connected throngh various openings in the cell-membrane.

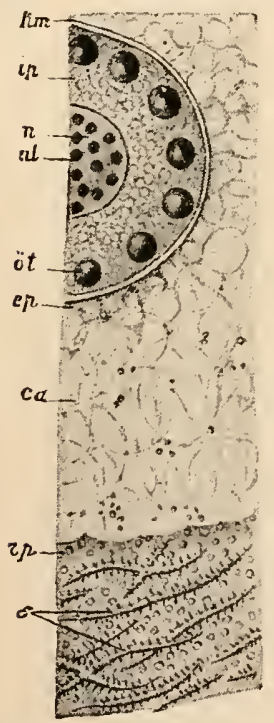

Fig. 5.-Thalassoplancta brevispicula, part of a section, aftcr Haeckel. $\mathrm{km}$, Capsular membrane ; ip, intra-capsular; ep, extracapsular protoplasm; $n$, nucleus ; $n l$, nucleoli ; öt, oil-drops; $c c$, alveolar calymm; $r p$, protoplasm on the surface of the calymna : $s$, spicules.
This division of the marine Sarcodina is wonderfully rich in forms and shapes. Without contractile racuoles. Unicellnlar algæe (yellow cells) live symbiotically with the Radiolaria. The family of the Polycyttaria among the Spumellaria is distinguished by the formation of colonies.

\section{A. Porulosa.}

Central capsule spherical, withont a principal aperture, with innumerable fine pores.

I. Spumellaria.-Nnelens central, dividing late in the life of the individual. Skeleton siliceous or wanting, never penetrating into the intra-capsular protoplasm. Thalassicolla, Collozoum, Spharozoum, Thalassoplancta (Fig. 5), Collosphara, Dictyastrum.

II. Acantharia.- Nnclens ecentric, dividing early.

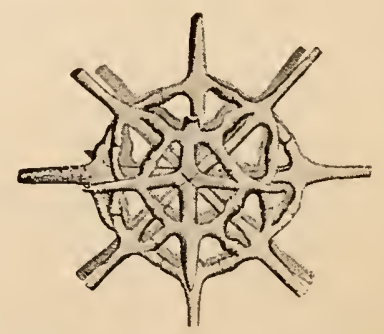

FIG. 6.-Phractaspis prototypus (after Haeckel), skeleton.

Skeleton of acanthin, radiating from the centre of the central capsule. Acanthometra, Phractaspis (Fig. 6). 


\section{B. Osculosa.}

Central capsulc egg-shaped, with a principal aperturc at the basal pole of the chief axis. Skeleton siliceons, always extracapsular. Nuclens dividing late.

111. Nassellaria.-Capsular membrane simple, a porons area at the oral pole of the chief axis. Nassella, Cortina (Fig. 7), Cornutella.

IV. Phæodaria.-Capsular membrane double ; at the oral pole of the principal axis an osculum closed by a radially striped lid, with a central opening produced in the shape of a chimney. A collection of pigment bodies (phrodium) in the calymna. Aulosphere, Aulactinium (Fig. 8), Cannopilus, Challengcria.

\section{Class III. Flagellata (Mastigophora).}

Organisms which are unicellular or united into simple cell colonies; properly standing on the boundary line between the animal and vegetable kingdoms, since some gronps are directly connected morphologically and physiologically with the lowest plants, others, chiefly by their manner of taking nourishment (ingestion of solid food), with animals. Furnished dnring the principal

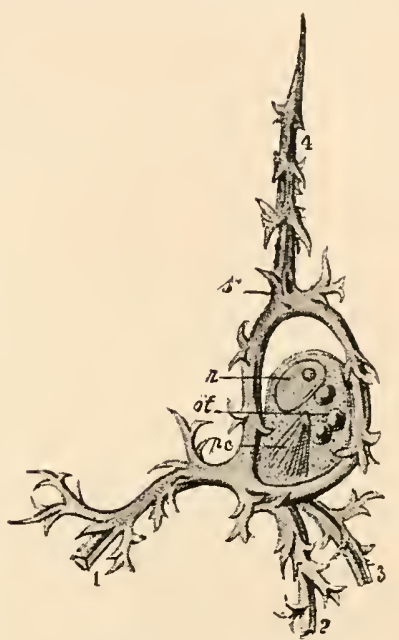

FIG. 7.-Cortina typus (after Haeckel) not quite fully drawn. $s$, Skeletal ring; $1,2,3,4$, principal rays ; $n$, $u$ cleus; öt, oil-drops ; $p c$, podoconus.

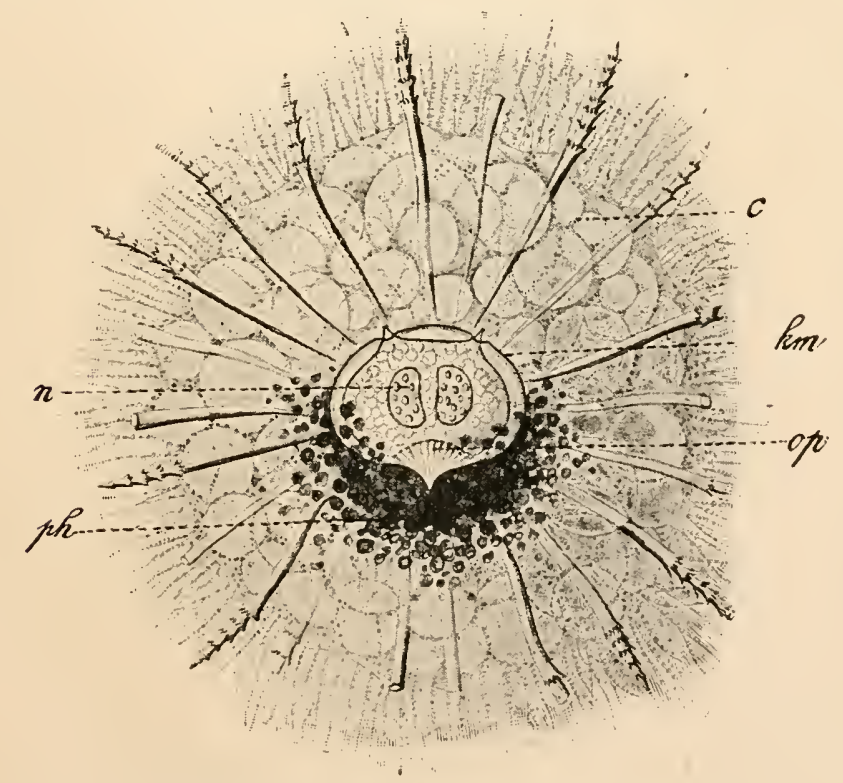

FIG. S.-Aulactinium actinastrum, after Haeckel. $n$, Nucleus ; c, calymua ; lim, capsular nembrane; op, operculum; $p h$, phreodium. 
serving for locomotion, and often also for capturing food. With contractile vacuoles. Multiplication by fission, or formation of sprores, or gemmation, often after previous copulation of the reproducing individuals.

\section{Order 1. Flagellata s. str.}

During active life armed exclusively with flagella (without collar or cilia). Moncs, Euglena, Chilomonas (Fig. 9), Eudorina, Pandorina, Stephanosphera, Volvox (Fig. 21, P. 21).

FIc. A-Chilomonas Paramæcium, after Bütschli. s, Oral aperture ; $c v$, contractile vacuole; $n$, nucleus.

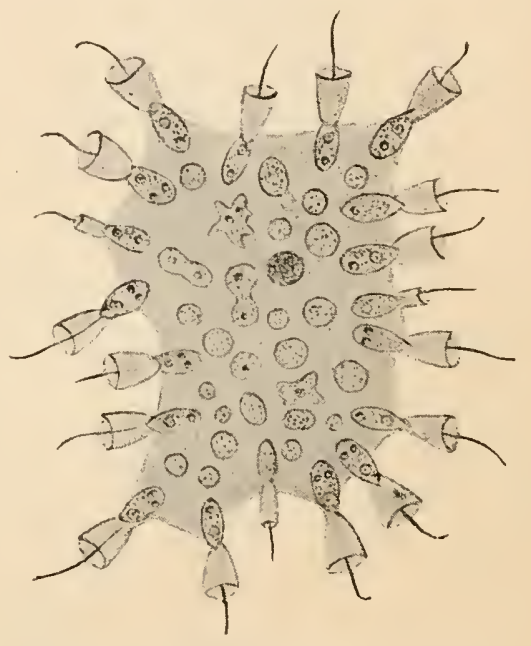

FIG. 10,-Protospongia Haeckelii, after Kent.

\section{Order 2. Choanaflagellata.}

Flagella at their basal portion surrounded by a fumnel-shaped collar. Phatansterium, Salpingocea, Protospongia (Fig. 10).

\section{Order 3. Cystoflagellata.}

The protoplasm shows a reticulated structure similar to that of vegetable cells. Noctiluca (Fig. 11), Leptodiscus.

\section{Order 4. Dinoflagellata (Cilioflagellata).}

Shelled forms ; besides the freely projecting flagellum there is a second, peculiarly placed, in a special groove running across the body, giving the appearance of vibrating cilia which deceived earlier observers. Peridinium, Ceratium (Fig. 12).

\section{Class IV. Gregarina.}

Parasitic Protozoa of elongated form. Invariably one nucleus. Without pseudopodia, without cilia, without contractile vacuoles, without special differentiation of the protoplasm, with outer cell integument. MIultiplication by spore-formation, with lrevious copulation or conjugation. 


\section{Order 1. Monocystidæ.}

Body simple. Monocystis (in the Earthworm), Uiospora (Fig. 13, $B$ ).

\section{Order 2. Polycystidæ.}

Body divided by a partition wall into anterior (protomerit) and posterior (dento-

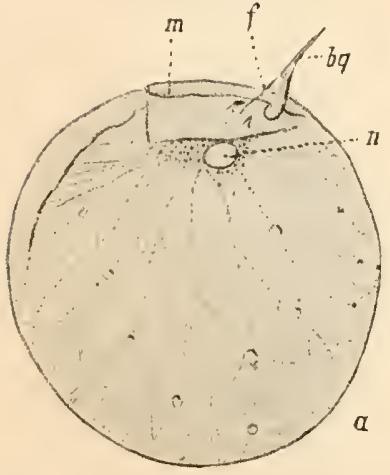

FIG, 11.-Noctiluca Miliaris (after Bütschli), somewhat altered. bg, Band-like flagellum; $f$, flagellum; $m$, oral aperture; $n$, nucleus; $b$ and $c$, spores of Noctiluca.

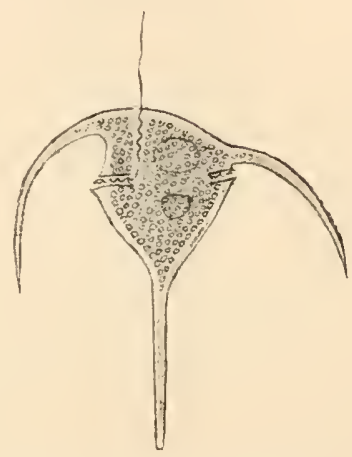

Fif. 12.-Ceratium Tripus (after Bïtschli) somewhat modified.

merit) divisions. The protomerit often again divides, the anterior division (epimerit) being furnished with hooks, etc., for adhesion; this part is lost in time. Nucleus in dentomerit. Actinocephalus, Stylorhynchus (Fig. 13, A), clepsidrina.

\section{Class $V$. Infusoria (Ciliata).}

Unicellular Protozoa, rarely united in simple colonies, with cilia or cilia-like yrocesses for locomotion and alimentation. Generally with contractile vacuoles, oral and anal apertures. With double meleus : a variously formed large macronucleus and a small micronucleus (erroneously called nncleolus). Reproduction by fission, conjugation frequent.

\section{Order 1. Holotricha.}

The whole surface is equally corered with finc cilia, often arranged in rows. Paramecium (Fig. 20, p. 17), Trachetius.

\section{Order 2. Heterotricha.}

Possess, besides the clothing of cilia which spreads equally over the whole surface, a distinctly developed zone of bristle- or stylet-shaped cilia near the mouth. Spirostonum, Stentor (Fig. 15), Fieia, Bolantidium.

\section{Order 3. Hypotricha.}

Dorsal and ventral surfaces sharply distinguished. Ven.

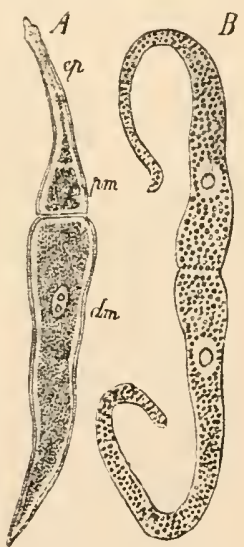

Fig. 13. - $A$, Stylorhynchus longicollis, after Aimé Schneider. $c p$, Epimerit ; pm, protomerit ; $d m$, deutomerit. $B$, Urospora Sænuridis. Conjugation of individuals, after Kölliker. tral surface ciliated. Chilodon, Euplotes, Stylonychia (Fig. 14), Oxytricha, Urostyla. 
CHAP.

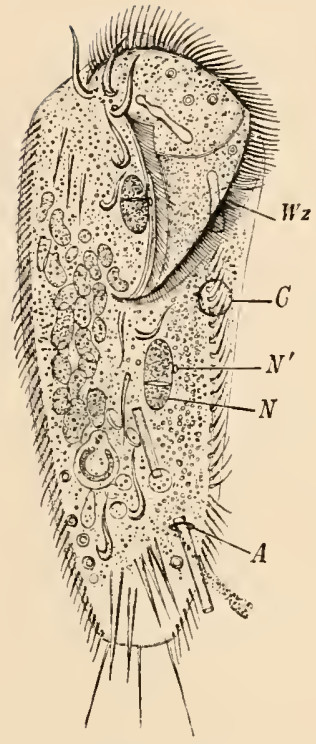

FIG. 14.-Stylonjchia mytilus, after Stein (from Claus's Zoology), seen from the ventral surface. $W z$, Adoral ciliated zone; $C$, contractile vacuole ; $N$, nucleus ; $N^{\prime \prime}$, micronucleus; $A$, anus.

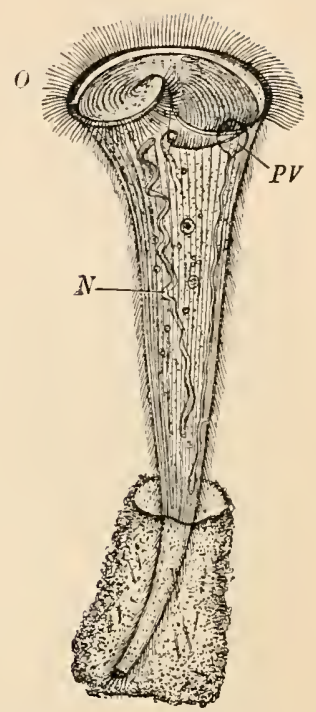

FIG, 15. - Stentor Roeselii, after Stein (Claus's Zoology). O, Oral opening with a:sophagus; $P V$, contractile vacuole $N$, nucleus.

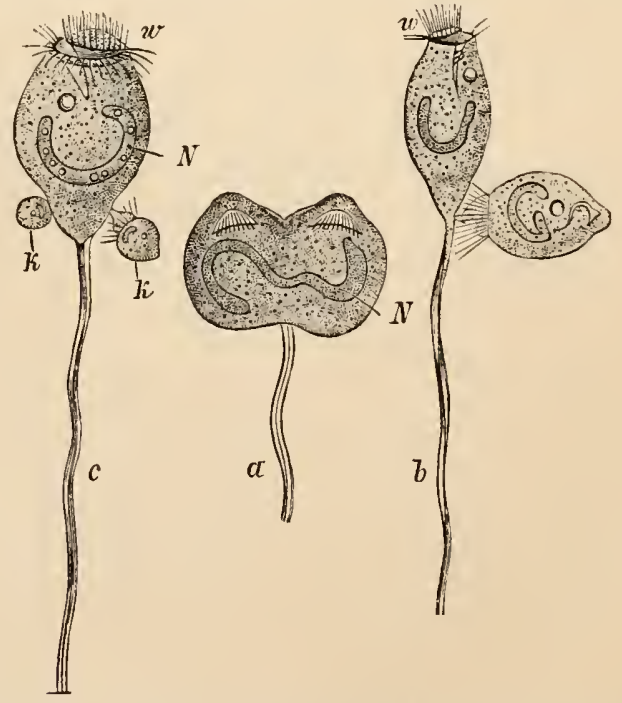

FIG. 16. - Vorticella microstoma, after Stein (from Claus's Text-book of Zoology). $a$, Dividing longitudinally ; $N$, nucleus ; $b$, after complete division one part severs itself after having formed a ring of cilia behine ; $w$, oral ciliary organ ; $c$, vorticellæ in conjugation; $k$, the adhering bud-like indiviluals. 


\section{Order 4. Peritricha.}

Body globular or cylindrical, only partially ciliated, either near the mouth in a spiral, or in a belt. Irorticella (Fig. 16), Carchesium, Epistylis, Trichodina, Strombidium, Tintinnus, Ophrydium.
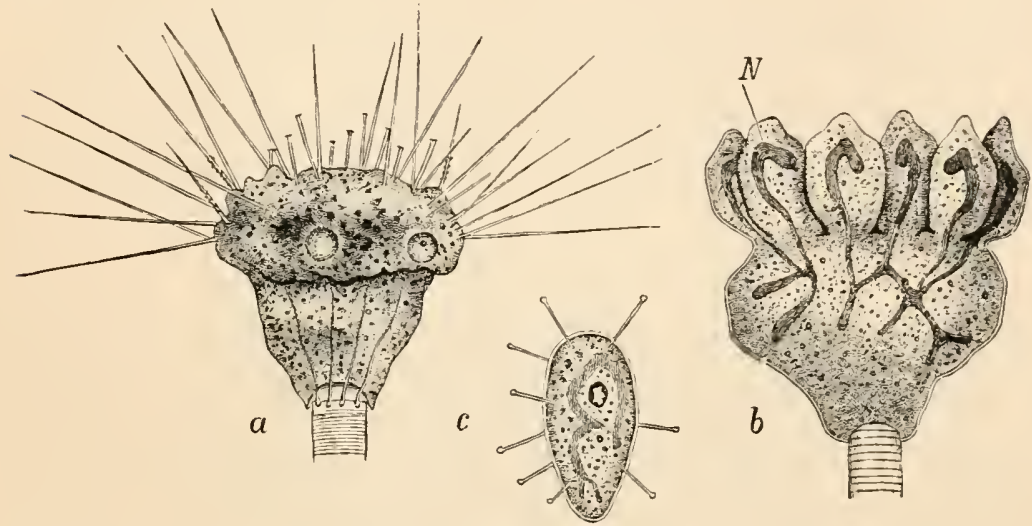

Fig. 17.-Podophrya gemmipara, after R. Hertwig (from Claus's Zoology); $a$, with protruled suctorial tentacles and capturing processes, with two contractile racuoles; $b$, with buds into which processes of the branched nucleus $N$ enter; $c$, nne of the buils broken loose.

\section{Class VI. Suctoria (Acineta).}

Ciliated only in swarm-spore stage. With suetorial tentacles, by means of which they penetrate the bodies of Infusoria (principally) and suck in their protoplasm. Reproduction by gemmation. Acineta, Podophrya (Fig. 17), Dendrocomctes.

\section{Cliss VII. Catallacta.}

Single genus and species: Magosphera planule (Fig. 1S), found swimming freely in the sea on the coast of Norway. A globular colony of pear-shaped cells, the stems of which meet at the centre of the sphere; the outer surface of the cells provided with eilia.

Reproduction: the colony dissolves into single cells, which sink to the bottom, become first ameboid, then encysted, and make a new colony within the capsule by means of sucessive division; this new colony frees itself later from the capsule.

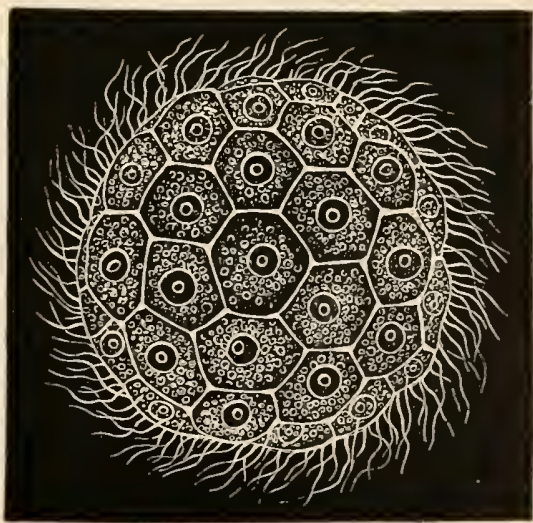

Fic. 1S. - Magosphæra planula, after Haeckel. 
The Protozoa are unicellular organisms, or simple colonies of similar unicellular organisms. The typical character of a unicellular organism often appears disturbed by the presence of more than one mucleus, the original simple nucleus by successive division separating into several or even many nuclei. These divisions of the nucleus are in some cases connected with reproduction, as its first stage, in others the rest of the cell remains altogether unaffected.

Although the Protista are micellular organisms they show a remarkable variety in form, and in some cases a great complexity of

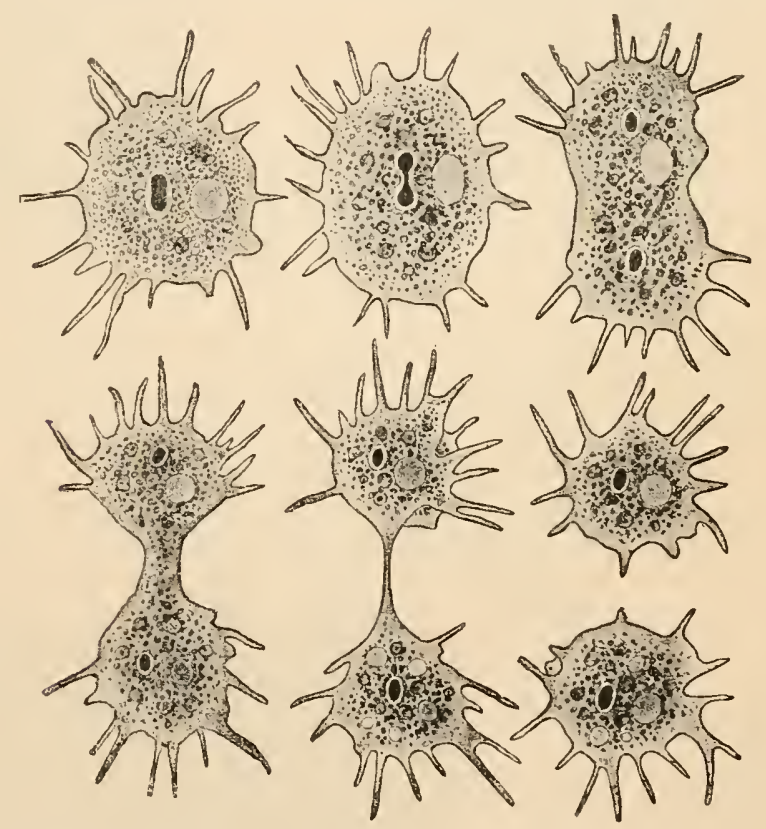

Fra. 19.-Amœba polypodia. In the successive stages of division. The light spot is the contractile vacuole, the dark spot the nucleus (after F. E. Schuize).

structure. Modifications may arise specially adapted to the most varied functions of life; these, however, unlike the modifications in the Metazoa, are always in one and the same cell. Nowhere in the organic world does the eell reach so high a degree of morphological differentiation as in certain Protozoa. In the lower Protozoa, on the other hand, the cell in its simplest form shows itself capable of all essential life processes. An Amcebu (Fig. 19) may consist of a small mass of uniformly granulated protoplasm containing a nucleus. Locomotion is caused by the streaming forward of the protoplasm at some points and the consequent formation of processes of varying 
shape (amoboid). At other points processes already formed are withdrawn. The mass of the plasm flows towards the newly formed processes, and locomotion thus appears as an irregular streaming. In this way small foreign bodies are taken into the Amaba body; if they can be assimilated they are digested, if not they are left behind as the Amala moves forward. The Amata grows as its nourishment increases. It multiplies by the nucleus becoming constricted in the shape of a dumb-bell and finally dividing into two nuclei. After complete division of the nucleus the plasm of the body also becomes constricted and falls into two parts, each with its nucleus. In this way each daughter Amabre is, except in the matter of size, like the mother. Reproduction by fission.

\section{Protoplasm.}

The protoplasm of many Protozoa (of certain Monera, of the Rhizopoda, a few Amelu, and most Flagellata) is tolerably homogeneous, i.e. uniformly granular. In most cases, however, there is a differentiation into an outer and an inner layer; the former firmer, hyaline or more often finely granular, and generally more contractile (cortical Iayer, ectoplasm, ectosare); the latter more liquid and granular (medulla, endoplasm, endosare). In some Heliozou the endosare is the more homogeneous, the ectosare granular. There is generally no sharply defined barrier between the two layers. In the Rudiolaria the protoplasm is divided by a membrane (capsular membrane) into two parts, the extra- and intra-capsular protoplasm, which, however, communicate with one another by means of various perforations of the membrane, and thus do not correspond with the ecto- and endo-plasm above mentioned. In a similar way, in the Rhizopode with calcareous shells, some of the protoplasm surrounds the shell.

The capsular membrane possesses either numerous fine pores (Spumellaria, Acantharia), or one single round aperture (osculum), with a porous cover or operculum (Nasellaria), or, in addition to two or more apertures, one principal aperture elosed by a radially striated cover produced externally in the shape of a tube (Phacodaria).

Both ectoplasm and endoplasm are distinguished, in the case of most Protozoa, by special structural modifications and differentiations. The ectoplasm supplies the adaptations for locomotion and alimentation-pseudopodia, cilia, flagella, suctorial tentacles which also serve as feelers, oral and anal apertures. It frequently forms on its surface a cell integument (cuticle) which may form the substratum of a great variety of shell structures. The ectoplasm generally also supplies the material for the various skeletons met with in many forms. The contractile vacuoles and the stinging capsules (trichocysts), where such are found, almost always lie in it. In some cases it gives rise to special contractile portions (Infusoria, Vorticellu). 
The digestion of solid food takes place in the endoplasm. In it lie the nucleus or nuclei. It often contains non-contractile vacuoles, food vacuoles, products of excretion (crystals), fat drops, oil drops, etc., gas-bubbles, pigment granules. The endoplasm occasionally shows slow streamings (eireulation in Infusoria).

In the Heliozoa, the protoplasm becomes, by means of the appearance of numerous non-contractile vacuoles, spongy, alveolar. In the Cystoflagellata we find a central plasmic portion from which the protoplasm radiates to the surface in a network forming numerous vacuoles. This arrangement of the plasm resembles that in the plant cells. Granular movement can be seen in the cords and strands of the protoplasm; between them lies cell-sap.

In many true Flugellata which take in no solid food but feed in the manner of plants the protoplasm contains small pigment bodies (chlorophyl or similar pigment), organs of assimilation which form amylum. Chlorophyl (proper to the animal body and formed by it) is also to be found in Infusoria (in a Vorticella) in a dissolved form.

Besides these there are unicellular alga, which live symbiotically with many forms of Protozoa in the same way as Algce and Fungi live together to form lichens (yellow cells, and pigment bodies of the phroodium (?), of the Radiolaria, chlorophyl bodies of many Infusoria).

\section{Adaptations for Locomotion.}

The locomotion of the Amceba (and many Monera) by means of blunt processes of varying shape has been described above. In the Phizopoda, Heliozoa, and Rutiolaria, there are long filose processes of the exoplasm (where such a differentiation exists) which radiate from the body on all sides-the so-called pseudopodia. These processes serve, however, more for taking in food and as a hydrostatic apparatus than as organs of active locomotion. There are two principal sorts of pseudopodiamyxopodia and axopodia. The former are not stiff, they are protrusible and retractile, can fuse with neighbouring pseudopodia into a network, and, chiefly in Rhiroporlu, can collect into small masses by flowing together outside the body at the points where they meet with food. Such myxopodia are characteristic of the Phizopode and most Radiolaria. The axopodia, which are found in the Heliozou and in Acantharic among Ruliolariu, are, on the contrary, more or less stiff, and not inclined to reticulate and fuse. In their axes there generally runs a stiff axial filament, a sort of elastic organ of support formed of organic substance. These axial filaments run towards the central point of the body - to the boundary of the endoplasm (Actinospherizm), or to the nucleus near the centre (Actinophrys), or they meet actually in the centre (Acunthuriu). All pseudopodia show more or less swift granular streamings.

In the lihisopoda with calcareous shells, part of the protoplasm spreads itself in a layer over the latter, and from this layer the psseudopodia radiate. In the 
Radiolaria, whose bodies are surrounded by a thick gelatinous enveloje (calymna), filled with racuoles and alveoles, the case is more complicated. The extra-eapsular protoplasm forms a layer on the exterior of the capsular membrane (sarcomatrix) and, further, a network on the surface of the calynna (sarcodyctium). From the latter, which is connected with the former by intra-calymnary protoplasmic cords and strands, the extra-calymnary piseudopodia radiate.

Flagella cannot be sharply distinguished from pseudopodia. They are processes of the exoplasm (where such exists) which, in the Flagellate and in early stages of the life of many other Protiste, appear at special points of the body in small numbers (one or two, rarely mole).

Undulating membranes have also been observed in a few Flagellata. Cilia are characteristic of the Infusoric and the young stage of the Suctoria. These are fine vibratile processes of the ectoplasm, which vary in length, strength, and shape; they are arranged in different characteristic ways in each division, either spreading over the whole body or restricted to certain regions, and specially forming spirals about the mouth, or belts.

In the Cystoflagellata (Noctiluca), besides the ordinary flagellum at the base of the oral aperture, there is a large band-like flagellum which moves slowly; this is a protoplasmic outgrowth of complicated structure (Fig. 11, p. 9, bg).

In the Gregurina special organs of locomotion are wanting; the ectoplasm here appear's peculiarly contractile, just as in the Infusoria, where it is often differentiated into parallel contractile and noncontractile strips (furrows and ribs). Another differentiation of the ectoplasm is the so-called stalk musele of the Trorticella (Fig. 16, p. 10), which in contracting rolls itself up spirally. Here belong also the myophrises of the Acanthometride-filamentous processes which can contract suddenly, but not repeatedly, and which are arranged on the sarcodyctium in a circle round each skeletal spine. It is supposed that they perform hydrostatic functions.

In the Suctoriu ale found variable processes, mostly terminated by a knob, and used as suctorial tubes, which are closely connected with psendopodia. The contents of the body of the penetrated Infusorian or Alg flows through the suctorial tube into the body of the Acinetan.

\section{Membranes, Shells, Skeletal Formations.}

These are extraordinarily numerous. Many Protista, Amoba, and Flagellatu are naked. In simple cases the protoplasm secretes at the surface a chitinous membrane (Gromia), which may be composed of small plates (Arcella). Occasionally small foreign particles are united, by a binding medium supplied by the body, into a sort of case (Difflugiu). A fine cuticle is found in most Infusoria; in some cases this may harden into shells or earapaces. A cuticle (cell-integument) is further found in Gregurine and many Flagellata, and can 
develop into a shell by becoming firmer and severing itself from the protoplasm. The structure of the shell of the Dinoflugellata is complicated ; in this case alone the shell consists of cellulose (the substance of the membrane of plant cells). Gelatinous envelopes are also widely dispersed; they are found in Heliozoa, all Pudiolaria (Calymna) and many Infusoria, especially in the attached forms. In the last case they are often plastered over with small foreign particles. In the marine Rhizopode there arise, by secondary impregnation of an originally chitinous membrane with carbonate of lime, and by a further deposit of the same, variously shaped calcareous shells. These have either one chamber (Monothalamia) or become many-chambered (Polythalamia), with varied arrangement of the chambers. The shells either possess one large aperture for the emission of the protoplasm (Imperforata), or they are perforated by numerous fine pores (Perforatu).

In Heliozoc pieces of skeleton come into existence by the impregnation of an organic substratum with silica; these generally lie loosely on the surface of the soft body. In Clathrulina, however, a globular, much fenestrated, siliceous skeleton is formed.

The skeletal formations of the Radiolaria, which are rarely absent, show a wonderful diversity of structure. They consist of fenestrated spheres, several of which, connected by means of rods, are often contained one within another, or of regularly arranged radial spicules, or of bivalve shells, etc. etc. We have to distinguish two altogether different skeletal forms. One consists of silica and never penetrates into the central capsule; the other consists of an organic substance akin to chitin (acanthin), and is always centrogen, i.e. it radiates from the middle of the central capsule (Acantharia).

In one principal division of the Gregarina (Polycistida) the extenderl body is divided by a partition into an anterior part (protomerit) and a posterior part (deutomerit). Another partition may cut off from the protomerit a front portion serving for adhesion and temporarily provided with hooks, etc. (epimerit). The partitions are, like the cell integument itself, products of the ectoplasm.

In contrast to the envelopes and skeletons above mentioned, we have the cysts or capsules. The formation of capsules and cysts (encystation) takes place in the most varied Protozoa for protection against dessication and putrefaction, after acquisition of food to admit of undisturbed digestion, in hibernation, etc.; very often reproduction (by fission, gemmation, or sporulation) takes place after the formation of, and under the protection of, a cyst.

\section{Adaptations for Ingestion of Food.}

The organs of locomotion (amoboid processes, pseudopodia, suctorial tubules, flagella, cilia, etc.) generally also serve for the seizing and sucking in of food, and for the formation of currents which 
bring it within reach. There are no special points of the body for the taking in of food in the Monera, Sarcodina, Gregarina, Suctoriu, and those Flugellate which feed after the manner of plants. In other Flagellata and in the Infusoriu, there is at one special part of the body (in the Flagellata at the base of the chief flagellum) a depression of the ectoplasm (mouth and œsophagus), through which solid food is passed into the endoplasm. In the Infusoria there are, closely connected with the mouth, cilia specially arranged, in circles or spirals, which whirl into it the minute mutritive particles. A certain part of the body may also temporarily function as mouth. In this case the aperture is only visible at the moment of feeding. An anal aperture or anal spot can also be found for the evacuation of undigested remnants of food.

\section{Adaptations for Excretion.}

The so-called contractile vacuoles may, with doubtful accuracy, be considered as adaptations for excretion, i.e. for removing from the body the useless products of metabolism. These vacuoles are found in most Amoba, Heliozoa, Flugellate (excepting Cystoflugelluta), and Infusoria, but are wanting in the Phizo-

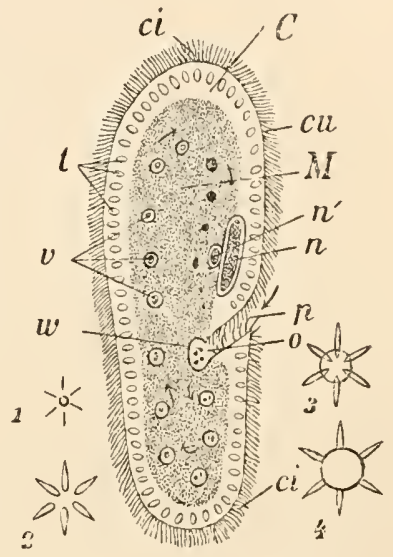

Fig, 20.-Paramecium aurelia. M, Medulla; $C$, cortical layer; $n$, macronucleus ; $n$ ', micronucleus ; $c u$, cuticle; $c i$, cilia ; $t$, trichocysts ; $v$, food racuoles; $p$, lharynx; $o$, cell mouth or cytostome; $w$, water. 1, 2, 3, 4, Form. ation of vacuole (after Ray Lankester). poda, Radiolaria, Gregarina, and Cystoflagellata. They vary greatly in number. Where there is only one it generally has a fixed position. There is no sharp distinction between contractile and non-contractile vacuoles. The first are vacuoles without walls, filled with liquid, which in cases where a differentiation into ecto- and endo-plasm exists generally lie in the former. They gradually expand and then contract more quickly, often suddenly. Before and during contraction they move towards the surface and empty out their contents through an aperture only visible at the moment of evacuation. They again arise as a small drop, or as several drops which unite later. Perhaps they also serve the purpose of keeping up an exchange of water (evacuation of water taken in by the mouth), and thus of respiration.

\section{Trichocysts.}

Small vesicles containing threads, which can be shot out rapidly like the nematocysts of the Colenterata, are sometimes found in the ectoplasm of the Infusoria and in one of the Flagellata (Fig. $20 \mathrm{t}$ ). 


\section{Stigmata (red eye-spots).}

Stigmata are found, generally singly, in many coloured Flagellata. It is highly doubtful if these are organs sensitive to light.

\section{Nuclei.}

These seem to be absent in the Monera. In all the other Protozoa they are found, either singly (many Amoba, some Heliozoa, all Gregarina, and most Flagellata and Infusoria) or in numbers. They lie in the endoplasm-in the Radiolaria in the central capsule, in the Gregarina in the deutomerit-and are either vesicular, with membrane, sap, and one or more nucleoli, occasionally with a sort of nuclear framework, or homogeneous. They vary greatly in shape. The nuclear processes in most Infusoria present complications. We here find a double nucleus, viz. a large macronucleus, and, lying more or less close to this, a small micronucleus (formerly erroneously called nucleolus). The micronucleus plays an important part in conjugation; the macronucleus, on the contrary, during this process falls to pieces and degenerates in a peculiar manner. When conjugation begins, the micronucleus divides twice, i.e. into four parts. Three of these four parts disappear, while the fourth again divides into two nuclei-the migratory nucleus and the stationary nucleus. The most important process during conjugation is the mutual exchange of the migratory nuclei of the two conjugating individuals A and B. The migratory nucleus of $A$ passes over into $B$ and fuses with the stationary nucleus of $B$, while the migratory nucleus of $B$ passes over into $A$ to fuse with the stationary nucleus of $\mathrm{A}$. A new macronucleus and a new micronucleus arise, in the individuals which separate after conjugation, out of the nucleus which results from the fusing of the migratory and stationary nuclei.

The division of the nucleus is either a direct division (constriction, dumb-bell stage, separation into halves), or it resembles the indirect nuclear division found among Metazoa, which will be described later.

\section{Reproduction.}

The phenomena of reproduction among the Protozoa deserve more detailed investigation, as we find included under this head a tolerably complete series of intermediate stages between the simplest reproduction by fission and sexual reproduction.

Reproduction by simple binary fission (cross, longitudinal, and diagonal fission) takes place in nearly all divisions of the Protozoa. It is especially characteristic of the Monera, many Rlizopoda, many Flagellata, and all Infusoria. It is, however, not observed in the Gregarina.

Reproduction by budding or gemmation is, in the simplest cases, 
distinguished from the above in that one part (the bud) is smaller than the other (the mother). The small size of the bud in most cases makes possible the production of numerous buds on the surface of the mother. This sort of reproduction is often found together with reproduction by fission in Rhizopodu, Heliosou, Pudioluria, a few Gregurinu, Noctiluca, and Suctoria.

In many forms reproduction by fission and gemmation are probably preceded by a conjugation (temporary connection or fusing) or copulation (permanent fusing) of two individuals.

In many Protozoa, belonging to the most varied forms, the individuals which are produced by fission or gemmation do not separate entirely from each other, but remain more or less closely comnected, and so form colonies of unicellular organisms.

These colonies are of the greatest importance, as they represent a lower stage of the cell colonies of the Metazoa, and in many cases reproduce in a manner which strongly reminds us of the sexual reproduction of Metazoa and plants (see below).

As an example of reproduction by gemmation we choose the Noctiluca, where it occurs, probably after previous copulation of two individual Noctiluca, side by sile with simple reproduction by fission. The typical process is bricfly as follows. Gemmation oecur's only in such individuals as have, when copulation has ended, lost their organs of locomotion and mouths, and are thus simple globular bodies, on the walls of which the chief mass of protoplasm (central plasm), with the nucleus, is still to be found in its original place. The central plasm at this spot bulges out somewhat, its nucleus divides by a kind of indirect fission, and the prominence at the same time separates into two by a furrow. The division of the protoplasm is, both here and in the following stages, merely superficial, since its deeper part remains undivided. By continuous fission, 4, 8, 16, 32, 64, and up to 512 nuclei arise, and the same number of superficial prominences of protoplasm. Then each prominence with its nucleus separates below the surface also from its neighbours and forms a separate bud, on which a flagellum and a peculiar process are developed; this bud leaves the mother animal as a spore (Fig. 11, b, c, p. 9). The further development of these spores into young Noctiluce has not yet been investigated. The whole process of the formation of buds is very similar to the discoidal furrowing of the meroblastic egg in the Metazoa, of which we shall speak later.

Reproduction by continuous fission and spore-formation is very common among the Protozoa. In the latter case the whole body falls to pieces, or else the greater part of it simultaneously dissolves into a usually very large number of nucleated portions, i.e. spores. Both these methods of reproduction are generally accomplished in resting encysted individuals, and often after previous copulation or conjugation ; this is especially the case with Gregurina and Flagelluta. They may occur together with ordinary reproduction by fission. The spores are generally capable of free movement, occasionally amøeboid, or as swarm spores they are furnished with a flagellum or several flagella (Flagellata, Rialiolaria, some Heliozoa, and Rihizopoda). Occasionally (Gregarina) the spores themselves redivide, and only the portions thus arising grow into adult animals. 


\section{Reproduction of Colony-forming Protozoa.}

Freely swimming and stationary attached colonies alike come into existence by incomplete fission and gemmation. Among the colonial Radiolaria (the Polycyttaria among the Spumellaria) separate colonies can mingle with each other; colonies also can multiply by fission.

The ordinary method of reproduction of colonial Flagellate and liculiolariu is the production of swarm spores furnished with flagella, which takes place by simultaneous, or more often by successive, division of the body into numerous portions.

In the Padioluria the contents of the central capsule alone take part in the formation of spores; and this process is preceded by the early or later division of the originally simple nucleus. In the case of Riadiolaria which do not form colonies, every spore becomes a Radiolarian. In the colonial species, however, two sorts of spores are developed alternately-(1) isospores, representing the usual Pudiolarian spores, and (2) anisospores, of which again there are two kinds, smaller microspores and larger macrospores. The isospores develop direct into young Radiolaria; the anisospores most probably do so only after the copulation of a micro- and a macro-spore. The young licudiolarian, by repeated fission and gemmation (formation of so called extracapsular bodies), produces a colony. The macro- and micro-spores are either formed in one and the same individual, or in different individuals of the colony. We have here in all probability a regular alternation of generations, one of which reproduces by means of isospores, the other by copulating anisospores.

The reproduction of the colony-forming Flagellata is particularly important and interesting. In the simplest cases every individual of the colony falls by successive fission into a certain number of portions which sever themselves from the mother-colony, forming daughter-colonies. In other cases (Pandorina), after a number of generations reproducing themselves as above, a generation arises whose individuals also divide; but the resulting portions (gametes) do not remain united, they separate. These gametes copulate in pairs, the individuals of each pair often differing in size. The product of copulation (zygote), after a resting stage of some duration, again produces a colony by continuous incomplete fission. The reproduction of the Eudorina is distinguished from that of the Pandorina by the formation of two sharply contrasted sorts of gametes, male and female. The sexual generation which produces gametes, and which follows a series of generations reproducing in the usual asexual manner, is either male or female. In the female colony there are certain individuals (ovoid gametes) distinguished by unusual size; in the male the individuals divide into groups (plates) of 32-64 spermoid gametes, each of which has two flagella. The plates sever themselves and swim about freely. If such a structure comes in 
contact with a female colony, it remains attached to it and breaks up into single male gametes. Tolvor (which leads almost directly by its method of reproduction to the higher plants and animals) is closely connected with Eudorina.

In Volvox (Fig. 21) the colony appears on a higher scale of development, as a division of labour takes place among the different individuals. Only some individuals are capable of reproduction ; in the asexual generation these individuals are the parthenogonidia (every parthenogonidium produces, by continuous incomplete fission, a colony which separates from the mother colony); in the sexual generation they are gametes. Unlike the Endorina, Volvox produces, in one and the same colony, male and female gametes. The female gametes are simple individuals of the colony, only distinguished by their greater

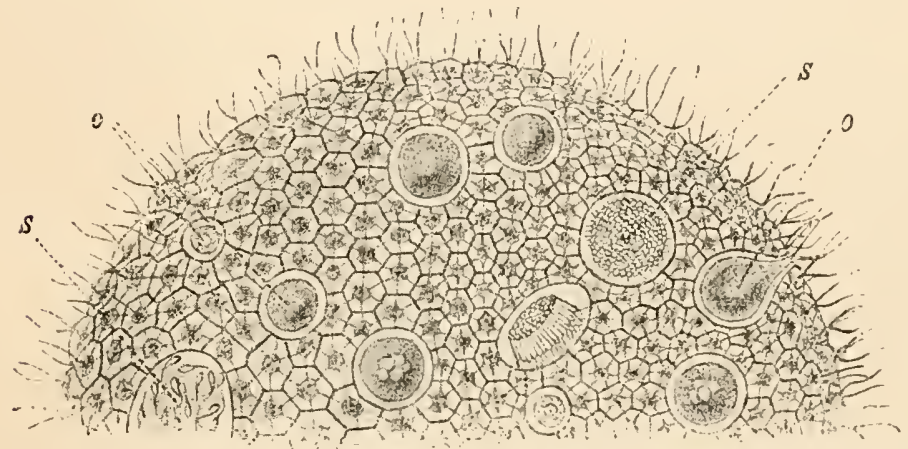

Fig, 21.-Volvox globator.--Sexual, hermaphrodite colony, after Cienkovsky and Bütschli, combined and somewhat diagrammatic. $S$, Male gametes (spermatozoa); 0 , female gametes (eggs).

growth. The male gametes, on the contrary, arise in masses, by the successive fission of certain individuals (cells) of the colony. From one such mother-cell as many as 128 male gametes may proceed. The male gametes separate, move about by means of their flagella, and copulate with the female gametes. By successive division (into 2, 4, 8,16 , and so on) of the stationary zygotes a colony, i.e. a young lolvor, arises.

We have here before us a true alternation of generations, asexually reproducing generations alternating with sexually reproducing generations. The sexual reproduction corresponds with the method of reproduction of the Metazoa and higher plants. The hermaphrodite Volvox (Flagellate colony) corresponds with a very simple hermaphrodite metazoon. The female gametes represent the eggrs, the male gametes the spermatozoa; the copulation of the female and male gametes corresponds with a simple form of fertilisation of the egg by means of spermatozoa. The zygote represents the fertilised egg. The formation of a new Volvox colony by successive fission of the zygote 
answers to the repeated division of the egg-cell, described in the Metazoa as furrowing or segmentation.

In the colonial Infusoria also the copulation of larger with smaller individuals has been observed (Fig. 16, p. 10, c).

\section{Review of the most important Literature.}

\section{General works on Zoology, Comparative Anatomy, Ontogeny, etc.}

G. Cuvier. Leçons d'anatomie eomparée, mubliées par Duméril et Duremoy. 5 rols. Paris, 1799-1805. It. Second edition, 8 vols. Paris, 1835-46.

J. F. Meckel. System der vergleichenden Anatomie. 6 Bände. Halle, 1821-1833.

C. E. von Bär. Ueber Entwickelungsgesehiehte der Thiere. 2 Bände. Kionigsberg, 1828 bis 1837.

J.: Müller. Handbueh der Physiologie des Mensehen. 2 Bde. 4 Aufl. Coblenz, 1844.

R. Leuckart. Ueber die Norphologie und die Vemoandtsehaftsverhälnisse der wirbellosen Thiere. Braunschweig, $184 \mathrm{~s}$.

v. Siebold and Stannius. Handbuch der Zootonnie. Berlin, 1854. (T'ertebrates incomplete.)

F. Leydig. Vom Bane des thierisehen Körpers. I. Band. 1. Hälfte. Tübingen, 1864. (With atlas.)

The same. Lehrbueh der Histologie des Mensehen und der Thiere. Frankfurt, 1857.

C. Vogt. Zoologisehe Bricfe. 2 Bände. 1859.

E. Haeckel. Generelle Morphologie der Organismen. 2 Bde. Berlin, 1866.

The same. Natürliehe Sehöpfungsgesehiehte. New edition, 1890.

The same. Anthropogenie. Leipzig, 1876.

T. H. Huxley. A Manual of the Anatomy of Invertebrated Animals. 1877.

The same. A Hanual of the Anatomy of Vertebrated Animals. 1871.

C. Gegenbaur. Grundzüge der vergleiehenden Anatomie. Leipzig, 1870.

The same. Gmundriss der vergleiehenden Anatomie. Leipzig, 1s78. Translated by F. J. Bell, revised by E. Ray Lankester, as Elements of Comparative Anatomy. London, 1878.

F. M. Balfour. Comparative Embryology. 2 vols. London, 1880-\$1.

C. Claus. Lehrbueh der Zoologie. 3 Auflage. Marburg u. Leipzig, 1885 .

H. Ludwig. J. Leunis Synopsis der Thierkunde. 2 Bände. Hannover, 1883-1886.

C. Vogt $\iota$. E. Jung. Lehrbuch der praltischen vergleichenden Anatomie. I. Band. 1888.

V. Carus. Gesehichte ter Zoologie. Mïnchen, 1872.

Ch. Darwin's Works.

Milne-Edwards. Leçons sur la physiologie ct l'anatomie comparée de l'homme et des animaux.

Bronn's Klassen und Ordnungen des Thierreichs, etc. etc.

\section{Protozoa.}

E. Haeckel. Studien über Moneren und andere Protisten. Leipzig, 1870.

The same. Die Radiolarien. Eine Monographie. Bd. I. II. $u$. III. Berlin, 1862, $1887,1885$.

The same. Repont on the Radiolaria collected by H.M.S. "Challenger." London, 1887.

M. Schulze. Ueber den Organismus der Polythalamien. Leipzig, 1854. 
R. Hertwig. Der Organismus der Radiolarion. Jena, 1879.

Ch. G. Ehrenberg. Die Infusionsthicre als vollkommone Organisnen. Leipzig, 1838.

Claparède et Lachmann. Études sur les Infusoires et les Rhizopodes. Genève, 185s1859.

Fr. Stein. Der Organismus der Infusionsthiere. I.-III. Leipzig, 1559, 1867, 1879.

o. Bütschli. Ueber die Conjugation der Infusorien, in: Studien über die ersten Entwickelungsvorgänge, etc. Frankfurt, 1876.

Saville Kent. A Manucal of the Infusoria. London, 1880-1882.

Dujardin. Histoire naturelle des Infusoires, in: Suites à Buffon. Paris, 1811.

Carpenter. Introduction to the Study of the Foraminifera. London Ray Soc., 1862.

J. Müller. Ueber die Thalassicolen, Polyeystineu und Aeanthonnetren. Abhandl. der Berliner Alademie, 1558.

K. Brandt. Dic koloniebildenden Radiolarien (Sphacrozö̈en) des Golfes von Neapel. Berlin, 1885.

O. Bütschli. "Protozoa," newly edited, in Bronn's Klassen und Ordnungen des Thierreichs. I. Band. Not yet completed.

Balbiani. Various treatises in the Journal de l'Anatomie et de la Physiologic. I. - IV. Various important treatises of Haeckel, Hertwig, Schneider, Engelmann, Maupas, F. E. Schulze, Greef, Bergh, Czienkovsky, Jikeli, ete.

\section{Egg Cells, Sperm Cells, Fertilisation, Sexual Reproduction of the Metazoa.}

Whereas Protozoa are either simple cells or colonies of similat cells, all other animals, or Metazoa, appear as complicated communities, the individual cells of which are no longer similar. Division of labour arises among the cells; every cell (or group of cells) in the community having to fulfil only one special function is constituted in correspondence with this function (polymorphism of the cells of a Metazoan colony). However wonderfully complicated such a cell community may be, it always develops (except in cases of asexual reproduction) by means of the continuous division of one single cell, the fertilised egg. This is the product of the fusing of a female reproductive cell with a male reproductive cell, i.e. it is the result of fertilisation. Reproduction by means of such sexually differentiated reproductive cells is called sexual reproduction. In all forms of Metazoa (with a few not quite certainly established exceptions) sexual reproduction occurs at least at times, and constitutes an essential characteristic by which Metazoa are distinguished from Protozoa. It is true that we found in the latter the beginnings of sexual reproduction. As among the Protozoa a series of phenomena lead up to the sexual reproduction of the Volvox colony, so the latter is directly connected with the simplest form of the sexual reproduction of the Metazoa.

In sexual reproduction we have to bear in mind two distinct points :

1. The fusing of the cells, or more accurately of two cell nuclei, which here takes place-a phenomenon which is anilogous to the processes of copulation and conjugation in the Protozoa. The 
origin and meaning of this phenomenon are not certainly ascertained. Many see in them a strengthening of the product of the fusion, i.e. the young new individual.

2. The different sizes, or the the sexual dimorphism of the fusing reproductive cells. This is to be explained by the principle of the division of labour. The reproductive cells have a double object to fulfil: (1) such a cell must mingle with another (fertilisation); and (2) must, after mingling, form a new organism like that of its parents. To secure the first object free locomotion is useful, so that the reproductive cells may seek each other and meet; and further, in certain circumstances a power of resistance to external influences is needed. To fulfil the second object the cell must be of a considerable size, and contain, if possible, nutritive material which can be used during development. Both these objects cannot be fulfilled by each of the reproductive cells without disadvantage. Here division of labour steps in. Some cells fulfil the first object ; they move about witl great ease; they are resistent, and moreover very small (the smallest cells of the organism). Their smallness has a further advantage; they are produced in greater numbers, and can easily penetrate the second sort of reproductive cell. These are called male reproductive cells, sperm cells, sperm filaments, or spermatozoa.

Other cells fulfil the second object. They are large and often filled with much reserve material (the largest cells of the organism). They substitute size and mass for free locomotion. These are called female reproductive cells, or egg cells.

Male and female reproductive cells are either formed in one and the same metazoan individual (hermaphroditism), or in two different individuals, male and female (gonochorism, separation of the sexes). The latter appears among the Metazoa generally as the rule, the former as the exception. The causes which determined the separation of the sexes are most probably quite similar to those which brought about fertilisation in the animal kingdom. If one remembers that even among hermaphrodite animals a copulation of two individuals often takes place, or adaptations are present which prevent the fertilisation of the eggs of an animal by the spermatozoa of the same individual (self-fertilisation), the recent opinion that all Metazoa were originally sexually separated, and that hermaphroditism has developed secondarily from the male or female condition gains in probability.

The utility of cross-fertilisation places in a new light the utility of a sexual differentiation of the reproductive cells into freely movable spermatozoa and massive eggs. So as still further to secure crossfertilisation we find copulation in very many Metazoa. These animals possess special copulatory organs, by means of which the spermatozoa from the male body are carried into the sexual organ of the female, and thus into the neighbourhood of the egg. 


\section{The Animal Egg.}

The mature egg, capable of fertilisation, is everywhere in the animal kingdom a simple cell, and shows the typical structure of such a cell. It consists of protoplasm, called yolk, and of a nucleus which is named the germinal vesicle in an unfertilised egg. The egg is either naked or surrounded by one or more membranes and envelopes. These are of very different nature according to their origin. They are either secreted by the egg cell itself, and then answer, as real primary yolk or egg integuments, to the membranes of ordinary cells, or they are in various ways supplied by the surrounding tissues of the mother body, and are laid round the egg externally. In this case they may be considered as secondary or accessory egg envelopes. The eggs arise in special organs of the Metazoan body, called ovaria or germaria. These, in the simplest cases, are masses of cells, some of which by stronger growth become egg cells.

The processes of the formation, growth, and ripening of the egg in the animal kingdom are as various as is the structure of the ovary itself. It is especially the necessity for the abundant nourishment of the eggs which determines the most manifold modifications. The eggs are developed either from a mass of protoplasm with nuclei scattered in it, or from an assemblage of similar little cells clearly defined one from the other. In the first case the nuclei, in the second the cells, multiply by fission. After this multiplication has lasted for some time the protoplasm round the nuclei in the first case separates off and gives rise here also to independent cells. All these young cells are young egg germs, and capable of growing and ripening into eggs; but only in the rarest cases do all the cells become eggs-a large number of germ cells have almost always another fate.

The nourishment of the egg, speaking generally, is secured in the following ways. In animals without a blood-vascular system and body cavity the ovaries lie on the wall of the intestine, or of a gastro-vascular system, which proceeds from the main intestine (Coclenteratu, Platodes). In many animals the eggs are developed on the wall of the body cavity and nourished by the body fluids, into which they sooner or later pass and mature while suspended in them (many higher worms). In the case of the greater number of the higher animals the nourishment of the egg is secured by a rich provision of blood-vessels in the ovaries. In those cases where only some of the egg germs are developed into eggs, the remainder often serve as nourishment for these or contribute to their nutrition. Amoboid moving egg cells can feed upon the neighbouring egg germs after the manner of Amobee; or the surrounding egg germs store up food, which they give over to the growing egg cell, either by emptying their contents into it (Cephalopoda) 
or by transfusion (follicle formations). In Insects the egg germs can develop in the ovaries alternately into nutritive cells and egg cells. In most Platodes the case is very complicated; the germ cells of an original germarium here fall into two more or less distinct groups. The germ cells of one group (germarium) become egg cells; those of the other group (vitellarium) become nutritive or yolk cells filled with nutritive yolk. In other Platodes only some of the originally numerous germaria retain their primitive function, while all the others are changed into vitellaria to supply nutritive yolk. The eggs either absorb the nutritive yolk of the yolk cells

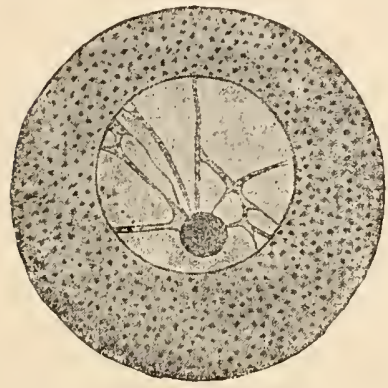

Fig. 22. - Ovarian egg of an Echinoderm, after $\mathbf{0}$. Hertwig. In the middle the germinal vesicle with the nuclear framework and the germ. inal spot.

before fertilisation, or else many yolk cells are stored in an egg capsule together with a few fertilised egg cells, and are used up during development.

The nucleus or the germinal vesiele (vesicula germinativa) of the animal egg is remarkable for its relatively great size. It consists of an outer layer, in most cases differentiated into a distinct membrane, surrounding the light-coloured clear nuclear fluid. In this lie one or more solid nueleoli or germinal spots (maculæ germinativæ), which are often connected with each other and with the nuclear membrane by a network of fine threads. In many eggs the germinal vesicle lies, throughout, in the centre of the egg; in others it does so at least in the very early stages.

\section{The Egg Yolk.}

Investigations made by means of the improved optical appliances for research have lately shown that protoplasm itself (in Protozoa, egg cells, and tissue cells) exhibits a fine structure. It consists of very small firmer particles, arranged in the finest network of threads, which form the spongioplasm, and, lying between them, clear homogeneous more fluid portions, forming the hyaloplasm. Protoplasm thus constituted only in the rarest cases forms the whole of the yolk. In most cases reserve nourishment in the form of fat or oil drops, small plates and spheres, is found in the protoplasm, these being used as food by the developing egg. These constitute, in contradistinction to the formative yolk-i.e. the actual living active protoplasm of the egg-an inert lifeless constituent, only serving as nutriment, the deutoplasm or nutritive yolk. The quantity and arrangement of the deutoplasm in the egg is of great importance, since this determines the course of its first segmentation.

It rarely happens that there is no deutoplasm in an egg. Less 
rarely we find only a very small quantity equally distributed throughout the protoplasm (holoblastic alecithal eggs, Fig. 23, $C$ ). Such eggs are found among animals which can at a rery early stage of development find their own food, or else among those whose embryos are developed within, and nourished by, the mother boly.

In most cases the egg contains a considerable quantity of nutritive yolk. Two different types of eggs are distinguished, according to the arrangement and position of this yolk.

\section{Types of Telolecithal Eggs.}

A. In the simplest case the comparatively small quantity of nutritive yolk is imbedded in the formative yolk, principally in one hemi-

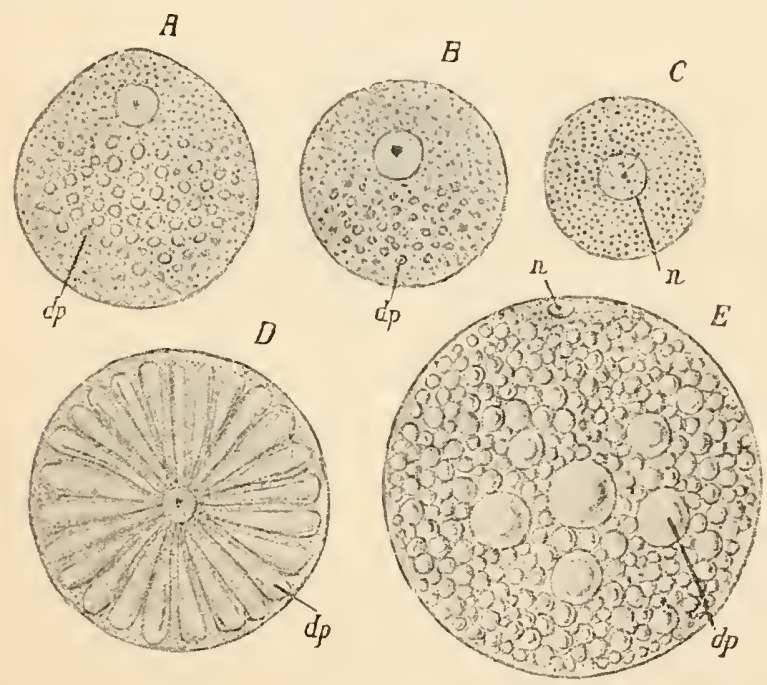

FIG. 23.-Structure of different eggs. $A$ and $B$, Holoblastic telolecithal eggs. $C$, Holoblastic alecithal egg. $D$, Centrolecithal egg (of a spicer). E, Meroblastic telolecithal egg. $d p$, veutoplasm; $n$, nucleus, or germinal resicle.

sphere. This hemisphere is called the vegetative; the other, which contains the germinal vesicle, the animal hemisphere. Corresponding animal and vegetative poles are also distinguished.

B. The quantity of the nutritive yolk increases so much that the formative yolk is reduced to a smaller or larger segment at the animal pole, in which lies the germinal vesicle. Besides this a thin layer of protoplasm spreads all round the egg as a rind. In the remaining portion of the egg the formative yolk is so much displaced by the development of the nutritive yolk, that it remains merely as a cementing substance in the interstices between the elements of the latter (holoblastic telolecithal eggs, Fig. 23, A). 
C. The quantity of formative yolk is, in comparison with the enormously developed nutritive yolk, so small that it is only a small mass enclosing the germinal vesicle at the animal pole, and a very thin layer round the whole egg. In by far the greater part of the egg the formative yolk is quite supplanted by the nutritive yolk (meroblastic telolecithal eggs, Fig. 23, E).

\section{Types of Centrolecithal Eggs.}

The formative yolk is arranged in a regular layer round the whole egg, and besides this in a mass containing the germinal vesicle at the centre of the egg. The region between the centre and the circumference is occupied by nutritive yolk, either

A. In largely preponderating quantity (holoblastic centrolecithal eggs of many Crustaceans), or

B. Almost, or quite exclusively (meroblastic centroleeithal eggs of the Tracheata and many Crustaceans, Fig. 23, D).

\section{The Egg Envelopes.}

These are divided into (1) primary envelopes-yolk membranes, egg membranes; and (2) secondary accessory envelopes.

I. The yolk membrane is secreted by the yolk itself. It can be formed at different stages of the ripening of the egg, and shows great diversity of structure. Occasionally it is double. It is often penetrated by numerous pores (zona radiata). Not infrequently there is a special opening, the micropyle. Both the pores and the micropyle are connected with the nutrition of the egg, and serve in many cases for the passage of the spermatozoa.

II. The secondary envelopes are also very various. They are alike in one point-none of them are formed by the egg itself.

a. The chorion is a membrane which is very often secreted by the cells of the ovary which surround the egg (follicle cells). It lies between the egg and the follicle cells.

b. Other accessory envelopes are sometimes found, which are only added to the egg later by means of special glands on its way through the passages leading out of the ovaries. Such are the egg capsules, albuminous and gelatinous envelopes, calcareous shells, etc. Either only one of these egg envelopes is formed, or else two or more are simultaneously produced.

As an example of the development and ripening of an egg, we choose first the egg-formation of the mussel (Fig. 24, $A, B, C$ ). The eggs here arise out of definite cells of the germinal epithelium, which grow more strongly and soon project beyond the epithelium, with which, however, they remain for a time connected by a long stalk-like process. Through this stalk, in all probability, the nourishment of the egg by the epithelium takes place. Yolk granules, continually increasing in number, appear in the protoplasm of the egg. The nucleus becomes vesicular. The egg secretes on its surface a yolk integument, which is broken through at the point 
where the cgg joins the germinal epithelium, so that when the egg severs itself an opening, the micropyle, is left.

The marine planaria offer a further example of a simple egg-formation (Fig. 24, D). These possess very numerous ovaries, whose nourishment is provided for by their

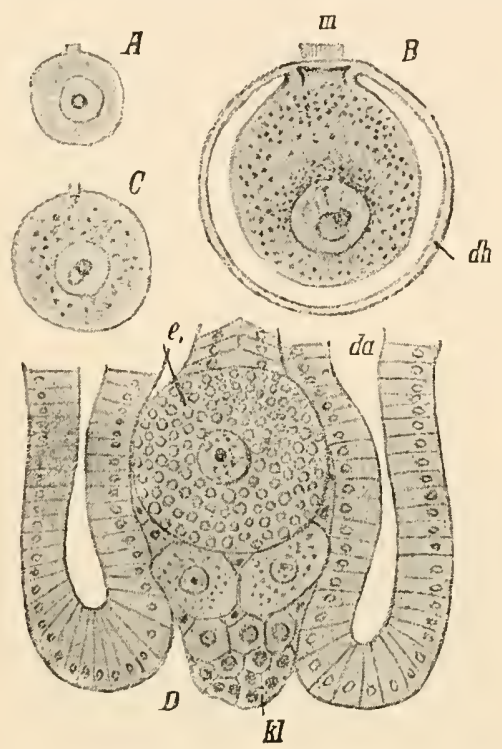

Fig. 24.-A, $B, C$, Three ovarian eggs of a mussel in different stages of development, after Fleming. $m$, Nicropyle; $d h$, yolk membrane. $D$, Ovary of a marine planarian with eggs in different stages of development; $d a$, branch of the intestine or gastro-canal; $k l$, germinal layer ; $e$, alvanced egg.

position between the branches of the intestine and close to its walls. In each orary there is a small germinal layer $(k l)$ formed by a mass of small colls with nuclei and little protoplasm. Some of these cells grow and become cggs, numerous yolk granules forming in them, and their nuclei changing into the characteristic germinal vesicle. Other cells remain small; they take up a position between the strongly growing egg cells, and so form a framework in the ovary, which is continued into the oviduct.

As a type of a perfect meroblastic telolecithal egg with complicated cnvelope-formation we have the bird's egg (Figs. 25 and 26). The egg is fertilised within the mother body, and has already begun to develop when it is laid. The different parts which can then be recognised have very differcnt meanings and origins. In the

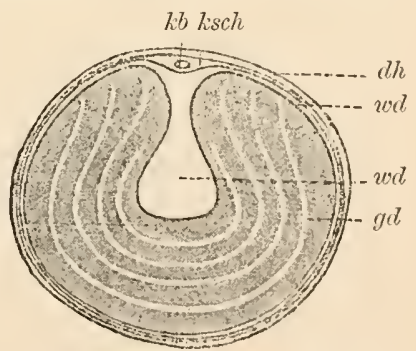

Fig. 25.-Ovarian egg cell of a Fowl. $k s c h$, Formative yolk; $k b$, germinal vesicle; $u$, white yolk; $g d$, yellow yolk ; $d h$, yolk membrane. (After O. Hertwig.) interior of the egg we recognise the yellow yolk spherc, the wcll-known yellow of the egg (Fig. 25). This is formed in the ovary, and represents the real cgg. In the ovary it is merely a simple meroblastic egg coll, consisting of the following parts : 
1. An outer yolk membrane, secreted by the yolk itself.

2. The formative yolk, a small whitish mass in which lies the germinal vesicle at one pole of the egg, viz. the animal pole.

3. The yellow nutritive yolk, which represents the prineipal mass of the egge, and which appears in concentric layers.

4. The white nutritive yolk, which forms a thin outer layer round the yellow yolk beneath the yolk integrment and the formative yolk, and which also sinks into the middle of the yellow yolk from the animal pole in the form of a thick strand with a swollen rounded end.

When the egg thus formed passes ont of the ovary into the oviduct, the walls of the latter secrete around it the last envelopes, which are:

1. The albumen with the chalaza, i.e. somewhat denser spirally twister

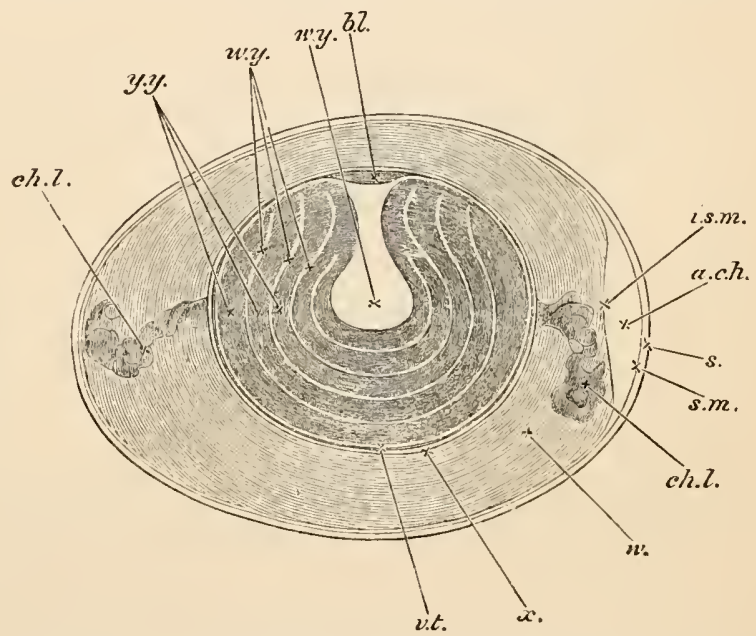

FIG. 26.-Diagrammatic longitudinal section of a newly-laid Hen's egg, after Allen Thomson aud 0. Hertwig. b.l. Formative yolk; w.y. white yolk; y.y. yellow yolk; $w$. albumen; ch.l. chalaza ; a.ch. air-ehamber; $i . s . m$, inner; s.m. outer layer of the shell membrane; s. sliell. v.t. yolk membrane; $x$, a somewhat fluid layer of albumen surrounding the yolk.

strands of albumen, which go from the yolk membrane out towards the two ends of the egg.

2. The double shell integument, which surrounds the albumen on all sides. The two membranes which form this integnment separate, and between them a eavity filled with air arises at the blunt end of the egg-the air chamber.

3. The porous calcareous shell. These three parts, therefore, represent the accessory integuments of the egg.

\section{Male Reproductive Cells, or Spermatozoa (Fig. 27).}

These belong to the smallest cells formed in the animal body. Each spermatozoon is a simple cell, as is shown by its development which is generally complicated, and is very difficult to observe. A very common form of the spermatozoon is the so-called pin-shaped. Such a spermatozoon consists of a small knot, the head, representing the remains of a 
cell nucleus, and a mobile filamentons appendage, the tail, which is of protoplasmic nature, and is much like the flagellum of the Flagellata. Besides the tail there may be accessory flagella. Between the head and the tail a special intermediate portion is sometimes interposed. Other forms of spermatozoa are occasionally found ; round, pear-shaped, etc., either stationary or moving like Amabee. The spermatozoa arise in the testis from a germinal layer or epithelium, as do eggs. After repeated division of the original formative elements, cells are produced which are equivalent to egg germs, and which may be distinguished as sperm germs. Whereas, however, the egg germs become eggs direct by means of growth and maturation, the sperm germs are still further divided and produce spermatozoa. We have already seen a phenomenon similar, though not in all points parallel, in Voliux. An ordinary cell of the colony

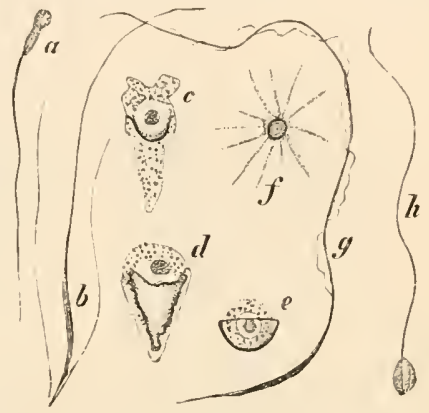

Fig. 27.-Various forms of Spermatozoa. $c$, of a Mammal; $b$, of a 'Turbellarian, with two accessory flagella; $c, d$, and $e$, of Nematoda; $f$, of a Crustacecin; $g$, of a Salamander (with undulating mem. brane); $h$, The commonest pin-shapelform. there becomes by growth a large egg, or by division a mass of small spermatozoa.

\section{Maturation of the Egg.}

The ejection of the directive or polar bodies is the last stage in the maturation of the egg which precedes fertilisation. The germinal vesicle moves towards the surface of the egg (towards the animal pole in the case of eggs differentiated into poles), and here undergoes
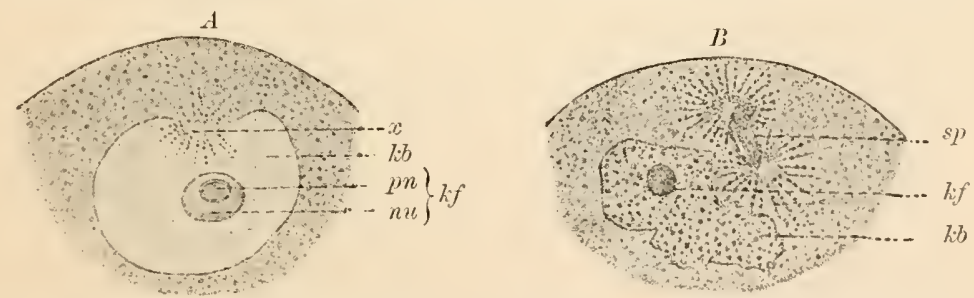

F1G. 28. -Disorganisation of the germinal vesicle and formation of the nuclear spindle in eggs of Asterias glacialis, after 0 . Hertwig. $x$, Prominence of protoplasm ; $7 f$, germinal spot which rlivides into two distinct substances, $p n$ and $n u ; 7.0$, germinal vesicle; $s p$, nuclear spindle.

considerable changes. It becomes partially disorganised (Fig. 28). Out of part of its contents is formed that spindle-shaped figure (Fig. 28, B) which is characteristic of indirect nuclear division (see below, pp. 35,36). The one half of the spindle enters a small mass of protoplasm which projects from the surface of the egg. This prominence 
then becomes completely constricted off from the egg (Fig. 29) as the first polar body. In a similar manner a second polar body is formed. The formation of a polar body thus appears like a process of gemmation, or a sort of cell division, in which one cell-the daughter cellthe polar body, is very much smaller than the other-the egg.

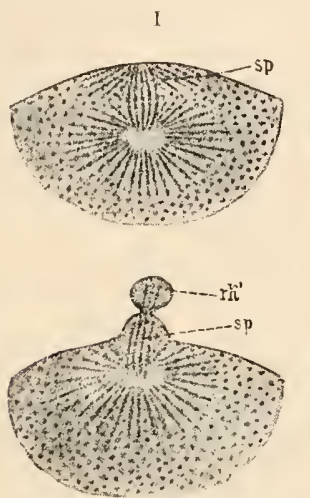

IV
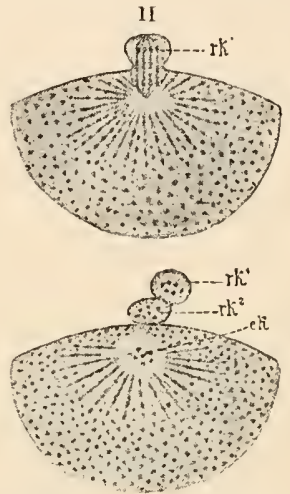

$\mathrm{V}$
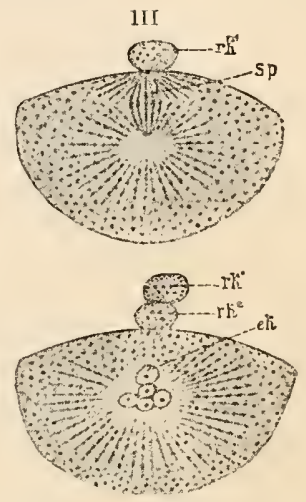

VI

Fic. 29.-Formation of the polar bodies in Asterias glacialis, after O. Hertwig. $s p$, Nuclear spindle; $r k 1$, first, $r k^{2}$, second polar body ; $e k$, female pronucleus.

The half of the nuclear spindle which remains in the egg after the formation of the second polar body changes into an egg nucleus very different from the original germinal vesicle, especially in its size, being much smaller. This germ is known as the female pronucleus.

In many divisions-e.g. many insects, - there are species in which, alternating with the sexual generations, which multiply by means of fertilised eggs, there occur other generations, which reproduce by means of parthenogenetic eggs, i.e. by means of such eggs as develop without fertilisation. In these eggs, according to some observers, only one polar body is formed. Many hypotheses have been brought forward as to the meaning of all these various phenomena of maturation. I can here only refer to the works of Bütschli, Balfour, Minot, Sabatier, van Beneden, Weismann.

Processes similar to those of the expulsion of the polar bodies from the egg have been observed in the formation and ripening of the spermatozoa. The nucleus of the ripe spermatozoon is called the male pronucleus.

When the polar bodies have been expelled the egg is capable of fertilisation.

\section{Fertilisation.}

This process takes the following course; out of numerous spermatozoa pressing towards the egg there is only one, normally, which fertilises it. This is the one which first touches the egg at a definite point as it appear's, viz. at the animal pole, in eggs differentiated into 
poles, near the polar bodies. Here, at the touch of the head of the spermatozoon, a prominence of the outer protoplasmic layer is formedthe receptive prominenee-into which the spermatozoon penetrates. Gradually it presses further into the egg, its tail seeming to fuse with

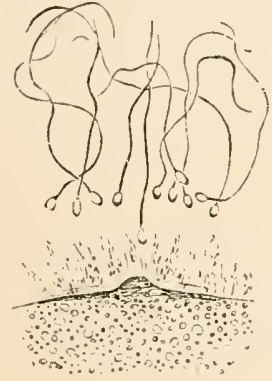

A

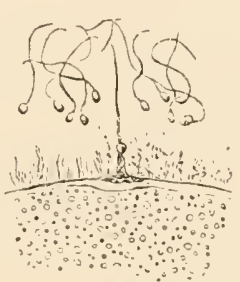

B

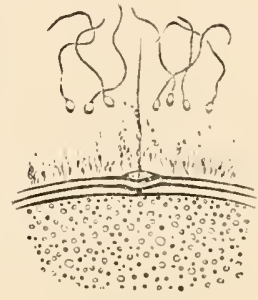

$r^{\prime}$

F1G. 30.-Fertilisation of eggs of Asterias glacialis, after Fol (from O. Hertwig's Lehrbuch der Entwiclilungsgeschichte). One of the spermatozoa which have entered the mucilaginous envelope comes in contact with the receptive prominence. In $C$ the yolk membrane is formed.

the protoplasm of the egg; the head (the remains of the original nucleus) increases somewhat in size. As male pronucleus, it moves forward to meet the female promucleus. Finally they fuse and form one single nucleus, the so-called segmentation nucleus. The egg is fertilised.

It seems tolerably certain that where the egg envelopes have a micropyle, the spermatozoon enters through it. When the first spermatozoon has penetrated the egg, the micropyle is closed by a fresh secretion from the yolk, so that no more spermatozoa can enter.
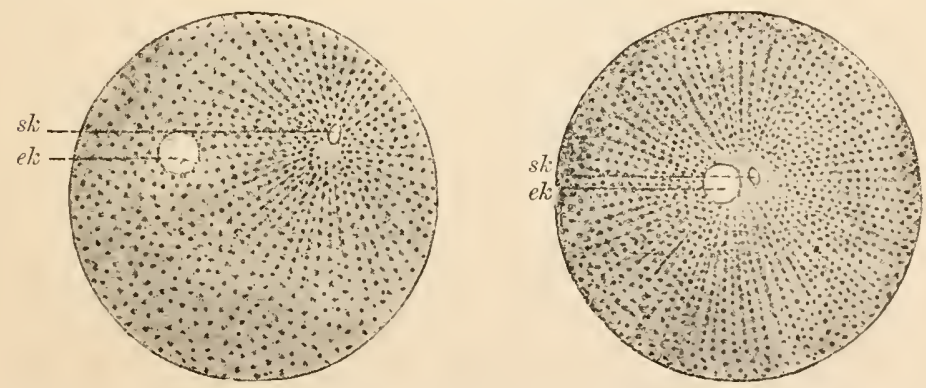

Figs. 31 and 32.-Fertilised eggs of a Sea-urchin, after O. Hertwig. Male (sk) and female (eh) fronuclei moving towards each other.

In other cases, at the moment when the first spermatozoon presses in, a membrane begins to rise from the yolk, which makes the entrance of other spermatozoa impossible. There are adaptations also with the object of preventing the entrance into the egg of more than one spermatozoon. 
Abnormally, two or more spermatozoa may enter an egg. In such a case several male pronuclei may fuse with the female. Compare on this roint the works of Fol and Hertwig. It is not improbable that twin- and triple-formations may be produced by such over-fertilisation. The development after over-fertilisation in all cases deviates characteristically from the normal course.

The most essential morphological characteristic of fertilisation is the fusing of two sexually differentiated cell nuclei, the male and the female pronuclei. In the conjugation of the Protozoa (Puramcecium) also we have to do ( $c f$. p. 18) with a fusing of two nuclei (the stationary and the migratory nucleus). Fertilisation in this latter case, however, is mutual, and we cannot distinguish the conjugating cells as male and female.

Fertilisation is either internal, i.e. takes place within the mother body, or external, i.c. spermatozoa and eggs are expelled from the parental bodies and meet each other outside in water. In the first case at least the reproducing animals possess special organs of copulation.

Various theories about the nature of fertilisation have been recently brought forward, especially by Bütschli, Balfour, Sabatier, van Beneden, Hertwig, Weismann, Geddes and Thomson, and others.

\section{Literature.}

\section{Comprehensive Works.}

Besides Balfour's Comparative Embryolory consult especially :

o. Hertwig. Lchrbuch der Entwickelungsgeschichte des Mcnschen und dor Wirbelthiere. 3d edition. Jena, 1890.

W. Waldeyer. Eierstock und Ei. Leipzig, 1870.

The same. Bau und Entwickclung der Samenfäden. Anat. Anseiger. Jena, 18s7, where complete bibliography is given.

\section{Tissue Cells and Cell Tissue.}

We have till now considered (1) unicellular organisms, and (2) the egg- and sperm-cells, which fuse to form the starting point in the individual development of all the higher, i.e. multicellular, animals. TVe will now briefly deal with the manner in which the Metazoan body is composed of cells, and consider the various cells of which it consists. The observation of the cells of the animal body and of their complexes, the tissues, is the object of the science of tissues or Histology. How different cells and complicated tissues arise out of simple indifferent cells, is the subject of Histogeny.

As our first principle we can state that all cells and tissues of the adult animal body arise by means of repeated division from the fertilised egg-cell. These phenomena of division are the same as those with which we became acquainted among the unicellular Protozon as widely spread asexual reproductive processes. Whereas, however, in most Protozon the products of division separate, and, like the mother cell, lead an independent life, in the Metazoa the descend- 
ants produced by repeated fission of the fertilised egg-cell remain bound together in space. Similar cases were found among the Protozoa; we called them cases of colony formation. While, however. there, all the cells of the colony remained alike and each maintained itself quite like a Protozoan individual, the cell communities of the Metazoa by dividing among the individual cells the various duties of life, so that some cells are exclusively adapted for the performance of one function, some for the performance of another, raise themselves into stable and well-ordered states, the citizens of which (the cells) are dependent upon one another and can no longer exist alone.

The division of the egg-cell and its descendants occurs under peculiar inner conditions, which chiefly concern the nucleus. Direct nuclear division during cell division is distinguished from indirect or karyokinetic nuelear division. The first and, as it appears, the rarer agrees in essentials with that already figured in the Amceba (p. 12, Fig: 19). The second shows various modifications. The following course may be taken as typical (Fig. 33, $A-H$ ).

[Among the constituents of the cell nucleus are to be distinguished the achromatin,that part which does not stain at all or only very slightly when treated with colouring solutions, viz. the nuclear fluid, and a part of the constituents of the fibrous
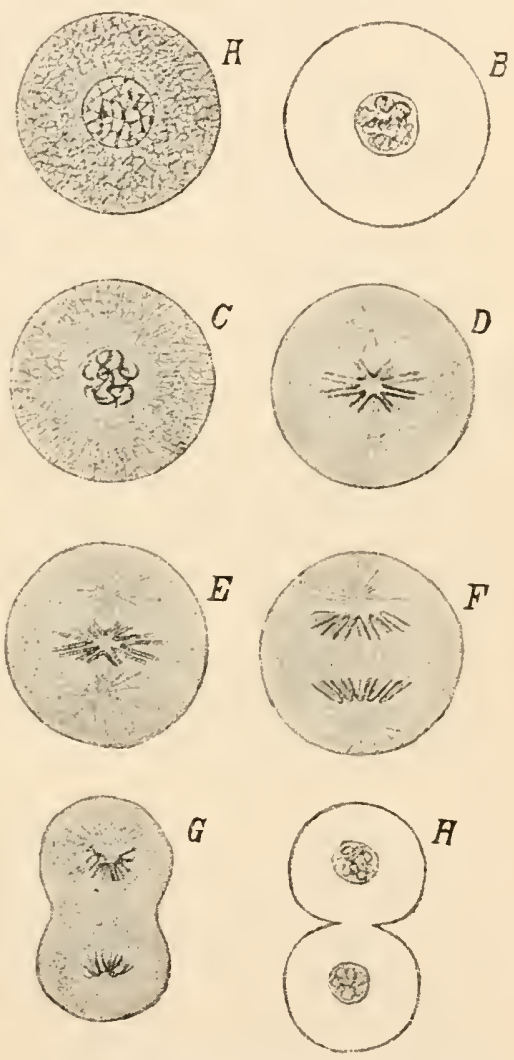

Fig. 33. $-A \cdot H$, Consecutive stages of celldivision, with indirect division of the nucleus (diagrammatic). net-work; - and chromatin, which freely imbibes colouring matter, viz. the nucleoli and other granules of the fibrous network.]

1. At the beginning of cell division, there appear near the nucleus two opposite attraction centres, round which the portions of protoplasm group themselves in a radiate manner (formation of the amphiasters). The chromatin of the nucleus arranges itself as a tangle of fibres (Fig. 33, $B$ ).

2. The nuclear membrane becomes indistinct; the tangled chromatin falls into several loops (Fig. 33, C). 
3. These loops arrange themselves in an equatorial plane between the two attraction centres, in such a way that their free ends are directed ontwards and their angles inwards. Fine achromatine fibres run to the attraction centres (Fig. 33, D).

4. The chromatin loops split lengthwise, so that their number is doubled (Fig. 33, E).

5. The one half of the chromatin loop which has thus arisen moves towards one attraction centre, the other towards the opposite centre. The halves thus move away from each other; fibres of achromatin stretch between them (Fig. 33, F).

6. The chromatin loops of each side have moved quite near their attraction centres. Their order now becomes irregular, and they again unite into a single tangle, round which again a nuclear membrane can be recognised (resting stage, Fig. 33, $G$ and $H$ ).

During the last stages, at the surface of the cell in a plane between the two attraction centres, a circular furrow appear's, which becomes deeper and deeper, and finally, when the two new nuclei have reformed, divides the cell into two halves, each with a new nucleus.

The cells which arise in the animal body by repeated division of the egg develop in various ways, but always in such a way that the greater number of them remain bound together in a special manner, forming the so-called tissues. Four chief sorts of such tissues can be distinguished :

1. Surface or epithelial tissue.

2. Connective tissue.

3. Nerve tissue.

4. Muscle tissue.

\section{Epithelial Tissue.}

This is the simplest form of tissue, and, as Comparative Histology and Histogeny teach, the most primitive complex into which cells can combine. It may therefore be correctly described as primitive tissue, from which all other tissues are clerived. Even among the Protozoa epithelium-like combinations of cells occur, as, e.g., in Volvox, where the individuals (cells) of a colony are placed side by side in a layer which, like a spherical mantle, encloses a central cavity. Such a form is, in many Metazoa, the immediate result of the first division of the egg; it is here called the Blastulı. The epithelial character consists in the regular juxtaposition of cells into superficially extended membranes. These cover the outer and inner surfaces of the animal. The cells of an epithelium lie either in a single layer side by side (unilaminar epithelium), or several layers lie one above another (multilaminar epithelium). Different sorts of epithelium are always distinguished according to the differences in the individual cells which form them. Thus we speak of tesselated epithelium when the cells are flat, of columnar epithelium when the cells are cylindrical, and so on. The 
epithelial cells generaliy secrete extemally layers of varying thickness, which often harden and possess different chemical and physical properties; these form a cuticle over the epithelium.

In the simplest cases every epithelial cell possesses nearly all the qualities of a Protozoon. Division of labour, however, soon steps in, so that the epithelial cells belonging to different areas undertake different functions. In a simple condition, which we meet with in certain low Netazoa, e.g. the Hydra, and which is also passed through by many higher Metazoa in the course of their development, the wall of the pouchlike body consists of two contiguous epithelial layers, an outer (ectodermal epithelium) and an inner (endodermal epithelium), the latter lining the central cavity of the pouch (archenteron). The two layers pass into each other at the opening of the pouch (mouth). This stage is known as the Gustrula. A certain not very sharply defined division of labour occurs between the cells of the inner epithelinm and those of the outer epithelium. The cells of the onter epithelium appear to be specially suited, in correspondence with their

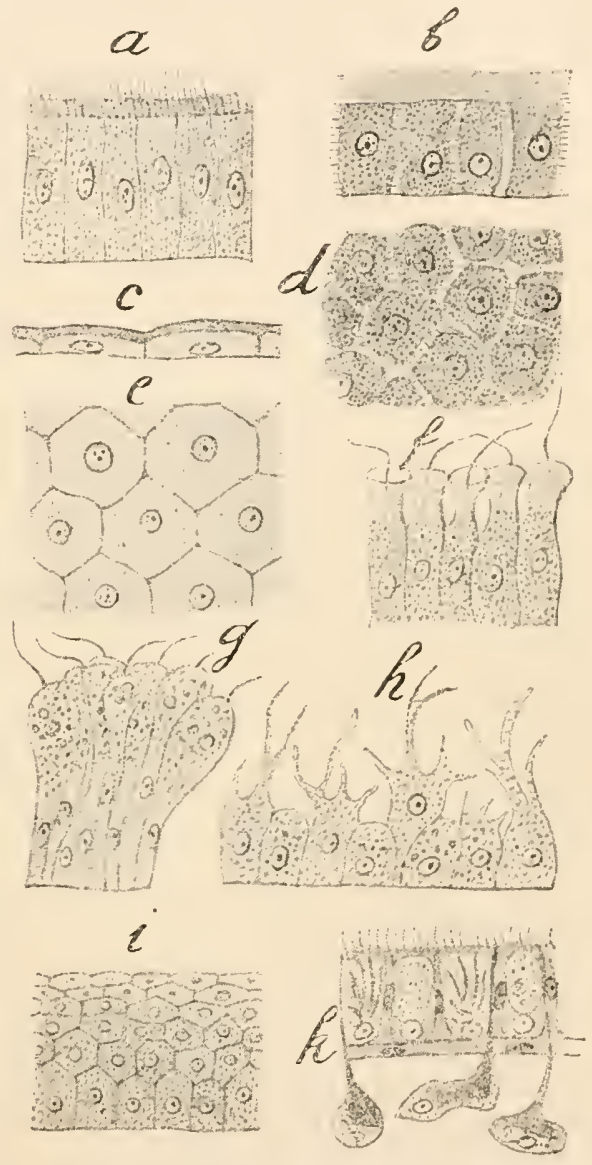

FIG. 34.-Various forms of epithelium. $a$, Ciliated epithelium; $b$, columnar epithelium in profile; $d$, surface view; $c$, tesselater epithelium; $e$, the same from the surface; $f$, epithelium of collar cells, with flagella (from the endoderm of a sponge); $g$, flagellate epithelium; $h$, epithelium of intestine with amoeboid processes; $i$, multilaminar epithelium; $k$, body epithelium of a marine planarian, with pigment cells, rod cells, and sub.epitlelial glands.

position, to carry on the relations between the animal body and the outer world, and further to promote locomotion and movement; those of the inner epithelium are adapted more for the ingestion and digestion of the food taken into the gastric cavity. In correspondence with these functions, differences in the structure and in the size of the cells of the two layers appear. The higher we rise in 
the animal kingdom the more sharply defined and the more thorough is the division of labour. The epithelial areas no longer consist of similar cells, but the cells of the same epithelium, having different functions to perform, are differently constructed.

The comparison of the adaptations by which different cells (especially epithelial cells) of the Metazoa seem to be suited for definite functions, with the adaptations we have described among the Protozoa, is very instructive. In the latter, in the most complicated cases, different portions of one and the same cell appear specially adapted for the performance of definite functions. Among the Metazoa, however, in a number of tissue cells one of the many adaptations of a complicated unicellular Protozoon becomes the principal adaptation suppressing all or most of the others, or totally obliterating them; in this way cells suited for the performance of one special function arise. We find among the Protozoa - as adaptations for morement, for taking in food, and for respiration-cilia, flagella, and so on. Epithelial cells of Metazoa rery often assume such adaptations as the most prominent characteristic of the cells. Either all cells of an epithelium are corered with cilia-then we speak of eiliated epithelium-or only groups of cells or single cells are thus covered. The cilia of a cell may be replaced by a flagellum, e.g. in the endoderm of the sponges. Then the epithelial cells so provided are called flagellate cells, which often strongly remind one of the Choanofiagellata.

These cilia and flagella serve among the Metazoa, as among the Protozoa, for very various purposes.

1. They cause locomotion in Metazoa of small size which live in water (cilia of the body epithelium of a few Rhabdocelide, ciliated plates of the Ctenophora, cilia of the wheel organ of some Potifera), and especially in the free swimming larval stages of many Metazoa (general ciliation of many larve, ciliated rings and bands of the larve of Platodes, Termes, Molluscs, and Echinoderms).

2. They serve for whilling food within reach, as they surround the oral aperture, e.g. Rotatoria.

3. They continually cause new digestible material to pass over the digesting epithelium; in many cases they at the same time cause in the enteric cavity a constant renovation of water and of the food suspended in it. Intestinal respiration. Ciliated epithelium of the intestinal eanal.

4. They constantly bring fresh oxygenated water into contact with the epithelium. Respiration. Ciliated epithelium of the gills.

5. If they carry on these activities at certain parts of the epithelium where sensory nerves come to the surface, they subserve special functions of sensation. Ciliated grooves. Olfactory pits.

Very many Protozoa use pseudopodia and amoboid processes for locomotion and ingestion of food, and also perhaps for respiration. In many Metazoa the taking of nutritive particles into the intestinal 
epithelial cells by means of the protrusion of pseudopodia-like or amoboid processes is an important function of these cells, which serve exclusively for purposes of nutrition. In many lower Metazoa the amœboid character of one or of all the cells of the intestinal epithelium is so marked that they sever themselves from the complex of epithelial cells and float about independently in the intestinal cavity.

Formations similar to the contractile vacuoles of many Protozoa are found in the so-called excretory cells of the Turbellaria. In their protoplasm, and in that of their processes, small drops (products of metabolism) collect, and these may mingle to form one large drop (vacuole). The drop is emptied into the lumen of the cell (see Fig. 109, p. 152), and thence expelled by means of the excretory ducts.

In certain Protozoa the ectoplasm gives rise to stinging cells. In most Celenterata the production of such stinging capsules, the so-called nematocysts, is always the chief function of very many ectodermal cells (cnidoblasts) which do no other work for the organism.

In the Protozoa a membrane or shell for the protection of the unicellular organism is provided by the secretion of a resistent external envelope; so also in the Metazoa the epithelial cells, and naturally the cells of the outer body epithelium especially, provide a protection or covering for the body by the formation of outer cuticular membranes. Such cuticular formations arise by the mingling of the secretions of different cells, or the transformed products of the protoplasm, to form a layer. They may vary very much chemically and physically, and stand in just the same relation to the epithelial cells which produce them as do the glandular secretions to the gland cells. To these cuticular formations belong the chitinous integuments of the Annulata and Arthropoda, which sometimes by calcareous deposit become carapaces as hard as stone; these integuments are secreted by the epithelium (hypodermis) which underlies them.

The Cuticle is often penetrated by fine perpendicular pores, which probably owe their origin to the fact that, as the cuticle increases in thickness, the cell protoplasm remains connected with the cuticular surface by fine processes. A fine cuticle is also to be found in ciliated epithelium, in which case the cilia pass through the pores to the exterior.

There are, however, among the Metazoa a series of cells with special adaptations and functions which are wanting in the Protozoa. The aggregation of a large number of cells which can adapt themselves to the most various activities, presents much more favourable conditions for a far-reaching division of labour than are offered in the case of unicellular organisms. In the first place, we have in the epithelium the most various glandular cells-cells which are distinguished by peculiarities of form and structure, and possess a protoplasm capable of transforming the nutritive substances provided by the body into different sorts of secretions, or of assimilating from the body super- 
fluous or waste material, which they then remove out of the body. Dermal glands secrete mucus or other substances.

When glandular cells remain single they form unicellular glands; if many combine for the same purpose they are called multicellular glands.

In the simplest cases, these glands are epithelial cells, chiefly distinguished by their size, and often pear'-shaper. The nucleus

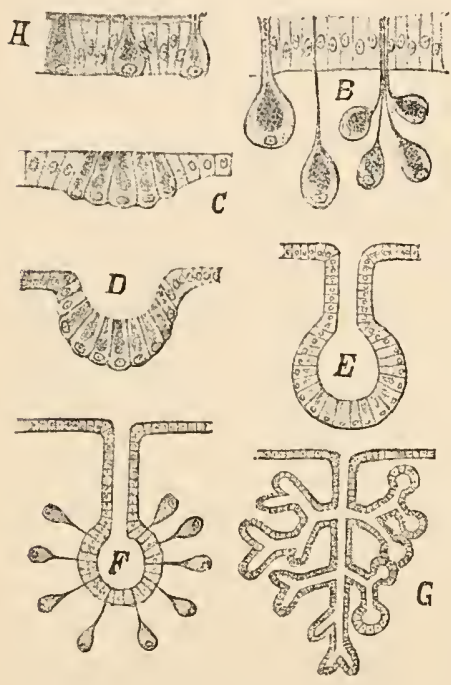

FiG. 35.-A-G, Various forms of glands. lies at the basal end of the cell, i.e. the end away from the free surface of the epithelium. The secretion collects in the cell and is pushed forward towards its surface. Where a cuticle is developed it is often broken through above the gland cell, forming a pore for the discharge of the secretion (Fig. 35, $A$ ).

Unicellular glands often partially leave the epithelium, the greater part of the gland projecting into the underlying tissue. They then only penetrate between the epithelial cells by means of thin processes, the efferent ducts (Fig. 35, B).

A greater or smaller area of epithelium often consists entirely or principally of glandular cells (Fig. $35, C)$. Such areas generally sink into the epithelium, so that a glandular epithelial sae arises, into whose cavity the secretion is emptied (Fig. $35, D, E)$. Such sacs again may form many branches (Fig. 35, $G$ ). The glandular portion is then frequently limited to the blind and often lobate ends of the sacs, while the rest serves as an efferent duct. Glandular cells again can sink under the epithelium of these glandular sacs, and only remain connected with it by their efferent ducts (Fig. $35, F)$.

It is only natural that certain cells of the epithelium which envelopes the body should undertake the function of carrying on the relations between the body and the outer world, i.e. of receiving impressions and imparting them to the body. Such epithelial cells are called sensory cells. They can either occur singly or form, in combination, a sensory epithelium. Originally these cells are very slightly differentiated, very slightly qualified for the reception of varied impressions. But here also, as the organism grows more perfect, division of labour steps in. Certain sensory cells appear qualified for the perception of definite sorts of impressions only. They enter into combination with certain tissue elements and form specific sensory organs, which give rise to perceptions of either touch or sound, sight, 
smell, or taste. The sensory cells will engage our attention again later.

Epithelial cells may become pigment cells by the deposition in their protoplasm of pigment material; these pigment cells are an important element in the external colouring of the animal. Deposited in certain sensory cells, pigment serves for the absorption of light and heat rays, and so contributes to the sensations of light, colour, and warmth.

Certain epithelial cells often perform the function of supporting their companions. They form, by mingling with each other, a tissue with meshes, the interstitial tissue, which is related to the other epithelial cells as the mortar in a wall is related to the bricks.

Since the protoplasm of neighbouring epithelial tissue mingles, and since in epithelial cells it is the nuclei only and not their protoplasm that divide, masses of protoplasm with nuclei scattered throughout them may arise. In such masses no cell boundaries can be recognised. They are called syneytia.

The epithelial cells do not always lie close to each other; they are sometimes separated by clear intercellular spaces for transmission of fluid, or by intercellular substances; but in such cases they remain connected by means of very fine protoplasmic processes which stretch across these intercellular spaces.

\section{Connective Tissue.}

Under this name is comprised a long series of tissue forms, which may have very different origins, structures, and functions. They originate either directly or indirectly from the epithelium. Their essential office is to bind together different portions of the body and different organs, or to serve as support for these by their possession of a certain degree of firmness. We divide the connective tissues, according to an important difference in their origin, into two principal groups.

I. Gelatinous tissue (Fig. 36) takes its origin direct from an epithelium. To

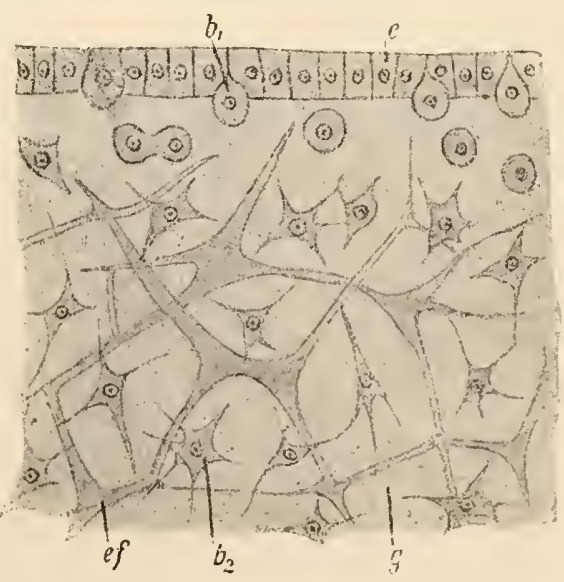

Fic. 30.-Gelatinous tissue of a Scyphomedusa (diagrammatic). $e$, Epithelitum; $g$, Jelly; $b_{1}$, epithelial cell passing into the jelly ; $b_{2}$, branched cells in the jelly; ef, elastic fibres. this belong, e.g., the gelatinous tissue of Heduse and the Ctenophoru. Between the inner epithelium which lines the intestine and the 
outer which covers the surface of the body a homogeneous jelly, containing a large proportion of water, is secreted by the epithelium. Cells leave the epithelium and enter the jelly, where they assume a different form. Sometimes they become spindle shaped, sometimes much branched cells connected together by their branches, sometimes elastic fibres. Occasionally such cells show amoboid movement. They can even become contractile muscle-cells.

II. The Connective tissue proper' does not take its rise direct from the epithelium. In early stages of development of the animal variously sized groups of cells sink out of the epithelium below the surface, multiply by fission, and so produce the actual formative cells of the connective tissue. This fills the interstices between the organs and other tissues, or forms pillars, strands, plates, and rariously shaped supporting masses. It often forms membranes round other organs and tissues, or lines cavities. Such a superficial extension may even assume the character of an epithelium.

Two chief types of connective tissue proper are to be distinguished.

A. The cells of the connective tissue lie close together and form no intercellular or connecting substance.

Vesicular connective tissue (Fig. 37). Vacuoles filled with fluid occur in the cells, which, growing in size, cause vesicular swelling.
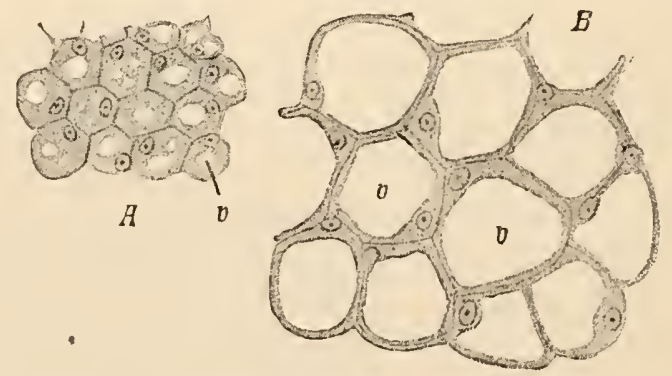

FlG. 37.-A, Younger, $B$, older vesicular connective tissue of a Platode. $v$, Vacuoles.

The protoplasm is then often limited to a thin layer surrounding the vacuole, and this can mingle with the neighbouring cells. Small aggregations of protoplasm may still be found massed round the nuclei.

Vesicular comnective tissue passes into reticular connective tissue, when the fluid-filled spaces of neighbouring cells unite with one another. The connective tissue then takes the character of a spongy network containing imbedded nuclei, and the intracellular fluid which has flowed together becomes in a certain sense intercellular (reticular connective tissue of many Platodes). In fatty tissue (Fig. 38) smaller or larger fat drops appear in the protoplasm of the cells. In pigment tissue colouring matter is deposited.

B. The formative cells of connective tissue form extermally a substance, the intercellular substance, in which they come to lie em- 
bedded. This substance is either secreted by the protoplasm of the cells, or it is produced by the metamorphosis of the outer protoplasmic layers.

However much developed the intercellular substance is, accorling to recent research it is probably nearly always penetrated by very fine

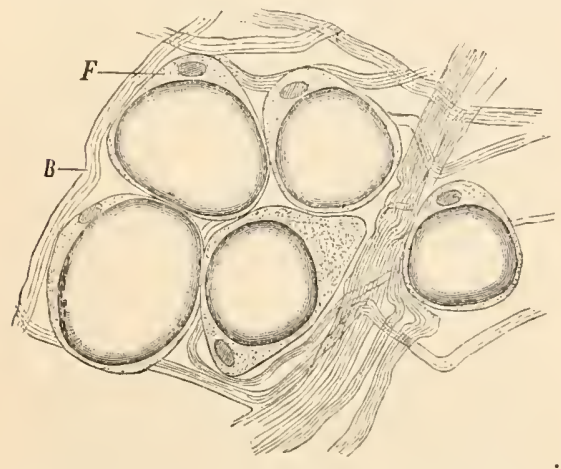

Fic. 3S. - Fatty tissue, after Ranvier (from Claus's Text-book of Zoology). F, Fat-cells ; $E$, connective tissue fibrils.

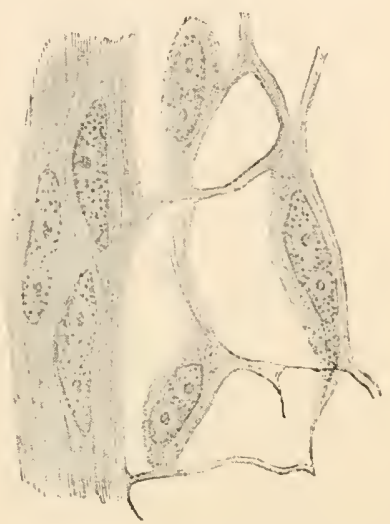

Fig. 39.-Chorda tissue, after Leydig.

processes of the connective tissue cells, which are thus maintained in organic union. Various hollow spaces are also frequently found in it.

Cellular vesicular connective tissue arises from the vesicular connective tissue above described by the cells secreting an external membrane or cuticle which connects them together, e.g. Chorda dorsalis (Fig. 39).

There are kinds of cellular connective tissue in which the cells do not take the vesicular form, but remain compact and mostly round. The intercellular substance is inconsiderable in comparison with the cells. If it increases in mass, the tissue passes into the next form.

In fibrous connective tissue the intercellular substance is considerable. When boiled it yields glue. It is differentiated into fibres, which often unite in bundles, showing the most varied arrangements.

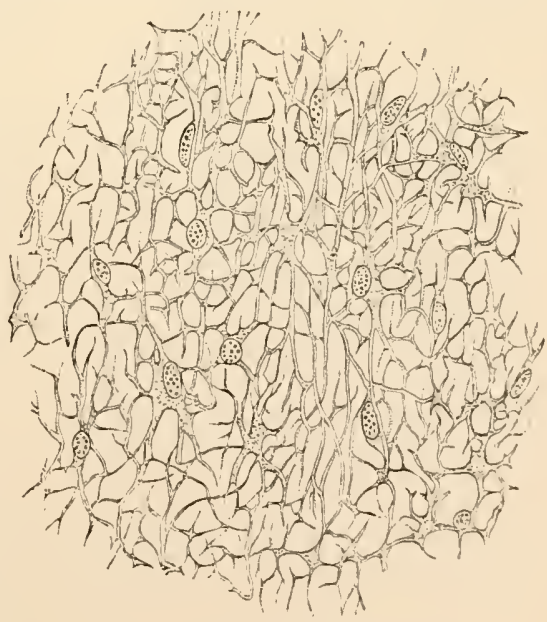

FIG. 40.-Reticular connective tissue, after Gegenbauer.

They often run parallel, often cross each other, or branch and anastomose with each other. The cells of the comnective tissue seldom 
remain round; they generally assume a long spindle shape or a branched form. In the last case there again arises a sort of reticular connective tissue. The processes of the cells themselves are often differentiated into fibres, which associate themselves with those formed from the intercellular substance. Fibrous connective tissue may have a loose texture or a firm texture, as in tendinous tissue (Fig. 41). The fibres swell on treatment with acids and alkalis. If they are elastic and reticular, and if they do not swell under the influence of acids and alkalis, we have elastic connective tissue.

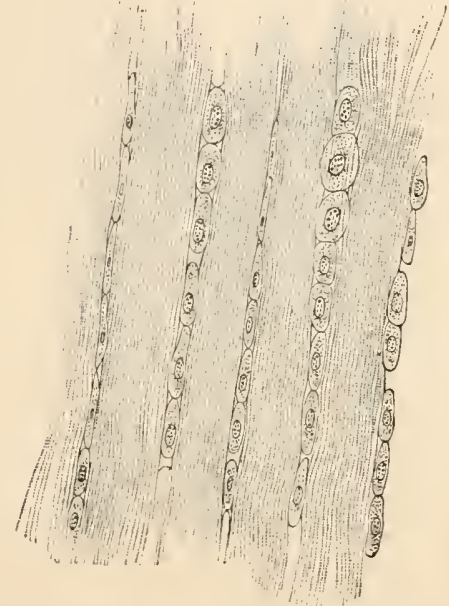

Fic. 41.-Tendinous tissue, from the longitudinal section of a sinew, after Gegenbauer.

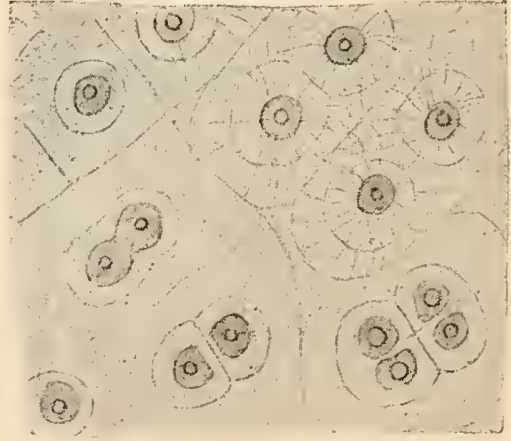

Fic. 42.- Hyaline cartilage. To the right above are depicted the protoplasmic threads which connect the cartilage cells.

Cells of connective tissue may become pigment cells by the deposition of colouring material.

Cartilaginous tissue is a very good instance of the structure and rise of real connective tissue. The cells generally remain round. They secrete membranes, which continually become thicker and stronger by their own growth, and which finally mingle with those of the neighbouring cells and form a tolerably firm intercellular substance, the cartilaginous substance, which in boiling yields chondrine. The cartilage cells continue to divide; the daughter cells again surround themselves with membranes. Sometimes the membranes of various generations can still be distinguished-the less easily, of course, the older they are (Fig. 42).

If the cartilaginous substance is homogeneous and structureless we have hyaline eartilage; if it is fibrous we speak of fibrous eartilage. In cartilaginous tissue also the intercellular substance seems penetrater by exceedingly fine processes of the cartilage cells, which apparently 
were already present when the first membrane was secreted. Caleified cartilage is formed by the appearance of calcareous deposits in the intercellular substance.

Cartilaginous tissue, on account of its firmness, serves as supporting tissne in vertebrate and in some invertebrate animals.

Bone tissue forms, par excellence, the supporting tissue of vertebrates. The intercellular or bone substance becomes as hard as stone by a combination of lime-salts with some ground sulbstance, which yields glue on being boiled, and does not dissolve under treatment with acids. In it are scattered the cell elements (bone cells); they are

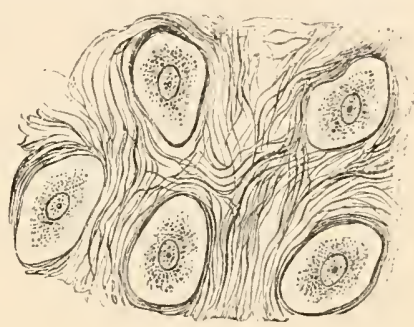

FtG. 43.-Fibrous cartilage, after Claus. much branched, and connected by their processes; they are arranged in parallel layers, often concentrically round the cavity (Fig. 4t). Bone tissue arises out of indifferent connective tissue cells, which are arranged in strands or flat expanses, and which function as formative cells of the bone tissue, osteoblasts (Fig. 45, a). They produce on one side bone substance, often in the direction of cartilaginous masses, which they supplant, at the same time forming processes which remain im-

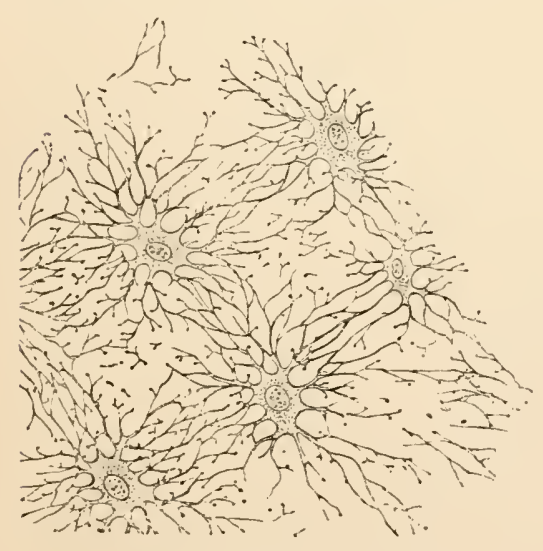

Fic. 44.-Bone cells, after Gegenbauer.

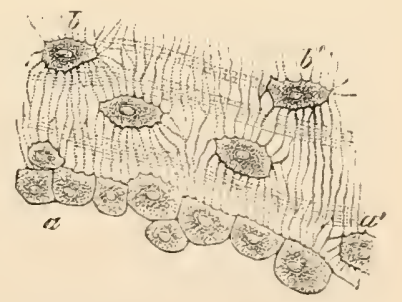

Fig. 45.-Bone tissue. $a$, Osteoblasts ; $b$, bone cells (after Gegenbauer).

bedded in the bone substance. New masses of bone substance being constantly formed from the osteoblasts, some of the latter come to lie in the bone substance, and become bone cells.

Dentine is nearly related to bone tissue. Here the formative cells (odontoblasts) do not enter into the dentine which they have secreted; they all remain at its base, but send into it numerous finely branched processes (fibres), which run parallel to each other in as many little 
channels of the bone substance. The fibres are connected by fine anastomoses.

It is clear from the above that bone tissue shows much similarity in its origin with gelatinous tissue, and dentine with epithelial cuticular formations.

The blood cells and lymph cells which float in the blood, the lymph or the colomic fluid of animals, at first rise out of connective tissne cells. The blood has even been described as fluid connective tissue, the blood fluid representing the intercellular substance, the blood corpuscles the connective tissue cells. Lymph corpuscles often show amoeboid movement, and are capable of taking in solid materials (e.g. products of excretion, food material, products of suppuration, and foreign bodies).

\section{Neuromuscular and Muscle Tissue.}

The elements of both muscle and nerve tissue originally come from the epithelial cells. Both tissues appear simultaneously in the animal kingdom, and are connected in their origin. In its simplest form neuro-muscular tissue is met with among the lower Colenterata (e.g.

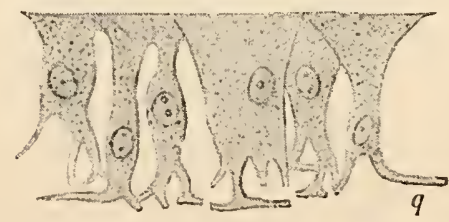

FIG. 46.-Neuro-muscular cells of the Hydra, after Kleinenberg. $q$, Muscle processes of the same.

Hylice). Here, in the outer epithelium, are found cells which form processes inward, and produce a layer of fibres close under the epithelium. These fibres are contractile, and represent muscle processes of the epithelial cells. The latter, which contain the nucleus, take part with their companions in limiting the surface of the body. These cells undertake the relations with the outer world, being suited to receive external impressions. The stimulus created by such impressions is carried through the protoplasm of the cell to the muscle processes, which contract in consequence. The cells, with their processes, are accordingly called neuro-muscular cells. In them the chief functions are of nerve and muscle tissue localised, in the most general undifferentiated manner, in different parts of one and the same cell. In consequence of the intimate connection of the neuro-muscular cells with one another, a locally created stimulus of one or more cells is communicated to the neighbouring cells, and thus to their muscle processes. The principle of the division of labour here again supplies the liey for understanding the further differentiation of neuro-muscular tissue. One portion of the neuro-muscular cells undertakes principally the function of contractility, and the greater part of its protoplasm becomes differentiated into contractile substance; another portion of the neuro-muscular cells, while remaining in close organic connection with the first, performs the function of receiving external impressions, 
changing them into sensations and carrying on the stimulus to the muscular elements.

In accordance with this, muscle tissue in its simplest form appears as a system of epithelial muscle cells (Fig. 47,a). They still lie in the epithelium, but no longer take part in limiting the body surface. They form inwards muscle processes which run under the epithelium. They are distinguished from neuro-muscular cells by the fact that their chief function is contractility, and that the body of the cell no longer acts as a neural portion. This cell body then appears merely a remainder of the original formative substance of the fibres; it lies below the upper epithelial cells, wedged in between them. In this way a neuro-

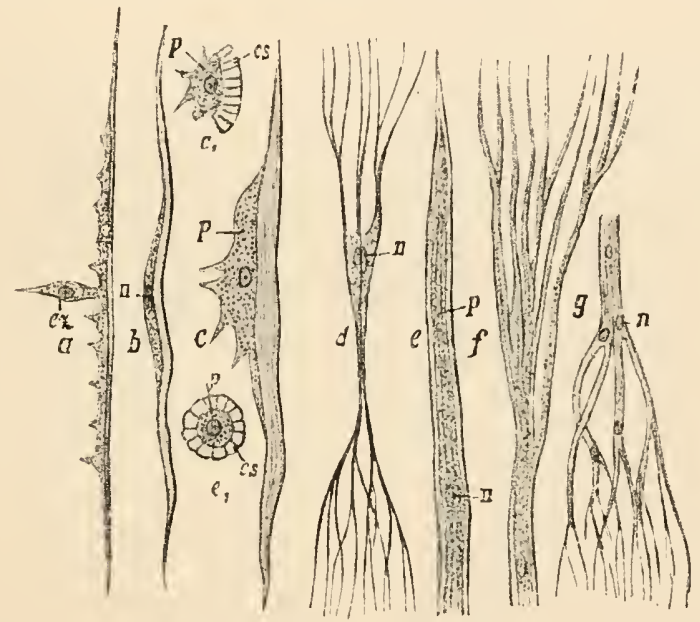

Fig. 47.-Muscle fibres. a, Epithelial muscle cell (ez), with fibre; $b$, sub-epithelial muscle fibre, with attached protoplasmic body, both of Cnidaria; $c$, longitudinal section of muscle fibre of a Nematode; $c_{1}$, transverse section of the same; $e$, of an Hirudo; $e_{1}$, the same in transverse section; $d$, dorso-ventral muscle fibre of a marine Planarian; $f$, the same of an Hirudo; $g$, branched muscle fibre from the jelly of a Ctenophore; $p$, protoplasm, or, in $e$ and $e_{1}$, medulla; $c$, contractile substance; $n$, nucleus.

muscular cell becomes an epithelial muscle fibre, with a protoplasmic body containing a nucleus attached to it. From this to sub-epithelial muscle fibres (Fig. 47,6 ) is a short step. These no longer lie in, but under the epithelium. They consist of a contractile fibre, which carries along its whole length, on the side bordering on the epithelium, a thin layer of protoplasm.

In other cases, e.g. in the Ctenophora, epithelial cells can leave their complex and enter into the jelly secreted below the epithelium. Here they often grow into fibres branched at each end (Fig. 47, g), whose protoplasm changes into a contractile substance. Such fibres are known as mesenchymatous muscle cells, as opposed to epithelial muscle cells. 
The above differentiations of muscle tissue are seen within the division of the Cnidaria. Tarious forms of muscle elements can here be found in one and the same animal.

Even if it is not impossible that muscle fibres respond to certain direct stimuli by contraction, it is generally characteristic of them that they respond only to stimuli communicated to them by the nerre elements.

A general division into two principal types of muscle fibres may be made: (1) smooth, and (2) transversely striated.

Smooth muscle fibres are almost always simple muscle cells. One single cell forms a fibre. The contractile substance is either formed by the cell on one side, so that the cell with the nucleus appear as an attached body (Fig. $47, c, c_{1}$ ), or the contractile substance becomes differentiated on the whole surface of the formative cell, and then tubular' muscle fibres arise (Fig. $47, e, e_{1}$ ). In these we distinguish the outer contractile corticle layer from the central medulla which contains the nucleus; this medulla fills the axis of the muscle fibre, and represents the more or less unchanged remnant of the protoplasm of the formative cell. The contractile substance of the smooth muscle fibres often appears longitudinally striated, and under the influence of suitable reagents separates into the fine long fibrillæ which are the cause of this longitudinal striation. The smooth muscle fibres are often branched at one or both ends, especially in those cases in which they have an isolated course (Fig. $47, d, f^{\prime}$ ). The above described muscle fibres of the Colentercta are of this sort.

Striated muscles.-These are considered as physiologically the most efficient muscle elements. Even among the Colenterata, the contractile fibres of the epithelial muscular cells appear transversely striated. The muscle processes of several cells unite to form a group of striated fibres. Striated fibres form the chief mass of the musculature in the Arthropoda and Vertebrata. They arise out of muscleforming cells, the greater portion of one such cell becoming differentiated into transversely striated fibre. The remainder of the protoplasm, with the nucleus, often persists on the surface of the fibre. Perhaps it is this protoplasmic layer which produces the Sarcolemma, the membrane which envelops the muscle fibre. In nearly all cases, however, the number of nuclei increases as the muscle fibre grows and differentiates further; the fibre is thus to be considered as a manycelled structure proceeding from one cell by incomplete division. Often, however, several cells lying one behind the other share in the formation of a muscle fibre. Striated muscle fibre appears not only transversely but longitudinally striated. The transverse striation comes from a regular alternation of singly refractive with doubly refractive elements.

There are, at the present time, many different opinions about the finer structure of the striated muscle fibre. According to the last view of Van Gehuchten, supported by investigations of the transversely striated muscle fibres in the Arthropoda, 
the muscle fibre, like the protoplasm of the cells in general, consists of a network of elose and very fine fibres, the spongioplasm, and of an intermediate homogeneous fluid substance, the liyaloplasm. The former is contractile and elastic, the latter is purely passive. In muscle fibres the spongioplasm is regularly arranged (Fig. 49, $\mathrm{A}$ ). It consists of parallel filaments, which run longitudinally and are bound by transverse filaments at regular intervals in a plane at right angles to the longitudinal axis. A transverse section lying in such a plane would form a plate with reticularly arranged filaments and hyaloplasm between them (Fig. $49, B$ ). There are no

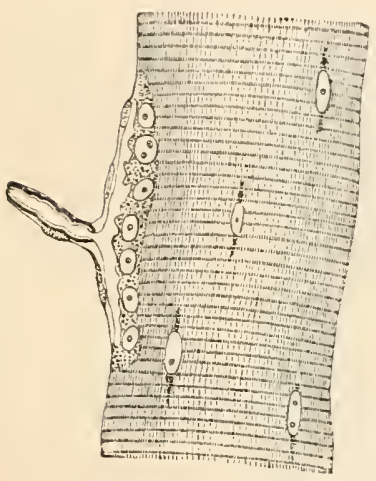

FIG. 48. - Transversely striated muscle fibre, after Gegenbauer.

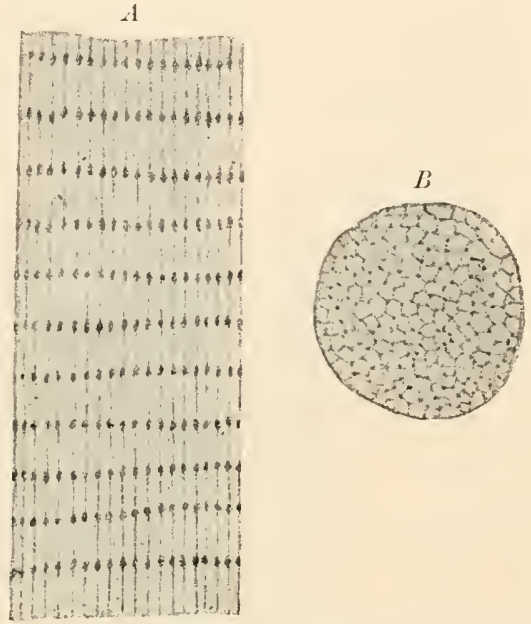

Fic. 49.-Transversely striated muscle fibre of an Arthropod, after Van Gehuchten. A, Lateral view. $B$, In transverse section.

transverse connections between the longitudinal filaments, except at these regular intervals, so that on a transverse section of the fibre made at any other part of it only the transverse section of the longitudinal filaments would be seen. It is clear how, by such an arrangement of the finer portions, the transversely and longitudinally striated appearance of the fibre conld be produced. There are weighty objections, however, to these views of Van Gehnchten.

The muscle fibres contract in response to stimuli transmitted to them by the motor nerve fibres. They therefore always stand in connection with the ends of such fibres in a manner which cannot here be further described.

Muscle fibres joined together by comnective tissue unite to form bundles, bands, or tubes. These again can be united in layers or in thick muscle strands.

Muscle fibres, smooth as well as striated, arise, even in many higher Metazoa, out of epithelium; in many of these, however, the muscleforming cells (Myoblasts) are descendants of cells which at an early stage of their development sank below the level of the epithelium to which they belonged. Both kinds of formation may occur in the same animal. 
CHAP.

\section{Nerve Tissue.}

As muscle elements pure and simple may be imagined to arise out of neuro-muscular cells by the gradual differentiation of most of the protoplasm of one part of the cell into contractile substance, the muscular function thus being brought to the front at the expense of the other possible functions, so nerve elements may be produced by the suppression of the contractile part of the cell and the further differentiation of the neural portion. We can perhaps imagine that the simple sensory cells of the body epithelium of the lower Metazoa arose in this way, always presupposing that they remained in connection

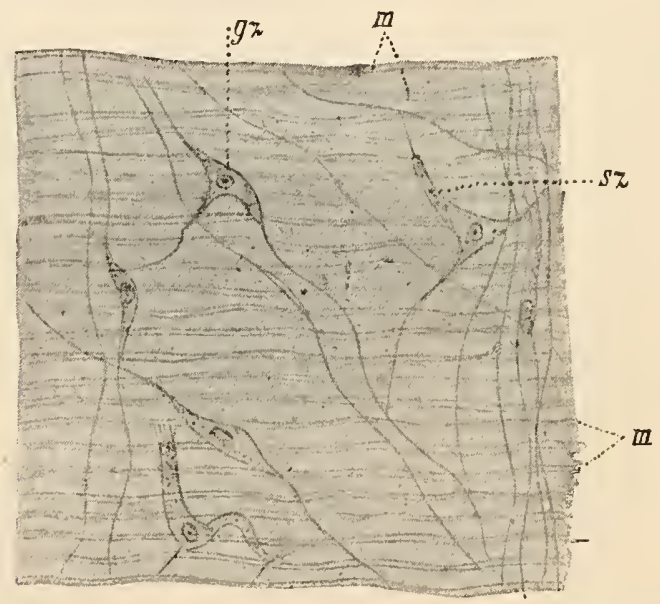

FIG. 50.-Piece of a muscle lamella of the septum of an Actinian (Anthea cereus), with nerve plexus, after $\mathbf{O}$. and R. Hertwig. $m$, Muscle fibres; $s z$, sensory cell, with sensory hair; $g z$, ganglion cell.

with the neighbouring contractile elements, either by simple contact or by processes. In this way a stimulus received by the sensory cells could be transmitted to the muscle cells. The sensory cells are epithelial cells, which are generally distinguished by a delicate, usually immobile, sensory hair, projecting outwards. Division of labour could then go further. Single sensory or nerve cells of the most undifferentiated sort, found in contact with other sensory cells and muscle cells, could give up their connection with the surface of the body and sink into the lower part of the epithelium, thus playing the part of intermediaries between sensory and muscle cells (Fig. 50), and transmit the stimulus received by the former to the latter. Such cells are found in many Colentercte. They are here already known as ganglion cells. They possess processes by which they are connected with each other and with the sensory cells and muscle fibres. They represent the 
central elements of the nervous system; in them the impressions which have come from the sensory cells become sensations which can be transformed into will impulses; from them proceed the stimuli which cause the muscle fibres to contract.

The nervous system becomes complicated as low down as among the Calenterata, but more especially in animals of a higher grade. Between the central parts, i.e. the ganglion cells on the one side, and

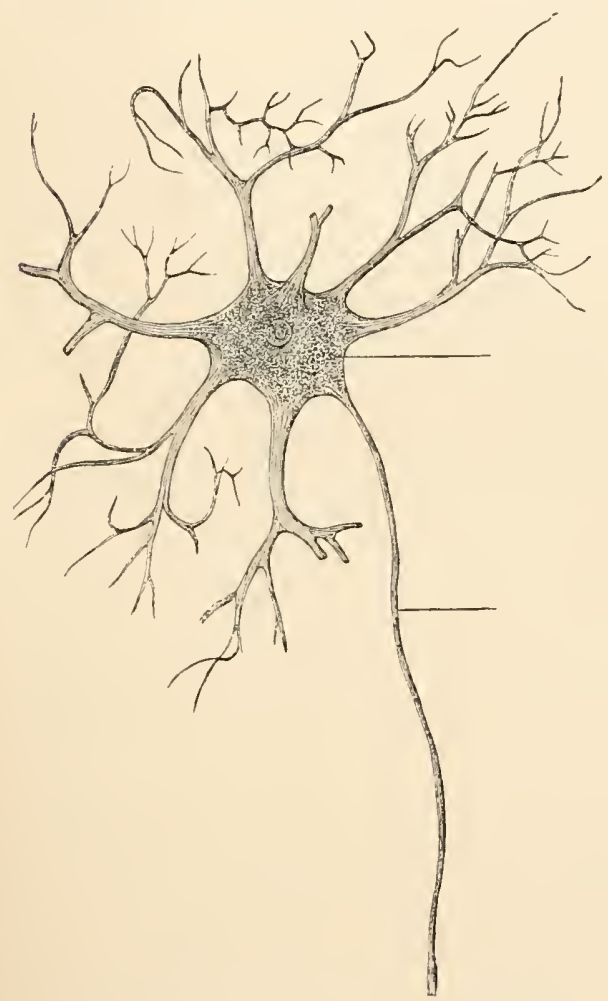

Fig. 51.-Ganglion cell from the anterior cornu of the human spinal cord (after Gegenbauer). $p$. Pigment; $n$. nerve.

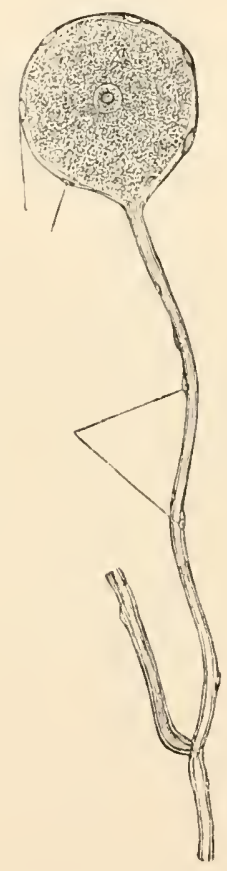

FIc. 52.-Ganglion cell from a human spinal ganglion (after Gegenbauer). $n$, Nuclei of the neurilemma.

the sensory and muscle cells on the other, nerve cells are interposed, which, being stretched like fibres, become nerve fibres. These undertake exclusively the function of the transmission of sense impressions from the sensory cells to the ganglion cells, and the transmission of stimuli from the ganglion cells to the muscle fibres.

Besides this, the glanglion cells no longer appear scattered, arranged in a plexus, but they unite into masses, which are defined as the central organs of the nervous system, e.g. the brain. The nerve fibres also unite into nerves. There are two sorts of nerve 
fibres: (1) Sensory nerve fibres, which transmit sensory impressions from the peripheral sensory cells to the central organ; (2) Motor nerve fibres, which transmit stimuli from the central organ to the muscles. The majority of sensory cells also do not remain in their undifferentiated condition. Division of labour steps in here also. Some cells seem specially suited for the reception of light and colour sensations, others for those of sound, others again for sensations of smell and taste. Tactile cells still remain in the most undifferentiated condition. Many sensory cells which are qualified to receive one and the same class of stimuli become, by the addition of accessory tissues, combined into complicated sensory apparati-the specifie sensory organs : the organs of sight, hearing, smell, taste, and touch.

The ganglion cells possess one or more processes (unipolar, bi-polar, multi-polar ganglion cells), one or more of which pass over into the nerve fibres, while others only serve perhaps for the nourishment of the cells. The process of a unipolar ganglion cell sooner or later divides into at least two branches, one motor and the other sensory. The ganglion cells in peripheral ganglion centres are often enclosed in envelopes of connective tissue.

Nerve fibres may have many branches, and are often finely striated in a longitudinal direction. They are either naked-in some of the lowest Metazoa-or enveloped in a sheath, the neurilemma, which is supplied by the surrounding connective tissue. When many nerve fibres form one nerve, the single fibres of this nerve are, among all the higher animals, kept apart from one another by this sheath; the whole then in transverse section produces the effect of a spongy tissue, in whose larger or smaller meshes the transverse sections of the nerve fibres lie. The neurilenma is not generally continued on to the ganglion cells.

A further distinction between two sorts of nerves has been made, especially among the Vertebrata: (1) nerves without medulla, which remain simple; and (2) nerves containing medulla, in whose fibres two parts are found-an outer oleagenous tubular medullary sheath, and a fibre surrounded by this-the axis-cylinder. On entering a ganglion cell, the latter alone penetrates its process-it alone represents the path of transmission. Both these sorts of nerve fibre are enclosed in neurilemma sheaths.

In many of the lower animals the nervous system remains for the most part in its original place of formation, i.e. in the body epithelium. In the higher animals the nervous system remains in connection with the body epithelium through the sensory apparatus. This helps us to understand why, in the embryonic development of the highest animals, the nervous system is always produced by the outer epithelial layer.

\section{Literature.}

Th. Schwann. Mikroskopische Untersuchungen über die Uebereinstimmung in der Structur und dem Wachsthum der Thiere und Pfansen. Berlin, 1839. 
A. Kölliker. Mikroshopische Anatomic oder Gevebelchre des Menschen. 1850-54. 3 Parts.

The same. Handbuch der Gevebclehre des Mcnschen. 5th edition. Leipzig, 1867.

F. Leydig. Lehrbuch der Histologie des Mensehen und der Thicre. Frankfurt, 1857. (A standard work.)

The same. Vom Bau des thierischen Körpers. Tübingen, 1864. Vol. I. with atlas.

C. Frommann. Zur Lchre von der Struetur der Zcllen. Jencische Zcitschrift für Naturwiss. Bd. IX. '1875.

W. Flemming. Zellsubstanz, Ken, Zelltheitung. Leipzig, 1882.

H. Frey. Handbuch der Histologic und Histochemie des Henschen. 3d edition. Leipzig, 1870.

L. Ranvier. Traité tcchnique d'Histologic. A German translation of the same by Nieati and v. Wyss. Leipzig, 187 7.

H. Fol. Lehrbuch der verglcichonden mikroskopischen Anatomic. Leipzig, 1884. Till now only the first part has appeared, treating of technical mieroscopy.

$\mathrm{Ph}$. Stöhr. Lekrbuch der Histologic. 2d edition. Jena, 1888.

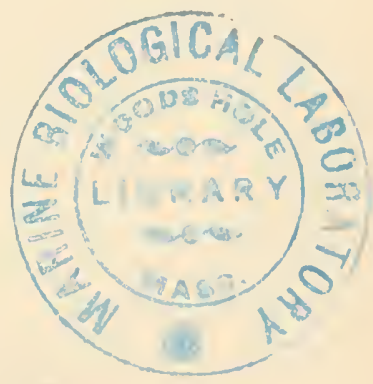




\section{CHAPTER II}

Introduction to the study of the Metazoa-Cœlenterata or Zoophyta as the lowest Metazoa constructed essentially of two cell layers-Yolk segmentation and formation of the two primitive germinal layers of the Metazoa (Gastræa theory).

\section{INTRODUCTION.}

In contradistinction to Protista or Protozoa we have real Animals or Metazoa. The bodies of the former consist of one single cell or of several similar cells (with the exception of $V o l v o x$ ), each of which, however, is competent to perform all vital functions (cell colony); the bodies of Metazoa, on the contrary, always consist of a number of cells which are not all similar, but have divided among them the different forms of vital activity (cell community). The division of labour may be more or less complete, and according to it the degree of morphological complexity and of physiological perfection is determined. There are animals which are morphologically (according to structure) and physiologically (according to their vital activities) only a little raised above the Protozoan colony, e.g. the Hydra.

The bodies of these animals consist of only slightly different sorts of cells: digesting cells, neuro-muscular cells, stinging cells, and formative cells of eggs and spermatozoa. All these kinds of cells are, however, indispensable to the existence of the Hydra body; not one of them can be removed from the borly without endangering its existence. The whole body is nevertheless physiologically an individual, but, as opposed to the cell, an individual of a second, i.e. a higher order - a person. Most animals remain at this stage of individuality. A Medusa, a Worm, a Crustacean, or a Mammal is such an individual of the second order. In many animal divisions, however, individuals of the second order multiply by fission or gemmation. The new individuals thus arising remain united, and together form individuals of the third order-an animal stock. The single individuals which collectively form such a stock may remain similar, and they then are related to the stock in just the same way as the cellindividuals of a Protozoan colony are related to the colony ; or division 
of labour again steps in, resulting in variety of development in body form and structure of the persons forming the stock (polymorphism). Then such a stock is also physiologically again an individual of the third order. The single persons become equivalent to instruments of this complex individual, and bear the same relation to it as the various cell elements of a single individual, e.g. a Hydra, bear to it. As instances of animal stocks without division of labour among the persons we have most Corals; and of stocks with far-reaching division of labour and polymorphism the Siphonophora.

Even in the lowest Metazoa the cell elements are not found scattered in the body without any special arrangement. On the contrary, we find even among the simplest Colenterata that they are arranged in two epithelium-like layers, which are closely contiguous and form the wall of the body, which is pouch-shaped and provided with an opening. In keeping with the physiological activities of the various cells, the stinging cells and the neuro-muscular cells form the outer layer, while the digesting cells form the inner layer, which is turned towards the pouch cavity, i.e. the gastric cavity. The reproductive cells lie protected in the deeper portions of the outer layer. These two layers, which occur in the development of all Metazoa, are called the Ectoderm and the Endoderm.

Either similar or dissimilar cells or tissues, therefore, may combine to form cell or tissue complexes. Such complexes are called organs when the cells or tissues combining to form them perform in common one or more functions. The endoderm of the Hydra is a primitive organ, all the cells of which undertake the digestion. The tentacles of the Hydra are slightly more complicated organs; they serve as organs of touch, as weapons, and as organs for seizing food. For these purposes they contain neuro-muscular and stinging cells. For the nutrition of the tentacles canals lined with endoderm enter them from the gastric cavity. In this way the most various elements are drawn into the service of one or of several functions after which the organs are named. We therefore speak of the sensory organs and the organs of movement, respiration, etc.

Several organs of the same sort with similar functions may occur in the same body (this is especially the case among the higher animals); these are then portions of an organic system-muscular system, vascular system, nervous system, etc.

The observation of the construction of the animal body out of cells, tissues, organs, etc., is the object of Anatomy, microseopic and maeroseopic. These become Comparative Anatomy when the structure of animal bodies is considered comparatively. Comparative anatomy, again, is the indispensable aid of zoology in one of its chief tasks-the discovery of the natural relations of affinity among animals and of the conjectural course of development of the animal world in the earth's history. Comparative anatomy seeks to define the relations of affinity between the different portions which combine to form the animal body. 
It deals naturally, not only with the bodies of animals now living, but also with the bodies of animals of past geological periods in so far as these are attainable in a fossilised condition; not only with the bodies of adult animals, but with all the consecutive stages of development of such animals. For an animal form is characterised not only by its structure in a fully grown and sexually mature stage, but by its structure in all the previous consecutive stages of its development. Comparative anatomy only considers organs, as we have already said, according to their structure and their connections of affinity, not according to their physiological activities. The relationship of two organs rests upon their descent from the same organ of a common racial form. The proof of this relationship establishes the Homology of the organs in different animals. Thus the anterior or posterior extremities of the Amphibia, Reptiles, Birds, and Mammals are homologous to each other and to the pectoral or ventral fins of the Fish, because these organs have a common origin. The limbs of the Vertebrata and those of the Arthropode are not homologous, but only analogous, because they cannot be referred to a definite organ in a common racial form. They were first formed independently within each of these groups, and the superficial similarity which they exhibit is only the result of their adaptation to the same function.

Zoological research has further proved that in the process of time organs can undertake functions quite different from those which they originally performed (principle of the ehange of functions). The airbladder of fishes, for example, is principally a hydrostatic apparatus used by these animals for rising or sinking in the water. At the same time, in certain fishes the air-bladder may also undertake the secondary function of a respiratory apparatus. This secondary function becomes in the higher Vertebrata the chief function; the lung rises out of the air bladder, and the original function is quite lost. The so-called rudimentary organs are of great importance in comparative anatomy; these are degenerated organs which are not in the condition to perform any useful function for the organism. They are remains of originally well-developed and functionally important organs, retained by inheritance, but in the act of clisappearing. Thus the human processus vermiformis is a small remainder of an intestinal cecum which is greatly developed in certain Mammalia of a lower order and energetically takes part in the work of digestion.

How is the rise of the lowest, simplest Metazoa to be imagined? This question is answered by various theories; one of these, the Gastræa theory, has been very generally accepted. This theory rests upon two series of facts:

1. In the development of very many Metazoa there arises, by repeated division of the egg cell, a hollow group of similar cells, which in its structure shows a general correspondence with a Protozoan colony (Volvox, Magosphoera). The cells of this group 
(blastula) arrange themselves in all Metazoa in a double layer, and in many cases they do this in the simplest manner, i.e. by the wall of the hollow sphere sinking in at one spot. The sunken portion lines the non-invaginated portion of the hollow sphere, and so we have a pouch with a double wall (ectoderm and endoderm). The inner layer, the endoderm, surrounds a cavity, the areh-enteron, which opens outward by an aperture, the primitive mouth or blastopore. The outer layer, or ectoderm, everywhere supplies the outer integument and the nervous system of the animal; the inner, the enteric epithelium and the glands which proceed from it. This germinal form is called Gastrula.

2. The body of one of the lowest Metazoa, e.g. one of the simplest Calenterata, throughout life consists of two layers, which in all essentials correspond with the two germinal layers of the Gastrula. The outer layer, the ectoderm, represents the outer integument; the inner, the endoderm, the epithelial wall of the intestinal cavity. The latter surrounds the intestinal cavity, which opens at one point, the mouth.

From these two series of facts the following conclusions may be drawn :-

1. All Metazoa are descended from one common ancestral form, which possessed essentially the structure of one of the lower Colenteratu. This hypothetical ancestor, the Gastrou, is met with in all Metazoa as a transitionary stage in their development-as a Gastrula.

2. The Gastrece itself arose in a similar way from a Protozoan colony in the shape of a hollow sphere by the formation and the gradual deepening of a depression, just as in the individual development of many animals the gastrula arises by invagination out of a hollow group of cells, the product of the segmentation of the egg.

\section{The three chief Divisions of the Metazoa.}

A. The body consists essentially of two layers-the ectoderm and the endoderm. There is no middle layer as a rule, and where such does oceur, its elose relation to either the ectoderm or the endoderm, or to both, is clear. Intestine with one external aperture-the mouth. A body cavity between the intestine and the integument is wanting ; so also are blood-vessels and excretory organs. A nervous system is either wanting, or, where it occurs, is little centralised.

Comprises: The Second Race or Phylum of the Animal Kingdom-Zoophyte or Calenterata.

B. With well-developed mesoderm sharply distinguished from the ectoderm and endoder'm. Gastric cavity with a single aperture opening externally (mouth). Body earity and blood-vascular system wanting. Excretory organs (water-vascular system) present. Nervous system centralised.

Comprises: The Third Race or Phylum of the Animal Kingdom-Platodes.

C. With well developed mesoderm, sharply distinguished from the ectoderm and the endoderm. Intestine, with two external apertures (oral and anal). Generally with a body cavity in mesoderm. Blood-vascular and excretory systems usually Iresent. Nervous system centralised. 
Comprises all the remaining races of the animal kingdom,-viz. the fourth, Termes ; the fifth, Arthropoda; the sixth, Mollusece; the seventh, Echinodermata; the eighth, Tunicatc; and the ninth, Vertebrate.

THE SECOND RACE OR PHYLUM OF THE ANIMAL KINGDOM.

\section{ZOOPHYTA OR CELENTERATA.}

\section{Systematic Review.}

CuAss I. Gastræadæ. Without pores in the body wall and without tentacles.

, II. Porifera or Sponges. With pores in the body wall, without tentacles.

, III. Cnidaria or Stinging Animals. Without pores in the body wall, with tentacles.

Of the three chief classes of the Colenterata, the Gastrcadce show essentially the structure of a Gastrula, while the other two groups contain animals more highly differentiated, which, developing in entirely different directions, camnot be comprehended in one description.

Class I.

The Gastræadæ.

Systematic Review.

A. The Physemaria, Haliphysema, Gastrophysema.

B. The Dicyemidæ. Dieyema (Fig. 53).

C. The Orthonectidæ. Rhopalure (Fig. 54).

Appendage: Trichoplax adhorens (Fig. 55).

The Gastrcedce are animals whose structure essentially corresponds with that of the Gastrula. In some forms the organisation is complicated; in others, no doubt in adaptation to the parasitic manner of life, somewhat simplified. The Physemariu are bi-laminar tubes attached to the sea bottom by that portion of their bodies which is opposite to the aperture. The ectoderm consists of fused cells (syncytium); the endoderm of collar cells, each with a flagellum. The sexual products are developed in the endoderm. Foreign bodies are contained in the ectoderm. Were the body wall of the Physemaria perforated by pores they would have to be considered as the simplest sponges.

The bodies of the Dicyemide (Fig. 53) and Orthonectidce (Fig. 54) which are parasitic in Cephalopoda, Echinodermata, and Turbellaria, also consist of two principal layers; the ciliated ectoderm forms an unbroken layer of not very numerous cells round the inner solid layer, which is generally considered to be endoderm, and this layer consists either (Orthonectide) of a mass of cells, or of one single multinuclear axial cell (Dicyemidce). The oral opening and gastral cavity have here disappeared in the same way as in the Cestoda. The body of the Orthonectide is outwardly ringed, and between ectoderm and endoderm has a layer of ectodermal muscular fibres. In the Orthonectide spermatozoa and eggs are produced in the endoderm, but in different 
dissimilar individuals. In the Dicyemide no spermatozoa have yet been discovered, but many egg-like germs, which apparently without fertilisation develop as eggs within the axial cell.

The course of development is as follows. The egg or the unicellular germ divides into two unequal portions. The larger segmentation cell which is thus produced (macromere) remains at first undivided, while the smaller (micromere) divides repeatedly. The descendants of the latter grow round the larger cell, finally completely surrounding it,

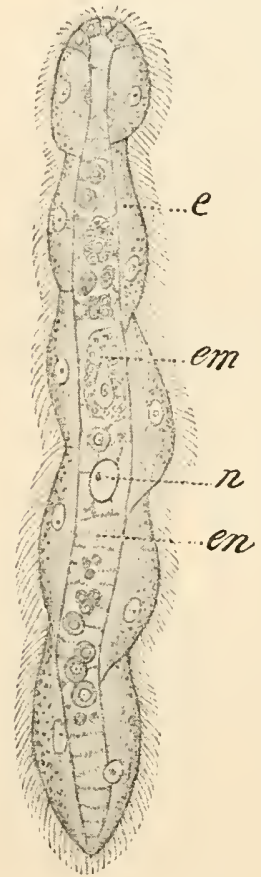

FiG. 53.-Young Dicyema, after Whitman. $e$, Ectoderm; en, endoderm cell, with nueleus (n); em, embryo.

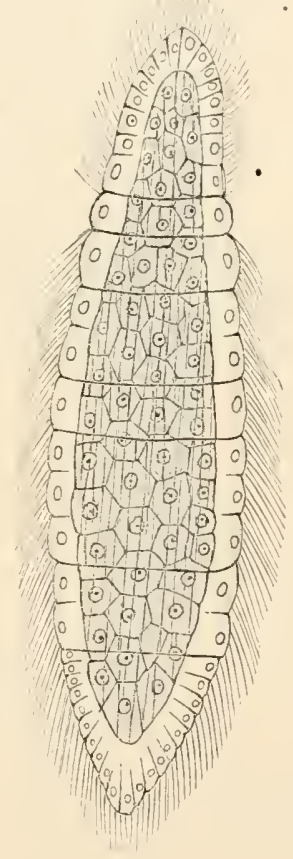

FIG. 54.-Rhopalura Giardii, $q$, after Julin.

and form the ectoderm, and, in the Orthonectide, the muscular fibres as well. The large cell remains undivided in the Dicyemidee and becomes the axial cell, while in the Orthonectidce it yields by division the group of endodermal cells.

Appendage : Trichoplax adhærens (Fig. 55).-This is a remarkable animal discovered in the Graz marine aquarium, which presents the appearance of a thin flat ciliated body like an Amaba, irregular and varying in shape. It is composed of three layers-the lowest, which adheres to the surface on which the animal rests, consists of cylindrical cells, the uppermost of tesselated epithelium. The layer 
between these consists of branched and partly anastomosing cells, which lie in a hyaline ground substance. The cells of the lowest layer possess processes, which pass into the processes of the cells of the middle layer without sharp distinction. As long as we have no know-

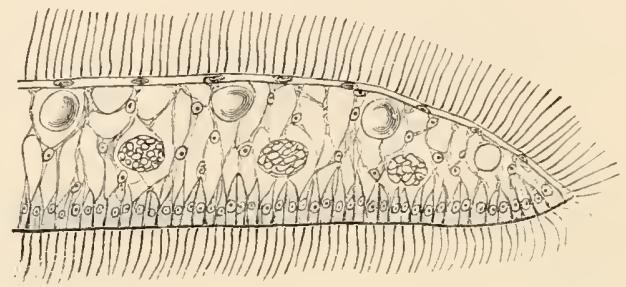

FIG. 55.-Part of a vertical section through the body of Trichoplax adhærens, after F. E. Schulze.

ledge of the reproduction and development of this animal, judgment as to its morphology must be suspended.

[Note.-Cf. p. 175. Where the author suggests that the Dicyemidee and Orthonectide, on account of their similarity to the sporocysts, are degenerated Trematodc. -Tr.]

\section{Literature.}

E. Haeckel. Biologische Studien. Heft II. 1877.

Ed, van Beneden. Recherehes sur les Dieyemides. Bull. Académie Belgique. Bruxelles, 1876.

C. 0. Whitman. A Contribution to the Enbryology, Life-History, and Classification of the Dieyemicls. Mittheil. aus cl. zool. Station zu Neapel. T. IV. 1882.

A. Giard. Les Orthonectides. Journal de l'Anatomie et de la Physiologic. T. XV. 1879.

E. Metschnikoff. Untersuchungen über Orthoncetiden. Zeitschr. f. wiss. Zoologie. Bd. 35. 1881.

Julin. Contribution it l'histoire des Mesozacircs. Arehives de Biologie. T. III. 1882.

F. E. Schulze. Ueber Triehoplax adhaerens. Zoolog. Anzeiger. Bd. VI. 1883. S. $92-97$.

\section{Cldss II. Porifera or Sponges.}

\section{Systematic Review.}

Sub-Class I. Calcaria. - Skeleton composed of spicules of carbonate of lime, always present. According to the structure of the soft body, Ascones, Sycones, and Lencones. Olynthus, Ascandra, Syeandra, Leucandra.

\section{Order 1. Calcispongiæ.}

Sub-Class II. Non-Calcarea.-Skeleton seldom wanting, but never of calcareous spicules, rather of siliceous spicules or spongin fibres. According to the structure of the soft body, Leucones. 


\section{Order 2. Hexactinellidæ.}

Siliceous needles, isolated or bound together by masses of silica into a continuous firm framework, tri-axial. Flagellate chambers cylindrical, placed radially, similar to the radial tubes of Syeandra. Host forms fossil. Living: Euplectclla, Hyalonema.

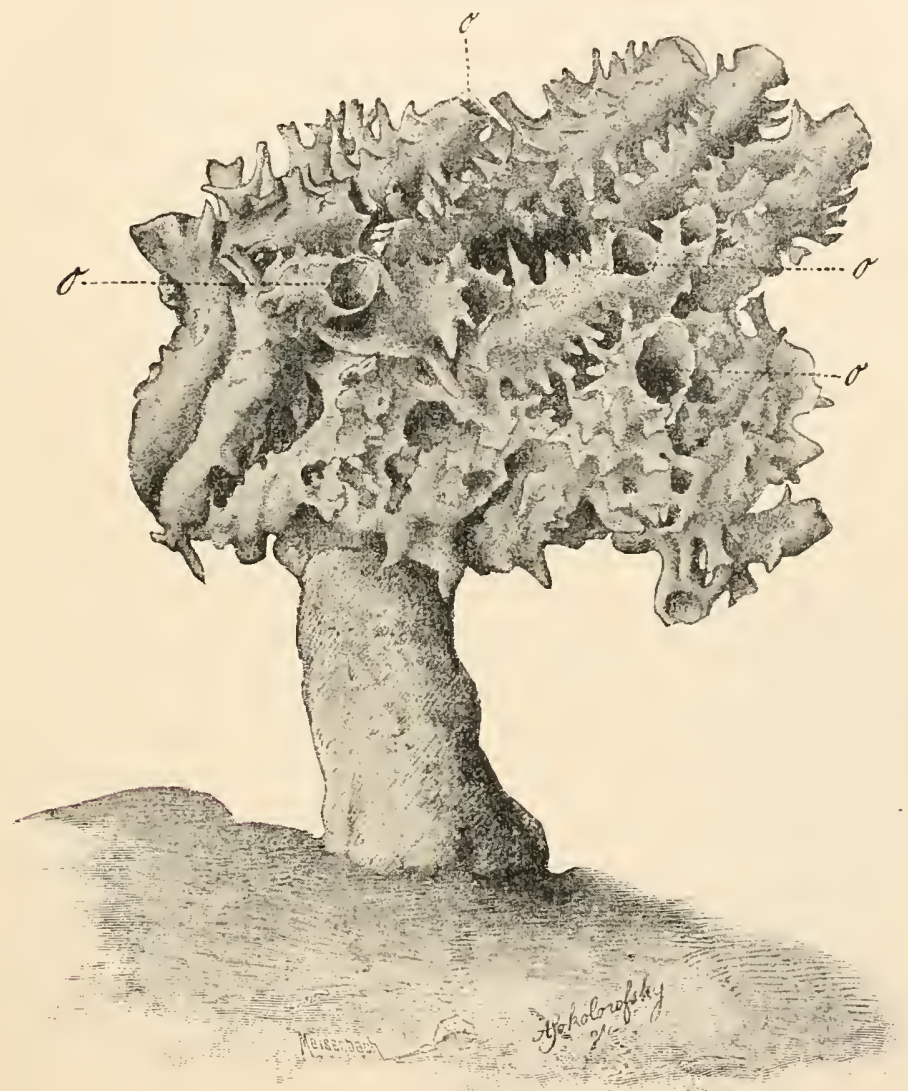

Fid. 56.-Skeleton of a horn sponge attached to a stone. o, Oscula.

\section{Order 3. Spiculispongiæ.}

Skeleton consisting of independent siliceous spicules of various kinds, rarely wanting. The spicules are often bound together into bundles by an organic substance, or form firmly comnected skeletons interlocking by means of knotty outgrowths; they are, however, never cemented together by siliccous masses. Geodia, Plakina, Chondrosia, Oscarella, and Halisarca (without skeleton), Tethya, Tuberella, Suberites.

\section{Order 4. Halichondrina.}

Skeleton composed of siliceous spicules, chiefly uniaxial, cemented togetler by a more or less horny substance (spongin). Halichondria, Reniera, Spongilla (in fresh water) Myxilla, Clathria. 


\section{Order 5. Ceraspongiæ (Fig. 56).}

Skeleton consists of horn fibres (spongin). Proper spicules wanting. Fragments of foreign spicules, sand, etc., are often used for strengthening. Spongelia, Euspongia officinalis (bath sponge), Aplysina.

The form of the body in the Poriferu is so wonderfully varied that no general description of it is possible, on account of their great variety in shape. Sponges or sponge stocks can be knob-like, pear-shaped, crust-like, funnel-shaped, cylindrical, or spherical. Many are irregularly branched. Some have a radiate structure. All are attached, or have part of their bodies buried in mud.

With the exception of the Spongillide, all sponges live in the sea.

In many sponges the external forms to be met with, even in one and the same species, varies to an extraordinary degree. The same individual even, in different parts of its body, may show differences of texture and structure, and variations in the composition of the skeleton.

The inner structure of sponges is not less varied. As an example let us take olynthus (Fig. 57). This sponge is vasiform and rather

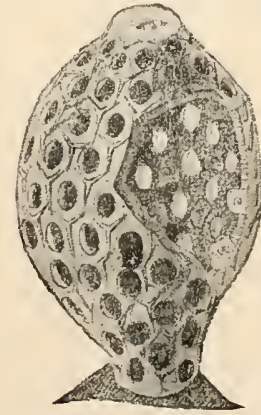

FIG. 57.-Olynthus, after Haeckel. thin walled; it is attached by its blind end, while the opposite free end is broken through by an opening (osculum). The body wall is perforated by pores which can open and shut. The water streams through the pores into the body cavity, which may be compared with the gastric cavity of the gastrula, and flows out through the osculum. The wall, as far as is at present known, consists of two layers: (1) an outer layer formed of a tolerably homogeneous fundamental substance, in which are imbedded cells and calcareous needles; (2) an inner epithelium of collar cells. Perhaps here also, outside the layer which contains the skeleton, there is a thin tesselated epithelium, in which case the body would consist of three layers - an outer ectodermal layer, an inner endodermal epithelium, and an intermediate mesodermal layer of connective tissue. Those sponges, which are essentially of the same degree of organisation as the Olynthus, are called Ascones.

A higher degree of organisation is attained when the body wall becomes thicker and cylindrical tubes or pouches arranged close together penetrate into the thickened wall radially round the central cavity (Fig. 58). The outer surface of the sponge is then often raised in numerous cones over these radial tubes. The radial tubes are lined with collar epithelium, while the epithelium of the central or gastral cavity is changed into a pavement epithelium. The onter pores in this case lead first into the radial tubes, from these into the central cavity, and thence through the osculum to the exterior. Sycones. 
In most sponges, however, the "canal system " is more complicated. The collar epithelium is limited to numerous so-called "ciliated chambers," which are sac-like, and generally lie scattered in the much thickened mesoderm of the body wall (Fig. 59, $g k$ ). The pores of the outer surfaces of the body lead into muchbranched canals of varying width, which are lined with tesselated epithelium; these, as afferent eanals, enter the ciliated chambers. Other canals of varying width, which often unite into larger canals, lead out of the chambers as efferent eanals into the variously shaped central cavity, which again opens outward by means of an osculum. Such forms are known as Leucones.

The movement of the flagella of the collar epithelium maintains a constant stream of water through the canal system of the sponges. The water enters by the pores, passes through the canal system, and flows out again through the osculum.

The canal system may vary extraordinarily in details. Its structure and arrangement are of importance in classification.

The coalescence of the afferent canals often causes a system of large lacunæ and cavities lying quite near the surface, the sub-dermal spaces; into these the pores open either directly or throngh canals, the water prassing on from the sub-dermal spaces by special canals into the ciliated chambers.

The caul system of the sponges may be greatly dereloped in comparison with the solid matter of the middle layer (mesoderm), or the solid tissue may preponderate. In the first case the sponge has a loose, in the second a firm, texture.

The mesoderm of the sponges is represented by a middle layel of connective tissue, chiefly gelatinous, with cells imbedded in it. The latter are either spindle-shaped or star-shaped, occasionally vacuolated. Some of them often contain colouring matter (pigment cells); others can move like Amcebce (migratory cells). Long spindle-shaped and finely-branched cells occasionally lie concentrically at the commencement of the afferent canals, and no doubt serve as contractile cells for closing the pores.

The mesodermal connective tissue is, in sponges, the place of formation of the very raried skeletal structures. These consist either of carbonate of lime, or of silica, or of horn known as spongin. 
Skeletons of silica and of horn fibres are found combined. The siliceous or calcareous skeletons consist of small bodies of extraordinarily different shapes, the so-called spicules, most probably formed in the

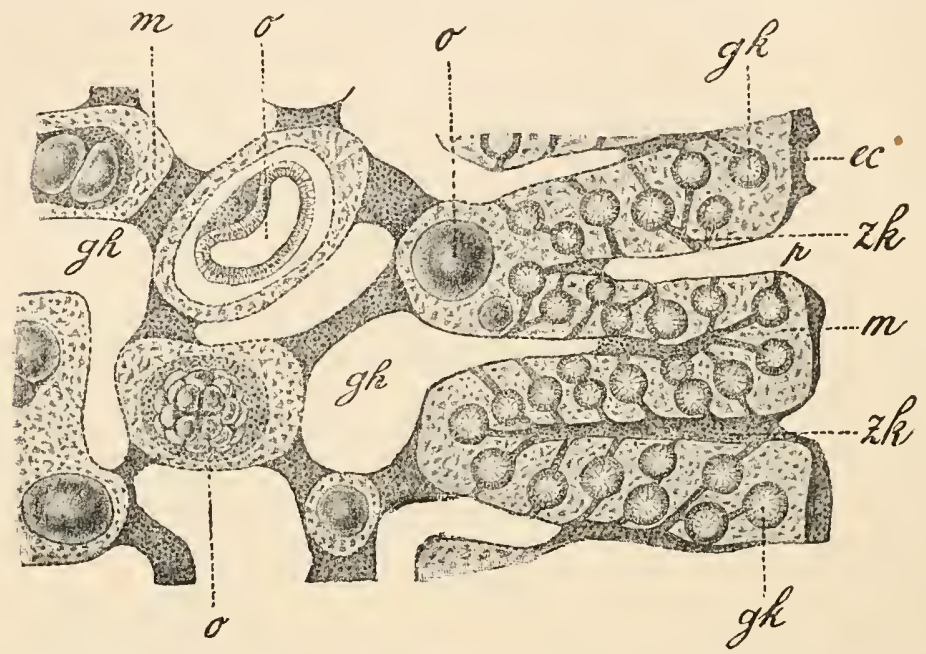

FIG. 59. - Part of a section through Halisarca lobularis, after F. E. Schulze. $e c$, Ectolermal pavement epithelium; $g h$, gastral cavity ; $m$, mesoderm ; $p$, pores ; $g h$, ciliated cliambers ; $z k$, aflerent canals; 0 , eggs in different stages of segmentation.

cells. There are uniradiate, triradiate, quadriradiate, sexiradiate, multi. radiate forms, stars, spheres, etc. The skeleton of a sponge may con-

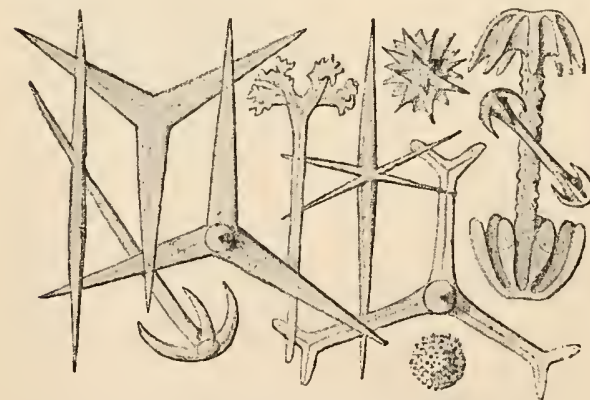

Fig. 60.-Various forms of skeletal spiculæ from Sponges. sist of only one sort of spicule, or two or more sorts may occur together.

The single spicules lie either loosely near each other, or are cemented together into coherent frameworks. The same is the case with horn fibres. The ordinary bath sponge is only a framework of such horn fibres; it is merely the skeleton of a marine animal (Fig. 56).

A nervous system is not yet with certainty proved to exist in the Poriferc.

Reproduction is either asexual or sexual.

Asexual reproduction takes place by external or internal budding or gemmation.

External gemmation.-A sponge may put out buds at various 
points of the body surface. These, without detaching themselves, grow larger, and can in their turn form buds. Sponge colonies thus arise. As buds may at various points grow together, the colony itself may again have the appearance of a plexus or framerrork. The holes and interspaces of such a colony may then again assume the character of a canal system (pseudo-canals). These must, however, according to their origin, be sharply distinguished from the real canal system which runs through the walls of every sponge individual Separate sponge individuals may also fuse and form colonies. The number of oscula generally corresponds with the number of individuals which form the colony (Fig. 56, o).

In the so-called internal gemmation groups of cells called gemmulæ detach themselves from the sponge body, and after a period of rest develop into complete sponges. Observer's differ as to the finer processes which take place during the derelopment of these gemmulie.

Sexual reproduction.- Sponges are either hermaphrodite or direcious; in the former case the eggs and spermatozoa are not produced at the same time in the same individual or colony; they are protandrously hermaphrodite. The eggs and spermatozoa seen to develop from mesoderm cells.

Development. - The course of development of the sponge from the fertilised cgg, which often begins within the mother body, seems, to judge from the as yet insulficient and often contradictory observations which have been made, to be so raried

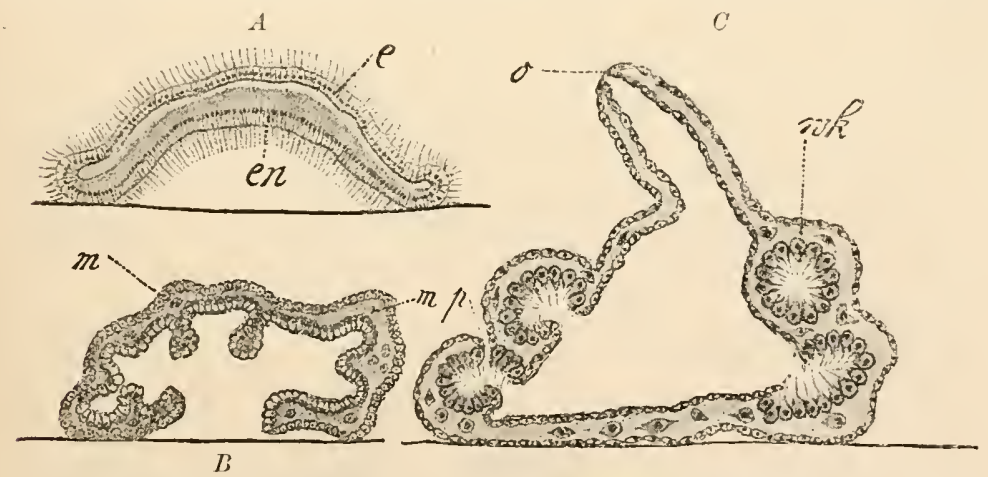

FIG. 61.-Sections of three stages of development of Oscarella lobularis, after $\mathrm{K}$. Heider. $A$, Gastrula which has attached itself. $B$, Ruliments of mesoderm and canal system. $C$, Formation of the osculum and ciliated chambers. e, Ectoderm; en, endoderm; m, mesoderm; o, osculum ; p, pores; $w \%$, ciliated chambers.

that it is hardly possible to form a generally applicable scheme. We select the newly investigated derelopment of Oscarella (Halisarca) lobularis (Fig. 61).

By means of repeated egg division a freely swimming larra arises, the Blastula. This is a hollow sphere, whose wall consists of one single layer of flagellate cells. The blastula by invagination becomes a gastrula. This attaches itself by the gastrula mouth or blastopore, and the aperture gradually narrows and finally closes. 
Gelatinous substance is secreted between the ectoderm and endoderm, and into this cells migrate most probably from the endoderm. Thus the connective tissue mesoderm arises. At the same time radial invaginations of the endoderm which lines the arch-enteron are formed in the mesoderm, and grow towards the ectoderm. These invaginations are romded off and become the ciliated chambers $(w h)$. Their communication with the gastric carity becomes narrowed. The ciliated chambers become connected with the surface, either by the formation of pores through the external membrane (in the case of chambers lying superficially), or by the formation of short invaginations of the ectoderm, which finally reach the ciliated chambers. The osculum arises at the aboral pole, by the lengthening and breaking through of the body cavity. Sycone stage.

According to these observations, the epithelium of the ciliated chambers, the efferent canals, and the central cavity (gastric cavity) is of endodermal origin ; the tesselated epithelium on the surface of the body and the epithelium of the afferent canals (at least partly) of ectodermal origin.

According to other observers, in fresh water sponges the ectoderm is thrown off by the larva, and the whole adult sponge is derived from the endoderm.

The observations of several investigators agree in establishing the fact that the gastrula of the sponge attaches itself by the edges of the blastopore. The osculum of the sponge therefore represents neither the blastopore of the gastrula nor the mouth of the Celcntercta. The Porifere thus appear as a laterally developed group' of the lower Metazoa, which do not admit of direct comparison with other Colcntercetce, but are only distantly related to them.

\section{Literature.}

0. Schmidt. Dic Spongion des Adriatischen Mecres. Leipzig, 18622. Drei Supplemente, 1864 bis 1868 .

The same. Grundsüge ciner Spongienfance des attantischen Gebictes. Leipzig, 1870.

E. Haeckel. Dic Kalkschwïmme. 3 Bde. Berlin, 1872.

0. Schmidt. Die Spongienfaune des mexikenischen Mecibusens und des caraibischen Hecres. Jena, 1880.

F. E. Schulze. Thtersuchungen über den Bau und dic Entwickelung der Spongion, in Zeitschrift f. $w$. Zoologic. Bd. 25-35. 1876-1881.

G. C. Vosmaer. Porifore. In Eronn's Klasscn und Ordnungen des Thiorreichs. Leipzig, 1882.

N. Poléjaeff. Report on the Calcarca in Chall. Exped. Rep. vol. VIII., part XXIV. London, 1883.

F. E. Schulze. Ficport on the Hexactinellide. Chall. Exped. Rep. vol. XXI., part LIII. London, 1887.

Comprare also the older works and treatises of Grant, Lieberkiihn, and Bowerbank, and newer investigations of Zittel, Barrois, Keller, Heider, Iarshall, Lendenfeld, Götte, etc.

\section{Class III.-Cnidaria.}

\section{Systematic Review.}

\section{Sub-Class 1. Hydrozoa.}

Prototype: Hydropolyp or Hydrula. In all Hydrozoa an ectodermal œsophagus is wanting; the mouth leads direct into the endodermal gastric carity. Gastral filaments are wanting. The sexual products mostly arise from the ectoderm. The sexes are generally separate. 


\section{Order 1. Hydridæ Fresh-water polyps).}

Single intividuals or small stocks without envelopes consisting of a few similar indiriduals. Reproduction asexual by gemmation, and sexual. Hydra develop̨ direct from the egg. Hermaphrodite. Hydre, in fresh water.

\section{Order 2. Hydromedusæ.}

Hydroid colonies, which are at least dimorphic, since, besides the sterile mutritive nolyps, there arise by gemmation sexual persons, which either detach themselves as Crospedote Medusce and swim abont freely, or remain united with the colony as medusoid gonophores. In one series of Hydromaluse the attached Hydroid form is

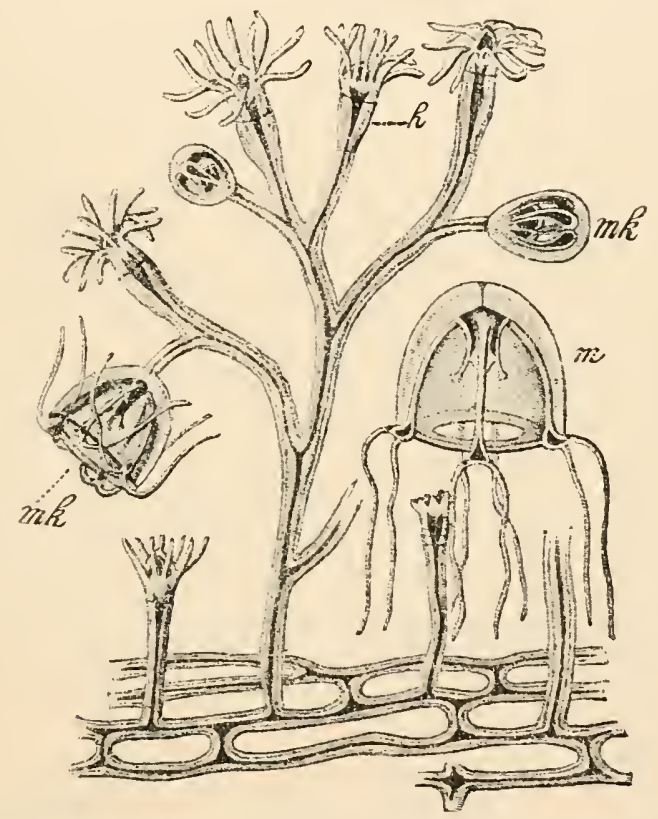

Fig. 62--Bougainvillea ramosa (after Allman), with budding Medusie. $h$, Nutritive polyps; $m k$, Medusa buds; $m$, detached young Medusa (Margclis ramosa).

suplressed, as the Crospedote Meduse develons direct from the fertilised egr into another Hedusce. The systematic relationship of single forms is naturally determined both by the Hydroid and by the Iedusa forms. As the whole life-history and development of only a minority of the many species is available, and in many species only the Hydroid form is known, in other's only the Medusa form, a natural system of the Hydromeduse is still a desideratum.

\section{Hydroid form.}

\section{Medusa form.}

\section{Sub-Order 1. Hydrocorallia.}

Hydroid stocks, with calcified periderm skeleton. The sexual products are Wanting. produced in gonoulhores. Stylaster, Hillepore. 


\section{Hydroid form.}

\section{Sub-Order 2.}

\section{Medusa form.}

\section{Anthomedusæ.}

Small hydroid colonies, naked or covered with a chitinous envelope (periderm). The chitinous envelope never widens into a cup (thece) round the poly? head. In many forms the Mcaluse are reduced to gonophores, which do not detach themselves.

Syncoryne Sarsii.

Podocomyne carizca.

Eudendrium ramosum.

Bougainvillea ramosa (Fig. 62).

Stauridium clatonema.

Cordylophora lacustris \}

(in fresh water).

Tubularia laryax.

Unkinown.

\section{Examples.}

Cruspeclote Menzer, without marginal vesicles and otoliths, with ocelli at the bases of the tentacles. Gonades in the outer wall of the gastric peduncle: 4 , seldom 6 or 8 , radial canals.

\author{
Sarsia tubulosa. \\ Dysinorphosa carnea. \\ Lisuse octocilia. \\ Irargetis ramosa (Fig. 62, m). \\ Cladoneme radiatum. \\ Wanting. \\ -Wanting. \\ Ctenaria etcnophora.
}

Sub-Order 3.

\section{Campanaria.}

Small hydroid stocks with chitinous periderm, which widens round the polyphead into a theca, into which the head with the tentacles can be withdrawn. The Medusa buds or sessile gonophores generally arise united into grouls in special modified polyls devoid of tentacles and mouth (gonangia). 


\section{Hydroid form.}

mouth and tentacles, and they are surrounded by a chitinous periderm. It is as little known in this case as in that of the Hydrocorallia, whether these gonophores are degenerate. INolusce which remain sessile, or simple sexually differ. cntiated Hydropolyp buds.

\section{Sub-Order 4.}

Wanting.

Wanting.

Sub-Order 5.
Medusa form.

\section{Trachomedusæ. \\ Crespedote Meduse with auditory or- gans (tentaculocysts), with cndodermal otolith cells, which sometimes stand freely on the margin of the umbrella. sometimes enclosed in auditory capsules, Ocelli generally wanting. Gonades always in the course of the radial canals. Number of radial canals 4, 6 , or $S$, never more: between them often blind centri- jetal canals. Direct development with metamorphosis. Otindias Müllevi, Itho- palonema velatum, Aglantha digitalis, Geryonia proboscidalis, Carmarina herstecte.}

Order 3. Siphonophora.

Polymorphic, freely swimming Hyclrozoce stocks, whose individuals or persons, Crespedote Medusce, are modified for special functions. 


\section{Sub-Order 1. Siphonanthe.}

The heteromorphic persons bud on a rariously formed stem, which may be compared with the gastric peduncle of a Medusc.

Family 1. Calyconecta.-Without jmeumatophore and feeler (taster); with one or more swimming bells at the upper end of the stem. The remaining heteromorphic persons arranged in groups (cormidia), which can detach themselves from the stem as Eudoxice and Ersace. Praya (Fig. 85, P. 111), Diphyes, Abyla, Hippopodius.

Family 2. Physonecta.-With pmeumatophores, without aurophore, with sereral swimming bells, and with feelers. Apolemia, Agalma, Anthemodes, Halistemma, Physophora, Forshelia.

Family 3. Auronecta. - With one large pneumatophore, under which stands a circle of swimming bells, and in the dorsal middle line of the latter a large medusoid air bell (aurophore), which secretes gas, and may be considered as a modified swimming bell. Stem shortened and thickened. Without feeler (?). Stephatia (Fig. 84, p. 110), Auratic, Phodatia.

Family 4. Cystonecta.-With large pneumatophore, without aurophore. Swimming bells and covering pieces wanting. Physophyse, Physalia. Stem under the pmemmatophore very much shortened, and flattened into a disc.

\section{Sub-Order II, Disconanthe.}

The heteromorphic indiriduals bud from the under side of a dise, which contains a many-chamlered pneumatophore, and may be compared with a Mcdusc umbrella. The margin of the disc earries a ring of numerous tentacles. In the middle of the subumbrella stands the central gastric peduncle as chief siphon.

Family 5. Disconecta._Discatia, Porpita, Porpalia (Fig. Si, p. 114), Velelle.

\section{Sub-Class II. Scyphozoa.}

Prototype: The Scyphopolyp or the Scyphuld. In the Seyphosoc we find an ectodermal cesophagus. Gastral or mesenterial filaments are present in all cases on the septa or gastric ridges. The sexual products arise out of the endoderm. The sexes are grenerally found in separate individuals.

\section{Order 1. Anthozoa (Corals).}

Attached individuals or colonies. The body remains essentially on the same grade as the Scyphula. The ectodermal cesophagus sinks in the form of a tuhe into the spacious gastric cavity, and round it the latter is divided by septa into a variable number of separate pouches. The free internal edges of these septa run through the gastric cavity to the aboral end of the body.

\section{A. Octocorallia.}

Sub-Order 1. Alcyonaria.-Generally with 8 septa and 8 pinmate tentacles. Polyp' colonies of very various shapes. Skeletal forms very raried. Aleyonium, Pennatula, Kophobelcmnon (Fig. 63), Gorgonia, Isis, Tubipona.

\section{B. Tetracorallia.}

Sub-Order 2. Rugosa.-Number of septa great, a multiple of 4 . With calcareous skeleton. Fossil Paleozoic forms. 


\section{Hexacorallia}

Sub-Order 3. Antipatharia (horn eorals). - With 6 or 24 simple tentacles. Colonies with horny axial skeleton. Antipathes ( 6 tentacles, only 2 dereloped septa), Gerardia (24 tentacles and septa).

Sub-order 4. Madreporaria (stone corals). - Mostly colonies, more rarely individuals with strongly developed caleareous skeleton. $6 n$ simple tentacles, and septa present in great numbers and varionsly arrranged. Madrepora, Astroides, Fungia, Astrcea, Mceandrina, Cladocora, Caryophyllia, Flabellum.

Sub-Order 5. Actinaria (flesh corals). Mostly individuals with $6 n$ tentacles, and septa generally in considerable numbers and varied arrangement. Without skeleton. Cerianthus, Zoonthus, Aetinia, Anemonia, Adamsia, Edluedrdsia.

\section{Order 2. Scyphomedusæ (Acraspeda).}

Mostly free-swimming individuals of bellor dise-shape, in which the mesodermal supporting lamella is developed into a large gelatinous mass. The ectodermal cesophagus lies within a gastric peduncle which hangs down from the middle of the subumbrella. The 4 radial pouches of the Scyphula degenerate in the higher forms. The exumbrellar and subumbrellar walls of the peripheral portion of the gastric cavity grow together in such a way that only a variously developed system of radial gastro-canals remains. With tufts of gastral filaments. A true velum is wanting; in its place, marginal lobes, containing processes of the gastro-canal system are present.

A. Mcdusce with deeply vaulted umbrella.-The 4 radial gastric pouches and the septa which separate them more or less clearly retained.

Sub-Order 1. Stauromedusæ. -4 septa retained (Istecrnaric) or reduced to 4

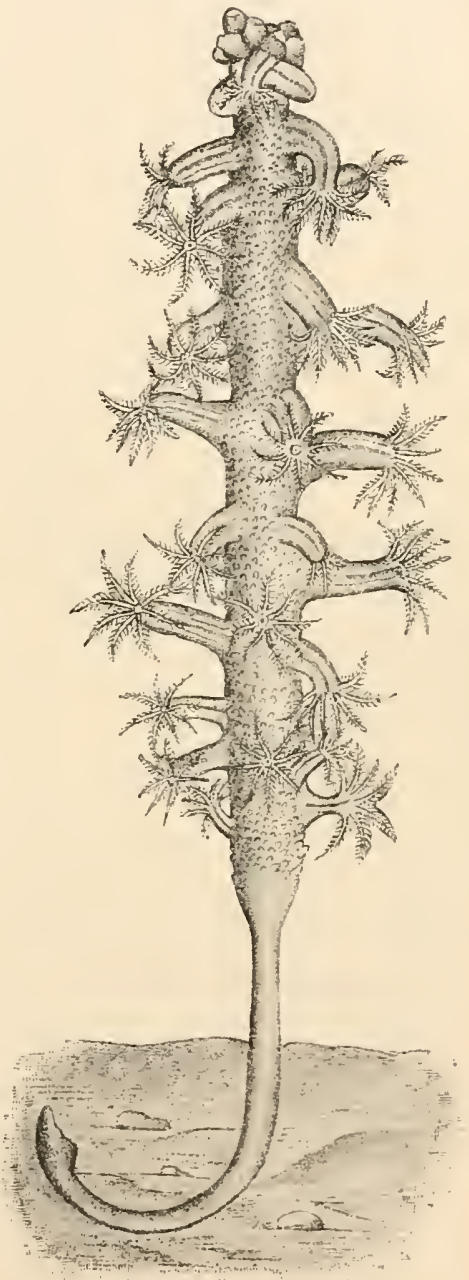

FIG. 63.--Kophobelemnon Leuckartii pillars (Tessera), 4 or 8 gonades in the subumbrellar wall of the 4 gastric pouches, without sensory bodies (rloplalia). Lucernaric (attached, with \& inarginal lobes, each carrying a tuft of stinging batteries). Tesserce (free, without distinct marginal lobes, with 8 tentacles).

Sub-Ordcr 2. Peromedusæ.-The 4 septa reduced to 4 pillars, in consequence of which the 4 gastric ponches are united into a circumferential sinus. With 4 
inter-radial rhopalia. S or 16 marginal lobes, 4 or 12 tentacles. Pcricolpe, Periphylla.

Sub-Order 3. Cubomedusæ (Charybdeidæ). 4 septa retained. 4 pair of gonades on the septa, freely protruding into the gastric pouches. With 4 perradial rhopalia, which contain tentacnlocysts with endodermal otolith sacs, and are provided with one or more eyes. 4 interradial tentacles or tufts of tentacles. Mostly witl velarimm. Charybdea, Chirodropus.

B. Mecluse with flat, disc-like umbrella.-The 4 primary gastric pouches of Scylhula degenerated by disappearance of the septa, instead of which there are 8 , 16,32 , or more radial canals of varying width, and often branched or anastomosing, as survivals of the gastric cavity on the growing together of the subumbrellar and exumbrellar intestinal walls. The 4 interradial gastric ridges or tænioles are retained as remains of the septa, and these carry the phacelli, or tufts of gastral filaments. Derelopment either direct with metamorphosis, or with alternation of grenerations. In the last ease an attached Scyphule arises ont of the gastrula and develoj's into a young attached Mcdusa (Scyphistoma). This multiplies in most cases by a sort of repeated fission or gemmation (strobilation). The constricted IFchese (Ephyra) changes throngh metamorphosis into the adult form.

\section{Sub-Order 4. Discomedusæ.}

Family 1. Cannostomæ.-With simple mouth tube, without oral arms, with square mouth, and short solid tentacles. Nausithoë (Fig. 67, p. $7 \tilde{i}$ ).

Family 2. Semostomæ. - With 4 long flag-like oral arms and cross-shaped mouth. With long hollow tentacles. Pelagia noctituea, Cyanea, Auretia aurita.

Family 3. Rhizostomæ.-Mouth grown together. With numerous small suckers on the 8 long root-like oral arms; without tentacles. Cassiopece, Pilcme (Rhizostoma), Cotylorhiza, Crambessa, Cannorhiza (Fig. 70, 1. 85).

\section{Sub-Class III. Ctenophora.}

Cnidaria with sensory bodies at the aboral pole; with 8 meridional rows of ciliary or ctenophoral plates, with ectodermal nesophagrts. Without gastral filaments. Develorment direct, without alternation of generations. MIesodermal jelly strongly developed, with muscle, nerve, and comnective tissue elements. Hermaphrodite.

Order 1. Tentaculatæ. - With 2 capturing filaments with one row of simple lranches; the filaments can be withdrawn into saes situated in the lateral lerradii. Gastro-canals ending blindly.

Family 1. Cydippidæ._-Body globular or egg-slaped. Hormiphora (Fig. 68, 1. 79).

Family 2. Lobatæ. - Body compressed in the lateral plane, with 2 oral lobes in the median plane. Euchuris.

Family 3. Cestidæ.-Body band-like, compressed in the lateral plane, without oral lobes. Cestres.

Order 2. Nuda. - Without capturing filaments. Mouth wide, œsophagus very spacious. Gastro-canals much branched and anastomosing.

Fanily 4. Beroidæ.-Bcroë.

The Hydrozoc and Scyphozoc probably descend from attached forms, which are only distinguished from gastrula attached by the aboral jole, either, on the one hand (Hyclrozoa), by their possession of circumoral tentacles, or, on the other (Scyphosoa), by the formation of an ectodermal cesophagns. Indications of this descent can still be seen in the freely swimming Hydromedusce and Scyphomedusce in their radial 
structure and in the absence of all organs at the aboral side of the body (exumbrella), i.e. at that part of the body by which the stationary forms are attached; and further in the fact that very many Hydromeduse and many Scyphomedusce actually pass through such a stage of attachment in the course of their development. As for the Ctmophora, their descent from attached forms, and, generally, their position among the Cnidaria, seems very doubtful. The presence of complicated sensory bodies at the aboral pole, and the constant occurrence of 8 rows of rowing plates with correspondingly arranged gastro-canals, and the marked departure from the strictly radial tyle, point to the fact that in their case the adoption of the swimming manner of life dates very far back.

\section{General.}

We shall better understand the varied organisation of the Ciniluriu if we keep clearly in mind that they can in all cases be referred to one of the three following forms:

(1) the Hydropolyp or Hydrula, (2) the Scyphopolyp or Scyphula, (3) the itewiohora.

1. The simplest form (from which all others can be dednced) is that of the Hydropolyp or Hydrulu.

A Hydropolyp (Fig. 6t, A) (type : Hiylou) is a pouch-shaped gastrula attached by its aboral pole, and possesses, round its mouth, hollow tentacles as evaginations of the body wall. The gastric cavity is continued into the tentacles. Between endoderm and ectoderm there is a structureless supporting membrane $(s l)$.

A more highly developed form, the Cirspedote Medusa (Fig. 64, E) may proceed from the Hydropolyp by adlaptation to a free-swimming manner of life. The aboral portion of the Hydropolyp boly (from the attached pole to the tentacles) spreads out like an umbrella or bell, and becomes the exumbrella of the Medusu. The oral portion of the borly (from the tentacles to the

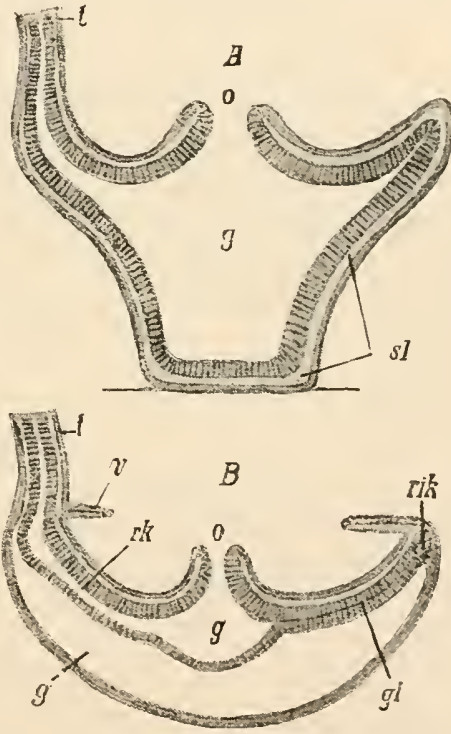

Fra. 64.-A, Diagram of a Hydropolyp (longitudinal section); $\mathbf{B}$, of a Craspedote Medusa. 0 , Mouth; $g$, gastric cavity; $t$, tentacle; sl, supporting lamella; $g^{\prime}$, jelly be. tween ectoderm and endoderm; $r k$, radial canal; gl, vascular lamella or cathammal plate; $v$, velum; rit; circumferential canal. mouth) also widens out, deepens, and becomes the subumbrella. The thus have a convexo-concave body, on whose circular margin the tentacles are radially arranged (Fig. 65, $A$ ). The mouth lies in the middle of the concave side, and generally on the summit of a projection (gastric peduncle, gastric tube).

The supporting membrane of the IIydropolyp thickens very much, 
and becomes the gelatinous dise of the Medusu, an elastic passive organ for locomotion and support. The partial fusing of the inner wall of the oral portion of the body with that of the aboral portion considerably reduces the gastric carity lying between them, which originally spread throughout the whole extent of the disc. There remain only :

1. the cavity of the gastric peduncle into which the mouth leads.

2. A central stomach above the oral peduncle. These two parts form the main intestine.

3. A peripheral canal at the edge of the disc (the circumferential canal) which is continued into the tentacles.

4. Radially arranged connecting canals between the central
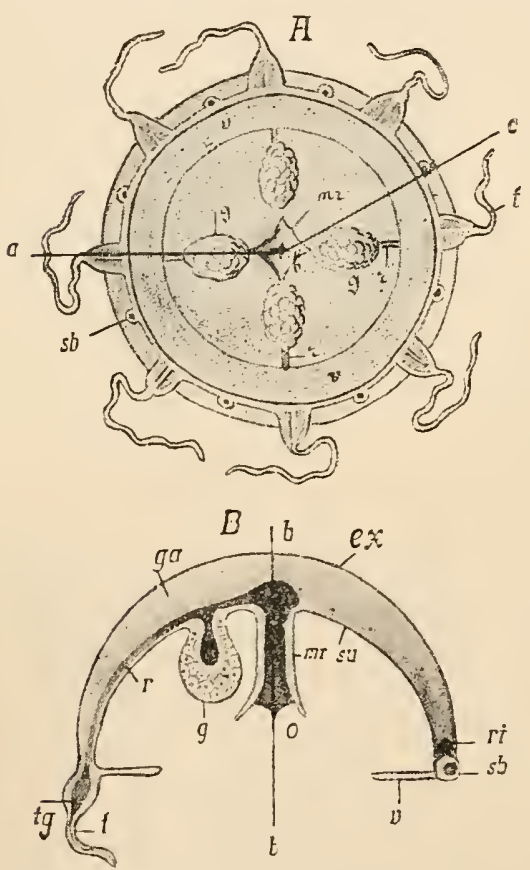

FIG. 65.-- Eucope campanulata, partly after Haeckel $A$, From the surface. $B$, Section in the direction $a-b-c$ in Fig. $A$. $a-b$, Perradius; $b-c$, ad. radius ; $t$, tentacle; $s b$, marginal vesicle; $g$, gonades ; $m r$, gastric peduncle; $r$, radial canals; $r$, veluu ; ri, circumferential canal; ex, exumbrella; su, sub. umbrella; $g c t$, jelly; $t g$, tentacular ressel; $b-b$, main axis.

way between the perradii have been called interradii.

Half way between the 4 perradii and the 4 interradii lie the 8 adradii $(b-c)$; half way between the 8 former and the 8 latter lie the 16 subradii. stomach and the circumferential canal. These canals become nutritive gastro-canals, which also serve the purpose of bloodressels (which are wanting) and convey food from the central stomach to the organs at the disc's edge. These two portions form the peripheral intestine.

In some Craspedote Medusce, besides the radial canals and the circumferential canal, the endoderm from the centre to the circumference persists, its two layers being pressed together by the strongly dereloped oral or subumbrellar and aboral or exumbrellar jelly, thus forming the so-called vascular lamellæ or cathammal plates, the layers of which, separating in radial strips, form the radial canals.

The radial eanals in simple Medusce are 4 in number, and are placed cross-wise. The radii in which they lie are called perradii (Fig. $65, A, a-b)$. In order to define the position of other tentacles, canals, and organs, the radii exactly half 
From the margin of the disc a thin muscular membrane projects into the subumbrellar carity like a diaphragm: it is known as the Velum $(v)$, and is one of the principal locomotory organs of the Crasperlote Meduse.

There are many other organs at the margin of the disc, the principal being:

1. A double nerve ling.

2. Marginal vesieles.

3. Eye spots.

4. A ring of nematocysts.

The shall speak of these organs later on.

The derivation of the Medusu form from the Hydropolyp is the more probable as Meduse belonging to many divisions, in their individual development, proceed from Hydropolyps by lateral budding. Such Medusce are then specially developed buds which have the function of forming the sexual products and of scattering them abroad.

2d Form: the Scyphopolyp or the Scyphula (type: Lucernaria or a simple Coral individual) is the original form of the Scyphorou, as the IIydropolyp is of the Hydrozor. It is distinguished from the Hydropolyps in that at the oral pole the region about the mouth sinks in to form an resophageal tube (Fig. 99, p. 130). The epithelium which lines it is thus ectodermal. Around this tube the gastric carity falls into 4,6 , or $\&$ compartments separated by walls; these partition walls, whose free edges project into the gastric cavity as septa or tænioles, bearing either mesenterial thickenings or gastral filaments, are continued along the body wall even to the aboral end of the body. All Corals remain essentially at the stage of the Scyphopolyps (Fig. 66 ; Fig. 82, p. 10\%). Their typical form is that of the cylinder or reversed truncated cone. The two ends of the body are almost circular; by the aboral pedal dise the animal attaches itself, and hollow tentacles stand round the oral dise (especially at the edge). In the middle of the oral disc lies the generally elongated slit-like external mouth.

The external mouth, in keeping with the Scyphopolyp plan, leads, not directly into the gastric cavity, which is lined with endodel'm, but into a tube which has arisen by an invagination from without, and is therefore lined with ectoderm. This tube (œsophageal tube, stomodaeum) is open at both ends. One opening, the external mouth, leads to the exterior; the other (the enteric aperture) leads into the spacious gastric cavity.

The body wall consists of ectoderm and endoderm, between which a solid middle layer is interposed, of which we shall speak later. The endoderm and the middle layer raise themselves from the body walls, forming rertical ridges which project into the gastric cavity throughout the whole length of the body; these ridges are the septa. In the neighbourhood of the cesophageal tube these septa project far enough 
to fuse with its walls, so that the gastric cavity here appears divided into chambers or compartments arranged radially round the osophageal tube (Fig. 66, to the left).

In the remainder of the body (Fig. 66, to the right) the septa project their free inner edges into the gastric cavity, which thus appears divided into a central portion and into radial niches separated by the septa (analogons to the gastro-canals of the other Cnideriu). These niches, in the neighbourhood of the cesophageal tube, are continued direct into the radial compartments between the tube and the body
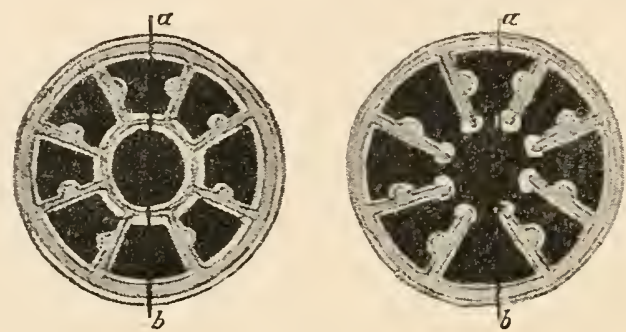

F1G. 66.-Diagrammatic transverse section of a Coral individual ; to the left on the level of resophagus, to the right on the level of the gastric cavity. $a-b$, Direction of the plane of symmetry.

wall, and these compartments again are continued into the axial cavities of the tentacles, which are lined with endoderm ( $c f$. Fig. 82, p. 107). The axial cavities of the tentacles occasionally open externally at the tip by a pore.

The number of tentacles represents, generally, the number of the septa. The Octocorcllia have 8 septa, and 8 tentacles placed so as to alternate with them. The Tetrucorallia generally have a large number of septa which are always a multiple of 4 . The Hexacorclliu possess 6 or $6 n$ partition walls and tentacles, arranged in a definite order which cannot here be described. We can only say, quite generally, that the oldest septa project farthest, and the youngest septa least far, towards the axis.

Most Corals have not a strictly radial structure; on the contrary we often find, anatomically and ontogenetically, a bilateral symmetry in the arrangement of the parts of the body. The slit-like shape of the mouth even is a departure from radial structure. A plane through the chief axis of the body in the longitudinal direction of the mouth (Fig. $66, a-b)$ is, in fact, a median plane-the only plane which divides the body into two exactly similar halves.

More exact ontogenetic investigation has shown that (e.g. in the Hexacorallia) two septa lying opposite each other to the right and left of this plane are first formed; these septa incompletely divide the gastric cavity into two portions of unequal size. Two new septa are then formed symmetrically in the larger-say the anterior-division; 
then two symmetrical septa in the posterior division. The rise of the other septa does not by any means occur in all Authisoa after one and the same simple plan. (In most Actinuric the other septa arise in pairs, each pair in the space between two older septa.) We repeat what we said above, that the septa project the farther towards the chief axis of the Corals the older they are. The tentacles also arise symmetrically with reference to the median plane over the interseptal spaces of the gastric cavity.

The mesenterial thickenings, or mesenterial filaments, are inserted in all Corals at the free inner edges of the septa.

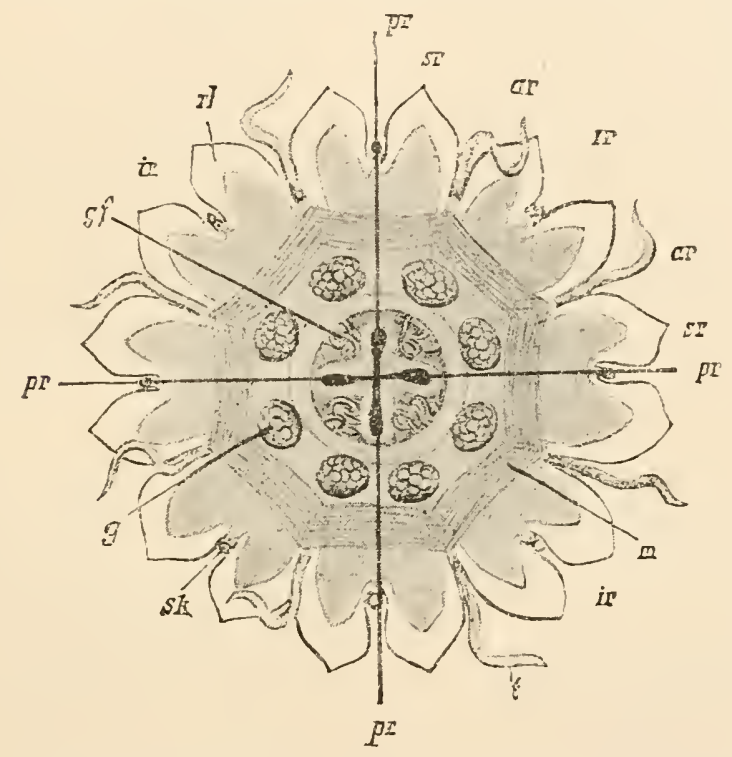

Fı. 6.-Nausithoë. $p r$, Perradii ; $i r$, interralii ; $a r$, adradii ; si, subradii ; $r l$, marginal lobes; $t$, tentacle; $\sigma f$, gastral filaments; $m$, circular muscle of the subumbrella; sl; seusory bodies (rhopalia); $g$, sexual glands (gonades); in the middle the cross-shaperl mouth.

As the free-swimming Craspedote Meduse can be referred back to the Hydropolyps or Hydrula, so the free-swimming Acruspede or Scyphomerlusa (Figs. 67 and 70, p. 85) can be referred back to the Scypleopolyp or Scypluta. The lower Acruspeda, with deeply vaulted, of ten cup-shaped body, are only slightly distinguished from the Scyphlulu, and we find among them forms still attached (e.g. the Lucernario).

The 4 radial gastric pouches separated by septa are still present, or they flow together to form a great circumferential sinus, the septa dwindling into 4 small points of connection between the subumbrellar and exumbrellar gastric walls, between which the circumferential sinus remains in wide-open communication with the central 
stomach. The 1 septa which carry phacelli or tufts of gastral filaments are continued as gastric ridges or taenioles on the exumbrellar gastric wall to the aboral pole of the body. In the higher Acraspedu, the Discomeduse, the exumbrellar and subumbrellar walls of the peripheral intestine (circumferential sinus) coalesce, so that here again there arises a cathammal plate, in which variously-shaped radial canals and radial pouches remain as survivals of the circumferential sinus; at such points the lamellæ of the cathammal plate separate, leaving between them spaces, the lumens of these canals. The derivation of the Discomeduse from a Scyphula form is further justified by the fact that in many of them the Scyphula appears as an attached early stage (Fig. 99, p. 130).

The third form of the Cnidaria is the Ctenophore (Fig. 68). Its body is ovate, with 2 dissimilar poles; its principal axis, which connects the two poles, coincides with the long axis of the oval. At one pole of the chief axis (the oral) lies the mouth. The opposite pole here, as in other Cnidaria, is called the aboral pole.

The oral aperture leads into a spacious cavity lying in the chief axis, which has its rise, ontogenetically, through an invagination from the exterior, and is lined, like the osophageal tube of the Scyphozoa, with ectoderm. We call this cavity the œsophageal cavity ("stomach" of authors) (s).

In form the asophageal cavity is neither round nor radial, but very much flattened; in a transverse section its lumen appears like a slit. In this we find the first departure from the radial body structure of the Medusa. A plane running in the direction of the flattened osophageal tube, and in which the chief axis lies, is called the median plane $(c-d)$.

The osophageal tube leads through another opening into a smaller cavity lying above it and lined with endoderm-the stomach $(m)$. The stomach is elongated at right angles to the chief axis and the median plane, and thus, when the animal is viewed from either the oral or the aboral pole, forms a cross with the oesophagus. A plane rumning through the chief axis in the direction of the stomach stands at right angles to the median plane, and is called the lateral plane $(e-f)$.

The median and lateral planes thus cross each other at right angles in the chief axis, just like the cross axes of the Medusa, each axis consisting of two opposite perradii. While, however, in the radially constructed Medusu the cross axes are quite similar, and the planes which run through them in the chief axis divide the body into four entirely similar quarters, the two cross axes in the Ctenophora are not alike, and the lateral and median planes divide the body into four quarters, of which only the two which are diametrically opposite are similar. Either of the two planes by itself, however, cuts the body into two similar halves.

At the aboral pole of the Ctenophora, as opposed to all other Calen- 
terute, there is a complicated sensory organ, the sensory body, which, according to its structure, is best described as an auditory organ, but perhaps serves for regulating the position of the body in the water.

From near the aboral to near the oral pole, there run along the surface of the body in 8 meridians 8 rows of swimming plates, the so-
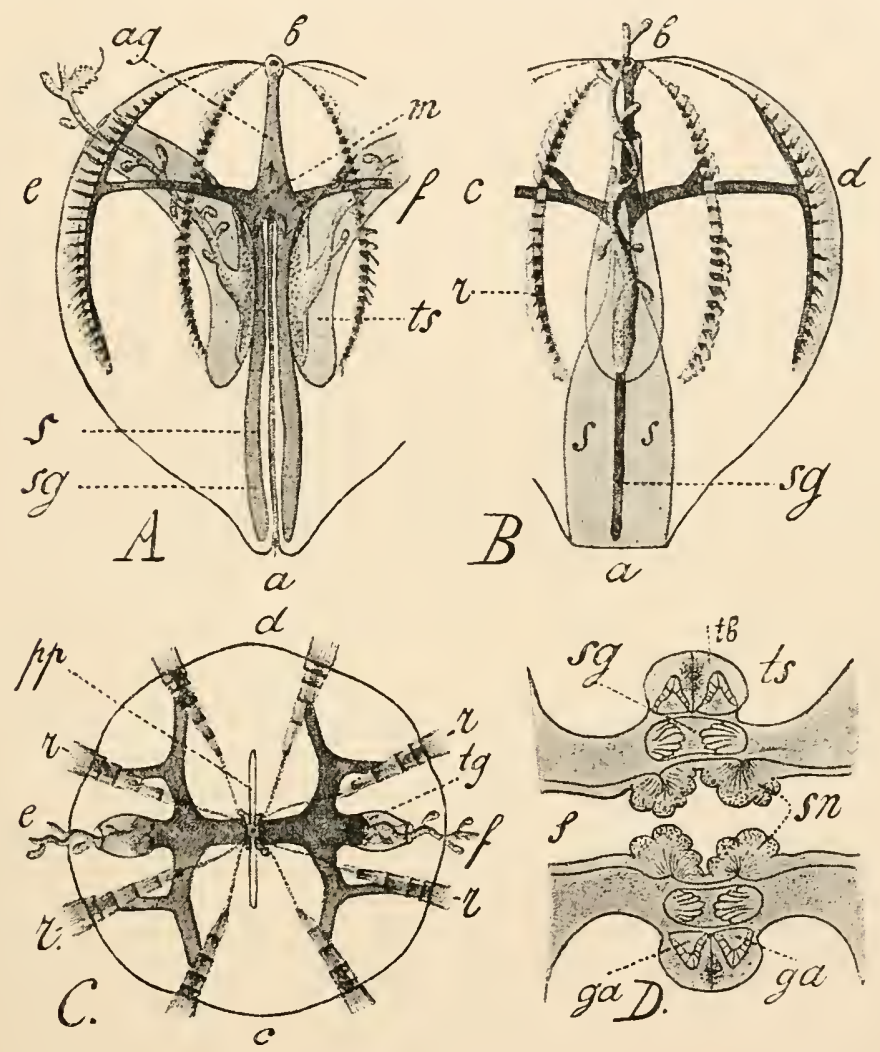

F16. 68.-Hormiphora plumosa, after Chun. A and $B$, From the side: $A$, seen in the direction $c \cdot d$ in Fig. $C ; B$, seen in the direction $c \cdot f$ in Fig. $C$. $C$, As riewed from the aboral or sensory jole. $a-b$, Chief axis; $c \cdot d$, direction of the median plane; $c-f$, direction of the lateral plane ; $a$, oral ; $b$, aboral pole; $m$, stomach; s, cesophagus; $s g$, cesophageal vessels; ty, tentacular vessels : $a g$, aboral ressel; $r$, ribs; $t s$, tentacle sheath; $\nu p$, polar plates. $D$, Portion of a transverse section through the cesophagus $(s)$; $t b$, tentacle base; $s w$, wesophageal papille; ga, branches of the tentacular ressel.

called ribs $(r)$. If we use the terms applied to the Medusu, these ribs are adradial.

Between cesophagus and stomach on the one side and the outer integument on the other, there is a jelly which is strongly developed in most Ctenophora, and in which various tissue elements are imbedded.

Gastro-canals, lined with endoderm, similar to the radial canals of 
the Meduse (or the radial gastric pouches of the Corcts), branch out from the stomach in various directions through the jelly, reaching almost to the surface of the body. We can distinguish four kinds of these canals.

A. Four canals which to a certain extent rise interradially out of the stomach. Each of these canals branches dichotomously, and 8 adradial canals thus arise and run to the ribs, where they enter as many adradial meridian or rib vessels, which run under the ribs.

B. Two canals which run along the broad side of the cesophagus perradially and in the lateral plane (i.e. in the lateral perradii) towards the oral pole, where they end blindly; these are the œsophageal vessels ("gastric vessels" of authors) $(s g)$.

C. Two canals which arise perradially and in the lateral plane (i.e. in the lateral perradii), and run to the walls of the tentacle sacs (tentacular vessels) $(t g)$.

D. An unpaired canal (ag) running in the chief axis of the body towards the aboral pole, and dividing, under the sensory body into 2 branches, which lie in the median perradii. Each of these branches again divides into 2 , and so 4 interradial small branches arise; 2 of these, which are diametrically opposite, generally open externally at the sensory pole, while the others, at right angles to the latter, end blindly. Less frequently all 4 branches open externally. The sensory body lies between these 4 branches of the aboral ressel ("funnel ressels" of authors).

In many Ctenophore there is a further development of two solid pinnate tentacles, into which the gastro-canal system is not continued. In quite young animals the tentacles lie near the aboral pole. At a later stage, however, they move towards the oral pole.

The tentacles are inserted at the base of sac-like depressions of the onter integument, the so-called tentacle sheaths $(t s)$ into which they can be withdrawn. They lie in the lateral perradii. In many C'tenophora the body is round in transverse section; in others it is compressed either in the lateral or the median plane. The lateral compression is so great in the Cestidce that the body appears drawn out into a long ribbon in the median plane.

If we now compare the Ctenophoral forms with other Cnidarian forms, we are at once struck by important distinctions between them. The Ctenophora dejart in a peculiar manner, thongh in a direction different from that of the Corals, from the purely radiate fundamental form, the two cross axes being unequal. They agree with the Scyphozoc in the possession of an ectodermal oesophagus, but otherwise differ decidedly from them.

According to the opinion of some observers, the Ctcnophore must be derived from Craspedote Medusce. The transition from the one group to the other is made evident by an interesting Cladoncmid, Ctenaria Ctenophora. In this animal the umbrella is much vaulted, the subumbrella much deepened; 4 radial canals rise out of the stomach and bifurcate into $S$ adradial canals. There are only two pimate, perradially placed tentacles. We need only say that the subumbrellar carity of Ctenaria 
can be compared with the esophageal eavity of the Ctenophore. The further homologies (or analogies?) in the gastro-canal system and in the tentacles then follow of themselves.

\section{The Body Epithelium.}

It is not possible to carry out a sharp histological distinction betwreen the ectodermal epithelium which clothes the whole exterior of the Cnidarian body and the endodermal gastro-canal epithelium. We here find the ectoderm and the endoderm, histologically, still in a rather undifferentiated condition; this is seen most clearly from the fact that the endoderm can in some groups supply nerve and muscle elements and stinging cells. These are tissue elements, which among the higher animals arise almost exclusively out of and in the ectoderm.

The close connection of the body epithelium of the Cniduria with the nervous and muscular systems is characteristic. The cell-elements of these systems often take part with the other ectoderm cells in limiting the outer surface of the body; or they lie wedged in between them somewhat below the surface. Finally, we find them in many Cnidaria close under the body epithelium, but often still outside of the supporting membrane which divides the ectoderm from the endoderm.

The body epithelium is either naked, or may be covered with cilia or flagella over greater or smaller expanses. The swimming or rowing plates, which are arranged in eight meridional rows in the Ctenophora, arise out of cilia cemented together.

In the body epithelium of all Cnidariu, except the Ctenophora, the stinging cells are found as a very characteristic element (Fig. 69, ", b). These stinging cells contain a stinging capsule, with a spirally coiled filament, often bearing barbed hooks; when the skin is irritated this filament is evaginated and shot forward, and has the effect of a sting.

The stinging capsules or nematocysts are microscopic adhesive organs, and are to the Cnidaria at the same time weapons of defence and of offenec. They are particularly numerous in exposed parts of the body, and in organs which are used in seizing jrey-round the mouth, on the tentacles, at the margin of the disc in the Meclusce. On the tentacles of

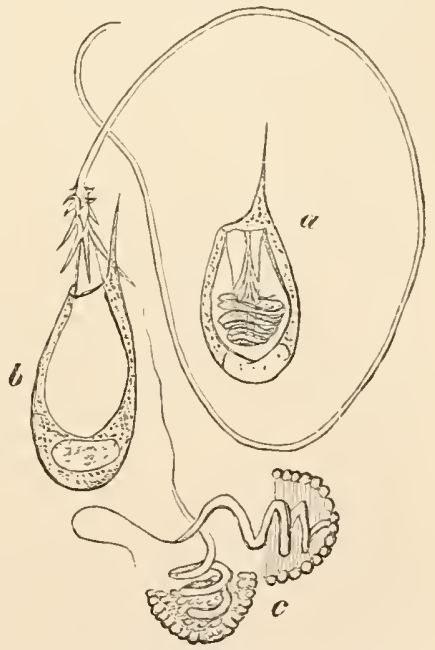

FiG. 69, - $a, b$, Stinging cells of a Hydroid, Cordilophora, after F. E. Schulze. $c$, Seizing or adhesive cells of a Ctenophore, after Chun.

Hydro- and Scypho-medusa, and especially on the capturing filaments of the Siphonophora, they are assembled in masses, and form "stinging lnobs "or "stinging batteries." 
In the body epithelium of the Ctenophora we find peculiar adhesive cells (Fig. 69, c) with uneven and sticky surfaces. Their bases are prolonged into spirally coiled contractile filaments.

Besides the nerve cells, the sensory, muscle, stinging, flagellate, ciliated, and covering cells, various glandular cells and pigment cells are found in the body epithelium of many Cnidario, and are especially numerous in the Ctenophora.

\section{The Gastro-canal System.}

The gastro-canal system in its general arrangement has already been mentioned in the general review. It is the most characteristic system of organs of the Cnidaria, and in some groups reaches a very high degree of complication. This complication stands in direct relation to the complication of other portions of the body, which fact is at once comprehensible when we learn that in the Cnidaria the gastrocanal system undertakes not only the digestion, but also the circulation. The more massive the body and the more numerous and complicated its organs, the more necessary is it that the nutrition of these organs should be provided for by gastro-canals or vessels.

From such a standpoint the complicated arrangement of the gastro-canal system of the Medusce and Ctenophore is at once comprehensible. In the Hedusce the margin of the umbrella is distinguished by the possession of numerous organs (tentacles, velum, auditory vesicles, stinging cells, nerve ring, eye spots, and sensory bodies). The subumbrellar side is strongly muscular, while the exumbrella is devoid of organs. The jelly being so largely developed as a passive orgau for motion and support, the special gastro-canals (radial vessels) must run near the subumbrella to convey food to the organs on the margin of the disc. This purpose is also served by the circumferential canal, iuto which they enter. The relations of the gastro-canals to the other organs of the body are just as clear in the case of those Ctenophorce which have a massive gelatinous tissue between the ectoderm and endoderm. The most important organs of the body, apart from the sexual organs, are in this group : the sensory body of the aboral jole, the 8 ribs, and the 2 tentacles; answering to these, we find an aboral vessel, also 8 vessels running from the stomach to the ribs, and which enter 8 meridional vessels, and, further, 2 vessels which rum to the base of the tentacles.

According to the ontogenetic origin of the gastro-canal system, two principal types can be distinguished in the Cnidaria. In one type, which is found among the Hydrozoa, the whole gastro-canal system rises out of the endodermal enteron of the larva. In the second type, which is characteristic of the Scyphozoc and Ctenophora, the gastrocanal system consists of an ectodermal and an endodermal portion. The former, which we call stomodaeum in embryos, larvæ, and generally in young transition stages, and œsophagus in adult animals, arises at the oral pole by a depression of the ectoderm into the body. This cesophagus is represented in the Scyphomeduse by the inner lining of the oral or gastric peduncle as far as the point of insertion of 
the gastral filaments, in Coruls by the tube which leads into the gastric cavity, and in the ctenoplora by the beginning of the gastro-canal system, hitherto unsuitably named the stomach. The mouth of the Hydromeduse thus leads direct into the endodermal gastric cavity; whereas the mouth of the Scyphomeduse, Anthozou, and Ctenophora leads first into the ectodermal oesophagus, and from that through the enterie aperture, which corresponds with the mouth of the Hydromeduse, into the endodermal gastro-canal system.

In all animals, from the Celenterata upwards, there is an eetodermal cesophagus.

The endodermal gastric cavity is met with in its simplest form in the Hydroida as a simple pouch adhering closely to the inner surface of the ectoderm, from which hollow or solid processes extend into the axes of the tentacles. In the long, or principal axis of the body, thickenings of the gastric wall, gastric ridges, which are occasionally 4 in number, regularly arranged crosswise, are commonly found.

We have already described the form of the gastric cavity of the Scyphulu in the introduction; and we also there described the general arrangement of the gastro-canal system in the Authozoa. We add here that the septa which separate the gastric pouches from each other round the oesophagus are occasionally broken through near the oral disc by an aperture, so that a sort of circumferential canal arises. The hollow processes of the gastro-canal system in the tentacle axes sometimes penetrate to the exterior at the tips of the tentacles through pores. The free edges of the septa, which are turned towards the principal axis of the Coral individual, are thickened, and are prolonged as mesenterial filaments, freely projecting into the gastric cavity. The epithelium of these filaments contains numerous gland cells, and sometimes stinging cells as well. Some of these filaments, the socalled acontia, are particularly long and vermiform, and can be quickly shot out of the body, either through the mouth, or through special pores in the body wall. These are found in the Actinu.

How the gastro-canal system of the Craspedote Medusce (Hydromedusce) can be traced back to the gastric cavity of the Hydrula form, and the gastro-canal system of the Acraspeda (Scyphomeduse) to the gastric cavity of the Scyphula form, has already been shown in the general review.

The radial canals in the Craspedote Medusce are comparatively seldom limited to the number 4 . In most forms their number is greater, and in a few (Equriule) they are very numerous (over 100) and run radially from the central stomach to the margin of the disc, and here enter the circumferential canal. There are also in a few Crospedote, near and between the radial canals, centripetal canals, which start from the circumferential canal and run a certain distance towards, but do not reach, the central stomach. The radial canals may be branched, and these branches may either end blindly or enter the circumferential canal. The central stomach may be divided, the 
divisions being superimposed one on another in the principal axis. The lowest division is the oral stomach, continued in the oral or gastric peduncle, which hangs down from the middle of the sul,umbrella. The gastric peduncle, at whose free end lies the mouth, may be very variously developed, from a short wide tube to a long tubular structure protruding far beyond the subumbrellar cavity. The mouth is either simple, square, or cross-shaped, or produced into 4 points or lobes, and sometimes supplied with oral tentacles, or with variously shaped papillie. The edge of the mouth is generally well armed with nemato-cysts.

The gastro-canal system of the Acruspecla or Scyphomeduse (Fig. 67, p. 77 ; Fig. 70) shows, in the arrangement of its single sections, a still more varied structure than that of the Craspedota. In some groups it is wonderfully complicated, and sometimes shows great similarity with the gastro-canal system of certain Craspedote : in such cases, when we further think of the great similarity in body form, it is difficult to believe that the Acraspele and Craspedota are two sharply divided branches of the Cinidaria.

Let us first consider the oral tube or oral peduncle, which, unlike that of the Craspedutu, contains the ectodermal osophagus. The oral tube is usually short, and has either a simple square or cross-shaped aperture, or, as in most large Acraspeda, is produced into 4 long strong oral arms. These 4 perradial oral arms become, by means of a bisection so deep as to reach their bases, the $\delta$ oral arms of the Phisostome, which are distinguished by the following peculiar organisation.

Each oral arm becomes deeply furrowed on the side turned to the chief axis, forming a channel in the longitudinal direction. This inner channel corresponds with an externally projecting mid-rib. The chamel becomes deeper, and the curled edges of the oral arm which border it unite over it and grow together, so that it now becomes a closed canal. Such concrescence is completed along the whole length of the oral arm to its base, and also spreads to the edges of the oral aperture lying at the base of the arms, and the canal thus becomes completely closed. The concrescence of the curled edges of the arm, however, takes place in such a way that numerous small open canals remain (suctorial mouths) (Fig. $70 \mathrm{D}, \mathrm{sm}$ ); these lead from the exterior into the central canal of the arm. This again leads into the closed resophagus. In all lihizostome the original oral aperture is thus closed, and is replaced by the numerous suctorial mouths on the hollow oral arms.

In the endodermal gastro-canal system, here as among the Craspeclota, we can distinguish a central or main intestine from the peripheral intestine (Kranzdarm). The main intestine can separate into two divisions, one lying above the other, the lower of which always communicates with the peripheral intestine.

On the wall of the main intestine of all Acraspeda (as opposed to 
the Craspedota), there are 4 interradial or 8 adradial mobile gastral filaments, or, usually, tufts (phacelli) of gastral filaments, whose bases define the boundary between the cesophagus and the endodermal main intestine. The peripheral intestine is very variously developed. In
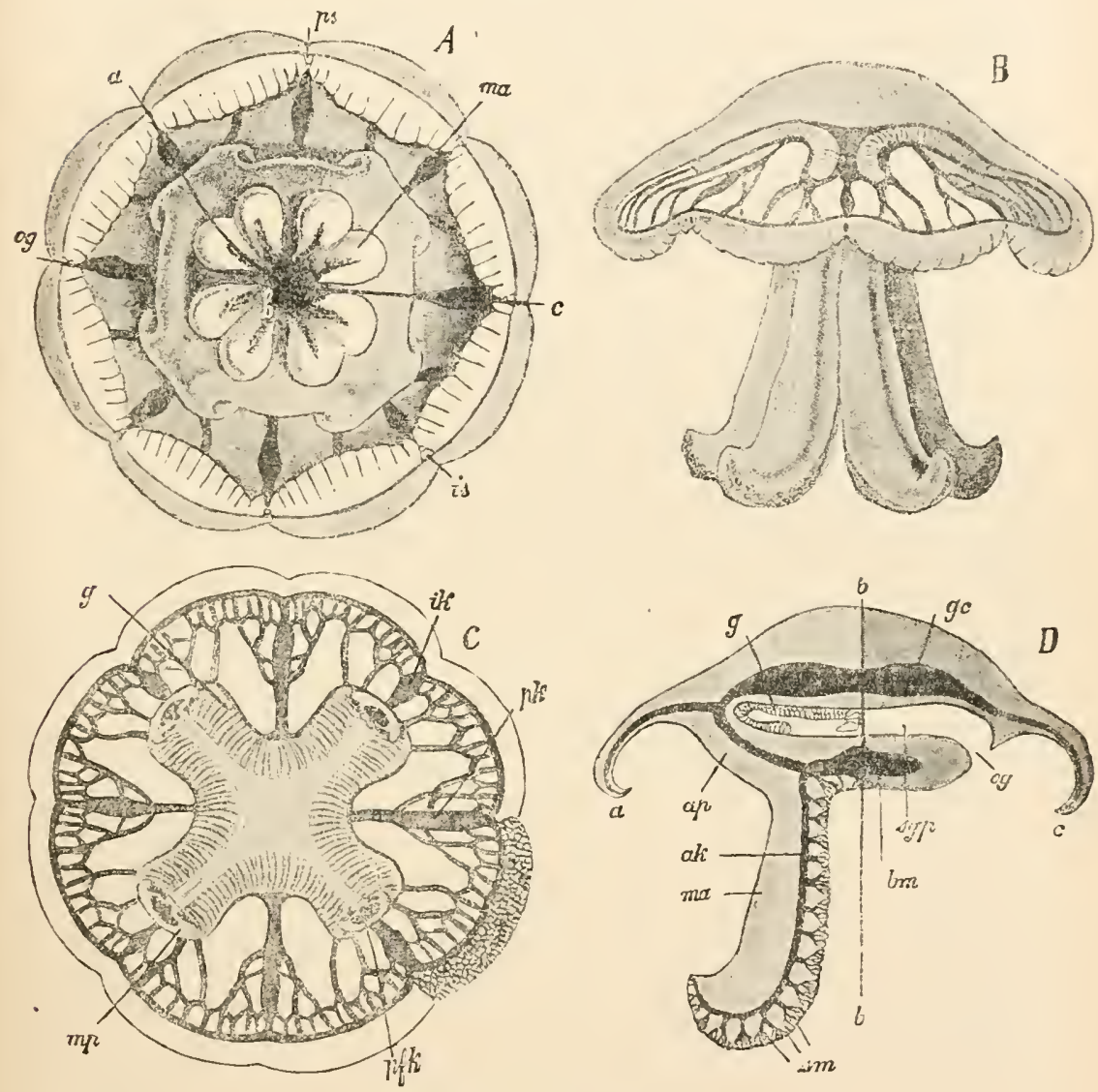

Fis. 70.-Cannorhiza connexa, after Haeckel. A, Scen from the subumbrella; $D$, from the side; $C$, from the subumbrella, after removal of the oral arms and buccal stomach by cutting through the oral pillars. $D$, Section in the direction of the principal axis and the line abe in Fig. $A$. $a-b$, Near an interradius; $b-c$, perradius ; og, subgenital ostia ; ma, oral arm ; $p s$, perradial, is, inter. radial sensory body ; $g$, gonades ; $m p$, $a p$, oral pillars, arm pillars ; $p f k$, pillar canals ; $p h$, perradial ; $i k$, interradial gastro-canal ; $b-b$, principal axis ; $s g p$, subgenital porticus ; $b m$, buccal stonach ; $a l_{\text {, }}$ arm canal ; sm, stretorial mouths; gc, central stomach.

the lower Acraspeda, which also remind us of the Scyphula in their attachment by an aboral stalk (Lucernaria) and their cup-like shape, the peripheral intestine consists of 4 wide pouches divided by narrow septa, which communicate with the chief intestine and also open into 
a circumferential canal at the margin of the dise by means of breaches through these septa. If the septa are reduced to 4 small points of concrescence between the exumbrellar and subumbrellar walls of the peripheral intestine, directly on the circumference of the main intestine, the 4 pouches coalesce to form a spacious circular sinus, which commands the whole edge of the disc, and communicates with the principal gastric cavity between the points of concrescence. In the higher Acrospeda this circumferential sinus becomes divided, by the partial concrescence of its exumbrellar and subumbrellar walls, into $8,16,32$, or more radial chambers or radial canals, which in many forms, by anastomosing or branching, form a very ornamental net-work of canals running towards the edge of the disc (Fig. 70, C).

Exeretory pores of the gastro-canal system.-In various Medusu, in Acraspeda as well as in Craspedota, small apertures have been observed at the margin of the disc; these often lie on the points of papilla, and by means of them communication between the peripheral gastro-canal system and the outer world is established.

The gastro-canal system of the Ctenophora (Fig. 68, p. 79), in its general arrangement, has already been delineated. We add here that the meridional vessels in lobate Ctenophora, and also in the Cestidoe and Beroide, communicate with each other and with the osophageal vessels at the oral portion of the body, and that in the Beroidce they also send out numerous branching and anastomosing processes, some of which enter the jelly, or join to make a peripheral net-work. The nourishment of the often much-developed oral lobes of the lobate Ctenophora is provided for by the meridional vessels, which traverse the oral lobes in various arabesque-like patterns.

Histological.-Each epithelial cell of the gastro-canal system very commonly carries one single flagellum; these cells are thus flagellate cells. Among the epithelial cells there are gland cells, stinging cells, cells with various contents as products of metabolism, epithelial muscle cells, ctc. Very often the gastric epithelial cells send out amoboid or pseudopodia-like processes on that side of them which is turned to the lumen of the gastro-canal system, and by the help of these they take into their cell bodies small particles of food in the mamer of the Rinizopoda (intracellular ingestion of food).

\section{Museulature.}

In the Hydroidu and Siphomophore we find, in the first place, a system of longitudinal fibres which rum, buried in the epithelium, from the oral to the aboral pole, and in the tentacles. These fibres, which correspond to the processes of the ectodermal neuro-muscular or epithehial muscular cells, serve for contracting the body and the tentacles. In these forms again, and especially in the Siphonophora, there is a system of circular fibres which run under the endodermal epithelium as processes of the endodermal epithelial muscular cells. By the contraction of these fibres the body and the tentacles are 
extended. In the medusoid swimming bells of the Siphonophora, just as in the Craspedote Meduse, a layer of striated ectodermal circular muscle fibres is developed in the subumbrella and in the velum.

We find the two systems of muscles in the Meduse also, the longitudinal and the circular, though the latter is here ectodermal. The longitudinal muscle fibres are generally smooth, the circular muscle fibres usually striated. The muscle fibres are mostly processes from the epithelial muscle cells; but there are also muscle bands and strands which quite detach themselves from the epithelium, and run in the gelatinous connective tissue as independent mesodermal muscles. The exumbrella is poor in muscles, sometimes even having none at all. In the remainder of the body, the longitudinal as well as the circular musculature falls into three systems: (1) into a system spreading over the gastric or oral peduncle; (2) a system spreading over the subumbrella from the base of the oral peduncle to the margin of the disc ; (3) a system developed at the margin of the disc itself (musculature of the tentacles, the velum, and the velarium). In correspondence with this, the three systems of the longitudinal musculature are as follows :-

A. The longitudinal musculature of the oral peduncle (serving for its contraction and retraction).

B. The radial muscles, which run radially from the base of the oral peduncle towards the margin of the disc.

C. The longitudinal muscles of the tentacles and marginal lobes.

The three systems of the circular musculature are as follows:-

A. The circular musculature of the oral peduncle.

B. The circular musculature of the subumbrella, developed in the Craspedota over its whole extent, but in the Acraspeda generally forming a narrower but very strong peripheral muscle (Fig. $67, m$, p. 77 ) near the circumference of the subumbrella.

C. The strong circular musculature of the Craspedote velum, and the circular musculature of the Acraspede marginal lobes and velarium.

In Scyphostoma and many lower Acraspeda, especially in attached forms, e.g. Lucemaria, there are 4 (seldom 8) interradial septal or funnel muscles (peduncular muscles) which, starting from near the oral disc, or that portion of the subumbrella which borders on the oral peduncle, run through the body as far as the aboral attached apex of the exumbrella. They lie in the 4 septa which separate the 4 gastric pouches on their axial sides, and then proceed upwards in the prolongations of the septa, i.e. in the 4 gastric ridges or trenioles. According to recent research, they arise in the ectodermal cells of a solid prolongation of the 4 interradial septal funnels, which grow towards the aboral pole; we shall speak of these septal funnels later.

The endodermal musculature of the Corals, in contradistinction to that of all the other Cnidaria, is at least as much if not more developed 
than the ectodermal. The musculature is most highly developed in those Actinit which have no skeleton. It shows in its arrangement much similarity with that of the Scyphomedusce, e.g. the Lucernoriu. We have an ectodermal longitudinal muscle system and an endodermal circular muscle system (leaving out of sight for the present the fact that single portions of the musculature detach themselves from the epithelial matrix and become mesodermal).

I. The ectodermal longitudinal muscular system forms (a) the longitudinal muscles of the tentacles and $(b)$ the radial muscles of the oral disc. This system is wanting in the cesophagus, in the outer wall of the body, and in the pedal disc. Only in some forms, which possess no septal longitudinal muscles (Cerianthus), there are in the body wall strong ectodermal longitudinal muscles which serve as retractors of the body.

II. The endodermal circular muscular system extends all over the surfaces of the body, and forms a layer of circular fibres in the body wall, an inner circular muscular layer in the tentacles, a layer of concentric fibres on the oral disc, and a circular muscular layer round the cesophagus.

The musculature of the septa in Corcls deserves special attention; it consists of a system of longitudinal and of a system of transverse muscles. The longitudinal muscles run along the septa from the pedal to the oral disc, and serve as retractors of the body. They are mostly so strongly developed that they form longitudinal thickenings on each septum in the space between it and the next septum (Fig. 66, p. 76). The transverse musculature is less strongly developed. It is attached on one side to the body wall, on the other to the pedal dise, the oral disc, and the cesophageal tube. The transverse muscles lie on one surface of each septum, the longitudinal on the other side. Their relative positions on the different septa varies in different divisions, and is always very characteristic. There is generally only one plane, which can be made to divide the body in such a way that the arrangement of the muscles on the septa on each side of it is exactly similar. This median plane runs in the principal axis in the direction of the flattened esophagus or the slit-like oral aperture.

In most Actinia with numerous septa of various ages and sizes, septa of equal sizes always go in pairs. The longitudinal muscular thickenings of such a pair of septa are turned towards each other. The longitudinal muscles are therefore turned towards the space between the two septa of such a pair-the so-called intraseptal spaceand the transverse muscle layers are turned towards the space between this pair and the next on each side-the interseptal spaces.

In those Alcyonaria which have 8 partition walls, the muscular thickenings of the 4 septa which lie on one side of the median plane are all directed towards one side (Fig. 66).

There are, besides these, other types of muscle and septal arrangement in the Corals. 
The longitudinal muscles of the septa show a great analogy with the septal or peduncle muscles of the lower Acraspeler. The former appear, however, according to present knowledge, to be endodermal muscles.

The muscular elements of Corals are either epithelial muscle cells (endodernal musculature), or sub-epithelial muscle cells (ectodermal musculature), or mesodermal muscles (in some species at different parts of the bolly).

The following applies to the musculature of the Mcdusce, Siphonophora, and Corals. If it is much developed in one part, the muscle lamella lays itself, for the purpose of superficial increase, in parallel folds like the leaves of a book (Fig. $71, C$ ). Thiese folds may again fold themselves in a more or less complicated manner, so as to have a feathered appearance in transverse section.

$A$

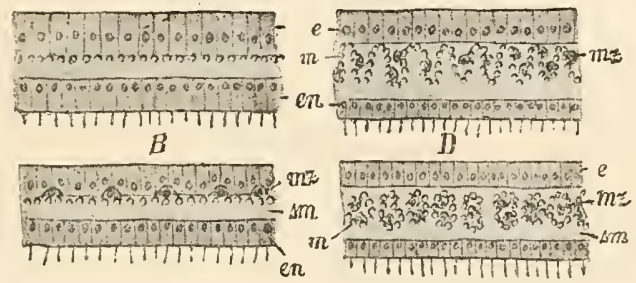

Fig. 71.-Diagrammatic representation of the various arrangements of the ectodermal Cnidarian musculature in transverse sections through the body wall. e, Ectoderm; en, endoderm ; $m$, muscle lamella ; $m z$, cell bodies of the muscle fibres; sm, supporting membrane, jelly.

The mesodermal supporting substance or supporting membrane takes part in the folding of the contiguous muscle lamelle by itself rumning within the folds in the form of lamellie.

When muscle folds completely detach themselves from their matrix, the epithelium, and when the free edges of each fold coalesce, there arise out of these subepithelial muscle folds mesodermal muscle tubes $(D)$, which are then surrounded on all sides by the suprorting substance.

In the musculature of the Ctenophora, we in the first place distinguish an ectodermal and a mesodermal portion, between which, however, no very sharp boundary can be made. The ectodermal musculature consists of elongated sub-epithelial fibres on the boundary between the epithelium and the jelly; these may have very various courses. Sometimes we can more or less clearly distinguish a system of longitudinal from a system of circular fibres. The ectodermal musculature is also continued on the asophagus. The mesorlermal musculature, which lies in the jelly, is more strongly developed than the ectodermal musculature; its fibres, which have an isolated course and are elegantly branched at each end (Fig. 47, g, p. 47), run in various directions, though usually radially, being stretched between the different parts of the gastro-canal system and the outer integument. The contraction of the tentacles and their lateral filaments is brought 
about by strands of longitudinal muscle fibrillæ which run in their solid axes and which may be partially striated. Longitudinal and circular muscle fibres have also been observed in the walls of the gastrocanals.

The Velum of the Crospedote Medusce (Fig. 64, B,, p. 73 ; Fig. 65, p. 74 ; Fig. $72, v$, p. 95 ) is a thin membrane which projects from the margin of the disc like a diaphragm into the subumbrellar cavity. The gastro-canal system is never continued into this membrane, which consists of the following portions :-

1. A continuation of the epithelium of the exumbrella.

2. A continuation of the epithelium of the subumbrella. These two epithelia coalesce at the free inner edge of the velum. Under the former lies a thin supporting lamella, the continuation of the disc jelly ; under the latter, a layer of ectodermal circular muscle fibres $(m)$, a continuation of the circular musculature of the subumbrella.

\section{Tentacles of the Cnidaria, Marginal Lobes of the Scyphomedusæ.}

All Cnidaria (with the exception of the Rhizostomce among the Scyphomeduse and the Amaltheidce among the Craspedota) possess tentacles arranged in a circle round the mouth, at a greater or less distance from it. These tentacles are evaginations of the body wall, into which (with the perhaps only apparent exception of the Ctenophora) hollow or solid processes of the endodermal gastro-canal system penetrate. The tentacles are pre-eminently organs for catching food, and at the same time sensory organs of touch. We shall see further on that some of them are partially transformed in the Craspedote and Acraspede Medusce into specific sensory organs.

The structure of the tentacles, their number, their division and arrangement on the body, and their relation to the gastro-canal system, offer in the various divisions many modifications of great importance in classification.

Form of the tentacle.-The tentacles are, speaking generally, cylindrical filaments. In the Hydroids they are usually simply filamentous, less frequently knobbed at the free end, and still less frequently branched (Cladocoryne). Among the Craspedote Medusce also we generally meet with filamentous tentacles. The family of the Cladonemide alone is distinguished by tentacles which are dichotomously branched, or feathered on one side (provided with collateral filaments), and often knobbed. The tentacles of the Siphonophora and the Ctenophora are also feathered on one side. The tentacles of the Acraspeda are simple. Among the Anthozoa, the Alcyonaria possess tentacles feathered in two rows, but all other divisions have simple filamentous or vermiform tentacles.

Number and arrangement of the tentacles.-Among the Hydroida 
the tentacles, in varying number, are either arranged in a circle at a short distance from the mouth (e.g. Hydra), or in two circles (e.g. Tubuluria), or they are dispersed over the body of the individual, though not on its stalk (e.g. Coryne). In the Scyphostoma the tentacles (about 24 in number) are inserted at the edge of the oral disc of the cup-shaped body. In the Craspedote and Acraspede Meduse the tentacles are invariably found on the margin of the disc. In the simplest case we find in the former 4 perradial, and in the latter 4 perradial and 4 interradial tentacles. In most Medusa the number of tentacles increases in a regular manner-secondary, tertiary, etc., being inserted between the primary. Only in a few Craspedota the number is reduced to two tentacles, opposite one another, and less frequently to one single tentacle (in the sub-family of the Euphysidce among the Codoridce, and in the tentacle-bearing "persons" of one principal division of the Siphonophora (the Siphonantha). Complete loss of all tentacles is a distinguishing mark of the Amalthceilce among: Craspedota and the Phizostomce among Acraspeda. In a few Meduse, especially among the Narcomedusce, the points of insertion of the tentacles move up from the edge of the disc a greater or less distance on to the exumbrella.

In the Corcls the number of tentacles inserted at the circumference of the oral aperture represents, in a general way, the number of gastric pouches separated by septa. Each tentacle lies above a gastric pouch, which is produced into it in the form of an axial canal. In the Alcyonaria we have 8 , in the Hexacorallia 6 or $6 n$, in the Tetracoralliu 4 or $4 n$, such corresponding tentacles.

The majority of the Ctenophora (Tentaculata) possess two solic tentacles or retractile filaments, feathered on one side, lying in the lateral plane; these can be withdrawn into special sacs or sheaths, and arise in the neighbourhood of the aboral pole; later, however, they generally move towards the oral pole.

Structure of the tentacles. - The tentacles of the Hydromedusce and Scyphomedusce consist: (1) of an ectodermal epithelium, generally with stinging knobs or batteries; (2) of a layer of ectodermal longitudinal muscle fibres lying directly under this; (3) of a structureless elastic supporting membrane; and (4) of an axis of endodermal cells. This axis is hollow in most forms, and the cavity is in open communication with the gastro-canal system of the body; or it is solid, and then consists chiefly of a single row of disc-like cells, which are superimposed like the coins in a roll of sovereigns (e.g. in Obelia, in many Trachomedusce, Narcomeduse, and the related Hydroids, also in Staniomedusce and Cannostomce). This axial pillar must serve as an elastic organ of support. The hollow tentacles are mostly far more mobile and more strongly contractile than the solid. The tentacles of Corcls are also hollow; their structure differs considerably from that of the Hydro- and Scyplo-meduse. The ectoderm and endoderm in Corals are separated by a supporting substance which contains cells of connective 
tissue. Under the outer epithelium lies an ectodermal muscle layer, and under the inner epithelium a similar endodermal layer. In some cases muscles may also run within the supporting substance.

The tentacles of the Ctenophora are solid. They are generally provided with seizing or adhesive cells. Their axes are usually occupied by strongly developed longitudinal muscle-fibres. These fibres arise, as it appears, at an early stage out of special "mesodermal" elements, i.e. a group of cells which sever themselves from the primitive endoderm of the young gastrula larva. We ought therefore, perhaps, to compare the solid axis of the Ctenophoran tentacle with the solid endodermal axis of the tentacles of many Medusce.

The marginal lobes of the Seyphomedusæ (Fig. 67, rl, p. 77 ; Fig. 70). The marginal lobes of the Scyphomedusce or Acruspedce are just as characteristic of them as is the velum of the Hydromedusce or Craspedota. As a real velum is wanting in all Scyphomeduse, so are marginal lobes wanting in all Hydromeduse. Like the tentacles, together with which they are found, the marginal lobes are processes of the body wall at the edge of the umbrella, into which the prolongations of the gastro-canal system extend. Unlike the tentacles, they are broad and flat, serving as rowing organs, with muscles on the concave subumbrellar side. In the simplest cases there are 8 adradial marginal lobes, mostly, however, there are 16 subradial lobes, and their numbers are often still further increased. In the Cubomedusce and in many Rhizostomce the lobes grow together to form a circular rim of varying width, the so-called velarium which, however, can always be easily distinguished from the true velum of the Cruspedota by its supply of gastro-carals. The clusters of tentacles of the Lucernaria are secondary outgrowths of the marginal lobes, between which rudiments of the primary tentacles can sometimes be found.

\section{The Nervous System.}

This, which appears in the Cniclaria for the first time in the animal kingdom as an independent system, is marked by a rather diffuse arrangement (want of definite centralisation), and by the close relation which it bears to the body epithelium during the whole life. In the Ifydra the outwardly directed cell body of the so-called neuromuscular cells probably plays the part of an undifferentiated sensory nerve cell. But as early as the Craspedote Medusce we find an independently developed nervous system, close under the epithelium, outside the supporting membrane or jelly; it forms a plexus of bipolar and multipolar ganglion cells with connecting fibrillæ. This plexus is connected by fibrillæe on the one hand with the epithelial sensory cells (tactile, auditory, visual, olfactory cells), on the other hand with muscle fibres. In correspondence with this, the nervous tissue is particularly strongly developed on the margin of the umbrella, which 
is so rich in sensory and locomotor organs. At this part in the Craspedote a central apparatus, in the form of a double nerve ring, is developed (Fig. $72, A$ and $B, n r_{1}, n r_{2}, 1$. 95). One of these nerve rings, the ipper one, is placed on the exumbrellar, the other on the subumbrellar margin, both close to the base of insertion of the velum. The first innervates chiefly the sensory organs of the umbrella margin, the latter the musculature of the velum; the two are connected by fibrilla running through the supporting membrane. A peripheral nervous system is present in the form of a plexus of ganglion cells and fibres connected with the lower nerve ring, especially on the subumbrella; it supplies the musculature of this part with nerves. The aboral exumbrella, not only in the Craspedota, but also in the Acruspeda, is devoid of a nervous system, as also of sensory organs and musculature ; this is explicable by the ontogenetic and phylogenetic derivation of these animals from a form attached by the aboral pole.

In the Siphonophora also a plexus of ganglion cells at various parts of the hody has been demonstrated.

In the Scyphomedusce or Acraspeda also a plexus of ganglion cells is developed in the subumbrella. It is connected with considerable central accumulations of nerve tissue on the subumbrellar margin. These are developed in the Cubomedusce as 8 (4 perradial and 4 interradial) ganglia, connected together by a circular nerve, from which sensory nerves proceed to the rhopalia (sensory bodies) and to the tentacles, and motor nerves to the musculature. In the Discomedusce there are also 8 ganglia at the bases of the 8 sensory bodies, but here there is no connecting nerve ring.

In the Corals a plexus of ganglion cells lying deep in the body epithelium has also been demonstrated. This is particularly strongly developed on the oral disc, and at the base of the tentacles.

In the nervous system of the Ctenophora we can, according to recent research, which still needs extension, distinguish the following parts: (1) a diffuse, ectodermal, ganglionic plexus under the body epithelium, which is spread over the whole surface of the body, and may be continued on to the wall of the osophagus; (2) fine, branching, nucleated strands, which penetrate the jelly, and are conuected with the muscles of the jelly by lateral branches-a connection between these strands and the ectoderm is not yet proved; (3) 8 meridional nerve strands, running under the 8 ribs, and ciliated bands (see description of sensory body), - the rib-nerves. It is a remarkable fact that it has till now been impossible to prove a connection between these three parts of the conjectural nerrous system and the sensory body at the aboral pole.

A fact which deserves special mention is that, in the Medusce and Siphonophora, and especially in the Actinia, a more or less extended plexus of ganglion cells may lie under the endodermal epithelium. 


\section{The Sensory Organs.}

We meet with special sensory organs for the first time in the animal kingdom among the Cniduriu. The development and distribution of these organs is directly related to the manner of life. In attached forms (Hydroids, Corels) there are only organs of touch (the tentacles); in free-swimming forms (Acruspeda, Craspedota, Siphonophoru, (tenophore) organs of smell, hearing, and sight may be added.

The organs of touch are primarily the tentacles of which we have already spoken. The sense of touch is due to special tactile cells belonging to the body epithelium; these are provided with a projecting tactile hair, which is either flexible, mobile, or stiff. The basal ends of such cells are continued into nervous processes which are connected with the nervous system. Tactile cells are to be found, not only in the tentacles of the Cnidariu, but in great numbers on the margin of the disc of the Medusce, and especially in the Ctenophora, scattered over the whole free surface of the body.

As organs of smell, or perhaps rather taste, we have:

1. Small club-shaped papillæ, which in certain Leptomeduse are found generally in great numbers at the edge of the umbrella between the tentacles, being attached to the margin by thin stalks. They contain a narrow blind canal, lined with thick cylindrical endodermal epithelium, which comes from the circumferential canal.

2. Pit-like depressions on the sensory bodies or rhopalia of the Acruspedu, lined with a sensory epithelium which is much folded and provided with long flagellate hairs.

Auditory organs (perhaps also organs for regulating the position of the body in the water) are found in Craspedote and Acraspede Medusce and in the Ctenophora.

We can distinguish three types of auditory organs: (1) auditory vesieles, or marginal vesicles with ectodermal otoliths; (2) tentaculoeysts, or auditory tentacles; and (3) the so-called sensory body of the Ctenophoirt.

I. The auditory or marginal vesicles are found in the division of the Leptomedusce (Vesiculate). These are, in the simplest cases, open pit-like depressions of the subumbrellar epithelium near the base of insertion of the velum. Within these auditory pits are one or more otoliths, which have come from ectodermal cells, while the cells which form the base of the pit bear auditory hairs, on which the otoliths rest (e.g. Nitrocoma). Auditory vesicles rise out of these auditory pits by the closing of the pit, which moves towards the exumbrellar side of the base of insertion of the velum and here forms an externally rounded protuberance (Fig. 72, A). Auditory pits and auditory vesicles receive their nerves from the subumbrellar nerve ring. In the simplest cases we find 8 adradial auditory vesicles, but the number is often much greater, and mounts up to many hundreds. 
II. Tentaculocysts or auditory tentacles are, among the Mecluse, the most widely spread organs of hearing. They are short transformed tentacles in which the solid endodermal axis in the Craspedote (Trachoand Nurco-meduse, Fig. 72, $B, C)$, or the peripheral distal end cells of the hollow tentacle-canal (Acraspedu, Fig. 73), form one or more otoliths, which are here, therefore, endodermal. The ectoderm of the tentaculocysts of the Craspedote and often also a sensory cushion round the base of the tentaculocyst carry long stiff auditory hairs. In many Trachomeduse the sensory cushion rises round the base of the tentaculocyst into a circular wall (Fig. 72, $C^{(}$), which may even completely close over the tentaculocyst. Thus closed vesicular auditory organs again arise, but these have quite a different origin and morphological signification from the true marginal vesicles of the Leptomedusce.

Between the inner wall of the anditory vesicle and the tentaculocyst which it encloses, the auditory hairs are stretched like chords. The tentaculocysts always receive their nerves from the exumbrellar nerve ring. In the simplest cases we find 4 interradial tentaculocysts, but their number is often considerably greater.

The sensory bodies or rhopalia of the Acraspeda (Fig. 73) are compound sensory organs, of which the auditory organ is the principal factor. These are, at the same time, metamorphosed tentacles into which a hollow process of the gastro-canal system penetrates. The endodermal cells at the peripheral blind end of these processes produce an otolith or a mass of otoliths. The outer epithelium of the auditory body carries the anditory hairs. In it, also, on
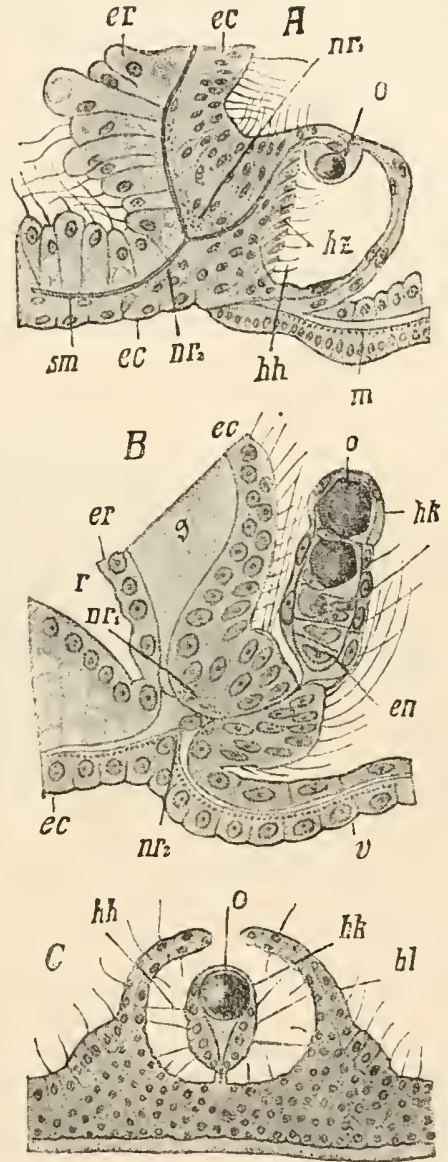

Fig. 72. $-A$, Auditory vesicles of Exquorea Forskalea. B, Tentaculocysts of Cunina lativentris. $C$, Tentaculocysts of Rhopalonema velatum. $A$ and $B$, Trans. verse sections of the margin of the disc; $C$, section of the margin of the disc, after Hertwig. $e e$, Ectoderm; er, endoderm of the circumferential canal ; $n r_{1}$, upper ; $n r_{2}$, lower nerve ring; $r$, circumferential eanal; $s m$, sulporting membrane; $o$, otolith; $h h$, auditory hairs; $h z$, auditory cells; $h k$, tentaculocysts; $b l$, auditory vesicles; $g$, jelly ; $m$, muscle lamellie; $c n$, endoderm cells of the tentaculocysts. In $A$ and $B$ the velum is bent centrifugally outwards. one side lie the eye or eyes; close to it also lie the olfactory pits. The 
whole epithelium round this compound sensory organ, which is protected in special indentations in the disc margin by lobes, is a sensory epithelium with a thick nerve plexus. There are either 4 or 8 , less frequently 12,16 , or even more rhopalia on the margin of the Acraspecte umbrella.

III. The sensory body at the aboral pole, so characteristic of the Ctenophore, is a compound sensory organ of a very peculiar kind, which, according to its structure, is an auditory organ, or rather, perhaps, an organ for regulating the movement of the swimming plates.

The sensory body is constructed as follows. It consists at first of a shallow pit-like depression between the 4 branches of the aboral

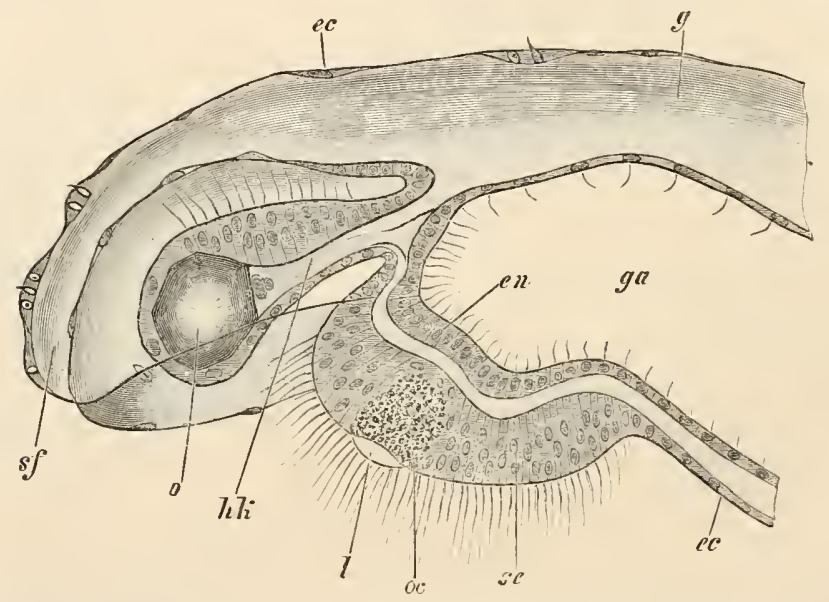

Fic. 73.-Sensory bodies of Nausithoë, after Hertwig (optical transverse section of the margin of the disc). $s f$, Sensory fold of the margin of the disc; ec, ectoderm ; $e n$, endoderm ; ga, gastrocanal; $h l$, anditory body ; $o$, otolitl ; se, sensory epithelinm ; $o c$, eye ; $l$, lens ; $g$, jelly.

so-called funnel vessel. The ciliated body epithelium which forms the base of this pit thickens considerably (Fig. 75, se). Its elements are thread-like cells. In this "sensory cushion" are found deposits of pigment, which perhaps represent simple organs of sight. Round the edge of the pit there rises a membrane which unites above in the shape of a bell, forming a sort of roof to the pit, which is thus transformed into a vesicle. The membrane is composed of the long cilia at the edge of the pit cemented together. It is broken through by slits. at 6 places, and through these the sea water can freely reach the interior of the vesicle. Two of these slits, which are opposite each other, belong to the median plane. The other 4 lie interradially. On the sensory cushion within the vesicle rise 4 S-shaped radially-placed springs; these likewise consist of fused cilia, and their free upper ends enter a globular mass of otoliths, which they support.

From the 4 springs 4 rows of cilia run out through the 4 
interradial slits in the bell-shaped roof. They divide into 8 adradial ciliated bands, which run along the aboral surface of the Ctenophoran body towards the upper end of the rows of swimming plates. Closely bordering on the sensory body are two ciliated epithelial bands, the so-called pole plates (Fig. 74, pp), whose edge is thickened. They lie in the median plane of the body; at the point where they come in contact with the sensory body are found the two above-mentioned median slits through the bell covering that body.

Organs of sight.- Simple organs of sight occur principally as pigment spots in such Leptomedusce as possess no marginal vesicles

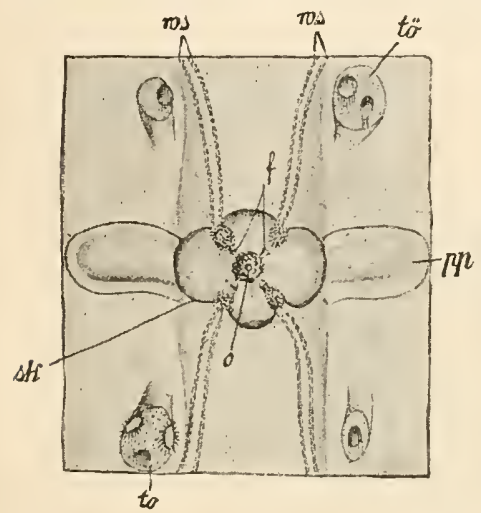

Fic. 74.-Aboral pole of the body of Callianira, after Hertwig. $w s$, Ciliated bands; $f$, springs carrying the mass of otoliths (o); sk, sensory body; $p p$, pole plates; tö, openings of the 4 branches of the aboral vessel or gastro-canal.

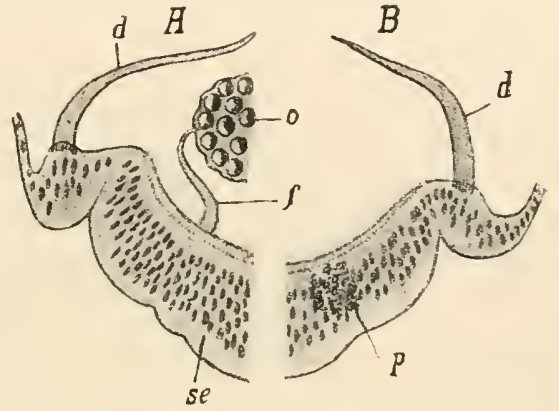

Fic. 75.-Halves of two sections through the sensory body of Callianira, after Hertwig. A passes through one of the 4 springs $(f)$ which carry the otolith mass $(0) ; d$, roof of the sensory pit; se, sensory epithelium of the sensory body; p), pigment.

(Ocellata), and in Anthomedusee. They consist of pigment cells and sensory cells, to which, in some cases, a cuticular thickening is added as lens. Such a lens is less often wanting in the visual organs of the Acraspede (Fig. $73, o c, l$ ), whose structure is occasionally considerably complicated; they form part of the marginal bodies. In the Cubomedusce a vitreous body and a retina are developed between the lens and the pigment cup. In Charyblea there are compound eyes; each marginal body bears 2 large unpaired and 4 small paired eyes. Eye spots, sometimes with lenses, are found at the tips of the feelers in some Siphonophore. In the Ctenophora there are, as has already been mentioned, pigment spots in the sensory cushion of the sensory body.

\section{Supporting Organs, Protective Organs, Skeleton.}

The formations belonging to this category, which are very heterogeneous, can at once be divided into two principal groups, according to their ectodermal or mesodermal origin.

VOL, I 
1. Ectodermal supporting and protective organs.-These are found in attached Cnidaria, and especially in those which form animal stocks by asexual reproduction (incomplete fission and gemmation). We can easily understand why such stocks, which in their natural state imitate trees, bushes, grass, feathers, crusts, leaves, etc., need special adaptations for holding the parts upright in the water, to support and at the same time to protect them. We also see why such supporting organs are of no use, or of very little use to attached Cnidaria which do not form colonies, and why they are often wanting, or only slightly developed in such forms. (Examples: Hydra, the attached Scyphomeduse, and the Actinia among Corals.)

The ectodermal supporting formations are simplest in the Hydroids. Here the body epithelium generally secretes a chitinous cuticle (peri-

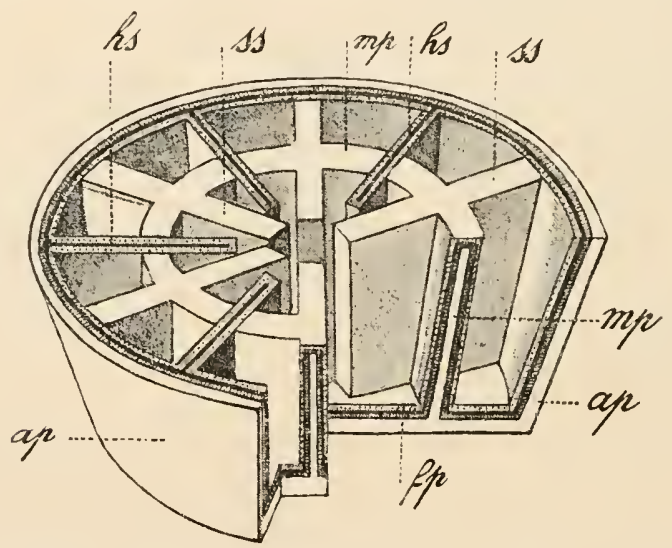

Fig. 76.-Diagrammatic representation of the structure of a Stone Coral (Madreporarian), after $\nabla$. Koch. Only the lower aboral portion of the body is taken into consideration. $f_{p}$, Footplate; ap, exotheca; mp, theca; $s s$, sklerosepta; $h s$, sarcosepta. White parts=calcareous skeleton. Streaked parts $=$ ectorierm. Black parts $=$ mesoderm. Dotted parts $=$ endoderm.

derm) which surrounds the body like a tube. This tube surrounds either only the stem, the branches of the stock, and the stalks of the individuals, or, further, it widens out round the individuals into cups into which they can be withdrawn. In the division of the $H y d r^{\circ}$ corallia the periderm becomes calcified, and forms a framework of many tubes, arranged in a complicated manner, and reticulately bound together.

The ealeareous skeletons of the Stone-corals (Hexacorallia, Madieporuriu), and the horny slieletons of the Alcyonide (Octacorallia) belong to the order of skeletons secreted by the ectoderm.

The origin of the calcareous skeleton of the Stone-corals (Fig. 76), and its relation to the soft parts of the body, are as follows:-

The young Coral, still devoid of skeleton, having attached itself by the aboral end of its body, secretes from the ectoderm of its pedal 
disc a foot-plate formed of globular calcareous grains, and thus connects the ectoderm of the foot with the surface to which the body is attached. Then from this foot-plate gradually arise, by calcareous secretion from the ectoderm, radially arranged perpendicular ridges, the star-ridges or sklerosepta. These are naturally covered on all sides with ectoderm, and they raise the pedal disc, in as many folds as there are ridges, into the gastric cavity. In the same way a calcareous tube, the theca (Mauerblatt), arises, partly by the coalescence of the ends of the star-ridges, and partly perhaps also by the rising of a circular wall out of the pedal dise; this again raises the basal body wall in folds into the gastric cavity, just as do the star-ridges. By the formation of this calcareous tube the gastric cavity is divided into a peripheral portion, lying outside the theca, and a central portion, the two being in open communication above its free upper edge.

In the axis of the Corul a calcareous pillar often rises from the pedal disc and projects into the gastric cavity; this is the columella. The star-ridges may fuse with this columella, they may also stand out above the before-mentioned tube as ribs. By a further calcareous secretion from the ectoderm round the base of the body wall, the exotheea arises ; this is lined by ectoderm, and forms an outer circular calcareous wall of varying height above the pedal disc.

The peripheral ends of the star-ridges can also unite with the exotheca, though of course only by breaking through the body wall; indeed the theca may entirely or partially coalesce with the exotheca, displacing the intermediate soft portions.

Most Madreporuria, by incomplete fission or gemmation, form variously-shaped Coral colonies, in each individual of which the skeletal arrangement just described is repeated. Complications may arise by the complete or partial fusing, or else the complete disappearance of the thecre of the rarious individuals, etc.

The star-ridges or sklerosepta never correspond in position with the ordinary septa or sarcosepta, but on the contrary alternate with them, so that a slileroseptum always lies between 2 sarcosepta, and a sarcoseptum between 2 sklerosepta. In consequence of this the sklerosepta imitate the sarcosepta in number and arrangement.

The skeletons of the Mulreporaria are either massive and close (M. aporosa), or they are perforated by small cavities (M. porifera). The calcareous skeletons of the fossil Rugosa had probably an origin similar to that of the Hexaconallio.

The second kind of ectodermal Coral skeletons, the horn skeletons, which are found in many Alcyonaria and in the Antipatharia, are usually hollow axial skeletons; they run through the bodies of these colonial Corals, and thus take the shape of their often elegantly branched stocks. It seems at first paradoxical that these axial skeletons should be ectodermal. So as to explain this fact, we shall briefly describe the formation of the horn skeleton of Gerurdia. The stocks 
of this Coral form a sort of crust over foreign bodies, preferring the axial skeleton of other dead Alcyonuriu. The surface by which they adhere to these bodies, and which is of course ectodermal, puts forth extcrnally, and thus between itself and the surface to which it adheres, a lamella of horn, which, together with the foreign body (axial slieleton of another Alcyonid), forms the axial skeleton of the whole stock. "Now, however, it not infrequently happens that the Gerardia colony tries later to spread out further than is allowed by the surface it rests on, and then growths which bear young polyps appear on its branches, and into these a new formation of horn enters, attached to the original horny secretion; this new formation has a similar origin with the first, but encloses no foreign body" (v. Koch). In the other Alcyonuria which have a horny axial skeleton, the formation of the skeleton is similar (Fig. 82, B, p. 107), but that part of the axial skeleton which is attached to a foreign substance is very nuch reduced, whereas the free part rising from it is considerably developed, and forms the generally nuch-branched principal mass of the skeleton. Horny axial skeletons are thus always lined with an ectodermal axial epithelium. In the axial skeleton of the Alcyonaria, lime may be found in larger or smaller quantities, and sometimes preponderates. In Isis horny joints alternate with calcareous. The mesoderm of the soft part of the Coral stocks which covers the axial skeleton often contains calcareous spicules. In such cases (e.g. Gorgonia) we have an ectodermal horny axial skeleton and a more peripheral mesodermal skeleton formed of calcareous spicules.

2. Mesodermal supporting organs.-The first of such organs which we shall consider is the thin structureless membrane, which, throughout the whole Hydroid body, scparates the ectoderm from the endoderm. In the Craspedote Medusce this membrane thickens into the more or less strongly developed structureless elastic disc jelly; it is retained as a thin membrane only in the tentacles, and generally also in the oesophageal tube. In the Scyphomedusce the mesodermal supporting jelly begins to be more highly differentiated, comnective tissue cells appearing in it, and fibres, which are either processes of such cells or differentiations of the intercellular substance (Fig. 36, p. 41). In the same waly we find, in the Corals, a hyaline mesodernal layer throughout which cells are scattered. The membrane is everywhere reduced to a thinner layer in the tentacles. In many Coruls (most Alcyonid(e) the skeletal elements are found in this layer. They consist of variously shaped calcareous spicules, which arise in special cells and are found in varying numbers. In the mesoderm of Alcyonium, and in the peripheral portions (the rind) of the stock of the precious Corals of commerce and other forms, they are isolated. Occasionally, however, a new calcareous substance is deposited between the calcareous spicules, cementing these into a firm mass, and leading to the formation of axial skeletons such as that of the precious Coral of commerce.

The greatest differentiation, histologically, within the Cnidaria is 
shown by the jelly which functions as supporting tissue in the Ctenophore, containing, as it does, nerve, muscle, and connective tissue elements. All these elements are usually represented by more or less branched fibres.

As to the origin of the various mesodermal supporting formations, we have the following remarks to make. The homogeneous supporting membrane of the Hydroids, and the corresponding jelly substance of the Hedusce, Corals, and Ctenophora is a product of secretion deposited between the ectoderm and endoderm. Whether both layers take part in this secretion or only one, and if so which, is a question difficult to decile. The cell elements which lie in the jelly, on the contrary, seem almost exclusively to arise by the immigration of cells from the ectoderm. In Corals the ectoderm soon becomes multi-laminar. The cells of the deeper layers become mesodermal connective tissue cells by the rise between them of homogeneous sub. stance. Many observers, therefore, consider the Coral mesodcrm as only a more deeply lying portion of the ectoderm.

\section{Funnel Cavities (Septal Funnels) ; Subgenital Cavities, Subgenital Chamber.}

These formations, met with in many Acraspeda (analogous formations are very rarely found in Craspedotu) are in the lower forms represented by 4 interradial funnel-shaped depressions of the subumbrella round the esophagus (Fig. 99, H, I, st, st', p. 130). They project more or less far into the gastric cavity, within the septa which separate the 4 gastric pouches. In Viscomedusce they become 4 somewhat flat interradial subgenital cavities. Their roof is close to the subumbrellar wall of the central gastric cavity in which the genital organs develop. The membrane which separates the two cavities thus becomes the genital membrane. In two families of the Rihisostoma, (the Versuridce and Crumbessidce), the 4 sub-genital cavities unite in the centre of the umbrella to form a spacious sub-genital chamber (porticns subgenitalis, Fig. 70 D, sgp, p. 85), which opens outward by four interradial apertures through the subumbrella into the umbrella cavity. The dorsal roof of the chamber is formed by the gastro-genital membrane, which separates it from the gastric cavity above it. The subgenital chamber separates the central gastric cavity from the esophagus. The two remain connected only by the $t$ canals which run perradially $(n f k)$.

\section{The Sexual Organs.}

The Cnidaria are either sexually separate, like the Hydrozoc and the Scyphozoc (with a few exceptions, e.g. Hydrc and a few Cludonemider, Cerianthus, Chrysaora), or hermaphrodite like the C'tenophonit.

In the colonial Cnidaria we find male and female individuals either in the same stock (monøcious), and this is the rule; or on different stocks (dinecious). 
Testes and ovaries are, taken as a whole, rery simply constructed; they are resicles or spheres, with numerous egg and sperm cells at different stages of development.

In Hydru both sorts of sexual products lie in the deeper part of the body epithelium. In the other colonial Hydroits they are met
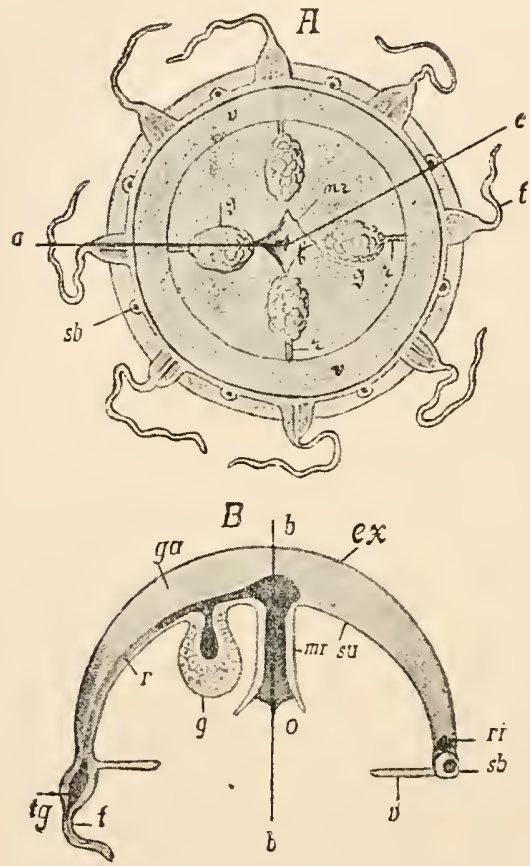

FIG. 77. - Eucope campanulata, partly after Haeckel. $A$, From the surface. $B$, Section in the direction $a-b \cdot c$ of Fig. $A$. $a-b$, Perradius ; $b-c$, adrarlius; $t$, tentacle; $s \delta$, marginal vesicle; $g$, gonades; $m r$, gastric peduncle; $r$, rallial canals; $v$, relum; $r i$, circumferential canal; ex, exumbrella; su, sub. unbrella; $g \iota$, jelly; $t g$, tentacular ressel; $b \cdot b$, prineipal axis. gastro-canal system, sometimes nearer the circumference, at other times nearer the central gastric cavity. In the Pelagidce and Cyenidee the gonades hang down as 4 gastro-genital sacs from the subumbrella into the umbrella cavity; in the Phirostome and Aurelide, on the contrary, they lie on the upper surface of the subgenital cavities or the subgenital porticus (Fig. 70, p. 85). In the Craspedota the ripe genital products pass directly out into the umbrella cavity by the bursting of the gonade; in the Acraspeda they pass inward into the cavity of the gastro-canal system, and reach the exterior thence through the mouth.

The sexual organs of Corals lie in the septa, near the free edges which project into the gastral cavity. 
In the hermaphrodite Ctenophor we meet with them on or in the walls of the meridional ressels, in such a way that on the one wall of the meridional vessel the male elements lie, and on the opposite wall the female elements. These sexual glands are so arranged that in each of the 8 regions of the body, separated by the meridians, there are either 2 testes or 2 ovaries. The ripe sexual products fall into the meridional vessels, and through the gastro-canal system reach the stomach and cesophagus and pass out through the mouth.

In the Cnidaria no special ways of transmission for the sexual products, and no special copulatory organs, are developed.

Concerning the origin of the sexual products we may say, generally, that in very many Hydrozoa they are developed out of the ectoderm, but in the Scyphozoa out of the endoderm. Observers are not yet agreed about the origin of the sexual products in the Ctenophora.

Since in the one form, the Hydroids, the sexual products come from the ectoderm, and in a related form from the endoderm, too great significance shonld not be attached to the place of their origin.

\section{The "Stratification" of the Cnidarian Body.}

In the lowest Cnidaria the body during life consists of two layers of epithelium separated by a supporting lamella; these two layers are similar to the two epithelial germinal layers of the gastrula larva. The musculature is formed by processes of the ordinary epithelial cells. Only the sexual products arise and continue to lie imbedded in the epithelium.

As the complication of the organism increases, there is a tendency for certain tissues and organs to detach themselves from the epithelium and to take up a position beneath it. This tendency is shown by the various tissues and organs approximately in the following order :-

1. The sexual organs, which in the lowest Cnidaria are already subepithelial, and in the higher Cnidaria come to lie altogether or partly in the jelly.

2. Connective tissue elements, which immigrate into the gelatinous supporting membrane.

3. The musculature, whose elements first arrange themselves into a subepithelial muscle layer, and then also move (partially at any rate) into the jelly.

4. The tendency to take up a position deep in the body affects the nervous tissue far less. In consequence of the inseparable connection of the nervous system, on the one hand with the sensory organs, which in accordance with their functions must remain at the surface, and on the other hand with the musculature which tends to sink below it, this system takes up an intermediate position.

We observe, then, in the Cnidaria the progressive development of an intermediate layer between the outer body epithelium and the inner intestinal epithelium, this intermediate layer being formed of 
heterogeneous elements of independent origin, connective tissue, musculature, nervous system, and sexual organs. The outer epithelium gives rise principally to the connective tissue and the nervous system, while the musculature and the sexual organs may be produced either by the outer or the inner epithelium.

It is evident that the development of such an intermediate layer, which we call mesoderm, is the necessary preliminary of a higher organological differentiation of the body.

\section{Reproduction.}

Asexual reproduction by fission and gemmation-Stock formation-Division of labour and polymorphism.

Asexual reproduction is very common among the Cnidaria side by side with sexual reproduction. Among the Ctenophora alone it has not been observed. In Hydra we find asexual reproduction by gemmation

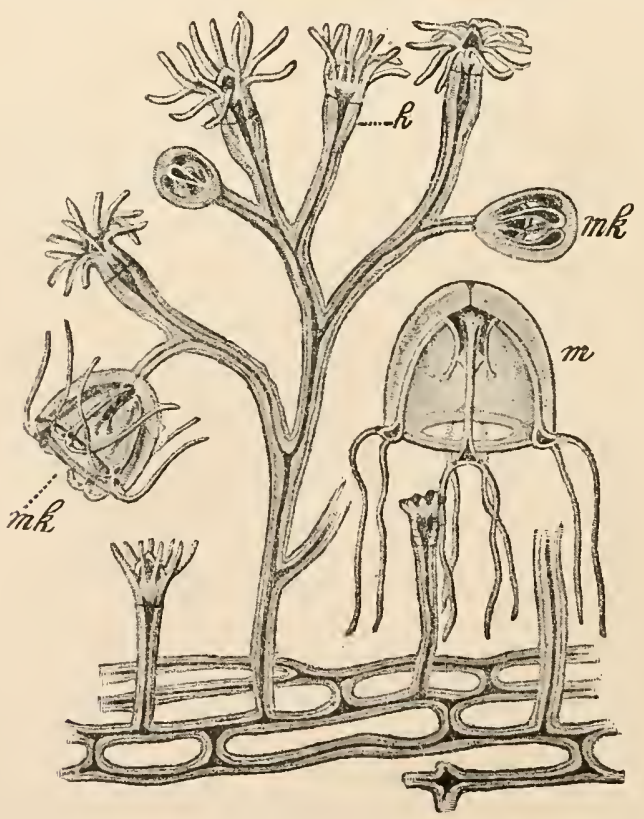

FiG. 78.-Bougainvillea ramosa (after Allman), with budding Medusæ. $h$, Nutritive polyps; $m k$, medusa buds; $m$, detached young Medusæ (Margelis ramosa).

side by side with sexual reproduction in adult animals. Buds are formed by hollow outgrowths of the body wall. These buds grow, and at the distal end a breach is formed-the oral aperture, round which the tentacles arise by means of new outgrowths. Such buds can detach 
themselves from the mother body, or they may in small numbers remain united with it for some time. In the last case small Hydru colonies composed of similar individuals arise.

In the same way elegant and richly branched colonies arise in most Hydroids (Fig. 78). The individuals of such stocks are, however, generally not similar, but, as a consequence of more or less division of labour, Dimorphism or Polymorphism takes place. We distinguish : (1) sterile nutritive persons, which remain on the level of the Hydroid, and undertake the feeding of the stock, the gastric cavities of all the individuals of the stock being in communication with one another; (2) sexual persons, which undertake the duty of ripening the sexual products, and also of planting them out and dispersing them, so that the young brood of IIydroids proceeding from the fertilised egg may attach themselves in new places and form new stocks. The sexual persons which are destined for a free-swimming life, and which are buds of the Hydroid stock, attain a structure corresponding with this manner of life, they become young Craspedote IIedusce, which detach themselves from the stock, swim away, and-often after longer or shorter metamorphoses-ripen the sexual products. That the Craspedote Medusa is only a metamorphosed Hydroid suited for a free-swimming manner of life has already been pointed out. In the accompanying illustrations (Fig. 79, $A-E$ ), we can see how a bud of a Hydroid stock develops into a Critspedote Medust.

The development of free-swimming sexual persons has also the further advantage that it makes cross-fertilisation possible.

In many Hydroids, however, there develop on the stock by budding sexual persons whose structure approaches more or less nearly to that of the Medusa, but does not reach it. Such medusoid sexual persons or gonophores (Fig. 80) do not detach themselves as freeswimming Medusce, but develop the sexual products while remaining connected with the stock. It is not possible to define the various sorts of medusoid buds as stages in the development of the Medusa form, as we cannot see what advantage could be gained by the greater or less development of the Medusc form in these attached sexual persons. They should rather be regarded as so many stages of degeneration, due to the fact that the sexual buds no longer detach themselves from 
the stock as free-swimming Mcdusce. Degeneration can go so far that the original Medusa organisation becomes quite unrecognisable (Fig. $80, C)$.

The division of labour among the persons of a stock goes still further in some Hydroids, and leads to the formation of polymorphic stocks. Besides the ordinary nutritive and sexual persons, feelers (tasters) devoid of mouth and tentacles, and thorn-like protective persons (guard polyps) provided with a hard periderm skeleton, may occur; between these latter the other persons can withdraw.

Reproduction by gemmation and fission is relatively rare in the Meduse of the Hydrozoa, and in the Craspedote Medusce generally. In the division of the Anthomedusce gemmation has till now been observed only in the family of the Sursiculce. Here numerous buds are formed either at the edge of the umbrella, or on the very much lengthened
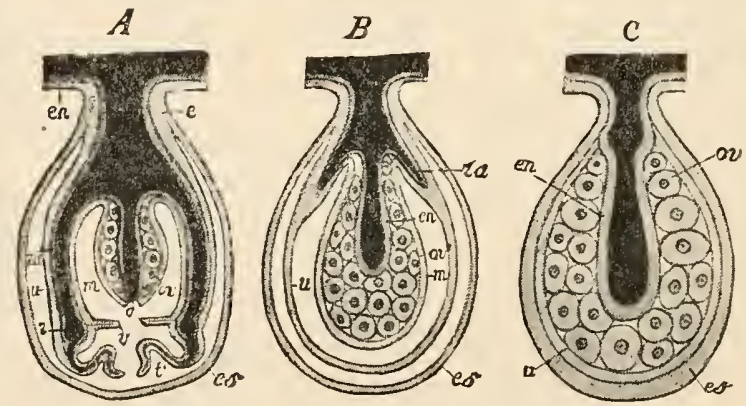

FIG. 80.-A, $B, C$, Three different types of gonophores from Hydrozoa. $e$, Ectoderm; en, endoderm ; es, outer ectollermal envelope of the gonophore ; $u$, umbrella ; ra, radial canal ; $r$, circumferential canal ; $t$, tentacles ; $m$, gastric peduncle; $o$, mouth; ov, gouade (orary); $v$, velum.

gastric peduncle. These buds grow into young Sursice like the mother animal, then detach themselves and swim about independently. Here we have formation of free-swimming Medusa-stocks without division of labour and without polymorphism of the individuals. The Medusce attain full development only after their detachment from the mother animal.

Reproduction by repeated binary fission has also been observed in Craspedote Medusce. In some cases (Gastroblasta) peculiar free-swimming Medusa-stocks arise which lave the following structure. A single Medusa provided with tentacles and marginal vesicles carries on its subumbrella numerous gastric pouches. The number of these gastric pouches determines the number of persons in the stock, which are so far incompletely divided from each other that their discs never separate.

Asexual reproduction by a sort of fission occurs also in young forms of the Discomedusce (e.g. Aurelia), i.e. in the young attached stage known as Scyphistoma and described above. In the simplest case 
(monodise Strobila) the disc of the Scyphistoma (Ephyie) constricts itself and separates from the peduncle, on which by regeneration a new disc is afterwards formed. New discs, howerer, are mostly formed between the peduncle and the older dises before the latter detach themselves; then we have the typical polydise Strobila (Fig. 81).

In Corals, reproduction by gemmation and by incomplete fission is very wide spread. It is, however, rare in the naked Actinia. It leads to the formation of those occasionally rery large Corul-stocks whose skeletons are well known as lieef or Stone Corul, the Coral of commerce and other Alcyonaria. The gemmation and stock formation of the Alcyonariu is the most fully investigated. At certain points of the mother-polyp outgrowths, the so-called stolons, make their appearance and are arranged on the motherpolyp in ways characteristic of each different group. They are either simple, or branched in a reticular manner. By new outgrowths, and local widenings of the endodermal canals which they contain, there arise, on these stolons, young daughter animals, in which the mouth,

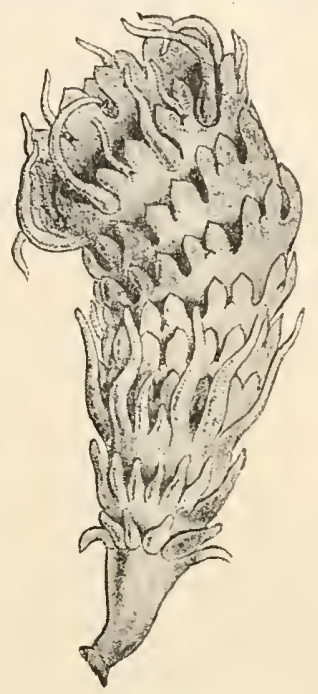

Fic. s1.-Polydisc Strobila of Aurelia aurita, after Haeckel. asophageal tube, septa, and tentacles are formed. In this way arise
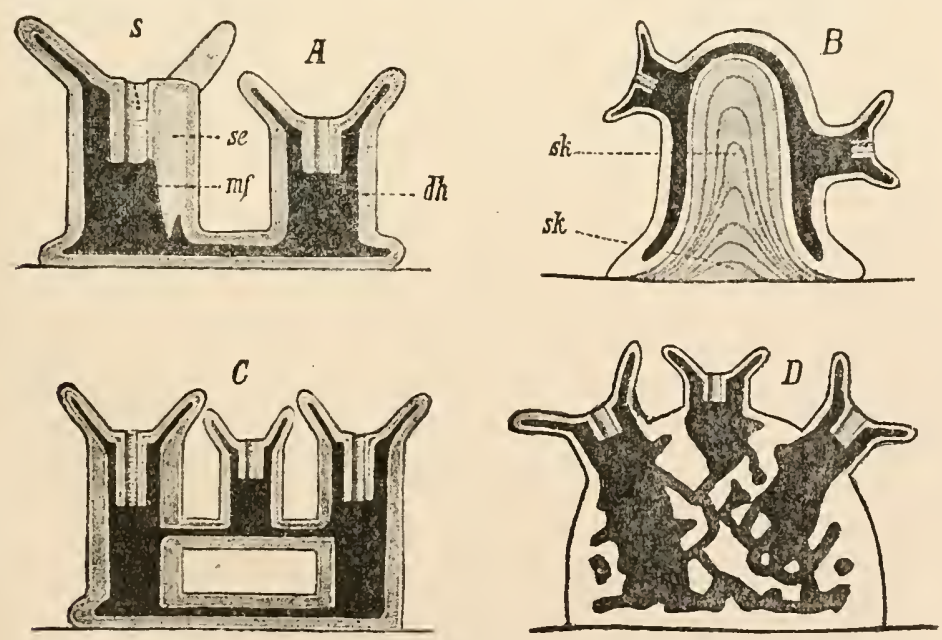

Frg. 82.-Diagrams illustrative of gemmation and stock formation in various Alcyonaria. $A$, General diagram. $E$, Gorgonia. C, Tubipora. $D$, Alcyonium. Black portions the cavities of the gastral system. $s$, Esophagus ; sc, septa ; $m f$, mesenterial thickenings ; dh, gastric cavity ; sk, axial skeleton, drawn in layers to illustrate the mauner of its origin. 
stocks formed of individuals whose gastric cavities remain connected, like those of the Reef Corul, by characteristic arrangements of the canal system. The above illustrations (Fig. 82, $A-C$ ) show diagrammatically the manner of gemmation and the beginning of stock formation in different Alcyonaria.

In the Alcyonaria also, division of labour takes place, with the resulting dimorphism or polymorphism of the persons (zooids). Thus, side by side with the normal persons there are other persons without tentacles and with septa reduced in number (two) whose chief function is the taking in of water into the canal system.

\section{Organisation of the Siphonophora.}

It is most suitable for our purpose here to describe the structure of the Siphonophora, as it can only be explained and understood by help of the phenomena of asexual reproduction by means of gemmation, of stock formation, and of the division of labour. The Siphonopliorc have actually been long considered by most investigators as polymorphic animal stocks, although zoologists had not agreed as to the significance of the separate parts.

The following description corresponds in general with the views recently put forth by Haeckel.

In the order of the Siphonophore two animal groups have till now been united, which, apart from the fact that both are Medusa-stocks, have nothing in common, and, in any case, have quite different origins. We shall therefore treat of these two groups-(1) the Siphonanthe and (2) the Disconanthe-separately.

I. The Siphonanthe.-These may be conceived of as colonies of Craspedote Medusce by comparing their whole body with a Craspedote Medusa on whose gastric peduncle numerous young Medusce have arisen by gemmation, somewhat in the same way as in Sarsia siphonophora. While, however, the mother Medusa of the Sarsia is radially constructed and all the daughter Medusce are like each other and like the mother, the mother animal of a Siphonanth which is recognisable in its young or larval stage is a much metamorphosed Mechuse. Its disc is mostly changed into an air vesicle, it possesses only one tentacle (which also occurs in the Craspedota), and its gastric peduncle is lengthened out into the generally very long "stem" of the Siphomanth. The daughter Medusce, budding from the stem, are neither like one another nor like the mother animal. They divide between them the general work, and are consequently variously modified to suit their special functions.

If we now more closely consider the body of a Siphonanth, we must first bear specially in mind those parts which can be compared with parts or organs of the mother Medusa of a proliferous Craspedote.

A. The pneumatophore or swim-bladder (Fig. 83) lies at the 
upper end of the stem, and represents a metamorphosed Medusa umbrella. (It is wanting only in the order of culyconectu, where the umbrella of the larval mother Medusa develops into the first provisional swimming-bell and is then thrown off.) At one point of the exumbrella an invagination forms at an early stage for secreting air, the aip vesicle, which expands so much that it represents by far the largest portion of the original disc; it always remains in open communication with the exterior by means of the aperture of the invagination (the pore of the air vesicle). Around the air vesicle, in the bell which has been so much modified and has become more or less globular, there are $S$ (less frequently 4 or 16) endodermal chambers divided by septa; these open under the air vesicle into each other and into the endodermal axial canal of the stem. These chambers correspond with the radial canals of the Meduse. The pneumatophore serves as a hydrostatic apparatus, which keeps the whole Siphonophora colony floating in the water. The air can be expelled through the pore of the air vesicle, and again secreted by the ectodermal glandular epithelium at its base.

B. Only one of the tentacles is fully developed. This is moved from the margin of the disc on to the subumbrella to the base of the stem, and is probably usually thrown off at an early stage.

C. The stem of the Siphonanth, which is generally long, tubular, and contractile, more rarely short and flat, answers to the gastric peduncle of a Medusa. An aperture (primary

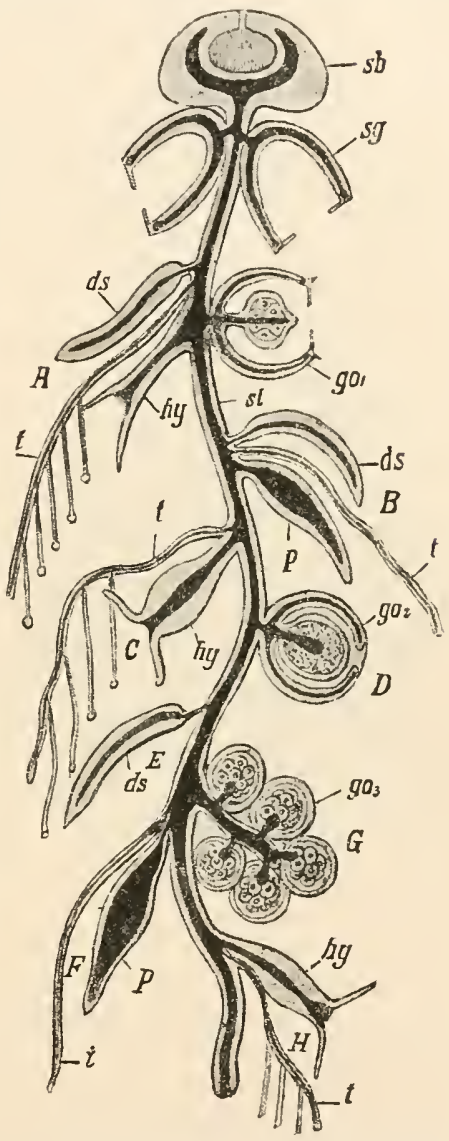

FiG. 83.-Diagrammatic representation. of the organisation of a Siphonanth stock. $s b$, Pneumatophore; $s g$, swimming-bell; $d s$, bract; $t$, tentacles; go $, g_{2}, g_{0}$, gonophores; $h y$, oral or gastrie peduncle (siphon); $p$, feeler or taster (palpou); $A \cdot H$, various groups of appendages which are never found in this way together in any single Siplon. anth. Black portion=gastric system.

oral aperture) is but rarely found at its lower end. The view that these three parts together are equivalent to a Medusa is supported by ontogenetic observation, as is to a certain extent evident from what has already been said. The gastrula which develops from the fertilised egg grows into a Siphonanth larva, such a larva possessing at first only 
these three parts - umbrella, tentacle, and gastric peduncle. This medusoid larva is bilaterally symmetrical. Its umbrella has a deep cleft, it possesses only one tentacle, its gastric peduncle is filled with yolk. The Siphonophorit colony arises on the gastric peduncle by gemmation.

Let us now consider the polymorphic appendages of the Siphonanth stem, which we compared with the daughter Medusce budding on the gastric peduncle of Sursia siphonophora. All these appendages are arranged on the stem in a line whose position is called ventral. The
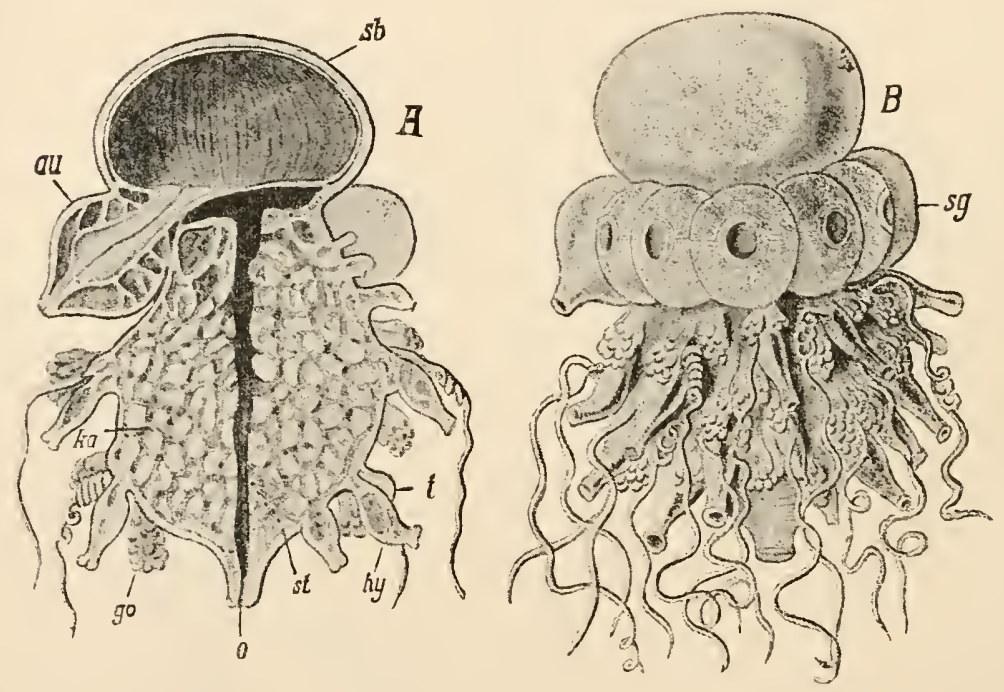

FIG. St.-Stephalia corona, after Haeckel. $A$, Halved longitudinally. $B$, From life. $s b$, Siviubladder; $\alpha u$, aurophore; $s g$, swimming-bells; $k a$, canal system of the stem (chief stomach, st); go, gonophore elusters; $o$, aperture (mouth) of the peduncle (chief gastric tube, st); $h y$, gastric tubes (siphons); $t$, tentacles.

line generally becomes a spiral, because of the spiral twisting of the stem. Highest up on the stem under the pneumatophore (when one is present) the so-called swimming-bells or nectophores are inserted ; these are wanting only in the Cystonecta. The swimming-bells exclusively and alone provide for the locomotion of the whole stock. They have lost all those Medusa organs which were of no use to or even hindered the fulfilment of this function, first of all therefore, mouth, gastric peduncle, and tentacles. The locomotory organ of the Medusa, the disc or umbrella, however, is all the more strongly developed ; it is much vaulted with a strong circular muscular layer in the subumbrella. Its edge projects in the shape of a true velum. At the base of the velum runs the circumferential canal, into which 4 radial canals enter. The swimming-bells are so inserted on the stem by their 
aboral or apical poles, that the aperture of the bell is turned downwards and outwards, away from the apex of the stem.

When the swimming-bells contract, and so expel the water downwards out of their subumbrellar cavities, the whole stock is propelled by the recoil in the opposite direction, i.e. upwards. The swimming-bells are not regularly, but bilaterally symmetrical, which is explicable by their insertion on the stem, and by the position they have to assume to effect the motion forward of the whole stock. Is to the number and arrangement of the swimming-bells, we find either one or two opposite each other, or several, or often very many, arranged in two or many rows in circles round the stem. The points of insertion of the bells, however, always lie in a spiral, which is sometimes much extended, sometimes much compressed. The direction in which this spiral is twisted is the opposite of that in which the other appendages are arranged. The radial vessels of each swimming-bell, which unite at its apical pole, are in open communication with the endodermal axial canal of the stem.

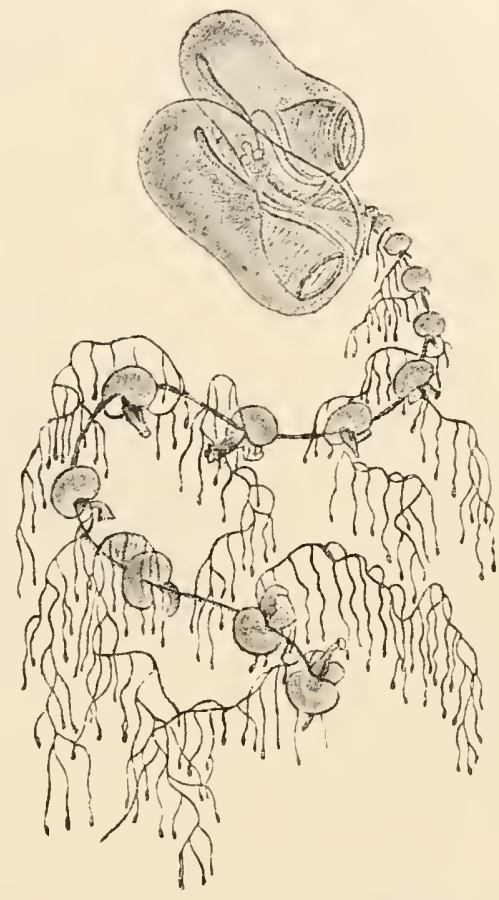

Fic. 85.-Praya galea, after Haeckel.

Beneath the swimming-bells the stem carries the following different kinds of appendages, which we may also consider as modified Meduse :

A. The gonophores or reproductive persons (Fig. $83, g 0_{1}, g 0_{2}, g 0_{3}$ ). -To these belong exclusively the function of forming the sexual products. They are either male or female. The typical organisation of a Crospedote Medusu is still more or less faithfully maintained in them. They possess a bell-shaped umbrella with velum, circumferential canal and radial canals, and, further, a gastric peduncle which projects into the subumbrellar cavity (occasionally with an oral aperture in addition), and in whose wall, as in the Codonidce among the Craspedote Meduse, the sexual products arise. The umbrella is here, probably, a protective apparatus. Occasionally the rudiments of tentacles are still found on the margin of the disc. Sometimes, however, the whole Medusa form is considerably degenerated.

B. Sterile persons. - These perform the functions of taking in food, and digestion, of protection, touch, etc. The Medusa structure in them 
is always obscured, and often so much so as to be unrecognisable. The following different kinds of such sterile persons may be dis tinguished:

a. Persons in which the following typical organs of a Medusa may still be recognised: (1) a variously-shaped protective or bract as metamorphosed umbrella. It serves as umbrella or shield, and affords protection, not only to the other parts of the same person, but also to the neighbouring persons, which can withdraw under it. (2) The oral or gastric peduncle (siphon), the chief organ for taking in food and digestion. The siphon is often stalked, and the edge of the mouth widened into a funnel, or produced into 4 points, or prolonged like a proboscis. (3) A very contractile tentacle or capturing filament, which is placed at the base of the gastric tube. The tentacle is feathered on one side, i.e. it is provided with one row of lateral branches, whose ends are armed with stinging batteries. Such a sterile person simultaneously performs the functions of taking in food and of protection (Fig. 83, $A$ ).

b. Persons distinguished from those just described by the fact that the contractile hollow siphon has lost its mouth, and so appears changed into a taster or feeler (palpons). The tentacle at the base of the feeler becomes an unfeathered, long, and very retractile sensory filament (Fig. 83, $B$ ).

c. Persons in which the umbrella is completely degenerated, and which consist of nothing but siphon and tentacle (Fig. 83, C).

d. Persons which have retained exclusively the function of protection, and in whom the umbrella alone, in the form of a bract, has attained development, while the formation of siphon and capturing filament has been suppressed (Fig. 83, E).

e. Persons reduced to tasters, without bracts and without sensory filaments.

C. Special swimming-bells.-Nectophores, agreeing in structure with the ordinary swimming bells developed at the upper end of the stem are found in some Siphonanths on other parts of the stem as well.

These various appendages, or heteromorphic persons (A-C), of which several may be wanting, occur in different and often very characteristic order and manner of division on the stem. They are, in the first place, arranged in many Siphonanths in distinct groups, repeated at regular intervals and separated by internodes of the stem.

The following are the chief modifications which occur in the conposition of such a group, which is known as a cormidium :

A. The cormidium consists of (1) a gonophore and (2) a sterile person with bract, siphon, and capturing filament (Fig. 86).

B. To these two persons a third person, a special swimming-bell, is added.

C. The cormidium consists of (1) one or more gonophores, (2) one sterile person with siphon and tentacle, but without bract. 
D. It consists of (1) one or more gonophores, (2) one siphon with tentacle but without bract, (3) one or more palpons with tentacle but without bract.

E. It consists of (1) a group of gonophores, (2) a siphon together with a tentacle, (3) one or more palpons without tentacle, (4) several bracts, some of which perhaps belong to the palpons and to the siphon.

Less frequently we find in the cormidium several siphons with tentacles.

The cormidia described under A and B can detach themselves from the stem, and only when they are thus free-swimming Eudoxice (A) or Ersece (B) do they ripen the sexual products in their gono-

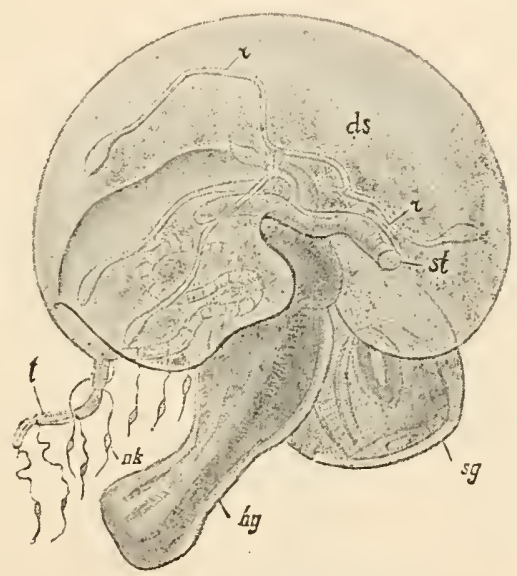

Fig. S6. - Single Cormidium (Eudoxia) from Praya galea, after Haeckel. ds, Protective or bract ; r, radial canals of the same; st, portion of the stem; $h y$, siphon or gastric pedunele ; $t$, tentacle; $n k$, stinging knobs; $s g$, gonophore.

phores. From the fertilised egg a medusoid Siphonophoran larva is then produced, and from this, by budding, comes the polymorphic Siphonenth stock.

In many Siphonunths the arrangement of the heteromorphic persons in special cormidia is either more or less obscured (e.\%. Phizophysa, several Agalmide and Forskalidce) or quite suppressed, so that the persons are irregularly distributed on the stem (Physalia, Agalmopsis). In this case the persons are generally appendages, in which, apart from the gonophores standing in groups or clusters, the medusoid structure is more or less completely degenerated : i.e. siphons with tentacle, taster with or without sensory filament, or isolated bracts.

This dispersed arrangement is to be explained in this way: the parts belonging to a sterile person, such as siphon or taster, bract or tentacle, become detached, and move away from each other, and stand 
separately on the stem. These dislocated portions or organs are able to multiply independently.

II. The Diseonanthe (Disealia, Porpeta, Porpalia, Velella).These have to be interpreted quite differently from the Siphonanthe. According to the harmonious and convincing teaching of ontogeny and comparative anatomy, these animals must be considered as Medusce with marginal tentacles. These Medusce have a gastric tube with mouth (principal siphon) in the centre of the subumbrella in the typical way, but also produce secondary siphons or palpons, by gemmation, on the subumbrella (just as in the Gastroblasta); out of the wall of these secondary siphons the Medust-shaped gonophores

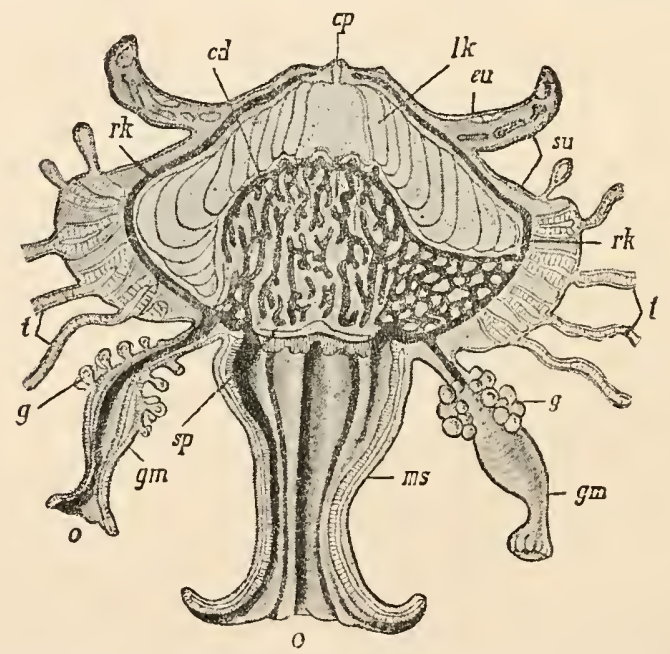

Fig. 87.-Porpalia prunella, after Haeckel. $c d$, Central gland; $l k$, air chamber; $c p$, central nore of the same; $r k$, radial canal ; sp, supporting plate ; $e u$, exumbrella ; su, subumbrella ; $t$, tentacles; $g$, gonades; 0 , mouth ; $m s$, lrincipal siplon ; gm, accessory siphons.

bud (Fig. 87). All the tentacles belong to the margin of the undivided persistent Medusa umbrella. In the umbrella (on which in Velelle a vertical crest, generally placed diagonally, rises) an air vesicle is developed on the exumbrellar side; this is often of very complicated structure, many chambered, and originally octoradiate; the chambers communicate with the exterior through numerous pores. The young stages of the Disconanthe are typical MIedusce, with 8 (later 16) tentacles at the disc margin, and with one central gastric peduncle or siphon. The gonophores detach themselves as free-swimming medusoid sexual persons, and only ripen the sexual products after their separation.

The view of the Siphonophoran body here brought forward takes up a position intermediate between two diametrically opposed theories, 
each of which has long had its supporters. According to one theory, the whole Siphonophoran body represents a single Medusa person, and all its separate appendages - the nectophores, siphons, tasters, tentacles and gonophores - are nothing but displaced organs of this Medusa, whose number increases by multiplication. According to the other theory, the Siphonophoran body is a free-swimming polymorphic Hydroid stock, and each of the appendages just enumerated, even each tentacle, is to be considered as a more or less modified person, suited to some special function, in consequence of an extreme division of labour, either, therefore, as a metamorphosed Hydroid, or (as e.g. the nectophores and gonophores) as a metamorphosed MLedusa.

\section{Life-history of the Cnidaria, Alternation of Generations.}

We shall return later to the special ontogeny of the Cnidaria, the arrangement of the layers of the body, and the development of the organs. Here we shall restrict ourselves to depicting the general course of their life-history.

Hydra multiply both asexually by gemmation, and sexually by means of fertilised eggs. From the latter, by a gradual course of development, Hydra again arise.

In very many Hydromedusce an attached Hydroid form arises out of the fertilised egg, out of which, by budding, comes a Hydroid stock, which is at least dimorphic and often polymorphic. Some buds become sterile nutritive persons, others sexual persons. The latter detach themselves from the stock as free-swimming Cruspedote Medusce (Fig. 78, m, p. 104) and form the sexual products. From the fertilised egg an attached Hydroid may again be produced. We thus find here, in the cycle of development, two consecutive generations, as it were, intercalated: (1) the dimorphic or polymorphic Hydroid stock which reproduces by gemmation; and (2) the Medusa which arises by gemmation, detaches itself, swims about, and reproduces itself sexually. Such an alternation of differently formed generations which multiply in different ways is called alternation of generations (metagenesis). It follows from our description that this alternation of generations is the result of division of labour between the single persons of a Hydroid stock. Each Medusa is originally equivalent to a nutritive person, and it owes its structure to adaptation to the special function of forming the sexual products and of dispersing them by means of its free locomotion.

We must not, therefore, consider the Hydroid form as a young stage of the Medlusa form. Nutritive polyp and Medusa are sisters. The one sister develops further than the other and reproduces sexually, while the latter remains sterile.

There are two other methods of development to be derived from the alternation of generations of the Hydro-Medusce. There are Hydroid stocks in which the sexual persons do not detach themselves 
from the stock, but remain connected with it as medusoid gonophores. From the fertilised eggs of such Hydroids other Hydroils are produced. On the other hand there are Hydro-Medusce in whose whole life cycle no attached Ifydroid stock is developed. From the fertilised egg of such a Craspedote Medusa another sexual Medusa is produced, often after a series of metamorphoses.

In the Discomeduse also a kind of alternation of generations occurs. The fertilised egg may develop into a young attached Medusa, which reproduces asexually by axial budding (strobilation, Fig. 81, p. 107)

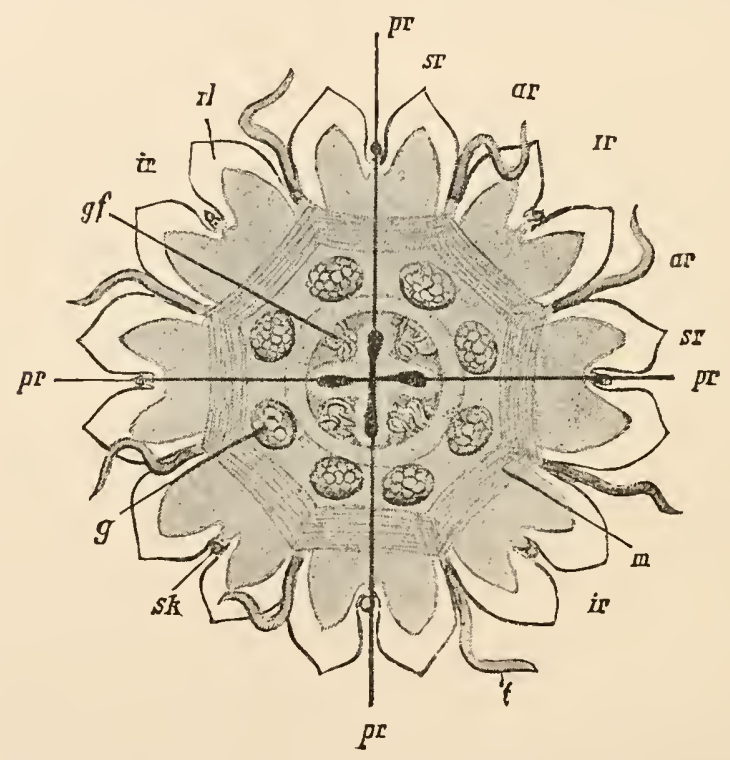

FIG. $88 .-$ Nausithoë. $p r$, Perradii ; $i r$, interradii ; $a r$, adradii ; $s r$, subradii ; $r$, marginal lobes ; $t$, tentacles; $g f$, gastral filaments; $m$, circular muscle of the subumbrella; sk, sensory bodies (rhopalia); $g$, sexual glands (gonades); in the middle the oral cross.

or by lateral budding. The constricted young Medusce (ephyr:e), whose organisation, but for absence of gonades, is essentially the same as that of Nausithoë (Fig. 88), undergo a more or less complicated metamorphosis, till they again become adult sexually mature Medusce. Here, however, the organism which multiplies asexually is really a young stage of the sexually differentiated Medusa, not a sister as in the Hydro-Nedusa. The young Scyphistoma does not need to multiply asexually. It can detach itself from the stem and develop direct into a Medusa. There are also very many free-swimming Scypho-Medusce from whose fertilised eggs a new Medusc is produced again direct without the intervention of an attached stage in which multiplication is asexual. This direct development is usually accompanied by meta- 
morphosis. Development with alternation of generations and without it can occur in the same species.

In Coruls a free-swimming larva is produced from the fertilised egg, and this attaches itself and develops into a Coral, which either remains a single individual or produces a Coral-stock by means of gemmation and incomplete fission.

The Ctenophora, without exception, develop direct.

From the fertilised egg of the Siphonophora a medusoid organism arises, which, by budding, yields the polymorphic animal stock. Here also (Physaliu, Disconanthe) the medusoid gonophores can detach themselves from the stock and lead a free life as sexual individuals. In many Siphonanthe groups of persons, the already mentioned Eudovie and Erscee, detach themselves from the stock, and swim about freely as minute new animal stocks. In their gonophores the sexual products are developed. From the fertilised egg a medusoid organism arises, which by gemmation again becomes the polymorphic animal stock. We thus have here again to do with a sort of alternation of generations.

\section{Literature.}

R. Leuckart. Zoologisehe Untersuchungen I. Giessen, 1853.

The same. Zur nähern Kenntniss der Siphonophoren ron Nisa. Arch. $f$. Toturgesehichte. 1854.

C. Gegenbaur. Beobachtungen über Siphonophoren. Zeitsehr. f. w. Zool. 1853.

The same. Neue Beiträge zur Kenntniss der Siphonophoren. Nova acta. Tom. 27. 1859.

C. Vogt. Nemoires sur les Siphonophores. Memoires de l'Institut genevois. 1854.

A v. Kölliker. Die Siphonophoren ader Schwimmpolypen von Hessinc. Leipzig, 1853.

Milne-Edwards et J. Haime. Histoire naturelle des Coralliaires. 3 vols. Paris, $185 \%-60$.

Th. Huxley. The Ocecnie Hydrozoa. Roy. Socicty. London, 1859.

De Lacaze-Duthiers. Histoire naturelle du eorail. Paris, 1864.

Th. Hincks. Natural History of the British Hydroid Zoophytes. 2 rols. London, 1868.

Kölliker. Antomiseh-systematische Besehreibung der Aleyonarien. Die Pennatuliden. Abhandlungen Senkenb. nat. Ges. Frankifurt. Bd. 7 and 8. 1872.

C. Claus. Ueber Halistemma tergestinum. Arbeit. Zool. Institut. Wien. 187 S.

G. J. Allman. A Honograph of the Gymnoblastie or Thubularian Hydroids. London, 1871-72. 2 vols.

N. Kleinenberg. Hydra. Leipzig, 1872.

O. and R. Hertwig. Das Nervensystem und die Sinnesorgane der Medusen. Leipzig, 1878 .

The same. Die Actinien. Jen. Zeitschr. f. Naturwiss. Bd. XIII. u. XIV. 18i9-S0.

R. Hertwig. Ueber den Bau der Ctenophoren. Jena, 1880.

C. Chun. Monographie der Ctenophoren. In: Faunce und Flora des Golfes ron Necopel. Leipzig, 1880.

E. Haeckel. System der Medusen. Jena, 1880, 1881.

A. Andres. Monografia delle Attinie. 1. Theil. In: Fauna und Flora des Golfes von Neapel. 1881. 
G. von Koch. Monographic der Gorgoniden. In: Fauna und Flora des Golfes von Neapel. 1887.

R. Hertwig. Die Aktinien der Challenger Expedition. Jena, 1882.

E. Haeckel. Report on the Siphonophora of the Challenger Expeclition. 1888.

A. Goette. Ueber die Entwickelung von Aurelia aurita und Cotylorhiza tubereulate. 1887.

Numerous important works and treatises by Metschnikoff, F. E. Schnlze, Haeckel, Moseley, L. Agassiz, A. Agassiz, Clans, Weismann, Hamann, Grenacher, Lacaze-Duthiers, Jourdan, Jikeli, Lendenfeld, Chun, C. Keller, Wilson, Fol, Semper, Dana, G. von Koch (a series of important treatises on Corals in Gegenbaur's Mtorph. Jahrb., vols. iv-ix), A. von Heider, ete.

\section{The fundamental law of Biogenesis. - Egg segmentation and the development of the two primary germinal layers of the Metazoa (gastrulation)-The ontogeny of the Cnidaria.}

Every Metazoon is, at the commencement of individual existence, a simple cell, an egg cell; i.e. its development starts from a point at which the Protozoon remains during its whole life. Further, by the repeated division of the fertilised egg of every Metazoon, a germ is prodnced, whose structure repeats in a general way the structure of a simple Ceelcnterate. This germ, which is known as the gastrula, consists of two cell layers, the ectoderm and the endoderm, which may be compared with the two layers composing the body of a simple adnlt Ceelenterate.

Fundamental law of Biogenesis. - The frequently observed parallelism between the consecutive stages of individual, or ontogenetic development, and the grades of development presented by the animal kingdom, is thus explained by the theory of descent. Every animal, in its ontogeny, passes throngh, in an extraordinarily abbreviated and concise manner, the long series of its ancestral forms. "Ontogeny, or the history of the development of the individual, is a short recapitulation of the history of the race, or phylogeny." This sentence, in which the fundamental law of Biogenesis is formulated, contains a generalisation of the fact that every animal passes on to its descendants by inheritance, not only its organisation at an adnlt stage, bnt also its own course of development.

In the course of time adaptation, i.e. the survival of the fittest in the strnggle for existence, interferes with the action of heredity, so that species do not remain constant, but change according to circumstances. In the same way, the ontogenetic process of development also, i.e. the series of consecntive stages of development of a species, may be snbject to snch modification that it no longer faithfully recapitulates the process of development of its ancestors. The repetition of ancestral development caused by inheritance is called "palingenetic"; the modifications of ancestral development cansed by adaptation are "cænogenetic."

It is extremely difficnlt to determine in a concrete case what is palingenetic and what is cænogenetic. It is at once evident that a pmely palingenetic conrse of development never occurs anywhere. It is only by the discovery of similarity between one stage of development in an animal and another adult animal, that we can decide that that stage has something palingenetic in it. When a comparison of a stage of development in one species with other species in an adnlt condition is not possible, we have no sure means of judging what is palingenctic in it and what cænogenetic. For instance, we know of no adult animal with which the Echinoderm larva can be compared ; and we cannot consequently know whether these larvæ have in any way retained the organisation of their primitive Echinoderm ancestors.

Our justification, again, for holding that a stage of development is probably 
palingenetic, when other organisms in adult condition possess essentially the organisation of that stage of development, stands or falls with the assumption that in the course of the earth's history some lower animal forms have remained very little altered by the side of others which have developed into higher organisms, and that it is not the case that nearly all lower animals living to-day are the degcnerate descendants of ancestors once highly devcloped. Palrontology teaches us, in fact, that during those epochs of the earth's history which are accessible to investigation, and among those organisms whieh we know in a fossilised condition, many forms and groups of forms have remained unaltered for immensely long periods, while other forms on the contrary have progressed. On the other hand, we cannot doubt that retrogressions in the development of the organic world are by no means rare phenomena. The acquisition of a stationary manner of life, for example, and still more of parasitism, necessitate such retrogressions. In many cases, in consequence of new conditions, sexual maturity may be shifted to an earlier stage of development, better suited for competition, and the "adult" form may gradually cease to be developed. The Axolotl, for instance, generally becomes sexually mature at a stage with external gills-a so-called larval stage-and reproduces itself at that stage. It only rarely develops into the "adult" animal. If, in consequence of certain conditions, the development into an adult animal were altogether and always to cease to take place, we should have beforc us a case in which an animal, according to the common conception more lowly organised, descended from one more highly developed. If we wish, therefore, to compare the developmental stages of an animal with the final stages of other animal forms, in order to demonstrate their palingenetic meaning, we must always be able to bring forward good reasons for believing that these animal forms are not simplified or degcnerated.

If the distinction between palingenesis and cænogenesis is difficult, even when we can illustrate it by adult animals, the difficulty increases when the comparison remains purely ontogenetic; i.e. when we can only compare developmental stages of one animal with developmental stages of other animals. It is now accepted, that when two animal groups have similar larval forms, these groups are racially related. The larva of Balanoglossus agrees in many important points with the larva of the Echinoderm ; Balanoglossus is therefore considered to be related to the Echinoderms. It is possible that this view is correct; but we cannot say that this relation is probable; for we can bring forward no reason to show that either of these larval forms has any palingenetic significance.

In dealing with ontogenetic problems we luave to take into account another series of considerations, which are partly a simple result of a consistent carrying out of the Darwinian principles. We give only the most important.

1. We are more likely to be justified in considering an ontogenetic process of development palingenetic, when it exhibits from first to last an unbrokell scries of self-supporting stages of development, so that we can imagine the larva at cach stage to be an adult sexually mature animal. But we certainly do not find such a method of development entirely realised anywhere in the animal world.

2. It is an advantage for an animal whose organisation is adapted to its conditions, i.e. which maintains with success the struggle for existence, to reach its adult form, not only as directly and as quickly as possible, but economically, i.e. without the development of parts which have become useless.

3. Such a direct and abbreviated development can take placc only when the developing animal is from first to last provided witl nourishment by means of which it can develop. This occurs either by the egg receiving from the mother body nutritive yolk to help in its development, or by its being nourished, as in viviparous animals, direct from the mother body. Everything that is connected with such 
nourishment of the developing animal is a secondary addition to the original development. We cannot think either of a bird embryo at the time of incubation, or of a mammalian embryo in its egg envelopes as an independent and self-feeding animal.

4. Direct development may occur together with gradual development or metamorphosis in the ontogenetic development of the animal. Of all the original independent stages of development, often only one or a few are preserved, viz. those which are specially capable of competition, whilst all the others disappear in the direct development. Thus the insect egg develops direct into the caterpillar or larva by the help of the nutritive yolk. The larva at this stage of development, being suited for competition, procures food for itself independently, grows vigorously, and then again develops direct (pupal stage) by the help of the stored-up food into the adult winged insect.

5. The effect of the struggle for existence on the larva at the various stages of development, and especially on those which feed independently, is just the same as on adult animals. It is therefore to be expected that the different mammers of life (attached, free-swimming, parasitic, ete.) during the stages of development should determine adaptations and modifications in the larval organisation similar to those in adult animals. Such modifications, however, have a limit not clearly known to us, just because the stages they affect are stages of development whose purjose is to produce an adult sexually mature animal.

6. The more important organs or systems of organs are, the earlier do they begin to form in the larva; or, in other words, the order of their development in time is in direct correspondence with their importance to the adult animal. Whatever holds good for the adult animal also naturally holds good for every organ and for every adaptation ; its development becomes more and more direct, and more and more abbreviated ; it adapts itself more and more to the purpose of reaching as soon as possible the form and arrangement which belong to the adult animal. Increasingly defined localisation of the developing parts is a necessary consequence of their earlier commencement.

We see from the above that in phylogenetic investigations it is perhaps still more difficult to decide the true bearing of ontogenetic than of anatomical facts. We can only attain to phylogenetic conchusions of a certain degrec of probability when comprarative anatomy and comparative ontogeny go land in hand, when comparative anatomy takes into account the developing organs, and when comparative ontogeny does not leave out of consideration the last stages of development.

Segmentation and gastrulation.- When we come to investigate in what manner the bi-laminar germ, the gastrula of the Metazoon, arises out of the fertilised egg, we find what appear to be very different methods of development. Numerous thorough investigations have proved that this variety of methods is almost exclusively caused by the quantity and distribution of the nutritive yolk in the egg. If we assign to the influence of the nutritive yolk the importance that is due to it, we shall be convinced that one single process underlies all these different phenomena. We must keep well in view, (1) that the nutritive yolk, or deutoplasm, is an inert, lifeless nutritive material deposited in the egg cell, and (2) that the formative yolk, or the protoplasm, with the nucleus it encloses, is the only living active portion.

We have already spoken of the variations in amount and distribution of the dentoplasm in the egg. We shall now describe the first appearance of segmentation or furrowing in the different kinds of eggs. The following are the types of eggs whose segmentation we propose to describe :-

Holoblastic alecithal egg. Holoblastic telolecithal eggs, with varying quantity of nutritive yolk: Eupomatus (Annelid), Discocelis (Polyclad), Boncllia (Echiurid), 
Ctenophora. Holoblastic centrolecitlal eggs : Goryonia (Craspodote Hodusa). Meroblastie telolecithal eggs : Shark. Meroblastic centrolecithal eggs: Insects.

The first divisions occur in directions which seem to be identical in the eggs of most animals. The first plane of division which, after previous nuclear division, seprarates the two daughter cells of the egg, i.e. the first two segmentation spheres, or blastomeres, runs in the direction of the principlal axis of the egg, from the animal to the vegetative pole. By the animal pole we mean that portion of the surface of the egg at which the spermatozoon entered, and near which, in tclolecithal eggs, the chief mass of the formative yolk lies. The point lying diametrically opposite to this we call the regetative pole. The first plane of division is, therefore, with relation to the two poles, meridional.

The holoblastic alecithal egg falls at the first division in to two similar blastomeres, each of which has a nucleus in its centre.

The holoblastic telolecithal egg falls generally into two blastomeres, each of which repeats the structure of the undivided egg. Each blastomere shows polar differentiation-at the animal pole lies the greatest mass of formative yolk with the mucleus, at the vegetative pole the greatest mass of nutritive yolk (Fig. 89, $B, C$ ).

The holoblastic centrolecithal egg (Geryonia) falls into two blastomeres, each of which repcats the structure of a telolecithal egg, the formative yolk only aplearing
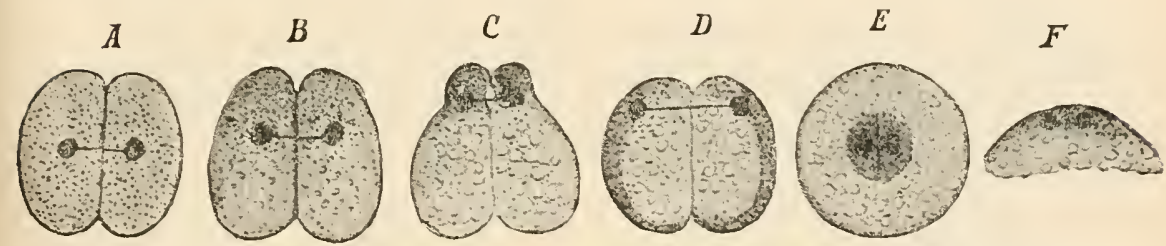

FIG. 89.-2-Blastomere stage of different eggs.-These are placed in this and all following illustrations, so that the animal pole is directed upwards, and the vegetative pole downwards. The nucleus is black, the formative yolk dark, the nutritive yolk light and granulated. $F$ represents merely a portion from the animal pole of an egg.

at the free surface of the blastomerc, and not at the side which is directed towards the plane of division. The nucleus of each blastomere lies superficially in the formative yolk (Fig. 89, D).

In the meroblastic telolecithal egg the inert lifeless nutritive yolk is so strongly developed in comparison with the living active formative yolk, that the formative yolk when dividing is not able to effect the division of the whole of the nutritive yolk. The former only therefore divides, the latter remaining undivided. We have thus a large sphere of nutritive yolk, with two masses of formative yolk divided by a meridional furrow at the animal pole, in each of which lies a nucleus (Fig. 89, $F^{\prime}$ ).

In the meroblastic centrolecithal, or rather mesolecithal, egg the central formative yolk again alone is able to divide under the influence of the nucleus, while the remaining portions of the egg continue at first undivided (Fig. 89, $E^{\prime}$ ).

The second plane of division is also meridional and stands at right angles to the first. It divides each of the first blastomeres into two halves exactly in the same way as the first plane divided the whole egg.

The third plane of division seems to be pretty generally equatorial. It is visible on the exterior of the egg as an equatorial furrow. It stands at right angles to the first two planes of division and to the chief axis of the egg, and divides the first 4 
blastomeres into 8 , of which the 4 animal portions form the animal part of the germ, and the 4 vegetative portions its vegetative part.

In the holoblastic alecithal germ the 8 blastomeres are of equal size, and the third plane of division shows itself outwardly as a strictly equatorial circular furrow (Fig. 90, $A$ ).

In holoblastic telolecithal germs each of the 4 blastomeres divides into a smaller animal blastomere, consisting almost exclusively of formative yolk, and a larger vegetative blastomere containing the nutritive yolk and a small quantity of formative yolk. The greater part of the latter lies towards the animal pole of the blastomere and contains the nucleus. Each vegetative blastomere of the germ of 8 blastomeres thus repeats the structure of a blastomere of the germ at the 4-blastomere stage. The more considerable the quantity of nutritive yolk in the germ, the larger is the vegetative blastomere as compared with the animal. The smaller blastomeres are called micromeres, the larger macromeres. The division of the 4 blastomeres into 4 micromeres and 4 macromeres looks as if the former budded from the latter (Fig. 90, B, C).

In the holoblastic centrolecithal (Geryonid) germ, after the appearance of the third plane of division, which is here strictly equatorial, the 8 blastomeres are of
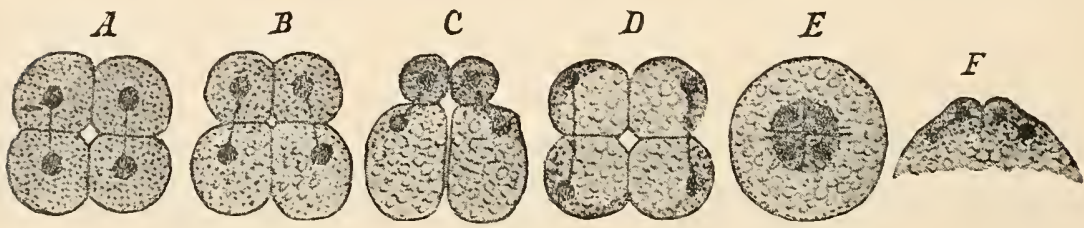

Fra. 90.-A, $F$, Diagrams showing the 8-blastomere stage of different eggs.

erual size. Each blastomere has a peripheral layer of formative yolk, with a nucleus imbedded in it, and a mass of nutritive yolk towards the centre of the spherical germ (Fig. 90, D).

The germ of the Ctenophora departs from the usual arrangement of the telolecithal holoblastic germ, since the third process of division is not equatorial. Each of the 4 blastomeres divides, in a plane slantingly meridional, so that the germ consists of 8 approximately equal blastomeres, of which 4 lie rather nearer the animal pole than the other 4 . The 8 blastomeres are grouped round a central space, which lies in the principal axis of the germ. Each blastomere shows the structure of the original Ctenophoran egg, the formative yolk lying chiefly at the animal pole of the blastomere, and the more considerable nutritive yolk forming its larger vegetative part.

In the meroblastic telolecithal germ, in consequence of the great development of the nutritive yolk, the "equatorial" division takes place quite near the animal pole. Exteriorly this division is visible as a circular furrow (polar circle) which divides the 4 prominences of formative yolk into 4 smaller central prominences with nuclei, and 4 peripheral prominences also with nuclei. The 4 central and the 4 peripheral prominences are not completely separated below the surface, either from each other or from the subjacent nutritive yolk (Fig. 90, $F$ ).

In the meroblastic mesolecithal germ the 8 central masses of formative yolk, each provided with a nucleus, are not sejarated from the great mass of nutritive yolk surrounding them (Fig. 90, E).

No general rule can be given for further divisions. Many meridional, equatorial, and cross divisions follow. The determination of the processes in detail is the more 
difficult in that divisions occur simultaneously at different points of the germ, and the number of blastomeres considerably increases. Starting with the 8-blastomere stage, we will further follow the course of development of each germ type.

1. In the holoblastic alecithal germ (Fig. 91), out of the 8 blastomeres, by repeated meridional and equatorial division, 16, 32, etc., blastomeres of about equal size are produced, which together form the uni-laminar wall of a sphere, which becomes hollow by the formation of a cavity (segmentation cavity, blastocœl) (total equal furrowing). At this stage the germ is called blastula, or cœloblastula, because it is hollow. During repeated division of the blastomeres the blastula becomes flattened at the vegetative pole $(C)$, the flattened part sinks into the segmentation cavity more and more, so that the invaginated portion, which consists of vegetative blastomeres, approaches the non-invaginated part by means of complete or partial reduction of the cavity. We now have before us a germ consisting of two layers of blastomeres, which have become epithelial. The outer layer is the ectoderm, the inmer the endoderm. At the edge of the aperture of invagination or blastopore the two layers pass into each other. The endodermal blastomeres or cells
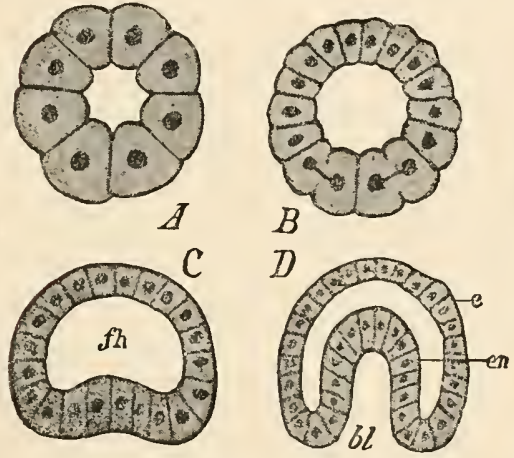

Fig. 91.-Segmentation and gastrulation of a holoblastic alecithal germ. $B$, Blastula. $D$, gastrula. $f h$, Segmentation cavity ; e, ectoderm; $e n$, endoderm; $b l$, blastopore.
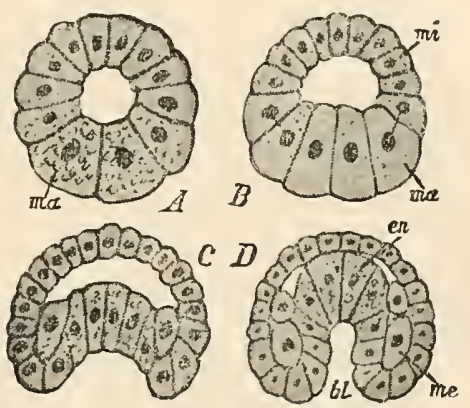

FiG. 92.-Segmentation and gastrulation of a telolecithal egg with little nutritive yolk (of Eupomatus). mi, Micromeres; ma, macromeres; $e n$, endoderm; me, mesoderm; $b l$, blastopore.

form together a hollow sac, the arch-enteron, the cavity of which opens externally through the blastopore. At this stage the germ is called gastrula, and in this casc cœlogastrula, because the blastopore leads into an open enteric cavity. This process, by which a blastula becomes a gastrula, is called invagination or embole.

2. In the holoblastic telolecithal germs, the phenomena of blastula and gastrula formation are at least apparently different according to the presence of much or littlc nutritive yolk. Let us first consider a germ with little uutritive yolk, as, for example, that of Eupomatus (Fig. 92). It consists of 4 animal micromeres and 4 vegetative macromeres. The difference in their sizes is not very great, because of the small mass of nutritive yolk, and the third plane of division lies near the true equator. First the 4 micromeres divide, then the 4 macromeres. We thus now have 8 micromeres and 8 macromeres. The micromeres continue to divide, and the macromeres follow at a slower rate. While, however, the micromeres always divide into two cells or blastomeres of pretty equal size, the equatorial divisions of the macromeres are such that each divides into a micromere, which is directed towards the animal side of the germ and contains less nutritive yolk, and into a macromere, turned towards the vegetative pole and containing more nutritive yolk. 
The number of micromeres thins increases, as in the first place they themselves divide, and in the second place new micromeres, produced by macromeres, become added to them. This process of the continual production of micromeres is extremely important for the comprehension of all following types of segmentation and gastrulation. The furrowing is total, but already a little unequal. The blastula which results is a cceloblastula, with a cap-like cover of micromeres and a lower part formed of a few yolk-containing macromeres. In consequence of the considerable size of the macromeres the segmentation eavity is somewhat narrowed. The gastrula is formed by invagination, and looks as if the layer of macromeres which sinks in were grown round on all sides by micromeres. The gastrula is a celogastrula, and the arch-enteric cavity appears narrowed in consequence of the large size of the macromeres.

Closely connected with the segmentation and germ-layer formation just deseribed is another process, an example of which is afforded by the developing germ of Bonellic (Fig. 93). The process is essentially the same; the apparent variations are explicable by the fact that the mass of nutritive yolk is more considerable. The 4 large macromeres, burdened with yolk, appear in conseqnence of their size as the fixed resting-point round which the processes of development take place. At first, as before, the 4 micromeres divide. The 4 macromeres are telolecithal blastomeres. The chief mass of the formative yolk left after the first division or budding no longer lies in the direction of the animal pole, but at some distance from it, towards the outer edge of the 4 micromeres. The division or budding of these 4 macromeres leads to the formation of 4 micromeres, which take up a position extemally, side by side with those already formed $(A)$. The 4 macromeres still contain a remnant of formative yolk, which, as it always lies at the

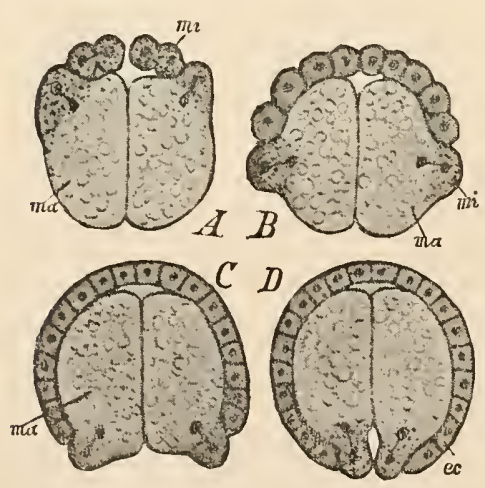

Fig. 93.-Segmentation and gastrulation of the egg of Bonellia, after Spengel. $m i$, Micromeres; ma, macromeres; $c c$, ectoderm. edge of the micromere eap, moves along the surface of the germ from the animal side of the macromeres towards the vegetative pole of the germ. Thus the process goes on $(B, C)$. As the micromeres divide, and as their number increases by the constant formation of new micromeres from macromeres, the macromeres are at last surrounded, everywhere except at a small space at the vegetative pole. This process is called epibole; it is the growth of micromeres over a resting mass of very large macromeres. It will be seen from the above description that this process and that of invagination are fundamentally identical. The gastrula which is formed is a solid sterrogastrula, whose enteric cavity is almost filled up by the large size of the yolk-laden macromeres. The micromeres present at this stage form the ectoderm; the macromeres represent the rudiments of the endoderm and of a part of the mesoderm. The blastula stage of this method of development is unrecognisable.

From the type of segmentation exemplified by Bonellic we pass on to one nearly related which oceurs in the Polyclada (Fig. 94). The formation of micromeres, and their growth over the macromeres, is just as in Bonellia. But here the 4 micromeres which are first constricted yield, by division, the whole ectoderm. The micromeres, which become constricted off from the macromeres in the second (and third) order, 
yield a grcat part of the mesoderm (musculature, sexual organs, connective tissne), and are overgrown by the ectoderm micromeres. All micromeres which are detached later belong to the endoderm. We have here before us a typical case of the tendency to shift back formations to very early stages of development. A typical gastrula is not developed in the Polycluda, since the separation of ectoderm and endoderm occurs as early as the 8-blastomere stage. We shall return to this later.

The Ctenophorc exlibit an interesting process of scgmentation and gastrulation intermediate between the gastrulation by means of epibole of the telolecithal holoblastic eggs and the gastrulation by delamination of the centrolecithal eggs to be spoken of later. The 8-blastomere stage of these animals has been described above.
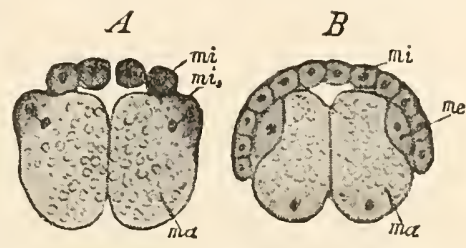

Fig. 94.-Segmentation of a Polyclad egg (of Discocelis). mi, First generation of micromeres (ectoderm - forming cells); $m i_{1}$, second generation of micromeres (mesoderm micromeres); ma, macromeres.

All the 8 blastomeres are telolecithal, with the formative yolk directed towards the animal pole. What occurs at the 4-blastomere stage of the telolecithal holoblastic esgs hitherto described, viz. the constriction of the 4 micromeres from the 4 macromeres, here takes place one stage latcr, at the 8 -blastomere stage. The 8 blastomeres in fact give off 8 micromeres towards the aboral pole (Fig. 95, $A$ ). The further segmentation is quite similar to that of Bonellic. The micromeres incrcase in number (1) by division, (2) by the continual addition of new micromeres towards the vegetative pole, by constriction from the macromeres $(B, C)$. After the micro. meres have thus grown round the macromeres, leaving a large region at the vegetative pole in which the macromeres come freely to the surface, the formation of micromeres rloes not cease, as in the Polyclada. The already formed micromeres, however, yield exclusively ectoderm ; the remaining macromeres, part of the inesoderm and the endoderm. Here also no very recognisable gastrula is developed.
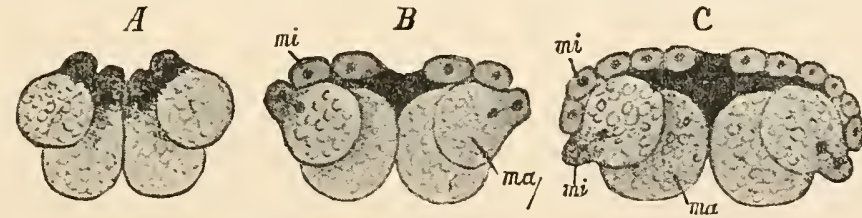

Fic. 95.-Three stages in the segmentation of a Ctenophoran egg. mi, Micromeres; me, macromeres.

In all processes of the formation of micromeres the following is to be specially noted. After a macromere has constricted off a micromere, or; what is the same thing, after a blastomere has divided into a small micromere witl little or no nutritive yolk, and into a large macromere with much nutritive yolk, the portion of formative yolk or protoplasm which remains in the macromere grows cvidently by the assimilation of nutritive yolk before the macromere can again divide.

3. Segmentation and gastrulation of the holoblastic centrolecithal germ. Te give as an example of this the Geryonid germ which has becn the most carefully investigated and is the best understood (Fig. 96). We are already acquainted with the 8-blastomere stage. Each blastomcre is telolccithal, with deutoplasm directed towards the centre of the gcrm and protoplasm towards the circumference. The 8 blastomeres divide into 16 , and then into 32 blastomeres of equal size, which 
all remain telolecithal in the same way as in the 8-blastomere stage. The 32 blastomeres of the spherical germ form a single layer round a considerable central cavity. A blastula-like stage thus occurs, though the germ has really another significance, as the central cavity does not represent the segmentation cavity of the alecithal germ, but, as we shall see, the enteric cavity.

When 32 blastomeres are formed, the formation of micromeres follows. From each blastomere a micromere is constricted off on the outer side, so that the germ now represents a double-layered hollow sphere, whose outer layer is formed of micromeres, and whose inner layer consists of macromeres. The micromeres increase in number (1) by themselves dividing, (2) by the formation once more of micromeres which are constricted off on the outer side of the macromeres. The micromeres form the ectoderm, the macromeres the endoderm, which surrounds a completely closed cavity - the enteric cavity. The germ thus represents a cœlogastrula withont blastopore. We call this a cœloplanula. The formation of the two germ layers in
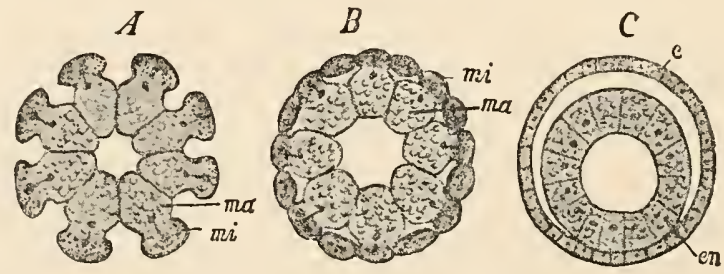

Fig. 96.-Segmentation and gastrulation of the Geryonid egg. mi, Micromeres ; ma, macromeres; $e$, ectoderm; en, endoderm.

the manner described above is called delamination. It must appear clear from our description that this cannot be sharply distinguished from epibole. Both processes rest on the formation of micromeres. In Bonellice and the Polyclada the first formation of micromeres, or delamination, takes place at the 4-blastomere stage, in the Ctenophora at the 8-blastomere stage, and in Geryonia at the 32-blastomere stage.

4. The meroblastic mesolecithal germ was left at the stage where the formative yolk or protoplasm was divided into 8 small masses, each with a nucleus, in the centre of the undivided nutritive yolk. If we compare this stage with the 8 hlastomcre stage of the Geryonid germ, we shall see that these 8 masses of formative yolk correspond with the 8 portions of protoplasm of the latter germ, only that in the former, in consequence of the originally different arrangement of the nutritive yolk, the masses of protoplasm lie at the centre, while in the latter they are peripheral. In the meroblastic germ the mutritive yolk is undivided, the formative yolk being incapable, at the time of division, of effecting the division at the same time of so large a mass ; in the holoblastic egg the formative yolk controls the whole less massive nutritive yolk.

The 8 central nucleated masses of protoplasm of the meroblastic mesolecithal germ (Fig. 97) we shall call merocytes. They are often branched, and have amoboid movements. Their processes penetrate the surrounding mass of yolk, and are also connected with the thin layer of protoplasm which is found at the surface of the germ. They feed at the expense of the dentoplasm.

The 8 merocytes divide into 16,32 , and so on, and move at the same time centrifugally through the yolk to the surface of the germ, where they form a simple continuous layer. It is this layer of merocytes which is called the blastoderm. The germ has now become centrolccithal, and agrees in its structure with the Geryonid 
germ before the formation of mieromeres or delamination, except that the central nutritive yolk is here still undivided.

The further development of the germ has unfortunately not yet been thoroughly investigated. Some observations tend to show that at this point, as in the Geryonid, germ, delamination or formation of mieromeres takes place. The merocytes at the surface divide in such a way that the outer portion separates off completely as a nucleated micromere layer detached on all sides, while the inner portion remains in

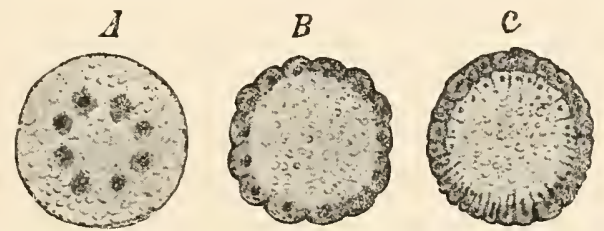

FIG. 97.-Segmentation and formation of blastoderm in the egg of an Insect.

the nutritive yolk as a nucleated merocyte layer. Thus the two germ layers are formed; the outer mieromere layer represents the ectoderm; the central mass of nutritive yolk with the merocytes which belong to it probably represents the endoderm.

The merocytes by increasing in number and feeding at the expense of the nutritive yolk, become able at last to overpower and incorporate it, i.e. they can divide it.

The gastrula is here a solid sterroplanula.

It has been observed in many cases that in the partial segmentation, i.e. in the multiplieation of the eentral meroeytes, only some of them move towards the surface, there to form the blastoderm, while the others remain in the yolk.

5. The meroblastic telolecithal germ (Fig. 98). We left this germ at the 8-blastomere stage, with undivided mass of nutritive yolk. We may here also call the masses of protoplasm merocytes. They stand in exactly the same relation to the eollection of protoplasm at the animal pole of the blastomeres of the holoblastic teloleeithal egg as do the merocytes of the mesolecithal meroblastic germ to the protoplasmie portion of the blastomeres of the Geryonid germ.

The 8 primary merocytes divide in the following manner. The 4 central merocytes divide into 4 secondary central merocytes in contact with one another at the animal pole, and 4 secondary peripheral merocytes. The former are now entirely severed from each other and from the nutritive yolk as micromeres. The latter remain comneeted with the yolk as merocytes. The primary peripheral

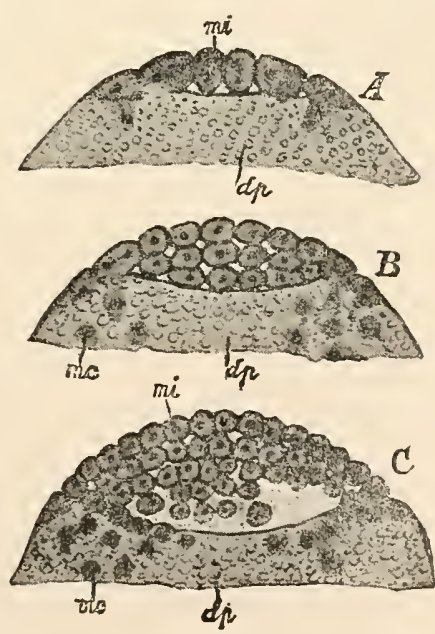

FIG. 98. - Segmentation of a meroblastic telolecithal egg (of a shark), after Rückert. mi, Micromeres; $d p$, deutoplasm; me, merocytes. merocytes also divide, but their descendants remain connected with the yolk as meroeytes. Some of them even sink into the nutritive yolk as branched and probably amœboid meroeytes. 
The region at the animal pole of the germ (egg) in which the micromeres and some of the merocytes are visible is called the germ or germinal disc.

The further course of segmentation is as follows:-

1. The micromeres already formed continue to divide independently.

2. Towards the edge of the germ dise new micromercs are constricted off from the merocytes, and then associate themselves to those already existing, so that the area of the micromere region, or germ disc, increases.

3. The merocytes at the edge of the germ disc, as well as those which lic deep in the nutritive yolk, constantly divide, so that not only does the germ disc grow at its edge, but the nutritive yolk becomes more and more crowded with merocytes, which penetrate further and further into it.

Finally, the germ shows the following structure : at the animal pole, in the middle of the germ disc, lies a flat mass of micromeres consisting of several layers, the rudimentary ectoderm. Lying at the edge of the germ dise, and imbedded in the yolk, are merocytes. The greater number of these merocytes yield the material from which, by the formation of micromeres in a way hereafter to be described, a large part of the mesoderm and the endoderm are built,up. By the constriction of micromeres from merocytes at the edge of the germ disc, and by division of the already formed ectoderm cells, the cap of ectoderm increases still more, so that it grows more and more round the germ as the blastoderm.

We see that in the development of the meroblastic telolecithal egg the gastrula form is musually indistinct, because of the enormous mass of the nutritive yolk. The micromere-cap respresents the ectoderm; the yolk with the merocytes the endoderm and part of the mesoderm. If a blastopore is sought for, this can only be represented by that portion of the germ which is not covered by the ectoderm cap, where the nutritive yolk comcs to the surface. The edges of the blastopore are represented by the edges of the ectoderm cap. The gastrula formation here also occurs by means of epibole; the gastrula is a solid discogastrula.

In the above description only the most important types of segmentation and formation of the two primitive germ layers have been brought forward. The processes in the animal kingdom are in reality extremely varied, yet most of them can be included without much difficulty under one or other of our heads. The great majority of investigations are still insufficient; because in some cases, as in the meroblastic eggs, observation is very difficult. The difficulty is to establish quite clearly the distribution of the formative yolk in the egg, and to follow the division of the blastomeres in detail.

The method of gastrulation does not afford any means of recognising the relationships of animals, as it is determined by the quantity and distribution of the untritive yolk, and this may be quite dissimilar in animals nearly related, and similar in widely separated forms.

The question, which sort of segmentation and gastrulation is the original, has been mueh discussed. Most authorities hold, not without reason, total equal furrowing, the formation of a coloblastula, and the subsequent formation of a cologastrula by invagination to be the original method. This view is supported chiefly by the following facts:-(1) the want of a nutritive yolk, which camot have been present in corresponding racial forms ; $(2)$ the similarity of the blastula with certain Protozoan colonies (Magosphara, Volvox); (3) the similarity of the cologastrula with the simplest Celenterate (Olynthus, Hydroids). Just this similarity makes it possible for us the more easily to imagine these germ forms as independent adult animals.

The free-swimming gastrula, which is nsually ciliated on the outer surface, possesses a mouth (blastopore) through which it can or could take food into the enteric cavity. 
It is important to note that in most of the higher bilaterally symmetrical animals the bilateral symmetry appears very early. The gastrula of these animals is bilaterally symmetrical, i.e. only one planc ean be made to cut it into two exactly similar halves. We can consequently distinguish in the gastrula upler and lower, anterior and posterior, right and left. The gastrula of the radiate Colcnterato, on the contrary, is radiate or rather uniaxial. There is one principal axis round which all the elements of the body are arranged in circles. This principal axis has unlike poles; at one pole, the regetative, lies the blastopore ; the other, the animal pole, is closed.

Bilateral symmetry is shifted back in many bilaterally symmetrical animals to much younger stages of development-to the blastula or the segmentation stages. In a few cases even the egg is bilaterally symmetrical, and the position of the future principal regions of the body can be determined even in it.

In the miaxial gastrula the blastopore is round and closes to a point. In the bilateral gastrula, however, it has become slit-like, and closes either from front to back or viee versa, in a line lying in the plane of symmetry or median plane of the body.

Ontogeny of the Cnidaria. - The segmentation is everywhere complete. The formation of the gastrula occurs by invagination, cpibole, or delamination. In the last case a cœloplanula arises direct. Where a coelogastrula or a sterrogastrula occurs it changes, in all cases except the Ctenophora, into a planula by the closing of the blastopore. This is generally free-swimming and ciliated, and has a tuft of long, mostly immobile sensory hairs at the original animal pole, which we now call aboral. A Hydroid arises ont of the blastula by the formation of the definite oral aperture by means of a breach where the blastopore closed, the animal having attached itsclf by the aboral end of the body. Round the mouth, the tentacles bud out as hollow outgrowths of the ectoderm and endoderm.

The direct development of a Craspedote Medusa from the fertilised egg is best known in Geryonia, with whose blastula we are already acquainted.

Between ectoderm and endoderm a jelly is formed, which constantly increases in mass, so that the ectoderm sac is separated by a great interval from the endoderm sac which it encloses. At one point only, the future oral pole, which probably agrees with the vegretative pole, the endoderm sac remains in contact with the ectoderm sac. The permanent mouth is formed at this point of junction by means of a breach, while at the same time, at some distance from the mouth, the velum arises as a circular thickening of the ectoderm, and the 6 tentacles as buds, into whose axes solid processes of the endodermal sac grow. The comnection of the endodermal tentacle axis with the gastral sac soon ceases. The oral surface of the larva, whieh is surrounded by the tentacles and the velum, sinks in and becomes the concave subumbrella. The Medusa form thus gradually comes into existence. How the radial vessels are formed in Geryonia has not been investigated.

A Scyphopolyp (Scyphula of the Acraspeda, Coral polyp) arises out of a planula in the following way (Fig. 99). The planula $(A)$ attaches itself by the animal or aboral end of its body $(B)$. At the oral end the body of the ectoderm sinks in in the shape of a pit and forms the ectodermal cesophagus with the external mouth $(C)$. The base of the esophagus then breaks through in the direction of the gastral cavity $(D)$, and so arises the enteric aperture. The oesophagus of the Scyphula is at first not a round but a flatly compressed tube $(F)$. On each side of it a prolongation of the enteron penetrates between it and the ectodermal body wall--the first 2 gastric pouches. Crosswise to these there is a further growth of 2 new pouchshaped invaginations of the enteron between the cesophagus and body wall. Thus arise around the cesophagus the 4 gastric pouches of the Scyplinla $(G, m t)$. The

YOL. I 
neighbouring endodermal walls of every 2 gastric ponches apply themselves to each other and form the partition walls or septa $(H, s e)$, which are continued also, with free axial edges, into the central gastric cavity, and there form the so-called gastric ridges. The first 4 tentacles $(E, t)$, arise around the oral dise as outgrowths of the ectoderm and endoderm. The endoderm forms a solid axis in the tentacles, which arise over the 4 gastric ponches, and which increase in number later.

In the Coral polyps the formation of the tentacles, gastric pouches, and partition walls, if not exactly like the above, is still similar, and the endodermal axes of the tentacles are hollow from the first.

The most important facts about the development of the Scyphnla into the Acraspede Medusa have already been given on 17 . $77,106,107$, and 116 .

The direct development of the Aeraspede Medusc ont of the egg is not yet suffi-
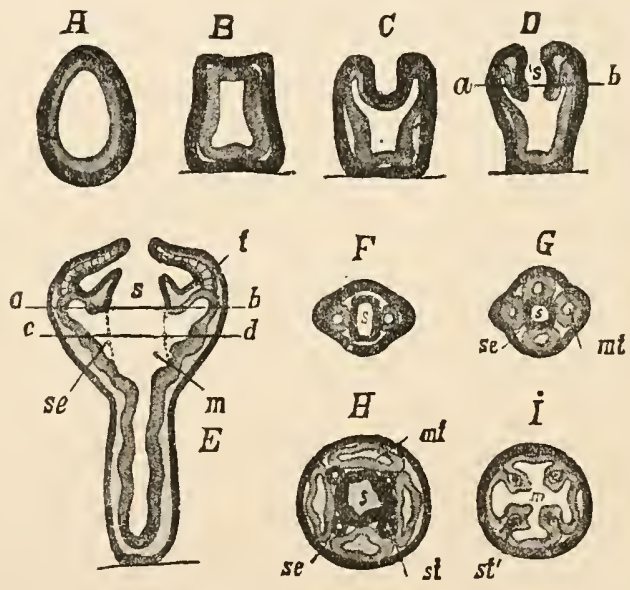

FIG. 99.-Development of the Scyphula of Aurelia Aurita out of the Planula, after Götte. $A$, Planula. $B$, The same after it has attached itself. $C$, Invagination of the osophagus. $D$, Breaking through of the enteric aperture. $E$, Scyphula. $F$, Transverse section through the stage $C$. (i, The saure through stage $D$ at the level of the line $a-b$. $H$, Transverse section through the Scyphula $(E)$ at the level $a-b . \quad I$, the same at the level $c-d$. Black, ectodem; streaked, endoderm. $s$, CEso. lihagus; se, septa ; $m$ t, gastric pouches; $t$, tentacle; $m$, gastric cavity ; $s t^{\prime}$, st, septal funnels.

ciently known. Compare what was said of the development of the mesoderm of the Coral (1. 100).

The development of the Ctenophore is in a certain way opposed to that of all other Cinidaria. The total mnequal furrowing of the telolecithal egg has already been described, as also the formation of a two-layered germ by epibole. We here again resume our account of the development.

After the 8 macromeres have formed a cap of micromeres which yield the whole ectoderm, they themselves divide into 16 macromeres, which arrange themselves as a plate on the vegetative side of the germ. Thereupon each of the 16 macromeres constricts off' one micromere on the under side, i.e. towards the vegetative surface of the germ (Fig. 100). The 16 micromeres so formed are a part of the mesodermal rudiment, the rudiment at any rate of the tentacle mesodern. They may be considered, perhaps, as part of the endoderm, as an early product of separation from it. The mesodermal axis of the Ctenophoran tentacle might then be compared with the endodermal tentacle canals or tentacle axes of the other Cniclaria. 
After the 16 mesoderm micromeres (me) have been formed, the macronicre plate bccomes defiressed, while, at the same time, the cctoderm cap spreads
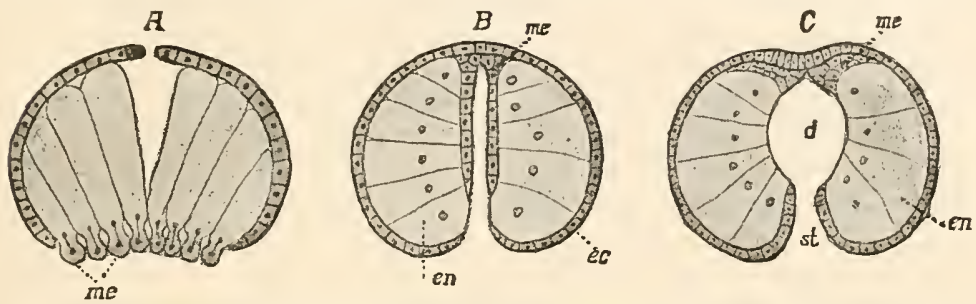

FIG. 100.-Three early stages of development of a Ctenophore (Callianira), after Metschnikoff, somewhat diagrammatic. ec, Ectoderm ; $e n$, endoderm ; me, mesoderm ; $d$, gastric cavity ; st, osophagus (stomodrum).

out more and more towards the vegetative pole. which we can already observe, besides the two primitive germ layers, a mesodermal rudiment $(B)$. The latter, by the invagination of the 16 macromeres which represent the rudiment of the endolermal gastro-canal systems, come to lie inside, towards the gastric cavity. Later on it reaches a josition quite at the animal polc, beneath the ectoderm $\left(C^{\circ}\right)$, its elements at the same time increasing by division. The ectoderm at the vegetative pole becomes depressed inwards round the blastopore, and thus forms a stomodrum (st), the rudiment of the resophagus (erroneonsly stomach) of the adult Ctenophore. The mesoderm at the aboral pole, viewed from this pole, assumes the shape of a cross. Two opposite limbs of the cross stretch out into the rudiments of the two tentacles, which appear as outgrowths of the ectoderm. The ectoderm thickens at the aboral pole to form the sensory body (Fig. 101, sk). Swimming plates appear as fused cilia in 8 meridians, arranged in pairs at the surface of the ectoderm. At first only a few swimming plates are formed in each row, but their number gradually increases. The hollow spraces of the gastro-canals appear as fissures penetrating from the gastric cavity to the circumference. Between the endoderm and the stomodrum on the one side, and the ectoderm on the other, a clear mass of jelly is secreted. The various elements which in the Ctenophorc occupy the jelly are, according to some investigators, derived from cells migrating inwards from the ectoderm; according to others they are yielded by the rudimentary mesoblast, which has been described above.
A cologastrula thus arises, in
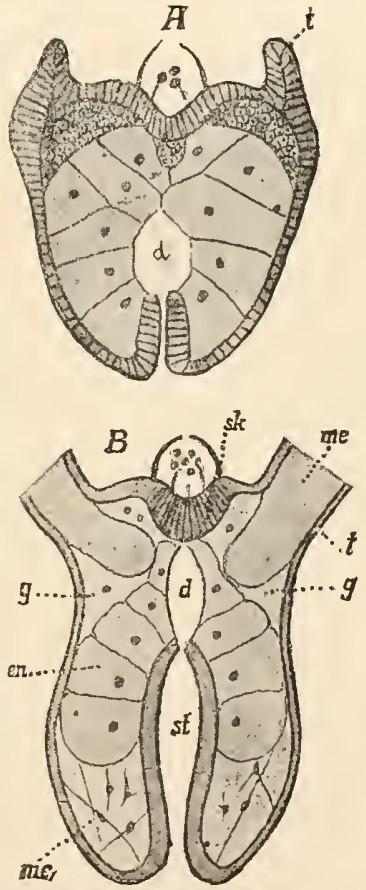

Fig. 101.-Two further stages of development of Callianira, after Metschnikoff. en, Endoderm ; me, mesoderm; me 1 , mesenchyme; $t$, tentacle; sk, sensory body; $d$, gas. tric cavity; st, osophagus (stomo. daum); $g$, jelly. 


\section{Literature.}

E. Haeckel. Die Gestrula und die Eifurchung, in: Jenaische Zeitschrift. Bd. IX. 1877 .

F. M. Balfour. Comparative Embryology. 2 vols. London, 1880-81.

A. C. Haddon. An Introduction to the Study of Embryology. London, 1887 (Tr.) Compare further the bibliography on p. 117. 


\section{CHAPTER III}

The organisation of the Flatworms-The life-history of the Cestoda and Trematoda-The development of the Marine Planaria-The influence of Parasitism.

\section{THE THIRD RACE OR PHYLUM OF THE ANIMAL KINGDOM.}

\section{PLATODES-FLATWORMS.}

\section{Systematic Review.}

\section{CLAss I. Turbellaria.}

Free-living Platodes, with ciliated body epithelium.

\section{Order I. Polycladidæ, Marine Planaria.}

Large Turbcllaria with flat, leaf-shaped borly, with numerous ovaries and testes, without vitellaria, mostly with 2 separate genital apertures. The intestine very much branched, the branches anastomosing.

\section{'Tribe 1. Cotylea.}

With ventral sucker. Mouth and pharynx in the middle of the body or further forward. Tentacles wanting or found at the anterior edge of the body. Anonymus, Thyscinozoon, Yungia, Cyeloporus, Stylostomum, Eurylepte, Prosthiostomum.

\section{Tribe 2. Acotylea.}

Without sucker. Mouth and pharynx in the middle of the body or further back. Tentacles wanting, or 2 dorsal neck-tentacles present. Planocera, Leptoplana, Tirigonoporus, Cestoplana.

\section{Order II. Tricladidæ (Fresh-water, Land, and Marine Planaria).}

The generally large body is long and flat. Mouth and tubular pharyux belind the middle of the body. One common external genital aperture with 2 germaria and numerous testes and vitellaria. The alimentary canal consists of an anterior unpaired portion and of two lateral posterior limbs, which are again provided with side branches. Planaria, Dendrocalum (in fresh water), Goodesmus, Bipalium (on land), Gunda segmentate (marine).

\section{Order III. Rhabdocœlidæ.}

In fresh and salt water. Small forms. Intestine, when clearly distinguishable, a straight tubular cecum without or with very slightly pronounced lateral branches. Body elongate, mostly cylindrical, more rarely flatly compressed. 
Tribe 1. Alloiocœla.

Intestine sharply separated from the parcnchyma, often with short lateral sacs. Numcrous small testes. Fcmale germ glands either 2 ovaries or 2 germ-vitellaria, or scparate germaria and vitellaria. Monotus, Plagiostoma, Vorticcros.

\section{Tribe 2. Rhabdocœla.}

Intestine sharply separated from the parenchyma, without lateral diverticula. In the parenchyma there occur spaces, generally of considerable size, filled with fluid, which form a sort of colome. 2 large testes. Female germ glands either 1 or 2 ovaries, or 1 or 2 germaria and vitellaria, or 2 germ-vitellaria. Vortex, Grafflla (parasitic), Macrorhynchus, Mesostoma, Prorhynehus, Microstoma and Stenostoma (in these two genera the sexes are scparate), Macrostoma.

\section{Tribe 3. Acœla.}

Without distinct intestinal canal ; with digesting parcnchyma. Without excretory organs; with numerous very small testes, and 2 ovaries. Nadina, Convolute.

\section{Class II. Trematoda.}

- Parasitic unsegmented Platodes, without covering of cilia, mostly with forked intestine. Mouth and pharynx at the anterior end of the body. 2 testes, 1 germarium, and 2 vitellaria branched or divided into numerous lobes.

\section{Order I. Ectoparasitica (monogenetic).}

With at least 3 suckers. Development direct, without alternation of generations, or heterogeny; life-history simple. Tristomum, Diplozoon (two young, not yet sexually mature animals early fuse in the shape of a cross, and only become sexually mature in this condition) Polystomum, Gyrodactylus.

\section{Order II. Endoparasitica (digenetic).}

With at the most 2 suckers. Life-history with heterogeny. Distona hopaticum (life-history, 1. 169, Fig. 119), D. lancelatum, both in the bile ducts of the sheep. Distoma isostomum, Gynacophorus hamatobius, in the blood in the portal reins of man (in Africa), sexually separate; the male with a channel on the ventral side for the reception of the female. Amphistoma, Monostomum. The sporocysts and rediæusually live in water snails; the sexual generation mostly in the intestines of vertebrates.

\section{Class III. Cestoda (Tapeworm).}

Endoparasitic Platodes without cilia and without intestine, with numerous testes, 2 germaria, and 1 or 2 vitellaria broken up into lobes. With organs of adhesion only at the front end of the body.

\section{Order I. Monozoa.}

Unsegmented individuals. Amphiline, Caryophyllaeus, Archigctcs.

\section{Order II. Polyzoa.}

Cestode stocks arising hy strobilation: segmented tapeworms. With scolex and chain of proglottides. Phyllobothrium, Tctrarhynchus, Ligula (very indistinctly segmented). Bothrioccphalus latus; broad tapeworm (Fig. 117, C, p. 164) in human intestine. Over 3000 proglottides. With 2 pit-like suckers in the head. Genital apertures on the flat surfaces. Larva ciliated in water. Scolex-like young form in flesh of the Pike, of the Burbot, and perhaps of other fish. Schistocephalus. Tricenophorus. Tania; with 4 suckers. T. Saginata (mediocancllata) (Fig. 117, $A$, 
p. 164), without hooks on the rostellum, with over 1000 proglottides, sexual apertures placed on the edge; in the human intestine. The finn, a Cystieercus, lives in the muscles of the ox. T. solium (Fig. 117, $E$, p. 164), with double circle of hooks on the rostellum. Sexual apertures placed on the edge. About 800 proglottides. Finn : Cysticereus cellulose in flesh of the pig (Fig. 120, 1. 172). T. serrata, in intestine of the dog. Fim : Cysticereus pisiformis, in the liver of rabbits and hares. T.erassieollis, in the intestine of the domestic cat and of other Felide. Finn : Cysticercus fusciolaris, in the liver of the mouse. T. eucumerina, in intestine of the dog, and scolex-like finn in the body cavity of the dog-louse. T. eanumus, in intestine of the dog. Fim : Cenurus cerebralis, in brain and spinal marrow of the sheep, causing "staggers." T. echinoeoeeus, in the small intestine of the dog; finn, Echinocoeeus veterinorum in the liver of man and in that of different domesticated ungulates.

\section{General Remarks.}

The race of the Platodes forms a very natural division of the animal kingdom, containing the three classes of the Turbellaria, the Trematoda, and the Cestode. Their fullest development is shown in the organisation of the free living Turbellaria, which move forward by creeping or gliding, while in the Trematoda and Cestuda many degenerations and simplifications have taken place in consequence of parasitism. The organisation of the Turbellaria more than any other therefore supplies us with the clue to understand the systematic position of the Platodes and their affinities.

Of all Metazoc it is the Platodes, and especially the Turbellaria, whose general structure most agrees with that of the Colenterata, i.e. of the Cniduria. They might almost be placed near the Ctenophorct as creeping Cnidariu.

On account of the absence of a cœlome between the alimentary canal and the integument, and of a separate blood-vascular system, the function of circulation is performed, as in the Cniduria, by the digestive system as gastro-canal apparatus. An anus is wanting here as there. The Platodes show, however, on the other hand, many essential differentiations of organisation which we miss in the Cnidaria, and which are in great part to be referred to the creeping mode of life. All the Platodes are bilaterally symmetrical; we can distinguish in their bodies an anterior and posterior, an upper and lower, a right and left. The aboral surface of the body of the Cridariu becomes in the Platodes the dorsal surface, the oral the ventral surface, in whose centre the mouth originally lies. The sensory organs collect chiefly at that part of the body which goes first in creeping, i.e. at the anterior end, and the principal part of the central nervous system also, the brain, which originally lay at the aboral pole, i.e. at the centre of the dorsal surface, has, following the sensory organs, moved more or less far forward.

Those organs and systems of organs which, in the Calenterate, showed the tendency to leave the body epithelium and deposit themselves below it, forming a middle layer, have in the Platodes become markedly mesodermal, viz. (apart from the connective tissue) 
the sexual organs, the musculature, and the nervous system. The musculature is arranged under the body epithelium in a muscle layer whose elements have transverse, longitudinal, and diagonal courses. Dorso-ventral muscle fibres stretch between the ventral and dorsal surfaces. The whole arrangement of the musculature seems adapted for the creeping motion. The nervous system forms a plexus of nerves lying in or on the muscle layer, which is more strongly developed on the ventral than on the dorsal side. In this plexus single stronger nerve trunks are more clearly developed, and they meet together from various directions in one central point, the brain. In very many Platodes this nerve plexus forms the so-called ladder nervous system, in which we distinguish the following parts:-(1) the brain, lying at the anterior end of the body; (2) the two principal longitudinal trunks proceeding out of it and running on the ventral side; (3) transverse commissures which connect these latter.

The so-called water-vascular system is very characteristic of the Platodes. It is a system of fine canals, on the one hand ramifying in the mesoderm, and on the other emerging externally, which has certainly an excretory, and perhaps at the same time a respiratory purpose. In the Cnidaria no such system has been observed.

The Platodes are hermaphrodite. Besides the sexual reproduction by means of fertilised eggs, there is also (in Trematoda) parthenogenetic reproduction and (in Turbellaric and Cestoda) asexual multiplication by fission or gemmation.

For the comprehension of the relation of the Platodes to the Cnidaria, the knowledge of two animal forms, which have been considered to be intermediate forms betwcen the Ctenophora and the Turbellaria (Polyelada), is necessary. Only one specimen of each has till now been described. One of these forms is Coloplana Mecsinikorri, the other Ctenoplana Koucalevslii. Unfortunately our knowledge, especially of the first form, is very insufficient. Their sexnal organs and their development are unknown, so that we camnot be smre whether we have to do with young stages or with adult animals. But in any case both forms are of the greatest interest.

Ceeloplana is a little animal about $\frac{1}{4}$ of an inch long and $\frac{1}{6}$ broad, whose appearance quite coincides with that of a Polyclad. The body is flatly compressed and ciliated all over; it creeps on the ventral surface. In the centre of the dorsal surface lies a vesicle with a mass of otoliths. Near it on each side, right and left, is a long tentacle feathered on one side, which can be withdrawn into a special sheatl. In the middle of the ventral side lies the mouth. The gastro-canal system consists of the ruadrmply.lobed stomach and numerons anastomosing canals radiating from it. From the stomach 2 eanals rise towards the dorsal snrface of the body, where they apparently end blindly in front of and behind the otolith vesicle.

Ctenoplana has in general the same body form as Coloplana; but besides the general ciliation this animal also has on the dorsal surface eight short rows of stiff plates arranged like a rosette ; these correspond with the ciliated or rowing plates of the Ctenophora, and lie in special grooves, out of which they can be protrnded. The arrangement of the gastro-canal apparatus is like that in the Coeloplone. In the middle of the dorsal surface occurs a formation similar to the sensory body of the Ctcnophore. At the base of the depression containing the otoliths there is on each side a nerve centre with nerves froceeding from it, and near these on each side a 
solicl tentacle with short lateral branches. In the ncighbourhood of the tentacle on each side is found an aperture leading into a system of canals which branch in the body parenchyma, and which the discoverer of Ctenoplanu eompares with the water vascular system of the Platodes. Under the body epithelium hies a basal or skeletal membrane, under this a layer of longitudinal miscles, and under this again a layer of transverse muscles. Besides these there are dorso-ventral muscular fibres branched at both ends, whieh adhere on one side to the dorsal, and on the other to the ventral basal membrane. There are special bundles of muscular fibres for the protrusion and withdrawal of the ciliated plates.

These two forms agree with the Ctenophora ehiefly:

1. In the possession of an aboral sensory body.

2. In the possession of 8 rows of ciliated plates (Ctenoplcna).

3. In the possession of feathered tentacles.

4. In the general structure of the body.

Ceeloplene and Ctenoplane are not yet bilaterally symmetrical. The ehief axis runs, as in the Ctenophora, from mouth to sensory body. It is very mueh shortened. The lateral plane runs throngh both tentacles; the median or sagittal plane stands at right angles to it. Each of these planes divides the body into 2 similar halves. If such forms were always to move forwards in the direction say of its median planc, and if at this end special sensory organs were to develop, or the sensory body eome more forward, they wonld beeome bilaterally symmetrieal. Only one plane, viz. the median plane, would divide the body into 2 exaetly similar halves. We could then not only distinguish upper and lower, but anterior and posterior regions of the body.

Culoplana and Ctenoplane agree with the Polyclade:-

1. In the flatly compressed form of body, and in the capacity of moving forward by creeping.

2. In the general ciliation of the body.

3. In the possession of a skeletal membrane (Ctenopluna).

4. In the possession of a dermal mnsenlature, consisting of a longitudinal and a circular layer.

5. In the possession of dorso-ventral muscle fibres branched at both ends.

6. In the general arrangement of the gastro-eanals.

7. In the possession of 2 (in Polyclada, however, unfeathered) dorsal tentacles and of a dorsal nerve centre (?).

8. In the possession of a water-vasenlar system (Ctcnoplana?).

The peculiarities mentioned under 1-5 may be considered as due to the crecping mode of life.

Coloplanc and Ctenoplane are distinguished both from the Ctenophore and the Polyelala by the want of an ectodcrmal osophagus, -at least no such cesophagus has bcen described.

\section{The Body Form.}

Most of the Platodes are, as their name indicates, more or less flat. The Polyclada are leaf-shaper. In these all intermediate forms between the broad oval and the long ribbon occur. The Triclade are mostly long, lancet-shaped, with dorsal surfaces slightly arched. Among the land Triclala forms occur of great length. In the Iihablocala great variety prevails; there are flat, disc-shaped, plano-convex, and often spindle-shaped animals. Among the Trematodu the ectoparasites and a few small endoparasites (e.g. Distoma lepoticum, D. lanceolatum) 
are flat and compressed. Most of the endoparasitic Distoma species, on the contrary, are more or less cylindrical. The Cestoda or tapeworms are ribbon-like, and consist chiefly of a row of consecutive segments progressively increasing in size posteriorly (proglottides). In front, where the body thins away, the segmentation is indistinct. The thin neck portion swells into a knot-like tapeworm-head (scolex), which is provided with organs of adhesion.

\section{The Outer Body Epithelium.}

A distinct body epithelium occurs only in the Turbellaria. In the Trematoda and Cestode it is replaced by a resistant, elastic, cuticular membrane, which is generally perforated by very fine pores. It is indeed not impossible that this integument itself is a much modified epithelium. The body epithelium of the Turbellaria is ciliated. The ciliary motion serves principally (1) for Respiration (by the maintenance of a constant circulation of the water over the naked surface of the soft animal) and (2) for Locomotion (especially of the smaller forms).

Unicellular dermal glands open in the skin. In special glandular cells of the skin the so-called rod or rhabdite cells, spindle-shaped glandular secretions occur; the so-called rods or rhabdites, although found in other divisions, are specially characteristic of the Turlellaria. Whereas the rod-glandular cells in most Polyclade lie in the epithelium itself, in most Triclade and Phabdocolide they sink deep into the parenchyma, and only remain connected with the epithelium by means of long thin processes (rod-passages) in which the rhabdites are conveyed outwards and deposited in the epithelium. Typical stinging capsules also occur in the epithelium of many Turbellaria. There are besides numerous intermediate forms between true rhabdites and true nematocysts.

\section{The Gastro-canal System.}

This has entirely disappeared in the Cestoda. These endoparasites are nourished endosmotically by the juices which surround them.

In the other Platodes the gastro-canal system is well developed, and shows in a few divisions modifications almost as important and characteristic as those in the Cnidaria. We can everywhere distinguish in it two principal parts : (1) an œsophagus or pharyngeal apparatus, which comes from a depression of the outer integument and is consequently lined with ectodermal epithelium; and (2) the endodermal intestine or gastral apparatus. We will treat of these two parts separately.

I. The pharyngeal apparatus. This opens externally through the mouth, and internally through an enteric aperture into the gastral apparatus. 
The position of the mouth is in no animal race so extraordinarily variable as in the Platodes. We hold that the original position of the mouth is the central one, in accordance with the views set forth in the general remarks, and with its position in Ctenoplana and Caloplena. This position is found only in Turbellaria, i.e. among the Polyclade in the families of the Anomymidce, Planoceridce, and most Leptoplanide, and among the Pihubdocalicle in a few Accele and Mesostomilce. In the remaining Platodes the mouth is placed either more to the front or to the back, without in any case reaching the extreme anterior or posterior end of the body. The mouth lies somewhat further forward than the middle among the Polyclada in the Pseudoceridce, among the

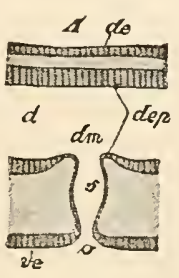

C

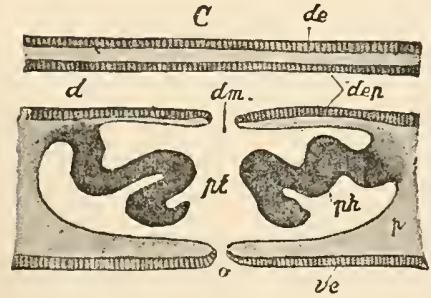

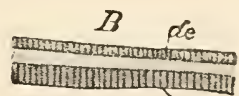
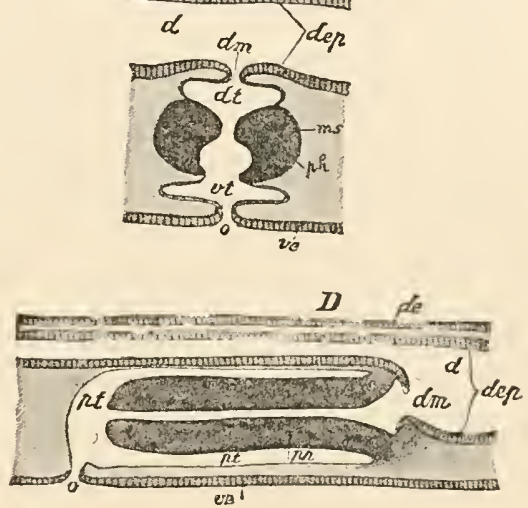

Fic. 102.- $A-D$, Diagrammatic representation of the Pharyngeal Apparatus of the Turbellaria. $A$, Of Convoluta ; $B$, of Mesostoma ; $C$, of Planocera ; $D$, of Prosthiostomum. de, Dorsal body epithelium; ve, ventral body epithelium; $o$, mouth ; $d m$, entrance to intestine ; $p t$, pharyngeal ponch ; $p h$, pharynx ; $d$, intestine ; dep, intestinal epithelium ; $s$, cesophagus ; $p$, parenchyma ; $d t$, dorsal œsophageal pouch ; $v t$, ventral œesophageal pouch ; $m s$, muscular lamella.

Phabdoccelidee in many Accele, and also in Mesostomide, Proboscidea, and Plagiostomide. It is found near the anterior end of the body in the Euryleptidee and Prosthiostomidee, among the Polyclade, in many Rhabdocela, and all Trematoda. It lies somewhat behind the middle in a few Leptoplanidce among the Polyclada, all Triclade, and many lihabdocalidce (especially in the Monotidce). It is met with near the posterior end of the body in the Cestoplanilce among the Polyclada, and in many Plagiostomidce among the Alloiocela.

The structure of the pharyngeal apparatus is very varied in the Platodes. We can only briefly describe the chief types.

The pharyngeal apparatus of the Convolutide, the Microstomider, and Macrostomidce among the Phabdocolidee, is distinguished by its great simplicity and its embryonic condition (in most Accele it is even 
entirely wanting). In the 3 families mentioned it consists of a simple asophageal tube between mouth and intestine (Pharynx simplex, Fig. 102, A). This simple resophagus becomes at first complicated by the massing of definitely arranged muscles around it. The muscular wall of the cesophagus, then, almost always projects in various ways more or less far into the lumen of the cesophagus, so that we can now distinguish in the pharyngeal apparatus 2 chief parts: (1) the csophageal or pharyngeal pouch, and (2) the muscular œsophageal bulb or pharynx which projects into it. When the cesophageal pouch is not spacious, and the pharynx with its free inner surface projects only a short way into it, the latter is generally round or barrelshaped, and is sharply marked off from the body parenchyma which surrounds it by a layer of muscle (Pharynx bulbosus, Fig. 102, $B$ ). In this form we meet it in nearly all PRabdoccela, in the Plagiostomidce among the Alloiocela, and further in all Trematoda.

In very many Turbellaria the pharynx projects as a circular fold into the mostly spacious pharyngeal sheath or pouch, and takes, like the latter, very various shapes; it is in this case never sharply severed from the surrounding parenchyma by a muscle layer (Pharynx plicatus). In all Polycladu, with the exception of Euryleptidce and Prosthiostomide, the pharyngeal pouch is very spacious, and often has secondary pouches, which again are occasionally branched; and the pharynx is a flat and broad band which hangs as a circular fold from the sides of the pouch (Fig. 102, C). Such a pharynx can be extended through the oral aperture, and, spreading out, envelop its prey on all sides, as in a sheet. In the Euryleptidce and Prosthiostomidee among the Polyclude, and in all the Triclade, and in the Monotidce among the Alloiocele, this circular fold becomes a more or less extended cylindrical muscular tube, which projects freely into the equally cylindrical pharyngeal pouch from its base. By contraction of the circular musculature this tube elongates and passes out through the oral aperture (Fig. 102, D).

The relation of the pharynx plicatus to the pharyngeal sac is similar to that of the variously-shaped oral or gastric peduncle of the Acruspede Medusa to the subumbrellar cavity into which it projects.

The musculature of the Platode pharynx consists of one or more longitudinal and circular muscular layers, and of muscle fibres arranged radially round the axis of the pharynx.

All over the free surface of the pharynx, and cliefiy at its free end, umicellular glands (salivary glands) open. These glands lie either in the pharynx itself, as in the pharynx bulbosus, which is sharply marked off from the parenchyma, or, as in the pharynx plicatus, seattered about in the parenchyma round the place of insertion of the pharynx. In the latter case they send only their long and thin processes (efferent ducts) into the pharynx.

The following is the rule for the position of the pharynx and the pharyngeal sac. When the month lies in the middle of the body the enteric aperture is found directly above it. The axis of the pharynx and its pouch then stand perpendicularly to the ventral surface. If the mouth lies to the front the enteric aperture lies behind it; 
the free end of the pharynx is directed forwards and is extended forwards. The opposite is the case when the mouth lies behind the middle of the body. The generally narrow round enterie aperture leads out of the pharynx or pharyngeal pouch into the endodermal gastral system.

II. The endodermal gastral system must be separately described for the various divisions of the Platodes.

An anus is everywhere wanting, as in the Cnidaria.

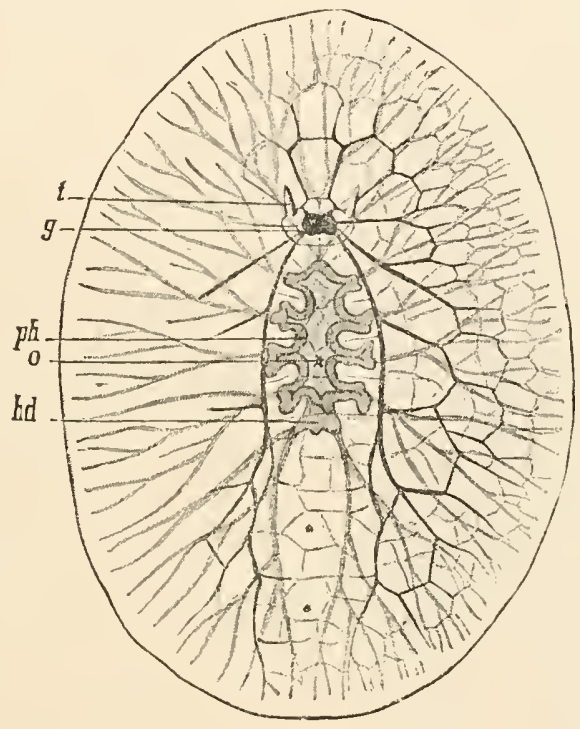

FIG. 103.-Intestinal and nervous systems of the Planocera. $t$, Tentacle; $g$, brain; $p h$, pharynx; 0 , mouth; $h d$, posterior end of the main intestine, the greater part of which is covered by the pharynx.

\section{Turbellaria.}

A. Polyclada (Fig. 103). - The gastral system here is very similar to that of the higher Cniderice (BLedusce and Ctenophora). It consists of (1) the main intestine and (2) the gastro-canals or intestinal branches. The longer the body the longer is the generally spacious main or stomach intestine. Where the pharyugeal apparatus is found in the middle of the body, the main intestine lies just above it; where the pharynx lies behind, the intestine in almost every case is found in front of it. If the pharynx is placed in front the main intestine lies nearly always behind it. From the stomach intestine the gastrocanals arise in varying numbers. They perforate the body parenchyma, penetrating towards the edge of the body in a horizontal direction on all sides, and freely branching or anastomosing with each other on the way. Pairs of gastro-canals can be distinguished, and there is one unpaired canal. The paired are found in 4 pairs at least, and often, 
especially in long forms, in very numerous pairs. The unpaired canal runs forward from the front end of the stomach intestine in the middle line of the body.

In a few Polyclada the gastro-canals open on the dorsal surface of the body (Yungia) through pores, or else on the edge of the body (Cycloporus). In Thysanozoon diverticula of the intestinal branches run into the lobate processes of the dorsal surface.

B. Trielada (Fig. 104). - A distinction between main intestine and intestinal branches cannot here be made. Three gastro-canals start

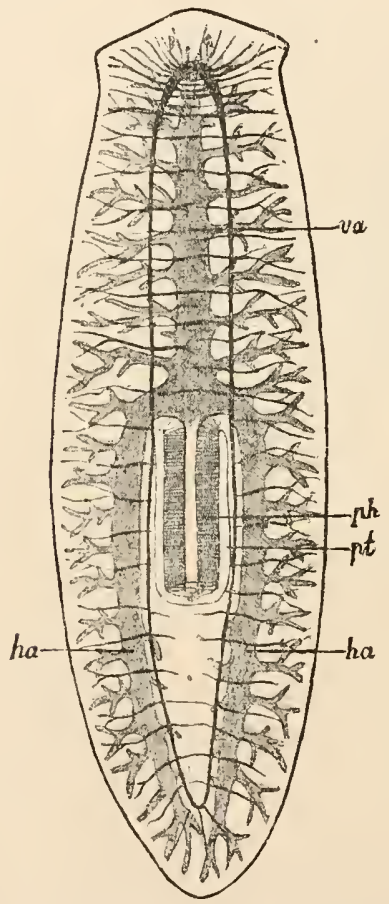

FIG. 104.-Intestinal and nervous systems of a fresh-water Triclade. $v u$, Anterior median intestinal branch ; $h a$, posterior intestinal branches; $p h$, pharynx; $p t$, pharyngeal pouch.

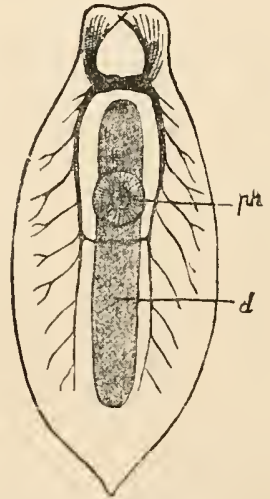

Fig. 105.-Intestinal and nervous systems of Mesostoma (Rhabdocœle). $p h$, Pharynx; $d$, intestine.

direct from the intestinal aperture; 1 mnpaired, which runs forward in the median line and often possesses lateral offshoots which again branch, and 2 paired, which run backward at the sides of the pharyngeal pouch and give off lateral branches towards the exterior.

C. Rhabdocœlidæ. - The gastro-canal system is reduced to a simple sac-like or tubular intestine (Fig. 105), which runs in the middle line of the body. This occasionally (especially in the Monotidee) has numerous short lateral diverticula. 
In the so-called Accele the alimentary canal is represented by a mass of star-shaped branched cells, in which no intestinal cavity can be demonstrated. Food enters this mass direct through the mouth or resophagus; it has been described as "digesting parenchyma."

Trematoda.-The gastro-canal system of the Trematoda most resembles that of the Triclacla. Since the mouth and pharynx lie to the front, the intestinal aperture leads into the anterior end of a short unpaired median portion of the intestine called the ropophagus; this soon splits into two forked branches which run backward (Fig. 106). In the broad leafshaped Trematoda to which most of the ectoparasitic forms and also the liver fluke belong, lateral branches, which again divide, run mostly outwards from these forked branches.

In certain forms (Stichocotyle, Aspidlogaster) the intestine runs back as an unpaired median crecum. When a median sucker is developed at the anterior end (oral sucker) the mouth lies in its base.

The intestinal epithelium of the Turbellaria is covered, over larger or smaller areas, with cilia. Intracellular taking in of food is very common in the Turbellaria. The musculature of the gastrocanal system is on the whole very feebly developed, and consists of longitudinal and circular fibres. In the Polyclada single circnlar muscle fibres succeed each other on the intestinal branches at regular intervals, so that in conserquence of the constrictions thus formed the intestinal branches assumc the aspect of strings of beads.

As an anus is wanting, the frecal masses are emptied out through the mouth. The gastro-canal system of the Turbellaria may, besides the functions of digestion and circulation, also have a respiratory significance.

\section{Supporting Organs, Passive Organs of Locomotion.}

These are in most soft and delicate Pla-

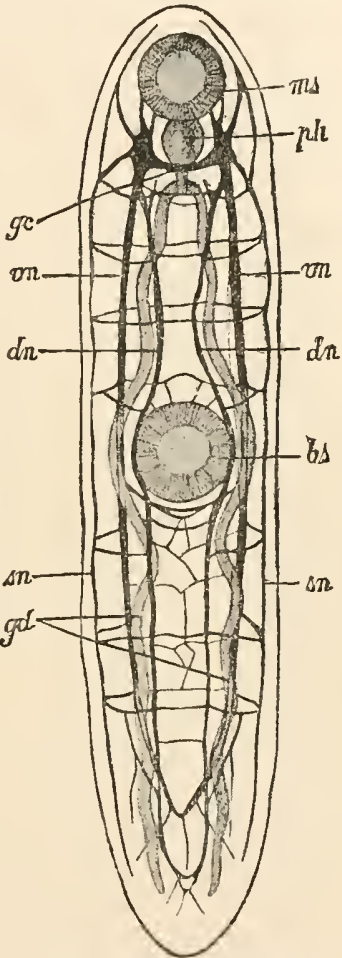

Fig. 106.--Intestinal and nerv. ous systems of Distoma isosto. mum (Trematode), after Gaffron. $m s$, Oral sucker; $p h$, pharynx; $g d$, forked branches of the intestinal eanal; $g c$, cere bral commissure ; $d n$, dorsal longitudinal nerves; $s n$, lateral longitudinal nerves; $v n$, ventral longitudinal nerves; $b s$, ventral sucker.

\section{todes little developed. In the Turbellaria,} at least in the Polyclada, the basal membrane, which is resistant and tolerably firm and elastic, plays the part of a supporting membrane, to which the dermal musculature is closely applied, and in which the dorso-ventral muscle fibres are inserted. The same part is also certainly played by the cuticle of the Trematodu and Cestodu. Besides this, the more or less compact parenchyma lends the body a firmer 
structure and a greater consistency, like the gelatinous tissue in the Cnidarit.

\section{The Musculature.}

The collective muscle elements of the Platodes may be brought into 2 chief groups: (1) the general body musculature, and (2) the special musculature of the organs, e.g. of the intestinal canal of the copulatory organs, etc. The latter cannot here be taken into consideration, as the musculature is adapted in every one of the extraordinarily numerous cases to the special activities of the organ.

The body musculature also is by no means so uniform throughout the race as to make a generally applicable scheme possible. It again falls into (1) the dermal musculature and (2) the dorso-ventral musculature. The first lies under the basal membrane of the integument or under the outer cuticle, the second runs transversely through the parenchyma between the various organs and connects opposite points of the basal membrane or the cuticle.

1. The dermal musculature is composed of layers, which are generally clearly separated. In each of these layers all the fibres run in a certain direction. We can distinguish longitudinal, tranverse, and diagonal fibre layers. The diagonal fibre layer is naturally always double. The longitudinal and the transverse layers may also be double. We find the largest number of layers -5 or 6-in the Polyclada; in the Triclada their number is smaller, we here find outer circular and inner longitudinal fibres, between which diagonal fibres may be intercalated. The same is the case in the Phabdocelide, in which the musculature is weaker than in any other Turbelluria. It is generally much weaker on the dorsal than on the ventral side, on which the animals creep. Certain dorsal muscle layers may be altogether wanting. In the Turbellaria the diagonal muscle layer seems always to lie between the others.

The sequence of layers in the dermal musculature of the Tiematodu, is as follows: the circular or tranverse muscle layer lies externally; then follows a strong longitudinal muscle layer ; and inside comes the diagonal muscle layer. In the Cestoda the diagonal muscle layer is replaced by a strong inner circular muscle layer, lying pretty deep under the skin, and divided from the outer circular layer and the longitudinal muscle layer by a layer of parenchyma.

2. The Dorso-ventral or Sagittal Musculature.--Its fibres are branched at both ends (Fig. $47, d$, p. 47 ), and run through the parenchyma from the dorsal to the ventral surface. Where intestinal diverticula are developed, the fibres naturally run between them as muscle septa, filling up the spaces. Where, as in the brodd discshaped Polyclada, the ramifying intestinal branches of the stomach intestine radiate out towards the circumference on all sides, the septia project more or less far from the latter towards the former, and where 
numerous pairs of lateral intestinal branches succeed each other more or less regularly, they are separated by equally regular muscle septa or dissepiments. This is the case in elongated Polyclude and Tirclutu, and especially in the marine Triclada (Gunda), in which the lateral intestinal diverticula are unbranched. In all cases, when sexual maturity is attained, the formation of septa is more or less obliterated by the development of male and female germ glands, which are generally placed between the intestinal branches.

\section{Organs of Adhesion.}

These are very widely spread among the Platodes. One division of the Polyclada, that of the Cotylea, is characterised by the possession of a muscular sucker, which lies about the middle of the rentral surface, always behind the mouth and the "genital apertures. By means of this sucker the Cotylea often temporarily attach themselves to some object on the sea bottom. Besides this, very many Turbellaria of the most various divisions, possess special adhesive cells with rough surfaces which serve for attachment.

In the parasitic Trematoda and Cestoda the organs for adhesion are specially strong and variously developed. They here serve to fasten the body either outwardly to the skin, or inwardly to the intestinal wall of the animal inhabited, or host. They are principally pit- and disc-like suckers, with or without stalks, whose number, form, and arrangement are of the greatest importance in classification. We select only the most important.

In the digenetic Trematoda there are at the most 2 pit-like suckers (Fig. 106), one of which, in whose base the mouth nearly always lies, is found at the front end of the body as oral sucker ( $m s$ ). The other is either wanting (Monostoma), or lies at a variable distance from the anterior end on the ventral side (bs) (Distoma), or at the posterior end of the body (Amphistoma).

In the monogenetic Trematoda there are often 2 suckers or sucker-pits on each side of the mouth. Besides these, at the posterior end of the body, there is a very large stalked ventral sucker (Tristoma); or the hinder portion of the body becomes transformed into a large sucker-disc, which again may carry sucker-pits in varying numbers and in symmetrical or asymmetrical arrangements (Polystoma).

In the class of the Cestoda also the presence of suckers or suckerpits is the rule (Fig. 117, p. 164). They here always lie at the foremost end of the body, singly (Amphilinct), two in number (Bothriocephalus, Schistocephalus, Trianophorus), or four in number (Tceniade, Tetrarhynchidee, Tetraphyllidce). In the Tetraphyllidce they often have long stalks.

As a further strengthening of the apparatus for adhesion there are often hooks, ridges, teeth, etc., as in the ventral suckers or on the adhesire discs of many monogenetic Trematoda, in the suckers of many 
Tetraphyllidae, or at the foremost end of the body, the apical cone, or rostellum of many Teriadce.

In the Tetruihynchide at the foremost end of the body there are 4 proboscides furnished with barbed hooks, which can be protruded from special proboscis sheaths and withdrawn again by special muscular retractors.

\section{The Nervous System.}

The nervous system in the Platoles is completely detached from the body epithelium. Nearly all its elements lie in or close under the dermal musculature.

In the Polycludu (Fig. 103, p. 141) it consists of a close network of finer or coarser nerves, which is spread in or under the dermal musculature over the whole body, and which, like the musculature, is less developed on the dorsal than on the ventral side. In this plexus specially strong nerves occur, which, converging from all sides and thus growing thicker, unite in a nervous centre, the brain, which lies deep in the parenchyma under the anterior median intestinal branch between the middle and the front of the body. The more elongated the Polyclada are, the nearer the brain lies to the anterior end, and the more conspicuously do the longitudinal nerve trunks stand out among the nerves converging towards the brain. The most strongly developed of these longitudinal nerves are, in order of importance, 2 inner nerves, which run on both sides of the median line, 2 lateral and 2 dorsal. From the brain special nerves proceed to the sensory organs.

The brain in all Polycluda (with one single exception) lies in front of the mouth. Only in Oligocludus (Euroleptidre) does it lie behind the mouth over the beginning of the pharyngeal pouch. The two inner longitudinal trunks in this genus embrace the front end of the pharyngeal ponch, and are connected only behind the same by means of a web of commissures. The brain, the first part of the longitudinal trunks, and the first transverse commissure between these, thus form together a ring which surrounds the anterior portion of the pharyngeal pouch.

In the Triclada (Fig. 104, p. 142) the brain always lies far forward. The ventral inner longitudinal trunks are always specially strongly developed, and are on the one side connected together by a web of commissures, and on the other give off anastomosing branches outwards. In Gunda both the branches which proceed outwards and the commissures are very simple and regular, and correspond in number with the successive pairs of lateral branches of the intestine. Te thus have here a typical ladder nervous system.

In the Phabdocalida (Fig. 105, p. 142) we generally meet with the nervous system in a simpler form. It consists of the brain, which lies in the anterior portion of the body, and, proceeding from it, of the two ventral longitudinal nerves, and of several smaller nerves which 
spread out in the anterior part of the body. Commissures between the longitudinal nerves appear in larger numbers only in the MLonoticke among the Alloiocrela, which show near relationship to the Triclada in other points also. In Mesostoma Ehrenbergii there is a tranverse commissure behind the pharynx; in Nicrostoma lineare two other nerves besides the longitudinal nerves proceed backwards from the brain, surround the pharynx, and unite behind it.

In the Accela, according to earlier investigators, a nervous system was wanting; but lately a somewhat complicated nervous system has been proved to exist. It consists of 2 ganglia lying one behind the other in the anterior part of the body (the front ganglion being the smaller), and six longitudinal nerves, 2 inner, 2 middle, and 2 lateral which run along the edge of the body. The 2 inner arise from the posterior ganglion, the 2 middle and the 2 outer from the front ganglion. All these 6 nerves are connected by transverse commissures which go off at right angles and themselves again anastomose.

The nervous system of the Tiematoda (Fig. 106, p. 143) is closely connected with that of the Triclade and Polyclada. It consists of a brain, from which proceed, besides small nerves which run to the sides and the front, 6 nerve trunks running backwards, viz. 2 dorsal, 2 inner ventral, and 2 outer ventral or lateral. The 2 ventral are connected together and with the lateral by more or less numerous transverse commissures, as are the lateral with the dorsal, and the dorsal again together; these tranverse commissures may again anastomose with each other.

The nervous system assumes this form especially in ectoparasitic Trematoda (Tristoma) and in Distoma isostomum. In many other Trematoda, however, perhaps in most species of Distoma, the commissural system appears to have degenerated; and of the 6 longitudinal nerves only the inner ventral nerves seem to be strongly developed, as in the Rhabdoccela.

The brain lies above the mouth in all Trematoda; when the mouth

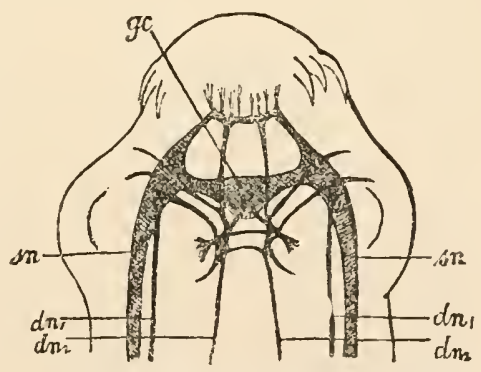

Fig. 107.-Nervous System in the Scolex of a Tapeworm (Tænia serrata) after Niemic. of the $S$ weaker longitudinal nerves only the 4 on one side $\left(d n_{1}, d n_{2}\right)$ are depicted. sn, Lateral nerves; $g c$, chief or cerebral commissure. is placed in the pit of the oral sucker, the brain extends as a transverse bridge over the front part of the pharynx.

The nervous system of Amplitina quite agrees with that of the Distomidce.

The nervous system of the typical Cestoda (Fig. 107) consists of two lateral longitudinal trunks, which pass through the whole body 
and are connected by means of a chief commissure (brain commissure) at the foremost end in the scolex. There are generally several more besides, often $S$ longitudinal nerves, which, however, do not stretch backwards beyond the scolex, and further other nerves, which proceed to the suckers, the hooks, and in the Tetrarlynchidee to the 4 muscular proboscides, etc. Apart from the brain commissure, all these nerves in the scolex are connected together in a complicated way by circular square, polygonal, or cross-shaped commissures. In the segments (proglottides) no commissures between the longitudinal trunks have yet been observed.

The brain (cerebral ganglion, cerebral commissure) of the Platodes is not to be considered exclusively as a contral nervous system, since more or less numerous ganglion cells exist in the larger nerve trunks also, at those points where the nerves and commissures branch off. Thus the ganglion cells in many Triclada are found in the ventral longitudinal trunks of the ladder nervous system, principally at the points of departure of the transverse commissures. We are thus led to conjecture that the double ganglia of the ventral ganglionic ehain of the Vermes have proceeded from these points in a ladder nervous system.

The nervous system of the Platodes is in our opinion of the greatest significance from the point of view of comparative anatomy, because it joins on to that of the Cnidaria on one hand, and on the other is, in many groups, modified in a direction which points to the nervous system of the Vermes, and also perhaps of the lowest Molluses. If we consider the matter without prejudice the following seems characteristic of the nervous system of the Turbollaria and Trematoda. (1) The arrangement of the nervous system in the form of a nerve plexus all over under the skin, dorsally as well as ventrally, in close connection with the musculature which has to be innervated. In this condition we recognise a great similarity to the higher Cnidaria. (2) The development of a central organ (brain). We have seen in the Cnidaria that nerve centres are formed in close connection with the sensory organs, which is comprehensible a priori, since it is in the nerve centres that the junction of the sensory nerves with the motor nerves or nerve fibres takes place. Now the finer structure of the brain of the Platodes shows, most ummistakably, that the brain is nothing more than a specially developed part of the nerve plexus, in which motor and sensory nerves unite. The sensory organs become, in connection with the development of bilateral symmetry, more and more localised in the anterior end of the body, i.e. in the end which goes first in creeping; and therefore the centralised nerve plexus (or in other words the brain), in which the motor and the sensory fibres unite, must, following the sensory organs, shift more and more towards the anterior end of the body.

In Acole we find 2 cerebral centres; in Cestoda the many often very complicated commissures between the nerves in the scolex must collectively be considered as the brain ; in certain land Trielada the only part which can be called the brain is a not very sharply demareated tract of the longitudinal trunks at the anterior end of the body, in which the transverse commissures lie specially crowded together, and into which also the sensory nerves enter.

Bearing in mind the fact that in the Ctenophora, in Coloplana, and in Ctenoplana the seusory body is developed in the middle of the dorsal surface, we must consider this as the original position of the brain. As a necessary result of the development of this central portion, the peripheral nerves, the nearer they approach to this part, unite into increasingly massive trunks, which finally enter the brain. In eonsequence of the position of the brain at the anterior end of the body, the nerres proceeding 
backward are always the thicker nerves, while the lateral and front nerves are the shorter and thinner. The greater development of the musculature on the creeping surface has as a consequence the greater development of the ventral trunks. The elongation of the body further causes a retrogression of the onter longitudinal nerve trunks, so that finally the 2 inner longitudinal trunks remain as the main trunks, which from the first are very strong, since they have to innervate the most important muscular organs which lie in the median line between them (pharynx, copulatery apparatus, suckers). Thus in the end the regular ladder nervous system of Gunda is deducible from a general nerve plexus in the integument, determined by the elongation of the body, the localisation of the sensory organs at its anterior end, and the strong development of the musculature on the ventral surface.

The brain in the Platodes appears the more evidently to consist of 2 lateral halves or ganglia connected by a bridge of fibres, the more strongly the 2 longitudinal trunks of the nervous system are developed in comparison with the whole nervous system.

\section{The Sensory Organs.}

The Platodes possess sensory organs, which according to their structure may be described as eyes, auditory organs, or organs of touch. To these belong also ciliated pits, whose function is unknown. Many consider them to be olfactory organs. The development of the sensory organs stands in direct relation to the mode of life. They are best developed in the free-living Turbellaria. In the parasitic Tremadotu their degeneration begins, and the Cestodle no' longer possess any specific sensory organs.

\section{A. Eyes.}

These are found in most Turbelleriu and ectoparasitic Trematoda. They are wanting in adult endoparasitic Trematoda, but, on the other hand, are found in their young stages, which are free-living, at least for a time.

All Polyclada possess eyes in large numbers, often as many as several hundreds. In their arrangement the following points are worthy of note. A group of eyes is always found above the brain and in the tentacles. Many forms possess, besides these, other eyes at the anterior margin of the body or all round the margin. In the Triclade there are either 2 eyes near the anterior end, or numerous eyes along the margin of the whole body, or along its anterior margin. In the Phabdocelide there are generally 2 or 4 eyes (less frequently one unpaired eye) directly on or over the brain; this is also the position of the 4 eyes of the ectoparasitic Trematoda and the 2 eyes of the free-living larva of the endoparasitic Tremutoda.

In all the Platodes (except the Accelu and Microstomider) the eyes lie under the epithelium in the parenchyma; in the Phabdocela and Trematala directly on or in the brain. Yet in the case of the Polyclade at least, it can be ontogenetically proved that the eyes at their first appearance arise in the ectoderm of the embryo and only secondarily sink below the surface. 
The eyes are simple pigment spots in many Rhabdocolide ; in others a refractive body is added. The eyes of the Triclada, Polyclada, and ectoparasitic Trematoda are somewhat more complicated. They consist of a pigment cup (often unicellular), at whose aperture lie one or more nerve or retinal cells as perceiving elements. In the cavity of the eyecup lie homogeneous non-nucleated rods or clubs, apparently processes of the retinal cells. A fine optic nerve is connected with the group of retinal cells. In the Polyclada, where there are numerous eyes, the sensory nerves from the brain branch, sending a single branch to each eye.

\section{B. Auditory Organs.}

These are not widely spread among the Platodes. They are only found in the lihabdocelide, and there almost exclusively in the division of the Acala, and among the Alloioccela in the family of the Monotider. They are always found singly, and lie on the brain, and consist of a small spherical vesicle filled with fluid; an otolith or auditory stone (composed of carbonate of lime and an organic substratum) is also enclosed in this resicle.

\section{Organs of Touch.}

These are universal in the Turbellaria. In the first place the skin is everywhere very sensitive. This sensitiveness is caused by the presence of delicate tactile hairs or tufts of immobile tactile hairs, which are found in great numbers principally at the exposed parts of the body, especially at the anterior edge and on the tentacles. The tentacles may be considered in a special manner to be organs of tonch ; they are present in very many Polycluda, but less frequently in Triclada and Phabdoccelide. In the Polycladan family of the Planoceridee we find on the dorsal surface, between the middle and the anterior end, two lateral, mobile, stylet-shaped, solid tentacles (Fig. 103, $t$, p. 141), which can occasionally be withdrawn into temporary depressions of the skin. They may be directly compared with the tentacles of Coelo- and Ctenoplana, but are distinguished from these and from the contractile tentacles of the Ctenophore (1) in that they have moved from the middle of the back more or less far towards the front, and (2) in that they have no lateral branches. In the Pseudoceridce and Euroleptide there are at the anterior edge tentacular folds of the leaf-shaped body, into which branches of the intestine generally penetrate. In a few Triclade also, and in Vorticeros among the Phabdocelide, feeler-like projections or thickenings at the anterior margin of the body have been described.

The so-called proboscis is a highly developed specific organ of touch which distingnishes a Rhabdocalan family, the Proboscidea. The anterior end of the body of many Turbellaria is very retractile; in Mesostoma rostratum it can be telescopically withdrawn and protruded. The permanent arrangement in the Proboscidea can be deduced from such a 
condition. The proboscidal apparatus of such an animal consists of an invagination at the anterior end of the body, on to which the outer epithelium is continued. This invagination can be evaginated and again withdrawn by means of special retractors. The invagination, as well as the retractors which are inserted in it, are surrounded by a saclike muscular integument, by whose contraction the proboscis is protruded. Fig. 108, $A, B, C$, represents the proboscis in various stages of protrusion. The whole apparatus shows in every detail a similarity
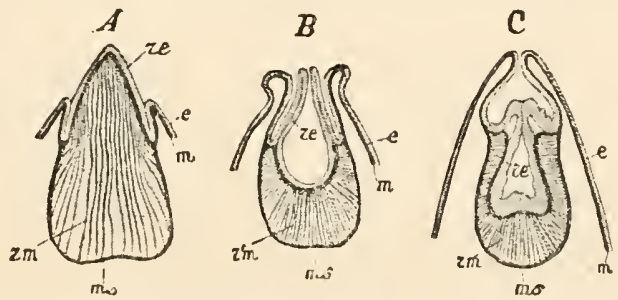

FIG. 10S.-Proboscis of Macrorhynchus croceus. A, In a protruded condition; $E$, half protruded; $C$, withdrawn (after $\nabla$. Graff). $\quad r e$, Proboscis epithelium, which is a continuation of the body epithelium $(e)$; $m s$, muscular envelope which divides the proboscis from the body parenchyma; $m$, dermal muscle layer; $\mathrm{rm}$, muscles for withdrawing the proboscis.

which cannot be ignored to the 4 proboscides of the Tetrarhynchide and the proboscis of the Nemertina to be described later.

In the Trematoda the sensation of touch seems specially localised in the suckers.

\section{Ciliated Pits.}

In certain Phabdocelide, viz. in the Microstomida, Prorhynchide, and Plagiostomidee, there are 2 paired strongly ciliated integumental pits which lie laterally on a level with the brain, and are supplied with a nerve ring by the brain. They have been regarded as olfactory pits. In the Triclada, also, similar strongly ciliated parts of the epithelium of the end of the head have been observed, to which special sensory nerves proceed. In Bipalium, a land Triclad, there are pits supplied with special nerves in large numbers at the anterior margin of the body which is broadened out in the shape of a crescent. Whether the ciliated furrow which in all Polyclada runs along the anterior margin of the body in the epithelium of the ventral side belongs to the formation here described cannot yet be decided.

\section{The Body Parenchyma (Reticulum).}

The whole space between the body wall and the gastro-canal system, as far as it is not filled by specific organs, is occupied by a cellular connective tissue, the details of whose structure are very various. This connective tissue, which corresponds with the gelatinous tissne of the higher Cnillaria, is called parenchyma or reticulum. It often becomes 
finely lacunar by the formation of many vacuoles filled with fluid. The lacunæ may coalesce in sinuses which conduct fluid, which, however, generally remain small; but in a few Rihabdoccele they become large hollow spaces filled with a perivisceral fluid. In such cases the body parenchyma can assume the constitution of a membrane, covering the inner organs like an epithelium. In the Accela, where there is no parenchyma separate from the intestine, the former, composed of starshaped cells filling the whole body apart from the specific organs, may be described as digesting parenchyma.

\section{The Excretory or Water-vaseular System.}

This is very characteristic of the Platodes, and as yet has been found to be wanting only in the Acala among the Phabdocalider. It consists of a system of very fine transparent canals (excretory capillaries) which branch out in the parenchyma and between the muscles, and which enter into a system of wider, equally transparent canals, which open externally in various ways. In the formation of the extremely thin walls of the capillaries only a few cells take part, so that the nuclei lying in the wall occur at long intervals, and in a transverse section of a canal the wall enclosing the central lumen belongs to a single cell. The capillaries thus represent perforations of linear rows of cells, and are described as intracellular. The wider canals, on the other hand, in the Cestode at any rate, appear lined by a thin epithelium, and are thus intercellular. The blind

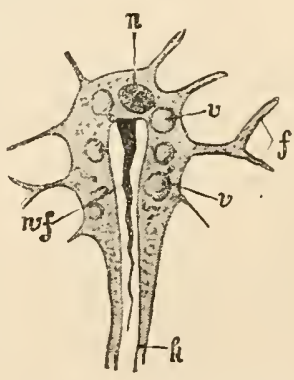

FiG. 109.-Excretory cell at the end of a fine excretory canal $(k)$ of a Turbellarian. $n$, Jucleus; $v$, vacuole; $f$, processes of the cell; wf, flame. end of each excretory capillary is formed by one cell (Fig. 109), which possesses fine protoplasmic processes running into the parenchyma. In this cell, which, on the surface turned to the lumen of the capillary, carries a tuft of fine vibrating cilia (the flame) projecting into the lumen, excretory products (drops, granules, etc.) collect and are emptied out of the cell into the capillary. The excretory products are forwarded out of the capillaries into the wider vessels partly by the motion of the abovementioned cilia, and partly perhaps by the independent contractions of the canals, and thence reach the exterior. Sometimes also in the lateral walls of the capillaries and larger canals flames are found which belong to the excretory cells in those walls. The larger canals sometimes have a continuous lining of cilia. It is not impossible that the greater part of the transparent fluid which fills the canals is water taken in from outside. If so, it is occasionally emptied out and again taken in. In this way the water-vascular system may also perform a respiratory function. 
The whole water-vascular system shows a decided similarity to a greatly developed dermal gland which has sunk deep under the skin, as is often the case in the Platodes (dermal mucus glands, rod glands, accessory glands of the copulatory apparatus). The excretory cells must then be considered as glandular cells, and the canals as glandular efferent ducts. We can actually regard the water-vascular system as a dermal gland, which has undertaken the special function of excretion. In consequence of the strong development of the parenchyma, and especially of the middle layer of the body, and because of the absence
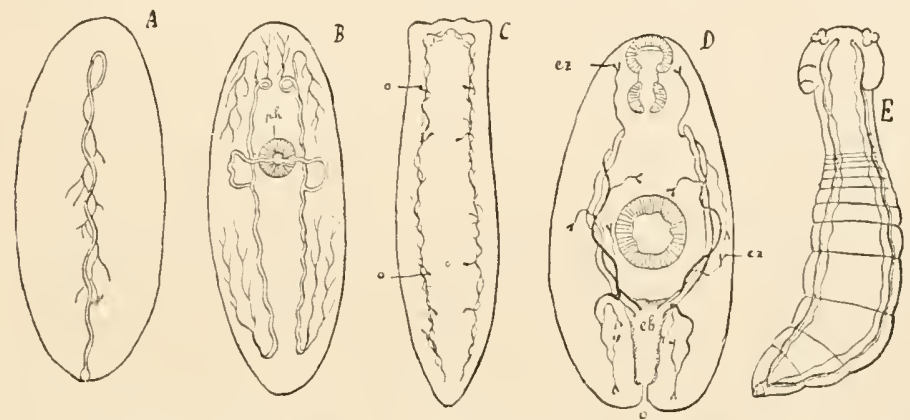

FIG. 110.-Water-vascular system of various Platodes. $A$, of Stenostoma; $B$, of Mesostoma, after $\nabla$. Graff ; $C$, Dendrocœlum, after Ijima ; $D$, Distomum divergens, after Fraipont ; $E$, Phyllacanthide, after Pintner. ph, Pharynx; o, cxternal aperture; ez, excretory cells (terminal cell); $e b$, contractile vesicle.

of a body cavity, this gland is obliged to search for the products of excretion all over the body-hence its great ramification.

Concerning the arrangement of the principal canals and their external apertures (Fig. 110) the following is noteworthy.

We have no sufficient information as to the water-vascular system of the Polyclada.

In the Triclade (Fig. $110, C^{\prime}$ ) a main canal runs on each side of the body (Gunda has two such canals on each side, a ventral and a dorsal, bound together by canals), and these open externally on the dorsal side of the body by means of somewhat numerous special branches and excretory pores placed one behind another. These pores are arranged pretty regularly, in Gunda at least, and correspond in number with the lateral intestinal diverticula-the transverse commissures of the nervous system, -in short with the number of those organs which are regularly paired from one end of the body to the other.

In the Rihabdocolidce we can distinguish 3 principal types.

A. There are 2 lateral principal vessels, which have separate external openings on the ventral side, either $(a)$ at the middle or the front part of the body by special branches opening externally direct (Prorhynchida), or $(b)$ by 2 cross branches which enter the pharyngeal pouch (Fig. 110, E, Mesostomidce, Vortex?), or (c) direct by two openings lying at the posterior end of the body. 
B. There are 2 longitudinal trunks which open externally at the posterior end of the body by means of a common terminal piece (many Vorticidee, Proboscidea).

c. There is a single median principal branch with an opening at the posterior end of the body (Stenostoma among the Microstomille, Fig. 110, $A$ ).

In the Trematoda also we find typically 2 longitudinal trunks which open externally, either together through a common contractile terminal vesicle of very varying size at the posterior end of the body (digenetic Trematoda, Distoma, Monostoma, Fig. 110, D), or separately, anteriorly and dorsally, by means of 2 widened terminal portions.

In Distoma hepaticum there is a wider and larger median longitudinal trunk, which stretches pretty far forward, and into which collecting canals enter from all sides. The external aperture lies at the extreme posterior end of the body.

In the Cestoda (Fig. 110,E) in the simplest cases there are on each side 2 longitudinal trunks running through the whole body, which are united anteriorly in the scolex by a loop. At the extreme posterior end of the body (at the end of the oldest segment) all the four branches open outwardly by means of a contractile vesicle (Taniade, Tetrabotheride, Tetrarleynchides). In the Botleriocephalida, Caryophyllidee, and Ligulide the number of longitudinal trunks is increased to from 10 to 24 , which anastomose in a definite way. A contractile terminal vesicle, into which all the longitudinal trunks enter, occurs only in the end of the oldest segment of the tapeworm; in all other segments, after successive detachments of the older segments, the longitudinal trunks open outward directly and independently ; some of them, however, may close, and thus end blindly. Te have an apparent exception to this rule in Tcenia cucumerina, in which, as segments detach themselves behind, a new contractile terminal vesicle is always formed in the next segment. In many Cestoda, besides the terminal apertures of the water-vascular system, special secondary openings have been observed, generally in great numbers. These are canals, which proceed at right angles from the main canals and open outward through pores. These secondary exits are generally found only at the front end of the body, in the scolex (in Tricenophorus, many Tcenice, and Tetrarhyncha), less frequently in the proglottides also (Botleriocephalus punctatus and a few other forms).

The larger canals show a tendency towards the formation of islands in very many Platodes, and especially in the Cestoda. They then break up into a morc or less complicated anastomosing network. It is probable that the numerous longitudinal trunks bound together by anastomoses in the above-named Cestoda have proceeded from a few (4) longitudinal trunks by the formation of islands.

\section{The Sexual Organs.}

All Platodes, with the exception of the genera Microstoma and Stenostoma among the Phabdocela and of Distoma homatobium among 
the Trematoda, are hermaphrodite. The male sexual products, however, almost universally develop before the female-a phenomenon which has received the name of protandrous hermaphroditism. Both male and female sexual apparatus consist (1) of places of formation of the sexual products which are imbedded in the body parenchyma (ovaries and testes), (2) of special canals, efferent duets, which conduct the sexual products away from the places where they were formed to (3) the outer copulatory apparatus. We will describe these three parts in succession.

\section{A. The Places of Formation of the Sexual Products.}

1. The Female Germ Glands. - We meet with these in the Platodes in two forms. First, and this is the simpler and no doubt also the older condition, as simple ovaries, in which the egg germs ripen into eggs, in whose protoplasm particles of deutoplasm or nutritive yolk occur. Secondly, and this is the derived condition, in the double form of germaria and vitellaria. The germaria yield the egg germs, i.e. the young egg cells. The vitellaria, however, have undertaken the work of supplying these egg cells with the nutritive yolk which is necessary for their further development. Comparative research has shown that the vitellaria are not newly formed accessory glands of the female sexual apparatus, but that they are metamorphosed ovaries or portions of ovaries adapted to a special function. It need not be pointed out that the germaria are ovaries.

In the Polyclude there are only ovaries and no vitellaria. The ovaries (Fig. 24, L, p. 29) are roundish bodies whose structure exactly corresponds with that of the female gonades of the higher Cnidaria. They lie in great numbers (Fig. 111, o) on and between the intestinal branches or gastro-canals in the lateral parts of the body.

In the Triclada, besides a few eggs in the discharged egg cocoons, there are extraordinarily numerous yolk cells, which serve to nourish the former. Light is thrown on this phenomenon by the fact that in certain Polyclada and Mollusca several eggs may be deposited in one cocoon, of which, however, only some develop; the others sooner or later become disorganised and serve as food for the former. Thus perhaps the yolk cells in the Triclade cocoon may be considered as modified egg cells, which develop no further, but serve as food for the few fertilised egg cells which do develop. Division of labour, therefore, has stepped in among the germ-preparing organs, the ovaries ; some yield eggs capable of fertilisation and development; others yield modified egg cells laden with yolk, which serve as food for the above, and are no longer capable of fertilisation and development. The first are the germaria (Fig. 112, ks), the second the vitellaria (ds). These two are homologous structures, and in a young condition look quite alike. In consequence of the large number of yolk cells which are given to the eggs, the vitellaria are far more numerous than 
the germaria, of which only 2 remain; but as these have only to yield eggs without yolk, they are quite sufficient in number. They generally lie at the anterior end of the body, whilst the vitellaria always occur in the lateral parts of the body between the intestinal branches.

In the Rhabdoculicte the germ-preparing organs are considerably

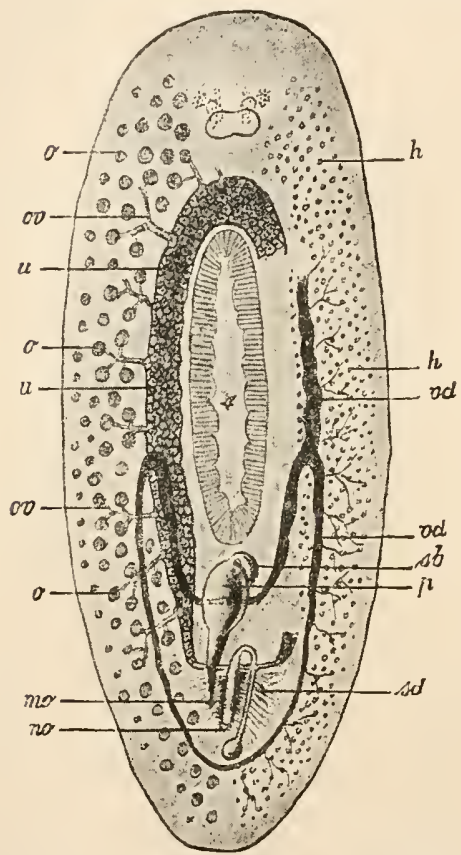

FiG. 111.--Sexual organs of a Polyclad (Leptoplana). To the left only the female, to the right only the male organs are depicted. $o$, Ovaries ; ov, oviduct; $u$, uterus ; $h$, testes; $v l$, vasa deferentia; $s b$, seminal vesicle; $p$, penis; sd, shell gland; mo, male sexual aperture; wo, female aperture.

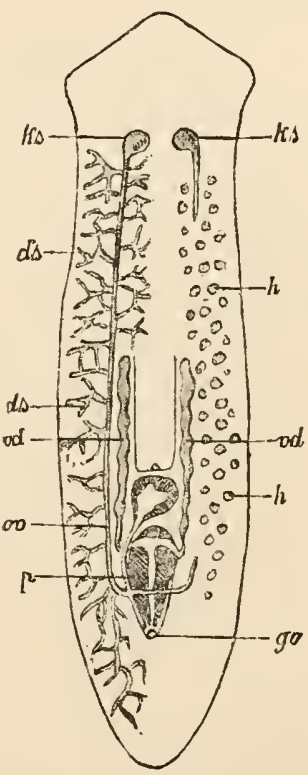

FIG. 112.--Sexual organs of a fresh-water Planarian (Triclad). ks, Geruuaria ; $d s$, vitellaria; $h$, testes; ov, oviluct; $v d$, vasa deferentia; $p$, penis; go, common external genital aperture.

reduced in number, but on the other hand are, in relation to the body, much larger than the single ovaries of the Polyclada. Many forms possess ovaries only. The Acceta, and the Macrostomidce among the Rhabdoccela, have 2 lateral ovaries, the Microstomidce only 1 ovary. In many Rhabdocelide so-called germ-vitellaria attain development, one often clearly separated portion of the ovary yielding only egg germs, the other only yolk.

One single germ-ritellarium is found in the Prorhynchidce. Proxenetes among the IIcsostomidce, Schultzia among the Vorticide, and Cylindrostoma among the Plagiostomidec possess two. 
In the greater number of Rhabdocala and Alloioccela, however, there is a complete separation into germaria and vitellaria. The germaria are mostly small and round, the vitellaria $(d s)$ are large, often lobate, branched or reticulate. The vitellaria are generally double; where they are single reticulate branched masses, their originally double condition can be recognised by the duplication of their efferent ducts. The germarim is either double or single.

One germarium is found in most IIesostomide, Gyrator among the Proboscidea, most Vorticide, and Solenopharynx. Two are found in Promesostoma, most Proboscidea, Provortex and Grafilla among the Vorticide, and the Alloiocele.

Separate germaria and vitellaria are found in all Trematoda and Cestoda. The germaria (Figs. 114 and 115, ks) are either simply round, or lobed, or branched. The vitellaria ( $d s$ ) are mostly (excepting in the T(enice) very extensive, and branched in a reticulate manner, or else broken up into a large number of small globular bodies or saccules.

The Trematoda possess a median germarium and 2 lateral vitellaria, the Cestoda 2 germaria and either 2 lateral vitellaria or a small posterior vitellarium (Terice).

II. The male germ elements or testes are present in the Polyclada (Fig. 111, h) in greater numbers than the ovaries. They always lie in the lateral parts of the body between and under the intestinal branches. The same holds good of the numerous testes of the Triclada (Fig. 112, h). In Gunda segmentuta the testes lie on each side in a single longitudinal row in the dissepiments which separate the consecutive intestinal branches. They thus repeat themselves in the body just as regularly as do the intestinal branches, dissepiments, transverse commissures of the nervous system, and the external apertures of the water-vascular system. In the Rhabdocolide there are either 2 testes (Fig. 113, h, Rhabdocola), or the testes are broken up into numerous lobes or vesicles, which are scattered in the parenchyma (Acola, Alloiocola). Nearly all Trematoda (Fig. 11t, $h$ ) possess 2 round, or lobed, or branched testes, while in the Cestoda (Fig. 115, h) there are numerous scattered testicle vesicles.

\section{B. The Efferent Duets of the Sexual Products.}

The Female Ducts. - The female sexual glands are produced into tubular ducts, which collect the sexual products and carry them to the exterior. The ducts are either egg ducts (oviducts) when they proceed from the ovaries or germaria, or yolk ducts (vitello-ducts) when they carry out material formed in the vitellaria. The anatomy of this part is so varied that we can only select the most important points.

In the Polyclada (Fig. 111) numerous oviducts (ov) proceed from the numerous ovaries. These ducts frequently unite to form larger ducts, which again enter more spacious tubes, generally rumning in the longitudinal direction on both sides of the middle line. Numerous 
eggrs collect in these tubes, which are called egg receptacles or uterus tubes $(u)$. As they enter the female copulatory apparatus they unite in an unpaired terminal portion, the egg passage, into which the threadlike efferent ducts of the numerous glands $(s d)$ which are imbedded in the surrounding parenchyma open. The glands whose hardening secretions yield the egg shell which covers the egg or eggs are

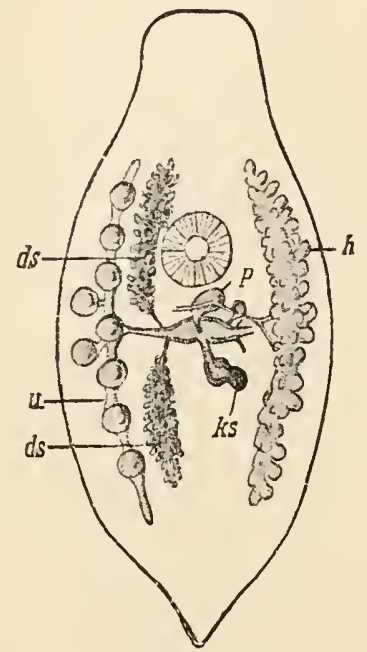

Frc. 113.-Sexual organs of a Rhabdocœle (Mesostoma Ehrenbergii). To the left the test is is omitted; to the right the vitel. laria aud the uterus are left out. $h$, Testis ; $d s$, vitellaria ; $u$, uterus ; $p$, penis; $k s$, germarium.

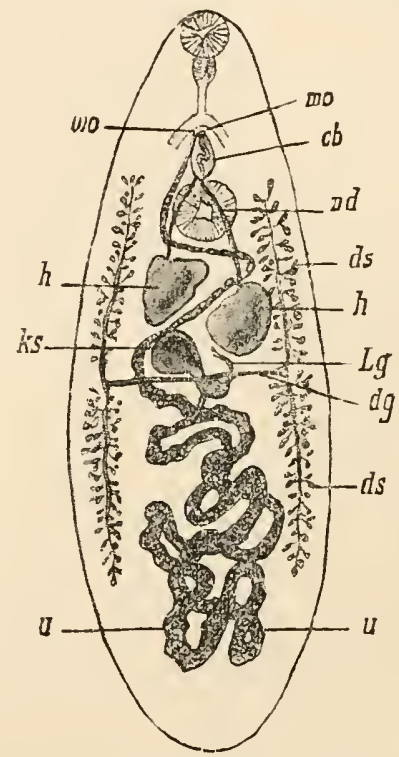

Fic. 114.-Sexual organs of a Trematode (Distoma), after Leuckart. $h$, Testes; $k s$, germarium; $u$, uterus; $d s$, vitellarium; $d g$, yolk or vitelloduct ; $v l$, vasa deferentia ; $L g$, Laurer's canal ; $c b$, cirrus pouch ; mo, male, wo, female sexual aperture.

collectively linown as the shell glands. They occur almost universally in the Platodes.

In the Tricluda (Fig. 112) there are 2 lateral longitudinal oviducts $(o r)$, which conduct the eggs from the 2 germaria in the front of the body backwards to the copulatory apparatus. Apertures are found on. the way, through which the vitellaria empty their products into them. Before passing out into the copulatory apparatus they unite to form a short unpaired egg passage, into which the efferent ducts of the shell glands open.

In the Rhabdocalidce (Fig. 113) the female sexual glands are generally placed with their ends directly on the outer copulatory apparatus, and open into it. There is often a union of the vitellaria and the germaria before their exit into a common terminal portion. The shell 
glands open either into the outer copulatory apparatus, or into a special fold of the same into which eggs and yolk are conducted, and which will here be called the uterus. In the Accula and Alloiocrela no definite connection between the germ glands and the copulatory apparatus can be demonstrated. The sexual products here make their way through the parenchyma to the copulatory apparatus.

In the Trematoda (Fig. 114) an oviduct proceeding from the ovarium is found, then two yolk ducts $(d g)$ which collect the yolk from the two lateral vitellaria. The oviduct and the yolk ducts together enter an unpaired canal which we shall call egg passage. This passage falls into 2 parts-one small part at the beginning, the ootype, into which the 3 ducts mentioned enter, and a long, generally coiled

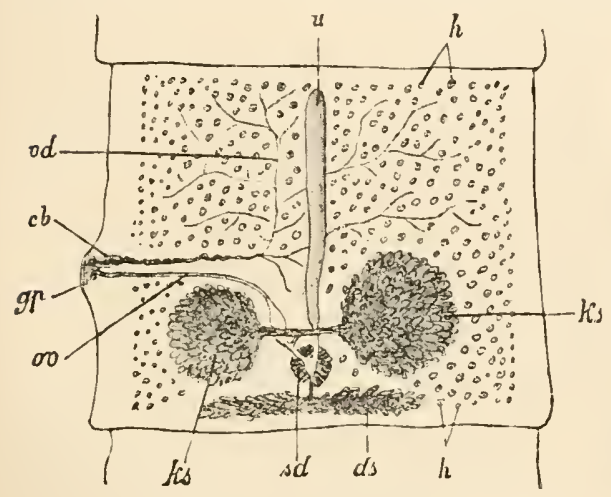

FIG. 115.-Sexual organs of Tænia saginata (medio-canellata), after Sommer. $h$, Testes; $v d$, rasa deferentia; $c b$, cirrus pouch; $g p$, genital pore ; $o v$, oviduct; $k s$, germaria ; $s d$, shell glands; $d s$, vitellarium; $u$, uterus.
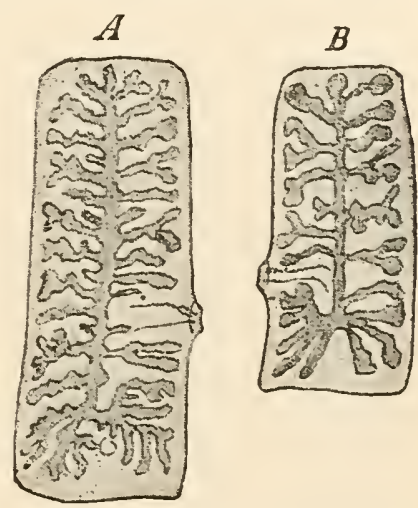

Fig. 116.-Fully ripe proglottides (segments). A, of Tænia saginata; $B$, of Tænia solium. The dendriform figure represents the uterus.

portion, the uterus $(u)$, leading from the ootype to the female genital aperture. The ootype receives the efferent ducts of the shell glands. Fertilisation takes place here, and also the union of the yolk with the egg; and here a shell is formed round the fertilised egg. The ootype has an exit either in the dorsal or the ventral surface of the body through one more canal, Laurer's canal $(L g)$, through which, probably, in copulation, the sperm reaches the ootype from outside. The fertilised eggs pass from the ootype into the uterus, where they often collect in enormous numbers, at least in the Distomide. The uterus in these animals is consequently very long, and runs to the female copulatory apparatus in numerous coils, which in the adult often fill the greater part of the body.

The Cestoda (Fig. 115) are closely allied to the Trematodu, especially in forms in which, as in Bothriocephalus, the sexual apertures lie on one of the surfaces, and in which there are 2 lateral vitellaria. The collecting passages of the vitellaria unite in such forms into 
2 yolk ducts, which, as well as 2 oriducts, enter the ootype by a common terminal piece, into which the efferent ducts of the shell glands open. From the ootype a canal proceeds to the copulatory apparatus $(o v)$ on one side, and on the other side arises a widened uterus filled with eggs (Fig. 115, u; Fig. 116) running in coils, or provided with lateral sacs; this uterus often reaches the exterior by a special aperture which recalls Laurer's canal in the Trematoda. Where there is only one vitellarium, only one yolk duct naturally enters the ootype (as in Fig. 115).

II. Male ducts. - In the Polyclada numerous very fine canalicules enter the larger semen ducts, vasa deferentia (Fig. 111, vl), in which the spermatozoa collect, and these canals again have their exit in the male copulatory apparatus $(p)$. The fine canals correspond to the oviducts, the wider ones to the uterus of the female sexual apparatus. In the Triclude there are 2 lateral vasa deferentia (Fig. 112, $v(l)$, into which some at least of the testes empty their contents direct, while the manner in which the testes which are at a greater distance from the vasa deferentia empty themselves is not yet fully understood.

In the Phabdocela (Fig. 113) the 2 testes are often continued without any sharp demarcation into 2 semen ducts which enter the male copulatory apparatus either separately or by means of a common terminal portion. In the Accela and most Alloiocala special ducts are wanting; the spermatozoa reach the copulatory apparatus through the parenchyma. Only in the Monotidee among the Alloioccela the transmission takes place by means of special ciliated vasa deferentia. The two testes of the Trematoda (Fig. 114) send out two semen ducts $(c d)$ which unite into one common duct. In the Cestodu also (Fig. 115) many of the numerous canalicules proceeding from the testicle vesicle enter a common vas deferens leading to the male copulatory apparatus.

\section{The Copulatory Apparatus.}

There is wonderful variety in the structure and position of the copulatory apparatus in the Platodes. Nearly related species often differ greatly in this point.

I. The male copulatory apparatus is always more complicated in structure than the female. It consists in the simplest cases of a muscular pouch which projects from the surface into the parenchyma, and into whose blind end, which is directed inwards, the semen duct, or ducts, enter. It is found in this form in certain Phabdocolidce. In most Turbellaria, however, it becomes complicated, and then we can generally distinguish the following distinct portions: (1) a penis sheath or penis pouch, (2) the actual penis, (3) a seminal vesicle, and (4) a granular gland. The penis and penis sheath show a structure which is on the whole like the structure of the pharyngeal appa- 
ratus described above. The penis is, in fact, a muscular circular fold which projects into the penis sheath from its wall in a manner similar to that in which the pharynx projects into the pharyngeal pouch. As the pharynx is protruded out of the pharyngeal pouch through the mouth, so is the penis protruded through the sexual aperture. During copulation the wall of the penis sheath also is pushed out or eraginated. The penis sheath is occasionally double, or there are several sheaths, each of which is related to the one outside it as the penis is to the penis sheath, and the whole apparatus may be telescopically extended and protruded. The penis is sometimes conical, sometimes cylindrical, sometimes bent, either naked or armed in rarious ways. Its free end is often a hard chitinous tube. Between the penis on the one side and the terminal portion of the semen duct on the other, there is a resicular expansion with muscular wall, the seminal vesicle (Fig. $111, s b$ ), in which the semen collects, and which, by its contraction during copulation, causes the ejection of the semen through the penis canal (ductus ejaculatorius). In nearly all Turbellaria there is, in connection with the male copulatory apparatus, a granular gland, the structure of which differs greatly in details. It forms a finely granular secretion, which mixes with the semen,

The male copulatory apparatus of the Trematode (Fig. 114, cb) and that of the Cestoda (Fig. 115, cb) are very similar in structure.

In mechanism it corresponds with a Tetrarhynchus proboscis. There is a cylindrical or club-shaped penis sheath. Into the inner blind end of this penis sheath enters the unpaired terminal portion of the vas deferens. On entering the penis sheath it generally expands into a seminal vesicle, and then runs as a coiled thin tube through the penis sheath to emerge at the sheath's outer end through the male genital aperture. This tube, which is often furnished internally with barbed hooks or covered with an elastic cuticle, is forced out as an actual penis by the contraction of the penis sheath. The space between the penis and the penis sheath is filled with loose connective tissue. The penis and penis sheath are generally called cirrus and cirrus pouch in the Trematode and Cestoda. Glands connected with the copulatory apparatus have also been observed.

II. The female copulatory apparatus very often, in many Turbellarice and in all Trematode and Cestode, consists of a simple tube of varying length, the vagina, which connects the egg passage or the ootype with the female sexual apparatus. This tube often serves merely as a place for depositing the eggs, not for copulation, i.e. it does not receive the penis. This is at least often the case with those Polyclada which have more than one copulatory apparatus, but only one female genital aperture.

In very many Turbelluriu, however, the vagina is differentiated into a strong muscular organ, often provided with a hard cuticle, the bursa copulatrix, which is adapted for the reception of the penis 
during copulation. This may be developed independently as an accessory organ of the female copulatory apparatus. There is in many forms another broad, round, or pear-shaped accessory organ, the receptaculum seminis, a reservoir in which the semen is preserved after copulation.

In the Trematoda, many Cestoda, and in Trigonoporus among the Polycluda, the ootype, or the uterus, or the egg passage, is connected with the exterior by another special passage, Laurer's canal, already mentioned. The physiological signification of this canal is not yet certainly understood.

\section{The Position and Number of the Copulatory Apparati and the Sexual Apertures.}

It may be considered the rule that one male and one female copulatory apparatus are present, and that each opens externally by its own special aperture somewhere in the middle line on the ventral side. The two sexual apertures are generally very near each other, and in many forms-most Trematoda, Cestoda, and Triclada, and in many Polyclada and Rhabdoccelide-come to lie in the base of a more or less deep depression of the outer skin-atrium genitale-so that only one common outer sexual aperture is present.

In this point there is great variety in details, and many often striking deviations. In the Polyclada the sexual apertures always lie behind the mouth, in the Cotylea, in particular, between the sucker and the inouth. The male aperture always lies in front of the female. Stylochus and Stylochoplence have a common external sexual aperture. In Anonymus there are several copulatory apparati and sexual apertures in 2 lateral longitudinal rows. Many Pseudoceride possess 2 male copulatory apparati. The female copulatory apparatus and its aperture always remain single. In Stylostomum there is one common external aperture for the pharynx and the penis.

In the Triclada the common sexual aperture lies behind the mouth, the male copulatory apparatus in front of the female.

In the Pihabdocelide the arrangements are extraordinarily varied. There are sometimes two separate apertures, sometimes an atrium genitale, and thus a common external sexual aperture. Sometimes the male aperture lies in front of the female, and sometimes the reverse is the case. In Prorhynchus the male copulatory apparatus opens in the mouth.

The genital apertures of the Trematoda, which either enter a common shallow atrium genitale or are very near together, generally lie at the anterior end of the body ; in the Distomidce, between the mouth and ventral sucker. Less frequently they lie at the posterior end of the body (e.g. Gasterostomum, Opisthotrema), or asymmetrically to the left near the anterior edge of the body (e.g. in Tristomum).

In the Cestoda there is generally a common external genital pore, or else the genital apertures are very near each other. The porus genitalis or the two genital apertures of each proglottis either lie at the edge (Tetraphyllide, Tetrarhynchide, most of the Toniad(e, Tricenophorus), or on one of the flat surfaces, which is therefore the ventral side (Ligula, Bothriocephalus, Schistocephalus, a few Tanice). In Amphitina they lie at the posterior end of the body. 
Copulation is generally mutual, both the copulating individuals acting as male and as female. Self-fertilisation, however, also seems to take place, e.g. in Cestocle, and perhaps also in a few Trematoda and Turbellaria.

Development. - Like the atrium genitale, which is only a pit-like depression of the outer skin, so the male and female copulatory apparati arise, at least according to investigations made in the Polyclada, by folds from the exterior. The portion of the female genital organs which arises from invagination apparently reaches to the egg passage or ootype, so that not only the glands which open into the male genital organs, but the shell glands also of the female genital organs must be considered as modified dermal glands.

\section{Asexual Reproduction and its Origin-The Organisation of the Cestoda.}

Many Platodes, and especially the Turbellaria, show a marked capacity for regeneration. The body can not only re-form parts torn off', but broken off pieces of various sizes can become regenerated into new animals. Such a capacity of regeneration is very widespread, chiefly among lower stationary animals. In the Coelenterata it is almost universal. The great advantage of this capacity for the preservation of the individual and of the race is evident. For attached animals, or very long or delicate soft-bodied animals, who are more exposed than others to mutilation and injuries to the body from enemies, etc., it is of very great importance. We can perhaps trace back to it the power of asexual reproduction by fission and gemmation which occurs in the Metazoa. We speak of such a method of reproduction when an animal form shows the peculiarity of falling into 2 or more pieces, apparently spontaneously, i.e. from causes unknown to us, these pieces becoming regenerated into organisuns similar to the common mother animal ; or when, from unknown causes, a smaller or larger piece of the body regularly detaches itself, the body thus reduced again replacing the lost portion, while the detached part becomes regenerated into a complete animal.

Thus e.g. Lumbriculus, one of the worms belonging to the Oligochata, falls spontaneously, or apparently spontaneously, into 2 or more pieces, each of which can become regenerated into a whole animal. Certain marine star-fish throw of one or more arms apparently spontaneously, which they soon replace by regeneration. As if this were not enough, each detached arm can again be regenerated into a complete star-fish.

This conjectural origin of asexual reproduction is, howerer, almost always unrecognisable; because different parts of an individual develop into whole individuals before they have fully separated, or an animal replaces a part by regeneration before this part has completely detached itself. Temporary animal stocks thus arise. If the parts do not detach themselves typical animal stocks arise, which by division of labour between the portions which are being regenerated into whole individuals (i.e. between the individuals which have arisen by gemmation), and by the development of a form and organisation in each adapted for some special function, may become polymorphous animal stocks.

The reproduction and life-history of the Acraspede Medusa, e.g. of Aurelia, is specially suitable for the elucidation of the above view. We know that from the fertilised egg of this Medusa, under certain circumstances, another Iredusa may proceed, without any attached stage multiplying asexually. Generally, however, the larva developed from the fertilised egg attaches itself and becomes a coral-like animal, the Scyphula, and later develops into an attached young 
Mrectusa, the Scyphistoma. When this Scyphistoma has developed to a certain stage, in one case the larger portion of the body tear's itself from the stem as a freeswimming Iedusa. The remaining stem can, however, become regenerated into a complete attached Meduse (monodisc strobila), and the whole process may be repeaterl. We thus have here multiplication by detachment and subsequent regeneration. The detached piece has indeed so little to regenerate in it that the regenerative process may be described as cicatrisation.

Or again the stem of the Scyphistoma becomes regenerated into a new Scyphistoma before the first Medusa has detached itself, and when this regenerative process continues without the Medusc at once fully detaching themselves we have a polydise strobila. We call the whole process strobilation, and it has been described as asexual multiplication by axial budding. The polydise strobila is a temporary animal stock.

What has here been said helps us to understand the

\section{Organisation of the Cestoda Body.}

In the body of the large majority of Cestoda the seolex (Fig. 11i) is distinguishable from a row of subsequent segments or proglottides
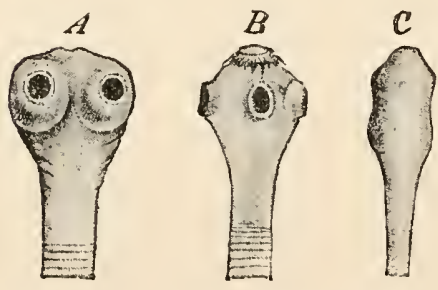

Fig. 117.-Three heads of Tapeworms (scolices). $A$, of Tænia saginata; $B$, of Tænia solium; $C$, of Bothriocephalus latus. (Fig. 110, E, p. 153 ; Figs. 115, 116). The small pear or cone-shaped scolex itself consists of the head and neck. The former carries the organs of adhesion (suckers, hooks, proboscides), by means of which it attaches itself to the intestinal wall of the host. In it lie the single commissures between the longitudinal trunks of the nervous system which may be regarded as brain commissures. It therefore corresponds with the anterior end of the Trematoda body. The thinner neck portion of the scolex is followed by the flattened segments, which are small at first but increase in size posteriorly. The neck portion of the scolex constantly produces new segments, which push back those already existing. The oldest and largest segment of the whole chain is therefore the hindmost. In the segments the genital organs develop ; indeed, the whole hermaphrodite genital apparatus of eacl segment answers to the whole genital apparatus of a Trematode. The male genital organs are first developed in each segment, then the female; then follows fertilisation, and finally the segment is little else than a case which, besiles the remains of the genital organs, is almost exclusively occupied by the extended uterus containing thousands of fertilised eggs. The low of segments from the head to the last segment represents the row of consecutive stages of development of the genital organs. The last segments from time to time detach themselves singly, or several together, and reach the exterior with the excrement of the host.

On comparing the head and the segments we find that the head has no genital organs, and none of the segments have the organs of adhesion 
and the brain commissures; or, when we compare the head and proglottis with a Tremutode, we find that the head has not the trunk, and the proglottis not the head, of the Trematode body. The head and one proglottis together, however, answer to the head and trunk, and thus to the whole body of a Trematode, apart from the fact that an intestinal canal is altogether wanting in the Cestorla.

We, however, know forms whose body during life consists only of head and trunk, which is not clearly divided into a scolex and a proglottis. Such forms are Amplitina, Caryophylleus, and Archigetes. These may be regarded either as intestineless Trematoda, or unsegmented Cestoda. They are, in any case, transition forms between the Trematoda and Cestodu. The relation existing between them and the segmented Cestodu is somewhat similar to that between the Acruspeda which are attached throughout life (e.g. Lucernaria), and the polydisc strobila of Aureliu.

A segmented tapeworm must in fact be considered as a strobila. The young, still unsegmented tapeworm, which attaches itself to the intestinal wall, i.e. the scolex, answers to the young stage of one of the unsegmented Cestoda mentioned above (Amplitina, Caryoplaylleus, or Archigetes), in which the genital apparatus is not yet developed in the slightly developed trunk, the future neck. Now follows the incomplete constriction of that part of the body of the scolex (the trunk or the first proglottis) in which later the genital organs develop. Regeneration of the constricted part then takes place; this part is again constricted and again regenerates, and so on. The single parts remain connected for a longer or shorter time, and form the segments of the tapeworm chain or strobila. Finally, like the oldest Medusa dises of a polydisc strobila of Auretiu, the oldest segments of the tapeworm strobila detach themselves. The points in which the process differs in the two groups are essentially the following. The Meduse which detach themselves from a polydisc strobila develop further, and their sexual organs attain development only after detachment. The segments of the Cestodu which detach themselves, however, are already more than mature (sexually); they have performed their function, the production of fertilised eggs, and they make no attempt to regenerate the part which is wanting to make them complete Platodes, i.e. the head. In the Medusa strobila, further, that part of the body by which it is attached, viz. the apex of the exumbrella, is an insignificant part of the body both physiologically and anatomically, while the part by which the tapeworm is attached contains at least the principal part of the central nervous system.

It does not seem difficult, in the case of the Tapeworm, to trace back strobilation to the phenomenon of regeneration. Proceeding from forms, like Amphitina, capable of regeneration, we can understand that by the peristaltic movements of the intestinal canal in which the animals lived parasitically, and by the outward movement of the excrement, the trunk, with the genital organs it contains, would be torn 
off and ejected, the head which remained being, however, able to produce a new trunk by regeneration. This process-the tearing off of the trunk with the eggs, the continued attachment of the head, and regeneration-must have been of the greatest use to these parasitic forms. By the tearing off of the trunk and its ejection the greater dispersal of the eggs was secured, and the probability of the infection of new hosts or intermediate hosts thus increased. The attached head could keep its ground in the already attained favourable refuge for the parasite, and easily regenerate a new trunk and new genital organs. The strobila consisting of many segments, however, offered the immense advantage that many segments could be benefited by the favourable nutritive conditions of parasitism, and could develop the genital organs; on the other hand, by the periodical tearing off of the trunk of an unsegmented Tenia, not only a longer time must pass before a new sexually ripe trunk would form, but the favourable conditions of nutrition would be much less utilised.

There are Tenire with only very few segments (Tenia Echinococcus, with 3 to 4 proglottides); others possess several hundreds.

In a few Tenice, such as Ligula and Tricenophorus, the outer segmentation is more or less indistinct; internally, howerer, we find the same repetition of the genital organs as in the typically segmented tapeworms, from which these forms must without doubt be derived.

In freshwater Tivicluda, multiplication by fission has been observed.

Among the Rhabdocala, in the genera Nicrostoma and Stenostoma, we find interesting processes of reproduction by axial budding. They can be best investigated in $M$. lineare. In the posterior end of the body of an individual a double transverse partition wall forms between the intestine and the skin. Immediately behind this the organs characteristic of the head portion of the Ricrostoma,the pharynx and the brain,- with the nerre commissure surrounding the pharynx, form. The two septa subsequently move somewhat apart. An annular constriction of the body takes place between them, and the intestine finally also becomes constricted. Only then does the spontaneous separation of the two pieces occur. Long before this separation occurs, however, new phenomena have appeared in both pieces. In the first place the posterior piece grows to the same size as the anterior. Then in the posterior part of each a head portion again forms. The posterior parts of each principal piece thus marked off then grow to the size of the two parts lying in front of them. The whole body now consists of 4 pieces of equal size. This process is repeated twice in the same way, till 16 pieces are formed, i.e. till the worm stock consists of 16 individuals, the one most to the front possessing the original pharynx, the original brain, etc. Then follows generally the spontaneous separation of the individuals.

Reproduction by gemmation occurs further in the young stage of Tcenia called the Finn, and especially in those finns which are known as Conurus and Echinococcus. This will be described later on. 


\section{Ontogeny of the Polyelada.}

As a short illustration of the development of the Platodes from the fertilised egg, we choose the Turbcllaria (Polyclaclide). [The ontogeny of the Rhabdocrela is almost unknown, and the development of the Triclada seems to us to be markedly cœnogenetic. The eggs of these latter animals develop at the expense of the numerous yolk cells in the midst of which they lie imbedded within the egg cocooll, and it might with justice be said that the eggs and embryos of the Triclada live parasitically on these yolk cells, which is not the case in the Polyclada.]

We have already (Fig. 94, p. 125) described and illustrated the first stages of segmentation. The 4 micromeres which are first separated by constriction yield the whole ectoderm; the next 4 or twice 4 in like manner produced form a large part of the later mesoderm. The descendants of the 4 ectoderm micromeres grow round the whole germ by repeatedly dividing, thus enelosing not only the 4 macromeres, but also the 4 or 8 mesoderm mieromeres. They thus form at last a continuous layer of epithelial cells round the whole germ, which is only broken through at the regetative pole by a longitudinal slit corresponding with the ventral medium line of the embryo. This longitudinal slit is defined as the blastopore ; it soon completely closes. The germ is now at the stage of a bilaterally symmetrical planula, in which there is already a formation of mesoderm between the endodermal rudiments (the 4 macromeres, which meantime by division of one of them have increased in number to 5) and the ectoderm.

The 4 or 8 mesoderm micromeres soon increase in number by fission, and thus form either a ring of mesoderm cells or 4 masses of mesoderm cells (2 anterior and 2 posterior). The macromeres, now surrounded on all sides, continue to give of by constriction micromeres, which again increase by fission and yield the intestinal epithelium. The yolk-containing macromeres finally become disintegrated, and the yolk is used up by the intestinal cells. Near the original blastopore a depression of the ectoderm occurs, the stomodrum, as the first beginning of the pharyngeal apparatus. The germ is now, apart from the fact that it is bilaterally symmetrical, at the stage of a Scyphula or a young Ctenophoran larva.

The mesoderm cells extend more and more between the endoderm and the ectoderm; the sensory organs first appear in the ectoderm, on the side opposite the stomodæum, near the original animal pole, but shifted somewhat along the median plane, so that now anterior and posterior ends can be elearly distinguished. These sensory organs take the form of 2 or 3 eyes, and of cells which carry tufts of long hairs. In connection with these sensory organs, which in the case of eyes soon sink down below the ectoderm and become mesodermal, the paired cerebral rudiments arise as products of the ectoderm, and these also soon sink under the surface and become mesodermal. The two rudiments become secondarily connected by transverse bridges. The principal nerve trunks seem to arise as outgrowtls of the cerebral rudiments which form the so-called neural plate.

The ectodermal body epithelium becomes provided with cilia at an early stage. In the centre of the endoderm the enteric cavity arises in consequence of the increasing absorption of the yolk by the endoderm cells, which arrange themselves peripherally like an epithelium. Into the base of this carity the stomadæum soon breaks. The enteric aperture is thus formed. The stomodaum changes in the following way into the definite pharyngeal apparatus. A circular invagination forms in it, the first beginning of the pharyngeal pouch. This is surrounded by a collection of mesoderm cells. Into the pharyngeal pouch the pharynx itself grows as a circular fold, consisting of mesoderm cells and a covering of epithelium. The 
body, which till now has been tolerably round, begins to flatten; the surface in which the mouth lies can as the ventral surface be distinguished from the dorsal surface under which lie the eyes and brain. The mesoderm cells ererywhere spread out between the intestine and the body epithelium, and form a continuous mass, which is thicker at the ventral side. Those layers of mesoderm which lie close under the epithelium yield the dermal musculature; the deeper mesoderm cells yield the body parenchyma, and most probably also the germ-preparing organs of the genital apparatus.

In a series of Polyclada whose embryos leave the egg shell very early as freeswimming Müller's larvæ (Fig. 118), a ring of strong and long cilia which encircles the body arises directly in front of the mouth; this is the so-called preoral ciliated ring, rumning out round 4 or 8 processes of the body, one of which lies immediately before the mouth and one in the middle line of the back, while the
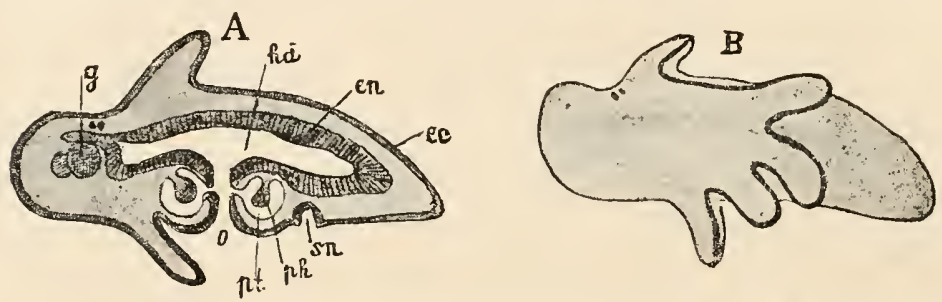

FiG. 118.-Müller's Polyclad larva (of Thysanozoon or Yungia). A, Median longitudinal section. $g$, Brain; $7 d d$, main intestine ; $\iota n$, endoderm; $\ell$, ectoderm ; sn, sucker ; $p h$, phargnx ; $p t$, pharyngeal pouch; $o$, moutl. $B$, The same from the side. The black line indicates the course of the preoral ciliated ring.

other 2 or 6 lie laterally in pairs. These processes, with their strong cilia, are drawn in and reabsorbed when the free-swimming larve sink to the bottom and begin the creeping mamner of life.

The differentiation of the originally single enteron into main intestine and gastrocanals follows in consequence of the growth of mesodermal septa from the periphery more or less far inwards.

The position of the mouth and pharynx on the ventral surface in the adult animal is determined by the relative growths of the anterior and posterior halres. If they grow equally, these organs lie centrally; if the anterior half grows the more strongly, they lie posteriorly; if the posterior grows the more, then they lie anteriorly.

\section{The Life-history of the Trematoda.}

Whereas from the fertilised eggs of the ectoparasitic or monogenetic Trematoda other Trematoda develop direct without their young being assigned to another animal or host than that occupied by the adult, the development and life-history of the endoparasitic or digenetic Trematoda is remarkably complicated. We choose as an example the tolerably complicated life-history of the fluke, Distoma heputicum (Fig. 119), which is parasitic in the liver of the sheep, causing the "sheep rot." The eggs of the fluke leave the liver of the host by the bile ducts, pass into the intestine, and are ejected with the excrement. They only develop when they meet with water. In this case there develops in the egg shell $(A)$ a ciliated embryo, which leaves the 
egg shell and swims about freely $(B)$. It is club-shaped; at the thicker anterior end it has a small median prominence, behind this an X-shaped eye spot, and under this a ganglion, and further a granulated mass which is considered to be the intestinal rudiment. We can also recognise : ciliated cells of the excretory system. The greater mass of the body, however, is formed of germ cells, which are considered to be partheno-
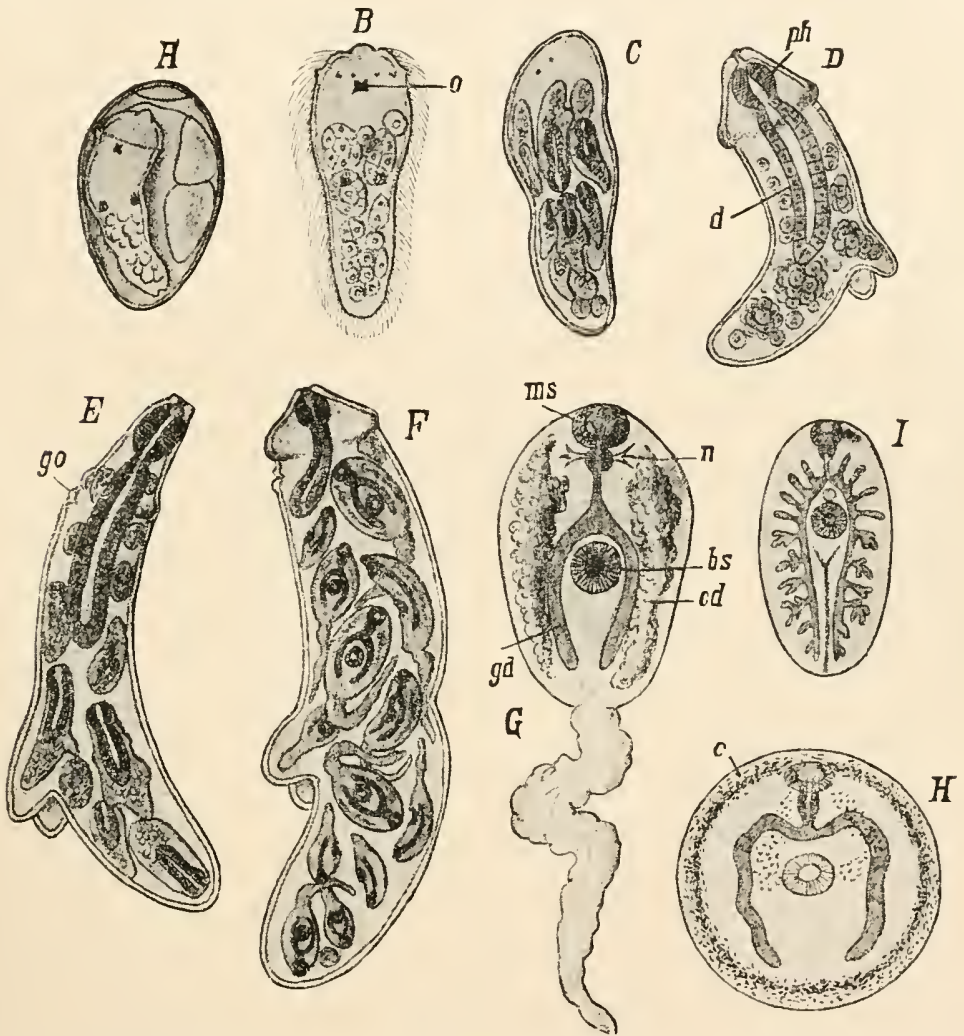

FIG. 119.--Life-history of Distoma hepaticum, after Leuckart. A, Egg with embryo. B, Free-swimming ciliated embryo; o, eye spot. $C$, Sporocyst. $D, E$, and $F$, Rediæ; ph, pllarynx ; go, birth aperture; $d$, intestine. $G$, Cercaria ; $m s$, oral sucker; $n$, nerve ganglia; $b s$, ventral sucker; $g d$, forked branches of the intestine; $c d$, glands, whose secretion yields the cysts. $H$, Encysted young Distoma ; c, cyst. I, Young Distoma in the sheep's intestine.

genetic eggs, possessing the capacity of developing without being fertilised. These germ cells divide (furrow) early, and become cell spheres.

The embryos must meet with a water-snail, Limncus truncatulus, and penetrate into its respiratory cavity in order to develop further. They here lose the covering of cilia; the eyes, the ganglion, and the granulated mass become disorganised. Their bodies represent a pouch, containing 
in its interior a certain number of cell spheres which have developed out of the germ cells or parthenogenetic eggs. Instead therefore of the young animals, which are called Sporocysts $(C)$, developing further into new Distoma, they not only remain at a low stage of development, but they even suffer a considerable degeneration. It seems as if early reproduction were the only function of this Sporocyst. The cell spheres which they contain actually develop again into new germs, which leave the Sporocyst's body as Riedice $(D, E)$, the Sporocyst finally disintegrating, and thus never developing into a fluke. The Redice which have become free, being developed out of the parthenogenetic eggs of the Sporocysts, reach a higher stage of development than their mother. They have at the front end of their body a sucker-like formation, and also a pharynx, a simple intestinal tube, and a birth aperture behind two blunt processes. Here also we find numerous germ cells between the intestine and the body wall; these begin early to develop, i.e. to - divide. The Redice in fact, like the Sporocysts, do not grow into flukes: they first creep about in the respiratory cavity of their host, Limmerus truncatulus, and then penetrate into its liver. The germs which develop in them again become Redice, which pass out by the birth aperture and are parasitic in the liver with their parents. This second generation of Redice $(F)$ again reproduces itself parthenogenetically. From their germs, however, at a warm time of year are developed, not Reclice again, but larve which are called Cercarice $(G)$. These Cercarice already show the structure of a young Distoma; they are flat, have oral and ventral suckers, a pharynx and a forked intestine, a double ganglion joined by a transverse commissure in front of and above the pharynx, both the principal branches of the excretory system, and besides these - and this is characteristic of the Cercarice - a movable caudal appendage. The Cercarice leave the mother body, i.e. the Redice, by the birth aperture, forsake their host, and reach the water, in which they swim about for a time by means of their tail. They then settle upon grasses or plants growing in water in flooded meadows, lose their tail and become encysted by the help of the secretion contained in two very large glands which lie laterally in the body. In this encysted condition $(H)$ they can remain a long time, and can withstand desiccation. They reach the sheep's intestine if occasion offers in the fodder, and there presumably the cyst is dissolved and the young Distoma enters the liver through the bile ducts. Such a young Distoma, with the first branchings of the intestine, is depicted in Fig. 119, I.

The life-history of other endoparasitic Irematoda runs, as far as we know, the same course. The free-swimming Cercaria, however, often enters into a second intermediate host, in which it becomes encysted and loses its tail. This second host is generally an invertebrate animal. The encysted Cercaria enters the body of the final host (generally a vertebrate animal) when the second intermediate host is eaten by the latter.

Several different generations, therefore, follow each other in a 
regular manner in the endoparasitic Trematodt. The generation which multiplies by fertilised eggs always reaches the full degree of organisation of the Trematoda; the following generation, which reproduces itself parthenogenetically and lives in other hosts, never reaches that degree of organisation; they are ripe extraordinarily early, and perish after they have produced another generation, which also remains at an early embryonic stage. The different generations are known as Sporocysts, Redice, and Distoma generations. The regular alternation of such generations is called Heterogeny.

\section{The Life-history of the Cestoda.}

From the fertilised eggs of the Cestoda there proceed, generally while they still lie in their egg shells in the uterus, embryos which, since they are prorided with 6 hooks, are called the 6 -hooked embryos. The fate of this embryo, which only in Bothriocephalus is ciliated and swims about freely in water, is very different in different Cestoda. In T'cenia cucumerina, which is parasitic in the intestine of the dog, it enters the body of the dog louse, Trichodectes canis. It here gets rid of the egg shell and reaches the body cavity, where it develops into a small worm, at one end of which the head develops with its rostellum and its 4 suckers, while at the other the pore of the excretory system can be made out. The head is somewhat sunk into the body. The body is filled with numerous calcareous granules. Te have here simply an unsegmented, not yet sexually developed, tapeworm, which may be compared with a young Amphilina, or Curyophylleus, or Archigetes. Through the dog's habit of licking and cleaning itself, the present host of this young form, which we may simply call scolex, is liable to be swallowed. While the louse is digested, the scolex withstands digestion, the calcareous granules neutralising the acid juices of the stomach. It fastens itself to the intestinal wall, and begins to produce, by terminal budding or strobilation, the chain of proglottides in which the genital organs develop.

In this simple case we have one and the same individual, from the egg to the strobilising intestinal scolex. The 6-hooked embryo, the scolex in the body cavity of the louse, and the strobilising scolex in the intestine of the dog, are the same individual in various stages of development and in various habitats. In most of the Cestoda, in consequence of peculiar complications in the derelopment, this is by no means so clear. In a series of Cestoda, to which Trenia solim and T. saginate belong, the 6-hooked embryo in the tissues of its host changes, by the accumulation of fluid internally, into a vesicle surrounded occasionally by a special capsule or cyst formed out of those tissues. From the wall of this resicle, which is called Finn or Cysticercus, there arises, at the base of an invaginated hollow cone, a tapeworm head with suckers, rostellum, etc. (Fig. 120). While most investigators regard this process as 
one of gemmation, we hold it to be simply one of growth and differentiation. The head with the vesicle is, according to our opinion, a young sexless Cestode answering to the scolex of Tonia cucumerina in the body cavity of the louse, only in this case the trunk or proscolex becomes extended into a large vesicle by the accumulation of fluid before the head of the tapeworm with its suckers, etc., forms. The

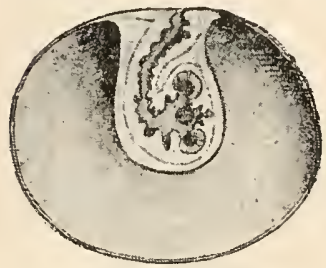

FIG, 120.-Cysticercus cellulosæ. Finn of Tænia solium, cut in half. The scolex, which is invaginated into the vesicle, is seen with its suckers and rostellum. After Leuckart. the form of the first proglottis, which in the developed tapeworm chain at length becomes the last and oldest, and new segments follow this one.

The vesicle of the Cysticercus of different tapeworms varies in size according to the amount of fluid contained. It is sometimes a large sphere, sometimes merely a small swelling at the posterior end of the worm-like Cysticercus.

In a few tapeworms development is complicated by the occurrence of an alternation of generations, the young unsegmented form in the intermediate host, the finn, multiplying asexually by gemmation. On the wall of the finn there thus arise, not only one rudimentary head, but several, indeed very many heads. Such a finn is called a Cœnurus. It occurs in Tania ccenurus. In the finn known as Echinococcus (of T'enia Echinococcus of the $\operatorname{dog}$ ) there arise internally in the vesicular body by invagination of the wall numerous daughter vesicles, and even two generations of such vesicles, on whose walls several heads form.

We must further remark here that asexual scolices living free in water have been observed.

\section{The Influence of Parasitism on the Structure and Development}

\section{of Animals.}

In the race of the Platodes, for the first time among the Metazoa, the parasitic manner of life is met with as a very widely spread phenomenon. Of the three classes which form this race, the two classes of the Trematoda and the Cestoda consist 
entirely of parasitic forms, while most of the Turbellaria live freely. The transition from the free life to the parasitic brings with it such far-reaching changes in the conditions of existence that the original organisation, development, and life-history of the animals must necessarily be strongly influenced by it. This influence can be stated in a way which suits all cases in the animal kingdom where, in a naturally demarcated animal group, parasitic forms appear side by side with free-living forms. Similar variations in the conditions of cxistence have as a consequence similar variations in structure and derelopment.

We can, apart from fine shades of difference in manner of life, distinguish two principal groups of parasites : (1) the Ectoparasites, which are parasitic on the outer surface of other animals, and (2) Endoparasites, which are parasitic in the intestine or other inner organs. The ectoparasites in many ways form the transition from non-parasitic to endoparasitic animals, for they still retain relations to the onter world which the latter have cntirely given $u$ p.

Parasitic life is the most convenient manner of life for the attainment of food. Parasites feed at the expense of the juices or tissues of their hosts, which are abundantly within their reach. Once on or in the host's body, it is of the greatest utility for them to retain the position they have gained. Hence the numcrous and varied adaptations for the attachment of the body. In the Trematoda and Cestoda we find suckers, hooks, and protrusible proboscides armed with barbed hooks and other organs of adhesion. Many parasites possess a sucking apparatus to suck the juices of the host. Trematoda suck with the oral sucker and pharynx the mucus on the surface of the body, or the food pulp in the intestine, etc.

The ectoparasitic Trematoda possess a well-developed alimentary canal, which is often even richly branched; in the endoparasitic forms, which are supplied with food already partly dissolved, the work of digestion is facilitated. The intestine in endoparasitic Trematoda is reduced to two main branches or to a simple cecum; in the Sporocyst generation, which multiplies parthenogenetically, it has become quite rudimentary. Here feeding takes place simply by the diffusion of the juices of the host through the outer skin of the parasite. The same is the case in the Cestoda, which have entirely lost their alimentary canal. We may therefore state that progressive accentuation of parasitism is accompanied by progressive reduction of the gastro-canal system, ending in its entire disappearance.

The capacity of active locomotion is generally of very little use to endoparasites. We accordingly find in them that those parts which serve for locomotion, locomotive organs and musculature, are more or less reduced. On the other liand many ectoparasites (not indeed exactly Platodes) possess a well-developed carracity of locomotion, which is of great importance to them, chicfly for the object of infecting new hosts (e.g. the flea). Very many ectoparasites can, in fact, live a free life for a time. The locomotory system and its musculature are therefore generally less degenerated in them than in endoparasites.

In consequence of the rery limited locomotion of endoparasites the power of directing themselves by special sensory organs is unuecessary, at least while parasitism lasts. The ectoparasitic Trematoda already are far more sparingly supplied with sensory organs than the free-living Platodes. They still possess eyes, although of a very simple sort. The endoparasitic Trematode have lost even these sensory organs, which occur only temporarily in the freely moving young stages of the ciliated larvæ and the Cerearice. In the Cestoda special sensory organs are altogether wanting.

The degree of development of the nervous system depends (1) on that of the musculature, and (2) on that of the sensory organs. We thus understand the gradual simplification of the nervous system, especially the sensory portion, from the ectoparasitic Trematoda to the endoparasitic, and finally to the Cestoda. On 
account, however, of the strong development of the musculature of the organs of adhesion the nervous system in relation with them is more or less strongly developed. Compare the strong development of the nervous system in the head of the Cestodc with its great reduction in the segments.

Parasites seem to have a very slightly developed need for respiration. Judging from what we find in other divisions of the animal kingdom, the respiratory organs very often become degenerated, especially in endoparasites. The parasitic Platodes have no covering of cilia.

The excretory system in the Platode parasites is developed at least as strongly as in the free-living forms.

The genital organs also are as strongly developed, indeed even more strongly developed, in the former than in the latter. Ripe Distoma or ripe segments of Cestoda consist almost exclusively of the genital apparatus and the genital products. But to this we shall return.

We therefore see that with increasing accentuation of the parasitic mode of life there is a proportional reduction of the sensory organs of the nervous systems, of the special digestive system, of the locomotory organs, and also of the respiratory organs, and thus a degeneration of all the organs except the genital and the excretory organs and the organs for adhesion and sucking.

The influence of the parasitic mode of life on the development, and generally on the whole life-history of the parasite, is not less striking.

If the parasite were to remain during life and in all stages of development parasitic on or in the same host, it would perish when the latter died, and the whole race to which it belongs would soon also perish. There must therefore be some provision or other for the infection of new hosts. This infection takes place in the simplest way in most ectoparasites. Many of these retain during youth their free mode of life, so that they can themselves seek out their hosts. Others retain throughout their power of free locomotion, and vividly recall in their mode of life the beasts of prey.

In the ectoparasitic Trematoda very little is known about the manner of infection of new hosts, but we do know-and this is very important-that the course of their development is direct and without intermediate hosts belonging to animal groups different from that of the final host. In the endoparasites the life-history is, as we have seen, more complicated. But here also originally free-living young forms must have provided for the spread of the individuals and the infection of new hosts, and thus for the preservation of the race. The observation of free scolices gives countenance to the presumption that originally a free-living young form, a scolex, developed from the fertilised egg, and in some way or other again found its way into the body of the final host. Most prarasites are specialists, i.e. they thrive only in the bodies of one or of a few definite animal species. It is certain, however, that of their eggs or young forms only very few on the average reach the bodies of true hosts; many perish without reaching any host, many find their way to the wrong place, go astray in the body of a host other than the usual one and there perish, or they may for a time hold their ground and also, as experience shows, develop somewhat further, never, or very seldom at any rate, attaining full development. This perhaps throws light on the origin of development by means of intermediate hosts. Carnivorous animals devour certain animals as their favourite food ; the latter are themselves carnivorous or herbivorous. If the eggrs or young of a parasite accidentally reach the body of an animal which is the favourite food of its proper host, and if they could there remain alive for a longer or shorter time, the probability of their reaching in their new (intermediate) host the intestine of their proper host would be greatly increased. This or some similar advantageous manner of being smuggled into the body of the proper host might become established 
as that most advantageons for the preservation of the race, and would finally become the normal mode of infection.

In the systematic review the intermediate hosts of several Trematoda and Cicstodu are given, as well as the final hosts. The biological relations between the host and the intermediate host can easily be recognised, especially in the case of the Ccstoda.

Occasionally there are two intermediate hosts in the normal course of life. Freeliving young forms, c.g. the ciliated larva of the Trematoda, often effect the transition of the parasite from host to intermediate host, or, as the Cercarice, from intermediate host to definitive host.

In the Cestoda it is possible for parasitism to thrive to such an extent by the passive transmission of varions stages of the parasite from host to host that the animals never lead a free life. The degenerating influence of the parasitic mode of life has here told upon all stages of development.

However refined the artifices for infecting new hosts may be, the result of the process must always to an extraordinary extent depend upon chance. It is a chance when the egg or the embryo of the Distoma hepaticum reaches the water, a chance when it meets a Limneus truncatulus, a chance when the encysted Cercaria, with the plant on which it lies, is eaten by a sheep. Thousands and thousands of eggs thus miss their aim. There is therefore another way of providing for the maintenance of the race in parasites, riz. their extraordinary fruitfulness and their highly developed capacity of reproduction. This capacity is very easy for them, becanse the conditions of existence in which they find themselves are the most favourable possible. A Distoma, indeed a single proglottis of a Tania, is capable of prodncing thousands, or even hundreds of thousands, of eggs and embryos. And if of all these eggs but 1 or 2 on the arerage reach their aim, the maintenance of the race is provided for. Propagation by gemmation comes to the assistance of sexual propagation by fertilised eggs in the segmented tapeworms and in the young forms known under the names of Echinococcus and Conurus.

In those cases also, in the Trcmatoda, where generations living in the so-called intermediate host are not surrounded by conditions so favourable that they can develop into adult Trcmatoda with male and female organs, they still possess the capacity, in spite of their reduced condition, of producing at an early stage a sort of egg, the germ cells; these dispense with fertilisation and nevertheless develop (parthenogenetic reproduction of the Sporocysts and Redice).

When we consider the degenerated condition of the Sporocysts there is some justification for assuming that the Dicyemidee and Orthoncctidee (cf. p. 60), which are very similar to these Sporocysts, are degenerated Trcmatoda from whose life-history the typical Trematodc generation has completely disappeared.

\section{Strobilation and Segmentation.}

We have seen that the bodies of most Cestoda are segmented, and we have shown this segmentation to be the result of an axial budding or strobilation. The whole segmented body is thus an animal stock. In a few Turbellaria, especially in Gunda, segmentation also occurs, but in quite another way; this is the regular paired arrangement of the organs which in the Polyclada and Triclada are generally present in considerable numbers. There is a repetition at regular intervals of the transverse commissures of the nervous system (the ladder nervous system), the male and female sexual glands, the lateral intestinal branches, the dissepiments lying between them, and the external 
apertures of the water-vascular system. Such a segmented body represents a simple Platode individual, not a Platode stock; it does not arise by budding. Strobilation and segmentation are therefore to be clearly kept apart.

\section{Literature.}

L. v. Graff. Monographie der Turbellarien. I. Rhabdocoelida. Leipzig, 1882.

Arnold Lang. Die Polycladen (Secplanarien) des Golfes von Neapel. (Founu une. Flore des Golfes von Neapel XI.) Leipzig, 1884.

Is. Ijima. Ueber Bau und Entwickelung der Süsswasserplanarien (Trieladen). Zeitschr. f. wissenseh. Zoologic. 1885.

R. Leuckart. Die Parasiten des Menschen. 2d edition not yet completed.

Numerous treatises and works by Sieboldt, Leuckart, Pagenstecher, Ercolani, Vogt, M. Schnltze, O. Schmidt, Qnatrefages, Hallez, v. Graft', Selenka, Götte, Wagener, v. Beneden, Zeller, Braun, v. Kennel, Schauinsland, Thomas, Sommer, Landois Pintner, Kiichenmeister, Fraipont, Lang, etc. 


\section{THE ORGANISATION AND DEVELOPMENT OF THE WORMS}

(VERMLS)

The race of the worms is, even after the exclusion of the Platodes, which till now have been included in it, by no means a natural, well-demarcated division of the animal kingdom; now, as heretofore, it is like a lumber room, to which all those groups are relegated which cannot be placed elsewhere. It is therefore difficult to characterise the race of the worms in other than negative terms. All worms are bilaterally symmetrical animals ; their detailed structure, however, is most varied. They are raised above the Colenterata and Platodes by the possession of an anus, and of a blood-vascular system which undertakes physiologically one of the functions of the gastro-canal system of these animals. Where these systems are wanting a secondary degeneration has perhaps taken place. The mouth lies at the extreme anterior end of the body, originally always on the ventral side. A body eavity is either wanting, or is developed in varying degrees. Under the outer body epithelium there is found in all unshelled forms a generally strong muscular layer (dermo-muscular tube). The nervous system is developed in very different ways. The only constant point is the presence of a nerve centre placed above the œsophagus (brain, supra-œsophageal ganglion). There is also generally a nerve ring surrounding the osophagus, the œsophageal ring, from which longitudinal trunks run backwards in varying number, position, and arrangement. All these portions - brain, œsophageal ring, and longitudinal nerves-belong to the central nervous system. Excretory organs (nephridia) are found in all divisions, but under the most different conditions. They often perform the function of conducting the sexual products out of the body. Segmented body appendages (extremities) are as completely wanting as is a specialised muscular organ of locomotion placed on the ventral side (foot). A strictly localised central organ of the blood-vascular system (heart) has been observed only in the Brachiopoda. 


\section{THE FOURTH RACE OR PHYLUM OF THE ANIMAL KINGDOM.}

\section{VERMES.}

\section{Systematic Review.}

\section{Class I. Nemertina (Rhyncocœla).}

Body ciliated, externally unsegmented, elongated, generally somewhat flattened dorso-ventrally. Without distinct body cavity, intestine straight, mostly with lateral diverticula, anus at the posterior end of the body. Above the intestine a proboscidal apparatus, generally emerging in front of and above the mouth. The central nervous system consists of a brain lying between the proboscis and the ceso. phagus, and of two lateral longitudinal trunks. Blood-vascular and excretory systems present. Sexes separate. By regular repetition of the inner organs (lateral intestinal diverticula, circular commissures of the longitudinal nerves, sexual glands) a sort of inner segmentation often arises (Pseudometamerism). Almost exclusively marine.

\section{Order 1. Palæonemertina.}

Head without deep lateral longitudinal furrows. Proboscis without stylets. Mouth behind the brain. Carinella, Polia.

\section{Order 2. Schizonemertina.}

On each side of the head a deep longitudinal groove. Proboscis without stylets. Mouth behind the brain. Lineus, Borlasia, Cerebratulus, Langia.

\section{Order 3. Hoplonemertina.}

Head without deep lateral longitudinal grooves. Proboscis armed with one stylet or several. Mouth generally in front of the brain. Amphiporus, Drepanophorus, Tetrastemma, Nemertes.

\section{Order 4. Malacobdellina}

Head without lateral longitudinal grooves. Proboscis without stylets. One sucking disc at the posterior end of the body. Malacobdella. Parasitic in marine mussels.

\section{Class II. Nemathelmia.}

Body cylindrical, spindle-shaped, or thread-like, unsegmented, covered with a thick cuticle. Body cavity generally spacious. Intestine straight or wanting. Anus at the posterior end of the body. Neither blood-vascular nor excretory system comparable with those of any other worms. Sexes usually separate. Nervous system an cesophageal ring, a medio-dorsal, and a medio-ventral longitudinal trunk. An inner metamerism is wanting, but the circular commissures of the longitudinal nerves may repeat themselves in the Nematoda with tolerable regularity. Mostly parasitic.

\section{Order 1. Nematoda.}

With intestinal canal, without proboscis. Family Enoplido, mostly free-living in the sea, less frequently in fresh water or on land, without cesophageal bulb, often with eyes. Family Anguillulide, small, partly parasitic, partly free-living animals, with double æesophageal bulb, without eyes. Tylenchus scandens, in grains of wheat. Anguillula aceti, in paste, fermenting vinegar, etc. Rhabditis nigrovenosa, in damp 
muddy earth. Sexes separate. The females are viviparous, and produce only a few young ( 4 at most), which, after being hatched, find their way into the lungs of frogs and toads, and there develop into mature her. maphrodite animals (Ascaris nigrovenosa), from whose fertilised eggs the free-living Rhabditis generation again arises. The life-history thus exhibits a sort of heterogeny. Spharularia bombi, the Rhab. ditis-like young form lives in the earth. The fertilised females find their way into the female humble bee, where they are parasitic in the body cavity or in the intestine. The uterus, which is filled with embryos, soon begins to hang out from the female genital aperture, and becomes a large pouch, to which the worm-body finally forms merely a small insignificant appendage. Mermithide, without anus. The young are parasitic in the body cavity of Insects; they make their way out into damp earth, where they become sexually mature and reproduce themselves; Mermis nigrescens.

Filariide: Filaria medincnsis (medina worm), may have a breadth of $0.5-2 \mathrm{~mm}$. and length of nearly a metre ; in the subcutaneous connective tissue of man, in warm regions of the old World. The young in small Crustacea (Cyclopide). Trichotrachelide: Trichocephalus dispar, with swollen hinder body, in the human crecum.

Trichina spiralis (Fig. 121) lives sexually mature as the so-called intestinal Trichina in the small intestine of man and in that of many mammals; is viviparous; the

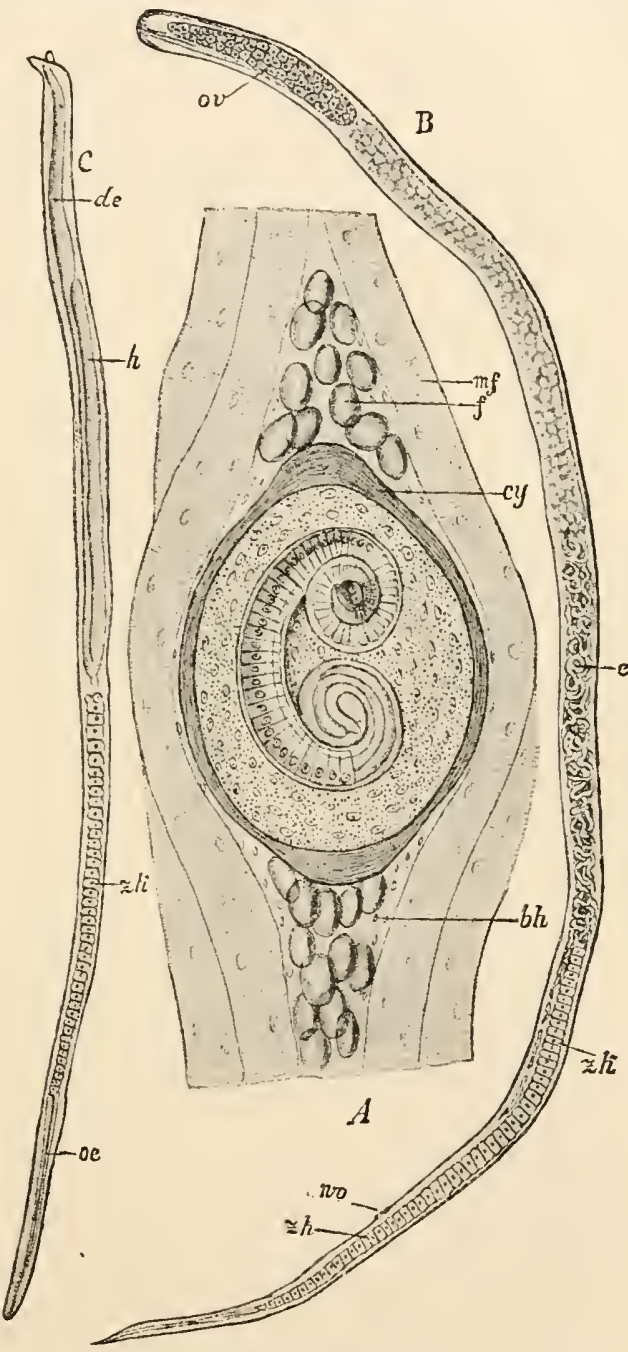

Frg. 121.-Trichina spiralis (after Claus). A, Encysted muscle Trichina; $m f$, unaltered muscle fibres; $f$, fat globules; $c y$, cyst; $b h$, envelope of connective tissue. $\quad B$, Femalo intestinal Trichina ; ov, ovary; $e$, embryos; $z k$, cell bodies (in the post cesophageal division of the intestine); wo, female a perture. $C$, Male intestinal Trichina; $a$, esophagus; $h$, testis; $d e$, ductus ejaculatorius.

female $(B)$ is ca. $3 \mathrm{~mm}$, the male $(C)$ half as long. The young bore their way into the intestinal wall, pass from lere through the body cavity, or with the blood 
in the veins into the musculature, penetrate the muscle fibres, and there surround themselves with a cyst or capsule which afterwards becomes calcareous $(A)$. Encysted muscle Trichince cause triclinosis. Men become infected by eating trichinous pork which is uncooked or not sufficiently cooked. Pigs are much exposed to infection on account of their omnivorous habits. The principal carriers of Trichina, however, are rats which happen to eat the dead bodies of iufected aninals, and so secure the continued existence of the parasites.

Strongylida: Dochmius (Anchylostoma) duodenatis, with strong oral capsule armed with teeth. Female as long as $2 \mathrm{~cm}$., male lialf as long. In the human small intestine (Egypt, Brazil, India, the Antilles, Switzerland, Italy, Belgituu). Chiefly among labourers in pits, mines, or tumels. Causes the so-called miner's anæmia. Eustrongylus gigas, female $30-100 \mathrm{~cm}$. loug. In the pelvis of the kidueys of the dog and other mamulals. Ascaridee: Ascaris lumbricoides, wale up to 25 cul., female to $40 \mathrm{~cm}$. in length. In the human small intestine. Oxyuris vermicularis, female up to $1 \mathrm{~cm}$. in length, male half as long. In the human large intestine. Specially common in children.

The Gordiidee hold an isolated position among the Nematoda on account of peculiarities of inner organisation which will be spoken of in the anatomical portion. The mouth in adult animals is closed, and the intestine partly degenerated. Gordius aquaticus, in the adult sexually mature condition free in fresh water. The embryos find their way iuto insect larvæ, where they become encysted. If these larve are devoured by preying insects which live in water, the embryos develop in the body cavities of these new losts, cscaping into the water as sexual maturity approaches. $30-90 \mathrm{~cm}$. long, $1 \mathrm{~mm}$. thick.

Order 2. Acanthocephala (Fig. 172, p. 258).

Mouth and intestine wanting. At the anterior end a protrusible proboscis armed with hooks. Entirely parasitic. Echinorhynchus: E. gigas, in the small intestine of the pig. Larve in cockchafer grubs.

\section{Class III. Annulata (Segmented Worms).}

Body elongated, cylindrical, or more or less flattened dorso-ventrally. Skin soft, or with more or less hard and rough chitinoid cuticle. Marked metamerism or segmentation of the inner organs ; generally also outwardly visible. The body cavity, with the exceptiou of Hirudinea aud Myzostomida, well developed. The bloodvascular system generally well developed, seldom quite degeneratcd. The intestinal caual ruus mostly in a direct line from the mouth to the terminal auus. The nervous system consists of a brain, an œsophageal ring, and a usually distinctly segmented chain of ventral ganglia. The excretory system (wanting in MIyzostoma) consists of segmentally arranged paired nephridia. Nephridia often perform the function of conducting the sexual products to the exterior.

\section{Order 1. Hirudinea=Discophora (Leeches).}

Body externally ringed. $\Lambda$ definite number of consecutive rings correspoud with an internal segment. Round the mouth an oral sucker, at the hinder end of the body under the anus a ventral sucker. Skin soft. Setæ wanting. Intes. tine mostly with paired lateral diverticula. Body cavity degenerated and communicating with the well-developed blood-vascular system. Numerous pairs of nephridia segmentally arranged (looped canals), which are not used for conducting the sexual products to the exterior. Hermaphrodite: testes in several pairs, seg- 
mentally arranged, with special efferent ducts ending in a single median external aperture. A pair of germaria placed in front of the testes; female aperture behind the malc; both in the anterior end of the body. Parasites or carnivorous; fresh water, in the sea, or on land.

\section{Sub-Order 1. Rhynchobdellidæ.}

With cylindrical tubular pharynx lying free in the pharyngeal ponch, and protrusible through the mouth. Clepsine, Pontobdclla, Branchellion (with gill-like aplendages on the back). The two latter in the sea, parasitic on sharks.

\section{Sub-Order 2. Gnathobdellidæ.}

The pharynx is a muscular thickening of the œsophageal wall, which projeets in to the lumen in the shape of 3 plates or ridges occasionally toothed.

Hirudo medicinalis (the ordinary leech), Homopis Aulastomum (horse-leech), Nephelis. Some Hirudinide live on land. The remaining Gnathobdellide are fresh-water forms.

\section{Order 2. Chætopoda.}

The external segmentation of the body mostly corresponds with an inner segmentation. In special segmentally arranged glandular saccules of the outer integument (setigerous glands) arise setre, which project freely above the skin. Body cavity well developed, separated from the blood-vascular system. The scxual produets develop in special regions of the epithelial lining (endothelium) of the body cavity, into which they generally soon fall, and escape thence through more or less strongly modified nephridia (vasa deferentia, oviducts, genital pouches, segmental organs). The following division is artificial, and is only retained from practical considerations.

\section{Sub-Order 1. Oligochæta.}

The setigerous glands do not open on special blunt processes of the body (parajodia); outer appendages (antennæ, feelers, feeler-cirri, cirri, gills, etc.) arc wanting. Hermaphrodite. Direct development. In fresh water or on land. Fam. Aphanoncura: Aolosoma. Fam. Naidomorpha: Nais, Dcro, Stylaria. Fam. Chotogastridce: Chatogaster. Fam. Discodrilide (posterior end of body modified into a sucker ; parasitic on Crustacca): Branchioblella. Fam. Enchytraida: Pachydrilus, Enchytraus, Anaehceta. Fam. Tubificida: Tubifex, Psummoryctes, Clitellio, Limnodrilus. Fam. Phrcoryetide: Phreoryctes. Fam. Lumbriculide: Lumbriculus, Pihynehelmis, Stylodrilus. Fam. Criodrilida: Criodrilus. Fam. Lumbricides: Allurus, Dendrobena, Allolobophora, Lumbrieus (earth-worm). And the related forms Urocheta, Eudrilus, Acenthodrilus, Pcrichceta, Pleurocheta, Moniligaster.

An uncertain position within the Chatopoda is taken by the so-called Archianineliula (Polygordius, Protodrilus, Ctcnodrilus, Histriobdclla) and Saccocirrusforms whose organisation exhibits simple embryonic characteristics.

Between the Oligochata and the Polyehata stand the families of the Capitcllitle (Capitclla, Notomastus, Dasybranchus), and Ophcliaee (Ophelia, Travisia, Polyoph. thalmus). The first have no blood-vessels. In both the parapodia are much reduced. Gills may be present or absent. Head not distinctly separated.

\section{Sub-Order 2. Polychæta.}

The setæstand on very strongly developed segmentally arranged elevations or parapodia. On the head, antennæ or feeler-cirri ; on the trunk segments, cirri, gills, 
or other appendages, which generally stand on the parapodia. Sexes mostly separate. Development with metamorphosis. Marine.

A. Sedentaria = Capitibranchiata (Tubicolous worms).-Pharynx (proboscis) mostly non-protrusible; without jaws. Eyes wanting, or small but numerous in the head. Parapodia slightly developed, the upper with hair-like seta; the lower are transverse swellings with hooked sete. Gills chiefly on the anterior segments, or limited to the head. Live in various kinds of tubes. Fam. Cirratulide: Cirratulus. Fam. Arenicolide: Arenicola. Fam. Spionide: Spio. Fam. Arieiidee: Aricia. Fam. Chlorhamidce: Siphonostoma. Fam. Terebellide: Lanice (Terebella), Polymnia, Amphitrite. Fam. Serpulidee: Serpula, Sabella, Spirographis, Myxicola, Protula. Fam. Hermellidee: Sabellaria (Fig. 147, p. 221). Fam. Sternaspidec: Sternaspis.

B. Errantia = Dorsobranchiata (carnivorous Amnelids).-Pharynx protrusible, mostly with jaws; head distinct, mostly with a few large eyes. Parapodia well developed. Gills generally on the dorsal parapodia. Free-swimming or creeping animals, many of which live, at any rate at certain times, in tubes of their own making. Fam. Aphroditea: Aplirodite, Hermione, Polynoe. Fam. Amphinomida: Amphinome, Euphrosyne, Notopygos. Fam. Eunieide: Diopatra, Eunice (Fig. 124, p. 18s), Halla. Fam. Nereidce: Nereis, Nephthys. Fain. Glyeeride: Glyeera. Fam. Syllidee: Haplosyllis, Syllis, Exoyone, Autolytus, Nyrianida. Fam. Hesionidec: Hesione. Fam. Phyllodocida: Phyllodoce. Fam. Alciopides: Aleiope, Asterope. Fam. Tomopteride: Tomopteris.

\section{Sub-Order 3. Echiuridæ.}

Body tubular, in adult condition unsegmented or indistinctly segmented, without parapodia, without cirri, without gills. In front, on the ventral side, 2 hooked setre. In the terminal portion of the much-coiled intestine 2 anal glands enter (modified nephridia of the anal region), which may be considered as excretory organs. There are besides 2 or 3 pairs of nephridia, or only one nephridium. Anterior end of the body over the month produced into a long variously shaper mobile prostomium (cephalic lobe) with rentral furrow. Witl blood-vascular system. Sexes separate. Development with metamorphosis. Marine animals with unknown mode of life. Echiurus (Fig. 148, p. 223), Thalassema, Bonellia. The diminutive Turbellaria-like ciliated males of this last species live parasitically in the females.

\section{Order 3. Myzostomidæ.}

Body flat, disc-shaped, extcrnally unsegmented. Margin of the body with cirrusor wart-like processes. On the ventral side, in two longitudinal row's, 5 pairs of parapodia, with hooks and supporting rod. In addition to the parapodia, on each side 4 suckers. Pharynx as in the Rhynchobdellide among the Hirudined. Intestine with branched lateral diverticula. Body cavity reduced. Cireulatory, excretory, and respiratory organs wanting. The nervous system consists of the osophageal ring, and of a ventral chord fuser into a ventral ganglionic mass. The brain is reduced. Hermaphrodites. The oviducts and the intestine together enter a cloaca. The seminal ducts have two separate external apertures on the ventral side. Besides hermaphrodite individuals, there are, in certain species, small males (complementary males). Parasitic on Crinoids (Fig. 175, p. 262).

\section{Class IV. Prosopygia.}

Body naked or shelled, varying greatly in form. Round the mouth a circle of ciliated tenacles, which are often inserted on a common horseshoe-shaped tentacle- 
carrier (lophophore), which may itself be produced into arms on each side. Without parapodia, and mostly without setæ. The anus is nearly always placed far to the front. The intestine runs backwards, but bends forwards again in a loop. Body unsegmented, or quite indistinctly segmented. Blood-vascular system wanting, or developed in varying degrees. Number of nephridia reduced (at the most 2 pairs); they occasionally serve as ducts for the transmission of the sexual products, and emerge to the front not far from the anus. Sexes separate. Only Phoronis is hermaphrodite. Live in the sea; only a few forms in fresh water.

\section{Order 1. Sipunculacea.}

Body elongated, tubular, naked. The front part of the body, which is mostly thinner, can be invaginated like a proboscis into the larger and longer hinder part (trunk) by means of special retractors. Body carity very spacious. Blood-vascular system (?) much reduced or wanting. The central nervous system consists of brain, cesophageal ring, and median rentral longitudinal trunk. Segmentation is perhaps denoted by nerve rings, which are regularly repeated. Live in mud or lurk in loles ; marine.

\section{Sub-Order 1. Sipunculidæ.}

Anus dorsal and anterior, on the boundary between the proboscis and the trunk. Mouth surrounded by tentacles. Usually 2 typical nephridia, opening extemally in the neighbourhood of the anus; also serving as efferent ducts for the sexual products. The vascular system consists principally of 2 tentacle vessels, which accompany the fore-gut. Sipunculus (Fig. 138, p. 208), Phascolosoma.

\section{Sub-Order 2. Priapulidæ.}

Anus dorsal at the posterior end. No tentacles around the moutl. No bloodvascular system. No nephridia. Two anal glands which emerge close to the anus and function in the jounc as excretory organs and in adults as genital organs. Priapulus (at the posterior end a tuft of appendages which probably function as gills), Halycryptus (without this caudal appendage).

\section{Order 2. Phoronidæ.}

Body rermiform, in an attached chitinous tube: Numerous tentacles stand on a horseshoe-shaped base around the mouth. Anus quite to the front, towards the dorsal side, near the mouth. Around the mouth a nerve ring (cesophageal ring). Two nephridia emerging to the front, serving at the same time as ducts for the transmission of the sexual products. A simple blood-rascular system present. Hermaphrodites. Single species: Phoronis.

\section{Order 3. Bryozoa.}

Small animals. Anus towards the dorsal side, near the mouth. A cerebral ganglion between mouth and anus. Nephridia, when present, in one pair of embryonic type, emerging near the mouth and not acting as ducts for the transmission of the sexual products. Numerous tentacles on a base, which is often horseshoe-shaped, around the mouth. Form, mostly by gemmation, variously shaped attached stocks.

\section{Sub-Order 1. Pterobranchia.}

Tentacle-carrier lengthened out on each side into a long arm-like process directed dorsally and posteriorly, and carrying the little tentacles in two longitudinal rows along its whole length. Intestine limited to the swollen anterior part of the body, 
which is prolonged backwards like a stalk. Body cavity little developed. Colonial, in tubes which raise themselves on a common creeping stem. Rhabdopleura, Cephaloctiscus is a related form.

\section{Sub-Order 2. Ectoprocta.}

Anal opening outside of the tentacle carrier. Tentacle carrier not produced. Anterior body naked, posterior body shelled. Without stalk. Anterior body so enveloped in a fold of the posterior body as to be either temporarily or permanently surrounded by a sheath (tentacle sheath) out of which it can be protruded. Body cavity tolerably spacious. Shell often calcareous. Colonial. Phylactolamata.

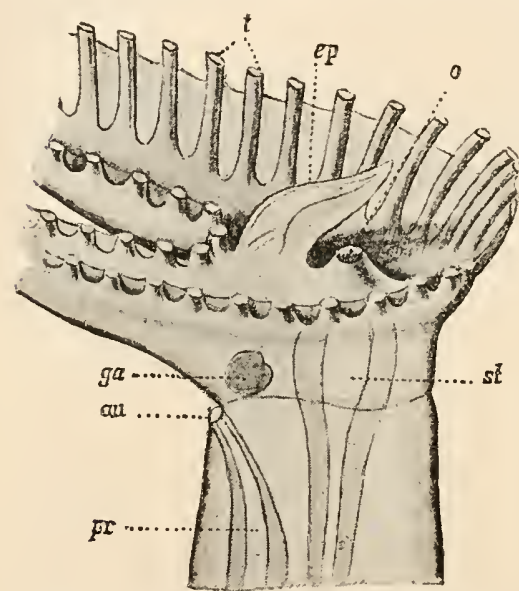

FIG. 122.-Anterior body of Lophopus (after Allman), from the right side. $t$, Tentacles cut off near the base; 0 , mouth; $e p$, epistome; st, foregut; gc, ganglion; an, anus; $p r$, hind-gut. The free ends of the tentacle-carrier are cut off.

Tentacle carrier horseslioe-shaped. Inhabit fresh water. Cristatclla, Alcy. onella, Fredericclla, Lophopus (Fig. 122), Plumatella (Fig. 139, p. 208). Gymnolcmata. Tentacle-carrier cireular. Live, ${ }_{\mathrm{f}}^{\mathrm{f}}$ with the exception of Paluclicella, in the sea. Cellepora, Eschara, Bugula, Flustra, Alcyonidium, Hornera, etc.

\section{Sub-Order 3. Entoprocta.}

Anal opening inside the tentacle carrier. A tentacle sheath wanting. Body stalked. With one pair of nephridia. Body cavity reduced. Pedicellina, colonial. Loxosoma, living singly. Marine.

Order 4. Brachiopoda (Fig.178, p. 269).

if The dorsal and the ventral body walls form a fold directed to the front, so that the body is covered by dorsal aud ventral mantle folds, which may coalesce behind and at the sides. The mantle folds secrete calcareous, and occasionally horny shell valves, a dorsal and a ventral. The veutral valve is generally the more concave. At the sides of the mouth are inserted the two long oral arms set with lateral cirri; these arms lie spirally rolled up in the mantle cavity, which is formed by the mantle folds, and are often supported by a special calcareous skeleton united to the dorsal valve. Anus wanting, or lies asymmetrically and anteriorly, to the right, near the mouth. In Crania only it lies quite behind, in the dorsal middle line. Central nervous system is an osophageal ring with weakly developed brain and infra-cesophageal ganglionic swellings. One pair (less frequeutly two pairs) of nephridia, at the same time ducts for the transmissiou of the sexual products, open to the right and left of the mouth into the mantle cavity. Blood-vascular system probably present, with a heart placed above the intestine. The posterior end of the body is often prolonged into an attached stalk, which emerges either between the shell valves (Lingula), or through a hole in a posterior upward bulging of the larger ventral valve. In many cases the stalk is wanting, and the shell is fasteued to the surface on which it rests direct by the ventral valve. Exclusively inhabitants of the sea. The larger proportion of the species and geuera are fossil. The species Lingula has maintained itself since the Paleozoic epoch. 


\section{Sub-Order 1. Testicardines.}

The shell valves are hinged together by interlocking processes. An amus is wanting. Terebratula, IValdheimia, Theidlum (attached by the larger shell valve). Argiope, Rihynconella (Fig. 125, p. 191), Spirifer.

\section{Sub-Order 2. Ecardines.}

Without hinge. Intestine with anus. Crania, Lingula.

Class V. Rotatoria (Wheel Animalcule, Fig. 123 ; Fig. 161, p. 245).

Small, mostly microscopic animals. Inner segmentation wanting. At the anterior end a variously shaped ciliated organ (wheel organ); posterior end prolonged in a frequently segmented appendage (foot-stalk). Cloacal aperture dorsal on the boundary of body and foot. A vascular system wanting. One pair of nephridia, of the embryonic type, with several inner ciliated cells, emerge with the anus and the oviduct into the cloaca. Sexes separate. The males small, with degenerated alimentary canal. Chiefly fresh-water animals. Forms living in attached tubes or envelopes: Floseutaria, Stephanoecros, Melicerta, Laeenularia. In these the wheel organ is produced into lobes or tentacles. Free-living forms : Notommata, Hydatina (Fig. 161, 1. 245), Brachionus (carapaced), Asplancha, Seison (1)arasitic on Nebalia).

We must place near the Rotatoria the peculiar species Dinophitus (Fig. 162, p. 246), which has the same appearance as certain annelid larvæ. Male and female are alike, or the male is smaller, without intestine. The whole ventral side of the body is ciliated. Besides this there are several ciliated rings lying one behind the other on the body. A wheel organ is wanting. Nephridia in segmental arrangement of the embryonic type.

\section{Appendage to the Race of Vermes.}

\section{Class VI. Chætognatha (Fig. 152, p. 227).}

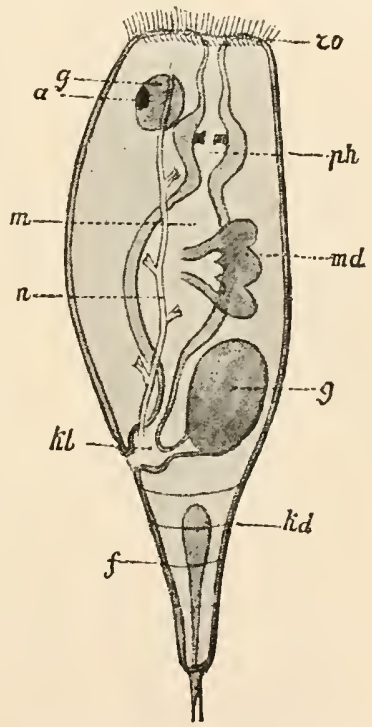

FIG. 123.-Diagrammatic representation of the organisation of a Rotifer, from the side. ro, Wheel

Body cylindrical, elongated, with horizontal border of fins (lateral fins, caudal fin) round the posterior body. Head tolerably distinctly separated from the trunk. Body cavity spacious; divided by organ; $g$, brain ; $a$,eye; $p h$, pharynx; $m$, stomach; $n$, nephridium; ind, gastric gland; $g$, genital gland; $k l$, cloaca; $k d$, cement gland of the foot $(f)$.

partition walls into three consecutive parts-head

earity, trunk eavity, and tail cavity. Mouth surrounded by setre (jaws). Intestine straight, anus ventral, at the commencement of the tail. The central nervous system consists of the brain, the esophageal commissures, and a large ventral ganglion lying in the trunk. Without vascular system. Hermaphrodites-ovaria in the trunk cavity, testes in the caudal cavity. Paired efferent ducts (transformed nephridia?) emerge to the right and left at the end of the trunk and of the tail. Live in the sea. Sagitta, Spadella. 
Among the worms, generally near the Rotatoria, we place the little group of the Gastrotricha. Small animals witl ciliated ventral surface; with pointed processes arranged in longitudinal rows on the dorsal surface. Posterior end running out into two lateral points. Intestine straight, the mouth followed by a nuscular pharynx. Anus at the posterior end. Hermaphrodites. Nephridia insufficiently known. Blood-vascular system wanting. Iehthydium: principally inhabitants of fresh water. The Echinodera, which are often placed near the Nematola, are minute marine animals without cilia, with ringed bodies; with setre. Inner organisation not sufficiently known.

The phylogenetic relations of the worms are still a subject of much dispute. There are many different views. The Nemertina form a natural well-demarcated class which in many points of their organisation (nervous system, excretory system, absence of body cavity) recalls the Turbellaria, but they are raised above the Platodes by the possession of a blood-vascular system and an anus. The pseudo-metamerism of the Nemertian borly is similar to that of certain Turbellaria (Trielada). The systematic position of the Nemathelmia is quite uncertain. Their ancestors were probably more highly developed worms, in whom adaptation to the parasitic mode of life has led to degeneration. Perhaps the Gordiida among the now living Nematoda are the nearest to the ancestral form. The Ammulata form a large group extraordinarily rich in forms, in which the typical segmented condition of the body may be regarded as primitive. The Myzostomido, Echiurida, many simply organised Chotopoda, and iu some respects the Hirudinea, are to be regarded as one-sidedly developed, partly simplified or degenerated forms. Opinions are very divided as to the racial history of the whole class. Nany investigators, anong whom we include ourselves, hold the segmentation (metamerism) of the Annulate body to be a continuatiou of the pseudo-metamerisin of animals resembling the Turbellaria and the Nemertina. Others consider the Annulate body as a sort of animal stock, which has arisen by axial buddiug. They see in the Rotatoria the nearest approacl to the unsegmented (not budding and not stock forming) racial form, while we, on the other hand, are inclined to consider the wheel animalcule as simplified animals which attaiu sexual maturity at an earlier stage of development, so that they now no longer rise above the degree of organisation of a young Annelid larva. The class of the Prosomygia falls into a few natural orders to some extent sharply distinguished from each other ; their organisation is in many respects quite comprehensible, if we refer it back to an old adaptation to a more or less attached mode of life, and bear in mind the degenerating action of shell, case, or tube formations on the bodies of segmented worms originally luore highly developed. The systematic position of the Chotognatha also is very uncertain. They are, perhaps, best considered as Annulatc with a small number (3) of segments. It has till now been impossible finally to decide the systematic position of Gastrotricha and Echinodera.

\section{Form of Body and Outer Organisation.}

The body of the Nemertina is elongated, ribbon-shaped, being more or less flattened dorso-ventrally; it is ciliated all over the surface, soft skinned, unsegmented, and without outer appendages. The mouth lies ventrally at or near the anterior end of the body, and in the form of a longitudinal slit. In front of it, and generally quite at the foremost end of the body, is the proboscidal aperture. Moutl 
and proboscidal aperture are united into a single external aperture only in Amphiporus, Malucobdella, and Geonemertes palaensis. On each side of the head there is often a strongly ciliated longitudinal furrow or lateral cleft. The anus is terminal. In the parasitic Malucobdella the posterior end forms, in front of and under the anus, a ventral sucker disc.

The body of the Nemathelmia, which is covered by a rough, frerpuently ringed cuticle, is elongated and spindle-shaped, without outer appendages, and with at the most small papillæ or small fringes at the anterior and posterior ends. Mouth and anus are, when present, terminal. The Acanthocephala possess at the anterior end a proboscis which can be withdrawn into a special sheath, and which is provided with looks directed backwards; this serves for attachment to the intestinal wall of the host. The males have at the posterior end a protrusible copulatory organ, which, when protruded, is bell-shaped.

The various classes of the Anmulata must be dealt with separately.

The body of the Hirulinea is long, and generally flattened dorsoventrally; less frequently it is cylindrical (Pontobdella, Piscicola). Round the mouth there is a small oral sucker and posteriorly, always under the anus, a ventral sucker, which is usually larger than the oral. The body is divided by furrows into numerous consecutive rings; these do not, however, correspond in number with the inner segments. In all the Hirudinea the number of the latter corresponds with the number of the ganglia, and is 33 . The number of rings to a segment in the central part of the body is typical for the various genera and species. Among the Phynchobdellide it is 3 (Brenchellion, Clepsine), or 6 (Calliobdella, Ichthyobdella, Pontobdella), or 12 (Piscicola); among the Gnathobdellide it is 5. In all Hirulinea the segments are shorter at both the anterior and posterior ends of the body, the number of rings in them being gradually reduced. Where the separate rings of the typical central segments are in any special way externally marked, the marks are repeated in regular succession throughout the body, i.e. when such marked rings have not disappeared in the shortening of the segments. These marks take the form of tactile papille, warts, protuberances, pigment spots, nephridial apertures, etc. The large protuberances on the integument of Pontobdella play a most important part in the dermal respiration. In Branchellion, on each side of each ring in the middle region of the body, there is an integumental appendage which functions as a gill. The appendages on the first ring of each segment swell at their bases and form contractile vesicles.

In the Choetopoda the outer segmentation generally answers to the inner. The former is most distinctly to be recognised by the arrangement of the setre, which are repeated in strict accordance witl the segments. The setre generally stand in groups. Every segment, except the oral, carries typically on each side two bundles of setx, one dorsal and the other ventral. 
The shape, number, and arrangement of the setre vary in details to an extraordinary degree, and are of the greatest significance for classification. Setæe are wanting only in a few Chotopock, as in the Enchytraidee (Anacheta) and in Brachiobdclla among the Oligochate, in the so-called Archiannclida (Polygordius, Protodritus, etc.), and in the Tomopteridce. In Chectogaster the dorsal rows of sete are wanting; and in Saccocirrus also only one longitudinal row is found on each side. In the stationary Polychcta each ventral bundle of setæ is developed in the form of a transverse row of short hooks. The bundles can break up into their component

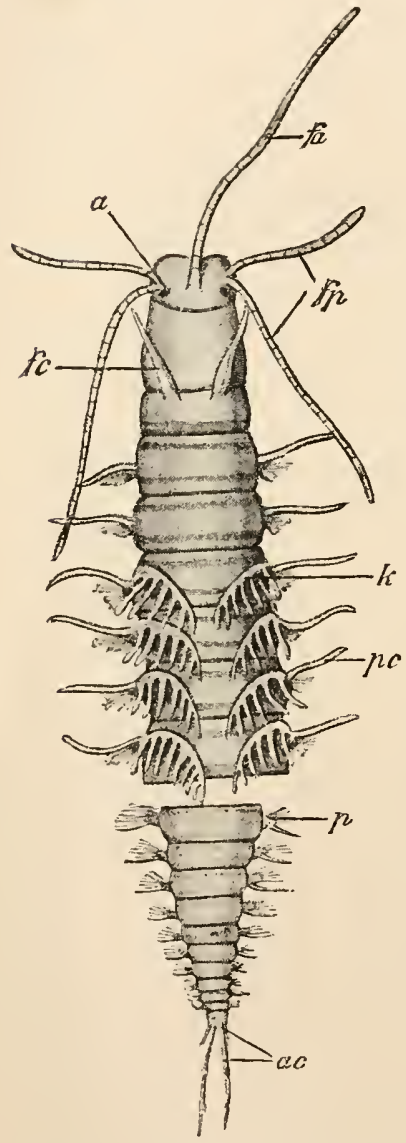

FIG. 124. - Eunice limosa (after Ehlers). Anterior and posterior ends of the body; dorsal side. $f a$, Unpaired feeler; $f p$, paired feelers; $a$, eyes; $f c$, feeler-cirri ; $k$, gills; $p c$, dorsal parapodial cirri; $p$, parapodia; $a c$, anal cirri. parts, the setæ being arranged in Pcrichceta in a single row round the segment. The setre may disappear in certain regions of the body. They are specially reduced in number in the Echiuricte (see systematic review).

The bundles of setæ stand either simply in the integument, or on special elevations of the body wall, the so-called parapodia (Fig. 158, p. 237). The former is the case chiefly in the Oligochatu and Echiuride, the latter in most of the Polycheta. The parapodia are well developed as strong rowing and locomotory organs principally in the Errantia, while they are reduced in the Sedentaria, especially the ventral parapodia, which are for the most part insignificant ridges carrying hooks. In a few tube-worms (e.g. Seipulidec) the parapodia are entirely obliterated, no cloubt in adaptation to the tubicolous manner of life. They are also wanting in the Archiannelida. We do not always find separate ventral and dorsal parapodia ; there is often on each side only one row of parapodia. We then, however, find in each parapodium a dorsal and a ventral branch. Whether the uniserial or the biserial arrangement is the original camnot yet be decided.

In the Polychate the parapodia themselves again carry characteristic appendages (Fig. 124). These are the cirri, unsegmented or segmented filaments, one of which, in the simplest cases, occurs on each parapodium. We can thus distinguish dorsal and ventral cirri. The cirri may undergo the most varied transformations. Thus the dorsal cirri, or their lateral branches, frequently become gills, which are often delicately branched and provided with 
blood-ressels. In the Aphroditide they become broad dorsal scales (elytra). In some cases (e.g. Cupitellide, Glyceride) the dorsal parapodia may carry, besides the typical cirrus or the cirrus transformed into a lateral organ, a gill, which, in contradistinction to the gill which arises from the cirrus, is called a lymph gill; it is provided with hæmolymph by continuations of the body cavity (in the absence of a bloodvascular system). The cirri may stand at the base of the parapodia, or may even move away from them. They may even be retainełl in those cases where the parapodia disuppear.

The head of the Polychete is characterised by special appendages, the front ones being called feelers, the back ones feeler-cirri. They never stand on parapodia, which are just as constantly wanting in the true oral segment as are setæ. In most of the delicate tubicolous Polychete a reduction of the parapodial cirri or parapodial gills goes hand in hand with the reduction of the parapodia on the trunk; they are retained only in the anterior segments. In the Serpulide all the parapodial appendages are reduced, and therefore the head appendages are transformed into greatly developed tentacle gills which often form a stately crown. In Sternaspis on each side of the anus there is a tuft of gills.

In the Oligocheta, Archiannelida, Echiuride, and some of the CapitelTide, not only the parapodia but their appendages (cirri, gills) are wanting. Only, Alma niloticu, a very insufficiently known Oligochete which is found in muddy ditches in Egypt, carries dorsal gills on the hinder part of its body. In all these divisions the head appendages are also wanting. Only the Archiannelida (Polygordius, Protodrilus) possess two feelers at the extreme front of the head. In the Echiveride the head is produced in front of and over the mouth into a long process provided with a longitudinal furrow or channel on the rentral side (proboscis, prostomium); this in Bonellia is forked at its end.

The inner segmentation is reflected outwardly in most Chcetopoda, not only by the regular repetition of the setæ (and the parapodia of the Polychet(a), but also by an outer division of the body into rings, which is caused by the occurrence of more or less distinct regularlyrepeated constrictions. These constrictions are generally found between 2 consecutive segments, and thus the rings, in number and position, answer to the real segments. It only seldom occurs that each segment is again ringed. In many of the lower Oligochceta, indeed in the Archiannelida and some of the Echiuride, no distinct mark of rings or segmentation is recognisable on the integument.

The body of the Chatopoda is outwardly either homonomously segmented, i.e. all consecutive segments of the trunk are alike, or heteronomously segmented, when the segments in different regions are differently developed, both as concerns their outer shape and their provision with various setæ, parapodia, cirri, gills, etc. We can in the latter case distinguish different regions of the body (e.g. thoracic region, branchial region, abdominal region, etc.) The integument of the Chceto- 
poda is covered with a chitinous cuticle which is specially strongly developed in the Polychcota Errantia. The cuticle is weaker and much more delicate in most of the Oligocluceta which live in mud, and in the tubicolous Polycluceta.

For the general form of body and outer organisation of the Myzostomidee compare the systematic review.

The form of the body in the Prosopygia is extremely varied. The most important points have already been referred to in the systematic review. The body is as little segmented externally as internally.

In the Sipunculacea (Sipunculus, Priapulus, Halicryptus) a regular outward ringing of the trunk occurs. The rings, at least in some cases, correspond with the muscle bundles of the circular musculature and with the lateral nerves which proceed from the ventral strand. In Sipunculus there are, in addition to the circular furrows on the trunk, still deeper and more distinct longitudinal furrows, so that the whole skin seems divided into regular die-shaped areas. There are similar longitudinal furrows on the "proboscis" of Priapulus. Papillæ are very wide spread on the bodies of the Sipunculacea, principally on the proboscis.

A closer comparison of the proboscis of the Sipunculacea with the similarly named organ of the Eclivuridee (which formerly were united with them in the class of the Gephyrea) shows great morphological difference between the two organs. The proboscis of the Sipunculacea is the front portion of the body, which can be invaginated into the hinder portion. The mouth lies at its anterior end. The proboscis of the Echiuride is a prolongation of the head portion (prostomium), which lies in front of and above the mouth and cannot be invaginated. The mouth lies at its base. In the proboscis of the Sipunculacea runs the fore-gut, while the fore-gut is in no way connected with the prostomium of the Ecliviridce.

The Sipunculacea possess a rough cuticle; in Phoronis it is delicate, and the skin therefore secretes a detached chitinous envelope, which serves as a dwelling tube. The Bryozoa generally form a rough hard cuticle (cell, ectocyst) whose aperture can be closed by a cover, and which often calcifies. In a similar way the mantle of the Brachiopode secretes a bivalve shell which is generally calcareous, less frequently horny.

This shell of the Bractiopoda (Fig. 125) cannot be compared with the similarly bivalved shell of the Mussel (Lamellibranclicata, Cochlide). The two shell valves of the former are dorsal and ventral; each valve is symmetrical; the median plane of the body divides each valve into two lateral congruent halves. In the mussels, on the contrary, we distinguish a right and a left shell. The median plane passes between the two shell valves. Each valve is asymmetrical. The gaping edge of the shell in the mussels is ventral, in the Brachiopodu anterior; the closed edge where the two valves 
are joined by a hinge is dorsal in the mussels, in the Brachiopoda it is posterior.

We have already, in the systematic review, said what is most important concerning the oral tentacles and oral arms, which are very characteristic of the Prosopygia; the various positions of the anus were also described. Refer to it also for the outer form and organisation of the Rotetoria and Chectognatha.

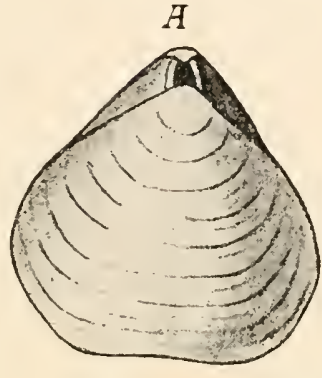

FIG. 125.-Rhynconella psittacea. $A$, From above. $B$, From the left side.

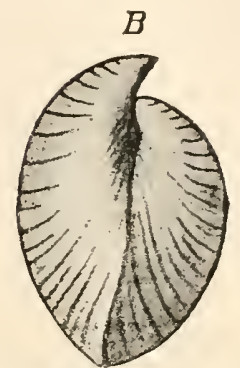
de.

\section{The Integument.}

The integument of the worms consists first of the outer cuticle, and second of the subjacent body epithelium, which secretes the cuticle, and which in most worms (just as in the Arthropoda) is called the hypodermis.

The cuticle is very variously developed. It is thin and delicate in the soft-bodied forms, especially in the Nemertina, where it is perforated by very fine pores to allow the cilia to pass through. Where it is strongly developed, as in many Annulata, Prosopygia, Nematoda, and Rotatoria, it gives protection and support to the body, and as skeleton offers support and surfaces of attachment to the body musculature. It consists of a substance allied to chitin, and occasionally calcifies (in Bryozoa, Brachiopoda) into a very hard envelope or shell. It often shows stratification, and seems to be composed of various crossing systems of very fine adhering fibrillæ. It may in general be conceived of as a secretory product of the glandular hypodermis cells which underlie it, or as a product of metabolism of the protoplasm of these cells. To the same category as the cuticle belong various sorts of tubes and envelopes which, detached from the integument, surround the bodies of many Annelida (tube-worms) and possess a chitinous substratum. We must further consider the setæ of the Chatopoda as cuticular formations of certain hypodermal glands, which can be seen, at least when they first appear, to be composed of fibrillæ and fibres in close contact and glued together.

The cellular hypodermis, which usually consists of one layer, can best be examined in the Anmulata, where it is composed of the two following principal elements-(1) gland cells; these are naked and large, and yield the material for cuticular formations; over each gland cell there is generally a pore in the cuticle; (2) thread-like cells; these are generally slender cells whose protoplasm is strongly modified and falls into fibres. They often lose their nuclei, and are arranged round the gland cells in such a way as to form for the 
latter a loose supporting tissue, in whose meshes the gland cells lie. Gland cells of the hypodermis form the chief component part of the subdermal setiparous sacs of the Chcetopoda; these are the setiparous glands which produce the setre.

The setiparous glands may undergo important transformations. In Polyodontes (Aphroditidee), for example, the setiparous glands of the dorsal branch of the parapodia are changed into large spinning glands, whose thread-like secretion yields the material for the structure of the tubes they inhabit. In Aphrodite the dorsal setiparous glands produce setie and hairs, which form the hairy felt covering the respiratory chambers. The setiparous glands may again become simple dermal glands. Anachatu, for example, no longer possesses setæ, but, in place of the 4 rows of setie of the related Enchytrceus species, has 4 rows of flask-shaped hypodermal glands projecting into the body cavity. The mucous glands are peculiar dermal glands which are common, especially in naked and soft worms (Nemertina, Hirudinea).

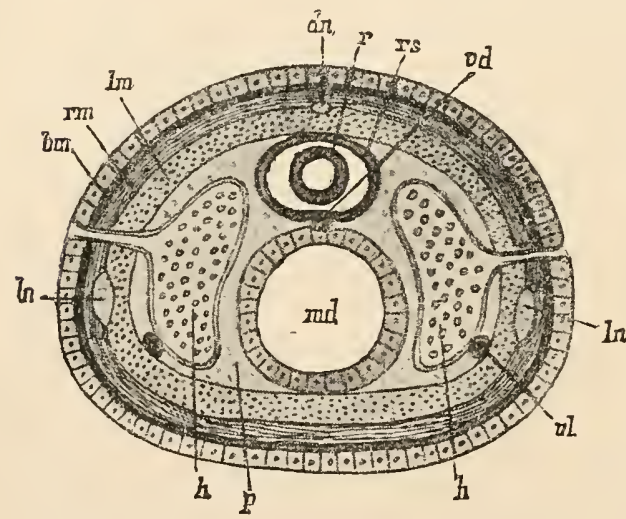

Fig. 126.--Transverse section through the middle part of the body of a Nemertian, half diagrammatic. $\ln$, Lateral longitudinal nerves; $d n$, medio dorsal nerve; $b m$, basal mem. brane; $r m$, circular muscle layer; $l m$, longitudinal muscle layer; $r s$, proboscis sheath ; $r$, proboseis ; $v d$, dorsal vessel ; $v l$, lateral vessels; $h$, testes ; $p$, parenchyna ; $m d$, mid-gut.

The hypodermis may be very insignificant in comparison with the cuticle. Its elements may fuse into a subcuticular layer of protoplasm. In the Gordinde among the Nemathelmia we still find it clearly developed into an epithelial layer at the anterior and posterior ends of the body, while in the rest of the body it is reduced to a subcuticular finely granulated layer containing scattered nuclei. In this reduced form we meet with the hypodermis in all other Nemathelmia, where it is often hardly recognisable. It seems here to be almost entirely taken up in the formation of the strong cuticle. The same is the case in the Bryozoa.

In the Hirudinea and in most Oligochceta, as sexual maturity begins, the hypodermis undergoes a peculiar metamorphosis in a series of the segments near the genital apertures (in the Hirudinea always the tenth, eleventh, and twelfth.) The gland cells here swell greatly and come to lie in several superimposed layers, and there thus arises a girdlelike thickening of the body which is outwardly visible (the clitellum).

In the gill-less Annulata (higher Oligochceta, Hirudinea) capillaries of 
the blood-vascular system may penetrate as far as into the hypodermis, and so enter the service of the general cutaneous respiration.

In Chcetopoda, a plexus of ganglionic cells lying immediately under the hypodermis can be demonstrated, which is connected by nerre fibrillæ with the threatl-like cells of the hypodermis.

In many worms (Aphanoneura, Aichiannelida, Saccocimus, Opheliacea, various Polychete of families widely separated, and further in the Priapulide, Phoronida, and Sagitta) the central nervous system lies in the hypodermis in such a way that no sharp distinction can be seen between the usual hypodermis cells and the nerve elements. In many Anmulatu whose central nerrous system lies under the hypodermis, the former nevertheless passes into the hypodermis at the most anterior and posterior ends, the anterior part of the brain into the hypodermis of the prostomium, and the most posterior end of the rentral chord into the hypodermis of the tail segment.

The sensory organs of most worms, which will be described elsewhere, belong to the hypodermis.

The hypodermis is often separated from the underlying tissues by a thin supporting or basal membrane.

\section{The Dermo-muscular Tube.}

Immediately under the outer integument in most worms the body musculature lies in the form of a dermo-muscular tube, which repeats the shape of the body. It consists in general of two well-dereloped layers, an outer layer of eireular fibres and an inner layer of longitudinal fibres.

These two layers are found in all Nemertina, except Cephalothrix, where the circular muscle layer may be wanting. In the Schizonemertina, and further in Polic and Fulenciniu, there is, in addition, an outer longitudinal layer, which may eren be more strongly developed than the inner layer; in Curinina, Cuinella, and Curinoma there is also an additional circular layer. All these layers form in the Nemertina a continuous tube, nowhere broken through in any way worth mentioning.

Among the Temuthelminths, all the Tematodu possess only the longitudinal muscular layer (Fig. 127, $(m)$. This is broken through in 4 lines rumning in the longitudinal direction, and thus falls into 4 longitudinal portions. Two of the 4 longitudinal lines are median (dorsal and ventral) and 2 lateral. In these lines of interruption the subcuticular granulated dermal layer (hypodermis) is thickened, and in it lie definite organs of which we shall speak later. In the Gordiide the ventral line only is clearly marked.

In the Acunthocepluta, besides the longitudinal muscular layer, an outer circular muscular layer is added.

In the Annulata the dermal musculature almost everywhere appears in the typical form. The circular layer is rery rarely 
(Archiannelida) wanting. Other layers are, however, sometimes added to the two typical layers, for instance, a layer of fibres which cross

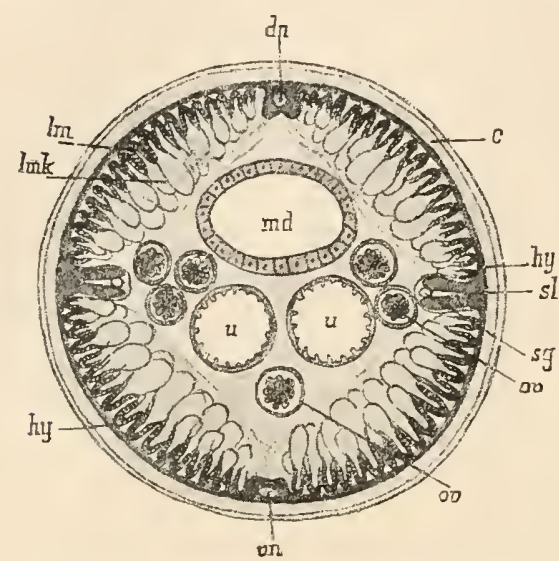

Fig. 127.-Transverse section through a Nematode (Ascaris). $(l n$, Medio-dorsal, $v n$, medio-ventral longitudinal nerve in the line which represents the midrle line of the borly; sl, lateral lines; $c$, cuticle; $h y$, hypodermis; $s g$, lateral vessels; ov, ovarial tubes; $l m$, longitudinal inuseulature; $l m k$, cell elements of the longitudinal muscular fibres; $u$, uterus; $m$, mid-gut.

strongly developed than the circular musculature.

The dermal musculature of the Myzostomide is difficult to make out. We may perhaps distinguish: (1) a system of fibres which radiate from the centre to the circumference; (2) a system of fibres concentrically arranged, and rumning parallel to the edge of the body. The first system must represent the circular musculature of the Anmulatu, the second their longitudinal musculature.

The various groups of muscles which serve in the Chcetopodu for moving the bundles of setre, the parapodia and their appendages, must be regarded as special local modifications of the dermal musculature. In the Sternaspide, as in the Sipunculide, we find parts of the longitudinal musculature differentiated into dorsal and ventral retractors of the anterior introvertible portion of the body.

The general body musculature is developed in a very different manner in the Prosopygia. The naked Sipunculacea possess a strong and typically developed dermo-muscular tube, consisting of an outer circular and an inner longitudinal layer (Fig. 128). Between these two, in the Sipunculide, a thin layer of diagonal fibres is interposed. The longitudinal and circular muscles generally run in regular bundles or bands lying side by side, and these correspond with the outwardly visible longitudinal and circular ridges. The 
longitudinal musculature supplies the retractors of the proboscis (Fig. 138 , p. 208); the number of these retractors varies, and is of great importance for classification; they are attached to the dermo-muscular tube on the one hand at the anterior end of the proboscis (anterior portion of the head), and on the other at the anterior or middle portion of the trunk, and rum freely through the body cavity.

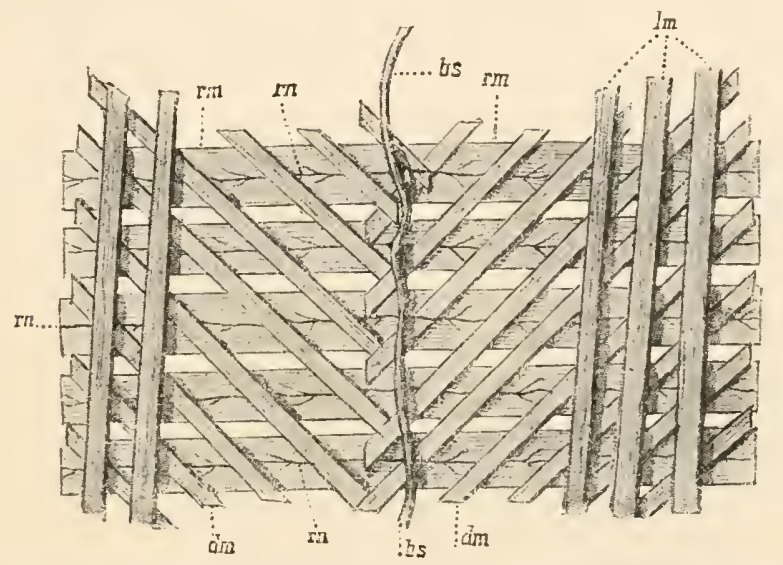

Frg. 12s.-Portion of the musculature of the body wall of Sipunculus, diagrammatic (after Andreae). lin, Longitudinal museles, partly left out; rm, circular muscles; d $m$, diagonal muscles, cut away in the mirldle line; $b s$, ventral chord ; $r$, nerve rings.

In the Phoronide which live in chitinous tubes there is a typical bilaminar dermo-muscular tube.

In the Bryozou we can no longer speak of a dermo-muscular tule. Its extreme reduction is to be referred to the development of a stiff skeleton (shells, cells, ectocysts), which deprives a dermo-muscular tulse of its function. Only such portions of the general musculature remain as are necessary for the withdrawal and protrusion of the soft-skinned anterior end with its tentacles, or (Phabdopleura) for the contraction of the stalk of the body, which is movable within its tube (longitudinal muscles of the stalk). In the Endoproctu also there is, especially in the stalk, a delicate longitudinal muscular layer immediately under the skin. The elastic cuticle (which takes the place of the circular musculature), or (Pterobranchic) a cartilaginous substance which forms an axial strand in the stalk, serves to counteract these muscles.

The musenlar apparatns which serves for the protrnsion and withdrawal of the anterior tentacle-bearing end of the body out of and into the eells, in those Brywzoc provided witl a temporary or permanent tentaele sheath, has been best observed in the fresh-water forms (Fig. 189, 1). 20S). It eonsists esentially of 3 prarts : (1) of retraetors which ru: in a longitudinal direction (like those of the Sipunculacen through the body eavity, and are attaehed on one hand to the anterior end of the body near the tentacles, on the other to the borly wall at the base of the eell: 
(2) of a system of fibres stretched between the invaginated wall of the proboscis sheath and the neighbouring outer body wall (parieto-vaginal muscles); (3) of circular muscles, generally developerl only on the anterior body wall, though in Paludicella they appear as subdermal muscular hoops in the whole borly, and by their contraction canse the protrusion out of the cells of the withdrawn anterior end of the body with its tentacles. All these circular muscles are to be considered as remains of the circular muscle layer; the retractors and parieto-vaginal muscles as remains of the longitudinal musculature of a dermo-muscular tube.

In the Brechiopodu a typical dermo-muscular tube is as little developed as in the Biryoroa; its absence is here also evidently to be referred to the development of a shell. As remains of a dermomuscular tube, there are: (1) lying under the integument of the mantle, wealkly-developed fibres running transversely and longitudinally ; (2) the arm muscles (protractors and retractors); and (3) the

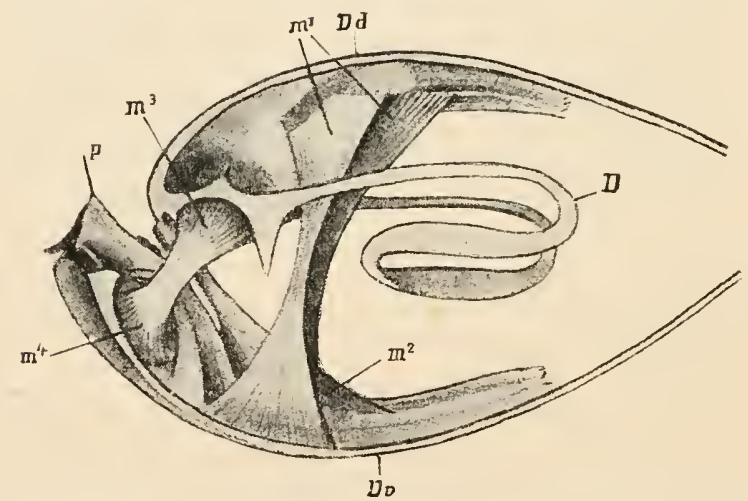

Fif. 129.-Preparation of Waldheimia fiavescens (after Owen), seen from the right side, to demonstrate the musculature, the peduncle $(p)$ and the calcareous framework $(D)$ which serves to support the arms. $D d$, Dorsal, $D v$, ventral shell valve; $m_{1}, m_{2}, m_{3}, m_{4}$, muscles for opening and closing the shell.

longitudinal muscles of the peduncle, which, in the almost universal absence of a circular musculature, are counteracted by its elastic wall.

In the Brachiopoda a system of strong dorso-rentral muscles passing through the body cavity (Fig. 129) serve for closing and opening the two valves of the shell (adductors and divaricators). They are attached to both the shell ralves in the posterior region of the body in the neighbourhood of the hinge (where this is present). These muscles cannot be regarded as dislocated or modified portions of the dermo-muscular tulse.

In Dinoplitus there is found under the borly epithelium a very weakly developed dermo-muscular tube (circular and longitudinal muscle layers).

The muscles of the Rotatoria mostly run as isolated fibres in the longitudinal direction, or circularly round the body. 'ithe longitudinal 
muscles are always more strongly developed, attach themselves at both ends to the integument, and serve chiefly for drawing in the anterior end with the wheel organ, for shortening the tail or foot, and, in tubicolous forms, for withdrawing the body into its case.

The dermo-muscular tube of the Chotognatha, which swim with arrow-like speed, is very strongly developed, in keeping with its high degree of activity. A circular muscle layer is, however, wanting. The longitudinal musculature (Fig. $130, \mathrm{~lm}$ ) is divided by 4 longitudinal lines of interruption ( 2 lateral, 1 mediodorsal, and 1 medio-ventral) into 4 areas (2 dorsal and 2 ventral).

Worm-like contractions do not occur, in consequence of the want of a circular musele layer. By alternate contractions of dorsal and ventral musculature, and by the co-operation of the horizontal fins, the elastic body is quickly propelled forwards. It was chiefly the similarity of the muscular arrangement of the Chetognethe with that of the Nematode which eaused many zoologists to place the former with the $V^{\text {remathelminthes. }}$

In the genus Spadella there is a thin layer of transverse muscle fibrille lying in the body cavity, closely applied to the ventral musculature. The arrangement of the musculature in the head of the

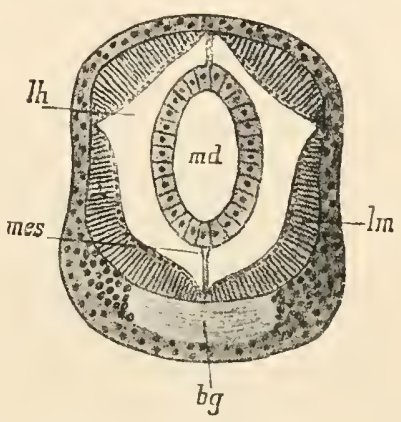

Fic. 130. - Transverse section through the trunk of a Sagitta (after o. Hertwig). lh, Body cavity; mes, mesentery of the intestine; $m d$, midgut; $l m$, longitudinal museulature; $\mathrm{bg}$, veutral ganglion.

Chatognatha undergoes a marked complication. The most important head muscles are those which serve for moving the seizing hooks.

\section{The Proboscis of the Nemertina and Acanthocephala.}

These organs may be treated of together, although they arise quite independently, and are not homologous.

In the proboseidal apparatus of the Nemertinu (Fig. 131) we distinguish the following principal parts: (1) the proboscis sheath; (2) the proboscis; (3) the retractor muscle of the proboscis.

The proboseis sheath $(r s)$ is a tube closed on all sides which lies above the intestinal canal in the parenchyma of the body. Its muscular walls consist principally of a circular and a longitudinal muscle layer. The proboscis sheath stretches more or less far back, often to near the hindermost end of the body.

The proboseis $(r)$ is also a cylindrical tube. It lies invaginated into the proboscis sheath. The space, closed in on all sides, between proboscis sheath and proboscis is filled with fluid. The walls of the proboscis sheath and of the proboscis join each other not far behind the foremost end of the body. From this point a short tube (rhyneho- 
dæum, $r d$ ) stretches to the most anterior end of the body, to emerge generally separately from the oral aperture in front of and above it. The whole proboscidal apparatus is entirely separate from the intestinal canal. The rhynchodreum thus leads through the proboscidal aperture
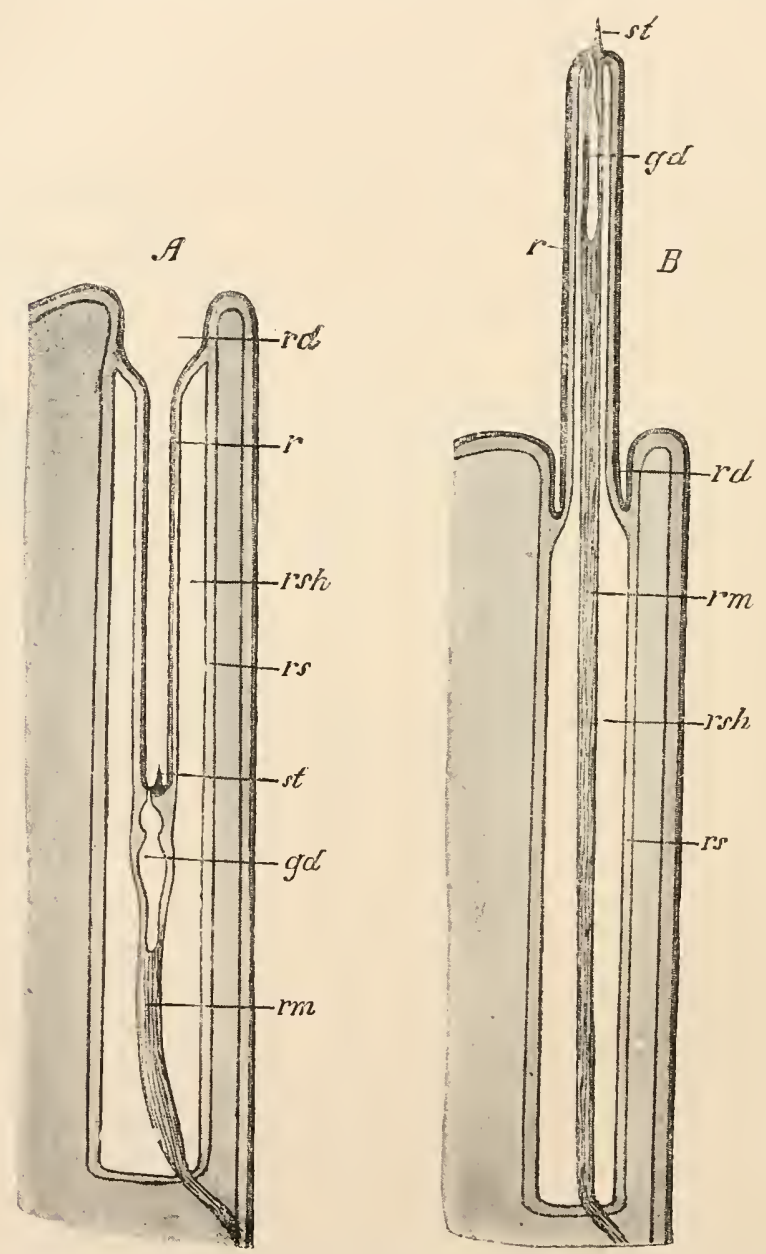

FIG. 131.-Diagrammatic representation of the proboscidal apparatus of the Nemertina. $A$, Proboscis withdrawn. I, Proboscis protruded. $r$, Proboseis; $r s$, proboscis sheath; $r s h$, cavity of the latter; st, stylet; $g d$, poison gland ; $r m$, retractor musele; $r d$, rhynchodæum.

into the central cavity of the proboscis which closes blindly behind. The wall of the long proboscis is extremely muscular, the arrangement of the fibres being occasionally very complicated. It is internally lined with epithelium which is continued on to the rhynchodrum, 
and which, at the external aperture of the latter, passes into the outer body epithelium.

At the blind posterior end of the proboscis a strand of muscle fibres is inserter, the retractor $(\mathrm{im})$ of the proboscis, which runs freely inside the proboscis sheath to its posterior end, breaking through its walls to lose itself in the dorsal longitudinal musculature. The proboscis can be evaginated from the proboscis sheath. This occurs principally by a contraction of the muscular walls of the proboscis sheath. In an evaginated condition the proboscis projects from the anterior end of the body as a long tube, while the rhynchodæum remains in its position. The inner wall then lies outside, the outer wall inside; the blind posterior end is at the extreme point of the protruded proboscis, and its epithelium then represents still more clearly than before a simple continuation of the outer body epithelium. The anterior part of the extender retractor then lies in the central cavity of the proboscis into which the fluid of the proboscis sheath penetrates. By contraction of the retractor the proboscis is again invaginated.

At the blind end of the invaginated proboseis there is found in the Hoploncmertina a stylet $(s t)$ projeeting into the prohoseidal eavity, and at its side aeeessory stylets, mostly small and in the course of formation. These stylets, when the proboseis is fully protruded, come to lie at its foremost end and projeet freely. Further, the duct of a sac-like gland (poison gland) (gd) to whose posterior end the retraetor is attaehed, is also often found at the end of the prohoseis. In the unarmed Nemertina numerous rod-shaped borlies or stinging eapsules lie in the epithelium of the prohoseis. Only in Amphiporus, Halacobdella, and Geonemertes palaensis the mohoseidal aperture opens into the esophagus from above, so that the proboseis is protruded through the month. Few observations have been made as to the function of the Nemertion proboseis, whieh when irritated is generally so energetieally projeeted that it tears itself off at its edge of insertion in the rhynehodremm. It probably serves as a weapon both for defence and offenee.

We lave already in the Platodes become aequainted with organs similar to the proboseidal apparatus of the Nemertine. The proboseis of the Proboseiden (p. 150) among the Rhubdocolo (Trerbellaria), representing an invagination of the most anterior body wall whieh has become permanent, may possibly be homologous with the Nemertion proboscis. There is a further extraordinary eorrespondenee in general arrangement between the proboseidal apparatis of the Nemertinu and each of the 4 proboseidal apparati of the Tetrarhynchide among the Cestode.

The proboscidal apparatus of the Acanthocephala (Fig. 17:2, p. 258) consists of the following principal parts: (1) the proboscis, (2) the proboscis sheatl, (3) the proboscis retractor, (4) the retractors of the proboscis sheath, (5) the retinacula.

The proboscis in its evaginated condition represents the cylindrical or conical anterior end of the body, narrowed and outwardly armed with numerous hoolis or stylets. The proboseis sheath is a muscular pouch with a double wall, closed on all sides. It is attached at the hase of the proboscis to the body wall, and projects thence backwards into the body cavity. It receives the proboscis when the latter is invaginated. By its contraction the proboscis is protruded. The 
proboscis retractor consists of longitudinal muscles, which, running inside the proboscis sheath, are attached on one side to the base (posterior wall) of the proboscis sheath, and on the other to the apex of the proboscis. By its contraction the proboscis is invaginated. The proboscis retractor is continued at the posterior end of the proboscis sheath into the two muscular retractors of the proboscis sheath, which run through the body cavity, one being dorsal and the other ventral, to attach themselves to the dermo-muscular tube. These retractors hold the proboscis sheath in its place. At the base of the proboscis sheath there arise further two occasionally muscular strands, the retinacula, which run laterally through the body cavity into the body wall, and carry back within them lateral nerve strands which come from the cerebral ganglion lying in the base of the proboscis sheath.

\section{The Intestinal Canal.}

The intestinal canal in the Worms is, in general, well developed and provided with an anus. Only in the endoparasitic Accnthocephale every trace of an intestinal canal has disappeared. In the males of the Potatoria also, and the males of certain species of Dinophilus, the intestine is more or less completely degenerated. The intestine of the dwarf male of Bonelliu, which lives parasitically in the female, is without mouth or anus. In the sexually mature Gordiule also the mouth is closed by an overgrowth of the cuticle. An anus is wanting in varions Nematude, such as Mermithidee, Ichthyoneme, and Filuria medinensis. In the hermaphrodite generation of Alluntoneme miralite the intestine is quite reduced. A more or less far-reaching reduction of the intestine can also be found in other Nemutodu, e.g. Atractonemu, spherularia. The intestine ends blindly in the Testicarlines among the Brachiopoda, and in Asplenchna among the Rotatoria. All these defects and degenerations represent a derived condition, in contrast with the well-developed intestine which is provided with an ants. The degeneration can for the most part be ontogenetically established.

The walls of the intestine consist almost everywhere of 2 layers, an outer muscular layer, which we might name the intestino-muscular tube in contradistinction to the dermo-muscular tube, and an inner epithelial layer turned towards the intestinal lumen.

We can, from an ontogenetic point of view, distinguish three divisions in this intestine, the first two being already known to us in the Colentercte and Plutodes. (1) The fore-gut which proceeds from the stomodium of the larva or embryo. Its epithelium is of ectodermal origin, and it seems chiefly to supply the various adaptations for seizing food, for reducing it into smaller pieces, and for passing it on further (pharynx, jaws, teeth). (2) The mid-gut comes from the mid-gut (mesenteron) of the larva; its epithelium is of endodermal origin. It forms the principal digesting portion of the intestine. 
The hind-gut, mostly short, often hardly distinguishable, comes from the proctodæum of the larva or embryo; its epithelium is derived from the ectoderm. It ejects the undigestible remains of food through the anal aperture. We will treat of these three divisions separately, taking the worms in order.

\section{A. The Fore-gut.}

The fore-gut is called the gullet or œsophagus in the Nemertina. It is chiefly to be distinguished from the mid-gut which follows it by the finer structure of its walls. Here and there glands have been observed entering it ; these are salivary slands. There are no special muscular swellings in the cesophagus of the Nemertina, a want which is compensated for by the development of a special proboscidal apparatus.

The asophagus of the Nematode is always distinctly separated from the mid-gut, and lined by a strong cuticle, a continuation of the cuticle of the outer integument. Its muscular wall is always thickened into a generally round or egg-shaped pharynx, which consists principally of muscle fibres placed radially to its axis. The mouth often lies at the base of a variously shaperl buccal cavity, provided with hard teeth, lips, papille, etc., and the pharynx itself may fall into two consecutive parts by means of a transverse constriction. Less frequently glandular tubes entering the buccal cavity have been observed.

The fore-gut of the Annulate shows very various adaptations. In the Hirudinea we can already distinguish two types. In the Rihynchobdellide a pharyngeal apparatus is developed, which agrees even in details with that of the Tricludu, Alloiocela, and many Polyclude among the Plutodes. The mouth leads into a cylindrical pharyngeal pouch proceeding backwards, at whose posterior end a muscular cylindrical tube, the pharynx, rises, and projects freely forwards into the pharyngeal pouch. We have then-to use the terminology adopted in connection with the Platodes-a tubular pharynx plicatus, which is protruded (not evaginated) from the oral aperture. In the Guutholdellide, on the contrary, the muscular wall of the cesophagus itself is thickened and projects into the lumen, generally in the form of three longitudinal folds or ridges. These ridges are often very strongly developed (jaws), and at their anterior projecting edges they are finely and sharply toothed (jaw teetli). The use made of jaw and teeth by the medicinal leech is well known. From the wall of the pharynx many strong muscle fibres radiate out to the body wall. The ducts of well-developed salivary glands enter into the pharynx.

Eolosoma among the Oligochata shows a very simple arrange- 
ment. The fore-gut is limited to the head segment, and forms a single pharyngeal carity with a weakly developed muscular wall. In all other Oligochcetc the fore-gut stretches through several segments, and is divided into two parts by a transverse constriction, an anterior part, the buceal cavity, and a posterior part, the pharyngeal cavity or pouch. The dorsal wall of the pharyngeal cavity is nearly always considerably thickened, and projects into the pharyngeal cavity in the form of a variously shaped muscular pharynx. The pharynx is attached by muscles to the body wall, and can be protruded in order to take in food, the pharyngeal pouch being at the same time necessarily everted. Various glands - pharyngeal glands, salivary glands, and septal glandsmay enter the pharyngeal pouch. The part of the intestine which in the Oligochrta follows the pharyngeal pouch and is generally termed the oesophagus belongs, according to recent ontogenetic investigations, to the (endodermal) mid-gut, and will thus be treated of later.

Among the Polychete we again come upon very various forms of the fore-gut. In most of the tubicolous forms it is a short soft-skinned division which follows the mouth and is called the osophagus. In Terebellide the osophagus carries a ventral muscular appendage, the nesophageal sac. Most of the Polychcete, however, are characterised by the possession of a pharyngeal apparatus, which, especially in the Errontiu, reaches a high degree of complication and can stretch through
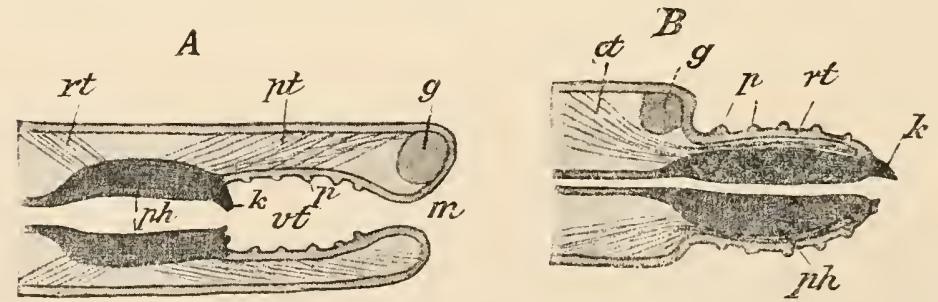

Fic. 132.-Diagrammatic representation of the pharyngeal apparatus of a carnivorous Annelid. $g$, Brain ; $p h$, pharynx ; $k$, jaw ; $m$, mouth ; $r t$, retractors ; $p t$, protractors ; $v t$, anterior soft-skinned portion of the pharyngeal apparatus; $p$, its papillæ. $A$, Pharyngeal apparatus in a withdrawn condition. $B$, ln a protruded condition. In $E$, ct indicates retractors ; $r t$, anterior softskinned portion of the pharyngeal apparatus.

many segments. We may in a general way distinguish three modifications of this pharyngeal apparatus.

1. The pharyngeal apparatus consists of two portions. The anterior portion, into which the month lears, is a soft-skinned tube, which is often provided internally with papillæe. The wall of the posterior portion is thick, on account of the strong development of its muscular layers, and represents the actual pharynx (generally called proboscis). Its anterior end carries papillæ projecting inwards or a conical process, or' besides these (Errantiu) two hard chitinous jaws. This pharynx can be so pushed forward that its anterior end which is thus armed projects freely outwards, and is then everywhere surrounded by the 
anterior soft-skinned portion, whose papille then lie externally. The anterior soft-skinned portion, therefore, is turned outwards like the finger of a glove, and the pharynx proper is pushed after it. The protrusion takes place either through pressure of the perienteric fluid in consequence of a contraction of the chmo-muscular tube, or by the contraction of special protractors of the pharynx. The withdrawal is effected by means of special retractors. This is the most common arrangement of the pharyngeal apparatus (Fig. 132).

2. The anterior soft-skinned portion is wanting, or is rery weakly dereloped. The mouth then leads almost directly into the muscular pharynx, which is itself evaginated so that when protruded its inner surface comes to hie outside (e.g. in the Capitellide, Fig. 133).

3. The pharyngeal apparatus consists of two portions, one above the other, the upper one of which (cesophagus) is less muscular and forms the communication between mouth and intestine; while the under one (jaw-carrier), which is blindly closed and enters the cesophagus in front, is extremely muscular and carries hard jaws, which are generally numerous, in special folds and sacs. These jaws come to the exterior when the pharynx is protruded, and can be moved one against the other (Eunicider, Fig. 134).

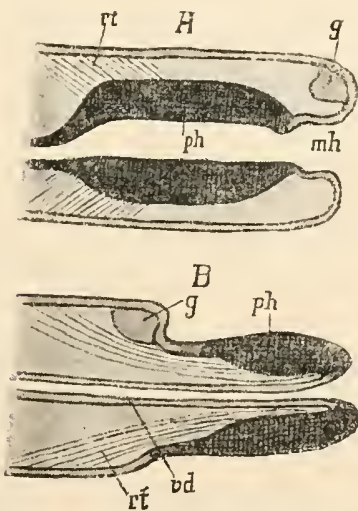

Fig. 133.-Representation of the pharyngeal apparatus of an Annelid, second diagram. $g$, Brain; $p h$, pharynx; $r$, retractors; $m h$, buecal cavity; $v d$, osophagus. $A$, ln a withdrawn condition. $B$, In a protruded condition.

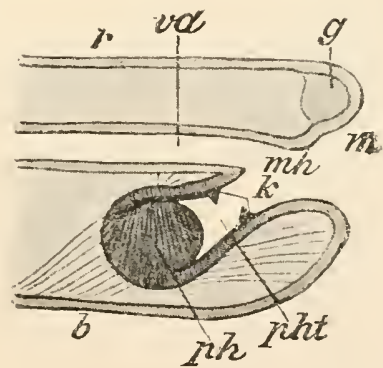

Fig. 131.-Third diagram of the pharyngeal apparatus of an Annelid (Eunicide), withlrawn. g, Brain ; vrl, esophagus; ph, pliarynx; pht, lliaryngeal sac; $k$, jaws; $m h$, buecal cavity ; $m$, mouth ; $r$, dorsal, $b$, ventril side.

Among the so-called Archiannelida, Histriotrilus alproaches nearest to the third type on account of its ventral pharyngeal bulb armed with jaws. The pharynx (cesophagus) of Polygordizs is distingnished by the want of a muscular layer, and by the great thickening of its cpithelial wall, which is very thin only in the ventral middle line. Under the pharynx there lies a thin-walled channel, closing blindly and communicating by a longitudinal slit with the pharynx. In Protodritus a muscular accessory organ, bent in the shape of a $U$, and lying under the beginning of 
the intestine, enters the pouch-shaped non-museular cesophagus quite to the front, behind the oral aperture. Polygordius and Protodritus thus approach the T'erebellida in the arrangement of their fore-gut.

The genus Stcrnaspis, which possesses a strongly musenlar pharynx, is distinguisherl by the fact that the seven anterior segments of the body can be invaginated.

Glands entering various parts of the pharyngeal apparatus have been observed in many Polychete.

In the Echimidce the fore-gut is, relatively speaking, little distinguished from the mid-gut, and it even takes part in the formation of the loops which the intestinal canal makes in the body cavity. Three divisions are distinguished in it from before backward-the pharynx, the esophagus, and the crop. It is the osophagus in which the muscular layer is specially strongly developed. It is not certain whether any part of the fore-gut can be protruded. Food is in any case seized by means of the prostomium (proboscis) and conducted to the mouth along its ventral groove.

The Mysostomide possess a pharyngeal apparatus, constructed on the plan of that of the Rhynchobdellide among the Hirudinea. At the free end of the pharynx there are tentacle-like processes.

In the Prosomgia the fore-gut is in general very short and not strikingly developed. This is evidently in keeping with the manner of taking food of these mostly attached animals; their feeding is chiefly accomplished by the help of special outer appendages of the head (tentacles, arms). (In a similar way we found that in the Chatopode inhabiting tubes or living in mud and provided with at crown of tentacles or a prostomium, the pharyngeal apparatus is far less developed than in the other forms.) Among the Sipunculacea a well-developed cesophageal bulb is present in the Priapulide only; its inner cuticle forms numerous teeth projecting into the lumen. The musculature is very powerful, and consists principally of circular and radial muscles. In the Phoronide, Bryozoa, and Brachiopoda the foregut is represented by the connective piece between mouth and intestine surrounded by a muscular layer, and is not very well marked; this is generally described as the nesophagus.

In the liotatoric (Fig. 161, p. 245) the mouth leads first into a narrow ciliated buccal cavity (osophagus), in connection with which a muscular layer is only rarely found. The buccal cavity is followed by the distinctly separate oesophageal bulb or pharynx, which is provided with a chitinous masticatory apparatus and strong musculature for moving it. The masticatory apparatus consists of a middle part (incus) and 2 lateral parts (mallei), each of which again consists of 2 pieces connected by a hinge (uncus and manubrium). The buccal cavity and the pharynx together ought to be considered as the foregut. In the pharynx of various Rotatoria salivary glands enter.

The fore-gut of the species Dinophitus (Fig. 162, p. 246), by its ventral muscular appendage whose hollow anterior end enters the 
œesophagus directly behind the mouth, recalls in a striking mamner the arrangement found in the Archimmelide and the Terebellide. The ciliated fore-gut itself falls into 2 parts, a straight anterior osophagus, and a short posterior fore-stomach into which 2 lateral salivary glands enter.

In the Chatognatha the very simple fore-gut which lies in the head is compressed transversely, and provided externally with a muscular layer whose fibres run dorso-ventrally.

\section{B. The Mid-gut.}

The mid-gut comes from the endorlermal mesenteron of the larva or embryo. The relations of the various divisions of the gut to the embryonic gut are, however, clearly established in only a few cases, so that the demarcation of the mid-gut from the fore- and hind-guts is to a great extent arbitrary. In the epithelium of the mid-gut numerous gland cells are nuiversally found.

The mid-gut of the Nemertina rums through the whole body, generally in a straight line, from the nesophagus to near the anus. It lies under the proboscis. It usually has numerous unbranched lateral sacs or diverticula, which occasionally lie one behind the other pretty regularly, and so cause a segmentation of the gut similar to that in the Triclude. In the Hoplonemertina the gut sends off towards the front an unpaired diverticulum under the asophagus.

A musculature peculiar to the mid-gut has not yet been discovered in the Temertina.

The mid-gut of Malacobdellu possesses no lateral diverticula : it has instearl a serpentine course.

In the Nemutorlu also the mid-gut has a straight course through the body. A special enteric musculature seems everywhere wanting.

With few exceptions the mid-gut of the Ammulate also runs in a straight line through the body. It is almost everywhere surrounded outwardly by a muscular layer, consisting of circular and longitudinal muscle fibres.

The mid-gut of the Hirutinea shows mostly paired, lateral, segmentally arranged crea or diverticula, the last pair of which is often very long and extends backwards on both sides of the hind-gut. Sometimes only

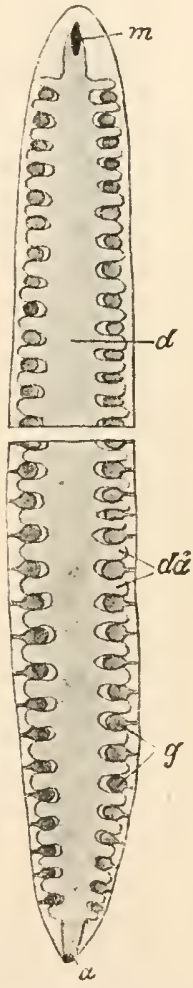

Fig. 135. - In testinal canal and genital or. gans of a Nemer. tian, diagramma. tic. m, Mouth; $\alpha$. anus ; $d$, gut; $d i i$, intestinal diverti. cula: g, genital glands opening outwards by lateral pores. this last pair of diverticula is retained, or the direrticula may be altogether wanting (e.g. Nephelis, Lumbricobdella). 
In the mid-gut of the Oligoclicetu we distinguish two principal divisions, the cesophagus (which according to recent

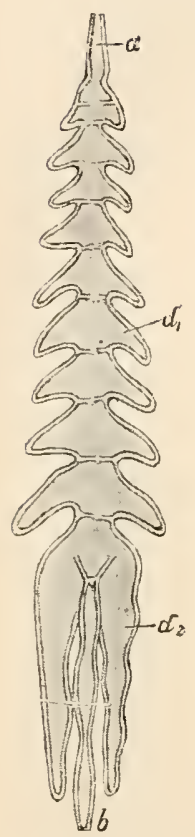

Fig. 136,-In

testinal canal of Hirudo medicinalis. $\alpha$, Pharynx ; $b$, anus ; $d_{1}$, paired lateral diverticula of the mid-gut; $d_{2}$, pos. terior longer diverticula. observations also comes from the endodermal mesenteron) and the stomach-intestine. The esophagus is generally a tube with narrow lumen and weak walls. In the terrestrial Oligochatu and the Naidomorph the cesophagus has somewhere in its course a muscular swelling (seldom double), the muscular stomach (gizzard). Besides this, 3 pairs of glandular lateral sacs enter the posterior portion of the cesophagus of the Lumbricide and related terrestrial Oligocluete: these are known as the lime-secreting glands, or Morren's glands.

The large stomach-intestine often shows constrictions between the consecutive segments. In the Lumbricicle the absorbing surface of the stomach intestine is increased by the fact that its dorsal wall is folded longitudinally into the lumen of the intestine, and so forms a tube lying in the dorsal middle line of the gut, but open longitudinally towards the body cavity; this is the typhlosolis (Fig. 165, p. 250, ty).

In the mid-gut of the Polychuta also we can distinguish an anterior division, mostly shorter and narrower, from the posterior wider stomach-intestine. At the boundary between the two special glands may enter, like the Morren's glands of the Oligocheetu. The stomach intestine usually shows successive segmental swellings, caused by constrictions at the partitions between the segments. These swellings are often prolonged lateraliy into cieca; these are particularly long in Aphrodite and the peculiar species Sphincter; in Aptrodite the cæca themselves are again branched (hepatic tubes).

In the Syllicle and Hesionide two lateral sacs enter the anterior end of the mid-gut (or posterior end of the fore-gut?) ; these can be filled with air like a swim-bladder. The mid-gut usually has a straight course, but in the Chlorhemide, Amphictenide, and above all in Stemaspis, it forms more or less striking loops.

The Cupitellide and a few Eunicide are distinguished by the possession of an accessory intestine ventral to the main intestine, and opening into it anteriorly and posteriorly in the Capitellidee, but in the Eunicide, as it appears, only anteriorly. In Capitella ventral ciliated channels run forwards along the cesophagus and backwards along the hind-gut from these openings. The constituents of food are never met with in this accessory intestine, and it probably has a respiratory function.

In the Echinuide (Fig. 137) a very striking mid-gut lies in numerous loops and windings around the longitudinal axis of the body. 
It has an accessory intestine lying close to it which passes anteriorly and posteriorly into longitudinal ciliated channels in the main intestine,

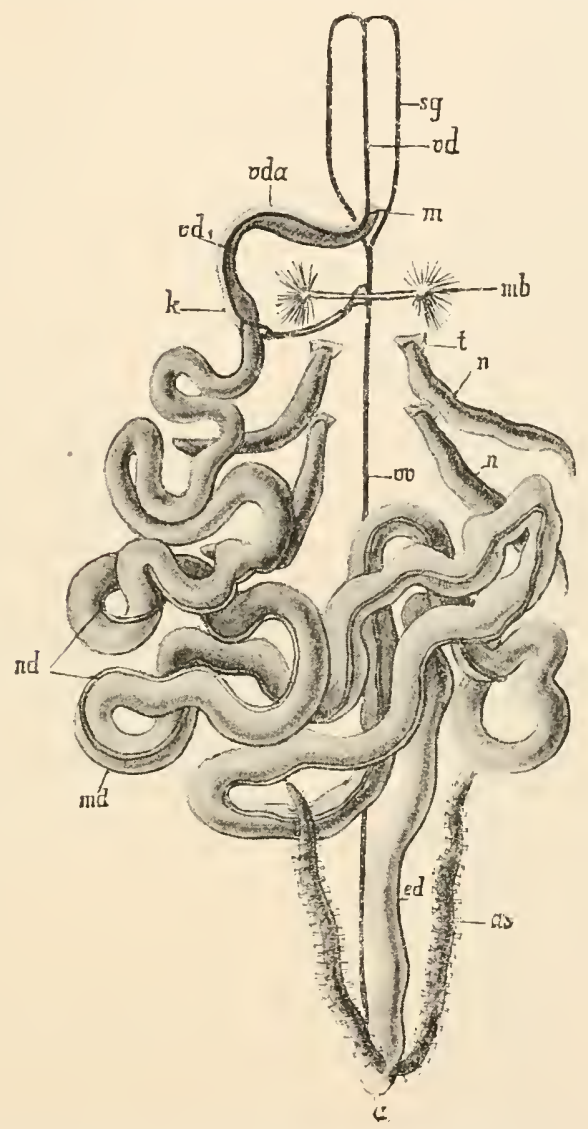

FIG. 137.-Enteric canal, vascular system, and nephridia of Echiurus. s $y$, Lateral ressels of the prostonium ; $v d$, dorsal ressel of the prostomium: $v d_{1}$, dorsal vessel of the fore-gut $(v d a) ; k$, crop; $m d$, mik-gut, with the aeeessory intestine $(m l) ; v v$, ventral vessel; $n$, nephridia; $t$, their funnel ; $a s$, anal glands ; $e d$, hind-gut ; $a$, anus ; $m b$, museles of the anterior hooked setæ ; m, mouth.

and is justly considered as the comecting piece of these channels arched over and thus separated from the intestine.

The mid-gut of the Myzostomide (Fig. 175, p. 262), with its branched diverticula which stretch as far as the lateral edge of the body, recalls the mid-gut of the Annelid species sphincter, whose body is also broad and disc-like.

While among the Sipunculacea the mid-gut in the Priapulide runs in a straight line through the body, in the Sipunculide (Fig. 138) it forms a descending limb which runs through the trunk to the posterior 

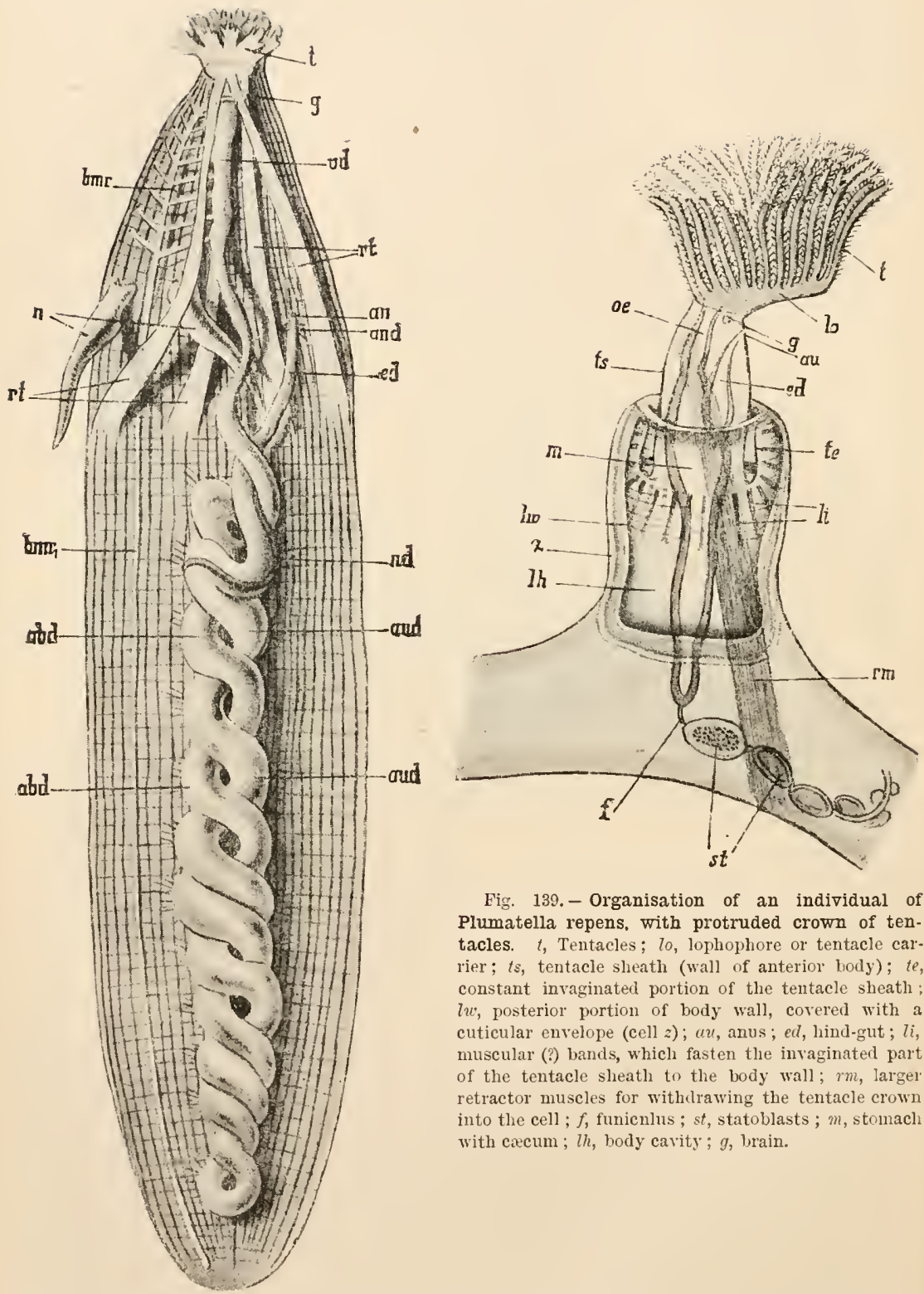

Fig. 139. - Organisation of an individual of Plumatella repens, with protruded crown of tentacles. $t$, Tentacles; 10 , lophophore or tentacle carrier; $t s$, tentacle sheath (wall of anterior body); te, constant invaginated portion of the tentacle sheath ; $l v$, posterior portion of body wall, covered with a cuticular envelope (cell z); au, anus ; ed, lind-gut; $l i$, muscular (?) bands, which fasten the invaginated part of the tentacle sheath to the body wall; $r m$, larger. retractor muscles for withdrawing the tentacle crown into the cell ; $f$, funiculns ; st, statoblasts ; $m$, stomach with cecum; $7 h$, body carity; $g$, brain.

FIG. 138.-Anatomy of Sipunculus with protruded proboscis, partly after Vogt and Jung: the body is cut open longitudinally. $t$, Tentacles ; $g$, urain; $v d$, fore-gut ; rt, proboscis retractor; $n$, nephridia; $b m r$, that portion of the rentral chord which lies in the proboscis and runs freely in the body cavity; $b m r_{1}$, ventral chord of the trunk, marking the rentral middle line; an, anus; and, anal glands; $e d$, lind-gut; $n d$, accessory intestine; $a b c$, descending limb; atd, ascending limb of the mid-gut. 
end of the body, and then bends round to run forwards as an ascending limb. The two limbs twist round each other and form a spiral. A ciliated channel runs along the whole course of the mid-gut. Where this ceases, at its posterior end, a blindly closed diverticulum is attached to the gut, winding round its end; this may be homologous with the accessory intestine of the Chotopodu.

The intestine of Phoronis, like that of the Simunculuced, forms a descending limb, and on the dorsal side of this an ascending limb.

The arrangement in the Bryozor (Fig. 139) is closely comnected with that in the already described Prosopygiu. A descending limb of the intestine, not very sharply distinguished from the fore-gut, leads into the expanded stomach, from which arises an ascending $\lim b$ which passes into the hind-gut. The stomach is occasionally prolonged into a somewhat sharply demarcated caecum directed backwards.

In the mid-gut of the Brachiopola we distinguish an anterior widened part, the stomach, into which the asophagus enters, and an adjoining narrower part, the stomach-intestine. The stomach carries one or more pairs of lateral diverticula which branch and divide into massive glandular lobes, called the liver; these envelop the stomach on all sides. The stomach-intestine forms either a simple or complicated coil and then runs backwards (Crania), or bends on one side round to the front (the other Ecarlines), or ends blindly (Testicardines).

In Dinophilus (Fig. 162, p. 246) and the Rotutoriu (Fig. 123, p. 185; Fig. 161, p. 245) the mid-gut forms in the female a well-rleveloped pouch-shaped stomach, which is sharply divided from the fore- and hindguts. The epithelium of the stomach is either itself glandular, or there are special large glandular appendages. An intestinal musculature is either wanting or very slightly developed.

The mid-gut of the Chatognathe (Fig. 152, p. 227) takes a straight course through the trunk cavity of the body, without lateral appendages. A muscular layer is wanting.

\section{The Hind-gut and the Anus.}

The hind-gut comes from the proctodieum of the larva, and forms in the worms a tube, often very short, but generally clearly separater from the mid-gut; this tube opens externally through the anus, and is frequently called the rectum. The anus is either a separate aperture. or else it unites with the apertures of other organs of the body. This union is brought about through pit- or sac-like depressions of that region of the body wall in which these apertures lie near each other: a eloaea is thus formed, which then opens externally by a new common aperture, the cloacal aperture.

The juxtaposition of the external apertures of inner organs and the invagination of the region common to these aprertures are very frequent in the aninal kingdom. We will give only a few eases in illustration. In many Plotodes the originally separate male and female genital apertures come to lie at the base of a common genital 
cloaca. The male genital aperture may even be eombined with the mouth (c.g. in Stylostomum among the Polyclade and in Prorlynchus among the Pihabdocota). In the Mesostomidce among the likabdocele the longitudinal branches of the watervascular system, which generally emcrge independently at the surface of the body, enter the pharyngeal pouch, which itself represents an invagination of the outer body wall (stomodexum). In a few Nemertinc the otherwise miversally separated proboscidal and oral apertures may be united (Amphiporus, Malacobdella, Geonemertes palaensis).

The following are the most important combinations of the anal aperture with the apertures of other organs. There are three kinds of such combinations.

1. Union of the anal aperture with the apertures of the nephridia or excretory organs. - In the Priupulicke the two anal organs which serve primarily for excretion and secondarily as genital ducts emerge quite near the anus. In Sipunculus slightly developed anal glands have been observed entering the end of the hind-gut; these are perhaps (?) homologous with the anal organs of the Priupulide. In the Echiuride, which in many ways occupy a position intermediate between the Chcetopoda and the Sipunculaceu, both the anal glands (anal nephridia) also enter the hind-gut. In the Rotatoria also anus and nephridia enter a common cloaca.

2. Union of the anal with genital apertures. - In the male Nencatoda the genital aperture emerges with the anus into a common cloaca; and the same is the case in the female Rotatoria.

3 . Union of the anal with both nephridial and genital apertures.-This occurs, as may be seen from 1 and 2 , in the femule Rotatoria, where all three apertures open into a common cloaca.

The position of the anus and the cloaca. - The anus has a terminal position in the Nemertina, Nematola, and Anmuluta. In the Nematoda it lies ventrally at a little distance from the posterior end of the body; in the Annulata generally dorsally, but always in the last segment, except in Notopygos (Amphinomide), where it lies several segments from the posterior end on the back. In the Chetognathu it lies ventrally at the boundary between the trunk and the tail regions; in the Rotatoria dorsally at the boundary between trunk and foot. In attached tubicolous Rotatoriu it has moved somewhat forwards on the back, so that the hind-gut bends round forwards. The Prosopygia are distinguished by the fact that the anus lies on the back, moved far forward; and in the Sipunculide it even lies at the houndary between proboscis and trunk; in Phoronis and the Bryozoa quite anteriorly on the back, either (Ectoprocta) outside the tentacle carrier or (Endoprocta) inside it. Where an anal aperture is retained in the Brachiopoda it lies anteriorly, to the right, near the mouth. There are, however, a few exceptions to the rule which generally holds for the Prosopygia. In the Priapulide and in the Brachiopod genus Craniu the anus lies behind. 


\section{The Body Cavity, the Musculature which passes transversely through it, the Dissepiments and Mesenteries.}

In the Nemertina we cannot yet speak of a body cavity (ccelome). Apart from the comective tissue, which penetrates between the muscles of the dermo-muscular tube, the space between the intestine and that tube is everywhere filled by a gelatinous tissue which is morphologically equivalent to the gelatinous tissue of the Colenterutu and the parenchyma of the Platodes. The various organs-genital slands, blood-vessels, nephridia-are imbedded in this gelatinous tissue. Dorso-ventral muscle fibres pass through it and form (1) a sort of enteric musculature, the intestine passing between them and lolding them apart, and (2) passing between the enteric diverticula a sort of muscular septa separating them; these septa, just like the diverticula themselves, lie one behind the other with more or less regularity, and recall the septa which are developed between the gastro-canals of the Platoles.

In the Nemathelmiu there is a very spacious body cavity filled with fluid, which, in the Nematola, occupies the whole space between the dermo-muscular tube and the intestine; and in the Acunthoceplualu, where an intestine is wanting, it is represented by the whole interior of the body, which is surrounded by the dermo-muscular tube. In this cavity lie the genital organs, bathed on all sides by the body fluid, and further, in the Acunthocephulu, the lemnisci. In the latter the genital organs are attached by a muscular band or ligament to the posterior end of the proboscis sheath, and also by lateral muscular bands to the dermo-muscular tube. The body cavity of the Nemathelmie is not lined with a special epithelium (endotheliums), but is limited directly — externally by the body musculature, and internally by the walls of the intestine.

The Gorliide occupy an isolated position among the Nemathelminths in the morplological condition of the coelome, as in many other points of their organisation. In animals not quite sexually mature we find between the intestine and the body wall a considerable mass of cells, which disappears for the most part at the time of the development of the genital glands, and is probably used as material for nourishing these glands. Wre then find, in place of the cell mass, a spacious bolly cavity, which, however, in contradistinction to other Nemuthelminths, is lined on all sides by an epithelium, often of several layers, lying on the inside of the dermo-muscular tube (Fig. 170, p. 256). This epithelium, in contrast to the epithelium of the intestinal canal and to the outer body epithelium, we call the peritoneal endothelium. This endothelium forms, in the median plane of the borly, a partition wall which separates into 2 lamelle; these run dorsoventrally, having the intestine between them. At the sides of the ventral median nerve they unite with the endothelium of the body 
wall. By the special arrangement of this partition wall (mesentery) the body cavity is rivided into 3 principal chambers; 2 lateral, and 1 unpaired ventral chambers, in which the intestine runs. We shall return to some peculiarities of this mesentery later on, when treating of the genital organs.

The presence of an endothelium and of a dorso-ventral median mesentery raises the Gordicile almost to the level of the higher worms, and supports the view that they should be considered as such (probably Annulatu) degenerated by parasitism.

We cannot yet decide what should be considered as the body cavity in the IIirudineu among the Anmulutr. The space between the intestine and the body wall is filled by a connective tissue or parenchyna whose elements undergo the most varied transformations. We find pigment cells, fat cells, fibres. Blood-ressels and blood-sinuses arise by the flowing together of the contents of neighbouring cells. The collective mass of the connective tissue elements is more strongly developed in the Gnathobdellide than in the Rithnchobdellide. In the latter division a connected system of blood-sinuses, whose walls are not muscular but lined with an endothelium, and in which the central nervous system lies, must be considered as a slightly-dereloped or else much reduced body cavity. In the Gnothobdellidie the sinns, which contains the ventral chord, the resophageal commissures, and the brain, seems to be such a reduced body cavity. This sinus, however, is not lined with an endothelium. The fact that in all Hirulinew the blood-vaseular system is in open communication with the sinuses makes it difficult to decide whether the canal and sinus systems represent parts of the body cavity; and if so, to what extent this is the case. The sinuses are filled with a fluid which, in the Phynchobdellider, contains colourless blood corpuscles.

Muscle fibres, branched at both ends and attached to the dorsal and ventral body walls, run through the body parenchyma. They form muscular dissepiments between the enteric diverticula, the arrangement of which recalls that of the dissepiments in the Nemertina and Turbellariu, and, in correspondence with the metameric arrangement of these diverticula, are themselves metameric.

For the Chetopodu we can establish a general morphological scheme of the body cavity, which, however, undergoes considerable modifications in a few divisions. Between the intestine and the body wall there is always a body cavity filled with fluid, which is entirely separated from the blood-vaseulal system. The body cavity is divided in the following way. A dorsal mesentery connecting the intestine with the dorsal middle line, and a ventral mesentery connecting it with the ventral middle line of the body wall, divide the body cavity into 2 lateral chambers, a right and a left. Muscular partition walls, septa, or dissepiments, comparable to the dissepi- 
ments of the Turbellaria, Nemertina, and Hirudinea, divide the body cavity into as many consecutive chambers as there are segments. These transverse partition walls always run between 2 consecutive segments. They are bored through by those organs which run longitudinally through several segments; viz. the enteric canal, the blood-ressels, and the nephridia. It is the septa which bring about the segmental constrictions of the intestine. The consecutive chambers of the body cavity are seldom completely separated from one another, the septa being mostly perforated, so that a free communication of the coelomic fluid in adjacent chambers of the body cavity is possible.

All the walls of the boly cavity and the organs lying in it are lined with a peritoneal endothelium, which undergoes the most various modifications. The endothelium of the body wall is distinguished as the parietal layer ; that of the intestine as the visceral layer.

The chloragogen cells are peritoneal cells with definite excretory functions; they are especially strongly developed in the Oligochote, and are attached to the dorsal vessel and its branches, particularly to the network of blood-ressels which surround the intestine. The brown granules which they contain are products of excretion taken from the blood, and most probably reach the exterior through the nephridia by the detachnent and dissolution of the chloragogen cells. Tre find such cells also in the Polychata. The excretory organs probably also draw the excretory sulsstances direct from the blood, i.c. from the network of vessels which surround the renal tube.

The division of the body eavity may vary greatly in details. The dissepiments may become reduced or wholly disappear in large tracts of the body, so that consecutive chambers of the body cavity coalesce. Especially where a protrusible jroboscis is developed, the segments through which this organ stretches undergo a reduction of their dissepiments. Dissepiments and mesenteries are generally typically developed in an early stage, even where in the adult condition great transformations take place.

The mesenteries may be reduced to isolated bands, fastening the intestine to the body wall, and these may also be developed only in certain regions of the body. On the other hand, the body cavity may undergo a still greater process of division (especially in Polychota). For example, a membrane rumning under the intestine, attached on each side near the ventral chord to the body wall, often divides the body cavity into an upper chamber containing the intestine, and a lower chamber in which the ventral ehord runs. Further, 2 lateral lamelle often run through the body in a dorso-ventral direction, slanting upwarls and outwards from both sides of the ventral middle line; these cut off 2 lateral cavitics from the borly cavity, which may be described as renal chambers, as they gencrally contain the greater part of the nephridia. These lamelle enclose transverse muscle fibres (Fig. 158,1 . 237).

The dissepiments undergo a striking reduction, especially in the bodies of those Chatopola in which the enteric canal forms loops, and in which the segmentation of the body is more or less obscured (Chlorhcemide, Sternaspide, Echiuride). A spacious

- body carity is thus formed. In the Capitellide the want of a separate blood-rascular system is compensated for by a strikingly pronounced prartitioning of the body cavity.

Communication between the body cavity and the outer world 
takes place in two ways. Firstly, by the nephridial eanals, which will be described later, and which are originally present in pairs in each segment, and, secondly, by the dorsal pores. These have been clearly observed in the Lmmbriciele and related land Oligocherta, and are medio-dorsal perforations in the body wall, lying in the anterior end of each segment. They are wanting in the head segment and in a certain number of the subsequent anterior segments.

Accorling to some writers, dorsal pores are present also in Enchytreide; and cephalic pores leading into the head cavity are to be found in ditferent families of the Oligochectu. But the presenee of these pores has again recently been disputed.

In the Mysostomile a body cavity filled with fluid is wanting. The organs found between the intestine and the body wall, above all the genital organs, are embedded in a body-parenchyma of connective tissue. Still the question remains to be decided, whether the space in which the sexual products lie does not answer to the body cavity of other worms. Dorso-ventral muscle fibres run through the parenchyma and form, in the same way as in the Hirudinea, Nemertinu, and Turbellaria, a kind of muscle septa between which secondary muscle septa coming from the edge are intercalated, in the spaces between the sexual organs and the enteric diverticula. In the middle region of the body the septa leave a considerable space open in which we find the intestine, with the uterus dorsally above it and the ganglionic mass of the ventral chord under it.

In the manner of division of the body cavity the Cleatogratha are closely allied to the Chctopoda. The borly cavity is divided by 2 dissepiments into 3 consecutive chambers. The first dissepiment lies at the boundary between head and trunk, the second between trunk and tail, and the 3 chambers separated by the septa are the head, trumk, and caudal cavities. The enteric canal divides the head and trunk cavities into 2 lateral portions; in the trunk cavity the intestine is often fastened to the body wall by a dorsal and a ventral mesentery; a dorso-ventral mesentery-like partition of the caudal cavity is also found, although the intestine is there wanting. The parietal and visceral layers of the peritoneal endothelium are continued on to the mesenteries and the dissepiments, and form their chief component part, as they are not provided with muscles.

The body cavity of the Prosopygiu shows very different arrangements. That of the Sipunculacen is large and spacious, like that of the Echiuride; dissepiments are wanting. The intestine, in the Sipunculicle, is fastened to the body wall by delicate mesenterial strands which are wanting in the Priupulide. In Priapulus the body cavity is continued into the caudal appendage. A large expanse of the peritoneal corering of the intestine is ciliated in the Sipunculida, and, as in the Echimille, a longitudinal muscular band runs along the intestine. The colomic fluid generally contains amoboid lymph cells; and besides these, in the Siprnculiule, the sexual products and other 
peculiar borlies whose siguificance is not yet clear are found floating in it. In Phoronis also the body cavity is well developed, and lined throughout by a peritoneal endothelium. At the most anterior end of the body there is a septum which separates the cavity of the prostomium and the tentacles from the body cavity. The descending limb of the intestine is fastened to the body wall by a ventral mesentery, which, on the limb which ascends forwards to the anus, becomes a dorsal mesentery. The descending limb is further connected with the body wall by 2 lateral mesenteries. Among the Bryozou the body cavity in the Pterobranchice and Endoprocta is extremely reduced, but in the Ectoprocta well developed. It is continued into the tentacles, and is often lined with a ciliated endothelium, at least this can be demonstrated in the fresh-water Bryozoc. The intestine is fastened to the body wall on all sides by fibres which are considered to be muscular. The gastric cæcum is also suspended from the posterior body wall by a strong non-muscular strand, the funiculus. In Puludicella there is also a second fumiculus. In the Brachiopoda the cavity containing the viscera is lined by an endothelium generally ciliated over a great part of its surface. The enteric canal is fastened to the body wall by a more or less complete dorso-ventral mesentery, which, when complete (e.g. in Crania), divides the body cavity into two lateral halves. There are often lateral membranes or bands as well fastening the intestine to the borly wall - a gastro-parietal band in the region of the stomach, and an ileo-parietal band in the region of the hind-gut. These bands have been compared with septa, which implies that the Brachiopod body was originally composed of three segments. This view is supported by other anatomical and ontogenetic facts. The body cavity in the Bracliopoda is continued in the hollow spaces of the mantle. An endothelial lining of the body cavities of Potatoria and Dinophilus has not yet been proved. Distinct mesenteries and septa are wanting. Fine fibres of connective tissue here and there comnect the organs lying in the body cavity with its walls; no constant arrangement, however, is found.

The phylogenetic origin of the body eavity of the worms, and generally of the higher Hetazoc, is not at present certainly established; it is also impossible to say decidedly how far the hollow spaces in the body, called body cavities, are homologous in the various divisions of the Vermes. In the Amulate and many other higher animals it has long been known that special parts of the peritoneal epithelium arc the flaces of formation of the sexual products. We are therefore justified in asking the question, whether the ovaries and testes of the lower acolomous worms out of whose germinal epithelim the sexual products are formed, do not correspond with the chambers of the body cavity (cœlome) of the higher worms.

\section{The Nervous System.}

The Nemertina (Figs. 140, 141).-The central nervous system consists of the brain, which is placed in front of or over the aesophagus and under the anterior portion of the proboscidal apparatus, and of 
two longitudinal trunks, proceeding from the brain and running somewhat ventrally in the lateral parts of the body; these end near the

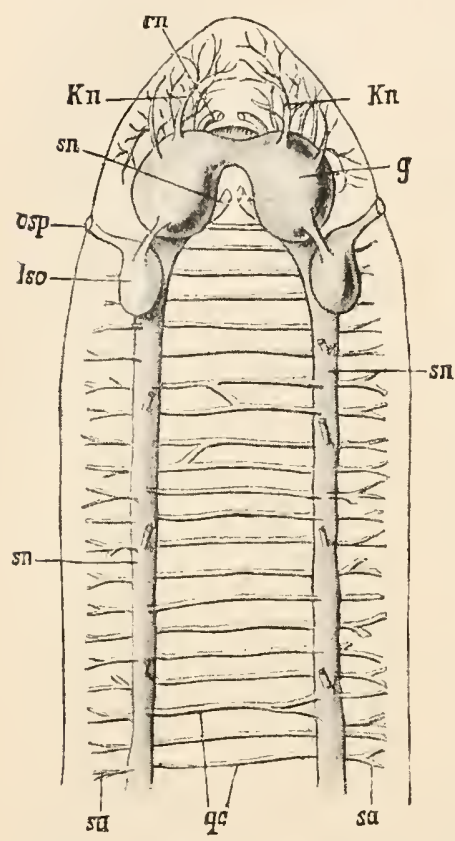

Fic. 140.-Nervous system of the anerior part of the body of a Nemertian (Drepanophorus Lankesteri), after Hub recht. $g$, Cerebral ganglia; osp, aperture of the lateral organs (eiliated grooves); lso, eerebral lobes of the ciliated organs; rm, proximal portion of the proboseis nerves; $k n$, nerves of the head; $s n$, cesophageal nerves; sn (further down), lateral longi. tudinal trunks; $y c$, transverse eommissures ; $s t$, lateral branches of the longitudinal trunks. nerve sheath, which innervates the dermo-muscular tube, we can, in the Schizonemertina, observe thicker strands, which form annular commissures between the three principal nerves running in the longitudinal direction. In the Hoplonemertina the nerve sheath is wanting; the commissures run separately, and sometimes show a markedly metameric arrangement.

In the whole structure of this nervous system a considerable agreement with that of the Platodes (Polyclada, Triclada, Trematoda) eannot be ignored. The brain and the longitudinal trunks of the Nemertina answer to the brain and the ventral longitudinal trunks of the Platodes. Whether the unpaired dorso-median Iongitudinal nerve of the Nemertina answers to the two dorsal longitudinal nerves of the Platodes cannot yet be deeiderl. The longitudinal trunks (and also the brain) lie either 
imbedded in, or direetly under the epithelium (Carinina, Carinella), or they are enclosed in the museulature of the body wall (Cephalothrix, Cerebratulus), or they lie on the imer sille of the musenlature (Amphiporus).

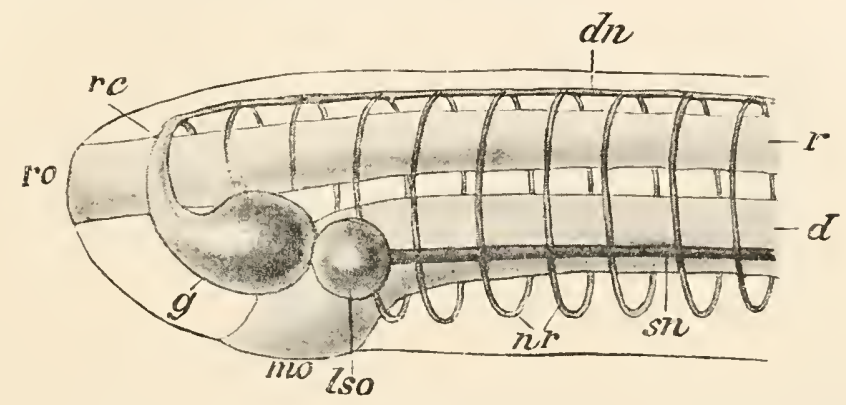

Fis. 141.-Anterior end of the body of a Nemertian from the side, diagrammatic (partly after Hubrecht). (", Brain; $r c$, proboscis commissure; $d n$, mectio.lorsal nerve; lso, cerebral lobe of the lateral organ ; $s n$, lateral nerve; mo, month ; $r$, proboscis; $d$, intestine; $n r$, nerve rings, commissures between lateral nerves and the medio-dorsal nerve; ro, proboscilal aperture.

In Malaeobdclla ganglionic swellings were formerly erroneously deseribed as oecuring in the eourse of the longitudinal trunks.

Nemathelminths. - The nervous system of the Tematodu (Fig. 142 ) consists of a ring surrounding the asophagus, the sides of which often swell out into a ganglion. A dorsal and a ventral longitudinal nerve arise out of the ring, and these run in the middle line to the posterior end of the body. The two nerves are connected together by transverse commissures which run under the cuticle outside the musculature. The transverse commissures of the right and left sides of the body do not exactly correspond. Numerous nerves proceed forwards from the resophageal ring towards the apex of the head.

Attempts lave been made to trace back the nervous system of the Ninatoda to that of the Platodes in the following way. By union of the dorsal longitudinal trunks in the niddle line the medio-dorsal nerve of the Nematoda arose, and hy the union of the ventral longitudinal trunks the medio-ventral, whieh in young Ascaride and in a Pleetus is still distinetly paired. The lorsal half of the Nemetodan axsophageal ring answers to the brain of the Platodes with its often distinct lateral swellings. The ventral half of the cesophageal ring answers to the proximal portious of the ventral longitudinal trunks, still separated in the region of the cesophagnis, but fused in the ventral middle line to form the merlio-sentral nerve. The lateral nerves which run a short distance at the anterior end of the Nematoda are considered to be the remains of the lateral longitudinal nerves. The transverse commissures of the vematuda correspond with the transverse commissures which connect the various longitudinal nerves of the Platodes. We prefer, however, to eon prare the nervous system of the Nematorla with that of the Lemertina, beeanse there we have an unpaired dorso-median nerve, and the nerves corresponding with the outer lateral longitudinal nerves of the Platorles are wanting. The lateral swellings of the brain also are developed more clearly as lateral ganglia conneeted by a transverse eommissure than is the ease in the Platodes. 
In the Acanthocephula (Fig. 172, p. 258) there lies at the base of the proboscis sheath a ganglion which sends several nerves forwards

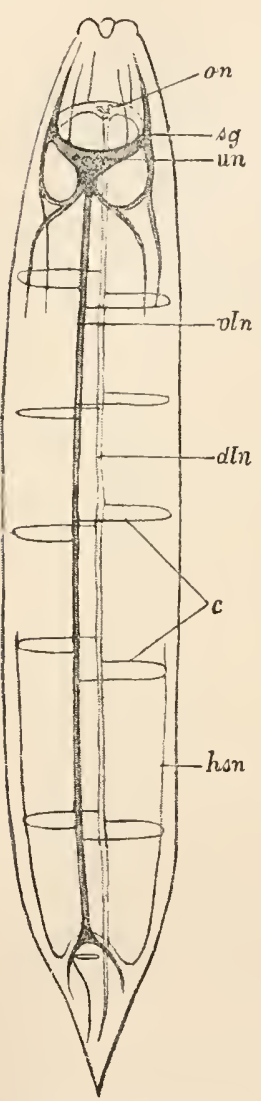

Fic. 142. - Diagram. matic representation of the nervous system of the Nematoda, after Buitschli. on, Upper, un, under portion of the oesophageal ring; $s g$, lateral swellings of the same; $v l n$, medio-ventral; $a l n$, medio-dorsal longitudinal nerve; $c$, commissures between the two; hsn, posterior lateral nerves (bursal nerves).

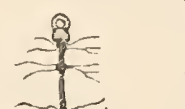

to the proboscis sheath, the proboscis, and the neck. Posteriorly there proceed from the ganglion two lateral longitudinal nerves, which first enter the retinacula at the posterior end of the proboscis sheath and rum in them to the body wall, and then to the posterior end of the body. A dorso-median longitudinal nerve has also been observed. In the male, besides the anterior ganglion, another ganglion in the region of the genital apparatus (lying anteriorly on the base of the withdrawn bursa) has been described; this gives off nerves to the genital apparatus, and is also connected by two nerves with the posterior ends of the lateral longitudinal nerves of the body.

The nerrous system of the Acanthucephata is up to the present time not elearly understood. If there really is a medio-dorsal longitudinal nerve it perhaps eorresponds with the medio-dorsal nerve of the Nematode, and then the lateral longitudinal nerves perhaps represent the ventral longitudinal nerves, whieh fuse in the middle line in nost Tematode. What the relations are between the cesophageal ring of the Nemetode and the ganglion of the proboscis sheath of the Acanthocephala, or whether any sueh relations exist, are questions.s whieh must be left on one side.

The Gordiule also deviate from other Nematola in the structure of the nervous system. Round the rudimentary pharynx lies at ganglionic mass (peripharyngeal ganglion) which is much thickened, chiefly ventrally, and is produced into a ventral chord (Fig. $170, \mathrm{p}$.
256 ). This runs backward in the middle line and swells into a caulal $256)$. This runs backward in the middle line and swells into a caudal
ganglion under the terminal portion of the genital ducts. In the male 
it divides at the most posterior end of the body into two strong branches which rum into the caudal bifurcation. The peripharyngeal ganglion is connected on each side with the hypodermis, as is the ventral strand at the extreme posterior end of the body, in the caudal bifurcation, and indeed along its whole length by means of numerous unpaired median nerves. Nerve fibres radiate forwards from the peripharyngeal ganglion. A medio-dorsal nerve is wanting. It is probable that the peripharyngeal ganglion and the ventral strand of the Gorliitre are homologous with the osophageal ring and rentral chord of the Anmulute.

Annulata.-Here we can establish a general scheme for the central nervous system. It consists (1) of a brain which lies over the anterior portion of the enteric canal, and (2) of the segmented ventral chord, running through the body in the rentral middle line. These two are

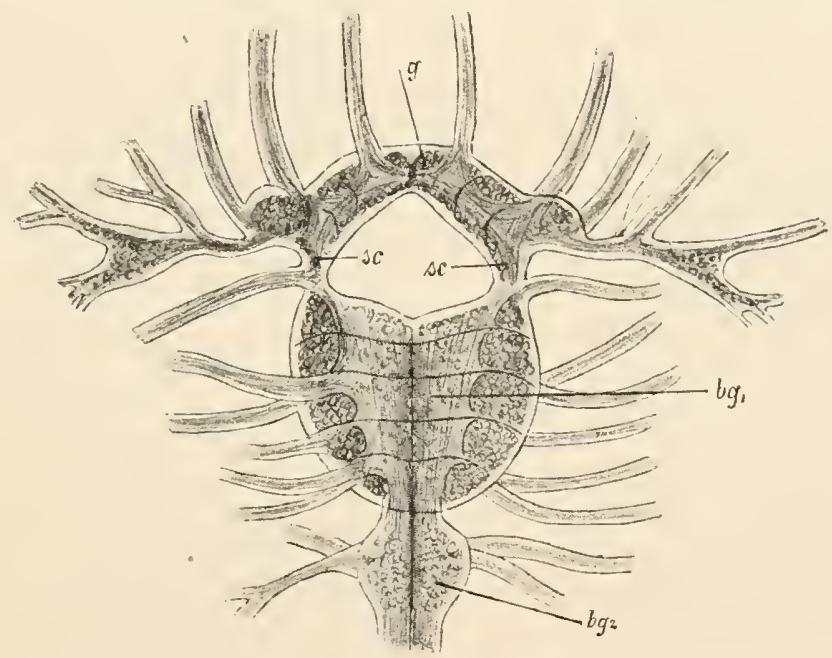

FIG. 144.-Esophageal ring with diverging nerves of Hirudo, enlarged (after Hermann). $g$, Brain; se, osophageal commissure; $b g_{1}$, first ganglion of the ventral chord (infra-cesophageal ganglion); $b g_{2}$, second ventral ganglion.

connected by 2 commissures, the esophageal commissures, which embrace the fore-gut between then. The anterior end of the intestine is thus surrounded by a nerve ring, the so-called oesophageal ring, which enters the brain dorsally, and the first ganglion of the ventral chord ventrally (Figs. 144, 146). The brain (supra-cesophageal ganglion), whose composition out of 2 lateral halves comected by transverse commissures can generally be clearly seen, lies originally in the first, the cephalic or oral segment. The anterior ganglion, or rather double ganglion, of the ventral chord (infra-cesophageal ganglion) probably originally belonged to the second segment of the body. The remaining double ganglia of the ventral chord follow the infra- 
œsophageal ganglion, one in each segment. The 2 ganglia of each double ganglion are connected together by short transverse commisissures, and witl the corresponding ganglia of the preceding and succeeding double ganglia by longitudinal commissnres.

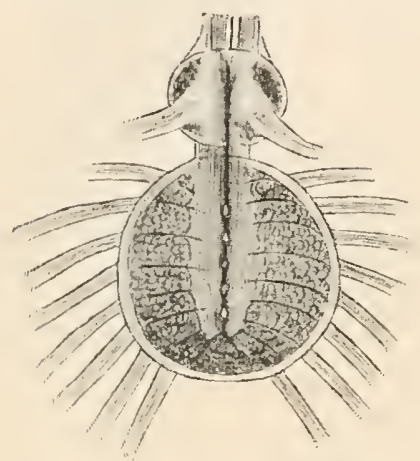

Fig. 145,-Terminal or (sucker) ganglion of Hirudo, with preceding gan. glion, after Hermann.

Besides the resophageal commissures nerves proceed from the brain to the integument and the sensory organs of the head; and from the ganglia of the ventral chord nerves supply the integument, sensory organs, and musculature of the segments to which they belong.

The musculatmre of the fore-gut (pharynx, proboseis, etc.) is provided with nerves arising either direct from the brain or from the osophageal commissures. These nerves are caller resophageal nerves (often also nervi vagi), and the plexus they form in the fore-gut is called the cosophageal nervous system. In the most various divisions there is also a further plexus of ganglionic cells and nerve fibres in the walls of the micl-gut (visceral nervous system, sympathetic nervous system) whose connection with the central nervous system requires further investigation.

Difference of opinion prevails as to the pliylogenetic origin of the nervous system of the Annulate. We prefer that view which not only derives the brain of the Annulata from that of the Vemertina and Platodes, but also sees in the segmenter ventral chord with asophageal commissures the further developed ladder nervous system formed in these lower divisions by the longitudinal ventral trunks and their transverse commissures. Ganglionic cells are found in the Platodes and Nemertina everywhere in the larger longitudinal trmnks, and are present in great numbers in the Polyclace and Triclude at the points of divergence of the transverse commissures and lateral branches. These latter are repeated in an extremely regular manner and in a segmental arrangement as early as in certain Triclada (Gunda) and Nemertine (Drepanophorus). If we imagine the ganglionic cells of the longitudinal trunks crowded together at the points of divergence of the transverse commissures and side branches, and their number perhaps inereased still further, these points of divergenec must swell into ganglia and the longitudinal trunks become longitudinal commissures between the successive ganglia. The longitudinal trunks with their ganglia only need to move together into the ventral middle line, so as to become the typical ventral chord of the Annulate. The mouth and oesophagus prevent such a moving together in the anterior part of the body, and so the first part of the longitudinal trunks becomes the cesopliageal commissures of the Anmulete.

An approximation of the longitudinal trunks, which, it is true, never leads to direct contact, may be observed as early as the Nemertina, not to speak of the Platodes. Whereas as a rule among these forms the paired longitudinal trunks lie laterally, sometimes even over the enteric diverticula (Amphiporus Moseleyi), they are found in Drepanophorus placed somewhat ventrally and nearer each other. On the other 
land, the ventral chord of the Annelide can, by the separation of its symmetrical halves, assume the appearanee of a ladder nervous system (e.g. in the Hermellidor, Fig. 14i).

In very many Annulate (many Oligocherte and Polycheter) the brain stands in

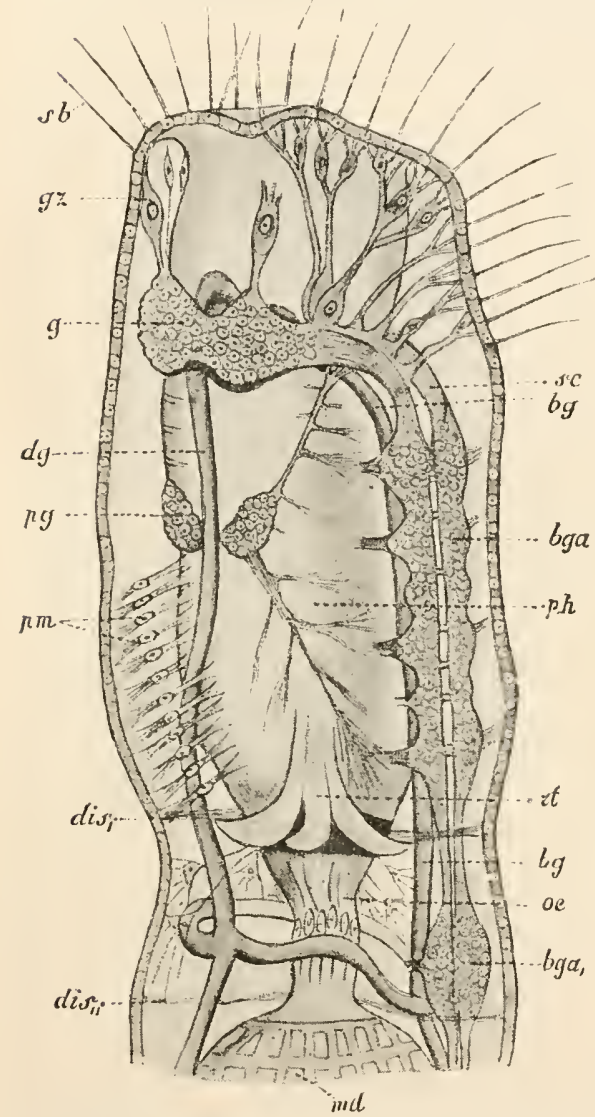

F16, 146,-Anterior part of the body of Chætogaster diaphanus, from the side, after Vejdovsky. $s b$, Sensory setie; $g z$, ganglionic cells of the cup-shaperl organ; bge, ladder-like ventral chord of the pharyngeal region; dis, $d i s_{2}$, first and second dissepinents ; $p m$, pharyngeal muscles; $b g \iota_{1}$, ventral ganglion in the osophageal segment; $g$, brain; $p g$, pharyngeal ganglion; $m d$, stomach-intestine; $r t$, jetractors (?) of the pharynx; $s c$, œsophageal commissure; $d g$, dorsal vessel; $b g$, ventral vessel; $a$, oesophagus ; $p h$, pharynx.

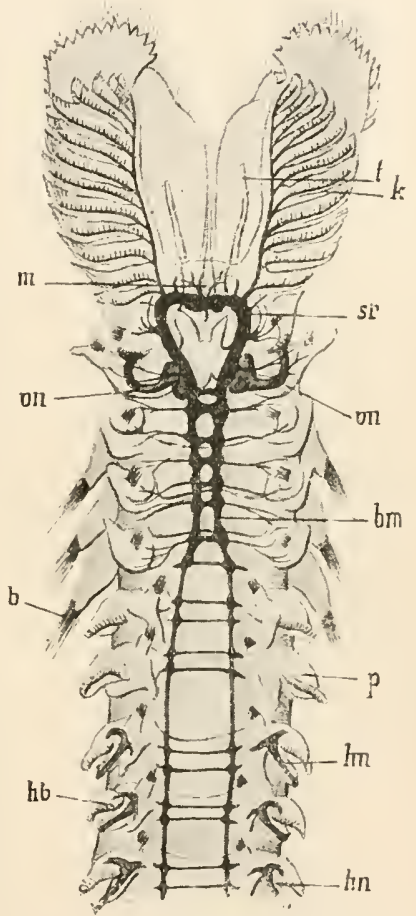

Fic. 147,-Nervous and nephridial systems in the anterior portion of the body of Sabellaria alveolata, from the ventral side, atter $\mathbf{E}$. Meyer. The nervous system is made black. Si, (Esophageal ring; $b m$, rentral chord; $t$, tentaeles; $k$, feeler grills; $m$, mouth ; $b$, bundles of setx; $h b$, hooked setx; $p$, parapodia: $v n$, anterior pair of ne. phridia; $h n$, posterior nephridia through which the sexual products are discharged.

direet eonnection with the hypodermis of the head segment. It often shows more or less distinct lobes, always symmetrically arranged, which look like special ganglia. The brain, which originally (and also ontogenetically) belongs to the head segment, ean in some eases stretch into the seeond segment; it can even more back into the 
second, third, or fourth segment (in certain earthworms). The infra-œsophageal ganglion is also by no means always placed in the sccond segment of the body; here and there it lies in the head segment, or in the first and second segment, or it moves farther back-farthest of all in Pleione, where it lies in the fifth or seventl segment. In the Hirudinea (Figs. 143 to 145) the infra-cesophageal ganglion fuses with a few of the subseqnent ganglia of the ventral chord, forming a considerable infra-cesophageal ganglionic mass, in which, however, by the number and arrangement of the diverging peripheral nerves, and by the arrangement of the ganglionic cells and fibre commissures, its composition out of several ganglia can be more or less distinctly recognised. The sane is true of the large posterior (sucker) ganglion (Fig. 145), which is composed of six fuser ganghia.

As far as the ventral cliord is concerned, the presence of a single ganglion in each segment is the rule; but there are exceptions to this rule in the most varied gromps. Sometimes one or two accessory ganglia are added to the principal ganglion, e.g. in the Serpulidce two ganghia are typically present in each segment. On the other hand the ganglionic masses may become very indistinct or be altogether wanting (Archiannelide, and isolated forms in the most varied groups). In - Sternaspis the ventral ehord shows ganglionic swellings only in the most posterior part of the body. The fusion of the two lateral halves of the rentral chord is often limiter to the ganglia, whilst the longitudinal commissures run as completely separated strands. These again may lie so close to each other that they appear externally to be one single strand. It may even in various forms cone to a fusing of the two commissures, so that the ventral chord then consists of a single strand, which, e.g. in the Archiunnelide, does not even show the segmental ganglionic swellings, and then recalls in a striking manner the ventral strand of the Gordide. From the ganglia of the ventral chord there arisc on each side nerves, generally 2 or 3 , which run upwards in the body wall and innervate the musculature, the integmment, and the segmental sensory organs, where such are present. It has been shown in some cases that this innervation takes place by means of a sub-epithelial nerve plexus developed all over the body. Lateral nerves may also diverge from the longitudinal commissures between 2 consecntive ganglia. The same is the case in the most anterior longitudinal commissures - the esophageal commissures.

There is often (especially in Hirudinea) in the ventral chord a delicate median strand of longitudinal fibres which is called the intermediate nerve. The ventral chord is nearly always covered by a single or double slicath of comnective tissue (neurilemma sheath), in which longitudinal inusele fibres run, principally in Oligoehete and Hirudinece.

Certain tubes with a wide lumen and wall formed of neurilcmma, which run back in varying but always small numbers on the dorsal side of the ventral ehord, deserve special attention. These tubes, which are called neurochord strands or giant nerve tubes, begin anteriorly in the cesophageal commissures or in the infracesophageal ganglion, and streteh to the most posterior end of the ventral chord. They were in all prolsability originally the nemrilemma sheaths of giant nerve fibres, arising from larger ganglionic cells which lay in the ganglia at different parts of the ventral chord. Various obscrvations make it mrobable that the nerve fibres in the ncurochord tubes in various Anmulata degenerate, the nemrochord tubes themselves persisting as elastic organs of support, containing a watery fluid mixed with the remains of the original nerve substance. Such degeneration is, however, denied by some authorities.

The typical position of the ventral chord, and generally of the whole central nervous systen of the Annulata, is in the body cavity on the imner side of the musculature. As the lorain very often passes into the hypodermis of the head with- 
out sharp limitation, so the posterior end of the rentral ehord in most oligochecta and Polychece prasses without sliarp limitation into the hypodermis of the anal segment. In many Chatopode of the most varied divisions, indeed in single gencra of different families, the nerrous system even in adult animals shows an cmbryonic condition, in so far as it lies outside the body musculature in the deeper part of the epirdernis. This position of the central nervous system is thus far from being characteristic of the so-called Arehiannelicke, and we (an in gencral give it no special systematic signifieance. We find besides in various divisions all transition stages, from the position of the ventral chord in the body eavity to its hypodermal position, since it can lie in the body musculature between the hylodermis and the body cavity. Mloreover, in Corvitelle, anteriorly, the ventral chord lies in the body cavity, then passes in between the musculature, and finally, posteriorly, comes to lie in the hypodermis.

The symmetrical halves of the rentral chord may separate in some cases, and the ventral chord can thus assume the form of a ladder nervous system (Figs. 146 and 147) (Hermella, many Serpulide, S'pinther, and in the pharyngeal region in the (Thertogestrider). In the Aphanoneura (ADolosoma) the ventral chord is said to be entirely wanting, or it lies in a quite embryonic condition imbedded in the hyporlermis.

The nervous system of the Echimidu? (Fig. 148) deserves special attention. A distinctly marked supra-cesophageal ganglion or brain is wanting. The resophageal ring is very much elongated, in keeping with the great length of the prostomium. Its two limbs (cesophageal commissures), which run laterally in the prostomium (proboscis), and which coalesce at its anterior end, give off numerous branches towards both the exterior and interior; those branches which run dorsally inwards may represent transverse commissures between the limbs of the oesophageal ring. Below and behind the mouth the limbs of the osophageal ring coalesce to form an unpaired rentral strand, which in adult animals has no ganglion swellings, but is supplied with ganglionic cells throughout its whole course; this strand rums in the rentral middle line on the body wall to the posterior end of the body, and gives off to the right and left

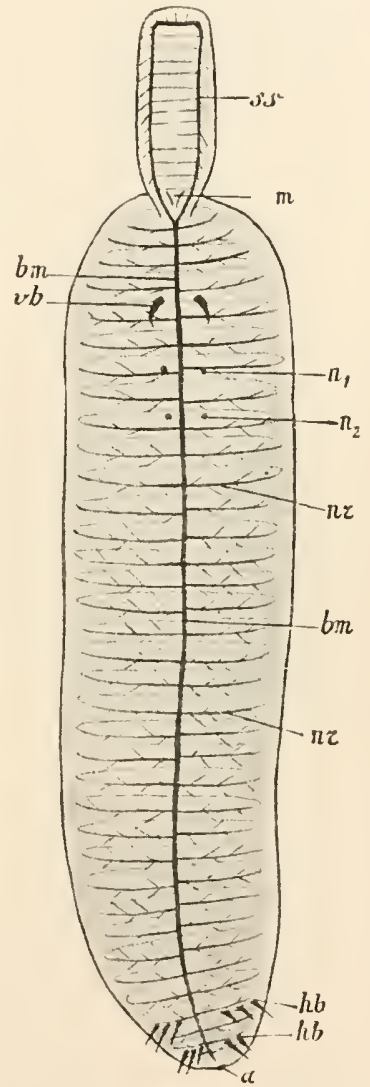

Fig. 148.- Nervous system of Echiurus, diagrammatic. ss, The two limbs of the oesophageal ring, which join at the anterior end of the prostomium and enter the extreme anterior end of the ventral chord $(b m)$ behind the mouth ; $n$, nerve rings; $v b$, anterior hooked setre; $h b$, the two posterior circles of setæ; $n_{1}, n_{2}$, apertures of the nephridia ; $a$, anus. at short intervals lateral branches which correspond with the rings of the outer integument. The corresponding right and left lateral 
branches pass into each otler dorsally, and thus form in the body wall numerous consecutive nerve lings.

The nervous system of the Myzostonizle (Fig. 149) is now very exactly known. It consists of an cesophageal ring surrounding the base

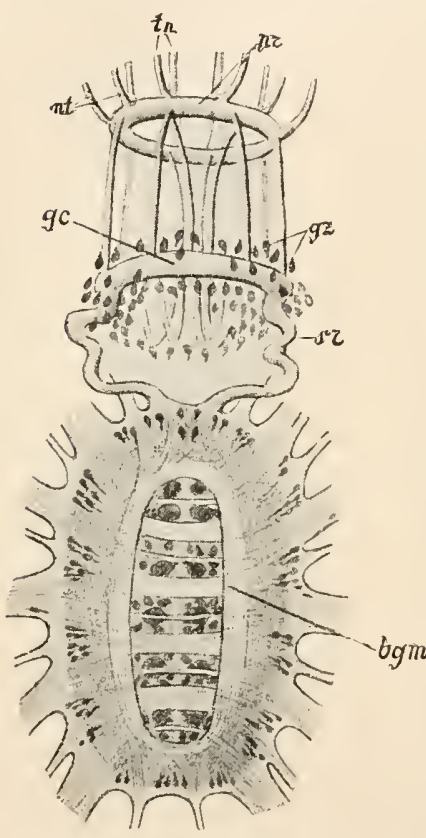

Fic. 149.- Central nervous system of Myzostoma, after Nansen. gc, Cerebral commissure; $p r$, pharyngeal nerve ring; bgm, ventral ganglionic mass, with the proximal part of the diverging nerves; sr, asophageal commissures; $t n$, tentacle nerves ; $g z$, ganglionic cells. of the pharynx, whose dorsal lateral portions are somewhat thickened, and so represent a weakly dereloped brain. Close to the oesophageal ring lie ganglionic cells. Further forward in the pharynx a second nerve ring (pharyngeal ring) is found, which is connecter with the nesoplageal ring by several longitudinal nerves, and gives off nerves to the tentacles at the free anterior edge of the pharynx. On the ventral side, under the integument, lies a large, elongated, ganglionic mass, from whose anterior end the two commissures (limbs) of the cesoplageal ring arise. The ganglionic mass represents a rentral chord which consists of sereral (probably 6) fused pairs of ganglia, and in which an intermediate nerve is to be found. From this ganglionic mass 11 alternately stronger and weaker nerves radiate on each side towards the circumference of the disc-shaped body ; these nerves branch in a complicated manner and innervate especially the musculature of the parapodia, the hooks, the cirri at the edge of the body, and the integument and its musculature. The existence of a sympathetic nervous system also seems probable.

Prosopygia. - The nervous system of the Sipnenculacen is in many respects closely related to that of the Echiuricle. As there is no long prostomium, the resophageal ring is also not elongated anteriorly, but forms a simple ring at the anterior end of the enteric canal. This ring in the Priapulicie is only a little thickened dorsally, while in the Sipunculide it enters a well-developed brain. Nerves diverge from the brain to the anterior end of the body and to the tentacles (where the latter are present). Nerves also diverge from the nosophageal ring; 2 of these in sipunculus supply the intestine, forming a ganglion on each side, while in Priapulus 4 penetrate the pharynx. The ventral strand, which is covered with ganglionic cells along its whole course, runs in the ventral middle line of the body to its extreme posterior end, where it swells somewhat. In its whole 
course it gives off, just as in the Echimide, corresponding right and left lateral nerves, which, rumning in the body cavity, unite dorsally to form nerve rings (at least in sipunculus). Each pair of nerves corresponds with one of the circular muscle bundles and with one of the more or less distinct rings of the outer integument. In the Priupulida it is said that there are weak but regularly recurring swellings of the ventral chord which correspond with the circular muscle bands. While in the sipunculide the central nervous system lies in the body cavity, in the Priapulide it is in close comnection with the hypodermis.

Whereas in the Echiuride the rentral chord is distinetly segmented in the early stages of development, such a segmentation is wanting in the Sipunculaced even in those stages. The veutral strand of the latter is nevertheless homologous with that of the Echiuride and with the ventral ehord of the Anmulute in general. The sarve rings of the Sipunculace evidently eorrespond with those of the Echiuridu. There can be no doubt as to the lomology of the brain and resophageal ring. We have also seen that the ventral chord, even in true Chotopoda, may present no ganglionic swellings, and may fuse into a single median ventral strand. It is a question whether the nerve rings of the Echiuride and Sipuneulacen are repreated segmentally. In the Echiuridce several body rings with smaller papillæ alternate with one with larger papillie. The setie only oceur on the rings which earry the larger papille. We also find that the nerve rings in the body rings with the larger dermal papille, are stronger than the others. It seems probable that several rings go to one segment, and that the mumber of these rings with larger papille and stronger nerve rings eorresponds with the true number of the segments. In the Chetopoda also (apart from the Hirudinea) one segment is sometimes externally divided into 2 or more rings, and more than one ganglion of the ventral chord may lie in one segment. In the Hevmellider and Serpulide we find typieally 2 pairs of ganglia in each segment, and further 2 transverse commissures and 2 lateral branches on eaeh side, whieh ascend in the body wall towards the dorsal middle line.

The nerrous system in other Prosopygic is remarkably weakly developed. The ventral chord is reduced to the infra-osophageal ganglion, and even this may be wanting. The small development of the nervous system is probably to be traced to the stationary manner of life, which results in a reduction of the specific sensory organs, and-by the development of tube-dwellings, shells, or cases-of the general body musculature (dermo-muscular tube).

Phoronis possesses a nerve ring surrounding the mouth at the base of the tentacles. The anus lies outside the nerve rins. From the dorsal part of the ring a nerve arises which runs backwards asymmetrically on the left side, through about two-thirds of the length of the body, and with a tube (notochord?) passing through it. The morphological significance of this nerve is unknown. The whole nervous system lies in the hypodermis outside the hasal membrane.

The nervous system of the Biachiopoda (Fig. 150) is weakly developed. It consists of a delicate nesophageal ring, whose upper portion is only very slightly swollen into a supra-resophageal ganglion. The infra-oesophageal ganglion is indicated by a thickening of the 
ventral portion of the cesophageal ring, and in some cases two lateral swellings can be made ont.

From the supra-cesophageal ganglion two nerves run into the arms;

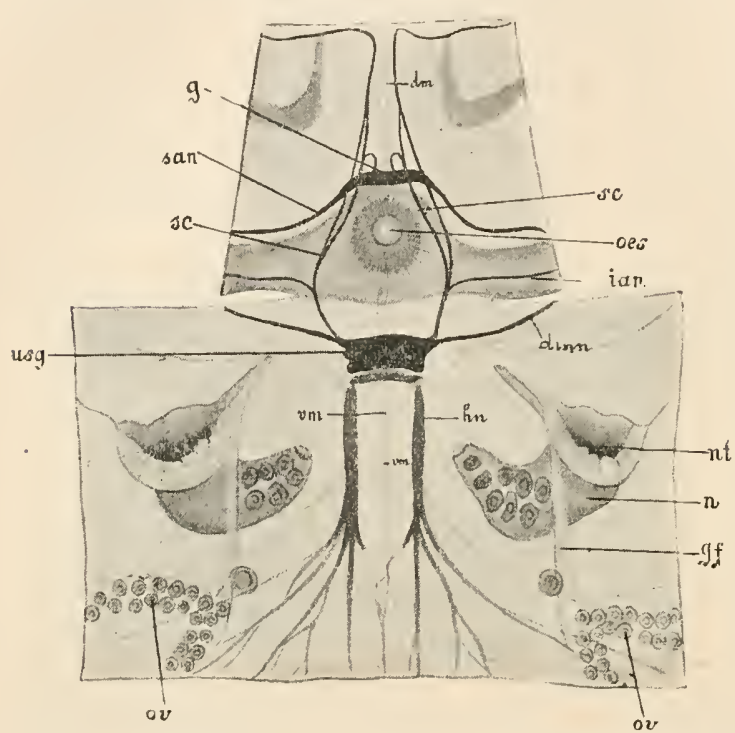

Fig. 150.-Preparation of Terebratula vitrea for demonstration of the nervous system, the ovaries, and the nephridia, after van Bemmelen. Anterior body wall after removal of the arm apparatus, the enteric canal, and the closing muscles, spread out and seen from within. Above lies a part of the dorsal boly wall; below, a part of the ventral body wall. $g$, Brain; sc, esophageal commissures; usg, infracesophageal ganglion; sun, arm nerve proceeding from the supra-œesophageal ganglion; $i a n$, ditto from infra-cesophageal ganglion; $\mathfrak{e s , ~ \omega s o - ~}$ phagus; $d m n$, dorsal mantle nerves; $h n$, nerves proeeding backwards from infra-cesophageal ganglion; $n$, neplıridia (oviduets); $n t$, nephridial funnel; $g f$, genital folds; $o v$, ovaries; $d m$, dorsal mesentery ; $v m$, ventral mesentery.

ing a plexus. The nervous system of the Brachioporlu lies under the integument.

In the Bryo:oa, only the supra-nsophageal ganglion of the esophageal ring is retained; it lies as a generally inconsiderable mass (occasionally with thickened lateral parts) dorsally over the fore-gut, between mouth and anus, under the integument. From this ganglion nerves run chiefly into the tentacles, and further to the two ciliated pits, when such are uresent.

Rotatoria.-Over the asophagus there lies a ganglion (supra-cesophageal ganglion) which sends off nerves to the wheel organ, the cutaneous organs of touch, and the muscles. It lies under the integument.

In Dinophitus also, in front of and above the mouth (in the prostomium), is found a mass of fibres surrounded by ganglionic cells, which represents the supra-œsophageal ganglion. In Dinophilus gigas two longi- 
tudinal nerves rise out of it, which pass by the mouth, and run on both sides of the body immediately beneath the integilment to its posterior end. These longitudinal nerves must represent the separated lateral halves of the ventral chord of the Annulate. Transverse commissures seem to be wanting.

Chrtognatha (Figs. 151 and 152). -The nervous system is here well developed. The central nervous system and the peripheral nerves lie, with the exception of a single portion, external to the musculature in the body epithelium. The brain or supracsophageal ganglion lies dorsally in the head segment, while the infra-œsophageal ganglion lies ventrally in the trunk segment and surpasses the cephalic ganglion in size. The cephalic and ventral ganglia are connected by 2 long commissures. Besides these 2 commissures, the supra-cesophageal ganglion gives off 2 strong nerves which penetrate the mesoderm forwards and downwards, and which we may call motor nerves, 2 lateral nerves which supply the integument of the head, 2 outer posterior nerves which, after a short course, reach the 2 eyes behind the supra-cesophageal ganglion (nervi optici), and 2 inner posterior nerves which supply the unpaired sensory organ lying behind the eyes which is supposed to be the olfactory organ (nervi olfactorii). A great number of nerves radiate from the ventral ganglion, among which the continuations of the 2 osophageal commissures, after rumning through the ventral ganglion, are found as 2 strong longitudinal strands, which, after giving off numerous lateral nerves, themselves end in fine nerve fibres. All nerves diverging from the ventral ganglion and the posterior longitudinal nerves pass finally into a plexus of ganglionic cells and nerve fibres, which is developed

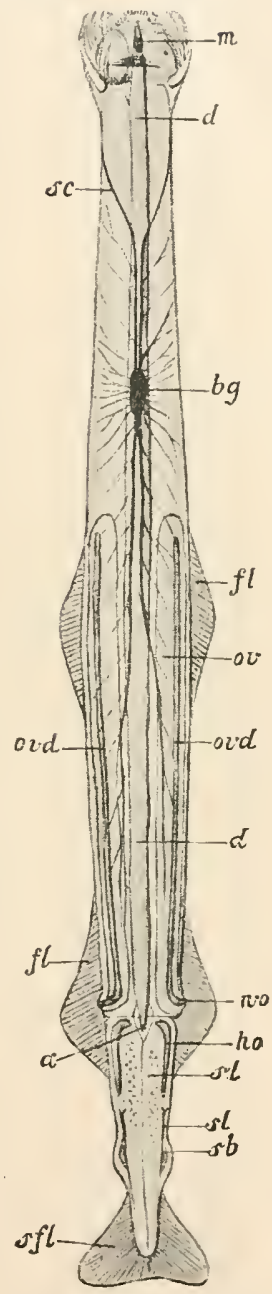

Fig. 152. - Sagitta hexaptera, seen from the ventral side, after O. Hertwig. $m$, lloutl ; $d$, intestine ; $s c$, cesophageal commissure; $b g$, rentral ganglion; $t$, fins; or, ovarium; ovd, oviducts ; $w o$, female genital aperture; $a$, anus; 70 , testes ; sh, tail carity; sl, sperm cluct; sb, sperm resicle; $s f$, caudal fin. 
in the epithelium all orer the body. The motor nerves of the supraasophageal ganglion form a ganglion each on the sides of the fore-gut in the cephalic segment (lateral cephalic ganglia), with small accessory ganglia. The musculature of the head and the fore-gut are supplied with nerves by these ganglia. This mesodermal part of the nervous system of Sugittu recalls the cesophageal nervous system of other worms. We do not yet know how the trunk and caudal musculature are supplied with nerves.

\section{Sensory Organs.}

All the different kinds of sensory organs are found in the wormsorgans of touch, sight, hearing, smell, and taste. Besides these, in a few divisions we meet with sensory organs which cannot at present be classed in any of the above categories - the lateral organs of the Chetopola, the lateral eyes of Polyophthalmus, and the segmental organs of the Hirudinea. It must not be forgotten that the functions of the sensory organs of the worms are as little experimentally established as are those of most other invertebrate animals; and that it is almost entirely their position and structure which lead us to consider them auditory, olfactory, etc. The function of the organs of touch indeed is more surely established. That the worms in some way or other see with the sensory organs which have been indicated as eyes may also be considered certain, though we do not know what and how they see.

The sensory organs are most numerous and best developed in animals leading a free aquatic life (Polychete, Erruntiu, Chetognatha), and among these again the good swimmers take the first place. The worms which are attached at the bottom of the water and those which lurk in holes are not quite so fully provided. In worms living: in mud and sand or in earth the sensory organs are much reduced, and this is the case in the highest degree in parasitic and attached animals. In the latter, however, the strongly developed organs of touch form an exception. Where the sensory organs are reduced in adult, stationary, or parasitic animals we often meet with them well developed in their young stages, when they as larve move about freely. In order of frequency we have the organs of touch, which are universally distributed, then the eyes, then the olfactory organs and organs of taste. Organs of hearing have been certainly observed only in a few cases (Arenicolidee, Serpulacea, Terebelloidea).

\section{A. Organs of Touch.}

Everywhere, except in the worms provided with a thick shell, the entire integument is the seat of a highly developed sense of feeling or touch. This sense is served in a special manner by epithelial sensory cells, which carry at their free end sensory hairs or sete, and at their basal ends are continued as nerve fibres, which are themselves 
generally processes of peripheral ganglion cells. A plexus of nerre fibres and ganglion cells lying immediately under the body epithelium can now be proved with certainty to exist in various worms, especially in the Chcetroda and Chotognatha. In parasites with a thick outer cuticle papilla, rod- or seta-like processes of this cuticle, which are principally developed at the anterior end and near the genital apertures, play the part of organs of touch. As a rule the tactile cells are most numerously present in that part of the integument of the worm where the body has most points of contact with its immediate surroundings. Such points are, above all, the anterior end of the body, the neighbourhood of the mouth, and the various appendages. There are some such appendages which, on account of their position and their specially rich provision of tactile cells, may be regarded as specific organs of touch. We may mention in illustration the feelers on the heads of the Chcetopoda, especially of the Polychecta, the cirri of the parapodia, the prostomium of the Echiuride, the tentacles of the Prosopygia (cirri on the oral arms of the Brachiopoda), and the wheel organ of the Rotatoria. It is obvious that such organs of touch in worms inhabiting tubes or shells can only attain development at the anterior end of the body, which carries on the relations with the outer world; and it is equally intelligible that in such worms these same organs should carry on other relations to the onter world as well (prehension of food, respiration). Hence the strong derelopment of the tentacular apparatus in the tubicolous and shelled worms (tubicolous Annelids, most Prosopygia, and the tubicolous Rotatoria).

The sense of touch is very strongly developed in the Himulinea. The tactile cells, each of which is provided with a fine hair, form groups (tactile cones), which are arranged in 18 longitudinal rows. They are developed on the warts or papillæ, when such occur (Fig. 156).

\section{B. Eyes.}

Their occurrence, number, and arrangement.-In many genera and species of Nemertina the eyes are wanting. In others small eyes occur in varying numbers $(2,4$, or many) at the anterior end of the body. In the Nemutoda the absence of eyes is the rule, the presence of 2 simple eye-spots at the anterior end of the body (in some of the free-living forms) the exception. The Acanthocephala are without eyes. In the Anmulata the presence of eyes is the rule, their absence the exception. The Hirudinea possess 1 to 5 pairs of eyes in the anterior rings of the body. Among the Oligochata, which mostly live in mud or earth, only the Naidomorpha possess eyes-one pair in the head segment. In the Arcliumelida which have a similar mode of life, or are, like Histriodrilus, parasitic, the eyes are either wanting or reduced in the adult animal. Most of the Polychetu are provided with eyes, which lie, with very few exceptions, in the head segment. Most of the Errontiu have 1 or 2 pairs of well-dereloped eyes, which 
in the Alciopide reach a remarkable size; many Sedenturiu are eyeless; where, however, eyes occur they lie as small so-called eye-spots, generally in great numbers, in the prostomium, at the part where the brain is connected with the hypodermis. In Fulriciu eye-spots occur at the posterior end of the body; in some species of Sabellu on the tentacle gills. For the so-called lateral eyes of Polyophthalmus see below. The Echiurite, which live in mud or lurk in holes, and the parasitic Mysostomide, are blind. The absence of eyes is characteristic of the whole class of the Prosopygiu. The Potetoria possess an unpaired or a paired eye-spot lying on the brain, but this is wanting or rudimentary in the adult condition in stationary forms. Dinophitus has 2 eye-spots in the prostomium. In the Chortognather 2 eyes lie on the dorsal side of the head, behind the brain, in the body epithelium.

Structure of the eyes.-A comparative morphology of the eyes of worms is at the present time a desideratum. At any rate it now appears certain that the eyes in the various divisions need not be homologous. The eyes which appear in pairs are perhaps homologous, such as those developed in larve of the Trochophora type in close connection with the cerebral rudiment; these very often disappear through metamorphosis, or degenerate. As a detailed account of these always more or less complicated organs is here impossible, we select a few for brief description, viz. the eyes in Capitella, in Alciope (the most highly developed eye among worms), in a Chatognathan, and in Hirudo.

1. The eye of Capitella.-The numerous eyes (ocelli) of Capitella lie in the prostomium at the part where the brain fuses with the hypo-

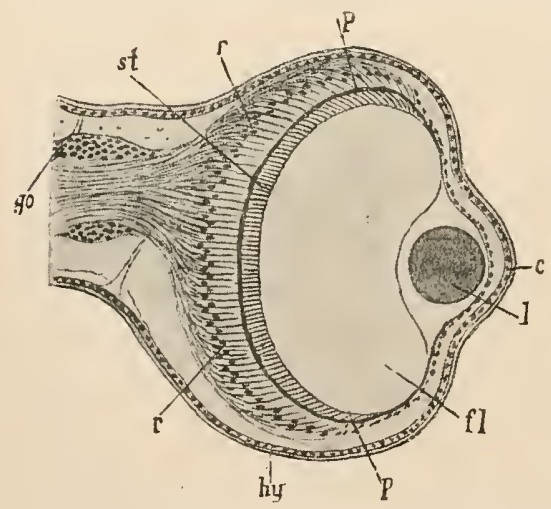

Fia. 153.- Section through the eye of an Alciope (Callizona Grubei). $h y$, Hypodermis; $c$, cornea; $l$, lens; $f$, eye fluid ; $p$, pigment of the retina ; $r$, retinal cells; st, rods; go, ganglion opticum of the brain (after Carrière). each side of the head. They are covered by a thin layer of hypo-

dermis. The following are the elements of a single eye. We find shipper-shaped refracting cells, whose outer portion is homogeneous and transparent, while the inner part contains pigment. Each of these cells is continued as a nerve fibre towards the brain, this nerve fibre entering a ganglion cell of the central optic lobe. The refracting cells of the eyes are connected together by thread cells of the hypodermis. The cuticle is arched over the eye.

2. The eye of Alciope (Fig. 153). - The two eyes of Alciope stand out spherically, one on 
dermis with its cnticle, which form the outer cornea orer the centre of the protruding eye. The eye itself is a vesicle whose posterior thicker wall forms the retina, while the anterior thinner wall is the inner cornea. The elements of the retina are long cells standing closely pressed together, in which three parts can be distinguished: (1) towards the brain, the cell body with a nucleus; $(2)$ the rod, which is directed towards the hollow of the bulb; and (3), between these two, a thin layer of pigment. Under the cornea lies the spherical lens. The rest of the eye is filled with fluid. The retinal cells are continued into nerre fibres, which soon enter the ganglion cells of the optic lobe (ganglion opticum); the latter is connected with the brain by a mass of nerve fibres.

3. The Chotognathan eye (Fig. 154) is spherical. In the centre of the sphere lie 3 bi-convex lenses imbedded in pigment; to the outside of each of these 3 lenses a third part of the whole retina is applied in such a way that the three parts together form the wall of the sphere. The retina consists of cells ; the portion of each of these cells which is in contact with the lens is rod-like, and the part which is turned ontwards is the cell-borly with its nucleus. At the circumference of the sphere, each retinal cell is continued as a nerve-fibre.

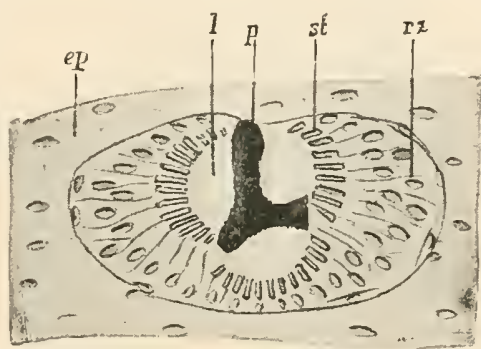

Fie. 15t.- Section through the eje of Sag itta hezaptera, after 0 . Hertwig. ep, Body epitheliun ; $l$, lens ; $p$, ligment; st rods ; $r z$, retinal cells.

All the nerve fibres unite in the nervus opticus (Fig. 151, p. 227). The Chotognathan eye may be considered to have come from 3 simple fused ocelli.

A comparison of the three eyes just described shows how greatly the eyes of worms may vary in structure.

4. The eyes of Himulo (Figs. 155, 156) lie in the anterior rings of the body and vary in number. They are cylindrical and stand at right angles to the somewhat modified hypodermis with which they are in contact. The optic nerve enters at the base, its fibres passing into long sensory cells which lie in the axis of the eye. Around the axis are arranged large clear cells, each containing a mucleus and a refractive substance. The whole organ is imbedded in strongly pigmented connective tissue. Our present knowledge of the structure of these organs hardly justifies us in calling them eyes ; morphologically they are transformed tactile organs.

\section{Olfactory Organs (Ciliated Organs).}

In many worms of the Nemertian and Chetopoden divisions there are found, at the anterior end of the body, 2 lateral strongly ciliated 
parts of the hypodermis, the so-called ciliated organs, ciliated clefts, ciliated pits, ciliated prominences, which are regarded as olfactory

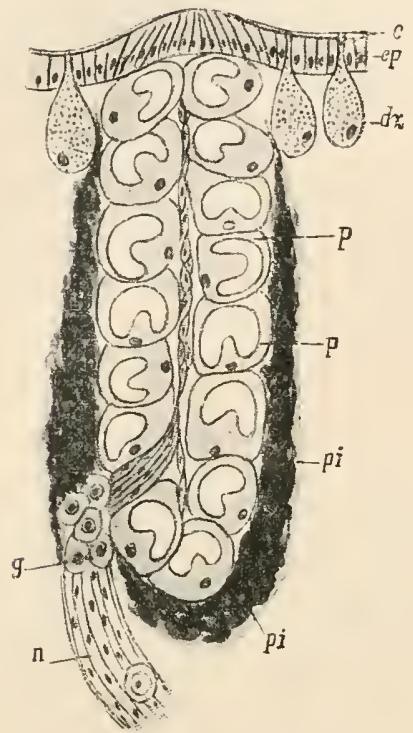

Fig. 155.-Section through the eye of a land leech. $c$, Cuticle; $e_{p}$, hypodermis ; $p$, large elear cells ; $g$, ganglion cells ; $n$, nerve ; $d z$, cutancous gland cells ; pi, pirment (after Whitman).

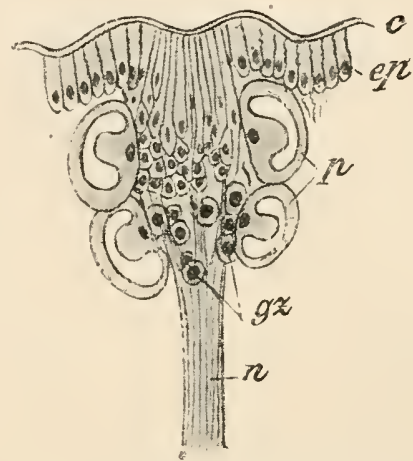

Fic. 156.- Section through a tactile sensory organ of Macrobdella, after Whitman. c, Cuticle; $e p$, hypodermis ; $p$, large clear cells; $g z$, ganglion cells; $n$, nerve. The sensory cells are here clearly seen to be long hypodermis cells, the tactile hairs which they carry are not depicted.

organs. The body epithelium at these points consists of ciliated sensory cells, whose bases are prolonged as nerve fibres. These nerve fibres are comnected under the sensory epithelium with a plexus of ganglion cells, which is itself again connecter with the brain. In the Chetopola the ciliated parts just mentioned are frequently depressed in the form of pits or sacs, and are often protrusible. A special olfactory lobe (ganglion olfactorium) may be developed on the brain in close proximity to the ciliated organ, this lobe bearing the same relation to the olfactory organ that the lobus opticus or ganglion opticum bears to the eye. In the Nemertina these olfactory lobes are very strongly dereloped, and often sharply separated from the brain ( $c f$. p. 216 and Figs. 140,141). The ciliated organs here are pits which open outwardly by means of longitudinal clefts at the sides of the head, and which in the Schisonemertina are continned inwardly as ciliated canals, penetrating to the interior of the cerebral olfactory lobes. It is probable that all these ciliated organs are homologons formations, and correspond with the ciliated grooves at the extremity of the head in the Turbelluria.

In the Chetopode such organs have been found more or less developed in the Capitellide, Eunicide, Nereidee, Phyllodocide, Syllide, Opheliacea, Typhloscolecidae, 
Sabellida, Archianinelida, Tomopteride, Ctenodrilus, and Aphenonewre. Sensory organs of similar structure and in a similar position have been observed in Éryozoc (Locosome lihabdopleure) and in Phoronis.

In the C'llatognatha (Fig. 151, p. 227) a circular band, partly consisting of ciliated epithelial cells, lies like a ridge on the ordinary epithelium cells. It is considered to be an olfactory organ, and lies behind the eyes between the head and the trunk; this unpaired sensory organ is innervated by a pair of olfactory nerves rumning between the nervi optici.

\section{Organs of Taste (Cup-shaped Organs).}

There occur also certain sensory prominences of the borly epithelium, essentially similar in structure to the olfactory organs just described, and called cup-shaped organs from the fact that they can be withdrawn into pit- or cup-shaped depressions of the integument. They always occur in large numbers and widely scattered. As, however, they are specially numerous at the edge of the mouth, in the oral cavity, and also in the pharynx, they are held to be organs of taste.

The structure and distribution of these organs in the Capitellide is well known. In Notomastus, Dasybranchus, and Heteromastus they occur only in the prostomium, thorax, and pharynx, in Mastobrunchus and Capitelle on the abdomen also. Similar sensory organs are found also in Oligochete (Lumbricide, Chetogastriile, Enchytrceide), especially numerous in the head, chiefly on the upper lip. Among the Polychetu they have been observed in the Nereide. (Nephthys) and the Eunicidce (on the pharynx and in the buccal cavity). In the Hivudinea, where they were first observed and exactly described, they are always found on the lips. Cutaneous sensory organs, which are found in great numbers in the sipunculide and Echiviride on the papille not only of the body, but of the proboscis as well (often arranged, like the papillie themselves, in longitudinal or transterse rows), probably also belong to the category of cup-shaped organs.

\section{E. Lateral Organs.}

These retractile sensory organs only occur in the Chetopoda and agree essentially in structure with the cup-shaped organs. The numerous thread-like sensory cells of these organs carry sensory hairs, and are connected on the one hand with transverse muscle fibrillæ which together form a retractor for the organ, and on the other hand with a plexus of ganglion cells which is again connected by a special nerve with the ventral chord. The above is the case in those Capitellitle which have been most carefully examined in this connection. The lateral organs are most clearly distinguished from the cup-shaped organs by their strictly segmental arrangement. There is a pair in each segment, one on each side between the dorsal and the 
ventral parapodia. They are found not only in the Capitellidu, but also in Polyophthalmus and the Amphictemile, and among the Otigocheter in the Lumbriculide. There are many reasons for considering the lateral organs to be homologous with the dorsal cirri of the ventral paraporia of other Polycherta, and in the family of the Glyceride we can follow, almost step by step, the transformation of these cirri into lateral organs. The cirri, being sensory organs, their gradual reduction into papilla causes the tactile cells scattered in their hypodermis to collect together to form the compact sensory epithelium of the lateral organs.

Strands of lateral ganglion cells appear always to occur in the lateral lines of the Oligncheta, entering the brain anteriorly. They are closely connected with the hyporlermis, and in the Lumbriculidus supply the lateral organs with nerves. They are probably also connected with the intestinal nerrous system.

The function of the lateral organs is at present an unsolved problem.

\section{F. Auditory 0rgans.}

There is a remarkable absence of auditory organs in the Vermes. They only occur in the Polychete, and there also only occasionally in a few families, viz. in the Arenicolide, in the Terebellide (Lamice), and Serpulide (Myxicolu, Amphiglene, Fubriciu). Their occurrence has also been proved in several Terebellid larve, in the larre of Enpomatus (Serpulide), and in a nearly related Chotopmden larva. They are paired, and lie in Arenicola on the osophageal commissures in the head segment, and in this case receire their nerves from the brain. In other forms they lie, as it appears, in the first trunk segment, and are supplied with nerves by the infra-cesophageal ganglion. In this point, as well as in their development, they recall the auditory organs of the mollusca. In adult animals they are vesicular (otocysts), the wall being formed by epithelial cells (sensory cells, auditory cells). The vesicles contain a fluid in which one or more otoliths are suspended.

\section{G. The Lateral Eyes of Polyophthalmus.}

Eye-like organs are found in strictly segmental orler somewhat beneath the insertion of the transverse muscular bands in the lateral line of Polyophthalmus. They occur in P. pictus in the Sth to the 19th body segments, and are closely comnected with the hypodermis which is free from pigment, and which with the cuticle covers each eye. Each eye consists of a lens, a pigment cup, and a body which consists of prismatic cells placed in this cup. The pigment cup and cell body together perhaps form a sort of retina (?) It must be expressly noticed that besides the lateral eyes, Polymphthalmus possesses cephalic eyes as well (3 in number) and lateral organs, and that it is very doubtful whether the lateral eyes are visual organs. 


\section{Excretory Organs-Nephridia.}

(Occasionally Ducts for the transmission of the Sexual Products.

Nemertina.--The excretory apparntus, which is always paired, consists of canals lined with epithelium and mostly ciliated, which as a rule rise in the blood sinuses of the body and open externally. It is limited to the anterior portion of the body. The efferent ducts always lie laterally over the longitudinal trunks of the nervous system. Its arrangement differs greatly in details. In all Nemertinu, the epithelial walls of the excretory canals (nephriclia) are glandular.

In Curinella (Paleonemertina) an excretory portion separates itself from the lateral vessels of the blood-vascular system, and falls into two parts, a glandular part and a reservoir. On the one side it is connected with the lateral vessels at two points, on the other with a canal which opens externally. In Carinoma the nephridium on each side consists of (1) a very short longitudinal canal which communicates with the lateral vessels at three points, and (2) an efferent duct which opens externally. In Carinina also the nephridial system on each side consists of two parts: (1) a compact mass of small canals, which projects inwards towards the blood sinus of the cesophageal region, and which (2) is connected with a nephridial cavity narrowing at its posterior end into a canal which opens externally.

While in the Paleonemertina (with the exception of Carinina) the nephrilia are in open communication with the blood-vascular system, such a communication has till now not been proved in other Nemertina. In the Schizonemertina on each side of the anterior region of the body there is either a single longitudinal canal or else a longitudinal network of canals, in which, however, one principal canal can generally be distinguished. These longitudinal canals, which lie in or on the

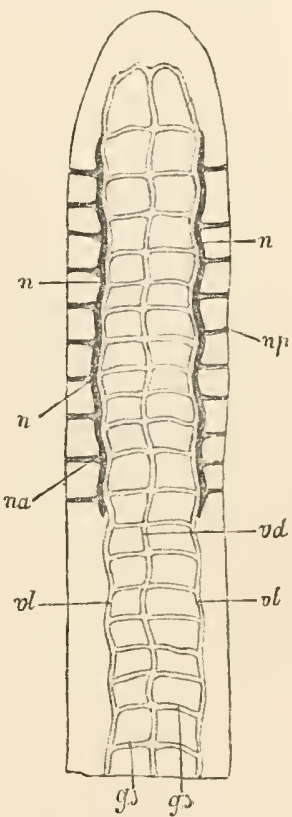

Fra. 15i.-Nephridial and circulatory system in the anterior portion of the body of a Nemertian, diagrammatie. n, Longitudinal canals of the nephridial system; $n p$, lateral a pertures of the same; $n a$, efferent ducts; $v i$, dorsal ressel; $v l$, lateral ressel; $g s$, transverse ressels between the dorsal and lateral vessels.

blood sinuses or lateral vessels on the inner side of the longitudinal muscle layers, reach the exterior on each side either (1) posteriorly through an efferent duct, or (2) through two ducts opening near the midldle of their course, or (3) through several often very numerous lateral ducts which are more or less metamerically arranged.

In the Hoplonemertina and Malacobdellide also, on each side, in the anterior region of the body, a longitudinal canal is found. This 
gives off, along its whole length, branches which again ramify. The longitudinal canals and their branches lie neither on nor in the blood sinuses, but are directly imbedded in the gelatinous connective tissue (body parenchyma). The longitudinal canals either open externally through several lateral efferent ducts, or on each side by one lateral canal, which may branch off from the longitudinal trunk either anteriorly, in the middle, or posteriorly.

The nephridial system of the Schizonemertina and Hoplonemertina shows a certain agreement with that of the Platodes. Here, as there, we meet with lateral longitudinal trunks which open externally on each side, either through one aperture (e.y. in the Platodes among the Rhabdocelida: Derostoma, Prorhynchus, Gyrator, Mesostoma; and among the Trematoda: Polystomida), or through numerous lateral ducts in more or less segmental arrangement (e.g. in Platodes among the Triclada). The longitudinal trunks of the Nemertinc may even, as in the Platodes, be broken up into a plexus, or they may be present in numbers. Where the nephridial system in the Nemertina (Hoplonemertina) is neither in direet nor indirect communication with the blood-vascular system, it belongs to the branched type, as in the Platodes, which have no blood-vascular system. In the Nemertinc, it is true, the nephridial system lies only in the front or foremost portion of the body. Terminal exeretory cells have not been proved to exist, and the canals are lined with a ciliated epithelium, while in the Platodes (everywhere and in all divisions?) each canal runs within cells arranged in a single row (intracellular. These differences, however, ought not to prevent a recognition of the homology between the excretory systems of the Platodes and the Nemertina.

Nemathelmia. - The Nematorlu and Acanthocephata must be described separately. In the first, longitudinal canals occur in the lateral lines; till now no inner lining of epithelium has been proved to exist. The two longitudinal canals unite at the anterior end of the body to form a longer or shorter unpaired canal, which opens externally near the brain by a ventral median pore. The homologies of these canals, which are considered to be excretory canals, are quite uncertain. In the Gordiulce they are wanting. The canal-like space (section of the body cavity) which surrounds the intestine of these animals is said to divide (in Gordins Preslii) in front of the cloaca into two branches, and these perhaps open into the cloaca. Whether this canal is an excretory tube is, however, quite uncertain.

In the Acanthocephala, in the subcuticle of the integument, a system of canals is found which will be described in the section on the vascular system. The anterior part of this canal system, which is quite separated from the posterior part, was formerly claimed as an excretory system; but there are difficulties in the way of accepting this view, chiefly because it has no external aperture.

Annulata.-The following scheme may be given as of general application to the excretory or nephridial system. It consists of paired tubes (nephridia), open at both ends, which are repeated segmentally. Each nephridium is in open communication with the body cavity or blood sinuses by an inner aperture; the external aperture lies in the integument. The nephridia therefore form an 
open eommunieation between the boly eavity and the exterior, and serve ehiefly for eonducting the waste produets of metabolism out of the body. Since the genital products are, in many Annulutu, developed out of the endothelium of the body cavity, then free themselves from the matrix, and ripen when floating freely in the coelomie fluid, an opportunity is given to them also of reaehing the exterior through the nephridia. The nephridia thus frequently undertake, in addition to their purely excretory function, the transmission of the genital produets to the exterior. This secondary function nay often beeome the principal function in some of the nephridia, which may then undergo a complete transformation, and in the Polychetu are called genital tubes.

As already explained, paired nephridia originally oceur in all the

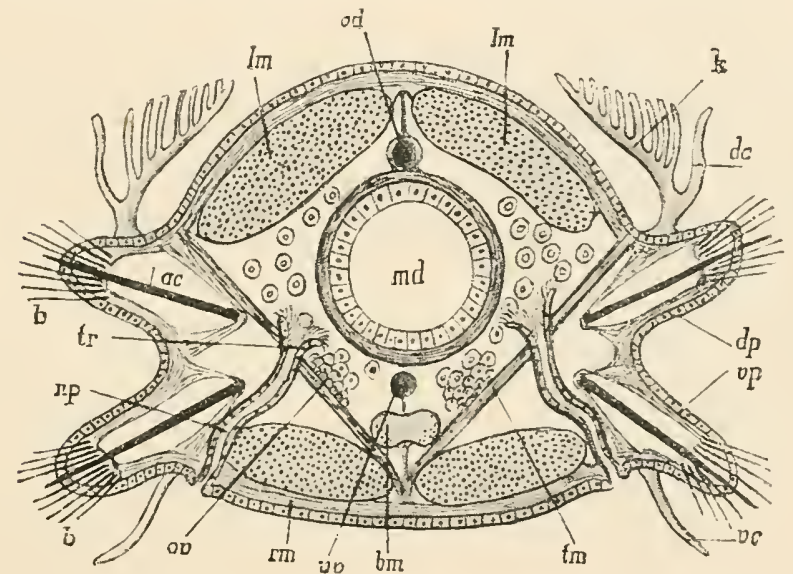

Fig. 15s.-Transverse section through a trunk segment of a carnivorous Annelid, diagrammatic. $b$, Setæ; ac, aciculum (supporting seta); $7 m$, longiturlinal musculature; $v c$, dorsal vessel ; $k$, gill; $d c$, dorsal cirrus; $d p$, dorsal parapodium; $v p$, ventral parapodium; $v c$, ventral cirrus; $t m$, transverse muscles; $b m$, ventral chord ; $v_{0}$, ventral vessel ; rm, circular musculature ; $o v$, ovary; $n p$, nephridia ; $t r$, nephridial funnel; md, mid-gut. In the body cavity are eggs.

segments of the Annulate body, even in the cephalic or oral segment. It may, however, happen that the nephridia in a smaller or greater number of segments do not attain development. It is further rery generally found that some of the nephridia begin to form early in the embryo or larva or young animal, and function as embryonic or larval kidneys, but afterwards entirely disappear when the permanent nephridia attain development. We shall call those which temporarily appear in the ontogenetic development provisional or embryonic nephridia. We can again distinguish two sorts of such provisional nephridia. (1) Those which appear in that region of the embryo or larva which corresponds with the subsequent heal segment, and hie at the anterior end of the eell mass (mesodern streaks), from which the most important organs of the segmented mesoderm come; these are 
the embryonic head nephridia or the head kidneys. (2) Those which appear in the trunk segments; these are the provisional trunk kidneys. The permanent nephridia, on account of their frequently strict segmental arrangement, are often called segmental organs, or on account of their looped or winding course (in Oligochete and Himulinea) looped canals.

We will first describe the three sorts of nephridia separately, and then discuss their morphological significance and their relations to each other.

A. The embryonic head nephridia (head kidneys).--These appear temporarily in the larva or embryo, and are laired. Their inner end lies in the cmbryonic head cavity. They have been ohserved in many Oligochesta and Polychocte. They are ciliated canals, which are not in open communication with the head cavity. The lumen of these canals is intracellular, i.c. the nephridia arc rows of consecutive cells perforater to form a canal. In this point the embryonic head nephridia agree with the permanent nephridia of the Oligochete and Hirudinee, and with the canals of the water-vascular system of the Platodes. They are occasionally branched $(e . g$. in the larve of Echiurus and Polygordius), like the water-vascular system of the Platodes and the nephridia of many Nemertina. Lateral branchings of the principal canals also occur in the permanent nephridia of the Hirudinca and Otigochota. Terminal cells provided with bundles of cilia (flames) often occur at the imner ends of the branched or simple nephridia; the flames project into the lumen of the canal, in which they undulate. These terminal cells resemble those of the water-vascular system in the Platodes.

B. The embryonic or provisional trunk nephridia.-These have till now been observed in comparatively few cases; it is, however, probable that they are widely distributed. They occur (like permanent nephridia) in strictly segmental arrangement as paired canals in those generally anterior. segments, in which in adults permanent nephridia are wanting.

Among the Oligochete it has been proved that in Rhynchclmis, in the 5 anterior trunk segments in which nephridia are wanting in adult animals, 5 pairs of provisional nephridia, which degenerate later, attain development in the embryo. In the Cupitcllide the nephridia are always wanting in a large number of anterior segments (thorax and anterior part of the abdomen), but this is only the case in adult animals. In the young animals, however, we meet with provisional neplridia in most of these segments, which are the better developed the younger the animal, and the further forward the segment to which they belong. In other words, the nephridia arise first anteriorly, and their degencration proceeds in order from before backward (in the thoracic and in some of the anterior abdominal segments) in proportion as the permanent ncphridia of the abdominal region attain development. In Nercis cultrifcra (Fig. 159) there are found in the larval stage 5 pairs of provisional or larval trunk nephridia in the 5 anterior segments, in which in adult animals we mect with no nephridia. As in most Oligochceta nephridia are wanting in some of the anterior segments, it is probable that provisional nephridia occur in these segments in the larval forms. The same may be conjectured, of the Polychata. In the Otigochate the nephridia are wanting in the genital segments, except in the Lumbricide. But here also provisional nephridia attain development in these segments at early stages. In the Hirudinca mrovisional nephridia arc developed in early cmbryonic or larval stages (2 pairs in Nephelis, 3 pairs in Hirudo, 4 pairs in Aulostoma) which disappoar early. As the larve are, at the time when provisional nephridia are present, still unsegmented, it camot be certainly decided what 
is their morphological significance. A certain number of the anterior and of the posterior segments of the adult Mirudo are without nephridia. 'This fact farours the conjecture that the larral nephridia of the Hirudinea are the provisional nephridia of the anterior trunk segments. Possibly the foremost fair of larral nephridia of the Hiruline represent the embryonic head nephridia (headkidneys) of other Annulata.

Concerning the structure of the prorisional trunk nephridia, the following may be saicl. In the Copitellide and Oligochutu they show in general the same structureas the permanent trunk nephridia. In vereis they are distinguished from the permanent nephridia by the want of an inner aperture opening into the body carity, i.e. of a fimmel: both by this fact and the fact that the nephridial canal is intracellular they recall the larval head nephridia of many Anmulate. The larval nephridia of the Hiruline have neither imer nor outer aperture.

$\because$ The permanent nephridia. - In every Annulute nephididium, if we for the time ignore the numerous complications and modifications presented by the different dirisions, the following three portions may be distinguished:-(1) an inmer ciliated a perture opening into the body cavity or into a blood sinus; this from its shape is often called the funnel; $(\mathcal{z})$ a canal connected with the above, which is generally ciliated, and often has glandular walls; and (3) a terminal portion opening externally. The central part or nephridial canal is intracellular in the Hirudinea and Oligochata, and generally much coiled (looped canal) (Fig. 160). In the Polycheta it is usually intercellular (lined with a many-celled epithelium) and not coiled in a complicated manner. The portion of the Annulate nephridium which projects

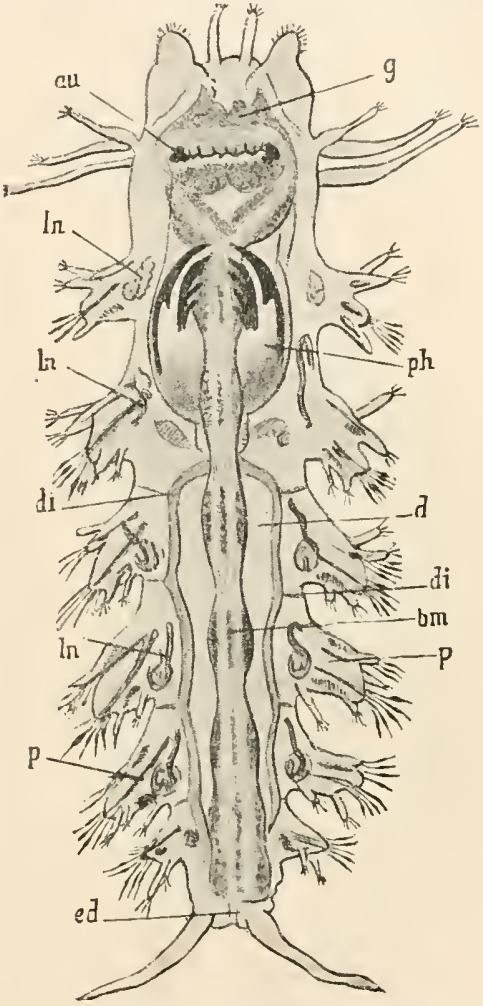

FIG. 159.-Diagram of a very young specimen of Nereis cultrifera, after Edward Meyer. $g$, Brain ; $a u$, eves; In, larval trunk nephridia; $p h$, pharynx with jaws; $d i$, dissepiments; $d$, intestine ; $b m$, ventral chord; $e d$, hind-gut; $p$, parapodia with cirri and setæ. On the head are the tentacles and sensory cirri. into the body cavity is ontwardly covered by a continuation of the peritoneal endo. thelium.

In the Hirudince the permanent nephridia are wanting in a number of the anterior and posterior segments. In the rest of the body they are found in strictly segmental arrangement, one pair in each. segment. 'The position of the funnels in the body varies very much; they lie either in the ventral blood sinus (Clepsine), or in those simuses in which the testes lie (Hirudo, Aulostoma), or in other blood sinuses of the body. The nephridial canal has many windings and loops which lie close together, the finer details of which it is extremely difficult to make out. Finally, it opens externally either directly without terminal swelling (Clepsine), or it opens into a vesicle lined with epithelium (ciliated in 11 . 
medicinalis), which opens externally through a pore. That part of the nephridial canal which comes after the funnel is distinguished by the fact that fine, branched, and often anastomosing canals enter its intracellular principal lumen. The cells of this portion are in fact perforated by branching canals. In Hirudo the fumel is closed towards the blood simms in which it lies.

The nephridia in the genera Pontobelclla, Branchellion, and Piscicolo differ much from the above, as they form in each segment a complicater network of canals which are always intracellular, this network opening outwardly by 2 apertures and entering the blood simuses of the body throngh 2 funnels.

The ncphridia of other Oligochecte show (Fig. 160) great correspondence with

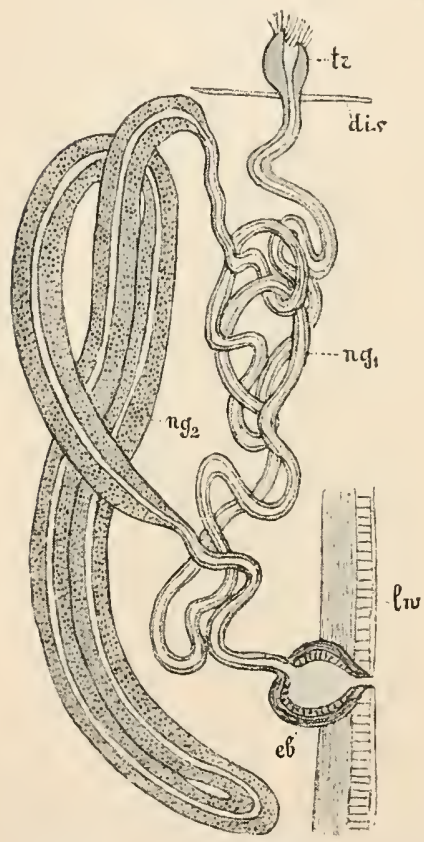

FIG. 160. - Nephridium of an oligochæte, diagrammatic. $t r$, Funnel; dis, dissepiment; $n g_{2}$, glandular; $n g_{1}$, nonglandular portion of the nephridial duet; $e b$, terminal vesicle; $l w$, body wall (partly after Vejdovsky). those of the Hirudined. The funnel of a nephriclium projects from the anterior wall of each dissepinent into the cavity of the segment lying anterior to that in which the rephridium lies. Starting from the fumnel, the nephridial canal, which is everywhere intracellular, first passes through the dissepiment, forms more or less complicated loops in that segment of the body cavity which lies posteriorly (in these coils we can generally distinguish several different portions), and finally emerges through a terminal frortion into a vesicle which opens outwardly. This vesicle is often provided with muscular walls. The fumel and external aperture of a nephridium thus always lie in two different segments ; the two external apertures of a prair of nephridia lie in the same segment as the inner funnels of the pair of nephridia which come next in order posteriorly. This position of the imer and onter apertures of the nephridia in 2 consecutive segments is maintained even in those cases where, as in the middle body segments of Phrcatotherix, the nephridial canal passes through several dissepiments, ruming back from its ciliated funnels through several segments; it then forms a loop and bends forwards again. In the nephridia of the Choetogastride the ciliated funnels are wanting. In them, as in the Hirudince, numerous branched and anastomosing intracellular canals enter the central canal. In a species of Acanthodritus (Lumbricide) there are typically 4 pairs of nephridia in each segment (even in the genital segments). There is said to be a similar arrangement of nephridia in the anterior segments of Perichete mirabilis.

The permanent nephridia of the Polychetu are tubes with cellular walls; their often ciliated central canal is thus as a rule, in opposition to that of the Oligocheta and Hirudinen, intercellular. (Intracellular nephridial canals, however, also occur.) The nephridial tube is almost always so bent that we can distinguish in it two limbs, one centripctal, at whose inner end lies the fumel, which is mostly wide open and provided with cilia, and another centrifugal, which opens outwardly by breaking through the body wall. The nephridia lic in the nephridial or renal chambers of the body cavity which have already been described (p. 213), and they may 
lie wholly in one segment, or else, as in the Otigochate, each pair of nephridia belongs to two consecutive segments.

Although there are many Polychete in which the pairs of ncphridia are repeated throughout the greater part of the body with great uniformity and in strictly segmental arrangement, therc are, on the other hand, many groujs in which we find great deviations from this arrangement. We can only mention the most important.

In the Capitcllide permanent nephridia occur, as a rule, only in the alklominal region, either in the greater part of that region or only in the anterior, or only in the posterior portion. There is cither one pair in each segment or several (Copitelle); even as many as 6 pairs may occur in each segment. In most Copitcllide more or less mmerous pairs of nephridia are elanged into genital tuhes, which will he further deseribed below, and it is always the anterior pairs of nepluriclia whieh undergo such a transformation. The permanent nephridia of capitclle are distinguished by the fact that they lossess, as a rule, more than one fumel.

In the Terebelloidea the nephridia only occur in the thoracic region, and in strictly segmental arrangement. In this region the dissepiments are wanting, with the exception of a strongly developed diaphragm which divides the crelome of the thoracic region into an antcrior and a posterior eavity. The nephridia of the anterior thoracic cavity function as organs of excretion; those of the posterior conduct the genital products to the exterior. In Lanice conchilege there is a very striking nephridial arrangement. The 3 pairs of nephridia of the anterior thoracic cavity do not emerge externally direct, but the 3 nephridia of each side enter a short nephridial dnet which has a single external aperture. In a similar way the 1 nephridia of the posterior thoracic cavity enter on each side a longitudinal nephridial duct, which, however, has not 1 opening but 4. It may therefore be said that the $f$ nephridia on each side are eonnected by a longitudinal canal.

In the Cirratulide, Serpulacea, and Hermella (Fig. 147, 1. 221) an anterior sterile region and a posterior genital region may be distinguished, the genital products attaining development in the latter. In the anterior sterile region, which consists of a varying number of segments, only one pair of nephridia occurs. This yair alone has an excretory function. They are long, and extend through several segments. In the Cirratulida they emerge ventrally by separate apertures in the third segment; in the Scrpulace and Hermelle, however, they unite anteriorly to form an umpaired duct, which reaches the exterior near the extreme anterior part of the body in the dorsal middle line. In the genital region the nephridia are repeated in strictly segmental arrangement, and serve as genital tubes for conducting the sexual products to the exterior.

In Stcrinaspis, two brown lobate bodies lying in the 5th and 6th segments are regarded as nephridia; these possess neither a lumen nor an internal aperturc, and end in the integument between the sixth and scventh segments.

In the Echiuridce (Fig. 137, p. 207) there are two sorts of organs which have been considered as nephridia, the so-called segmental organs and the anal tubes. The segmental organs have quite the structure of the permanent Polychrtan nephridia, and we can hardly doubt their homology with the latter. They occur either in 2 pairs (Echiurus), or 3 pairs (Thalessemu), or unpaired and singly (Bonellic), and possess well-developed internal funnels. Their outer apertures lie behind the anterior hooked setre. Their principal function is the transmission of the genital products out of the body cavity. The anal tubes are 2 long tubes which on the one hand enter the 
lind-gut, and on the other are in open communication with the body cavity by means of numerous ciliated funnel apertures, one of which always lies terminally. An excretory function is ascribed to them. Whether they represent a pair of modified nephridia cannot at present be decided. The fact that they are supplied with numerons funnel apertures ought not to stand in the way of such a view, as typical permanent nephridia in the Polycheta (Cupitellu) and Oligochetete (Anuchetu) may be provided with accessory funnels.

Organs which may with certainty be pointed to as nephridia have until now not been observed in the Myzostomidæ.

The problem of the morphological relations between the permanent nephridia, the provisional trunk nephridia, and the embryonic head nephridia, is still nnsolved. It is closely connected with the questions as to the significance of segmentation in the Ammulcte body and the morphological significance of the body carity and the mesodcrm. It is very probable that the permanent segmentally-arranged nephridia in all the Annulate are homologons. The histological difference between the nephridia of the Hirudinea and Oligochate on the one hand and those of the Polychete on the other, which consists in the fact that in the former the nephridia are perforated rows of cells and in the latter as a rule tubes with epithelial walls, would in that case be unessential, as also would be the absence or presence of branchings. It is further probable that the provisional trunk nephridia are morphologically equivalent to the permanent nephridia. They are distinguished from the latter only in that they appear earlier and disappear in proportion as the permancnt nephridia appear and assume their functions. The homology between provisional trunk nephridia and permanent nephridia is supported by the cireumstance that no case has as yet been known in which permanent nephridia have attained development in a segment where provisional nephridia have previously a preared and then disappeared. Capritelle, in which in the tenth and eleventh segments both provisional and permanent nephridia develop, is an exception, but only an apparent exception, for we have seen that in this animal several pairs of permanent nephridia oceur in one segment. It is probable that the embryonic head nephridia are homologous with the trunk nephridia (provisional and permanent). The whole nephridial apparatus wonld then have to be judged of in the following way. Originally a pair of nephridia ocenrs in each segment of the segmented Ammulate body, even in the head segment. All the pairs of nephridia are segmentally homologous with each other. The larra or cmbryo of the now living Anmulate consists of the embryonic head segment and the unsegmented rudiment of the trunk. The differentiation of the trunk occurs from before backward ; the first and oldest segment to be developed is the first trunk segnent; then follows the second trunk segment, and so on. In correspond. ence with this, the pair of nephridia of the head segment first appears (embryonic liead kidneys), then the pairs of nephridia of the anterior trunk segments, several of which (provisional trunk nephridia) may degenerate gradually as new nephridia, the permanent trunk nephridia, begin to form behind them. The cause of the disappearance of the liead and the provisional trunk nepliridia in the course of development is perhaps to be found in the fact that the foremost body segments in the adult animal are crowded with organs (pharynx, brain, ete.) Besides this, in the whole animal kingdom organs which attain development very early and function during larval or embryonic hife show a tendency to degenerate enly, as if they were soon worn out. Further in the Oligochate (excepting the Lumbricidce) the nephridia in the genital segments degenerate when the various sexual organs attain derelopment. 
The nephridia as organs of excretion.-The original and most general function of the nephridia is that of excretion. The discharge of the excretory products occurs in two ways. The nephridia may either take up the excretory products direct out of the body fluid or out of the blood by means of the open funnels, or the excretory products may collect in the walls of the nephridia and thence reach the nephridial cavity. The nephridia are often surrounded by a rich network of blood-vessels which yield up to the nephridial walls the excretory material they contain.

The nephridia as ducts for the sexual products. - Since the nephridia establish an open means of communication between the body cavity and the outer world, an opportunity is offered to the sexual products floating in the coelomic fluid to choose this way of reaching the exterior. In the Polychete the nephridia in fact act at the same time as sperm ducts and oviducts. In the simplest cases this new function does not bring about any marked variation in the form and structure of the nephridia, the funnels at most showing slight enlargement at the time of sexual maturity. It often happens, however, that some of the nephridia act almost exclusively as sperm ducts and oviducts. Their funnels are then strikingly enlarged, while at the same time the (excretory) nephridial canal diminishes in size and becomes simplified. Some of the nephridia in the Capitellide undergo even more profound modification. The funnel becomes enormously enlarged, and connected with the exterior by means of a new canal, which breaks through the body wall and opens outwardly through a genital pore, while at the same time the nephridial canal may become reduced and may quite disappear. Thus arise the genital tubes ; they act as ducts for the sexual products and as copulatory organs. The sperm ducts and oviducts of the Oligocheta have also long been considered as modified nephridia, and it cannot be denied that they show great agreement with nephridia in their structure and composition (funnel, canal, or duct and terminal resicle) as well as in their development. Nevertheless it is a striking fact that in the Oligocheta, where the nephridia occur in strictly segmental arrangement (one pair in each segment), either permanent (Lumbiricile) or provisional nephridia (other Oligochete) are found in the genital segments also, side by side with the sperm ducts and oviducts. In Acunthodrilus, where 4 pairs of nephridia occur typically in each segment, there are also 4 pairs in the genital segments. These are difficulties which camnot be ignored in the way of establishing a homology between the oviducts and sperm ducts of the Oligocherta and nephridia. 'The ducts for the sexual products in the Hirudinea and Myzostomide can certainly not as yet be considered as modified nephridia.

The phylogenetic origin of the nephridial system of the Annulata is still quite uncertain. There are three differcnt views. According to one of thesc, the whole nephridial system of the Annulate corresponds with the water-rascular system of the Platodes and with the excretory system of the Nenertina, which (in the 
Triclucte and certain Nemertina) already shows a more or less distinet segmentation, in that the efferent ducts are segmentally repeated. In all Platodes and Temortina, however, longitudinal canals are present throughout the whole body or in the anterior part of the body, which can open externally through more or less distinctly paired and segmentally arranged ducts, whilst in all Annulatc the nephridia are separate at their first appearance, and with a rery few exceptions (Lonice) remain seprarate during life. While the water-vascular system of the Platodes is markedly branched, such branching is less marked even in the Nemertina, and in the Annulata (Otigochecte, Polyehota) is generally altogether wanting. This may be explained by the fact that in the parenchymatous Platodes the excretory organs have to seek out the excretory products all over the body, while the development of a bloodvascular system and a body cavity affords spaces for collecting these products, out of which the nephridia can take them direct. The nephridial fumcl in the Annulata, which ontogenetically originates quite separately from the other parts of the nephridium, would then be a new adaptation, a collecting apparatns, suited for taking up the excretory material out of the blood simuses or body cavity, and for discharging it through the nephridial canals. According to a second view, only the embryonic head kidneys of the Annulata correspond with the water-vaseular system of the Platodes, with which they certainly often show a great structural resemblance. $A$ third supposition is that the head kidneys of the Chotopola and the embryonic kidneys of the Hirudinca answer to the excretory organs of the Nemertina, while the permanent neplnidia may have arisen from the efferent ducts of the ovaries and testes of the Nemertina. This last conjecture is opposed by the fact, which is unanimously supported by all recent investigations, that the original function of the Annulatan nephridium is excretory, and that only secondarily some of the nephridia undertake the transmission of the sexual products.

Prosopygia.-The number of the nephridia is everywhere in this class very small ; there are never more than two pairs. In the Sipunculicte (Fig. 138, p. 208) there are two large tubular nephridia like the permanent nephridia of the Polychata, especially of the Echiuridee. They emerge laterally at the limit between the proboscis and the trunk (near the anus). Less frequently (Phuscolion) only one nephridium occurs. The nephridia, besides their excretory functions, serve as ducts for the transmission of the genital products. In Sipunculus anal tubes which enter the hind-gut have been observed, which are perhaps homologous with the anal tubes of the Eclivuride and the Priupulide. The Priapulide have only two richly-branched anal tubes emerging near the anus. At the blind ends of the branches are found terminal cells with long flagella projecting into the canals, similar to those which are characteristic of the water-vascular system of the Platodes and of some of the embryonic head nephridia and the provisional trunk nephridia of the Anmulute. The anal tubes of the Pricupulice are said to act as excretory organs in youth, and in later stages as places of formation and ducts for the transmission of the sexual products. Phoronis possesses one pair of nephridia which open outwardly and anteriorly by two lateral apertures, and besides their excretory function also undertake the transmission of the genital products out of the body cavity. Among the Bryozoc nephridia have till now been found only in the Endoprocta. They are paired 
canals like the embryonic head nephridia of the Ammulutu, which issue between mouth and amus into the so-called vestibulum. The Brachiopodu (Fig. 150, 1. 226) possess one pair, less frequently (Phynchonella) two pairs like those permanent nephridia which in the Polychecete, Sipunculider, and Phoronis discharge the sexual products. They emerge to the right and left of the mouth into the mantle cavity.

\section{Rotatoria and Dino-} philus. - Dinophitus gyno ciliutus (Fig. 162) possesses five pairs of nephridia, which show a remarkable agreement with the provisional trunk nephridia of certain Polychete (Nerei: cultrifera, Fig. 159, p. 239).

They lie one behind the other in the trunk region in those segments which are outwardly indicated and demarcated by ciliated rings. The nephridia of the Potatoria (Fig. 161) consist of two looped, and in certain places much convoluted canals, which run longitudinally near the intestine; these open into the cloaca, generally forming a contractile terminal vesicle. The longitudinal canals usually have short accessory branches, whose ends (ciliated lobes, vibratile organs) seem to be constructed like the ends of the water-vascular system of the Platodes, and of

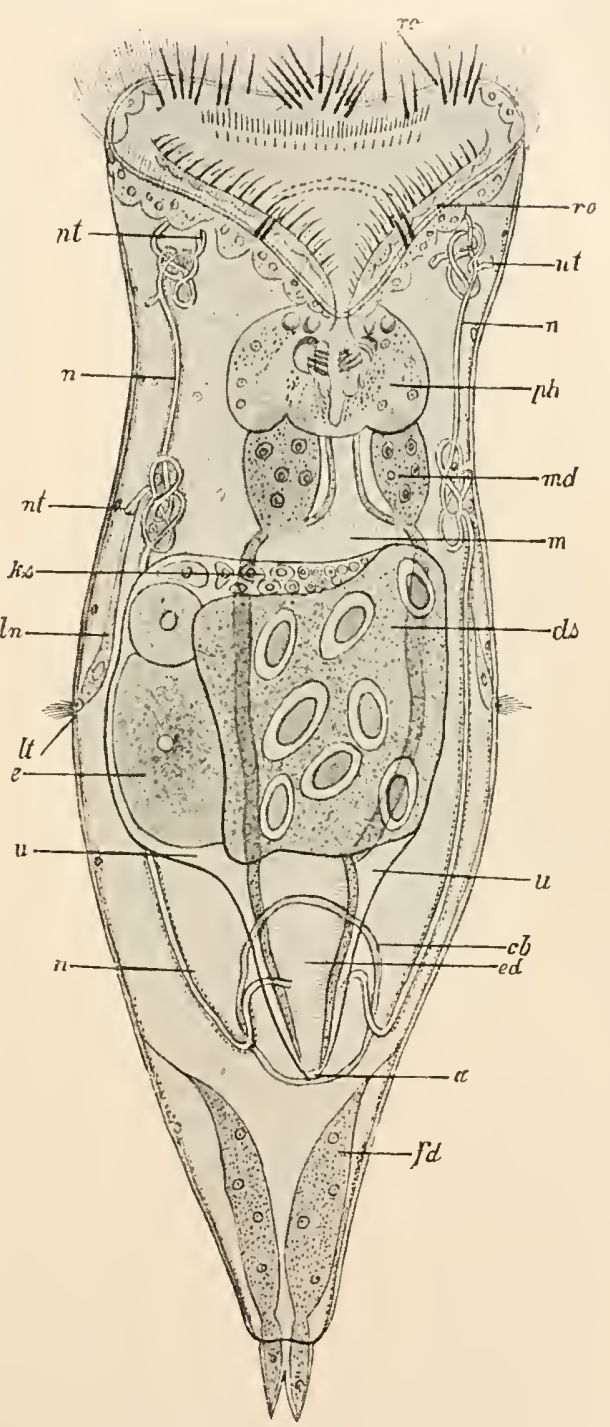

Fug. 161.-Organisation of Hydatina senta, after Plate. ro, Wheel organ ; $n t$, nephridial ciliated cells ; $n$, nephridia ; $p h$, pharynx; $m l$, gastric glands; $m$, stomach; $d s$, vitellarium; $k s$, germarium; $c b$, outline of the contractile vesicle ; $e d$, hind-gut ; $u$, uterus ; $\alpha$, anus ; $f l$, cement or pedal glanıls ; $l t$, lateral feeler: $l n$, nerve of the same; $\varepsilon$, advanced egg.

the embryonic head nephridia of the 
Anmulutu. This correspondence indeed is apparent in the whole nephridium.

The only organs which can perhaps be pointed to as transformed

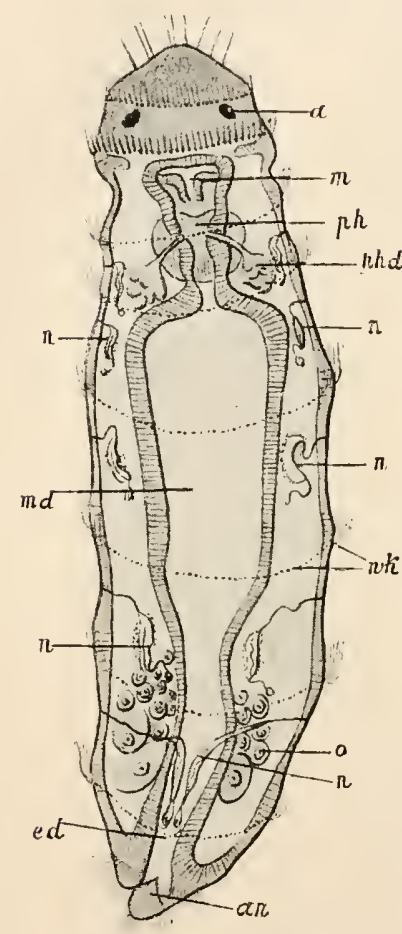

FIG. 162.-Organisation of Dinophilus gyrociliatus, female, after E. Meyer. $a$, Eye; $m$, mouth; $p h$, pharynx; whd, pharyngeal glands; $n$, nephrilia; mi, mid-gut; wk, ciliated rings ; $o$, ovarium ; $a n$, anus ; el, hind. gut.

blood-vessels enter. Specific respiratory organs are wanting in the Oligochete and the Aichionnelida. Among the Oligochectu, only the insufficiently known Alme nilotica possesses branchial appendages at the posterior part of the body. The Polychate, on the contrary, are pretty generally supplied with gills, which are usually branched appendages of the Parapodia (Fig. 124, p. ISs; Fig. 158 , p. 237); these in some cases, however, may emancipate themselves from the parapodia and may be independently inserted on the back. The comparative morphology of the gills of the Polychate has not yet been thoroughly worked out. We may perhaps at once distinguish two sorts of gills-lymph gills and blood gills. The lymph gills are processes of the parapodia which are distinct from 
the parapodial cirri; they may occur simultaneously on the rentral and dorsal parapodia. They are found in the Capitellide and the Glycerida, and in the absence of a separate blood-vascular system are provided with continuations of the body cavity carrying hemolymph. The blood gills, on the contrary, are often branched appendages of the parapodia which are penetrated throughout by blool-vessels. ITe can again distinguish two sorts of blood gills-dorsal gills and cephalic gills. The dorsal gills are transformed cirri of the dorsal parapodia, or transformed lateral off-shoots of such cirri. They occur, like the paraporlia themselves, in segmental order, but may often attain development only in certain regions of the body (branchial regions). The cephalic gills, on the other hand, which we meet with specially in tubicolous Annctids, are transformed tentacles or feeler-cirri of the head, and often form a beautiful crown of gills or tentacles projecting above the aperture of the tube. These crowns are at the same time also the seat of a fine sense of touch, and, further, organs for the drawing in of nourishment. In the Subellida (Branchiommu) eyes may be developed on the cephalic gills. Where gills attain development they are almost always either ciliated or mobile, so that a constant exchange of the respirable medium, oxygenated water, is secured. In the thoracic membrane of the Serpulidie there is a rich network of vessels, and this no doubt lias a respiratory significance. In Sternaspis, on each side of the anus, there is a tuft of filamentous gills. We do not find special respiratory organs in the Mysostomida, the Chatognatha, and the Riotutoria, in whom a bloodvascular system also is wanting. In all these forms cutaneous respiration must take place, facilitated in the wheel animalcula by the activity of the wheel organ. The cutaneous respiration in the Echiuride is principally localised in the prostomium. In the Prosopygie the tentacles which stand round the mouth, or the oral arms furnished with cirri (Brachiopoda) chiefly act as gills, and these organs are either penetrated by blood-ressels (Phoronis, Brachiopode?) or supplied with canal or vessel-like processes of the body cavity (Sipunculide, Bryo:oa). In the Brachiopoda the inner surface of the mantle has in all cases an additional respiratory significance. The Pritpulider among the Simunculucet possess no oral tentacles; in them respiration takes place through the integument. Besides this, howerer, there can be little doubt that in Priapulus the deeply-lobed caudal appendage into which, in the ahsence of a blood-vascular system, a continuation of the body carity extends, may be regarded as a respiratory organ.

Just as the cutaneous respiration may be concentrated in certain localised parts of the integument, in which places the principle of inincrease of surface is applied, accompanied by a richer vascularisation, the enteric respiration also may be localised. The accessory intestine which is found in some Polychetu and Simunculacen is said to represent such a respiratory portion of the enteric canal. Respiratory organs are wanting.in the $N^{2}$ emathelminths. 


\section{Blood-Vascular System.}

There is no organic system in the worms which is so variable as the blood-vascular system. It is sometimes wanting, sometimes highlydeveloped. We even find that it may be wanting in certain groups whose nearest relations possess it. Thus, as we find a blood-vascular system sometimes present, sometimes absent, in the most different order's of the most different classes, its small morphological worth is evident. Even where worms are supplied with a circulatory apparatus it rarics so much in structure that no morphological comparison is possible, at any rate at present.

Nemertina (Fig. 157, p. 235). - In this class of the Termes for the first time in the animal kingdom we meet with a bloodvascular system. In the Puleonemertinu (excepting Valenciniide and Inllicice) it consists of 2 lateral vascular trunks, uniting posteriorly above the intestine, and anteriorly entering a lacumar system, which likewise establishes communication between them. In the

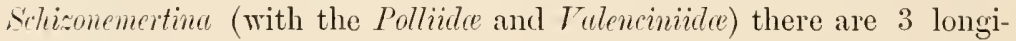
tudinal vessels, 2 lateral, and 1 medio-dorsal which lies above the intestine, in the proboscidal region between the proboscis and the intestine. The 3 vessels become lacunar antcriorly, and communicate above and below the proboscis sheath. In the rest of the body they are comnected together by transverse vessels. The same is the case in the Hoplonemertina, only a lacunar system is here wanting, and the rascular system is completely closed. The blood is colourless or contains red blood corpuscles. The ressels are lined with endothelium and occasionally hare muscular walls.

Nemathelminthes.-The Nematode have no vessels. In the Acenthoceplula, thronghout the whole subcuticle, a peculiar network of canals extends, whose morphological and physiological significance is still little understood. The system of canals, which are hollow spaces without walls of their own, running in the very much thickened subcuticle, consists of 2 completely separate parts - the canal system of the trunk and the canal system of the neck, the proboscis, and the lemnisci. In the trunk canal system we find 2 specially distinct longitudinal trunks which run either laterally, or dorsally and ventrally. The neck, head, and lemniscal canal system enters a circular canal situated at the base of the neck. The lemnisei (Fig. 172, l, p. 258 ) are two pouches, generally of a brown colour, which hang from the base of the neck into the body cavity and are processes or appendages of the subcuticle of the neck. A canal enters each lemniscus from the circular canal, and divides into two branches directly after entering; these branches run longitudinally through the lcmniscus. Besides these, narrower canals also occur in the lemnisci.

Annulata.-The Hirudinea and the Chetopoda are separated by sharp and radical differences in the blood-vascular system. In the Myrostomide blood-vessels are altogether wanting. 
Hirudinea. - In describing the body cavity we have already drawn attention to the difficulty of distinguishing it from the blood-vascular system. We are, besides, not certain that these are two originally separate systems, and it seems almost necessary to consider the whole together. There occur almost universally 4 longitudinal vessels (Fig. 163) -1 dorsal, lying over the intestine, 1 ventral, in which the ventral chord lies, and 2 lateral, which in many cases pulsate. Of these 4 vessels the ventral one (ventral sinus) may best be considered as the principal part of a reduced body cavity. The dorsal vessel is wanting in $N_{e}$ phelis and some land

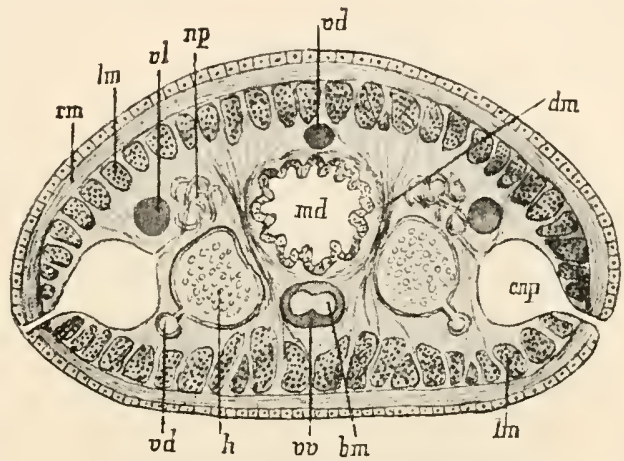

Fic. 163.-Transverse section through Hirudo, diagram. matic. rm, Circular;musculature; $l m$, longitudinal muscular layer ; $v t$, lateral ressels; $n p$, looped canals (nepliridia); $v d$, dorsal ressel ; $d m$, dorso-rentral musculature; enp, terminal vesicle of the nephridia; $b m$, ventral chord; $2 v$, ventral ressel; $h$, testes; $v d$, vas deferens ; md, mid-gut. leeches. The longitudinal

vessels are connected together, chiefly at the anterior and posterior ends of the body, by fine vascular branchings. Such a connection also takes place in various ways in other parts of the body. The peripheral

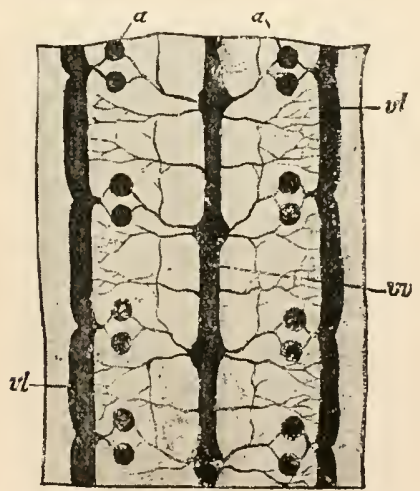

Fic. 164.-Vascular system in 4 segments of the middle part of the body of Nephelis, after Jaquet. $v v$, Ventral vessel; $\imath l$, lateral vessels; $a$, anpullie. Guuthobdellide the blood is red. Hrmoghobin is found dissolved in the blood plasm.

By the presence of one dorsal and two lateral ressels, the blood2 well-developerl systems of branched and often anastomosing capillaries, one of which lies in the integument and penetrates into the body epithelium, the other spreading out over the intestine. The excretory and sexual organs are richly supplied with blood-vessels. In Nephelis (Fig. 164) and land leeches there are, in connection with the anastomoses between the lateral and ventral vessels, ampullie or bloorl vesicles in segmental arrangement, one on each sirle (land leech) or two together (Nephelis). In Branchellion on each side, at the base of every third gill, there is a blood sinus, widened into a vesicle. The blood everywhere contains colourless amoboid corpuscles, and often free nuclei. In the

vascular system consists principally of 
vascular system of the Hirulineu recalls that of the Nemertina. They also agree in the possession of blood sinuses.

The vascular system of the Chcetopode is strikingly different from that of the Hirudinea. It is entirely separate from the body cavity.

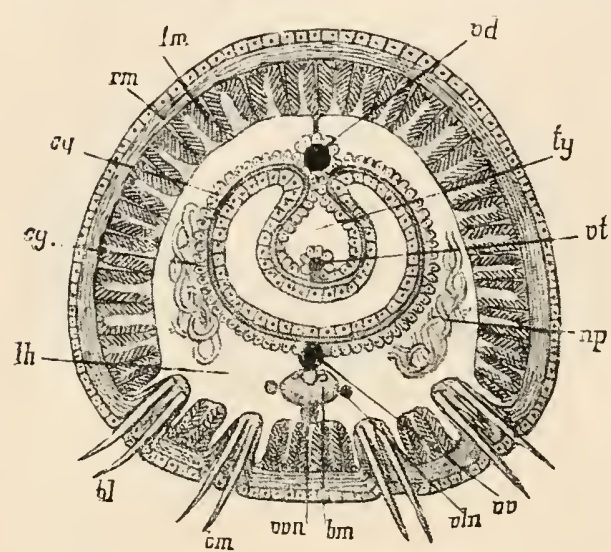

Fig. 165.-Transverse section through a Lumbricus, diagrammatic. $\quad t h$, Body cavity; $\mathrm{cg}$, chloragogen cells; $r m$, circular musculature; $l m$, longitudinal musculature; $d v$, dorsal vessel; ty, typhlosolis; $v t$, typllosolis ressel; $u p$, nephridia; $v v$, ventral vessel; $v l n$, lateral vessel of the ventral chord; $b m$, ventral chord with the neurochord tubes; vvn, sub-neural vessel; $b m, 2$ setre of the ventral row ; $b l, 2$ of the lateral row.

one, sometimes the other. In the details of the arrangement, development, and course of the vessels there is extraordinary variety, which makes it impossible to describe them briefly and comprehensively. In a very simple case the ventral vessel divides at the anterior end of the body into 2 branches, which, surrounding the fore-gut, enter the anterior end of the dorsal vessel. The dorsal and ventral vessels are further commected in each segment by lateral vascular loops; it is from these especially that branches proceed to the body wall. Vessels coming from a vascular network surrounding the intestine also enter the dorsal vessel; this network in many cases may be replaced by a blood sinus lying between the epithelial and the muscular walls of the intestine. The blood in the vessels of the Chatopoda is generally red, and contains colourless corpuscles.

The following are brief descriptions of the blood-vascular systems of an Oligocheten and of a Polychectan (arbitrarily selected).

Lumbricus (Fig. 166) (as an example of the Oligochcetc).-There are 5 longitudinal vessels; first a medio-dorsal vessel;-second and third 2 medio-ventral ressels, one of which lies under the intestine and above the ventral chord, and represents the ventral vessel which is always found in the Chotopoda, while the other is much fincr and runs under the ventral chord, the former is known as the ventral vessel, and the latter as the sub-neural vessel; - fourth and fifth, 2 delicate 
ressels which accompany the ventral ehord throughout its whole length, rumning to the right and left of it; these are the lateral vessels of the ventral chord. The sub-neural ressel is connected with the lateral vesscls of the rentral chord at intervals by transwerse anastomoses. The dorsal ressel, near the mid-gut, has segmental swellings, so that it here assumes the form of a string of beads. In the genital segments it is comected with the ventral vessel by 5 pairs of wider pouch-like contractile vascular loops, the so-called hearts. In the region of the mill-gut the lorsal vessel gives rise in each segment to 3 pairs of vessels. The first pair rum laterally in the body cavity and enter the sub-ncural ressel. They give off' in their course ressels to the body wall and the integmment, and further, in the lower part of their course, anastomoses to the rentral ressel and the lateral ressels of the ventral chord. The two posterior pair's rum on the intestine where they break up into an extremely rich and elose network. The typhlosolis and the muscular stomach are also supplied from the dorsal ressel. Anteriorly, between the third and fourth lairs of hearts, there arises from the dorsal ressel on each side a vascular trunk, whose complicated branches sulply the anterior prart of the body, the intestine, the body wall, the first prair of Morren's glauds, the plarynx, the resophagus, etc.; these are also connected with the ventral and sub-neural vessels. In each segment the ventral vessel gives rise to a lateral pair of vessels, which branch in the body wall and the integument. These branches anastomose in that part of the body which contains the stomach intestine with the branches arising in each segment from the first pair of lateral vessels of the dorsal vessel, which latter maintain a communication between the dorsal res.

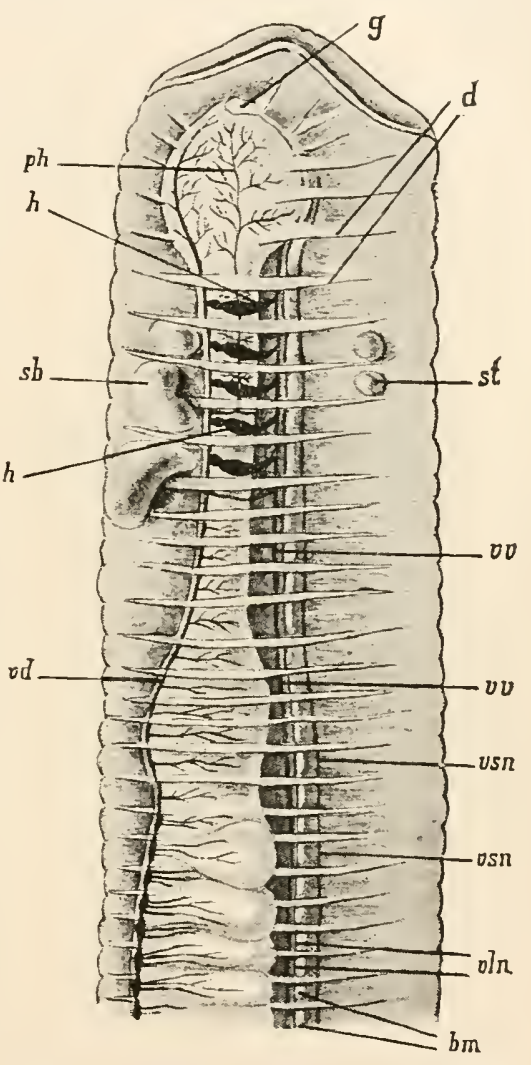

Fig. 166.-Anterior portion of the body of Lumbricus terrestris, opened, to show the vascular system. The intestine is seen from the right side (after Jaquet). $g$, Brain ; $d$, dissepiments ; st, sperm sacs; $p h$, pharynx; $s b$, seminal vesicles; $v d$, dorsal vessel; $v v$, rentral vessel; $v s n$, subneural vessel; $v \ln$, lateral vessels of the ventral chord; $b m$, ventral cliord; $h$, contractile vascular loops (hearts) between the dorsal and ventral ressels. sel and the sub-neural vessel. The ventral and dorsal vessels give off branches to the extreme anterior end of the body, which ramify in the body wall and pharynx. The ventral vessel further divides at its anterior end into 2 branches, which penetrate to the brain and so form an cesophageal ring. The contractile part of the blood-vaseular system possesses museular walls.

Nephthys scolopendroides (Fig. 167) may be taken as an example of a Polychetain with homonomous segmentation of the body. We find here the two most important typical vessels, the dorsal and the ventral. Both lie close to the wall of the 
intestine. From the posterior end of the pharynx to the end of the body the dorsal vessel gives rise in each segment to a pair of lateral vessels, which run to the body wall and especially to the dorsal branch of the parapodia and there ramify. Soon

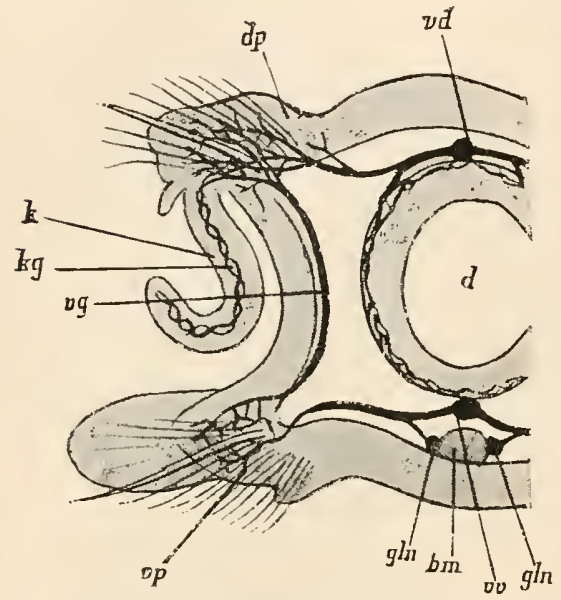

FIG. 16-.-Part of a transverse section through a segment of the body of Nephthys, rliagrammatic, to demonstrate the arrangement of the blood-vessels (partly after Jaquet). $d p$, Dorsal ; $v p$, ventral parapolium, with bundles of setre and supporting seta ; $v d$, dorsal vessel; $v v$, ventral vessel; gln, lateral vessels of the ventral chord; vg, connecting vessel between the dorsal and ventral parapodia; $d$, intestine; $b m$, ventral chord; $k$, gills; $k g$, branchial vessels. after its rise ont of the dorsal ressel each lateral vessel gives off a branch to the enteric wall, this branch there forming a rich vascular network. At the foremost end of the mid-gnt the dorsal vessel shows a slight swelling ; it then leaves the intestine and runs along the inner side of the body wall in the region where the pharynx lies to the extreme anterior end of the hody. It here divides in to 2 branches, which run backwards, to pass into the anterior end of the ventral vessel at the posterior end of the pharyngeal region. The departure from the general plan of the principal vessels in the pharyngeal region is evidently caused by the great development of the pharynx. If they lay as close to the pharynx as they do to the intestine in the rest of the body, they would be broken by its protrusion. The rentral vessel gives rise in each segment to a pair of lateral vessels, which rum along to the base of the ventral branches of the parapodia, passing into the latter and there ramifying. A connection between the lateral branches of the dorsal vessel and the lateral branches of the ventral vessel takes place in the following way. Between the dorsal and ventral branches of a parapodium there runs on each side a vessel which ramifies on one side in the dorsal branch, on the other in the ventral branch. These ramifications of the connecting vessels anastomose with the ramifications of the dorsal or ventral lateral vessels. On the ventral side of each dorsal parapodial branch a sickle-shaped gill is inserted. Two ressels from the vascular system of the dorsal parapodial branch enter the gill, and with many windings and auastomoses run through its whole length. Besides the dorsal and ventral vessels, Nephthys possesses also two extremely delicate lateral vessels of the ventral chord, which are connected by fine branches with the lateral branches of the ventral vessel.

This arrangement of the blood-vascular system can, however, only to a very limited extent be considered typical of the Polychocto. In the different families, indeed, very great variations are to be found. The blood-vascular system is extraordinarily plastic. It follows the smallest modifications in the structure and arrangement of the other organs of the body. Its special form is above all dependent on the arrangement and development of the gills. In the Terebellide the dorsal vessel forms in the anterior part of the body a tubular pulsating heart, which is narrowed anteriorly, and which supplies the gills lying on the most anterior body segments with blood-ressels. At its posterior end it splits into two branches, which encircle the intestinc. These branches unite below the intestine to form a sub-intestinal vessel which runs a certain distance backwards over the ventral vessel. Then the sub-intestinal vessel 
again divides into two branches, which encircle the intestine and again unite in the dorsal middle line to form a dorsal ressel ruming to the extreme postcrior end of the borly. In the Cirratulide (Chetosone), at the posterior region of the body where there are no gills, a separate dorsal vessel and an enteric vascular plexus are both wanting. They are here replaced by a blood sinus which continuously surrounds the intestine insicle its muscular wall. This sinus is continued anteriorly into a strong pulsating dorsal vessel (heart) which runs through the whole branchial region and gires off vessels to the gills directly or indirectly. In the Scrpulide the enteric canal is generally cmbedded along its whole length in a blood sinus, and a dorsal ressel is wanting. Lateral vessels frequently rum along the sides of the intestine, and are connected by segmentally arranged transverse loops with the ventral vessel, and in the case of Serpulide provided with a thoracic membrane these lateral vessels give off branches segmentally to this membrane which break up in it into extraordinarily numerous and fine ramifications. In the Serpulide, where the gills are developed exclusively in the head segment, each branchial filament is penetrated by a single vessel, and the afferent and efferent blood passages first separate at the bases of the gills. In nearly all other Polychata we can distinguish afferent and efferent vessels (branchial arteries and branchial veins) which pass into each other at the ends of the branchial filaments. In the Capitellide and Glycericte a bloodvascular system separate from the body eavity is wanting. The blood mingles with the celomic fluid (hæmolymph). In Mastobranchus alone there are still found rudiments of a blood sinus surrounding the intestine. In many Polychata there is found, in that broader part of the dorsal vessel which is called the heart, a strand, generally of a brown colour, lying freely in its lumen. This is called the heart body. Its function is not yet clear. In Chetosone 3 such bodies are found.

The blood-vascular system of the Echiuride (Fig. 137, p. 207) is very simple. It consists of a ventral vessel rumning through the whole body and lying above the ventral chord. Behind the mouth this vessel divides (like the ventral ehord) into 2 branches which, embracing the mouth between them, pass along the 2 siles of the prostomium to its extreme anterior end, where they unite (like the 2 limbs of the cesophageal ring). A dorsal vessel arises from the point of junction, which, ruming backwards, traverses the prostomium and then runs along the fore-gut to the posterior end of the crop. Here it divides into 2 limbs, embracing the intestine, and these enter the ventral vessel together. The dorsal vessel is thus connected with the ventral vessel by 2 pairs of loops-one anterior, represented by the lateral vessels of the prostomium, and one posterior, at the limit between the fore-gut and the mid-gut. 'The dorsal vessel is not continued back over the fore-gut.

Prosopygia.-A vascular system is wanting in the Priapulide among the Sipunculacen, and in all Bryozoa. In Sipunculus there are two vessels, one dorsal and the other ventral, which accompany the fore-gut. Both end posteriorly near the place where the proboscis retractors are attached to the body wall. Anteriorly they enter a sinus which lies in front of the brain at the base of the tentacle crown, encircles the oral cavity, and is in communication with the inner cavities of the tentacles. By the contraction of the dorsal and ventral vessels the fluid they contain is forced into the circular simus, and from it into the tentacles, which consequently extend and expand. The elements which float in the coelomic fluid are met with in the vascular fluid, so that an open communication between the body cavity and the vascular system probably exists. In Phoronis there is a closed blood- 
vascular system with red blood corpuscles. A dorsal blood-vessel conducts the blood into a ressel which runs along the base of the tentacle crown and gives off branches to the tentacles. Other branches conduct the blood back into a second vascular ring which runs on the outer side of the former. A vessel rises from each side of the external vascular ring, which unites with that from the other side under the oesophagus, and runs back as ventral vessel asymmetrically in the left chamber of the body cavity; this vessel has numerous lateral ceca. Besides these vessels there is a blood sinus around the stomach intestine. All the vessels are contractile.

The opinions of the most recent investigators as to the blood-vascular system of the Brechiopola vary greatly. Some deny the existence of any circulatory apparatus. There is only, they say, a system of sinuses belonging to the body cavity. Other investigations confirm the old view according to which, in some Brachiopodu a contractile tubular heart lies above the stomach, and a vein arising from the heart over the fore-gut. There are also said to be vessels in the arms, and also vessels called genital arteries.

A blood-rascular system is wanting in the Rotatoria, Dinophitus, and the Chectognetha.

\section{Genital Organs.}

Division of the sexes generally prevails among the worms. The exceptions to this rule, apart from single cases, are the Hirudinea, Oligocheta, MIyzostomidle, Chectognatha, Phoronis, and many Bryozoa.

Nemertina. - The genital apparatus (Fig. 135, p. 205) is here very simple. The ovaries in the female and the testes in the male are present in large numbers, and are found in the shape of small sacs in adult animals throughout that region of the body through which the mid-gut runs. They lie in the parenchyma (jelly) under the musculature. Each ovary and each testis, at the time of sexual maturity, becomes directly connected with the exterior by means of a special duct. The genital glands on each side generally lie in a longitudinal row in such a way that between two consecutive diverticula of the intestine there always lies an ovary or a testicle. They are therefore more or less regularly metameric in their arrangement, in correspondence with the more or less regular metameric arrangement of the enteric diverticula themselves. In some Nemertina there are also genital glands scattered about the parenchyma, each gland, however, has an independent external aperture. In this arrangement we find great agreement with the Turbellaria (especially the Polyclade and Triclade). In the latter, however, the oviducts and sperm ducts arising from the genital glands unite to form common channels of exit.

Nemathelminths. - 1. Nematoda. - The male genital apparatus is umpaired, and emerges at the posterior end of the body in the cloaca ; the female apparatus is paired, and emerges externally on the ventral 
side in front of the anus, generally near the middle of the body. The male genital apparatus (Fig. 168) is a single continuous tube, lying in the body cavity, which falls into several divisions between its blind inner end and its external aperture. The testicle division

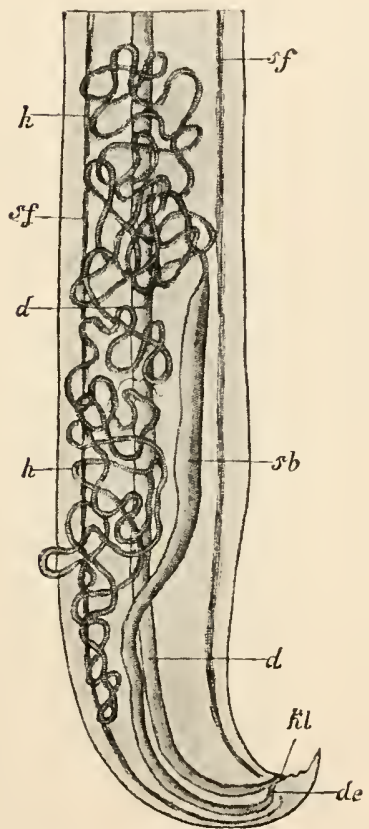

Fig. 165.-Ascaris lumbricoides, male genital apparatus, after Vogt and Yung. sf, Lateral lines; $h$, testes; $d$, intestine; $s b$, sperm vesicle; $k l$, cloaca; de, ductus ejaculatorius.

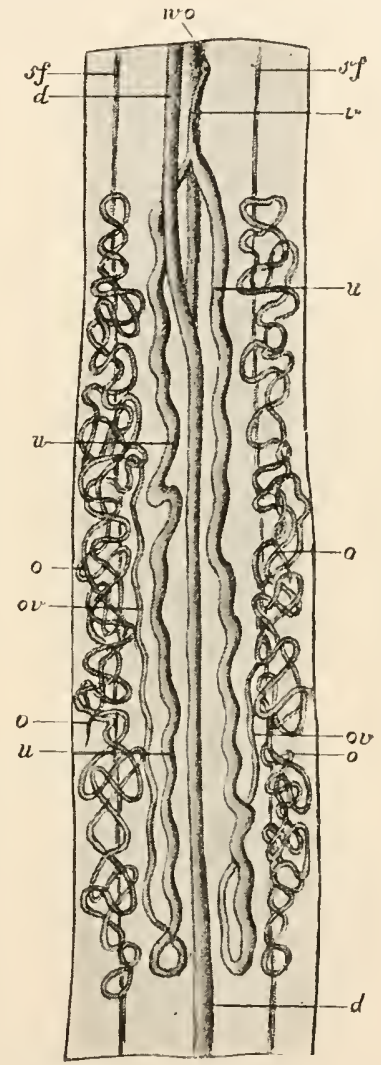

Fig. 169.-Ascaris lumbricoides. female genital apparatus, after Vogt and Yung. wo, Female aperture ; $v$, vagina ; $s$, lateral lines; $d$, intestine ; $u$, uterus; ovaries; $o v$, oriduets.

forms a thin much twisted tube into which a solid axis (rachis) projects from the blind end; attached to this rachis the sperm cells are found at different stages of development. The germ layer lies at the blind solid end of the testicle tube. The nearer we approach to the efferent duct the more advanced are the stages of development and ripeness of the spermatozoa. The testicle division passes into a shorter, wider, pouch-shaped division, the sperm vesicle, 
and this emerges by a short and narrow terminal piece, the ductus ejaculatorius, into the cloaca. Above the ductus ejaculatorius there often lie two elongated sacs, invaginations of the cloaca. Each sac contains a chitinous spiculum. In copulation the spicula may be protruded from the cloacal aperture by special muscles attached to the spicular sacs. In the female genital apparatus (Fig. 169) each of the paired genital tubes repeats in essentials the divisions of the male apparatus. The extraordinarily long ovarial tube lies in numerous windings in the body cavity. In its axis there also lies a rachis, to which the young eggs are attached. The ovarial tube is continued into a wider part, the uterus, at whose commencement fertilisation generally takes place, that is if the eggs have not already been fertilised in that terminal portion of the ovarian tube into which the rachis does not reach. The uterus contains fertilised eggs in the first stages of their segmentation, and even young embryos. The two uteri unite at their ends and pass into a short common terminal division, the vagina, which is often muscular, and opens outwardly in the ventral middle line through the female genital aperture.

2. Gordiidæ.-The genital apparatus of the Gorliide is quite different from that of the Nematoda. The male apparatus also is paired. The male and female genital apertures emerge into the last division of the intestine (cloaca). The female genital glands (Fig. 170) are lobed ovaries which lie in large numbers in pairs one behind

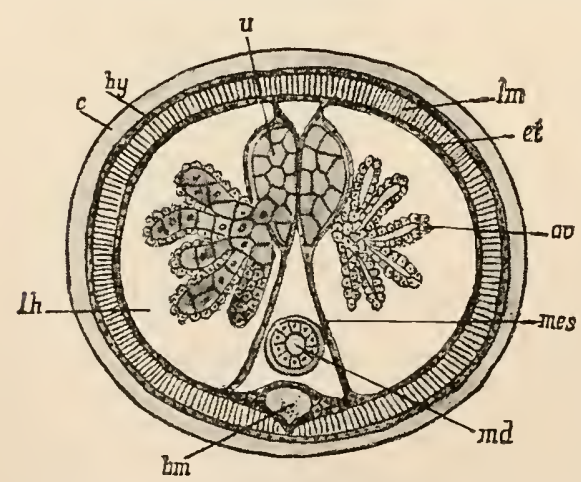

Fic. 170.-Transverse section through Gordius, after Vejdorsky. $l h$, Body cavity ; $c$, cuticle; hy, hypodermis; $\imath$, uterus; $l m$, longitudinal museulature; $e t$, endothelium of the borly cavity; ov, ovarium; mes, mesenteries ; $m d$, miki-gut ; bm, ventral chord. the other on both sides of the dorsal mesentery. They are developed very late at the expense of the mesodermal cells, which in the young Gordiiclae almost entirely fill the body cavity. Some of the eggs which ripen in the ovaries reach the body cavity, entirely filling its lateral chambers and so forming those masses of eggs which were formerly erroneously considered to be ovaries. The further fate of these eggs is not known. Another portion of the eggs, however, pass out of the ovaries into two tubes lined with epithelium which lie in the dorsal mesentery. These tubes, which might be called uteri, run backwards, and when approaching the posterior end of the body become narrow and bend round as oviducts to the ventral side, where they enter a pear-shaped glandular accessory organ of the small degenerating eloaca, the atrium. There is further an unpaired vesicle, the receptaculum seminis, placed under 
the posterior part of the uterus; this is connected with the atrium, and during copulation becomes filled with spermatozoa. In the male genital apparatus the actual testes have not yet been found. The other parts correspond with the various divisions of the female apparatus. We can distinguish sperm saes (corresponding with the uteri of the female), sperm duets, and the well-developed cloaca, a flaskshaped organ whose terminal part can be evaginated. There is no orgall corresponding with the receptaculum of the female.

3. Acanthocephala; Female Apparatus (Fig. 171).-In quite young animals the ovaries are enclosed in the ligament by means of which the genital apparatus is suspended from the base of the proboscis sheath. Masses of egos (swimming ovaries) early reach the body cavity, probably by the bursting of the ligament, and in sexually mature animals are there present in great numbers together with single detached eggs. From the body cavity they are transmitted to the exterior by a muscular apparatus which is of very complicated structure, although consisting of a limited, but for each species definite and constant, number of muscle cells. We distinguish in it first an apparatus for swallowing the ova, the uterus bell, to the bottom of which the posterior end of the ligament is attached. It is in open communication with the body cavity by means of a large anterior and a small posterior aperture. It alternately expands and contracts, and thus draws in the eggs which float in the colomic fluid. From the uterus bell the eggs pass into the anterior apertures of two short canals which are called oviducts. The oviducts emerge into a tubular unpaired division, the uterus, and this opens externally at the posterior end of the body by a short terminal piece, the vagina. Through the posterior aperture of the uterus bell the umipe eggs which have been drawn in with the others are returned to the bolly cavity.

Male Apparatus (Fig. 172, p. 258).-

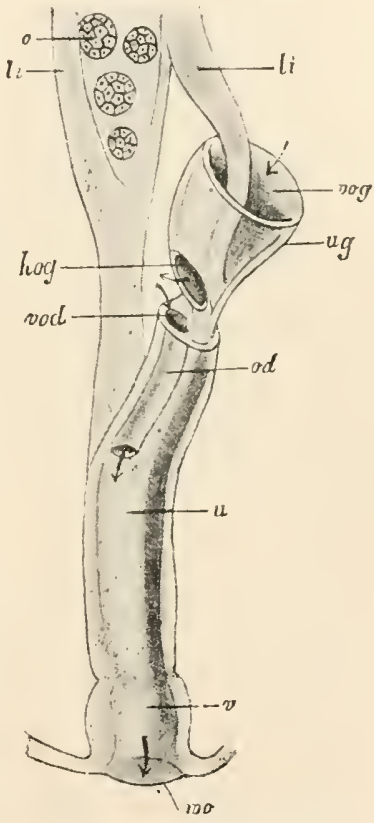

FIG. 171.-Female genital apparatus of an Echinorhynchus, diagrammatic. $u g$, Uterus bell. $v \circ g$, anterior aperture of the same; hog, posterior ditto; vod, anterior a pert ure of one of the two oviducts $(o d) ; u$, uterus ; $v$, vagina; $w o$, female aperture ; $o$, ovaries; $l i$, ligament. The arrows indicate the course taken by the eggs in passing from the body cavity to the exterior.

Two, or less frequently three, testes lie in the ligament. Each is continued in the form of a sperm duct. Each of these sperm ducts has three pouch-like invaginations along its course (sperm vesicles). Posteriorly they unite to form one common muscular vas deferens, which enters the bursa at the point of a conical muscular projecting 
penis. The bursa is a spacious sac-like invagination of the posterior end of the body which can be evaginated in copulation. Three pairs

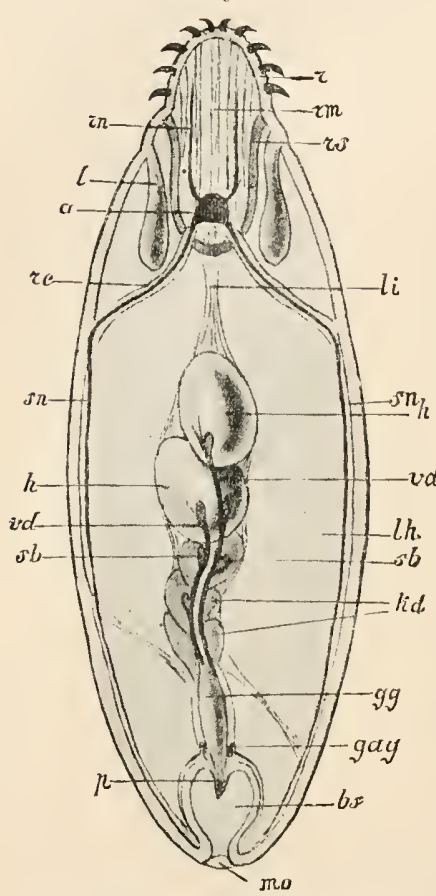

FIG. 172.-Representation, partly diagrammatic, of the organisation of a male Echinorhynchus. $r$, Proboscis with barbed hooks, protruded; $r m$, retractor muscles of the proboscis; $r s$, proboscis sheath; $r n$, proboscis nerves; $y$, cerebral ganglion ; re, retinacula; $l i$, ligament; $s n$, longitudinal nerves; $h$, testes; $v d$, vas deferens; $s b$, vesiculie seminales; $7 d d$, cement glands ; $g g$, common vas deferens; gag, genital ganglion ; bs, bursa ; mo, male genital aperture ; $l h$, borly cavity ; $p$, penis ; $l$, lemnisci. of cement glands are generally connected with the male apparatus, their ducts entering the terminal division of the vas deferens (ductus ejaculatorius).

Annulata. - The Hirulineu are hermaphrodite. Their male genital apparatus (Fig. 173) has the following general structure. Several testes lie in pairs segmentally arranged in the middle region of the body, generally between the consecutive lateral diverticula of the mid-gut, within the muscular septa separating these diverticula; the testes thus divide these septa into anterior and posterior lamellie. A shor't efferent duct arises from each testis. The ducts of all the consecutive testes of one side emerge into a vas deferens which runs through the whole length of the testicle region. In front of the most anterior testis the two vasa deferentia converge towards the

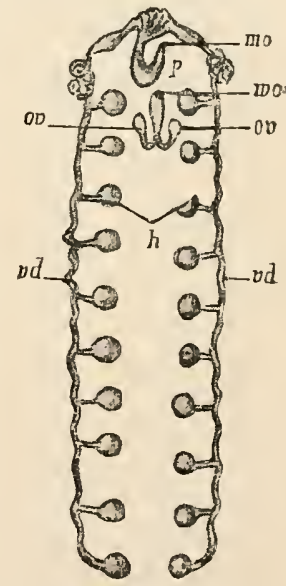

FIG. 173.-Genital organs of Hirudo. p, Penis ; mo, male ; wo, female genital aperture; ov, ovaries ; $h$, testicles; $v d$, vas deferens.

middle line, here to open outwardly by a common aperture, or in some cases by a common unpaired copulatory apparatus (penis).

The number of testes may in some cases be greatly increased (Nephelis, Lumbricobdella), and this probably results from the subdivision of each testis into several vesicles. Complications often occur in the last portion of the vasa deferentia. For example, in Hirudo, the vas deferens, before entering the penis through a short terminal passage, forms a tangled coil on each side. Glands are often connected with the penis. The male genital aperture in Hirudo is in the 10th segment, between the 30 th and 31 st rings.

The female genital apparatus (Fig. 173) lies behind the male aperture, and generally between the vasa deferentia. It consists of 
two ovaries. From each ovary an oviduct arises, which, joining that of the other side, passes into a sac-like muscular terminal division, the vagina (Gnuthoblellide), or opens outwardly direct (lihynchobdellide).

In the land leeches (Lumbricobdella, Cylicobdella) the oviducts remain separate until they enter the ragina. The oraries here oceur in numbers as swellings of the ovirlucts. In the Rhynchobdcllide the oraries are elongated sacs; in the aquatic Gnathobdellide they are short and lobed, and usually contained in a ronnd sac. In Hirudo the ducts unite, some distance before entering the vagina, to form a common oviduct, into which numerous glands (albumen glands) enter. The female aperture of Hirulo lies in the 11th segment, between the 35 th and 36 th rings.

The arrangement of the hermaphrodite genital apparatus of the Hirudinea vividly recalls the conditions which prevail in the Turbellariu (Polyclede and Triclade).

oligochæta.-The sexual, but more especially the transmitting, organs of the Oligochete are so completely different from those of the Hirudinea, that it is not possible at present to refer the two to one common type. Testes and ovaries are always very few in number ; the former occur in one or two pairs, the latter in a single pair. The former always lie in front of the latter. The collective male and female genital apparatus occupies a limited number of segments in the anterior part of the body. The segments lying between the 9 th and 14 th generally form the genital zone. Less frequently (Aphanoneura, Chatogastrida) the genital organs lie farther to the front. While in the Hirudinea, Nemertina, and Nematoda the egg and sperm passages are, as in the Plutodes, direct canal-like continuations of the ovaries and testes, they are, in the Oligocheta, separated from the first from the germ glands, and show much agreement with nephridia in their structure. They are therefore pretty generally regarded as nephridia which have assumed the function of conducting the genital products out of the body. We must not, nevertheless, forget that the sperm ducts and oviducts, even if they really are transformed nephridia, must in the segments referred to represent supernumerary nephridia, since, in the adult Lumbricida and in the young stages of other Oligochata, besides the oviducts and sperm ducts, typical nephridia occur in the genital segments as well as in the rest of the body. In the male genital apparatus we must distinguish three parts, viz. the testes, the sperm sacs, and the sperm ducts. In the Lumbricide there are almost always two pairs of testes, while the rest of the Oligocherte only possess one pair. The testes seem everywhere to break up at an early stage into the formative cells of the spermatozoa, so that in adult sexually mature animals they are retained at the best as rudiments. The sperm formative cells are early gathered into special sperm sacs, in which they develop further and produce the ripe spermatozoa. These sperm sacs, formerly regarded as testes, are large vesicles which develop on the dissepiments of the testicle segments as sac-like 
outgrowths of their posterior lamelle. They are divided internally by lamellie into numerous compartments and chambers, in which the developing spermatozoa lie, and are in open communication with the body cavity. The manner in which the sperm formative cells pass out of the testes into the sperm sacs is not known. The sperm sacs, even in nearly related genera and species, differ considerably in their number and special arrangement. In some Lumbricide a middle unpaired portion is formed, a sperm eapsule, and the sperm saes then appear merely as paired appendages to this capsule. In the Chotogustride alone no sperm sacs are developed.

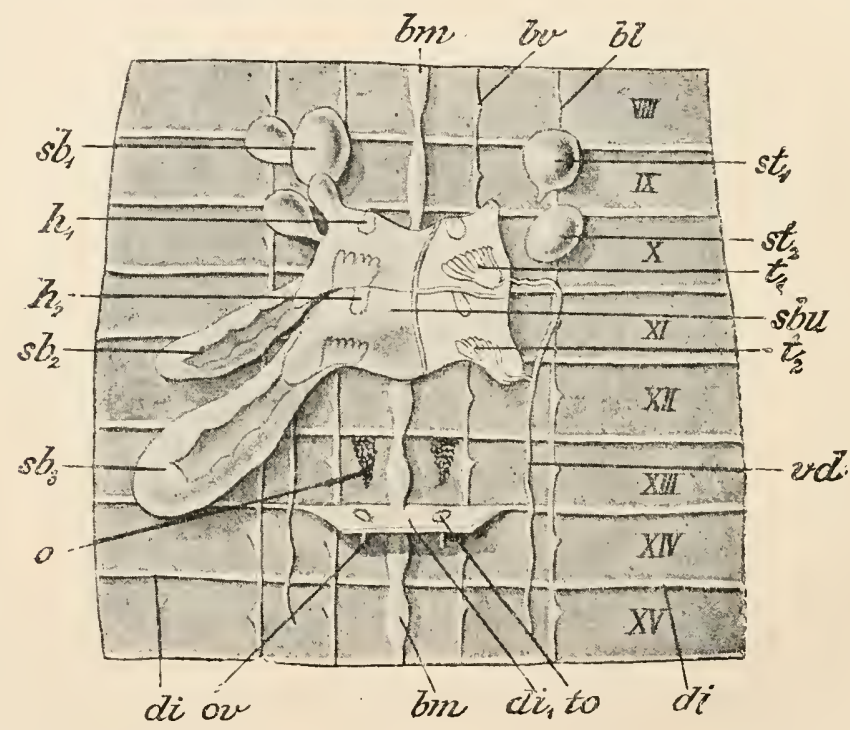

Fif. 174.-Lumbricus agricola. Genital organs, after Vogt and Yung. To the right the sperm sacs and a part of the unpaired sperm capsule are removed. $b m$, Ventral chord; st ${ }_{1}, s_{2}$, receptacula seminis ; $t_{1}, t_{2}$, sperm funnels ; sbu, unjaired sperm capsule; $d i$, dissepiments cut off at their bases ; $v d$, vas deferens ; to, funnels of the oviducts ; 0 , ovaries ; ov, oviduct ; $d i_{1}$, part of the dissepiment between the 13 th and 14 th segments; $s b_{1}, s b_{2}, s b_{3}$, paired sperm sacs; $h_{1}, h_{2}$, testes; YlII-XV, sth to 15 th segments.

The sperm formative cells in this famiiy develop fully in the body cavity, and the ripe spermatozoa are collected direct out of the coelomic fluid by the fumnels of the sperm ducts. Each sperm duct consists of a preseptal funnel, and of a duct which penetrates the septum and opens externally through a widened terminal division, the atrium (arising by an invagination of the outer integument). Where only one pair of testes is present there is generally only one pair of sperm ducts. This is the case in the Nicidomorpha, Chatogustride, Tulificide", and Enchitrueide. In other Otigochetu, however, especially those which live on land, and in most Lumbriculide, there are two pairs of sperm ducts. In this case all the four ducts are either entirely 
distinct from each other, or else the anterior and posterior ducts on each side enter a common atrium (many Lumbriculide), or the ducts of each side unite to form a common duct, which opens outwardly without the formation of an atrium (Lumbricide). The sperm funnels lie in the same segments as the testes. In those Lumbricide which have a median sperm capsule they lie in it.

Female Genital Apparatus. - This consists of the two ovaries, the two oviducts and receptacula seminis. The eggs either ripen in the ovaries, or the ovaries fall into a few groups of egg cells. Only one cell in each group then develops into an egg. The eggs occasionally pass out of the ovaries into special egg sacs corresponding to the sperm sacs, and pass out from these through the oviducts. In many of the lower Oligochate there are no special oviducts. It is not really understood in what way the eggs are here transmitted to the exterior. The receptacula seminis are paired sacs which open outwardly in special segments of the genital zone. They arise as invaginations of the integument, and oceur in most Oligncheete in one pair, in the Lumbricide, however, in two (less often three) pairs. They are closed towards the body cavity, are in no way connected with the rest of the genital apparatus, and are during copulation filled with sperm from without.

Fig. 174, which depicts the genital aplaratus of Lumbricus agricolc, will help to elneidate the above. In the 9 th and 10th segments we see the 2 receptacula seminis, in the 10th and 11 th the sperm capsule divided by a transverse partition wall into an anterior and a posterior part, with its 3 appendages (the sperm sacs) to the left; to the right the 3 sperm saes and the cover of the sperm capsule are removed. We see the anterior and posterior testes of the right sile of the body, and further the 2 righthand sperm fumnels and their ducts, which in the 12th segment unite to form the unpaired vas deferens emerging in the 15 th segment. In the 13 th segment the 2 ovaries lie at the 2 sides of the rentral chord. Behind these, on the anterior side of the dissepiment between the 13th and 14 th segments are the funnels of the oviducts which open ontwardly in the 14 th segment.

Polychæta.-The description here may be brief. With isolated exceptions, the sexes are separate. The matrix from which, generally only at certain periods, the ovaries or testes are developed, is the endothelium of the body cavity. The position of the germ glands varies greatly. They are sometimes found on the so-called genital plates, sometimes on the dissepiments, or on the mesenteries, or they may be outgrowths of the endothelial covering of the ventral vessel, etc. The ovaries or testes are generally repeated in many, or at any rate in several, segments. Their form varies as much as their position; they are sometimes cellular thickenings, sometimes massive knobs, or tufts of strands, etc. The egg or sperm cells sever themselves sooner or later from the oraries and testes, and ripen when floating freely in the coelomic fluid. From this they are discharged through nephridia which are more or less strongly modified 
at the time of sexual maturity, or through nephridia which are permanently transformed into genital tubes.

In Sternaspis, in the female one ovary is found, and in the male one testis. The genital gland in both sexes has the form of a four-lobed pouch, which lies between the loops of the intestinal tube, and passes into 2 efferent ducts opening outwards, between the 7 th and 8 th segments. The genital products do not enter the body cavity, but pass from the cavity of the genital gland to the exterior throngh the efferent ducts. The question as to whether these ducts represent modified nephridia must be decided by further research.

The My:ostomide (Figs. 175 and 176) are hermaphrodite. Their sexual apparatus does not easily admit of comparison with that of the other Annulute, but rather recalls in many points that of

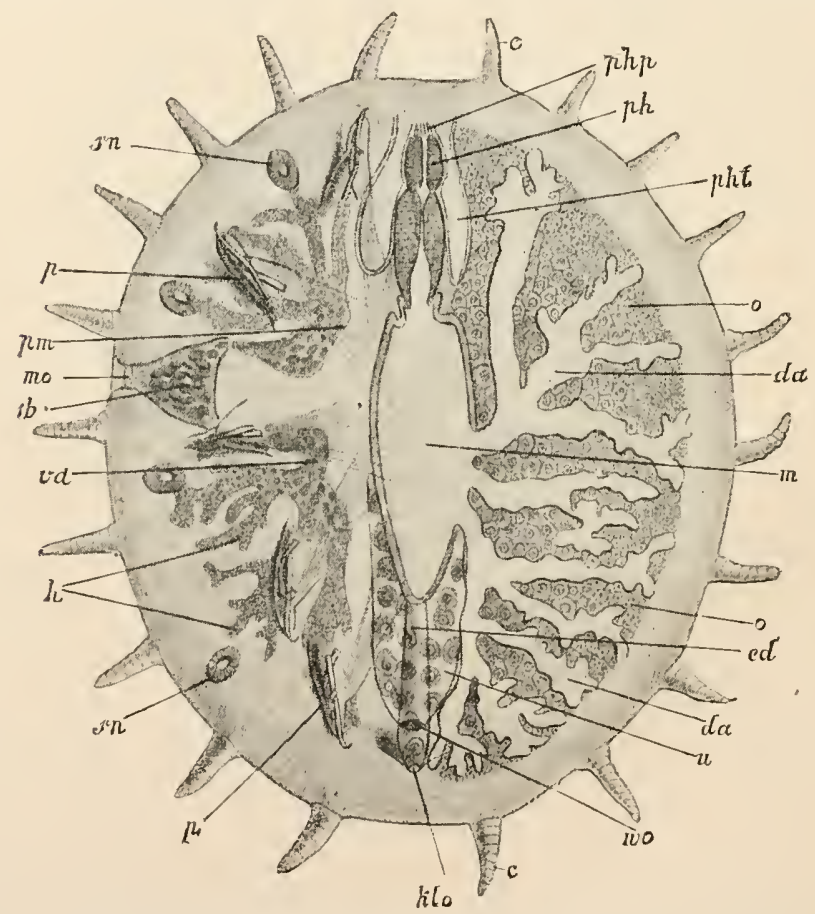

FIG. 175.-Organisation of Myzostoma cirriferum, after $\nabla$. Graft. To the left the parapodia $(p)$, the suckers $(s n)$, and the male genital apparatus are represented. To the right the enterie branches $(d c)$ and ovaries $(0) . \quad c$, Cirri ; $p h p$, pharyngeal tentacles; $p h$, pharynx; pht, pharyngeal pouch ; m, stomach (mid-gut); ed, hind-gut; $u$, uterus ; wo, female genital aperture, which enters the cloaca; $k l o$, aperture of eloaca; $p m$, muscles for moving the parapodia; mo, male genital aperture; $s b$, sperm vesicle; $v d$, vas deferens; $h$, testes; $p$, parajodia with hooks and sulporting rod.

the Platodes. It is, however, probable that this is more a case of analogy than of homology. In the sexually mature animals the parenchyma is filled with numerous egg cells which lie in 
masses between the branches of the intestine, especially on the dorsal side. These masses of eggs are regarded as ovaries. It is, however, possible that they consist of eggs which have left the real ovaria.

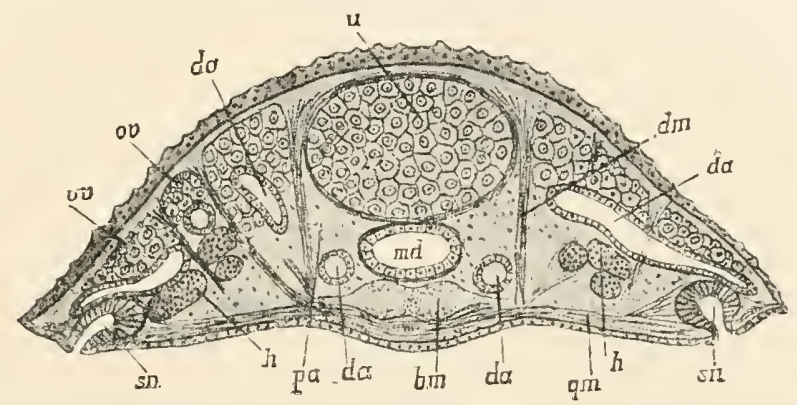

Fig. 176.-Section through Myzostoma, after $\nabla$. Graff. ov, Ovaries; da, intestinal branches ; $u$, uterus; $d m$, dorso-ventral muscle fibres; $s n$, suckers; $h$, testes; $q m$, transverse muscles; $b m$, ventral ganglionic masses; pa, parenchyma; md, intestine.

The origin and places of formation of the eggs are not known with any certainty. The ripe eggs pass into a spacious uterus which lies on the dorsal side of the stomach-intestine. One dorsal and two lateral oviduets connect the uterus with the cloaca. The male genital apparatus is paired. On each side branched solid testicle strands lie in the parenchyma below the intestine and its branchings. On each side an anterior and a posterior vas deferens collect the sperm from the testes. Both vasa deferentia enter a muscular lateral sperm vesiele, which lies between the $3 \mathrm{~d}$ and 4 th suckers, and which opens outwardly at the edge of the body.

Prosopygia.-The places of formation for the eggs and spermatozoa of the Sipunculide, Phoronidle, and Brachiopoda are definite points of the endothelium of the body cavity. The sexual products fall into the coelomic fluid, and are emptied out thence by the nephridia, as was the case in the Polychreta.

In the Sipunculicte the formation of the germs takes place for the most part at the base of the ventral proboscis retractors. Phoronis is hermaphrodite.

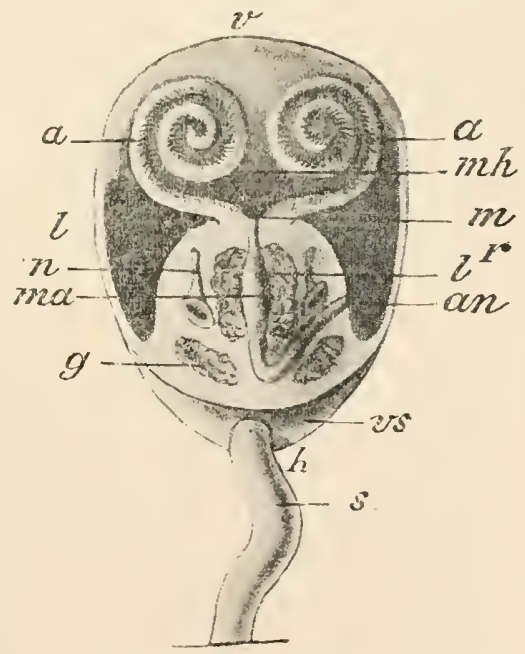

Fig. 177.-Diagrammatic representation of the organisation of a Brachiopod, from the dorsal side; the dorsal halves of shell anrl mantle are removed. $a$, Aruls ; $m$ h, mantle carity ; $m$, mouth ; $l$, liver; me, stomach; $n$, nephridia; an, anus ; $g$, genital glansls; $\imath * s$, part of the ventral shell which projects backwards over the dorsal shell; $v$, anterior; $h$, losterior ; $r$, right; $l$, left.

The male and female sexual products arise 
on the asymmetrical ventral vessel. According to recent research it is probable that in most, perhaps in all, Brcchiopoda the sexes are separate. The germ glands are outgrowtlis of the endothelium of the lorly cavity, and lie as branched or reticulaterl strands, in the Testicardines in pairs in the body cavity of both mantle folds, in the Ecardines in the mantle folds and in the body cavity of the trunk, or in the latter alone (Fig. 150, 1. 226 ; Fig. 177, 1. 263).

In the Priupulicle the anal tubes, which in early stages act as excretory organs, become later the places of formation of the genital products. They are then at the same time germ glands and efferent ducts.

In the Bryozoa there seems to be no definite rule; separation of the sexes is sometimes found, and at other times hermaphroditism. The ovaries and the testes arise, in the Ectoprocta, as cell outgrowths on the inside of the body wall or on the funiculus. The first position is most characteristic of the ovaries, the second of the testes. In the fresh-water Bryozou, however (Fig. 139, p. 208), there also arise on the funiculus the statoblasts, which are to be regarded as parthenogenetic eggs. Special efferent ducts are wanting. The eggs and spermatozoa fall into the body cavity. We do not yet know for certain how they reach the exterior. Many observers maintain that in hermaphrodite Bryozoc self-fertilisation takes place in the body cavity. In many marine Ectoprocta (Chilostomata and some Cyclostomata) the ripe (fertilised) eggs are taken up into special capsule-like foldings of the body wall, the so-called ooecia or ovicells, and these are regarded as modified individuals which have arisen by gemmation. This view does not as yet rest on sufficient foundation. The sexes seem to be separate in the Endoprocta, but it may perhaps be the case that the ovaries and testes do not develop at the same time. Two testes lie between the stomach and body wall, and pass into 2 sperm ducts, which emerge into a sperm vesicle, the latter opening by a pore into the restibulum (the depression between the tentacles at the bottom of which the mouth lies). The female genital apparatus shows a similar arrangement: 2 ovaries, 2 oviducts, and an unpaired terminal division which also opens into the vestibulum by a pore. The genital apparatus of the Pterobranchia is not yet sufficiently known; under the 2 eyes of Cephalodiscus lie 2 ovaries.

Rotatoria (Fig. 161, p. 245).-Separation of the sexes here prevails. The usually unpaired, seldom paired, female germ gland lies near, generally below, the intestine, and consists of two parts - a germarium, which yields the egg germs, and a vitellarium, which richly supplies the young cells with yolk. The germ gland, which we may call the germ-vitellarium, is surrounded by a membrane which passes into a fine oviduct opening into the cloaca. The last part of the oviduct, where the eggs often remain for some time, may be called the uterus. In the male a testis with a ras deferens and protrusible penis are found, which latter lies at the posterior end of the body; through it also the contractile terminal vesicles of the nephridia open outwardly. 
In Dinophilus (Fig. 162, p. 246) the sexes are separate. An ovary lies on the outer surface of the intestinal wall, ventrally on the boundary between the mid-gut and the hind-gut. It may perhaps be developed out of an endothelium, which, however, has not yet been proved to exist. The ripe eggs fall into the body cavity and are emptied out through a pore which forms temporarily in the body wall in front of the anus. The male sexual organs are not yet sufficiently known.

In the male of D. "putris, at the posterior end, a conical organ (penis) is found, which lies in a sac out of which it can be protruded and into which it can be withdrawn.

The Chetognathe (Fig. 152, p. 227) are hermaphrodite. The ovaries are two long tubes which lie in the posterior part of the two lateral chambers of the trunk cavity. Throughout their whole length they are attached laterally by a mesentery to the body wall, this mesentery enclosing them all round like a sac. On the outer side of each ovary, and enclosed in its mesentery, lies a long oviduct, ending blindly to the front, and opening outwardly behind near the septum which separates the trunk and the tail carities. It is not yet known how the eggs reach the oviduct and are discharged. The two testes lie as lateral cell thickenings or germ masses projecting into the body cavity from the body wall of the tail cavity. Groups of young sperm formative cells sever themselves and fall into the two lateral chambers of the tail cavity. The ripe spermatozoa are discharged through the sperm ducts. In each sperm duct we can distinguish an imner ciliated funnel, a duct, and a vesicle; these open externally at the sides of the caudal segment. Thus in the arrangement of the reproductive organs, especially in that of the male genital apparatus, we find great similarity between these animals and the Chetopode, Sipunculide, Phoronis, and the Bruchiopodu.

Sexual Dimorphism in Worms.-Apart from the difference between the sexual organs and outer eopulatory organs, there are, in many worms in which the sexes are separate, insignificant external differences between the male and the female. In some worms, however, the differences in inner organisation cause a remarkable sexual dimorphism in outer appearance and in size between the two. This is especially the case in the Rotatoria, Dinophilus, and Bonellir. It is always the male which, in comparison with the female, appears redueed and generally dwarferl. The Rotatorion male is smaller than the female, with degenerated enteric canal and simplified wheel apparatus. The males are known only in the minority of genera and speeies, and are much rarer than the females. In Scison alone the males and females are alike. The fertilisation of the Rotatorian eggs has till now not been observed. The females usually produce two sorts of eggs-delicate-skinned summer eggs, and hard-shellerl eggs which last throngh the winter. In Dinophilus vorticoides the two sexes are not different; in $D$. apatris the male is smaller, with eiliated rings. Mouth, intestine, and anns are wanting. The males of Boncllic, which are ciliated all over, and are in appearance not unlike the Rhabdocelan Turbellario, are minute in comparison with the females; these males live parasitically on the female in varying numbers on the proboscis, in the osophagus, or in the 
nephridium which serves as uterus and oviduct. The intestinal canal is without mouth or anus, a vascular system is wanting, nor have they the prostomium which in the female is strongly developed as a proboscis. In short, apart from the sexual organs, they remain on the larval level. In some Mysostomidce there are so called complementary males, which are considerably smaller than the hermaphrodite individuals on which they live. Their organisation is like that of the hermaphrodites. As rudiments of ovaries and oviducts have been discovered in their bodies, we can only consider these complementary males as originally hermaphrodites with one-sided development of the male genital apparatus, or as young hermaphrodites with the fernale genital alpraratus not yet developer.

\section{Parthenogenesis.}

Reproduction by means of unfertilised egrgs certainly takes place in the Rotatoria and Bryozoc. It was formerly thought that only the summer eggs of the wheel animalcule could develop, without fertilisation, while the winter eggs must be fertilised, but the act of fertilisation has not yet been observer in connection with these latter. The statoblasts of the fresh-irater Bryozoc are parthenogenetic eggs, and such eggs are also found in some marine Eryozoa. These eggs are enclosed in hard cases provided with many arrangements (air rings, processes, etc.) serving to disperse them in the air or water.

\section{Asexual Reproduction by Gemmation and Fission.}

Many worms, especially the Icmertina, Chectopoda, Sipunculide, Phoronis, and the Bryozoc, are distinguished by a highly developed eapacity of regeneration, which is of the greatest use for the maintenance of the individual and of the race. Such portions of the body as have been lost through adverse external circumstances, broken off, bitten off, ete, are quickly regenerated, even such as contain the most important organs, $c . g$. the anterior part with the brain. Isolated broken off pieces may occasionally be regenerated into whole animals. As already indicated, we may perhaps some day be able to refer back the capacity shown throughout the animal kingdom for asexual reproduction by gemmation and fission to such an accidental multiplication by voluntary or enforced falling to pieces of the body with subsequent regeneration.

Among the Vermes this form of reproduction oceurs in the Polychata, Oligochata, and Bryo:oc.

Polychæta.-One of the Capitcllicla, Clistomastus, constricts off (most probably periodically) the posterior part of the body, which contains the sexual products, reforming it again by regeneration. In a Syllis, Haplosyllis spongicola, which lurks in holes at the bottom of the sca, the parapodia and sete of a number of the posterior segments become more strongly dereloped as sexual maturity approaches. The group of segments thus modified, containing the sexual products, severs itself, and swims about freely in the sea as a sexual swimming bud, dispersing the sexual products. In other Syllide (Syllis, Autolytus) at the anterior end of the swimming bucl a new hearl is formed with highly developed eyes, and this takes place even before it is severed. The detached swimming bud then represents a complete individual (per'son), in which the sexual products ripen. The individual from which the swimming bud has severed itself forms no sexual products, but is able at its posterior end to produce new swimming buds. The detached swimming buds or sexual animals may, aprart from the fact that they contain the sexual organs, be distinguished from the mother animal by other, chiefly external, points of 
their organisation. We thus have before us an alternation of generations. A mother animal which remains asexual produces asexually sucecssive daughter animals which differ from the mother animal externally; these detach themselves and reproduce sexually by means of fertilised eggs ; we thus have alternating asexual and sexual gencrations. In Myrianida (also a Syllis) new buds arise on the mother animal even before the lindermost has detached itself. There thus arises a chain of buds of which the hindermost is the oldest and the foremost the youngest. This is a case of axial gemmation which is very similar to strobilation.

Oligochæta. - In antumn Lumbriculus falls into pieces which are all able to regenerate into complete animals. In the genera AEolosoma and Ctcnodrilus no sexual organs and no sexual reproduction have as yet been observed, only asexual reproduction. In Cteinadritus monostylos the body becomes constricted in the middle, and finally seprates into two pieces, each of which may again divide. These pieces regenerate into normal animals after detachment. It is otherwise in Ct. pardalis. Here, in cach segment (except the foremost) behind the dissepiment of the preceding segment, a budding zone appears, in which brain, (esophagus, etc., form. The development of these budding zones takes place from before backward. The segments thus transformed finally separate. In each of them the fore-gut and hind-gut become connected with the mid-gut and the typical segmentation is developed, so that each becomes a complete individual. In Eolosome, as in the Syllider, several posterior segments are included in the first bud. While the head forms anteriorly in this bud, it as well as the mother body increases in length, and the latter develops other buds posteriorly beforc the first and oldest, i.e. the hindermost bud detaches itself. The processes of gemmation are most complicated in Nais and Chetogaster, since here in the (anterior) mother individual as well as in the daughter individual new thenomena of gemmation appear before they become detached from cach other. Chains of several individuals rarying in age and stage of development thus arise. The age and degree of development may be given in a formula. $A$ indicates the foremost and oldest individual, in which at first the daughter individual $B$ appeared; then the bud $C$ began to form in the individual $B$, and so on. An order of development of buds which has been observed in Tais baibuta (from before backward) is as follows : $A, F, D, B, E, C$. Finally, the chain breaks up into its separate parts, which no longer multiply asexually, but increase the number of their segments, and as sexual individuals can develop sexual products. There is therefore here also a kind of alternation of generations, since sexual and ascxual reproduction mutually exclude one another.

\section{Stock Formation.}

The peculiar Syllis rumosa, which lives in deep-sea sponges, forms by means of lateral gemmation much-branched stocks, in which, as in most other syllicle, special sexual individuals develop and detach themselves. This is the only case of lateral gemmation in the Chotopoda. Among the Bryozoa, animal stocks of the most various shapes arise hy lateral gemmation. They are sometimes tree-like, sometimes tufts, or they may be spread out like webs or crusts; sometimes many single animals rise from a creeping stem. Te thus find repeated in the biryosiue the forms assumed by the Hydroidu. In Loxosoma alone the buds detach themselves, so that a permanent stock is never formed. On the stocks of many Chilustomen Biryozoc peculiar appendages, so-called vibracularia and avicularia, are found. The 
former are prominences on the wall of the ordinary individuals (zooecia), each of which carries a long seta, by means of whose free movement particles of food are brought within reach, and the water surrounding the colony is kept in motion. The stalked avicularia are catching apparati which hold small animals fast till they die. The mechanism is similar to that of a crab's forceps or a bird's beak; a movable mandible is hinged upon an immovable beak, and is worked by special muscles, so that the forceps can open and shut. Avicularia and vibracularia are, like the above-mentioned ooecia and ovicells, regarded as metamorphosed individuals without intestine. This assumed polymorphism of Chilostoman stocks is, however, as yet weakly supported. In marine Bryozoa all the individuals of a stock are connected together by a network of nerve threads, forming what has been called a colonial nervous system.

\section{Ontogeny of the Worms.}

The cggs of worms are either holoblastic alecithal, or holoblastic telolecithal. In the latter case the yolk may vary very much in quantity. The course of segmentation and gastrulation varies in correspondence with the constitution of the egg. There is sometimes (in the holoblastic alecithal egg, cxample Sagitte) a total and tolerably equal furrowing, forming a coloblastula, and then by invagination a colo. gastrula. Sometimes the furrowing is more or less unequal, and often connected with the formation of micromeres ( $f$. p. 124, segmentation of Bonellia). We find, always according to the quantity of yolk stored in the egg, all the stages from a cocloblastula to a sterroblastula, from an invagination to an epibole, and from a cologastrula to a sterrogastrula. Alecithal eggs or telolecithal eggs with little nutritive yolk, cœloblastulæ and coelogastrule, are found in those groups of worms in which a freeswimming and independently feeding larra develops very early. This is the case in very many marine worms, especially in Nemertina, Polycheta, Sipuneulide, Bryozor, Phoronis, Brachiopoda, and Chatognatha. Telolecithal eggs with much nutritive yolk. sterroblastule and sterrogastrulæ, are found in those cases where the developing animal only begins to move and to feed very late, i.e. in an almost adult condition, and especially where a so-called direct embryonic development takes place, e.g. Oligocheta, Hirudinea, Rotatoria.

Before passing on to describe the more important larval forms among the Vermes, we will briefly describe the development of Eunomatus uncinatus (Serpulidx) (Fig. 178, ef. also Fig. 92, p. 123). The blastula has a small blastocœl. The cells of the upper (animal) lialf are smaller and more numerous than those of the lower (vegetative) half. The former form the ectorlerm, the latter the endoderm. At an early stage, at one side of the blastula, which we may call the anal side, 2 round cells appear with remarkable distinctness at the limit between the ectoderm and the endoderm. By the rise of these primitive mesoderm cells the blastula becomes bilaterally symmetrical. Besides an aboral or animal side and an oral or vegetative side, we can also distinguish an anterior and posterior (where the 2 primitive mesoderm cells lie), and likewise a right and a left, and a median plane. The two primitive mesoderm cells lie to the right and left of the median plane. The vegetative or endodermal wall of the blastula then becomes invaginated into the segmentation eavity to form the arch. enteron while at the same time the ectoderm grows out over the invaginated part. The process thus stands lialf way between invagination and epibole. The primitive mesoderm cells, lying at the posterior edge of the blastopore, sink between 
endoderm and eetoderm, i.e. deeper into the segmentation cavity. This grastrula formation takes place in such a way that the blastopore is a median ventral longitudinal slit. This closes from baek to front, until anteriorly, i.c. cxcentrically, only a suall aperture remains. An equatorial eiliated ring, the preoral eiliated ring, appears early in the gastrula larva. In the cell thickening which carries this ring of cilia a cirenlar ncre is developed. At the aboral pole the ectoderm thickens to form the neural plate, which carries a tuft of cilia. Direetly round the narrored blastopore the ectoderm beeomes invaginated like a funnel, and forms the larval cesopliagus or the stomodæum, which gradually aplroaches the anterior ventral edge of the preoral eiliated ring. 'The arehenteron elongates downards and backwards. Several smaller eells are severed by fission from the primitive or pole cclls of the mesoderm, and these are spread out in the segnentation cavity (primary body cavity) and form varions larval organs, e.f. muscle fibres and the larral head

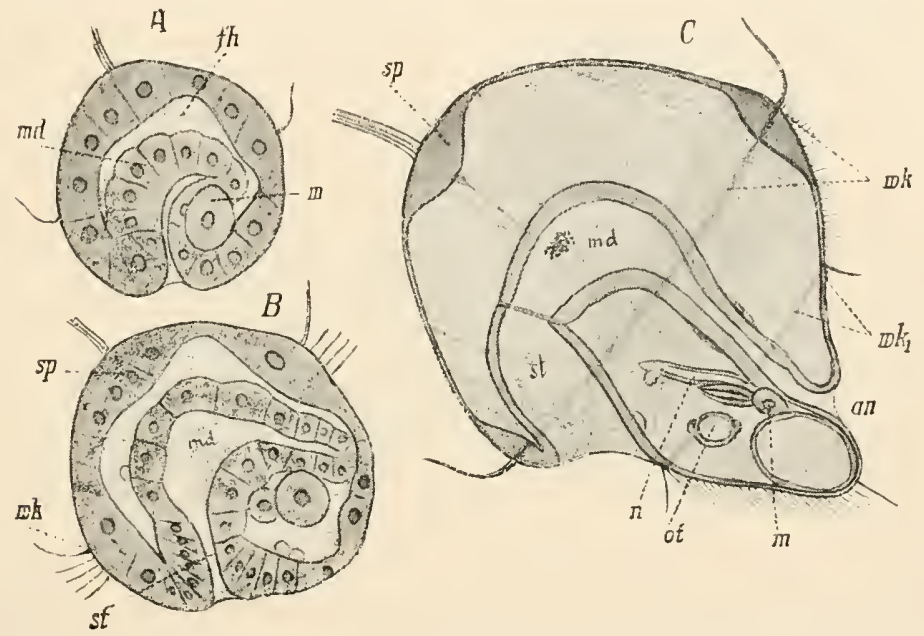

Fig. 17s.-A, $B, C$, Three stages of development of the larva (Troehophora) of Eupomatus, from the side. $m$, Polar cells of the mesoderm ; ml, mid-gut; $f h$, segmentation cavity; $s p$, neural plate; $v \%$, preoral ciliated ring; st, stomodeum; $w k_{1}$, postoral ciliated ring; $n$, larval head nephrilium; ot, otolith; an, anus (after Hatschek).

nephridia. The primary body eavity lengthens. That half of the body whielı lies behind and below the preoral ciliated ring assumes a eonieal form. The proint of the eone is the posterior end. From the posterior end to the mouth the body beeomes flattened. On the dorsal surfaee the posterior end of the intestine opens by means of a small invagination of the eetoderm, the proctodæum with an anus; this oecurs not far from the prosterior end of the larra. Diametrically opposite to this, at the neural area, whieh is surrounded by the preoral ciliated ring, lies the ncural plate, whieh represents a part at any rate of the rudiment of the brain. A pigment spot (eye) arises asymmetrically in a eell of the neural area. Behind the mouth a slighter postoral eiliated ring appears. The whole eetoderm between the preoral and postoral ciliated rings is covered with short cilia, and thus forms an adoral ciliated zone. A narrow medio-ventral ciliated band forms from the moutl to the posterior end. Two anditory vesieles are developed out of two ectodermal eells immediately behind the postoral ciliated ring, and sink beneath the surface later. Two eell streaks or bands are developed from the two pole eells of 
the mesoblast whieh lie near the posterior end; these lie close to the ectoderm ventrally on each side, and develop anteriorly by eonstricting off smaller cells and by the continuous division of the same; they are the two mesoderm streaks. The larva has now reached what is known as the Trochophord stage. It swims abont freely by means of its ciliated rings. The hindermost smaller portion of the body with the intestine, proetodeum, and the prosterior prart of the mesoderm streaks, represents the rudiment of the afterwards segmented trunk plus the anal segment; the whole of the larger anterior portion contains the rudiment of the head or oral segment.

Larre of the Trochophore type oceur not only in worms, but are also common among Molluses.

In addition to the Tiochophora the following are some of the most important kinds of worm larve.

The free-swimming larva of the Sipnenculide (Fig. 179) is already much further developed when hatehed than the Polychetan Trochophora, with which, however, it has much general similarity. In the Sipunculus larva the eharacteristic rreoral ciliated ring of the Trochophore larva is wanting, but sueh a ring, weakly

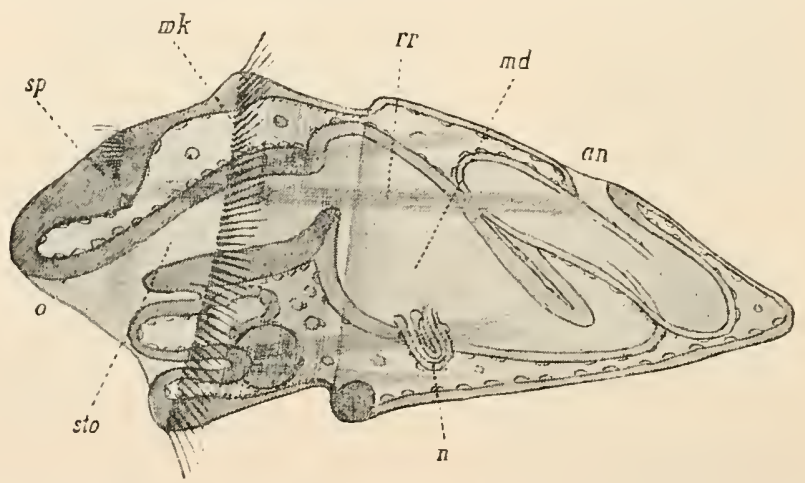

FIG. 179.-Larva of Sipunculus, after Hatschek. o, Mouth; sp, weural-plate; sto, stomodieum $w l$, post-oral ciliated ring; $r$, retractors of the auterior body (proboseis); md, mid-gut; $n$ nephridium; $a n$, anus.

developed, is said to occur in the Phascolosoma larva. A postoral ciliated ring, on the other hand, is strongly developed. The intestine consists, as in the Trochophord larva, of stomodæum, mid-gut, and proetodæum. The latter is moved somewhat from the posterior end on to the back, and the postanal part of the body growing faster than the preanal part, the anterior position of the amus whieh is characteristie of the adult animal comes about. The neural plate with 2, and later 4, larral eye-spots is found in the same place as in the Polychetan Trochophora. A larval head kidney is not formed. The mesoderm, on the contrary, is far more developed than in the Polychectan Trochophora. The retractors of the anterior body (proboseis), and the two trunk nephridia, have ahready begun to form. There is a spacious body eavity, but this does not eorrespond with the primary body cavity of the Trochophora, but rather with the seeondary body eavity of the Ammlate whieh appears within the mesodermal streaks, so that under the integument and around the intestine there is already a layer of mesoderm eells answering to the parietal and visceral layers of the mesodern of the Anmulato. While, however, in the Annulate the mesodermal streaks become segmented and the body cavity is thereby divided into eonsecutive pairs of chambers, in the Sipunculide there is neither segmentation of the mesoderm nor of the body cavity. 
Bryozoa. - It is very diffienlt to describe the different, and for the most part still insuffieiently known, larval forms of the Bryozod, and to establish their relations to the adult animals. We must confine ourselves to a description of the larra of Pedicellina (Endoprocte) (Fig. 150). A ciliated ring on a circular elevation divides the larval body into two regions. In the oral region, which is eiliated all over, lic the mouth and anus, the latter on a conical prominence. Behind the mouth lies a prominence with a tuft of cilia. Between the mouth and anus there is a depression, the vestibular pit. The whole oral region ean be withdrawn into the aboral, so that the moutl and anus. come to lie at the base of a depression wlose edge is formed by the eiliated ring, and which is called the restibnlnm. In the middle of the aboral region rises a eiliated tuft. From the base of this ciliated tuft an organ consisting of long ectodermal cells, the so-called cement gland, projeets into the interior of the larva. There is also in the aboral regrion another organ projecting inwards like a sac, into which a short canal enters from outside, this is

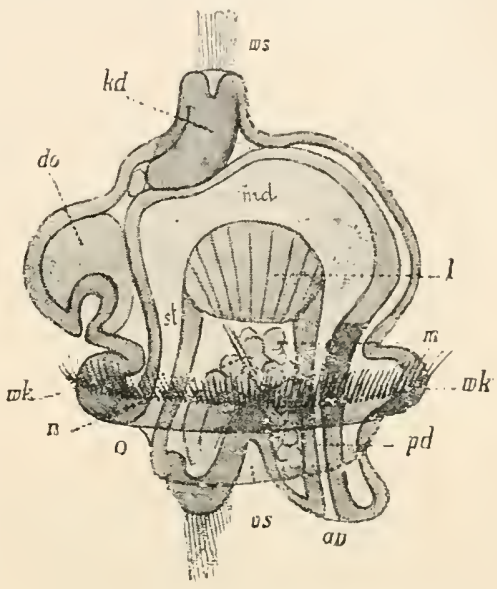

FIG. 1S0.-Larva of Pedicellina (after Hatschek), from the side. 0, Houth ; n, nephridium; $w k$, ciliated ring; do, dorsal organ ; $k d$, "cement gland" ; ws, ciliated tuft ; $l$, "liver" ; m, meso(lerm cells; $p d$, proctodxum; $t h$, anus; $\imath$ 's, restibular pit; st, stomodrum; mol, mitt-gut. the so-called dorsal organ. Both these organs are said to disappear in later metamorphosis. In examining the inner organisation we find a stomodeum, a sac-like mid-gut, and a lind-gut rising up to the anus. The wall of the intestine turned towards the vestibulum is much thickened and is called the liver. Museles arranged in various ways serve for retraeting the oral region. Between the stomach-intestine and the body epithehum of the oral region lies a mass of mesoderm cells, and connected with this on each side a small ciliated canal (nephridia of the adult animal ?). If we wish to compare these Endoprocton larvæ, which show considerable resemblance with the Ectorroctan larva of Hembranipora known as Cypho-
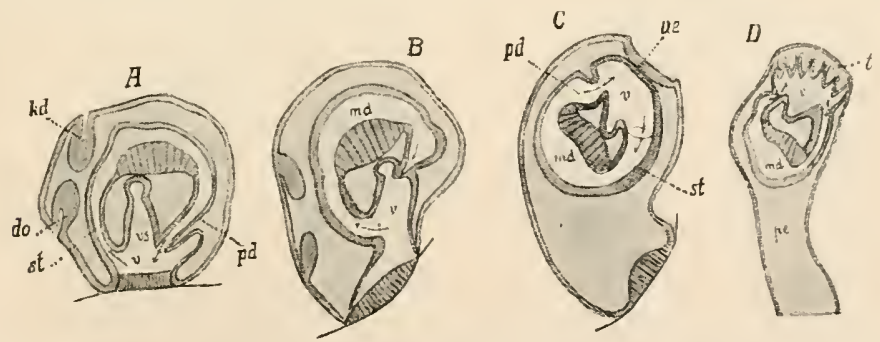

F1G. 181.-A, B, C, D, Four stages of the metamorphosis of the attached larva of Pedicellina. do, Dorsal organ; kd, "cement gland"; st, stomoileum; md, miil-gut; pd, proctodienm ; $v$, vestibulum; $v s$, vestibular pit; $t$, rudiment of tentacles; $p e$, peduncle. The arrows indicate the direction from mouth to anus. ve, Invagination of the body wall towarls the vestibulum (after Barrois).

naxtes, with a Polychatan Trochophora, we must consider the ciliated ring as equivalent to the preoral ciliated ring of the latter. Then the so-called cement gland 
with the ciliated tuft would answer in position to the neural plate of the Trochophora. The further development of the Pelicellina larva involves a preculiar metamorphosis (Fig. 181, $A-D$ ). The larva attaches itself by the oral region, while at the same time the restibulum closes by the growing together of its free erlges over the mouth and the anus. Thereupon the whole cnteric canal, with the altered restibulum turns round, inside the sac-like ectoderm which encloses them, so that later, reversing the larval order, the restibulum, with the stomodium and lroctodeum entering it, is turned to the free end, i.c. the original aboral region of the larva. The restibulum becomes connected with the cxterior by means of a new invagination of the ectoderm ; at the point of junction the tentacles alpear. According to this ontogenetic observation the anus would lie, not dorsally, but ventrally, behind the month, and so would the ganglionic mass, which would thus not be homologous with the hrain of other worms. Further investigations, however,
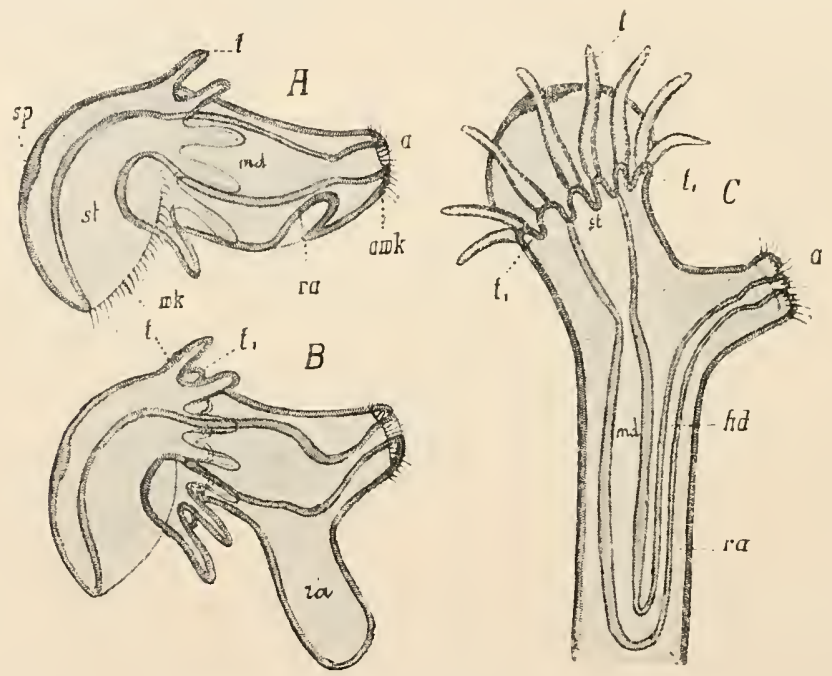

Fig. 1S..-A, $D$, C; Three stages of the development of the larva of Phoronis (Actinotrocha), from the sirle. $s p$, Neural plate; $w$, ciliated organ; $s t$, stomodrum; $t$, larval tentacles; $t_{1}$, definitive tentacles; $m d$, mid-gut ; ru, rudiment of the trunk (staik), invaginated in the larva $A$, protruded in $B$, developed into the trunk in $C$; $a$, anus ; $a w \%$, anal ciliated ring ; $h d$, hind-gut (partly after Metschnikoff).

especially as to the development of the nervous system, are needed to elucidate these points.

The larva of Phoronis (Fig. 1S2) is known by the name of Actinotrocha. The mouth and anus lie at opposite enrls of the ciliated larval body. Over the month a large prostomium hangs down, whose edge carries stronger cilia which probably correspond with the preoral ciliated ring of the Trochophora. A larval ganglion (neural plate) lies in the ectoderm of the prostominm, and is in one species provided with 4 eye-spots. Belind the month lies a ring of larval tentacles, and immediately belind this the rudiments of the definitive tentacles, at whose bases the nerve ring of the adult Phoronis begins to form. Around the ants we find a strongly ciliated ring. Behind the definitive tentacles on the ventral side lies the rudiment of the trunk, invaginated into the larval body. The secondary body cavity is well developed. In front of the invaginated rudiment of the trunk a nephridium like the 
head nephridia of the Trochophor lics on each side. These become the prermanent nephridia of the adult Phoronis. The Actinotrocher thus formed sinks to the botton of the sea; the invaginated trunk protrudes and grows quickly, the mid-gut at the same time entering it and forming a loop with ascending and descending limbs. The whole prostomium, with the neural plate and the larval tentacles, are thrown off anil devonred by the yonng Phoronis. Through all these processes the body las approached the adult stage; it is quite evident that by the protrusion and rapid growtl of the trumk, and the compraratively slight growth of the rest of the original larral body, the anus comes to lie dorsally near the mouth. This process readily allows of being referred back to the similar process in Simeneulus, only there the rudiment of the trunk is never invaginated into the larral body.

Brachiopoda.-The free-swimming larva of Aryiope (Fig. 183) consists of three consecutive divisions, which are called the anterior, nirldle, and posterior segments.

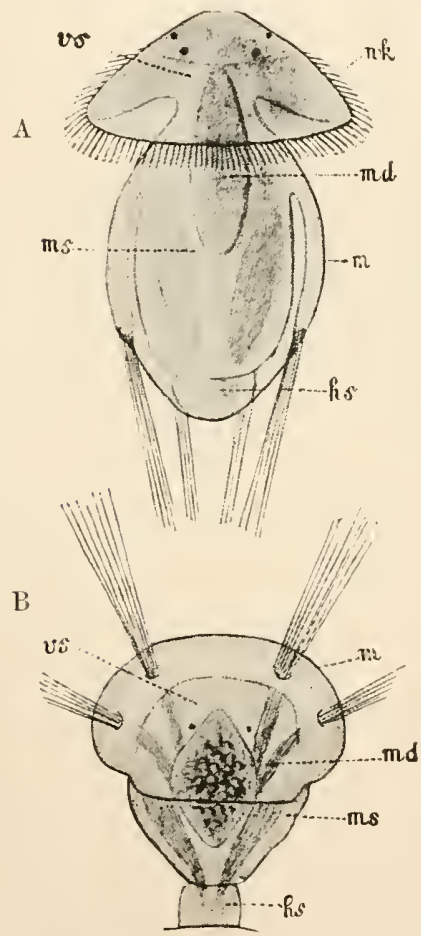

Fig. 183.- $A$, free-swimming, $l$, attached larva of Argiope, from above (after Kowalewsky). $v$ s, Anterior segment; ms, middle seguent; $h s$, posterior segment; $m$, mantle; md, mill-gut; wh, ciliated organ.

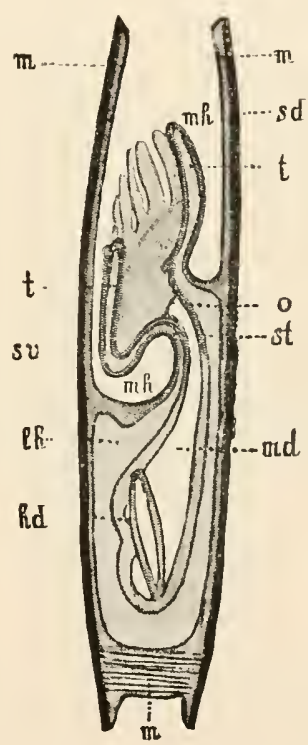

FiG.1S4.-Vertical median longitudinal section through an advanced embryo of Lin. gula, after Brooks. $m$, Mantle folds; $s d$, dorsal, $s v$, ventral shell ; $t$, tentacles ; $m h$, mantle cavity; $l h$, body cavity ; st, stomodieum ; 0 , mouth : md, mid-gut; hel, hiud-gut ; $m$ (below), shell muscles.

The anterior segment is umbrella-shaped, and carries anteriorly 4 eyes. The margin of the umbrella has longer cilia than the rest of the body. The middle segment has dorsal and ventral folds directed posteriorly, and covering the posterior segment. At each side of the free cdgc of the ventral fold two bundles of setic are 
found. The mid-gut is the only part of the intestine which is developed. Between the intestine and the outer integument of the larva are found the paired seeondary body cavity, mesenteries, and museles. The larva attaches itself by the end of the posterior segment which grows out into a stalk. The two folds of the middle segment bend forward like valves and form the mantle, the reduced anterior segment eoming to lie in the mantle cavity. The bundles of setre are thrown off. The stomodxum is formed by an invagination of the body wall of the anterior segment, whose base breaks through into the anterior end of the mid-gnt. It lies a little below the eyes which afterwards degenerate. The rudiments of the nervous system and of the nephridia have not been observed. In Terebratulina tentacles develop as buds on the eircular edge of a dise which projects from the dorsal mantle fold. The tentacles inercase in number and are grouped in the shape of a horse-shoe. The tentacular dise is then anteriorly prolonged into two proeesses, the arms, on which the double row of tentacles become the arm eirri. We here recognise great agreement with the Bryozoc and Phoronis. Assuming that the point where the eyes lie on the umbrella-shaped anterior segment in the Brachiopod larva corresponds with the neural plate of Actinotroche, the agreement between their courses of development is considerable. 'The posterior segment of the Brachiopod larva perhaps answers to the evaginating trunk part (stalk) in Actinotrocha. The oral nerve rings in the Brachiopode and in Phoronis must be homologous.

A free-swimming larva which oecurs among the Nemertina is ealled Pilidium (Fig.

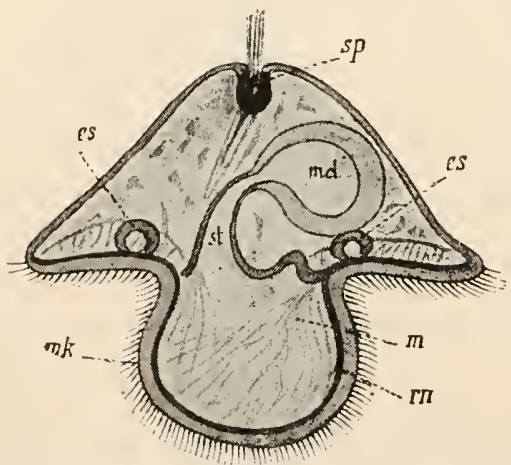

F1G. 185.-Pilidium-Larva of a Nemertian from the side (after Salensky). sp, Neural thickening with ciliated tuft; $w k$, eiliated ring; $r n$, nerve of the same ; $m$, muscles ; st, stomodaum; md, mid-gut; es, eetoderm saes.
185). It is helmet-shaped. We ean distinguish in it a convex aboral region and a somewhat eoncave oral region. The (iliated ring is found on the boundary between these two, which corresponds with the edge of the helmet. Along the hase of the ciliated ring runs a nerve. The eiliated ring, which answers to the Trochophoran preoral eiliated ring, is produeed to the right and left into two pendent lobes, which are comparable with the ear-flaj's of many lielmets. At the highest point of the aboral region is a depression; in it the ectoderm is thickened, and carries a ciliated tuft. This answers in position to the neural plate of the Trochophoru. The mouth lies in the middle of the oral region. It leads into the stomodreum, and this into a sae-like mid-gut which lies excentrically (belind). A proetodaum is wanting, and does not attain development during larval life. The space between the intestine and the ectoderm is a spacious segmentation cavity or primary body cavity. In it lie muscle fibres, and generally branched star-like mesoderm cells. The ectoder'm of the oral region is invaginated into the primary body cavity at 4 points, forming 2 pairs of sacs. One pair of these saes lies in frout of and the other belind the stomodrum. The further development of these sacs is as follows (Fig. 186, $A, B, C, D$ ): 'They sevel themselves from the ectoderm of the larva. They then beeome connected in pairs, then the anterior fused pair unites with the posterior pair, so that now, on the oral side of the Pilidium, in its body cavity, a hollow plate arises with inner and outer walls. The inner wall grows round the enteric eanal on all sides, 
and forms the permanent outer integmment of the young Nemertian. The outer, thinner, wall then forms inside the Pilidiun integument a sac-like eovering for the young Temertiun, the amnion. This integument with ciliated ridge and neural plate, i.c. the primary ectoderm, falls away together with the amnion when the young Timertian issues from the Pilidium. At an early stage we find on the inncr side of the ectoderm sae a layer of eells, whieh in the Pilidium arise ont of the ectodermal wall of the sae itself, but in the related Desor's laria are said to be deriver firom the mesoderm eells which lie in the primary body eavity. The 4 layers of cells thus arising represent the rudiment of the definitive mesodem. The central nervous system arises ont of 2 ectodermal ontgrowths which unite to form the brain in the young Nemertiun. They grow out posteriorly into two strands, the lateral nerves. The proboscidal apparatus rises firstly out of an invagination of the ectoderm above the brain, and secondly out of parts of the mesodern wheh surromul this invagination.

The Pilidinin larva takes up a position internediate between the young Turbellution larva of the Polyclede ( $f$. 1. 167, Müller's leriea) and the typical Trochophoren larva. It agrees with the fomer in the absence of a roctodam. The 4
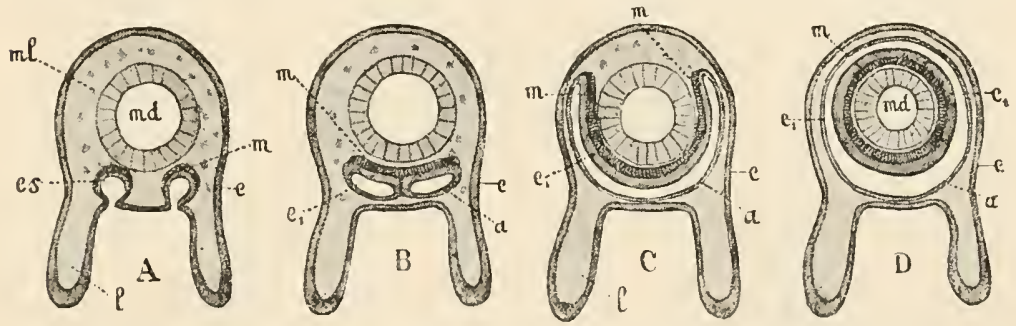

Fic. 1st.- $A, B, C, D$, Four diagrammatic transverse sections behind the mouth througin a Pilidium larva during metamorphosis, to illustrate the method of formation of the nresorlerm and secondary (definitive) ectoderm. $e$, Larval ectorlerm; $e_{1}$, definitive ectoderm : $a$, amuion ectoderm; es, ectoderm sac; $m$, mesoderm ; $l$, lateral lobes of the larva; md, mil-gut; ml, larval mesodern.

rudiments of the mesoderm probably answer to the 4 mesoderm masses of the young Polyclad larve or embryos.

A Nemertien larva related to the Pitidium, Desor's larva, shows the larval characteristics less developer. The eiliated ring and the ectodemal thickening with the ciliated tuft which eoresponds with the neural plate are wanting. But the definitive ectoderm is formed, as in Pilidium, of diseswhieh detach themselves from the nimary ectoderm. Many _emertina develop without metamorphosis.

If we glanee over the larval forms of worms we see that all are distinguished by reculiarities of strueture whiel are explained by the ciremintance that the animals feed independently and swim about freely at a very early stage of development. The simplest organs of locomotion whieh ean be developed early are the cilia. They appear in all larve. Ciliated rings are universally present; the most constant is the preoral, which is provided with a special nervous system (nerve ring). Almost everywhere we find a spraeions larval body eavity filled with fluid. The larve are hydropie, their specifie gravity being nearly that of water. They are provided with a functional hollow enteron and other functional parts-nervons system, sensory organs, museles, exeretory orcans. It is pretty generally found that those parts of the larval body which function at an early stage are thrown off or reabsorbed at the end of larval life, and that the organs of the adult animal eonsist of cell material which is present in the larva as undifferentiated germ matcrial perform- 
ing no specific functions. A comprarison of the larva with the adult animal shows that the body of the former corresponds with the anterior portion of the body of the latter, i.e., in segmented animals with the head segment. The smaller portion of the larva corresponds with the posterior end of the adnlt animal, while the trunk, with the cxception of the mid-gut, remains in its embryonic condition in the larva. This is again to be explained by the fact that the embryo, which is provided with little or 110 nutritive yolk, must early derelop organs necessary for independent feeding and locomotion, and these most indispensable organs lie chiefly at the anterior end of the body. This also explains why the locomotory organs of the larra, the ciliated rings, lie near the month, mostly somewhat in front of it; and why, besides this, there sometimes appears a preanal eiliated ring; why also, in certain (Polytrochan) Annclic larw, other segmental ciliated rings appear as the segments of the trunk develoj!

Direct Embryonic Development.-This is chiefly found in fresh-water worms. The embryo is provided with enough nutritive yolk, generally stored in the cndoderm cells, to cnable it to develop direct (usually within an cgg shell). Hence it follows that the organs necessary for free independent locomotion and feeding as an culbryo are unnecessary. 'The comprarison of the dircet development of the embryo, say of Lumbricus, with that of a velagic larva, e.g. a Trochopleora, is very instructive.

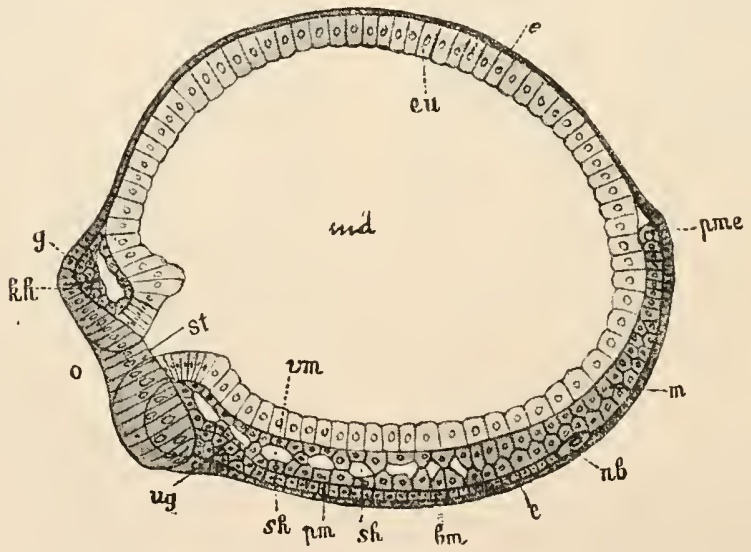

FIG. 18T.-Embryo of Lumbricus (after Wilson). Optical median longitudinal section. e, Ectoderm; pme, pole cells of the mesoderm; m, mesodermal streaks; sh, rudiments of the segmental borly cavities in the mesorlerm; $n b$, neuroblast cells; bm, rudiment of the ventral ehord; $2 \mathrm{~m}$, visceral layer; $p m$, parietal layer of the mesoderm somites; $u g$, rudiment of the infra-cesopliageal ganglion; $g$, rudiment of the brain; $k$, heal eavity ; $o$, mouth ; st, stomodæum ; md, micl-gut ; en, endoderm.

The egg of Lumbricus is supplied with little yolk. The egg and the embryo which develop out of it are nourished in another manner. In every capsule there are several eggs in the midst of a mass of albumen which nomishes them. The embryo (Fig. 18 7 ) is at a certain stage egg-shaped, and surrounded on all sides by a thin unciliated ectodermal epithelium. The mouth lies anteriorly, somewlat near the ventral side; it is surrounded by an epithelial thickening, and leals into a short stomodieum. This again opens into a very spacious mid-gut, whose epithelial wall lies close to the body wall all round. On the rentral side only, masses of cells, the two germ streaks, to be describerl later, are intercalated between the intestine and the body epithelium. A proctodreum is wanting, it 
develops only at a later stage. Anteriorly, above the mouth and directly under the cutoderm from which it is derived, lies a mass of cells-the rudiment of the hrain. In many other worms with direct derelopment the mid-gut is solid and not hollow, in consequence of the large masses of yolk contained in the endorlem cells (primitive macromeres).

Since embryonic head nephridia have been observer in some oligochata, the chief diflerences between them and the Polycheten Trochophore are the following: Cilia are wanting in the former, and especially a pre-oral ciliated ring. Sensory organs (eyes, ciliated tufts) are wanting. A body cavity is wanting, and also a proctodreum. On the other hand, as we shall see later, the mesoderm is much more rleveloped than in the Polychatan Trochophora above described. The parts of the body present in the embryo represent the rudiments of the definitive organs, they do not, as in a free-swimming larva, fulfil specific functions, and therefore selfom disappear in the course of further development. The Gnathobdcllide form an exception, for in them a metamor phosis takes place, and, according to recent rescarch, the larval integument with its muscular and nervous systems, and further the provisional trunk nephridia and the cesoplagnes, are said to disappear.

Development of the Outer Integument.- We may say, generally, that the outer integument or body epithelium of the worms is derived from the embryonic or larval ectodern. 'The ectoderm either changes, without sulfering any loss worth mentioning, into the body epithelium; or some parts of the larval ectoderm which perform specific functions are thrown off ; or clse certain portions of the larval cetoderm sever themselves, and unite on all sides of the body within the larval ectoderm to form the permanent ectoderm or hody integument (c.g. Sipunculide, Nomortina). We consider these processes as a kind of ecrlysis. In the Ginathobdcllida (Hirudinca) alone it is said that the secondary ectoderm is not formed from the larval cetoderm, and that the latter is quite lost. The larval and definitive sensory organs, the larval and definitive nervous systems, and the larval and definitive setiparous saes (of the Chotopoda) are products of differentiation of the ectoderm. The last mentioned are groups of glandular hypodermis cells, which sink under the integmment, the setre arising in them as secretions. The ectodermal setiparous glands are enveloped by mesodermal elements which supply their musculature.

Development of the Mesoderm and the Mesodermal Organs.-The mesoderm is for us a topographical conception. All that lies in the adult animal between the outer integument and the intestinal epithelium belongs to the mesoderm. The relations of the various mesodermal organs and systems of organs to the outer integument are very varied. These relations are closest in the nerrous system in consequence of its dependence on the (ectodermal) sensory organs. As already described (cf. p. 223), in many worms the central nervous system remains in the integrment, even in the adult animal, and is thus not mesodermal. The mesodermal position of the nervous system is, however, the general rule, as it is even as early as in the Platodes. As, however, it nearly always develops entirely seprarate from the rest of the mesoderm, we shall describe its development first.

The Brain.-In some cases the brain, or a part of it at any rate, develops out of the ectodermal neural plate (many Annclids, Sipunculide). The clements of the nemral plate probably arise in comection with the provisional or definitive sensory organs of the head (eyes, neural tuft, tentacles), though this camnot be established in detail. There are thus different parts which mite together to constitute it a sensory nervous centre. The nenral plate must thus represent an organ similar to the sensory body of the Ctenophore or the marginal centres of the Neduse. It is often thrown off with the larval integument (c.g. in Phoronis, Pitilium), and the oral nerve ring or the brain arises anew out of the secondary ectoderm. 
Ventral Chord of the Annulata. - The ventral chord seems always to begin to form separately from the neural plate. It arises either as a contimous thickening of the ectoderm in the ventral middle line, or as a prair of thickenings one on each side of this middle line. The differentiation of the rudiment of the ventral elord into the definitive ventral ehord goes hand in hand with the development of the rest of the trunk, and proeeeds from before backward. It cither remains, like the brain, eonnected during life with the ectoderm, or it becomes constricted off from it and takes up a position either in the musenlature of the body wall or still decper in the lody eavity. At the posterior end of the body it almost always retains its embryonie condition, as it here remains throughont life in its place of formation, the integument. The IFirudines and Lumbricus among the Oligochete differ rery much from other Ammulete and sipunculide. The ventral chord here does not arise in situ in the eetodermal integument; but two eetodermal segmentation spheres (micromeres) appear very early near the posterior end, and take up a position under the eetoderm, lying symmetrically on each side near the middle line. New eells are

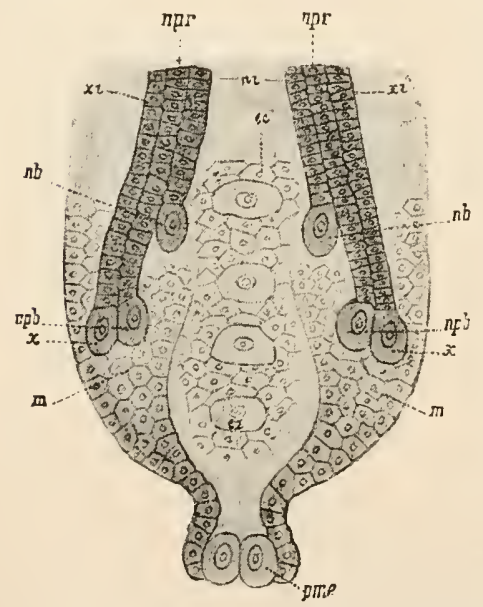

FiG, 188,-Superficial aspect of the germ streaks in a Lumbricus embryo (after Wil. son), me, Pole cells of the mesoderm (meso. lilasts); $n b$, pole cells of the ventral chord (neuroblasts) ; $n p b$, pole cells of the nephritlial rows (nepluroblasts); $x$, pole cells of the cell rows $(x)$ of unknowu significance; $e c$, ectodern ; $e z$, large ectroderm cells ; $n p r$, nephrillial cell rows; ni, neural cell rows; $m$, mesoblast strealis. continually constricted off anteriorly from these neuroblasts (Fig. 188, nZ), whieh again divide, and a eell strand thus arises on cach side of the ventral middle line, immediately beneath the integument. The two cell strands, whieh form part of the germ streaks of the Hirudinee and of $L u m$ bricus, represent the rudiment of the rentral chord, which, beginning behind the mouth, hecomes continuously differentiated from before backward. It is evident from this that the rudiment of the rentral ehord is unusually loealised, and at the same time is to be referred to a very early stage of development. The conneetion of the rentral chord with the brain through the nesopliageal commissure seems everywhere to take place seeondarily. It may perhaps in time be proved that the eentral nervons system in the IToms and Patodes rrocecds ontogenetically and phylogenetieally from two chief parts, viz, first from the sensory part of the brain, i.e. from the united sensory centres or sensory ganglia of the anterior end of the body, and second from the motor central nerrous system, i.e. the rentral chord, the cesophageal commissure, and the motor part of the brain of the Ammlata, the longitudinal trunks and the motor part of the brain of the other worms and Platoles. In the Nemertina, however, the lateral nerves are said to grow out from the hrain posteriorly. This may perhaps here, and also in the Turbellaria, point to a concentration of the whole eentral nervous system into one single rudiment.

In the development of the other component parts of the mesoderm, we find that, just as the rudiment of the rentral ehord in the Hirudined and Lumbricus is shifted lack to an early stage, and is condensed into two germ eells (the neuroblasts), so the rudinent of all other mesodermal organs in worms are extremely eondensed and loealised and shifted back to early stages, so that generally a few germ cells or a 
limiter germ zone represents the eondensed rudiment of all mesodernal organs, with the exception of the nervous system.

We aeeordingly find in the Hirudiner (Clepsine) and in Lumbricus, in early stages of development, even during segmentation, on each sile of what morphologically eorresponds witl the posterior end of the embryo, 4 or 5 micromeres, which soon sink lown under the eetoderm - micromeres, or are grown round by them. The 2 which he posteriorly are the largest ; they lic close to each other, and in front of them 3 or 4 lie on each side of the rentral melian line (Fig. 185). The 2 inner mieromeres we ahready know; they are the neuroblasts. Just as 2 lows of eells derelop anteriorly from the neurollasts, forming the rudiment of the ventral ehord, rows of eells also develop anteriorly from the remaining polar cells. The single or double cell rows which lie near the neural rows are the nephridial rows; the prolar cells from which they develop, are the nephroblasts. They yield the material for the nephridia, which become differentiated from liefore baekward. The most anterior ne. phridia are temporary ; they are the larval or embryonie nephridia. It is not yet known what part of the mesoderm is formed by the lateral rows of cells with their posterior polar eells. The cell rows which proceed from the most posterior lar. gest polar eells represent the rudiments of the body musculature, the endothelium, septa, and mesenteries. We shall return to their further development.

All these cell rows taken together are known as the paired germ streak.s. They lie at the two sides of the ventral middle line betwcen the intestine and the integument. The germ streaks thus yield all the mesodermal organs, nervous system, nephridia, museles, endothelium, ete. In the Gnathoudcllide, where the whole
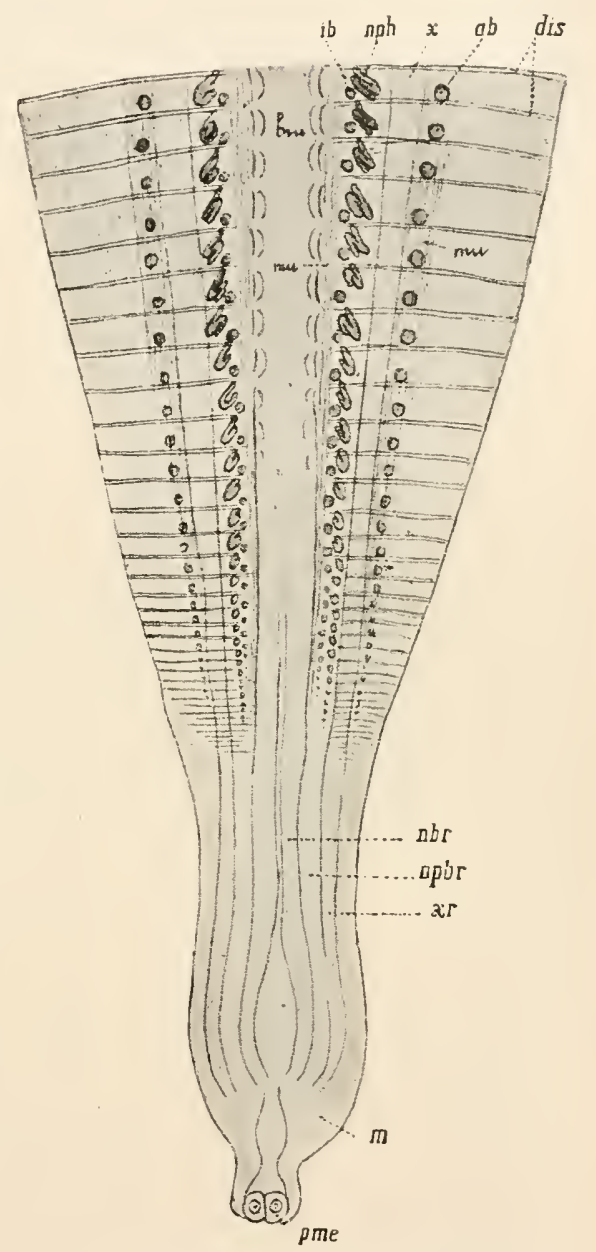

FIG. 189.-Surface view of the germ streaks of a somewhat older Lumbricus.embryo, after the disap. pearance of the anterior polar cells (after Wilson). pme, Polar cells of the mesoderm $(m) ; x, x$, eell rows of unknown significance; $n p h r$, nephridial cell streaks; $n b r$, neural cell streaks, rudiment of the rentral clord $(\mathrm{m} m)$; dis, dissejuments; $i b$, inner ; $a b$, outer rows of setiparous glands; $m p h$, rudinents of the nephridia; $m u$, longitudiual musculature.

larral ectodem is lost, the germ streaks are said cren to produee the definitive body epithelium as well. 'This statement, however, reinires eonfirmation. 
There are germ streaks in many worms similar to those in the Hirudinea and Lumbricus. But it appears that these do not consist of contiguous rows of cells, hut that each germ streak is the product of a single polar cell at the end of the embryo or young larva. We have describer these two prolar cells in Eupoinatus as primitive mesoderm cells. The germ streaks which proceed from them are called mesoderm streaks; they seem to yield the whole mesoderm with the exception of the nervous system. Here, therefore, the ruliments of almost all the mesodermal organs are localised and condensed into two blastomeres which appear at an early stage at the posterior erlge of the blastopore.

In the larva of Lopadorhynchus (Polychate), as the trunk grows, what is called the postoral ventral plate of the ectodem is said to split from front to back into an inner museular flate and an outer neural plate, the ventral chord being principally formed from the latter.

Further Development of the Germ Streaks (Figs. 187-189).-In Lumluicus the two cell rows of the germ streaks, which are formed from the two large prosterior polar cells, soon begin to be differentiated from before backward. Their cells divide. The simple cell rows thus become solid plates or strands. They extend forwards on both sides and meet dorsally above the mouth. In this cephalic portion of the germ streaks a central cavity apjears which enlarges and becomes the cavity of the head. The outer layer of cells attaches itself to the outer integrment of the head, and becomes the outer musculature and endothelium of the head segment. The inner layer forms the musculature of the pharynx and its endothelial covering. Behind the head on each side clefts also occur in the abovementioned cell strands, and these, forming in segmental order from before backward and inereasing in size, form the rudiments of the praired segmental chambers of the celome. They separate the cell strands in each segment into a prarietal layer contiguous to the integument and a viseeral layer contiguous to the intestine. The cell strands are thus divided into paired segmentally consecutive portions. In each segment on each side both the parietal and the visceral layers grow up between integument and intestine till they meet in the dorsal middle line. The partition wall which is here formed in this way, and which divides the two lateral chambers of the body eavity, is the rudiment of the dorsal mesentery which is often temporary. A ventral mesentery arises in a similar mamner. The cell material, which separates the eonsecutive chambers of the body cavity forms the dissepiments. The prarietal layer forms the musculature of the body wall and the parietal endothelium; the visceral layer forms the muscular layer of the intestine and the visceral endothelinm.

Development of the Blood-vascular System.-This system arises (T'crebclla, Psygmobranchus) as a eavity filled with fluid between the epithelial intestinal wall and the contiguous visceral layer of the mesoderm. The chief vessels arise as longitudinal bulgings of the mesodermal walls of this enteric sinus, which finally becone constricted off from it, passing from the form of grooves to that of elosed canals. In Lumbricus and other Oligochceto the dorsal vessels arise in a similar way as clefts between the enteric epithelium and the enterie muscle layer. They are at first paired, but generally unite to form the impaired dorsal vessel. In a few Lumbricide, however, even in adult animals, over a larger or smaller region of the body, they may remain double.

Development of the Nephridia.-In the anatomical section we distinguished three parts in each nephridium : (1) the funnel ; (2) the nephridial duct; and (3) the terminal portion which opens outwardly, which in the Hirudinee and Oligochete is often widened out into a vesicle. It appears that in Lumbricus the nephridia develop in the following way. The nephridial ducts develop in pairs in each 
segment as outgrowths of the nephridial cell rows. Each duct consists at first of one cell or of a few cells, and later of a row of cells bent in the shape of the letter $\mathbf{U}$, which projects into the body cavity and is thus provided with an onter endothelimm. One limb of the cell row remains in contact with the integmnent, the end of the other attaches itself to the posterior wall of the clissepiment which lies in front of it. At this point an imner canal first appears in the solid row of cells. The terminal portion arises by an invagination of the integument. The fumel begins to form from one cell on the anterior wall of the dissepiment at the point where, on the posterior wall, the end of the nephridial duct lies. This cell only secondarily becomes a hollow ciliated fummel, which then unites with the nephridial canal through the disscpiment. The fumnel thus arises separately from the nephridial canal out of the epithelimm of the body cavity, and not out of the nephridial rows of cells. In the Polychata also the fummel and the nephridial duct of each nephidinm are said to arise separately.

Development of the Sexual Glands. - It may he considered certain that in the Annulctc and Prosopygic the ovaries and testes are developer from special parts of the endothelim of the body cavity.

The Development of the Mesoderm in the Chætognatha (Fig. 190).- The nervous system here lies in the integmment of the body and does not belong to the mesoderm.
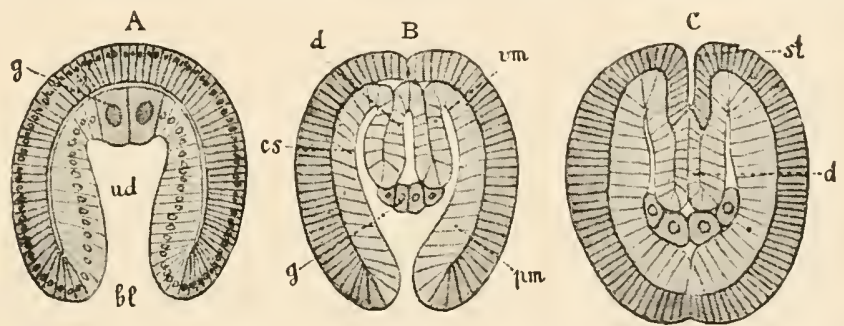

Fig. 190.-A, $D, C$, Three early stages of development of Sagitta (after O. Hertwig). $a$, Gastrula; $u$, blastopore; $u d$, arch-enteron; $g$, primitive cells of the sexual organs; $v m$, visceral layer ; $p m$, parietal layer of the mesolcrm; $d$, rudiment of mill-gut; $c s$, colome sacs ; st, stomodrum ; $d$, intestime.

In this case the mesolerm devclops in a mamer different from that in the worms as yet described. A ceelogastrula forms whose nincipal axis answers pretty accurately to the longitudinal axis of the adult Sagitta. The aboral pole of the gastrula corresponds with the future anterior end of the body. Two large cells which soon livide cnter the base of the arehenteron from the endoderm at an carly stage. These 4 cells are the rudiment of the testes and ovaries. Then on each side there arises out of the base of the archenteron a fold of the endoderm, which grows into the archenteric cavity towards the blastopore. These 2 folds divide the archenteric cavity into a central cavity and two lateral cavities, which communicate at the free edges of the folds. The central cavity is the definitive enteric cavity; its epithelial walls, i.e. the inner epithelial lamelle of the folds, represent the rudiment of the definitive enteric cpithelium. The folds close dorsally and ventrally to form the cnteric tube, the latter carrying the 4 sexual cells at its freely projecting cond. The two lateral cavities, which may almost be looked upon as 2 sac-likc invaginations of the archenteron (colomic sacs), form the commencement of the borly cavity. Each sac has an outer epithelial wall in contact with the ectoderm, and an inmer wall in contact with the cuteric tube. The former is the parietal, the later the visceral layer of the mesolcrm. 'The former probably forms the musculature and the endothelium of the body wall, the latter the enteric endothelinm. At the aboral 
pole of the larva a small depression of the ectoderm beeomes connected with the enteric tube. The permanent mouth and the stomodreum thus arise. The primitive mouth closes. The enteric tube becomes a solid strand, which eontinnes to grow till it reaches the closed primitive month, i.e. the posterior end of the body. An enterie eavity does not again appear till a later stage. On the ventral side, a little in front of the posterior end of the body, an anus forms. The postanal intestine degencrates, its 2 visceral layers of the mesoderm forming the septum of the caudal segment. From the 4 genital eells the testes and ovaries develop. We thus see that in Sagitte the mesodermal organs have a double origin : first, 2 (afterwards 4) large endoderm eells lying at the base of the archenteron, which form the rudiments of the sexual glands; secondly, the whole middle and oral epithelial wall of the arehenteron of the ecelogastrula ; this represents a germ zone, continued at the edge of the blastopore into the ectoderm, and at the aboral portion of the larva into that part of the wall of the archenteron from which the definitive intestime is producerl. This germ zone forms at an early stage two lateral ecelome sacs as a consequence of the formation of the folds above mentioned; the eavities of these saes produce the body eavity, and their walls the endothelium of the body carity, and probably also the musculature of the body wall.

Two hollow lateral celome saes of the archenteron ap'pear at an early stage in one of the Brachiopoda, Argiope, much in the same way as do those in Sagitte ; these, constricting themselves off from the intestine, are said to form the body eavity and the mesoderm. The development of the mesodermal organs has, however, up to the present time been insufticiently observed.

Various theories have been put forward as to the pliylogenetic significance of the different processes of development to whieh the mesodermal organs owe their rise ontogenetically, all these theories resting upon the assumption that the ontogenetie iroeess exactly repeats, sometimes in one loint sometimes in another, the phylogenetie development. These theories rest mon weak foundations as long as comparative anatomy knows of no series of animal forms whieh shows us the gradual rise of the mesodermal organs in a mamner similar to that seen in the successive ontogenetic stages of development. It is very doubtful whether the whole mesoderm, exeept the nervous system, can he derived pliylogenetically from such simple organs as the ecelome sacs, or from cell groups sueh as the polar cells of the mesoblast, once present in simple gastrula-like racial forms. Observations are increasing in number which tend to show that ontogenetically also there is no single rudiment of the whole mesoderm, but rather several rudiments for the different mesodermal organs. Our review of the history of development of the worms supports this latter view. It may perhaps in time be established that the manner in which the varions mesodermal organs alprear in the Cniduria moving from their plaees of formation, the ectodermal body epithelium and the endodermal enterie epithelium, into the deeper parts of the body wall, is essentially the same as that in which the mesodermal organs originally arose in the ancestors of the Platodes and the Fomes. The ontogenetic development of the mesoderm would then represent this process very much abbreviated and loealised, pushed back to very early stages. If, in the Hirudiner (in Clepsine at least) and in Lumbricus as opposed to the other Ammlate, the rentral ehord does not arise in situ in the eetoderm but is formed by two blastomeres, the neuroblasts, which arise at an early stage, it is diffienlt to see why the polar eells of the other mesorlermal organs (nephroblasts, mesoblasts, ete.) should not represent similar early developing eondensed and localised rudiments. And why should not these different rudiments themselves be pushed back to, and localised and condensed in, a rudiment such as the early developer primitive mesoderm eells or zones? In the Polyclade we see at an 8-micromere stage (Fig. 94, p. 125) the rudiment of the whole eetoderm, 
with the nerrous system loealised and eondensed in 4 micromeres, the rudiment of the mesoderm in 4 other mieromeres, and the rudiment of the whole endorlermal enterie system in the 4 maeromeres.

Development of the Intestine.-The intestine of the worms eonsists as a rule of three parts of different origin-the fore-gnt, the mid-gut, and the hind-gut. From the endorlermal arehenteron of the gastrula only the mid-gnt is derived. At an early stage in larval life an anterior eetodermal invagination, the embryonic or larral resophagus or the stomodimm, beeomes connected with it, while a similar invagination at the posterior end yields the proetodeum. While the proetodem becomes in a direct manner the hind-gut, which is often very short, the fore-gut does not always proeed direet from the stomodreum. Sometimes, e.g. in the Hirudined, the stomodiemm disappear's and a new resophagns arises independently in its place. Sometimes the definitive resophagus hegins to form ont of the stomodreum which as such disalprears. This is the ease in many Polychrete. The musculature of the fore-gut, which is often very strongly developed as the pharynx, seems everywhere to be formed from the eeplualic portion of the mesodermal or germ streaks. The origin of the musenlar wall of the mid-gnt and its endothelium, where this is present, from the visceral layer of the mesodermal streaks lias already been described.

\section{Literature.}

\section{Nemertina.}

W. C. M'Intosh. A Monorgraph of the British Annclicls. Part I. Nemerteans. London, 18:-2-74.

J. v. Kennel. Bciträge zur Konntuiss der Vencrtinen. Arbeiten d. sool. Instituts in WVür $\approx$ burg. Bd. IV. 1878.

A. A. W. Hubrecht. Report on the Nenertea, in Report on the Seientific liesults of the Iroyage of H.M.S. Challenger. Zoology. Vol. XIX. Part LIV. London, iss7.

Treatises by Quatrefages, Hubreeht, Oudemans, Moseley, L. v. Gratf, Dewoletzky. Ontogeny: Hubrecht, Salensky, Götte, barrois, ete.

\section{Nematoda.}

A. Schneider. Monographie der Nematoden. Berlin, 1866.

R. Leuckart. Die Poreasiten des Ienschen. New edition in prepraration.

Works and treatises by Meissner, Eberth, Biitsehli, Selneider, Lenckart, Claus, E. van Beneden, de Man, Rohde, Selnulthess, ete.

Ontogeny: Biitsehli, Gütte, Hallez, etc.

\section{Gordiidæ.}

F. Vejdovsky. Zur Morphologic der Gordidden. Zeitschr,f, $u$. Zool. Bd. XLIII. 1866 .

The same. Stution über Gordiiden. Ilid. Bd. XLVI. 188s. With Bibliography.

\section{Acanthocephala.}

Carl Baltzer. Zur Kemtniss der Echinorhynchon, in Arch. f. Neturgeschichte. 1880.

A. Säfftigen. Zur Organisation der Echinorhynchen, in Jlorphol. Jehrbuch von Gegenbaur. $10 \mathrm{Bd} .1885$.

Treatises by Greef, Sehneider, Andres, ete. 


\section{Hirudinea.}

A. Moquin-Tandon. Monographic de la famille lles Himulinécs. With Atlas. 2d edition. Paris, 1846.

R. Leuckart. Die Purusiten des Mensehen. New Elition in preparation.

A. Gibbs Bourne. Contributions to the Anatomy of the Hirudinea. Queart. Joum. Mierose. Soc. Vol. XXIV. 1884.

St. Apathy. Analyse der Aussem Körperform der Hirudineen. Witth. Zool. Station Teapel. Bil. VIII. 1888.

Treatises by Brandt and Ratzeburg (Nedicin. Zoologic, 1829), Leydig, O. Schultze, Hermann, Whitman, Jaquet, v. Kennel.

Ontogeny: Rathke, Rolin, Biitschli, Bergh, Whitman.

\section{Chætopoda.}

Franz Vejdovsky. System und Morphologie der Oligochacten. Pragne, 1884.

Ed. Claparède. Reeherches anatomiques sur les Oligochetes. Geneva, 1862.

The same. Lrs Annélides Chétopodes du golfo de Taples. Geneva, 1868. Supplement, 1870 .

The same. Recherehes sur la strueture des Annélides sédentaires. Geneva, 1873.

Ernst Ehlers. Die Borstenü̈rmer (Annelida Chactopoda). Leipzig, 1864-68.

A. de Quatrefages. Histoire naturelle des Annelés. With Atlas. Paris, 1865.

C. Semper. Die Venuandtsehaftsbezichungen der gegliederten Thiere. Arbeiten aus dem zool. Institute in Wïraburg. Bd. III. 1876.

B. Hatschek. Studien über Entwicklungsyeschichte der Aincliden. Arbeiten des zool. Instituts zu Wicn. Bd. I. 1878.

J. Fraipont. Le genre Polygordius, in Fauna und Filora des Golfes ron Neapel. XIV. Berlin, 1887.

H. Eisig. Die Capitelliden des Golfes ron Neapel, in Fauna und Flora des Golfes von Neapel. XVI. Berlin, 18s7.

E. Meyer. Studien über den Körperbau der Anncliden. I. Mitth. a. d. zool. Station a Neapel. $7 \mathrm{Bd}$. 1887.

H. de Lacaze-Duthiers. Recherches sur la Bonellie. Annales d. Seiences natur. 1858 .

J. W. Spengel. Beitrïge zur Kenntniss der Gephyreen (i.e. the Echiuridac). I. in Mitth. a. d. zool. Station zu Ncapel. 1879. II. in Zcitschr.f. wiss. Zoologie. Bd. XXXIY. 1880.

R. Greef. Dic Echiuren (Gephysea Armata), in Nova acte. Bd. XLI. Halle, 1879.

Nmmerous treatises and works by d'Udekem, Audonin et Milne-Edwards, Hering, Gegenbanr, Claparède, Grube, Ratzel, Leydig, Perrier, Vejdovsky, Ude, Jaquet, A. Agassiz, Greef, Spengel, Eisig, E. Meyer, Pruvost, Vignal, Kükenthal, Ehlers, Hatschek, v. Graff, Riesch, Focttingrer, v. Kennel, Bülow, and others.

Ontogeny: Lovèn, Krohn, Claparède, Netschnikoff, A. Agassiz, Salensky, Kowalevski, Klcinenberg, Vejdorsky, Wïlson, Hatschek, Götte, and others.

\section{Myzostomidæ.}

L. v. Graff. Des Genus Myzostonct. Leipzig, 1877 .

J. Beard. On the Life-history and Development of the Genus Myzostoma. Mitth. zool. Station Neapcl. 5th vol. 1884.

Fridtjof Nansen. Bidreg til Mysostomernes Anatomi og Histologi. With English résumé. Bergen, 1885. With bibliograpliy. 


\section{Sipunculacea.}

W. Keferstein. Beiträge sur anatomischen und systematischen Kenntniss der Sipuneuliclen. Zeitschr, f. w. Zool. Bd. XT. 1865.

E. Selenka (with de Man and C. Bülow). Die Sipuncutiden. Wiesbaden, 1883.

J. Andreae. Beiträge aur Anatomie und Histologie des Sipunculus nudus. Zeitschr: f. $u$. Zool. 36. Bd. 1881.

W. Apel. Beitrag zur Anatonie und Histologie des Priapulus candatus (Lam.) und des Halieryptus spinulosus ( $v$. Sieb.) Zeitsehr. f. u. Zool. 42. Bd. 1885.

Treatises by Grube, Krohn, Ehlers, A. Brandt, H. Théel, Sjengel, Selenka, Hatschek (Ontogenie ron Sipunculus), Horst, Sluiter, Scharff, Schauinsland.

\section{Phoronis.}

A. Kowalevski. Anatomie und Entreieklungsgesehichte von Phoronis. 1867.

W. H. Caldwell. Note on the Strueture, Development, and Affnities of Phoronis. Proc. Roy. Soc. 1882.

Further: Metschnikoff and Schneider.

\section{Bryozoa.}

G. J. Allmann. A Monograph of the Fresh-veater Polyzon. liay Society. 1856.

H. Nitsche. Beitrïge zur Kenntniss der Bryozoen. Zeitschr. f. $w$. Zool. Bd. XX. 1869. Bd. XXI. 1871. Bd. XXV. Sulpl. 1875.

Ed. Claparède. Beiträge zur Anatomie und Entrickelungsgeschiehte der Srebryozoen. Zeitschr. f. $w$. Zool. Bd. XXI. 1871.

L. Joliet. Contributions à l'histoire des Bryozoaires des côtes de la France. Arề. Zool. expérim. Tome V. 1877. Tome VI. 1878. Tome VIII. 1880.

Th. Hinks. A History of the British Marine Polyzoa. London, 1880.

Karl Kraepelin. Die deutsche Süssuasser Bryosoa. Eine Honographie. I. anatomische systematiseher Theil. Hamburg, 1887.

Treatises by Dumortier, P. J. van Beneden, Repiachoff, Smitt, O. Schmidt, C. Vogt, Salensky, Vigelius, Waters, Haddon, Allman, Sars.

Ontogeny : Schneider, Barrois, Hatschek, Haddon.

\section{Brachiopoda.}

R. Owen. On the Anatomy of the Erachiopoda. Transact. Zool. Soc. London, 1835.

C. Vogt. Anatomie der Lingula anatina. Neue Denlischr. d. schreiz Gesellsch. f. Naturwissensch. Bd. VII. 1815.

T. H. Huxley. Contributions to the Anatomy of the Brachiopode. Annals and Magaz. of Nat. Hist. 2 d series. Vol. XIV. 1854.

A. Hancock. On the Organisation of the Brachiopoda. Phit. Trans. 1858.

J. F. van Bemmelen, Untersuchungen über den anatomischen und histologischen Bau der Brachiopoda Testicardinia. Neue Zeitschr. f. Naturu. Bd. XVI. 1883.

L. Joubin. Reeherches sur l'anatomie des Brachiopodes inarticulés. Arih. de Zoologie expérimentale. 2d série. Tome IV. 1886.

H. de Lacaze Duthiers. Histoire de la Thicidie. Ann. Sc. naturelles. 4ième série. Tome XV. 1861.

Further treatises and works by Cuvier, Daridson, Carpenter, Gratiolet, ILorse, Shipley, Schulgin, Beyer.

Ontogeny : Lacazc Duthiers, Kowalevski, Morse, Brooks, Shipley 


\section{Rotatoria.}

Ehrenberg. Die Infusionsthicrchen als vollkommene Oryanismen. Leipzig, 1838.

Fr. Leydig. Ueber den Ban und die systcmatische Stellung der Fiüleithiere. Zeitschi. f. $w$. Zoologic. 13d. VI. 1854.

Karl Eckstein. Die Rotatorien der Ungegend von Giessen. Zeitschr. f. w. Zool. Bd. XXXIX. 1883.

Ludwig Plate. Beiträge zur Naturgeschichte der liotatoricn. Jena. Zeitschr. $f$. Sature. Bd. XIX. N. F. XII. 1885.

Further treatises and works by Dujardin, Weisse, Dahrmule, Leydig, Gosse, Cohm, Clapràde, Metschnikoft; Semper, Möbius, Plate, Zelinka, Salensky, Hudson, Joliet, etc.

\section{Dinophilus.}

Eug. Korschelt. Ueber Bau und Entrickelung des Dinophitus apatris, in Zcitseh: f. $u$. Zool. $37 \mathrm{Bd} .1882$.

Further: O. Schmidt, Mereschkovsky, Weldon, E. Meyer.

\section{Echinoderes and Gastrotricha.}

E. Metschnikoff. Ueber einige wenig bekannte nictere Thieiformen. Zeitsch: f. $u$. Zool. Bd. XV. 1865.

H. Ludwig. Die Ordnung Gastroticha. Zeitschr. f. w. Zool. Bd. XXVI. 1875.

W. Reinhard. Kinorhyncha (Echinoderes), ihr anatomischer Ban und ithe stellung im System. Zcitschr: f. $\varkappa$. Zool. 45 Bd. 1887.

Cf. further: Dujardin, Greef, Schulze, Bitschli.

\section{Chætognatha.}

o. Hertwig. Die Chactognathen. Eine Monographic. Jen. Zeitsch. f. Naturu. Bd. XIY. 1850 .

G. B. Grassi. I Chetognati, in Fauna und Flora des Gulfes ron Neapel. 5. Monogivephic. 1883.

Further, the works of Kroln, Wilms, Kowalevski, etc. 


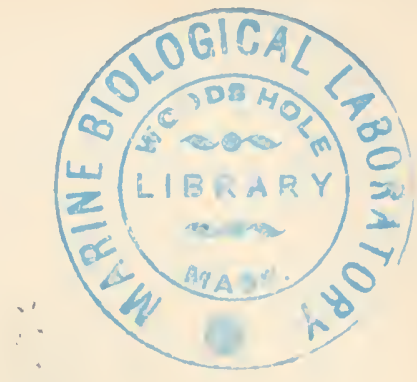

\section{CHAP'TER V}

The first division of the Arthropoda-The organisation and development of the Crustacea.

THE FIFTH RACE OR PHILUM OF THE ANIMAL KINGDOM.

\section{ARTHROPODA-ARTICULATA.}

Bilaterally symmetrical animals with chitinous exoskeleton, segmented body, and paired jointed extremities on all or some of the segments. With brain, œsophageal commissures, and segmented rentral chord. With heart lying above the intestine. Sexes separate, with one pair of sexual glands and originally paired ducts from these glands.

\section{First Sub-race or Sub-phylum.}

Branchiata.-Aquatic animals. With the exception of the anterior antenna all the appendages are morphologically biramose. Respiration cutaneous or by means of gills, which are almost always appendages of the basal joints of the limbs.

\section{Singlat Class. Crustacea.}

First appendage to the Sub-race Branchiata: The Trilobites, Gigantostraca, Hemiaspidæ, and Xiphosura.

Second appendage to the Sub-race Branchiata: The Pantopoda or Pycnogonidæ.

\section{Second Sub-race or Sub-phylum.}

Tracheata._Land animals. Limbs not biramose, consisting of a single row of joints. Respiration by means of trachese (tubular or book-leaf trachea).

\section{Class I. Protracheata.}

ClAss II. Antennata (Myriapoda and Hexapoda).

Cldss III. Chelicerota sive Arachnoidea.

Appendage to the Phylum of the Arthropoda.

The Tardigrada or Bear animalcules. 


\section{THE CRUSTACEA.}

\section{Systematic Review.}

\section{Sub-Class I. Entomostraca.}

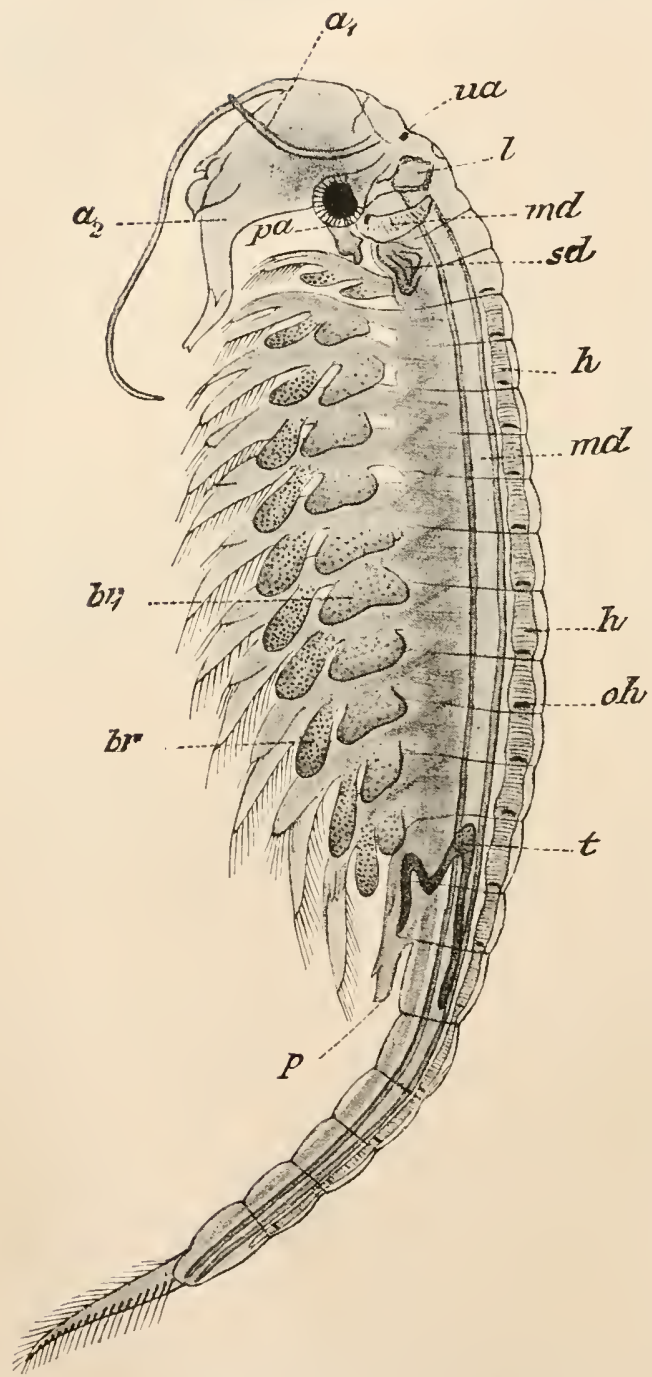

Fig. 191.-Branchipus stagnalis, male. $\sigma_{1}$, Anterior antenna; $t_{2}$, posterior antennæ, seizing antennæ with accessory appendages ; u, unpaired eye; $l$, liver ; md (above), mandible ; $s i l$, shell gland; $h$, heart or dorsal vessel ; oh, slit-like apertures (ostia) of the lieart; $m d$ (below), intestine ; $p$, penis ; $b r$, branchial sac; $b r_{1}$, branchial leaflet; pa, paired stalked eyes (after Claus).
The trunk consists of a varying number of segments. We can here often distinguish an anterior division bearing limbs from a posterior division which has no such appendages. Each division, however, consists of a varying number of segments. The genital apertures usually lie between the two divisions of the trunk. A dorsal shield is often present, and is developed in various ways. The limbs are very variously shaped. Besides the usual lateral cyes, the unpaired frontal eye of the Narplius larva is retained by the adult animal. A masticatory stomach is wanting. A Nauplius larva is liatched from the egg. Mostly small animals.

\section{Order I. Phyllopoda.}

With swimming feet which carry branchial sacs, mandibles without feelers, and reduced maxillæ.

\section{Sub-Order 1. Branchiopoda.}

Body distinctly segmented with numerous trunk segments, and numer ous pairs of swimming feet. Carajace seldom wanting, either flat and slield-shaped or in the form of a bivalve shell. Heart an elongated dorsal vessel with numerous pairs of ostia. In fresh water. Branchipus (Fig. 191) (without shell), Apus (with flat carapace), Estheria, Limnadia (with bivalve shell). 


\section{Sub-Order 2. Cladocera (Daphnidæ), Water Fleas.}

Body small, with few indistinct segments and 4 to 6 pairs of swimming feet. The posterior antenne are large rowing feet.

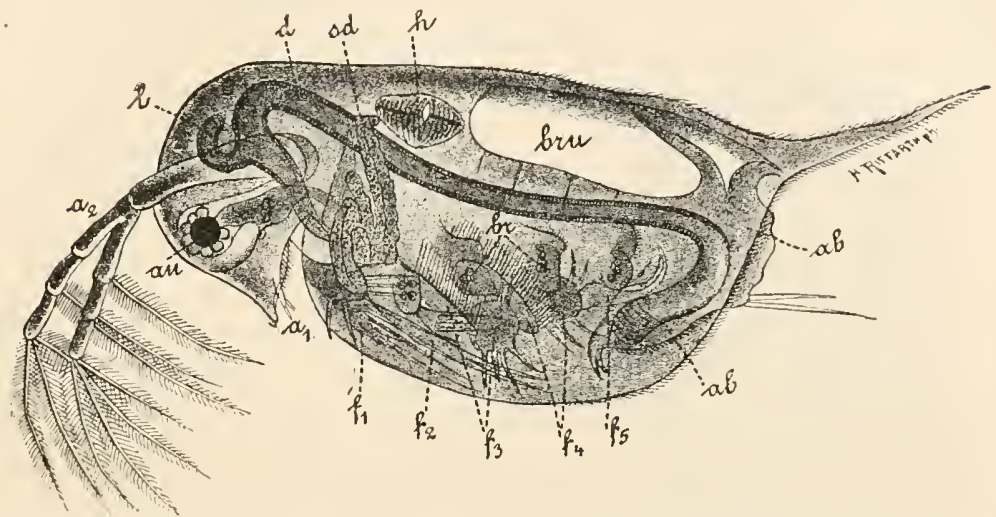

Fig. 192.-Daphnia similis, young female (after Claus). $u_{1}$, Antennule; $\alpha_{2}$, second (rowing) antenna; $l$, hepatic cecum; $u$, eye; $d$, intestine; sc, shell gland; $h$, heart ; br $a b$, abdomen; $b r$, branchial sac; $f_{1} \cdot f_{5}$, trunk feet; $g$, brain.

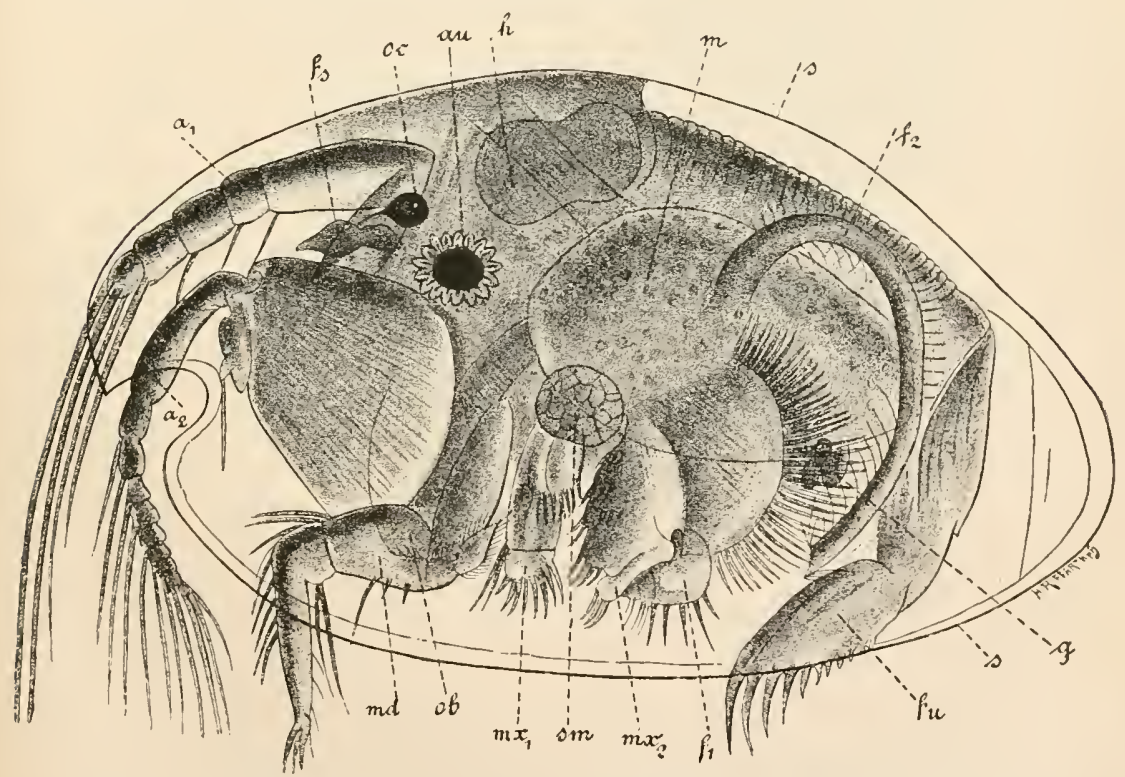

Fig. 193.-Cypridina mediterranea, female, from the side (after Claus). $a_{1}$, Anterior, $\alpha_{2}$, posterior antennx ; $f s$, frontal organ ; oc, unpaired eye ; au, paired eye ; $h$, heart ; $m$, stomach; $s$, slell ; $f_{2}$, cleaning foot; $g$, sexual organs (?); $f_{1}$, first foot; $m_{2}$, second maxilla; sm, sliell wuscle, $m x_{1}$, first maxilla; ob, upper lip; $m d$, mandible.

Branchial sacs may be wanting. With bivalre shell. Head frecly projecting. Fcmale with dorsal brood cavity between shell and trunk. Heart sac-sliaped with

YOL. I 


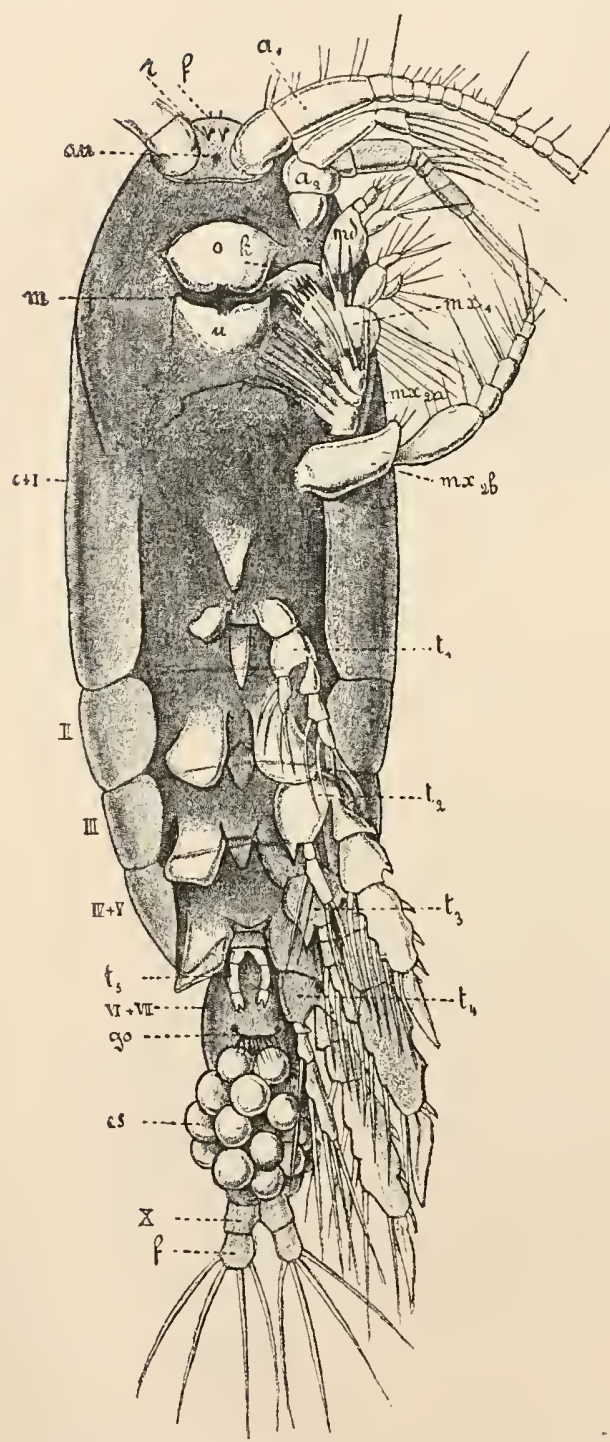

one pair of ostia. Mostly in fresh water. Daphnia (Fig. 192), Sida, Moina, Lynceus, Polyphemus, Leptodora, Evadne (marine).

\section{Order 2. Ostracoda.}

Body small, consisting of few segments indistinctly seg. mented, with bivalve shell. Besides the 5 pairs of welldeveloped limbs to be attributed to the head, viz. the antenne, mandibles, and maxillæ, all or some of which may be developed as creeping or swimming feet, we find only 2 pairs of trunk limbs. The heart may be present or wanting. Fresh-water form: Cypris. Mlarine forms: Cythere, Halocypris, Cypridina (Fig. 193).

Order 3. Copepoda (with

biramose or rowing feet).

\section{Sub-Order 1. Eucopepoda.}

Body small, mostly distinctly segmented, without sliell fold. The trunk consists of 10 segments, the 5 anterior carrying 5 pairs of biramose rowing feet, while the 5 posterior are limbless. The foremost trunk scgment is fused with the head. Antennæ, mandibles, and maxillæ (the two branches of the posterior maxillæ separated from one another) are well developed, at any rate in the free-living forms. The mouth parts in the parasitic forms either suck or pierce. Heart sometimes wanting; when present it is

Fig. 194.-Clausocalanus mastigophorus (Claus), feniale, from the ventral side (after an original drawing by W. Giesbrecht). Only the extremities of the left side of the body are depictel. $a_{1}$, Anterior, $a_{2}$, posterior antennæ; $m d$, manclible with masticatory ridge $k$; $m x_{1}$, anterior maxilla; $m x_{2} a, m x_{2} b$, anterior and posterior maxillipedes=endonodite and exopodite of the second maxilla; $t_{1} t_{5}$, rowing feet (biramose), $t_{5}$, rudimentary; $f$, frontal organ; $r$, rostrum; $a u$, eye ; $o$, upper lip; $m$, mouth ; $u$, under lin ; $c+I$, head and 1st trunk segment; II-X, 2d-10th truuk segments; $I-I$, limb-bearing segments (thoracic segments); VI-X, limbless segments (abdo. minal segments); $V I+V I I$, genital double segment; go, genital aperture; es, orisac (unpaired) : $f$, furce. 
sac-shaped. The females carry about the fertilised eggs in a paired or unpaired ovisac. Gills are wanting. Free-living or commensal Copepoda: Cyclops, Canthocamptus, in fresh water; Cetochilus, Clausocalanus (Fig. 194), marine; Notodelphys, commensal in the branchial cavity of the Ascidians. Parasitic Copepoda : Coryeceus, Sapphirina (some of which are only occasionally or temporarily parasitic), Chondracanthus, Culigus, Lernoed, Lerncocera, Penella, Lemanthropus, Lernceaseus, Aehtheres, inchorella.

\section{Sub-Order 2. Branchiura (Argulidæ), Carp Lice.}

Body consists of the flattened shield-shaped cephalo-thorax and the small flat abdomen (caudal fin) divided longitudinally. In front of the oral suctorial tube a

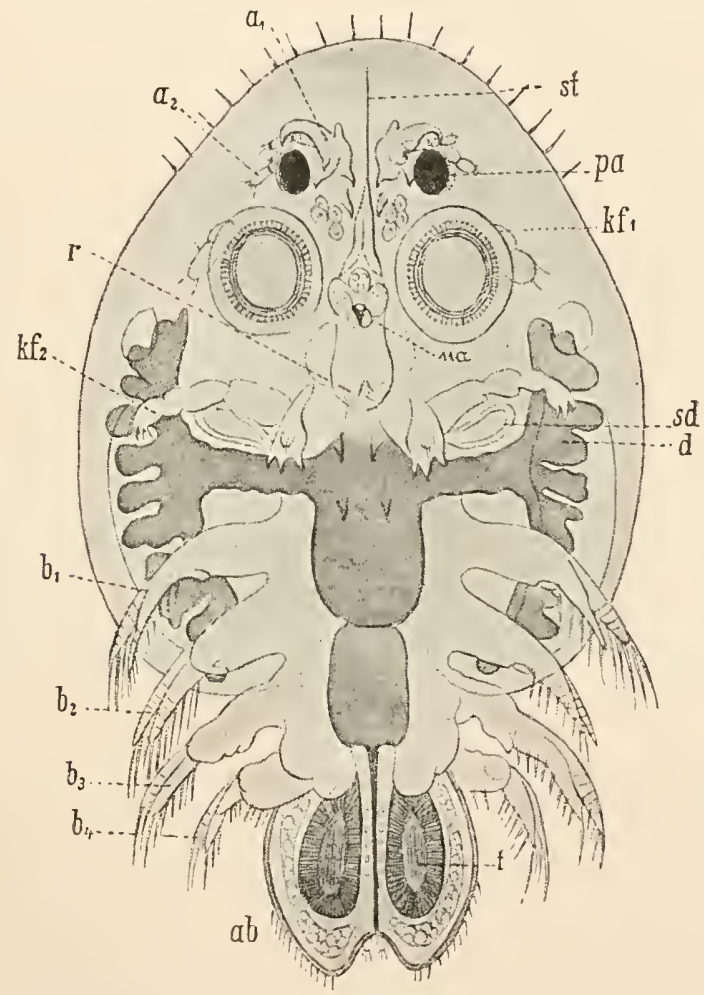

FIG. I95.-Argulus foliaceus young male (after Claus). $a_{1}$, Anterior, $\alpha_{2}$, posterior antenna ; $p$, paired eye; ua, unpaired eye; $r$, beak or suctorial tube enclosing the mandibles and maxille; $k f_{1}$, anterior maxillipede with the adhering disc; $k f_{2}$, posterior maxillipede; sd, shell glands ; $d$, intestine with its lateral brauched diverticula; $b_{1}, b_{2}, b_{3}, b_{4}$, thoracic feet; $a b$, abdomen; $t$, testes.

long protrusible stylet. Four pairs of long cirrus-like biramose swimming feet. Two large compound lateral eyes. Testes in the caudal fin. Heart present. Fenales without ovisacs, attach the eggs to foreign objects. Argulus (Fig. 195), on the carp.

\section{Order 4. Cirripedia.}

Characteristics of the attached forms: body indistinctly segmented, attached by the head end, surrounded by a mantle which generally calcifies and then forms a 
shell or case. Anterior antennæe (adhering antennæ) minute, posterior antennæ reduced. Oral limbs small, partly reduced. Six (less frequently 4) pairs of long biramose tendril-like feet. Without heart. Hermaphrodite, occasionally with dwarf males, less frequently sexes separate and dimorphic. Live in the sea.

\section{Family 1. Lepadidæ (Pedunculata).}

Hearl end elongated into an attached peduncle. Lepecs (Figs. 204 and 205), Conchoderma, Scallellum, Pollicipes, Ibla.

\section{Family 2. Balanidæ.}

Peduncle wanting. Body surrounded by a ring of calcareous plates. Balanus (Figs. 206 and 207), Tubieinella, Coronula.

\section{Family 3. Alcippidæ (Abdominalia).}

Body surrounded by a flask-shaped integumental mantle, with 3 or 4 pairs of feet, corresponding with the last 3 or 4 pairs of other Cirripedes. Live in the calcareons shells of other Cirripedes and Molluses. Alcippe, Cryptophyalus.

\section{Family 4. Proteolepadidæ (Apoda).}

Body maggot-like, without tendril-like feet. Anterior (adhering) antennæ ribbonshaped. Mouth a sucker. Enteric canal rudimentary. Parasitic in the mantle of other Cirripedes. Proteolepas.

\section{Family 5. Rhizocephala (Kentrogonidæ), perhaps to be separated as a}

special sub-order or order from the other Cirripedes.

Body pouch-shaped, answers to the cephalic portion only of related Crustaceans. Integument split into 2 lamelle; between them is a brood cavity which opens outwardly by means of an aperture in the outer lamella. Enteric canal wanting. Limbs wanting. Hermaphrodites, with dwarf males. Parasitic on the abdomen of Decerpocla. The pouch-shaped body has an adhering peduncle from which spring the branched "roots" which penetrate everywhere between the viscera of the lost and convey nourishment into the body of the parasite. The larval stages (Nauplius- and Cyprislike larvæ) are like those of other Cirripecles. Seceulina (Fig. 208), Peltogaster.

\section{Sub-Class II. Malacostraca.}

The body consists of 3 regions with constant number of segments. (1) The head, originally formed of $\mathbf{5}$ segments; (2) the thorax, consisting of 8 segments, of which the anterior segment or segments, or all the segments, may fuse with the head to form an incomplete or a complete cephalo-thorax; (3) the abdomen, which (reckoning the telson) consists of 7 segments, (in Nebalia alone, including the terminal segment, of 8). All the segments of the body except the last (and in Nebalice the last but onc) carry limbs. The most anterior thoracic feet often move into the neighbourhood of the mouth to serve as foot-jaws and to assist in taking in food. The sixth pair of pleopoda (abdominal limbs) almost always differs in shape from the rest, and often forms with the telson a caudal fin. A shell fold springing from the posterior cephalic region is very common. A pair of compound lateral eyes is always found, as is also a masticatory stomach. The female genital apertures lie in the 6th thoracic segment, the male in the last. Development sometimes with, sometimes without, metamorphosis. The larva hatched from the egg is rarely a Nouplizes. In many Thoracostraca the larvæ pass through the Zocea stage.

\section{Legion I. Leptostraca.}

An extremely important group, which of all living Crustaceans stands the nearest 
to the racial form of the Malcostraca, and is often placed as a special sub-class between the Entomostraca and the Malacostraca. Borly slender, covered with a bivalve shell, which extends back, leaving only the last 4 abdominal segments free. Besides this there is a movable cephalic plate. Head, with the 5 typical pairs of appendages, distinct from the thorax. All the 8 segments of the short thorax are distinct, with $S$ pairs of similar biramose lamellate feet. On the basal joint of the protopodites of these segments there is a large ejipodial lamella functioning as a gill. The 4 anterior pairs of pleopoda are strong biramose rowing feet, the 2 posterior pairs are short and uniramose. The last segment of the abdomen carries two furcal processes. On the head are 2 stalked compound lateral eyes. Heart elongated, with 7 pairs of ostia, stretches throngh the thorax and the abdomen as far as into the 4th abdominal segment. Masticatory stomach yresent.

Single order and family, Nebe. lidce: Nebalia (Fig. 196), Parancbatia, Nebaliopsis, marine forms.

The fossil Paleozoic forms Cercttiocaridie (Archaostrace), Hymenocaris, Ceratiocaris, etc., are probably related to the Leptostrace.

\section{Legion II. Arthrostraca (Edriophthalmata).}

A shell fold is wanting, except in the division of the Anisopoda. The first thoracic segment (less frequently the second also) is fused with the head, and the foremost pair of thoracic feet are transformed into foot-jaws. The 2 lateral eyes are sessile.

\section{Order 1. Anisopoda.}

First and second thoracic segments fused with the head. Cephalothorax with lateral shell fold, which on each side covers a respiratory cavity. Both the pairs of maxillie have feelers. The feelers of the anterior pair project into the respiratory cavity as cleaning appendages. The maxillipede has an cpipodial appendage functioning as gill. The pair of limbs belonging to the second thoracic segment, which is also fused with the head, are developed as powerful forceps. Abdomen with biramose swimming feet. Heart in the thorax, grenerally with 2 pairs of ostia (the heart of Apscudcs lias only 3 ostia). Apseudes, Tanais, Leptochelia. 


\section{Order 2. Isopoda.}

Body broad, often flattened dorso-ventrally. Only the foremost thoracic segment is fused with the head, the other 7 are free. No freely projecting shell fold.

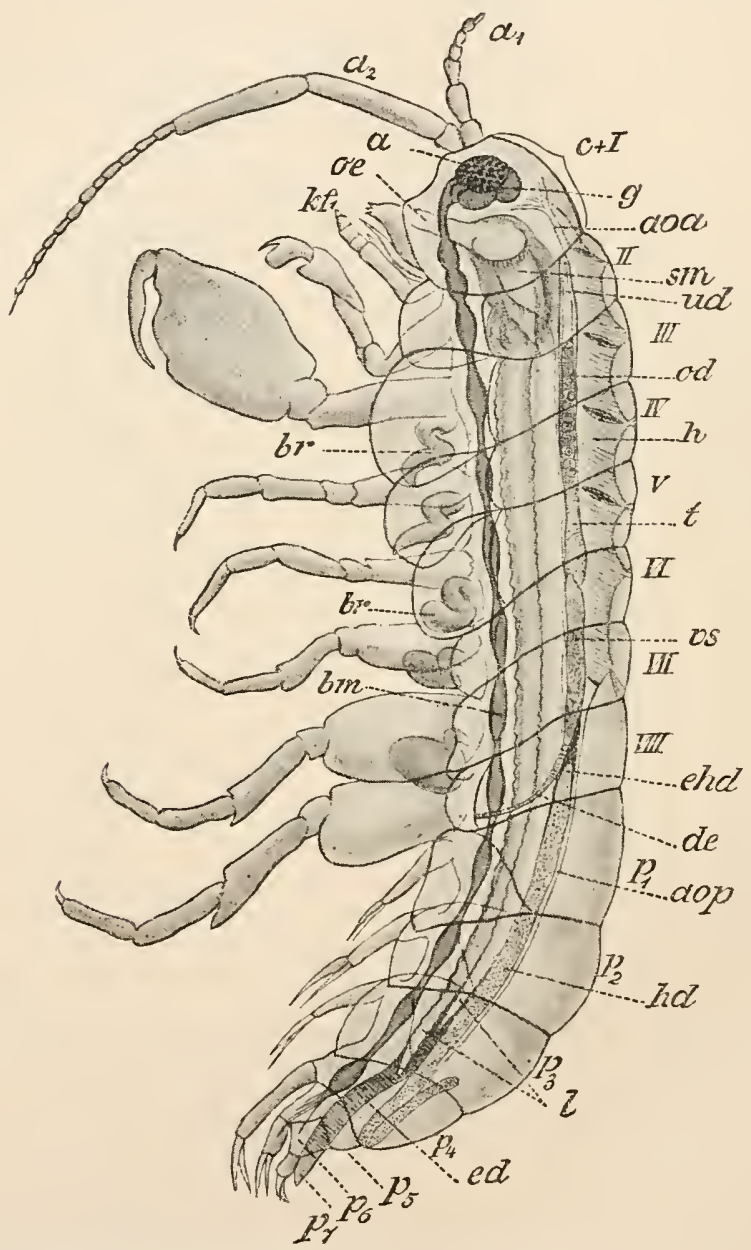

F1G, 197.-Organisation of Orchestia cavimana, male (after Nebeski). $c+I$, Head +1 st thoracic segment; $I I-V I I I$, free thoracic segments with their extremities; $p_{1-1} \eta_{7}$, abdominal segments; $a_{1}$, anterior, $\alpha_{2}$, posterior antenna ; $a$, eye ; $\alpha$, œsol hagus ; $k f$, foot-jaw ; $b r$, gills ; $l m$, ventral chord ; $g$, brain ; cou, anterior aorta ; sm, œsophagal stomach; ud, unpaired intestinal creum; od, eggbearing part of the germ glands ; $h$, heart ; $t$, testis ; $v$, vesica seminalis ; de, ductus ejaculatorius ; $\epsilon h d$, entrance of the urinary gland $(h d)$ into the intestine; aop, posterior aorta; $l$, ends of the hepatic tubes; $e d$, posterior end of the intestine.

The 2 pairs of maxillæ without feelers. Abdomen generally short, often reduced, mostly consisting of 6 segments with biramose lamellated pleopoda, whose branches, especially the endopodites, function as gills. Heart in the abdomen, generally stretches as far as into the posterior thoracic region, with 1 to 2 pairs of ostia. 
Cymothoidea, hermaphrodite, some living free, others parasitic on fishes: Cymothoc, Aniloera, Cirolana, Neroeita, Aega, almost exclusively marine forms. Spharomida, frec living, mostly marine, Spharoma. Pranizida, free in the sea, the 3 anterior

A

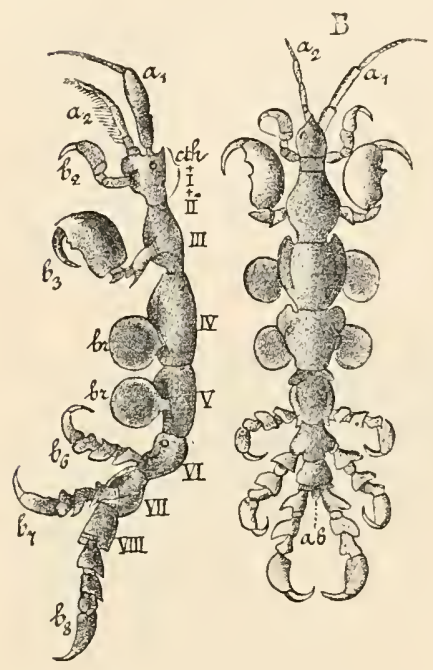

Fic. 19s.-Caprella acutifrons, after P. Mayer. $A$, male from the side; $B$, from the back. $a_{1}$, Anterior, $a_{2}$, posterior antenna; $b_{2}, b_{3}, b_{6}, b_{7}, b_{8}, 2 d$ to sth thoracic feet, the $2 \mathrm{~d}$ moved on to the throat; $b r$, gills in the place of the 4 th and 5 th thoracic feet; $c$ th $+I+I I$; cephalo-thorax $=$ head +1 st and $2 \mathrm{~d}$ thoracic segments; III.VIII, free thoracic segments; $a b$, truncated abdomen.

FIG. 199.-Diastylis stygia, male (after G. O. Sars). $\iota_{1}$, Anterior, $a_{2}$, posterior antenna; $c t h$, cephalo-thoracic shield ; $1 T$. $V I I I$, free thoracic segments; $a b_{1}-a b_{i}, a b_{-}$. dominal segments ; $p_{1}, 1$ st pleopod; $p_{6}, 6$ th lleopod; $e n$, endopodite ; $e x$, exopodite.

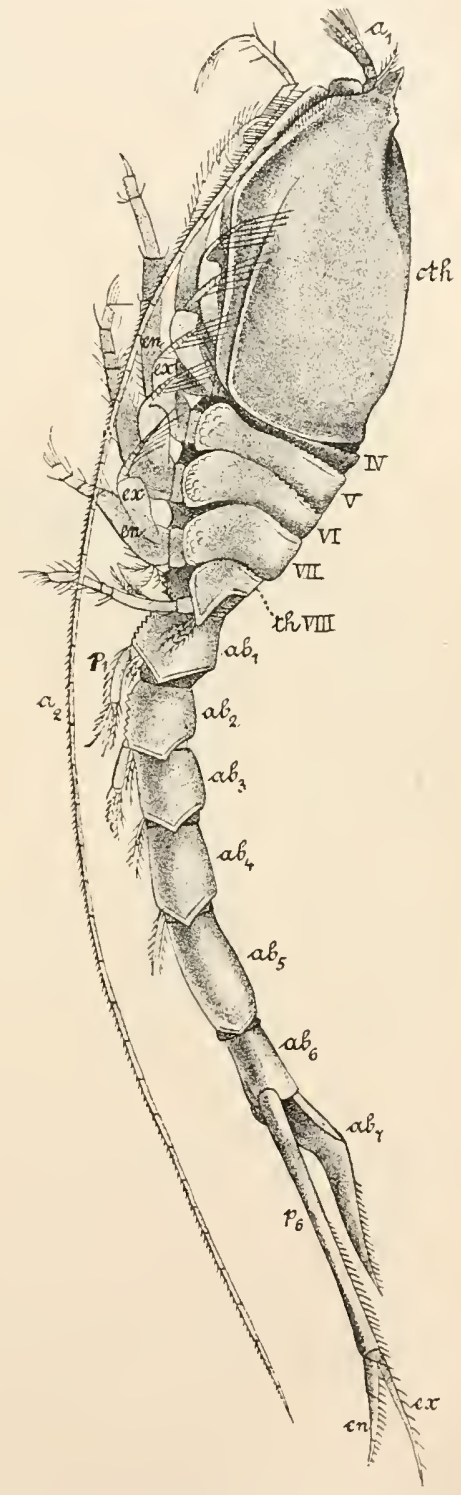

thoraeic segments fused with the head. Aneeidce, female parasitic, male free-living, Anceus. Idotheide, free living, principally marine, Idothea. Asellide: Asellus, fresh water. Oniscide, on land: Oniseus, Poreellio. The divisions of the Bopyridce 
and Cryptoniscidce contain parasites which are chiefly hermaphrodite with dwarf males. Body of the female deformed. Bopyrus (sexes sejarate), Gyge, Entoniseus, Cryptoniscus.

\section{Order 3. Amphipoda.}

Body laterally compressed. In the typical Amphipode only the foremost thoracic segment is fused with the head, in the Caprellide and Cyamidce the two anterior segments. The gills are found on the thoracic feet as pouch-shaped epipodial appendages. Where the abdomen is well developed it carries 6 pairs of hiramose feet, of which the 3 anterior, generally more strongly developed, serve as swimming feet, the posterior, directed backwards and often stylet-shaped, as springing feet. Heart in the thorax with 3 , seldom 1 or 2 prairs of ostia.

\section{Sub-Order 1. Crevettina.}

Head and eyes small. Foot-jaws with their limb-like feelers form a large under lip. Marine forms : Corophium, Talitrus, Orchestia (Fig. 197), Lysianassa. In fresh water, Gammarus.

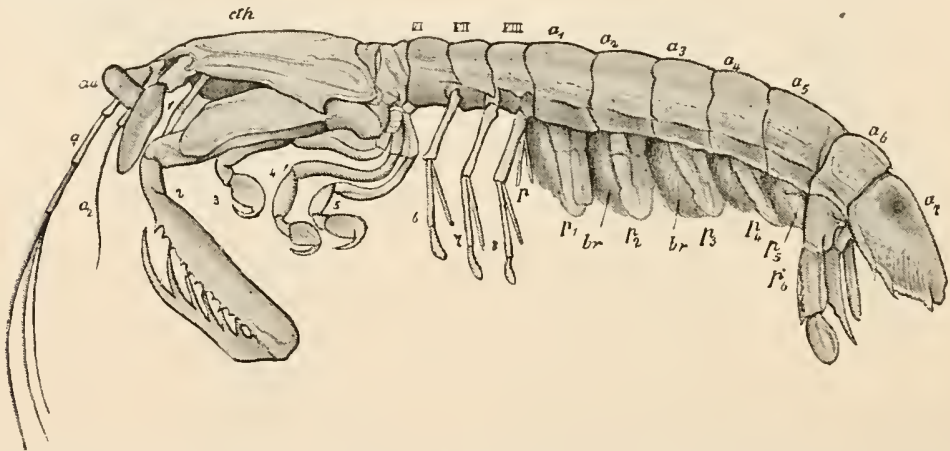

FIG. 200.-Squilla, from the side. cth, Cephalo-thoracic slield; VI, VII, VIII, the 3 posterior

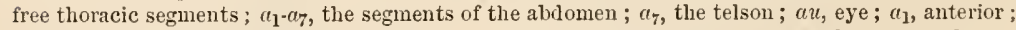
$a_{2}$, posterior antenna; $1-8$, the 8 thoracic feet, of which 1 is the 1 st foot-jaw and 2 is the $2 d$ footjaw or the large seizing foot, $3,4,5$ are the posterior seizing feet, $1-5$ are called oral feet, $6,7,8$, the 3 biramose rowing feet of the 3 posterior thoracic segments; $p$, penis; $p_{1}-p_{6}$, the pleopoda (swimming feet), $p_{6}$ forming with the telson the powerful caudal fin; $b r$, the branchial tufts on the exoporlites of the pleopoda.

\section{Sub-Order 2. Hyperina.}

Head and eyes large, the latter often divided into frontal and lateral eyes. Foot jaws form a small lower lip without feelers. Marine forms: Hyperia (eyes not divided), Phronima, Platyscelus, Oxyeephalus.

\section{Sub-Order 3. Lämodipoda.}

Abdomen truncated. The 2 anterior thoracic segments fused with the head. Gills on the $2 \mathrm{~d}$ and $3 \mathrm{~d}$ free thoracic segments; limbs on these segments often reduced. Marine forms : Caprellide, body very slender and thin-Caprella (Fig. 198), Proto, Protella; Cyamidee, body broad and flat, parasitic on the skin of whales, Cyamus.

\section{Legion III. Thoracostraca (Podophthalmata).}

With a shcll fold which covers a larger or smaller part of the thorax and fuses with the clorsal integument of all or some of the anterior thoracic segments, always, however, projecting freely laterally and covering the respiratory cavity as branchiostegite. A varying number of anterior thoracic segments, or all the thoracic segments fused, at least dorsally, with the head to form an incomplete or a complete cephalo- 
thorax. The 2 lateral eyes stalked (cxcept in the Cumacert.

\section{Order 1. Cumacea.}

Shell (cephalo-thoracic shield) small, leaving the 5 posterior free thoracic segments uncovered. Eyes sessile, close together or fuscr into one, weakly developed, occasionally wanting. Two pairs of foot-jaws. The first with a very large epiporlite carrying a gill. Of the 6 subsequent pairs of thoracic feet, the first 2 always carry exopodites as well as endopodites, the next 3 also often have exopodites, but this is never the case with the last. Abdomen long and slender. In the female the pleopoda are wanting, excepting the last pair. Marine form, Diastylis (Fig. 199).

\section{Order 2. Stomatopoda.}

Cephalo-thoracic shield rather small, not cover. ing the 3 distinct posterior thoracie segments. Body elongated, flattened dorso-ventrally. Abdomen large and strong. The 5 anterior pairs of thoracic feet (oral feet because moved to near the mouth), are holding or seizing feet with epipodial lamellæ, but without exopodites. The 3 posterior pairs of thoracic feet are biramose limbs without epipodial appendages. The 5 anterior pairs of pleopoda are strong lamellated swimming feet, whose exopodites carry branchial tufts. The 6 th pair of pleopoda forms with the telson a powerful caudal fin. The heart with several pairs of ostia is elongated into a dorsal vessel ruming through the abdomen. Ovaries and testes in the abdomen. Marine, Squille (Fig. 200).

\section{Order 3. Schizopoda.}

Cephalo-thoracic shield well developed, like a delicate integument covering the whole thorax. The dorsal integument of the last 5 thoracic segments, or of the last thoracic segment, is not united with it. The 8 pairs of thoracic feet are formed pretty much alike, and are biramose (with exoprodite and endopodite); we can, however, generally describe

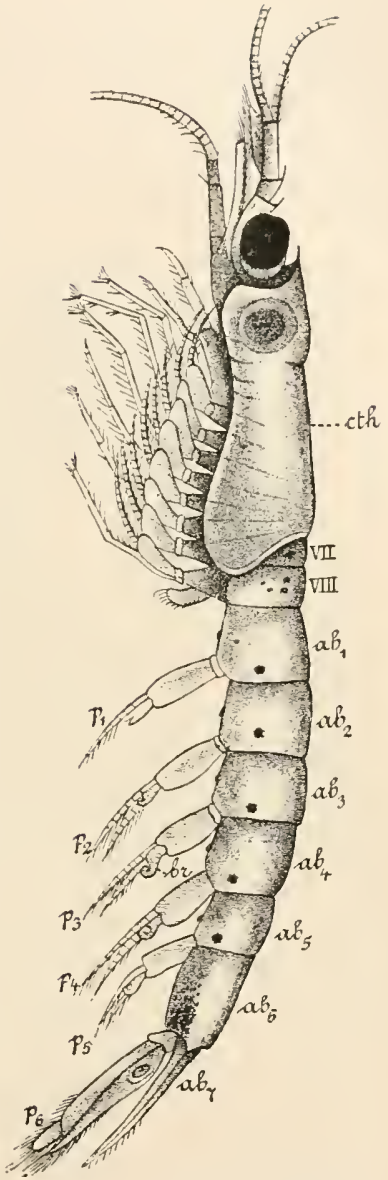

Fig. 201.-Siriella Thompsonii, male (after G. O. Sars). cth, Cephalothoracic shiele; VII, VIII, 7th and Sth thoracic segments; $a b_{1}-a b_{-}$, abdominal segments; $p_{1}-p_{6}$, pleriroda; $b r$, gills. the 2 anterior pairs of thoracic feet as foot-jaws, as they may have masticatory ridges. Abdomen strong, slender. Pleopoda very small in the female, strongly developed in the male. The last pair of pleopoda, well developed in both sexes, forms with the telson a rowing or swimming fin. Marine.

\section{Family 1. Mysidæ.}

Thoracic feet without gills, the first pair with large vibratile epipodial lamellæ. Last 5 thoracic segments free under the dorsal shield. Auditory organs in the endoprodites of the 6th pair of pleopoda. Mysis, Siriclla (Fig. 201); in the male, gills on the pleopoda. 


\section{Family 2. Lophogastridæ.}

With branchial tufts on the thoracic feet; last 5 thoracic segments as in the Myside. Lophogaster.

\section{Family 3. Euphausidæ.}

With branchial tufts on the thoracic feet. Only the last thoracic segment is free under the dorsal shield. Euphausia, Thysanopoda.

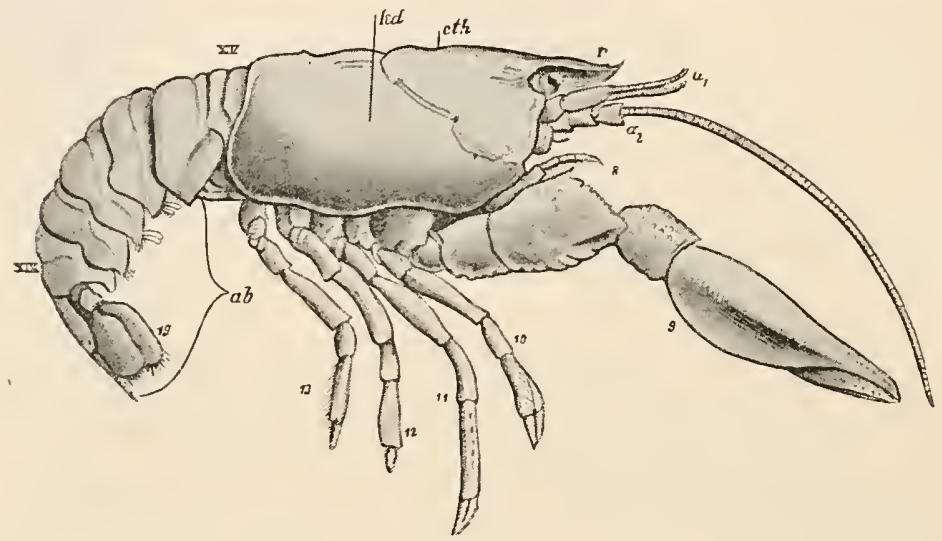

FIG. 202.-Astacus fluviatilis, male, from the side. $c t h$, Cephalo-thorax; $a b$, abdomen ; $h d$, branchiostegite of the cephalo-thoracic shield; $X I V$, first, $X I X$, last but one abdominal segment; $r$, rostrum; $a_{1}-a_{2}, 1$ st and $2 d$ antennæe; 8 , third foot.jaw or maxillipede; 9 , chelate foot; 10 , $11,12,13$, the 4 remaining ambulatory feet; 19 , the pleopoda of the 6 th abdominal segment, which with the telson or terminal segment form the caudal fin (after Huxley).

\section{Order 4. Decapoda.}

Cephalo-thoracic shield large, generally firm and hard, calcareous, covering the whole thorax, and fused with the dorsal integument of all the thoracic segments. Exopodite of the $2 d$ maxilla forms a vibratilc plate which regulates the streaming of the water in the branchial cavity. The 3 anterior pairs of thoracic feet developed as foot-jaws or maxillipedes, the 5 posterior, some of which are armed with pincers, as ambulatory feet (hence "Decapoda"). In the adult these ambulatory feet consist only of protopodite and endopodite, while the exopodite is almost always wanting ; auditory organs on the basal joints of the inner antennæ. Development direct or with metamorphosis. In the latter case a Nauplius is seldom (Caridicle) hatched from the egg ; the larvæ hatched are generally further developed, and pass through a Zowa and a Mysis stage. This order is very rich in forms.

\section{Sub-Order 1. Macrura.}

With well-developed abdomen, which is at least as long as the cephalo-thorax. Mostly with the full number of pleopoda, the last pair of which forms with the telson a powerful caudal fin. Caridide (shrimps) : Penceus, Palcomon, Crangon, Pontonia, Alpheus, Scrgestes, Lucifer, in the sea. Astacidce: Astacus fluviatilis (Crayfish, freshwater ; Figs. 202 and 203), Homarus (lobster), Nephrops, Callianassa, Gebia, marine. Palinuride: Palinurus, Scyllarus, in the sea.

Sub-Order 2. Anomura (this division cannot be sharply demarcated).

Abdomen moderately large; caudal fin mostly reduced. The hindermost pair of ambulatory feet or the two posterior pairs reduced. Third foot-jaws limb-like. Paguridee, hermit-crabs, marine, in empty shells of Molluses ; abdomen soft skimed, asymmetrical, with degenerated pleopoda serving as clinging organs. Pagurus, Eupa- 
gurus, Birgus (in holes in the ground). Hippidce, marine, live in mud; posterior body hard skinned, the half of it bent forwards. The Galateide (Galatea) approaeh the Haerura, and the Porecllanide (Porcellana) the Brachyura.

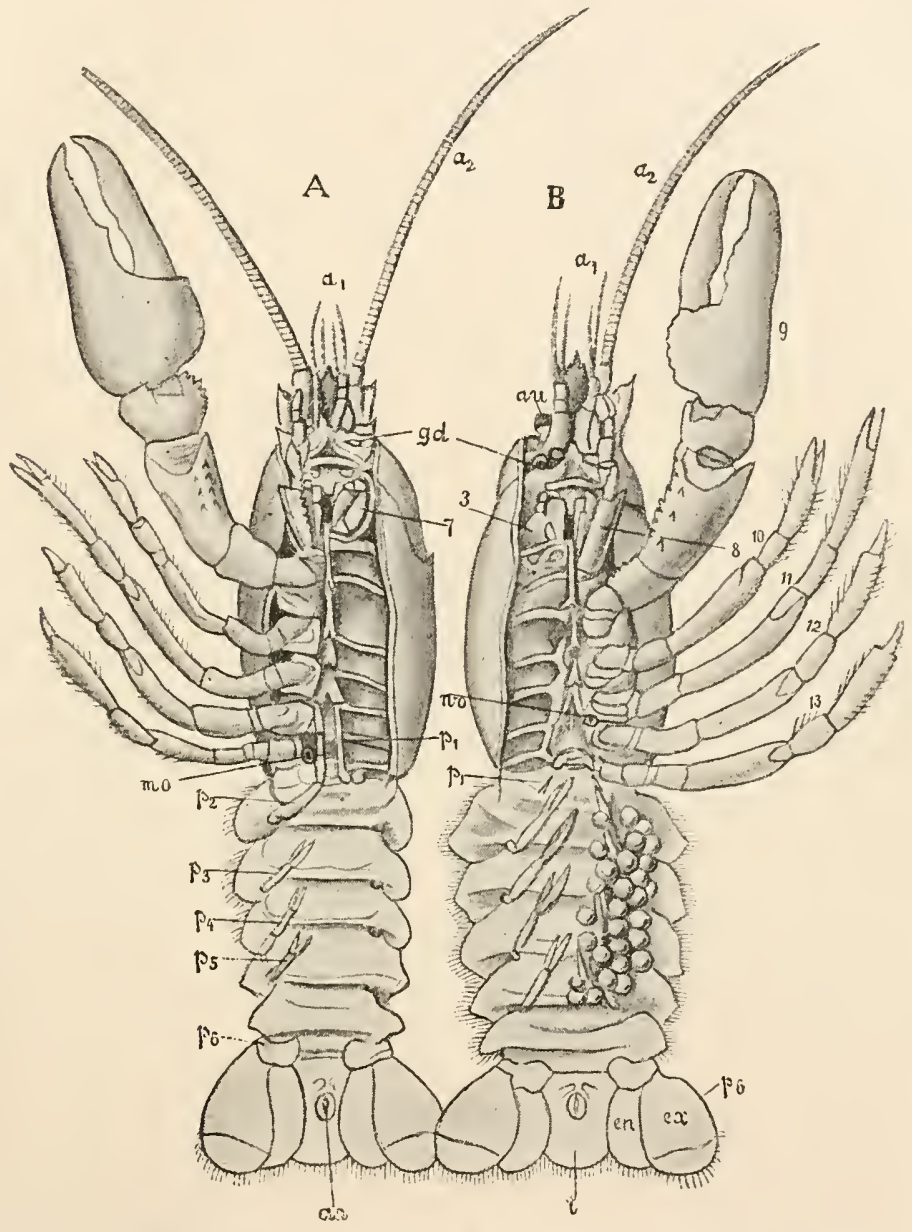

Fic. 203.-Astacus fluviatilis, from the ventral side. $A$, male; $B$, female. In the male the Sth to 13 th and 15th to 1sth extremities of the left 'side of the body are remored; in the female the 21 and 4 th to 13 th of the right side. 3-13, Extremities of the cephalo-thorax; $a_{1}-a_{2}$, anterior and posterior antennæ; gd, aperture of the artennal glands; wo, female; mo, male genital aperture; $p_{1}-p_{6}$, pleopoda; $e n$, endopodite; $c x$, exopodite of the last pair of pleopoda; $a n$, anus; $t$, telson (after Huxley).

\section{Sub-Order 3. Brachyura (Crabs).}

Body flattened. Posterior body without anal fin, reduced, bent round on the ventral side of the eephalo-thorax. In the male only the two anterior pairs of pleopoda are usually retained. Notopoda, in the sea: Dromia, Dorippe, Lithodes. Oxystomata, round erabs: Calappa, Ilia, in the sea. Oxyinyneha, triangular erabs: Iaja, Pisa, Stenorhynchus, Inachus, Lambrus, in the sea. Cyelometopa: Telphusa 
(fresh water), Cancer, Fantho, Pilummus, Eriptica, Portunus, Carcinus, in the sea. Catometopa, square crabs: Pinnotcres, Ocypocla, Grapsus, in the sea, Gccarcinus, land-crabs.

\section{Outer Organisation. ${ }^{1}$}

Nowhere in the animal kingdom does the study of outer or'ganisation afford so much of interest to the comparative anatomist as among the Aithroporla. The more or less hard chitinous envelope which outwardly covers the body and all its limbs not only serves as a protection to the inner organs, but also represents the skeleton to which the musculature is attached inside. Herein lies the chief cause of the specially close relations between inner and outer organisation in the Arthropoda.

In describing the outer organisation of the Crustacea we must take into consideration in turn (1) the body, (2) the extremities, and (3) the gills.

\section{A. The Body.}

We denote by this term the whole animal minus its appendages. It consists of a number of consecutive joints (segments, metameres, somites).

The consecutive segments are movably articulated together. The chitinous integument investing the whole animal remains thin and soft between adjoining segments and forms intersegmental membranes.

The study of comparative anatomy leads us to suppose that originally each segment except the last possessed a pair of limbs, so that the number of the limbs answered to the number of somites. We may diagrammatically represent the Crustacean body as consisting of a great number of segments, as is the case in the Annuluta. The most anterior or head segment is distinguished by the possession of the eyes, the mouth, the brain, and a pair of extremities, which as feelers differ from all the other extremities; these latter resemble one another more or less closely ; their special modifications will be described below. The anus lies in the hindermost segment, which has no limbs.

This diagrammatic representation of the segmentation of the Crustacean body is not exactly realised in any known Crustacean. In fact we everywhere find important deviations even in those which are considered to stand nearest the racial form.

We find first of all that in all Crustaceans the anterior region of the body is outwardly unsegmented, and, in opposition to our typical Crustacean, carries not one but five pairs of limbs. We are inclined to assume that this region has arisen by the fusing of a head segment with the four following segments, this assmmption being supported by similar phenomena observed in various groups of Crustacea.

Thus the most anterior nnsegmented region of the body, which

1 In order to emphasise the great morphological significance of the Leptostracan body, Nebalia is treated of in this division apart from the other Malacostraca. 
carries 5 pairs of limbs, is known as the head, as apart from the trunk, i.e. the whole of the remaining segmented body.

The trunk of the Entomostrace consists of a very varying number of segments, which in different regions may differ greatly in many respects (heteronomous segmentation of the trunk). The trunk of the Mulacostirce always consists of a constant number of segments, viz. fifteen. It always falls into two sharply distinguished regions, each with a constant number of segments, an anterior thoracic region, consisting of 8 segments, and a posterior abdominal region (pleon) containing 7 .

The trunk of the Leptostraca (Nebalic), which in classification takes a place half way between the conjectural racial forms of the Entomostraca and those of the MIalacostruca, though really more nearly related to the latter, also consists of (1) a thorax of 8 segments (which exactly answers to the thorax of the MLalacostraca), and (2) an abdomen of 8 segments.

There is nothing to hinder us from assuming that in all Crustaceans the segments which are numbered alike correspond, for instance the $2 \mathrm{~d}, 6 \mathrm{th}$, and 10th trunk segments of an Isopod with the $2 \mathrm{~d}, 6 \mathrm{th}$, and 10th trunk segments of a Phyllopod.

As in the Anmulate, so also in the Crustacen, the somites become differentiated ontogenetically in regular order from before backward, so that the youngest segment always appears posteriorly in front of the anal segment, this latter containing the formative material for the segments which are to appear in the course of development. There is therefore also nothing to hinder us from assuming that the anal segments of all Crustaceans correspond, of however many segments the trunk may consist.

Apart from the above-mentioned conjectural fusing of the 5 most anterior primary segments to form the unsegmented head of the Crustacean, the metamerism of the trunk, either of the whole trunk or of single regions of it, may be obscured or even entirely obliterated. Such obscuration or obliteration may in almost all cases be referred to one or more of the following causes :-

1. To the appearance of a shell or carapace as a fold arising from the dorsal side of the posterior head region, which spreads in varying form more or less far back over the body, covering or enveloping the same. Such a carapace serves for the greater protection of the body, and also is often closely connected with the respiratory functions. Since a shield-like integumental fold is formed in an essentially similar manner in the most various groups of Crustaceans and their larval forms, we have reason for assuming that it represents a primitive peculiarity of the Crustacean body. By the concrescence of the shield or shell with the integument of all or a portion of the trunk segments, the outer metamerism of the body is obliterated to a greater or less extent.

2. To the fusing of the anterior trunk segments with the head in 
order to associate the limbs of these segments with the limbs already present on the head in the work of taking in food.

3. To the fact that the extremities in certain regions of the body give up their various functions (which are almost always associated with movement), and consequently become reduced or quite disappear. The independence of the segments which carry such reduced limbs is then more or less lost, that is if the said region does not in any other way gain a locomotory significance.

4. To the loss of the capacity for active locomotion by adaptation to the parasitic mode of life; this adaptation leads to the reduction of the extremities and the more or less complete obliteration of the metamerism of the whole body.

Having prefaced these remarks by way of elucidation, we proceed to sketch in outline the external morphology of the body in the principal groups of the Crustacea.

\section{Entomostraca.}

Phyllopoda.-In Branchipus (Fig. 191) the trunk appears distinctly segmented, and falls into an anterior and a posterior region which are called thorax and abdomen respectively. The 11 segments of the thorax carry 11 pairs of limbs ; the abdomen, which consists of many segments, is limbless, and ends in 2 so-called furcal plates. A shield or shell fold is wanting. The head carries 2 stalked movable lateral eyes. In Apus the body is covered for the most part with a flat shell fold, not fusing with any of the anterior thoracic segments. The trunk consists of a large number of segments, the most josterior being limbless. In the Estheridce the body is quite enveloped in a bivalve shell, which also covers the limbs laterally. The trunk consists of numerous segments. The posterior segments, which have no limbs, form a short abdomen, as opposed to the thorax of many segments. A bivalve shell also occurs in the Cladacerce ; here also the shell covers the limbs. In this case, however, it leaves the well-marked head uncovered. In the trunk the segmentation is obliterated. It carries $t$ to 6 pairs of limbs, and ends in an minsegmented abdomen devoid of appendages.

Ostracoda.-The body is entirely enveloped in a bivalve shell, into which also the limbs can be withdrawn. The whole body is megmented. Besides the 5 pairs of cephalic limbs there are only 2 other prairs, so that the trunk appears extraordinarily reduced.

Copepoda.-A shield or shell-fold is here in all cases wanting. The manner of life of the animal leads to very various modifications of the body. In most freeliving gnathostomatons Copepoda the trunk is distinctly segmented (Fig. 194). Wc can distinguish in it a thorax of 5 segments carrying appendages, and an abdominal region also of 5 segments, but without appendages. The most anterior thoracic segment is fused with the head to form an incomplete ceplialo-thorax. The abdomen ends in 2 spine- or bristle-carrying processes which diverge in a fork (furcal processcs). In certain female Notodelphycle each of the 4 free limb-carrying segments has on the dorsal side an unpaired wing-like fold.

In the siphonostomatous Copepoda and Argulide we observe an advancing obliteration of the segmentation of the trunk and a recluction of the abdomen as the parasitic manner of life becomes more marked. The body, in a few of the parasitic Siphonostomata (Lernceille, Lemcopodide, Chondraeanthide), assumes such various and extraordinary forms that no similarity to other Crustaceans can be recognised.

Cirripedia.-These, in an adult condition, are attached or parasitic animals. 
The similarity to Crustaceans in outer appearance is only retaincd in the free-moring young stages, while in the adult forms this similarity is hardly recognisable. If we first consider the attached Lepolide (Figs. 204 and 205), we can distinguish outwardly an attached peduncle and a flattened shell, with a slit-like aperture on one side carried by the peduncle; this shell consists (in Lepas) of 5 calcarcons plates. If we open the shell we find within it the indistinctly segmented body, which carries long tendril-like feet (Fig. 205) and is attached to the shell near the point of insertion of the peduncle. The tendril-like feet are found on that side of the body turned away from the peduncle. A thorough ontogenetic and anatomical study of Lepes has now proved that these parts are to be described as follows. The peduncle

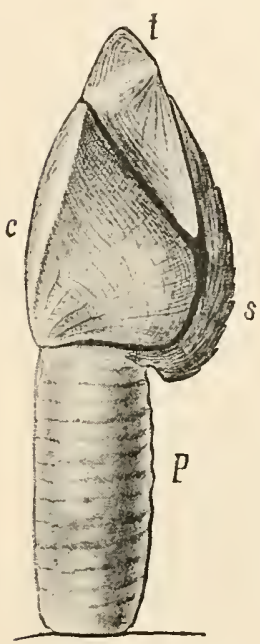

Fig. 201.-Lepas anatifera after Darwin. Seen somewhat diagonally from the carinal side. $c$, Carina ; $t$, tergun ; $s$, scutum; $p$, peduncle.

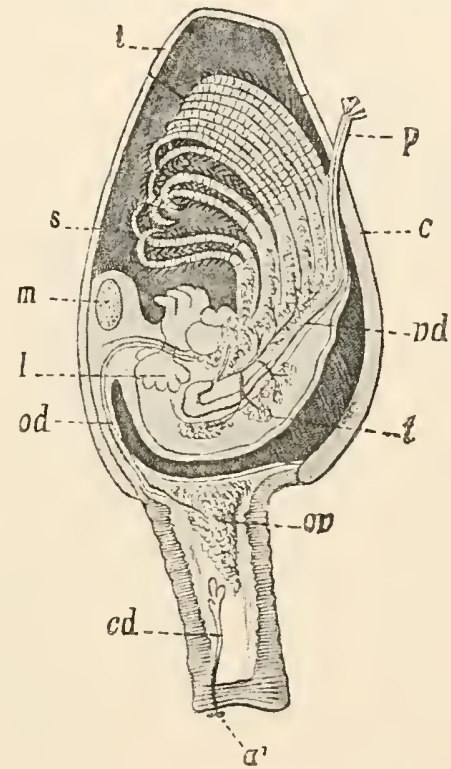

Flg. 205.-Organisation of Lepas, after Claus. The right half of the fold of the body integument with its calcareous plates removed. $t$, Tergum; $s$, scutum ; $c$, carina ; $m$, closing muscle of the scuta; $l$, liver; $o d$, oviduct; or, orarium; $c d$, cement glands; $c^{1}$, anterior (adhering) antenna ; $t$, testes; $v$, ras deferens; $p$, cirrus-shaped penis.

corresponds with the prolonged anterior portion of the Crustacean head, which has become attached, and which still carries on its anterior end the much-simplified anterior antenne in the shape of very small adhering organs (Fig. 205, $a^{1}$ ). The shell is an integumental fold arising from the posterior head region. It answers to the shell or shicld of other Crustaceans. In the chitinous integument of this fold in the Cirrepedia, however, there arise by calcification the various calcareous plates, to which we shall again refer. The part of the indistinctly segmented body enclosed by the shell which lies anteriorly next the peduncle corresponds with the posterior head region, while the remainder, which carries the tendril-like feet, answers to the thorax of an Entomostrxecin; and in addition to these prarts there is a small truncated portion representing a reduced abdomen. The abdomen carries a long 
appendage, the male copnlatory organ $(p)$. This is bent forwards on the ventral side, and lies betwcen the tendril-like feet. The thorax consists of 6 indistinct segments.

In Lepas we find, as already mentioned, 5 sliell pieces or calcareous plates of the integumental fold (mantle), one mnpaired and four paired. The mnpaired piece $(c)$ lies on the dorsal side and is called the carina. The paired pieces $\langle s, t)$ lie to the right and left; the anterior are called the scuta, the posterior the terga. The cleft in the mantle or shell lies posteriorly and ventrally. Accessory shell pieces, mpraired as well as paired, may be found in addition to the above.

In the Lalanide (Figs. 206 and 207), in contradistinction to the Lepadide, the

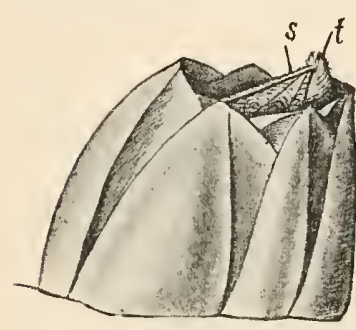

Fig. 206.- Case of Balanus Hameri, from the sick (after Darwin). $s$, Scutum; $t$, tergum.

ing lost the tendril-like feet. degradation in the Rhizoecphala, which live parasitically on the abdomen of Decopoda. In this case we find only an unsegmented sac (Fig. 208), cntirely devoid of limbs, containing the viscera (testes, germarium, cement glands, ganglion), and itself cnveloped in another onter sac-like membrane. This outer membrane which smrrounds the brood cavity has been considered, erroneously it appears, as the mantle. An aperture in it leading to the exterior is termed the cloaca. The body is attached to that of the host by means of a short pednncle. On this stalk of attachment arise long branched filaments which penetrate the body of the host and conduct nourishment from its body to the

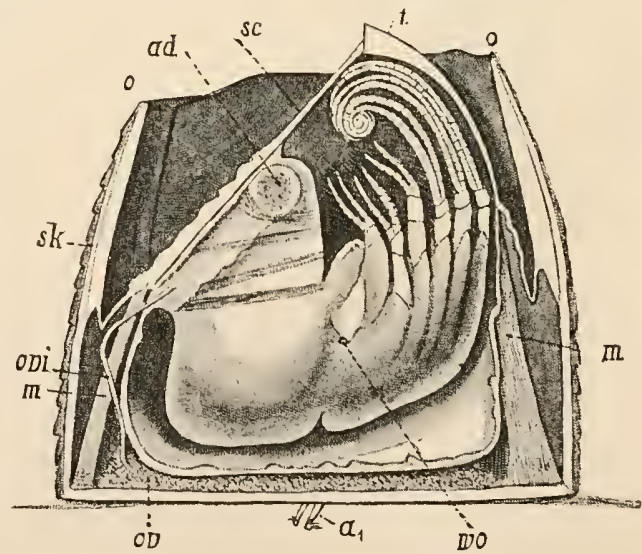

Fig. 207.-Balanus tintinabulum, after remoral of the right half of the calcareous ring. $0-0$, Edges of the aperture of the ring $s k ; s c$, scutum; $t$, tergum; $\alpha_{1}$, anterior (adhering) antennæ; $o v$, ovarium; ovi, oviluct; wo, female genital aperture; $m$, muscles for moving the scuta and terga ; ad, musculus adductor scutorum (after Darwin). parasite in a manner similar to that in which the roots of a plant convey nomrishment out of the earth.

The Rhizocephale are classed as a special order of the Entomostraca (Kentrogo$n i d \alpha)$. It is from their ontogeny alone that we learn that they are Crustaceans at 
all and nearly related to the Cirripedes. In the course of their development they pass through stages similar to those of the Cirripedes, free-swimming and providerl with Crustacean limbs.

In many Cirripedes there are by the side of the ordinary hermaphrodite individuals, complementary dwarf males differently formed, which will be referred to later.

\section{Leptostraca.}

In the segmentation of the trunk, the Leptostraca (Fig. 196) take an intermediate place between Entomostraea (especially Phyllopoda) and Malccostraca. As in the latter, the thorax which follows the head consists of eight limb-bearing segments, here very short but distinet. After the thorax comes the well-developed

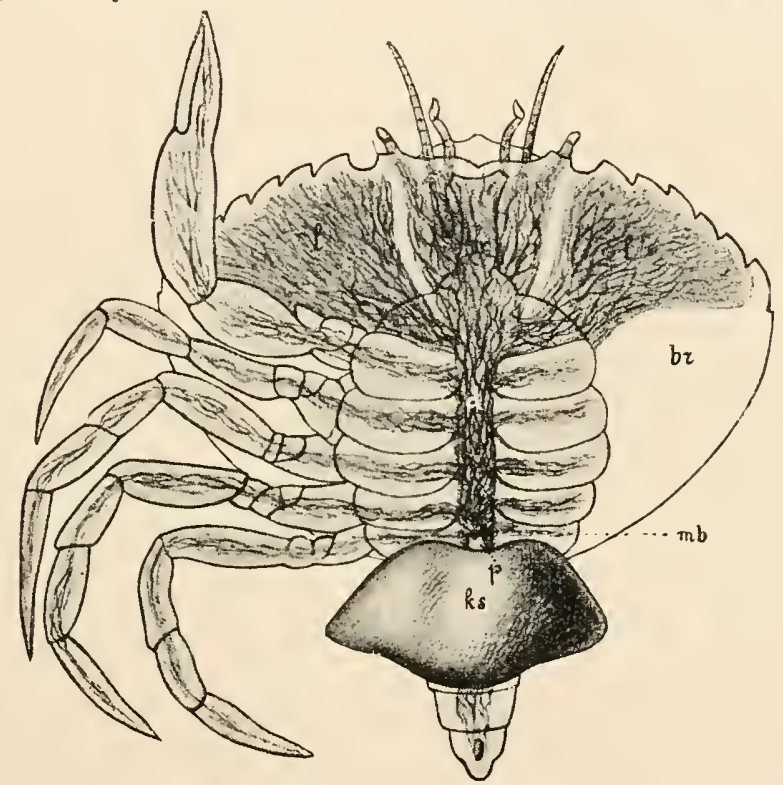

FIG. 208. - Sacculina carcini $i n$ situ on the host (after a somewhat diagrammatic original drawing by Professor Delage, Paris). $b r$, Branchial region ; $l$, hepatic region ; $d$, intestinal region of the host (Carcinus); $k s$, body; $p$, peduncle of the Sacculina; $m b$, basilar membrane out of which the roots of the parasite proceed.

powerful abdomen consisting of 8 segments, i.e. of one more segment than the typical Malacostraean abdomen of 7 segments. The abdomen is further followed by the 2 so-ealled fureal processes. Only the 6 anterior abdominal segments carry limbs. The 6 limb-bearing abdominal segments must correspond with the 6 anterior abdominal segments of the Malacostraec. On the dorsal side of the posterior head region an integumental fold arises, which in the shape of a delicate laterally compressed bivalve shell covers the thorax and the 4 anterior abdominal segments, but does not fuse with them. This shell also, like the corresponding shells of many Entomostruea, covers a large part of the limbs (Fig, 196). The head carries on each side a stalked compound (facet) eye.

\section{Malacostraca.}

There are two peculiarities specially to be noticed in the segmentation of the body of this large division. 
First.-Apart from the unsegmented head, which carries the typical number of limbs ( 5 pairs), the trunk always consists of two regions, the thorax and the abdomen. They both have a constant number of segments, the former 8 , the latter 7. Each of these, with the exception of the last abdominal segment, is typically provided with a pair of limbs. 'The limbs of the 6 th abdominal segment often form with the 7 th or terminal segment a caudal or rowing fin.

Second.-The segments of the thorax show a tendency to fuse with the head. Either the first segment or several anterior segments fuse with the head to form an incomplete cephalo-thorax, or all the thoracic segments unite, and with the head form a complete cephalo-thorax, which then shows external signs of the original segmentation only on the ventral side.

Arthrostraca (Amphiporlc, Isopoda, and Anisopoda).--The foremost thoracic segment is fused with the head. Seven thoracic segments thus remain free (Fig. 197). The eyes are sessile (Edriophthalmata). In the Amphipoda the body is laterally compresserl. The Caprellidce (Amphipoda) (Fig. 198) present many imprortant peculiarities. The $2 \mathrm{~d}$ thoracic segment is also fused with the head, so that only 6 thoracic segments are left free. The abdomen is reduced to a stuml. The body of the Isopode is dorso-ventrally flattened. In a few Isopoda even more thoracic segments become fused with the head. Thus in the Pranizidco (Anecus) the $3 d$ thoracic segment is comprised in the incomplete cephalo-thorax. A shell-fold, though as a rule wanting in the Arthrostraen, is found in the Anisopoda, althougl slightly developed. In these latter the 2 anterior thoracic segments are fused with the hearl. In parasitic Isopoda the metamerism of the body may be indistinct and obliterated, and the body itself become asymmetrical.

Thoracostraca. - A shell-fold is everywhere developed, proceeding from the head; this, as a cephalo-thoracic shield, fuses dorsally with the integument of a larger or smaller number of thoracie segments, but, mlike the corresponding integumental fold of the Entomostraca and Leptostraca, it only covers the thorax, never the extremities and the abdomen. On the head (excejt in the Cumacea) there are 2 stalked faceteyes (Poclophthalmata).

I. Cumacea (Fig. 199). - The cephalo-thoracic shield remains small; the cephalothorax includes the 3 or 4 anterior thoracie segments; the 4 or 5 posterior ones remain free and distinct from one another. The abdomen is long and slender, and distinctly segmented. In the female it carries no feet; the 6th segment only has on each side a pair of biramose stylet-like limbs. The two eyes (when prescnt) are fused into one mpaired eye, or are very close to one another.

II. Stomatopoda (Fig. 200). - The cephalo-thoracic shield is fused with the most anterior thoracic segments and covers the thorax with the exception of its 3 posterior segments which remain free. The broad abdomen is very strongly developed, and longer than the cephalo-thorax. The strongly developed lamellate limbs of the 6tl abdominal segment form with the limbless terminal segment (telson) an imposing candal plate (swimming fin).

III. Schizopoda (Fig. 201).-The soft-skimned cephalo-thoracic shield generally covers the whole thorax, and fuses with the dorsal integument of a varying number of its segments. One or more segments, however, always remain unfuscd. In the Myside the last 5, in the Euphausidce only the last thoracic segment, remains unfused. Abdomen elongated and strong, ending in a swimming fin.

IV. Decapoda (Figs. 202 and 203).-The strong cephalo-thoracic shield, which occasionally becomes through calcification of its chitinous integument as hard as stone, generally covers the whole thorax, and is also fused with the dorsal integument of the thoracic segments. A complete cephalo-thorax is thus formed. The pleura of the cephalo-thorax, which project freely downwards at the sides, cover the 
two respiratory eavities, and are called gill covers or branchiostegites. The form and dimensions of the abdomen are very various. In the Macrus the abdomen is strongly developed. In the good swimmers (c.g. Carididce) the whole borly is laterally eompressed, while in those Macrure which generally erawl, or only swim oeeasionally and not well (Astacida, Palinuride, Galatheidce, Thalassinidee), it is more or less flattened dorso-ventrally. The abdomen always ends in a strong eandal fin (terminal segment with the limbs of the 6 th abdominal segment). In the Paguricto (hermit erabs), whieh live in empty molluse shells, the last thoraeie segment is seprarate and not fused with the cephato-thorax; the abdomen, which is eoverer by the molluse shell, is soft-skinned, the eaudal fin redueed and bent round forwards. The Brachyurce are distinguished by the faet that the abdomen is reduced to a small plate, whieh is bent forward on the ventral side of the cephalo-thorax, so that in looking at these Crustaceans from above only the eephalo-thorax ean be seen. The abdominal limbs are reduced in number and form. The caudal fiu is atrophied.

\section{B. The Extremities.}

According to the scheme sketched above of the segmentation of the Crustacean body, every segment except the last is provided with a pair of jointed extremities which articulate ventrally and laterally with the body. In order to complete the scheme with reference to the limbs, we must distinguish between the limbs of the most anterior segment and the rest. The first pair are not biramose, but consist of a single row of consecutive joints. All the other pairs are biramose. In such a biramose limb we distinguish 3 parts; the shaft or stem (protopodite), the inner branch (endopodite), and the outer branch (exopodite). The shaft consists of 2 joints, a proximal joint articulating with the body, and a distal joint carrying the 2 branches. The 2 branches themselves are again jointed; the inner branch is turned towards the median plane of the body, the outer branch away from it.

The limbs of the Crustacea undergo the most various transformations according to the special functions they perform. They can always, however, be referred back to the typical forms, the first pair to the unbranched (uniramose) form, and all the rest to the biramose form.

This typical arrangement is found in the Nauplius, which is the youngest Crustacean larva, universally found among the Entomosticueu and occurring also in a few Mulacostraca. The Neuplius, which hatches from the egg, is unsegmented, and always possesses 3 pairs of appendages, the first uniramose, the second and third biramose.

The limbs of the Neuplius become in all cases the three anterior pairs of limbs of the adult animal. The most anterior pair becomes the anterior antennæ, the second the posterior antennæ, and the third the mandibles of the adult. In the course of the metamorphoses of the Nauplius, which are accompanied by numerous moults, the larval body elongates into the adult animal, and behind the appendages of the Nurplius new appendages bud from the body as a rule in order from before backward. All these newly formed 
appendages originate as biramose limbs; the biramose character may, however, be more or less indistinct, or may even be lost as the limbs develop into the corresponding limbs of the adult.

In attempting a comparative review of the limbs throughout the class of the Crustacea, only the most important points can be touched upon. The setæ with which they are often provided, and whose form and arrangement are extremely important for classification, cannot here be taken into consideration.

\section{The Limbs of the Head.}

In all the Crustacea the head carries 5 pairs of limbs, which are called, following the order from before backward, the anterior antennæ, posterior antennæ, mandibles, anterior maxillæ, and posterior maxillæ. The 3 anterior pairs correspond with the 3 pairs of limbs of the Nouplins.

«. The Anterior Antennæ (Antennules) (Fig. 209).

These lie in front of the mouth, and consist typically of a single row of joints. As a rule they function as organs of touch, but usually also carry the olfactory organs, and occasionally the auditory organs.

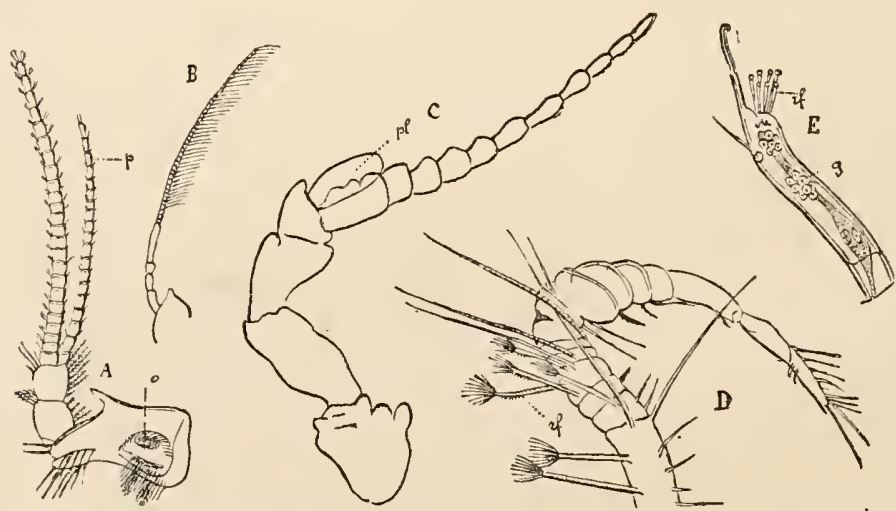

Fic. 209.-Anterior antennæ (antennules) of various Crustaceans. A, Of Astacus (after Huxley); o, auditory sac. B, Of Munnopsis typicu, Isopod of (after Sars). C, of Nebalia Geoffroyi $\delta$ (after Claus), without the setæ; $p l$, plate. $D$, of Cyclops serrulatus $\delta$ (after Claus); $r f$, olfactory hairs. E, Of Daphnia pulex (after Leydig); $r f$, olfactory hairs ; $g$, ganglion.

Entomostraca. - In all Entomostraca the antennules consist typically of a single row of joints. In the Phyllopoda (Fig. 209, E) they are small, carry numerous olfactory hairs, and are called feelers or olfactory antemn. In the Ostracoda (Fig. 193) they are strongly developed and occasionally provided with olfactory hairs, but chiefly function as locomotory organs for crawling and swimming. The anterior antennæ of the Copepoda are strongly developed as swimming feet in the free-swimming forms, and are longer than any of the other limbs (Fig. 194). They carry olfactory hairs, and serve in the males as organs for seizing and holding the female during copulation (Fig. 209, D). In the parasitic forms they are usually much 
shortened. The anterior antemnx of the Cirripalia (Figs. 205 and 207) are very small, and ean no longer be ealled limbs. The eement glands, whose seeretion serves for fastening the body to the surfaee it rests on, open on them. These antennx, as well as all other limbs, are wanting in the Rhizoceplecle. In all Cirripcdes, however, even in the Rhizoccphala, they are well dereloped in the free-swimming young forms (the Neuplius and the so-ealled Cypris-like larva).

Leptostraca.-In Ncbalia (Fig. 209, $C$ ) the antennules are well developed. They eonsist of a 4-jointed shaft whieh earries two appendages, one in the form of a plate; the other, whieh is slender and flagellate, has many joints and earries olfaetory filaments. These two appendages ean in no wise be eonsidered as the exopodite and endopodite of a biramose limb, as these latter always arise from the $2 d$ (distal) joint of the shaft or protopodite. The shaft, with its many-jointed flagellum, eorresponds with the undivided uniramose antenna. The plate is a new formation.

Malacostraca.-Here also the anterior antennæ are well developed and provided with olfactory filaments. They usually eonsist of a 3 - or 4 -jointed shaft and 2 flagella, one of whieh (aceessory flagellum) is a seeondary moduetion of the antemule (Fig. 209, A). There are sometimes 2 aeeessory flagella, and sometimes they are altogether wanting (Isopoda), and in this latter ease the antennule shows its typieal miramose form (Fig. 209, B). The form of the IFalacostracen antemules varies very mueh in details; it shows more or less eonsiderable variations in the two sexes. That the antemules of the Mralacostraca also were originally uniramose as opposed to all the other biramose appendages, and that the aceessory flagella are new formations, is prineipally proved by the Nauplius larva whieh oeeurs in some of the Malacostraca; its first pair of limbs (the later antennules) being always uniramose.

\section{b. The Posterior Antennæ (Fig. 210).}

These correspond with the $2 \mathrm{~d}$ pair of limbs of the Nauplius, being its first pair of biramose limbs, and often serve as feelers. They consist typically of the 2-jointed shaft or protopodite, an outer branch (exopodite) and an inner branch (endopodite). They appear in this form in many Entomostrace.

Entomostraca.-Among the Phyllopoda the posterior antennæ appear in the Cleudocera as strong biramose rowing antennæe (Fig. 192). In Apus they are redueed, and in Branchipus transformed into pineers. Among the Ostracoda in the Halocypricle and Cyprinidce they are biramose swimming feet. The exopodite is, however, eonsiderably redueed, and in the male supplied with seizing hooks. In the Cypridides and Cythcridce, however, they are uniramose, i.c. withont exopodite. The posterior antenne of most Copcpoda are clinging organs. In a few free-living forms they are typieally biramose (Fig. $210, D$ ), in others uniramose, eonsisting of several joints (Fig. 210, C). In the parasitie Copepoda, however, they appear degenerated into short simple elinging hooks (Fig. 210, E). The posterior antemnæ are always ranting in adult Cirripelcs.

Leptostraca (Nebalia) (Fig. 196).-The posterior antennæ eonsist of a 3 -jointed shaft and a many-jointed Hagellum, whieh is unusually long in the male. The exopodite is wanting.

Malacostraca.-In this division the posterior antenne is very eommonly a 5-jointed shaft and a thin (ringed) many-jointed flagellum, the $2 d$ joint of the shaft carrying a seale (squame). This strueture of the posterior antemni is to be explained as follows. The first 2 joints of the shaft answer to the protopodite, 
ally typically biramose, but appear in rarious ways transformed in consequence of having undertaken the function of mastication. It is always the basal joint of the protopodite, as that lying nearest the mouth, which changes into a rariously formed, hard, masticatory portion (corpus mandibulare), and is often toothed on the side turned towards the mouth; the rest of the limb is more or less degenerated.

Entomostraca.-In the Phyllopoda (Fig. 211, $G$ ) the mandible is reduced to the horny masticatory portion. The mandibles of the Ostracoda $(H)$ have retained the typical form. The strongly developed masticatory joint is followed by a segmented "feeler," whose first joint (corresponding with the distal joint of the protopodite) may carry a little fan-like plate. This represents the exopodite, while the feeler, with the exception of its first joint, represents the endopodite. The mandibles in the free-living Copepode $(E, F)$ are toothed masticators (hence Gnathostomata)

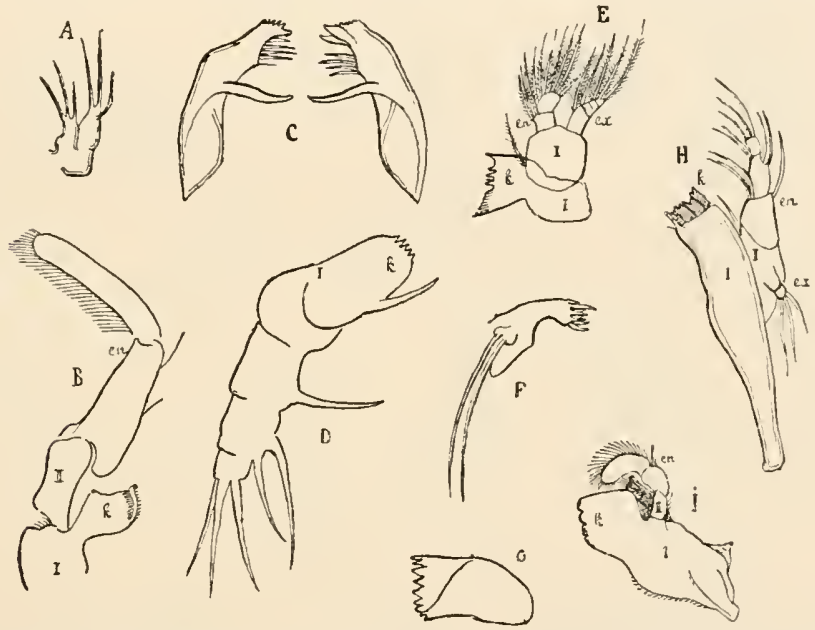

FIG. 211.-Mandibles of various Crustaceans. A, Lucifer, Nauplius (after Brooks). B, Nebalia (after Claus). C, Campylaspis nodulosa, Cumacean (after Sars). D, A larva of Branchipus, 0.S min. long (after Claus). E, Notodelphys Almannii (after Thorell). F, Cyclops tenuicornis (after Claus). G, Apus lucasanus (after Packard). H, Xestoleberis aurantia, Cythcrid Ostracor (after Dahl). $I$, Astacus fluviatilis (after Huxley); $I$, proximal, $I I$, distal joint of the protopodite; $e x$, exopodite; en, endopodite (feeler); $k$, masticatory part or ridge.

and carry feelers. The first joint of the feeler (2d joint of the protopodite) may carry a segmented exopodite. In most parasitic forms the mandibles are changed into stylet-shaped organs for sucking and piereing (Siphonostomata). Anrong the Cirripedes the mandibles are wanting in the Rhizocephala, and in other groups are developed as masticatory portions without feelers.

Leptostraca $(B)$ and Malacostraca $(A, C, I)$. - The exopodite is everywhere wanting; it is only present in the Nauplius stage of a few Malacostraca. The mandible consists of the basal masticatory or eutting joint, and a frequently 3 jointed feeler, whose first joint belongs to the protopodite, while the last two represent the joints of the endopodite. The feeler may here and there be wanting; it is entirely wanting in the Cumacca $\left(C^{\prime}\right)$.

We see from the above review that among all Crustacea only the Ostracoda and 
the Copepoda (more especially the latter) still retain in the strueture of the mandibles the original tylical biramose form, since they alone retain the exopodite in the arlult animal.

\section{The Anterior Maxillæ (Fig. 212).}

These lie, in all Crustaceans, close to the mouth, and serve chiefly for mastication, like the mandibles and the posterior maxillæ. The biramose character is much more commonly retained in them than in the mandibles, the exopodite being more frequently present.

Entomostraca. - Phyllopoda $(D)$, the anterior maxillie are reduced to simple mjointed masticatory ridges without feelers. In the Ostracoda $(B, C)$ also the masticatory ridge is the principal part, but there is a feeler as well, and in the Cypridce

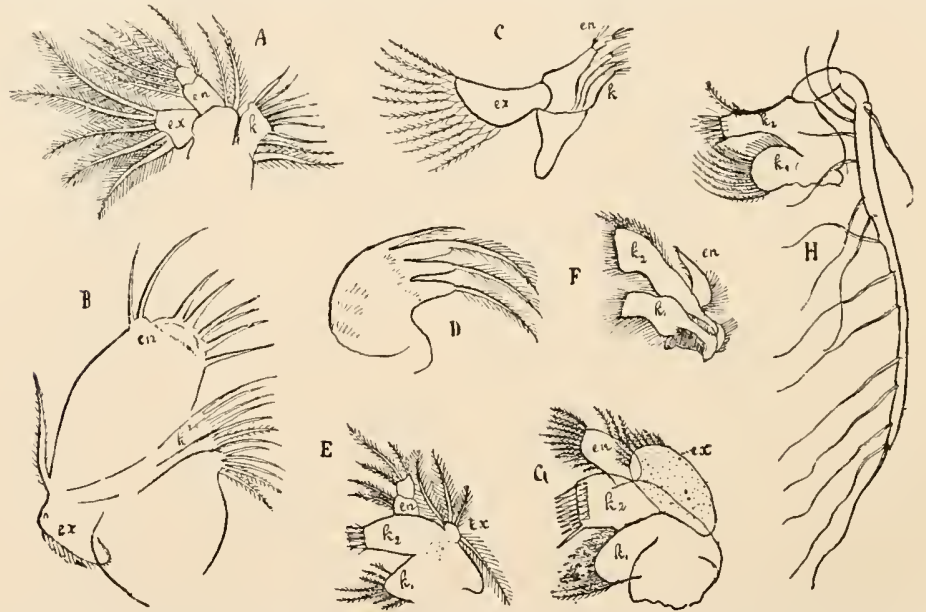

Fig. 212.-Anterior maxillæ of various Crustaceans. $A$, Notodelphys agilis (after Brady). $B$, Cypridina stellifera (after Claus). C, Cythera viridis (after Zenker). D, Daphnia similis (after Claus). E, Euphausia pellucida, last Calyptopsis stage (after G. O. Sars). F, Astacus fluviatilis (after Huxley). G, Euphausia pellucida, alult (after G. O. Sars). $H$, Paranebalia longipes (after G. O. Sars). ex, Exopodite; en, endopodite; $k$, mastieatory ridge; $k_{1}$, inner ; $k_{2}$, outer masticatory ridge.

and Cytheride an exopodite, in the form of a fan-like plate, which is vibratile, and when the maxilla moves promotes respiration. The anterior maxille of the freeliving Copepoda $(A)$ have masticatory ridges, feelers, and sometimes also fan-like exopodites; in the parasitic forms, on the contrary, these parts are much reduced. The anterior maxillie of the Cirripedia are simple masticatory ridges without feelers ; they are wanting in the Rhizoccphala.

Leptostraca. - The anterior maxille of Nebclia $(H)$ are provided with two masticatory ridges (lacinir), and carry a long, jointed, whip-like appendage, which is regarded as an endopodite. This is bent backward dorsally, at least in the female, and serves for cleaning the inside of the shell fold.

Malacostraca $(E, F, G)$.-The maxillie are flatly compressed. The exopodite is often wanting. The distal joint of the protopodite carries a masticatory ridge (lacinia interna), and so does the basal joint of the endopodite (lacinia externa). The remaining one or two joints of the endopodite form the feeler (palp). 
Ontogeny and comparative anatomy enable us to trace back the anterior maxillie of the Mralacostrace to the typical biramose foot. In those Malacostraca which pass through frce Nauplius and Protozoce stages the maxillæ are distinctly recognisable as consisting of a protopodite with a masticatory ridge on the distal joint, an endopodite of two or more joints with a masticatory ridge on the lasal joint, and an exoprodite in the form of a fan-like plate. The exopodite is retained as a vibratile fan-like plate in most Mysidce (Euphausia, Thysaropus, Mysis), and in a very reduced form in many Decapoda.

\section{e. The Posterior Maxillæ (Fig. 213).}

The posterior maxille have the same general typical structure as

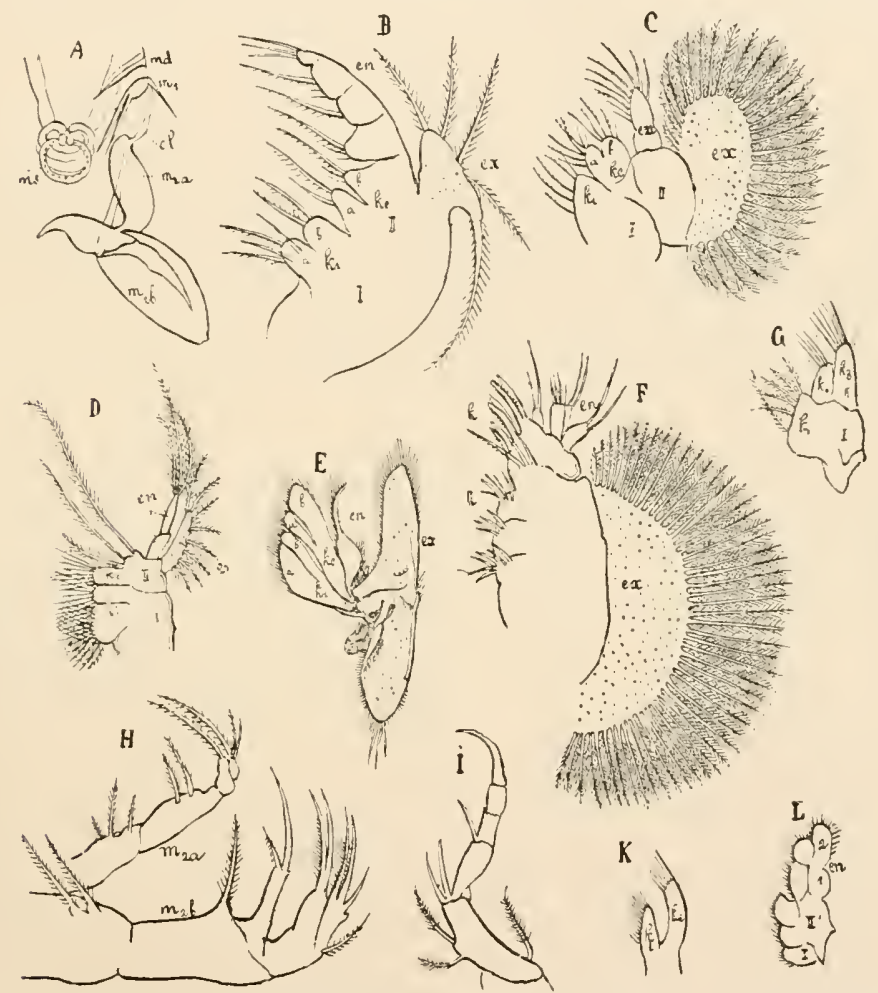

Fig. 213.-Second or posterior maxillæ of various Crustaceans. A, Lernæa branchialis o (after Claus); $m s$, edge of the month; $m d$, mandible; $m_{1}$, anterior maxilla; $c l$, chitinous ridge ; $m_{2} a, m_{2} b$, anterior and posterior maxillipedes. $B$, Penæidan larva (Acetes?) (after Claus). $C$, Eucopia australis (after G. O. Sars). D, Paranebalia longipes (after G. O. Sars). E, Astacus fluviatilis (after Huxley). F, Cypridina messinensis (after Claus). G, Cirolana spinipes (after Schioedte). $H$, Cyclops coronatus ; $m_{2} u$, inner ; $m_{2} b$, outer maxillipede (endo- all exo-porlite of the 2d maxilla). $I$, Limnocythere incisa, anterior limb (after Dahl). $K$, Lysianassa umbo (after Goes). $L$, Lysiosquilla maculata (after Brooks). I, Proximal, $I I$, distal joint of the protopodite; $k i$, lacinia interna ; $k c$, lacinia externa; $a, b$, divisions of the same; $e n$, endopodite ( 1 alp, feeler); $e x$, exopodite (fan plate). In $G: k_{1}$, Lacinia interna; $k_{0,}, k_{3}$, divided lacinia extema; $k$, masticatory ridge (lacinia). In $L: 1$ and 2 , joints of the endopodite.

the anterior, and like the latter serve for mastication. But they 
often show more clearly than the anterior maxillæ the biramose character; e.g. in the Malacostraca the exopodite is almost everywhere retained as a vibratile plate.

Entomostraca. - In the Phyllopoda, the posterior maxillæ are, like the anterior, reduced to simple masticatory ridges. In the Cladocera they are indeed only to be found in the embryo.

The posterior maxille of the Ostracoda $(F, I)$ show very various arrangements. They sometimes function almost exclusively as masticatory organs, sometimes they are locomotory organs as well, sometimes only the latter. In the first ease the masticatory ridge is well developed, the endopodite (feeler) small and 2-jointed, the exopodite (fan plate) either rudimentary (Cypris) or very strongly developed (Cypridina). In the second case the endopodite is longer and many-jointed. In the third case the maxilla is formed like an ordinary limb and the fan plate has disappeared. The arrangement of the posterior maxille in the Copepode is very interesting $(A, H)$. The endopodite and exopodite are here retained as appendages, which are nsually jointed. Instead, however, of their being placed on a protopodite, they are inserted direct on the body, so that we might be tempted to consider them as special limbs. They have been called anterior and prosterior maxillipedes. In the parasitic Copepoda they serve as clinging organs and end in hooks. In the Argutide (Fig. 195, p. 291) each of the anterior maxillipedes is changed into a large adhering dise. The posterior maxille of the Cirripedia are small, much reduced, and fused together into a sort of lower lip. 'They are wanting in the Rhizocephala.

Leptostraca $(D)$.-The 2d maxillæ of Ncbalia are biramose, with protopodite, endopodite, and exopodite. The protopodite carries 3 lobate masticatory ridges. The endopodite has 2 joints. The exopodite is mointed and narrow, and is a transition form between the jointed branch and the broad flat fan plate.

Malacostraca $(B, E, G, K, L)$.-The posterior maxillæ are more easily recognised as metamorphosed biramose feet than the anterior maxilla, in that they (except in the Arthrostr(ce) have retained besides the protopodite and the endopodite the exopodite as the so-called fan plate. The protopodite generally carries 2 masticatory ridges (lacinire), one on the proximal, the other on the distal joint. These lacinix are often divided.

The posterior maxille of the Arthrostraec are very much simplified, most of all in the Amphipoda $(K)$, where the exo- and endo-podite are wanting, and both the masticatory ridges of the protopodite are simple. In the Isopoda the lacinia of the distal joint of the protopodite is divided; the exo- and endo-podite are wanting. In the land Isopode and the parasitic forms even the protopodite, with the masticatory ridges, is more or less degenerated.

In the Thoracostraea the posterior maxille of the Sehizopoda (C) show the arrangement above described as charactcristic of the Malceostraca. Both masticatory ridges are divided (Thysanopus, Euphausia), or the proximal remains undivided (Mysis, Lophogaster, Siriella, Eucopia). In the Cumacea the endopodite (palp) is wanting, and the exopodite is small. In the Stomatopoda the exopodite is wanting, but on the other hand fan-like lobes are developed on the 2-jointed endopodite. The proximal masticatory ridge is undivided, the distal divided. In the Decapoda $(B, E)$ the proximal as well as the distal masticatory ridge is divided; the endopodite (palp' or feeler) is small and unjointed (in the larva only has it two or more joints), and the exopodite is well developed in the shaje of a fan plate, with a crescent-shaped process directed backwards, which regulates the streaming of water in the branchial cavity. 


\section{$f$. The Paragnatha.}

We may here in passing notice certain peculiar processes which in the Thoracostrace and a few Entomostruca (Ostracala and Copepoda) rise independently between the mandibles and maxillo on the ventral integument of the head, and are called paragnatha. They cannot be considered as separate limbs, as they are never imnervated by special ganglia. They may perhaps represent the proximal masticatory ridges of the anterior maxille which have become independent. In Apseules (Anisopodu) a ridge-like portion is marked off from them.

\section{The Limbs of the Trunk.}

The limbs of the trunk can be deduced from biramose feet. Their number varies in the Entomostiaca, but is constant in the Mulacostraca. In the latter we always distinguish, in correspondence with the segmentation of the trunk, 8 pairs of thoracic limbs and 6 pairs of abdominal limbs or pleopoda.

There is nothing to prevent us from assuming that the trunk appendages of the Entomostrace correspond with those of the Malacostraca, pair with pair from before backwards.

\section{a. Entomostraca (Fig. 215).}

Phyllopola.-The Branchiopoda and Cladocera must be described separately. Eranchiopode (Fig. 214 ; Fig. 215,C) : the numerous (10 to 36) pairs of trunk limbs are formed pretty much alike. They are wanting on a varying number of posterior (abdominal) segments. All the limbs are leaf-shaped swimming feet with branchial appendages. They also serve for whirling food within reach. Their structure is essentially as follows. An unjointed or indistinctly jointed stem carries on its imncr side (that turned to the median plane of the body) 6 appendages or lobes (endites) and on the outer side a flat respiratory liate and a pouch or sac-like branchial appendage (epipodite). It is at present impossible, without straining, to deduce all these parts from the typical component parts of a biramose limb. The respiratory plate is gencrally held to be an exopodite. In the Limuce. diade (Limnetis, Estheria, Limnadia) there are 10 to 27 pairs of swimming feet.

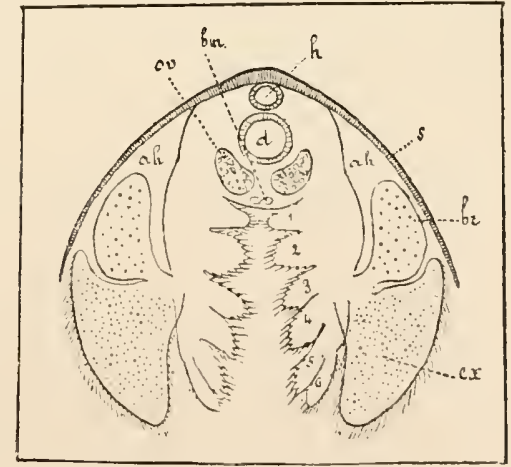

Fic. 214.-Apus. Transverse section in the neighbourhood of the 7 th or sth pair of feet. $h$, Heart ; $d$, intestine ; $o v$, ovaries ; $b m$, ventral chord; $\alpha h$, respiratory cavity between the shell $(s)$ and the body ; $1-6$, endites; $b r$, gills ; $e x$, respiratory plate (after Packard). The respiratory plate is divided into two.

The Apodidce (Apus) usually possess 35.50 pairs of swimming feet. The endites are jointed, and may be described as flagellate appendages; they are rery long (the 5 th especially) on the 1st pair of swimming feet. The 11th pair of feet carry on 
each side a basin-like brood capsule serving for the reception of the eggs, formed out of the shaft and its respiratory plate. Each of the limb-bearing trunk segments lying behind the 11 th carries several (up to 6) pairs of swimming fect, gradually diminishing

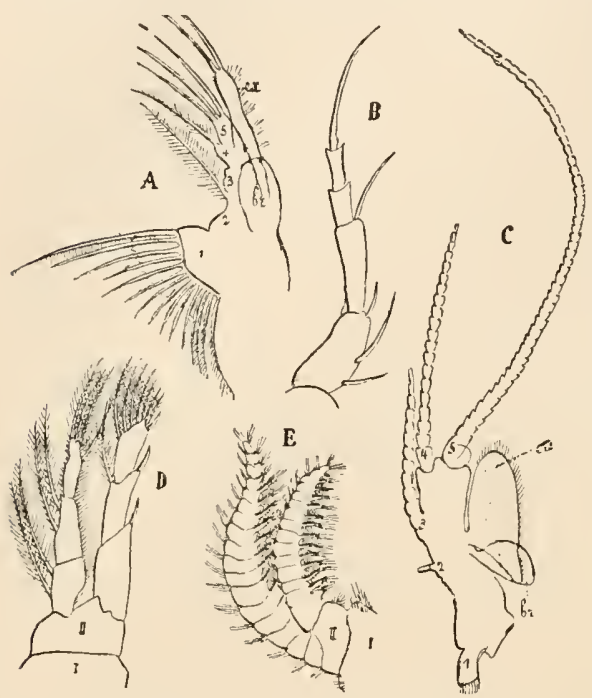

Fic. 215.-Trunk feet of some Entomostraca. $A$, Daphnia similis $q, 2 d \operatorname{limb}$ (after Claus). $D$, Limnocythere incisa, last (3d) limb, i.e. 2 d trunk limb (after Dahl). C, Apus longicaudatus $\hat{\jmath}$, 1st limb (after Packard). $D$, Notodelphydæ, Doropygus porcicauda O, swimming foot of the 4 th pair (after Brady). $E$, Balanus perforatus, $2 d$ cirus (after Darwin). 1, 2, 3, 4,5 , Endites ; $e x$, respiratory plate or exopodite; $b r$, gill; $I$ and $I I$, joints of the protopodite. Cypridina the latter are inserted dorsally on the trunk, and are here long manyjointer appendages ( $f f$. Fig. 193, p. 259). Locomotion is effected chiefly by the limbs of the head.

Copepoda (Figs. 194 and 195, PP. 290 and 291 ; Fig. 215, D)).-The 4 or 5 pairs of feet are limited to the anterior part of the trunk, which as thorax is opposed to the limbless abdomen. The most anterior pair is inserted on the 1st thoracic segment, which is fused with the head, and is generally unlike the other pairs in its form. The thoracic limbs, as rowing feet, cause the swimming movement of the Copepoda. They, unlike those of the Phyllopoda, exhibit in a fine typical manner the biramose character, as they consist of a protopodite of 2 joints, an exo- and an endo-podite. The cxo- and endo-podites generally have 3 joints (in the Argulidce they are long and many jointed) and function as flat oars. Adaptation to a parasitic mode of life in the Copepocla leads to the reduction and occasionally to the disappearance of the thoracic feet, e.g. in the Chondracanthina the 31, 4th, and 5 th pairs of thoracic feet are wanting, and in the Lerncopodide all the thoracie fect have disappeared.

Cirripedia (Fig. 215, E). - The trunk cxtremities of these Crustaceans are biramose ; their exo- and endo-podites are long and many-jointed, and are described as tendril- 
like feet. They are alternately protruded and withdrawn through the shell- or mantle-clcft, and serve for taking in particles of food and at the same time as respiratory orgaus. Six pairs of tendril-like feet are found in the Lepadide and Balanide, 3 or 4 pairs in the Abdominalia. In the Proteolepadide and Rhi:ocephala the tendril-likc feet entirely disappear.

\section{b. Leptostraca.}

Nebalia, in the morphology of its trunk limbs, represents in many respects a transition form between the Entomostraca and the Thoracostraca. We can distinguish thoracic fect and abdominal feet (pleopoda) corresponding with the division of the trunk into a thorax of $\mathrm{S}$ segments (exactly answering to the Malacostracan thorax) and an abdomen (pleon) of 8 segments. The 8 pairs of thoracic feet are similar to one another, as in most Entomostraca. They are (Fig. 216) lamellate, strongly recalling the leafshaped limbs of the Phyllopoda, between which and the thoracic feet of the Malacostraca they form a comnecting link. Each thoracic foot of Ncbalice consists of the 3 parts characteristic of a biramose foot, viz. a protopodite of 2 joints, an exopodite, and an endopodite. The proximal or basal joint of the protopodite carries a doubly-tipped branchial lamella (epipodite), probably corresponding with the branchial appendage of the trunk feet in the Phyllopoda. On the one side of the distal segment is inserted the 5-jointed cndopodite as a direct prolongation of the protopodite, and on the other the unjointed exopodite in the form of a branchial lamella, probably homologous with the respiratory plate on the trunk feet in the Phyllopocla.

In the abdomen (pleon) only the 6 anterior serments carry limbs. The 6 pairs of limbs probably correspond with the 6 pairs of pleopoda in the Mala-

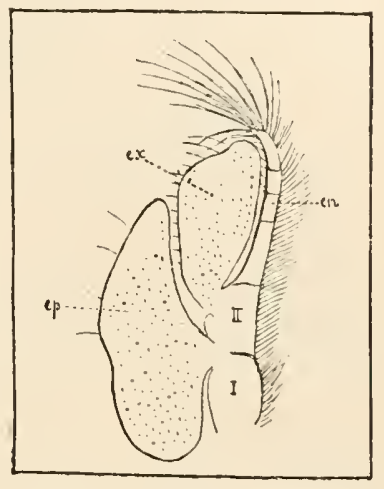

FIG. 216.-Nebalia, leaf-shaped thoracic foot (after claus). $I, I I$, Joints of the protopodite; en, endopodite; $e x$, exopodite ; $e l$, epipodite.

costraca. The 4 anterior pairs (Fig. 225, D) serve for swimming; they are typical biramose feet (with proto-, exo-, and endo-podites), and show some similarity to the swimming feet of the Copepoda. An epipodite is wanting. The last 2 rairs of pleopoda (Fig. 225, E) are short and miramose, and consist of one or two joints.

\section{c. Malacostraca.}

The trunk feet fall into thoracic feet and abdominal feet (pleopoda) in correspondence with the division of the trunk into a thorax of 8 segments and an abdomen (pleon) of 7 . We find $S$ pairs of thoracic feet and 6 pairs of pleopoda, the last abdominal segment being always devoid of appendages. It is better to consider the extremities of the thorax and of the abdomen separately.

\section{The Thoracic Limbs.}

As a varying number of the anterior thoracic segments may fuse with the head, a varying number of the anterior thoracic feet often enter into close relations with the month, as accessory organs for the taking in of food (foot-jaws, maxillipedes). The thoracic foot of Nebalia described above may be considered as the primitive form of the thoracic feet in the Malacostraca.

In a typical Malacostracan thoracic limb the proximal joint of the protopodite 
carries an cpipodite, while the exopodite and the 5-jointed endopodite are attached to the distal joint. Very often both the exopodite and the epipodite disappear, and the thoracic foot is then an unbranched, 7 -jointed limb. The proximal joint of the protopodite occasionally fusing with the skeleton of the thorax, the distal joint alone is recognisable.

Arthrostraca (Fig. 217).-Here, where the most anterior thoracic segment is fused with the head, the most anterior pair of thoracic feet are associated with the

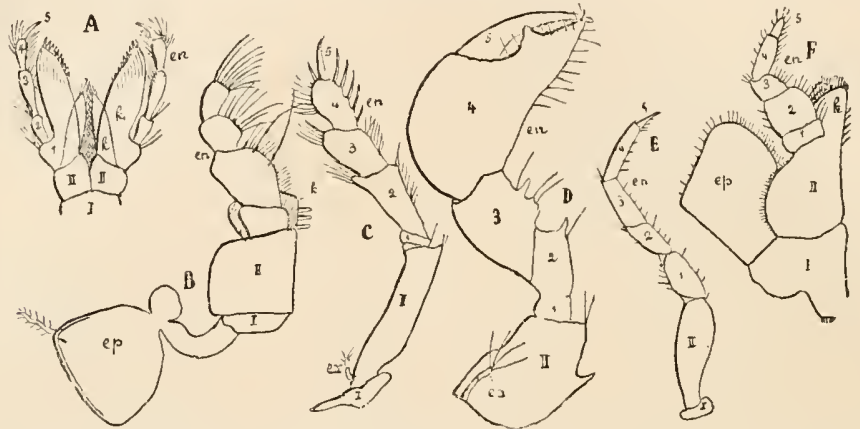

FIG. 217.-Thoracic limbs of some Arthrostraca. A, 1st pair of thoracic feet (maxillipedes) of Amphithoë penicillata (Costa). $B-D$, Apseudes. $B$, lst right thoracie foot; $C$, 3 thoracic foot; $D, 2$ d thoracic foot (after Boas). $E$ and $F$, Asellus. $E$, od thoracic foot; $F$, 1st thoracic foot (after Boas). I, II, Joints of the protopodite; $1-5$ joints of the endopodite $; k, k$, masticatory ridges ; $e p$, epipodite; $e x$, exopodite; en, endopodite.

oral limbs as a pair of maxillipedes. The absence of the exopodite is the general rule for the thoracic feet of the Arthrostraca. The proximal joint of the protopodite often fuses with the thoracic skeleton. On the basal joint of some thoracic feet there is, in the female, a lamellate appendage, the brood plate or lamella. The brood

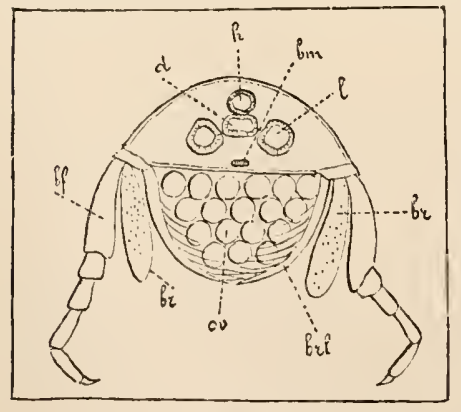

Fig. 218.-Corophium longicorne (Amphipot). Transverse section through the thorax (after Delage.) $d$, Intestine; $h$, heart; $b m$, ventral chorl ; $l$, liver ; $b r$, gill ; brl, brood lamella; ov, eggs in the brood cavity; $b f$, thoracic feet. gills of the Caprollide (Fig. 198, p. 295) are generally limited to the 4th and 5th pairs of thoracic feet, and these thoracic feet are then reduced to the proximal joint of the protopodite. In the Isopoda gills are wanting on the thoracic feet, except on 
the maxillipede, on which an epipodial appendage in the shape of a firm plate has leen retained (Fig. 217, F). The Anisopoda deviate in many ways from other Isopoda (Fig. 217, B-D), especially the genus Apscudes. The anterior thoracic foot (maxillilerde) $(B)$ possesses a large epipolial appendage, which by its vibration eauses a constant current of watcr in the respiratory cavity formed by the shell-fold. On the $2 \mathrm{~d}$ and $3 \mathrm{~d}$ thoracic feet $(C, D)$ of Apseudes there are rudimentary exopodites, a fact of great importance in tracing back the thoracic feet of the Arthrostrace to biramose feet. The thoracic feet of the second pair are transformed into strong chelate feet in the ordinary manner, i.e. the ultimate (5th) joint of the endopodite is opposable to a distal process of the penultimate (the 4 th).
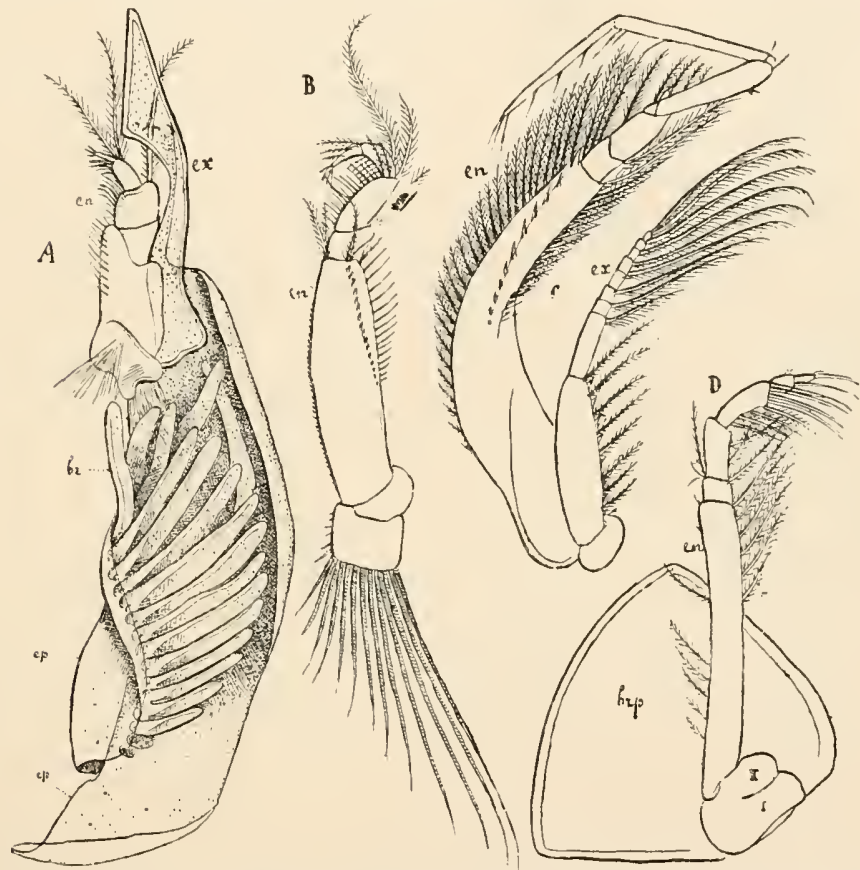

Fif. 219.-Thoracic feet of Diastylis stygia $\$$ (after G. O. Sars). A, 1st, B, 2d, C, 4th, D, 6th thoracic feet. $e p$, Epipodial plate; $b r$, gill on the same; $e n$, endopodite; $e x$, exopodite, which in $A$ is a hard lamella; brp, brood plate.

Thoracostraca.-In the Cumacea (Figs. 199 and 219) the most anterior thoracic foot has become a maxillipede. The remaining thoracic feet are long. Broodlamellæ oceur on the basal joints of the $2 \mathrm{~d}$ to the 6 th prairs in the female. The exopodite is wanting in the 1st (?), $2 d$, and 8th pairs; in the female usually also in the 6 th and 7 th ; on the other feet it is present and serves for swimming. The endopodite has 5 joints. An epipodial appendage is developed only on the 1st thoracic foot (maxillipede), but here is very large. It has numerous branchial tubes. The distal joint of the protopodite of the maxillipede carries a masticatory ridge.

Among the Stomatopoda (Figs. 200 and 220) the 5 anterior pairs of thoracic feet are formed very differently from the 3 posterior pairs. The latter arise from the 3 free posterior segments of the thorax, which are not covered by the cephalo- 
thoracic shield. The $\mathbf{5}$ anterior pairs, which have moved to the neighbourhood of the mouth, have no exopodite in an adult condition, though it is to be found in their larval stages (Fig. 220). They all possess a disc-shaped epipodial appendage
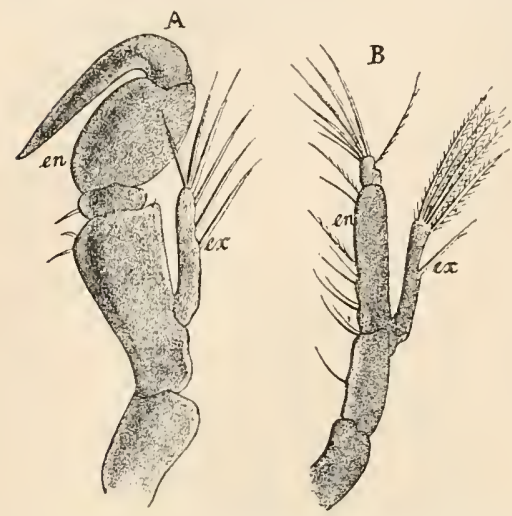

Fic. 220.-Thoracic feet of a Squilla larva, after Claus. $A$, al maxillipede. $B$, one of the subsequent 3 thoracic feet. en, Endopodite; $e x$, exopodite.

strace, and leaning on the other to those of the Decapoda. All the 8 pairs of thoracic feet are still more or less similarly formed, and are biramose. It is best to describe the Euphausidce first, then the Lophogastrido, and lastly the Mysidce.

In the Euphauside (Fig. 221, F-I) the thoracic feet consist of the 2-jointed protopodite, a 5-jointed endopodite, and an exopodite which is composed of a onejointed shaft and a flagellum which is freruently ringed. All the 8 pairs of thoracic limbs have epipodial appendages on the basal joints of the protopodites; these appendages are simply pouch-like on the first pair, but are more or less branched on the other pairs, and form gills. The 2 anterior pairs of thoracic feet are slightly different from the subsequent pairs, the proximal joint of the protopodite having a ridge-like process. Herein we see the beginning of the metamorphosis of these thoracic feet into maxillipedes. In Euphausia the cndopodite is wanting in the last two pairs, in Thysanopus in the last pair.

In the Lophogastridce (Fig. 221, $A$ and $B$ ) the 1st thoracic foot has already become a maxillipede, and the $2 d$ also approaches the form of one. On the 1st pair the epipodial appendage becomes a broad vibratile plate. In the female brood-lamelle are found on the basal joints of the protopodites of the other feet. Gills arisc near this basal joint, but from the integument of the thorax itself; these correspond with the epipodial gills of the Euphausidce, and may be described as appendages dislocated from the proximal joint of the protopodite.

In the Myside (Figs. 201, 221, C.E') both the 2 anterior pairs of thoracic limbs are maxillipedes with masticatory ridges. The first maxillipede carries a vibratile epipodial plate. Some or all the other feet may in the female carry brood-lamellæ (Fig. 222). Branchial appendages are wanting on the thoracic limbs of the Aysidce.

The Decapoda (Figs. 223, 224, 202, 203) have the three anterior pairs of thoracic feet transformed into maxillipedes, which no longer serve for locomotion but only for taking in food. The exopodite is well developed in them, and flagellate; the epipodite lies in the branchial cavity in the form of a long lamella. In the Brachiura it is whip-like and resembles a cleaning foot. The anterior maxillipedes have 
FIG. 221.-Thoracic feet of Schizopoda (after G. 0 . Sars). $A$ and $B$, Lophogaster typicus. $A$, 1st thoracic foot (maxillipede); $B, \quad 2 d$ thoracic foot of the $q$, with brood-lamella. $C-E$, Mysis flexuosa. $C$, ist thoracic foot (maxillipede); $D, 2 d$ thoracic foot (maxillipede); $E$, 3d thoracic foot. $F \cdot I$, Thysanoessa gregaria. $F$, 1st, $G$, 5th, $H$, 7 th, $I$, Sth thoracic feet. $I, I I$, Joints of the protopodite, $1-5$, of the endopodite; $e n$, endoporlite ; $c x$, exopodite; $b r$, gills ; $e p$, epipodial plate; $b r l$, broodlamella ; $k$, masticatory ridge.
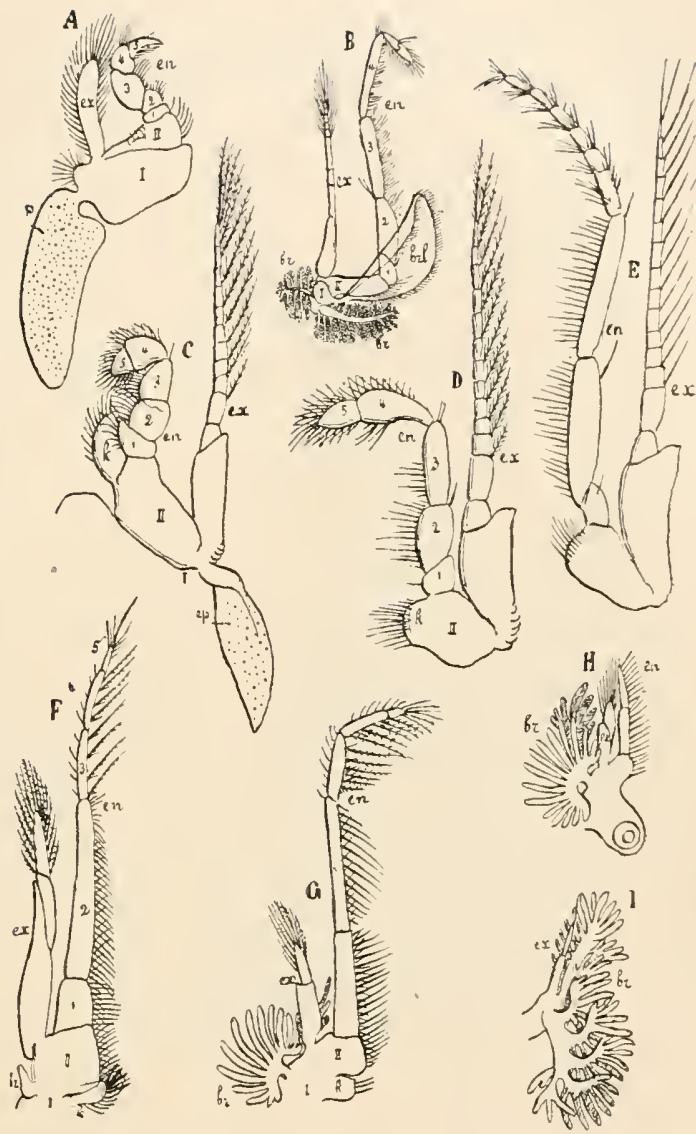

Fig. 222.Boreomysis scyphops ? (after G. 0 . Sars). The free portion of the cepl. alo thorax cut off at $x$ to show the free thoracic segments $I I$ VIII lying beneath with the branchial folds $b r$. aul,

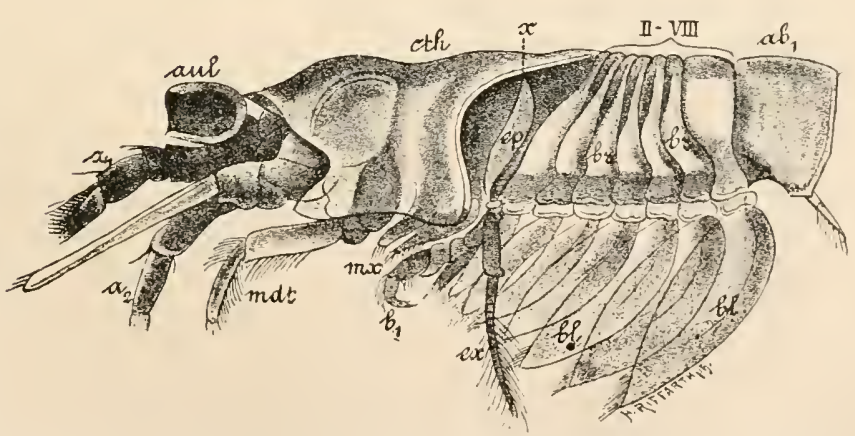

Cup-shaped ophthalmic lobe without eye (without pigment or visual apparatus); $a_{1}$, $a_{2.2}$, anterior and posterior antennæ; mdt, mandibular feeler; $m x$, maxille; $b_{1}$, lst thoracic foot with exopodite $(e x)$ and epipodite $(e p)$, the latter in the uncovered branchial cavity $b l$, brood lamella of the 2d-Sth removed thoracic feet; $a b_{1}$, lst abdominal segment ; $c t h$, cephalo-thorax. 
well-developed masticatory ridges. In contradistinction to the maxillipedes, the 5 posterior pairs of thoracie feet are described as ambulatory feet. The Decapoda owe to them their name. They are distinguished by the want of the exopodite, so

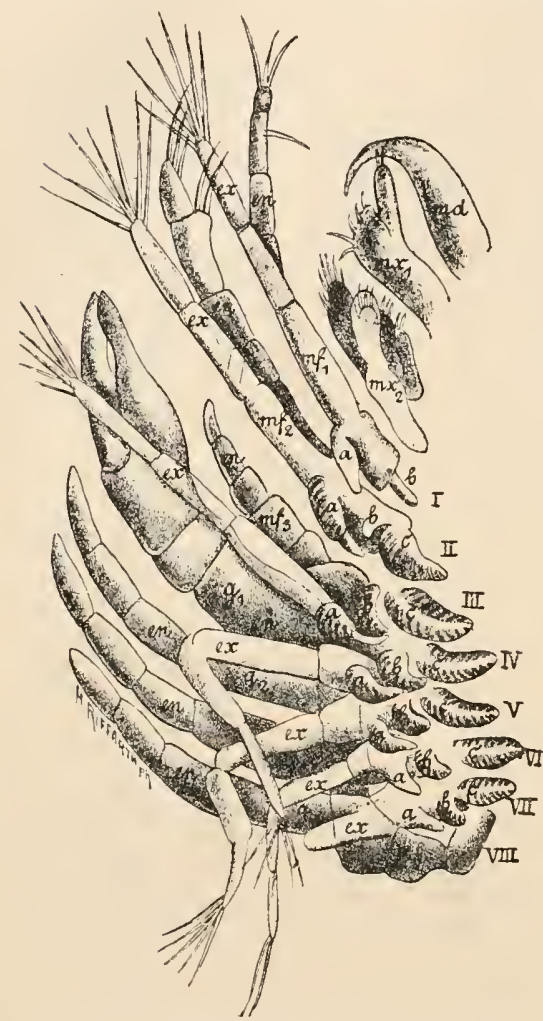

Fig. 223.-Older larva of Calliaxis in advanced Mysis stage. Gills and extremities of the cephalothoracic region (after Claus). $m d$, Mandible; $m x_{1}$, anterior, $m x_{2}$, posterior maxillæ; $I-I I I I$, thoracic feet, of which $m f_{1}=1$ st maxillipede, $m f_{2}=2 \mathrm{~d}$ maxilli. pede, $m f_{3}=3 d$ maxillipede, $g_{1}-g_{5}$, = ambulatory feet ; $c x$, exopodites; $c n$, endopodites; $a$, epipodites $=$ podobranchiæe $; \quad b$, arthrobranchice ; $c$, pleuro. branchiæ. which are better developed in the male (as copulatory feet) than they are in the female.

Isopoda.-The pleopoda of the Isopoda are biramose limbs, whose endo- and exo-pochites are unjointed, and generally delicate-skinned, lamellæ, which serve for respiration. The last (6th) pair of pleopoda either forms together with the last abdominal segment a rowing fin $(F)$, as in the marine Isopoda, or is stylet-shaped, as in fresh-water and land Isopoda. In the parasitic Bopyridec and Cryptoniscide the pleopoda are reduced or entirely wanting. In the land Oniscidce the outer lamelle 
of the anterior pleopoda contain air chamhers. In the Anisopode the pleoproda are biranose swimming feet, not serving for respiration.

Thoracostraca.--In the Stomatopoda we find on the strong abdomen 6 pairs of well-developed typical biramose pleopoda. The 5 anterior prairs are swimming feet, each of whose outer lamelle carries a branehed gill. The 6 th pair of pleoproda form with the telson ( 7 th abdominal segment) a strong caudal fin.

In the Cumaeca the 6th pair of pleopoda $\left(A, p_{6}\right)$ consists of long bifureaterl processes. The pleopoda of the 5 anterior abdominal segments are wanting in the female; in the male they are swimming feet $(H)$, and either present in their full numbers or in 2 to 3 pairs.

In the Schizopoda the 6th pair of pleopoda $(C)$ forms with the telson a eaudal fin. Where there is an auditory organ it lies on the imner lamella of this pleopod. The 5 anterior pairs of pleopoda are well-developed biramose swimming feet, in the male

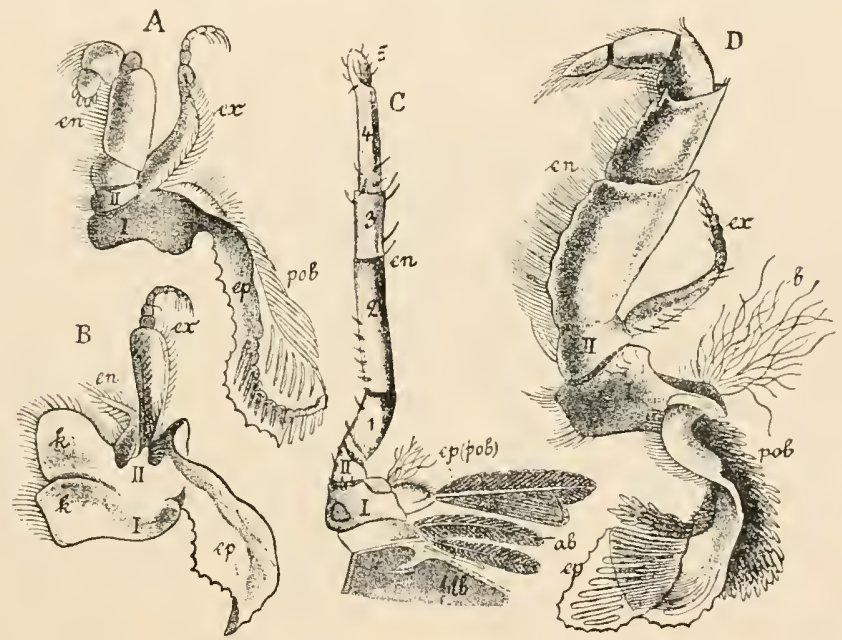

FIG. 224.-Thoracic feet of Astacus fluviatilis (after Huxley). A, 2d thoracic foot (21 maxillipede). $B$, lst thoracic foot (1st maxillipede). C, Part of trausverse section through the thorax, showing an ambulatory foot and gills. I), 3d thoracic foot ( $3 d$ maxillipede). $I$, $I I$, Juints of the protopodite; 1.5 , of the endopodite $e n$; $e x$, exolodite ; pob, podobranchire ; $a b$, arthrobranchix: $p l b$, pleurobranchiz; $k$, masticatory ridge.

at least. The 2 anterior pairs serve as eopulatory organs in the Euphausider. In the male of Siriella the pleopoda earry gills $(E)$.

Decapoda $(I-N)$. - The development of the pleopoda stands in direct relation to the development of the abdomen itself. In the long-tailed Decapoda (Macrura) of pairs of biramose pleopoda are generally found. The 6 th pair with the telson forms a strong eaudal fin. The 5 anterior pairs play no very important part in locomotion. In the Brachyura the pleopoda, in correspondence with the great reduetion of the abdomen, are reduced. A caudal fin is usually wanting. In the male only the 2 anterior pairs of pleopoda are found, in the female 4 pairs. The caurlal fin is generally redueed in the Anomura, and the pleopoda are truneated and only developer on one side. The 2 anterior pairs of pleopoda very generally serve in the Decapodan male as eopulatory organs. In the female the pleopoda often earry the eggs after their discharge and fertilisation. 


\section{The Respiratory Organs-Gills.}

Respiration always takes place in Crustaceans by means of the outer integument. In small Crustaceans, in which the cuticle lying orer the hypodermis is thin and delicate, the whole body sturface

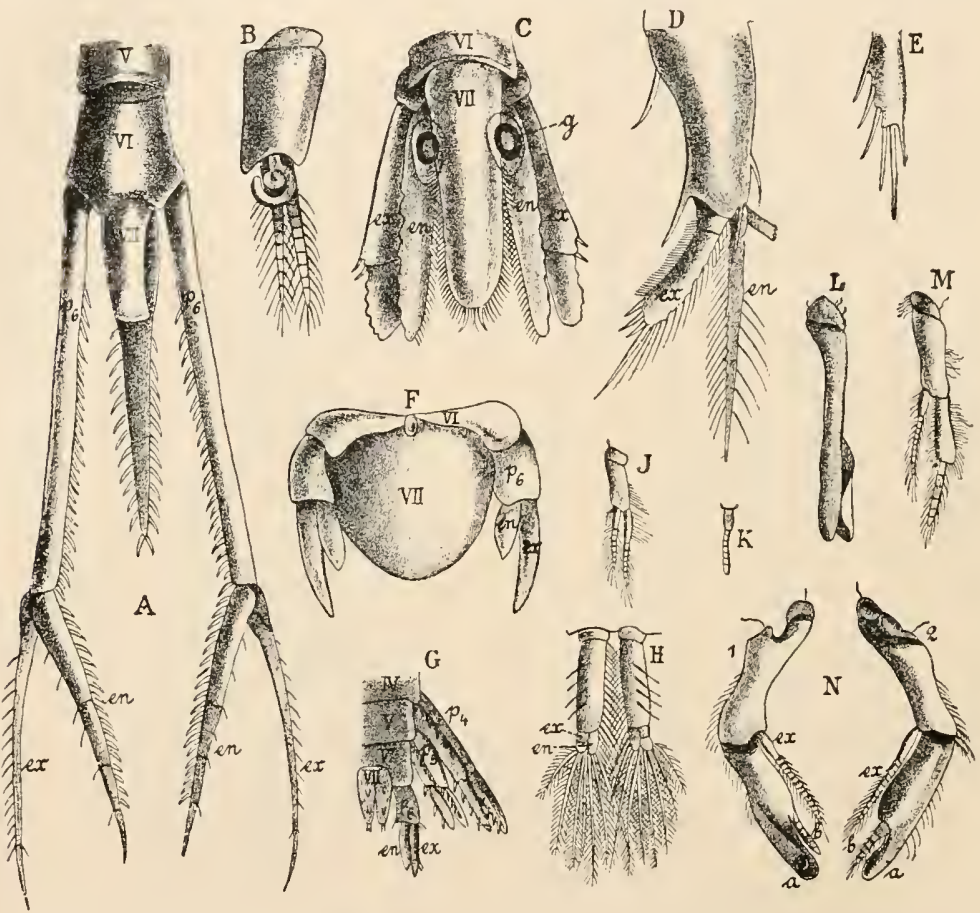

Fig. 225.-Pleopoda (abdominal feet) of Leptostraca and Malacostraca. $A$, End of the abdomen of Diastylis stygia (after G. O. Sars) ; $\Gamma$, $V I, V I I$, abdominal segments ; $V I I$, telson ; $\eta^{\prime}$, pleopoda of the 6th segment; en, endopodite; ex;, exppodite. $1,2 d$ pleopod with gills, exo-and endo-podite of Siriella Thompsonii (after G. O. Sars). C, End of the abdomen (caudal fin) of Siriella gracilis (after G. O. Sars); $V I$, 6th abdominal segment ; VII, 7th abdominal segment (telson); $c n, c x$, endo-and exo-podites of the 6th pleopoda, which together witl the telson form the caurlal fin; $g$, auditory organ. $D$, An anterior pleopod of Nebalia (after Claus); ex, exopodite; en, endopodite. E, Nebalia, 6th pleopod of the $\$$ (after Claus). F, Anilocra (Isopod), caudal fin ; $V I$, 6 th abdominal segment; VII, telson; $p_{6}$, 6th pleopod with exopodite $(c x)$ and endopodite (en) (after Delage). $G$, Lysianassa producta (Amphipod); end of the abdomen with the 4 th, 5 th, and 6 th pleopoda, $p_{4}, p_{5}, p_{6} ; I V, V, V I, V I I$, aboominal segments ; en, endo., ex, exo-podite (after Goes). $H$, Diastylis stygia, 1st pair of pleopoda ; $e x$, exo-, en, endo-podite (after G. O. Sars). $I-N$, Astacus fluviatilis. $I, 3 \mathrm{~d}$ pleopod of male; $K$, lst pleopod of female; $L$, st pleopod of male; $M, 3 d$ pleopod of the female; $N$, 2d pleopod of the male. 1, Anterior surface; 2, posterior surface; $e x$, exopodite; $a$, the rolled-up plate of the endopodite; $b$, jointed end of the endopodite (after Huxley).

breathes. This is especially the case in Ostracodu, Copepoda, many Cladocerc, and many Cirripedia, which have no specific respiratory organs.

In the great majority of Crustaceans, however, the respiration is particularly active at definite parts of the body, even if in addi- 
tion the whole integument or a large portion of the same is capable of respiration in a lesser degree.

The respiratory functions in the Crustacea, as elsewhere, are promoted and facilitated by various adaptations. Among these we must note (1) the increase of the respiratory surface, the outer integument, (2) the flowing of the blood to and from the respiratory parts, (3) adaptations which serve to bring about a continual change of the aerated water which bathes the respiratory parts, and (4) adaptations designed for the protection of the necessarily delicate-skimmed respiratory organs.

The principal increase of the respiratory surface is due to the integumental fold which rises so generally from the head and appears in very different forms as mantle, dorsal carapace, bivalve shell, or

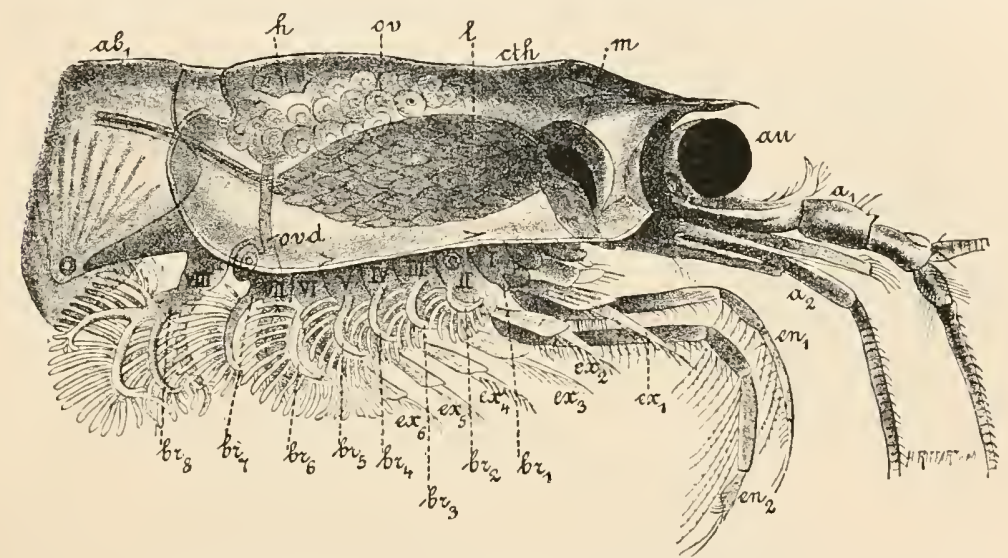

Fic. 226.-Euphausia pellucida $\nmid$ (after G. O. Sars), cephalo-thorax (cth) and first abdominal segment $\left(a b_{1}\right)$ from the side. $h$, Heart; ovt, oviduct; ov, ovary ; $l$, liver ; $m$, stomach ; $a u$, eye ; $u_{1}$, anterior, $a_{2}$, posterior antenna; $e x_{1}-c x_{6}$, exopodites of the 6 anterior thoracic limbs; $e n_{1}, e n_{2}$, endopodites of the 2 anterior thoracic limbs; the 4 following are not drawn; endo- and exo-podites of the 7 th and sth thoracic limbs rudimentary; $b r_{1} \cdot b r_{8}$, gills on the protopodites $(I-F I I I)$ of the thoracic limbs ; $b r_{1}$, first gill, a small epipodial appendage.

cephalo-thoracic shield. Wherever this fold remains soft-skinned it always helps in the respiration. It is often only the inner wall of the fold which remains soft-skinned, and we frequently meet with adaptations which serve for the purpose of setting in motion the water found in the cavity between the fold and the body (respiratory cavity). There are in Mulucostruce (Zocec levere, Tunaide, DIyside, Stomatopodu) epipodial appendages of the maxillie or of the anterior thoracic feet, which, during the movements of the limbs which carry them, vibrate and cause a stream of water in the respiratory cavity in which they lie. In a similar way in the Ostracodu the movement of the fan-like plates, the so-called branchial appendages, which may occur on the 4 th, 5 th, and 6th pairs of limbs, bring about a constant stream of water over the body surface. In the higher Malacostrace, especially in the 
Decupod", the integumental fold, which becomes very hard and thick, loses its respiratory significance, and as branchiostegite becomes a protective cover to the delicate gills which lie laterally in the respiratory cavity under it.

In the Balunide a pair of fold-like projections of the mantle stand out into the mantle cavity. These folds may again form numerous lateral folds, so that the mantle surface is very much increased. These formations have been assumed to be gills.

In some Cypridide (Ostracoda) the body carries on each side near

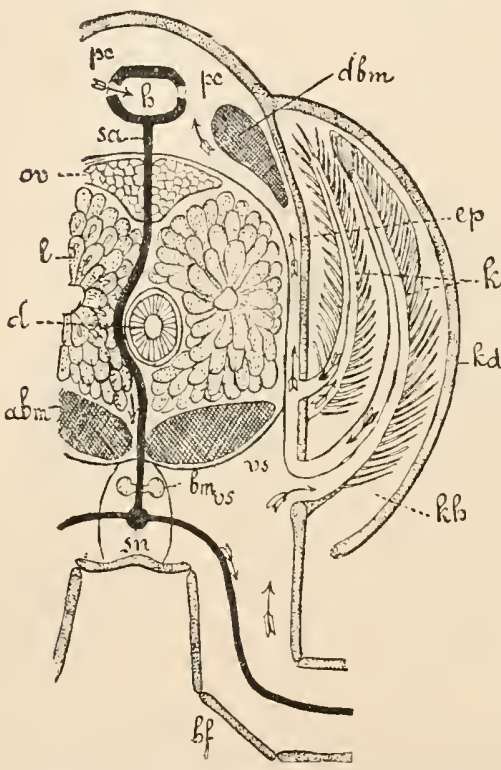

FIG. 22\%.-Transverse section through the cephalo-thorax of the Cray-fish near the heart, diagrammatic: $k \lambda$, Branchiostegite; $k$, gills ; $k h$, respiratory or branchial cavity; $e p$, lateral wall of the cephalo-thorax; $p c$, pericarlium ; $h$, heart; $s a$, sternal artery; $l$, hepatopancreas; $d$, intestine; abm, ventral longitudinal museles running to the abłomen; $a b m$, dorsal longitudinal muscles running to the abdomen; bm, ventral chord; $s n$, subneural vessel ; $b f$, ambulatory foot ; $v s$, ventral sinus; $o v$, ovary. The arrows indicate the direction in which the blood flows (after Huxley and Plateau). besides the delicate shell-fold, the lamellate thoracic feet function in a special manner as respiratory organs. Their two branchial plates (epipodite and exopodite) correspond with the branchial and respiratory plates of the Phyllopoda. The branchial plate (epipodite). of the proximal joint of the protopodite is morphologically equivalent to a Decapodan gill. the dor'sal middle line, under the shell, a row of small branchial lamella.

The function of respiration in the large majority of Crustaeeans is performed by the limbs or their appendages. This is comprehensible, since the change of the water caused by the movement of the limbs is of the greatest use in promoting respiration.

In many Lepadide among the Cirripedia the tendril-like feet have cylindrical or lancet-shaped appendages which with doubtful accuracy have been indicated as gills. They are found on the first pair or pairs, and occasionally on all of the tendril-like feet, and are usually inserted on them near the base.

The leaf-sliaped swimming feet of the Phyllopodu are very well suited for respiration. The appendages which are called gills and respiratory plates in this order have already been described. The gills of the Phyllopoder are epipodial appendages, perhaps corresponding with the gills of the Thoracostruece.

$$
\begin{aligned}
& \text { In the Leptostrace (Nebalia), } \\
& \text { late thoracic feet function in } \\
& \text { Their two branchial plates } \\
& \text { the branchial and respiratory } \\
& \text { ial plate (epipodite). of the } \\
& \text { rphologically equivalent to a }
\end{aligned}
$$


In the Isopodu the delicate-skinned lamelle of the pleopoda serve for respiration, either both the lamella of a foot or only the imner, the outer one being hard-skinned and serving as a covering plate to protect the inner one.

The gills of the Stomatopoda (Squilla) are found as branched
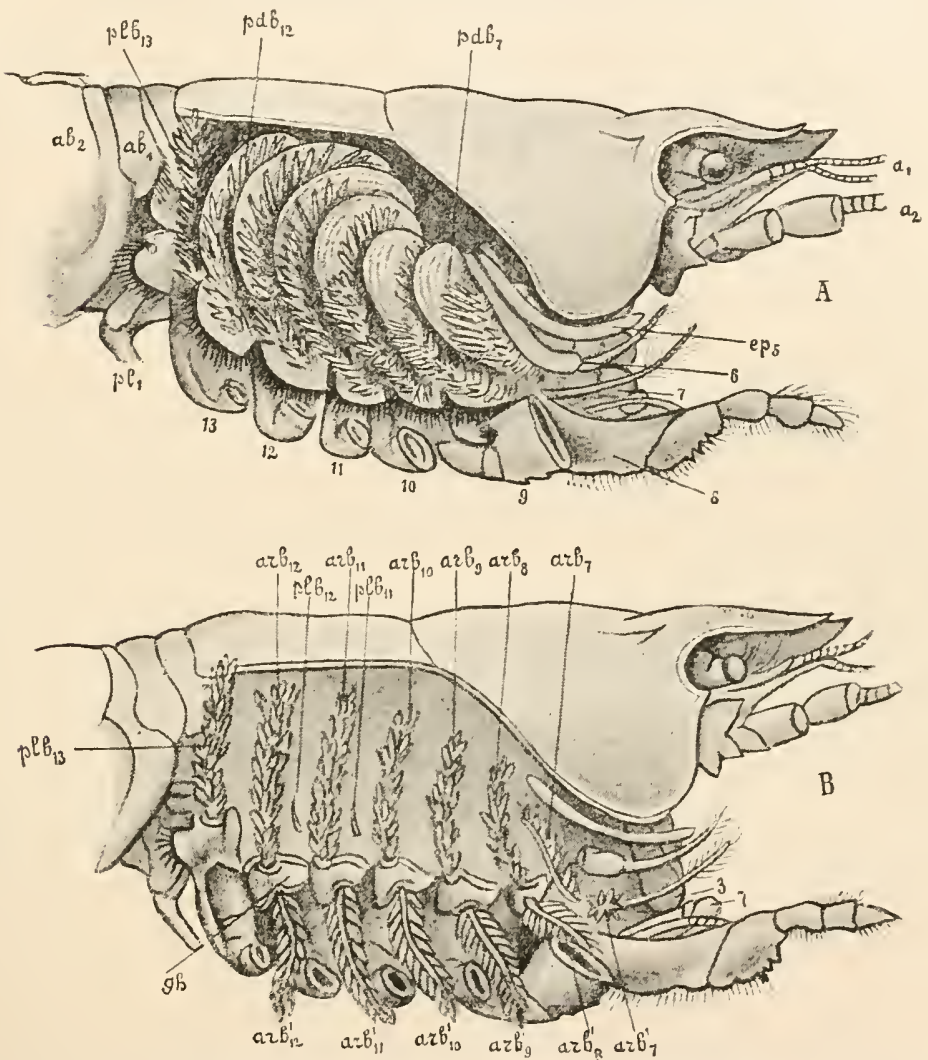

FIG. 228.- $A$ and $B$, Gills of Astacus fluviatilis. In $A$ the brancliostegite is removed. The gills are seen in their natural position. In $B$ the podobranchiæ are cut off, and the outer arthrobranchiæ turned back downwards. Twice the natural size. $a_{1}, a_{2}$, 1st and $2 \mathrm{~d}$ antennæ; 3 , mandible; $e p_{5}$, epipodite of the $2 d$ maxilla; 6 , 1st maxillipede; $7,2 d$ maxillipede; 8 , 3d maxillipede ; 9 , forceps (cut-off); $10-13$, the 4 succeeding ambulatory feet; $p l_{1}$, 1st pleopod; $a b_{1}, a b_{2} 1$ st and $2 d$ abdominal segments; $p d b$, podobranchia; $a r b$, inner, $a r b 1$, outer arthrobranchiæ; $p l b$, pleurobranchiæ ; the numbers attached show the appendages to which the gills belong, in order from before backward, beginning with the anterior antenna as No. 1 ; $g h$, articular membrane between the body and basal joint of the protopodite (after Huxley).

appendages on the outer lamellæ of the abdominal swimming feet (pleopoda). The arrangement of the gills in Siriella (Mysidce) is similar; they here also occur in the males as appendages of the pleopoda, but on their inner branches.

The gills of the Amphipoda, Schizopoda (except the Mysidce), and 
Decupode are always originally epipodial appendages on the basal joints of the protopodites of the thoracic feet. They may be considered as homologous formations, and perhaps correspond with the gills of the Phyllopodu and the basal branchial plates (epipodites) of Nebuliu.

The pouch-shaped Amphipodan gills have already been considered.

Schizopoda. - The branchial tufts of the Euphauside (Fig. 226), whose branches are feathered, project freely from the basal joints of the protopodites of the thoracic limbs into the surrounding water without being covered by the lateral lamellie of the cephalo-thoracic shield. The branching of the gills becomes increasingly complicated from the anterior to the posterior thoracic limbs. On the most anterior thoracic limb the gill is a simple aprendage.

In Lophogaster we find 2 to 7 such gills. These consist of 3 feathered branches, the upper one of which lies in a branchial eavity covered by the lateral lamella of the eephalo-thoracie shield. The gills are said not to rise direct from the basal joint of the protopodite, but close to it from the body. None the less they should be considered as dislocated epipodial appendages.

The gills of the Deeapoda (Figs. 227, 228) deserve more detailed description. Over the sides of the thorax to the right and left there is always an arched extension of the cephalo-thoracic shield, which, as branchiostegite (Fig. 227, $k d$ ), cover's a respiratory cavity $(k h)$ in which the gills $(k)$ lie. The branchiostegite extends ventrally to the points of insertion of the thoracic limbs, where the respiratory cavity on each side communicates by means of a longitudinal slit with the surrounding merlium. We distinguish in the first place, according to their manner of insertion, three sorts of gills-podobranchiæ, arthrobranchix, and pleurobranchiæ. The podobranchiæ arise from the basal joints of the thoracic limbs, the arthrobranchiæ from the articular membranes between the basal joints and the body, and the pleurobranchiæ from the body itself, but directly above the basal joints of the thoracic limbs to which they belong. All gills are to be considered phylo-genetically as epipodial appendages of the basal joints of the protopodites, the arthro- and pleurobranchiæ having moved from their original places. Agrain, we distinguish two sorts of gills, according to their special form, viz. trichobranchiæ and phyllobranchiæ. In the trichobranchiæ numerous branchial filaments stand round a common stem

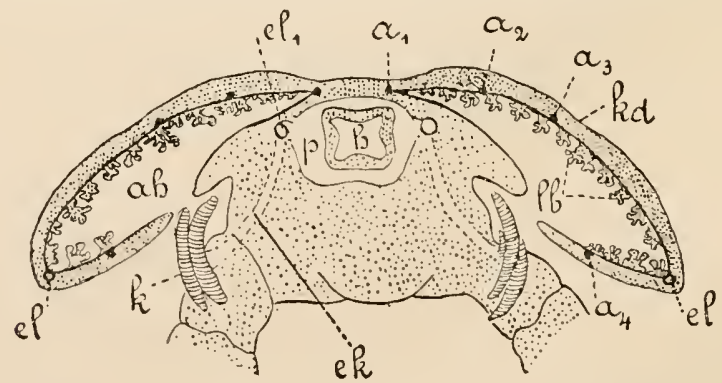

FIG. 229.-Birgus latro. Diagrammatic transverse section in the region of the heart (after Semper). $k d$, Branchial or lung cover ; $h$, heart ; $k$, gills ; $a h$, respiratory cavity ; $p$, pericardium ; $e k$, branchial blood-canals leading to the heart $; a_{1}, a_{2}, a_{3}, a_{4}$, lung or slell vessels leading from the heart; $l b$, respiratory tufts; $c l$, pulmonary vessels leading to the heart; $c l_{1}$, the same near their entrance in to the pericardium.

or a common axis, like the bristles of a bottle brush. In the phyllobranchiæ the branchial filaments are small lamellæ arranged in two rows on the stem, like the 
barbs on the shaft of a quill. Phyllobranchie and trichobranchire, between which there are many transitory forms, are not found together in the same specics. Trichobranchie are found in the Macrura (with the exception of the Sergestidce, Caridida, and the genera Gebia and Cullianassa); phyllobranchiæ are found in all Anomura and Bractynera, and in those Macrurce which do not possess trichobranchie.

Podobranchie, arthrobranchix, and pleurobranchire may occur together, even on the same thoracic segment. They undergo many modifications and degenerations. The arrangement of the branchial apparatus in the varions Decapodan genera and species may be given in branchial formulie. We shall here give the branchial formule of Astacus fluviatilis and of Cancer pagurus.

\section{Branchial Formula of Astacus fluviatilis (Cray-fish), after Huxley.}

\begin{tabular}{|c|c|c|c|c|c|c|c|}
\hline \multirow{2}{*}{\multicolumn{3}{|c|}{ Thoracic segments and limbs. }} & \multirow{2}{*}{$\begin{array}{l}\text { Podo- } \\
\text { branchie. }\end{array}$} & \multicolumn{2}{|c|}{ Arthrobranchia. } & \multirow{2}{*}{$\begin{array}{l}\text { Pleuro- } \\
\text { branchie. }\end{array}$} & \multirow{2}{*}{ Total. } \\
\hline & & & & Anterior. & Posterior. & & \\
\hline \multirow{9}{*}{$\begin{array}{l}\text { VI. 1st } \\
\text { VIl. 2d } \\
\text { VIII. } 3 \mathrm{~d} \\
\text { IX. } 1 \mathrm{st} \text {. } \\
\text { X. } 2 \mathrm{~d} \\
\text { XI. } 3 \mathrm{~d} \\
\text { XII. 4th } \\
\text { XIII. 5th }\end{array}$} & illi & & $0(\mathrm{ep})$. & 0 & 0 & 0 & $=0$ (ep.) \\
\hline &, & & 1 & 1 & 0 & 0 & $=2$ \\
\hline & & & 1 & 1 & 1 & 0 & $=3$ \\
\hline & ula & $y$ foot & 1 & 1 & 1 & 0 & $=3$ \\
\hline & & , & 1 & 1 & 1 & 0 & $=3$ \\
\hline &, &, & 1 & 1 & 1 & Rudim. & $=3+$ Rudim. \\
\hline &,, & , & 1 & 1 & 1 & Rudins. & $=3+$ Rudim. \\
\hline & & , & 0 & 0 & 0 & 1 & $=1$ \\
\hline & & & $6+$ ep. + & $6 \div$ & $5+$ & $1+2$ Ru. & $=18+\mathrm{e} p \cdot+2 \mathrm{R}$ \\
\hline
\end{tabular}

\section{Branchial Formula of Cancer pagurus (after Huxley).}

\begin{tabular}{|c|c|c|c|c|c|c|}
\hline \multirow{2}{*}{\multicolumn{2}{|c|}{ Thoracic segments and limbs. }} & \multirow{2}{*}{$\begin{array}{l}\text { Podo- } \\
\text { branchix. }\end{array}$} & \multicolumn{2}{|c|}{ Arthrobranchire. } & \multirow{2}{*}{$\begin{array}{l}\text { Pleuro. } \\
\text { branchiæ. }\end{array}$} & \multirow{2}{*}{ Total. } \\
\hline & & & Anterior. & Posterior. & & \\
\hline \multirow{2}{*}{\multicolumn{2}{|c|}{ 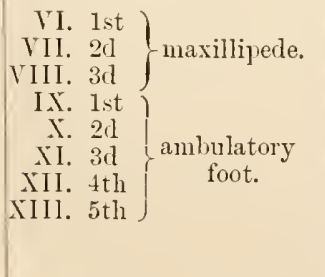 }} & $\begin{array}{l}0(\mathrm{e} p \cdot) \\
1 \\
1 \\
0 \\
0 \\
0 \\
0 \\
0\end{array}$ & $\begin{array}{l}0 \\
1 \\
1 \\
1 \\
0 \\
0 \\
0 \\
0\end{array}$ & $\begin{array}{l}0 \\
0 \\
1 \\
1 \\
0 \\
0 \\
0 \\
0\end{array}$ & $\begin{array}{l}0 \\
0 \\
0 \\
0 \\
1 \\
1 \\
0 \\
0\end{array}$ & $\begin{array}{l}=0(\mathrm{ep} .) \\
=2 \\
=3 \\
=2 \\
=1 \\
=1 \\
=0 \\
=0\end{array}$ \\
\hline & & $2+e$. & +3 & +2 & +2 & $=9+\mathrm{ep}$. \\
\hline
\end{tabular}

While in other Decapoda the water enters the respiratory cavity through the lower longitudinal slit, in the Braelyura the water passes in and out only throngh certain small apertures, which are variously placed. Many Brachyura and Anomure may live for a longer or shorter time or almost exchusive on land, and show various adaptations which make it possible for them to retain water in the respiratory cavity, or to draw back into that eavity water which leaves it, or to breathe air direct. It wonld lead us too far to describe all these adaptations in detail. We shall only consider the respiratory organs of Birgus latro (Anomura), which lives in holes in the earth (Fig. 229). The respiratory cavity of this animal falls into two rarts, an 
upper partly closed, and a lower more open, division, the lower edge of the branchiostegite being bent inwards and somewhat upwards. The reduced gills lie in the lower division. The upper division holds air and functions as a lung. The integument of the outer cover (branchiostegite) of this upper division carries a great number of branched tufts, projecting into the air-filled eavity, and containing complieated arrangements of raseular spaces. For the special relation of the vascular system to the respiratory organs in Birgus, see the section on the circulatory system.

The manner in which in the Crustacea the blood which has become poor in oxygen is conducted out of the body to the respiratory organs, and the blood rich in oxygen conducted out of the respiratory organs into the body, will be described in the section on the blood-vascular system.

\section{The Integument.}

The chitinous secretion of the hypodermis (body epithelium) which we met with in the Annulutu is eren more strongly developed in the Arthropoda. It covers the whole surface of the body and its appendages as a cuticle, serving not only for protection, but also as outer skeleton (exo-skeleton) for the attachment of the muscles. This chitinous envelope is very differently constituted in the different divisions of the Crustacea, sometimes even in different parts of the same animal. In most Decapode and Stomatopoda, many Amphipoda and Isopode, and on the shell-fold of Ostracoda and Cirripedia, however, the usually thick chitinons cnticle becomes very hard and firm by deposits of lime salts (carbonate and phosphate of lime); in certain Brachyura, Cirripediu, and Ostrucodu it is even as hard as stone. The cuticle is, however, always comparatively thin, delicate, and flexible between the joints and on the respiratory surfaces.

The constitntion of the exoskeleton presents obstacles to the growth of the body. These are overcome by moulting or ecdysis. Under the old exoskeleton a new one is developed, which is at first soft and extensible; but after the first has been thrown off it soon hardens. The metamorphoses of the Crustaceans take place by means of several repeated moults. In this process not only the outer chitinous integument of the body, but the cuticular lining of the alimentary canal also is removed and renewed.

The cuticle, of whose further structure we cannot here speak more in detail, is penetrated by fine perpendicular pores.

Dermal glands, which take part in excretion, a fact which may be proved by feeding with carmine, are very common, especially in soft-skinned Crustaceans.

It is hardly possible as yet to give a detailed comparative account of the structure and distribution of the various forms of glands. But we may give a few eases which for one reason or another are specially interesting.

The segmentally arranged ventral and leg glands of Eranchimus consist of small groups of dermal gland cells, found on the segments of the middle body. In every segment a pair of ventral glands are found on the outer sides of the double ganglion of the ventral chord, and a pair of leg glands in the basal lobes of the leg. The segmental repetition, the character as dermal glands, the position (in the region of the legs), and their rod-like secretion entirely justify the opinion that these glands are 
homologous with the spinning and setiparous glands of the Annelida and the coxal glands of other Arthropocta.

In the basal joints of the $S$ pairs of thoracic limbs of Nebalic hypodermal glands have been obscrved; it is probable that these perform excretory functions. Their position recalls the leg glands of Branchipus.

We may herc further inention-the dermal glands which occur in the basal joints of certain limbs of the Phronimidee; and the beautifully constructed dermal glands in the limbs of the Corophiidce ; the unicelhular dermal glands seattered in various parts of the body of Orichestia; the scattered dermal glands of the Anisopoda (Tanais, Apscudes); the hook glands of Caprollide; and the so-called cement glands of female Dccapoda, which lie on the ventral side of the abdomen, and whose hardening secretion serves for the attachment of the eggs.

In Tanais and the Corophizlce the secretion of the above-mentioned glands hardens in water, and prob. ably helps, by cementing together foreign particles, to form the tubes inhabited by these animals.

Special interest is claimed by the uni- and multi-collular dermal glands lying scattered under the chitinous cuticle of the Coryceide (Copepoda), because in them the connection of the gland cells with nerve fibres can be easily observed. A unicellular dermal gland with cuticular duct, which opens through a pore of the chitinous integument of the body, is in the Coryccide generally coupled with a terminal ganglion cell lying under a scnsory seta. The nerve which runs to this pair of cells divides into 2 threads, one of which is connected with the gland cell and the other with the ganglion cell.

\section{The Museulature.}

A continuous dermo-muscular tube, such as is characteristic of the worms in general, and specially of the Anmulata, is wanting in the Crustaceans, and indeed in the Arthropoda generally. The development
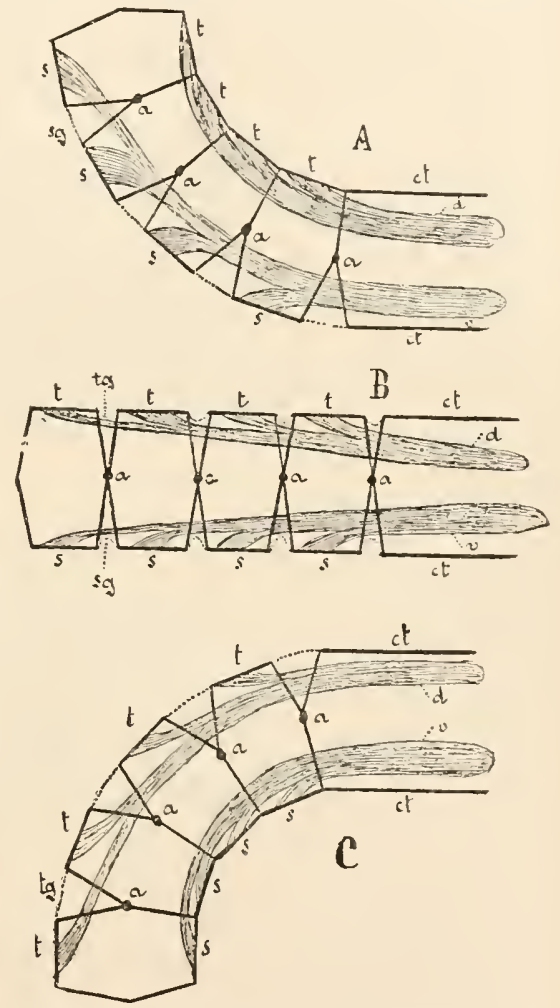

Fig. 230.-Diagrams to demonstrate the mechanism of the motion of the segmented body in the Arthropoda. One larger segment $(c t)$ and $t$ smaller. The exoskeleton is denoted by black lines, the interarticular nembranes by dotted lines. The hinges between consecutive segments are marked $a$. $t$, Tergal (dorsal) skeleton; $s$, sternal (ventral) skeleton; d, dorsal longitudinal muscles=extensors (and flexors in an upward direction); $v$, ventral longitudinal muscles=flexors. In $B$, the row of segments is stretched; in $A$, by the contraction of the muscle $d$, bent upwards; in $C$ downwards. tg, Tergal; sg, sternal interarticular membranes. of the cuticular integumental covering into a much firmer exoskeleton makes a greater localisation of the musculature possible. 
The may assume, that in the homonomous segmented ancestors of the Crustacea, whose conjectural organisation we have already in many points diagrammatically sketched, 4 strongly-developed longitudinal muscles ran through the body. Two of these muscles ran dorsally and two ventrally on each side of the middle line. They were segmented in correspondence with the segmentation of the body, and in such a manner that the single muscle segments or myomeres lay intersegmentally, i.e. with one end attached to the integument of one segment, and the other to the integument of the next following or next preceding segment.

We have no difficulty in assuming that the dorsal and ventral pair of longitudinal muscle strands answer to the 4 similarly placed masses of longitudinal muscles which occur in the Polychceta. Wc can find nothing, certainly, corresponding with the circular musculature of the Annclida. Traces of the latter may perhaps, however, be seen in the muscles which run at right angles to the longitudinal muscles, and which are attached on the one hand to the integument of the body, and on the other to the basal portion of the appendages which they move.

Setting aside at first the muscles belonging to the inner organs, we can arrange the whole musculature of the body in three principal groups, viz. (1) the musculature of the body, (2) the musculature of the limbs, and (3) the musculature common to both.

The formation and segmentation of the body and limbs in different divisions varies so much in details that a comparative review of the musculature cannot be attempted. We may, however, explain the principle according to which the muscles are arranged, and perform their functions not only in all Crustaceans, but universally in all Arthropoda. We have to bear in mind-(1) that the passive locomotory organ, the skeleton, is in the Arthropoda an exoskeleton, which is in each segment of the body and in each joint of its extremities a chitinous tube; (2) that the muscles lie on the inner side of the skeleton, and are attached to the same from within; (3) that the muscles are stretched intersegmentally, i.e. between the consecutive segments; (4) that the chitinous integument between two segments is thin and flexible, forming the interarticular membrane; (5) that the tubular exoskeleton of two adjacent segments or joints is hinged together in each case at two transversely opposite points.

The arrangement and working of the musculature is illustrated by Fig. 230, which shows us 5 segments, one larger $(c t)$ and 4 smaller, in vertical projection. The firm hard portions of the exoskeleton are marked by strong outlines, the delicate and flexible interarticular membranes $(t g, s g)$ by dotted lines. The hinges between 2 consecutive skeletal segments are marked $\boldsymbol{~}$. Such a hinge is found on each side ; in the projection the corresponding right and left hinges are seen as one. A dorsal muscle $(d)$ is attached to the larger segment $(c t)$, and runs through the smaller segments, being inserted in the dorsal or tergal skeleton $(t)$ of each by means of a bundle of fibres. A ventral muscle $(v)$ does the same on the ventral or sternal side $(s)$. 
The skeletal segments may be compared to a double-armed lever whose fulcrum lies in the hinges. If the dorsal muscle contracts, it draws the dorsal arm of the lever (the tergal portion of the skeleton) in the direction of the pull towards the larger segment; the tergal interarticular membranes become folded, the ventral stretched, and the 4 segments bend upwards (Fig. $230, \lambda$ ). If the rentral muscle contracts, while at the same time the dorsal slackens, the row of segments will be bent downwards (Fig. $230, C^{\prime}$ ).

It is evident that the same effect would be attained if the dorsal
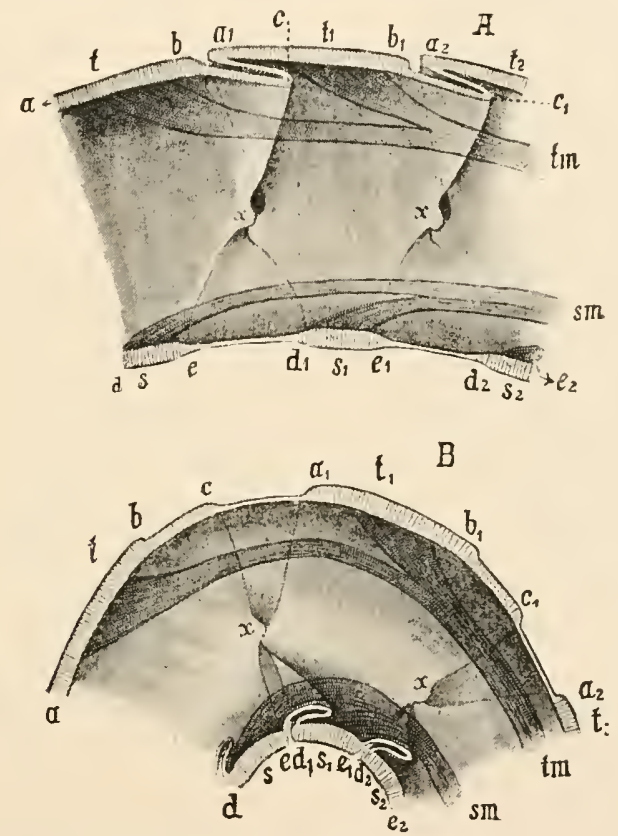

Fig. 231.-Two abdominal segments of the Cray-fish, diagramnatic. $t, t_{1}, t_{2}$, Tergal; $s, s_{1}, s_{2}$, sternal exoskeleton; $x$, hinges; $b-c, b_{1}-c_{1}$, articular facets, which when the row of segments is straightened take the position shown in $\mathrm{B} ; a_{1} \cdot b_{1}, a_{2}-b_{2}, c-a_{1}, c_{1} \cdot a_{2}, e-d_{1}, e_{3}-d_{2}$, interarticular membranes ; $t m$, tergal ; $s m$, sternal longitudinal muscle. $A$, Row of segments nearly straiglitened ; $D$, Row of segments bent ventrally by the contraction of the sternal longitudinal muscle, stretching the intertergal membranes.

and ventral muscles, instead of collectively rumning from the smaller segments to the larger segment, only ran from one segment to the next following, as we assumed to be the case in the racial form, and as is really the case in the thorax and abdomen of many Crustaceans (Branchipus, many Isopoda, Amphipoda, etc.) The row of segments would then likewise bend dorsally on the contraction of the dorsal myomeres, and ventrally on the contraction of the ventral.

In reality only the ventral bending takes place in the Crustacea; the comparatively weakly developed dorsal longitudinal muscles serve only for straightening the 
borly, as we see from the movements of the abdomen of the Cray-fish (Figs. 231 and 232). In its normal position the abdomen is somewhat stretched, and lies more or less as a straight posterior prolongation of the cephalo-thorax. Each dorsal (tergal) skeletal segment (Fig. 231, $A, t, t_{1}, t_{2}$ ) has its most anterior somewhat thinner portion $\left(b-c, b_{1}-c_{1}\right)$ pushed some distance under the posterior edge of the preceding segment.

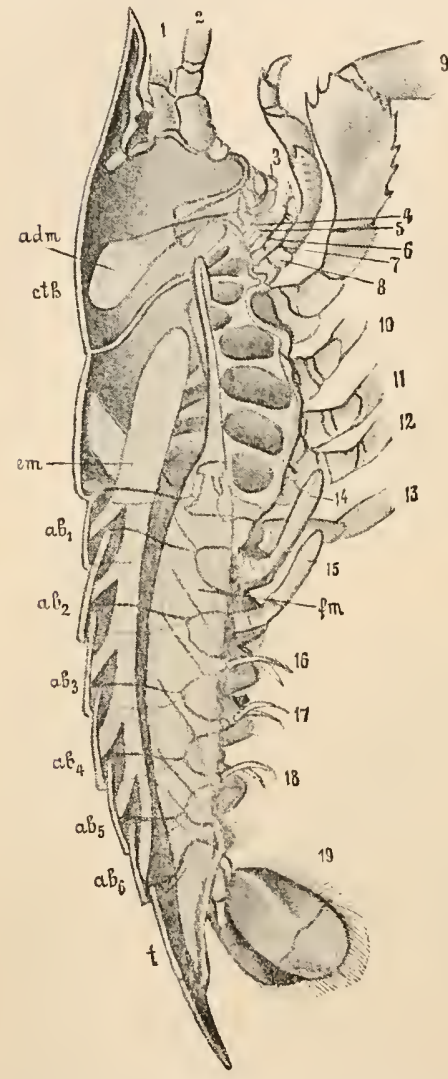

F1G. 232.--Astacus fluviatilis. Longitudinal section to represent the most important muscles and their relation to the exoskeleton (after Huxley). cm, Ex. tensor; fm, flexor of the abdomen; adm, adductor of the mandibles; cth, cephalothorax; $a b_{1}-a b_{6}$, abdominal segments; $t$, telson; 1.19, limbs, 1-13, of the cephalothorax, 14-19, of the abdomen.
The interarticular membrane $\left(c-a_{1}, c_{1}-a_{2}\right)$ bcing lient backwards and outwards. The ventral 9 lard skeleton consists of relatively narrow transverse segmental stripes $\left(d-c, d_{1}-c_{1}, d_{2}-c_{2}\right)$, connceted by large intersegmental membranes $\left(c-d_{1}, c_{1}-d_{2}\right)$, which in a state of rest are somewhat stretched. The pair of dorsal muscles $(t m)$ are attached on the one hand anteriorly to the lateral walls of the eephalothorax (corresponding with the large segment of our diagram, Fig. 230), and inserted, on the other hand, by just as many pairs of bundles as there are abdominal segments, to the inner surfaces of the terga, a pair of muscles being inserted in each.

The pair of ventral or sternal muscles ( $\mathrm{sm}$ ) are attached antcriorly to the ventral side of the cephalo-thorax to a row of processes of the exoskeleton directed inwards, and partly bound together by transverse ridges, which roof over the thoracie portion of the ventral chord and the sub-neural vessel. Posteriorly the sternal longitudinal inuseles are successively inserted on the inner sides of the sternal skeleton of the abdominal segments. The fibres of this muscle are twisted like the strands of a rope.

If the pair of sternal or flexor muscles contracts, the abdominal row of segments corresponding with our diagram bends ventrally (Fig. 231, $B$ ) till, as is the case in swimming, the telson tonches the ventral side of the cephalo-thorax. While in this position the intersternal membranes of the abdomen are folded, the whole tergal integument is stretched, and the tergal articular facets anil interarticular membranes are drawn out from under the terga which cover them, and come freely to the surface. If now the sternal muscle slackens, and the pair of tergal or extensor muscles (Fig. 231, $A$; Fig. 232) contracts, the abdomon is straightened, the terga pass under one another like the tiles of a roof, and the intersternal membranes are stretched. A dorsal bending of the body is impossible, first because the intersternal membranes do not allow of further stretching, and secondly, because the terga can only be pushed one beneath the other as far as the posterior limit of their articular facets. This is best exemplified by the illustration (Fig. 231, A). 
The mechanism for the movement of the appendages is in principle the same as that of the body. It is, lowever, crident that if the hinges of the joints of an appendage were arranged at equal distances along two parallel straight lines the row of joints of the extremity could only bend in one plane, as is indecd the case in the row of body segments. But the two hinges of the consecutive joints are in reality so placed as to make free movement possible. The exoskeleton of the body segments is rclated to the exoskeleton of the basal joints of the appendages which it carries just as a large joint of a limb is to a smaller. The muscles which on the onc hand are inserted in the exoskeleton of the first joints of the extremities, by preference attach themsetves on the other to the tergum of the corresponding segment.

The mechanism of the forceps (chcli) of the Cray-fish (Fig. 233) is as follows. The forceps is formed by the two terminal joints of the chelate foot. The last joint but one is produced into a pointed process $(z f)$. The last joint $(e g)$ articulates with it in the ordinary way by means of two opposite hinges.

Romnd the hinges the two joints are connected by means of a thin and flexible interarticular membrane. Two muscles serve in the way shown in the illustration
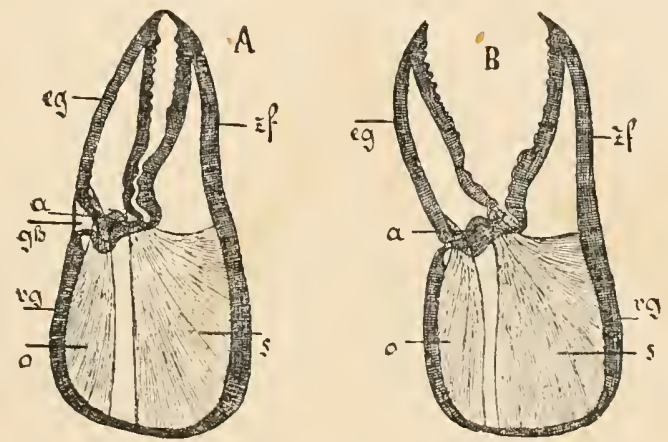

Fig. 233. - Forceps of the large chelate foot of the Cray-fish, diagrammatic. A, closed. $I$, Open. $e g$, Terminal joint; $v g$, last joint but one with the pincer lirocess $z f$; $a$, linge on which the terminal joint moves; $g h$, interarticular membrane; o, opening muscle (abductor); $s$, closing muscle (adductor).

for moving the terminal joint. By the contraction of the smaller the movabic joint describes an arc away from the fixed process (Fig. 233, $B$ ), opening the forceps. If the much stronger muscle which lies on the other side of the hinge contracts the chela closes $(A)$.

The muscles of Crustaceans are often attached to the exoskeleton by means of sinewy and even chitinous terminal pieces. In the latter case we can speak of an endoskeleton. Both arrangements serve for the increase of the surface of attachment of the muscles.

In those Entomostraca in which the strongly-developed shell-fold surrounds the whole body as a bivalve shell (Ostracola, Estheridce), a strong shell-muscle connecting the two valves transversely serves for closing the shell. We find such a shell-muscle among the Malucostract, also in the Leptostraca (Nebalia).

As in all Arthropoda, the body musculature is transversely striated. 


\section{The Enteric Canal.}

The intestine of the Crustacea has a simple straight course through the body. The mouth lies on the ventral side of the head, bordered and protected by an upper and an under lip (paragnatha); it is surrounded by appendages which serve for the taking in of food (mandibles, maxilli, and maxillipedes). The anus is found in the terminal segment of the body. We must distinguish, according to their ontogenetic origin and structure, 3 sections in the intestine: the fore-gut, the hind-gut, and the connecting mid-gut. The fore- and hindguts, proceeding respectively from the ectodermal stomodæum and proctodrum of the larva or embryo, are lined internally by a chitinous cuticle (intima). This cuticle, secreted by the hypodermis, passes at the mouth and anus into the chitinous exoskeleton. Only the epithelium of the mid-gut, which proceeds from the mesenteron, is of endodermal origin. The mid-gut in almost all Crustaceans is distinguished by the possession of diverticula which play the part of a hepatopancreas.

As in other divisions of the animal kingdom, so also in many Crustaceans, pronounced parasitism has brought about a degeneration of the enteric canal. In the parasitic Cirripedic we find various stages of degeneration leading to the condition of the Rhizocephala, in which an enteric canal is wanting not only in the adult animals, but also in the free-swimming larve. In the parasitic Isopoda the hind-gut with the anus, and sometimes a large part of the mid-gut as well, may entirely disappear.

\section{A. The Fore-gut.}

There is a characteristic difference between the condition of the fore-gut in Entomostrace and Malucostraca. In the former it is a simple alimentary tube (œsophagus), which, passing between the œesophageal commissures, runs dorsally, to pass later into the mid-gut which runs backwards. In the Malucostruca, on the contrary, it falls into at least two divisions, that which follows the buccal cavity, the ascending narrower œsophagus, and the broader masticatory or fore-stomach which lies in the head, and which leads to the mid-gut. Special salivary glands entering the esophagus seem generally to be wanting in the Crustacea (such glands have only been observed in Crayfish), but glands emerging on the upper lip, in the buccal cavity, and on the maxillæ, are common; these are usually called salivary glands. They probably belong to the category of the leg-and the other dermal glands.

For the present we set aside the special modifications which the fore-gut may undergo; its structure is essentially the following. Its wall consists of a layer of hypodermis cells, which rest upon 
an outer, often chitinons, basal membrane, and secrete, like the hypodermis of the integument, internally, a chitinous cuticle (intima). The fore-gut is embraced by circular muscular hoops, serving to narrow its lumen; groups of muscles, mostly paired, attached on one side to the intestinal wall, on the other to a portion of the neighbouring integument, effect its expansion and other movements. The hypodermis of the cesophagus is often difficult to discover.

Entomostraca.-The end of the resophagus often projects in the form of a cone or funnel into the first part of the mid-gut, somewhat as does the uterus of a mammal in to the vagina. This projection, which in Brenchimes is bi-lobed, and set with small cuticular papillæ, perhaps corresponds with the masticatory stomach of the Malacostrace.

The intima of the esopliagus is generally longitndinally folded, which permits of its enlargement.

In the Ostracoda the oesophagns may be enlarged before passing into the mid-gut into a so-called crop.

In the Lcptudorce (Daphnidce) two divisions have been distingnished in the foregut, an ascending pharynx and a strikingly wide cesophagns rmming backwards. This latter may perhaps belong to the mid-gut.

Malacostraca. - The possession of a masticatory or fore-stomach is characteristic of the Crustacea belonging to this second principal division. It is found in the Leptostraca, though in a somewhat simpler form than in the other. Lulacostracu. The masticatory stomach is a spracious sac of varying form. It is chiefly distinguisherl by the fact that its wall projects into its cavity in the form of definitely arranged folds, ridges, valves, plates, lamellæ, and other prominences, on which the chitinous intima is specially strongly developed, so as together to form a very complicated framework. The special form of the masticatory stomach, with its projections, ponches, etc., and its chitinous framework, is cxtremely important in classification. A more detailed account, however, wonld take far too much space. The masticatory stomach generally falls into two divisions, an anterior cardiac division, into which the cesophagus enters, and a posterior pyloric division, which opens into the mid-gut. In the anterior division the food which has already been torn in pieces by the oral appendages is still further cut and ground up by the masticatory framework, and the digestion takes place chiefly in the posterior division, into which the secretions of the glands of the mid-gut enter. ${ }^{1}$ The special formation of the wall with its chitinous framework, in this second division, both hinder's too rapid passage of the food to the mid-gut, and prevents its return into the masticatory stomach.

The parts of the masticatory framework are moved by suitably arranged muscles, which are attached to the neighbouring integument.

In many parasitic Isopoda, which suck in food in a fluid condition, the masticatory stomach is much simplified.

The intestine of the Entoniscidce will be described at the end of this section (p. 341 ).

In the Decapocta, on the anterior wall of the cardiac division of the masticatory stomach, are found two concretions, principally consisting of carbonate and phosphate of lime; these are the so-called crab's eyes or gastroliths. In 
the Cray-fish they are developed in summer and are largest just before the skin is cast. During this jrocess they reach the cavity of the masticatory stomach, are there ground up, dissolved, and re-absorberl. It is highly probable that they yield the calcarcous material for the hardening of the new after the casting of the old skeleton.

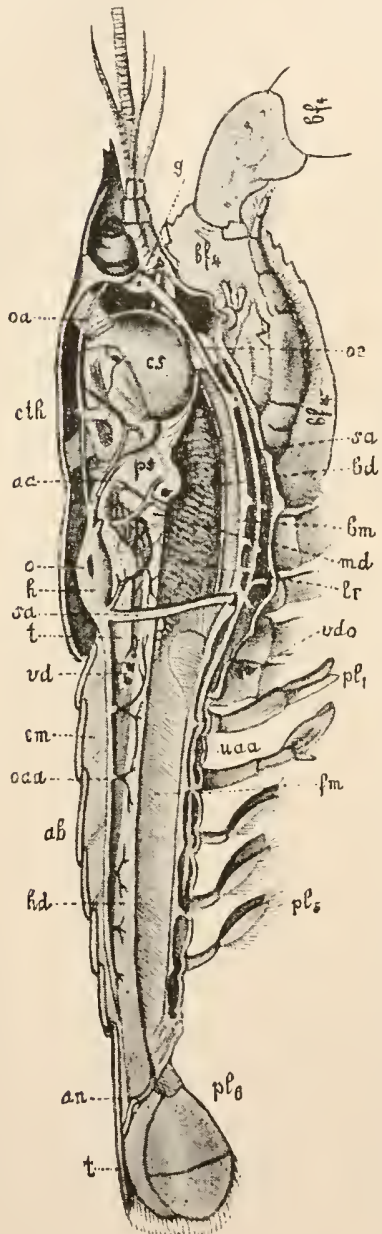

The whole intima of the fore-gut, together with the complicated chitinous framework of the masticatory stomach, is removed when the integument is shed; it is vomited from the mouth.

\section{B. The Mid-gut.}

This represents the endodermal portion of the enteric canal, and its epithelium shows clearly its endodermal origin even in the adult, being differently constituted from the ectodermal epithelium of the fore- and hindguts. The mid-gut again differs from the two other divisions of the intestine in having no chitinous intima answering to the outer chitinous cuticle of the body. It is nearly always distinctly marked off from the fore- and hind-guts by constrictions or valve-like arrangements. Besides this its anterior end, and occasionally its posterior end also, is marked by the entrance of glandular diverticula which represent invaginations of its wall. These, among which the hepatopancreas of the higher Malucostruce shows the greatest development, we shall describe in the section on the diverticula of the mid-gut. The form and extension of the mid-gut are very varied, while in the Entomostruct and many Malucostrace it represents by far the largest portion of the enteric tube, rumning from the head to near the posterior end of the body; it has in other Alule-

FIg. 234.-Astacus fluviatilis, median section of the body, seen from the right side. The thoracic feet and antenne of the left side are incompletely drawn (after Huxiey). oa, Ophthalmic artery (aorta cephalica); aa, antennal artery ; cth, cephalo-thorax ; 0 , lateral ostium of the heart; $h$, heart; $s a$, sternal artery; $t$, testes ; $v d$, vas deferens ; em, extensor muscles of the abdomen ; occt, upper abdominal artery (arteria abdominalis); $a b$, ablomen; $h d$, hind-gut; $a n$, anus; $t$, telson; $g$, brain (supra-osophageal ganglion); $b f_{4}, 4$ th thoracic foot (chelate foot); oc, cesophagus ; cs, cardiac portion of the stomach; $p s$, pyloric portion of the stomach; $b c$, right aperture of the hepatopancreas into the stomach; bm, ventral chord; md, mid-gut; $l r$. liver (hepatopancreas); $v d o$, male genital aperture; $p l_{1}, p l_{5}, p l_{6}, 1$ st, 5 th, and 6 th $p_{\text {leopoda }}$ uce, lower abdominal artery; fm, flexor muscles of the abdomen. 
costrace (at least in the Decupuda, Isopoda, and probably also in the Anisopodu) ahmost entirely disappeared as a special division of the enteric tube. It is here used up in the formation of its strongly developed glandular diverticula, the hepatopancreatic tubes. In these cases the hind-gut which proceeds from the ectodermal proctodreum represents by far the largest portion of the enteric tube, running through the body from the masticatory stomach to its hindermost end.

The fact that in the Isopodu and the Decapoda the whole enteric tube with the exception of the point of entrance of the hepatopancreas, proceeds from the cmbryonic or larval stomodxum and proctodeum is ontogenetically established; in the other Malacostrace ontogenetic investigations as to the limit between mid-and hind-guts have yet to be made. Up to the present time conchsions as to the extent of the hind-gut have been based exchusively npon that of the chitinous intima.

The walls of the mid-gut and of its diverticula show the same general structure. The distinct epithelium is placed on a basal membrane and sometimes shows on the surface turned towards the lumen of the intestine a (non-chitinous) cuticular limiting membrane. On the outer side of the basal membrane the mid-gut and its diverticula are encircled by hoop-like, regularly repeated, circular muscles, which are seldom transversely striated. Longitudinal muscles are more rare, and where they occur are not numerous. They lie on the inner side of the circular muscles. In life we can observe, not only in the mid-g'ut but also in its diverticula, rhythmical waves of contraction, which are often very strong; these also bring about, especially in the smaller Entomostrace without hearts, a sort of circulation of hremolymph in the lacunar system of the body.

\section{The Mid-gut of the Entomostraca.}

This generally falls into an anterior widened division (stomach, chyle stomach, stomach-intestine) and a posterior narrower division which we might designate the small intestine. The diverticula of the mid-gut, present usually in a single pair, open into the former division.

The details of the arrangement of the mid-gut diverticula of the Entomostrace are rery varied. The two diverticula of the Branchiopoda are themselves subdivided. They vary greatly in size. In Apus they have lateral branches beset with numerous glandular lobes. In the Cladocerce (Fig. 192, p. 289) two short horn-like diverticula are generally found, which are directed forwards. In the Ostracoda the two diverticula are so long that they often project on both sides into the shell fold. Diverticula of the mid-gut are wanting in a good many Copepoda; in others they are fresent singly or in pairs, simple, or elsc complicated by the formation of accessory ceea. The arrangement of the two diverticula of the dise-shaped flattence Branchiura (Argulus) (Fig. 195, p. 291) recalls that in many Branchiopoda. Each of the two diverticula divides first into an anterior and a posterior branch, each of which again branches, and the branches penetrate as far as the lateral edges of the cephalo-thorax. In the generally longitudiually folded stomach of the non-parasitic Cirripedes diverticula also not unfrequently enter ; Balanus has $S$ diverticula, which may be branched (D. perforatus). 


\section{The Mid-gut Diverticula of the Malacostraca.}

Among these we shall first distinguish those which enter at the anterior end of the mid-gut from those which enter at the posterior end. The former are universal. They correspond with the mid-gut diverticula of the Entomostrucu, and are generally called livers. Taking into account their physiological activity, however, the name of hepatopancreas is more suitable.

In the Leptostraca we find 4 pairs of hepatic tubes, 3 pairs of which, one upper, one lateral, and one lower, are very long and run along the mid-gut, reaching far into the abdomen. The short 4th pair stretches to the front of the head. The

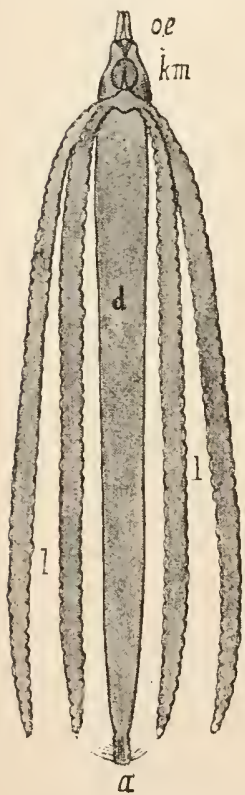

Fig, 235. - Enterio canal of Asellus aquat. icus (after G. O. Sars). oe, Esophagus; $\mathrm{km}$, inasticatory stomach; $l$, mid-gut; $a$, anal-gut (rectum); $l$, hepatic tubes (hepatopancreas). tubes join on each side to form a short wide sinus, and these sinuses, uniting at the two sides, enter by a common aperture the posterior end of the masticatory stomach ventrally.

In the Arthrostraca also there are 1 to 3 pairs of diverticula entering the begimning of the mid-gut which is occasionally widened so as partly to surround the masticatory stomach. Among these there are often 2 (in the normal Amphipoda 4) tubes rumning backwards along the intestine, which, aceording to their function and the structure of their epithelium, specially deserve the name of a hepatopancreas.

The arrangement of the glands of the mid-gut in the Sthizopode, the Cumacer, and the larvæ of the Decopode is similar to that in the Leptostraca and Arthrostrace. They are distinguished by 3 pairs of long hepatic tubes entering the most anterior portion of the mid-gut. In the Stomatopoda, distributed along the whole length of the mid-gut, there are 10 pairs of branched tufts of hepatic tubes. The adult Decapoda are distinguished by the possession of a paired hepatopancreas, which to the right and left enters the posterior and lower end of the masticatory stomach. By means of much branching the liver assumes the character of a very voluminous tubular gland filling a large part of the cephalo-thorax, and falling on each side into 3 lobes-an anterior, a lateral, and a posterior. If we examine only the extreme forms of the cells which unite to form the epithelium of the Malacostracan liver, we can distin. guish two sorts of eells : first, ferment cells, whose raried secretions (which may be liquid or solid, coloured or colourless) digest fibrine; second, hepatic cells, whose fatty secretion contain a colouring matter related to the gall pigment of vertebrates. In consequence of these obscrvations we cannot describe the slands of the mid-gut simply as a liver, but rather as a hepatopranereas. We cannot, also, carry out a sharp distinction of the cells into ferment cells and hepatic cells; many transition forms oceur.

The glandular cieca which enter the posterior end of the mid-gut are found in the Amphipoda, i.c. in the Caprollide and the Crevettina. They occur as one pair, except in Mclitu, which has only one such glandular tube. Physiologically they must (in the ('rcecttina) be considered as urinary glands. Morphologically they cannot he comprared with the Malpighian ressels of the Trachcata, since they do not belong to the hind-grut, but to the mid-gut.

In the posterior portion of the mid-gut of Nobulia there is at the imer side of 
the dorsal enteric wall a longitudinal chamel, which, at the end of the mid-gut, is continued into a cxecum, reaching into the anal segment posteriorly, and enrling in two lateral projections.

\section{The Hind-Gut.}

The hind-gut in Crustaceans is as a rule slort and limited to the last segment or segments of the body. Its epithelium is lined with a frequently very strong chitinous intima. Its wall is almost always provided with well-developed hoop-like circular muscles. Special muscles or groups of muscles (dilators) are stretched between the hind-gut and the neighbouring integument (and widen the former by their contraction). In those Isopoele, Anisopoda, and Decapodu in which the hind-gut is very long, taking the place of the small intestine of other Crustacea, we find these dilators only at the posterior differentiated division of the hind-gut, called the rectum.

Among the Amphiporla, Orchestia has a hind-gut which is strikingly long for this group, reaching as far forward as into the 7 th thoracic segment.

The anus lies in the terminal segment-dorsally in the Entomostraca, ventrally in the Malacostraca.

Special glands or diverticula entering the hind-gut are wanting in the Crustacea.

In the Lynceidee among the Cladocera, however, a glandular contractile cecum is found ventrally in the hind-gut, which in Plcuroxus is prolonged into a long vermiform appendage wound round the gut.

In the stometopode it is said that 2 glandular saccules enter the anal gut. As other excretory organs arc wanting in the adult animals these are supposed to have excretory functions.

In the meantime it is not certainly proved that these glands of the Lynceide and Stomatopode really belong to the hind-gut and not rather to the terminal division of the mid-gut.

The widening of the hind-gut on the contraction of the dilators draws in water through the anus, and subsequent contraction of the lumen of the gut expells it again with frecal particles. It has been stated without sufficient foundation that these sucking morements, at least in certain Entomostraca (Phyllopoda), imply a respiratory function in the hind-gut.

The chitinous intima of the hind-gut is ejected through the anus when the integument is shed.

The peculiar modification which the enteric canal undergoes in the females of many parasitic Isopoda can here only briefly be described, taking as an example Portunion monadis (Entoniscidce). The narrow esophagus leads into a large sac composed of two lateral sacs. The inner wall of the sac projects into its humen in the shape of numerous long processes covered with chitinous intima. In this dirision of the gut, which has been called the cephalogaster, the absorption of the food takes place. The cephalogaster is continued posteriorly into a second division, the typhlosolis, whose wall, much thickened dorsally, projects into the lumen in such a way that the latter in a transverse section is crescent-shaped, the concare side being directed upwards. A strong cuticle lines the typhlosolis and carries closely-placed long and stiff hairs which, projecting from the 
opposite walls, mingle in such a way as to form a fine sieve apparatns, only ahmitting of the passage of fluids. The typhlosolis, which is fastened to the body wall by a pair of strong muscles, is followed by a third extremely muscular division, which is called Rathke's organ, and carries on energetic rhythmic contractions. A small tubular blindly closed terminal division, which is the only representative of the mid-gut, receives the dncts of two large contractile hepatic tubes. A hindgut and anns are wanting. The whole intestine stretches only to the $3 d$ thoracic segment. Portunion manadis sucks the blood of its host (Carcinus). The peculiar structure of the enteric canal, in which Rathke's organ and the cephalogaster alternately contract and expand, seems adapted to this sucking process.

The enteric canal of the minnte male of Portunion which lives in the body of the female does not show the peculiar transformation which it undergoes in the femalc. It is straight, and possesses two hepatic tnbes, a hind-gut, and an anms.

\section{The Nervous System.}

The nervous system of the Crustacea is constructed on the same type as that of the Anmulata, and must be derived from the latter. The result of research in comparative anatomy and ontogeny justify us in giving the following diagrammatic representation of its general structure and original constitution. This scheme stands in direct relation to the generalised plan of the segmentation of the body of the Crustacean sketched above (p. 300). In the most anterior segment of the body (head segment) the brain (supra-œesophageal ganglion), consisting of two symmetrical lateral halves, lies in front of and over the cesophagus, giving off nerves to the umpaired eye, the anterior antennse and the frontal sensory organs (see below). Each of the other segments of the body possesses two ganglia (a double ganghion) lying very near each other in the ventral middle line. The two ganglia of each segment (the two symmetrical halves of each double ganglion) are connected together by means of a transverse commissure, and with the corresponding ganglia of the preceding and subsequent segments by longitudinal commissures. The two most anterior longitudinal commissures which connect the double ganglion of the second segment with the brain embrace the oesophagus. These are the œsophageal commissures. The whole central nervous system thus consists, as in the Ammlata, of the brain and the segmented ventral chord (ventral ganglionic chain), whose segmentation corresponds with the segmentation of the body. From each double ganglion of the ventral chord nerves proceed to the body musculature of the segment to which it belongs, and to the musculature of the limbs with which that segment is provided. There are therefore one double ganglion for the $2 \mathrm{~d}$ pair of antennæ (in the $2 \mathrm{~d}$ segment), a similar one for the 2 mandibles (in the $3 \mathrm{~d}$ segment), 2 pairs of ganglia for the anterior and posterior pair of maxille (in the 4th and 5 th segments), and so on, a pair of ganglia in each segment for the limbs which belong to it.

It must, however, be sprecially noted that the assumption of a special ganglion for 
the posterior antenne is not yet seeurely established. Sueh a ganglion would have to be comprared with the infra-resophageal ganglion, and the segment corresponding with it to the first trunk segment of the Anmulata. In most Crustaceans, however, the nerves for the posterior antenne do not arise from a distinct ganglion but from the esophageal eomnissures; their plaees of origin in the higher Crustacea have indeed moved as far forward as the brain. There are, however, many important reasons, to be brought forward later, in favour of the assumption of an originally distinct pair of ganglia and a speeial segment for the posterior antenne.

All the more important and striking deviations from the typical Crustacean nervous system can be classed under the following heads.

1. Approximation of the two ganglia of a double ganglion by the shortening of the transverse commissure which unites them, and finally the fusing of these two ganglia into one; its composition out of two lateral ganglia can, however, often be seen externally, and always internally, on examination of its finer structure.

2. Approximation and contact of the longitudinal commissures connecting the consecutive ganglia.

3. Approximation and contact of the consecutive ganglia by the shortening of the longitudinal commissures. This may lead to the fusing of the consecutive ganglia into one ganglionic mass, in which the original composition out of several ganglia can sometimes be clearly recognised; at other times, however, this is very indistinct, or eren quite unrecognisable.

4. Longitudinal displacement and shifting of the ganglia, generally from behind forward. Ganglia may be displaced from one segment into another.

5. Shifting of the points at which nerves leave the ventral chord. These displacements, however, apparently never affect the real origin of the nerves in the centres of the nervous system.

6. Entire disappearance of ganglia. This is perhaps only to be proved with certainty of the most posterior ganglia of the body.

All these changes go hand in hand with transformations of the whole organism, especially with modifications in the segmentation of the body and in the development of the extremities. In the young stages of many Crustaceans it often happens that certain ganglia are still separate which in adult animals are fused. We see from this how important the knowledge of ontogeny is for a right comprehension of the morphology of the nervous system.

The concentration of the nervous system (the fusing of originally distinct ganglia to form larger ganglionic masses) can be observed in most of the natural divisions of the Crustacea.

For the sake of clearness we shall in each group of the Crustacea place the most conspicuously segmented nervous system in the foreground, while the description of the deviating, concentrated, or simplified nervous systems will be distinguished by the use of small print. 


\section{Entomostraca.}

The nervous system of the I'hyllopoda (Fig. 236, D), especially that of the Branchiopoda (Branchipus, Artemia), best corresponds with the scheme of the Crustacean nervous system given above. The transverse commissures between the ganglia of the ventral chord are tolelably long, and so the whole rentral chord has the character of a ladder nervous system. The two ganglia of a double ganglion are connected together by two transverse commissures. We must note as specially important that the pairs of ganglia for the oral appendages, i.e. for the mandibles and maxillæ, have remained distinct. Behind these 3 pairs of ganglia come (in Branchipus) the 11 pairs of ganglia of the limb-carrying segments, then the 2 pairs of ganglia in the genital segments. Behind these, ganglia only occur as rudiments in the two following segments.

The nerves for the posterior antennæ arise out of the cesophageal commissures, which are provided with a layer of ganglionic cells; this layer can the better be considered the ganglion of the 2d antennæ, since in front of the mandibular ganglion, and behind the cesopliagus, the cesophageal commissures are commected by a double tranverse commissure, corresponding with the double transverse commissures of the other ganglia of the ventral chord.

The nerves for the umpaired frontal eye, for the paired stalked eyes, and for the anterior antenne spring from the brain.

In eorresponrlence with the greatly reduced segmentation of the whole body in the Cladoece (Phyllopod) its central nervous system is also mueh less pronomeed. The ladder-like ventral elord consists of 7 pairs of ganglia, the foremost of which (infra-csophageal ganglion) innervates the mandibles and maxille, and the other 6 the 6 pairs of limbs. In front of the infra-cesophageal ganglion we find here a transverse commissure connecting the cesophageal commissures. The nerve for the 2d antennæ arises from the infra-asophageal ganglion. In Leptodor the 6 ventral ganglia in the adult animals are fused into one ventral ganglionic mass, while in the young animals they are still tolerably distinct.

The nervous system of the Ostracoda deserves further investigation. The ventral chord of Cythere which follows the brain and oesophageal commissures is said to consist of an infra-cesophageal ganglion and 4 subsequent ventral ganglia. The infra-csophageal gangtion is said to show its composition out of two ganghia and to innervate the jaws, while the 3 subsequent ganglia give off nerves to the limbs, and the last ganglion nerves to the most posterior divisions of the body and the genital apparatus.

In contrast with the above, the ventral elord of Halocypris appear's much concentrated. It consists of an infra-cesophageal ganglion with nerves to the jaws and maxillipedes, and a small ventral ganglion. Out of the latter arise 2 pairs of nerves, which probably innervate the musculature of the limbs and the abdomen.

In the various divisions of the Copepode the central nervous system 
shows several degrees of centralisation, from a more or less decentralised condition to the almost complete fusion of brain and rentral chord to form one ganglionic mass, pierced through by the cosophagus. The segmentation is most complete in the free-swimming (oppeporda, from which all the others are to be derived. In the Calanida, for example, we have (apart from the brain) a ventral chord consisting of 7 ganglionic swellings which stretches more or less far into the abdomen.

In other free-living Copepoda the number of ganglia is reducerl, and the abdominal ganglia become small or disappear. But in the Coryceidce (Fig. 236, $H$ ) we already lave only one single ganglionic mass surrounding the cesophagus, from which nerves radiate to the sensory organs, extremities, the musculature of the body, etc. 'The nervous system in rarious delicate parasitic Copepoda shows a similarly concentrated, though partly also reduced, condition.

The nervous system of the Carp-lice (Arguldile, Fig. 236, G), which are closely comnected with the true Copepola, is relatively highly developed. The concentrated rentral chord consists of 6 ganglia with much-shortened longitudinal and transverse commissures. The 4 posterior ganglia supply the 4 pairs of limbs, the 2 anterior the jaws, maxillipedes, and clinging feet. At the points at which the oesophageal commissures join the brain there are 2 ganglionic swellings, from which nerves go to the 2d antennæ.

Among the Cimipedes the nervous system of the Lepacticte is the most richly segmented. They possess a brain, long oesophageal commissures, and 5 or 6 ventral ganglia. The nerrous system of the socalled Cypris-lite larer, that is, of those which develop into hermaphrodite individuals, is similar.

The so-called complementary males of the Lepulide, on the contrary, and their Cumis-like larter, only possess a cerebral ganglion (supra-csophageal ganglion) and a thoracic ganglion, which alone represents the whole rentral chord. In the Balanide the rentral ganglia are fused into one large rentral ganglionic mass. Degeneration goes very far in the whole nerrous system of the Rhisocephata (Sacculina, Peltogaster $)$, which are so much degenerated by parasitism; we here find it in the form of one single ganglion, from which varions nerves radiate (cf. Fig. 248, p. 373). This ganglion is said not to correspond with the larval supra-cesophageal ganglion, but to arise anew in the development of the adnlt animal.

\section{Malacostraca.}

I. Leptostraca.-The interesting genus Nebalia, which of all living Mrtacostraca stands nearest to their racial form, possesses an extraordinarily richly segmented nerrons system. If this pronounced segmentation recalls, on the one hand, the nerrous system of the Phylloporla (Branchiopoda), it shows on the other (especially in the structure of the brain) a decidedly Malacostracan character. 'The ganglia for the posterior antenne are moved far forward on the œsophageal commissures, and form, as in all Malacnstraca, the most posterior division of the brain. The transverse commissure, which corresponds with them, lowever, 


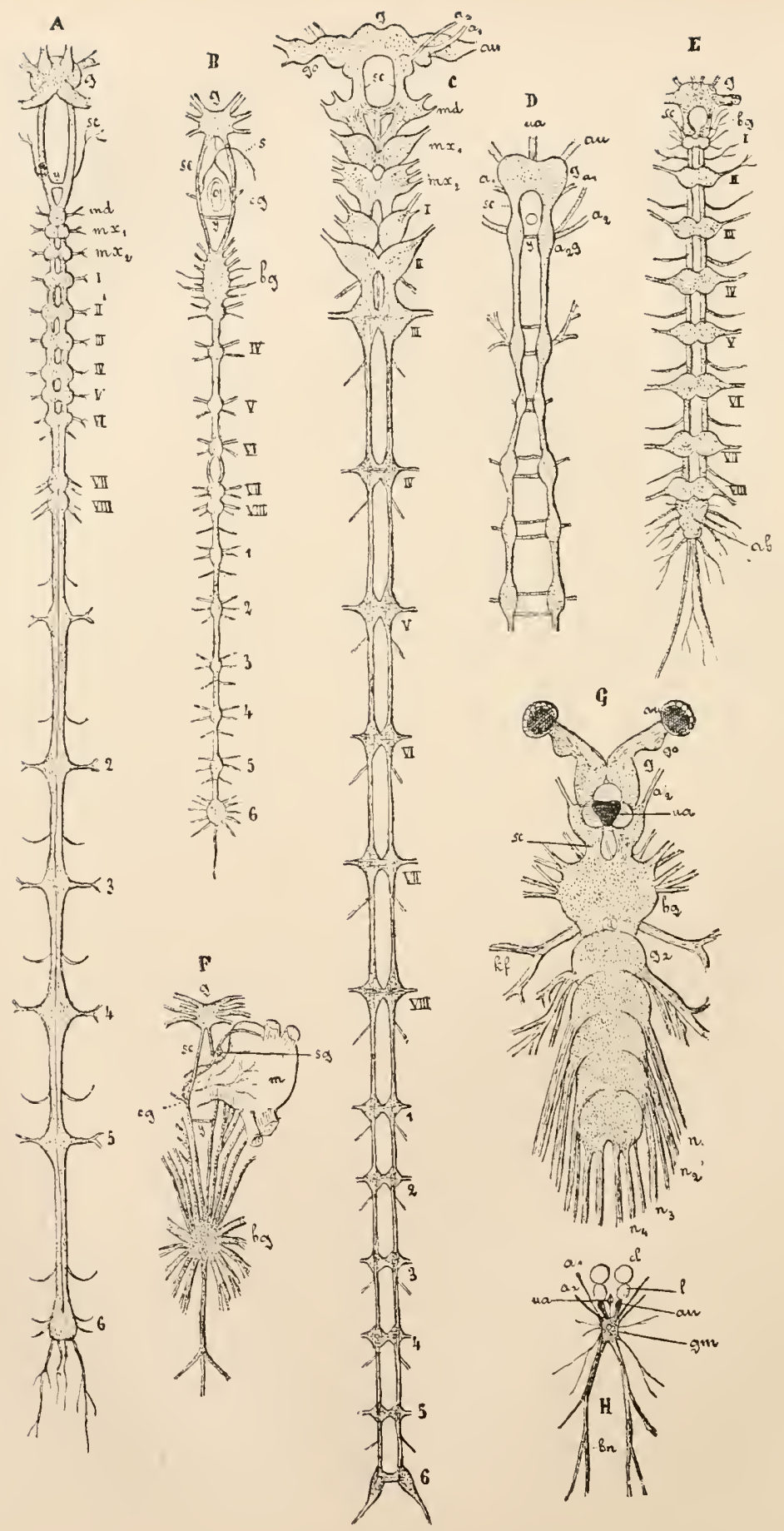

FIG, 236. 
Fic. 236. - Central nervous systems of various Crustaceans. A, Of Euphausia pellucida (after G. O. Sars). B, Of Astacus fluviatilis (after Vogt and Yung). C, Of Apseudes Latreillii (eonbined from sereral figures by Claus). D, of Limnadia (after Klunzinger), anterior portion. $E$, of Asellus aquaticus (after G. O. Sars). $F$, Of Maja squinado (after Milne Edwards). $G$, Of Argulus Corregoni (after Claus). $H$, Of Sapphirina Edwardsii (after Haeckel). gg, Brain; $a u$, nerves of the paired eyes; $u$, unpaired eye with its nerve ; go, ganglion opticum ; $a_{1}$, nerve of the Ist anteuna ; $\alpha_{2}$, of the $2 \mathrm{~d}$ antenna; $s c$, esophageal commissures; $y$, post-cesophageal tranverse eommissure of the same (commissure of the antennal ganglia of $2 d$ antenna?); (ag ganglion of the $2 d$ antenna (in $D$ ); $m d$, mandibular ganglion ; $m x_{1}, m x_{2}$, ganglia of the 1 st and $2 d$ pairs of maxille; I-IIII. thoraeie ganglia; $b g$, sub-cesophageal ganglion, consisting of several fused ganclia; $1-6$, abdoninal ganglia; $s$, sympathetic nervous system; $s g$, ganglion of the same; $c g$, commissural ganglion; $m$, stomach (in $F$ ); $a b$, fused abdominal ganglia (in $E$ ). In $G$, $g_{2}$ signifies 21 ventral ganglion; $n_{1} n_{4}$, nerves for the 4 pairs of limbs; $h \cdot f$, nerve for the clinging foot. In $H$, gm signifies the ganglionie mass (brain fused with ventral ehord) broken through by the cesophagus ; $c l$, corneal lens ; $l$, lens; $b n$, posterior strong nerves, the lateral pairs of whieh go to the limbs.

has remained separate behind the esophagus and in front of the mandibular ganglia. The ganglia of all the pairs of limbs, even those of the oral limbs, have remained separate on the ventral chord, which has 17 ganglionic swellings. We thus find, counting from before backward: (1) a mandibular ganghion, (2) and (3) 2 maxillary ganglia; (4) to (11) 8 thoracic ganglia, and (12) to (17) 6 abdominal ganglia. It is a significant fact that in the larva the 6 abdominal ganglia are followed by a small 7 th swelling, belonging to the limbless 7 th abdominal segment; this, however, entirely disappears at a later stage. This fact is rightly interpreted to mean that there must originally have been more than 6 pairs of pleopoda.

In contradistinction to the ladder-like nervons system of the Phyllopocla, the ganglia in Nebclia are fused in the middle line to form a double ganglion, and the longitudinal commissures are moved nearer each other. The latter are very much shortened in the thoracic region in correspondence with the abbreviation of the thoracic segments.

II. Arthrostraca, Anisopolu.-The richly segmented nervous system of Apseudes (Fig. 236, C) is closely connected with that of Nebulia. The brain and cesophageal commissures are followed by an infra-cesophageal section, in which we can clearly distinguish the separate ganglia for the mandibles, the two pairs of maxillie, and the pair of maxillipedes. It is important to note that the maxillipedal ganglion, which corresponds with the first thoracic ganghion of Nebclia, is here more closely connected with the preceding ganglia, in keeping with the commencing transformation of the first pair of thoracic feet into a pair of maxillipedes. The 4 infra-œsophageal ganghia are followed by 7 double ganglia for the thorax and 6 for the abdomen, the last and largest of which is probably composed of two or more fused together. The ganglion for the posterior antenne is mored towards the brain, but the transverse commissure corresponding with it is clearly visible behind the asophagus, in front of the mandibular commissure. The ganglia of the ventral chord are clearly donble, and connected by two separate longitudinal commissures.

In Tanais fusings and displacements seem already to have taken place in the ventral chord. The rentral chord here has, it is said, only 12 ganglia. 
Isopoda.-Among the true Isoporla several genera (such as Spharoma, Illothea, Glyptonotus) are, in the rich segmentation of their nervous systems, closely connected with Apseudes. In Sphorome we even find a 7th abdominal ganglion. The double nature of the central nervous system is everywhere more or less distinctly marked. The transverse commissure corresponding with the ganglia of the $2 \mathrm{~d}$ pair of antenne seems to be more or less completely fused with the mandibular commissure.

In many Isopode there is fusion in the ventral chord and displacement and reduction of the pairs of ganglia. The mandibular, maxillary, and maxillipedal ganglia in the first place fuse to form an infra-esophageal ganghionic mass. Then a rerluction in the number of the ganglia takes place chiefly in those of the abdomen. In some Isopoda 5 abdominal ganglia occur, in others (Torcellio, Oniscus, Asellus, Fig. 236, E) we find as the remains of the abdominal ventral chord only one ganglionic swelling attached to the last thoracic ganglion, and in others even this is wanting. The number of the separate thoracic ganglia is less frequently reduced.

In those Entoniscida (Portunion mamadis) which are specially strongly modifierl through parasitism we find, besides the brain (which is everywhere retained), 2 thoracic ganglia and one abdominal ganglion at some distance from them, under the heart; while in the not less strongly modified parasitic Bopyrider 7 thoracic ganglia are said to occur.

Amphipoda.-Here in all cases we have a fusing of the anterior ganglia of the ventral chord, so that the nerrous system no longer shows at any point that segmentation which we neet with in many Isopodu. In the nervous system of the Gommurite we can still distinguish, apart from the brain, an infra-cesophageal ganglion consisting of several fused ganglia, and further 7 thoracic ganglia in the 7 free thoracic segments, and 4 abdominal ganglia in the 4 anterior abdominal segments.

In Phronima the centralisation goes still further. There are only 5 thoracic ganglia behind the infra-cesophageal ganglionic mass, which consists of 6 fused ganglia. The last of the 4 abdominal ganglia is formed by the fusion of 3 ganglia which are still separate in the embryo. Not only the points of divergence of the nerves for the $2 d$ antemne, but also those of the nerves of all the oral alprendages are shifted forward on to the cesplageal commissures. The nervous system of many Iyperidce is similar to that of Phronima. In others, however, concentration goes still further, as not only the last 2 thoracic but also the last 2 abrlominal ganglia may fuse together. In the most extreme cases we thus find only an infraesophageal ganghionic mass, 4 thoracic and 3 abdominal pairs of ganglia, In the Caprellide the reduced abdomen retains no ganglia. Besides the brain and the sub-resophageal ganglion which supplies the mandibles, maxille, and maxillipedes, we find 7 thoracie ganglia, the 7 th of which lies behind the 6 th in the last thoracic segment but one. Three small ganglia belonging to the abdomen follow close hehind the 7 th thoracic ganglion. In young animals 4 more pairs of abdominal ganglia begin to form, and then fuse with the 3 small ganghia of the adult animal above mentioned.

III. Thoracostraca.-In many Schisopodd (Euphausic, Fig. 236, $A$, Boreomysis) all the ganghia for the oral and thoracic limbs, 11 in number, seem to have remained separate. 
In others the number is evidently reduced by the fusing of originally scparate ganglia. In Gnathophansia we find besides the infra-cesolnageal ganglion (which most probably consists of the fused mandibular and maxillary ganglia) S, in Eucopia however only 6 , thoracic ganglia. The most anterior thoracic ganglion has in this latter case probably united with the infra-cesoplageal ganglion, and the last thoracic ganglion with the last but one. This is made probable by the fact that in the last thoracie segment no ganglion occurs. In Hysis (relictet) the thoracie ganglia are eren said to be fused into a longitudinal strand. The cesophageal commissures are in many Schizopodu (Euphausia, Boreomysis) connected directly behind the resophagus and in front of the most anterior ventral ganglion by a transverse commissure, which perhaps corresponds with the commissure of the ganglia of the posterior antennæ often mentioned above.

All the Schizopolu seem to possess 6 abdominal ganglia. The nerves which supply the body musculature of the abdomen diverge from the longitudinal commissures half-way between 2 consecutive ganglia. This arrangement seems to be characteristic of all Throncestrace.

In the Cumucec (Diastylis) the ventral chord consists of 16 pairs of ganglia; the three most anterior of these, which have moved near each other, supply the oral limbs; 7 thoracic, and 6 abdominal pairs of ganglia follow.

The nervous system of the Stomatopoda in its segmentation shows very clearly a close relation to the metamerism of the body. In the cephalo-thoracic portion of the ventral chord only the 3 ganglia of the 3 most posterior thoracic segments have remained separate, i.e. of those segments which, uncovered by the cephalo-thoracic shield, carry the biramose ambulatory feet. All the other preceding ganglia are united into a large infra-œsophageal ganglion. The cesophageal commissures are very long, and show behind the csophagus the transverse commissures often mentioned above. The 3 posterior thoracic ganglia are followed by the 6 abdominal ganglia which are characteristic of the Thoracostrace.

Decapoda. - Tre here find many grades of concentration, from the still tolerably richly segmented nervous system of the Maciura to the nervous system of the Bruchyura, in which all the ganglia of the ventral chord have fused into one single thoracic ganglionic mass. Taking as a type of the Mucruru the Cray-fish, Astucus fluriutilis (Fig. $236, I)$, the highly developed brain gives off the nerves for the eyes, the anterior antennie, and from its posterior part for the posterior antenne. The cesophageal commissures are of considerable length and connected behind the osophagus by a transverse commissure. In the course of each asophageal commissure lies a small ganglion, the so-called commissural ganglion. From these 2 commissural ganglia various nerves liverge, among which the visceral nerves and the nerves of the mandibles are to be specially noted. The latter indeed have their roots in the infra-œsophageal ganglion, but are united with the esophageal commissures as far as the commissural ganglia. The osophageal commissures enter an infra-asophageal ganglionic mass which consists 
of 6 united ganglia, i.e. of the mandibles, 2 maxillæ, and 3 maxillipedes. The last swelling of this infra-aesophageal ganglionic mass (the $3 \mathrm{~d}$ maxillipedal) is pretty clearly marked off. The 5 distinctly separate large thoracic ganglia for the 5 posterior thoracic segments and their extremities (the ambulatory feet) follow, and of these the 4th and 5th ganglia are very near each other. In the abdomen we find 6 ganglia, the last is the largest, and, as in all Hulucosticucu, may well represent 2 or even more originally separate ganglia. In the Cray-fish, as in nearly all Thorccostrucu, the 2 ganglia of the originally double ganglion and the longitudinal commissures between the consecutive ganglia of the ventral chord are so closely connected in the middle line that their double nature is not outwardly perceptible. The longitudinal commissures separate from each other only between the penultimate and antepenultimate thoracic ganglia (6th and 7 th), so as to let the sternal artery pass between them.

In a few Macrurc the 2 most posterior thoracic ganglia are fused, or there is a chose approximation of all the cephalo-thoracic ganglia (Carieliela, Palinurus). Here, however, the 6 abdominal ganglia remain separate, while in the Paguride only 1 abdominal ganglion is present, in correspondence with the great rednction of the abdomen. We finally come to the Brachyura (Fig. 236, F), in which, in correspondence with the great reduction of the abdomen and the concentration of the cephalo-thorax, the whole rentral chord is fused together into a great thoracic knot, from which numcrous nerves radiate out to all sides.

\section{Sympathetic Nervous System.}

This seems to occur in all Mulucostruca, at least it has been obserred with considerable uniformity in representatives of the three principal divisions, the Leptostrace, Arthrostraca, and Thoracostraca. In the Cray-fish a nerve with double roots arises on each side out of the commissural ganglion, proceeds forwards to the upper lip and mounts upwards at the sides of the oesophagus. The two nerves unite on the upper side of the stomach to form a median nerve which swells into a ganglion. From this ganglion a branching nerve runs backwards and spreads out in the wall of the stomach and gives off branches to the liver and also probably to the heart. The sympathetic nervous system is further connected by an unpaired nerre with the posterior portion of the brain.

So highly developed a sympathetic nervous system seems wanting in the Entomostrace. But it is noteworthy that in the Phyllopuctu (Bronchipus) a nerve arises on each side out of the oesophageal commissures which runs to the upper lip. The 2 nerves unite to form a labial ring, which is connected with a median ganglion and gives off nerves to the upper lip, the muscles of the osophagus, ete.

Structure of the Brain.-The brain of the Crustacea rises in the Malacostrace to a very high degree of complication. This complication, which reaches its highest point in the Decapocla, is seen in the complicated arrangement of the ganglionic cells and 
of the conrses of the fibres, and shows itself externally by the formation of lobes. It is probable that the brain of the ancestors of the Crustaceans contained the centres for the mpaired frontal eye, for the anterior antennæ and perhaps also for the frontal sensory organs, together with the fibrous connections between these centres themselves, bctween these centres and the cesophageal commissures, and lastly the anterior transverse comnections of the cesophageal commissures. A higher complication is cansed in most of the Crustacea now living (all Malacostrace and many Entomostraca), first by the ocenrrence of the paired eyes, and second by the fact that the originally infra-cesophageal ganglia of the posterior antenne mite with the brain from behind. We can in these cases distingnish three prineipal regions in the brain. First, an anterior region (fore-brain), with the centres for the mpaired eye (wherc this persists) and for the paired cyes. The opitic nerves of the latter, whose fibres in the brain of the higher Crustacea form a chiasma, entcr on each side a frequently very large optic ganglion, which is the largest accessory lobe of the forebrain. Besides this the fore-brain has, especially in the higher Malacostrace, other lobate formations. Second, a mid-brain which adjoins the fore-brain, and contains the centres for the nerves of the anterior antenne. Third, the hindermost region of the brain (hind-brain), which is formed by the ganglia for the posterior antennie, whose transverse commissure is to be found behind the cesophagus, where it has, as already described, of ten remained as a separate transverse commissure between the cesophageal commissures.

Neurochord strands or giant nerve tubes, like those with which we became aequainted in the Annulate, occur in the ventral chord of the Thoracostraca. An intermediate nerve also, of varying extent, has here and there been observed in the rentral ehord.

\section{The Sensory Organs.}

\section{A. Eyes.}

These are, as a rule, well developed in the Crustacea, and often show a high degree of complexity, especially in the Mulucosticucu, occasionally also in certain Entomostruca. Visual organs are either wanting or very much reduced in the adult condition of most of the parasitic and attached Crustacea (Cirripedia), also in many deep-sea forms and in others which live in dark places. Setting on one side a few divergent forms of Crustacean eyes, we can distinguish 2 linds, which may occur simultaneously in the same animal: the unpaired frontal eye (accessory eye) and the paired lateral eyes (principal eyes). Both belong to the head. The unpaired eye lies abore the brain, the paired at its sides.

The unpaired eye occur's in the young larval forms of all Crustaceans (Nauplius eye): it is always retained in the adult Entomostiacu, sometimes well developed, sometimes in a reduced condition. In the Malucostraca it degenerates in the course of development. From the universal distribution of the umpaired eye in the Entomostrace and young Mulacostraca we may conclude that it was present in the ancestors of the Crustaceans.

Paired eyes are found in all Malacostiace and many Entomostrucu. They are either movable stalked eyes or fixed sessile eyes. The first may be imagined to arise out of unstalked eyes by the raising of that 
part of the head immediately surrounding the eye, by its articulation, and further growth into a stalk. Formerly the stalked eyes were often erroneously considered to represent a pair of extremities. In the development of the Crustaceans the paired eyes always appear much later than the unpaired eye, and we have reason for assuming that the unpaired eye is phylogenetically older than the paired. The following is a short review of the occurrence and distribution of the paired or principal eyes.

Entomostraca. - Phyllopoda : in the Estheridce aud Apuside the paired eyes have moved towards each other in the middle line. The Eranchiopoda have movable stalked eyes. The two principal eyes of the Cladoccro have fused in the middle line to form a trembling frontal eye, which, however, is wanting in Monospilus. Ostracoda: the Cipridinide possess besides the unpaired eye paired morable lateral eyes. In the Cypritle and Cytheridce also paired eyes occur, which may fuse together to form one unpaired eye. Whether these correspond with the paired eyes of other Crustaceans is not known. Copepoda: the Carp-lice, which are nearly related to the Copepodu, possess besides the unpaired eye 2 large lateral eyes. In the true Copepocla the latter are generally wanting, but praired eyes do occur, e.g. in Pontellide, and these perhaps correspond with the lateral eyes of other Crustacea. The paired eyes of the Corycacide on the contrary do not easily admit of such a comparison. It is, however, not improbable that the racial forms of the Copepode possessed paired compound eyes, which liave been agrain lost. Cirripedia: in the adult animals the paired eyes are wanting throughout, but on the other hand the Cygris-like lerve of the attached forms are provided with large lateral eyes.

Malacostraca. - Lateral eyes occur everywhere. They are stalked in the Leptostrace and all Thoracostrace except the Cumacca. In the last case the sessile eyes are generally fused in the mildle line; they may, however, be altogether wanting. In the Arthrostraca, which have also been called the Edriophthalmata (in contradistinction to the other Malacostraca, which are known as the Podophthalmata), the eyes are sessile. The facts that movable stalked eyes occur in the Phyllopode (Branchipus), and that the eyes of Leptostraca (Nebalia), which in every way stand nearest the racial form of the Malacostraca, are similarly stalked, make it appear probable (other facts also being taken into consideration) that the paired eyes of the Arthrostrace were once stalked.

Among the Amphipode the Phronimide show peculiarities. They possess two prairs of compound eyes, one frontal pair and one in the region of the cheek. The two eyes of the same side, however, must have proceeded by division from the single eye of the Amphipole which in the Hyperide is very large superficially.

Structure of the Eyes. - The unpaired eye was formerly described as an $\mathrm{x}$-shaped eye-spot, with or without a refractive body. On account of its general distribution in the Entomostruca, it is also called the Entomostracan eye. Its structure will be best illustrated by means of an example.

The frontal eye of Culchellu mediterruneu (Fig. 237), a free-living Copepol, consists of 3 single eyes united together, 1 umpaired median and ventral, and 2 lateral and dorsal. Each single eye is composed of a pigment cup and a strongly refractive transparent "lens" laid in and on it. The term "lens" is, however, not applicable. It is composed of several cells, each of which is connected, whether at its 
outer or inner side is not yet quite certain, with a fibre of the optic nerve, and must therefore be considered as a retinal cell.

The great similarity in structure between such a single eyc and the eyes of Platodes should not be overlooked. The three-fold structure of the unpaired Crustacean eye seems to be characteristic. Occasionally, e.g. in Branchipus, 3 separate nerves leave the brain to run to the 3 single eyes.

The structure of the paired lateral eyes of the Crustacea (stalked and unstalked) is much more complicated. We have here the compound eye so characteristic of the Aithropode. Even though, in single divisions of the Crustacea, it presents important modifications and complications in its structure, we nevertheless evidently have to do (with a few exceptions to be mentioned later) with homologous visual organs. Let us take for description the paired eye of Brenclipus,

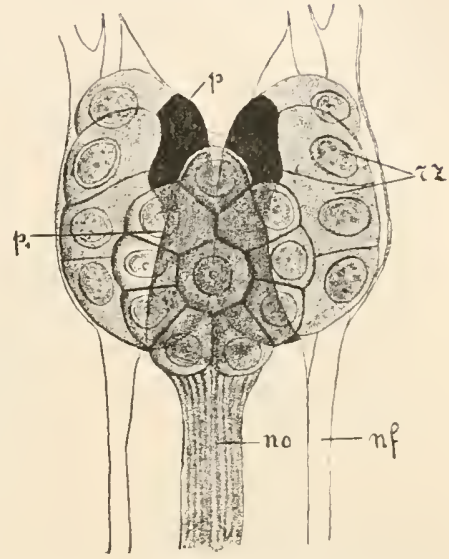

FIc. 23\%.-Eve of Calanella mediter ranea $\&$ juv, from below (after Gren acher). $p$, Pigment plates of the paired $; p_{1}$, of the unpaired portion; $r z$, retinal cells ; $n o$, optic nerve; $n f$, nervi frontalis. which presents in a tolerably simple manner the typical structure of the compound eye. The movable stalk of the hemispherical eye of Brunchipus (Fig. 238, B) contains the optic nerve; this swells in the stalk into a ganglion, the ganglion opticum, which must be reckoned as belonging to the brain. The optic ganglion is followed at the distal end near the base of the eye by a second ganglion, the retinal ganglion. Nerve fibres radiate towards the eye from the nerve cells of this retinal ganglion. The eye itself is separated from the cavity of the eye stalk by a thin basal membrane. The nerve fibres which radiate from the retinal ganglion penetrate this membrane to enter the retinal cells immediately on the other side of it. The eye represents the half of a hollow sphere with thick walls, whose outer spherical surface corresponds with the outer surface of the eye, and whose inner (concave) surface corresponds with the basal membrane. It consists of numerous closely packed single eyes arranged radially. In each single eye or ommatidium (Fig. 238, E) we distinguish three chief constituents:-

1. The Retinula, i.e. that portion of the whole retina of the compound eye which belongs to each of the single eyes. This is the proximal portion coming next to the basal membrane.

2. The crystal cone, and

3. The hypodermal elements with the superjacent chitinous cuticle, the cornea of the Arthropodan eye.

A. The Retinula consists of 5 long cells regularly grouped

VOL. I 
round a central axis: into the proximal ends of each of these cells a fibre from the optic nerve enters. The central axis is a tubular rod called the rhabdom. The 5 cells of the retinula contain pigment in the immediate neighbourhood of the rhabdom, and this pigment occurs in such large quantities in the thicker nucleated portions of the cells, that in each retinula a distal pigment layer is formed. Above
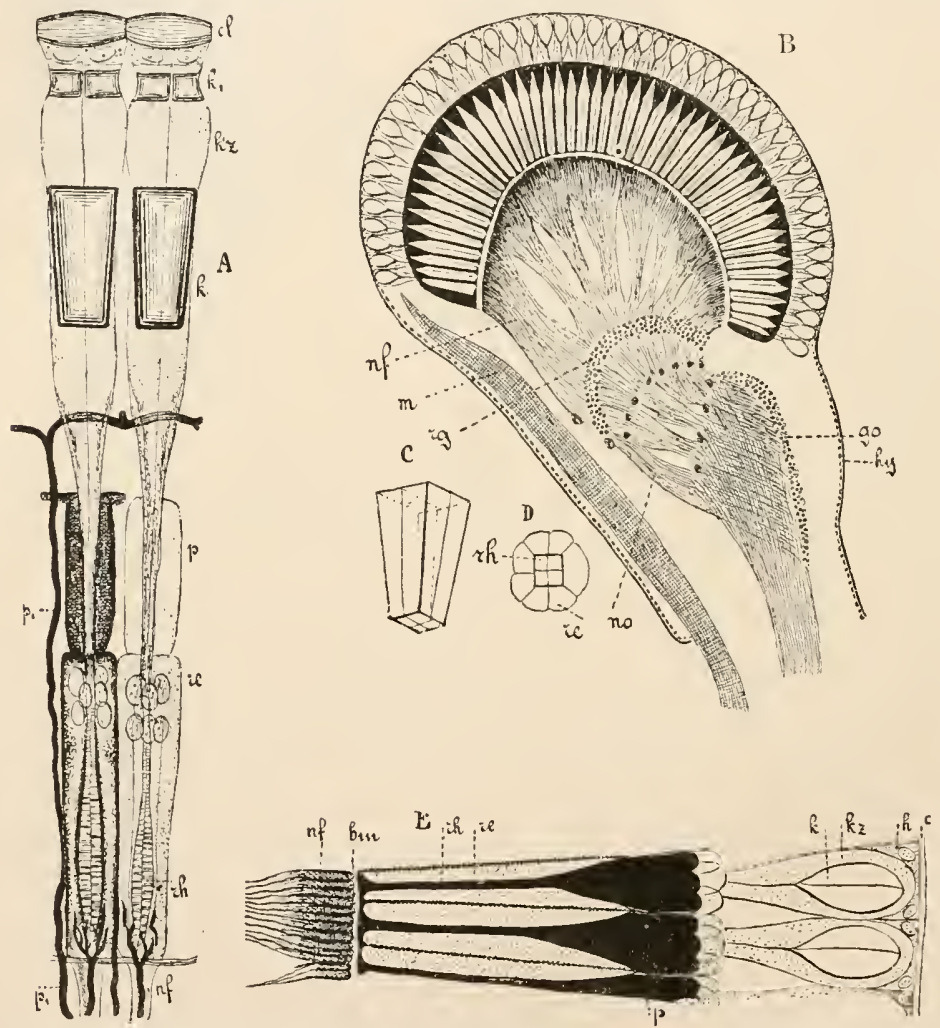

Fig. 23S.-Compound Crustacean eye. $A, 2$ single eyes (ommatidia) of Palæmon Squilla. The pigment is removed from the ommatidium on the right hand. C, Isolated crystal body of an ommatidium, consisting of 4 picces. $D$, Transverse section through a retinula, about the iniddle of its length; $r e$, retinal cells; $r h$, rhabdom consisting of 4 pieces. $B$, Section through the stalked eye of Branchipus. $E, 2$ ommatidia of the same animal, on a larger. scale (figs. $A, C, D$, after Grenacher, $B$ and $E$, after Claus); $c$, cornea (cuticle); $c l$, corneal lens; $h y$, hypodermis cells ; $k$, crystal cone $k_{1}$, outer crystal body ; $k z$, crystal cells ; $p$, pigment ; $\mathrm{p}_{1}$, in fig. $A$, pigment strands running between the retinulie from the layer of nerve fibres; re, retinula; $r h$, rhabdom ; $n f$, nerve fibres; $b m$, basal membrane; $m$, muscle; $r g$, retinal ganglion ; go, ganglion opticum ; no, nervus opticus.

this layer, terminal unpigmented portions project. These 5 ends together embrace the proximal ends of

B. the refractive erystal cells. These are 4 in number and together form a cone, which contains in its distal portion a solid crystal 
body secreted by the crystal cells. The layer of the crystal cells of the compound eye is corered by

C. The transparent smooth chitinous integument (cornea) with subjacent hypodermis cells, a continuation of the general body integument.

The principal distinctions to be pointed out between the stalked eye of the higher Crustacea and that of Bronchipus are in the cornea and the optic ganglion. In the former the cornea (chitinous cuticle) is somewhat thickened over each single eye, forming for each a corneal facet or corneal lens, which is convex either on its inner or outer side or on both sides (Fig. 238, $A, c l$ ). The cornea then appears, when viewed from the surface, to be divided into regular polygonal areas, each of which corresponds with a corneal lens of a single eye.

Again, whereas the ganglion opticum is simple in Brunchipus, in the stalked eyes of the Mulucostruce it falls into 3 ganglia also placed in the eye stalk.

There are nany important rariations in detail in the structure of the Crustacean compound eyc; these chiefly concern the number of cells in a retinula, the number of crystal cells in a single eye, the number of single eyes in the whole eye, and the specific arrangement of the elements. The Decupode and Isopode possess 7 retinular cells, the Branchiopoda and Amphipoda 5, the Schiropola 4. The single eyes of the Cladocera have 5 crystal cells, the Decapoda and the Branchiopoda 4, the Isopoda, Amphipode, and Schizopoda 2. In the Isopode only a few single eyes are found which are not closely packed ( 4 in Asellus, 20 in Porcellio). The isolater corneal lenses (not Hattened into polygonal facets) are here biconvex.

Each of the paired eyes of the Corycacidce consists of one single eye, which in Corycaeus is strikingly large and long. It is in many respects markedly different from the ommatidia of the compound eyes of other Crustacea.

In the Euphuside among the Schizopode there are, besides the two compound stalked eyes, other "accessory" eyes. These are found on the basal joints of the second and penultimate pairs of thoracic feet, and further, one in the rentral middle line of the abdomen between the pleopoda of each of the 4 anterior segments. Whether these organ belong to the category of visual organs is very doubtful; we only know for certain that they are luminous.

\section{B. Other Sensory Organs.}

Among the other sensory organs of the Crustacea the most widespread are the tactile, and what are generally supposed to be olfactory, organs. In many Entomostrece we find, in addition, the so-called frontal sensory organs of unknown physiological significance. Auditory Organs occur in all the Decupode, and have also been observed in isolated cases in other divisions. Other structures which have been described as sensory organs with unknown functions must be passed over in silence, because of their sporadic occurrence and also because too little is known about them. 
1. Specifie Organs of Touch.-The points of the limbs, especially of such as serve for locomotion or for holding food, possess a finer sense of touch than the other parts of the surface of the body.

Special Tactile Setæ are the principal organs of touch. These are found chiefly on the antenne, but also on other extremities, and occasionally also on the body itself. These setæe are distinguished from other setze, spines, etc., whose function is almost entirely mechanical, by the fact that one or more ganglion cells lie at their bases connected by nerve fibres with the general nervous system (Fig. 239, D).

$\because$. Olfactory Organs are found in the shape of pale delicate knobs, filaments, tubes, or points (Fig. 239, $A, b$ ), which are often grouped in bundles or transverse rows, and occur on the anterior antemne.

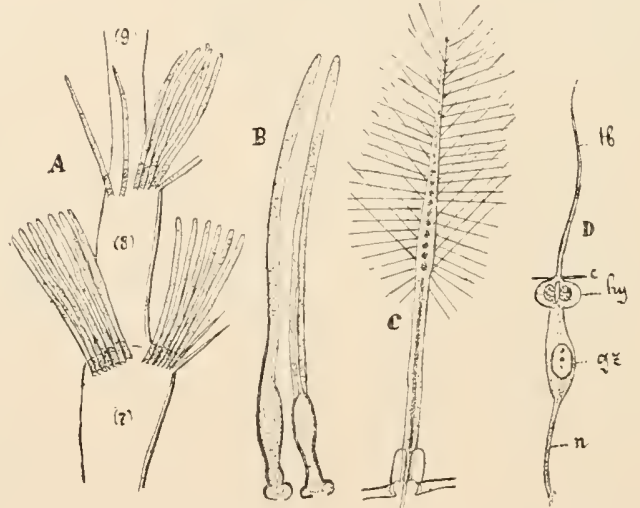

FIG. 239.-A, $7,8,9$, joints of a 13-jointert flagellum of the anterior Antenna of Nebalia (male) with the olfactory tubes. $B$, Two Olfactory tubes, more strongly magnified, $C$, Feathered sensory seta (auditory hair) from the antepenultimate pair of thoracic limbs of Apseudes, with cuticular basal capsule. $D$, Tactile hair $(t b)$ of Branchipus. $c$, Bolly cuticle ; hy, hypodermis cells of the seta ; $g z$, ganglionic cell; $n$, nerve fibre (after Claus).

Less frequently similar structures are also found on the second antennæ. They always occur in greater numbers in the male than in the female. The chitinous cuticle of these olfactory processes is thickest at their bases; towards their free end it is thin and delicate. At the base of each olfactory process a nerve fibre enters without forming a ganglionic cell, and continues into the interior of the process, rumning through it and filling it to its free end. The nerve fibres originate in ganglionic cells which, lying in the same or preceding joint of the antenna, belong to the antennal nerve.

Whether the so-called Calceoli of the Amptipode are olfactory organs, or whether, perhaps, they represent a kind of auditory organ, must remain undecided.

3. Frontal Sensory Organs.- The characteristic position of these organs which occur in one pair is the frontal region very near the brain. They are projecting filaments, cones, rocks, or other cuticular 
appendages, into which 2 nerves, the frontal nerves, enter, generally forming ganghionic cells. In Bronchipus, in place of the cuticular process, there is only an inconsiderable thickening of the cuticle with large hypodermis cells surrounded by ganglionic cells lying under it. Frontal sensory organs have been ohserved not only in the Entomostiace and Entomostiacan larva, but also in the Mulacostiacan larva ( $i$ e. when it is a Neuplius), and from this we are justified in concluding that they were original structures present in the Crustaceun racial form.

4. Auditory Organs of the Decapoda.-These lie on the basal joint of the anterior antenne (antennule). In all Decopocta they occur as pit-shaped depressions of the chitinous integument, which generally remain open, but in a few cases (Hippolyte) may close and form a vesicle. In the open auditory vesicles the aperture is often covered by a compact row of setre projecting from one of the edges, less frequently by a thin projecting fold. The auditory pits contain sand particles taken in from outside, which probably function as otoliths, like the concretions of fluorcalcium in the closed auditory resicles. At the base of the auditory pits, or on the imner wall of the auditory vesicles, feathered hairs arise; these are (1) otolith hairs, which carry the otoliths, and ( 2$)$ free hairs, projecting into the cavity of the auditory pit. The distinctly marked, swollen base of the auditory hair is extremely delicate and thin-walled, and permits a considerable oscillation of the hair in response to the waves of sound. The auditory nerve, which branches from the antennal nerve and has its root in the brain, first sends off fibres to single ganglionic cells. Filaments from these ganglion cells enter the auditory hairs at their bases and are attached near their points to rodshaped bodies.

It is usually said of the two closed auditory vesicles of the Myside (Sehizopoda), that they lie in the tail. More correctly, they lie in the inner lamella (endopodite) of the last pair of pleopoda, which, together with the telson, form the candal fin. Their structure does not deviate essentially from that of the Decapodan auditory organs. They are innervated from the last abdominal ganglion.

Oxycephalus (Amphipola) possesses two anditory vesicles lying above the brain and containing otoliths.

There is some justification for classing the sensory organs of the Decapoda, Schi:opoda, and Amphipoda above described as auditory organs; but we must not fail to mention that more recent experimental investigations greatly support the riew that they also serve for regulating the position of the body, and for maintaining its equilibrium.

Feathered setr, which in structure show greatagreement with the auditory hairs of the Decapoda, oceur on the antemne and also in other parts of the body in many Malacostrace, and have often been considered as auditory organs. This is, however, still an mdccided point. It is, however, probable that the auditory organs of the Decapoda have developed phylogenetically by the localisation of feathered sensory hairs and by the pit-like depression of those jarts of the integument which carried them. The ntilisation of foreign particles of saml as otoliths also supports this riew. 


\section{YII. The Blood-Vaseular System and the Body Cavity.}

In the Crustacea (and in the Arthropoda generally) we find no closed blood-vascular system. Those portions of the eirculatory system which are provided with special walls, stand in open communication with blood lacunæ. These lacunæ have no special walls, but are only spaces between the various organs of the body, and represent the body cavity.

Scheme of the Cireulatory System.-According to what is now lnown of the Crustacea we may imagine the circulatory system in the racial form of these animals to be essentially as follows: A contractile, tubular, dorsal vessel (heart) rums longitudinally through the body in the middle line above the intestine. The direction of the flow of blood in this dorsal ressel is from behind forward, as in the dorsal vessel of the Ammlatu. In each body segment the dorsal ressel possesses a pair of lateral slit-like apertures, the so-called ostia, through which its interior is in open communication with the blood sinus surrounding it ; this is the perieardial sinus, a part of the body cavity. The blood fluid (hæmolymph) enters the dorsal ressel through an aperture at its posterior end as well as through the lateral ostia from the pericardial sinus, and flows out at its anterior end. It then rums backward through the lacunar system more or less constantly in contact with the integument of the body and limbs where respiration takes place, and finally re-enters the pericardial sinus.

Entomostraca. - The scheme just sketched corresponds more exactly with the circulatory system of the Branchiopoda (Phyllopoda) than with that of any other known Crustacean. The contractile dorsal vessel (heart) of Branchipus (Fig. 191, p. 2S8) rums through the whole trunk and possesses a pair of ostia in all segments except the last, in which there is one terminal ostium. Anteriorly the heart is continued into an Aorta without ostia which enters the head and opens into the lacumar system of the body. In this latter system a ventral principal stream from before backward can be distinguished incompletely separated from the pericardial sinus by a septum stretched transversely over the enteric wall. The respiration takes place in the whole surface of the delicate integument of the body and limbs, but is apparently specially active in the branchial sacs. From the ventral principal stream an accessory stream runs into each limb down one side to the point, there to bend round and to run back up the other side to rejoin the principal stream.

The heart of the other Entomostrace (Figs. 192 and 193, p. 289) (where such an organ occurs) is always much shortened, sac or pouchshaped and only supplied with one pair of ostia. Anteriorly, in front of the anterior terminal ostium, the heart is sometimes (in many Copepoda, Branchiura, and Cludocera) continued into a longer or shorter aorta. A posterior ostium is added to the heart of the Copepoda. The ostia through which the blood flows into the heart are generally pro- 
vided with ralves to prevent its return into the pericardial cavity on the contraction of the heart.

The heart is always placed above the intestine in the most anterior trunk region.

With regard to the presence of the heart in the Entomostraca, all Cladocera possess hearts. Among the Ostracoda it is only found in the Halocypridce and Cypridiniule, among the Copepoda only in the C'alanide, Pontellida, and Brenchiura. In the latter it lies far back in front of the so-called caudal fin and is continued anteriorly in a long aorta as far as the brain. In the Cirripectia a separate blood-vascular system is altogether wanting.

It would be a mistake to assume that those Entomostraca which appear to be simple forms because of the want of a heart and gencrally of a separate bloodraseular system, are therefore also original forms. As in the worms, so also in Crustaceans, the want of this system of organs must certainly be considered as a derived condition. The causes why a reduction of the heart goes as far as complete lis. appearance are indeed only known to a very small extent. Small size of body may here and there have some influence, occasionally the rhythmical movements of other inner organs (e.g. the stomach of many Copepoda) seem to suffice to set in circulation the blood or ccelomic fluid in the lacunar system; a heart is thus rendered superfluous.

We have one remarkable exception to all that has been said above as to the circulatory system in the Crustacea. One genus of parasitic Copepode (Lemanthropus) possesses a richly branched blood-vascular system widely spread in the body and its appendages, and completely closed from the body cavity. A heart is wanting. The yellowish red blood is propelled along the principal vessels by the movements of the enteric canal, and flows forwards in two ventral longitudinal trunks and backwards through an unpaired dorsal vessel.

Malacostraca, Leptostraca. - A knowledge of the circulation in the Leptostraca (Nebalia, Fig. 196, p. 293) is of great importance; it recalls in many respects that of the Branchiopoda, and in others points to that of the Malrcostraca. The long tubular heart stretches from the most posterior head region through the whole thorax into the 4 th abdominal segment, and possesses 7 pairs of ostia. The 3 most anterior of these lie laterally in the heart in the posterior part of the cephalic region, the 3 following dorsally in the $2 \mathrm{~d}$, 4 th, and 5 th thoracic segments, and the 7 th and largest in the 6 th thoracic segment. In the last 2 thoracic segments, and in the abdomen the heart has no ostia. These pairs of (venous) ostia through which the blood enters the heart from the pericardial sinus, are, as in all Crustaceans, provided with valves. The heart is continued into an anterior and a posterior aorta, through which the blood flows out into the body. Valves hinder its return from the two aorta into the heart. Besides the aorta, branched arteries occur in both pairs of antennæ and in the abdomen. The principal portions of the lacunar blood-vascular system are the pericardial sinus and a sinus lying under the intestine.

The respiration is in all cases specially active at the thin inner 
surface of the shell (which is kept clean by long maxillar feelers), and in the lamellate exo- and epipodites of the thoracic feet. In these parts a brisk circulation takes place. The blood which flows through the

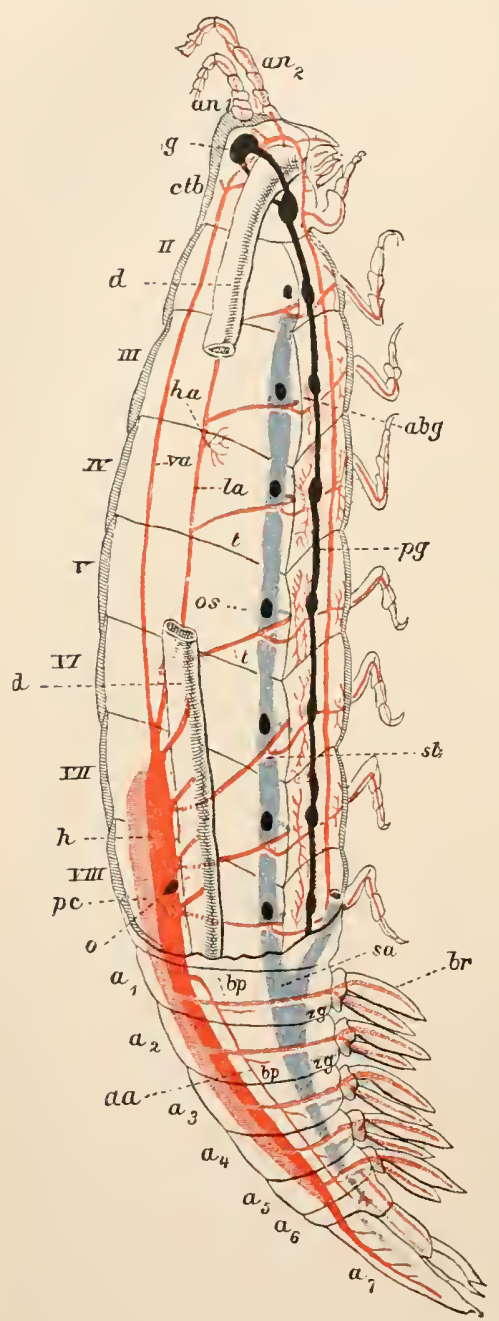

shell comes from the anterior aorta and re-enters the heart by the dorsally placed ostia.

Arthrostraca. - First of all we must here point out an important difference in the position of the heart in the two principal divisions of the Arthrostrace, the Isopoda and Amphipoda. In the Isopoda by far the largest portion of the heart, which is provided with 1 to 2 pairs of ostia, lies in the abdomen; in the Amphipoda, however, the tubular elongated heart which is almost everywhere provided with 3 pairs of ostia lies in the thorax. This difference may be explained by supposing that the Isopoda have retained only the abdominal portion, and the Amplipoda only the thoracic portion of the primitive Ialacostracan heart which ran through nearly the whole length of the body, and was provided with many pairs of ostia. The localisation of the respiration has probably played the chief part in bringing about this differentiation, since in the Isopoda respiration takes place in the rami, and principally in the endopodites of the abdominal feet (pleopoda), but in the Amphipoula chiefly in the pouchlike branchial appendages of the thoracic feet.

In the Anisopoda the heart lies as in the Amphipoda in the thorax.

FIG, 240.-Diagram of the circulatory system of the Isopoda, seen from the side. The right thoracic and cephalic walls remored. A part of the intestine (d) cut away (after Delage). Arterial system red, venous system llue, nervous system black. $a n_{1}$, Anterior; $a n_{2}$, posterior antennæ; $c t b$, cephalo-thorax; II.VIII, 7 free thoracic segments; $a_{1}-a_{7}, 7$ abdominal segments; $b r$, gills (pleopoda); $g$, brain; $d$, intestine ; $h$, heart ; 0 , ostium of the heart; $p c$, pericardium ; v $v$, anterior aorta ; $l a$, lateral arteries ; $t$, thoracic arteries ; $h a$, hepatic artery ; sl, lateral sinuses of the thoracic region; $s c$, abdominal sinus; $a b g$, points of insertiou of the thoracic feet; $p g$, subneural vessel (the dotted line should stop at the red line); $b p$, branchio-pericardial vessels; $z g$, vessels leading to the gills; $\alpha a$, abdominal aorta ; os, ostia (?) of the lateral sinuses. 
The following is a rather more detailed description of the circulation of the Arthrostraca.

Isopoda (Figs. 240 and 241). The heart, which lies for the greater part in the abdomen, and is provided with 1 to 2 pairs of lateral ostia, is closerl blindly behind. Out of it 11 arteries arise, viz. (a) a medio-dorsal thoracic aorta running to the head and the eyes, and supplying the cerebral ganglia, and the 2 pairs of antenne, $(b)$ one lair of lateral arteries for the anterior thoracic segments, and the posterior cephalic region together with the extremities of these regions, $(c) 3$ pairs of thoracic arteries for the 3 posterior thoracic segments and their extremities, $(d) 1$ pair of abdominal aortx for the abdomen and its limbs, which function as gills. The thoracic aorta forms anteriorly in front of the brain a ring which embraces the cesophagus, from which a subneural artery runs longitudinally under the ventral chord the whole length of the body. This also gives off branches to the limbs. Besides the blood lacunæ which lie between the riscera, there is generally in the thorax a large, paired, ventral blood sinus, which in the abdomen becomes unpaircd. 5 prairs of ressels conduct the renons blood ont of the abrlominal sinus into the pleopoda which function as gills. 5 pairs of efferent ressels (reins) conduct the blood which has become arterial in the gills into the pericardial sinus; it prasses thence through the ostia

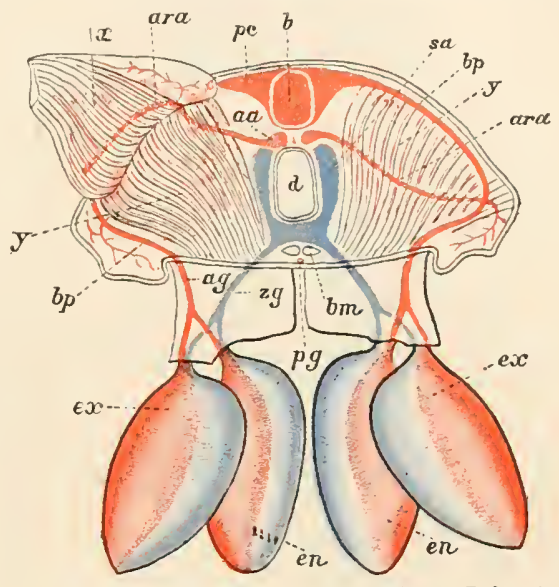

FIG. $f 1$-Conilera cylinåracea (after Delage). Transverse sectiou of the aldomen. Most of the letters lave the same meaning as in Fig. 240. $b$, Heart: $x$ and $y$, muscle layers (muscle lamella) for moving the gills (pleopoda), flexor and extensor; $x$, is laid back; ara, the abdominal arteries which supply them ; $e x$, outer ; $e n$, inner brauchial lamella of the pleopoda (exo- and endopodites); ag, efferent; zf, afferent branchial vessel; $b m$, ventral chord; $p g$, subneural vessel ; sa, abdominal siuus.

into the heart, and by the contraction of this latter it is again dispersed through the arteries.

Amphipoda (Fig. 242). The Amphipode present a striking contrast to the Isopodc in that in the latter the vascular system, in the former the lacunar system, is the most 1ronomeed. The long tubular heart which generally lies in the 5 or 6 anterior free thoracic segments, usually possesses 3 pairs of ostia, less frequently one (Corophium) or 2 (Platyseclidce). It is continued into an anterior and a posterior medio-dorsal aorta, which pour the blood either direct or through further arterial branches into a large ventral sinus which lies between the integument and the intestine and runs through the whole lengtl of the body. Special afferent bloor streams (vessels?) conduct the mixed blood into the extremities of the thorax and abdomen, thus also into the branchial pouches of the thoracic limbs. Special efferent streams collect the blood in these extremities (thus also the blood which has become artcrial in the gills) and conduct it back through 7 vascular loops in the thorax and through 6 in the abdomen into the pericardium, which stretches back beyond the heart to the end of the abdomen. In Corophium the abdominal portion of the pericardium and the abdominal vascular loops are wanting. The bloodvascular system of the Coprcllicle agrees in the main with that of other Amphipode, allowance being made for the reduction of the abdomen. 
It follows, from the above description, that in the Amphipoda the arterial blood cannot in any way be sharply distinguished from the venous blood.

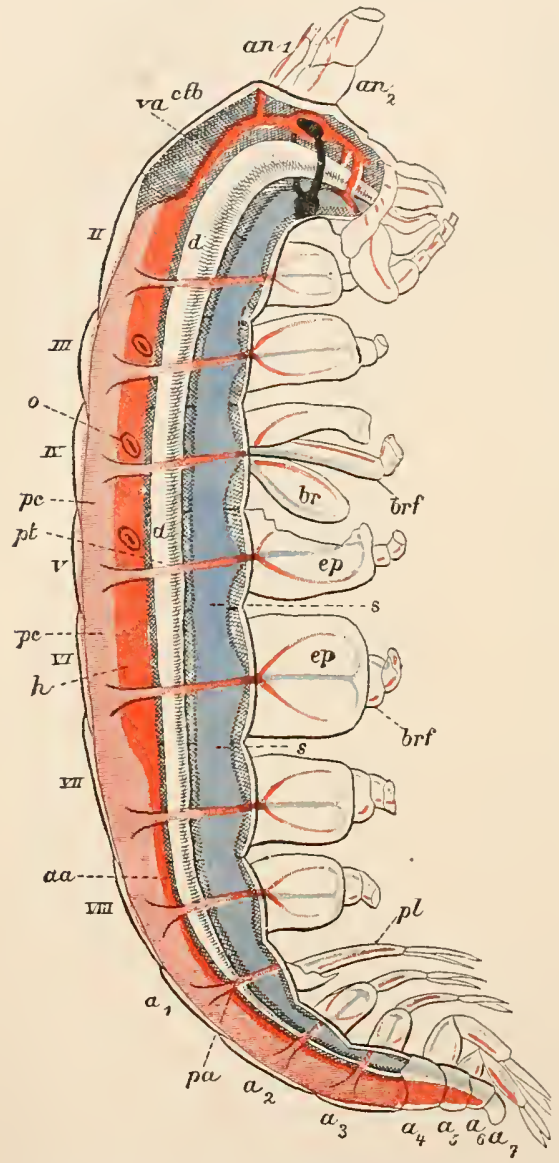

FiG. 242.-Diagram of the circulatory system of the Amphipoda, from the side (after Delage). Most of the lettering as in Fig. 240. pt, Pericardial vessels rising from the epineres $(e p)$, extremities (brf), and gills $\left(b r^{\circ}\right)$ of the thorax; $p a$, pericardial vessels of the abilomen; $s$, rentral sinus; $e p$, epimeres. The epimeres of the thoracic segments $I V$ and $V$ partly eut off ; $p l$, pleoporla.

Anisopoda.-This division of the Arthrostraca, though in many points aplroaching more nearly the organisation of the Isopode than that of the Amphiporla, shows in its bloodvaseular system greater similarity to the latter. Two abdominal aorte, however, arise from the posterior end of the thoracic heart, and the pericardial sinus is continued into the abdomen. The heart of Apseudes possesses two ostia on the left side and only one on the right; in youth the 2 pairs of ostia are present. As to the significance of this fact see below (p. 367).

In all Arthrostrace the paired ostia, as well as the points of origin of the aorta are provided with valves.

Thoracostraca.-The circulatory system here is linked on to that of the Isopoda. Starting with the Stomatopoda, the circulatory system of the older larve of Squilla, known as Alima and Erichthus, which can hardly be distinguished from that of the adult, have been the most carefully investigated. The heart (Fig. 243) extends as a many-chambered dorsal vessel from the maxillar region (behind the stomach) through the thorax and the abdomen to the end of the 5th abdominal segment. Two divisions can be distinguished in it, a short, wide anterior, and a long posterior division. Probably the anterior division alone cor-

FIG. 243.-Circulatory system of an older Squilla larva before it has passed into the Squilla form (after Claus). $h$, Heart, continuer posteriorly into the many-chambered dorsal vessel which is richly provirled with pairs of ostia $(0)$; $\alpha c$, cephalic aorta ; $\alpha_{0}$, optic artery; $\alpha \omega_{1}, a_{2}$, arteries of the two pairs of antennæ; am, marginal artery of the dorsal shell; ast, arteria sternalis; $a l$, hepatic artery; $a s$, shell artery; $a_{1}$, lst lateral artery of the dorsal vessel; $a a b_{1}$ to $a a b_{6}$, lateral arteries of the abdomen; $d r$, glandular saccules on the hind-gut; $l$, hepatic lobes in the telson; $p_{6}, 6$ th pleopod (uropod); $k b$, branchial leaves (epipodial appendages of the oral feet). 


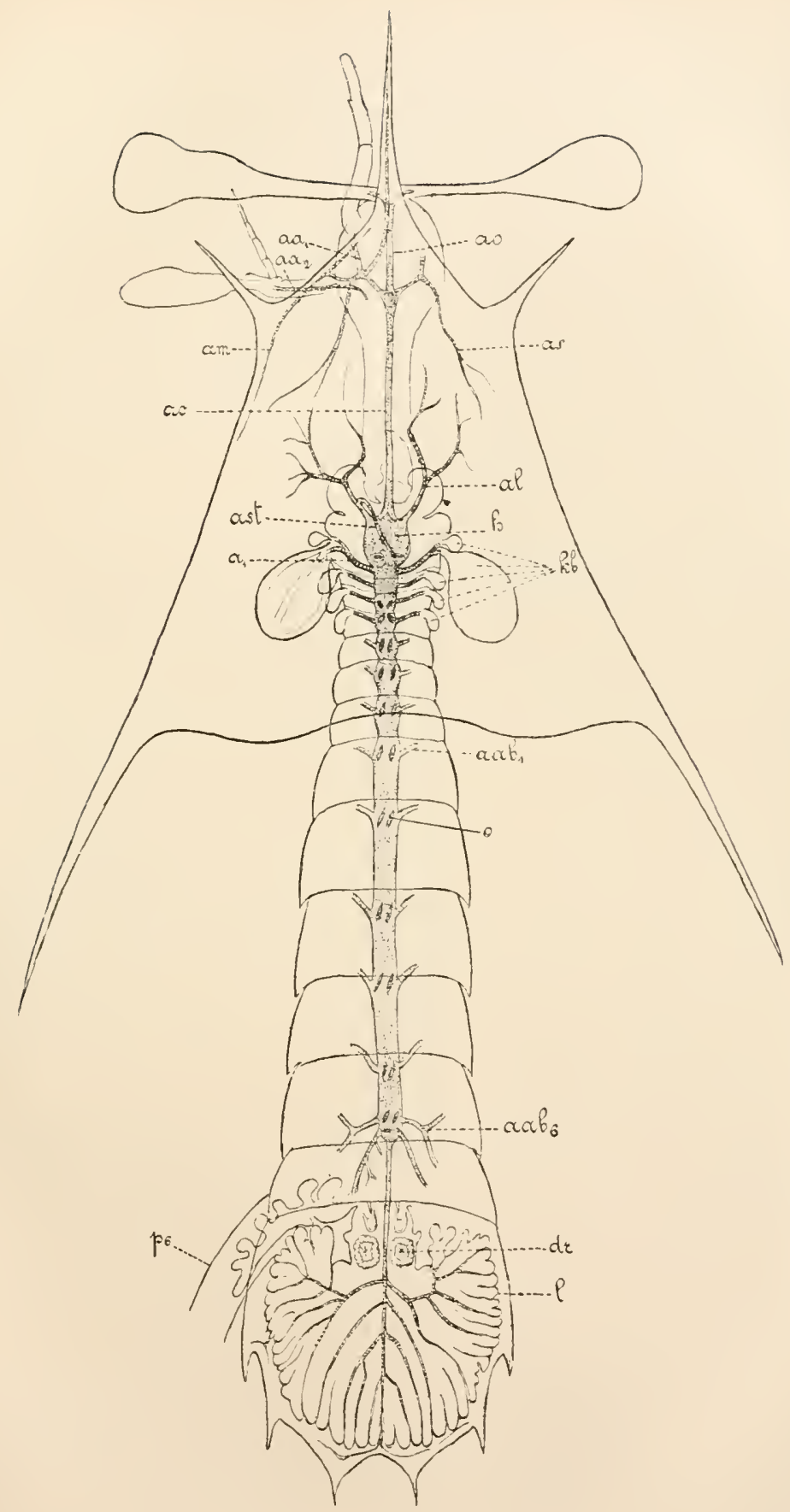

Fig. $2+3$. 
responds with the heart of the Decapoda. It reaches to the posterior limit of the first maxillipedal segment, possesses a large pair of ostia, and gives off the following vessels: (a) an anterior $m$ paired cephalic aorta $(a c),(b)$ and $(c)$ an anterior weaker and a posterior stronger pair of arteries. The second division, the many-chambered dorsal vessel, possesses 12 pairs of ostia, and gives off 13 pairs of arteries and an unpaired posterior aorta. To complete the whole picture of the circulatory system and to show its relation to that of the Isopode, we must add that a median subneural vessel runs under the rentral chord through the whole body, that the whole. venous system is lacunar, and that there are two principal venous sinuses, one rentral, and the other dorsal. The arterial system, on the other hand, is composed of richly-branched vessels having walls of their own and breaking up into capillaries.

As to the more detailed arrangements, the cephalic aorta supplies the eyes, the two pairs of antenne, the brain, and the anterior lateral regions of the shell. The most anterior pair of arteries supplies the mandibles and maxillæ, and the central part of the shell. The large $2 d$ pair of arteries probably supplies the maxillie and maxillipedes; one artery passes between the longitudinal commissures of the ganglia of the 1st and $2 d$ maxillipedal segments to connect itself with the subnemal vessel (compre the sternal artery of the Schisopoda and Dccapoda). The subneural vessel gives off primarily vascular loops to the ganglia of the ventral chord, but it also gives off branches to the limbs. The $\mathbf{1 3}$ pairs of arteries of the many-chambered dorsal vessel supply the thorax and abdomen with their extremities in such a way that the pair of arteries belonging to a pair of ostia spread ont, not in the segment in which the ostia occur, but in that immediately in front of it. The whole heart seems to have been shifted back one segment, so that the pair of ostia lying in the first abdominal segment (there are 7 pairs of ostia in the abdomen) originally belonged to the most posterior thoracic segment. The posterior aorta richly supplies the telson with lateral branches. In the venous system paired lateral blood sinuses conduct the blood ont of the extremities and other organs into the large ventral sinus. The blood streams thence [into the pericardial sinus and through the ostia back into the heart. It is only in the abdomen, whose limbs carry the gills, that the blood which has become arterial appears to flow direct back into the pericardial sinus, avoiding the ventral sinus.

A comparison with younger Squille larve of the so-called Erichthoid stage makes it highly probable that 2 pairs of anterior ostia of the dorsal vessel there present disappear in the course of development. While, as a rule, in the many-chambered dorsal vessel a pair of ostia lies over each ontgoing pair of arteries, there are no ostia to correspond with the two most anterior pair.

Among the Thorccostraca a chambered dorsal vessel provided with many pairs of ostia and reaching into the abdomen is only found in the Stomatopoda. This more primitive condition has here been retained, evidently in connection with the localisation of the respiration in the branchial tufts of the abdominal limbs.

The blood-vascular systems of all the other Thoracostraca, at least of the Schiropoda and Decapoda, closely resemble one another, and must be contrasted with that of the Stomatopoda. [The blood-vascular system of the Cumacea is not yet thoroughly investigated; it probably agrees to a great extent with that of the Schizopoda and Decapoda.] 
The heart of the Schi:opoda, Decapodu, and Cumacea appears, as contrasted with that of the Stomatopodo, extraordinarily shortened and provided with very few ostia ( 2 to 3 pairs). It always lies in the thorax and never stretches into the abdomen. This shortening was evidently caused by the localisation of the respiration in the thoracic region (gills of the thoracic feet, cephalothoracic shield as respiratory organ), and by the more or less extensive fusing of the thoracic segments.

Among the Schisoporlu the heart is still elongated in Siriclle, where it runs through nearly the whole thorax into the last thoracic segment. It is progressively shortened in Mysis and Mysodopsis. In Euphausia it has the concentrated form of the Decapodan heart, and has, like the latter, 3 pairs of ostia, one dorsal, one lateral, and one ventral, while in the other Schisopoda and in the Zorea-larece of the Decapoda, there are but 2 pairs of ostia.

The Circulatory system of Astacus (Fig. 234, p. 338, and Fig. 244) may be taken as an example. The following ressels rise out of the heart: $(a)$ anteriorly the unpaired cephalic aorta, which supplies with its rich branchings the brain and the eyes. (b) Two anterior lateral arteries (also called antennal

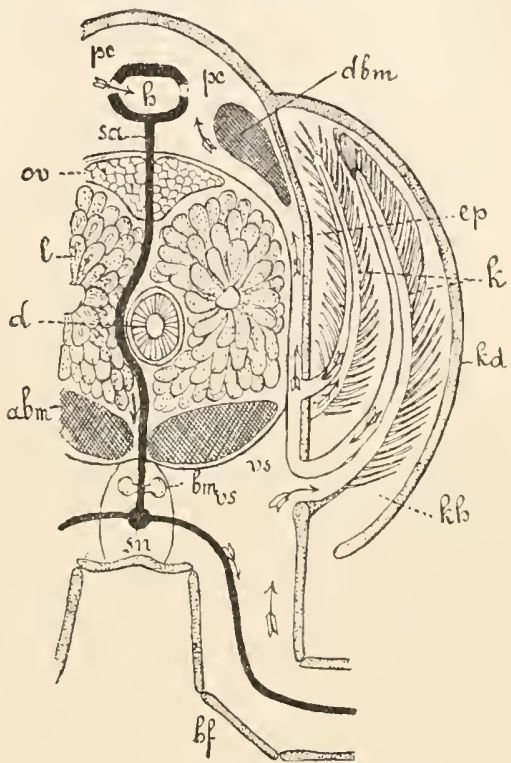

FIG. 244.--Transverse section through the cephalothorax of the Cray-fish in the region of the heart, diagrammatic. $k d$, branchiostegite: $k$, gills; $k h$, respiratory or branchial eavity; $e_{2}$, lateral wall of the cephalothorax; pc, pericartiun ; $h$, heart ; $s a$, sternal artery; $l$, hepatopancreas ; $l$, intestine; $a b m$, ventral longitulinal muscles to the abulonen; $d b m$, dorsal longitulinal muscles to the abdomen; bm, ventral elord; sn, sub-neural ressel; $b f$, ambulatory foot; $v s$, ventral sinus ; $o r$, ovarium. The arrows give the direction of the flow of blood (after Huxley and Plateau). arteries). These give off branches to the stomach, the antennal glands, the anterior and posterior antennx, and the cephalothoracic shield. (c) The two hepatic arteries. These arise at the anterior and lower edge of the heart and branch in the liver. ( $d$ ) The sternal artery. This arises from the lower and posterior end of the heart, which is produced in the shape of a bulb, descends on the right or left side of the intestine, passes between the longitudinal commissures of the penultimate and ante-penultimate thoracic ganglia, to enter the sub-neural vessel below the rentral chord. This must be considered as a modified lateral artery of the heart (see Stomatopoda). (e) The posterior aorta arises out of the posterior end of the heart, and runs over the intestine backwards through the abdomen, giving off in each 
segment a pair of lateral arteries which supply the intestine, integument, and musculature of the abdomen. The sub-neural vessel which receives its blood from the sternal artery, is already known to us in the Isopodu and Stomatopoda, here, however, and in all Decupoda it plays a much larger part, since lateral branches from it supply all the limbs from the maxillie to the last pleopoda. It also serves for nourishing the ventral chord, this being its almost exclusive function in the Stomatopoda, the limbs there being more often supplied by branches of the lateral arteries of the heart. All the arteries branch richly and pass into arterial capillaries, which open into the venous lacunar system of the body. Even though the flow of blood in this lacunar system is, as in all Crustaceans, regular and constant, and though venous blood canals often come into existence, we do not find among the Decupode any veins with walls of their own. The system of venous cavities, taken as a whole, represents the body cavity. WTe can only give a few details as to the course of the venous blood. It nearly all Hows together into a large ventral blood sinus in the cephalothorax, from the lateral parts of which canals condict it into the gills, while other canals convey the blood which has become arterial in the gills array from them to the pericardial sinus. The respiratory organs are therefore here placed in that part of the circulatory system which conveys the blood out of the body back to the heart, and this is the ease in all Arthropoda. The arterial blood coming from the gills leaves the pericardium, and, mixed with the blood which flows back out of the cephalothoracic shield, enters the heart through its ostia. The ostia as well as the points of origin of the arteries of the heart are provicled with valves. The valves of the former prevent the return of the blood into the pericardium, those of the latter its return out of the arteries into the heart. When the heart contracts (systole) the blood contained in it is driven into the arteries, and when it again expands (diastole) it sucks in blood out of the pericardium through the ostia.

In the Mysidce (with the exception of Euphansia) there are 2 or 3 unpaired hepatic arteries, springing from the ventral wall of the heart. The abdominal portion of the sub-nemral vessel is wanting. In the male of Siriclla, which carries gills on its pleopoda, the latter receive their blood from branches of the lateral arteries of the posterior aorta. In the Schizopoda, Cumace, and larece of Decapoda in which the gills are not yet developed, the blood circulation in the cephalothoracic shield with its fold is very brisk, and there is no doubt that in those forms which have no special gills the respiration principally takes place in it. In Siriclla and Mysis and perhaps also in other Schizopoda it is most probable that the integument forming the inner wall of the respiratory cavity has also a respiratory function (comp. Fig. 222, p. 321). The channels which convey the blood ont of the thoracic feet back to the heart cause ridge-like projections in this integument which may be called branchial rilges. The constant vibrations in the respiratory cavity of the epipodial appendages of the first thoracic foot create a constant exchange of water in it.

We have already described (p. 329) the respiratory organ of the air-breathing Birgus latro. We will here briefly deseribe the cirenlation of the blood in connection 
with it. The respiratory organs are branched tufts which arisc on the inner surface of the branchiostegite. The shell circulation which is found in all Thoracostraca and which also plays a grcat part in the respiration of many water-breathing forms, here brings about air-brcathing. In the branchiostegite (here better "lung cover") and its tuft-like appendages thcre is a rich meshwork of blood sinuses, spread ont between the vessels which conduct the blood in and out. The blood passes through a large vessel out of the venous blood sinus of the

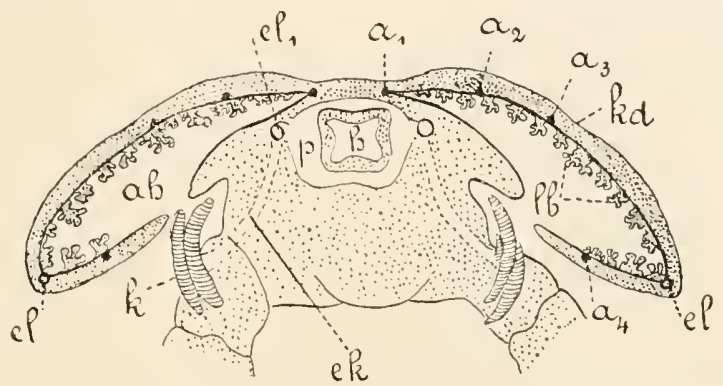

Fig. 245. - Birgus latro. Diagrammatic transverse section in the region of the heart (after Semper). $k d$, Gill or Iung cover; $h$, heart; $k$, gills; ah, respiratory cavity ; $p$, pericardium; $c k$, branchial blood channels leading to the heart; $a_{1}, a_{2}, a_{3}, a_{4}$, lung or shell vessels leading from the heart; $l b$, punonary tufts; $c l$, pulmonary blood channels leading to the leart; $e l_{1}$, the same near their entrance into the pericardium.

head into the lung cover. This vessel divides into 4 branches, 3 of which run to the upper and 1 to the lower portion of the lung cover, and brcak up into the meshwork of blood sinuses above mentioned. From this the blood which has become arterial is collected by vessels which unite into a great trunk, running first along the edge of the lung cover backwards, then upwards, and finally forwards, to unite before entering the perieardium with the vessel coming from the small gills.

The blood of the Crustacea is usually colourless; it is occasionally, however, slightly yellow, green, or red. In the latter case, e.g. in the Biranchiopoda, the colouring material of the blood is hæmoglobin. The colourless blood corpuscles are almost always able to change their form in an amehoid manner.

Judging from the varying position and form of the Crustacean heart, we come to the conclusion that the original Crustacean heart was, as in Branchipus, a long, many-chambered dorsal vessel provided with many segmental pairs of ostia. All other forms of heart have been developed from this by reduction of the anterior or the posterior portion, and by the disappearance of numerous pairs of ostia. These reductions have had for their principal causes the localisation of the respiration, the various differentiations of the different portions of the body, and the fusing of segments. The already mentioned ontogenetic fact that pairs of ostia may disappear in the course of development (Apseudes, Stomatopoda), agrees with this view. In many Isopoda the ostia lie alternately to the right and left in the heart; this arrangement perhaps comes into existence by the disappearance of alternate ostia in the heart at first provided with paired ostia. 
The fact that in many Crustacea, e.g. the Branchiopmed, which go through a long series of metamorphoses from the Nouplius larva, the pairs of ostia are formed with the heart in order from before backward, cannot be brought up as an objection to the above. For this method of development corresponds in general with the manner of ontogenetic differentiation of the Arthropodan and Anmelid body which takes place in that order. The whole question is closely connected with the view to be treated of later as to the phylogenetic significance of the Crustacean larval forms.

\section{The Exeretory Organs (Antennal Glands, Shell Glands).}

Although comprehensive comparative investigations as to the methods of excretion are still wanting, we at least know that this function is performed in very various ways and by very various organs. We shall here take into consideration only two of these organs, the shell and the antennal glands. Certain intestinal appendages and dermal glands which also seem to serve for excretion, are mentioned in the sections on the intestine and the integument. It must not, howerer, be thought that this exhausts the number of parts of the body which have some share in excretion.

Confining ourselves to the antemal and shell glands, we note:-

(1) Number and Position. Each of these glands occurs as a single pair. The former emerge at the basal joint of the posterior antemne. The gland itself lies either entirely in this basal joint or more or less in the adjoining eavity of the head. The shell gland lies in the shell fold or in the cephalothoracic carapace in a region which originally corresponds with the 2d maxillar segment. Its aperture lies on or near the posterior maxillæ.

(2) Oceurrence.-The antennal gland is widely distributed in the Crustacea. It seems wanting only in the Isopola. While in the Malucostruca it is, as a rule, best developed in the adult, in the Entomostrace it only appears in the larval stages, and it but rarely persists in the arlult even as a rudiment. In the Decopoda the antennal gland has been called the green gland. The shell gland is widely distributed among adult Entomostraca. Among the Malacostiaca it has been observed in Nebaliu, and further, in the Isopoda, Anisopoda, Cumacea, and in the larve of some forms (Sergestes, Euphausia) in whose adult condition it is wanting. In Nebctia it is found in a reduced condition.

(3) Structure and Development.-The structure of the antenual gland (Fig. 246) is everywhere essentially the same. Te distinguish in it (1) a terminal saccule, (2) a coiled urinary canal which emerges through (3) a urinary bladder on the basal segment of the posterior antennie. The constitution of the epithelial wall is different in the terminal sac and in the urinary canal. The wall of the latter is often shown in transverse section to consist of one single cell, its lumen thus 
being intracellular. In the higher Crustacea, however, the cells appear in greater number and more closely crowded, the lumen being intercellular. The urinary canal is very long in the Maldecostracu, and lies in complicated coils. At its distal end (near the opening) it widens into the urinary bladder. The terminal sac, as well as the urinary canal, may be further complicated in the higher Crustaceans by the formation of lateral invaginations.

The shell gland has essentially the same structure as the antennal gland.

That we have to do in the antennal and shell glands with excretory organs is shown by the fact that when the animals are fed with carmine, carmine particles are after a time met with in the glandular sacs, at least in those of the antennal glands.

According to observations made on the Cladocera, the shell glands are said to be of mesodermal origin. The antennal glands (of the Crey-fish), on the contrary, are said to come from a dermal depression, and so belong to the dermal glands. further confirmation.

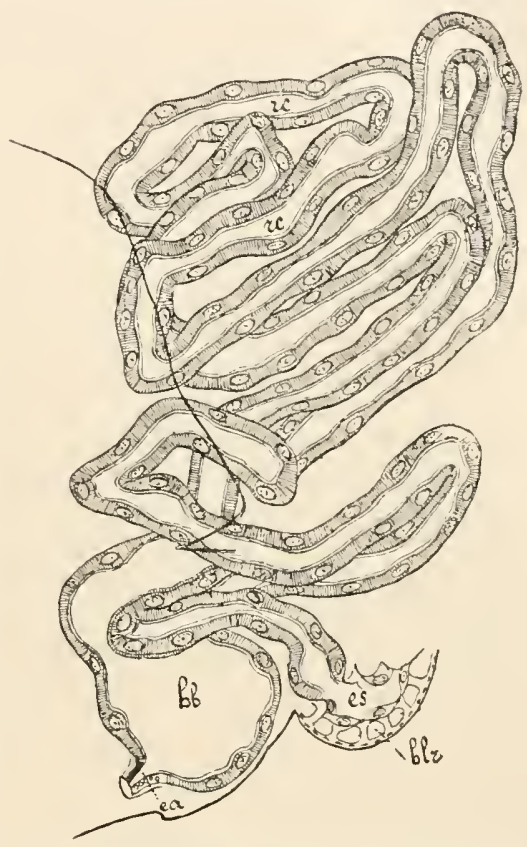

Fig. 246.-Left Antennal Gland of Mysis (after Grobben). $r c$, Urinary canal; $h b$, urinary bladder; es, terminal sac; ber, blood lacuna; $e x$, urinary passage (efferent duct).

These statements, however, require

Morphological Importance.-Lcaving out of consideration the different origins mentioned above attribnted to these glands it alpears probable, from their essential agreement in structure, that the shell and antemnal glands are segmental homologous formations. From their wide distribution in the Entomostraca and Ialacostraca or their larre, we may further conchdc that these glands are, phylogenetically, very ancient organs, derived from the racial forms of the Crustacea. The view that they are homologous with the nephridia of the Annulata may be supported by many facts in their coarser and finer structure. This view wonld gain greatly in probability if it could be shown that both are developed out of the mesoderm. This homology has not, however, yet been established.

This is, perhaps, the place to mention the cement glands of the Cirripedia, which emerge on the last joint but one of the small adhering antenne (anterior antennæ). The hardening secretion of these glands serves to attach the animal to the surface on which it rests.

Besides these, eertain glandular tubes of the Cirripedia, which emerge on the outer maxilke and were formerly taken for olfactory organs, harc recently been 
pointerl out as formations equivalent to the nephridia of the Anmulata (segmental organs). They are said to be in open communication with the body cavity.

\section{X. The Connective Tissue.}

The connective tissue found throughout the Crustacean body can here receive only bricf attention. Plates, membranes, ete. of comnective tissue lie elose under the hypodermis and envelop the enteric canal and the sexual organs, and, as neurilemma, the nervous system. Connective tissue strands, fibres, mesenteries, in various places bind the inner organs together and attach them to the integument The lacunar blood-vascular system, the body cavity, is lined to a great extent, though certainly not contimously, with connective tissue.

A special form of comnective tissue, widely found in Crustaceans, is the fat body, which varies greatly in details. This often envelops the intestine and the lieart. In the connective tissue cells of the fat body are found fat-drops, fat-globules, and also often protein granules. The fat body evidently plays a part sometimes larger, sometimes smaller, in metabolism. It is generally variously developed at different ages and times of the year, and also in the two sexes. In the larval forms it is often strongly developed before the moult, which accompanies a metamorphosis, and forms a reserve of nourishment for the process of transformation. In a few Crustaceans, which take no food at the time of sexual ripeness or of the hatching process, it is strongly developed before this time and much reduced after it.

Connective tissue cells may often become star-like, branched, and oceasionally contractile pigment cells. Pigment also occasionally occurs in liypodermal and intestinal cells.

\section{The Sexual Organs.}

The sexes are separate in the Crustacea, except in a few cases which will be duly mentioned.

The male and female sexual organs are constructed on one type and have a similar position in the body. They are, as a rule, paired. More than one pair never occurs. We can listinguish corresponding divisions in male and female organs; viz. first, the germ-preparing organs (ovaries in the female, testes in the male); second, the ducts of the genital glands (oviducts, in the female, vasa deferentia in the male); third, terminal divisions of these ducts, sharply distinguished anatomically and ontogenetically from the preceding (vulva, vagina, receptaculum seminis in the female, muscular ductus ejaculatorius in the male); and fourth, outer copulatory organs.

The ovaries and testes cannot in their earliest stage be distinguished. They can early be recognised as distinct cell groups in the mesoderm, their rudiments can sometimes be traced back to one or two segmentation cells.

The oviducts and vasa leferentia arise out of the mesoderm apart perhaps from the rudiments of the germ glands.

The terminal sections of the ducts arise by invaginations of the outer integument.

The outer copulatory apparatus consists either of transformed limbs or appendages of limbs, or of processes, folds, prominences, etc. of the integument. 
There is no doubt that the sexual organs in all Crustacea were originally paired. Some of them may, however, become umpaired, either (as in most Copepodu and Thorucostraca) by the two germ glands becoming connected by an unpaired uniting portion, of by the two ducts uniting over a greater or smaller extent to form a common unpaired oviduct or vas deferens, or by the ducts emerging through a common aperture. We can, however, always recognise the double nature of the sexual apparatus in some one (generally the larger) portion of it.

The ovaries and testes are either simple or branched or coiled tubes or sacs which occupy in the body a dorsal position on each side of the intestine, often between the heart and the intestine. They lie in the trunk sometimes more to the front sometimes more to the back, and sometimes along nearly its whole length. Where there are connecting portions between the germ glands of the two sides they lie dorsally above the intestine.

The genital apertures are found on the ventral side except in the Cluduceru and some Copepolu, where they lie dorsally.

In the Entomostraca, setting aside the Cirripedia, the apertures lie, as a rule, immediately behind the limb-bearing anterior division of the trunk, at the limit between this and the limbless terminal division called the abdomen. The single or double segment in which they emerge is called the genital segment. There is thus in the Entomosticuce no definite constant segment of the body in which the genital apertures lie.

In the Malucostrecu, on the contrary, apparently including the Leptustruce, the position of the genital apertures is definite and constant. The male genital apertures everywhere lie in the most posterior (i.e. the Sth) thoracic segment, usually (Thorucostruca) in the basal joint of the Sth pair of thoracic limbs. The female apertures are in the third from the last (the 6th thoracic segment, if we reckon in those fused with the head), and mostly in the basal joint of the protopodite. There are no exceptions to this rule.

The Spermatozoa of the Crustacea are often distinguished by their remarkable size and shape. In the Decapolu they are provided with radially arranged processes, and are, as also in other divisions of the Crustacea, immobile.

Numerous spermatozoa are often enclosed in a common envelope (spermatophore) formed by the secretions of the glandular portion of the male ducts. The eggs of many Crustacea possess besides a yolk membrane other accessory envelopes secreted by the female ducts. On adaptations for the care of the brood, see p. 379.

Should the view prove correct, that the oviducts ancl rasa (leferentia and also the antennal and shell glands correspond with the Anmulatan nephridia, then, considering the different position of the male and female genital apertures, several pairs ( $t$ at the least) of the segmental nephridia of the Ammulatu have been retained in the Crustacea. 
Entomostraca.-In the Branchiopoda, the germ glands are paired; in Branchipus (Fig. 191, p. 288) they are tubular and hie in the abdomen; in Ams they are richly branched and lie in the limb-bearing division of the trunk. In Branchipus the oviructs are widened out at their ends and enter a uterus in which the eggs remain for a time receiving a shell yielded by special nterine glands. The uterus lies in a pouch formed by a concrescence of genital prominences, the moditied limbs of the two genital segments (12th and 13th trunk segments).

The vasa deferentia are also widened out at their ends (sperm vesicles) and enter a muscular ductus ejaculatorius, which, when the penis is evaginated, is drawn out

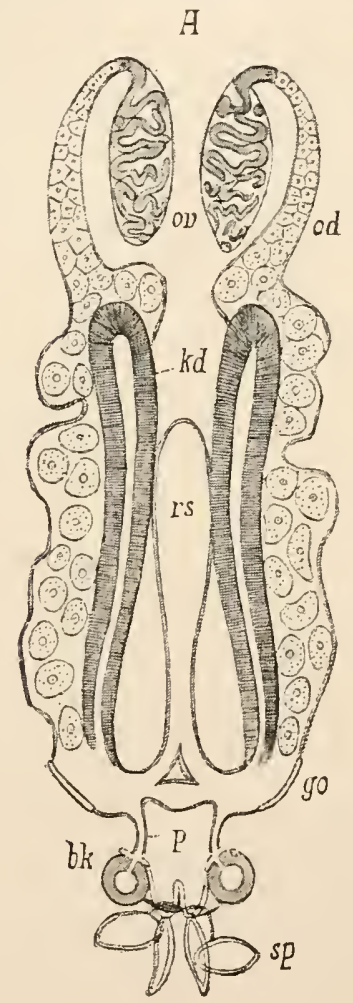

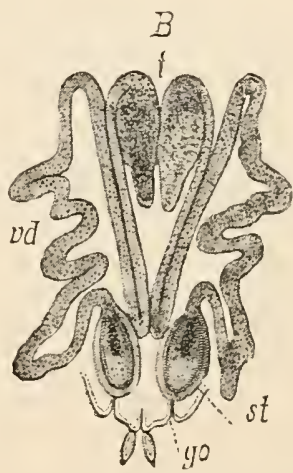

FIG. 247.-Genital organs of Lernanthropus (after Heider). $A$, Female, $B$, male organs. ov, Ovary; oul, oviduct; lil, cement glands ; $r s$, receptaculum seminis ; go, sexual aperture; $p$, pore canal to the spermatophore; bl; brown body ; sp, spermatophore; $t$, testis; $v d$, vas deferens; st, spermatophore pouch.

with it inside it. The penis is an ectodermal outgrowth of the second genital prominence.

In the Cladocra, the ovaries and testes are simple paired tubes. The oviducts emerge dorsally into the posterior end of the brood cavity (sce on Care of the Brood, 1. 379). The vasa deferentia with the ductus ejaculatorius emerge by paired apertures on the ventral side of the limbless posterior division of the body.

In the Ostracode the germ glands are praired, as also are the rasa deferentia and the oriducts. The testes often fall into several tubes. The ductus ejaculatorius witl the sperin vesicle may be umpaired (Cypridina). The copulatory apparatus of the male is to some extent complicated (transformed lindermost limbs). In the female, two genital prominences corresponding with those of the male contain the receptacula seminis. In Cypris the ovarial tubes extend into the shell-fold. 
Copepoda.-The germ glands are mostly mpaired, and placed symmetrically in the anterior trunk segment dorsally on the intestine. That they were originally double is oceasionally apparent. In many parasitie Copepode (Fig. 247) the germ glands are distinctly paired and not eomnected by any transverse bridge. In Supplivina a transverse bridge occurs. The ovirlucts are paired, and generally branched. Their ends are glandular or provided with glandular invaginations (cement glands), whose secretion yields the material for the egr saes. A receptaeulum seminis common to the two oviduets is often found. The paired ajertures lie in the first abdominal segment (sometimes at its posterior edge) either ventrally, laterally, or (rarely) dorsally. The sperm passages are paired or unpaired; in the latter ease they are generally on one side. They are provided with a slandular division, whieh yields the envelope of the spermatophore, and often with a wider portion funetioning as spermatophore poneh. The apertures in the genital segment are paired or unpairer ; in the second case frequently asymmetrical.

Argulidæ. - Two pairs of testes oceur in the caudal fin, and there are 2 vasa deferentia with eommon sperm vesiele. A glandular tube, coming from the anterior part of the body, enters each vas deferens. The two rasa deferentia unite under the intestine into a common duetus ejaculatorius, which opens at the end of the last thoracie segment on a papilla-like projection. The ovary is unpaired, and even from its first appearance asymmetrical; it lies in the thorax. The oviduct first aplears paired, but it is afterwards atrophied on one side, and emerges at the base of the caudal fin. Two receptacula seminis, entirely separate from the female genital apraratus oceur on the under side of the caudal fin.

Cirripedia.-The strikingly lobate oraries are paired in the Balanide, and lie deep down in the shell ring (Fig. 20 $\bar{\tau}, 7.304$ ) in that part of the body eavity which extends into the mantle fold. In the Lepadicte (Fig. $205, p .303$ ) the ovaries, which are to some extent mited, lie in the anterior eephalic portion of the body called

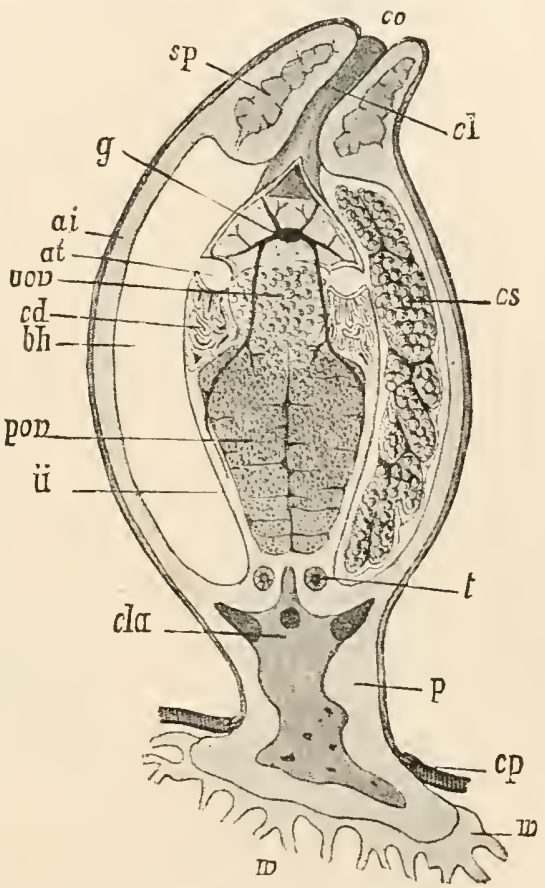

Fic. 24s.-Longitudinal section through a mature Sacculina carcini externa, at right angles to the plane of symmetry (after Delage). co, Cloacal aperture; sp, splincter of the cloaca (cl); g, ganglion ; $a i$, outer integumental lamella, covering the broul cavity ; at, female genital atriun, into which the unpaires portion (uov) of the ovary and the cement glands $(c d)$ enter; $b h$, brool cavity, shown empty to the left, with egg sacs (es) containing the developing eggs to the right; pov, the paired part of the ovary ; $i$, immer integmental lamella covering the boily lroper or visceral sac; $p$, stalk entering the aperture in the shell carapace (cp) of the host; $v$, at tachments of the roots on the stalk; cla, central lacuna of the stalk continued into the lacunce of the outer integumental lamella, the roots, etc., representing the bocly cavity ; $t$, testes.

the pedunele. In both the Balanide and the Lepadida the terminal division of the oviduct energes on a projection on the basal joint of the anterior prair of tendril-like 
fcet. This position deserves special notice, because the sexual apertures in no other Crustacean lie so far forward.

In the Rhi:occphala (Fig. 248) the oraries, in the shape of two lobate united masses, fill the greatest part of the visceral sae of the body which corresponds with the head of other Cirripecles. They open on each side into an atrium (at), into which the cement glands (col) also enter, and which itself opens into the brood cavity (bh). The orary in Sacculina is said at its first annearance to be unpaired.

The testes in the Balanide and Lepadide (Fig. 205, $t$ ) occur as two richly-branched tubes at the sides of the intestine and are continued as 2 vasa deferentia, which swell out into sperm resicles before uniting at the base of the cirrus at the extreme posterior end of the body to form the common ductus ejaculatorius. The 2 testes of the Phi:oceplucla (Fig. 248, $t$ ) are simply tubular, and their vasa deferentia emerge at
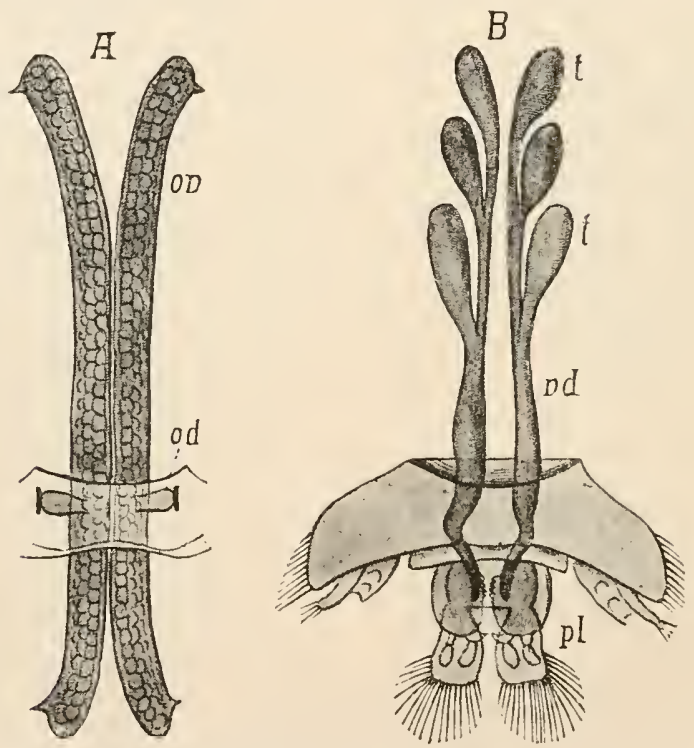

Fig. 249.-A, female, $B$, male genital apparatus of Asellus aquaticus (after $\mathbf{0}$. Sars). $o r$; Ovary ; od, ovifluct; $t$, testicle lobes; $v d$, vas deferens ; $p l$, 1 st and 21 pairs of pleoporla.

that part of the brood cavity where the visceral sac is produced into the stall. See also below as to the sexual relations in the Cirripedic.

There is much more uniformity in the genital organs of the Malacostrace than in those of the Entomostrack. While the two oraries and the two testes remain separate in the Leptostraca and Arthrostraca, in the Thoracostraca, with few exceptions, they arc joined above the intestine by an intermediate piece.

Leptostraca. - The oraries and testes are long tubes which in the sexually mature animal run dorsally at the sides of the intestine from near the masticatory stomach to the last abdominal segment. The two short sperm ducts of the male cmerge in the manner typical of the Malacostraca on a projection on the basal joint of the 8th pair of thoracic feet. The aperture of the oviduct also probably lies, as in other Malacostraca, in the third thoracic segment from the last.

Arthostraca.-The testes and ovaries are nearly always simple paired tubes, which sometimes run through the largest prortion of the thorax and abdomen, some- 
times are limited to the thorax, or to onc portion of the thorax. In most Isopocde the testis generally falls on each side into three pouches (Fig. 219, $B$ ), which, however, possess a common vas deferens. The oviducts open in the antepenultimate thoracic segment into the brood cavity, recptacula seminis often developing at their ends.

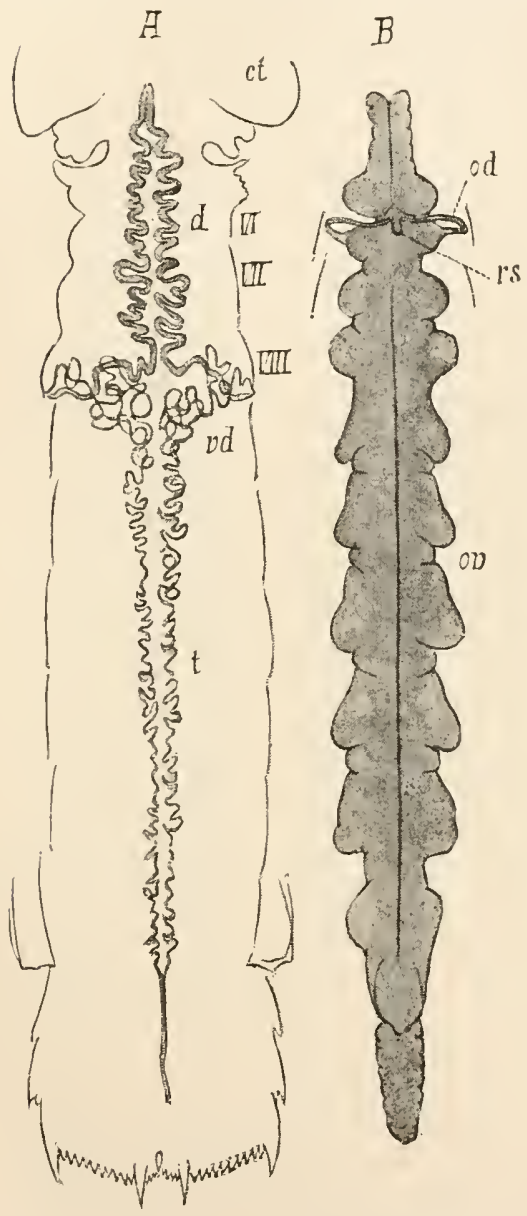

Fig. 250.-Genital organs of Squilla mantis (after Grobben). $A$, Male, $D$, female organs. ct, Posterior end of the cephalo-thoracic shield; VI, $V I I, V I I I$, the 3 hindermost free thoracic segments ; $t$, testis ; $v d$, vas deferens ; $d$, appencled glands ; $o v$, ovary; od, oviduct; $r s$, receptaculum seminis.
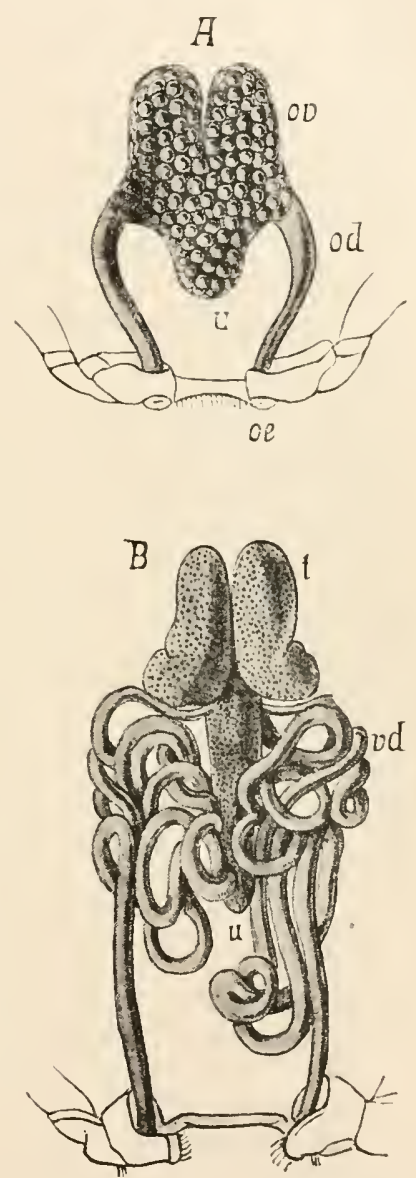

Fiq. 251.-Sexual organs of As. tacus. A, female, $D$, male organs. ov, Ovary; $u$, unpairel portion of the same; od, oviduct; oe, genital aperture; $t$, testes ; $v d$, vas deferens (after Huxley).

The female genital apertures very often (Isopoda, Anisopoda) only appear at the time of the formation of the brood pouch. Peculiar phenomena appear at the time of reproduction in the Oniscide. The two receptacula (representing inraginations of the onter integument) are at first not in open communication with the ends of the oviducts. Only after sperm has, during copulation, entered the receptacula, do they 
pass into the oviducts by the bursting of their walls, and thus bring about the fertilisation of the eggs in the ovaries. The animal then casts its skin, and with the skin the reeeptacula seminis, so that the two genital apertures are no longer fresent. The fertilised eggs pass from the ovarium into the body cavity and thence through a newly-formed unpaired birth aperture in the last thoraeie segment but one into the brood eavity. A new bateh of eggs is fertilised later in the ovary by sperm left over from the first copulation, and this reaches the brood cavity in the same way. After this second batch of eggs has been developed in the brood cavity and the young that are hatched have left it, the animal moults, and then again appears as it was before eopulation.

Thoracostraca. - The genital organs of the Cumacece and in some respects also those of the Schizopoda need more thorough investigation. The paired sexual glands of the Thoracostraca are united by an umpaired piece which lies in the thorax in the Decapoda and Schizopoda, and in the telson in the Stomatopoda (Fig. 250), and always above the intestine. This piece is wanting only in the Cumacea (?) and Paguridce. Except in the Stomatopocta and Paguriclce where the ovaries and testes lie in the abdomen, the germ glands are entirely or for the greater part restrieted to the thorax. They everywhere lie between the intestine and the heart. The testis on each side is a tube which either remains straight (Stomatopocla), or is coiled up in a complicated manner (e.g. in Paguristcs, Carcinus), or is provided with simple lateral invaginations (Palinurus), or is much branched and carries small sacs at the ends of the branches (Astacus). It is enclosed in an envelope of connective tissue. The long and much coiled vasa deferentia run, like the oviducts in the female, posteriorly where the germ glands are in the thorax, and anteriorly where they are in the abdoncn. They fall into two divisions, a proximal portion lying near the testes and a distal glandular portion often provided with small invaginations, this latter division being continued into the strongly muscular ductus ejaculatorius. This opens outwardly at the basal joint of the last pair of thoracic feet either on a slight-swelling (IAcrura) or at the point of an elongated tubular penis (Brachiura, Schizopoda).

In the Stomatopola there emerges at the point of the penis, besides the ductus ejaculatorius, the duct of a paired tubular accessory gland (Fig. 250, $A, d$ ) which lies in the frce thoracic segments, and the two parts of which are comnected anteriorly by an unpaired intermediate piece.

The ovaries agree in general with the testes in position and shape, but they are simpler inasmuch as they are simple tubes or vesieles. In Squilla they have segmental bulgings. The oviducts are shorter and not so much coiled as the sperm ducts. They emerge at the typical point in the antepenultimate thoracic segment, in Squilla immediately at the side of a median receptaculum seminis.

We cannot here enter on the subject of egg and sperm formation in the Crustacea. But the egg formation in the Cladocera, as it is peculiarly interesting, must be briefly described. Successive groups, each consisting of four germ cells, sever themselves from the germ layer when the production of summer eggs takes place, but only one cell out of each group becomes an egg, the others being used up as nourishment. In the production of winter eggs, however, only one cell out of every second group of germ cells becomes an egg, whilc the remaining 7 cells of the two groups serve as nourishment for the one egg.

\section{Sexual Dimorphism.}

This is more or less marked in all Crustacea. Therc are indeed no outer or inner portions of the body which in some one species, genus, or order of Crustacea are not differently constructed in the two sexes, and these differences have great biological significance and are of great importance in classification. We can here only select the most important and most widely distributed. 
The sexual differences are all to be nltimately explained as adaptations for ensuring reproduction and for preserving the young. Adaptations facilitating the copulation of the male and female are principally found in the boty of the male. Adaptations for securing the favourable development of the egrss are met with in the female.

Male Sexual Characteristics. - (a) The males of the (rustacea are throughout smaller and often also more agile than the females. This distinction of size is specially remarkable in parasitic and attached Crustacea, where the minute males (as in the Cimipedia and pereesitic Isopodi1) are described as dwarf males. On the other hand, in all cases where the females are so deformed and degraded by parasitism as to be hardly recognisable or evell altogether unrecognisable as Crustaceans, the males appear less degenerated; they are usually still able to move freely, are provided with distinct limbs, and show some resemblance to the nearest related free-living forms. This slighter degeneration on the part of the males may be considered as the persistence of a larval stage, the parasitic Crustacea undergoing, as we shall see, a striking metamorphosis. Free-living larval forms with Crnstacean characteristics, however, bring about the infection of new hosts. The degradation and crippling of the body only take place after the larva has attached itself on its definitive host. In the males this degradation does not occur, or not to

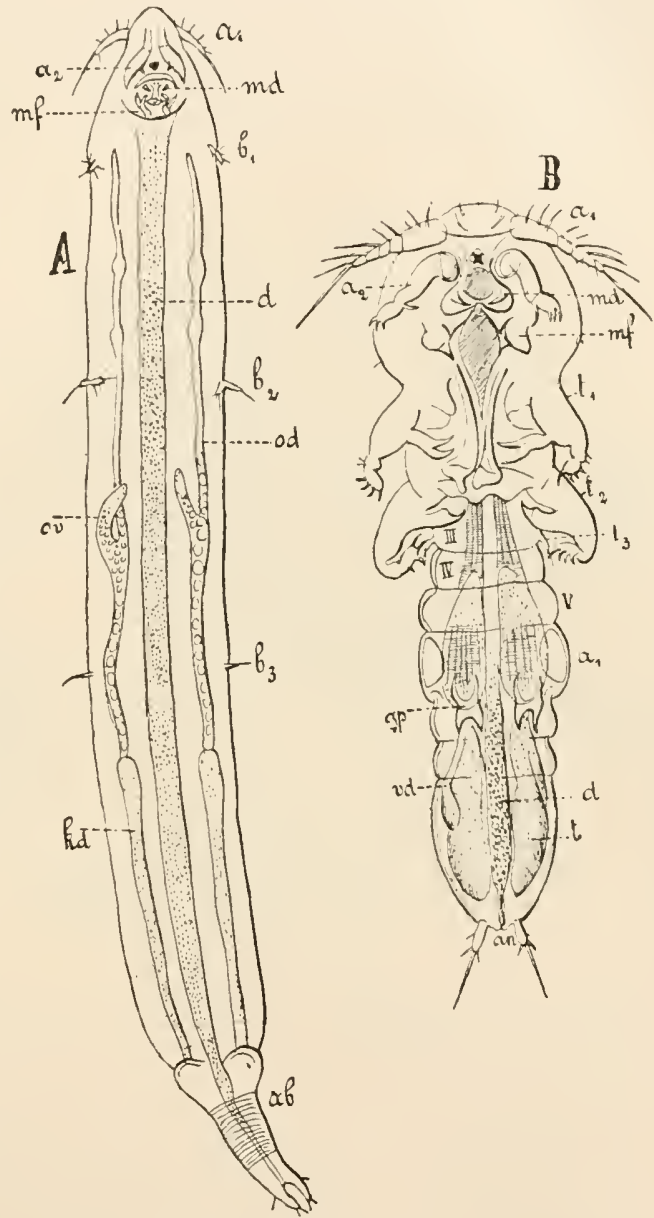

Fic. 252.-Lernaeascus nematoxys. A, Fernale, $D$, male, more highly magnified. $a_{1}$, Anterior; $a_{2}$, posterior antenne; md, manulibles; mf, maxillipedes; $b_{1}, b_{2}, b_{3}, t_{1}, t_{2}, t_{3}$, thoracic feet; od, oviduct; $o v$, ovary ; $k d$, cement gland; $a b$, abdomen ; $d$, intestine; $I I I, I V, I$, thoracic segments ; $a_{1}$, 1 st abilominal segment; $g p$, genital plate; $v d$, vas deferens; $t$, testes (after Claus).

the same extent, because they are obliged to retain their power of free locomotion in order to ensure the possibility of copulation and of fertilisation of the females. Since, however, the sole work of the male consists in the seeking out of, and the fertilisation of the female, we often find (as in the parasitic Cirripedia) great 
degeneration of the parts not immediately connected with reproduction. The intestine is thus wanting in the dwarf male of the Cirripecia which on reaching its destination, i.e. the body of the female, there leads a semi-parasitic life. If the male does not reach this destination, he has failed in his life-work and perishes. To this subject of dwarf males we shall have to return (p. 382).

The aceompanying figures (Figs. 252, 253, 254) illustrate the great sexual dimorphism found in certain parasitic Copepoda and Isopoda.

(b) The olfactory filaments (Riech- und Spitr-faden) on the anterior antennæ are always present in far greater numbers in the male than in the female.

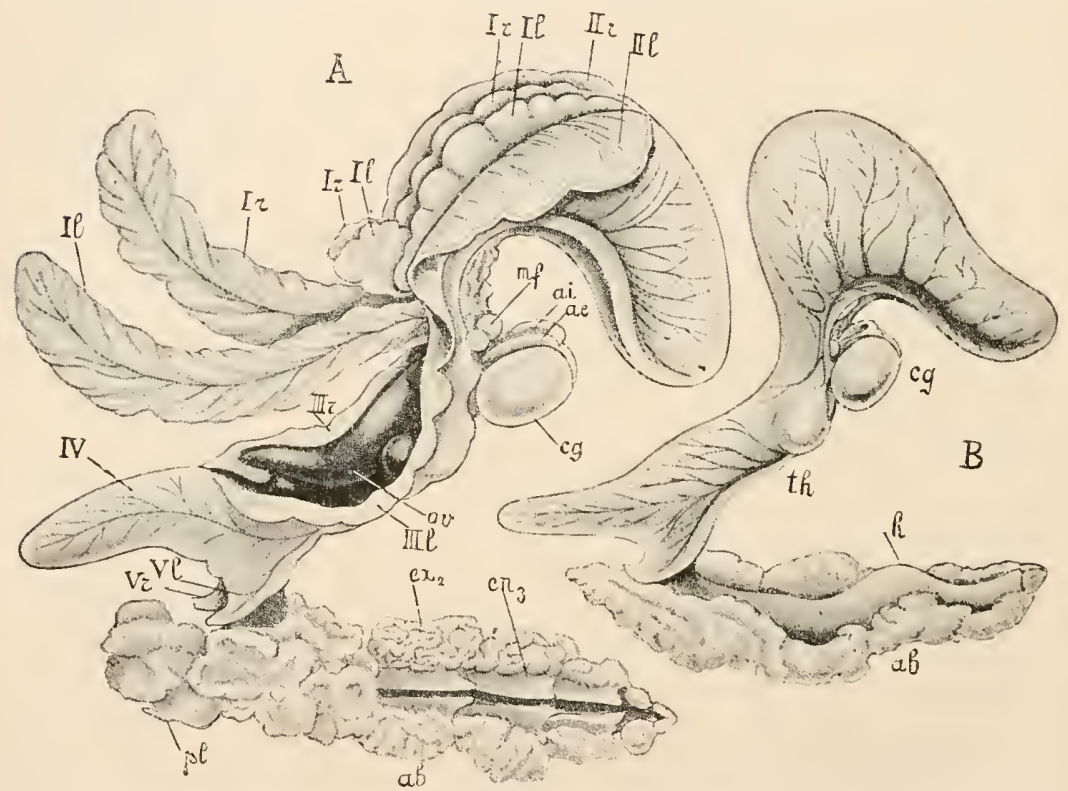

FrG. 253,-Portunion Mænadis. Alult mature female (after Giard and Bonnier). A, With the brood cavity partly opened in the ventral median line and the brood lamellæ separated. The abrlomen $(a b)$ is so placed that the ventral side is seen. Ir, The anterior middle and posterior lobes of the first brood lamella on the right sile; $I l$, the same of the first brood lamella on the left; $I I r$ and $I I l, 2,1$ brood lamellæe (right and left): $I I I r$ and $I I I l, 3 d$ brood lamella (riglit and left); $I V$, 4 th broor lamelle; $V r$ and $V l$, 5th broos lamellx (right and left); $p l$, pleural lamella of the lst abdominal segment; $e x_{2}$, exopodite of the pleopod of the $2 \mathrm{~d}$ abdominal segment; en $n_{3}$, endopodite of the pleoporl of the $3 d$ ablominal segment; $o v$, ovary; $c g$, cephalogaster; ac, outer ; $a i$, inner antennæ; $m f$, maxilliperle. $L$, Adult female, brood cavity not opened. The abdomen $a b$ is seen slantingly from above; th, thorax; $c g$, cephalogaster; $h$, carlial prominence.

(c) In the males of the most different divisions, apart from the actual copulatory organs, there are limbs transformed into "accessory organs of copulation" for the seizing, grasping, and holding fast of the female. Such are the posterior antenne of Branchipus, the seizing hooks in the anterior pair of limbs of the Estherida, the adaptations for holding the female in the $2 d$ antennæ or the maxillipedes of the Ostracoda, the anterior (seizing) antenne of the Copepoda, etc. In the Ampihipoda the seizing hooks on the anterior thoracic feet are more strongly developed in the male than in the female. In the Anisopoda (Tanais dubius) 2 forms of males have been observer, both of which seem to be peculiarly well organised for eatehing and holding the female. The one form may be called "scenters," the other 
"scizers." The former have numerous olfaetory filaments on the antenur, the latter much larger and very movable pincers on the ehelate feet. In the Decopodan males, the most anterior pair or the two most anterior pairs of pleopoda seem transformel in order to assist in eopulation. In the erayfish for example, they serve as tubes or chamnels for condueting the spermatophores away from the genital aperture to their lestination. The other pleopoda whieh in the female carry the fertilised eggs are redueed in the male, or may be, as in the Brachyure, entirely wanting. In

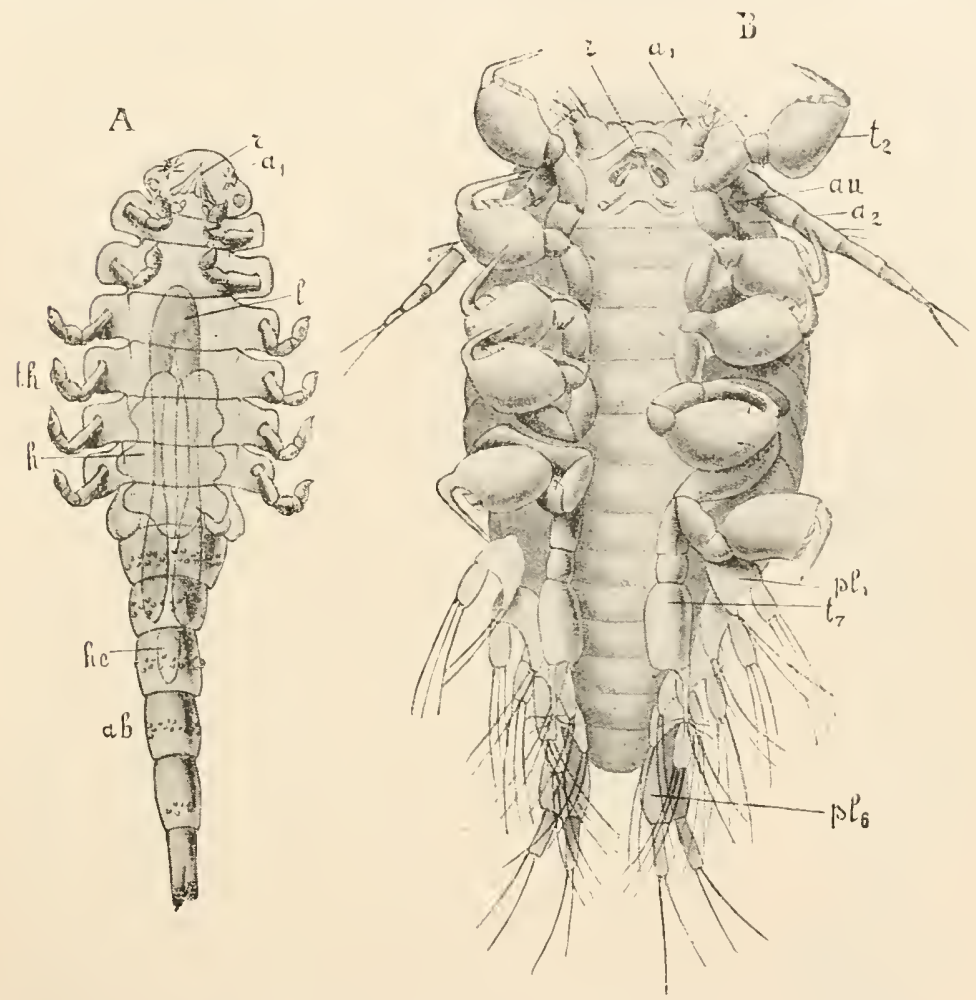

FIG. 25t. - A, Adult male of Cancrion miser (nearly related to Portunion, [Fig. 253, after Giard and Bonnier). $r$, Rostrum ; $a_{1}$, anterior antenna ; th, thorax ; $l$, liver ; $h$, testis ; he, heart ; ab), abdomen. B. Hatched embryo of Portunion Maenadis (after Giard and Bonnier) from the ventral sile. $t_{2}$, limb of the $21 ; t_{1}$, of the 7 th thoracic segment; $a_{2}, 21$ antenma; $l_{1}, 1$ st; $l_{6}, 6$ th $_{1}$ pleopod ; $c u$, eye.

the Irecapodan males also the ehela of the ehelate feet are more strongly dereloped than in the female.

Adaptations for the Care of the Brood. - It rarely happens in the Crustaeea that the female simply lays the eggs, attaehing them to some foreign object and learing them to their fate. We find almost everywhere, on the contrary, that the females retain the eggs on or in their own bodies in sneh a way that they are proteeted and often also nourished by the mother body. The eggs develop under the protection of the mother body, till the larre or young Crustaeeans are hatehed, and even these oeeasionally remain for some time in their birthplaee. 
In the Cirripedia the eggs are concealed in the interior of the shell between the mantle and the body of the animal. In the Rhizocephala the integument splits into an outer lamella (mantle) and an inner lamella (wall of the visceral sac). Between the two a brood cavity arises (Fig. 248, p. 373), into which the eggs, emerging from the female atrium, enter, and in which they develop. The egrgs are enclosed in a richly branched sac, formed of a chitinous membrane, and exactly repeating the form of the cement slands which enter the female atrium. The sac is in reality nothing but the inner cuticular lining of the cement glands which is ejected when the eggs are laid and becomes filled with the eggs as they leave the ovary. The Nauplii which develop out of the eggs in the brood cavity reach the exterior by means of its aperture called the cloaca. In the Branchiopodu there are various arrangements for the care of the brood. In the shelled forms, the eggs are concealed under the shell, either in aplendages of certain pairs of limbs which are transformed into ovisacs or brood pouches (Apus), or on filamentous appendages of such limbs (Estherider). In the Cladoeer the eggs develop in a brood cavity (Fig. 192, p. 289), whieh forms dorsally between the shell and the body, becomes entirely closed towards the exterior

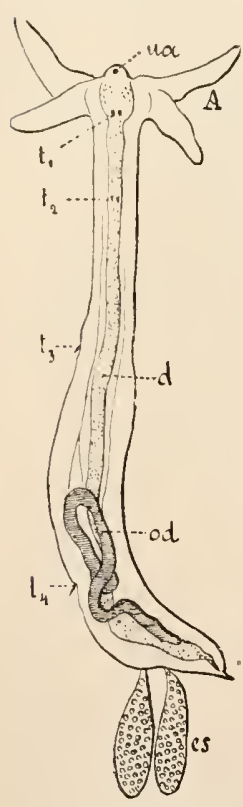

Fig. 255.-Lernaeocera esocina, female. $u$, Frontal eye; $t_{3}, t_{2}$, $t_{3}, t_{4}$, rudimentary thoracic feet; $a$, intestine ; $o d$, oviduct; $e s$, egg sacs; $A$, arm processes at the anterior end of the body (after Claus).

female than in the masses. The same Macrura also. by special arrangements, and contains a fluid for the further nourishing of the brood. In some Cladocera, a saddle-shaped thickening of the dorsal integument of the shell (Ephippium) covers every one or two winter eggs, and is cast off with the eggs as a protection during winter. This ephippium is often provided with adaptations which facilitate its passive distribution in space. In the Copepoda, the eggs which emerge from the genital apertures reach the interior of ovisacs which stand out freely from the body (in the genital segment), and which are formed from the secretion yielded by the cement glands. Where the two genital apertures lie somewhat far apart laterally or dorsally in the double genital segment there is a prair of ovisacs; where they lie very near each other on the ventral side, one unpaired median ovisac is formed (Fig. 194, 1. 290). These ovisacs are so characteristic of the Copeporla, that by this means the most deformed parasitic Copepodan females may be recognised (Fig. 255). In the Notodelphyde alone the eggs pass into a brood cavity enclosed by the integumental folds. The female of the Leptostrace sheltcrs the eggs and hatched larve between the lamellated thoracic feet. In the female of the Arthrostraca, Schizopoda, and Cumacea the brood lamelle on the basal joints of the thoracic feet already describerl develop at the approach of sexual maturity. These brood lamelle, by locking into one another from right and left, form the base of a brood cavity, whose cover is the ventral (sternal) integument of the thorax (Fig. 218, p. 318). The eggs reach this brood cavity and develop in it. The hatched young or larve often stay some time in it. The females of the Decapoder attach the emerging eggs to the pleopoda hy means of the secretion of the cement glands alrcady mentioned on the under side of the abdomen. In the Brachyura, whose shield-shaped abdomen is hent round on the sternal sicle of the cephalo-thorax, the abrlomen is generally decidedly larger and broader in the male, and more adapted for covering and protecting the egg differcnce, though not so pronounced, may be seen in the 


\section{Hermaphroditism in the Crustacea.}

Hermaphroditism is a rare phenomenon in the Crustacea, and only found in attached and parasitic forms, viz. in the attached and parasitic cirripedic and in parasitic Isopoda. ${ }^{1}$ The sexual relations in these groups are very interesting and unust be further briefly described.

The commoner Balanide and Lepadide are hermaphrodite. There are, however, Lrpadide (Ibla and many species of Scalpella) in which, besides the hermaphrodite inlividuals, dwarf males oceur. These latter live parasitically on the bodies of the hermaphrodite individuals, generally in a fold of the mantle at the closing edge of the scutum. In their structure and form they are nowise like the hermaphrodites. They do not arlvance beyond the so-called Cypris stage, their body is almost vermiform and possesses besides the antenne only 4 pairs of reduced tenrlril-like feet. 'The oral limbs are wanting. A mouth is wanting, the enteric canal is rudimentary, and the testes muraired. It is evident that these reduced dwarf males provide occasionally for the cross fertilisation of the hermaphrodite individuals.

There are again some species of Scalpella (Sc. omatum, regium, parallelogramma, nymphocola), and further the genera Cryptophialus and Aleippe, in which dwarf males oceur, but in which the individuals which correspond with the hermaphrodite individuals of the related cirripedic are not hermaphrodite, but only female. Here, therefore, sepraration of the scxes prevails with marked dimorphisn. The majority of the Cirripedia, however, seem to be hermaphrorite without dwarf males. The Rhizocephala are hermaphrodite with dwarf males, which remain at the Cypris stage.

The hermaphroditism of certain parasitic Isopode is of another sort. The Cymothoidea are protandrously hermaphrodite, i.e. in youth they are male, later, the male copulatory segments are lost and the adult animals are exclusively female (Fig. 256).

The sexual relations in the Eitoniscille (Portunion) are probably the following. These large, characteristically-deformed parasites (Fig. 253) are protandrously hermaphrodite, but there are, besides, small males (Fig. 254, $A$ ) which have remained in a larval stage, and besides these again other degenerate so-called complementary males. Out of several larræ which reach the host, those which have the best place on its body and are best nourished probably develop into adults which function as females, the second - best nourished larve remain as males in a larval stage, and all the others become degenerate complementary males.

The Bopyridæ, which are parasitic in the branchial cavity of the Caridide, are sexually separate and strongly dimorphic; the dwarf males live on the bodics of the females.

The origin of all these peculiar sexual relations is still very uncertain. Most frce living Crustacea are sexually separate, and so are also the free living forms related to the hermaphrodite Crustacea. From this, and from the fact that hermaphrodites are found among the parasitic and attached Crustacea, we may, with some probability, conclude that hermaphroditism in the

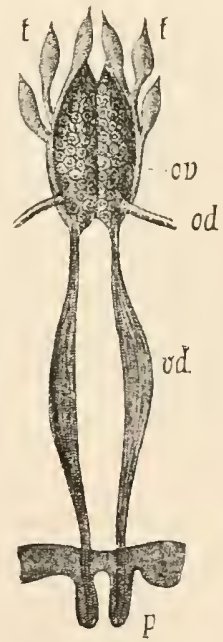

Fig. 256.-Hermaphrodite sexual apparatus of a young Cymothoa œstroides (after P. Mayer), somewhat diagrammatic. $t$, Testes; ov", ovary; od, oviluct; $r u$, vas clefreness; $p$, penis. Cirripedia and Isopoda is an aequired condition, perhaps brought about by the small

1 The Apuside' (Phyllopoda) have also lately been shown to be hermaphrodites, with the oceasional presence of males. 
chanee of fertilisation, which the attached or parasitic mode of life offers to sexually separate animals. To explain the occurrence of a hermaphrodite condition in general, we must assume (an assumption not without foundation) that the rudiments of the germ glands are indifferent, that in one case, under certain unknown circunstances, they may develop as testes, in another as oraries, and in others again produce ovaries as well as testes.

In the Cirripedia, the attached and parasitic modes of life are evidently extremely old. If the view that they are descended from Copepoda-like forms is correct, then the ancestors of the Cirripedia, when first the attached or parasitic modes of life appeared, were probably sexually separate, and dimorphic with small, free-moving males, as indeed is still the case in many parasitic Copcpodt. The attaehed and parasitic modes of life then became more and more pronounced in the female, and caused the appearance of hermaphroditism. The males, in the meantime, who had also taken on the Cirripede charaeter, remained as dwarf males, and so the possibility of occasional cross-fertilisation was preservel. In most Cirripedia the males have probably in time disappeared, and the purely hermaphrodite condition has become fixed. In others, the dwarf males proving under ecrtain conditions sufficient for ensuring fertilisation, have apparently led to the disappearance of hermaphroditism and the reappearance of sexual dimorphism.

In the Isopoda the sexual relations have probably devcloped in quite another way. How protandrous hermaphroditism arose in the Cymothoidea is indeed, at present, uncertain. But we can perhaps imagine the rise of the sexual relations in the Cryptoniscide and Entoniseidce in this way; these animals were originally, like the Cymothoided, protandrously hermaphrodite, then in time some of the larre dereloped only to the male stage and became larval or degenerate males.

In the gill-inhabiting Bopyricte the male stage, in the originally hermaphrodite individuals, must have been suppressed, as the dwarf males sufficed.

In the Amphipodan species Orchestic, the curious fact has been established that a certain part of the germ layer of the testes of the male produces eggs, while the other parts produce spermatozoa. The eggs, however, never, or only in exceptional eases, reach the exterior, and in any case do not develop further. The above fact, which does not stand alone, is at present unexplained.

\section{Parthenogenesis-Cyclic Reproduction.}

Parthenogenesis occurs in the Crustacea only in the Phyllopoda, viz., in Estheric and Apus (see note, p. 381) among the Branchiopoda and in the Cladocera. The males are much rarer than the females, and in the Cladocera appear only periodically in autumn.

The thin-shelled summer eggs develop parthenogenetically, and in many Phyllopoda in summer there is a suceession of generations of females multiplying parthenogenetically. The larger hard-shelled winter eggs, on the contrary, which are supplied with more nutritive yolk and are laid in autumn, require fertilisation.

\section{Xl1. Ontogeny.}

Wre can here present only a selection of the observations on the ontogeny of the Crustacea, which are so numerous and have such an important bearing on general morphological and biological questions. We shall first briefly clescribe the development of the outer boly form of some few Crustaceans which go through a long proeess of metamorphosis, and then give a sketch of the development of their inner organisation. 


\section{A. The larval history of the Crustacea-The Development of Apus (Order Phyllopoda, Family Branchiopoda).}

1st Larval Stage, Nouplius. -Ont of the egg is hatched an oval larva narrowing like a pear posteriorly, with a median frontal eye and three jairs of limbs, the most anterior of which is rod-shaped, while the two posterior are biramose. Its form and its setie are illustrated in Fig. 257, $A$.

On the dorsal side of the body the dorsal shield has begun to form. The anus lies in an indentation of the posterior margin of the body. This first stage is called
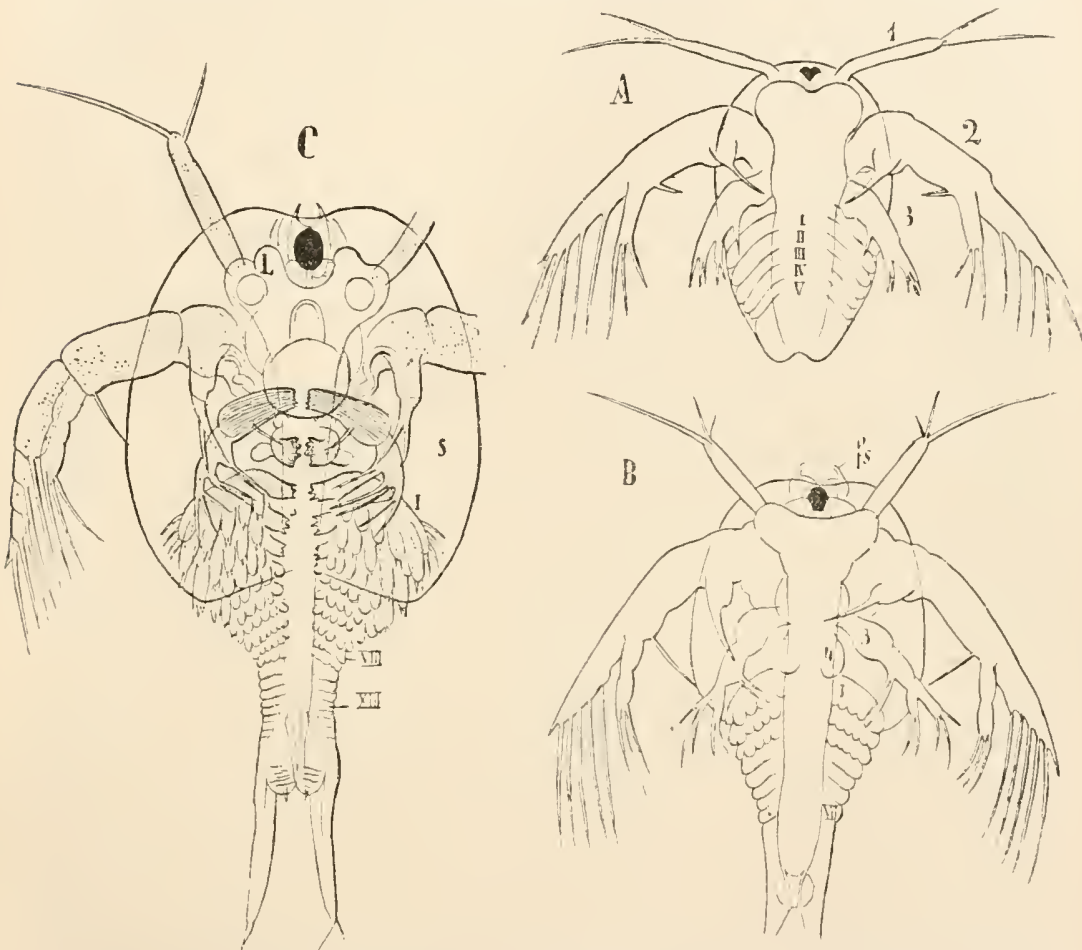

Fig. 257.-Larvæ of Apus (after Claus). A, Nauplius, just hatched, with the rudiments of the 5 anterior trunk segments I-IV. $L$, 2d larval stage, with the ruliments of the anterior maxilli and the first $i$ trunk segments. $C$, 4 th larval stage. $L$, Liver; $s$, shell; $f s$, frontal sensory organ.

the Nouplius larva : it is met with in essentially the same form as the first product of the egcr in many Crustaeeans; we shall therefore enumerate its general eliaracteristics. Body unsegmented with median frontal eye, with dorsal shield and frontal sensory organs (filaments, etc.) with 3 pairs of limbs, the first of which is simply rod-shaped, i.e. consists of a single row of joints, while the 2 posterior are biramose, i.e. consist of a protopodite, endopodite, and exopodite (shaft, inner and outer branch). In all Crustaceans the first pair of limbs of the Nauplius become the anterior antennæ, the second the posterior antennæ, the third the mandibles of the adult animal.

The Nauplius of Apus (Fig. 257, A) is distinguished from the typical Nauplius 
larva only by the fact that in the posterior third of the larval body, in front of its fosterior end, the rudiments of the 5 anterior trunk segments $(I-I)$ and their limbs can be recognised under the integument.

2d Larval Stage.-The Nouplius casts its skin and the larra in the 21 stage (Fig. 257, $B$ ) shows considerable modifications. The anterior body is broadened, the posterior body elongated in the shape of a conc. There are two frontal projecting stylets (frontal sensory organs). The dorsal shield has increased in size. On the basal joint of the $3 d$ pair of limbs (mandibular limbs) a masticatory process has formed. Behind the mandibular limbs are the rudiments of the first pair of maxillæ (4). The 5 anterior segments of the trunk can be more clearly distinguished, and also the rudiments of the $3 \mathrm{~d}$ and 4 th pair of trunk limbs, the latter as transierse ridges. Later a 6 th segment arises, and behind it the rudiments of the 2 subsequent segments. The bulgings at each side of the anus have become elongated into considerable fureal processes.

3d Larval Stage. - This is entered on at the $2 d$ moult. There are 6 anterior pairs of lobate trunk limbs, whose size and degree of differentiation decreases from before backward; these already clearly show the characteristic form of the Phyllo. podan swimmerets, with their endites, exopodites, and branchial sacs. Behind the 6 anterior trimk segments 2 more, and later 3 more, can be distinguished, and behind the anterior maxillæ the posterior have begun to form. The dorsal shield at first covers only the two anterior trunk segments.

The 4th Larval Stage appears with 7 anterior pairs of lobate trunk limbs (Fig. $257, C)$. Three to four anterior segments are covered by the dorsal shield. The Sth and 9 th pairs of limbs show the beginning of lobate formations; the 10th to 13th pairs of trunk limbs just arising. Rudiments of the paired eyes are visible. The rowing antennæ (2d antenne) are provided with large jaw hooks.

5th Larval Stage.-The 9 anterior pairs of trunk feet are lobate, the 10 th is in the act of forming a lobe, the 11th, 12th, 13th, and 14th prairs of feet are forming. Behind these are to be seen the rudiments of 6 new segments. Locomotion, hitherto caused by the 2 anterior pairs of limbs, is now chiefly prodnced by the trunk feet (swimmerets).

The mandibular foot is, as compared with the earlier stage, very much reduced, its principal part now being the masticatory process.

Further Larval Stages. - Frequent moults follow. New swimmerets are continually formed behind those already developed, and become differentiated from before backward. The mandibular foot is more and more reduced, till nothing remains but the masticatory process. The rowing limbs of the larvæ (2d antennæ) also become reduced. The dorsal shield continues to widen. The form of the adult animal develops very gradually.

From this larval history we see, 1st, that the body and its appendages in general become differentiated quite gradually from before backward, that new segments and limbs progressively, though also occasionally irregularly, form behind those already developed, and that these differentiations originate in the most posterior region of the body.

21. That there oceur deviations in details from this manner of formation. The maxille are an instance of belated alpearance in the order of the limbs from before backward. This fact is of importance because in the adult Phyllopoda as comprarel with other Crustaceans the maxille are very much simplified.

3 d. The mandibles, which in the adults are masticatory ridges without feelers, are in young larve well developed biramose limbs.

4th. The posterior antemne, which are reduced in the adult, are, as large biramose rowing arms, the elief organs of locomotion in the young larva. 


\section{Development of Cetochilus (Order Copepoda, Family Calanidæ).}

1st Larval Stage. Typical Nauplius (Fig. 258, A).-At the basal joint of the $2 d$ antenna there is a masticatory process characteristic of most Crustacean Nouplii. The mouth is overhung by an enormous upper lip, which is also characteristic of many other Nauplius larve. The anal aperture is not yet formed.

2d Larval Stage.-The body, and especially the posterior division, has grown longer. Anteriorly there is a small shell-fold. At the end of this stage the first pair of maxillie appear as small biramose feet behind the pair of mandibular feet.

3d Larval Stage. Metanauplius (Fig. 258, $B$ and $C$ ). - Behind the first pair of maxillæ the $2 \mathrm{~d}$, and behind these the 2 anterior pairs of trunk limbs, are forming,

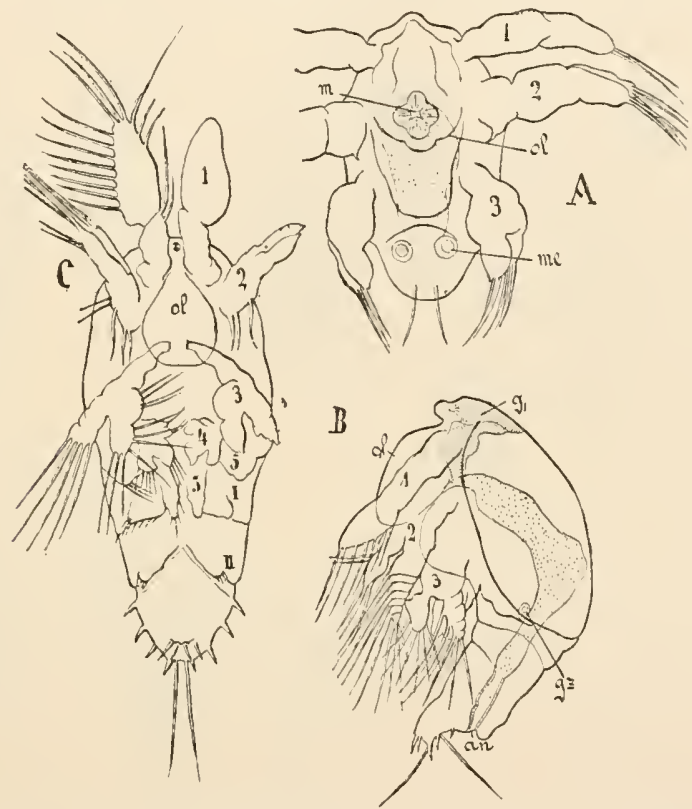

Fig. 258.-Larvæ of Cetochilus septentrionalis (after Grobben). A, Nauplius ; B, Metanauplius with the rudiments of the first 2 thoracic limbs from the sile. $C$, older Metanauplius. ol, Upper lip; $m$, mouth; $g$, brain; $g z$, genital cells; an, anus ; me, primitive mesoderm cells; 5 , the two maxillipedes of the left side (exo- and endopodite of the posterior maxille).

all as biramose feet. The dorsal shield corers the anterior part of the body as far as and including the $2 d$ maxillar segment. Masticatory ridges have developed on the basal joints of the maxillipedes

Further Larval Stages. - During several moults a third trunk segment forms.

Ist Cetochilus Stage. - The furce at the end of the body are completed. A 4th trunk segment and the $3 \mathrm{~d}$ trunk limbs begin to form.

From what we find in other Copepoda, the only parts needed to complete the form: of the adult animal are the remaining trunk segments and the 2 posterior trunk feet, all of which form during successive moults. The 2 pairs of maxillipedes which are separately inserted on the body, and are characteristic of the adult Copepoda in reality only correspond with the branches of the $2 d$ pair of maxillæ from which they come, and thus strictly speaking represent but one pair of extremities.

VOL. I 
We thus again sec that in the Copepode also the body with its limbs becomes progressively differentiated from before backward. Inasmuch as all the limbs of the adult animal are fully and typically developed, we find in this case, during the development, no reduction of limbs once (i.e. in larval stages) strongly developed.

\section{Development of Sacculina (Orter Cirripedia, Sub-order Rhizocephala).}

The comparison of the process of development in free-living Entomostrace with that in the prarasitic forms is very instructive. Let us take that Crustacean form

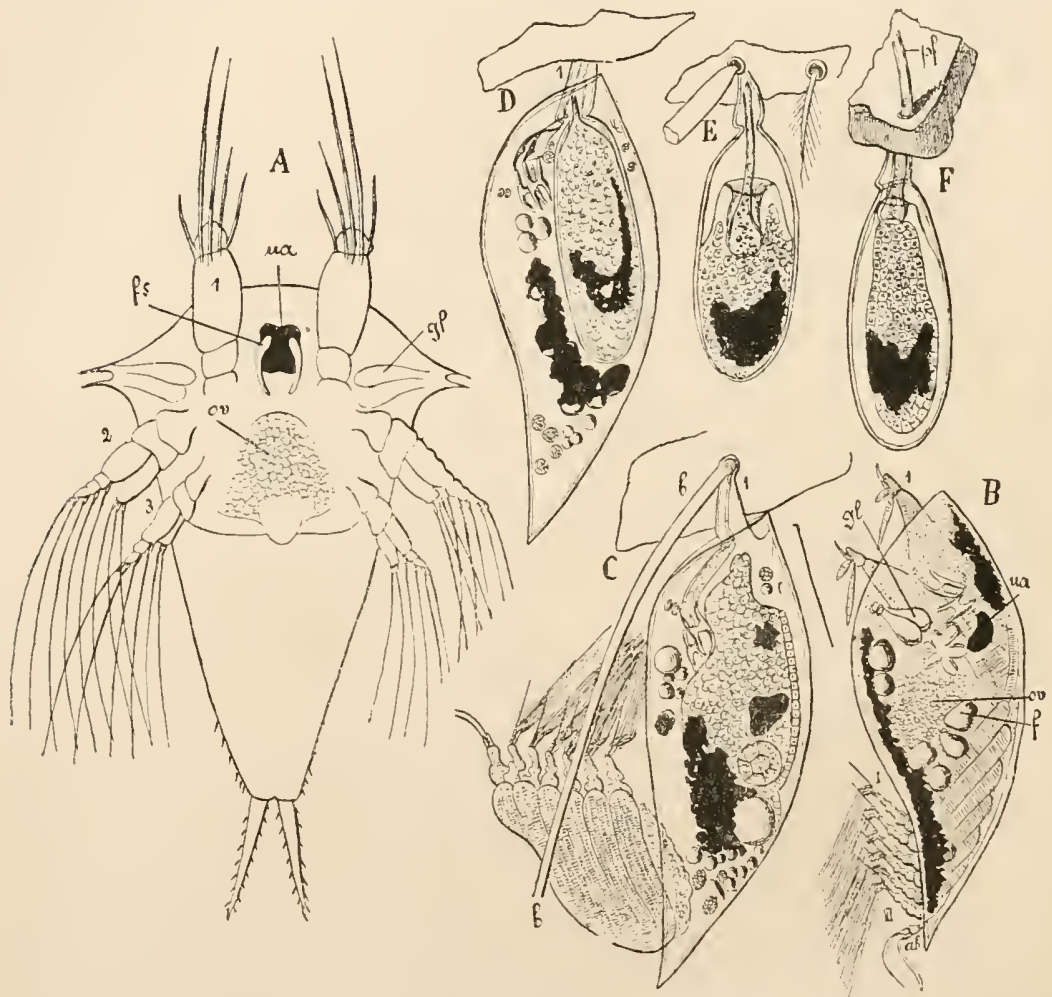

Fic. 25t.-Various larval stages of Sacculina Carcini. A, Nauplius after the first moult. $B$, Cypris stage from the side. $C$, The same, 3 hours after the larva has by means of its adhering antenne attached itself to a seta of the host. $D$, Formation of the Kentrogon larva. $E$, The same completed, the Cypris larval shell thrown off. $F$, The arrow has bored through the chitinous carapace of the host. The contents of the sac begin to pass into the borly cavity of the host through the arrow. $f s$, frontal sensory organ ; $u a$, Nauplius eye; gl, glands of the frontal horns ; ov, rurliment of the ovary; $f$, fat globules; $b$, seta of the host, to which the parasite has attached itself by means of its adhering antemiæ; $p f$, arrow of the Kentrogon stage; $a b$, abdomen (after Delage).

which in an adult hermaphrodite condition is the most degraded and deformed, viz. Sacculina (Figs. 208, 248). Although the adult animal cannot be recognised as a Crustacean, the series of larval forms through which it passes during its individual development most elearly proves it to be such, and related to the Cirripedio.

Nauplius Stage (Fig. 259, 1 ). - A typical Nouplizes with its 3 characteristic pairs 
of limbs is hatched from the egg. The shield-like dorsal integument forms on each sicle anteriorly a process (frontal horn) at whose base glands emerge. There are 2 frontal filaments (frontal scnsory organs) and an unpaired frontal eye. On the under sicle of the head is a median projection of considerable size in the place of the large upper lip of other Cirripale larve. At the posterior end of the body are 2 separate jointed caudal processes. Mouth, intestine, and anus are wanting. Near the Nauplius eye is a cerebral ganglion. About the middle of the body lies a mass of cells, the rudiments of the ovary. The Nouplius now monlts 3 times and undergoes during these processes a series of transformations preparatory to

The Cypris Stage (Fig. 259, B), which it enters after its 4 th moult. In this stage we find a laterally compressed shell entirely enclosing the body, and consisting of 2 lateral valves which pass in to each other, in the dorsal middle line, withont articulating. The body consists of 3 regions, the large head, the trunk, and a rudimentary terminal portion (the abdomen). The shell arises from the head. The head contains the rudiment of the ovary, and carries the Nauplizes eye, the frontal filaments and one pair of antenure which have proceeded from the anterior uniramose pair of limbs of the Nenplius. The two pairs of typical biramose limbs of the Nauplius $(2 \mathrm{~d}$ pair of antennæ and pair of mandibular feet) have disappeared. The trunk consists of 6 segments, which have formed during the last Nauptius stages behind the head portion, and it has 6 pairs of typical biramose limbs which cause the swimming movement of the larva. The short abdomen carries one pair of short appendages provided with sete. Mouth, intestine, and anus are wanting. The larre still feed at the expense of the nutritive yolk derived from the egg, which is thus gradually absorbed.

The Kentrogon Stage.-After a free life of at least 3 days the Cypris-like larva fixes itself by means of one of its two antennæ to the base of a seta on the back or on a foot of a very young crab. It then throws off the whole trunk, so that only the head is retained (Fig. 259, C,D). The organs retained in the lead become indistinct and, to a certain extent, fuse into a spherical mass which surrounds itself with a new hollow cuticle under the old one. The shell is then thrown off, and another new cuticle forms round the sac-shaped body within the old one, and in a craterlike depression of this new cuticle a hollow arrow-like process is formed (Fig. 259, E). The crater-like depression is then evaginated, the hollow arrow or borer is in this way pushed forward through the antennæ and pierces it and the soft chitinous cuticle at the base of the seta of the host, and thus penetrates the body of the latter (Fig. $259, F)$. Through this hollow arrow the whole contents of the ponch now pass over into the body cavity of the host, and after becoming surrounded with a new cuticle are known as

"Sacculina Interna."-All the organs of the adult Saculince are formed out of the cell masses which have in this way passed over through the arrow. Among others the testes are now first developed, and are thus, as compared with the ovaries, very late. The Saculina interna lies on the abdominal intestine of the host, and feeds by means of numerous root-like processes proceeding from its surface and penetrating the viscera of the host. As the Succutina increases in sizc it exercises pressure on the musculature and integument of the host, which die away on the under side of the ablomen in the immediate neighbourhood of the parasite, thus allowing the latter to pass out, while the roots (now proceeding from a stalk) remain inside the host.

Sacculina Externa.-The cloaca, till now closed, opens, and at its edge dwarf males are always fonnd; these have been shown to be animals which have remained at the C'ypris-like larval stage, but can be distinguished from the female Cypris-like larve by the fact that they levelop no arrow.

The attached Cirripedia (Lepadidu and Balcunide) like the Sacculina pass through 
a Nouplius and a Cym ris stage in the course of their developments. These larvæ differ from the corresponding larrie of Sacculina not only in the possession of an enteric eanal, but in a few other points as well. The Nauplius larva of the Cirripedic is characterised by a dorsal shield with frontal horns and posterior pointed processes, and by a large upper lip. Freqnent moults lead to the Cypris-like larva (Fig. 260); this has a bivalve shell with shell museles; its anterior antennæ have become adhering

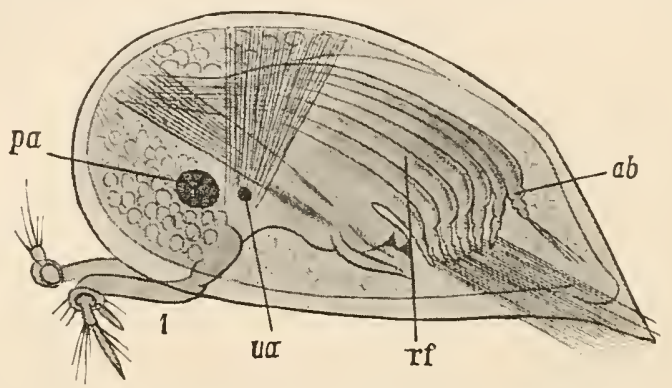

Fı. 260.-Cypris-like larva of Lepas fasciculata (after Claus).

antennæ. The posterior antenne and mandibular feet of the Nauplius larva have disappeared, and so has the upper lip. By the side of the median eye a paired compound eye has arisen. Behind the mandibular feet of the Neuplius simple anterior and perhaps also posterior maxillæ have begun to form. The trunk consists of 6 segments with 6 pairs of biramose feet serving for swimming. The abdomen has 2 furcal appendages. A cement gland opens on the 2 d joint of the adhering antenna, which is provided with a sueking dise.

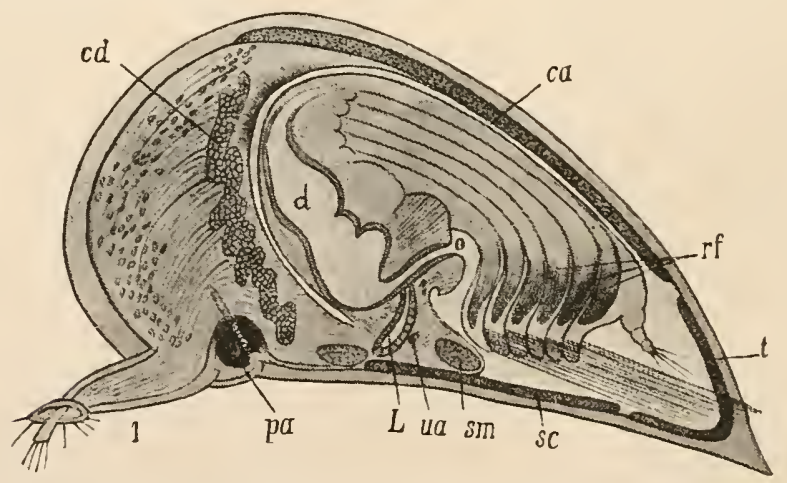

FIs. 241.-Pupa of Lepas pectinata, in optical sectiou (after Claus). In Figs. 260 and 261, the same lettrs are used : $p a$, paired eye; $u a$, unpaired Namplius eye; $r f$, trunk feet, in Fig. 261 with the tendril-like feet beginning to form inside; 1 , anterior (adhering) antennæ; $L$, liver ; sm, occlusor muscle of the scuta ; $a b$, abdomen; $c \alpha$, carina ; $t$, tergum; sc, scutum ; $c d$, cement gland.

The Cypris-like larva attaches itself by means of its adhering antennæ. A pupa stage follows (Fig. 261), during which the organs of the adult Cirvipede form nnder the larval skin. Within the maxillæ and the 6 pairs of trunk feet of the Cypris-like larva the mouth parts and the 6 pairs of tendril-like feet of the adult Cirripede begin to form. In the Lepadide the head grows out anteriorly into the stalk which carries the minute adhering antemn, and under the Cypris shell the 5 shell pieces 
form on the mantle-fold. The Cyuris shell is thrown off, and the praired eyes clisaluear.

The listory of the development of the attached and prasitic Cirripcdic is in many respects exceedingly interesting. The Cypris-like larra shows, apart from the absence of posterior antenne and mandibular feet, a distinctly Entomostracen character. Its 6 typical biramose feet recall the swimmerets of the Copepoda. The remarkable transformation of the free-swimming Cypris-like larva into the attacleed sexual animal must be referred to its adaptation to an attached mode of life; this adaptation consists in the formation of a hard shell or framework serving for protection, the transformation of the swimmerets into tendril-like feet suited for bringing food within reach, and the reduction of the paired eyes which are of no great use to the adult animal. A commencement of this adaptation to the attached mode of life may perhaps be seen even in the Cypris stage, viz., in the degeneration of the posterior antenne and mandibular feet, which in the Nauplins larva had played an important part, especially as organs of locomotion, whereas in the Cypris-like larva the trunk feet serve that purpose. The transformation of the Cypris-like larva into the parasitic Sacculina involves far more radical changes than those which take place in the development of the Lepadide and Batanida. The development of Sacculina may be described as a strikingly retrogressive metamor phosis. To explain the reappearance of the typical Nauplius and Cymis-like larve in the course of development, notwithstanding the degradation of the adult animal, it is necessary not only to emphasise the power of inheritance but to remember that free-moving young forms are extremely useful to prarasites for the infection of new losts ani the maintenance of the race. Tevertheless, even in the free-swimming larve of Sreculina, we recognise distinct signs of degeneration such as the absence of an alimentary canal. This degeneration could take place without damage to the maintenance of the race, because the adult Succutinc, in consequence of its exceedingly favourable conditions of nutrition, can give its eggs for their development so much mutritive yolk that the larvie proceeding from them are mnder no necessity of obtaining food from without. The occurrence, at first sight so remarkable, of an endoparasitic stage in the development of the Sacculina is not difficult to understand, for by passing through such a stage the parasite avoids the danger of being thrown off by the moulting of the host.

Larval History of the Euphausidæ (Order Schizopoda, Fig. 262).

1. Nauplius Stage.-Typical.

$\therefore$ Metanauplius Stage.-The masticatory ridge of the mandible develops, while the mandibular foot itself is reduced. The upper and under lips form. Behind the mandibles the rudiments of the 2 pairs of maxille and of the 1st pair of thoracic feet (maxilliperdes) appear as buds. The cephalothoracic shield is distinctly developerl, and the paired cyes first appear.

3. Calyptopis Stage (somewhat corresponding to the Protosocer stage of Pcincus) $\left(B, C^{\prime}\right)$.- The thorax and abdomen are demarcated, and the latter already elongater. Segmentation appears in the thorax, and later in the abdomen. No new extremities except the last pair of pleopoda (uropoda) begin to form.

4. Furcilia Stage.-The paired eyes become stalked. The most anterior pairs of thoracic and abdominal feet begin to form in succession from before backward.

5. Cyrtopia Stage.-The antemme are transformed and no longer serve for locomotion. The posterior pairs of thoracic and abdominal feet and the gills appear.

6. Post-larval Stages. - The adult animal is gradually formed, and the caudal fin definitely developed. It is hardly necessary to remark that all the thoracic feet 
and pleopoda are originally biramose and in this animal retain this character during life. No great importance should be attached to the names of the developmental stages (Culyptopis, Furcilia, Cystopia); they are referable to a time when the larva so named were thought to be different genera. We thus again see, from the larval history of the Euphenside, that the body with its limbs is differentiated from before backward. We notiee, howerer, special and important exceptions to this rule. In the first place the rucliment of the last pair of pleopoda

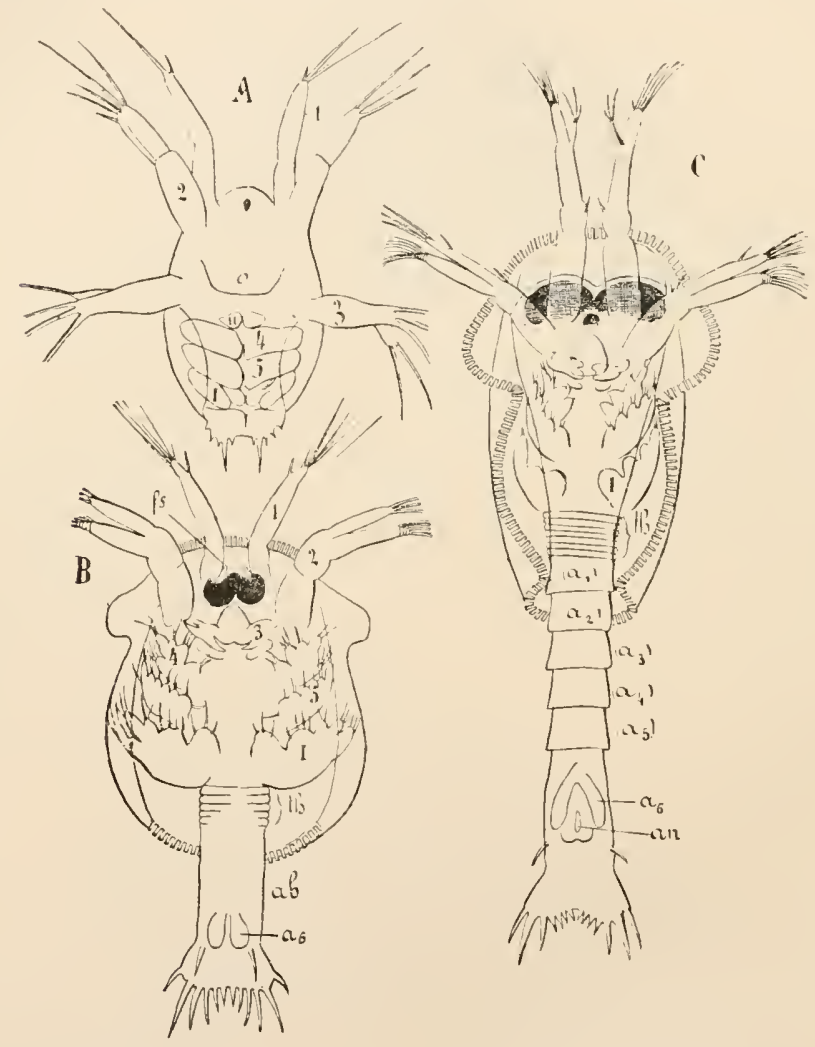

Fig. 262.- Larvæ of Euphausia. A, Nauplius, last form before moulting (after Metschnikoff). $B$, Protozoæa. C, the same somewhat older (after Claus). th, Thoracic segments; $a b$, abdomen; $\left(\mu_{1} \cdot \alpha_{6}\right)$, abrlominal segments ; $a$, anus ; $f$, frontal sensory organ; $1-5$, limbs of the head; $\alpha_{6}, 6$ th pair of pleopoda.

appears before those of the other pleopoda, before even those of the thoraeie feet. This is noteworthy on aeeount of the special form of and the important part played by these pleopoda as part of the caudal fin in the older stages of development and in the adult. We further note that although the thorax becomes segmented sooner than the abdomen, and although on the thorax as on the abdomen the extremities become differentiated in snecession from before backward, the rudiments of the extremities on the thorax and the abdomen are almost simultaneous and sometimes they even occur earlier on the abdomen. 


\section{Larval history of Penaeus (Order Decapoda, Sub-order Macrura, Family \\ Carididæ (Shrimps), Figs. 263 and 261).}

1. Nauplius Stage. $-A$ typical mnsegmented Nauplius (Fig. 263, $A$ ) is hatehed from the egg. The body possesses 110 dorsal shield; it carries 2 sete posteriorly.

2. Metanauplius Stage. - The dorsal shield begins to form. The 3rl prair of Xauplius limbs (mandibular limbs) shows the rudiments of the masticatory ridge. Behind this appear the rudiments of the 4 subseruent limbs (maxille and 2 anterior pairs of maxillipedes).

3. First Protozoæa Stage (Fig. 263, $B$ ). -The eephalothoracic shield has grown large. The posterior division of the body clongates till it is as long as the anterior mart. The 2 pairs of maxille and the 2 anterior lairs of maxillipedes have dereloped and are capable of functioning; the latter are biramose limbs with endo- and exolodites. The division which follows behind these is divided into 6 segments without any trace of extremities, and these segments are the rudiments of the 6 pos. terior thoracic segments (III-VIII). These are followed by the posterior body which is not yet segmented and shows no trace of cxtremities. The mandibular feeler has disappeared. The posterior body ends with two furcal processes. Near the median eye the paired eyes appear.

4. The Second Protozoxa stage (Fig. $261, A$ ) is very similar to the first, but on the abdomen the rudiments of the 5 anterior abdominal segments $\left(a_{1}-a_{5}\right)$ are visible. Behind the $2 d$ pair of maxillipedes on the first of the 6 newly former thoracic segments the rudiments of the $3 \mathrm{~d}$ pair of maxillipedes appear (III).

5. First Zoæa Stage.-The paired eyes stand out as stalked eyes. The 3d pair of maxillipedes has also become biramose. On the 5 subsequent pairs of thoracic segments the rudiments of the 5 pairs of "ambulatory feet" appear (Fig. 264, $P$, $I V-V I I I)$. On the segments of the abdomen also formations appear which are probably the rudiments of the pleopoda $\left(a_{1}-a_{6}\right)$. In any case the begimnings of the last pair of plcopoda which are destined to

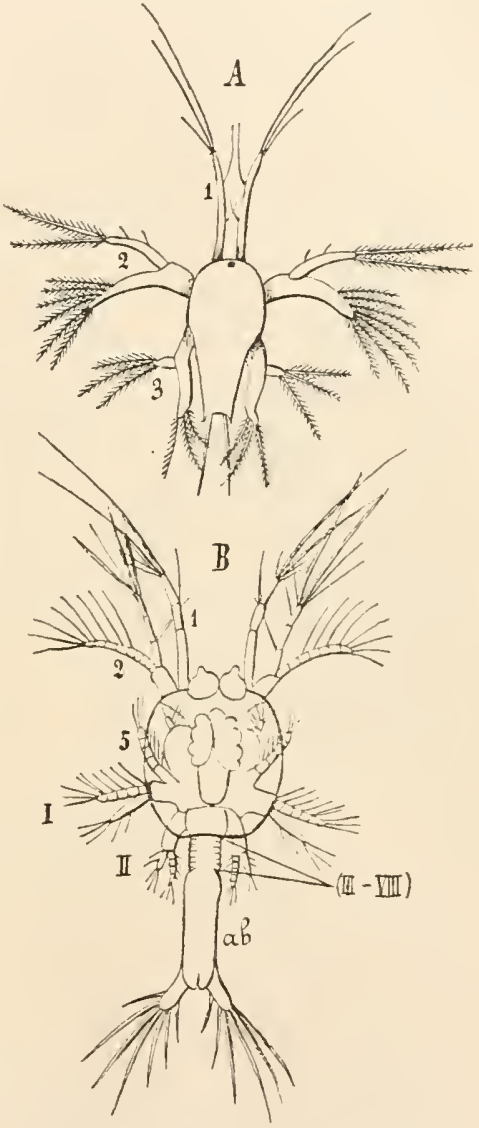

FIG. 263.-Young larva of Penaeus (after F. Müller). $A$, Nauplius ; $B$, Protozoæa. III VIII, Rudiments of the $3 d-s$ th trunk segments. $a b$, Abulomen; 1.5, limbs of the head; $I, I I$, of the thorax. In all subsequent figures the head limbs are denoted by Arabic, the thoracic limbs by Roman numerals, the abiominal limbs (plenporla) by $a_{1}, a_{2}$ etc., the telson by $t$, the exopodite by ex, and the endopodite by $\mathrm{en}$. form with the telson the caudal fin, are distinctly risible on each side as bi-lobed formations under the integument.

6. Second Zoæa Stage (Fig. 264, C).-The last pair of pleopoda project freely. On the two pairs of maxillie the small fan-plates (exopodites) have formed. The 5 
posterior pairs of thoracic feet (ambulatory feet) project freely as doubly-tipped protuberances. The formations on the abdomen of the 1st Zoce stage, which were indicated as the rudiments of pleopoda, are no longer to be seen. The cephalothoracic shield has a pointed process projecting anteriorly in the middle line. The animal still moves chiefly by means of the 2 pairs of antenne.

7. Mysis or Schizopoda Stage (Fig. 264, I).--This is so called because all the thoracic feet are developed, like those of the Schizopoda, as long biramose limbs (with exo- and endopodite), and here also serve for swimming. The branchial appen-

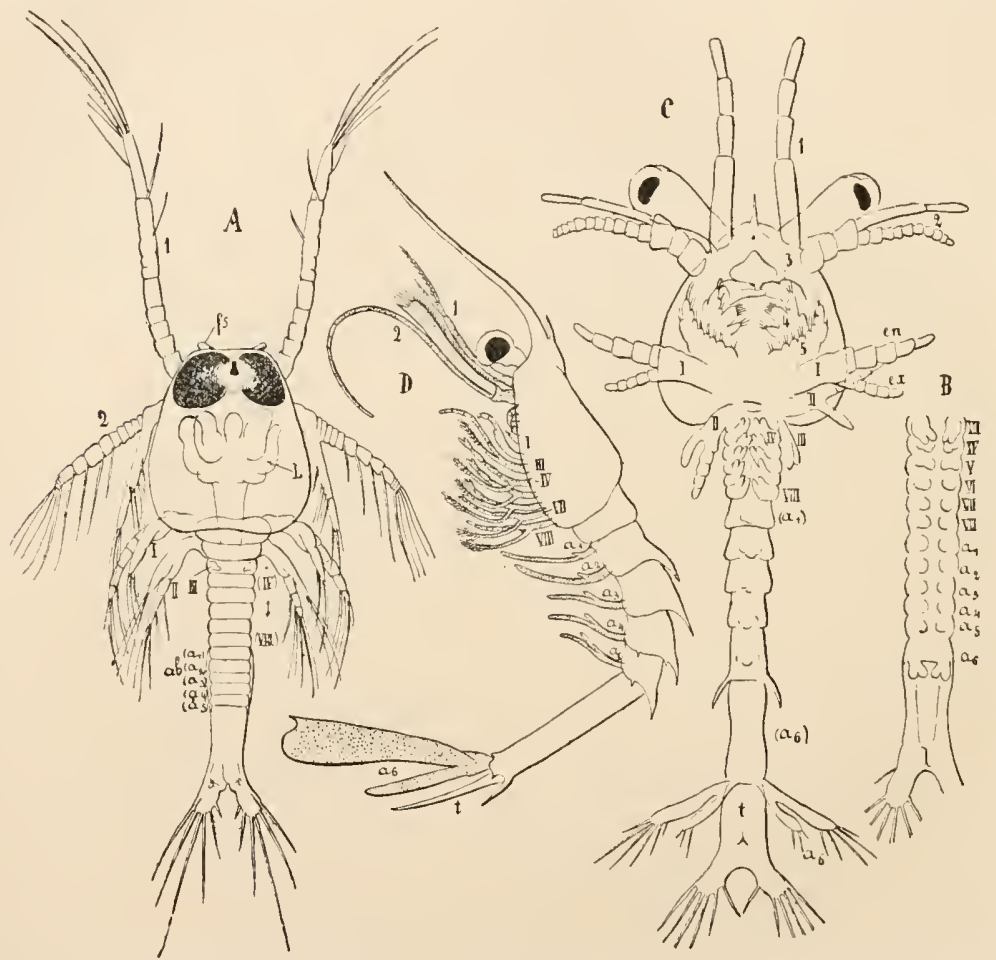

FiG. 264.- Older larvæ of Penaeus. A, Older Protozoæa, dorsal view. $\quad D, 6$ posterior thoracic segments, and abdomen, with the rudiments of the feet of a somewhat older larva. $C$, Further advanced Zoæa. $D$, Mysis stage of a Penaeus, from the side. $f s$, Frontal sensory organ; $L$, liver; $a b$, abdomen; IV.VIII, thoracic segments; $\left(a_{1}-a_{6}\right)$, abdominal segments; $t$, telson. In $C$ to the left, the $3 d$ thoracic foot ( $3 d$ maxillipede) is covered by the $2 d$ (after Claus).

dages of the thoracic feet appear. The pleopoda grow further during this period, the most anterior pair first, then the $2 d$ and then the others almost simnltaneously. The feelers undergo important transformations, which bring them nearer the adult form. Alterations likewise appear in the cephalothoracic shield. The anditory sac forms at the base of the antennæ. The mandible receives a feeler. The jaws approach their definitive form. By degrees, through several monlts, the larvæ reach

8. The Penaeus form, the exopodites of the thoracic feet becoming more or less reduced and the pleopoda developing further.

The Penceus development also shows us that the body with its appendages 
becomes differentiatel from before backward. But liere also the last pair of pleopoda adrances more rapidly than the others.

\section{Larval history of the Stomatopoda (Fig. 265).}

Unfortunately we do not know the whole series of larval forms in any of the Stomatopoda. They belong to two types, one of which is called the Erichthus, the other the Alima type. We shall only consider the first.

A. Youngest known Erichthoid larva $(A)$.-Three regions can be distinguished in the body, an anterior, a mildle, and a posterior. The anterior corresponds with the head, and from it arises as a fold of the integument a large dorsal shield which covers the second region as well. The head carries besides a median eye the two large stalked eyes, the two pairs of antenna, the pair of mandibles and the two pairs of maxille. The sccond region consists of 5 segments, corresponrling with the 5 anterior thoracic segments, and carries 5 pairs of biramose swimmerets $(I-V)$, the last 3 of whieh decrease in size from before backward. The 5 pairs of limbs answer to the 5 pairs of oral limbs in the adult Stomatopoda. The third region eonsists of 3 short limbless sesments (also eovered by the dor'sal shield) corresponding with the 3 josterior thoracic segments, and a very large eandal plate, also devoid of appendages.

B. In a somewhat older $2 d$ larva a new segment (the most anterior abdominal segment) with one pair of limbs has formed in front of the caudal plate. The 2d pair of thoraeie feet shows alterations preparatory to its transformation into large seizing feet.

C. In a third larva $(B) 2$ new segments with the rucliments of their limbs, and in older larve all the abdominal segments with their pairs of limbs excepting the 6 th, have begm to form in front of the candal plate, while the 3 posterior thoraeie segments are still limbless.

D. In a fourth Erichthoid larva the 2 anterior pairs of thoracie feet have lost their exopodites, but on the other land the rudiments of epipotites (gills) appear on them. The three subsequent pairs of thoraeie feet are reduced, and the last three thoracie segments are still limbless. On the 6 th abdominal segment the rudiments of the limbs (uropoda) appear.

E. In the subsequent stages, the $3 \mathrm{r} d, 4$ th and 5 th pairs of thoracic limbs are completely rednced, or else are represented only by small sac-like prominences $(C)$.

F. There now follows, after various preparatory intermediate stages, the completely developed Erichthus larva. (D) The 3d, 4th, and 5th pairs of thoracic limbs again appear in their definitive form, so that now the 5 anterior trunk limbs are developed as seizing or oral limbs. On the last three thoracic segments the rudiments of the biramose ambulatory limbs appear. By this time, not only the full number of segments, but the full number of limbs of the adult animal is reaehed.

In this larval history of the Stonnatopoda we note

(1) That the segments of the body become differentiated from before backward.

(2) That the limbs also as a general rule follow the same order. We observe this prineipally in the case of the ablominal limbs, since in the youngest Erichthoid larva the 5 anterior thoracic limbs are already developed. Of the pleopoda, the last (uropoda) appeared last, in opposition to the Decapoda, in which this latter takes frecedence of all the others and even of some of the thoracie limbs.

3. The last three weakly developed thoraeic limbs (ambulatory limbs) form the chief exeeption to the rule stated under (2), in that they first appear after the pleopoda.

4. It is a striking fact that the $3 \mathrm{~d}, 4 \mathrm{th}$, and 5 th pairs of trunk limbs whieh are early developed as biramose rowing feet become completely reduced, and are ther again formed in their definitive shape in the oldest Erichthus stage. 

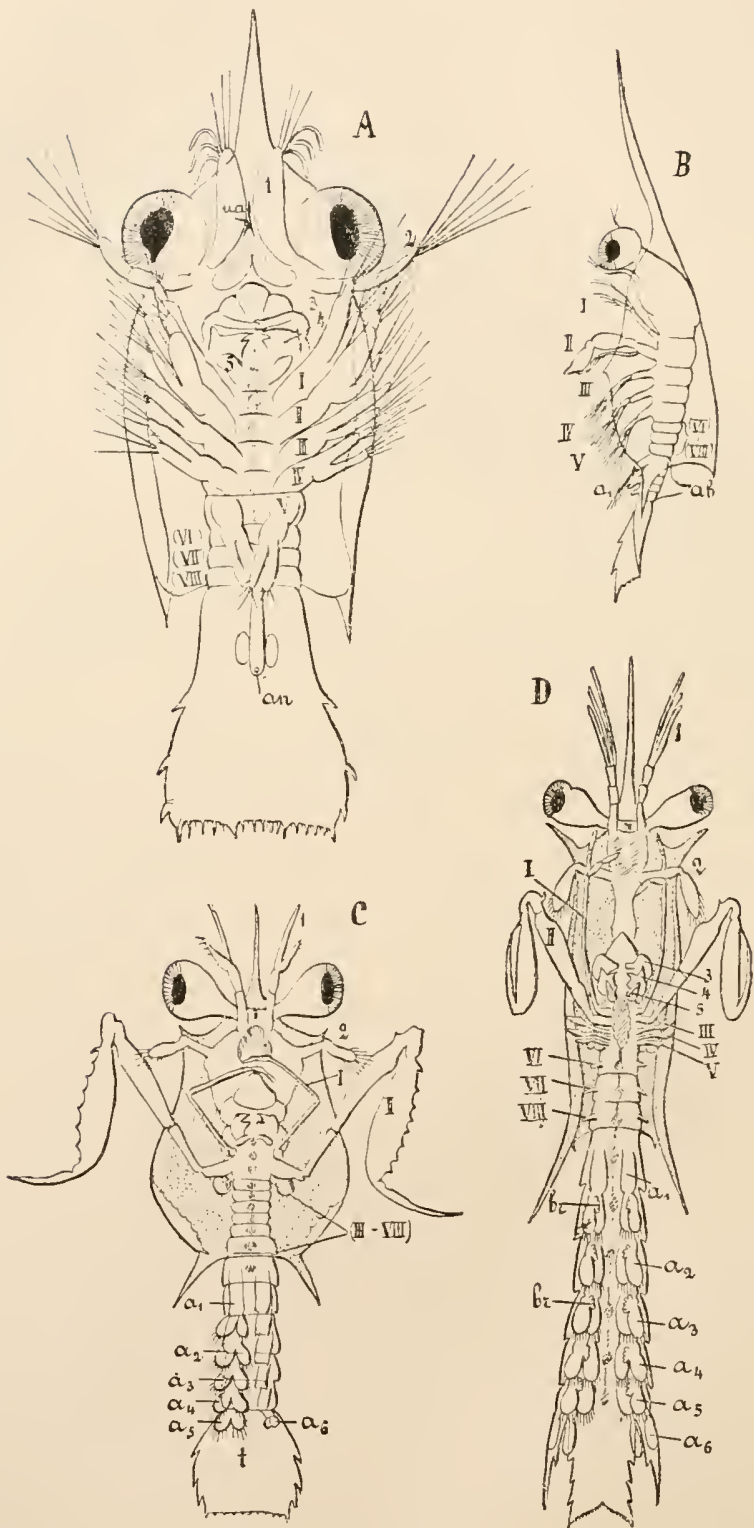

F1G. 265.-Stomatopodan larvæ of the Erichthus type. A, Youngest known Erichthoid larva. $B$, Somewhat older larva, from the side. C', Young Erichthus larva (Zoca). $D$, Older Erichthus larva with complete number of limbs. an, Anus; ua, nauplius eye; $b r$, rudiments of the gills ou the pleopoda; $a b$, abdomeu. The Roman numerals in brackets denote the corresponding limbless thoracic segments. $I-V$, OraI feet; VI.IIII, ambulatory feet; $t$, telson (after Claus). 


\section{Development of Palinurus and Scyllarus (Decapoda, Macrura, Fam. Loricata).}

The carly larval development is carried on within the shell; during this development 2 stages, a Nouplius stage and a very inportant further stage which miglit be called the embryonic Phyllosoma stage, are passed through. The characteristics of this latter stage are as follows: There are 2 pairs of antemne, mandibles, and 2 pairs of maxille. The thoracic limbs have all begun to form, i.e. 3 pairs of maxillipedes and 5 pairs of ambulatory limbs. The 2 most posterior (ambulatory limbs) are only present as minute buds. The 6 anterior are biramose, but the exopodites of the $2 d$ and $3 d$ pairs of maxillipedes are degenerated even during embryonie life. There are two stalked lateral eyes, and the median Neuplius eye. In the body 3 regions are to be distinguisherl. (1) Head with dorsal shield; (2) thoracic region, in which the segmentation is indicated; (3) a distinctly segmented but limbless abdominal region ending in a fork.

Before the larva is hatched, however, in addition to the 2 posterior pairs of ambulatory feet which remained undeveloped, the 1st pair of maxillipedes disappear, and the $2 d$ pair of maxillæ and the $2 d$ pair of antennæ degenerate.

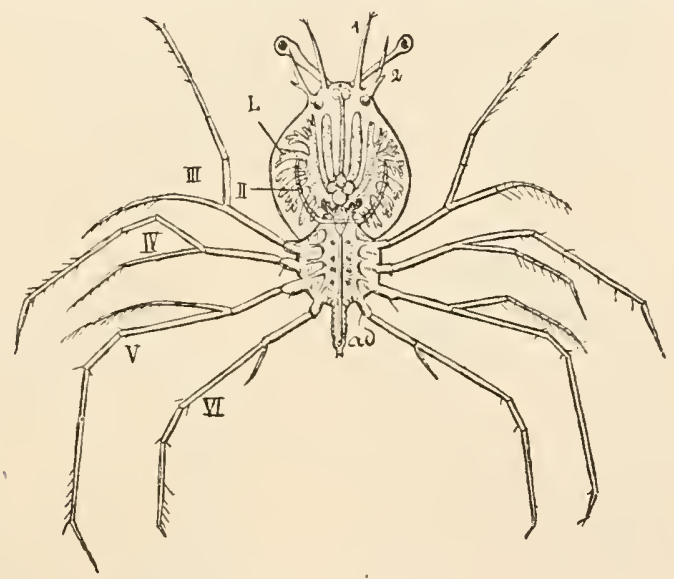

Fia. 200.-Phyllosoma of Palinurus (after Claus). ad, Abiomen; l, liver.

In the larva hatched from the egg the above-mentioned regions of the body can be recognised-it is much flattened dorso-ventrally (like a leaf), and as transparent as glass ; it is called the younger Phyllosoma (Fig. 266).

The older Phyllosoma larva is distinguished from the younger by the following characteristies. The 1st pair of maxillipedes has formed anew, and the 2 posterior pairs of ambulatory feet have developed. The 2 posterior maxillipedes again develop exoprodites, and on the ambulatory limbs the rudiments of the gills appear. The abdomen is more elongated and shows the rudiments of the pleopoda. The larra thus already has, apart from its strange form, typical Decapodan characteristics. Its transformation into the sexual form has not been observed.

In the development of the Loricata we note:-

1. That during the processes which go on in the last part of embryonie life the body with its extremities becomes differentiated typically from before backward.

2. That before the hatching of the Phyllosoma larva certain extremities or parts of extremities degenerate, to appear anew on the older Phyllosoma larva; this 
is espeeially the ease with the 1st maxillipedes, and the rudiments of the last 2 ambulatory feet. The Phyllosome shows in a speeially striking manner the eharaeter of a pelagic larva.

\section{Development of the Brachyura.}

A very eharaeteristie Zoæa larva (Fig. 267) is hatched from the egg. Its dorsal

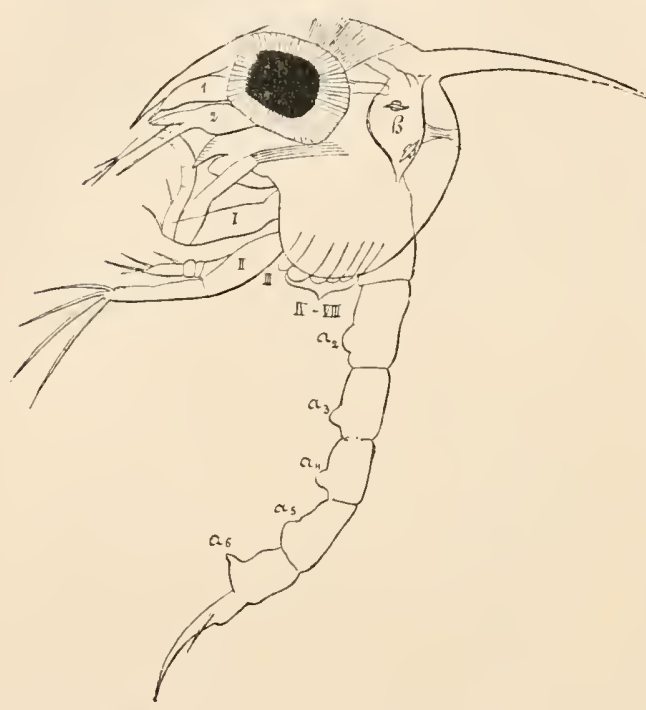
shield is marked by the possession of long spine-like proeesses, among which a frontal, 2 lateral and 1 dorsal are never wanting. All the head limbs are present. Of the thoraeic limbs we find only the 2 anterior pairs of maxillipedes; the other thoracie limbs, as well as that lart of the thorax to which they belong, are wanting or are only found in their first rudiments. The abdomen is segmented, and ends in a fork, but has no appendages.

In the later Zoæa stages the $3 d$ pair of maxillipedes appears, the 5 ambulatory feet arise as uniramose limbs (without exopodites), and the pleopoda begin to form.

FIG. 207.-Zoxa of Maja, after its moult (after Claus). $h$, Heart. The Zoce $t$ swims prineipally by means of the 2 biramose anterior pairs of maxillipedes, and also by means of the abdomen whieh, in comparison with that of the adult, is elongated and well developed.

The older Zoce ehanges into a Megalopa larva (Fig. 268).

This larva, but for the more strongly developed abdomen and the pleopoda, already resembles the sexual form. The maxillipedes and ambulatory feet appear as in the adult condition, and it must be speeially remarked that the ambulatory feet are never biramose, and that the Brachyura thus do not pass through any Schizopoda stage.

Through many moults the Megelopa is gradually transformed into the sexual form.

We need say only a few words about the development of the other Malacostraca. The Leptos-

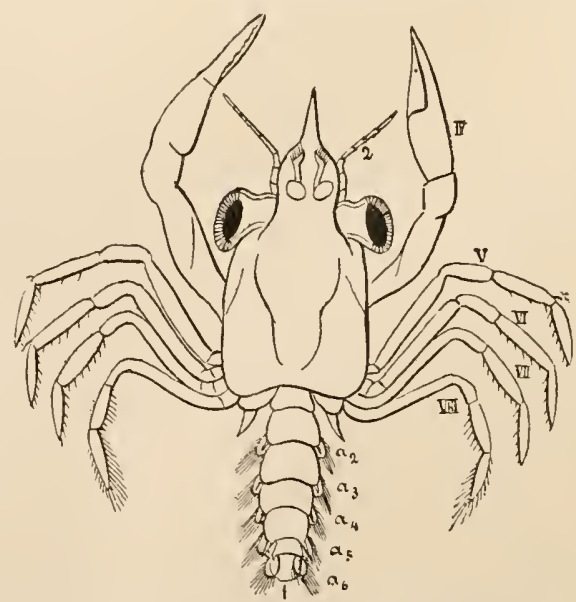

FIG, 268.-Megalopa larva of a Portunus with abdomen straightened out, dorsal aspect (after Claus). 
trace (Nibalia), the Amphipoda, and a few Decopoda (e.g. the Cray-fish), leave the egg in a form like that of the sexually ripe animal. On the other hand in the Isopoda, Myside, and Lophogastride among the Schizopode and the Cumacca, the young form hatehed from the egg nay be very little dereloped, and may even resemble a maggot-shaped Nauplius or Metanauplius; but there are no early freeswimming larval forms, as the young undergo their metamorphoses in the brood pouch of the mother. The development of the parasitie Isopoda is interesting, sinee here the free-moving young or larval forms whieh go in seareh of hosts, resemble the typieal Isopoda in form and development of the body and limbs mueh more distinetly than do the sexually mature animals.
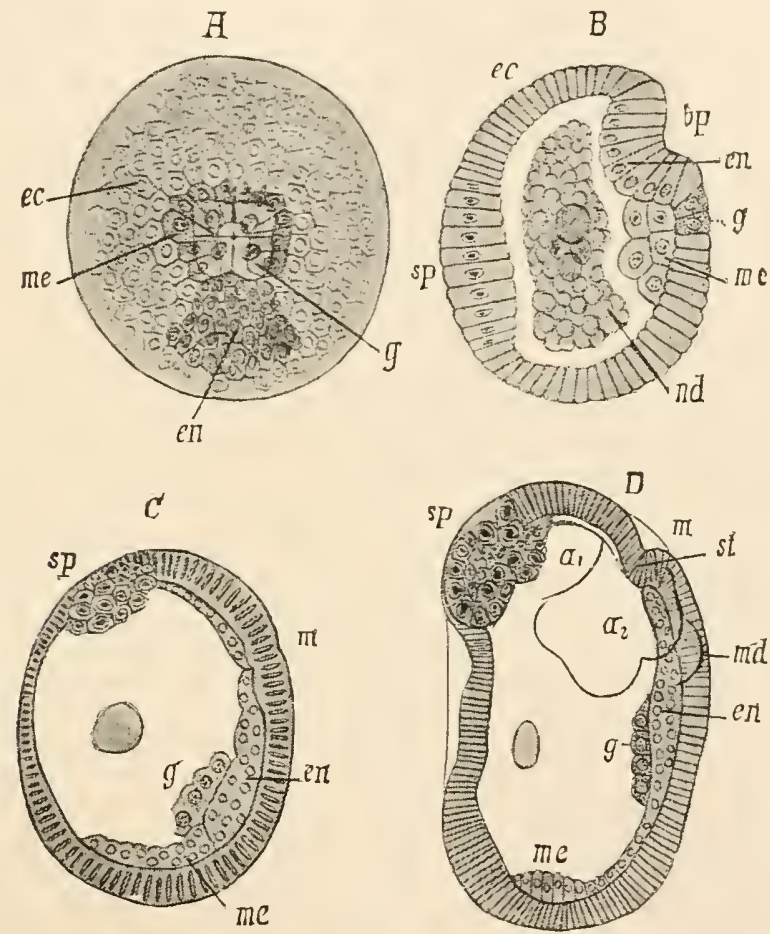

Fig. 269.-Moina rectirostris. Four early stages of development. A, Blastosphere, seen from the vegetative pole. $B$, Gastrula stage. $C$, somewhat older stage, with neural plate, closerl blastopore and sexual cells sunk below the surface; $D$, Nauplius stage, $B, C$, $D$, in optical longitudinal section. In $C, D$, the neural plate, and in $D$, the rudimeuts of the Nuuplius limbs are projected on to the section. ec, Ectoderm; me, mesoderm ; $g$, priuitive sexual cells ; en, endodemi ; $s p$, neural plate; $b p$, blastopore; $n d$, nutritive yolk; $m$, mouth ; st, stonrodrum ; $a_{1}$, anterior ; $a_{2}$, posterior antennæ; md, rudiments of mandible (after Grobben).

\section{B. The Arrangements of the Germ Layers and the Development of the Inner Organs}

may here be deseribed by means of a few examples.

\section{Moina rectirostris (Order, Phyllopoda ; Sub-order, Cladocera ; Fig. 269).}

The segmentation of the mesolecithal egg is superfieial, and somewhat unequal. In the 32 blastomere stage a blastomere lying at the regetative pole is distinguished 
by a specially large nucleus. This divides, and as the primitive sexual cell produces the rudiments of the germ glands.

A blastomere in contact with this sexual cell yields the endoderm, and the blastomeres, which surround the primitive sexual cell, and the primitive endoderm cell, yicld the Mesoderm (except the scxual organs and nervous system). In a later stage (Fig. 269, A) we find 4 genital cells, 32 endoderm cells, and 12 mesoderm cells; all the remaining blastomeres represent the ectoderm. First the 12 mesoderm cells sink down, then the endodermal plate becomes invaginated $(B)$. In place of the gastrula mouth, which probably closes, the definitive mouth appears later. The genital cells increasing in number to 8 , then sink down $(C)$. Nutritive yolk remains in the segmentation cavity. Two paired frontal groups of cells appear as rudiments of the neural plate. Later on this plate consists of several layers and yields anteriorly the brain, and posteriorly the retina. The cesophageal commissures and the ventral chord arise in situ as thickenings of the ectoderm. The mesoderm spreads itself out on the inner side of the ectoderm, on the surface of the rudiments of the genital glands, and around the mid-gut which is at first solid: this mid-gut alone proceeds from the endodermal invagination. The shell gland is of mesodermal origin and only opens secondarily at the point of the 2d maxilla. The compound eye is from the first paired.

\section{Cetochilus septentrionalis (Order, Copepoda).}

The segmentation is total and yields a blastula with a small segmentation cavity. Under the blastomeres at a certain stage 2 symmetrically placed cells can be distinguished as primitive mesoderm cells and a few others also symmetrically placed as endodermal cells. The dividing mesoderm cells sink deeper inwards. In still later stages we can recognise at the posterior end of the mesoderm, on each side, a large primitive mesodermal cell. The endoderm also becomes invaginated into the segmentation cavity. The gastrula mouth closes in a median line from before backward. The dividing mesoderm cells fill the segmentation cavity. The stomodæum and proctodæum arise by means of ectodermal invaginations. At a later (Nauplius) stage there arises at each side behind the Nauplius eye an ectodermal thickening commected with the brain, which severs itself from the integument but degenerates later. These are to bc considered as the rudiments of the paired compound lateral eyes with their optic ganglia, which are wanting in most Copepoda. A pair of mesoderm cells lying on the ventral side of the intestine represent the rudiments of the sexual glands. The 2 cells move higher on the 2 sides of the intestine, and become surrounded with smaller mesoderm cells, which yield the rudiments of the ducts, which at first are solid. In the 1st Cetochitus stage the paired genital rudiments fuse to form an unpaired dorsal sexual gland. The heart develops out of a pairerl rudiment of mesoderm cells.

\section{Branchipus (Phyllopoda).}

In the hatched Nauplius larva under the cuticle, the segments of the first maxille and the first two trunk segments, with their limbs, have already begun to form. An clongated portion follows, in which the segmentation of the mesoderm strealis lias begun. This does not reach as far back as into the anal segment. The two mesoderm strcaks unite posteriorly directly in front of the anal segment to form a ventral plate which forms a budding zone. Its cells rapidly increase, and as the development of the larva progresses new mesoderm segments continually become demarcated from the budding zone and spread out under the ectoderm to the dorsal middle line. But this segmented germ streak merely represents the parietal layer 
of the mesodern ; the visceral layer never becomes segmented, and differentiates "fuite appart from the prarietal layer. (In the anal segment on eacli sile there lie 2 large cells, which, however, do not divide and do nothing to increase the budding zone ly contributing cells.)

The cell material of the mesoderm segments, which arc successively formed at the anterior end of the budding zone, begins to group itself into three divisions, and this group is the more distinct the further the segment is removed from the budding zone, i.c. the older it is. The dorsal division yiclds the rudiment of the cardial chamber of the segment and that part of the dorsal longitudinal musculature which also helongs to it ; the lateral division yields the musculature of the limbs, the ventral the segmental division of the ventral musculature as well as the neurilemma of the ganglia. The limbs begin to form as outgrowths and bulgings of the ectoderm, into which cell-growths of the mesoderm penetrate. 'The ventral chord becomes differentiated from before backward. In cach segment in which a pair of limbs begins to form an ectodernal thickening appears on cach side of the ventral median line. The two thickenings in a segment represent the rudiments of the donble ganglion, which at first are not united by a transverse commissure. These rudiments free themselves from the cctoderm at a later stage. We thus find in an older Branchipus larva the whole ventral chord from back to front in all stages of differentiation. Posteriorly, where new pairs of ganglia are continuously formed with the new segments, these are still ectodermal thickenings. In the formation of the heart (many-chambered dorsal vessel) only one longitudinal row of perpendicularly arranged muscle cells on cach side takes part. The two rows grow together in such a way as to form a loollow tube. The heart becomes differentiated from before backward. In many larval stages a greater or smaller number of segmental cardial chambers are already developed anteriorly and already pulsate, while posteriorly new cardial chambers are in process of formation.

The rndiments of the compound eye appear in the Metanauplius larva on each side as a hypodermal thickening, which is then said to divide into two layers, a smperficial layer which yields the cornea and crystalline cone cells, and a dceper layer which yields the retinulæ with the rhabdoms. Another ectodermal thickening comnected with the first and belonging to the secondary brain chiefly yields the material for the optic and the retinal ganglia.

\section{Astacus fluviatilis (Figs. 270-280).}

The segmentation is superficial, and leads to the formation of a spherical blastosphere (blastula), in which the central nutritive yolk, which is divided in radially arranged yolk pyramids, is enveloped all round by the blastoderm as by an epithelium.

Stage A. At one point of the blastosphere the constitution of the blastoderm undergoes a change. The cells at this part are longer and stand closer together. This part corresponds with the future rentral side and is symmetrical; it can be denominated the ventral plate. This ventral plate consists of the following portions: the 2 cephalic lobes, the 2 thoraco-abdominal rudiments, and farthest back, the mujaired median endoderm disc (Fig. 271). The whole ventral plate is of one layer except at one point between the endodermal dise and the thoraco-abdominal rudiments. Large cells have sunk down inwards from the blastoderm as the primitive mesoderm cells $(B, I I)$. With the exception of the cudoderm disc, which becomes invaginated later, and the primitive mesoderm cells, the ventral plate and the whole remaining hlastodcrm represents the ectoderm. The latter yields at a later stage the sides and hack of the thoracic shield, but in the early stages of develojment is nothing more than a sac surrounding the yolk. 


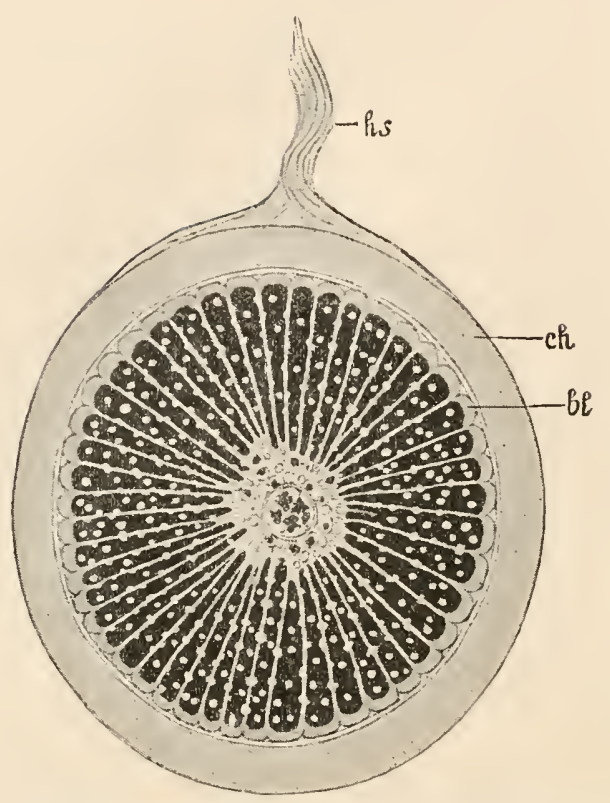

Fic. 270.-Astacus fluviatilis, section through an egg, after completed formation of blastoderm. ch, Chorion; $h s$, stalk of attachment; $b l$, blastorlerm cells. The nutritive yolk is black in this and the following Figs. (after Reichenbach).

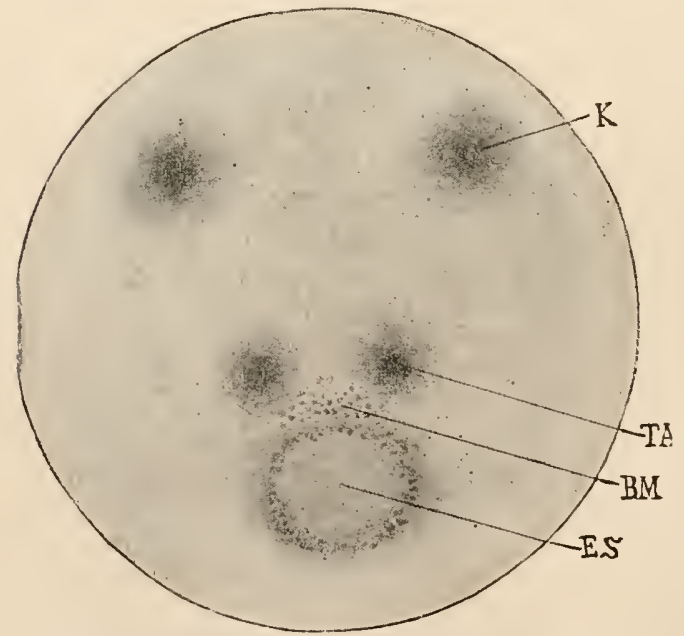

Fig. 271.-Astacus fluviatilis, part of the surface of an egg with embryo beginning to form.-Stage $\mathbf{A}$. $\hbar$ Cephalic lobes, with the rudiment of the eye ; $T A$, thoraco-ablominal ruliments ; $B M$, formative zone of the mesoderm; ES, endoderm disc (after Reichenbach).
Stage B. Embryo, with semicircular gastral furrow. - Only the ventral plate alters. At the anterior edge of the endoderm dise a semicircular furrow, or a fold projecting inwards, appears.

Stage C. Embryo, with circular gastral furrow.The thoraco - abdominal plates unite in the middle line. The semicircular furrow has become a furrow round the whole circumferencc of the endoderm dise and is thus circular. The middle part of the endoderm dise sinks down, so that it now becomes a de. pression with a somewhat raised floor (gastrula inva. gination). This depression represents the rudimentary midgut, and the outer edges of the original circular furrow are the edges of the blastopore or gastrula month. In front of the anterior edge of the blastopore lie the primitive mesoderm cells in active growth. and giving off cells towards the centre of the blastosphere (Fig. 275).

Stage D. The primitive mouth is in the act of closing.- In the centres of the two cephalic lobes are the rudiments of the eyes. Between the cephalic bobs and the thoraco-abdominal rudiments the first traces of the mandibles and antennæ appear. The primitive mouth closes from be. fore backward, its lateral edges growing together in the middle linc. The cells of the primitive intestine begin to consume nutritive yolk. 
Stage E. Embryo, with mandibles beginning to form. - In the middle of the thoraeoabdominal disc the (ectodermal) rudiments of the anus and hind-rgut (proctoliemm) aprear in the form of an anal pit. The mesodermal elements spread ont below the ectoderm.

Stage F. Embryo in the Nauplius stage (Figs. 272 and 276).The 3 most anterior pairs of extremities (Nauplins extremities) can be distinctly made out. Between the anterior antenne the first (paired) traces of the brain appear, and immediately behind there is a pit-like depression, the ectodermal rudiments of the mouth and fore - gut (stomodrum). In the posterior antennal and the mandibular segments the rudiments of ganglia appear as ectodermal thiekenings in the same way as in the formation of the brain. The thoracoabdominal ridge, surrounded by a deep furrow, projects anteriorly. The anus has moved forward on it and reaches the inner side of its anterior edge, i.e. the later ventral side of the end of the body. The ectoderm and mesoderm form a budding zone on the thoraco-abdominal ridge, and from this time new

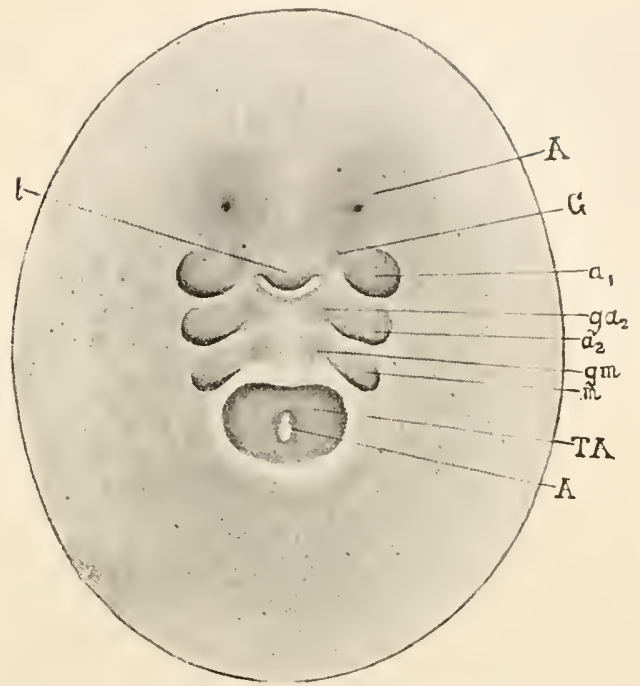

Fig. 272.-Astacus fluviatilis, embryo in the Nauplius stage. -Stage F. A (above), Ruliment of eye; $l$, upper lip; $G$, cerebral ganglion; $\alpha_{1}$, anterior antennæ; $g \alpha_{2}$, ganglion of the segment of the $2 \mathrm{l}$ antennx $\left(a_{2}\right) ; g m$, ganglion of the segment of the mandibles $(m)$; $T a$, thoraco-abdominal rudiments; $A$, (below) anus (after Reichenbach).

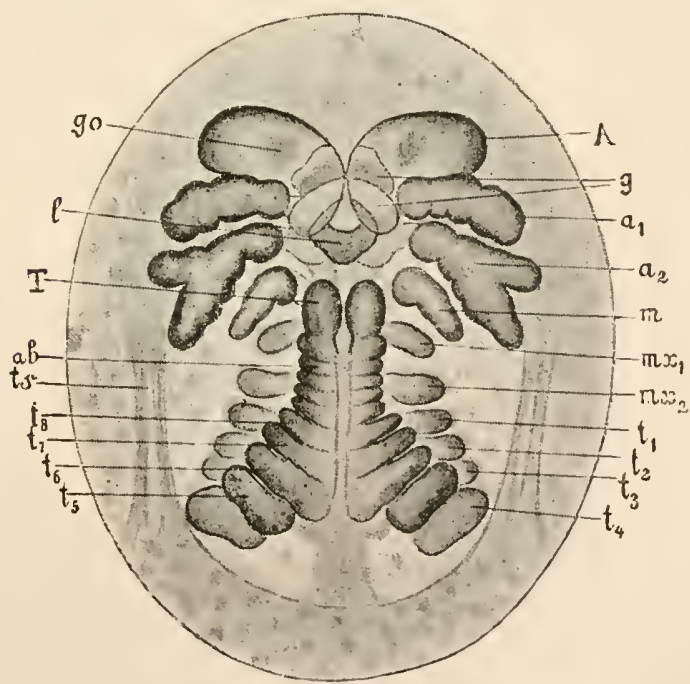

Fı. 273.-Astacus fiuviatilis, embryo with thoracic feet beginning to form.- Stage H. A, Eyes; $g$, brain and ganglia of the anterior antenne $\left(a_{1}\right) ; \iota_{2}, 21$ antennre; $m$, manlible; $m x_{1}, m x_{2}$, anterior and posterior maxille; $t_{1}-t_{8}$, thoracic feet, of which $t_{1}-t_{3}$ are maxillipedes; $t s$, ruliment of thoracic shield; $a b$, abdomen, bent back on the anterior portion of the thorax; $T$, telson; $l$, upper lip; go, ganglion opticum (after Reichenbach). 
segments with the rudiments of their cxtremities are continually differentiated anteriorly (but apparently posteriorly, since the rindiments of the thoraco-abdomen are bent forward). At this $(F)$ stage the rudiments of the maxillar segments and of the first maxillipedal segment are already present. The hind-gut has become longer, and with its blind end tonches the primitive enteric sac (mid-gut). On each

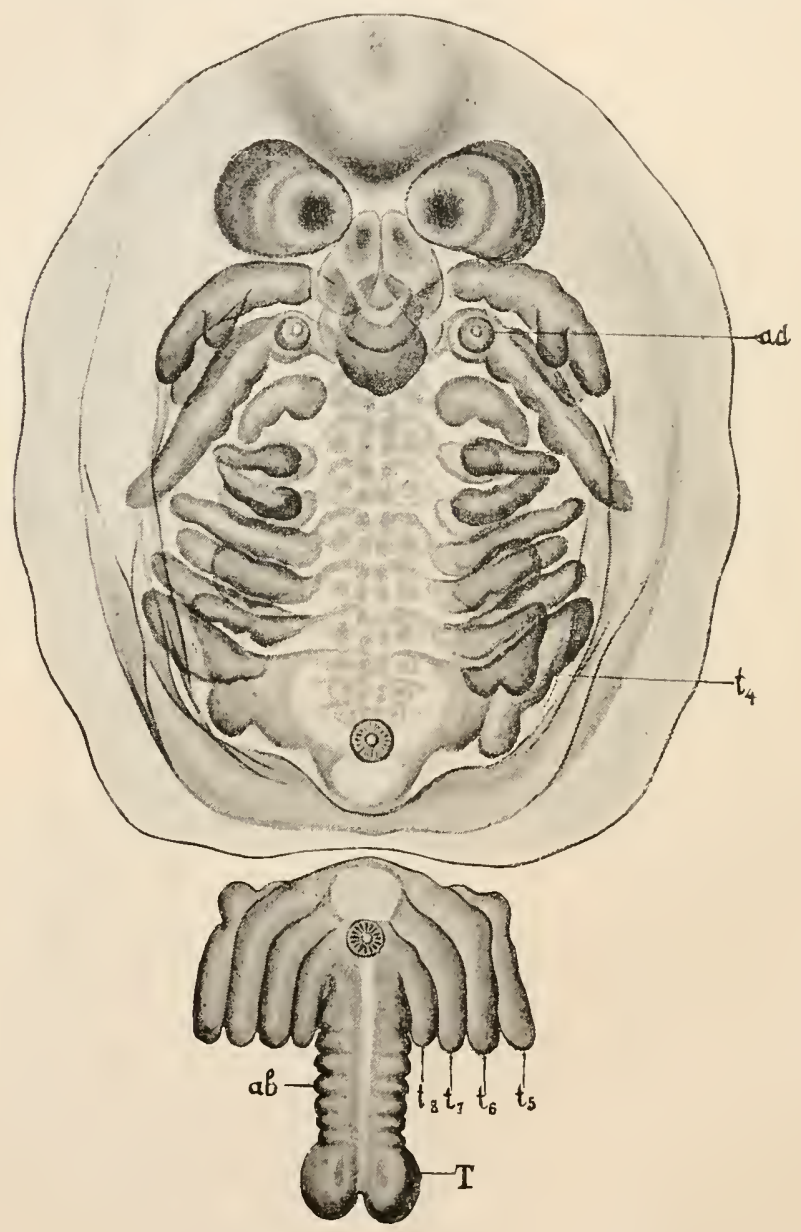

FIa. 274.-Astacus fluviatilis, embryo with the rudiments of all the limbs.-The thoracoabdomen, with the last 4 pairs of thoracic feet cut off and laid back. ad, Antennal glands; $t_{4}$ - $t_{8}$, 4th-Sth pair of thoracic feet (ambulatory feet); $t_{\frac{1}{4}}$, chelate feet; $a b$, abulomen; $T$, telson (after Reichenbach).

side the thoraco-abdomen is bordered by a curred integumental wall, the rudiment of the cephalo-thoracic shield.

Stage G. Embryo with rudiments of maxillipedes (Fig. 27 7 ). - The thoracoabdomen elongates in a longitudinal direction and shows at the end which is 
directed forwards (telson) a deep indentation. The budding zone, from which new segments have formed, borders directly on this indentation. The penultimate abdominal segment (6th) appears, and thus precedes in order of development a large number of segments which lic in front of it. The rudiments of its limbs are already visible.

Stage H. (Fig. 273 and 27S) Embryo with rudiments of ambulatory feet. - All the segments of the Crustacean body are formed; they have develojed in succession from the budding zone in front of the telson, so that the anterior and most differentiated are the oldest and the posterior least developed are the youngest (with the exception of the 6th abdominal segment). The budding zone itself has been exhausted in the formation of the segments. The rudiments of the eyes projeet as spheres. The ambulatory feet have developed. The telson appears deeply forked. The abdomen has become slender, and is so bent forward along the thorax that the telson almost tonches the upper lip'. The hind-gut has opened into the mid-gut, the epithelial eells of the latter having for some time become swollen by assimilating yolk, and being at this stage colummar. The yolk between the mid-gut and the ectoderm is absorbed, and the wall of the mid-gut is almost in contact with the cephalothoracic ectoderm. The ventral chord with its ganglia differentiates from before baekward, having arisen out of paired lateral strands, and a middle strand formed by invagination. The lateral strands are ectodermal thickenings with segmental swellings, which sever themselves from the eetoderm in order from before baekward (cf. also Fig. 279).

Stage J. Embryo with rudiments of abdominal feet.-The cephalothoracie shield has developed greatly, its lateral parts project freely as rudimentary branchiostegites.

Stage $\mathrm{K}$ then follows, with developed eye-pigment and the rudiments of the gills. Thereupon the young Crustaeean, whieh is already tolerably similar in appearance to the adult, is hatched from the egg. The fusing of the anterior thoracie ganglia to form the infra-œsophageal ganglion has begun. The forked telson has beeome a round plate, and the abdomen resembles that of the adult. The liver is formed almost exelusively by proeesses of folding of the wall of the mid-gut ( $f$. Figs. 274 and 280).

FIGs. 275-280.-Astacus fluviatilis. Median longitudinal sections through embryos at different stages of development. In Figs. $275,276,277$, and 279 only the ventral side of the embryo is depicted, in Figs, 278 and 280 the whole embryo in longitudinal section. In Fig. 280 the position of the embryo is the reverse of what it is in the other figures (all Figs. after Reichenbach

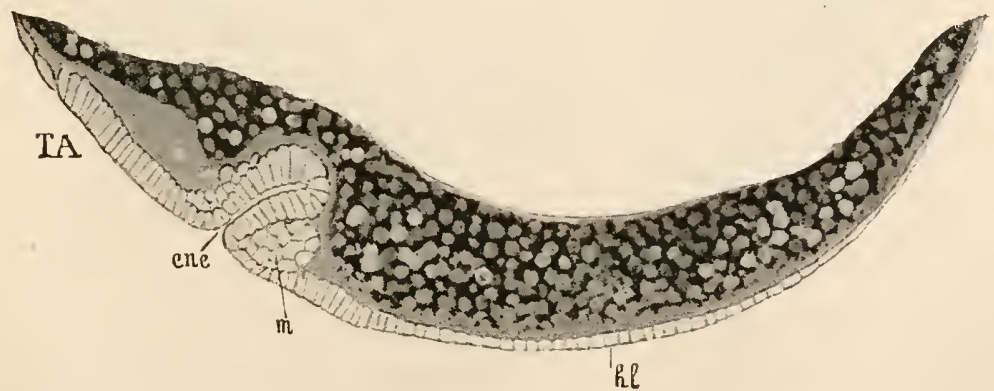

FiG. 275.-Stage C. TA, Thoraco-abdominal rudiments; ene, endodermal invagination (gastrula invagination); $m$, mesoderm ; $h$, ceplalic lobes. 


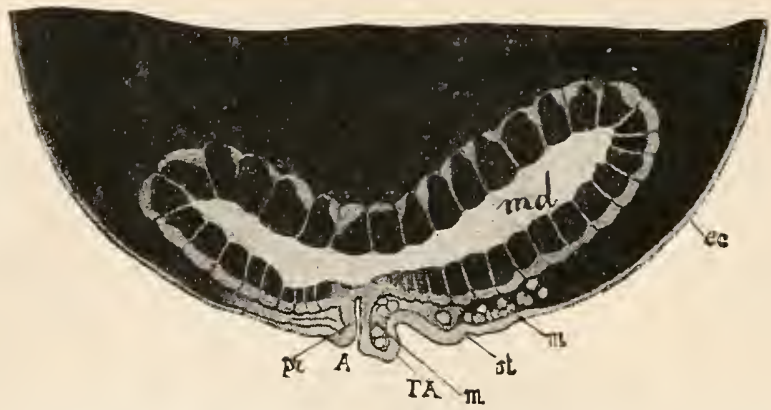

FIG, 276.-Nauplius Stage. Stage F. $m d$, Mid-gut, the endoderm cells have assimilated nutritive yolk; $\hat{\imath}$, proctodæum (hind-gut); $A$, anus; $T A$, thoraco-abdominal rudiment; $m$, mesoderm; st, beginning of invagination of the stomodxum; cc, ectoderm.

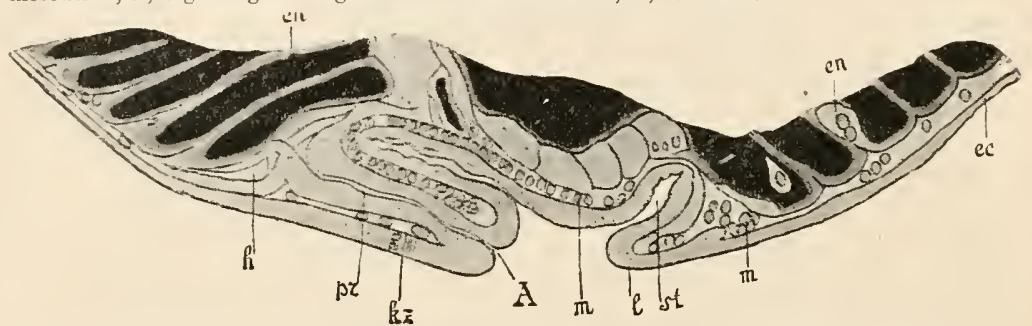

FIG. 277.-Stage G. $c n$, The endodermal cells laden with yolk; $h$, rudiment of heart; $r r$, proctodxum ; $k z$, germ zone; $A$, anus; $m$, mesoderin; $l$, upper lip; st, stomodæum ; $e c$, ectoderm.

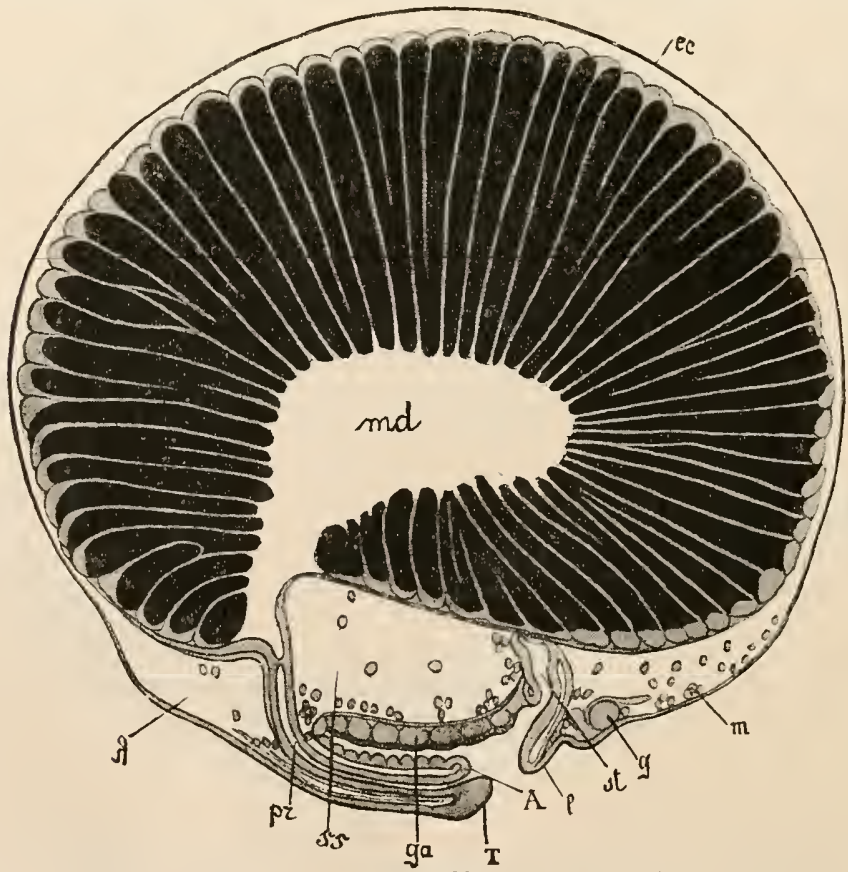

FIg. 278.-Stage H. Lettering the same. In addition: ss, sternal simus; ge, ganglia of the ventral chord; $T$, telsoll ; $g$, supra-cesophageal ganglion. 
Development of the eye.-Each eye eonsists of three elements : (1) a hypodermal layer, (2) an eetodermal invagination, and (3) a nerve mass.

The hypodermal layer beeomes many-layered; some of its elements eombine to form groups, eaeh of which eonsists of 8 eells, 4 of which (Semper's eells) seerete a eutieular eorneal faeet, while the 4 others produee the erystalline eone.

The ectodermal invagination (optie fold) deepens in the Tauplius stage and is eonstrieted off in stage (G) as a solid mass of cells. This mass develops into a fold, opens outward and upward, with an outer and inner wall several layers thick. The outer wall beeomes eonneeted with the layer of the erystalline eones, its eell elements form groups of 6 to 8 and beeome the retinular cells. The inner wall yields the nervous eomneetions of the retimular layer with the ganglion optieum.

The ganglion opticum arises like any other ganglion of the eentral nervous system as an eetodermal thiekening.

Between the hypodermal layer and the optie fold, mesodermal elements penetrate and grow, miting to form a fenestrated mass which seeretes a large quantity of pigment.

\section{XV.-The morphological significance of the most important Crus- tacean larval forms, and the Phylogeny of the Crustacea.}

That the Crustaeea form a single elass is evident to the student of eomparative anatomy and ontogeny. It is probable that they ean ultimately be traeed to one raeial form. Basing our eonjectures for the present simply on the comparative anatomy and classification of the group, we feel justified in deseribing this raeial form as follows.

The original Crustaeean was an elongated animal, eonsisting of numerous and tolerably homonomous segments. The head segment was fused with the 4 subsequent trunk segments to form a eephalic region, and earried a median frontal eye, a pair of simple anterior anteune, a seeond pair of biramose antennæ and 3 pairs of biramose oral limbs, whieh already served to some extent for taking food. From the posterior eephalie region proeeeded an integumental fold which, as dorsal shield, eovered a larger or smaller portion of the trunk. The trumk segments were eaeh provided with one pair of biramose limbs. Besides the median eye there were 2 frontal sensory organs. The nervous system eonsisted of brain, cesophageal eommissures and segmented ventral ehord, with a double ganglion for eaeh segment and pair of limbs. The heart was a long eontraetile dorsal vessel with numerous pairs of ostia segmentally arranged. In the raeial form the sexes were separate, the male with a pair of testes, the female with a pair of ovaries, both with paired ducts emerging externally at the bases of a pair of trunk limbs. The exeretory funetion was earried on by at least 2 pairs of glands, the anterior pair (antennal glands) emerging at the base of the seeond pair of antennæ, the posterior (shell glands) at the base of the seeond pair of maxillæ. The mid-gut possibly had segmentally arranged divertienla (hepatic invaginations).

This eonjeetural raeial form shows a eonsiderable eorrespondenee with the Annelida, and this correspondenee would be inereased if it eould be satisfaetorily proved that the biramose limbs of the Crustaeea with its exo- and endopodite answered to the dorsal and ventral parapodia, ${ }^{1}$ and the epipodial gills of the Crustaeea to the dorsal gills (of the dorsal parapodia) of the Annclida. The setiparous glands of the Amelide would eorrespond with the segmental leg glands of eertain Crustacea (Phyllopoda).

1 It must here be remembered that the question whether in the Polychata the uniserial or the biserial arrangement of the parapodia is the original is not yet satisfaetorily settled. 
The proof of the homology of the antennal and shell glands of the oviducts and vasa deferentia with Annulate nephrirlia would also be of the greatest imirortance.

Among the now living Crustacea there are two orders of the Eirtomostraca, viz., the Phyllopodte (the Branchiopoda especially) and the Copepoda, whose organisation best recalls that of the racial form, the former in the rich homonomons sergmentation of the trunk and the structure of the nervous system and the heart; the latter in the form of the limbs, especially the oral limbs, which still most clearly show their original biramose character. The Cladocere and perhaps the Ostrecode might be derived from animals like the Branchiopoda by the shortening of the body and the reduction of the number of segments. The ancestors of the Cirripades are probably nearly related to the immediate progenitors of the Copcporde.

At first sight the results of research in comparative ontogeny do not seem to harmonisc with the view just stated. Out of the egg of the Entomostrace and many Malecostrace the unsegmented Nauplius larva is hatched with only 3 pairs of extremities, without a heart, and without a segmented rentral chord. On account of this the Crustacean racial form was formerly nnirersally held to be a Nouplizes. like animal. It was assumed that from this racial form the Crustaceans of to-day developed phylogenetically through a series of gradual transformations, in a manner similar to that in which they develop ontogenetically at the juresent time from the Nauplius by a series of metamorphoses.

We consider these views incorrect, both for general and special reasons.

General Reasons.-(1) We know of no animal form which in an adult sexually mature condition resembles a Nauplius. (2) We are not justified, without further proof, in concluding that the early larval stages of an animal form closely resemble the ancestors of that form.

Special Reasons.-The assumption of a racial form like a . Tauplius leaves the problem of the rise of the typical Crustacean organisation, of the segmentation of the body, the segmented ventral chord, and the segmented dorsal heart quite unexplained. It must also be emphasiscl that the ducts of the sexual organs, except in one single case, emerge in regions of the body which in the Nanplizs are not at all devcloped.

On the other hand, the Nauplius, as characteristic larval, not racial form of the Crustacea, is explained withont difficulty by the assumption of a Crustacean racial form resembling the Annetida. Just as the racial form of the Crustacea is to be traced back to the Annelida, so is the larval form of the Crustacea to the larral form of the Annelida. We have already mentioned the tendency in the animal kinglom to shift back to earlier stages of development the characteristics of the adult animal. Hence in the Crustacea, Crustacean characteristics (such as limbs and dorsal shield) appear as early as in the larva which corresponds with the Trochophora of the Annclida. The method of moving by means of the limbs makes the old methor needless, so that the ciliated circles of the Trochophore larva are no longer mroduced.

In all Crustacea the 3 pairs of Nouplius limbs become the 3 most anterior extremities of the adult animal (2 pairs of antenne and the mandibles). The fact that, in the Nouplins, just these pairs of limbs appear first can again be explained without difficulty. As in the Annelide so in the Crustacea also, the body with all its organs becomes differentiated from before backward. At the posterior end of the body a growing or formative zone continually constricts of new segments anteriorly. It is thus evident that the most anterior extremities must appear first. But why just the 3 most anterior, and neither more nor less? A natural answer may perhaps also he found to this question. In a young larva which, like the Nauplius, is hatched early from the egg, only a few of the organs most necessary for independent life and independent acquisition of food can be developed. The 3 most anterior pairs of limbs which serve for swimming may be described as such most necessary organs. The 31 
-pair perhaps helongs to this category, because as mouth parts, generally provided with inasticatory processes, they serve not only with the others for locomotion, but also for conducting food to the oral apcrture. Where the cgg is provided witl a somewhat richer supply of nutritive yolk, the larva which hatches from it may, as a Mctancuplins, be provided with the rudiments of other limbs.

The Scuplius, however, as typical Crustacean larva, certainly shows many primitive Crustacean characteristics, such as the dorsal shield, the median eye, the frontal sensory organs, the special form of the posterior antenne and mandibles which, like the extremities which follow them, are developed as typical biramose limbs.

The Nauplius is thus to be traced back to a Trochophora larva, in which we already find Crustacean characteristics; it is unsegmented, contains the rudiments of the anterior cephalic portion of the adult Crustacean with the mouth, and the rudiments of the most posterior end of the body with the anus. Between the two lies an embryonic formative zone, from which, in the further development of the larva, the rest of the body begins to form and becomes differentiated, as in the Annelida, from before backward. The Nauplius is a typical Crustacean larva ; the ancestors of the Crustacea did not as yet possess a typical Nauplius larva, still less did they come from a Nauplius-like racial form.

As for the Malacostrace, the testimony of comparative anatomy is unequivocal, that the Leptostrace not only stand nearest to the common racial form of this whole sul,-class, but also retain many urimitive characteristics of the common racial form of all Crustacea. The Leptostrace appear as genuine Malacostraca, first on account of the formation of the regions of the trunk, which consists of a thorax of 8 segments and an ablomen; the latter, although it has one more posterior segment than the typical Malacostracan abdomen, still carries the same number of pleopoda. Both the oral and thoracic limbs show the typical Malacostracan character. The intestine proves itself to be a Malacostracan intestine by its masticatory stomach, and the special form of its hepatic glands, and the apertures of the genital organs have the position which is characteristic of the Malacostraca. On the other hand, by the possession of a bivalve shell-fold, the simultaneous development of the $S$ free thoracic segments and their appendages, by the rich segmentation of the nervous system, and the elongated heart with many pairs of ostia, the Leptostrace show themselves to be very primitive Malacostrace, whose ancestors must have been racially related to the Phyllopoda.

The relationships of the other orders of Malacostraca are, according to the present state of our knowledge, to be considered as follows: the Stomatopode form an order standing quite by itself, which, though showing further and somewlat peculiar development ( $c . g$. in the possession of gills on the pleopoda, sexual organs in the ablomen, numerous hepatic appendages, special form of the thorax and its extremities) has still retained, in many points of its organisation, primitive characteristics, as, for instance, the elongated dorsal vessel with many pairs of ostia, and the shellfold which leaves several thoracic segments free.

Of the other Halacostrace, the Schizopoda, and especially the Euphauside have, for the most part, retained characteristies belonging to the common racial form of the Halacostrace. Of these the chief are the special form of the biramose thoracic feet, their epipodial appendages which function as gills, the dorsal shell, etc. The Arthrostrace have evidently a common origin with the Schizopoda. Among the former the Anisopoda must occupy the most primitive place, as well on account of the occurrence of a small dorsal shell as of that of small exoprodites on the second and third pairs of trunk feet (Apseudes).

The Arthrostrace are otherwise characterised by degeneration of the shell-folds, 
transformation of the stalked eyes into sessilc eyes, and disaplearance of the exopodites on the thoracic feet.

The difference in the position of the heart in the Amphipode and Isopode is to be explainel, as already pointel out, by the fact that in the former only a thoracic portion, and in the latter only an abdominal portion of the primitive elongated dorsal ressel has been retained, in both cases, clearly in connection with the localisation of the respiration. The Cumacce stand nearest to the Schizopoda, but exhibit a few Isopodan characteristics. It is pretty certain that the Dccopolde come from Schizopoda-like ancestors; the Hecrure, and especially the Caridice, appear to be the most original forms, while the Brachyure and Anomure appear as one-sidedly, but very highly, developed branehes of the order.

We are again met by the question, what is the phylogenetic significance of the various larval forms of the Valacostrace? Just as the Nauplizes larva, which is characteristic of the whole class of the Crustacea, was held to be a stage of development repreating the common ancestral form, so a further developed Nalacostracan larva, the so-called Zoce was considered to be a larva characteristic of the Malacostrace, and assumed to correspond with onc of their racial forms.

These Zoce larre have been alrealy thus characterised: a large cephalothoracic shield, 2 componnd stalked eyes, a modian Nauplizes eye, head with 5 pairs of limbs, only the most anterior part of the thorax with thoracic feet (2-3) in a rudimentary condition, the remainder of the thorax wanting, or else rudimentary and limbless. Abdomen with full number of segments but without appendages. Tail bifurcated.

Those investigators who wished to find in this Zoced larva a larval form corresponding more or less with the racial form of the IIalacostrace had to assume that in the Malacostrace now living the last 5 or 6 thoracic segments are new formations, sinee they are wanting in the racial form. When therefore the structure and systematic position of the Leptostrace were better appreciaterl, and the larval history of the Euphauside and the Caridide better and more completely minderstood, these authors were obliged to take refuge in the following explanation. The carliest aneestors of the Malacostrace possessed the full number of trunk segments and the full number of thoracic feet, but a later form lost the last 5 or 6 trunk segments with their appendages, while, however, they were still retained by the larva. Finally these segments and their appendages again appeared (in the living Halacostrace known to $n$ or in fossil forms). In support of these very forced views the larral history of eertain Stomatopoda was cited; in these the $3 \mathrm{~d}$, 4th, and 5th pairs of thoracic feet are present in the young larva, but disappear later, to be finally reformed. In the larra of Scrgcstes also, the last 2 pairs of thoracic feet are reduced and appear again later.

So many objections, howerer, can be brought against this assumption that it must necessarily be relinquished.

In the first place it must be pointed out that of all the manifold known forms of Crustacea, and especially in that series (which indeed is not without gaps) beginning with the Phyllopode and ending with the Brachyuran Decapode, of which Branchipnes, Acbalia, Euphausia, Penacus are the most important, there is nothing to give the slightest indication that whole regions of the body with their extremities can disappear and reappear again later, or that between already existing segments new segments with their limbs can be intercalated.

We must therefore ask, to what extent the Zooce larra above characterised is distributed among the Malacostrace. In its typical form it is fomnd only in the Brachyure and (though slightly deviating in form) in the stomatopoda. This fact alone warns us to be careful, since the Brachyurc are decidedly the most recent and most specialised Dccopoda, and in their development the Schizopodan stage with the 
characteristic biramose thoracic feet does not once occur. The larral history of the Euphauside, Stomatopocia, and Curidide, the early developmental processes in the Loricata which take place within the egg, and the so-called direet development of so many Malecostrace show that the Malacostracan body becomes gradually differentiated in the typical manner (as in the Entomostrecre) from before backward. The larval history of Pcnacus shows further that, with the exception of the 6th pair of pleopoda, the extremities also begin to form and differentiate from before backward. In the Explanside the extremities of the posterior thoracic region differentiate almost simultaneously with those of the abdomen from before backward.

It is of the greatest importance for the comprehension of the typical Dccaporlan Zoce, and especially of that of the Brochyura, to bear in mind the established fact that in that larva, in spite of the apparent absence of the thoracic region comprising the 4 th to 8 th thoracic segments, the thoracic ganglionic mass through which the sternal artery runs lias already begun to form.

Not less important also is the fact that the Stomotopoden larva possess an elongated dorsal vessel with many pairs of ostia, while the Dccapodon Zocec and the other Thorcastracen larve which resemble it possess a compact thoracie heart, generally with 1 or 2 pairs of ostia. These facts sufficiently show how varied are the Thoracostracen larve which have been artifically combined into a Zocec group.

In all future attempts to understand the morphology of Crustacean larval forms the following considerations will probably have to be taken into account.

The grade of development and physiological importance of a section of the body or of a pair of limbs in the adult animal may be recognised by the earlier or later appearance of their rudiments; c.g. the extraordinarily carly appearance of the last pair of pleopoda in the Thorecostrrece, i.e. of that pair of pleopoda which in the adult differs so strikingly from the others, forming together with the telson the caudal fin, which is the chief organ of locomotion. A contrast to this is afforded by the late appearance of the reduced maxille of the adult Phyllopoda and Cirripedia.

Not only the special form of the adult animal, however, but also that of one or more of its larval stages may have some influence on the early processes of development, i.c. when thesc larval stages are not merely phases of development, but animals feeding themselves and leading an independent life and playing an important part in the life economy of the species, more or less like adult animals though mable to reproduce themselves. Such larve show throughout their organisation indeprendent adaptation to the special conditions of their existence, and it is the first and chief object of the preceding developmental stages to prepare their organisation, not that of the adult animal. From this point of view we shall perhaps some day be able to explain the Brachyuran Zoce with its reduced thorax and failing 4th to sth ambulatory feet, which in the adult animal are the only organs of locomotion, but in the Zocc are perhaps useless or even a hindrance. The larve lead a marine life, and their organisation is no doubt more or less adapted to this life. We see, therefore, how important it is to ascertain what are the functions of the different parts of each larva, in order to arrive at any sure conclusion as to the significance of the changes it undergoes.

One of the most important and most interesting problems of ontogeny is the reduction and subsequent reappearance of the same portions of the body, of which the larval history of the Nalacostraca yields us so many examples. (Comprare especially the larval history of the Stomatopoda and Loricata.) For the solution of this problem also the above points of view may prove of service. In the Stomatopota the last 3 prairs of thoracic feet, the so-called ambulatory feet, like the 5 pairs of ambulatory feet in the Brachyura, first appear at the end of larval life. The 5 anterior pairs, however, develop during the first period of larval life (youngest 
known Erichthoid larva) partly to disaplear in the 2 d periorl ant finally to reappear in their definitive form. The developmental history of the Loricata shows similar phenomena. The first attempt, later frustrated, to form all or most of the typical Malacostracan extremities, which we here observe is no donbt to be ascribed to the force of heredity. The temporary disappearance of some of the extremities is most probably a phenomenon of adaptation to the special conditions of existence of the larva, so different from those of the adult. If, however, these first fruitless and useless attempts were in the conrse of time to become gradually weaker, and finally entirely cease, then we should meet in the Loricata and Stomatopoda with phenomena quite similar to those in the Brachyuran development, where the formation of the last 5 thoracic segments, and their extremities occurs so extraordinarily late. In this way, also perhaps we can explain the fact that the Brachyuran ambulatory feet appear in their definitive form and not as biramose feet.

\section{Review of the most important Literature.}

Especially recommended as an introduction to the study of the Crustacea.

T. H. Huxley. The Cray-fish: An introduction to the study of Zoology ("International Scientifie Series," 1884).

\section{Comprehensive or more general works.}

J. E. V. Boas. Studien über die Vemeandtschaftsberichungen der Malacostraken, in Gegenbaur's Morphol. Juhrbuch. $8 \mathrm{Bd} .1883$.

Justus Carrière. Die Schorgane der Thiere, vergleichend-anatomisch dargestellt. Miinchen und Leipzig; 1885.

C. Claus. Untersuchungen zur Eiforschung der genealogisehen Grundlage des C'rustacen-systems. Ein Beitrag zur Descendenzlchre. Wien, 1876. Important.

The same. Neue Beiträge zur Morphologic der Crustacen, in Arb. aus dem Zool. Institute $\approx u$ IVicn. $6 \mathrm{Bd} .1886$.

J. Dana. Crustacea of U. S. cxploring expedition under Capt. Charles Willies. 2 vols. with Atlas. Philadelphia, 1852.

H. Gerstaecker. Arthropoden in Bronn's Klassen und Ordnungen des Thierreichs. $5 \mathrm{Bd}$. I. Abth. First half 1866-1879. Second half not yet completed.

A. Grenacher. Untersuchungen über das Schorgan der Arthropoden. Göttingen, 1879.

Carl Grobben. Die Antennendriese der C'rustacen. Arb. aus dem Zool. Institute zu Wien. $3 \mathrm{Bd}$. 1880.

Milne Edwards. Histoire naturelle des Crustacés. Paris, 1834-1840. Vol. III. with Atlas.

Fritz Müller. Für Darwin. Leipzig, 1864.

\section{Anatomy of single divisions.}

G. Bellonci. Sistema nervoso e organi dei sensi dello Sphatoma serratum, in Memorie Acced. Lincei. Vol. X. 1881.

Carl Claus. Neue Beobachtungen über Cypridinen. Zeitschrift f. wiss. Zoologie. $2313 d$.

The same, Zur anatomic und Entuciclelungsgeschichte der Copepoden, in Arehiv. $f$. Vaturgeschichte. 24 Jalirg. 1 Bd. 1858.

The same. Beiträge zur Kemtniss der Entomostration (Copepoden, Estherien). Marburg, 1860. 
The same. Die fiei lebenden Copepoden. Leipzig, 186:3.

The same. Die Hetamorphose der Squilliden. Abhandl. d. Königl. Gesellsch, d. II'issensehaften. Göttingen, 1871.

The same. Zur Kenntniss des Baues und der Entrickelung ron Branehipus stagnalis und Apus cancriformis. Abhandl. d. Königl. Gesellsch. d. Wissensch. Göttingen, 1873.

The same. Schriften zoologischen Inhalts. I. Die Familie der Halocypriden. Wien, 1874.

The same. Ueber die Entwiekelung, Organisation und systematische Stellung der Arguliden, in Zeitschr. f. wissensch. Zoologic. $25 \mathrm{Bd} .1875$.

The same. Zur Kenntuiss der Organisation und des feineren Baues der Daphniden. und verwandter Cladoceren, in Zeitsehr. f. wissenseh. Zoologic. $27 \mathrm{Bd} .1876$.

The same. Der Organismus der Phronimiden, in Arb. aus dem Zool. Institute su Wion. $2 \mathrm{Bd} .1879$.

The same. Kreislurforgane der Stomatopoden, Sehizopoden und Decapoden. Ibidem. $5 \mathrm{Bd} .1884$.

The same. Ueber Apseudes Latreillei Edw. und die Tanaiden. Tbidem. 5 Bd. 1854.

The same. Untersuchungen über die Organisation und Entrviekelung von Branchipus und Artemia. Ibidem. $6 \mathrm{Bd} .1586$.

The same. Ueber Lernaeaseus nematoxys und die Fomilie der Philichthyden. Ibidem. $7 \mathrm{Bd} .1887$.

The same. Ueber Apseudes Latreillei Edu. und dic Tanaiden. II. Ibidem. $7 \mathrm{Bd}$. 1857.

The same. Ueber den Organismus der Nebuliden und die systematische Stellung der Leptostraken. Ibidcm. \& Bd. 1 Heft. 1888.

Ch. Darwin. A monograph of the Cirripedia. Rey Society. 2 Vols. 1851, 1853.

Yves Delage. Contribution à l'étude de l'apporeil circulatoire des Crustacés édriophthalmes marins. Areh. de Zoologic expérimentale. 1. Vol. IX. Paris, 1881.

Anton Dohrn. Untersuchungen über Bau und Entuxickelung der Arthropaden. Leipzig, 1870.

A. Giard et J. Bonnier. Contributions à l'étude des Bopyriens. Travaux de l'Inst. zool. de Lille. Tome V. 1587.

C. Grobben. Die Geschlechtsorgane von Squilla mantis. Sitz-Ber. Akod. Wissenseh, Wien, 1876.

The same. Beiträge zur Kenntniss der männlichen Geschlechtsorgane der Decopoden. Arb. aus dem Zool. Institute zu Wein. 1 Bd. 1878.

Ernst Haeckel. Ueber die Gewebe des Flusskrebses, in HIüller's Archiv. 1857.

The same. Beiträge zur Konntniss der Coryeaciden, in Jenaisehe Zeitschr. 1 Bd. 1864.

C. Heider. Dic Gattung Lcrnanthropus, in Arb. aus dem Zool. Institute zu Wien. $2 \mathrm{Bd} .1879$.

v. Hensen. Studien über das Gehörorgan der Decapoden, in Zeitsehr. f. wissenseh. Zoologie. $13 \mathrm{Bd}$. 1563.

P. P. C. Hoek. Report on the Cirripedia collected by H. M. S. Challenger. Anatomical Part. Zool. Chall. Eetp. Part XXVIII. $18 s 4$.

Lemoine. Riehcrehes pour servir ì l'histoire des systèmes nerveux, musculaire et glandulaire de l'écrevisse. Annales des sciences naturelles. Série IV. Vol. XV. 1861.

Fr. Leydig. Naturgeschichte der Daphniden. Tiibingen, 1860.

P. Mayer. Carcinologische Hittheilungen. Mitth. d. Zool. Station zu Neapel. 1 und $2 \mathrm{Bd}$. 187S-1881. 
The same. Dic Caprelliden des Golfes von Teapel, in Fanna und Flora des Golfes ron Neapel. 6 Bd. Leipzig, 18s2.

Otmar Nebeski. Beiträge aur Kenntniss der Amphipoden der Adrice. Arb. ans dem Zool. Institute zu Wien. $3 \mathrm{Bd}, 1850$.

A. S. Packard jr. A monograph of North American Phyllopod Crustacea. Washington, 18s3. (Geolog. Survey of the Teritorics, 12 Anmul Report.)

G. O. Sars. Histoire naturelle des Crustacés d'eau douce de Torrège. Cliristiania, 1867.

The same. Carcinologistie Bidrag til Norges Faune. I. Mysider. Christiania, $1870-1872$.

The same. Iieport on the Schizoporla, in Report on the scientific results of the royage of H. H. S. Challenger. Zoology. Vol. XIII. 1885.

The same. Report on the Phyllocarida (Leptostraca). Ibid. Vol, XIX. 18st.

The same. Report on the Cumacea. Ibid. Vol. XIT. 1887.

R. Walz. Ueber die Fumilic der Bopyriden. Arb. aus dem Zool. Institute $\approx u$ Wion. $4 \mathrm{Bd}$. 1582 .

Max Weber. Die Isopoden, gescmmelt wïhrend der Fahrten des "Willem Barents" in clas nörlliche Eismeer, in Bijdragen tot de Dierkunde. Amsterdam, 1854.

August Weismann. Ucber Bau und Lebensersehcinungen von Leptodora hyalina, in Zeitschr. f. wissensch. Zoologic. $24 \mathrm{Bd} .1874$.

The same. Bcitrïge zur Naturgeschichte der Daphnoiden. Sieben Abhandlungen. Lei]zig. 1S76-1879. Separat-Abdruck aus Zcitschr. f. wissensch. Zoulogic. $27.33 \mathrm{Bd}$.

W. Zenker. Monographic der Ostracoden, in Aichiv. für Naturgeschichte, 20 Jahrg. $1 \mathrm{Bd} .1854$.

Many other works and treatises of von Blanc, Boas, Brooks, Berger, Burmeister, Brady, Bullar, Braun, Brocchi, Bellonei, Brandt, Beddard, Claus, Delage, Dietl, Friedrich, Gegenbaur, Grube, Giesbrecht, Gruber, Hcrbst, Kossmann, Kraepelin, Krieger, Klunzinger, Kröyer, Leydig, Lilljeborg, Leach, Lacaze-Duthiers, Fritz Miiller, W. Müller, P. Mayer, A. Milne Edwards, Noll, v. Nordmanı, Plateau, Patten, Pelseneer, Rathke, Sye, Semper, M. Sars, G. O. Sars, Spangenberg, Stuhlmamn, C. Vogt, v. Willemoes-Suhm, Vitzou, Yung, Zaddach, ete. ete.

\section{Ontogeny (besides those mentioned above).}

N. Bobretzky. Zur Embryologic des Oniscus murarius, in Zeitschr. $f$. wisscnsch. Zoologic. $24 \mathrm{Bd}$. $18 \pi 4$.

W. K. Brooks. Lucifer, a study in morphology, in Philos. Transactions of the Royal Socicty I. London, 1882.

C. Claus. Beiträge zur Kenntniss der Ostracoden. Entwickehungsgesehichte ron C'ypris. Marburg. 1S6S.

Yves Delage. Evolution de la Sacculine, Crustacé endoparasite de l'ordre nouveau des Kentrogonides. Arch. de Zoologie expérimentale de II. de Lacasc-Duthicrs. $2^{\circ}$. 2d Vol. Paris, $18 s 4$.

C. Grobben. Die Entwickelungsgeschichte der Moina rectirostris. Arb. aus dem Zool. Institutc $\approx u$ Wien. $2 \mathrm{Bd} .1879$.

The same. Dic Entwickclungsgeschichtc von Cetochilus scptentrionalis. Ibidcm. 3 Bd. 1 ss1.

Heinr. Reichenbach. Studicn aur Entwickelungsgeschichtc des Flusskrcbses, in Abh. d. Senkenb. Nut. Gesellsch. zu Frankfurt. 14 Bd. 1886.

In addition, treatises of E. van Beneden, Bobretzky, W. K. Brooks, Claus, Dohrn, Grube, Hoek, Joly, Lereboullet, Krohn, Kossmann, P. Mayer, Fritz Miuller, Pagensteeher, Richters, Uljanin, Spence Bate, Thompson, Metschnikoff, ete. 


\section{First Appendage to the Class of Crustacea.}

The Trilobites, Gigantostraca, Hemiaspidæ and Xiphosura.

\section{The Trilobites.}

These extinct Articulata are found only as fossils, and only in palæozoic formations.

Body (Fig. 281). The integument of the upper side was hard; but on the under side soft. The body falls into 3 divisions, cephalic shield, thorax, and caudal shield (pysidium). Each of these divisions is again divided by 2 almost parallel longitudinal dorsal furrows (the thorax most distinctly) into an arched middle area

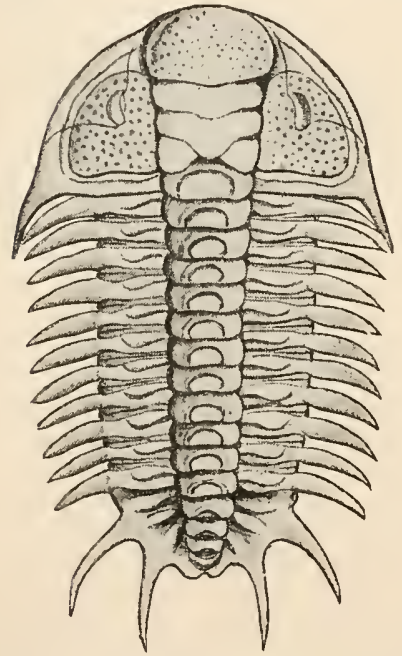

FiG. 281.-Cheirurus Quenstedtii, dorsal view.

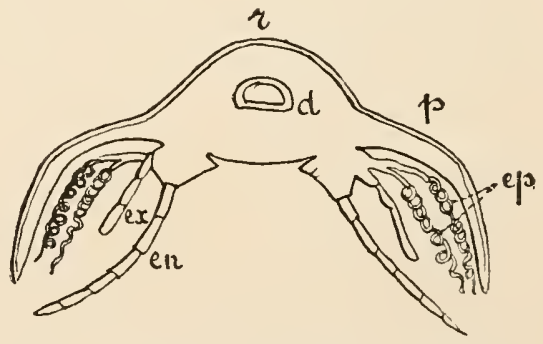

FIG. 282.-Restored trunk segment of a Trilobite, transverse section (after Walcott). 1, Rhachis; $p$, pleura; $e p$, epipodial appendages; en, endopodite; $e x$, exopodite; $d$, intestine.

(rhachis) and 2 lateral areas (pleura). The cephalic shield is unsegmented, semicircular, or crescent-shaped, with the rounded part to the front; it generally carries 2 large compound eyes. The occurrence of simple eyes is very doubtful. The thorax consists of a varying (usually rather large) number of freely moving segments. The eaudal shield seems composed of a varying number of segments more or less completely fused together. Nearly all (or all ?) Trilobites were able to roll up their bodies like woodlice, so that the anterior edge of the cephalic shield and the posterior edge of the caudal shield touched one another.

Limbs (Fig. 282). - These are retained only in rare cases. They are slender and long, and more or less like one another, segmentally repeated from the cephalic shield to the end of the caudal shield. Under the cephalic shield there are 4 pairs of limbs reckoned as 
maxillipedes, the most posterior of these being more developed than the rest; the most anterior is inserted behind the upper lip. The limbs of the trunk and pygidium are biramose with long endopodite and short exopodite, and with bifurcated epipodial appendages on the basal joint, which may be either filamentous or ribbon-shaped, simple or spirally twisted; these may safely be assumed to be gills. These gills also seem to occux on the limbs of the pygidium, but in a reduced condition. The enteric canal runs through the body in a straight line to the end of the caudal shield. In front of the mouth, at the lower and anterior edge of the cephalic shield, is found a shellpiece which is called the upper lip.

In some of the genera of Trilobites a pretty complete series of successive stages of development (larval stages) has been discovered. In the youngest stages the ecphalie shield is present, but the trunk is still quite incomplete. The devclopment of the latter generally oceurs in such a way that the pygidium takes precedence of the thorax, and that new segments continually become differentiated at the anterior end of the lygidium. In other words, the thorax differentiates in the order from before backward.

The available material suffices to show: (1) that the Tritobites are Arthropoda, and (2) that they are most nearly related to the Crustacea. Their Crustacean character is unmistakably supported by the fact that the trunk feet are biramose, and carry epipodial appendages. A closer comprarison with distinct orders of Crustacea, however, camnot be carried out, because in the Trilobites no limbs have been found placed in front of the mouth, and comprable with the anterior antenne. Whether these were entirely wanting, or rudimentary, or not capable of petrifaction, is quite uncertain. Should they still be found, then the 5 cephalic limbs could without difficulty be referred to the 5 typical limbs of the Crustacean head, and the Trilobites might then be regarded as original Entomostraca, to be derived from the same racial form as the Phyllopoda. We are prevented from comparing them with the Malacostrace on account of the different segmentation of the body and the inconstant number of the segments which does not agree with that of the lyalacostrace.

The Tritobites were marine. Agnostus (with only 2 thoracic segments), Trimucleus, Olenus, Paradoxides, Conocephalites, Sao, Calymene, Asaphus, Eronteus, Phacops, Chcirurus, Acidaspis, Lichas, Proetus, Harpes.

\section{The Gigantostraca (Merostomæ, Eurypteridæ).}

These are also extinct. They lived during the palæozoic epocl.

Body (Fig. 283). - The elongated scale-covered body of these, the largest of all Arthropoda, falls into head (cephalothorax ?), thorax, and abdomen. The unsegmented head is relatively small, and carries? compound lateral eyes, and very near the median line 2 ocelli. The thorax and abdomen each consist of 6 segments. The 6 th abdominal segment is followed by a caudal stylet or a fin-shaped terminal segment.

Extremities. - The division described as the head carries 6 pairs of extremities, composed of simple rows of joints, and thus not 
biramose. The anterior pair lies in front of the month, and in Eurypterus is a small finely jointed pair of feelers, while in Pterygotus

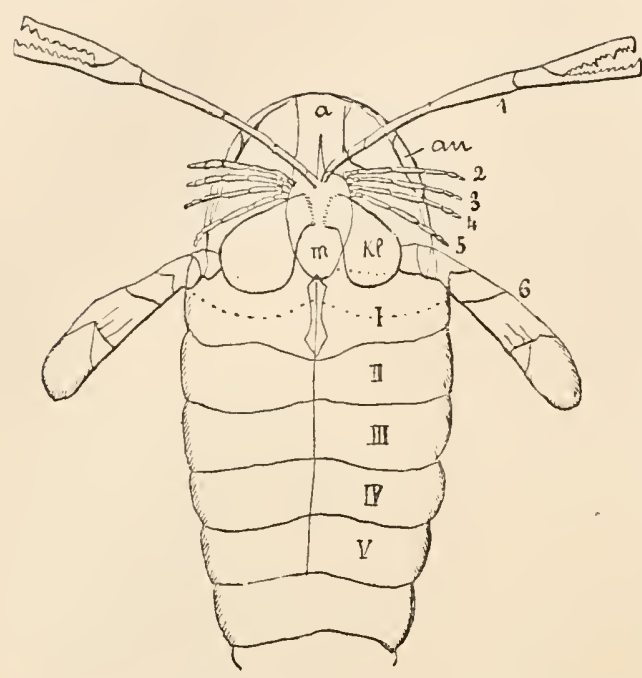

Fig. 283.-Pterygotus osiliensis. Upper Silurian. Under sicle restored, and smaller than natural size (after $\mathbf{F}$. Schmidt). u, Epistoma ; me, metastoma ; 1-6, feet; 1, chelicer; 6, rowing foot with large masticatory rilge, $h l ; I . V$, ventral plates; un, eye. most anterior largest plate is called the operculum. The abdomen is devoid of limbs. Behind the mouth is a large oval plate, the metastoma.

The systematic position of the Gigantostraca is not clear. In the number and position of the cephalic feet they agree with the Xiphosura. The leaf-like limbs of the thorax also somewhat recall those of Limulus, and above all the operculum in the 2 groups seems to be homologous. Their relation to the other Arthropoda, especially to the Crustacea and the Scorpionidce, whom they resemble in appearance, has often been pointed out, but nevertheless is not clear, because the morphological significance of the limbs, and especially of those which lie in front of the mouth, is not known with anything like certainty. Our knowlcdge of the structure of the Gigantostraca and Trilobites has during the last decade received such unexpected additions through palæontological investigations (e.g. discovery of the limbs of Trilobites) that we may hope for further advance.

Eurypterus, Pterygotus.

\section{The Hemiaspidæ.}

These are extinct palæozoic forms apparently related to the Tiphosura and perhaps forming a sort of connecting link between them and the Gigantostraca.

The body falls into 3 regions: a head of considerable size covered 
by a shield, a thorax consisting of 5 or 6 free (rarely fused) rings, and an abdomen consisting of 3 or more segments, and followed by a strong caudal stylet. The cephalic shield often has 2 compound lateral eres, ocelli are wanting. Two dorsal longitudinal furrows give the thorax an appearance like that of the Tirlobites. The extremities are unknown.

Lunules, Hemiaspis, Betinurus.

\section{The Xiphosura (Pœcilopoda, Limulidæ).}

The body, which is covered by a hard and thick chitinous carapace falls into 2 principal divisions, the cephalic shield (cephalothorax) and the hind body (abdomen). The hind body is followed by a large and long post-anal caudal spine which can move independently of the body. The cephalotholax is very large, almost crescent-shaped, with 2 literal horns directed backwards. On its dorsal side are the 2 compound lateral eres, and in front of them, nearer the median line, 2 ocelli. The flat segmented abdomen, which articulates with the cephalothorax, is almost hexagonal.

The upper side of the cephalothorax is arched, and the under side is concave.

Limbs (Fig. 284).- There are 7 pairs of limbs on the cephalothorax. The most anterior lie in front of the mouth; they are small and end in pincers. They are innervated from the anterior part of the oesophageal commissure, and (if a comparison with Crustacea is allowed) should perhaps correspond with the $2 \mathrm{~d}$ pair of antennæ, while limhs corresponding with the anterior antenna are wanting. The lst pair of limbs, which are called cheliceræ, are followed by 5 strong long pairs of limbs, also ending in pincers. They arise at the sides of the slitlike oral aperture, and each has a masticatory ridge on the basal joint. The masticatory ridges of the 4 anterior pairs of feet are armed with spines, those of the 5th pair, howerer, have a sharp cutting inner edge. The 5th pair of feet is further distinguished by a different formation of the terminal joint and by an appendage on the basal joint, which has been considered to be an exopodite. Behind the mouth there are two stylet-shaped processes, the chilaria.

The 7 th pair of limbs of the cephalothorax, which arises at its posterior edge, is quite differently formed from the preceding, and agrees far more with the abdominal limbs. It is called the operculum, and consists of 2 plates, which are united in the middle line, and corer the subsequent abdominal limbs. The latter, of which there are is pairs, are leaf-like, and shaped like the operculum. In all the leaf-like feet 2 rows of areas are marked by sutures, an outer row of large areas (exopodites) and an inner row of smaller areas (endopodites). The last areas or joints project freely. The leaf-shaped abdominal feet on each side carry on the upper surface (i.e on the surface turned 
to the boty) a gill consisting of numerous integumental folds, arranged like the leaves of a book.

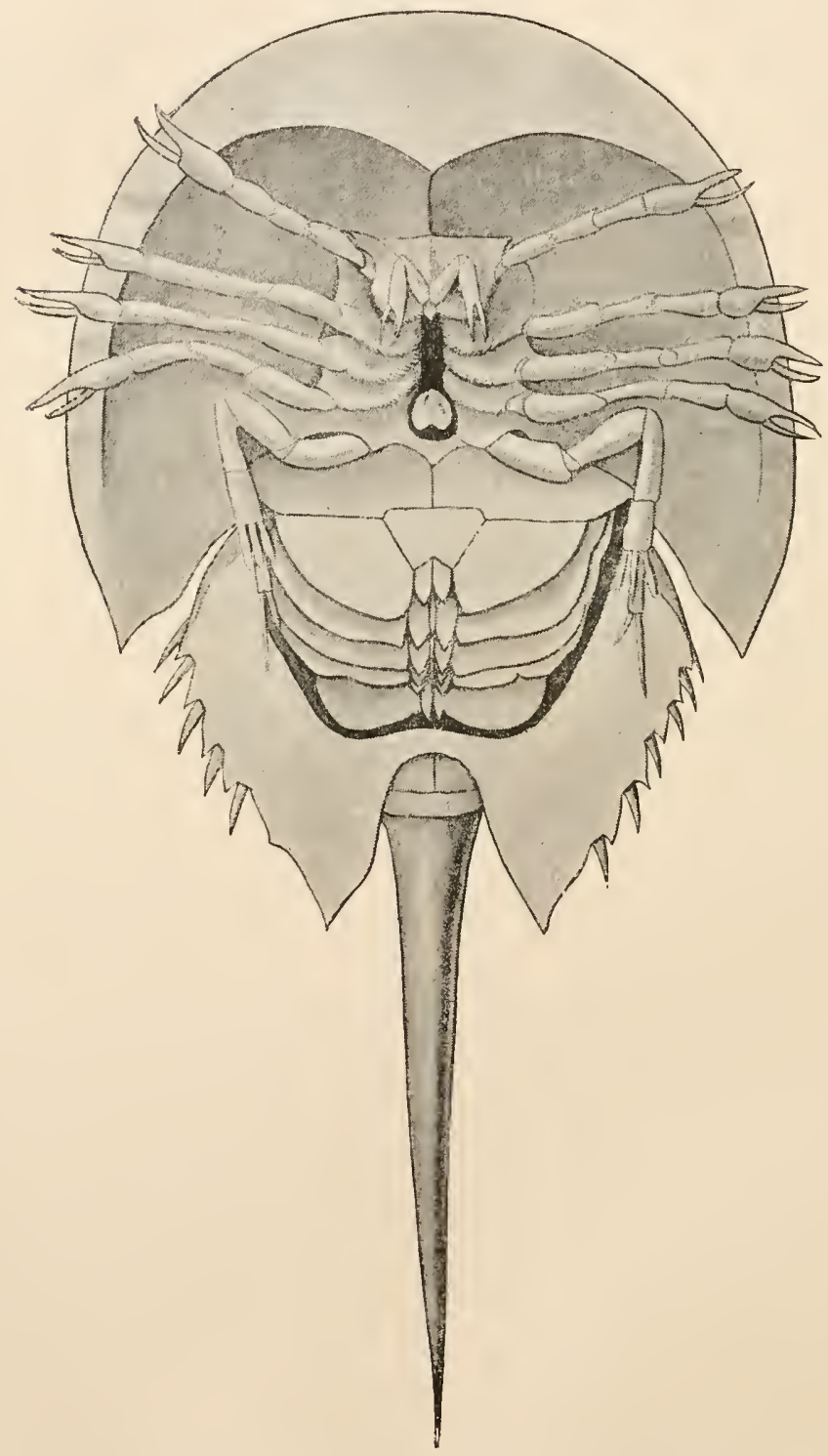

FIf. 28t.-Limulus polyphemus, young specimen from the ventral side (after Packard).

The leaf-like feet serve for swimming as well as for breathing. A sternal endoskeleton is present. 
Nervous System. - The central nervous system consists of a ganglionic mase lying in the cephalothorax and smromnding the wso-

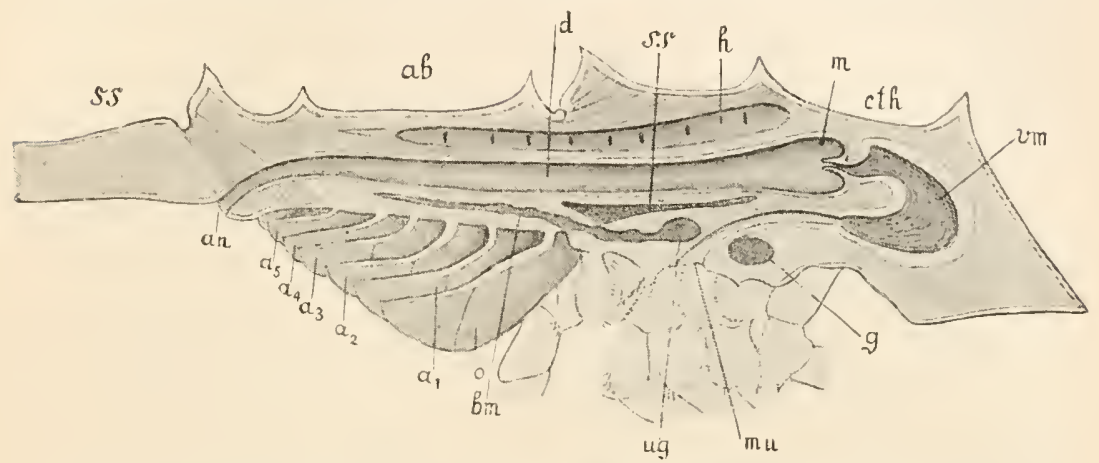

Fig. 2S5.-Median longitudinal section through a young Limulus polyphemus (after Packard). cth, Cephalothorax; $u b$, abdomen; ss, caurlal spine; vm, anterior stomak ; $m$, stomach; $h$, heart; ss, sternal cartilaginous endo-skeleton; $l$, intestine; ", brain; un, infra esophageal ganglionic mass; $b m$, ventral chort; 0 , opereuitu ; $a_{1}-a_{5}$, gill carrying abdominal appendages; mu, mouth ; cen, anus.

phagus ; it is continued into the abdomen as a ganglionic ventral chord. The circular ganglionic mass of the cephalothorax is found to consist of the brain, which lies in front of the osophagus, and gives off nerves to the lateral eyes and the ocelli, and of $\tau$ postoral pairs of ganglia with their transverse commissures, these ganglia lying near each other. The latter yield the nerves for the cephalothoracic limbs. The rentral chord of the abdomen consists of 6 ganglia, the last of which is the largest. The nerves to the leaf-like feet are given off by these latter.

The compound eye of Limulus (Fig. 286) deserves special description. The chitinous carapace is thickened over each of the two compound eyes; outwardly its surface is smooth, but inwardly, by the formation of conical processes, it pushes in the subjacent hypodermis to form towards the interior an equal number of papillie; each of these chitinous cones may be considered as a single lens. A completely separate retinula probably consisting of 10 cells, with rhabdom, pigment, and

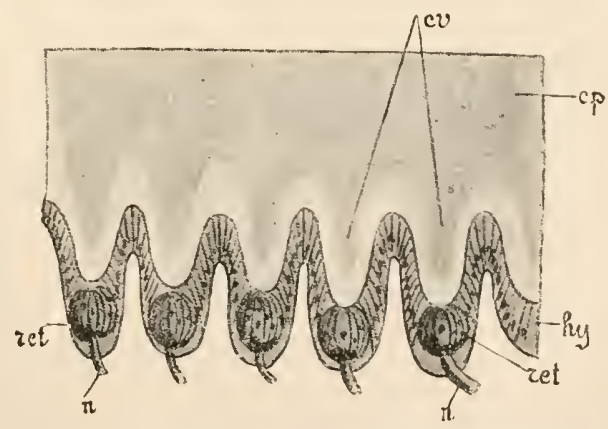

FIG. 286.-Part of a section through the eye of Limulus. $c p$, Chitinous carapace; $c v$, papilla-like thickenings of the same over each single eye; hy, hypollemis; ret, retinule; $n$, nerves of the single eyes.

nerve, corresponds with each of these single lenses. The retinule lie 
in the hypodermis. The compound eye of Limulus is thus seen to be composed of numerous independent unilaminate single eyes crowded together. Each single eye corresponds with the unilaminate eye of certain Mypriapola and Scorpionide, and the whole compound eye corresponds with the sum of the eyes on one side of these Arthropoda, except that the chitinous carapace in Limulus forms a thickening common to all the single eyes.

Enteric Canal.-From the large mouth a long esophagus rises npward and forward, to enter a muscular masticatory- or fore-stomach placed in the anterior part of the cephalothorax; the chitinous intima of this stomach projects in numerous longitudinal folds into its lumen. The fore-stomach is followed by a long straight mid-gut widened at its commencement ; this runs through the cephalothorax and abdomen and opens externally at the base of the caudal spine through a ventral anal aperture of the short hind-gut. The mid-gut receives the 4 ducts of 2 pairs of hepatopancreatic glands which branch freely in the cephalothorax. All through the intestine, except in the mid-gut, a chitinous intima is found.

Circulatory System.-The heart is an elongated dorsal ressel provided with $S$ pairs of ostia which can be closed by valves.

Sexual Organs. - The sexes are separate. The male, which is smaller than the female, is further distinguished externally by the fact that the most anterior or the two anterior postoral pairs of limbs do not end in pincers, but in claws.

The 2 ovaries are tubes forming a network of branches, those of the two sides communicating with each other at various points. The two oviducts form a sac-like wider portion before they emerge. The female sexual apertures lie on the inner side of the opercular plates (the side turned to the body), at their bases, to the right and left of the median line. The two testes consist of a large number of vesicles dispersed throughout the body and attached to sperm ducts which branch and anastomose freely. The male apertures have the same position as the female.

Coxal Glands. - On each side of the cephalothorax lies a red gland of considerable size whose outer aperture has only been found in young animals on the basal joint of the fifth pair of limbs. It is uncertain whether these coxal glands correspond with the shell glands of the Crustacea (which also emerge on the 5th pair of extremities, i.e. on the 2d maxilla). We have no right to assume that the 5th pair of extremities of Limulus answers to the 2d pair of maxillæ of the Crustacea ; it is indeed improbable that this is the case.

Ontogeny. -The 6 anterior pairs of limbs appear first and simultaneously, then follow the 7 th pair (operculum) and the 8 th (first gill-carrying abdominal limbs). On the cephalothorax there are indications of segmentation. The young Limulus hatched from the eggs shows a complete rudimentary cephalothoracic shield, the segmentation having then entirely disappeared. The abdomen, on the contrary, appears distinctly formed of 8 segments, but these are not movable upon each other. 
The caudal spine is still a very sliort and simple plate. The 2 compound eyes and the 2 ocelli are already present. Behind the 1st pair of alylominal feet the rudiments of the $2 d$ are visible. At this stage the larra has the appearance of a Trilotite, and this similarity is increased by two dorsal longitudinal furrows. The sradual transition from the Trilobite stage to the Limulus stage is brought alout by the appearance in order from before backward of the abdominal leaf-like feet. The

A

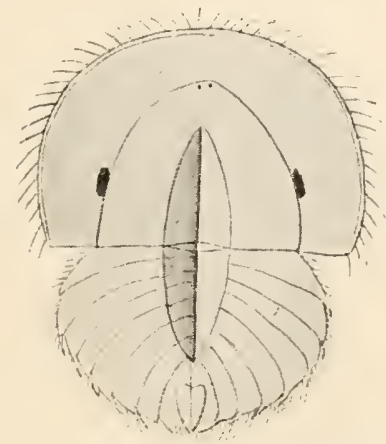

FrG. 20\%.-Limulus polyphemus in the so-called Trilobite stage. A, Dorial sirle; $I$, ventral sirle (after Kingsley).
B

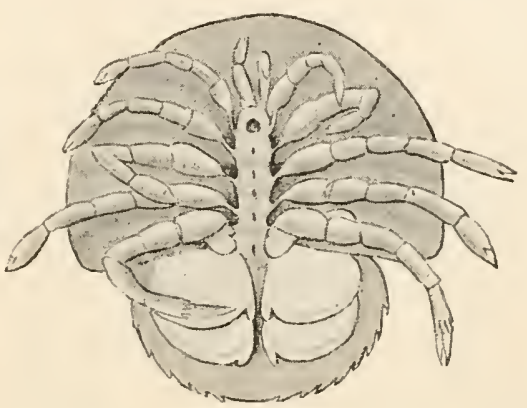

lcaf-like feet become biramose. Gills develop on them; in the Trilobite stage rudiments of gills were found only on the most anterior pair of abdominal feet. The abdomen loses its segmentation. The candal plate elongates by degrees into the catulal spine.

Systematic position. - The relationship of the Fiphosura to the Crustacea is in any case very distant, since it is at present impossible to homologise the extremities of Limulus with typical Crustacean extremities, or to compare in detail the segmentation of Limulus with that of any Crustacean. The biramose character of the leaf-like feet and of the 6th pair of thoracic feet is the only specific Crustacean characteristic shown by the Xiphosura, if we leave the gills out of consideration. The relation between the Xiphosura and the fossil Hemiaspide and Gigantostrace is evidently much closer. The Xiphosura, Hemiaspide, and Gigentostrace are themselves again perhaps racially connected with the Trilobites. In any case, however, in the present state of science, it seems probable that all these groups are only connected at their roots with the Crustacea. The relations of the Gigantostrace and Fiphosure to the Archinoiden, especially to the Scorpions, which is assumed by some observers, will be discussed later.

Single genus Limulus. -Marine, L. molucecenus, Molncea, Sunda Islands; L. polyphemus, East coast of Nortli America.

\section{Most Important Literature.}

For general guilance.

Karl A. Zittel. Handbuch der Pulcontologie. 1. Abth. 2. Band. Mollusen und Aithropode. Münehen und Leipzig, 1851-18s5.

Trilobitæ.

H. Burmeister. Die Organisation der Tritobiten. Berlin, $18+3$. 
J. Barrande. Systime silurien du contre de le Boheme. Vol. I. Prague, 1852. Supplement. $18 i 4$.

J. W. Salter and H. Woodward. A Monograph of British Tilobites. Patcontographical Society, 1867-1584.

Fr. Schmidt. Revision der ostbaltisehen silurisehen Tritobiten. I. Mém. de I'Acad. imu. de St. Pétersbourg. Sér. VII, tome 30. 1881.

C. D. Walcott. The Tritobite. New and old cridenee relating to its oryenisation. Butl. Mus. Comp. Zoology, Cambridge, Mess. Tol. VIII. 1881.

\section{Gigantostraca and Hemiaspidæ.}

J. Nieszkowski. Der Eurypterus remipes ans den obcrsilurischen Schichten der Insel Oesel, in Arehiv f. Neturgeschichte Liv-, Est-, und Kurtands. 1. Sér. 2. Band. 1859.

H. Woodward. A IIonogranth of British fossit Crastacen belonging to the order IIsostomata. Pulcontographical Socicty. Parts I-Y. 1866-18is.

Torks of Huxley, Salter, Woodward, Baily, Schmidt, etc.

\section{Xiphosura.}

Alph. Milne-Edwards. Recherehes sur T'Anatomie des Limules, in Ann. Sciences naturelles, $5^{0}$ serie, t. XVII. Paris, 1873.

A. J. Packard. The Anctomy, Histology, and Embryology of Limulus polyphemus, in Mem. Boston Socicty Natural History. Boston, 1850.

E. Ray Lankester. LimuTus un Arachnid, in Quart. Journ. Hier. Scionee, vol. 21. London, 1881.

J. S. Kingsley. Notes on the Embryology of LimuTus, in Quart. Journ. Micr. Scicince, vol. 25. London, 1885.

Treatises of J. van der Heven, Gegenbaur, Packard, Dohrn, R. Owen, Gulland, etc.

\section{Second Appendage to the Class of the Crustacea}

\section{The Pantopoda (Pyenogonidæ).}

The body, in comparison with the long and slender limbs, is extremely reduced, and falls into three divisions-proboscis or beak, trunk, and hind-body. The proboseis articulates with the most anterior trunk segment. At its point lies the mouth surrounded by three lips, and it contains internally the greater part of the fore-gut ("fish trap" apparatus). It consists of three pieces lying side by side longitudinally, an upper median piece and two lower lateral pieces. The trunk consists of 6 segments, the three anterior of which are always fused together; it has lateral outgrowths on to the ends of which the limbs are hinged. The hind-body is unsegmented, short, truncated, and devoid of limbs.

Extremities. -7 pairs of extremities occur typically. The first extremities (1), the chelicere, are inmervated from the brain, and in the young animal end in pincers; in the adult they are often reduced or altogether wanting. The following extremities (2-7) are innervated from the ganglia of the rentral chord, 2 and 3 from the most anterior ganglion, which consists in the larva of two separate ganglia. 
The 2d pair of extremities is generally shorter than those which follow, and in several genera is wanting. The $3 \mathrm{~d}$ pair of extremities is developed in the males of all P'untrimolu, and functions in them as egg-carriers. In several genera it is wanting in the females. The extremities $4-7$ are never absent, they consist of nine joints, and end in claws, and are in comparison with the body exceedingly long, giving the animal a spider-lilie appearance. All the extremities are uniramose.

The nervous system in the adult animal consists of a supraasophageal ganglion, an cesophageal commissure, and a rentral chord. The latter has 4 or 5 pairs of ganglia, from which arise the nerves for extremities 2-7; it ends posteriorly with one or two pairs of reduced ganglia, the last of which gives off nerves to the abdomen.

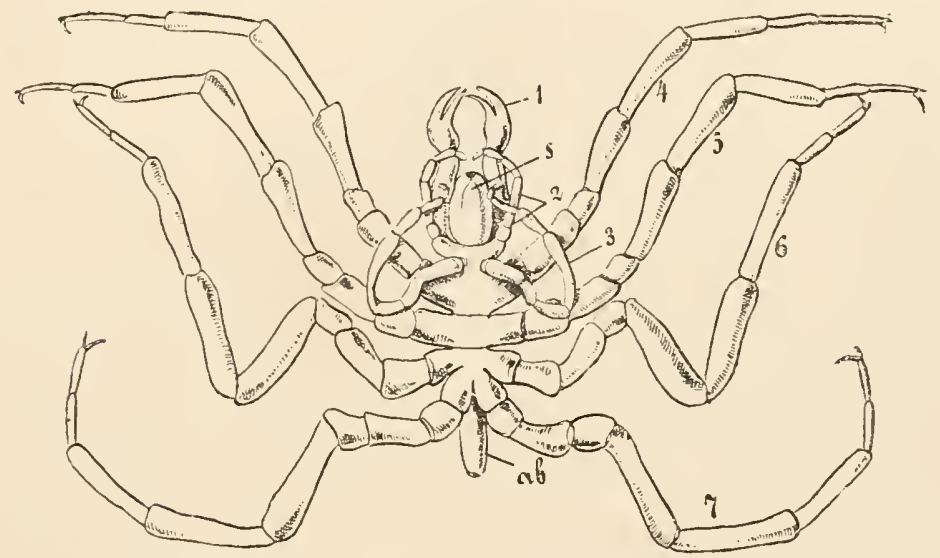

Fig. 28s.-Nymphon hispidum, male, rentral sirle (after Hoek). The setre are omitterl. 1-7, Limbs; (1, cheliceræ; 3 , egg-carriers); $s$, proboscis ; $a b$, abdomen.

Since the most anterior ganglion of the rentral chord consists of 2 or 3 pairs of ganglia, distinct in the larva, the complete number of the pairs of ganglia in the ventral chord is $8, T$ of which belong to the trunk and I to the abdomen. According to this the number of trunk segments and also of pairs of limbs must originally have been 8. From the supra-cesophageal ganglion the nerves for the eyes arise, and also those for the first pair of limbs and some of those for the proboscis. Some of the other proboscis nerves lave their roots in the anterior portion of the first rentral ganglion. The nerrous system of the proboscis with its ganglion is rery complicated.

Four eyes, each with a cuticular lens and a retina surrounded by pigment, lie on a prominence on the dorsal side of the first trunk segment.

The enteric eanal has 3 dirisions: fore-gut, mid-gut, and hind-gut. The fore-gut, placed in the proboscis, has a complicated inner framework and a "fish trap" apparatus. The straight mid-gut is provided 
with long eœea which project into extremities $1,4,5,6$, 7 , sometimes as far as the terminal joint.

The anus lies at the end of the hind-body. Special respiratory organs are wanting. The heart has $2-3$ pairs of ostia; its dorsal wall is formed by the dorsal integument.

The sexes are separate. The sexual glands are paired tubes, which extend through the trunk at the sides of and above the intestine, and are connected behind the heart by an umpaired piece. They gire off accessory tubes into the extremities $4-\bar{\tau}$, which emerge on the 2d joints. In the male, however, the genital apertures are wanting in the 4 th pair of extremities, and generally also in the 5th. In Pycnogonum and Filynchothorax only one aperture is found on each side in the females, and this is in the 7 th pair of extremities. In the males, in the fourth joint of extremities $4-7$ cement glands (coxal glands?) are found, whose secretion glues the eggs which issue from the female genital apertures into balls, which are carried about by the male on the $3 \mathrm{~d}$ pair of extremities, transformed into egg-carriers.

We find glands which are considered as exeretory organs in the $2 \mathrm{~d}$ and $3 \mathrm{~d}$ pairs of extremities, emerging on the 4 th or 5 th joints.

Ontogeny.-Most Pycnogonide pass through a more or less complicated metamorphosis. The youngest unsegmented larva carries 3 pairs of extremities, corresponding with extremities 1, 2, and 3 of the adult. The first ends in a claw. In spite of the agreement in the number of extremities this larva shows no near agreement with the Nauplius larva, and the extremities themselves, since they all consist of only one row of joints, do not show the character of the Nauplius limb. In the next stage new segments appear at the posterior end of the body and differentiate in the order from before backward. The enteric coen at first do not project into the extremities.

The cause of the entrance of enteric cœea and lateral tubes of the sexual glands into the interior of the limbs must be sought in the extraordinary reduction of the trunk and in the great longitudinal development of the limbs.

The Pantopoda seem to oceupy an isolated position among the Arthropoda. On account of the want of a typical Nauplius or Zoce larva we are not justified in placing them near the Crustacea, and they show no evident relation to any other class of Arthropoda. Many zoologists consider the Pantopoda to be related to the spiders, and establish the following homologies for the limbs. Extremity $1=$ cheliceræe or falces; extremity $2+$ the paired piece of the proboscis $=$ lower jaw and redipalps ; extremities 3-6=the 4 pairs of legs of the spider. Extremity 7 is wanting in the adult spiders, but it is pointed out that in a few Arachnoidea the rudiments of paired extremities temporarily appear on the abdominal segments during embryonic development. On the other hand it must be remarked that the connection of the two paired pieces of the proboscis of the Pantopoda with the second extremity, and the homology of the two parts taken together with the lower jaw and pedipaly of the Arachnoided, is by no means proved. The inner organisation and the development give little footing for a special comparison of the Pantopode with the Arachnoidea, since the ceea of the mid-gut have no great morphological significance.

The Pantoporla are exclusively marine. Nymphon, Pallene, Phoxichilidium, Ammother, Pycnogonum. Collossendcis gigas is a gigantic form in the deep seas. 
The longest extremity sometimes measures $30 \mathrm{~cm}$., while the whole body only attains a length of $8 \mathrm{~cm}$.

\section{Most important Literature.}

Anton Dohrn. Die Puntoporton des Golfes ron Teapel. Eine Monograplie in Fanna unel Flore des Goljes ron Neapet. 3. Band. 1881.

P. P. C. Hoek. Reprort on the Pyciegonicte, in lieport on the scientifie results of the voyaye of H.MI.S. Challenger. Zoology, vol. III. 1881.

In these works further bibliogiaphy is given. 


\section{CHAPTER VI}

\section{The second division of the Arthropoda.-Organisation and Development of the Air- breathing Articulata (Tracheata).}

\section{Systematic Review.}

\section{Cluss I. Protracheata (Onychophora).}

Body rermiform. A pair of preoral feelers at the point of the head. In the oral eavity a pair of horny jaws, at the side of the mouth oral papillæe (slime papillæ), uumerous pairs of short almost truneated limbs. liespiration through tubular traeher, whose outer apertures are scattered orer the whole body. Numerous segmentally arranged pairs of nephridia. Coxal glands on the legs. Heart a long dorsal vessel with numerous jairs of ostia.

\section{Class II. Antennata (Myriapoda and Hexapoda).}

One pair of preoral feelers, 3 pairs of oral limbs. Trunk either homonomously segmented with numerous pairs of jointed legs, or heteronomously segmented with the limbs limited to the three segments of the anterior region of the trunk, the thorax; the posterior region, the hind-body, being limbless. The head everywhere distinctly marked off from the trunk. Respiration by means of tubular tracheæ, whose outer apertures (stigmata) are segmentally arranged. The heart in the homonomously segmented Myriapoda is a long dorsal ressel, supplied with many segmentally arranged pairs of ostia; it runs through the trunk longitudinally : in the Hexapode it is restrieted to the abdomen.

\section{Class III. Chelicerota sive Arachnoidea.}

No preoral limbs eomparable with the antenne of the Antennata or Protracheata. Several anterior body segments $(\bar{\gamma}$, including the frontal lobes) are fused to form an unsegmented region, ealled the eephalothorax. This carries 6 pairs of extremities, the nost anterior of whieh lies in front of the mouth. The two anterior pairs are developed as oral limbs. The first are ealled the jaw-feelers (eheliceræ), and the seeond jaw-palps (pedipalps). The 4 remaining pairs of extremities are jointed legs, generally long. Abdomen segmented or unsegmented, or fused with the thorax, with no developed limbs. Respiration either exelusively through book-leaf tracher, or at the same time through book-leaf and tubular tracheæ, or exelusively through tubular trachea. Number of stigmata limited, at the most 4 pairs. The stigmata almost always lie in the abdomen. Heart, seldom wanting, restrieted to the abdomen. 


\section{Class I. The Protracheata (Onychophora).}

An accurate knowledge of the organisation of the only genus belong. ing to this division, Periputus, is of the greatest importance, because it combines ummistakable Annelid with ummistakable Tracheatan characteristics. Of all living Arthropoda, Peripetus lias perhaps best preserved the original organisation of the ancestors of the Trucheutu.

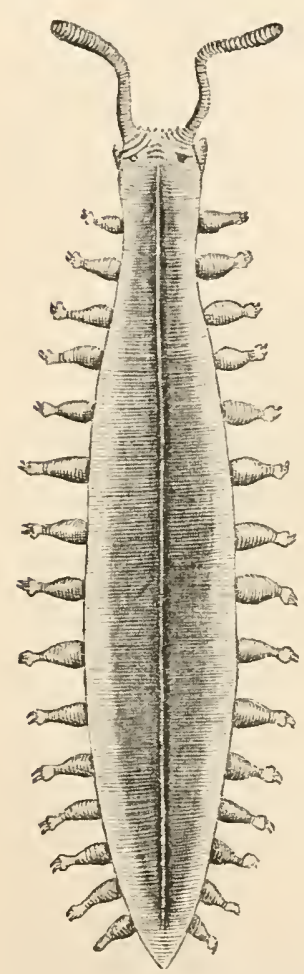

Hig. 289. - Peripatus Novæ Zealandiæ (after Sedgwick).

mouth. The anus lies terminally at the posterior end of the body.

Extremities. - The head carries anteriorly and dorsally two ringed and somewhat slender antennæ. In the buccal carity on each side lies a sickle-shaped jaw, consisting of two chitinous plates toothed along their inner sharp edges. On each side of the mouth arises a short ringed process beset with papillie. This process is called the oral or slime papilla. The trunk carries a varying number (14 to 42 , according to the species) of similarly formed limbs. These extremities are placed laterally at that part where the arched dorsal side bends in to meet the flat rentral side. Each extremity is truncated, 
with transverse rows of papille, which give it a ringed appearance, and each falls into two parts, a larger proximal conical leg and a smaller, narrower, distal foot, ending in two chitinous claws.

Integument.-The body epithelium (hypodermis) is externally covered by a delicate chitinous cuticle. The spines on the papillre and claws on the feet also belong to the cuticular formation secreted by the hypodermis. Under the hypodermis lies a peculiar subepithelial layer, formed of fibres running in various directions.

Musculature (Fig. 291). - Peripatus has a strongly developed dermomuscular tube, which consists of the following layers: (1) an external layer of circular muscular fibres; (2) a double layer of fibres crossing each other diagonally; (3) internally a strong longitudinal layer, con-

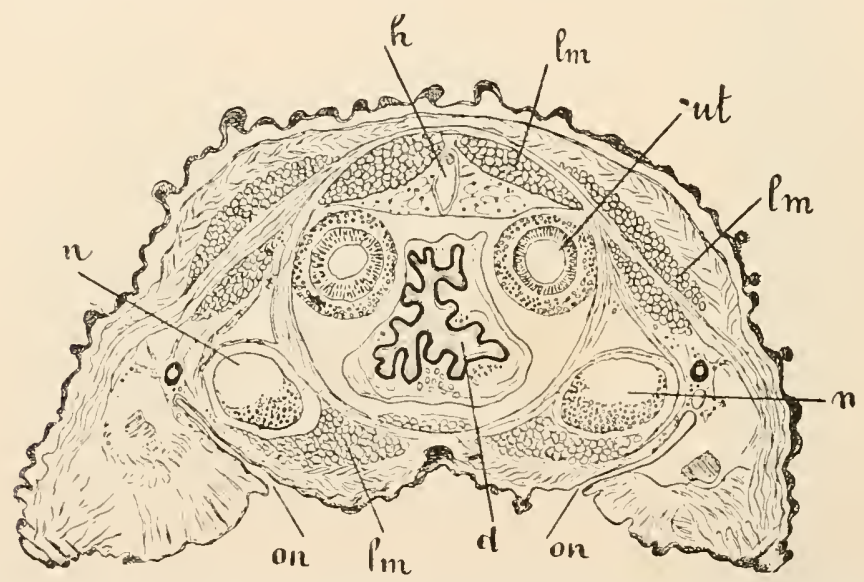

Fig. 291.-Transverse section through the antepenultimate segment of a female Peripatus Edwardsil (after Gaffron). n, Longitudinal trunks of the nervous system ; $h$, heart (contractile dorsal vessel); $l \mathrm{~m}$, longiturinal muscles; $u t$, uterus; $d$, intestine; on, outer apertures of the nephridia.

sisting of various bundles, whose arrangement on a transverse section of the body is shown in Fig. 291. In addition to these layers there are numerous sagittal or transverse muscle fibres corresponding with the dorso-ventral or transverse muscle fibres of the Annulata. Some of these fibres run through the body cavity in such a way as to divide it into a median and two lateral divisions, the former containing the heart, the intestine, and the sexual organs, the latter the longitudinal trunks of the nervous system and the segmental organs. The musculature of the extremities chiefly proceeds from the layer of diagonal fibres and the sagittal musculature. Special muscles serve for moving the jaws, claws, etc.

None of the muscle fibres of Peripatus, except those of the jaw muscles, ${ }^{1}$ are transversely striated.

The alimentary canal runs nearly straight through the body.

1 This exception, however, does not hold good for P. Leuckartii. 
It falls into the following divisions: buccal cavity, pharynx, oesophagus, mid-gut or stomach-intestine, and rectum. The buceal eavity, in whose base the mouth proper lies, arises ontogenetically by the growing together of a row of papillæ surrounding the mouth; the mouth and jaws are thus enclosed within a circular wall. In front of the moutl, within the buccal cavity, lies a median prominence, the tongue. At the back of the buccal carity, where it passes into the pharynx, i.e. at the posterior edge of the mouth, is an invagination directed backwards, into which the unpaired terminal portion of two salivary glands enters; these glands are long tubes ruming through the greater part of the body longitudinally in the lateral divisions of the body cavity. At the anterior end, near the bend towards the common terminal division, each salivary gland has a coecal vesicular appendage. The pharynx, which reaches to the region between the first and second pair of legs, possesses a very thick muscular wall: its lumen in a transverse section is $\mathrm{Y}$-shaped. The œsophagus is shorter. Its wall, which consists of an outer longitudinal and an inner circular muscular layer, is much thinner than that of the pharynx. These three divisions are lined by the chitinous cuticle.

The stomach-intestine stretches from near the two pairs of legs almost to the end of the body. Its wall is in folds, and its muscular layer (outer cir-

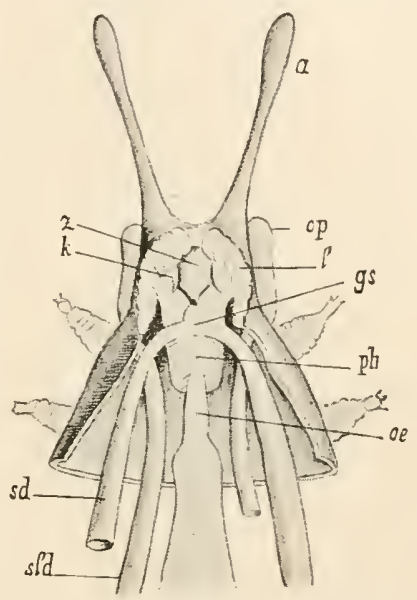

Fig. 292.-Anterior end of the body of Peripatus capensis, ventral side, lail open (after Balfour). $\pi$, Antenna; $z$, tongue; $k$, jaw; $d g$, salivary gland; $g s$, common teminal portion of the two salivary glanis; $p h$, pharynx; $(P, Q P>0-$ phagus; $l$, the lip papillie surrounding the buceal eavity; op, oral or slime papille; sld, duet or reservoir of the slime glands.

cular and inner longitudinal, i.e. the reverse of what obtains in all anterior sections of the canal) is exceedingly thin. It is nowhere fastened to the body wall by mesenteries. The rectum, which is distinctly separated from the mid-gut, is considerably narrower, with a tolerably well-developed muscular wall.

An endothelium (peritoneal epithelium) covers the outer muscular wall of the enteric canal and the other organs lying in or forming the boundary of the body carity.

The nervous system of Peripatus (Fig. 293) consists of a large brain placed in the head in front of and over the pharynx (supraasophageal ganglion), and of two ventral longitudinal nerve trunks proceeding from the brain, which run far apart in the lateral dirisions of the body cavity to its posterior end. In each segment, i.e. in each part of the body corresponding with a pair of extremities, the longitudinal nerves are connected by several transverse conmissures $(9-10$ in 


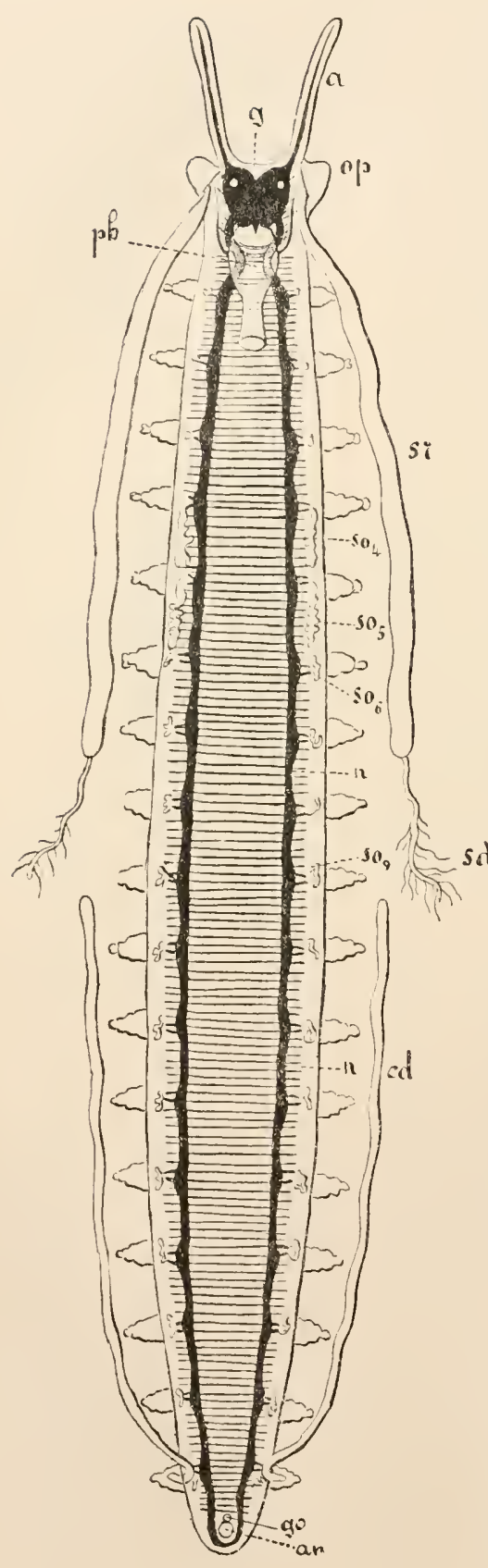

Periputus cupensis). The longitudinal trunks show slight segmental swellings corresponding with the extremities; they are also provided with a continuous layer of ganglion cells. At the posterior end of the body they pass over into each other above the rectum by means of a connecting portion in which the layer of ganglion cells is wanting. Numerous nerves go off laterally from the longitudinal trunks along their whole course; these diverge at regular intervals and more or less correspond with the transverse commissures. Each extremity is supplied with two such liateral nerves. The nerves for the jaws diverge at the points where the longitudinal trunks enter the brain; rather farther back (or at the posterior end of the cesophageal commissure) arise the nerves for the oral papilla. Besides small nerves, the brain gives off strong nerves to the antennæ. From its lower portion two more nerves arise which run to the tongue and the dorsal wall of the pharynx, and unite at the commencement of the esophagus into an unpaired mediodorsal nerve forming a sympathetic nervous system.

The two eyes correspond to some extent in their structure

Fig. 293.-Anatomy of Peripatus capensis (after Balfour). The enteric canal behind the pharynx is cut off and removed. $b$, Brain ; $a$, antenna ; op, oral or slime papillie; $s d$, slime glands; $s r$, slime reservoir, whieh at the same time acts as duct to the glands; $\mathrm{so}_{4}, \mathrm{so}_{5}, \mathrm{sO}_{6}, \mathrm{so}_{9}$, neplirilia of the $4 \mathrm{th}, 5 \mathrm{th}, 6 \mathrm{th}$, and 9 th pairs of limbs; $c d$, elonsated coxal gland of the last pair of feet ; go, genital aperture; an, anus; $p h$, pharynx; $n$, longitudinal trunk of the nervous system. 
with the Alciopidan eye of the Chetopoda described on p. 230 . But the space containing fluid between the lens and the rod layer is wanting. The Peripatus eye proceeds ontogenetically from a hollow invagination of the cephalic ectodern near the rudiments of the brain. The invagination closes and becomes the optic resicle. The connection with the brain is said to arise later by the growing out of the optic nerve from the brain.

The eirculatory system consists of a contractile dorsal vessel or heart rumning through the body from the first segment to the last but one. This heart is supplied with paired ostia arranged segmentally and provided with valves. It lies in a pericardial sinus imbedded on its rentral side in a tissue comparable with the fat body of the Insecta. This sinus is incompletely separated from the underlying body cavity by a horizontal septum. The septum, which is formed of endothelium and muscle fibres running transversely, is fenestrated on both sides of the middle line. A median longitudinal nerve runs on the dorsal wall of the heart, as in the Iulide. Besides the heart a very fine merlioventral longitudinal vessel is said to occur.

Excretory organs (nephridia). Each trunk segment of Peripatus is provided with a pair of nephridia. The nephridia lie in the lateral divisions of the body cavity and emerge on the under side of the extremities near their bases. Each nephridium (Fig. 294 ) consists of the 3 following parts:(1) a terminal vesicle which opens outwards through the external aperture; (2) a looped nephridial eanal bent back upon itself, which ends in (3) a funnel opening into the body cavity and placed near the terminal vesicle. WTe here find then the typical structure and arrangement of an Anmulatan nephiridium. In the 4th and 5th segment the nephridial canal is distinctly longer and forms many loops. The nephridia of the first three trunk segments are much smaller than the others; their canal is short and without loops. According to the species, the nephridia are apparently wanting in the penultimate or antepenultimate segment, i.e. the last or penultimate limb-bearing segment. It has, however, been proved that the ducts of the sexual organs which emerge here al'e transformed nephridia. Transformed

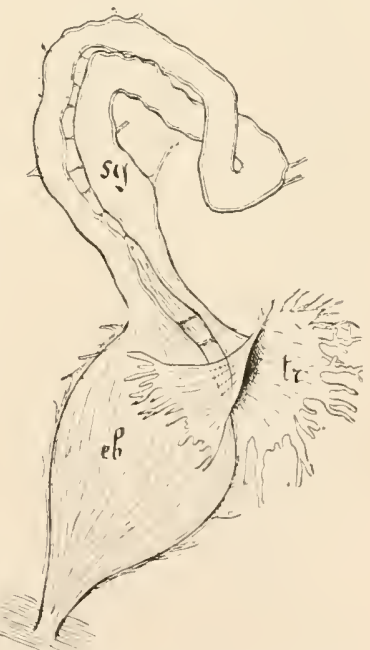

Fig. 204.-A nephridium of Peripatus Edwardsii (after Gaffron). tr, Fumnel; sg, looperl canal, or nepliridial duct; $e b$, terminal vesicle of the nephriclium. nephridia are also found in two so-called anal glands, which open in the last body segment (the anal segment without extremities) near the anus. These glands are wanting in the adult female, 
but appear temporarily in the course of development. It has also been ontogenetically proved that the salivary glands are the transformed nephridia of the segment carrying the oral papilla which has fused with the head; this is of extreme importance. Two blindly ending canals which open into the oral cavity near the base of the jaws have been pointed ont as nephridia of the jaw segment reduced to their ectodermal portion.

Respiratory Organs. - It is a fact of great importance that Peripetus possesses the respiratory organs which are characteristic of the Trucheutu, and which occur only in them. They consist of long, very fine, and thin chitinous tubes filled with air and widely dispersed through the body; in Peripatus they are not branched; they emerge united into tufts at the base of a flask-shaped depression of the integument. The outer aperture of such a depression may be called, as in the Tracheutu, the stigma. In $P$. Edwordsii the stigmata oceur in great numbers and quite irregularly all over the surface of the body. In $P$. copensis, on the contrary, at least some of the stigmata show a definite arrangement, viz. in longitudinal rows-on each side two, one dorsally and one ventrally. The stigmata in a longitudinal row are, however, more numerous than the pairs of legs.

Leg Glands (coxal glands) and Slime Glands.-In Peripatus capensis, in both sexes, there are paired glands emerging on the under side of the extremities, and only wanting in the first pair of trunk limbs. Every such coxal gland consists of a sac lying in the lateral division of the body cavity, and of a duct. The coxal glands of the last pair of feet are extraordinarily long in the male, and stretch far forward to near the middle of the body (Fig. 293, cl). In P. Edwardsii leg glands occur only in the males, not in each segment, but only in a certain number of segments lying in front of the genital segments; one, two, or three glands may occur in each limb.

There are two largely-developed thickly-branched slime glands (Fig. 293, sd), which must be considered as transformed leg glands, reaching far back into the body cavity. Their lucts run forward to emerge at the ends of the oral papillz. When the animals are irritated, these glands forcibly eject a secretion consisting of a tangle of viscid threads.

Sexual Organs. - The sexes are separate. The best known sexual organs are those of $P$. Edwwidsii. Those of other species seem in many points to be difierently formed. (1) Female sexual apparatus (Fig. 295). This is as a rule paired. The two lateral halves, however, are commected at two points; first, where the ovaries pass into the uteri, and second, to form the unpaired terminal division (vagina) leading to the exterior. The two ovaries are imbedded in a common envelope of connective tissue, and suspended to the pericardial septum in the median line by a ligament consisting of two muscles. They lie in the posterior portion of the body cavity. They are continued into the two uteri, which, close to the ovary, are united by an unpaired portion; 
separating again and winding about the intestine, they run first forwards then outwards, and finally backwards towards the median line, where they reunite to form the umpaired vagina, whose outer aperture lies rentrally between the penultimate pair of legs. Each uterus has in the part nearest the ovaries two appendages, a reeeptaculum seminis and receptaculum ovorum. The former is a sac opening into the uterus by means of two canals which unite at their mouths.

This peculiar method of junction of the receptaculum seminis and the uterus is explained by ontogeny. The receptaculum is originally

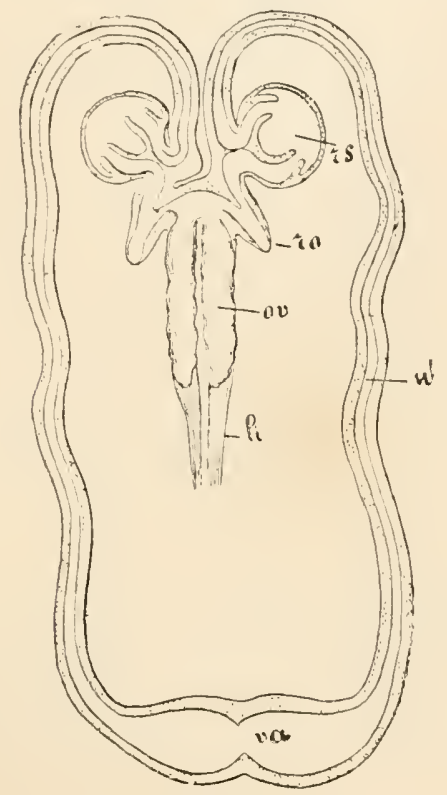

Fic. 295.-Female sexual organs of an older embryo of Peripatus Edwardsii (after Gaffron). $i i$, Orarial ligament; ov, ovarium; ro, fumel portion of the recepta. culum ovorum ; $r s$, receptaculum seminis ; $u t$, uterus ; va, vagina.

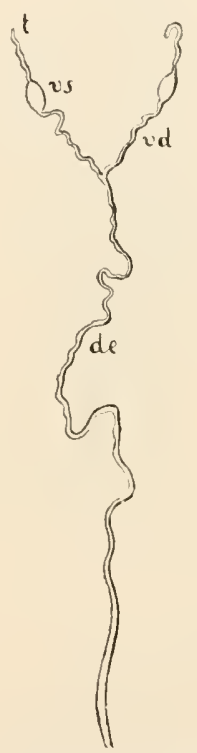

Fig. 296.-Male genital apparatus of an adult Peripatus Edwardsii spread out (after Gaffron). t, Testis; $v s$, vesicula seminalis; $v v d$, vas deferens; de, ductus ejaculatorius.

only a U-shaped loop of the uterus. The two limbs of the loops unite at a later stage (Fig. 295, rs), fuse together at their ends, and open into each other, the partition wall disappearing. The limbs of the U-shaped bend thus become the two connecting canals, and the median piece (the bend of the $U$ ) becomes the sac of the receptaculum seminis. The receptaculum ovorum, which enter's the part of the uterus lying between the ovary and receptaculum seminis, consists of a funnel, which enlarges at its free edge into a blindly-closed sac of connective tissue filled with fertilised eggs.

Pcripatus is viviparous. The eggs develop in the uterus, in which all stages of VOL. I 
development are met with, the youngest embryos close to the orary, the oldest near the ragina. The younger embryos are fastened in a peculiar manner to the wall of the uterus, in the older embryos this placenta-like comection ceases, but

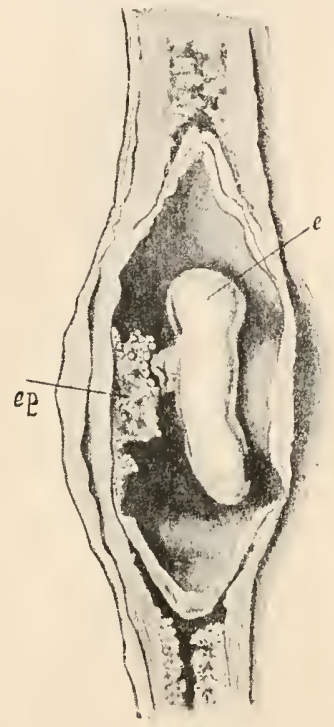

F1G. 297.-Part of a uterus of Peripatus Edwardsii, longitudinal section to show a brooul cavity, and the embryo $(e)$ container in it with its placenta $(e p)$, (after $\mathrm{v}$. Kennel). they lie in a closed sac formed by the epithelium of the uterus. The position of the embryo in the uterus is externally marked by constrictions of that organ. As the embryos camnot travel along the uterus, the latter. itself grows at the part nearest to the receptaculum seminis, while its last chamber shortens and degenerates; in this way space is provided for the attachment of new embryos to its wall. In copulation, which probably takes place only once, the semen enters the receptacuhm seminis. The eggs from the orary which have reached the receptaculum ovorum pass thence into the uterus.

In other species of Peripatus either the receptaculum seminis or the receptaculum ovorum may be wanting, and the eggs, which from the first have been better provided with nutritive yolk, do not attach themselves to the wall of the uterus.

2. Male genital apparatus (Fig. 296).This is paired, with the exception of the terminal portion, which opens outwardly at the same place as the vagina in the female. Each of the two tubular testes is continued into a short vas efferens, which opens like a funnel into a vesicula seminalis. From this again arises a fine coiled vas deferens, which, united with its companion, enters a long coiled terminal portion, the tubular ductus ejaculatorius. In the proximal part of the latter an envelope of complicated structure is secreted round the masses of spermatozoa, and a spermatophore is formed.

Ontogeny.-The development of Peripatus Edwardsii is complicated by the attachment of the cmbryos to the uterus wall, the latter undergoing considerable changes and forming a closed brood chamber (Fig. 29\%) round each embryo. In the case of each cmbryo an umbilical cord and placenta are formed, serving for its nourishment. Attached by the cord the cmbryo projects freely into the broou chamber. The side of the embryo turned away from the navel cord (which is a process of the dorsal side of its future head) becomes the ventral side. Around the entryo an envelope yielded by itself and called the amnion is formed, and is attached to the inncr surface of the uterus. As the embryo grows older, it gradually curls up within the brood cavity.

In Peripatus all those parts of the body which are metamerically or segmentally repeated (the mesoderm segments, extremities, nervous system, coxal glands, etc.) develop and differentiate in the manner universally characteristic of the segmented animals, i.c. progressively in order from before backwards.

The Mesoderm is differentiated into two rentral symmetrical mesoderm strcaks, which unite posteriorly (at the edge of the blastopore) in a median zone, and in this 
zone, throughout embryonic development, active jrocesses of growth go on. Besides this the cell material of the two mesoderm streaks themselves increases by a continuous process of division. Segmental cavities appear in the mesoderm streaks in continnons snccession from before backward, and these separate into mesoderm segments or mesoderm sacs with walls, which are at first unilaminar. The further differentiation of these mesorlerm sacs occurs in such a way that each falls into three carities, one of which becomes the nephridial funnel (Fig. $299, A-C$ ) while the others disappear as distinct cavities, and the cell material of their walls yields the mesodermal prortions (endothelium, muscles, connective tissue) of the trunk and of the extremities.

The extremities arise às outgrow ths of the body wall. The first pair of rndimentary

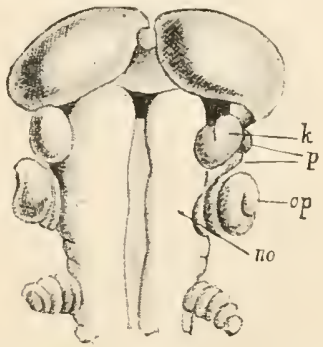

Ficr. 298,--Embryo of Peripatus Edwardsii, with growths beginning round the jaws. Anterior end of the body from the ventral side (after $\nabla$. Kennel). $k$, Jaws; $p$, papillæ, embracing the jaws laterally; op, oral papille; no, nephridial aperture of the segment of the oral papillx.

Fic. 299. $-A, B, C$, Diagrams to elucidate the development of the nephridia of Peripatus Edwardsii (after $v$. Kennel). Only one side of the body is represented in the transverse section. $I, I I, I I I$, The three divisions into which each mesoderm sac falls; $I I$, the division which forms the rudiment of the funnel. In $A$ the rudiment of the nephridial canal ( $u c$ ) has appeared as an invagination of the ectolerm, in $B$ it has united with the funnel ruliment $(I I) ; m$, mesoderm ; $l b$, body cavity; $n$, longitudinal trunks of the nervous system ; $d$, intestine.
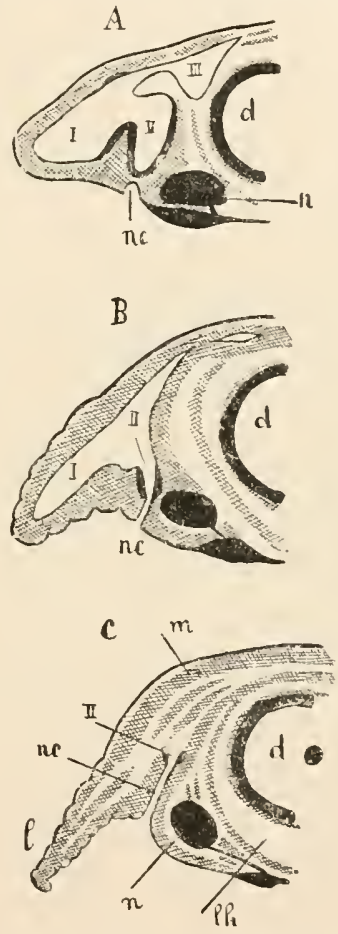

extremities, after the antemne, develop into the jaws ; the second into the oral papille (Fig. 29S). The two segments corresponding with them fuse with the primitive head segment to form the later secondary hearl.

The pharyux and cesophagus (stomodæum) and the hind-gut (proctorlenm) form by invaginations of the ectoderm which open later into the endodermal mid-gut. The bnceal cavity arises by the growing up of a rampart round the oral region, and in this cavity the jaws come to lie.

While the coxal glands (including the slime glands), which proceed exchnsirely from ectodermal invaginations, are clearly dermal glands, the nephridia (and the salivary glands, genital dncts, and anal glands, which are homologous with them) arise out of paired rudiments. The funnel comes, as has already been mentioned, from one part of a mesoderm sac and only later becomes comnected with an ectodermal invagination which yields the terminal vesicle, and, as it appears, the whole nephridial 
duct also, however long and coiled it may be. The salivary glands in the young recently hatched animal still function as nephridia and have fumels oprening towards
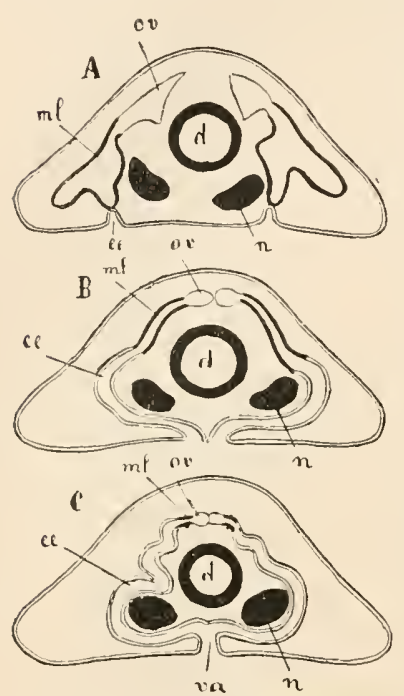

FIG. 300.- $A, B, C$, Diagrammatic representation of the development of the female sexual apparatus of Peripatus Edwardsii in transverse sections (after v. Kennel). ov, Ovary, proceeding from the median portion of the mesoderm sac; $m l$, that part of the female genital apparatus which corresponds with the nephridial funnel, and from which proceed chiefly the receptaculum ovorum and the liece which connects the uteri with the ovaries; $e e$, paired ectodermal in. vaginations, which become the uterus. In $B$ the two invaginations have approached -each other in the middle line, and in $C$ at this noint a new unpaired ectodermal invagination $(v a)$ has appeared, the rudiment of the vagina; $d$, intestine; $n$, longitudinal trunks of the nervous system. the body cavity, which afterwards close but are still retained in the adult animal as vesictular aprendages. Their nephridial ducts grow out far beyond the fummels to form blindly ending tubes posteriorly. Their apertures approach the middle line by the growing up of the oral enclosure and thus reach the floor of the buccal cavity. A new median invagination of the integument then yields their unpraired duct. The genital ducts represent the nephriclia of the penultimate limb-bearing segment and develop in a similar manner (Fig. 300). At first their outer apertures lie laterally, and aprart. Later they aprroach the middle line. The uteri in the female and vasa cleferentia in the male, which correspond with the nephridial canal of the typical nephridia, are joined by a new median unpaired invagination from without, and from this proceed, in the male the ductus ejaculatorius, and in the female the vagina.

The brain and longitudinal nerve trunks arise as prairer thickenings of the ectoderm, which differentiate from before backward and separate from the ectoderm. The rudimentary ganglia of the jaw segment fuse at a later stage with the rudimentary ganglia of the head segment to form the brain.

\section{The Systematic Position of Peripatus.}

If we try to estimate what has been said about the organisation and development of this animal from a comparative point of view, we come to the conclusion that Peripatus unites typical Annulatan eharacteristics with typical Arthroporlan and especially Tracheatan characteristics. The following are its Annulatan characteristics : (1) segmentally arranged nephridia of the type of the permanent trunk nephridia of Worms ; (2) segmentally arranged coxal glands, which are undoubtedly homologous with the Chætopodan setiparous glands ; (3) a dermo-muscular tube, which most nearly approaches that of the Hirudinea. The trumcated form of the extremities and the structure of the eye are less significant. The following are the Arthropodan and especially Tracheatan characteristics of Peripatus:-(1) the respiratory organs developed in the form of tracheæ; (2) the dorsal heart lying in a pericardial sinus and supplied with many pairs of ostia, and the lacunar circulatory system ; (3) the transformation of extremities into mouth parts (jaws); (4) the specific form of the salivary glands.

The nervous system deviates in a characteristic way from the somewhat similar nervous system of the Anmulate and of the Arthropoda, by the lateral position of the ventral longitudinal trunks, the slight development of the ganglia, and the large number of transverse commissures in each segment. The nervous system of Peripatus 
is a ladder nervous system, which shows striking similarity with that of the Amphineure, Placophora, and Zeugobranchia among the Mollusea, and that of certain Plutodes and Nemertine. There is no doubt, however, that the ladeler nerrous system of Peripatus is homologous with the brain and ventral cord of the Ammetes and Arthropode. Its speeifically deviating form may be regarded in two ways: (1) The ladder nervous system of Peripatus has arisen out of a typieal ventral cord by the moving aprart of its symmetrical haves and the increase of the transverse eommissures ; (2) in contrast with the ventral eord of the Ammlatr it represents a more primitive condition. The latter view seems to us the more plausible, since we arlhere to the opinion that the ventral cord of the Anmulate itself proeeded from a ladder-like nervous system by the moving together of the longitudinal trunks towards the ventral middle line. Peripatus, aecording to this view, would be related only to the typieally segmented racial form of the Ammulcte. The faet is perhaps not without significanee that the Phyllopode also (whiel are held to stand nearest of all the living Crustacea to the racial form) possess a ladder-like nerrous system. The large number of trans. verse commissures in each segment nust be a secondary eondition. In a few Anmulate we find more than one transverse commissure, also probably as a secondary condition; the same is also the case in the Phyllopola.

The tracheæ of Periputus may perhaps be regarded as dermal glands transformed by adaptation to life on land, glands similar to those long mostly unicellutar dermal glands whieh in certain Hirudinea and many Turbcllario spread far through the body parenchyma.

From the point of view of Comparative Anatomy it is of the greatest importance to have proved that the salivary glands and genital ducts are transformed nephridia, helping us as it does to understand the morphologieal signifieanee of these organs in the Trachecta. No less important is the almost certain froof that the slime and coxal glands are homologous, and that these dermal glands are homologous with the setiparous glands of the Annulata, especially with reference to similar glands in the Trachecuta.

It cannot be certainly proved that the antennæ, jaws, and oral papillæ of Peripatus correspond with the antennæ mandibles, and one pair of maxille of the Trachecte.

Single genus: Peripatus. Animals aroiding light, and living on land in damp, places, under the bark of old trees, under stones, etc. P. coprensis : on the wooded slopes of Table Mountain, Cape of Good Hope. P. Edwerdsii: Venezuela; related species in Trinidad. P. Norce Zealandice; P. Leuchartii: Anstralia.

\section{Literature.}

H. N. Moseley. On the Structure and Dcrelopment of Pcripatus capensis, in Philos. Transcetions. Vol. CLXIV. 1S74, and in Proc. Pioy. Soc. No. 153. Vol. XXII. 1874.

F. M. Balfour. The Anatomy and Development of Pcripatus capensis. Quart. Journ. Hicrose. Seienee. Vol. XXIII. 1883.

J. v. Kennel. Entwieklungsgeschicte ron Peripatus Eduardsii und P. torquatus. I. u. II. in Arbeiten Zool. Inst., Würzburg. Vols. VII. and VIII. 1885 to 1886.

E. Gaffron. Beiträgc aur Anatomie und Histologie von Peripatus, in Schneider's Zool. Beitrüge. Vol. I. 1883. 1885.

A. Sedgwick. A Monograph of the Derclopment of Peripatus comonsis, in Studies firom the Morpholorical Laboratory in the University of Cambridye. Vol. IV. London, 18s8. Also in Quert. Journ. of Micros. Science.

In these Treatises also further Bibliograplyy. 


\section{CLiss Il. Antennata.}

\section{Systematic Review.}

\section{Sub-Class I. Myriapoda. Millipedes.}

Trunk homonomously segmented, segments usually numerous, of nearly equal size, and, except the last, provided with feet. Without compound eyes. With numerous ocelli.

\section{Order 1. Symphyla.}

With not more than 12 leg-bearing trumk segments. One pair of branched tracher, whose stigmata lie in the head. Unpaired genital aperture in the 4 th segment. Scolopendrella (Fig. 301, 1. 444).

\section{Order 2. Chilopoda.}

Body more or less flattened dorso-ventrally. Each body ring carries only one pair of limbs and answers to a segment. The two pairs of maxille are separate. The first pair of trunk feet moved on to the head as maxillipedes with poison glands emerging on the terminal claw. Unpaired genital aperture on the penultimate segment. Fam. Seutigeride: with compound eyes. Trunk consists of 15 leg-bearing segments. Scutigerd. Fam. Lithobiide : trunk consists of 15 lerg-bearing segments. No compound eyes, but ocelli. Litholius (Fig. 323, 1. 464), Henicops. Fam. Scolopendritce: with 21 or 23 leg-hearing trunk segments (the maxillipedal segment not inchded). Body elongater. Scolopendre, Cryptops. Fam. Geoplitides: body very long, with 31-173 leg-bearing trunk segments. Geophitus, Himantarium.

\section{Order 3. Diplopoda (Chilognatha).}

Body mostly arched. From the 5th segment onwards each ring has 2 pairs of legs and thus corresponds with a double segment. The two pairs of maxille are fused to form the so-called gnathochilarium. Without maxilhipedes. Paired genital apertures between the $2 \mathrm{~d}$ and $3 \mathrm{~d}$ pairs of legs. The legs of the 7 th ring in the male are changed into copmlatory organs. Fam. Polyxenicle: 15 pairs of feet. Gnathochilarium rudimentary. Copulatory feet wanting. Polyxenus. Fam. Glomeride: 11-14 rings. Glomeris. Fam. Polydesmides: without eyes. 19-20 trunk rings, 2931 pairs of feet. Polydesmus, Brachydesmus. Fam. Chomdeumide : 30 trunk rings, 45-50 pairs of feet. Atractosoma, Craspedosoma, Chordeune. Fam. Lysiopetalide: number of rings large, indefinite. Lysiopetulum. Fam. Iutide: 30-70 or more rings. Iulus. Fam. Poly anide: gnathochilarium reduced. Number of the rings inconstant, 30-100 or more. Polyzanium.

\section{Order 4. Pauropoda.}

Feeler with several flagella. Only one pair of weakly developed maxillæ. 10 trunk segments. 9 pairs of legs. Trachere as yet not discovered. Genital apertures at the base of the second pair of legs. Pauropus.

\section{Sub-Class II. Hexapoda. Insecta.}

Trunk heteronomously segmented; the almost constant number of segments of unequal size, the body is divided into head, thorax of 3 segments, and hind body of 10 segments. Each of the 3 thoracic segments has a pair of legs. Abdomen limbless. Compound eyes as well as ocelli almost always present. Apertures of the sexual organs always at the end of the hind body. 


\section{Legion I. Apterygota.}

Without wings. With rudiments of abdominal limbs, at least in the Tlysenure. Without metamorphosis.

\section{Order 1. Thysanura.}

With 10 abdominal segments and 2-3 jointed bristle-shaped appendages (cerci) on the anal segment. Compound eyes and ocelli may be present or absent. Irrchitis,

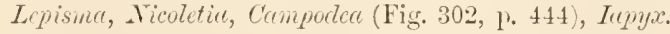

\section{Order 2. Collembola.}

With 6 abdominal segments or fewer. Nearly always a springing fork at the end of the hind-body. Without compound eyes. Occasionally with ocelli. Surintumus, Podure, Isotoma, Mecrotoma.

\section{Legion II. Pterygota.}

With a pair of wings on both the $2 d$ and $3 d$ thoracre segnents. There are unwinged forms, which, however, are descended from winged ancestors.

\section{Order 1. Dermaptera (Forficulidæ), Earwigs.}

Insects with gradual metamorphosis, and with biting mouth parts. The last abdominal segment has unjointed aprendages (cerci), which form a pincer. Fore-wings short, changed into horny wing covers. Hind-wings large, delicate skinned, fansliaped, can be folded longitudinally and transversely. Paired genital apertures, of which one may be rudimentary. Forficula, Labichro.

\section{Order 2. Orthoptera.}

Insects with gradual metamorphosis, witl biting mouth parts; with 2 pairs of membranous or parchment-like wings, sometimes wanting. Fore-wing gencrally shorter and more ehitinous than the hind-wing. Tarionsly shaped cerci on the hind body. Sexual apertures unpaired. Embidle, Blattide (cockroaches: Irriplanta, Blutter). Mentide (Mantis, praying insect). Pletsmide (stick or spectre insects, Bacillus, Plasina, Plyyllium). Saltatoriu, including the 3 families, Acridiula (grasshoplers: Acridium, Edtipode, Hecostethus, Stenobothrus, Tettix, ete.); Locustide (Locusta, Thamnotrizon, Platyclcis, Decticus); and Gryllicle (Gryllus, Gryllotalpa, Nyrmecoptille).

\section{Order 3. Ephemeridæ.}

Insects with incomplete metamorphosis. Mouth parts somewhat reduced, of the biting type. Hind-wing small or wanting, fore-wing large, wings finely membranous. Hind body with 3 (rarely 2) long cerci. Paired genital ducts, emerging separately. Larre apmeustic, Thyscmurc-like, with tracheal gills, and with biting mouth parts, live in water. Eplemera, Palingenia, Chroë.

\section{Order 4. Odonata (Libellulidæ).}

Insects with incomplete metamorphosis, and with biting moutl parts. Hind borly with 2 unjointed anal processes. Poth prairs of wings are large, and glass-like, with a rich network of reins. Thoracic legs mored forward. Larve in water with various sorts of tracheal gills, a jmeustic. Libcllule, Eschna, Culoptcryr, Alyrion. etc. 


\section{Order 5. Plecoptera (Perlaria).}

Insects with incomplete or gradual metamorphosis, with biting mouth parts. Hind body generally with 2 loug cerci. Botlı pairs of wings large, veins forming large meshes, the hinder pair often broader than the front pair, and partly foldable. The Thysanurch-like larre live in water, with tracheal gills, apneustic. The tracheal gills often persist in the imago. Perla (Fig. 317, 1. 456), Nemure.

\section{Order 6. Corrodentia.}

Insects without, or with gradual metamorphosis, with biting mouth parts. Wings often wanting. In the Termites they are finely membranous, and in the sexual animals deciduons. They are wanting in the workers. Some Psocite and the Mallophagr are wingless. The compound eyes are wanting in the Mallopharge. The wings of the winged Psocide are glassy, areolate, and like those of the Hymenoptcra. Young forms Thysanura-like. Termitide (white ants, which form communities, Termes, Calotcrmes); Psocidce (Troetes, Psocus, book lice; Mallopheagu, prarasites feeding on the fur of animals or feathers of birds; Trichodcetes, Philopterus, bird lice; Liothoum).

\section{Order 7 . Thysanoptera sive Physopoda.}

Insects with gradual metamorphosis, the larval form very like the imaginal. The last larval stage goes without food. Sucking mouth parts. The claws of the short feet with the adliering lobes of the tarsus changed into a protrusible vesicular apparatus. Wings very narrow, with reducerl veining, with long fringed edges, often wanting or rudimentary. Only 3 or 4 pairs of stigmata, one or 2 on the thorax, one on the first and one on the eighth ring of the hind body. Nerrous system concentrated. Thrips.

\section{Order 8. Rhynchota.}

Insects with gradual metamorphosis (in the males of the Coccide complete metamorphosis). Mouth parts form a proboscis adapted for piercing and sucking. Compound eyes are wanting in the parasitic Rhyuchota.

\section{Sub-Order 1. Phytophthires.}

With two pairs of membranous wings. Generally wanting in the female. The Coccidce have only fore-wings, the hind-wings being changed into halteres. Fam. Psyllide : with 2 pairs of wings (fore-wings parchment-like); Psylle, Livio. Fam. Aphictee: with 2 pairs of membranous wings, generally wanting in the female; Aphis, Chcrmes, Schi:oncura, Phylloxcra. Fam. : Coccitce, scale insects ; Coccus, Lccenium, Aspidiotus.

\section{Sub-Order 2. Pediculidæ (Aptera), Lice.}

Without facet eyes and without wings. Pediculus, Hcmatopinus, Phthirins.

\section{Sub-Order 3. Hetcroptera (Hemipterce), Bugs.}

Four wings (seldom wanting): The anterior horny wing-corers are membranous at their points. Hind-wings membranous. Gcocores (land bugs : Hydrometra, Halobates, Pentatome, Coreus, Corizus, Alychus, Pyrrhocoris, Lygacus, Niris, Capsus, Acanthia [bed-bugs], Recluviis, etc.) Hyclrocores (water-bugs: Ncpa, Ranatra, Naucoris, Corixe, Notonecta, cte.) 


\section{Sub-Order 4. Homoptera.}

Fore-and hind-wings similar in shape and membranous, but the fore-wings are always somewhat harder. Cicade, Fulgore, Pseutophana, Centrotus, Aphrophore, Tettigonia, Leclra, ete.

\section{Order 9. Neuroptera.}

Insects with complete metamorphosis and biting mouth parts. 2 pairs of membranous glassy wings, closely reticulate. Fam. Megalopterce: Myrmelcon, Vantispa, Henerolius, Chrysopa. Fam. Siclide: larre mostly in water, with tracheal gills. Siatis, Corydatis, Iiaphidia.

\section{Order 10. Panorpata.}

Insects with complete metamorphosis and biting mouth parts. 2 pairs of narrow membranous wings, widely reticulate. Larre catterpillar-like. Panorpa, Bittacus, Borcus (wings rudimentary).

\section{Order 11. Trichoptera (Phryganidæ), Caddis-flies.}

Insects with complete metamorphosis. Mandibles rudimentary. Maxille form a membranous blunt proboscis. Body mostly hairy, less frequently scaly. Hindwings generally larger than the fore-wings, folding like a fan. The larve, which resemble those of cockchafers, live in tubes or cases chiefly in the water, have tracheal gills, and are apmenstic. Phrygance, Limnophilus, Halesus, Hydropsychc, Mystacides, etc.

\section{Order 12. Siphonaptera sive Aphaniptera, Fleas.}

Insects with complete metamorphosis, with piercing and sucking mouth parts. No wings. No facet eyes. Parasites. Pulex, Sarcopsylla, Ceratopsyllus.

\section{Order 13. Coleoptera, Beetles.}

Insects with complete metamolphosis and biting mouth parts. Fore-wings as horny wing cases (elytra). Hind-wings membranous, can fold transversely and longitudinally, serve exchusively for flight. Larræ variously shaped, often Thysanura-like, occasionally like the cockchafer larve, seldom limbless (Curculionida), with biting mouth parts. Several thousand genera with over 80,000 species.

\section{Sub-Order 1. Cryptotetramera.}

The tarsi are four-jointed, one joint being rudimentary, Fam. Coccincllide, Endomyehide.

\section{Sub-Order 2. Cryptopentamera.}

Tarsi five-jointed, one joint beingl reduced and hidden. Fam. Chrysomelide, C'erambycilde, Curculionida, Bostrychide, ete.

\section{Sub-Order 3. Heteromera.}

Tarsi of the two anterior prairs of legs five-jointed, those of the posterior pairs four-jointed. Fam. Melvide (Cantharide), Ithipiphoride, Tenebrionide, EEdemeridu, Cistclide, ete. 


\section{Sub-Order. 4. Pentamera.}

Tarsi as a rule five-jointed in all legs. Fam. Iylophaga, Iralacodermata, Elateride, Buprestide, Lamellicornia, silphider, Pselephide, Staphylinide, Hydrophilida, Dytiscide, Curabille, Cicindelide, ete.

\section{Order 14. Lepidoptera.}

Insects with complete netamorphosis and sucking mouth parts, forming a proboscis which can generally be curled up. Body covered with scales. Both pairs of wings similar, membranous, covered with scales, rarely foldable. Hind-wings generally somewhat smaller than fore-wings. The larvæ are caterpillars, with anal feet, with biting mouth larts, rarely (Hicroptcryx) footless.

\section{Sub-Order 1. Microlepidoptera.}

Fam. Pterophoride, Tincide, Pypalide, Tortricide.

\section{Sub-Order 2. Geometrina.}

Fam. Phytometride, Dendrometride.

\section{Sub-Order 3. Noctuina.}

Fam. Ophiuside, Plusialce, Agrotide, Cueulliade, Acronyetide, ete.

\section{Sub-Order 4. Bombycina.}

Fam. Bombycide, Saturnide, Psychide, Zygenide, Cosside, Liparide, Euprepiade, Notodonticle.

\section{Sub-Order 5. Sphingina.}

Fam. Sesictele, Sphingidce.

\section{Sub-Order 6. Rhopalocera.}

Fam. Hesperide, Lyecnide, Satyride, Nymphalide, Heliconiide, Equitide.

\section{Order 15. Hymenoptera.}

Insects with complete metamorphosis, with mandibles adapted for biting and maxillie generally adapted for sucking. Usually \& membranous, transprarent, slightly veined wings. Various sorts of caterpillars-those of the Tcnthrclinicle and Uroceriele are footless, i.c. maggot-like.

\section{Sub-Order 1. Terebrantia.}

Female with ovipositor (borer or tube). Fanı. Tenthredinide, Uroccrider, Cynipide (gall flies). The larve of the Pteromalida, Braconide, Ichncumonida, Eveniade, are generally parasitic in the larve of other insects.

\section{Sulb-Order 2. Acaleata.}

Female with poison sting and poison glands. Fam. Formicidle (ants), Fossoric (sand wasps), Vespicle (social wasps), Apicle (bees). 


\section{Orter 16. Diptera.}

Insects with complete metamorphosis, with sucking and sometimes also piercing mouth parts. Fore-wings membranous, transplarent. Hind-wings transformed in to halteres. Larre maggot-shaped (withont legs), with or withont head.

\section{Sub-Order 1. Pupipara.}

Viviparous. The larve are born shortly before entering the pupal state. Parasites. Wings often rudimentary. Melophagnes, Braula, Nyeteribia.

\section{Snb-Order 2. Brachycera, Flies.}

Feelers short, generally three-jointed. Many families: Muscide, Conopide, Oestride, Symphide, Empide, Asitide, Bombyliude, Therevide, Tabanide, Leptide, Nylophagida, Stratiomyide.

\section{Snb-Order 3. Nemocera (Tipularia), Gnats.}

Feelers long, many-jointed, in the male often plumose. Fam. Bibionidce, Fungicole, Noctuiformes, Culieiformes, Culicide, Gellicole, Limnobiüce.

Of the above enumerated orders that of the Dermapterc is usnally plaeed as a family of the Orthopterc. The Ephemerida, Odonata, Plecoptera, Corrodentia, and Thysanoptera are often mnited into the order of the Pseudoneuropterc, and the Punorpate incorporated with the Neuroptera.

\section{Outer Organisation. ${ }^{1}$}

\section{A. The Body.}

\section{Myriapoda.}

The body consists of a head and a large number of uniform trunk segments, the anterior 3 of which correspond with the 3 thoracic segments of the Hexapola (Insecta). The head has almost certainly arisen from at least 4 fused segments.

Symphyla (Scolopendrelle).-The trunk in this division, which probably stands nearest to the common racial form of the Myriapoda and Hexapoda, consists of 12 distinct leg-bearing segments, and an anal segment with 2 processes which may be described as spinning stylets (Fig. 301). Two feelers, which lie in front of these spinning processes, are perhaps transformed legs, and indicate the existence of a 13 th pre-anal segment. If so, the whole number of trunk segments would be 13 or 14, and would then almost exactly correspond with the original number of segments in the Hexapodan trunk, in which the thorax has 3 and the abdomen 10 (perhaps 11) segments. The

1 This representation of the outer organisation can only be of the most general character. For details, which are of great zoological importance, we must refer the reader to systematic works on Entomology. 
Pauropoda have the smaller number of 10 trunk segments (including the anal segment). In the Chilopoda (Fig. 323, p. 464) and Diplopodu the number of trunk segments is larger and often very considerable (in Himantarium there are as many as 173). It is possible that this large number of segments is not an original peculiarity of the Chitopoda and

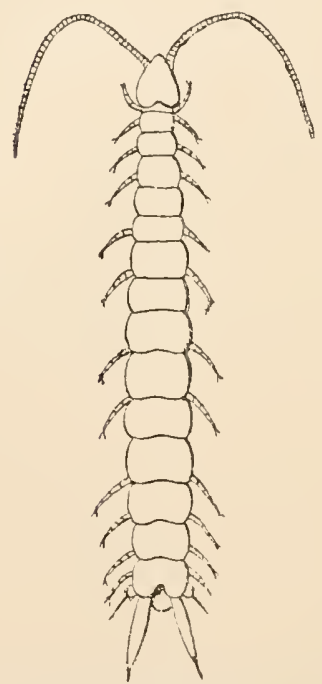

Fig. 301.-Scolopendrella immaculata (after Latzel).

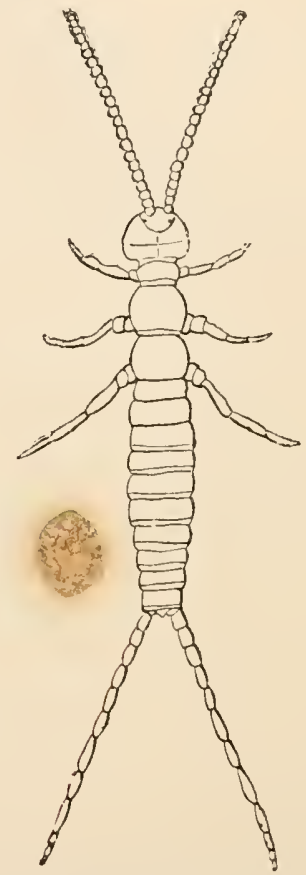

Frg. 302.-Campodea staphylinus, withont the setæ and hairs (after Lubbock).

Diplopole, but secondarily acquired, as in the serpents. In the Diplopoda only the 4 or 5 anterior trunk rings represent single segments, each subsequent ring is a double segment.

\section{Hexapoda.}

The body of the Hexapoda falls typically into 3 parts quite distinct from each other: head, thorax, and hind body (abdomen). The unsegmented head probably originally consisted of 4 segments. The thorax is composed of 3 segments: prothorax, mesothorax, and metathorax, answering to the 3 anterior trunk segments of the Myriapoda. The typical number of segments of the hind-body is 10 or 11. The thorax and the abdomen together form the trunk, which may be compared with the trunk of the Symphyla. Among the 
Apterygota the Thysanura possess 10 abdominal segments, and the Collembola a varying number, but always less than 10 . In the P'terygota the number of ablominal segments in the adult animals varies, and is generally less than 10. This diminution is caused by the fusing of those segments which are connected with the genital apparatus and lie in front of the last, and secondly by the fusing of the anterior abdominal segments (usually only the first) with the thorax. On the other hand in a few insects (Macrolepidopter, Dipteru, and Fihynchota) the last (3d) thoracic segment is joined with the abdomen.

\section{B. The Limbs.}

The limbs of the Insecte consist of single rows of joints. We distinguish the limbs of the head from those of the trunk. It is certain that each trunk segment was originally provided with a pair of limbs (as is now the case in Peripatus and the Myriapodu.). In the Hexupoda, however, only the limbs of the 3 anterior trunk segments, i.e. of the thorax, have been retained.

\section{The Limbs of the Head.}

There are, typically; 4 pairs of cephalic appendages, which are called, in the order from before backward, the Antennæ (feelers) Mandibles, anterior and posterior Maxillæ.

Comparing these cephalic limbs with the analogous limbs of the Crustacca, we see that in the Myricpode and Inscetc one pair of antennæ is wanting.

The cephalic limbs themselves are divided into 2 groups, the feelers, and the oral limbs or mouth parts (mandibles and maxillæ).

The feelers (antennæ) of the Myriapode and Hexupoda are always found in one single pair, and are pre-oral, springing from the forehead ; they are long and slender, many jointed, very variously formed in details, and very often different in the two sexes. They are organs of touch, and at the same time carry the olfactory organs. They are innervated from the brain.

The oral limbs (mouth parts) vary extraordinarily in form, according to the special functions to which they are adapted, these functions being chewing, triturating, biting, sucking, and piercing, etc. The tracing back of all these varionsly transformed mouth parts of the Hexapoda to 3 pairs of oral limbs (mandibles, and anterior and posterior maxillæ) is one of the greatest achievements of comparative anatomy. We can only take into consideration the principal forms of these oral limbs. The mouth parts of the Orthoptera form the best starting-point in our review, because in them the composition of the lower lip (labium) of 2 lateral pieces (posterior maxilla) is most evident. The whole apparatus (Fig. 303) is as follows. 
1. The upper lip (labrum $l b r$ ) is an unpaired piece which covers the oral aperture in front and from above, and has nothing to do with the limbs.

2. The Mandibles (upper jaws, md) consist on each side of a powerful but unsegmented masticatory plate with toothed edge.

3. The anterior maxillæ (lower jaw). Each of thése 2 maxillæ consists of a 2-jointed basal portion $\left(m x_{1}\right)$, which carries first a 5-jointed feeler ( $p m$, palpus maxillaris), and second, 2 unjointed

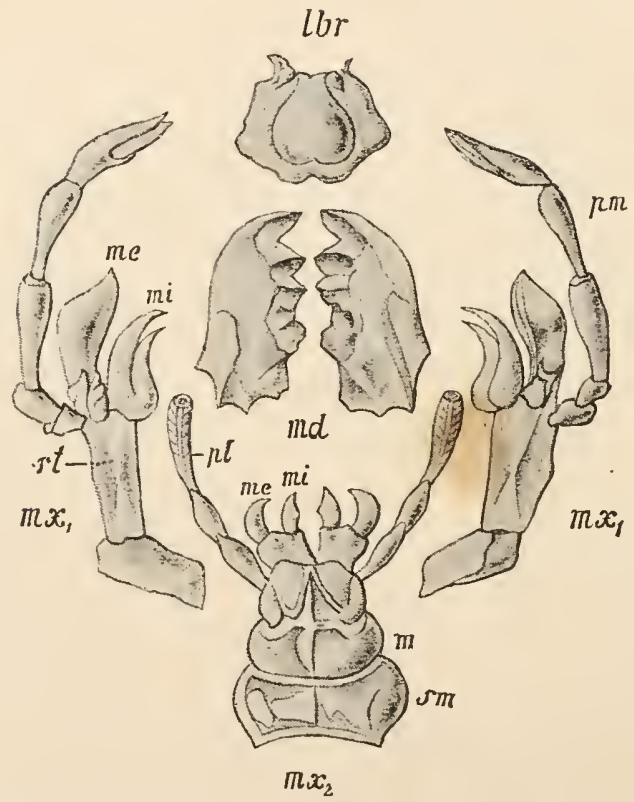

Fig. 303.-Mouth parts of Blatta (Orthoptera, after Savigny). Ibr, Labrum (upper lip); md, mandible; $m x_{1}$, anterior pair of maxillæ; $m x_{2}$, posterior pair of maxillæ=lower lip (labium); st, stipes (stem); $m$, mentum ; sm, submentum; mi and me, mala interna and externa, inner and outer ridges of the 1st aind 21 pairs of maxille; pm, palpus maxillaris, feeler of the anterior maxilla; $p l$, palpus labialis, feeler of the posterior maxillix.

masticatory ridges, one outer (me, mala externa) and one inner (mi, mala interna).

4. The posterior maxillæ together form the lower lip (labium, $m x_{2}$ ). Each posterior maxilla consists of the same parts as the anterior maxillæ (basal part, 3-jointed feeler pl, outer and inner masticatory ridges me and $m i$ ), but the 2 basal parts on each side have grown together behind and below the mouth in the middle line.

These mouth parts are adapted for biting and chewing.

We shall now describe the most important modifications of the above type in systematic order. 


\section{Myriapoda.}

Symphyla.-Mouth parts for chewing. Ulper lip, mandibles, and 1 pair of maxille with only 1 masticatory ridge and rudimentary feeler. The Pauropoda have similar mouth parts also weakly developed. The mouth parts of both groups require further investigation.

Chilopoda (Fig. 304). - The mouth parts, apart from the upper lip and the hypopharynx which belongs to the lower cesophageal wall, consist of the typical limbs, mandibles, anterior and posterior maxillæ. The anterior pair of maxille has well developed inasticatory ridges, but has no feeler or only a rudimentary one. The feelcrs are well developed on the $2 \mathrm{~d}$ pair of maxille, but the masticatory ridges are wanting. The basal portions of these maxillæ are sometimes separate, sometimes fused.

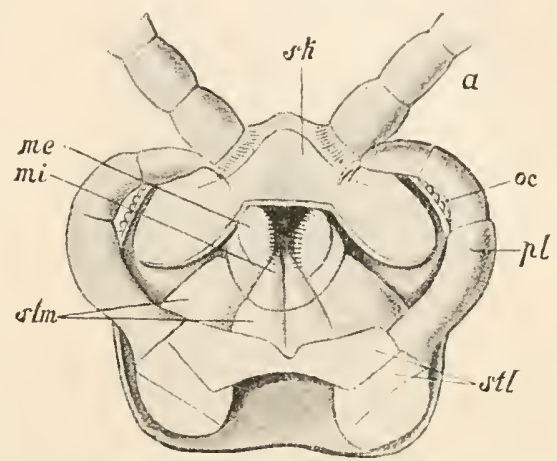

Fig. 304.-Lithobius validus. The head from below after removal of the maxillipedes (after Latzel). $a$, Antenna; sk, frontal portion of the cephalic shield; $o c$, grouped ocelli; $p l$, feeler of lower lip or of the $2 d$ pair of maxillie; stl, stems of the same fused in the middle line; st $m$, stems of 1st pair of maxille ; me, $m i$, outer and inner ridges of the same. plain. The powerful upper jaw is followed by the lower lip (guathochilarium, Fig. 305). This lower lip is said by some observers to consist of only 1 pair of maxille. Others explain the pieces represented in the figure in such a way

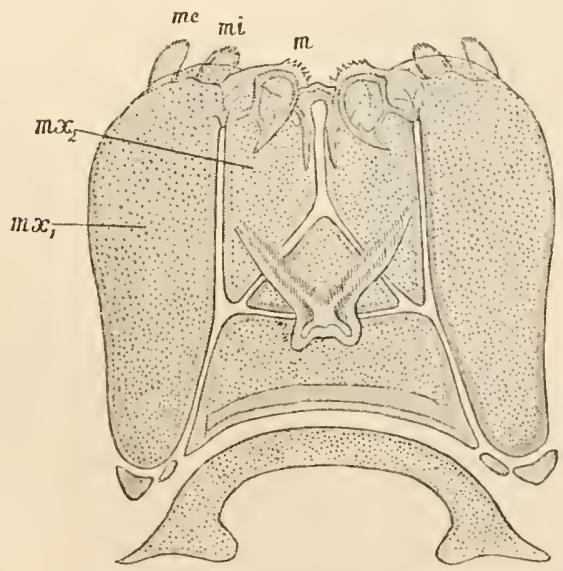

Fig. 305.-The Gnathochilarium of Lysiopetalum carinatum (Diplopoda, after $v$. Rath). m.r. Stem of the anterior ; $m x_{2}$, of the posterior maxille (?); me anil mi, outer and inner masticatory ridges of the anterior maxille; $m$, masticatory ridge of the posterior maxillae (lower lip). that the paired halves of the middle piece, each of which is provided with a masticatory ridge, correspond with the stem pieces of the posterior maxilly (lower lip), and the 2 lateral pieces each provided with 2 masticatory ridges with the stem portions of the anterior maxilla, the palps being absent. Although this last view, which rests upon analogous modification of the 2 pairs of maxillæe in certain beetle larve (Elateridce), is preferable from the point of view of comparative anatomy, it is not yet quite certainly established. The derelopmental history, as far as it is as yet known, seems rather to support the first view, since the mandibles and the gnathochilarium of the Diplopocta are said to come from the rudiments of 2 pairs of feet. A comparison of the mouth parts of the Myriapoda on a new ontogenetic basis is urgently needed.

\section{Hexapoda.}

Apterygota.-The mouth parts of the Apterygota are adapted for mastication ' 
and agree in all essential points with the Orthopteran type above deseribed. The composition of the Iower lip out of 2 maxillæ is especially clearly shown in the

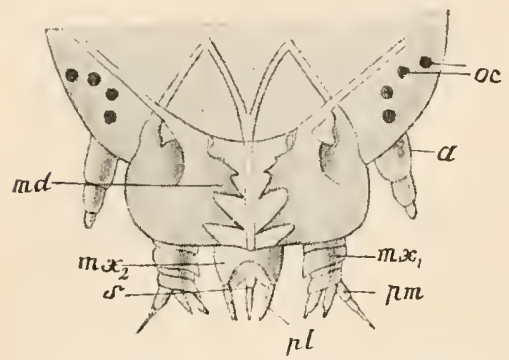

FIG, 306.-Mouth parts of a Macrolepidoptera larva (Ocneria). Lettering as in Figs. 303 and 309.

tion ; (2) anterior maxillæ, with separate basal portions, with 6 -jointed palps and 2 separate masticatory ridges; and (3) a lower lip (posterior maxillæ) whose basal

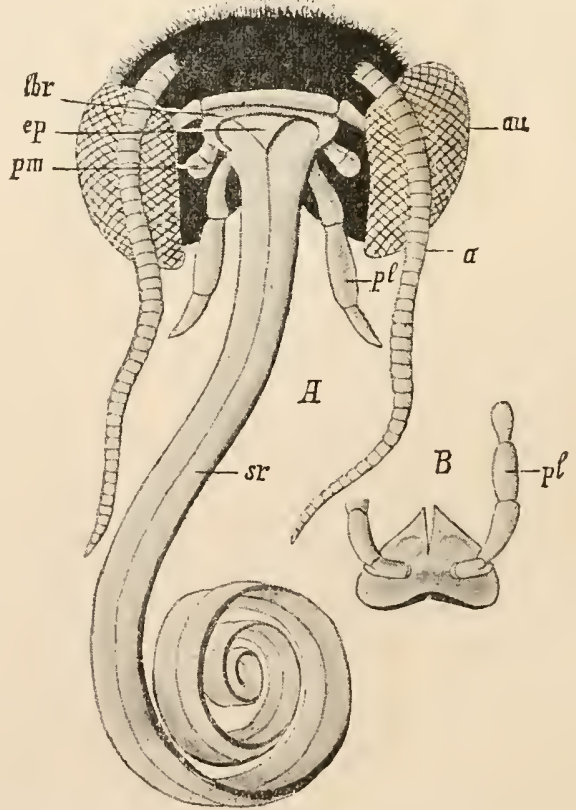

FIG. 307.-A, Mouth parts of the Macrolepidoptera. B, The lower lip (2d pair of maxilli), isolated. Lettering as before. $s r$, Sucking proboscis, corresponding with the fused ridges of the Ist pair of maxillæ.

portions are fused into one common piece, but carry 3-jointed palps and masticatory ridges still distinctly separate. The 2 inner ridges have grown together and form a short tube. In the other Hicrolepidoptera the mandibles lose their teeth and become rudimentary. On the anterior maxille only 1 ridge is found. The ridges 
of the 2 pairs of maxillie fit together to form a sucking proboscis which can easily he eoiled np. In the Macrolepilopterce the mandibles have disappeared, lnt the sueking proboscis formed by the '2 ridges of the anterior maxillie is on the contrary very strongly developed and eapable of being eoiled. The maxillar and labial palps are nearly always retained, the former generally in a very redueed eondition (1-jointed in the sphingince and many Rhopelocerc). In some of the latter the maxillar palp has, however, altogether disappeared.

A series analogous to that of the Lepidoptera is afforded by the $H y$ menopterce. At the head of the series

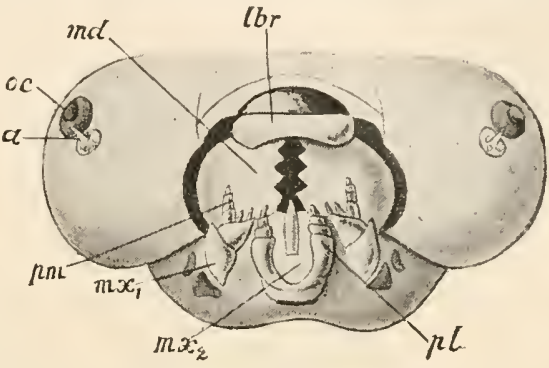

Fig. 308.-Mouth parts of a Tenthredo larva. Lettering as before. stands the Tenthrelinilce, whose mouth parts ishow great agreement with those of the Hicropterygina. Besides the mandibles which, as in the other Hymenopterce,

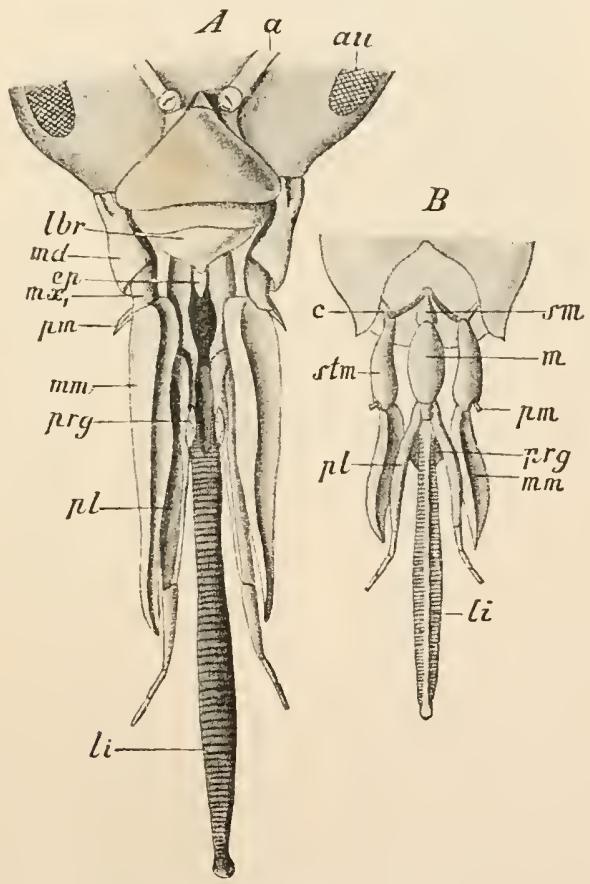

FrG..209.-A, Mouth parts of the Hymenoptera (Apis melifica). $\quad B$, The two pairs of maxille. $a u$, Facet eye ; $a$, antenna ; $l b r$, upper lip; $m d$, mandible; $c p$, epipharynx ; $m x_{l}$, anterior maxille; $p m$, palp of the same; $m m$, the fused ridges of the same; prg, paraglossa=outer ridge of the posterior maxillie (labium or lower lip); $l i$, tongue (glossa) =imner ridge of the posterior maxillæ; $c$, cardo; sm, submentum; $m$, mentum; stm, stem (stipes) of the anterior maxillæ.

are adapted for biting, we find anterior maxillie, on whose basal portions 6-jointer palps and 2 maxillar ridges are quite distinct. On the posterior maxillæe (lower lip) 
the basal portions are fused, the 24 -jointed palys are well retaincd, the outer masticatory ridges are sejrarate, lut the 2 inner ridges fuse to form a tube. In the other Hymenoptera (Fig. 309) the mandibles are always retained in a condition capable of masticating or biting; both the maxillæ go to form sucking or licking mouth parts. The palps on the anterior maxille become reduced, the basal portions elongate and the masticatory ridges grow together on each side into a long piece $(m m)$. On the under lip also the basal portion elongates, the feeler remains well developed, and slender, $2-4$ jointed; the inner ridges together form the long tongue, and the outer ridges small lateral appendages to it, called the accessory tongues (paraglossa).

The mouth parts of the Diptere (Fig. 310) are adapted for piercing and sucking, and together form a peculiar proboscis. The bristle-shaped mandibles in the male,
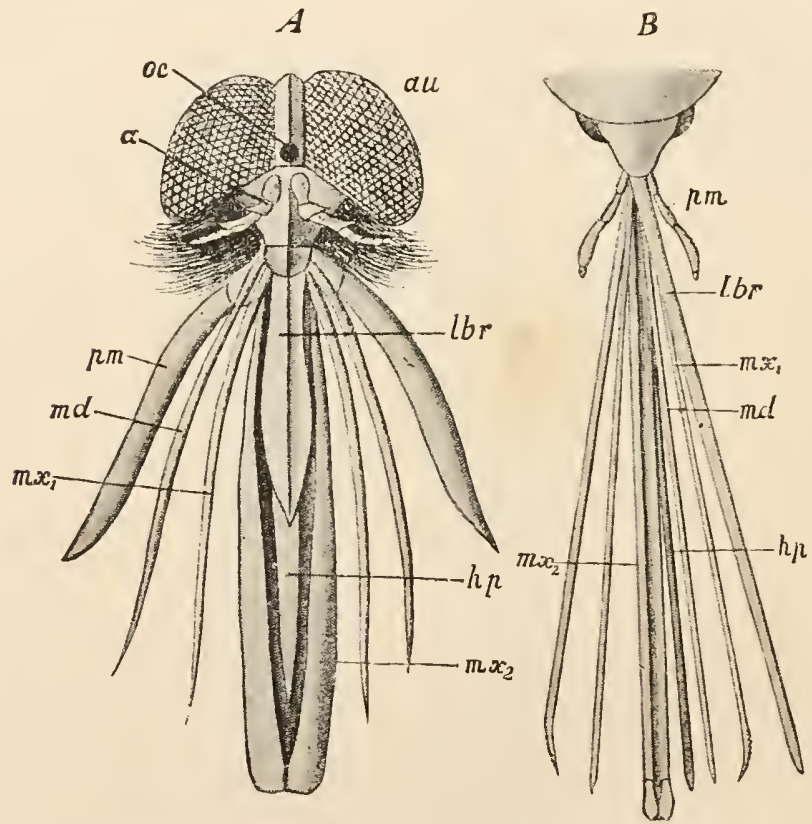

Fig. 310.-Mouth parts of the Diptera. A, of Tabanus. $B$, of Culex. Lettering as before. (", Antenna, au, facet eye; oc, simple eye (ocellus).

and occasionally in both sexes, are wanting as separate pieces, and are then no doubt fused with the upper lip. The proboscis is principally formed out of the following parts much elongated : first, the upper lip; second, the basal portion of the lower lip, 2 lips (labella) at the end of this representing the transformed palps; and third, a prolongation of the lower cesophageal wall (hypopharynx), developed into a piercing setæ, at whose point the salivary vessels emerge. The anterior maxillæ form 2 slender sete, which lie together with the seta-like mandibles in the sucking proboscis. Their 1-5-jointed palps are mostly well developed.

The mouth parts of the Rhynchote (Fig. 311) together form a proboscis adapted for piercing and sucking. The elongated, generally 4 -jointed lower lip (posterior maxillæ) forms a channel in which lie the mandibles and interior maxille, transformed into setæ covered at their basal part by the upper lip (labrum). 
The mechanism for sucking and stinging, which is occasionally very complicated, and to which certain adaptations in the cesophagus (pumps, "fish trap" apparatus, etc.), belong, cannot be here more exactly described.

The mouth parts of the other Hexapoda must be referred to one or other of the types depicted.

The mouth parts of the Coleoptere are for biting and masticating, sinilar to those of the Orthonterce; the masticatory ridges of the anterior maxillie are rarely transformed into a sucking tube.

The mouth parts of the Dermaptera, Ephemeride, Odonata, Plecoptere. Corrodentiu.
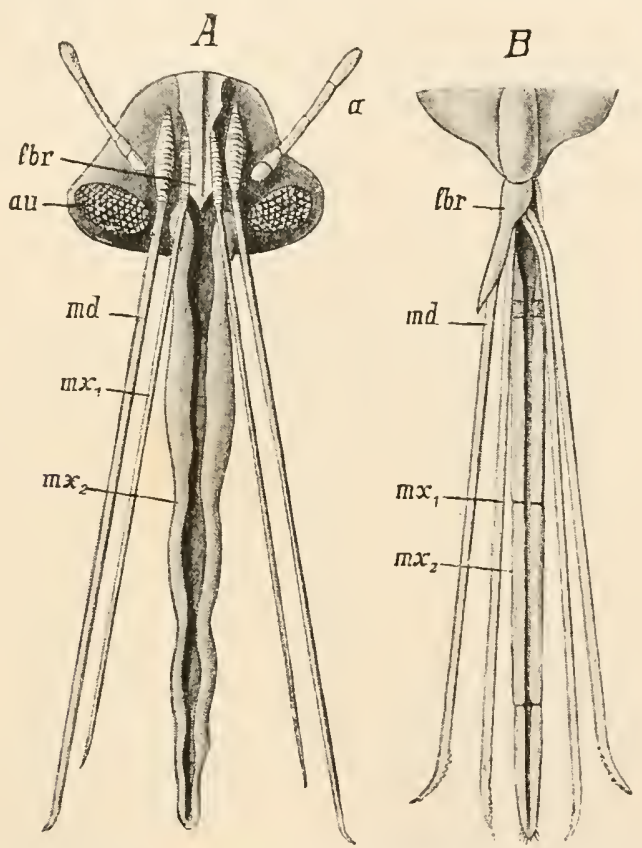

FIg. 311.-Mouth parts of the Hemiptera. A, of Pentatoma. D, of Pyrrhocoris. Lettering as before.

Seuroptera, and Panorpata are also adapted for biting, and belong with various deviations to the type of those of the Orthopterce and Coleoptera.

The mouth parts of the Thysanopterc (Physopoda) hold a position intermediate between the biting mouth parts of the Orthopterce and the sucking mouth parts of the lihynehote. The mandibles are changed into piercing setre, and come to lie within a short tubular proboscis, which arises by the growing together of the upper li! with the anterior maxille and the lower hil (posterior maxillæ). The 2 pairs of maxille have distinct palps and otherwise generally show the typical prarts variously modified. In the Trichopterc the mandibles are rudimentary, the 2 pairs of maxillæ together form a sort of proboseis (for piercing and sucking), the 4 palps remaining separate on it. The palps, however, as well as the proboscis itsclf, may disappear.

In the Aphaniptere (Flcas) the mouth prarts are for piercing and sucking. The mandibles are toothed ridges whieh, together with the upper lip form the sucking 
tube. The anterior maxille are short and ear-shaped with 4 -jointed palps. The 2 many-jointed palps of the small lower lip lie on the sucking tube laterally.

The various piercing and sucking mouth prarts found among Insects have no doubt developed independently of one another from masticatory mouth prarts.

The special morphology of the mouth parts is therefore necessary for a knowledge of the relationships of the members of one and the same order, but not for a knowledge of the phylogeny of the Insect-orders themselves.

It sometimes occurs that the larve of certain Insects (Megaloptera among the Nouropter $($ ) have sucking mouth parts while the adults possess biting mouth parts. This is an interesting fact, which shows how within a small group the larve may develop sucking mouth prarts in adaptation to special conditions of existence. In those Lepidoptera, Diptera, Aphaniptera, and certain Hymenoptera which are provided with sucking mouth parts, those of the larvæ, when not degenerated, are of the biting type.

\section{The Limbs of the Trunk.}

In the ancestors of the Antemmata (Myriupoda and Hexapada) in every case each trunk segment was certainly provided with a pair of limbs, as is still the case in Peripatus and in the Myriapola.

In the Hexupola only the 3 pairs of limbs of the 3 anterior trunk segments have been retained, these 3 segments together forming the thorax. Rudiments of extremities, however, are not wanting, as we shall presently see, on the segments of the hind-body even in the Herapodu.

The trunk limbs are throughout distinctly jointed and consist of

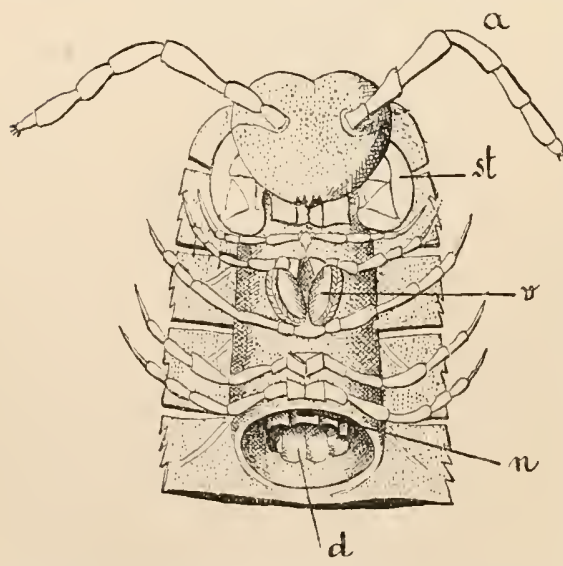

Fig. 312.-Anterior end of the body of a female Polydesmus complanatus, from the rentral side (after Latzel). $a$, Antenne; st, stems of the mandibles; $v$, vulvie (apertures of the female sexual organs); $n$, ventral chord; $d$, intestine. several parts, whose number and constitution is extremely important in classification. The legs may be variously formed according to their special functions. We thus distinguish ambulatory, springing, swimming, seizing legs, etc. Among the Myriupode the 1st pair of trunk feet in the Chilopole moves to the head as a pair of maxillipedes (Fig. 323, p. 464). These are very strong, and shaped like pincers. Their basal segments are fused together into a plate in the middle line. A poison gland lying in the maxillipede itself emerges at its terminal claw.

In the Diplopode (Fig. 312) the double segments (i.e. the rings following the 4 th or 5th trunk rings) have each 2 pairs of legs, while 
the 4 or 5 anterior rings are only provided with 1 pair each. One of the 4 or 5 anterior rings-in the Iulide it seems to be the 4 th - may be limbless. The extremities of the 7 th ring are usually transformed in the male into copulatory organs.

\section{Rudiments of abdominal limbs in the Hexapoda.}

In order to prove the existence of sueh rudiments we must recall the coxal glands emerging on the legs of Peripatus. Similar glands emerge in the Chitoporde on the eoxæ of the 4 or 5 last pairs of legs, on the pleura of the last leg-bearing segment, and on the anal segment. In the Diplopode these glands apparently eorrespond with the protmisible warts which ocenr in the Lysiopetalide on the coxal joints of the $3 d-$ 16 th pairs of legs, and also with the pores on the coxe of the Chordeumide. A knowledge of these organs in the Symphyle (Seolopendrelle), whieh perhaps of all living Antemnata stands nearest the common racial form of the Nyriopodo and the

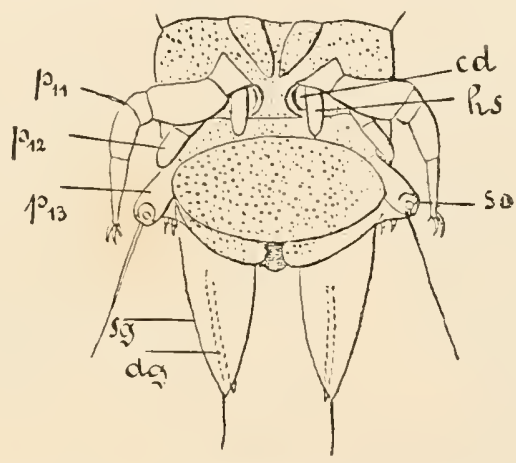

FiG. 313.- Posterior end of body of Scolopendrella immaculata, from the ventral side (after Latzel). $p_{11} 11$ th, $p_{12}$ 12th undereloped, pairs of legs, $p_{13}$, transformed legs (13th pair) carrying organs of touch $(s o)$; $s g$, spinning processes with the duct $(d g)$ of the spinning gland ; $c d$, coxal gland: $h s$, coxal spur of the 11th pair of legs.

Inseeta, is extremely important. On the coxal joints of the legs in Scolopendrella protrusible sacenles, apparently glandular (Fig. 313, ed), can be distinctly made out, especially on the 3d-11th pairs. Laterally from these saccules, which must be homologons with the coxal glands of other Myriapode and of Peripatus, there is a styletshaped appendage $h s$, which must be considered as a modified process of the coxal joint (eoxal spmr). In addition to these coxal saeenles, Scolopendrella possesses 2 spinning glands, which emerge externally $(d g)$ at the point of the spinning processes $(s g)$, on the terminal segment of the body. These glands also probably belong to the category of eoxal glands, and thins the spinning proeesses probably represent the last pair of limbs considerably transformed. The coxal saeenles of Seolopendrella and the coxal glands of the Myriopola and Protracheate (Peripatus) now throw monch light on similar arrangements in the lowest Hexapoda, the Apterygota. In Campodea there are in the first abdominal segment two indistinctly jointed appendages whieh are rudimentary"extremities. In the subsequent abdominal segments as far as to the Sth there oeenurs on each side ventrally a protrusible sacenle on whose outer side lies a mov. able pointed process. These saccules evidently correspond with the coxal glands of Scolopendrella, and are to be eonsidered as degenerated coxal glands, while the 
pointed process answers to the coxal spur of Scolopendrella. The coxal saccules and spurs of Campodea must therefore be regarded as remains of coxal joints of abdominal limbs, in short, as rudiments of coxæ. Similar organs are also found in other Apterc (Figs. 314 and 315), principally in the Thysanura. On the other hand, the coxal rudiments may be wanting or be limited sometimes to the saccules and sometimes to the spurs. It is interesting also to relate that the above-mentioned
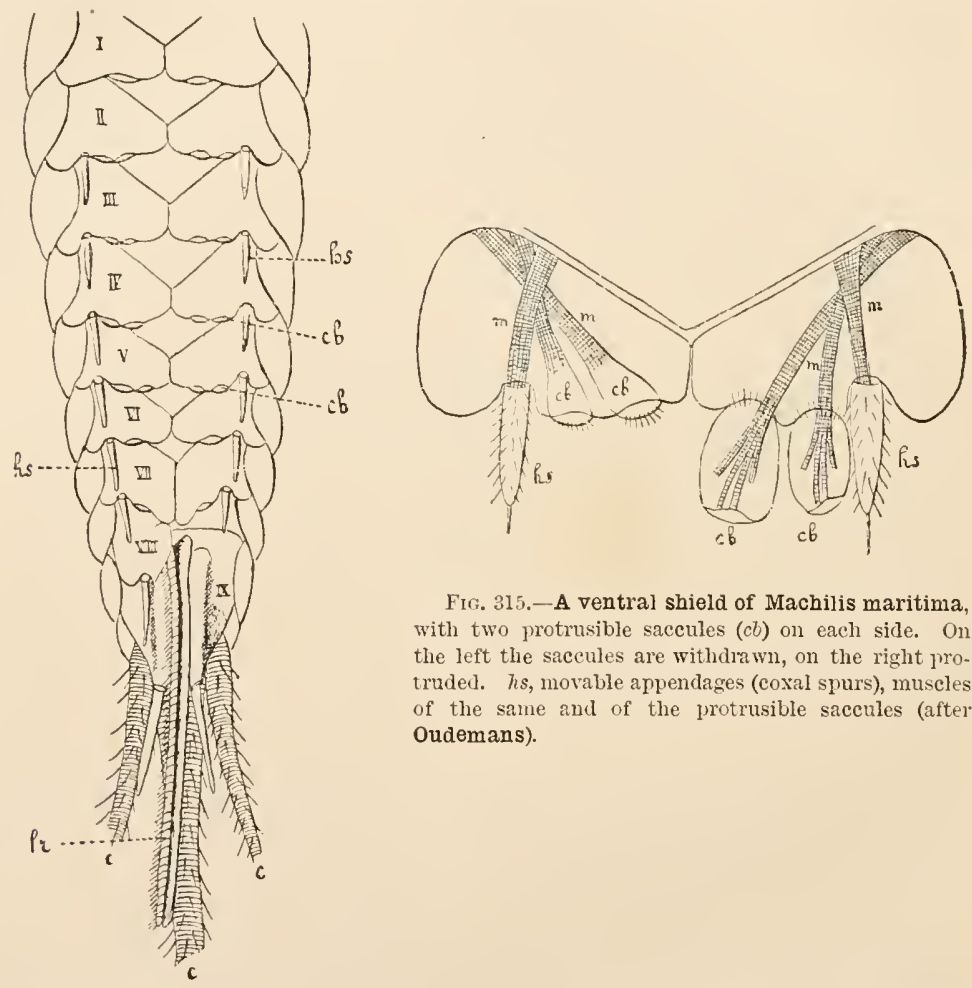

FIG. 315.-A ventral shield of Machilis maritima, with two protrusible saccules $(c b)$ on each side. On the left the saccules are withdrawn, on the right pro. truded. hs, movable appendages (coxal spurs), museles of the same and of the protrusible saccules (after Oudemans).

Fic. 314.-Ventral side of the hind-body of a female Machilis maritima (after Oudemans). The left half of the sth ventral shield is removed. I-IX, segments of the abdomen ; $c$, bristle-like jointed appendages (cerci) of the loth abdominal segment; $c b$, protrusible saccules=coxal glands in the act of degenerating; $h s$, movable appendages=coxal spurs, conjectural rudiments of abdominal feet; $l r$, ovipositors.

processes on the abdominal segments of the Thysanure were by many observers at once assumed to be degenerated abdominal feet.

In the winged Hexapoda (Pterygota) rudiments of abdominal feet have also been observed. They appear at certain embryonic stages exactly like the rudiments of the thoracic feet, i.e. as prominences or stumps on the most anterior, or on several anterior, or on all the abdominal segments, sooner or later again to disappear. They have been observed in Coleoptera (Hydrophilus, Fig. 316, A and B, Nelolontha), Orthopterc (Gryllotalpa, Mantis, Periplaneta, Ecanthus, Blatte), and Trichoptera (Neophalar concinnus). In a few forms (Gryllotalpa, Ecanthus, Periplancta, Blatta, Melolontha) the rudiments of the 1st pair of abdominal feet, before the hatching of the embryo, 
become short stalked resicles of consilerable size, which may be compared with the protruded coxal sacs of the Thysanure. A respiratory function has withont sufficient foundation been ascribed to both these structures.

Considering the widespread occurrence of rudimentary ablominal fect in the Embryos of winged Insects we are justifier in asking the question, whether the
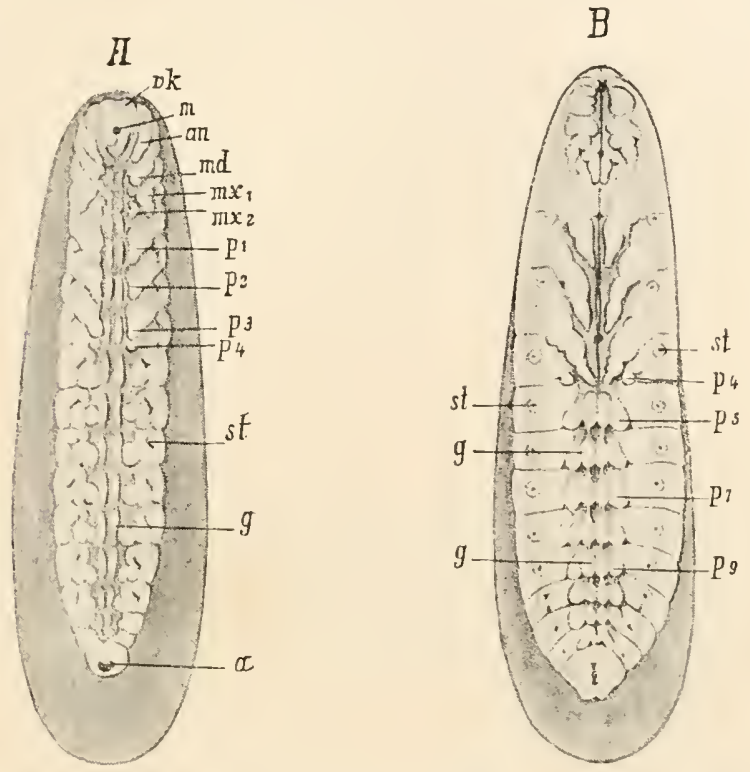

Fig. 316.-A and $I$ Hydrophilus embryos with the rudiments of extremities (after Heider). In the somewhat older embryo, $B$, the rudiments of ablominal feet, which disappear later, can be very distinctly seen; $a$, anal aperture ; $a n$, antenua ; $g$, rudiment of the ventral ganglionic chain ; $m$, oral aperture. $m l_{l}$, Mandible; $m x_{1}$, Ist maxillæ; $m x_{2}, 2 \mathrm{~d}$ maxille (rudiment of the lower lip); $p_{1}$, $p_{2}, p_{3}$, thoracic pairs of legs $; p_{4}, p_{5}, p_{7}, p_{9}$, ruliments of extremities of the $1 \mathrm{st}, 2 \mathrm{~d}$, 4 th, and $6 \mathrm{th}_{\mathrm{l}}$ abdominal segments ; st, stigmata; $v \%$, procephalon.

truncated feet (anal feet) of the larve of butterflies and wasps are not rather the remains of real limbs than new formations.

\section{The Wings.}

Wings are altogether wanting in the Hyriupude. Among the Hexupola the Apteryyota, as their name implies, are entirely wingless. Since neither the adult Apterygota nor the embryos at any stage of their development have wings or organs belonging to wings, we are justified in assuming that their ancestors also were wingless, in short that the wingless state is as much the original condition here as in the Myrierpode and Protracheata. This assumption is not without support from other points in their constitution. All other Hexupodu, howerer, are typically provided with wings, and originally indeed with 2 pairs, and although within the different orders of the Pterygota the wings 
may be reduced to 1 pair, or may be entirely wanting (in both sexes or only in the female), we here have to do with a derived condition and with animals which have lost the wings once possessed by their ancestors. In such insects the rudiments of wings or of organs belonging to wings ean often still be pointed out.

The wings are thin lamellate unjointed folds of the body wall, specially of the integument. The 2 lamellæ of a wing fold lie close to each other. The wings are veined like the leaf of a plant. The reins for the most part are thickenings of the chitinous cuticle. Within the narrow interior space of the wing, nerves and especially tracheæ enter, branching like the reins. Blood-ressels also accompany the veins. The arrangement of the veins is very important for classification. The exact investigation of the courses of the veins and their
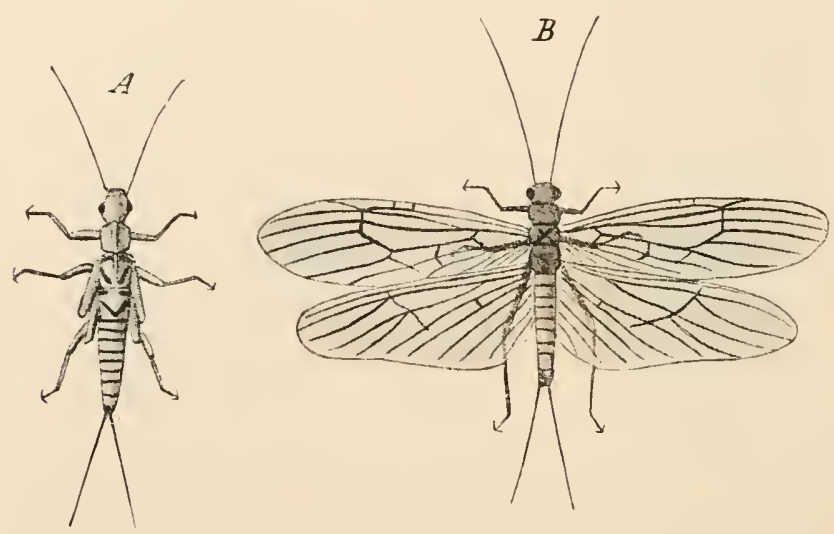

Fig. 317.-A, Larva. B, female imago of Capnia nigra (Periid) (after Pictet).

development, and especially the observation of rudimentary veins or veins in the act of disappearing, have led to the result that the wings of the various Hexapodan orders must be traced back not from one to the other, but to a common form of wing. Thus the examination of wings confirms the assumption that all orders of winged insects are derived from a common winged racial group.

The 2 pairs of wings are appendages of the meso- and meta-thorax of the Insects. There are never more than 2 pairs. Their narrowed basal portions are articulated with the dorso-lateral parts of the mesoand meta-thorax. Strongly developed wing muscles serve to move them (see section on musculature).

The problem of the phylogenetic origin of the wings of insects is extremely difficult, and as yet by no means solved. The rise of such organs is not explained by saying that they are integumental folds, which gradually increased in size, stood out from and eventually articulated with the body. The wings must in all stages of their phylogenetic development have performed definite functions. It is impossible that they were originally organs of flight. What function it was they 
performed before they beeame exelusively organs of flight is, however, entirely a matter of eonjeeture. The following riew is at present the most aceeptable. (1) The ancestors of the Hexupodo were, like the now living Apteryyota, wingless land animals breathing through tracher. (2) The Apterygotc-like ancestors of the fterygotan racial group beeame adapted to living in water. Dorsal integumental folds served for breathing in the water. The rise of such respiratory folds offers no diffienlty, since every increase of surface, small or large, is of serviee. (3) The respiratory appendages (into whieh traehere were eontinued) beeame morable and may perhaps have assisted in loeomotion (swimming). This assumption also offers no diffienlty, sinee the gills of many aquatic animals are morable, and their power of moring is an advantage on aecount of the exehange of water thus caused. In a new gradual ehange to land life the respiratory function became less important and the loeomotory function came to the front. Here, however, lies the greatest difficulty. It may, however, be assumed, that the animals while still living in water were eapable of gliding over the surface of the water by the swinging of their branchial leaves, just as flying fish do by means of their thoracic fins.

The limitation of the wings to the 2 pairs of the meso- and metathorax must be explained mechanieally, as more suited for the propulsion of the body in flight. We still see among living inseets an undoubted tendeney to the stronger development of one of the pairs of wings.

The so called tracheal gills of the larve of the Phrygenide, Sialide, and Ephemeridee may serve as an example for this eonjeetural formation of integumental folds serving for hreathing in water. The Phryganid larve live in the water in tubes of their own eonstruction, and possess on their soft-skimned abdomens thread-like appendages into which traeheal branches enter. Such appendages are ealled tracheal gills. Similar appendages are found on the abdomens of the Sialid larre. In the Ephemerid larvæ, which live free in water, there are found, on the seg-

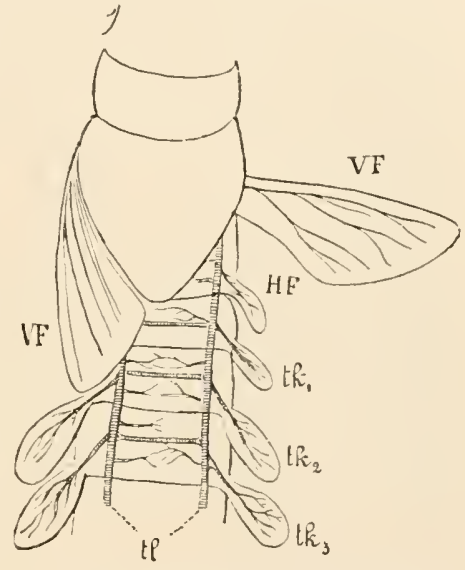

FIg. 318. - Thorax and anterior $a b$. dominal Segments of the Larva of Cloeon dimidiatum (Ephemerid), with tracheal gills $\left(t k_{1}, t k_{2}, t k_{3}\right)$ and the rudiments of the forewings $(V F)$ and hind-wing $(H F)$. $t l$, Tracheal longitudinal trunks (after $\nabla$. Graber). ments of the hind-body, 6 or 7 pairs of lateral, morable, traelieal gills (Figs. 318, 342,343 ), which are sometimes tufted, sometimes leaf-shaped, sometimes threadlike. An anterior pair may even be developed as a sort of branehial eover for the posterior pairs. All these traeheal gills are evidently integumental folds and resliratory organs which have arisen as adaptations to aquatic life. When they are leaf-shaped, the traeher which cnter them branch more or less riehly. They begin to form in a manner altogether sinilar to ordinary wings, and persist in the later larval stages together with the wing rudiments (Fig. 318).

Unsuceessful attempts have been made to trace back the wings of Inseets to other organs in other more or less remote animals, c.g. to the dorsal gills of the Chetopode, or to the dorsal folds of the Crustacea. If there is any suel eonnection the rudiments of the wings as primitive organs ought to appear in Inseet embryos; this, however, is not the ease.

Some information has already been given in the Systematie Review about the speeial form and arrangement of the wings in the various orders of the Insect $\alpha$. 


\section{The Integument and Glands.}

The integument is of the same type as that of the Crustacer and all other Aithropoda, the body being covered by a chitinons cuticle forming an exoskeleton. This cuticle is of varying flexibility and thickness, and shows many and great modifications, not only in the various parts of the borly and limbs of the same animal, but among the different members of the class. A knowledge of the constitution of the exoskeleton in the various parts of the body is of great importance in classification, as is also a knowledge of the setre, hairs, scales, etc., which belong to the category of cuticular formations. The epithelium which secretes the chitinous cuticle is here also called the hyporlermis.

During eedysis, which accompanies the metamorphoses of the Antennate and the growth of the larva, the whole exoskeleton is thrown off, together with the chitinous intima of that part of the intestine thus lined, the chitinous intima of the tracher, and the ducts of the glands. The chitinous integuments thrown off are known as exuvia.

Dermal glands are widely spread in the Antennatu; they appear in a great number of modified forms, emerge at the most various points of the body, and form secretions differing greatly in constitution. A comparative study of these on a wide basis is urgently neederl. Investigation is especially needed as to which glands in the Antennata correspond with the coxal and spinning glands of Peripatus, and which glands, if any, are to be considered as transformed nephridia. At present the observations in comparative anatomy and ontogeny necessary to enable us to give a definite answer to these questions are wanting.

Among the glands emerging ou the onter integument we may first mention the salivary glands, which open in the immediate neighbourhood of the mouth. They are everywhere found in the Antennata, generally lying at the side of the fore-gut, in the head or thorax, and oceur in 1-3 pairs. They are either simple or much lobed aciuose glands, or else fall on each side into 2 or more glandular sacs. The ducts of the glands of each side, however, nearly always unite in a common duct, which finally unites with the duct from the other side to form an unpaired canal, which usually emerges exterually on the lower lip or the hypopharynx, but in any case in the immediate neighbourhood of the moutll. Not infrequently a vesicular appendage (saliva reservoir) is found on each side of the canal. It sometimes happens that there are two separate apertures for a single pair of salivary glands, the unpaired terminal portion being absent. Where there are several pairs of glands, their ducts may also emerge separately ; usually, however, the ducts from each pair unite to form a common terminal portion.

The salivary glands are, as far as their development is known, invaginations of the oral edge of the stomodxum. According to some observations, it appears that the unpaired duct forms secondarily, the 2 salivary glands proceeding from paired rudiments.

Spinning glands (sericteries) occur in many Insect larve, and are specially strongly developed in those which pass through a pupa stage (e.g. caterpillars of Lepidoptera 
and larve of Tenthredinide). The thread-like secretion of these glands, which hardens when exposed to the air, forms the web of which the pupal envelope consists, but it may also serve for other purposes. The sericteries are glandular tubes which are paired, elongated, and coiled, often ruming through the whole length of the body ; the glandular cells of their epithelium often attain to an enormons size, and have cell nuclei in the form of branched networks. The 2 ducts unite, like those of the salivary glands, to form an unpaired terminal duet, whose aperture also lies near the mouth. Aceessory glands may also open into the ducts of the sericteries. The ducts of these and other dermal glands have a ehitinous intima, which, like the tracheal intima, may become thickened in a close spiral line.

The spimning glands of Scolopendrella have already been mentioned when descril)ing the rudimentary abdominal limbs. The glands there mentioned as emerging through pros at the points of stylets on the anal segment, and through the pleural pores of the last leg-bearing segment, are also said to be spinning glands.

Recalling the Protracheata, we are led to suppose that the salivary glands of the Antennata are transformed nephridia, and that the spinning glands belong to the same eategory as the coxal glands of Peripatus and the parapodial setiparous glands of the Chatopola. Compare also on this subject the section on the rudiments of abdominal limbs in the Hexaporla.

The morphological worth of the other numerons dermal glands which have been observed in the Antennata camnot at present be rightly estimated. We can only name a few of them.

The Myriapoda (Diplopoda) have stink glands for protection, which emerge through the "foramina repugnatoria" on the dorsal sicle of a varying number of trunk segments. These foramina are either paired, in which case they lie laterally, or umpaired in the middle line. In Paralesmus gracilis the secretion of the protective glands eontains prussic acid. These protective glands, of whiel only 1 pair oeeurs in a double segment, have been regarded as modified nephridia.

The glands of the Geophilide among the Chilopoda, which emerge through unpaired median ventral pores, may perhaps belong to the category of protective glands.

Stink glands, which yield a strongly smelling secretion evidently serving as a protection to the animal, are also found in many Insects (espeeially Heteroptere, Coleopter(t, and Orthopterct). They are sometimes paired, sometimes mpaired, and emerge at different points of the body. In many Colcoptera these organs are appendages of the rectum. An enumeration of the recorded observations, however, conld at present yield nothing of special interest to the comparative anatomist.

Poison glands.-The maxillipedes of the Chilopoda contain poison glands whose outer aperture lies in the terminal claws. In the female of many Hymenoptera a joison gland occurs, which pours its secretion into a stinging apparatus of complicated structure placed at the posterior end of the body. The poison gland itself consists of 2 simple or branched glandular tubes, which enter a poison vesicle or reservoir by means of a common unpaired terminal pieee (ef. Fig. 347, A, r. 487).

Leg glands are found in many Inseets on the terminal joints of the thoracic legs.

Wax glands oceur in many lihynehota (Aphides, Coeeidce). They lie either on the back in cross rows, or near the anus, and secrete filaments, plates, etc., of wax ; these are used either for forming a dorsal shield or a down which covers the borly, or for enveloping the excrement.

Rectal glands are papillie or thiekenings with glandular epithelium, very commonly found in the rectum of Insects.

In Mentis glands enter the coxre of the 1st prair of legs (coxal glands?). 


\section{The Musculature.}

The arrangement of the muscles in the body and their relation to the exoskeleton is the same in the Antemata as in the Crustaced (cf. Crustacea, p. 331). The musculature seems to be broken up into a very great number of single muscles, which are arranged in a definite manner suitable for moving the segments, the regions of the body, the limbs and their separate joints, the mouth parts, the ovipositors, stings, etc. The greater part of the muscles of the body can be traced luack to a paired system of dorsal and ventral intersegmental longitudinal muscles. While in the Myriapoda, in accordance with the homonomous segmentation of the body, the musculature is repeated in all the trunk segments, in the Hexapoda the musculature is very differently developed in the head, thorax, and abdomen. The musculature of the thorax is very strong, as might be expected from the fact that its 3 segments carry the limbs and wings. The wing muscles generally take a dorsoventral course in the lateral portions of the thorax. The most important parts among them are played by the elevators and depressors.

The musculature is transversely striated.

\section{The Enteric Canal.}

The mouth lies in the head between the mouth parts; the anus always in the terminal segment of the abdomen. The enteric canal, in most Myriapode and in the Apterygota, runs straight through the body and thus is not longer than the body. In the Pterygota, on the contrary, it generally forms more or less marked loops which are wanting or not so strongly developed in the larva. It everywhere falls into the 3 already known divisions: the fore-gut, which comes from the ectodermal stomodxum; the endodermal mid-gut and the hind-gut, coming from the ectodermal proctodium. These 3 divisions are generally distinct. Each of them can be further sub. divided, especially in the Hexapode, where special organs in the form of diverticula are always to be found. Tubular and pouch-like diverticula of the hind-gut (wanting only in a few Apterygota) are especially characteristic of the Antennata. They appear in varying numbers, function as excretory organs, and have received the name of the Malpighian vessels. The salivary glands and the spinning glands of the larva, both of which emerge at or near the mouth, have already been described.

Myriapoda.-The enteric canal runs straight through the body; only in the Glomerida is it coiled in its posterior part. The mid-gut has numerous short hepatic tubes. At the beginning of the hind-gut 1 or 2 pairs of long Malpighian vessels enter ; these run along the gut, frequently winding round it.

Hexapoda.-Each of the 3 principal divisions of the enteric canal may present various modifications, except in the Apterygota and the larvæ of those Insecta whose 
straiglit enteric canals present no complications. The canal is most specialised in carnivorous Insecte, while in those Insecte that feed on plants it is generally uniform, but much coiled.

The fore-gut often has 3 divisions: (1) a pharynx or oral cavity, (2) a narrow œsophagus passing through the asophageal ring, and (3) a variously shaped fore-stomach widencd out like a sac. The latter may be wanting as a separate division. If the fore-stomach is provided with a strong muscular wall it is called a crop (ingluvies). In the honey bee it is called the honey stomach. In Insects with sucking mouth parts, and especially in the Lepidoptera (Firs. 34s, p. 488) and Diptera, it is constricted off in the form of a stalked sac, which opens into the postcrior part of the fore-grut and is unsuitably called sucking stomach; it is more correctly a receptacle for fool. Between the crop and the mid-gut in many carnivorous Insectu (many Coleoptere, Nicuropterc, and Orthoptera) a muscular masticatory stomach is interposed; the chitinous intima of this stomach is much thickened, and in the form of spikes, spines, ridges, teeth, etc. projects into the lumen; these processes in transverse section form most beautiful and ornamental patterns. A peculiar pumping apparatus is in a few Phynchota connected with the pharynx. The fore-gut is internally provided with a chitinous intima, the continuation of the chitinous exoskeleton.

The mid-gut, which lies in the abdomen, is the most important division of the enterie canal for the assimilation of food; its cpithelium consists of srlandular cells and often projects into the lumen in the form of folds or villi. It is a somewhat wide tube frequently forming loops, and in it we can often distinguish an anterior wider portion, the chyle stomach, and a longer thinner posterior portion (small intestine). The chyle stomach in the carnivorous Coleoptera is beset with short diverticula, as if with villi; in the Orthoptera longer

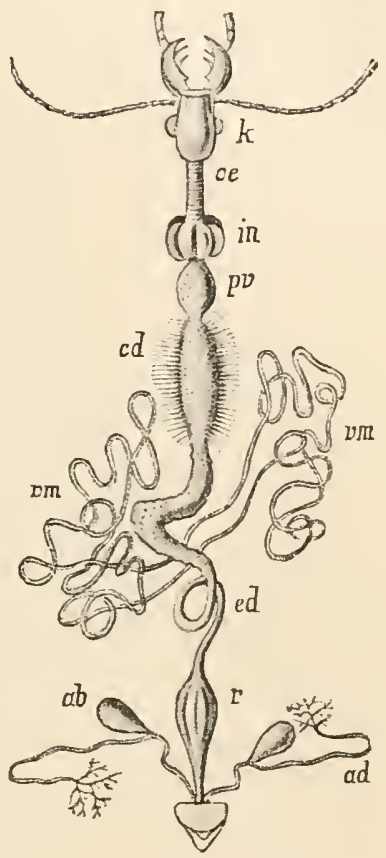

FIG. 319.-Digestive apparatus of Carabus auratus (after Dufour). 7 , Head witl mouth parts; oe, cesolhagus ; $i n$, crop (ingluvies); $p v$, masticatory stomach; $c$ l, chyle stomach covered with villi; $\imath^{\prime} m$, Malpighian vessels; $e d$, hind-gut with rectum $(r)$; $a$, anal glands with muscular vesicular appendages $a b$. diverticula cnter its anterior portion.

The hind-gut is lined with a delicate chitinous intima and lias a muscular wall which, at the terminal portion ending in the anus, is of considerable thickness. Its length varies, it is often very long and coiled.

The limit between the mid-and hind-guts is often difficult to definc, since the mid-gut also may have an intima, and its ontogenetic development is not sufficiently worked out. It is assumed, somewhat arbitrarily, that the hind-gut begins at the point where the Mlalpighian vessels enter. Although these are undoubtedly formations of the lind-gut, they do not necessarily always appear at its antcrior end. The hind-gut is often further subdivided. Its last dirision sometimes carries an unpaired crecum. Paired anal glands (stink glands) may also enter it. The anal parillie, etc. classed as glands have already been mentioned. The intestine of certain Phynchote, Psyllide, and Cicade is peculiarly constituted. The mid-gut and part 
of the hind-gut form a loop' (Fig. 322). The 2 limbs of the loop grow together for a certain distance, and wind round each other at this jart.

In the larve of some Hymenoptera, Neuroptera, Myrmeleon, and Diptera (Prpipara) the mid-gut ends blindly and is not yet connected with the hind-gut, the latter performing exclusively excretory functions (Fig. 321).

The Malpighian Vessels. - These are long, generally filamentons appendages, which begin to form as invaginations of the proctodæm. Their large epithelial

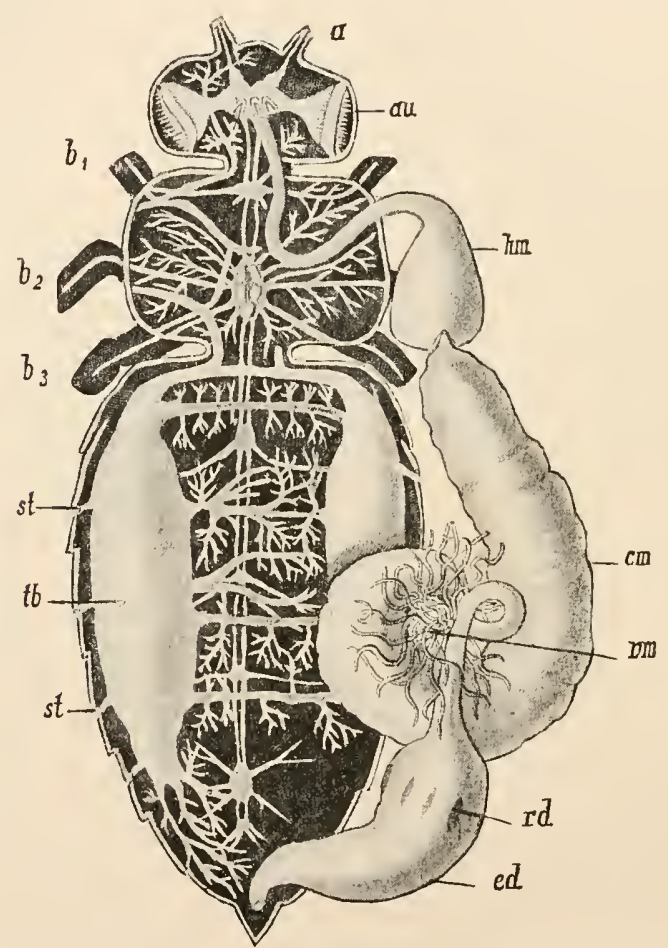

FIG. 320.-Nervous, tracheal, and digestive systems of the Honey bee (after Leuckart). The fine branchings of the tracheal system are not represented, the tracheal system on the right side of the figure is only partly drawn. au, Facet eye ; $a$, antenna ; $b_{1}, b_{2}, b_{3}$, the 3 pairs of legs ; $t b$, part of the tracheal longitudinal trunks swollen into a large vesicle; st, stigmata; hm, honey stomach ; $c m$, chyle stominch ; vm, Malpighian vessels ; $r d$, rectal glands ; $e d$, hind-gut.

cells (with nuclei often branched) contain colonred concretions in which uric acid is found. The Malpighian vessels occasionally have no distinct lumen ; they then consist of a few rows of cells. The number of the Malpighian ressels is as raried as their manner of entering the hind-gnt.

Apterygota.-Malpighian ressels are wanting in Iapy $x$ and the Collembola. In Campodec there are ca. 16, and they are here short; in the other Thysanur'a they arc long and $4-8$ in number. The tubnles always mite in pairs before entering the hind-gut.

Pterygota.-The Malpighian vessels are either very nmmerous and relatively short or less numerous (2-8) and long. They are more numerous in the Dermapterce (ca. 
30), Ephemeridae (ca. 40), Odonatu (50-60), Plecoptera (40-50), Orthoptere (30-50 or more), and Hymenoptera (very nunerous, often over 100, seldom below 12). On the other hand few (i.e. 2-8) are found in the Corrodentic (4-6), Thysannptere (4), Rikynchota (2-4), Neuroptera (4-6), Panorpata (6), Trichoptera (6), Lepidoptera (6, seldom 2 or 4), Diptera ( 4 or 5), Siphonaptere (4), and Coleoptera (4-6). They generally enter the hind-gut separately, but occasionally the ressels of cach side unite into a common duct, and sometimes the ducts from the two sides also have a common nnpaired terminal piece. Here and there the ressels open into a paired or unpaired urinary bladder attached to the hind-gut. In the Aplides there are on each side

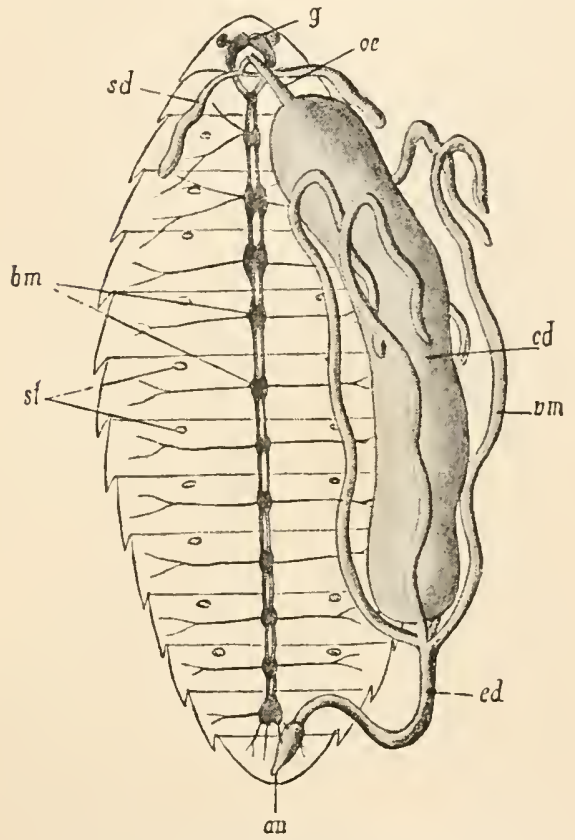

Fig. 321.-Larva (maggot) of honey bee, anatomy of the digestive and nervous systems (after $R$. Leuckart). I, Braiu ; bm, ventral chord; oe, nesophagus; sd, spinniug clands; $c d$, mil-gut, or chyle stomach; $e d$, hind-gut, not yet connected with the midgut ; $v$ m, Malpighian ressels ; an, anus; st, stigmata.

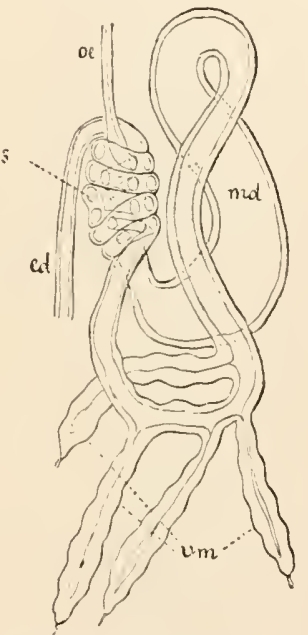

Fig. 322. - Enteric canal of Psyllopsis fraxinicola (after Witlaczil). oe, (Esophagns; md, mid-gut ; $e d$, hind-gut ; $v m$, Malpighian vessels; $s$, the coil formerl by the hiud-gut and the most anterior part of the mill-gut.

2 vessels which unitc together before entering a common duct. In Aletia, Danais (Lepidoptera), there are on each side 3 vessels with short common terminal pieces (Fig. 348, p. 488). In Galleria (Lepidopterce) there is an unpaired terminal piece into which 5 or 6 branched vessels enter. In Ephippigere and the Gryllider (Orthoptera) there are numerous ressels which, uniting into a tuft, enter the hind-gut through a long common ductus excretorins. In Orthe $i a$ (Coceidec) there are on each side 2 ressels which unite. The 2 terminal ducts themselves enter an unpaired terminal piece. The pupe of the Toctuinc have 3 pairs of vessels, united in pairs, entering an unpaired urinary bladder. Lygaeus (Heminterc) has on each side 2 vessels cntering a urinary bladder. 
The number of Malpighian vessels is occasionally smaller in the larva than in the adult. Thus the larva of the Honey bee (Fig. 321) has only 4 vessels. In the Blattide and Gryllide the number increases during the gradual development. In the Lepidoptera the larva usually possesses the same number as the adult. Among the Termites only do the young forms possess more numerous Malpighian ressels than the adults.

\section{The Nervous System.}

This appears in the form which is characteristic of the Aithropode

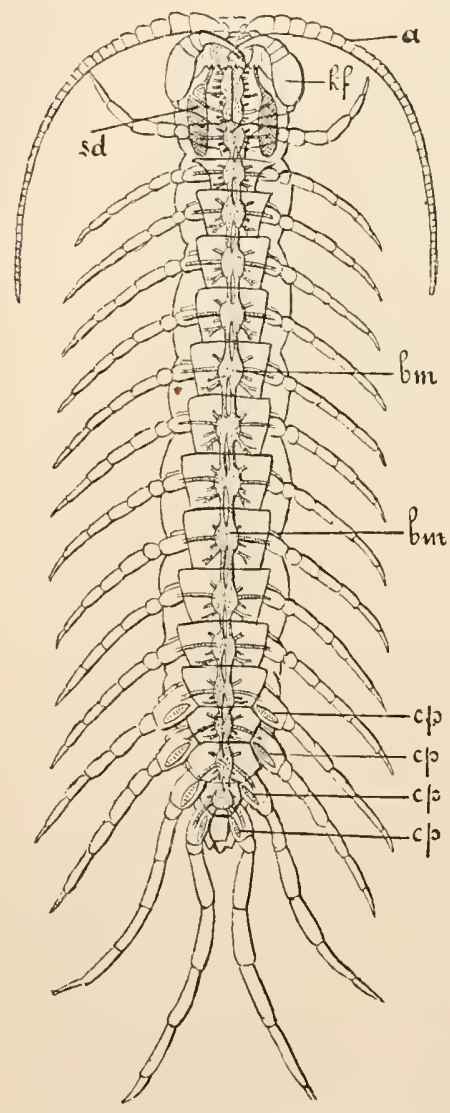

Fic. 323.-Lithobius forficulatus soen from the ventral side (after R. Leuckart). $a$, Antennæ; $l i f$, maxillipedes (poison feet); $s d$, salivary glands; bm, ventral chord ; $c p$, coxal pores.

Crustacea. This concentration takes place by the fusing of pairs of ganglia; it may appear in the abdomen as well as in the thorax and (esophageal ganglion), the cesophageal commissures, and the ventral chord. The brain, which lies in the head alove the oesophagus, often attains to a high degree of development (especially in the highly developed IIymenopter(i), and is distinguished by the formation of lobes (ganglion opticum, olfactory lobes, etc.) From it arise the nerves for the sensory organs which lie in the head, for the eyes, the antemne, and the olfactory organs on the antenna. We can always distinguish in the ventral chord a cephalic and a truuk portion. The former consists of the infra-œsophageal sanglion, composed of the fused ganglia of the oral limbs, which in the embryo are often separate. The trunk portion of the ventral chord must originally have consisted of as many double ganglia united by longitudinal commissures, as there are trunk segments, but the ganglia of some of the last trunk segments are always fused to form a terminal ganglion, generally somewhat larger in size than the rest. The ventral chord is found in this unconcentrated form in the Iysruepole, Apterygote, and many Pterygotu, and especially in the larve of the Hexapoda. We find, however, within varions orders of the Hexapoda more or less pronounced concentration of the ventral chord in a way similar to that described in connection with the and consists of the lorain (supra- 
generally, not always, proceeds in both from behind forward. A junction of the fused ganglia of thorax and abdomen to form a large thoracic ganglionic mass may even take place (as in the Brachyura and many Copepoda); such cases occur in the Diptera and Rhynchota. Although the larva generally possess a less concentrated nervous system than the imagines, so that the progressive concentration can often be followed ontogenetically in the same species, this is not always the case, in fact the very leverse occasionally occurs. The interesting relation between the rervous system of the larva and that of the imago will be again referred to.

From the ganglia of the ventral chord of the trunk (thorax and abdomen) arise the nerves for its integument, musculature, glands, and limbs. The 2 ganglia of a double ganglion are always closely contiguous, and appear as one mass consisting of two halves; the longitudinal commissures, however, which unite the consecutive ganglia very often remain separate. A sympathetic nervous system seems present in all Antennata.

\section{Myriapoda (Fig. 323).}

One ganglion is found in each trunk segment. The ganglia are mostly united by distinctly separate longitudinal commissures. In the Pauropoda and Sympllyzla, however, the ventral chord is a median strand with consecutive swellings, corresponding with the ganglia, and in this strand the longitudinal commissures are not separate.

The 2 anterior trunk ganglia (or in Symphyla only the first) generally form with the sub-esophageal ganglion a single mass, in which, however, the original composition can easily be made out. The limbless anal segment has 110 separate ganglion, and the ganglia of the 2 or 3 preceding segments are fused together.

The double segments of the Diplopoda each have 2 ganglia.

\section{Hexapoda.}

Apterygota. - In this division we have very good illustrations of the concentrated and noll-concentrated nerrous systems. The Thysanur $\alpha$ have a non-concentrated

FIG. 324.-Central nervous system of Machilis maritima (after Oudemans). au, Eye ; lo, lobus opticus; $g$, brain; an, antenual nerve; oe, cesophagus passing between the osopliageal commissures; usg, infia-osophageal ganglion; $I$-III, thoracic ganglia ; $1-\delta$, abdominal ganglia, the last $(S a b c)$ consisting of three fused ganglia; $s$, sympathetic nervous system of the ventral chord.

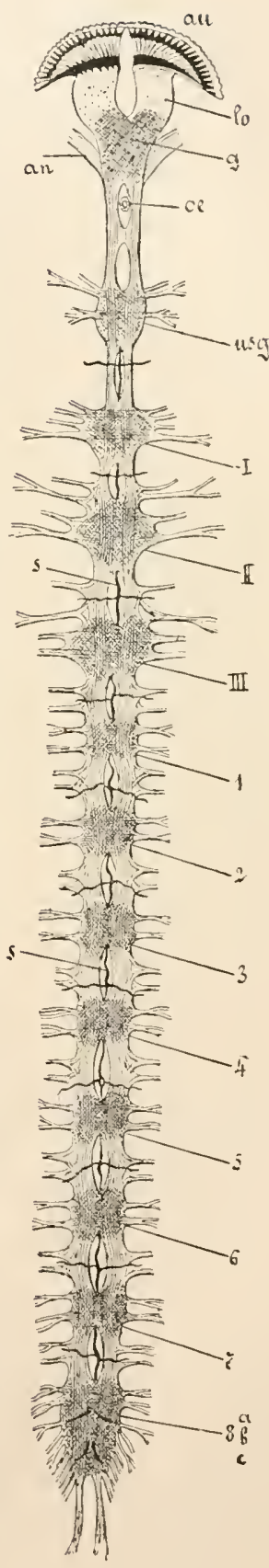

$2 \mathrm{HI}$ 
nervous system, consisting of the brain, cesophageal commissures, infra-cesophageal gauglion, 3 ganglia of the 3 thoracic segments and 8 (in Compodec 7 ) ganglia of the abdomen (Fig. 324). The finer structure of the last and largest abdominal ganglion and the number of nerves proceeding from it show that it consists of 3 fused ganglia. The number of abdominal ganglia would according to this be 10, corresponding with the number of segments. In the Collembola the number of abdominal segments is reduced, and in accordance with this reduction of the body there is, as it appears, only 1 abdominal ganglion. Sminthurus is said to have only 1 thoracic ganglion. The 2 longioudinal commissures remain distinctly separate in the Thysanure. From each ganglion 2 nerves are given off' on each side, and the same number rroceed from the cesophageal commissures. In front of the infra-cesophagreal ganglion and behind the cesophagus a transverse commissure comnects the cesophageal commissures.

Pterygota.-The nervous system of the winged Insectu shows very great variety in its arrangement: it is impossible here to go into details-the Diptera
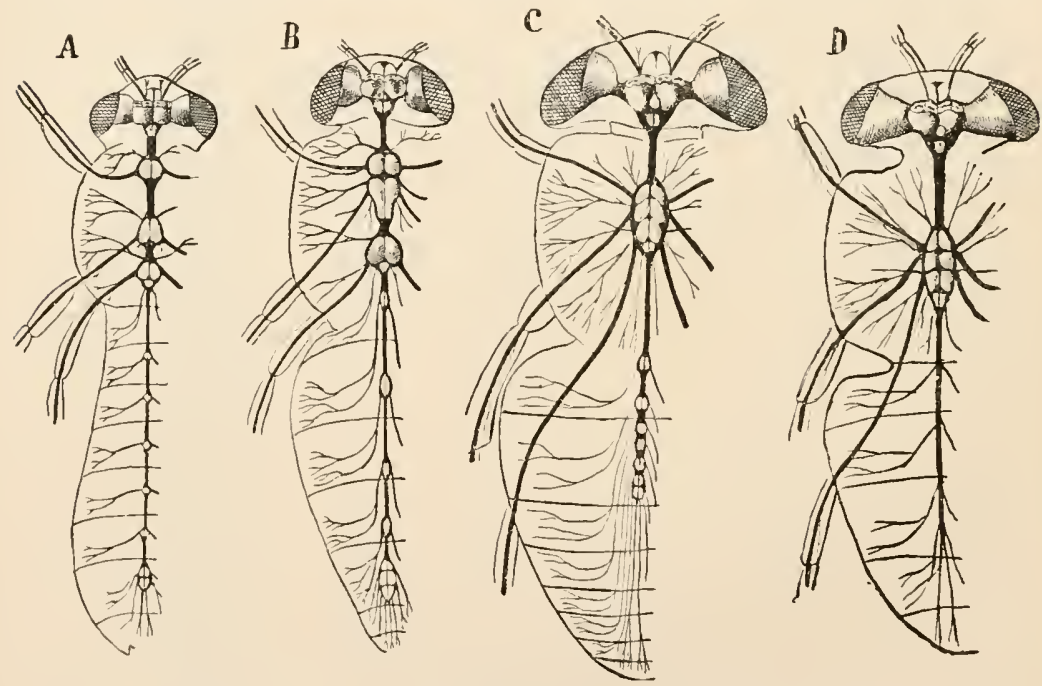

FIG. 325. $-A-B$, The nervous systems of 4 species of Diptera, to demonstrate their various degrees of concentration. A, Non-concentrated nervous system of Chrionomus plumosus, with 3 thoracic and 6 abdominal ganglionic masses. $B$, Nervous system of Empis stercorea, with 2 thoracic and 5 abdominal ganglionic masses. $C$, Nervons system of Tabanus bovinus, with one tloracic ganglionic mass and the abdominal ganglia moved towards each other. $D$, Nervous system of Sarcophaga carnaria. All the ganglia of the ventral chord except the infra-cesophageal ganglion, which always remains separate, are here united into one single thoracic ganglion mass (after $\mathbf{E}$. Brand).

(Fig. 325, $A-D$ ) are particularly instructive. In no other natural order of insects are the extremes so great, and yet counected by such numerons intermediate stages. The series begins with the suborder of the Nemocera, the Culicide, Culiciformes, Timelide, Fungicole (e.g. Chironomus, A), which have very slightly concentrated nervous systems. The rentral chord liere consists of an infra-cesophageal ganglion, 3 thoracic ganglia, and 5-6 abdominal ganglia. The last thoracic ganglion is not simple, but at least 1 of the anterior abdominal ganglia is fused with it. The last and largest abdominal ganglion is also not simple; it consists of scveral (in Chironomus probably 2) fused ganglia. The concentration of the nervous system among the 
Inigtera begins in the families of the Empide, Asilider, Therecide, Nyluphagita, Bibionider (e.g. Empis, $E$ ), where the 2 anterior thoracic ganglia become finserl, so that there are only two thoracie ganglia. In this respect the Diptera form a contrast to other insects with only 2 thoracic ganglia, c.g. many Colcoptere, Lepidopitere, and Hymenopter $\alpha$, in these cases it is the posterior thoracie ganglion which consists of the 2 fused posterior ganglia. Tabanus (Fig. 325, C) exhibits a nervons system in which all the 3 thoracic ganglia are fused into 1 thoracic ganglionic mass. This is the easc in the families of the Syrphide, Stretyomide, and Tabanide. The abdominal ganglia show a tendency to approach cach other and to fuse. Finally the highest degree of concentration among the Diptera is shown by the Muscite, Estride, and Pupipare, where all the ganglia of the ventral chord, except the infraresophageal ganglion, are fused into 1 large thoracic ganglionie mass (Fig. 325, D. Sarcophaga). From this mass a modian nerre then runs towards the end of the abdomen, giving of nerves to the abdominal segments at regular intervals.

A series similar to the above occurs in the Coleopterce, but the concentration here rarely goes so far as in the Diptera, since, though the abdominal ganglia may be wanting (in the Lamellicomice), the 2 thoracic ganglionic masses always remain separate. Wherever among insects scparate abdominal ganglia are wanting these are fused with the most posterior thoracie ganglion, from which the abdominal nerves then often radiate backward, like the canda eqnina in vertebrates. These abdominal nerves, however, may be mited on each side into an abdominal longitudinal bmolle, or these 2 longitudinal bundles may be finsed to form 1 median abdominal strand. The Rhynchota, the Mallophaga (Corrodentic), and the Thysanoptera possess a much concentrated nervous system. In many Rhynehote all the thoracie ganglia, not excluding the infra-resophageal ganglion, may fuse into 1 ganglionic mass, as is the case in the Coccide and also to a lesser degree in the Aphides.

All other insects have a non-concentrated or else slightly concentrated nervous system, with separate infra-øesophagcal ganglion, at least 2 thoracie and several abdominal ganglionic masses, at the most 8 and rarely only 1.

The full number of abdominal ganglia is not found in any insect larva or imago. In insect-embryos, however, the rudiments of all the 10 abdominal ganglia have been observed.

It is clear from the above that the arrangement of the nervous system can be as little used as a criterion for the natural division of insects as the structure of any other organic system by itself. It can at the most be used for limiting the subdivisions within the orders.

The relation of the larval Nervous System to that of the Imago.-(1) Where the nervous system of the imago is not concentrated, it is generally not concentrated in the larva ; this is evidently the original condition.

(2) Where single ganglia are fnsed in the imago, they are often separate in the larva. The honey bee affords an illustration of this; the bee larva (Fig. 321, p. 463) possesses the fully segmented nervons system : brain, infra-resophageal ganglion, 3 thoracic and 8 abdominal ganglia. The last abdominal ganglion comes from three rudimentary ganglia, which are separate in the cmbryo. The adult bee (Fig. 3:0, p. 462) possesses a brain, infra-cesophageal ganglion, 2 thoracic and 4 abdominal ganglia. The posterior and larger thoracic ganglion consists of the $2 \mathrm{~d}$ and $3 \mathrm{~d}$ thoracic ganglia fused together ; the composition of the last abdominal ganglion ont of 3 ganglia can still be clearly made out.

(3) Where the nervous system in the imago is mucl concentrated, it is very often (e.g. Huscidce) much concentrated in the larva also, and at the same time slightly differentiated. We have here a case of the imaginal characteristics being shifted back on to the larval stage.

(4) The nervous system in the larva is seldom much concentrated when not con- 
centrater in the imago. Myrmeleon is, however, a case of adaptation of the nervous system to the short compressed form of body of the larva.

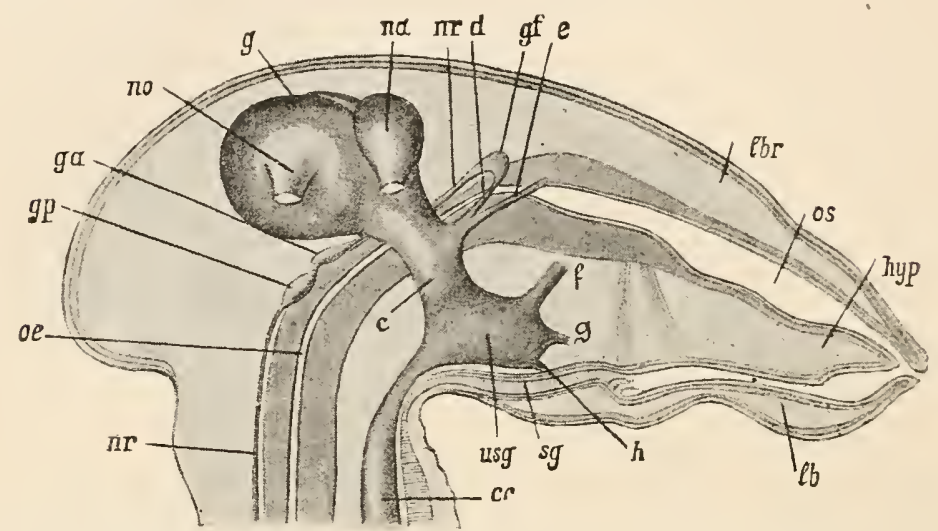

FIc. 326.-Median longitudinal section through the head of Blatta orientalis. The nervous system of the heal is drawn entire. hyp, Hypopharynx; os, oral cavity; lbr, upper lip; gf, ganglion

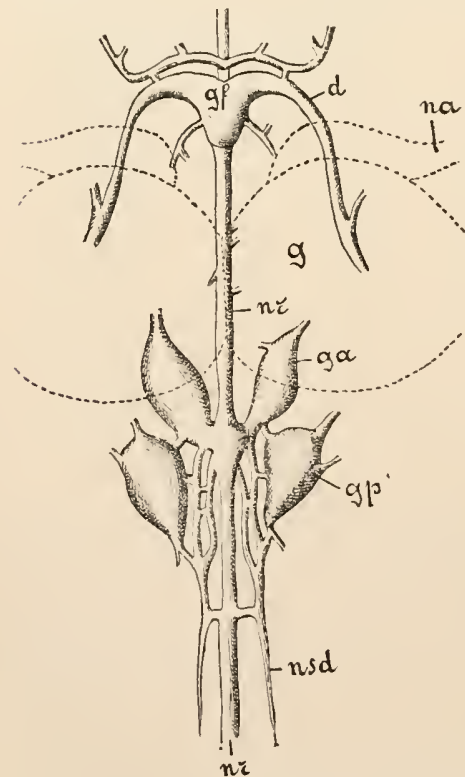

FIG. 327.-Anterior portion of the paired and unpaired visceral nervous system of Blatta orientalis, seen from above. The outlines of the brain $(g)$ and the roots of the antemnal nerve $(n a)$, which cover a portion of the sympathetic nerrous system, are given by rlotted lines. Lettering as in Fig. 326. nsd, Nerve to salivary-gland. The nervns recurrens $(n r)$ enters an unpaired stomach ganglion further back (after Bruno Hofer). froutale; $g$, brain; na, root of the antennal nerve; no, root of the optic nerve; gr, anterior; gp, pos. terior ganglion of the pairerl visceral nervous system; oe, cesophagns; c, osophageal commissure; usg, infra-osophageal ganglion ; $c$, longitudiual commi-sure between this and the first thoracic ganglion; $s g$, common luct of the salivary glands; $l b$, lower lip $=2 d$ pair of maxille; $n r$, nervus recurrens; $d$, nerve uniting the frontal ganglion with the osophageal commissure; $e$, uerve from this commissure to the upper lip; $f$, nerve from the infra-asophageal gangliou to the mandible; $g$, to the anterior maxillæ; $h$, to the lower lip (after Bruno Hofer).

(5) In many cases where in the larva there is an aplarently concentrated ventral chord, its ganglia are quite distinct although lying very close together. In the imago they separate and the longitudinal commis. sures become distinct, so that a non-concentrated or less concentrated inmaginal nervous system is developed.

The sympathetic nervous system seems to be prescnt in all Antemuata. It consists of an unpaired and a paired system. In Blatta, whose risceral nervous system (Figs. 326 and 327) has been the most investigated, the unpaired portion shows the following arrangement. In front of the brain on the cesophagus there lies an unpaired ganglion frontale $g f$, which gives off nerves to the upper lip and the oesophagus. It is connected by a nerve on each side with the œsophageal commissure, from which another nerve as well goes off to the esophagus and 
the upper lip. From the ganghion frontale an unjaired median nerve, the nervus recurrens $n$, runs back under the brain along the dorsal wall of the resophagus, and enters an unpaired stomach ganglion in front of the masticatory stomach. A lateral pair of nerves arises from this, 2 small ganglia occurring in their course.

The paired visceral nervous system consists of two pairs of ganglia ga and yp, which lie on the cesophagus, the anterior pair being covered by the brain. These nerves are connecterl with each other, with the nervus recurrens, and with the lorain by anastomoses. The nerrus recurrens and the paired ganglia give off nerve lianches to the cesophagus and to the salivary glands.

Besides the above nerves insects may have sympathetic thoracic and abdominal ganglia either paired or unpaired. The paired portion of the visceral system may also be wanting.

In the Lrpidoptera, close above the abdominal portion of the rentral chord, is found a longitudinal strand of comnective tissue, which seems to be a formation of the Neurilemma of the ventral chord. Muscles are attached to this which run to the neighbouring ventral exoskeleton. This strand, whose significance is not yet sufficiently explained, has been called the chorda supra spinale. It has nothing to do with the vertebrate chorda.

\section{TI. Sensoly Organs.}

\section{A. Eyes.}

We can distinguish single-lensed eyes or ocelli from compound eyes (facet eyes). The IIyriapoda have ocelli generally in large mumbers grouped closely together on each side dorsally. Only Scutigere has a compound eye on each side: this eye, however, differs in structure in many respects from the compound eye of the Insecti.

Most adult Hexupode have ocelli as well as facet eyes. The small ocelli then generally lie in threes on the frontal region between the two large facet eyes. The larve have ocelli only, these often occurring in great numbers. Ocelli are seldom found alone (i.e. without facet eyes) in adult Hcrapod", but this is the case in the Collembole among the Apterygote, and in lice (Pediculidce) and fleas (Apheniptera). Ocelli are wanting in adult Dermaptere, and among the Orthoptera in the Locustidce, among the Pihynchote in the Hydrocora, among the Lepidoptera in the Geometrine and Phopelocere, which thus as adults possess only facet eyes.

Structure of the 0celli.-The simply constructed ocellus of the Dytiscus larva is very instructive (Fig. 328). Above the ocellus the chitin thickens into a lens. Below it the hypodermis is depressed in the form of a pit. The hypodermis cells standing at the base of this depression form the retina of the eye. Each retinal cell is conmected with a nerve fibre, contains pigment, and produced outward towards the lens in the form of a rod. The cells at the edge of the depression are free from pigment at their outer ends, and push their way in between the retina and the lens, filling it up and forming a sort of vitreous body. The ocelli of other Insecte and IIyriapode are similarly 
constructed, with this distinction, that they are in most cases completely demarcated resicles, over which and below the lens the hypodermis

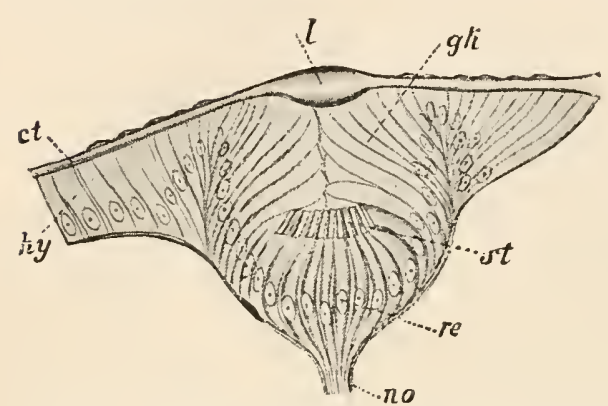

FIG. 32S.- Section through the ocellus of a young Dytiscus larva (after Grenacher). ct, Chitinous cutiele; $l$, euticular lens; gl, eells of the vitreous body; hy, hypolermis; st, rois ; re, retinal cells ; no, optic nerve.

functions as a ritreons body.

The structure of the compound eyes agrees in general with that of the compound Crustacean eye (cf. p. 35.3). There is always a bi-convex corneal lens for each single eye. Eucone and Acone eyes are distinguished, according to whether crystal cones are formed (as in the Crustacea) or not. Acone eyes are found in the Colenptera (exchnding the Pentemera), in the Heteroptera, the Tipularide among the Dipterc, and the Dermapteru. In the acone type (e.g. Tipulu) each corneal lens is separated from its neighbour by a strongly pigmented zone. Under each lens lies a conical group of 4 crystal cells, whose proximal end is imbedded between two pigment cells. The retimula, consisting of 7 cells ( 6 marginal cells and 1 axial cell), joins the abore. Each of the retinular cells contains in its proximal portion a melens, and in its distal portion a rod (rhabdomere). The single eyes are separated from each other by pigment cells.

The elements of the optic ganglia (ganglion opticnm and retinal ganglion) are arranged in a very complicated manner in the Insecta.

The Ocellus and the Facet Eye.-Attempts have been made to commect these two forms of eyes. According to the view most widely approved, the two eyes are to be derived from a primitive eye resembling the single eye (ommatidium) of the acone eye of Tipule. An increase of the elements of this primitive eye led to the formation of the ocellus; an increase in number of the primitive eyes and their approximation led to the formation of the compound facet eye. For eonfirmation of this riew we are referred to the groups of closely contiguous single cyes of the Hyriapoda, considered in connection with the compound eye of Scutigcra. But it is difficult to reconcile with this view several facts in the ontogeny of the eye, and especially the structure of the middle eyc of the Scorpion. Such a scorpion eye on the one hand contains only a single lens, while on the other the retinal clements are grouped into retinule.

The last word is certainly not yet spoken with regard to the finer structure and the morphological significance of the Arthropodan eye, and we must here briefly allude to an entirely new view. According to this view the compound eye consists of two layers : (1) of a hypodermis layer which yields the single corneal lenses, and (2) of a subjacent layer of single eyes. The latter is said to be a single layer, the elements of the single eye known as crystal cells, retinnlar eells, and pigment cells rumning with their processes through its whole thickness (Fig. 329, $A$ ). The rhabdomes and the rhabdomeres forming them are not sccreted products of the retinula, but belong, like the crystalline conc, to the crystalline cone cells, which are 
called retinophore. The crystalline concs are the clements actually sensitive to light. The retinophore are surrounded by pignent cells. A proximal (inner) ring of these cells corresponds with the so-called retinule, but these cells are also continued in the form of fine processes as far as the hypodermis. Fig. 329, A, illustrates this vicw. The layer of single eycs is said to answer to the posterior wall of a resicular eye, which first forms as an ectodermal depression and later becomes constricted off. The wholc compound eyc would according to this be a modified and differentiated ocellus, in which the epithelial cells of the posterior proximal wall of the eye-pit differentiate into retinophore and pigment eells, grouped together as ommatidia (as in the middle eyc of the Scorpion). The hypodermis, further, which spreads over the vesicular eye, instead of forming one cuticular lens, forms many such leuses, which as corneal facets correspond in number and position with the ommatidia. The ocelli themselves may also be comrared with the similarly constructed visual organs in the Annelide and Mollusca which arise as ectodermal invaginations.

If this new view of the facet eye is establisherl, i.e. if the so-called crystalline cones are not simply refractive hodies, but the actual terminal apparatus of the optic nerve, sensitive to light, it would lead to considerable modification of the theory of sight by means of the compound eye.

\section{B. Auditory Organs.}

In the most various parts of the bodies of the Insecta peculiar nerve endings occur which are evidently sensory; their structure is as follows: A peripheral nerve fibre enters a ganglionic cell, which is in its turn connected with the integument by means of a long slender stretched tube. An axial thread from the ganglionic cell enters the tube, and there ends in a terminal rod. The tube which conceals this rod is called the scolopophore, and that part of it which becomes attached to the integument is the terminal tube. Scolopophores with their ganghia are rarely found singly, they are usually united in groups of rarying size (Figs. 330, 331, and 332). If the number of scolopophores is small their terminal tubes are gathered into a bundle, but if 
great, the terminal tubes are generally isolated, running either irregularly or radially, or in the shape of a fan, etc., to the integument. These peculiar sensory organs are called chordotonal organs, and are considered to be auditory. A chordotonal organ may be either simply connected with the integument by a prolongation of its nerve, or bent at right angles to its nerve and rum parallel to the integument (Fig. 330). The latter is the case when the terminal tubes of the

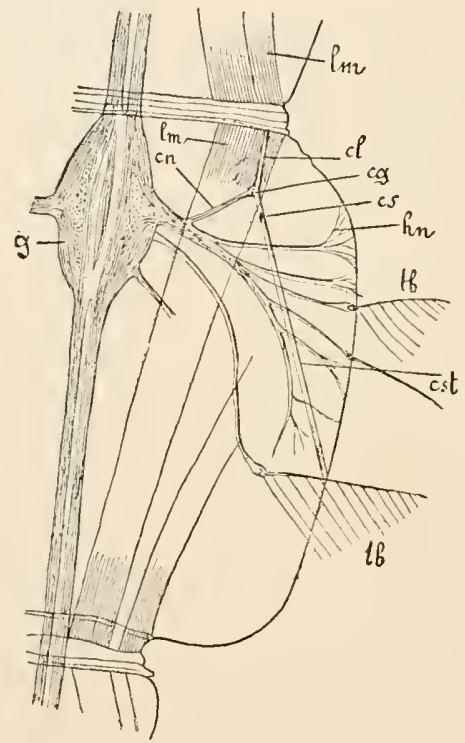

FIG. 330.-Right half of the 8th trunk segment of an older larva of Corethra plumicornis ; nervous system and sensory organs (after $\nabla$. Graber). g, Ganglion of the ventral chord; $7 m$, longitudinal museles; $c n$, chordotonal nerve ; $e l$, chordotonal ligament ; $c g$, chordotonal ganglion ; $c s$, rod of the chordotonal organ; cst, terminal strand; $t b$, tactile setx; $h n$, outgoing fibres of the integumental nerves.

chordotonal organ unite into one tube, and then the bent portion is connected with the integument by a second tnbe, the chordotonal ligament. The chordotonal organ, together with the chordotonal ligament, then form a chord stretched between two parts of one and the same segment.

The nerve forms a terminal ganglion cell at the point where it joins the chord.

If the exoskeleton is affected by vibratious of sound, this apparatus with its terminal rods is set in vibration, and a sensation of sound may thus be produced.

Chordotonal organs, which offer great varieties of structure, occur in all orders of the Pterygota, and are found in the most various parts of the body, in the trunk, in the legs, the wings, the mouth parts, and the antenne. They may appear in different forms in various parts of the body of the same animal. 
In the wings, but especially in the haltercs or balancers of the Dipter $\alpha$, which are minute transformed hind wings, they are connected with areas of the exoskeleton provided with peeuliar pores or papillie. They always lie superficially. A chordotonal organ is, further, never stretched between points of the integument of two con-

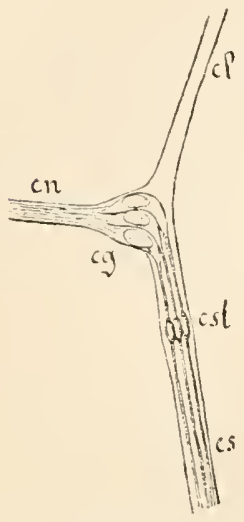

Fig. 331.- The Chordotonal organ of Fig. 330 , strongly magnitied. el, Chordotonal ligament; $c n$, chordotonal nerve; $c g$, chordotonal ganglion; $c$ st, chordotonal rod ; es, terminal tube.

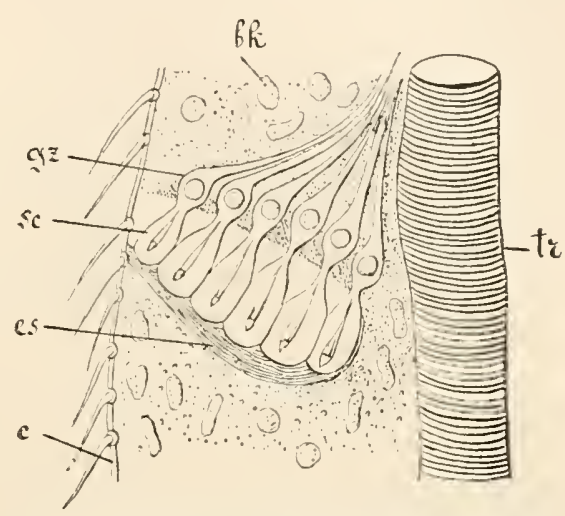

Fic. 332.-So.called sub.genual chordotonal organ in the tibia of the middle leg of Isoptery 8 apicalis (Perlid) (after $\nabla$. Graber). tr, Trachea; $b 7$, blood corpuscles; $g z$, nerve cells; sc, scolopophores with their rods ; es, terminal fibrous strands, attached to the integument (c).

seeutive segments of the body, or limbs, movable on one another, but always runs within one of the same joint or segment, and is thus not affected by the movements of the animal. The chordotonal nerves always arise ont of the ganglion belonging to their own segment. Chordotonal sensory organs have till now been chiefly observed in the larve of the Insecta.

The tympanal organs of the Saltatoria, which have been long known, agree in the finer structure of their nerve endings with the chordotonal organs. It was this agreement which led to the assumption that the so-called ehordotonal organs were also auditory organs, for the tympanal organs of the Saltatoria have long been universally regarded as auditory organs, although the animals continue to hear after their removal. This last fact favoured the vicw of the acoustic properties of the chordotonal organs, sinee the latter occur together with the tympanal or gans.

Scolopophores are very numerons in the Saltatoria (over 100). In the Acridiclce their terminal tubes are attached to points of the inner surfaces of the hypodermis of special prarts of the exoskeleton, which, as compared with the surrounding exoskeleton, are thimned away like a membrane and are called tympana (Figs. 333 and 334). Such a tympranum may be stretched between thickened portions of the skeleton, whieh form a frame for it; and, as in an outer ear, the integument may grow round it as a

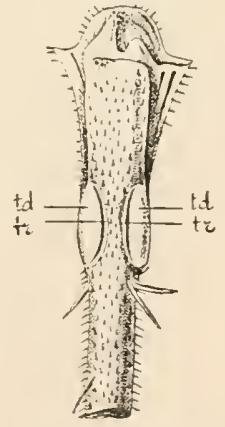

FIG. 333. - Tibia of the fore leg of Locusta viridis. sima. $t d$, Corer of the drum ; tr, fissure between the drum and its cover (after จ. Graber). covering fold for its protection. A tracheal trunk widens to form a cavity muler the tympanum, which may be compared with the hollow of a drum. Between the cavity 
and the tympanum lies the terminal nerve apparatus, the so-called "Miiller's" ganglion with the scolopophores, whose terminal tubes attach themselves by peculiar inner processes to the middle of the tympanum. The tympanum can be stretched by special muscles. In the Gryllide and Locustide the terminal tubes of the scolopopliores are

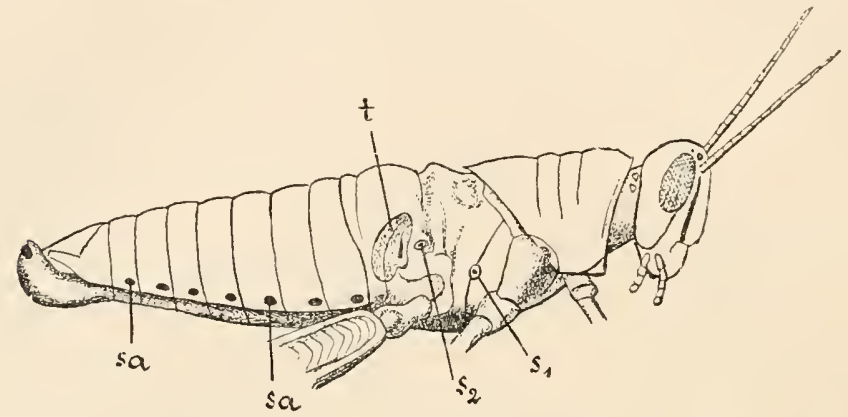

FIG. 334.--Side view of Acridium tartaricum. $s_{1}$, Stigna of the mesothorax; $s_{2}$, stigma of the metathorax; $s a$, stignata of the abdomen; $t$, crum of the tympanal auditory organ (after Fischer).

not attached to the tympanum itself, but above it to the integument. The Locustidu possess, besides the Diiller's ganglion with its scolopophores, another series of some-

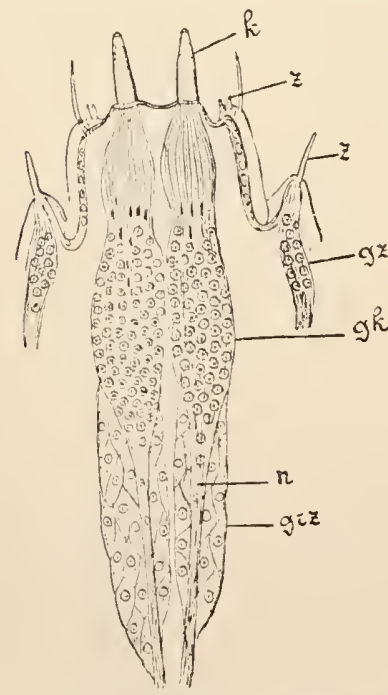

Fig. 335.- Sensory organs considered to be olfactory at the end of the Antennæ of Iulus Sabulosus, longitndinal section throngh the antenna. $k$, Sensory cones; $z$, sensory points; $g k$, ganglia of the sensory cones; $g z$, ganglia of the sensory points; $n$, nerve; grz, large cells in the ganglia of the sensory cone (after v. Rath). what different scolopophores, lying on a hollow formed by the trachea, which acts as a resonator.

The tympanal auditory organs of the Saltatorio lie either (Acridicte, Fig. 331) in a single pair at the sides of the first abdominal segment, or (Gryllide, Locustide, Fig. 333) on the tibie of the fore-legs. In the last case there are generally on each tibia 2 tympana lying op posite one another.

Between the basal portions of the maxille of Scutigere there lies on each side a pouch, from the hase of which small closely-packed plates and hairs rise into the cavity. These plates and hairs stand on equally closely arranged folds of the cuticle. It has been conjectured that thesc formations, which need further examination, may prove to be auditory organs.

\section{Olfactory Organs-Gustatory Organs.}

The seat of the sense of smell is, as in the Crustucea, to be sought in the antennie (and perhaps in the maxillar palps as well). The antennæe are in the Insecte very often more strongly developed in the niales than in the females. The olfactory organs are short processes in the shape of knobs or cones, and generally open at the point; they are found either free or at the base of pits in the antennæ. 
Beneath each olfactory process there is a pore in the cuticle, throngh which the filrille of a hypodermal ganglion pass (Fig. 335). Similar terminal apparati, which have been observed at the base and at the point of the tongue, and on the lower side of the maxilla of Hymeroptere, on the inner surface of the labellum of the proboseis in the fly, and in the gnathochilarium of the Iriplopodt, may perhaps be consiclered as gustatory organs.

Specifie organs of touch are found in the long, simple, or feathered seta (Fig. 330, p. 472) which oceur all over the body surface, and especially on the feelers and maxillar palps of the Antennata, on the labellum of the proboscis of the fly, etc. An axial thread enters the sensitive hair from a hypodermal ganglion cell, and runs through it.

\section{The Cireulatory System.}

This is very simple in the Antennata. The colourless or lightyellow or light-green blood, containing amoboid blood corpuseles, flows in definite directions in a lacunar system (body cavity). The circulation of the blood is maintained by the contractions of a dorsal vessel (dorsal heart), which in the extremely reduced condition of the arterial vascular system is almost the only part which has walls of its own. The dorsal ressel is a delicate tube rumning longitudinally abore the intestine, and covered externally and lined internally by membranes probably elastic. Between the two membranes there runs a system of delicate muscle fibres, which generally have a circular conrse and sometimes cross each other. The dorsal ressel falls into successire segmental chambers, separated by valvular arrangements, which prevent the streaming back of the blood from the anterior into the posterior chambers during the progressive contraction of the ressel from behind forwarl. The dorsal vessel is provided with paired lateral ostia, which, as it appears, are mostly placed intersegmentally, and maintain an open communication between the surrounding parts of the body cavity and the interior of the heart. The heart may be connected in various ways by muscular fibres with neighbouring parts of the body, i.e. with the intestine, with the dorsal integument, etc. Paired socalled alary museles are particularly constant in their occurrence; they are almost triangular, and become attached by their narrowed ends to the latero-dorsal body wall, while their broad ends are fastened to the chambers of the heart. These alary muscles together form an incomplete horizontal partition wall above the intestine, marking off a dorsal sinus in which the heart lies. This sinus may be called the pericardial sinus. This partition wall is arched upwards, and if the alary muscles which form it contract, it straightens out and becomes flat; the pericardium thus becomes more spacious, and the blood streams into it from the rest of the body cavity. It was formerly thought that the alary muscles served to expand the heart. 
This expansion, however, seems to be merely a result of the elasticity of its own walls. The whole mechanism, however, requires fresh investigation.

The heart ends blindly behind, lut is continued anteriorly into an aorta, which empties the blood into the lacunar system of the body.

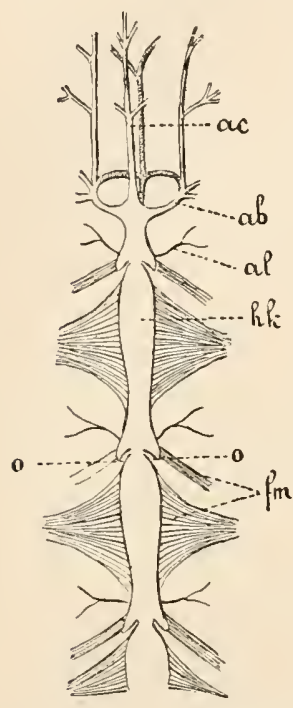

FIf. 336.-Anterior end of the heart of Scolopendra (after Newport). ac, Arteria cephalica; $a b$, arterial rings; $a l$, lateral arteries ; $h \hbar$, cardial chamber ; 0 , ostia of the heart; $f m$, alary muscles of the same. We can occasionally distinguish with special clearness a ventral sinus surrounding the ventral chord (in Myriapode, Orthoptera, and perhaps also in certain Apterygota); in this sinus the blood flows from before backward. A nerve supplying the heart like that in Periputus has here and there been observed.

Myriapoda (Fig. 336). - The heart runs through the whole body, and has as many chambers and pairs of alary muscles as there are trunk segments. From the most anterior chamber an aorta arises, which divides into three branches in the head. In the Iululce and Scolopendride lateral arteries are said to diverge in the neighbourhood of the ostia.

Hexapoda, Apterygota. - The heart of the Thysanura consists of 9 chambers, and has 9 pairs of ostia and 9 pairs of weakly developed alary muscles; this is the highest number reached among the Hexupoda. It runs forward as far as the last thoracic segment, or even to the second; this is an important fact, as in all Pterygotu, with the exception of a few Orthoptera (Blatte), the heart is exclusively confined to the abdomen. The aorta is short in the Thyscmura, as the heart extends so far forward. The number of cardial chambers and pairs of ostia is reduced in the

\section{Collembole (5 in Macrotomu).}

Pterygota. - With the exception of a few Orthopteru, the heart is restricted to the abdomen, and has $\delta$ pairs of ostia at the most. The number of pairs of ostia, of alary muscles, and of eardial chambers may be reduced like the number of the ganglia of the ventral chord. The aorta runs through the thorax and may be traced as far as into the head.

In the Lepidopterc the aorta bends up dorsally in the thorax, widens considerably and forms a loop (Fig. 348, ac, 1. 4SS). In a few cases the aorta has been found branched in the head. In the larva of the Ephemeride, blood ressels with walls of their own lass from the last cardial chamber into the three candal sete. The valves between the last cardial chamber and the one before it are here placed in such a way that they prevent the passage of the blood from the former into the latter. When the last chamber contracts, therefore, the blood is driven into the three arteries of the caudal setæ. 
The want of a developed arterial vascular system is eompensated for as well as eonditioned by the extremely profuse branehing of the respiratory organs (trachere), the oxygen being thus eonveyed to the blood in all parts of the body. Thus, whilst, as a rule in the higher animals, the blood in its elosed ehannels generally seeks ont the localised seat of the respiratory processes, here, on the contrary, the respiratory organs seek out the blood and the blood tissue in the most remote frarts of the body.

\section{Fat Bodies-Luminous Bodies.}

In the body cavity lies a mass of large cells filled with small drops of fat, and forming together the so-called fat body. This is variously shaped, and covers inner organs which appear enveloped in it; it also forms a layer under the integument, etc. It is specially strongly developed in the larva, and forms a reserve of nutrition, which is drawn upon during metamorphosis, during the formation and ripening of the sexual products, etc. The metabolism which goes on in the fat hody is very active, as is proved by the fact that its cells often contain concretions of uric acid. In some cases it has been proved that the fat body in the larva is rich in fat and poor in concretions of uric acid, while in the imago it is poor in fat and rich in concretions of uric acid.

There are Coleoptera which possess either on the abdomen (Lampyvide) or on the thorax (a few Eluteride, Pyrophorus) intensely luminous areas. The seat of light is a luminous organ which, morphologically, must be considered as a specially differentiated portion of the fat body. The cells of this luminous organ secrete, under the control of the nervous system, a substance which is burnt during the appearance of the light; this combustion takes place by means of the oxygen conveyed to the cells of the luminous body by the tracher, which branch profusely in it and break up into capillaries. A weakly luminous dorsal layer of the luminous organ, which lies ventrally in the penultimate and antepenultimate abdominal segments of the Lampyriclee, contains very numerous concretions of uric acid.

Other cell elements occurring in the body cavity (e.g. the pericardial cells lying on the alary muscles of the heart, and occasionally containing fat) cannot here be more closely considered. They form, together with the blood corpuscles and the fat body, the so-called blood tissue.

\section{The Respiratory Organs.}

\section{A. The Tracheal System.}

The respiratory organs of the Antennata are air-conducting canals (trachex) which, on the one hand, communicate with the outer world by means of paired, strictly segmentally arranged outer apertures (stigmata), and on the other spread all over the body, penetrating 
between the various organs and even the component parts of organs, breaking up into the finest capillaries. The essential structure of the tracher is everywhere the same, whether we examine a principal trunk or a fine terminal branch. The tracheal tube (Fig. 337) is lined internally with a chitinous intima, which is a continuation of the chitinous

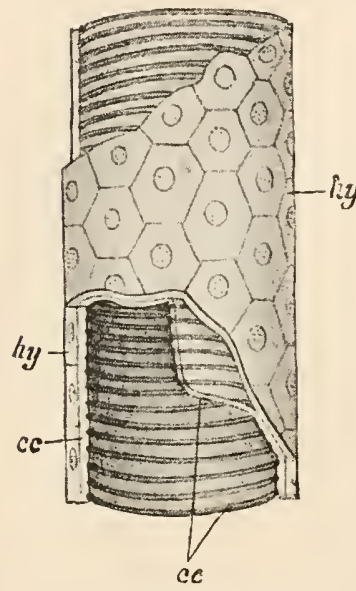

F1G. 33i.-Structure of a trachea. Diagrammatic; portions of the epithelium and chitinous intima removed in order to show the structure. $h y$, Tracheal epithelium $=$ tracheal hypodermis $=$ matrix of the chitinous intima $(c c)$, in which can be seen the spiral thickening (spiral thread).

stigma, at the beginning of each principal tracheal trunk, there is a closing apparatus which we cannot here more minutely describe; by means of this apparatus, into which nerves enter, the trachea can be completely closed towards the exterior. The air in the trachere is chiefly renewed by the respiratory movements of the abdomen (in the Hexpoda); these movements are caused by the contractions of the muscular fibres which run dorso-ventrally. By the contraction of the abdomen (exspiration) the trachere are compressed and the air driven out through the stigmata, or, if the stigmata are closed, forced into the tracheal system of the thorax, head, and extremities. By the expansion of the abdomen (inspiration) new air from without again enters the tracher, the elastic spiral of the tracheal tube playing an important part in its expansion.

We are justified in assuming, that the tracheal system of the Antennata originally consisted of as many pairs of isolated tracheal bundles and stigmata as there were body segments (excluding the anal segment). Reduction, however, has everywhere taken place, first of all at the anterier and posterior ends of the body, so that in some 
eases only a single pair of stigmata is left; the tracheal system undergoes corresponding modifications, the most important of which is the connecting together of the originally separate bundles of trachese by means of transverse and longitudinal anastomoses.

With reference to the scattered and irregular apertures of the trachere in the Protrcecheca, we must point out that the arrangement of the tracheal system in all Antennata indicates a strictly segmental order of tracheal apertures in the racial form. There is never more than one pair of trachere in one segment in the Antennata.

\section{Myriapoda.}

The most primitive arrangement is found in the Diplopocla, where one pair of stignata and one pair of tracheal bundles oceurs in each trunk segment. Each double segment also has 2 pairs of stigmata and 2 pairs of tracheal bundles. 'The seprarate

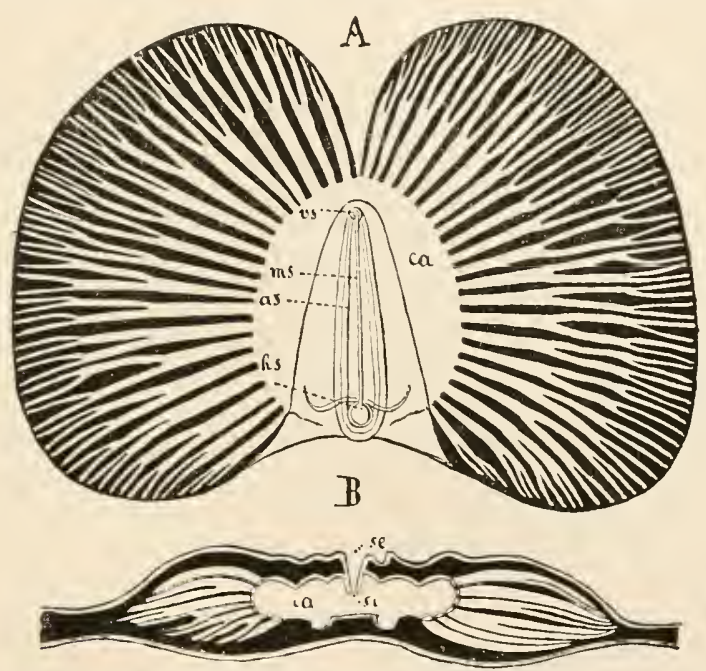

F1G. 338.-Tracheal mass of a dorsal plate of Scutigera coleoptera. A, from aloove; $D$, in transverse section through the inter-segmental fold of the dorsal plate; diagrammatic (after Haase). The trachex, which enter the air cavity $(c a)$ from both sides, are marked white. $2 s$, Anterior; $h s$, posterior stomatic aperture; as $(A)$ and $s e(B)$, outer; $m s(A)$ and $s i(B)$, inner stomatic slit.

tracheal bundles are not connected by anastomoses, Each stigma leads into a tracheal sac, whose base is produced in the form of pointed horns, into which the numerous but unbranched trachere enter. Branched tracher seem to occur only in the Glomeride.

The tracheal system of the Chilopoda is seen to be a secondary development from the fact that the trachere branch profusely, and that the trachere belonging to each stigma anastomose with one another transversely and longitudinally. Only in the Geophitide and Plutonium one pair of stigmata is retained on each leg-bearing segment, except the first and last. In the species Lithobius and in the Scolopendrider (except Plutonizm), beginning with the third trumk segment, a pair of stigmata is found with considerable regularity on cvery second segment. The last leg-bearing segment is here also withont stigmata. In Sentigerer and Henicops the stigmata 
belong to the trunk segments $1,3,5,8,10,12$ (and 14 when there are 15 trunk segments in all).

The tracheal system of Siutigere (Fig. 33s) is distinguished by many peculiaritics. The stigmata here are unpaired and lie in the dorsal middle line. Each stigma leads into an air sac, into which on each side ahout 300 closely packed, radially placed, branched tracheal tubes enter. This form of trachea is specially interesting, as perhaps helping to explain the origin of the so-called book-leaf trachere of the Arachnoidea, which will be described later.

The respiratory system of the Symphyla, which in other respects may be reckoned as very primitive Myriapodan forms, is much reduced. There are only 2 stiginata, and these are on the under side of the head under the feelers. This is the only case in the whole division of the Antemnata in which a pair of stigmata has been retained in the head. The branched trachere do not extend either into the legs and feeler's, or into the posterior region of the body at all.

In the Pauropola the tracheal system seems to be entircly degenerated.

\section{Hexapoda.}

Apterygota.-The tracheal system in a few Thysanura exhibits the original condition in so far that the longitudinal and transverse anastomoses are wanting (in a few species of Machitis, and in the Campodea, Fig. 339). In other Thysamura, however, they are present (Iapyx, Nicoletia, Lepisma, and a few species of Machitis). The most frequent number of pairs of stigmata seems to be 10 (Nicoletic, Lepisma, Lepismina); in this case two occur on the thorax and 8 on the abdomen. Machitis maritime has only 9 pairs of stigmata, 2 thoracic, and 7 abdominal. Iapyx is said to possess 11 pairs, viz. 7 on the abdomen, and-an arrangement standing quite alone among the Antennata-4 on the thorax. In Campodec the number is reduced to 3 pairs belonging to the thorax (the last pair possibly belonging to the first abdominal segment).

Pterygota (Fig. 340).- Transverse and longitudinal anastomoses appear to be everywhere present. Among the longitudinal anastomoses on each side one develops more than the rest, and at first sight it appears as if these tracheal trunks formed the central portion of the tracheal system, from which, besides numerous lateral branches penetrating the body, branches run to the stigmata, and there open outwardly. In the Diptera, Hymenoptera, and among the Coleoptera in the Hydrophitide and Lamollicomea, the trachere may widen ont in some places into large tracheal sacs without spiral crenulations, known as air sacs (Fig. 320, 1. 462). The number and arrangement of the stigmata vary within wide limits. In the same insect, at the same time, there are never more than 10 pairs of stigmata. Of these 10 pairs there is one pair on the mesothorax, one on the metathorax, and one on each of the first 8 abdominal segments.

The imagines of by far the greater number of insects are holopneustic, i.c. they possess many pairs of open stigmata, though the number of stigmata may be reduced, especially in the abdomen. The Aphaniptera alone have more than 2 pairs of stigmata in the thorax; in them there is one prothoracic pair, not met with in other adult Insecta. The tracheal system of the larve of insects exhibits interesting peculiarities, which are of great morphological importance.

1. The most primitive condition is found in those insects which undergo gradual metamorphosis, and whose larve live during all stages, like the imagines, on land (Orthopterc). These larre are holopneustic, and their tracheal system simply passes into that of the imago. Holopneustic larve may also occur in insects with complete metamorphosis, as in many Colcoptera (Maldeodermata), which thus appear to be a primitive group. 
2. In many Insects with incomplete metamor phosis the holopmeustic condition of the tracheal system is much altered in the larve by the adaptation to aquatic life. In the aquatic larve of the Ephomeride, Odonata, Plecoptera, for instance, there are 110 open stigmata, the tracheal system is completely closed, i. $\ell$. it is apneustic. The rudiments of the tracheal branches running from the stignata to the longitudinal trunks are, hoverer, present, but they are empty of air, and aljear

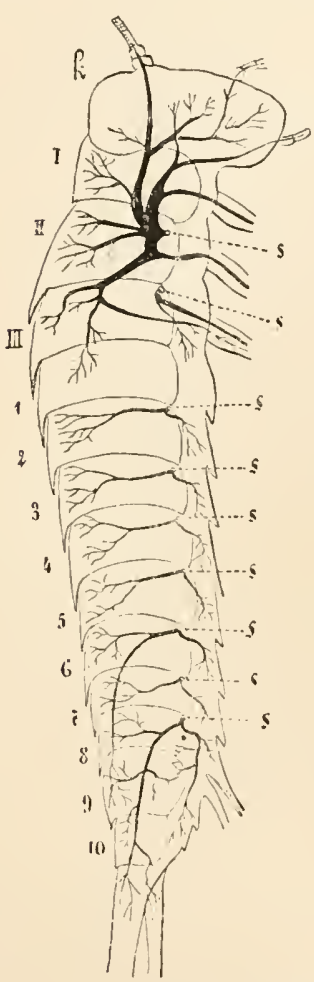

F1G. 339. - Machilis maritima, representing the traeheal systen of the right side (after Oudemans). $k$, Head ; $I, I I, I I I$, thoracic segments; $1-10$, abclominal segments; $s$, stig. mata.

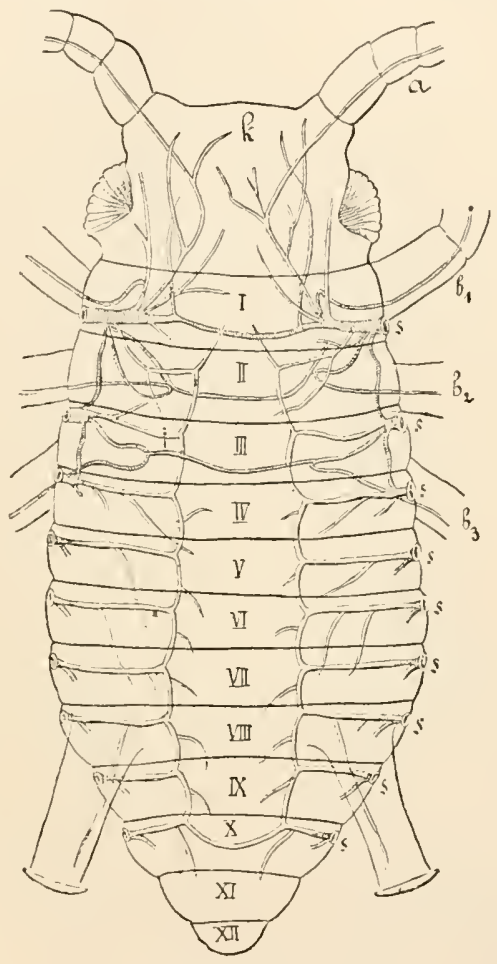

Fig. 340.-Half-developed larva of an agamous unwinged female of Aphis Pelar. gonii. The tracheal system seen from above (after Witlaczil). $l$, Head ; $a$, antemn; $I, I I$, $I I I$, segments of the thorax; IV-XII, segments of the abdomen: $b_{1}, b_{2}, b_{3}$, the 3 pairs of legs; $s$, the stigmata of the traeheal system.

in the form of strands (Fig. $343, v f$ ) ; these play an important part in the shedding of the larval trachere, and then for a time open outwardly. When the last larval stage passes into the imaginal stage these strands become hollow, and the tracheal system becomes holopneustic. All such larve breathe by means of tracheal gills.

3. In the majority of the larve of insects which undergo complete metamorphosis, the stigmata of those seginents which in the imago carry wings (meso- and metathorax) are closed, but on the other hand one pair of prothoracic stignata wanting in the imago is usually found. We cvidently have here a delayed differentiation of the trachere which suplly the wings and their musculature, referable to the absence 
of wings in the larve. The stigmatic strands belonging to these parts are present as rudiments. The tracheal system of these larve is peripneustic.

4. The tracheal system of peripneustic larve may be modified in various ways by adaptation to different modes of life: $(a)$ it may become apmeustic in larve inhabiting water, as in the larve of the Phryganide and Sialide, which breathe through tracheal gills. (b) By adaptation to life in water or parasitic life all the stigmata

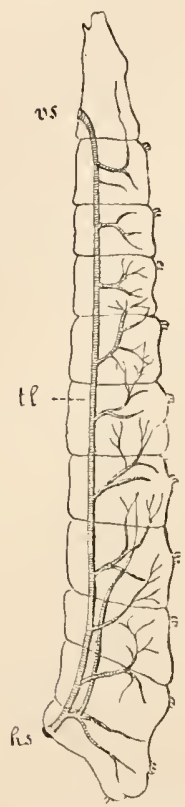

Fig. 341. - Right side of the tracheal system of a fly mag. got, seen from the side. $v *$, Anterior stigma; $h s$, posterior stigma; $t l$, longitudinal tracheal trunks. may remain closed in the larve except the last pair. The tracheal system is then called metapneustic. The larre then obtain air at the surface of the water or of the host, by means of this posteriorly placed pair of stigmata, which is often elongated like a siphon, or provided with other suitable structural adaptations. The larve of the water beetle and of many Diptera, which are aquatic or parasitic, are metapneustic. (c) There is occasionally besides the posterior an anterior prothoracic open fair of stigmata (Fig. 341). This amphipneustic tracheal system is found in many parasitic or half-parasitic Diptera larve (Oestridee, Asilidce), which stretch only their anterior and posterior ends beyond the medium which surrounds the rest of the body. The larval stigmata of the meta- and amphipneustic fly larvæ disappear during metamorphosis.

In all cases where the larva is not holopneustic, the stigmatic branches of the tracheal system are present as rudiments. We must distinguish between such first rudiments remaining latent during the larval period, and those rudiments of stigmatic branches which are found in the imagines of the various Insceta. The latter are the remains of stigmata which have disappeared. Several pairs of such stigmata are often found in the abdomen.

The peculiar arrangements of the tracheal system in insect larvæ show very clearly to what an extent special conditions of existence may influence the organisation of free-living larva.

\section{B. The Tracheal Gills (Figs. 342 and 343 ).}

Something has already been said about these respiratory organs of aquatic insect larva in the section on "wings." Tracheal gills, i.e. delicate membranous processes of the body into which trachea extend, are found not only in the larva of the Ephemeride, Trichoptera, and Sialide there mentioned, but also in the larve of the Plecoptera (Pertidee), Odonata, and the aquatic larve of a few species of Dipter, Hymenoptera, Lepidoptera, and Coleoptera. The tracheal gills of the Odonata are either external (Agrion) in the form of 3 branchial leaves on the last abdominal ring, or they are internal (Libellula, Eschna) in the form of folds in the rectum. In the latter case water is alternately drawn in and expelled through the anus. The tracheal gills of the larva of the Perliclee are very variously formed; they are pouch-shaped or tufted, etc, and occur at very different parts of the body. The same is the case with the tracheal gills which occur singly in the larva of Diptera, Hymenoptera, Lepidoptera, and Coleoptera. Larvæ which are provided with tracheal gills are 
apneustic. The tracheal gills, according to all observers, are respiratory organs, which have arisen independently of each other in various insect orders as adaptations to aquatic life. They are thrown off

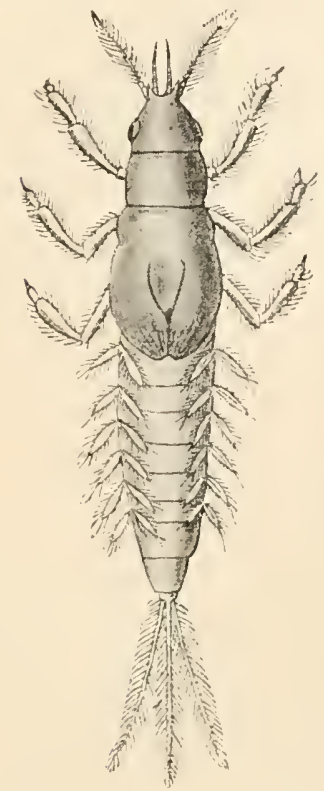

Fig. 342. - Ephemerid larva with two tracheal gills on each side of each $a b$ dominal segment, and with 3 caudal processes (cerci) (after R. Leuckart).

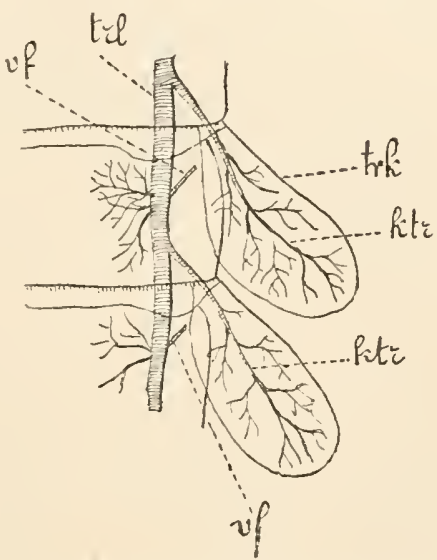

Fig. 343. - Right half of the middle abdominal segment of the larva of Baetis (Chloë) binoculatus with tracheal gills (after Palmen). $t r l$, Longitudinal tracheal trunks; $v f$, strand like threads of attachment of the longitudinal trunks to the integument (stigmatic strands); $k t r$, gill tracheæ; $t r k$, tracheal gills.

during the transition to the imaginal form in the Ephemeridce, Agrionidce, and Dipterce, but are retained in the imagines of the Perlidce, Aschnidle, Sialide, Lepidoptera, and Coleoptera.

\section{Sound-Producing Apparatus.}

It is well known that many insects can produce sounds. These sounds, which play many different parts in insect life, are principally produced-

1. By rapid vibrations of the wings (Hymenopterc, Diptera), and by the vibration of the halteres against the alulæ (Diptera).

2. By the vibration of leaf-like appendages in the tracheæ. These often lie in great numbers near the stigmata, and are made to vibrate during the respiratory movements of the animal by the inward and outward streaming of the air (Hymenoptera, Diptera).

3. By the rubbing together of rough uneven portions of the integument. The Acrididce stridulate by scraping their posterior femur 
like the bow of a fiddle over the projecting ribs of the upper wing. In the Locustidce and Gryllide only the males stridulate, by rubbing the rough basal portions of their wing cases against each other. In other insects sounds are produced by the rubbing together of other parts of the body.

4. In the singing Cicada also only the male can produce the wellknown shrill sounds. The sound apparatus is here somewhat complicated. It consists of a pair of drum-skins (thin elastic extensions of the cuticular skeleton) on the first abdominal segment, and of strong muscles moving these skins. The abdomen filled with air acts as a resounding apparatus. As a protection to the delicate drum-skins folds of the thoracic and abdominal cuticular skeleton arch over them from before and behind.

The sounds produced by male insects are calls for attracting the females.

\section{Sexual Organs.}

The sexes are separate in all Antennata. A comparative study of the sexual organs justifies us in giving the following general plan of the sexual apparatus. It consists of a pair of germ glands (ovaries in the female, testes in the male) which pass into paired duets, the latter opening separately. The sexual glands and ducts appear, as far as their ontogeny is known, to proceed from a paired mesodermal genital rudiment. Ectodermal invaginations of the cuticle are often connected with the ends of the ducts.

Since the ducts of the sexual organs in the Protracheatc are transformed nephridia, we may perhaps infer the same for those of the Antennata. There is, however, a considerable difference in the two cases, as the greater part of the ducts in Peripatus arise out of the ectoderm, while in the Antennata, on the contrary, they come from the mesoderm. But it must not be forgotten that in the Anmulata the greater part of the nephridium (nephridial duct) is of mesodermal origin

Sexual organs, which are paired throughout (as in the plan above sketched), are only found in reality in the Ephemeridce (Fig. 344, A). In all other Antennata there are unpaired portions of the sexual apparatus arising in various ways.

1. The two germ glands may fuse to form 1 unpaired germ gland, while the ducts remain separate either throughout their whole length or at any rate towards their ends, and always open externally through separate paired apertures. Such cases are found in the Diplopoda among the Myriapoda.

2. The germ glands remain paired. The ducts remain paired for the greater part of their course, only uniting to form a common terminal portion. This is the case in all Antennata except the Ephemeridee and the Diplopoda. 
In rare cases (Scolopendra) we find an unpaired germ gland and an unpaired dnct, into whose end, however, paired accessory organs (glands, receptacula seminis, vesiculet seminales) enter.

The unpaired portion may arise in very various ways.

$A$. In the male of certain Forficulide (Dermaptera) the ducts unite at one part of their course to form an unpaired sperm vesicle, from which the two ducts again as vasa deferentia separately run towards the two male genital apertures. One of these ducts, however, becomes reduced (Fig. $344, B$ ), while the other, as an mpaired ductus ejaculatorius, runs from the sperm vesicle to the outer aperture.

b. An unpaired invagination of the integument grows from without to meet the two ducts, so that these open externally as through an
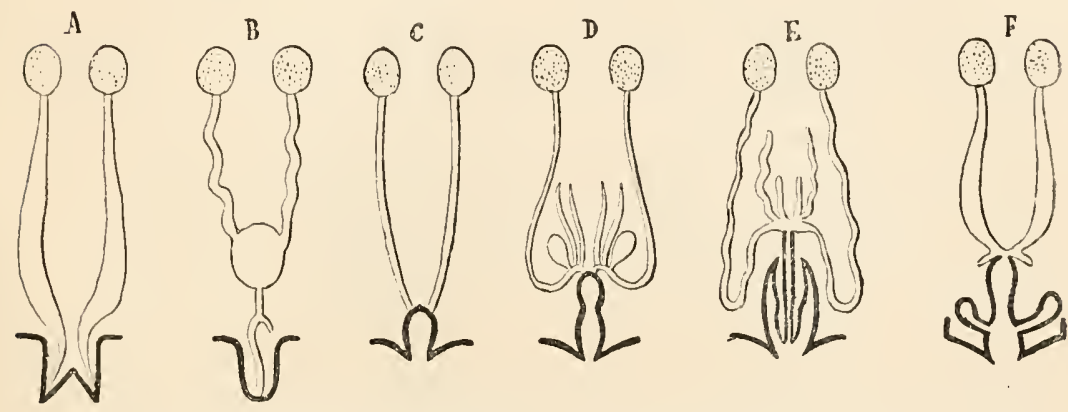

Fid. 344.-A-F, Diagrammatic representation of the sexual apparatus of various Insects. $A \cdot E$, Male organs. $F$, Female apparatus. The parts proceeding from invagination of the outer integument are indicated by thick black lines, A, Ephemerid. B, Forficula auricularia. $C$, Larva of Orthoptera. D, Edipoda (belonging to the Acricliide). E, Cetonia aurata (Coleopter( $)$ ). $F$, Aschna (Libellulid) (after Palmen).

unpaired terminal portion lined with a chitinous cuticle (Fig. 344, $(C-F)$. The 2 ducts may open into the unpaired terminal section either by two separate apertures or by a single aperture. This arrangement is found in the Apterygota, also in the Libellulide, Plecoptera, Orthoptera, lihynchota, and perhaps in other orders as well. Paired or unpaired accessory structures may appear in the terminal portion through secondary invaginations.

C. A second unpaired section is sometimes added to the unpaired terminal portion described under $B$; this section arises by the fusing of the two sperm ducts or oviducts throughout tracts of varying length to form one unpaired duct (ductus ejaculatorius, uterus, vagina, etc.), this unpaired duct enters the ectodermal invagination. This is probably the case in all the so-called higher insects (insects with complete metamorphosis).

The position of the outer genital apertures is very various.

In the Chilopoda among the Myriapoda the unpaired genital aperture lies in the penultimate body segment, i.e. in the genital segment, whose limbs may be transformed into genital appendages. 
In the Diplopoda and Pauropoda the two genital apertures lie behind the $2 \mathrm{~d}$ pair of legs, generally at the boundary between the $2 \mathrm{~d}$ and $3 \mathrm{~d}$ trunk segments.

In the Symphyla (Scolopendrella) the unpaired genital aperture lies on the 4 th trunk segment between the legs of this segment.
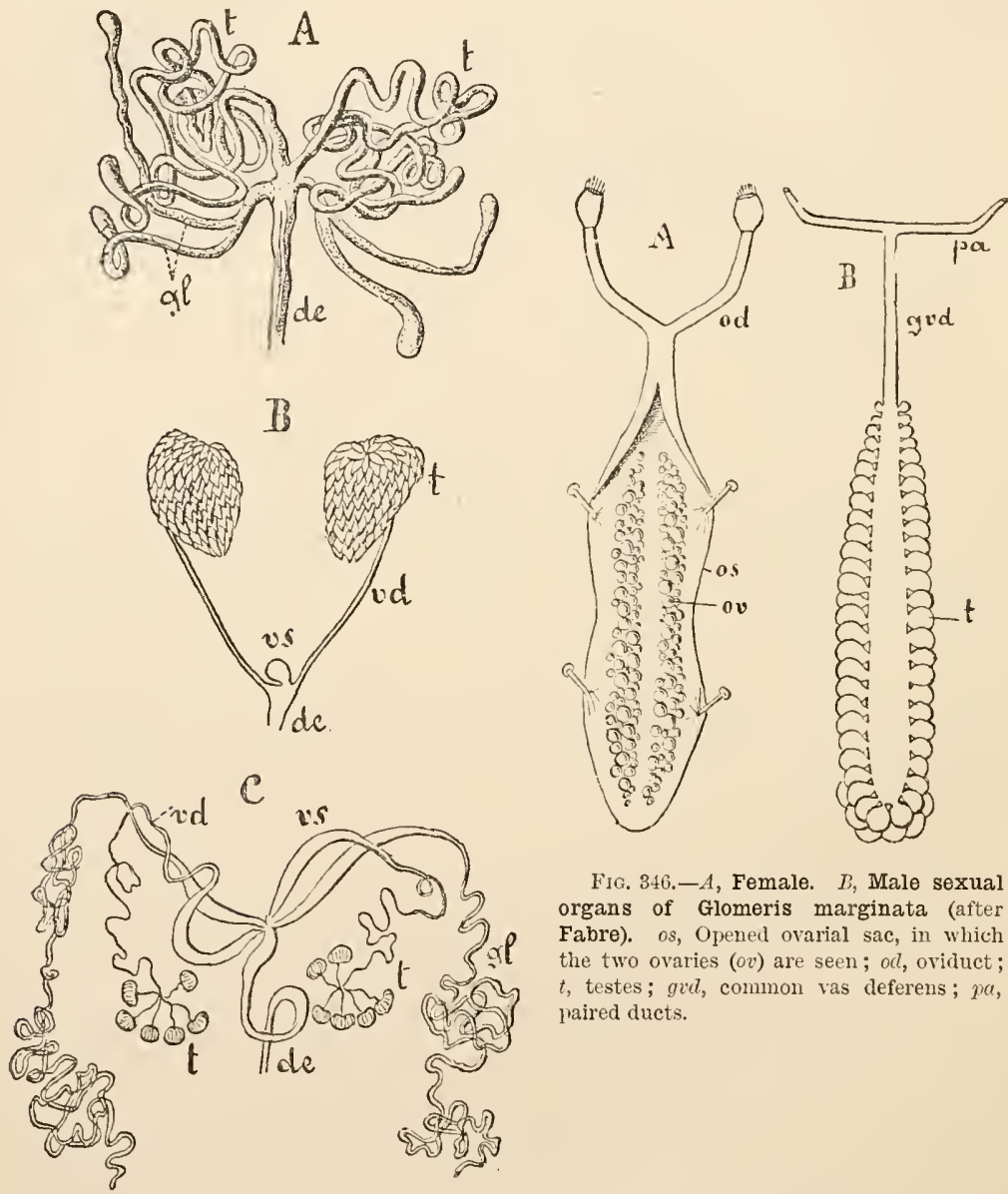

Fic. 346.-A, Female. $B$, Male sexual organs of Glomeris marginata (after Fabre). os, Opened ovarial sac, in which the two ovaries (ov) are seen; od, oviduct; $t$, testes; gul, common vas deferens; $p a$, paired ducts.

FIG. 345.-Inner male sexual organs. $A$, Of Melophagus ovinus. $B$, Of Acheta campestris. $C$, Of Melolontha vulgaris (after Carus and Gegenbaur). t, Testes; vd, vas deferens; $v s$, seminal vesicle; de, ductus ejaculatorius; $g l$, accessory glands.

In all Hexapoda the genital apertures lie at the end of the abdomen, in the male almost always behind the $9 \mathrm{th}$, in the female behind the 8 th (in the Ephemeridce 7 th) abdominal segment.

Accessory organs are almost always found connected with the ducts of the male and female sexual apparatus of all Antennata; the 
special arrangement of these is very varied. Single or paired sperm vesicles (vesiculæ seminalis), serving as sperm reservoirs, are often found in the male sex, either as invaginations of the ductus ejaculatorius or of the vas deferens. Accessory glands enter either the ductus or further back enter the vas deferens and mix a secretion with the sperm. Such glands occasionally yield a hardening secretion which encloses small masses of sperm in the form of capsules
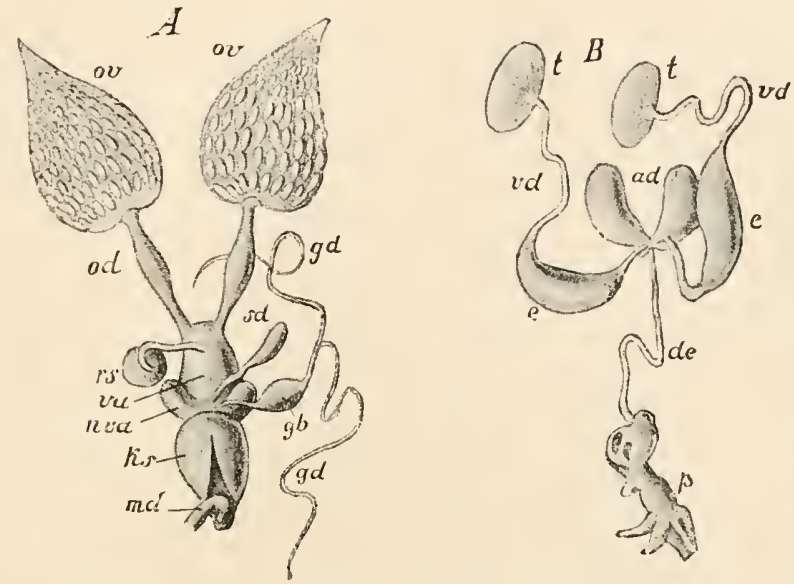

Fig. 347.-A, Female. B, Male sexual apparatus of the Honey-bee (queen and drone) (after R. Leuckart). ov, Oraries, consisting of numerous chambered orarian tubes; $v d$, oviducts; $r s$, receptaculum seminis ; va, ragina ; nva, accessory sac of the same; $k \mathrm{~s}$, bulb of the stinging apparatus ; nd, rectum twisted back and cut off; $s c l$, colleterial gland; $g \imath l$, poison glands; $g b$, poison vesicle; $t$, testes; $v d$, vas deferens; $e$, wider portion of the same; de, common ductus ejaculatorius ; $a d$, accessory glands; $p$, penis.

(spermatophores). The terminal section of the male sexual apparatus is often protrusible as a penis.

Special invaginations from the vagina serve as bursæ copulatrices for the reception of the penis during copulation, and as receptacula seminis for the reception and the preservation of the semen. In the Lepidnpterc (Fig. 348) the bursa copulatrix opens outward separately from the vagina, but is connected with the receptaculum seminis by a duct. The sexual apparatus often enters, close to the anus, the base of a common depression (cloaca). As in the male, so in the female, outer organs are formed by the integument of the last abdominal segments, and are brought into the service of the sexual apparatus as ovipositors, etc.

Colleterial or cement glands for attaching the eggs to foreign objects enter the vagina.

In most Diplopoda among the Myriapode the legs of the 7 th trunk ring are transformed into copulatory appendages.

The germ glands of the Hexapoda have still to be specially considered. The testes are, as has been ahready mentioned, almost always paired ; in the Lepidoptera 


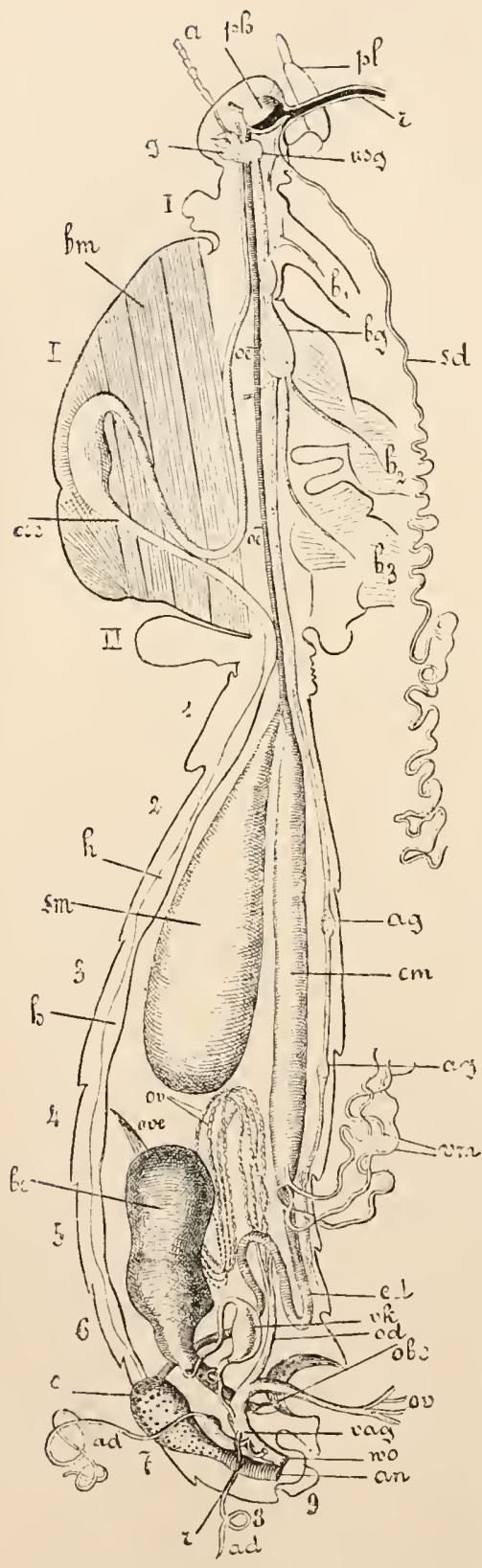

alone they may fuse to form an apparently muraired organ. Each testis consists of a smaller or greater number of blind tubes or testicle follicles; these, which are sometimes short, sometimes long and coiled, usually lie embedded in a common cnvelope. It may be accepter as a general rule, that where the testicle tubes are very long, they are few in number, and vice versâ. The Dipterce and Orthopteres may serve as examples of the two extremes. In the former (Fig. 345, A) there is on each side only one very long coiled testicle tube, in the latter there are often many hundred short tubes or follicles united into one mass $(b)$. The testis on each side also may fall into separate tubes or into separate groups of tubes $(c)$. Only one vas deferens is, however, found on each side, into this enter the testicle tubes united into one testis, or the separate testicle tubes, or the ducts of several groups of such tubes. Just as the testes consist of a varying number of long or short testicle tubes, so cach of the ovaries consists of a varying number of ovarian tubes, which together enter an oviduct. In each of these ovarian tubes (Fig. 349) we can distinguish three parts: (1) the terminal filament, (2) the terminal chamber, and (3) the actual ovarian tube, divided into chambers, this last is the largest.

FIG. 348.-Danais archippus (Lepidoptera) Female. Showing the anatomy after removal of the right half of the body. Lettering of the head: $a$, Antenna; $2 h$, pharynx; 27 , labial lalps; $r$, proboscis; $g$, brain ; $u s g$, infra cesophageal ganglion. Lettering of the thorax: $I, I I, I I I$, thoracic segments; $b_{1}, b_{2}, b_{3}$, the coxal joints of the 3 pairs of legs; bm, musculature; $a c$, arta cephalica with its swelling; $o e$, cesophagus; $b g$, thoracic ganglia of the rentral chord ; $s d$, salivary glands of one side, those of the other side cut off near their entrance into the common salivary duct. Lettering of the abdomen: 1-9, abdominal segments; $h$, heart; sm, so-called sucking stomach (food reserroir); cm, chilific stomach (mid-gut); $a g$, abdominal ganglia ; ed, hind-gut with colon $(c)$ and rectum $(v)$; $v m$, Malpighian vessels; or, ovarial tubes, those of the right side cut off; ove, tcrminal filaments of the ovaries; $b c$, bursa copulatrix; obc, its outer aperture; od, oviduct; $r(g)$, ragina ; wo, its outer aperturc ; $a d$, glandular appenlages of the vagina partly cut away; $\imath k$, connective eanal between vagina and bursa copulatrix with swelling (receptaculum seminis); an, anus (after Burges). 
The thin terminal filaments of the cgrg tubes are generally attacherl to or near to the dorsal ressel, and thus form a sort of suspencler. The elements of these are the same as those of the terminal chamber. The latter contains undifferentiated cell elements as remains of the ovarial rudiments, from which proceed (either in the embryo or the larva), on the one hand, the follicle epithelium of the ovarian tubes, and on the other, the ripening ecrgs and nutritive cells contained in these tubes. In the terminal chamber these cell elements remain undifferentiated, excepting when required for the renewal of the follicle epithelium, egos, and mutritive cells in the arlult insect. The third section which leads in to the oriduct has usually the form of a string of beuls. It contains the ripening eggs. The youngest and smallest lie nearest to the terminal chamber, the oldest and largest near the entrance into the oviduct. Two sorts of egg tubes have been distinguished: those without nutritive cells and those with mutritive cells. The most simple are the ovarian tubes without nutritive cells (Fig. $349, A$ ), which are found e.g. in the Orthopterce and Apterygota (excluding Campodea). Here in each tube there is a simple row of eggs from the terminal chamber to the oviduct. Between these consecutive eggs the tube appears constricted, and this causes the beaded appearance. Those parts of the egg tube which lie between two constrictions, each of which contains one egg, are caller ovarian chambers. In the ovarian tube with nutritive cells we must again distinguish two different types. In the one type (Fig. $349, B$ there is a regular alternation of egg chambers and nutritive chambers, each of the latter containing one or more nutri. tive cells, which serve for the nourishment of the ripening egc contained in the neighbouring chamber. The ovarian and

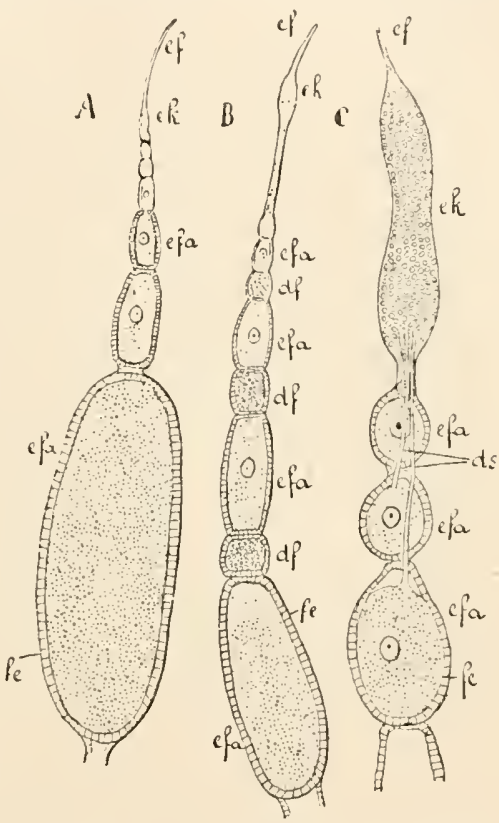

Frg. 349.-Various types of ovarian tubes, diagrammatic. A, Ovarian tube without nutritive cells. E, Egg tube with alternating nutritive and egg compartments. $C$, Ovarian tubes in which the terminal chamber (ek) is developed into a nutritive chamber, with which the developing eggs remain connected by means of strands $(d s)$; $f$, terminal filament; $e k$, terminal chamber ; efa, egg compartments or chambers; fe, follicle epithelium ; $a f$, yolk chambers. nutritive chambers may be distinctly separated externally by constrictions (Hymenoptera and many Colcoptera), or one nutritive and one egg chamber may lie in each section of the ovarian tube, which is externally visible as a swelling (Lepidoptere, Diptera). In the second type with nutritive cells, the actual tube consists (Fig. 349, $C$ ) of ovarian chambers only, the nutritive eclls here remain masser together in the large terminal chamber. The single eggs in the tube are united with the terminal chamber by connective strands, which convey the mutritice material to the eggs.

Egg cclls, nutritive cells, and the cells of the follicle epithelinm (cpithelium of the chambers of the ovarian tubes) are, according to their origin, similar elements, like the egg and yolk cells of the Platodes; division of labour learls to their later differentiation. Only a few of the numerous egg germs develop into eggs, the rest serving as envelopes and food for these few. 
In a few Thysanura (Machilis, Lepisma, and especially Iapyx) the ovarial tubes (5-7 on cach side) are placed in the abdomen in more or less strict segmental arrangement. Each independently enters one of the two oviducts, which run through the abdomen as straight canals. The two oviducts open externally by a shor't unpaired terminal piece; this common piece is said to be wanting in Nachilis, only the outer aperture of the two oviducts being in this case common to both. In Campodea and the Collembola the ovaries and testes on each side are simple tubes.

\section{Dimorphism-Polymorphism.}

In all insects the males and females differ, not only in the arrangement of their sexual organs, but also in various details of their outer organisation. This sexual dimorphism is in some cases very remarkable, and is generally connected with the absence of wings in the female, $e . \%$. in the scale insects (Coeeidce), in the luminous Colcoptera (Lampyridce), and in a few Bombyeina (Psyche, Orgyia). In the parasitic Strepsiptera the females are legless, wingless, eyeless, and feelerless, and are thus like maggots. They are viviparous, and remain, as long as they live, enclosed in their pupal envelopes, inside the host, i.e. in the abdomen of various Hymenoptera.

In colonial insects polymorphism arises in consequence of division of labour between the individuals of the colony. In many colonial Hymenoptera (bees and ants) only a few of the females (queens) are sexually mature and capable of reproduction. The great majority of the other females (worker's) have reduced sexual organs, and, among the ants, are wingless. Among the ants different forms of workers may appear (soldiers and workers proper). In the colonial Termites, and also among the Corrodentia, there are, besides the winged reproductive males and females, unwinged males and females with rudimentary sexual organs; these are again divided into castes (worker's, fighters), and vary in form accordingly.

\section{Development and Life-History.}

\section{A. The Metamorphoses of Insects.}

The greater part of the developmental processes, by means of which the adult insect is produced from the fertilised egg, take place within the egg-envelope. The time passed within the egg is the period of embryonic development. The organism which escapes from the egg-envelope, or in other words, is liatched from the egg, is always ahready very highly developed, and, apart from the fact that it las no wings, no mature sexual organs, and no compound eyes, is provided with all the typical insect organs in functional condition. It possesses a completely segmented body, antenure, mouth parts, thoracic limbs, developed nervous, digestive, and tracheal systems, the dorsal vessel, the body musculature, etc. It moves and feeds itself independently. It is called a larva. The larvæ of the insects are thus, when liatehed, far more highly developed than the larvæ of most other Invertebrata.

The changes which an insect undergoes before it becomes an adult sexually mature animal (imago) are extraordinarily various, and are conditioned by a whole series of co-operating factors, amoug which the most important are: (1) the degree of deviation of the imaginal form from the racial form ; $(2)$ the different modes of life and of places of habitation of the larve and imagines.

I. The Apterygota (Thysanura and Collembola) are considered to have retained their original wingless condition, and in other ways also appear to stand nearest to 
the common racial form of the Inseeta. The distinetion between larva and imago is here wanting. The young animal hatched from the egg resembles in all points the sexually mature form, which it reaches by simple growth accompanied by ecdyses and by complete development of the sexual organs. Both young and adult animals live on land and lead the same sort of life. Development without metamorphosis (Ametabole).

II. The adult insect is, apart from the complete development of the sexmal organs, principally distingnished by the possession of wings. In the simplest cases, in the Orthoptera, Corrodentia, Thysanoptera, and most Rhymehota, the larvæ lead the same kind of life as the imagines. They change gradually into the imaginal form, growing slowly through numerous ecdyses, while the wings arise and become more strongly developed each time the integument is shed. Gradual metamorphosis.

III. In the Cieada the modes of life of the imagines and the larve differ. The former live on trees and shrubs, the latter undergromnd on roots, and for this purpose possess strong fore-feet adapted for digging. The transition from the last larval stage to the imago must here be accompanied by a transformation of the fore-legs. Since an intermediate life between that on trees and on the earth is not easily conceivable, and since, consequently, any intermediate form betwcen ordinary feet and digging feet would be purposeless, the transition from the larva to the imago has become direct. The last larval stage is then what is called quiescent, i.c. the organisation of the imago devclops within the chrysalis at the expense of the accumulated reserve material. Gradual metamorphosis with pupal stage.

IV. The modes of life of the larve and imagines of the Ephemeride, Odonate, and Pleeopter' are very different. The imagines live on land, the larvie have become adapted to aquatic life. In the transition to the imaginal form the tracheal gills are generally thrown off (Ephemeride and many Libellulidee), the stigmata break through, and the tracheal system becomes holopnenstic. In other forms the metamorphosis and the growth of the larvæ oceur gradnally (in Chloë by means of more than 20 ecdyses). Incomplete metamorphosis (Hemimetabole).

In cases II. III. and IV. the transformation of the larva into the imago is, as a rule, accomplished very gradually. The still wingless larva hatched from the egg show's an external organisation like that which the Apterygota possess throughout life, even in their sexually mature condition.

V. Some Rhynehota are wingless (the Pedieulide, many bugs and the females of the plant-lice), and so are some Corrodentia (the Nallophaga), Orthoptera (various genera and species of Blattidce and Phasmidce), and Dermaptera. The wingless condition in these forms is derived, as opposed to that of the Apterygota; they are descended from wing-bearing Rhymehote, Corrodentic, Orthopterce, and Dermaptera, but their wings have been reduced in consequence of parasitism or of other habits of life. The larva hatched from the egg has not, therefore, to develop wings. This process is suppressed, and with it the metamorphosis. The young form becomes, by simple growth, the sexually mature imago. In contrast to the original ametabole of the Apterygota we have here an acquired ametabole.

VI. In contradistinction to the insects as yet mentioned, all others, i.e. the Neuroptera, Panorpata, Trichoptera, Lepidoptera, Diptera, Siphonaptera, Coleoptera, and Hymenoptera, are distingnished by so-called complete metamorphosis (holometabole). A wingless larva is hatehed from the egg, which indeed grows and moults, but, nevertheless, always retains the same organisation and undergoes no transformation during the larval stage. At the end of larval life, however, when the fat body has become strongly developed by rich nourishment, the larva moults and passes over into the differently formed pupal stage. The pupe are very variously shaped, often distinetly segmented with rudimentary extremities and wings, often 
with concealed extremities. They are generally quiescent, immovable, and not capable of taking food, and are often surrounded by special protective envelopescocoons. The best known cocoons are those of the Lepidoptera, which are spm by the caterpillars from the secretion of their spinning glands. At the end of pmpal life the envelope is opened and the imaginal insect (bcetlc, bntterfly, fly, ete.) issnes from it.

This complete metamorphosis evidently proceeds from an incomplete or gradual metamorphosis. The wingless larva adapts itself to various conditions of existence, or is provided by its parents with cxcessive nomrishment. It accmmmlates so much reserve material in its fat body that the further larval stages do not need to feed independently. By the smppression of numerons eedyses these successive larval stages are abbreviated into one stage, - the stage of the outwardly quiescent pmpa, within which the imago attains development at the expense of the reserve nourishment.

The larve of insects with complete metamorphosis vary moch in their organisation, each being adapted to its own special surromndings. Two principal groups can, however, be distingnished: (1) with feet, e.g. the larve of the Neuroptere, the "caterpillars" of the Lepidoptera, the larve of the Coleopterce and Trichoptera ; (2) without feet, maggot-like larve of the Diptera, larve of most Hymenoptera and Siphonapterc. The former by possessing legs are the least removed from the Thysanura-like larval form of other winged insects ; they move freely, and with few exceptions feed independently. Many are carnivorous, living either on land or in water ; many feed on plants, on the leaves (caterpillars) or roots (cockehafer grmbs). Among the Hymenopterc the larve of the Tenthredinide are vermiform, and like the butterfly caterpillars possess parapodia-like appendages on several abdominal segments in addition to the thoracic feet.

The modes of life of the fontless larve of the Dipterc and most IIymenopterc are very varied. They sometimes live free and are carnivorous, generally living then in water ; sometimes they arc parasitic in the bodies of other animals or in plant tissne; sometimes in putrefying matter, dung, ete, sometimes inside cases or cells which are filled with mutritive material; sometime they are fed by the adnlts, etc. etc. Headless maggots withont feclers or ocelli and with rednced month parts are distinguished from larve which have heads with these organs.

The larve of insects with complete metamorphosis are all originally peripnenstic. By adaptation to aquatic or parasitic life they may become amphipmenstic, metapucustic, or even apncustic, and in the last case may develop trachreal gills. The mouth parts of the larva may difier greatly from those of the imago. This difference is best known and most striking in the Lepidopterc, whose larve have masticating month parts, while their imagines have sueking month parts.

The more specialised the larva on the one hand and the imago on the other, and the greater the difference in organisation betwcen them, the more far-reaching naturally are the transformations by means of which during the pupal period the larval organisation becomes that of the imago. For instance, in the bee, the larva docs not pass direct into the pmpal stage, but first into the pre-pupal stage.

In certain Coleoptera several larval stages differing very much from one another are met with. The Coleopteran genus Sitaris (Fam. Neloidea) lives parasitically on a bee (Anthophore). The larve of this beetle, which are hatched from the egg, are active little animals with thoracic legs. They $l \mathrm{mrk}$ in flowers in order to spring mpon the bees coming to gather honey. They are thus carricd to the hive, where they seize npon the eggs of the bee as soon as these are laid in the honey of the cells, and devonr them. They afterwards moult and appear, after ecdysis, as metamenstic maggot-like larve with redneed feet, floating on the surface of the honey, the month placed below, and the posterior end on the surface. When the honey is 
cxhausted they pass into a pula-like stage, out of whieh, however, not the imago, lut a new larva emerges. Still furtlier juja-like stages of development then follow, till at last the final real pupa stage oceurs. Here we ean very elearly recognise, especially in the first two larval stages, the influence of various modes of life on the larve of one and the same animal.

Many Pteromalide (Hymenoptera) prass through a series of peculiarly shaped larval stages, which are as yet by no means explained. The larve live parasitically in the eggrs, larve, and pupe of other inseets, in whieh the P'teromatide lay their eggs ly means of an ovipositor, It is remarkable that the youngest larvie possess far less lighly developed immer organs than are usually found in the larre of other inseets.

The above is naturally but a very ineomplete description of this most interesting subject.

\section{B. The Embryonic Development of Insects.}

Hydrophilus, the water beetle, affords us a good illustration of this development.

The egg is a long oval, with pointed anterior and blunt posterior pole. The segmentation is that typical of the centrolecithal eggs, and leads to the formation of a blastosphere. In this blastospliere we ean distinguish a single superficial layer of small cells, the blastoderm, and, enveloped by it, the nutritive yolk with scattered nuclei.

The formation of the embryo proeeeds from one side of the blastosphere only, i.e. from the future ventral side, on which the blastoderm cells are higher than elsewhere. We may eall this portion of the blastoderm the embryonie rudinent. At an early stage we ean distinguish the boundaries of the segments, appearing externally as transverse streaks or lines. Anteriolly and posteriorly two longitudinal furrows appear, grow towards each other and unite, so as to mark off on the embryonic rudiment a peripheral portion, the lateral plates, from a eentral portion, the middle plate. The middle plate sinks below the surface, and so forms the floor of a ehannellike medio-ventral invagination, whose edges grow towards each other on each side. This invagination is represented in transverse section in Fig. $350, A$. Its edge is to be considered as the edge of the blastopore. How the lateral edges of this blastopore approach each other in the middle line and finally fuse with each other is illustrated by Fig. 352, $A, B, C$. After the closing of the blastopore the invagination becomes a medio-ventral longitudinal tube, over which the blastoderm of the former lateral plates spreads. From this invaginated tube proceed the mesodern and perhaps also the endoderm (epithelium of the mid-gut).

Even before the closing of the blastopore the rudiments of the embryonic en. velopes so common among insects, viz. the amnion and the serous envelope, alpear. They first appear as a fold of the blastoderm at the edge of the embryonic rudiment. This fold grows more and nore from all sides over the embryonic rudiment, finally covering it. The embryonic rudiment thus eomes to lie in the base of a cavity whose month, wide open at first, grows smaller and smaller by the growing and final closing together of the amnion folds; the final closing takes place over the anterior end of the embryonic rudiment. The tranverse seetion $B$, Fig. 350, shows the rising amnion folds, the transverse section $C$ shows them grown over the embryonic rudiment so as to form a continuous cover. In the surface views of Fig. 352 the folds are denoted by $\alpha f^{\prime}$ and $a f^{\prime \prime}$.

The cavity which is formed by the ammion is called the amnion cavity. Its roof, in correspondence with its origin, consists of 2 epithelial lamellæ, an inner one, which at the edge of the embryonic rudiment is continued into its blastoderm and represents the actual amnion, and an outer one, which at the edge of the embryonic rudiment is continued into the blastoderm of the whole remaining surface of the egg, and 

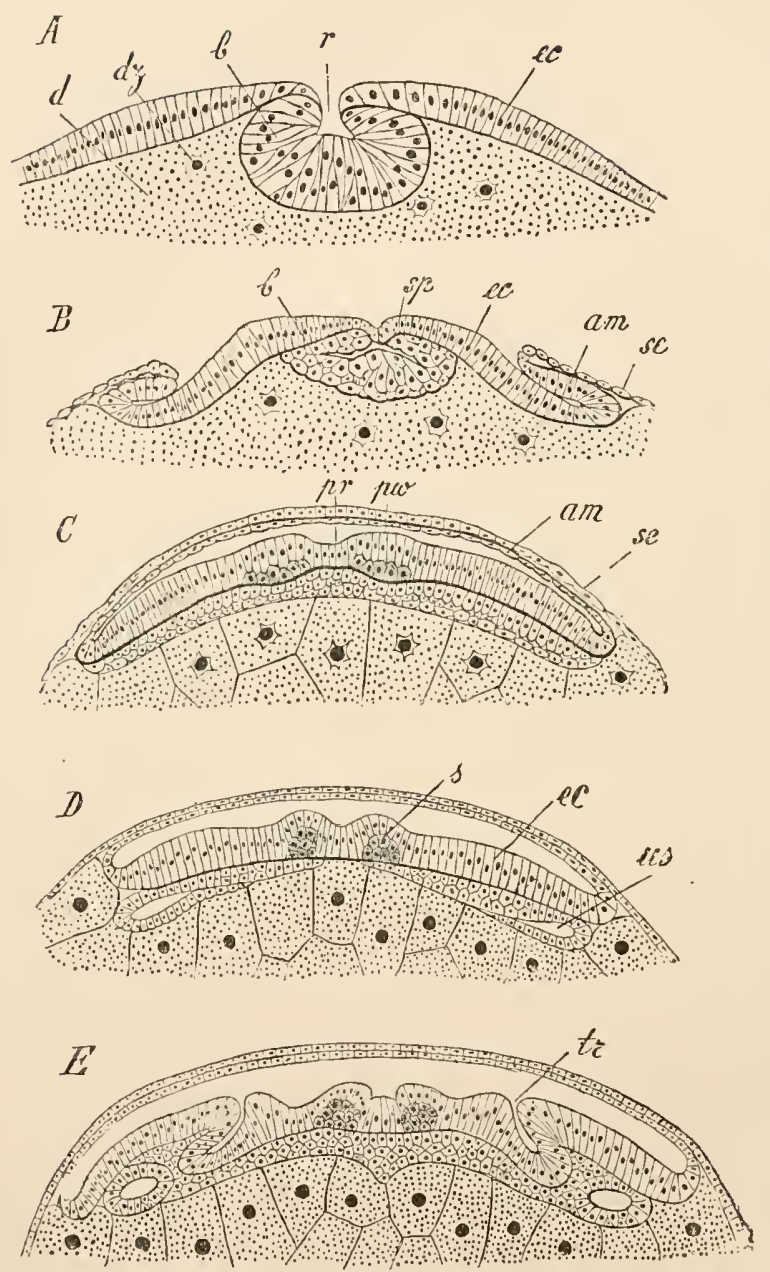

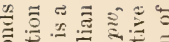

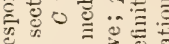

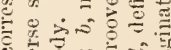

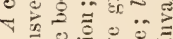

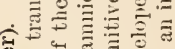

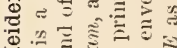

出

它

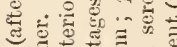

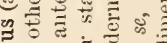

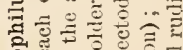

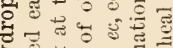

政

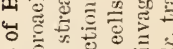

+ 药

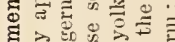

क्षे

$\Phi$

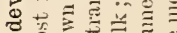

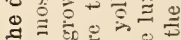

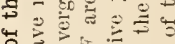

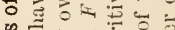

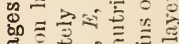

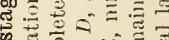

o

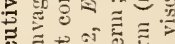

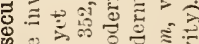

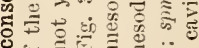

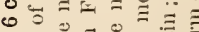

ส

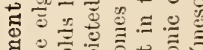

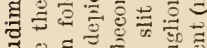

인

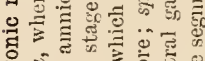

仓ัญ

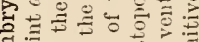

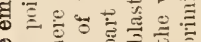

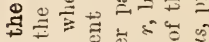

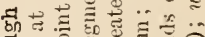

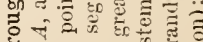

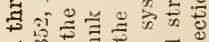

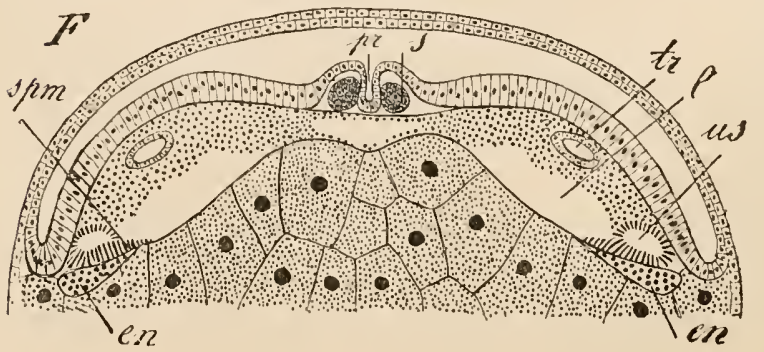

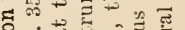

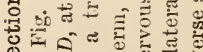

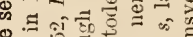

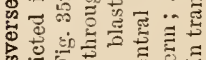
品

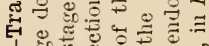

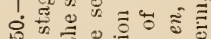

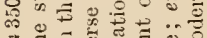
ङ

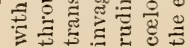


together with this represents an unbroken epithelial membrane, the serous envelope; this latter surrounds the whole egg with its embryonic rudiment and the amnion on all sides.

The amnion and the serous envelope have no share in the building up of the embryo. The latter develops exclusively out of the blastoderm of the embryonic rudiment and the invaginated tube, which we will call the germ streak. The blastoderm of the embryonie rudiment grows further and further dorsally at its peripheral edges, so that at last it envelops the embryo on all sides as ectoderm. Though somewhat out of its striet order, for the sake of elearness, this process as well as the fate of the amnion and serosa may be here illustrated by means of the following diagramatic transverse seetions. Fig. 351, A, represents the same stage as Fig. 350, F,
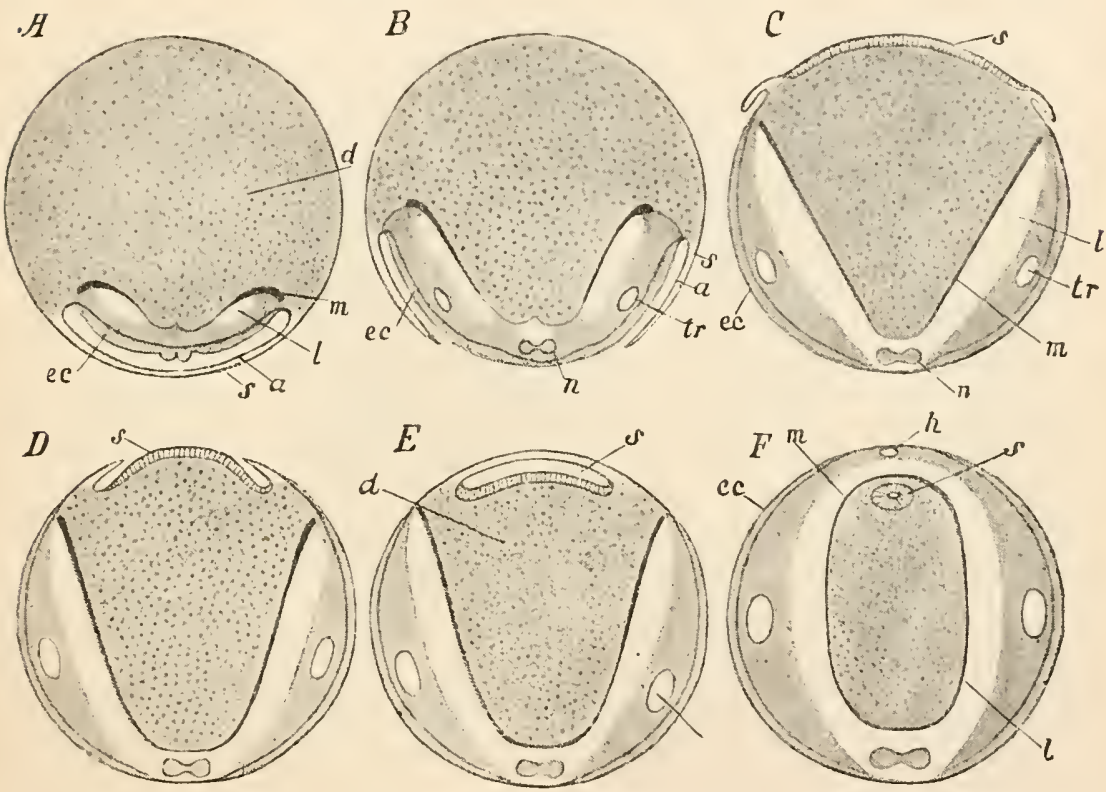

FIG. 351.-Formation of the dorsal tube (process of involution of the embryonic integuments) in Hydrophilus (after Graber and Kowalevsky). A, Transverse section through an egg, whose em.bryonic rudiment is still covered by the ammion $(\alpha)$ and serosa (s). $B$, Amnion and serosa having grown together in the middle line liave now torn open, drawing back on each side to form a fold. $C$, The foll, by the contraction of the serosa becomes more dorsal, $D$, The contracted serosa (dorsal plate) is being grown over by the fold. $E$, The dorsal tube has become closed by the growing together of the folds. $F$, The mid-gut is closed dorsally and has enclosed the dorsal tube (s). $\alpha$, Amnion ; $d$, nutritive yolk; $h$, heart ; $l$, colome ; $m$, rudiments of mid-gut; $n$, nervous' system ; $s$, serosa and the structures developed out of it, i.e. the dorsal plate and dorsal tube; $t$, principal tracheal trunk; $e c$, ectoderm.

but the position of the embryonie rudiment is reversed. In Fig. 351, $B$, we see the amnion and the serous envelope torn in the ventral middle line, after they had previously grown together. The amnion and the serous envelope thus form on each side a fold projecting ventrally. In $C$ the serosa has eontraeted and has beeome the so-ealled dorsal plate, whieh now eonsists of high eylindrieal epithelium. At the same time the ectoderm of the embryonic rudiments on both sides has extended 
further dorsally. In $D$ the fold (which proceeded from the amnion and a part of the serous envelope) has bent back and the dorsal plate has contracted still more. In $E$ the folds have overgrown the dorsal plate and their edges have grown together in the middle line. By this process the so-called dorsal tube comes into existence, and then sinks into the yolk. The ectoderm then joins over the dorsal side of the embryo. The tube of the mid-gut enclosing the yolk, together with the dorsal tube, is formed by the complete surrounding of the yolk by the endoderm. The dorsal tube is then bioken np with the yolk and reabsorbed within the mid-gut.

In other insects these processes take the same course. The most important difference is caused by the fact that from the first the yolk penetrates between the amnion and the serosa, so that the embryo with the ammion seems to be imbedded rleep in the yolk. The amnion remains comnected with the serosa at one place only. At the place where the two membranes adhere a rent arises later, through which the embryo together with the ammion are everted. In the Lepidopter a no dorsal tube is formed. The embryonic integuments are here simply constricted off from the embryo and serve as the first food of the young grub. This is jerhaps also the case in the Dipterce and Hymenopterce.

To return now to the developmental processes in the embryonic rudiment itself, we must go back to Fig. $350, B$. The blastopore here appears closed. The invaginated tube (germ streak) is compressed dorso-ventrally and has a slit-like humen. The transverse section $C$ of a still later stage shows us the germ-streak spread out flat nnder the ectoderm. On each side of the middle line the latter is thickened and bilaminar. The thickened prarts are transverse sections of longitudinal thickenings (primitive thickenings), between which there is a shallow median longitudinal groove (primitive groove). The deeper cells of the longitudinal thickenings form the two lateral strands, from which come the paired portions of the ventral chord. The socalled yolk furrowing las taken place at this stage, the yolk belonging to each nuclens being marked off, so that the whole is divided into irregular masses.

In the transverse section $D$ we see the germ streak divided into two lateral halves, a cavity appearing in each half; these cavities become those of the primitive segments. These appear more clearly demarcated in the transverse section $E$ of an older stage. They are the mesoderm cavities, which are repeated segmentally on each side. The remaining mesoderm of the germ streak has again united in the middle line. On each side near the primitive thickenings the ectoderm becomes invaginated to form a trachea. These tracheal rudiments appear segmentally in pairs, as is shown in the rentral surface view, Fig. 353, where their outer apertures (stigmata) are seen.

In the transverse section $F$ of a later stage the germ streak has drawn back somewhat from the surface of the yolk, and so gives rise to a cavity, which becomes the definitive colome and later joins the segmental cavities. The longitudinal trunks of the trachere are already formed, as shown in transverse section. The lateral strands of the nervous system have separated from the ectodcrm (hypodermis), and the primitive groove betwcen them has deepened. The fusing of its base with the lateral strands yields the transverse commissures of the ventral chord. We find in each side between the yolk and the segmental cavities a ncwly formed layer of cells. This cell layer represents the endoderm. Gradually extending all over the surface of the yolk, it becomes the epithelium of the mid-gut which encloses the yolk. The yolk is gradually absorbed later. The wall of the mesoderm cavities which is in contact with the endoderm follows the latter, as it grows over the yolk and yields, as the visceral layer of the mesoderm, the muscular wall of the mid-gut.

Long before all these processes have taken place the stomodæum has formed at the anterior (head) end of the embryonic rudiment and at the posterior end (in the terminal segment) the proctodæum, both being ectodermal invaginations which 
become comected with the mid-gut at a later stage. The Malpighian vessels arise as invaginations from the ectodermal proctodæum.

The limbs (Fig. 353) appear as paired bud-like outgrowths of the ectoderm and the subjacent mesoderm ; they appear between the primitivc thickenings of the nerve chord and the stigmata.

It is an important fact that besides the rndiments of the head and thoracic limbs, which alone are present in the adnlt animals, there occur at a certain stage distinct rudiments of abdominal limbs as well, those of the first abdominal segment being larticularly clear (cp. especially Fig. $353, B$ ). These rudiments degenerate later.

The origin of the two endodermal cell layers, which we saw appear in the transverse section (Fig. 350, $F$ ), is difficult to explain. At the stage at which this section is taken, the whole endodermal rudiment consists of two lateral cell streaks
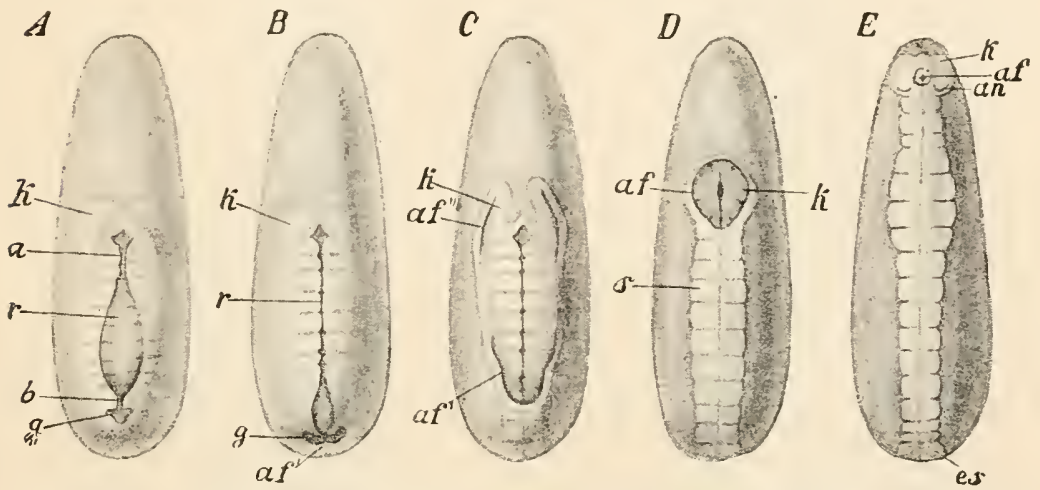

Fig. 352.-A-E, Ventral view of 5 stages in the development of Hydrophilus (after Heider). The anterior end is directed upward, $a$ and $b$, Points at which the blastopore first closes; af, edge of the aminion fold; $a f^{\prime}$, caudal fold; $a f^{\prime \prime}$, paired cephalic fold; $a n$, antenna; $e s$, terminal segment; $g$, pit-like invacination (rudiment of the amnion cavity); $k$, procephalic lobes; $r$, groove-like medio-ventral invagination; $s$, germ-streak covered by the amnion.

between the yolk and the two rows of mesoderm cavities. Anteriorly at the stomodieum and posteriorly at the proctodieum the two streaks pass into one another. At earlier stages the endoderm consists of an anterior and a posterior $\mathrm{U}$-shaped double streak. The limbs of the $\mathrm{U}$, which are very short to begin with, are at first directed backward in the anterior donble streak, and forward in the posterior streak; they gradually elongate till at last the two anterior limbs meet the two prosterior, and thus give rise to the two above-mentioned endodermal streaks. The first origin of the two U-shaped double streaks must probably be songht in the anterior and posterior cnds of the merlian invagination of the blastoderm of the embryonic rudiments, which elsewhere forms only mesoderm. The whole invagination would thus be the rudiment of the mesoderm plus the endoderm, and might be regarded as the gastrula invagination. In a transverse section of the still open anterior part of the invagination its base would represent the formative zone of the U-shajed endodermal streaks, while the lateral somewhat bulged-ont walls yield mesoderm. The mesodermal germ streak would thus be continued anteriorly in two lateral bulgings of a gastrula invagination, and we are therefore inclined to regard the mesodermal formation of insects as a modification of that manner of forming the mesoderm in which it proceeds from paired inraginations of the archenteron.

According to another view, the yolk with its nuclei represents the endoderm, and

VOL. I 
yields the epithelium of the mid-gut in a way which has not been more closely observed. Other observers, again, maintain that the whole enteric epithelium is formed from the proctodæum and the stomodæum.

It would perhaps be worth while to investigate whether the endoderm does not arise from the yolk cells by a kind of micromere formation, in a way similar to that in which the ectoderm is produced in many animals whose eggs contain much nutritive yolk (cp. p. 124, etc.)

The heart arises out of two lateral originally widely separated rows of mesoderm
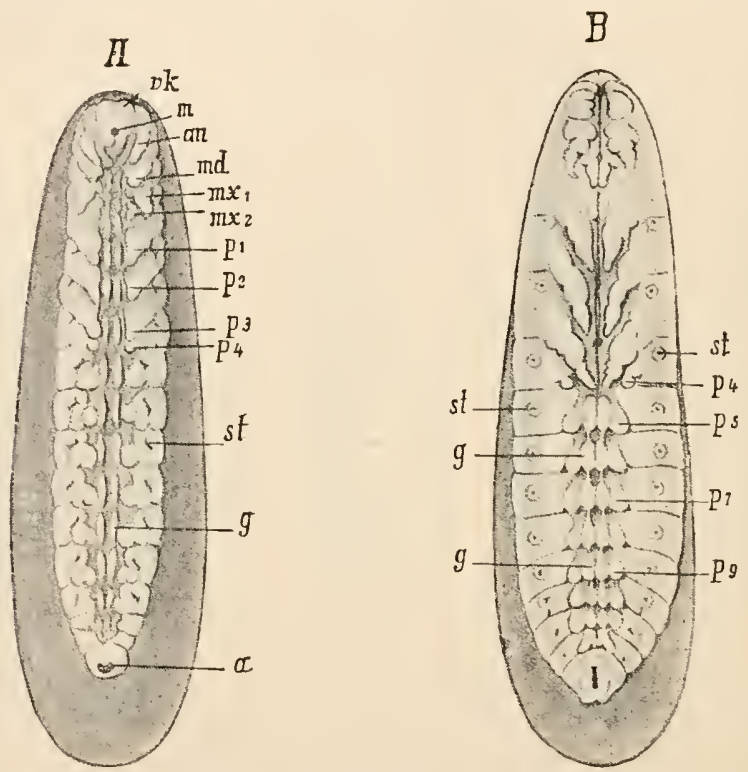

Fig. 353. $-A$ and $B$, Hydrophilus embryos with the rudiments of the extremities (after Heider). In the somewhat older embryo, $B$, the rudiments of abdominal feet, which disappear later, are distinctly seen. $a$, Anal aperture; $a n$, antenna; $g$, rudiment of the ventral ganglionic chain ; $m$, oral aperture ; $m d$, mandible ; $m x_{1}$, first maxilla ; $m x_{2}$, second maxilla (rudiment of the lower lip); $p_{1}, p_{2}, p_{3}$, thoracic legs $; p_{4}, p_{5}, p_{7}, p_{9}$, rudiments of the extremities of the first, second, fourth, and sixth abdominal segments; st, stigmata; $v k$, procephalon.

cells. Each row, by sending ont muscular processes, forms the side of a groore. The two sides move towards each other, uniting later in the middle line to form the cardial tube.

The brain arises, like the ventral chord, as two lateral ectorlermal thickenings (neural plates), which remain separate from each other for a considerable time, but from their first appearance are continuous with the lateral strands of the ventral chord. Besides this a second ectodermal invagination on each side takes part in its formation.

Opinions as to the development of the eyes in insects still differ very much. According to recent observations it appears probable that both the compound and the simplc eyes proceed from invaginations of the ectoderm, which become constricted off as vesicles, and only secondarily become connected with the optic portion of the brain (ganglion opticum).

The first alpearance of the sexual organs is not yet sufficiently investigated. 


\section{The Inner Processes in the Metamorphoses of Insects.}

In insects without metamorphosis or with gradual or incomplete metamorphosis the organs of the larva simply pass into those of the imago. There is no breaking ul' and disappearance of the larval organs, and no new formation of the imaginal organs, if we leave out of account the throwing off of tracheal gills and the formation of wings, compound eyes, and so on.

In insects with conplete metamorphosis the case is different. The larval organisation has here been alapted, independently of the imago, to special conditions of existence. A gradual continuous transformation of the larval organs into the often quite differently constructed organs of the imago, during which the different stages would feed independently, is inconceivable, since organs undergoing such complete transformations could hardly be capable of functioning. There are, further, numerous phenomena in the most various divisions of the animal kingdom which prove that organs which have functioned actively during larval life are only slightly capable of development and metamorphosis. They are more often reabsorbed or thrown off in the further course of development. We thus see why in insects with complete metamorphosis the transition from the larva to the imago almost necessarily takes place during a pupal stage, the pupa changing into the imago partly at the expense of the reserve nourishment accumulated by the larva, it being unable to acquire food for itself.

So as to understand the inner processes in the metamorphosis of the holometabolistic insect, we will take as an example the larva of Corethro plumicornis (Diptera, Tipularia). Nost of the larval organs here simply pass during metamorphosis into those of the pupa and of the imago. The larva, however, is footless and wingless. The rudiments of feet and wings form shortly before the pupal stage. Three pairs of ventral and 3 pairs of dorsal invaginations of the hypodermis appear and are callerl imaginal discs. In the bases of these invaginations outgrowths appear and grow continuously longer, while the invagination in which they lie deepens (Fig. 354). The outgrowths in the 6 ventral invaginations are the rudiments of the thoracic limbs, the outgrowths of the 2 posterior dorsal pairs of imaginal dises are the rudiments of the wings and halteres which thus lie hidden within the body, till they are protruded and attain devclopment. The muscles of the wings are already rudimentarily present in the embryo as cell strands, but they only begin to differentiate at the end of larval life.

The complete metamorphosis of some insects, especially of the Muscidce (e.g. Musca vomitoria), is accompanied by far more thorough transformations.

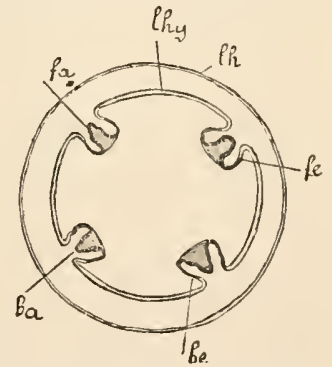

Fig. 354. - Rudiments of the imaginal discs in the larva of Corethra, diagrammatic. Invaginations ( $f e$ and be) of the larval hypodermis $(l h y)$, in whose bases the rudiments of wings $(f(t)$ and legs $(b a)$ arise; $l h$, chitinous integmment of the larva.

It must, first of all, be pointed out that the distinction between larval, pupal, and inaginal stages rests upon external phenomena. In the inner organisation the series of alterations is continuous; the larva on the one hand ahready possesses the rudiments of the imaginal organs, and in the pupa on the other, the larral organs only gradually disappear. Speaking generally the inner metamorphosis is such that the imaginal organs proceed out of parts of corresponding larval organs, which remain during larval life in an undifferentiated embryonic condition (formative centres); the portions which function during larval life gradually disappear during metamorphosis in proportion as the imaginal parts attain development. The amoboid blood corpuscles 
play an important part in the breaking up and disappearance of the larval organs; since they, as phagocytes (leucocytes) seize upon the elcments of the larval organs, and like amcebe take them into their protoplasm. The phagocytes thus laden with the wrecks of the larval organs and floating in the body cavity are themselves later turned into food for the developing imaginal portions, especially for the epithelia, into which they immigrate and break up.

At the cud of larval life there are found in the thorax imaginal dises similar to those in the Corethra larva. They here he, however (Fig. 355), much deeper in the body, and are connected with the hypodermis by means of long cell strands which arc hollow only in the neiglibourhood of the imaginal dises. The thoracie limbs and wings begin
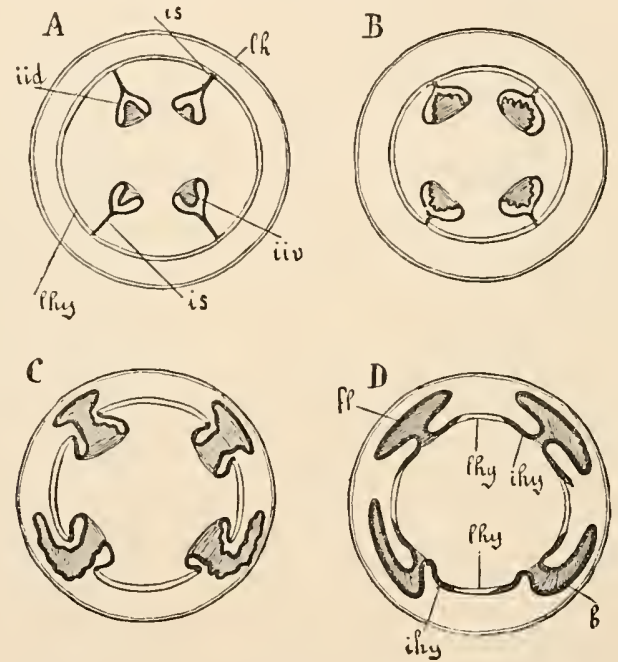

Fig. 355.-A, $B, C, D$, Diagrammatic representation of the development of the wings, legs, and the imaginal hypodermis of the Muscidæ from the imaginal discs of the larva during metamorphosis, diagrammatic transrerse sections. Ih, Chitinous integument of the larva, from which the subjacent hypodermis (lhy) has withdrawn; $i i d$, imaginal dises of the wings; $i$ iv, of the thoracic legs ; $i s$, the strauds connecting them with the hypodermis ; $f$, wing rudiments; $b$, leg rudiments ; ihy, imaginal hypodermis, spreading out in $D$ from the imaginal discs. The imaginal rudiments of the hypodermis are indicated by thick black outlines, the larval hypodernis by two thin parallel lines.

to form in just the same way as in Corethra as outgrowths within the imaginal sacs. At a later stage the processes of the imaginal dises which are connected with the hypodermis shorten and become hollow. The larval hypodermis then opens over the imaginal discs, which have moved outwards, and the feet and wings come freely to the surface. A new hypodermis layer spreads out from the imaginal dises over the thorax : this is the rudiment of the imaginal hypodermis, while in proportion as the imaginal hypodermis spreads, the larval falls to picces and disappears, in such a way that the larval and imaginal hypodermis taken together at all stages of the metamorphosis form a continuous cover round the body. While in the thorax the formation of the imaginal hypodermis proceeds from the imaginal dises, in the abdomen it proceeds (later than in the thorax) from the formative centres, the socalled islands, in the hypodermis. In each abdominal segment there are four larger and two smaller islands (Fig. 356). 
In trying to understand these metamorphosic processes we must always keep in view that ecdysis only affects the chitinous cuticle of the body, from which the subjacent hypodermis withdraws, secreting a new chitinous integument under the old one.

The formation of the head is rery peculiar. It is (as cesophagus and optic vesicles connected with the cesophagus) inraginated into the thorax, and is later evaginated anteriorly out of the thorax during the pupal stage. The anterior part of the cesophagus becomes in this process the neck, which after the evagination of the head connects it with the thorax.

Of the inner organs, the heart and the rudiments of the sexual organs seem to pass direct into the corresponding organs of the pupa.

The whole musculature of the larva except a few muscles of the second thoracic segment disappears. The imaginal comnective tissue and the greater part of the imaginal musculature are formed anew from the mesoderm

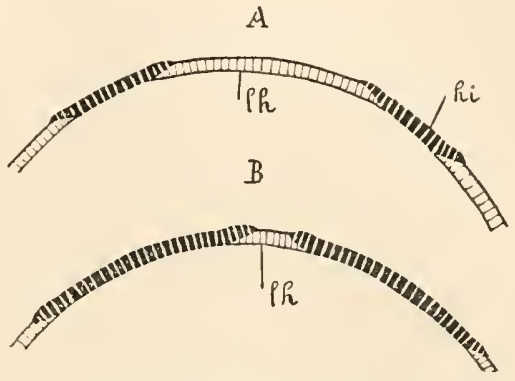

FIG. 356.- $A$ and $B$, Diagrammatic representation of the formation of the imaginal hypodermis in the abdomen of the Muscidæ, proceeding from the centres of the imaginal hypodermis (islands) (hi). $l h$, Larval hypodermis. elements, which early appear on the inner side of the imaginal discs. Perhaps the imaginal dises themselves yield, besides the thoracic hypodermis, the mesodermal layers belonging to them as well; this point, however, needs further investigation. Certain dorsal muscles of the second thoracic segment of the larva do not disappear, but are transformed during a temporary loss of their transverse striation into the wing muscles of the imago.

A large part of the larval tracheal system disappears. The imaginal tracheal system seems to be regenerated out of scattered cells and cell groups of the larval tracheal hypodermis. In the digestive tract the greater part of the mid-gut disappears. The imaginal mirl-gut forms anew out of persistent epithelial islands of the larval mid-gut. Parts of the fore-and hind-guts proceed direct from the fore- and hind-guts of the larva, while other parts arise out of circular islands or formative centres, the so-called imaginal rings, of the larval fore- and hind-guts.

The central portion of the nervous system (brain and ventral cliord) and probably also the beginnings of the larger peripheral nerves proceed by means of peculiar alterations and transformations from the corresponding parts of the larva.

The salivary glands of the larva fall to pieces and disappear, falling vietims to the leucocytes. The imaginal salivary glands are regenerated out of imaginal rings of the larval glands. The larval fat body is grarlually devoured by the leucocytes.

As already pointed out, the disintegration of the larval organs and the new formation of the imaginal organs do not belong to two distinct periods. Both processes go on side by side, so that in gencral there is"no discontinuity either in the outward form or in the structure of the organs. Physiological discontinuity prevails only in this sense, that the organs cannot, during transformation, perform their respective functions.

\section{Parthenogenesis-Cyclic Reproduction-Pædogenesis.}

Parthenogenesis occurs in many insects, and especially frequently in the plant lice (Phynchota) and in many Hymenoptera, though here also, most probably, it is not the only method of reproduction, but merely alternates with reproduction 
by means of fertilised eggs. In the colonial Hymenoptera only males come from unfertilised egos. In the Aphides, in summer, several generations of parthenogenetically reproducing, viviparous, generally wingless females succed one another. The last viviparous summer generation, however, produces winged males, and either winged or wingless females, whose fertilised eggs remain through the winter. From these latter the first summer generation of parthenogenetically reproducing females is again prodnced. The reproductive cycle of Phylloxerc is similar, with this distinction only, that all the generations are wingless, except that one out of whose eggs the sexual (male and female) generation is prodncerl. Phylloxerce is not viviparous.

The reproductive arrangements of Chermes are very peculiar; the males of this fir louse were, till recently, altogether unknown.

A wingless generation (I.) of Chermes abiet is hibernates on the fir-tree, and in the spring lays unfertilised eggs, ont of which a second winged generation (II.) of females is produced. Some of these females migrate from the fir to the larch. From their unfertilised eggs a third wingless generation (III.) of females comes, which winter in the larch, and in the spring of the second year lay unfertilised eggs, from which a fourth winged generation (IV.) of females comes. These fly back to the fir tree, and from their unfertilised eggs a fifth generation (V.) of males and females is developed.

The sixth generation (VI.) which comes from the fertilised eggs of this generation, again corresponds with the first hibernating generation with which we started. Some of the second winged generation (II.) of females, however, remained on the firtree. From the unfertilised eggs of these females which remained arises an unwinged generation of females, and these, again, are succeeded by a winged summer generation, and so on. In this second parallel series of generations of Chermes individuals which remained on the fir-tree, two generations of fcmales appear yearly, alternately winged and wingless, both reproducing parthenogenetically. Now it is probable that in this parallel series the generations do not thus reproduce (parthenogenetically) ad infinitum, but rather that, sooner or later, the parallel series re-enters the original series, so that then a generation of males and females again appcars. The different generations differ considerably from each other in form, even apart from the alternat. ing absence or presence of wings.

The Aphides afford an example of a kind of cyclic reproduction (heterogeny) in which the parthenogenetically reproducing females are viviparous. The unfertilised eggs here develop within the mother body. A similar phenomenon occirs in the Diptera (Cecidomyia) also; here, however, in the generation of females which reproduces parthenogenetically, the germarium which corresponds with the ovary becomes mature very early, i.e. in the larval stage. The unfertilised eggs are here developed within the larval body ; thus, in the cycle of reproduction of Cecidomyia, an imaginal generation reproducing sexually by means of fertilised eggs alternates with several generations of parthenogenetically reproducing viviparous larve. This special kind of heterogeny is called Pædogenesis. In one species of Chironomus also the pupa may occasionally lay eggs, which develop just in the same way as the fertilised eggs of the imago.

\section{Development of the Myriapoda.}

The embryonic derelopment of the Myriapoda, as far as it is known, does not greatly differ from that of Insecte. Embryonic envelopes, however, do not appear to form.

When the young Myriapoda are hatched, they are either provided with the definitive number of segments and legs, as is the case in the Scolopendridce and Geophitidce (Chitoporla), or they possess a smaller number, to which the missing 
ones are gradually added posteriorly during the many moults undergone hy the animal. The young of the Seutigeride and Lithobiudce (Chilopoda) have 7 pairs of legs. The number then increases to 15. The young Diplopoda (Fig. 357), on the contrary, have only 3 pairs of feet on the 3 anterior trunk segments, and a few posterior segments still limbless. They thus recall the type of the Insect larre. New segments gradually appear posteriorly and the number of legs increases. After each moult the number of rings is greater ; the increase generally takes place very irregularly, so that (c.g. Polydesmidce) stages with $7,9,12,15,17,18,19$, and finally 20 rings, succeed one another. From the above we see, firstly, that a sort of metamorphosis takes place in many Myriapoda, and, secondly, that the body there differentiates from before backward, a point which can no longer be made out in the Insecte.

\section{Phylogeny.}

Of the Antennata now living, the Symphyla, perhaps, stand nearest the common racial form. Yet even they are one-sidedly developed, and many of their organs, and above all, the tracheal system, by no means show a primitive arrangement. From the common racial form of the Antennata, the Myriapoda branched off to the one side, and the Hexapoda to the other. The different orders of Myriapoda perhaps developed polyphyletically, while for all Hexapoda we can assume one common racial form, resembling the now

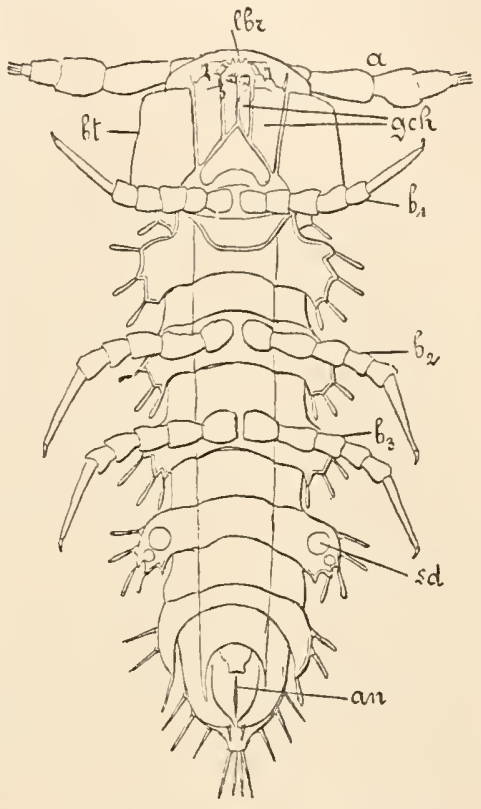

Fig. 357.-Larva of Polydesmus complanatus, just hatched (after $\nabla$. Rath). $l b r$, Upper lip; $a$, antenna; $b t$, sides of the head (cheeks); gch, gnathochilarium; $b_{1}, b_{2}, b_{3}$, the three pairs of legs of the larva; $s \bar{d}$, glands (saftdritsen); an, anus. living Apterygotc, and especially the Thysanura. There is thus no special reason for considering the Apterygota as originally winged insects, which became sexually mature at progressively earlier stages of development, and finally at a larval stage. At least one reason against such a supposition is the occurrence of the protrusible vesicles in the abdomen of the Thysanura, which is present in the Myriapoda (Lysiopetalidce and Symphyla), but almost entirely wanting in the Pterygota, only one pair appearing temporarily on the foremost abdominal segment in the embryo.

The racial form of the Pterygota is to be derived from the Apterygota-like racial form of all Hexapoda, from which the various orders of insects have been produced. These have of course developed independently of one another. Those orders, however, whose members undergo a gradual or incomplete metamorphosis, have retained the original characteristics to a larger extent than the rest. Of the remaining orders, again, it is the Lepidoptera, Hymcnoptera, and Diptera which are furthest removed from the racial form, and which reach the highest development among the Insecta.

Regarding the relation of the Antennata to the Protracheata, there can be no 
doubt that the two classes are racially comnected, and that Periputus has, far more than any member of the whole class of the Antemnata, retained the original Annulatan characteristics.

\section{Review of the most important Literature.}

\section{Myriapoda.}

\section{Anatomy.}

J. Bode. Polyxenus lagurus de Gecr. Ein Beitrag zur Anatomie, Morphologie und Entwickchungsgesehichtc der Chilognathon. Diss. und in: Zeitschrift $f$. d. gesammt. Naturwisscnsehaften. 1877.

Léon Dufour. Recherches anatomiques sur le Lithobius forficatus ct la Seutigera lincata. Ann. seiences nat. Tome II. 1824.

Hugo Eisig. Monographie der Capitelliden des Golfes von Neapel. Berlin, 1887. (Contains observations on the morphology of the coxal, spinning, and salivary glands, and of the nephridia of the Myriapoda, Hexapoda, and Protracheata.)

L. Fabre. Reeherches sur l'anatomic des organes reproducteur's ct sur le déreloppement des Myriapodes. Annales seiences nat. 4\%. Zool. III. 1855.

H. Grenacher. Ueber dic Augen einiger Myriapoden. Arch. f. mikr. Anatomie. $18 \mathrm{Bd} .1880$.

Erich Haase. Das Respirationssystem der Symphylen und Chilopoden. Zool. Beiträge von A. Schneider: 1 Bd. 1884.

Robert Latzel. Die Myriapoden der östemeichisch-ungarischen Monarchie. Erste und zweitc Hälfte. Wien. 1880-1884.

George Newport. On the organs of reproduction and the development of the Myriapoda. Philos. Transact. Roy. Soc., London, 1841 ( $\mathrm{f}$. also Ann. Mragaz. Nat. History. $1^{0}$. VIII. 1842).

The same. On the structure, relations, and development of the nerious and eireulatory systems. Ibid. 1843.

Otto von Rath. Beiträge zur Kenntniss der Chilognathen. Dissertation. Bonn, 1886.

Friedr. Stein. Ueber dic Geschlechtsverhältnisse der Myriapoden, etc., in Müller's Archiv. Jahrg. 1842.

See also works of Newport, Stein, Plateau, Voges, Sograf, Humbert, Chatin, Karlinski, Meinert, Haase, Brandt, Koch, Gervais, MacLeod, Packard, Ryder, Scudder, Savigny, Tömösváry, Wood-Mason, Heathcote, Brandt.

\section{Ontogeny.}

E. Metschnikoff. Embryologic der doppelfüssigen Myriapoden (Chilognatha). Zeitschr. f. wiss. Zool. $24 \mathrm{Bd} .1874$.

The same. Embryologisches übcr Geophilus. Ilid. $25 \mathrm{Bd} .1875$.

\section{Hexapoda.}

\section{Anatomy.}

G. Ernst Adolph. Ucber Insektcnflügel. Nova Acta K. Lcop.-Carol. Deutseh. Akad. Naturforscher. 41 Bd. 1880.

Blanchard. "Insectes" in Règne animal dc Curier. 
F. Brauer. Systematisch-zoologisehe Studien. Sitz.-Ber. math-naturwiss. Klasse k. Akad. Wiss. $91 \mathrm{Bd}$. 1 Abth. Wien, 1885.

Eduard Brandt. Numcrous trcatises (in German) on the nervous systems of different insects in: Horce societatis entomologice rossiece. Vols. 14 and 15 1879.

E. Burgess. Contributions to the anatomy of the milk-ueal butterfly (Danais Archippus). Anniv. Memoirs Boston Soe. Nat. Hist. 1880.

Burmeister. Handbueh der Entomologie. Berlin, I. 1832; II. 1838, 1839.

Justus Carrière. Die Sehorgane der Thiere, vergleichend-anatomisch dargestellt. Münich und Leipzig. 1885.

Carl Chun. Ueber den Ban, die Entwiekelung und physiologisehe Bedeutung der Reetaldrüsen bei den Insekten. Abhamul. Senkenb. Naturf. Gesellseh. Frankfurt a. H. $10 \mathrm{Bd} .1875$.

Léon Dufour. Recherehes sur les Hémiptères, les Orthoptères, les Hymenoptères, les Nevroptères et les Diptères. Mém. Acad. de sienees. Paris, Tome IV., 1833 ; VII., 1841 ; XI., 1851. See also numerous monographs in the Annales des seienees naturelles.

V. Graber. Ueber den propulsatorischen Apparat der Insekten. Areh. f. mikr. Anat. 9 Bd. 1873.

The same. Die tympanalen Sinnesapparate der Orthopteren. Denkschr. math.naturwiss. Klasse Akad. Wisseneh. $36 \mathrm{Bd}$. Wien, 1875.

The same. "Die Insekten." 2 Theile, in Naturkräfte. 21 and 22 Bd. IIinich, 1877.

The same. Die ehordotonalen Sinnesorgane und das Gehör der Insekten. Areh.f. mikr: Anatomie. $20 \mathrm{Bd} .1882$.

Battista Grassi. I progenitori dei Hiriapodi e degli insetti. 7 treatises from 1S861888 in the publications of various Italian Acadamies and Societies, relating chiefly to the Apterygota and Scolopendrella.

H. Grenacher. Untersuehungen über das Sehorgan der Arthropoden. Göttingen, 1879.

F. Grosse. Beiträge aur Kënntniss der Hallophagen. Zeitsehr. f. wissensch. Zoologie. $42 \mathrm{Bd} .1885$.

E. Haase. Ueber Adominalanhänge bei Hexapoden. Sitz.-Ber. d. Gesellseh. naturf. Freunde in Berlin. 1889.

G. Hauser. Physiologisehe and histiologisehe Untersuehnngen über das Gernehsorgan der Insekten. Zeitschr. f. wissensch. Zoologie. $34 \mathrm{Bd} .1880$.

F. E. Helm. Ueber die Spinndrïsen der Lepidopteren. Zcitschr.f. wissenseh. Zoologie. 26 Bd. 1875.

Bruno Hofer. Untersuehungen über den Bau der Speieheldrüsen und des dazu gehörenden Nervenapparates von Blatta. Nova Acta K. Leop.-Carol. Akad. Naturforscher. $51 \mathrm{Bd} .1887$.

K. Jordan. Anatomic und Biologie der Physapoda. Zeitschr. f. wiss. Zoologie. $47 \mathrm{Bd} .1888$.

Fr. Leydig. Zum feinern Ban der Arthropoden. Müller's Arehiv. 1855. Besides the text-books of Histology, many other classical works on the histology of the Tracheata and on their sensory organs.

Joseph Heinrich List. Orthezia eataphraeta. A monograph. Zeitschr.f. wissenseh. Zoologie. $45 \mathrm{Bd} .1887$.

John Lubbock. Monograph of the Collembola and Thysanura. Ray Society, London. 1873.

The same. Origin and Metamorplosis of Insects. Macmillan. 1890.

P. Lyonet. Traité anatomique de la ehenille, qui ronge le bois de saule. La Haye. 1762. 
J. MacLeod. La strueture des trachées ct la circulation péritrachéenne. Brussels, 1880.

Meinert. Anatomia Forficularum. Dissert. I. Copenhagen, 1863.

H. Michels. Beschreibung des Nervensystems von Oryetes nasieornis":im LarvenPuppen-und Käfcrisustandc. Zcitschr. f. wissensch. Zoologic. $34 \mathrm{Bd}$.

Newport. "Insecta," in Cycloperdia of anatomy and physiology. Vol. II. 1839.

J. T. Oudemans. Beiträgc zur Kenntniss der Thysanura und Collembola. Berlin, 1858. Holländische Ausgabc: Amsterdam, 1857.

J. A. Palmén. Zur Morphologie des Tracheensystems. Helsingfors und Leipzig, 1877.

The same. Ucber paurigc Ausführungsgängc der Gcsehlechtsorgane bei Insehtcn. Helsingfors, 1884.

W. Patten. Eyes of Molluses and Arthropods. Mitth. Zool. Station $\approx u$ Neapel. 6 Bd. 1886.

F. J. Pictet. Reeherehes pour servir à l'histoire et à l'anatomie des Phryganides. Geneva, 1834.

Réaumur. Mémoires pour servir à l'histoire des Inseetes. Paris. 12 vols. 1734. 1742.

J. C. Savigny. Mémoires sur les animaux sans vertèbres. 1 Partie. 1 faseieule. Paris, 1816.

Emil Schindler. Beiträgc zur Kenntniss der Malpighi'sehen Gcfüsse der Insckten. Zeitschr. f. wissensch. Zoologic. $30 \mathrm{Bd} .1878$.

A. Sommer. Ucber Hacrotoma plumbea. Beiträge zur Anatomic der Poduriden. Zeitschr.f. wisscnsch. Zool. $41 \mathrm{Bd} .1885$.

Joh. Swammerdam. Historic inseetorum generalis. Utrecht, 1669.

The same. Bijbel der natuure. Lugd. Bat. 1737-1738. Bibel der Natur. 1752.

Strauss-Dürkheim. Considérations générales sur l'anatomic comparée des animaux artieulés ct anatomie deseriptive du Melolontha vulgaris. Paris, with Atlas, 1828.

E. Witlaczil. Zur Anatomie der Aphiden. Arb. Zool. Instit. zu Wien. 4 Bd. 1882.

The same. Zur Morphologie und Anatomie der Coceiden. Zeitsehr. f. wissenseh. Zoologie. $43 \mathrm{Bd}$. 1885-1886.

The same. Die Anatomie der Psylliden. Zeitsehr.f. wiss. Zoologie. $42 \mathrm{Bd} .1885$. Comprehensive, but chiefly either systematic or biological works of Bonnet, Rösel von Posenhof, Ch. de Geer, Kirby and Spence, Ratzeburg, O. Heer, Taschenberg, Jäger, Westwood, and others.

Names of other authors, given without arrangement: Plateau, Gerstäcker, Landois, Kirbach, Langhoffer, Haase, Graber, Breitenbach, Walter, Liénard, WoodMason, Panl Mayer, Leon, Geise, Osc. Schmidt, Will, Lenckart, F. Dahl, H. von Wielowiejski, Emery, Forel, Engelmamn, Simmermacher, Koestler, Spichardt, Packard, Kraepelin, Berger, Flögel, Dietl, Zimmermann, Cholodkovsky, Dewitz, Korsehelt, Fanssek, Landois, Clans, v. Siebold, Pagenstecher, Hanin, A. Dohrn, F. Mïller, Adler, Cattie, Krancher, Grenacher, Hickson, Tichomiroff, Vayssière, Riley, Meinert, Scudder, Leydig, Schiemenz, Grassi, Beauregard, Wedde, Balbiani, Sehneider, Redtenbacher, Niall and Denny, Audouin, Westwood, Wagner, Lacaze-Duthiers, Stein, Nicolet, Gerstfeld, Brullé, Lubbock, Semper, Kölliker, Claparède, Rathke, Hensen, Lespès, Rabl-Riickhard, Grobben, Platean, Carlet, Dimmock, Bolles Lee, Kniippel, Ruland, Malpighi, Suckow, Loew, Targioni-Tozzetti, Owsjanikoff, Joh. Mrüler, Brandt, Dareste, Serville, T. de Charpentier, L. H. Fischer, Pictet, Hagen, Kirby, Curtis, Kaltenbach, Lichtenstein, Becher, O. Taschenberg, Herold, P. and Fr. Huber, de Saussure Brunner v. Wattenwyl. 


\section{Reproduction and Development.}

H. Ayers. On the development of Oceanthus niveus and its paresite Teleas. MYem. Boston Soc. Nut. Hist. Vol. III. 1884.

F. Brauer. Betrachtungen über die Verveandlungen der Insekten im Sinne der Descendenz-Theorie. Verh. d. k. k. zool.-botan. Gesellsch. in Wien. $19 \mathrm{Bd}$. 1869.

N. Bobretzky. Ueber die Bildung des Blastoderms und der Keimbläter bei den Insekten. Zeitsehr. f. wissenseh. Zoologie. $31 \mathrm{Bd}$. 1878.

L. Dreyfus. Ueber Phylloxerinen. Dissertation. Wiesbaden. 1889.

M. Fabre. L'hypermétumorphose et les moeurs des Mélö̈des. Ann. sciences natur. $4^{0}$. Tol. VII. 1857.

Ganin. Beiträge zur Kenntniss der Entwickelungsgeschichte der Insckten. Zeitschr. f. wissensch. Zoologie. 19 Bd. 1869.

v. Graber. Ueber die Polypodie der Insektenembryonen. Morph. Jahrb. $13 \mathrm{Bd}$. 1888.

B. Grassi. Studi sugli Artropodi. Intorno allo sviluppo delle api nell'uoro. Atti Acad. Scienze nat. Catania. $3^{0}$. Vol, XVIII. 1884.

Berthold Hatschek. Beiträgc zur Entwickelungsgeschichte der Lepidopteren. Jenaische Zeitschr. $11 \mathrm{Bd} .1877$.

K. Heider. Ucber die Anlage der Keimblätter von Hydrophilus piceus L. Abhandl. der Preuss. Akad. d. Wissensch. Berlin, 1885-1886.

O. and R. Hertwig. Die Cölometheorie. Jena, 1881.

A. Korotneff. Die Embryologie der Gryllotalpa. Zeitschr. f. wissensch. Zoologic. $41 \mathrm{Bd} .1885$.

A. Kowalevsky. Embryologische Stuclien an Hürmern und Arthropoden. Mém. Acad. impér. Pétersbourg. $7^{0}$. Vol. XVI. 1871.

The same. Beitrüge zur Kenntniss der nachembryonalen Entwickelung der Musciden. I. Zeitsch. f. wissensch. Zoologie. $45 \mathrm{Bd}$. 1887.

R. Leuckart. Die Fortpflenzung und Entwickelung der Pupiparen. Abhandl. d. Naturf. Gesellsch. zu Halle. 4 Bd. 1858.

The same. Die ungesehlechtliche Fortpflanzung der Cecidomyialarven. Arch. für Naturgesch. 1865.

E. Metschnikoff. Embryologische Stulicn an Insekten. Zeitschr. f. wissensch. Zoologie. $16 \mathrm{Bd} .1866$.

W. Patten. The development of Phryganids, with a preliminary note on the development of Blatta germanica. Quart. Joum. Mier. Science. N.S. Vol. XXIV. 1884.

J. van Rees. Leiträge zur Kenntniss der innern Metamorphose von Musca vomitoria. Zool. Jahrb. von Spengcl. Abth.f. Anat. und Ontog. 3 Bd. 1888.

Viallanes. Recherehes sur l'kistologie des Inscktes et sur les phénomènes, qui accompagnent le développement postembryonnaire de ces animaux, in Annal. Scienc. natur. $z 0 o l .6^{0}$. Vol. XIV. 1882.

Alfred Voeltzkow. Entwiekelung im Ei von Mnsea vomitoria und: Melolontha vulgaris. Ein Beitrag zur Entwiekelung im Ei bei Insehten. Arb. aus dem zool.-zoot. Institute Wü̈rzburg. 9 Bd. 1 Heft. 1889.

N. Wagner. Beitrag zur Lehre von der Fortpflanzung der Insektenlarven. Zeitschr. f. wissenseh. Zoologic. $13 \mathrm{Bd}, 1860$.

Aug. Weismann. Die Entwickelung der Dipteren im Ei. Zcitschr. f. wissensch. Zoologie. $13 \mathrm{Bd} .1863$.

The same. Die nachembryonale Entwickelung der Musciden. Zeitschr. $f$. wissenseh. Zoologic. 14 Bd. 1864. 
The same. Die Metamorphose der Corethra plumicornis. Zeitschr. f. wissensch. Zoologie. $16 \mathrm{Bd}$. 1866.

Emanuel Witlaczil. Entwickelungsgeschichte der Aphiden. Zeitschr. f. wissensch. Zoologie. $40 \mathrm{Bd} .1884$.

Other authors: Brauer, Ganin, Pagenstecher, Metschnikoff, Blochmann, Dreyfus, Fabre, Balbiani, A. Brandt, Biitschli, Dewitz, Dohrn, Graber, O. r. Grimm, Kölliker, Lenckart, Melnikow, P. Mayer, A. S. Packard, Tichomiroff, Zaddach, Rathke, Robin, Henking. 


\section{CLASs III. Arachnoidea sive Chelicerota-Spider-like Articulata.}

\section{Systematic Review.}

Order 1. Scorpionidæ (Fig. 359, p. 512).

The body is divided into a compact unsegmented cephalo-thorax and a long segmented abdomen. In the abdomen again a thick and broad pre-abdomen of 7 segments is marked off from a long slender post-abdomen of 5 segments. The terminal segment of the latter carries a poison sting. On the ventral side of the $2 d$ abdominal segment there is on each side a comb-like appendage. The jaw-feelers (chelicere) and jaw-palps (pedilalps) are provided with pincers. The pedipalps are leg-like, with large pincers. There are 4 pairs of book-leaf trachex (lungs), whose stigmata lie on the ventral side of the $3 d$ to the 6 th abdominal segments. Euscorpius, Buthus, Androctonus.

\section{Order 2. Solpugidæ (Fig. 358, p. 511).}

Head separate. Thorax of 3 segments, hind body eylindrical, of 10 segments. Cheliceræe with pincers, pedipalps long and leg-like. Tubular trachere. Stigmata in pairs on the 1st thoracie, and $2 \mathrm{~d}$ and $3 \mathrm{~d}$ abdominal segments. Gulcodes, Solpuga.

Order 3. Pseudoscorpionidæ (Chernetidæ) (Fig. 360, 1. 513).

Cephalo-thorax unsegmented or with two transverse furrows, abdomen broad, flat, of 11 segments. Neither poison stings nor caudal cerci present. Cheliceræ and pedipalps like those of the Scorpionidce. Tubular tracher. Two pairs of stigmata, on the $2 \mathrm{~d}$ and $3 \mathrm{~d}$ abdominal segments. With spimning glands. Small animals. Cherncs, Chelifer, Obisium, Chthonius.

\section{Order 4. Pedipalpi (Thelyphonidæ) (Fig. 364, p. 519).}

Cephalo-thorax unsegmented, distinctly marked off from the lind body. The latter flattened, consisting of 11-12 segments. Cheliceræe claw-shaped. Pedipalps large, ending either in claws or pincers. First pair of legs with flagellate ends, like feelers. Two pairs of book-leaf tracher, whose stigmata lie on the ventral side of the $2 \mathrm{~d}$ and $3 \mathrm{~d}$ abdominal rings. Thclyphonus (last 3 abdominal segments form a truncated portion clearly marked off from the rest of the abdomen and carrying a long jointed caudal cercus). Phrynus.

Near the Pcdipalpi are perhaps to be classed the small and insufficiently known divisions of the Tartaride and Hicrothelyphonile.

\section{Order 5. Phalangidæ.}

Cephalo-thorax unsegmented, hind body of 6 segments, compact, applied along its whole breadth to the cephalo-thorax. Cheliceræ pincer-like, pedipalps leglike. Legs often extraordinarily long and thin. Tubular trachere with one pair of stigmata which lies ventrally at the junction of the cephalo-thorax and abdomen. Without spinning glands. Phalangium, Leiobunum, Gonylcptus.

\section{Order 6. Cyphophthalmidæ (often placed as a family of Order 5).}

Cephalo-thorax unsegmented, abdomen of 8 segments. Of the psendoscorpionid type. Chelicere and pedipalps like those of the Phalangidce. Tubular tracher. Cyphophthalmus (without spimning glands, with one pair of stignata on the ventral side of the 1st abdominal segment). Gibboccllum (spiming glands at the base of the 
abdomen behind the sexual aperture ; 2 pairs of stigmata on the $2 \mathrm{~d}$ and $3 \mathrm{~d}$ abdoninal segments) (Fig. 372, p. 529).

\section{Order 7. Araneidæ-Spiders.}

Both cephalo-thorax and abdomen unsegmented, the latter large and egg-shaped. Abdomen joined to the cephalo-thorax by a short narrow stalk, 4 to 6 pairs of spinning mammillæ at the end of the abdomen. Cheliceræ claw-like with poison glands. Pedipalps leg-like, terminal joint in the male transformed in a peculiar manner into an organ for transmitting the semen in copulation (Fig. 377, p. 535). Tracher either exclusively book-leaf, or book-leaf and tubular at the same time.

\section{Sub-order 1. Tetrapneumones.}

With 4 book-leaf trachex, without tubular trachex. The 2 pairs of stigmata, ventral, behind the base of the abdomen. Generally 4 (in Atypus 6) spinnerets. Mygale (Avieularia, Fig. 374, p. 531), Cteniza, Atypus.

\section{Sub-order 2. Dipneumones.}

With 2 book-leaf tracheæ whose stigmata lie at the base of the abdomen, and with tubular tracheæ emerging through an unpaired (less frequently paired, e.g. Dysderidce) stigma behind those of the book-leaf trachere. The unpaired stigma of the tubular trachere is generally moved far back, so that it lies in front of the 6 spinnerets. This sub-order includes most of the web-spinning spiders. Fam. Dysderidce (2 stigmata for the tubular tracheæ): Dysdera, Segestria. Fam. Salti grada: Saltieus, Attus. Fan. Citigrada (Lyeoside): Lyeosa, Tarantula. Fam. Laterigrada: Mieromsnata, Philodromus, Xystiens. Fam. Tubitelaria: Dictyna, Tegenaria, Agelena, Argyroneta, Drassus, Clubiona. Fam. Retitelaria: Linyphia, Theridium, Pholcus. Fam. Orbitelaria: Epeira, Zilla, Meta.

\section{Order 8. Acarina-Mites.}

Abdomen fused with cephalo-thorax. Body unsegmented. Month parts adapted for biting, or piercing and sucking. Respiratory organs (tracheæ) either present or absent. Many Mites are parasitic.

a. Mites provided with tracheæ:-Fam. Trombidiide: Trombidium. Fam. Tetranyehide: Tetranyehus. Fam. Hydrachnide: Atax, Hydraehna, Hydrodoma. The sub-families of the marine Halacaridce: Aletes, Halaearus without tracher. Fam. Bdellides: Bdella. Fam. Oribatides: Oribata, Leiosoma. Fam. Gamaside : Gamasus (Fig. 361, p. 514), Uropoda. Fam. Ixodida: Ixodes, Argas.

b. Mites without tracheæ:-Fam. Tyroglyphidee (cheese Mites): Tyroglyphus. Fam. Dermaleiehidce: Listrophorts, Analges. Fam. Sareoptidce: Sarcoptes. Fam. Demodicidce: Demodex. Fan. Phytoptide: Phytoptus.

\section{Appendage to the Class of the Arachnoidea. The Linguatulidæ (Pentastomidæ)}

Body vermiform, generally flattened, and ringed externally. No oral appendages. Two pairs of movable hooks near the mouth. Without sensory organs, tracheæ, Malpighian vessels, or diverticula of the mid-gut. Male aperture in front, behind the mouth ; fcmale aperture at the posterior end of the body. Parasites, Pentastomum, P. taenioides (Fig. 378, p. 537). Parasitic in the nasal and throat cavities and in the ceplalic sinus of the dog and wolf. The embryos, enclosed in their egg envelopes, reach the exterior with the nasal mucns. If they are taken into the intestine of a rabbit or a hare (or of a few other mammals) the embryos become free, pierce their 
way through the enteric wall and enter the liver or lungs. They liere become encysted and undergo a remarkable metamorphosis, passing through many moults; the final result is a larva which has been named Pentastoma denticulatum. This larra finally breaks through its cyst and mores about. If it in any way (nost often with the flesh of its host) reaches the month and throat of the definitire host, it chooses its future place of location, and throngh a series of monlts develops into the adult Pcrtastomum.

\section{Outer Organisation.}

\section{A. The Body.}

If we compare the body of the Arachnoidea with that of the Antennatu, the most important difference that strikes us is that in the

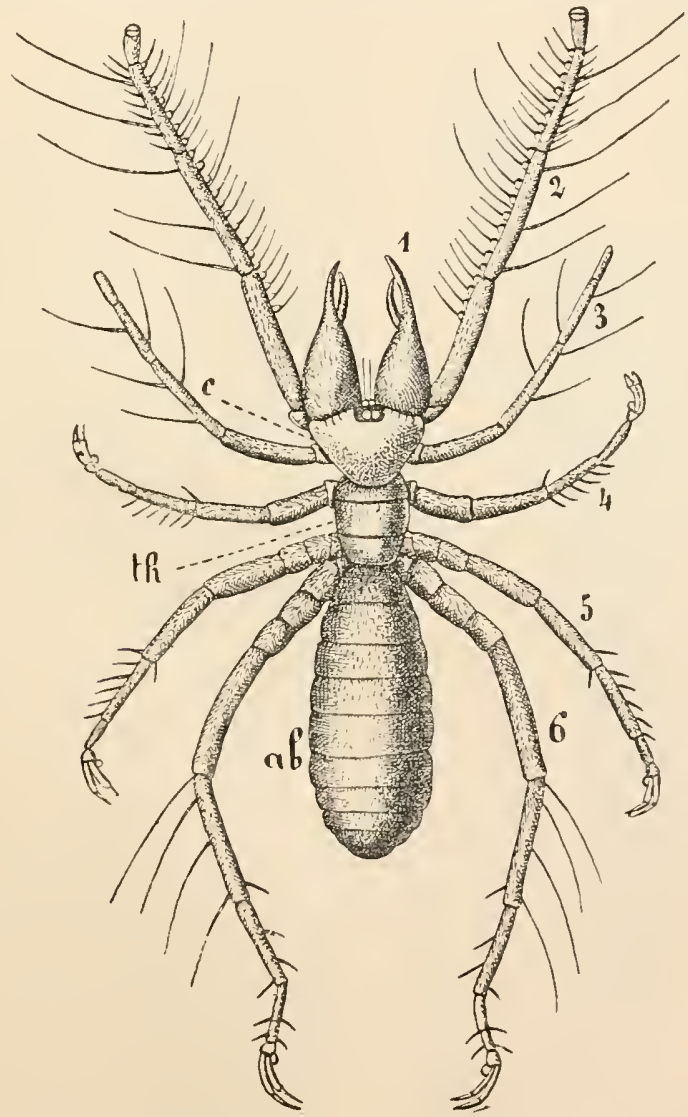

Fig. 35S.-Galeodes Dastuguei \& , natural size. 1-6, The six pairs of extremities ; 1, cheliceræ 2 , pedipalps ; $c$, head ; th, the thorax of 3 segments ; $a b$, the abdomen (after L. Dufour).

former no head distinctly marked off from the thorax, or, what is the same thing, on thorax separated from the head, can be distinguished. 
In the body of the Arachnoidea we find almost always a number of anterior segments, probably $\bar{\tau}$, fused to form a generally unsegmented cephalo-thorax. Following upon this cephalo-thorax there is an abdomen consisting of a varying number of separate or fused segments, which may again fuse with the cephalo-thorax, as is the case in the Acarina and Linquatulide(?) and thus the body appears neither segmented nor divided into regions. We thus, within the class of the Arachnoidea, have not only fusing of segments and an obliteration of segmentation, but also a progressive concentration of the whole body; there can be little doubt that the Arachnoidea are no exception to the rule that the more richly and completely segmented the body is the better has it retained the primitive arrangement. The segmentation is richest in

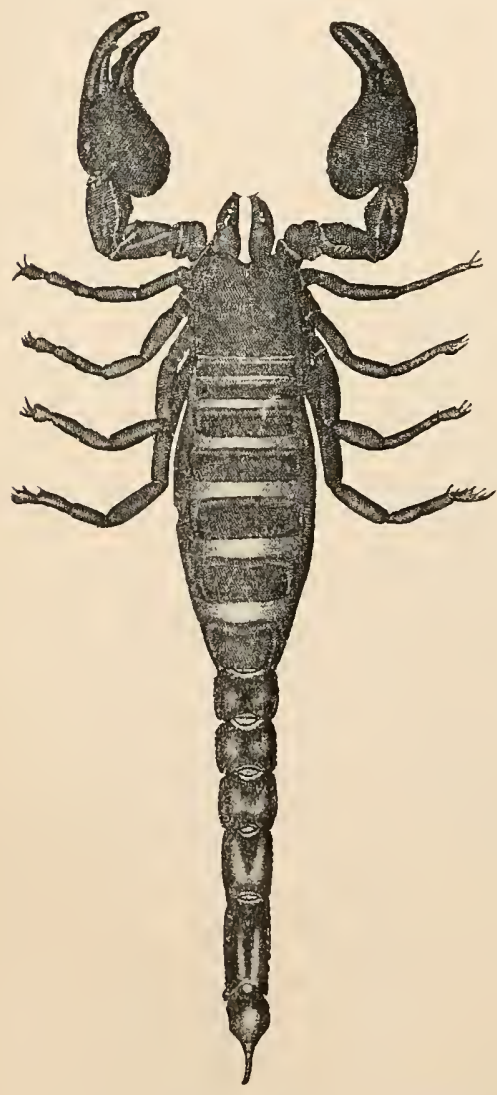

Fig. 359.-Scorpio africanus (after Cuvier, Riègne animal).

embryo, however, a segmentation frontal lobes, may be recognised. the Scorpionidee and Solpugide, but is very different in the two groups. The segmentation in both these forms claims special attention.

The Solpugidee (Fig. 358) vividly recall the Insecta in the metamerism of the body. In opposition to all other Arachnoidea, not only is the anterior division of the body, answering to the cephalo-thorax, distinctly segmented, but it even falls into two parts, an anterior unsegmented head, which may be compared with the head of the Antemnata, and a posterior thorax, consisting of three segments, which may be compared with the thorax of the Insecta and with the three anterior trunk segments of the Myriapoda. An abdomen of ten segments follows the thorax.

There are considerable difficulties in the way of comparing the segments of the body of the Solpugide with the head and a corresponding number of trunk segments of the Antennata; these difficulties arise chiefly in comparing the extremities and nervous system, and will be discussed later on. The ontogeny of the Solpugide is unfortunately almost unknown.

In the Scorpionidce (Fig. 359) the cephalo-thorax is, in the adult condition, unsegmented; in the into seven somites, including the The abdomen, on the contrary, 
is distinctly segmented and consists of twelve segments. In it, again, we can distinguish two divisions, distinctly marked off from each other. The anterior division, the lroad pre-abdomen, consists of 7 segments; the posterior, slenderer, tail-like division, the post-abdomen, of 5 segments. At the end of the post-abdomen is found the poison sting, which is often included as one of the segments. It ought, however, probably to be considered as an articulated appendage of the last segment, the latter being recognised, as in all Arthropoda, by the position of the anus.

Two small, insufficiently known groups of Arach. noidea, the Turteride and Microthelyphonide, appear, as far as the metamerism of the body is concerned, to occupy in some respects an intermediate position between the Solpregide and the Scorpionide, and in others between the latter and the Thelyphoride. In the Microthelyphonide an anterior and a posterior division can be distinguished in the cephato-thorax, and again, the latter shows on its dorsal surface indis-

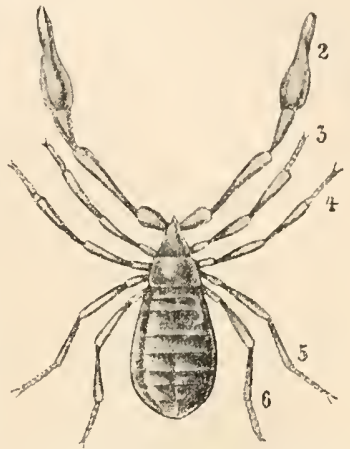

Fig. 360.-Chelifer Bravaisii (after Cuvier, Règne animal). $2-6$, Second to sixth pairs of extremities.

tinct division into three jarts which recalls the arrangement of the cephalo-thorax of the Solpugidce. The abdomen consists of ten segments, the last thrce bcing much narrower and smaller than the rest and rejresenting a sort of post-abdomen, whose terminal segment carries a long, thin, jointed candal filament. In the Tartaridce the thorax is divided by a distinct circular constriction into an anterior and a posterior division. The abdomen consists of seven or eight segments follower by a small, short, truncated post-abdomen, formed of a few (four) segments and carrying a variously-shaped candal appendage.

In the Pedipalpi the cephalo-thorax is unsegmented. The abdomen consists of 12 segments (Thelyphonus) or of 11 (Phrynus). In Thelyphonus the last 3 segments are very small and narrow, and form a sort of post-abdomen, which carries an anal filament.

The cephalo-thorax of the Chernetide (Pseudoscorpionidee), which recall the Scorpionida in their general type, is unsegmented or else has 2 dorsal transverse furrows. The abdomen consists of 11 (less often 10) segments. A pre-abdomen and a post-abdomen cannot be distinguished, and a poison sting or a candal or anal filament is wanting.

The cephalo-thorax of the Phalungicle (including the Cyphophthatmide $)$ is unsegmented. The abdomen, which is sometimes clearly, sometimes indistinctly segmented, is applied to the cephalo-thorax along its whole breadth. There is no separation of the abdomen into preabdomen and post-abdomen, and no caudal filament.

In the Aruneidce (the true spiders) the cephalo-thorax as well as the abdomen is unsegmented. The two are separated by a deep constriction.

In the Acaride the segmentation of the body as well as its division into regions is suppressed. It is rightly assumed that the unVOL. I 
CHAP.

segmented body has here come from the fusing of an unsegmented cephalo-thorax with an unsegmented abdomen. It only rarely occurs that the limbless abdomen is distinctly marked off from the limb-

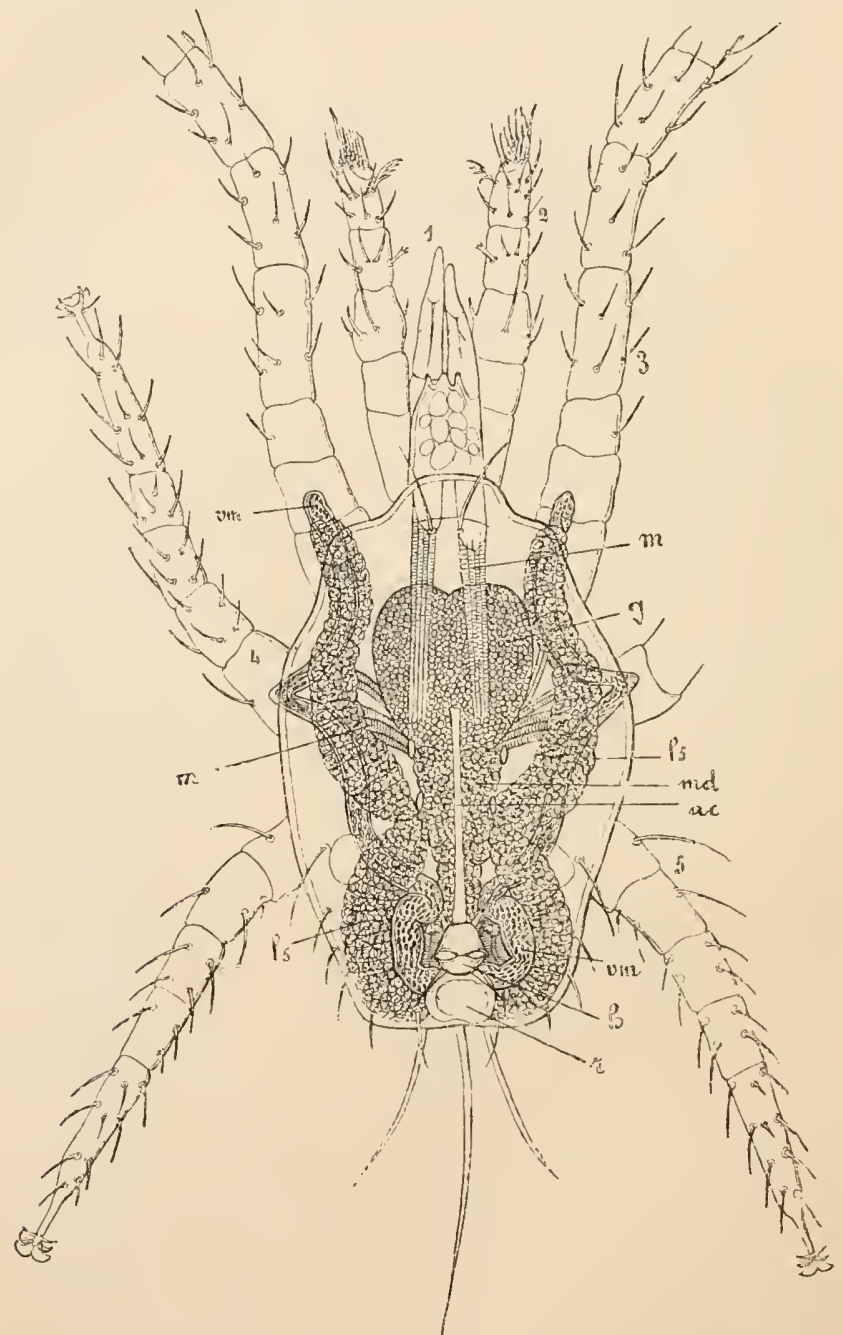

Fig. 361.-Larva of Gamasus fucorum (after Winkler). 1.5, The 5 pairs of extremities of tle larva (the sixth still wanting); 1 , the cheliceræ=mandibles; 2 , the pedipalps=naxillæ; $m$, muscles ; $v m$, Malpighian vessels ; $g$, brail = supra-cesoplageal ganglion : $l s$, diverticula of the miclgut (hepatic tubes); md, mid-gut; $h$, heart ; $a c$, aorta-cephalica ; $r$, rectal resicle.

bearing cephalo-thorax. An anterior portion of the body, often distinguished as the "head," and carrying the oral aperture, can certainly not be regarded as an original division of the body, i.e. a 
division derived from ancestors. It is also very doubtful whether a ringing of the body, which can here and there be recognised, has anything whatever to do with a true segmentation.

The body of the parasitic Linguutulide is elongated, vermiform, and ringed. But this ringing has again nothing to do with a real segmentation.

\section{B. The Extremities.}

The Arachnoidea are typically provided with six pairs of extremities exclusively belonging to the cephalo-thorax. The abdomen is everywhere limbless.

Of the 6 pairs of extremities the most anterior pair is known as the cheliceræ (mandibles, jaw-feelers, claw-feelers, falces), the second as the pedipalps (underjaws, maxillæ). The other 4 pairs are mostly similar in form and serve as ambulatory legs for locomotion.

The First Pair of Extremities - the cheliceræ-lie in front of and above the mouth. They are either 2- or 3-jointed, and serve for seizing, and often also for killing, prey. The terminal joint is clawlike. The chelicerie are chelate, when the terminal claw is, as in the chelate feet of Astacus, movable against a process of the preceding joint; they might be called elaw-jaws when the terminal claw can merely be bent round upon the preceding joint, as in the seizing feet of the Stomutopola.

The Second Pair of Extremities-the pedipalps or maxillælie on the two sides of the mouth, and everywhere function as oral appendages, being nearly always provided with masticatory ridges at their bases. The masticatory ridges, which elsewhere can move freely against one another, have in the Pedipalpi (Thelyphonidce), Cyphophthalmide, and Acarina, grown together in the middle line as an adaptation for sucking. As opposed to the masticatory ridge, the remaining part of the second extremity is called the palp or feeler. The manyjointed palp (originally 6-jointed) everywhere serves as an organ of touch, but may perform very different functions as well, and in correspondence with these functions may be very variously modified. In the Scorpionide, Chernetide, and in many mites it ends in pincers and functions as a seizing organ. In the Pedipulpi it ends as a claw feeler with a movable claw. The feelers of the Phulangide and of many Acarinu have a terminal claw. In the male Araneidre the terminal joint of the feeler is transformed into a copulatory organ. The feelers of the Solpugille'serve, like the 4 subsequent pairs of extremities, for locomotion, and are formed much like the rest. The same is the case in the Microthelyphonide, where the second pair of extremities not only resembles those which follow it, but is even devoid of the masticatory ridges.

The Third Pair of Extremities lies behind the moutl, and is in most Arachnoidea more or less like the 3 following pairs, and serves, like them, for locomotion. In the Scorpionide and Phalangide the basal joint is provided with a masticatory ridge. The third pair of 
extremities is differently shaped in the Pedipalpi; it is long and thin, with long flagellate ringed terminal joints. Here it is principally or exclusively used as an organ of touch.

The Fourth, Fifth and Sixth Pairs of Extremities are, as a rule, similarly shaped-6-jointed locomotory organs. In the Scorpionidee the fourth pair of extremities also carries a masticatory ridge.

In the Linguatulide, which are regarded as Arachnoidea degraded by parasitism, the limbs are reduced in number and form. Only two pairs of clinging hooks are found near the mouth. Definite data for a comparison of these clinging looks with any special pairs of the limbs of typical Arachnoidea are, however, wanting.

The homologies of the Arachnoidean limbs with those of other Arthropoda are difficult to establish. If we compare the Arachnoidea with the Antennata, and especially the cephalo-thorax of the former with the head and 3 anterior trunk segments (thorax) of the latter, we find that the Arachnoidea possess one pair of extremities less than the Antennatc in the corresponding regions.

In the Solpugida, in which the section of the body which corresponds with the cephalo-thorax of other Arachnoidea is, as in the Antennata, segmented, the head carries 3 pairs of extremities, viz. the cheliceræ, pedipalps, and the pair of limbs which follow these. Each of the thoracic segments following the head possesses a pair of limbs. Since the Antennatio carry typically 4 pairs of limbs on the head, viz., the antennæ, mandibles, anterior and posterior maxillæ, it follows-presupposing that the head of the Solmegidee really corresponds with that of the Antennata - that the wanting limbs belong to the head. Various facts, chiefly ontogenetic, make it probable that it is the antennæ of the Antennata which are wanting in the Solpugide and in the Arachnoidea generally, ${ }^{1}$ while the other limbs correspond according to their order of succession. In this way we reach the following homologies between the Arachnoidean and Antennatan limbs. -

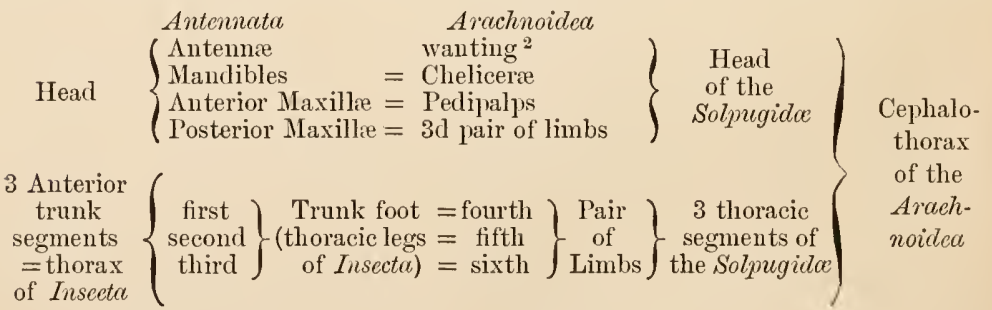

If these homologies are correct, then the chelicera especially, but also the pedipalps and the $3 \mathrm{~d}$ prair of extremities of the Arachnoidea, differ very greatly from the corresponding cephalic limbs of the Antennata, i.e. the mandibles and anterior and posterior maxille. The mandibles of the Antennata are never jointed and the maxillæ never elongated like legs, as in the Arachnoidea. Now since it is not conceivable that the 3 anterior pairs of much-jointed limbs of the Arachnoidea have procceded from the reduced and specialised oral appendages of the Antennata, we are compelled to assume that if there is any near relationship between the two groups,

1 While these sheets are passing through the press it is announced that the embryo of a large spider (Troehosa singoriensis, Laxm.) shows distinct rudiments of antennæ which disappear later ; and further, that more than 4 pairs of rudimentary abdominal limbs are visible, with traces of several pairs of stigmata. (Zool. Anzeiger, 11th May 1891.) [TR.] 
the Arachnoidea branched off from the common Tracheatan stem at a time when the oral appendages were still much jointed, and clongated like legs.

In connection with the assumed complete absence of the Antemnatan feelers in the Arachnoidec or Chelicerota, it is a striking fact that no rudiments which can be proved to be those of antennæ appcar, as far as we know, at any stage of development, even temporarily. ${ }^{1}$ And yet we must assume, keeping Peripctus in mind, that the ancestors of the Traeheatc possessed well-developed antennæ.

In recent times the near relationship of the Araehnoidea, and esprecially of the Scorpionide, with the fossil Gigantostreec and the Xiphosura has bcen zcalously maintained. It cannot be denicd that the 6 pairs of limbs of the Scorpion show greater agreement with the 6 pairs of limbs of the cephalo-thorax of Limulus than with the limbs of the Antennata. There are, however, other serious objections to the assumption of a nearer relationship between the Arcehnoidec on the one hand and the Xiphosure and Gigantostruce on the other (see p. 541).

\section{Rudiments of Abdominal Limbs in the Arachnoidea.}

1. In various Arachnoidea rudiments of abdominal limbs appear temporarily during cmbryonic development ; 6 pairs on the 6 anterior abdominal segments in the Scorpionidee (Fig. 379 , p. 538), 4 pairs in the Chernetide and 4 pairs in the Araneide (Fig. 380, 1. 539). Such rudiments of abdominal limbs will probably also be found in the embryonic stages of other Arachnoidea, whosc development has been hitherto not sufficiently investigated.

2. The Scorpionide possess in the adult condition on each side of the second abdominal segment ventrally a comb-like organ (Fig. 362, $k$ ), whose function is not yet fully known. These two "combs" are said to come from embryonic rudiments of the limbs of the second abdominal segment.

3. It is in the highest degree probable that the spimning mammille of the Arancide, which, 4 or 6 in number, risc on the hind body, represent rudimentary abdominal limbs. This is supported by the following facts: $(a)$ they arc for the most part jointed; (b) they, as recently observed, develop from the embryonic rudiments of abdominal limbs; $(e)$ the fact that they are spinning mammilla, i.c. that the spinning glands open on them. These facts gather weight when we remember the coxal and spinning glands of the Protrecheate and Antennata, and particularly the slime papille of Peripatus and the spimmerets of Seolopendrelle. The assumption that the spinning mammille of the Cyphophthalmid

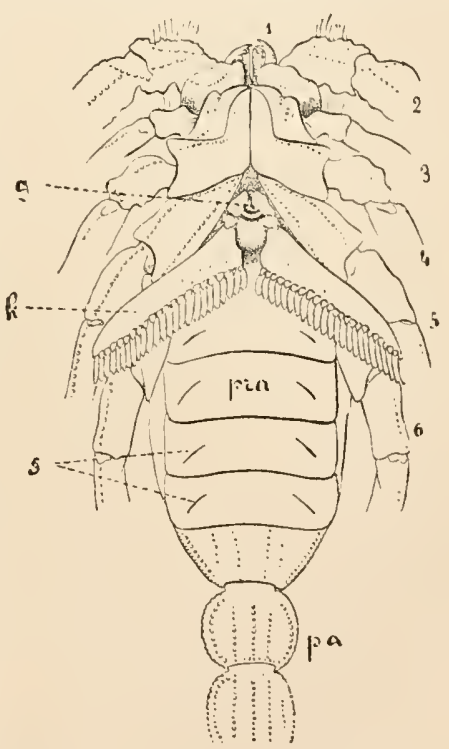

FIG. 362. - Buthus occitanus (Regne animal). Cephalo-thorax, pre-abdomen (pra), and the first segments of the postabdomen ( 1 ra), from the ventral side. Limbs (1-6) not fully drawn. 1, Cheliceræ; 2, pedipalps (jaw-feelers, clielate-feelers); $g$, genital aperture; $s$, stigmata; $k$, combs. genus, Gibbocellum, also represent rudimentary limbs, is open to the objection that the two pair of mammille lie in one and the same, i.c. the $2 d$ abdominal segment. 
The occurrence of rudimentary abdominal limbs in the Arachnoidea froves that the ancestors of these animals possessed extremities on the abdomen (at least on 6 abdominal segments).

\section{The Nervous System.}

The segmentation of the body is reflected in the segmentation of the nervous system. The Scorpionide, which of all Arachnoidea show the richest segmentation of the body, also possess the greatest number of ganglia in the ventral chord, while on the other hand in the Arencide and Acuride concentration both of body segmentation and of nerve chord reaches its highest point. As in other Arthropoda concentration of the nerve chord is due to displacements, fusings, and to reductions of originally separate segmentally-repeated pairs of ganglia; these processes may be directly observed during ontogenetic levelopment.

The brain is connected with the ventral chord by a short cesophageal commissure. From the brain arise the optic nerves, and also, in most eases, the nerves of the cheliceræ. The fact that the chelicere are immervated from the brain seens to oppose the assumption that they are homologous with the mandibles of the Antenuatu, since the latter always receive their nerves from the infra-øosophageal ganglion. It has been found, however, that in the earlier stages of development that portion of the brain from which the nerves of the chelicera arise, and which is often still distinctly separate in the adult animal, begins to form in the embryo as the first post-oral pair of ganglia. These later take part in the formation of the osophageal commissures, or else even fuse with the ganglionic rudiments of the segment of the frontal lobes, i.e. with the rudiments of the actual brain. This process is evidently similar to the fusing of the ganglia of the posterior antenna with the brain in the Crustacea. In the Phalangide, however, in opposition to the other Arachnoidea, the nerves of the chelicere are said to arise out of the anterior part of the great thoracic ganglionic mass. A similar observation has recently been made in the Acarina (Gamaside), where "the mandible nerves arise out of two spherical ganglionic masses of the infra-oesophageal ganglion, and pass through the supra-cesophageal ganglion."

Throughout the Arachnoidea, even in the ventral chord of the most richly segmented Scorpionide and Solpugicle, all the ganglia of the cephalo-thorax, and a number of the anterior abdominal ganglia, fuse to form one great thoracic ganglionic mass, from which arise the nerves for the second to the sixth pairs of extremities and for the anterior abdominal segments. In the abdomen there may be several separate ganglia (Scorpionide, Fig. 363), or only one or two (Thelyphonide, Fig. 364, Solpugide, Chernetide, Phalangida, Mygalide among the Arancide, Fig. 374, p. 531). In the Dipneumones (Arancide) and the Acaride (Fig. 365) on the contrary, the whole central nervous system, the brain and ventral chord, form a single mass 


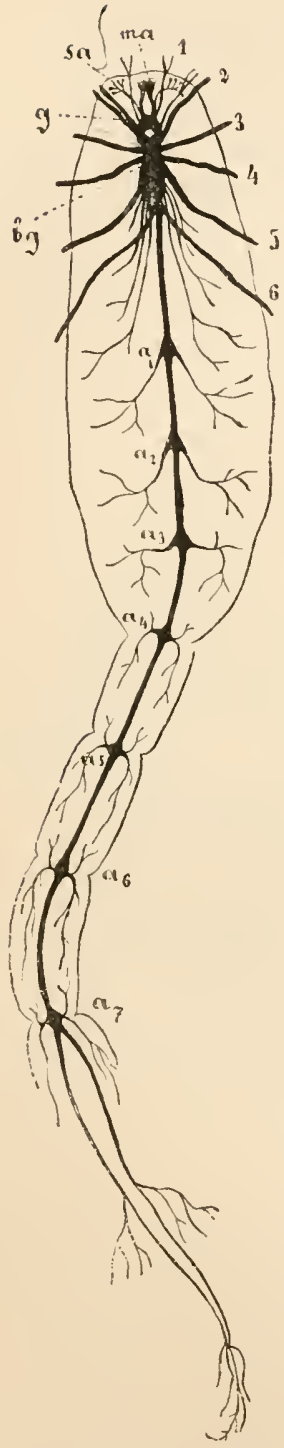

FIG. 303. - Nervous system of the Scorpion (after Newport). 1-6, Nerves of the 6 pairs of limbs; ma, niddle eyes ; $s \pi$, lateral eyes ; $g$, brain ; $h g$, large infra-cesopliageal ganglionic mass; $a_{1}-a_{7}$, ganglia of the abdomen.

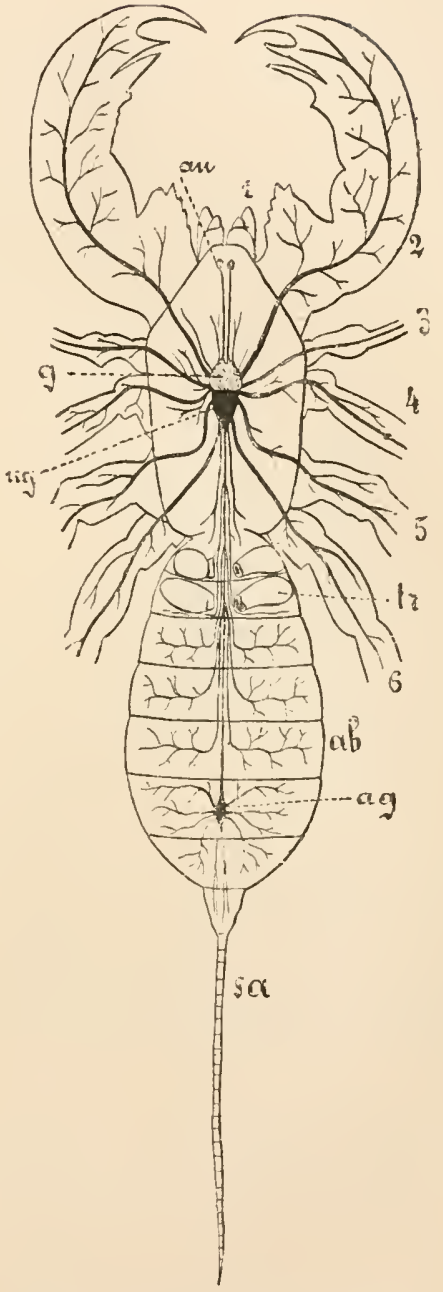

Fic. 361.-Nervous system of Thelyphonus caudatus (after Blanchard). 1-6, First to last pairs of limbs with the corresponding nerves from the thoracic ganglionic mass; $a u$, eyes; $g$, brain ; $u g$, thoracic ganglionic mass; $a b$, abdomen; $a g$, abdominal ganglion; sa, jointed caudal appendage. 
pierced by the esophagus; the greater part of this mass, which lies behind the cesophagus, represents the fused ventral chord, from which the nerves radiate.

The disappearance of a segmented abdominal ganglionic chain in the Arachnoidea may have been brought about by various co-operating factors : (1) by a forward displacement of the ganglionic masses, and the fusing of the same with the thoracic mass; (2) by the fusing of several abdominal ganglia to form one or two abdominal masses ; (3) perhaps also by the running of the ganglia into the nerve trunks which, paired or extcrnally unpaired, run through the abdomen; and (4) by the concentra. tion of the whole ventral chord into one single thoracic ganglionic mass.

In the Scorpionide, where the nervous system in the abdomen is still most richly segmented, there are 7 abdominal ganglionic masses, 3 in the pre-abdomen, 3 in the

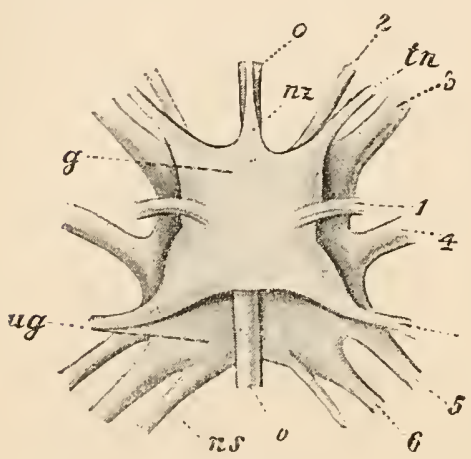

FiG. 365-Central nervous system (thoracic ganglionic mass) of Gamasus, diagrammatic (after Winkler). $g$, Portion lying over the cesophagus $(0)=$ brain; $u g$, portion lying under the cesophagus (infra-œesophageal ganglionic mass); $1-6$, nerves of the 6 pairs of limbs ; 1 , of the chelicere (mandibles); 2 , of the pedipalps (maxillæ) ; nz, nerve of the tongue ; $n s$, visceral nerve; $t n$, nerve of the maxillar palp.

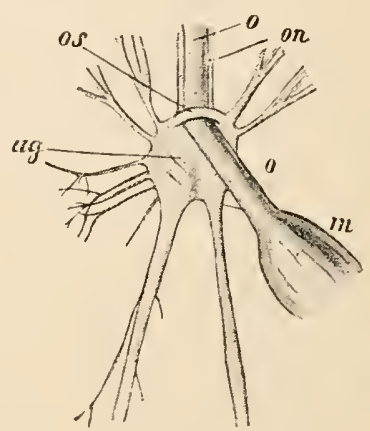

Fic. 366.-Nervous system of Pentas. tomum tænioides (after R. Leuckart). $o$, osophagus; $m$, anterior portion of the chylific stomach; on, œsophageal nerves; os, œsophageal ring running over the oesophagus; $u g$, infra-œsophageal ganglionic mass.

post-abdomen, and 1 on the boundary betwcen the two, which as yet cannot be certainly assigned to the one or the other.

The longitudinal commissures of the Arachnoidean ventral chord are, almost everywhere where they are distinguishable, fused in the middle line into an externally single median longitudinal strand.

The nervous system of the endo-parasitic Linguatulide (Fig. 366) is much reduced. It is restricted to one ganglionic mass lying beneath the osophagus and an apparently double commissure embracing the osophagus, in which no special cerebral swelling can be made out. This great reduction of the brain is chiefly due to the degeneration of the cyes.

A sympathetic nervous system has been proved to exist in various Arachnoidea (Scorpionide, Araneidce, Acarider), and consists of an umpaired nerve connected with the brain by paired ncrves and running along the œsophagus and stomach. Ganglia connected with the ventral chord have also been described as belonging to the sympathetic nervous system. 


\section{The Eyes.}

Most Arachnoidea possess eyes. These are unicorneal and are, except in the middle eye of the Scorpions, constructed on the same general plan as the ocelli of the Antemuta. The hypodermis is nearly always continued under the cuticular lens to form the so-called vitreous body.

Number and Position of the Eyes. - The eyes of the Arachnoidea are sessile and from 2 to 12 in number; they lie symmetrically arranged on the upper side of the cephalo-thorax.

Solpugida: 2 large ocelli on one common prominence. Scorpionide: 2-6 pairs of eyes, one pair of which, the great middle eyes, are placed close to the median line, and the rest at the anterior edge of the cephalo-thorax. Chemetide: 0,1 or 2 pairs of eyes. Pcdipalpi 4 pairs of eyes, the largest lying in the middle, the other 3
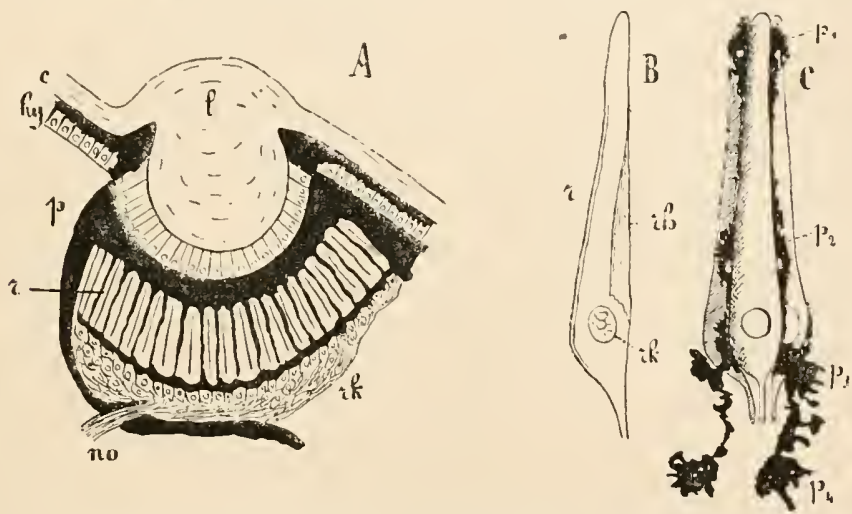

FIG. $367 .-$ A section through a middle eye of Euscorpius italicus (after Carriere). $\quad c$, Chitinous carapace; $l$, chitiuous lens; $h y$, hypodermis, continued as so-called vitreous body under the chitinous lens ; $p$, pigment cells ; $r$, retinulæ ; $r k$, the proximal nucleated portions of the retinulx ; no, optic nerves. $B, A$ single retinular cell $(r)$, with the rhabdomere $(r h)$, and the nucleus $(k)$. $C, \mathrm{~A}$ retinula with the pigment cells $p_{1}, p_{2}, p_{3}, p_{4}$. ( $B$ and $C$, after Ray Lankester.)

on the anterior edge of the cephalo-thorax. Phalangidce: usually 1 pair of eyes in the middle of the cephalo-thorax on a prominence. In Cyphophthalmus there is an eye on each side on a prominence; in Gibbocellum 2 eyes on each side at the edge of the ecphalo-thorax, each on a prominence. Araneide: generally 8, less often 6 or fewer cyes, symmetrically arranged, generally in 2 transverse rows on the cephalo-thorax. The special arrangement is of value for elassification. Acarina: eyes are wanting, or present in 1 or 2 pairs. Linguatulide : eyes wanting.

The Structure of the Middle Eye of the Scorpionidæ (Fig. 367). - The middle eye of the Scorpion takes, according to its structure, an intermediate place between a simple eye (ocellus) and a compound or facet eye. It agrees with the ocellus in possessing one single cuticular corneal lens, and with the facet eye in its retinal cells (understanding these cells in Grenacher's sense) which form groups, the so-called retinule. 
Under the cuticular lens an epithelial layer lies as a continuation of the hypodermis ; this represents the matrix of the lens and is ealled the vitreous borly. Under the vitreous body lies the layer of the retinulie. Each retinula is separatcd from its neighbonrs by pigment cells and consists of 5 retinal dells. One rhabdomere belongs to each retinal cell. The 5 rhabdomeres fuse in the axis of the retinula into one rhabdome.

\section{Glands Opening on the Outer Integument.}

These are very numerons in the Arachnoidea. Many of them are insufficicntly known, especially as far as their constitution and the physiological significance of their sccretions are concerned. We shall divide the different sorts of glands into two principal groups: (1) such as open upon limbs, and (2) those whose ducts have no apparent connection with limbs.

1. Glands opening on Limbs.-Among these we have in the first place the spinning glands of the Araneidæ, since the 2 or 3 pairs of spinning mammille on which they open are very probably rudimentary abdominal limbs. There are on each side several variously constructed spinuing glands, whose secretion, which hardens by exposure to air, serves for forming the varions sorts of webs. Among these different pairs of glands there is one pair which only seems to occur in the female and to serve for the spimning of the egg cocoon. Immediately in front of the anterior pair of the spinning mammillæ there is found in some Arancide a paired glandular region, the so-called Cribrellum, in which extremely numerous spinning glands open throngh fine pores. The cribrelhum perhaps also represents the last remains of another (4th) abdominal pair of limbs.

The spinning glands of the Arancide are rightly reckoned among those variously developed integumental glands (coxal glands, spinning glands, protrusible saes), which must be finally traced back to the segniental setiparons glands on the parapodia of the Annelida.

In Gibbocellum (Cyphophthalmidle) there are found on each side ventrally on the 2 d abdominal segment 2 spinning nammille, on which several spinning glands open.

Glands which open on the 4 prairs of ambulatory legs (either on one or on several) have often been observed. One large gland is found on each side of the cephalothorax of the Scorpionidce. It emerges, at least in the embryo and in young animals, on the coxal joint of the $3 \mathrm{~d}$ pair of ambulatory legs. On the 1 st and $2 \mathrm{~d}$ pair at the place where the glandular apertures lie in the $3 d$ pair, there are bulgings which suggest that there were once glandular apertures here also. The apertures of these coxal glands are usnally not demonstrable in adult animals.

Similar glands having apertures on the coxæ of the $3 d$ pair of legs are found in the Arancide also, in the Tetrapneumones (Nyyale, Atypus) as well as in some Dipneumones. Here also it is often difficult to prove the existence of the onter apertures in the adnlts, and here also slits may appear on other legs which correspond in position with the glandular apertures of the $3 d$ pair of legs.

The fact that the coxal glands of the Scorpionides and Arencide are ummistakably sinilar to the coxal glands of the Xiphosura in position (on the 5th pair of extremities), in structure, and in manner of opening, has been nsed as a further argument in favour of the relationship of these latter with the Arachnoidea.

In the Solpugide and Phalangida also coxal glands are said to occur, in these cases on the bases of the last pair of legs. Their ducts have, however, not been observed. The occurrence of coxal glands in the Acaride has also been described. In the Oribatide, for example, they lie at the bases of the $2 d$ pair of legs; in the Gamaside, it appears, between the coxal muscles of all the legs. It is not yet known if certain stigma-like pores near the bases of the 1st pair of legs of the Halacarida 
belong to the category of coxal glands. In Trombidium a gland with its opening lies on the terminal joint of each leg.

Glands of the pedipalps (the $2 d$ pair of extremities) have been observed in varions Arachnoidea (Atypus and other Arancide, Solpugide, Scorpionide, Phalangide, and Tetranychus anong the Acarides). They have been classed somewhat arbitrarily, some as salivary glands, others (Galeodes) as proison glands, and others again as spiming glands (T'tranyehus).

Glands emerging on the cheliceræ are also somewhat widely distributed. The best known and most investigated are the poison glands of the Araneidæ, which mostly lie in the cephalo-thorax, but often partly project into the cheliceræe themselves and always open outward on their terminal claws. In the Gomaside also there are glands at the bases of the chelicere. According to recent observations, the webs prepared by the Pseudoscorpionide are said to be formed by glands lying in the cephalo-thorax, whose ducts penetrate into the chelicere and open on the terminal joint. Earlier observers had asserted that the spinning glands and their apertures were to be found on the rentral side of the first abdominal segment. In the Lingnatulidce there are glands emerging at the bases of the 4 clinging hooks.

We thus find in the Arachnoidea a striking number of limb glands. This number will no doubt be still further increased on more thorough investigation, and it may perhaps be established, that many of these glands, especially those energing on the coxal joints of the extremities, belong, like the spinning glands of the Araneidce, to the category of segmental coxal glands homologous with the setiparous glands of the Annelida.

2. Glands not emerging on the Limbs.-Here belong the integumental grlands emerging through pores in the chitinous cuticle at various parts of the surface of the body ; these have been observed in different divisions, with special frequency, however, in the Acaridce and Linguatulide, and have been called oil glands, stigmatic glands, stink glands, etc. The poison gland of the Scorpion also belongs to these. It is paired, lies in the swollen terminal segment of the post-abdomen and emerges by 2 seprarate apertures at the point of the sting with which the tail is armed. In the Phalangide and Cyphoplethalmida (Gibboccllum) there is in the ceplialo-thorax one prair of glands (the so-called Krohn's glands), the 2 ducts of which are said to emerge through 2 apertures on the dorsal side of the ceplialo-thorax.

\section{The Intestinal Canal.}

This has as a rule a straight course through the body. We can again distinguish in it the three well-known divisions, fore-gut, midgut, and hind-gut.

The Fore-gut. - The month or buccal cavity is followed by the muscular pharynx, which functions chiefly as a suction pump, as it can be expanded by means of special groups of muscles attached to it, and contracted by circular muscles. The pharynx passes into the narrow œsophagus. This passes through the osophageal ring and enters the mid-gut. Before entering the latter it swells, in the Arancide, into a special sucking stomach.

The mid-gut forms by far the largest portion of the digestive tract. In the Arachnoidea it shows in a very high degree the tendency to form eœcal invaginations which surpass all the rest of the viscera taken together in size and importance. Where the cephalo-thorax and 
abdomen are distinctly separate, these invaginations may be repeated in each. The whole mass of the mid-gut with its invaginations repre-

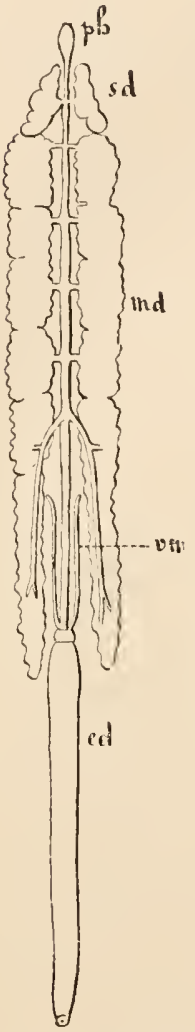

Frg, 368, - Digestive tract of the Scorpion (after Newport). $p h$, Phar. ynx; sd, salivary glands; $m d$, diverticula of the mid. gut ; vm, Malpighian ves. sels; ed, hinıl-gut. sents the digesting chylific stomach, and has glandular walls. The liquid nourishment reaches to the very extremities of these diverticula, which have been inaccurately called hepatic tubes.
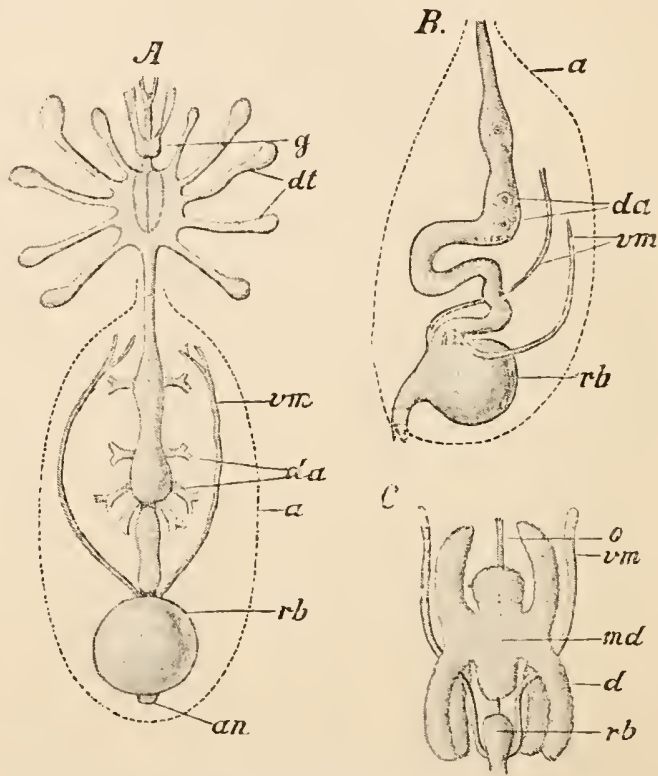

F1G. 369.- $A$, Digestive apparatus of Mygale caementaria (after Dugès in Cuvier's liène Animal). $B$, The abdominal portion of the same, from the side. $C$, Digestive apparatus of a Gamasus, diagrammatic (after Winkler). Lettering the same in the 3 figures: $g$, brain; $d t$, enteric diverticula of the thorax; $d a$, enteric diverticula (liver) of the abdomen $(a)$, only the portions entering into the abdominal mid-gut drawn; md, mirl. gut with diverticula (d) of Gamasus; $r m$, Malpighian vessels ; $r b$, rectal vesicle (cloaca) into which both the digestive tract anil the Malpighian vessels enter; 0 , œsophagus.

The hind-gut is generally very short. It opens externally through the anal aperture which is placed ventrally at the posterior end of the body. Into the hind-gut enter tube-like excretory organs, corresponding with the Malpighian vessels of the Antennata. There is generally one pair of these, less frequently several pairs. In the Accrinc an unpaired excretory tube is often found.

The fact that the Arachnoidea like the Antennatc have Malpighian vessels, while these vessels are not found in the Crustacea and Tiphosura and Pyenogonida, is of great importance in deciding the question of their systematic position. 
The dorsal wall of the hind-gut is often bulged out in the form of a muscular sac. It then looks as if the Malpighian vessels on the one hand and the mid-gut on the other entered a common terminal sac, not at its blind end but near the anal aperture. In the structure of its walls this rectal vesicle, which is also often called the cloaca, agrees with the Malpighian vessels, and not with the mid-gut. This favours the view that the excretory tubes of the Arachnoidea, like the Malpighian vessels of insects, are invaginations of the hind-gut, and consequently ectodermal formations.

Salivary grlands have often been described in the Arachnoidca, but our knowledge of them, especially of their manner of emerging, is very inadequate. The glands which open on the pedipalps are also often regarder as salivary glands. In certain Acarina (Oributida) a pair of glands emerging at the boundary between the fore-gut and the mid-gut has been observed. In varions Arachnoidea there are groups of glands in the upper lip.

The anatomy of the diverticula of the mid-gut varies greatly in the different orders. In the Scorpionidee (Fig. 368) they form a 5-lobed mass on each side in the pre-abdomen, this mass being connected with the mid-gut by means of 5 canals (hepatic ducts). In the mid-gnt of Solpuga (Galeodes) numerous branched diverticula are said to enter both its anterior and its posterior ends. In the Pseudoscorpionidce there are 3 diverticula of the mid-gut, 2 lateral, and 1 mpaired ventral. The two lateral diverticula again subdivide at their outer edges into 8 lobes. The mid-gut here forms a double loop. In the Microthclyphonide 5 pairs of shallow bulgings have heen observed in the mid-gnt. In the mid-gut of the Arancida (Fig. 369, $A, E$ ) we must distinguish a cephalo-thoracic and an abdominal division. The former often has 5 pairs of diverticula. The first two diverticula may anastomose with each other over the sternal side of the thorax and so form a ring. The lateral diverticula often bend round from the side towards the middle line of the body under the thoracie ganglion, first, however, giving off a blind branch to the coxal joint of each limb (e.g. in Epeire and many other Araneidec). In Atypus the thoracic portion of the nid-gut has only 3 pairs of diverticula, the most anterior pair in this case not forming a ring.

In the anterior portion of the abdomen of the Arancide the mid-gut, which is here somewhat expanded, forms a considerable number of diverticnla varying in size and much branched; these are united by comnective tissue to the mass which is erroneously called the liver. The coloured secretions occurring in some of the eclls of these diverticula distinguish them from the non-coloured diverticula of the cephalothoracic mill-gut.

The mid-gut of the Phalangide, is a tolerably spacions sac covered laterally and dorsally by numerous ( 30 ) blind tubes. These blind tubes enter the mid-gut through 6 lateral and 1 anterior pair of apertures.

The mid-gut of the Acarina (Fig. 369, C) also has longer or shorter bulgings, invaginations, or cecal diverticula, whose number varies. There are often 2 or 3 pairs.

The mid-gut of the Linguatulide is a straight tube without diverticula.

The Malpighian Vessels. - In the Scorpionide, 2 Malpighian vessels enter the hind-gut. In one spccies (SC. occitcnus) 4 vessels are said to occur, 2 of them being branched. In the Arancide, the Malpighian vessels consist of numerous fine branched and anastomosing tubes which finally unite on each side into two collecting ducts. The two ducts of one sile enter the rectal vesicle by a common terminal portion.

The tubes of the Phalangide, formerly considered to be Malpighian vessels, are said by more recent observers to emerge at the mouth. In this case they can of course not be regarded as Malpighian vessels. They require further investigation. 
In the Cyphophthatmidae, and especially in the genus Gibbocellum, 2 long Malpighian ressels are found which enter the sac-like expanded rectum (cloaca). Each ressel begins with a blind terminal tube, which breaks up into a plexus of fine tubules, uniting again into a single vessel entering the rectum. Malpighian vessels have been found in many Acarina. They are generally in the form of 2 long, occasionally coiled tubes, entering the hind-gut. Sometimes the 2 tubes mite in a common duct which enters the hind-gut, and they thus assume the form of the letter $\mathrm{Y}(A \operatorname{ta} x)$. In other Acarina the excretory organ is an mpaired tube lying on the mid-gut. In Hydrodome it emerges close behind the anus, but separate from it. In other cases numerous Malpighian vessels are said to enter the hind-gut near the anus (Argas). Here and there a rectal sac like that of the Arancide is found, and into this enter both the gut and the Malpighian vessels (Gamaside, Fig. 369, C, and Halarachnidce). The arrangement of the long Malpighian vessels in the larve and the first nymph stage of the Gamasidce is interesting. They here (Fig. 361, p. 514) reach far forward and form a loop at each leg which may reach into its third or fourth joint. The bhind ends of the two vessels reach far into the first pair of legs. In some Acaridu and in the Linguatulide no Malpighian vessels have as yet been found. Our knowledge of the Malpighian vessels of the Arachnoidea in general is exceedingly scanty.

\section{The Blood-vaseular System.}

Among the Arachnoidea this system shows very various stages of development. It is most highly developed in the scorpionide and next in the Arancidce. The blood nowhere flows entirely in blood vessels separated from the body cavity, but rather for a larger or smaller portion of its course enters blood sinuses and lacunæ, which represent the cœlome. In the Arachnoidea also distinct relations between the blood-vascular system and the respiratory organs can be established. Where the respiratory organs are very strictly localised, as in the bookleaf trachea of the Scorpionide and Aroncide, the vascular system with walls of its own is most developed; where the respiratory organs are dispersed over the whole body, as they are in the Antennata, and also where there are no special respiratory organs, the peripheral portion of the vascular system is reduced, as in the Antennatu, and even its central organ, the heart, may disappear.

The central organ, the heart (Figs. 370, 371), shows, like that of the Crustacea, various degrees of concentration, from the extended many-chambered dorsal vessel provided with numerous pairs of ostia (Scorpionide), to the short, one-chambered cardial sac with one pair of ostia (Acaride). This progressive concentration is evidently closely connected with the progressive concentration of the whole body.

That the heart lies in a pericardium has only been with certainty observed in a few cases. Muscles and strands of connective tissue, which are attached on the one side to the heart or the pericardium (the latter appears to be the case in the Araneidce), and on the other to the integument, seem to occur pretty generally.

After the heart itself the most constant portion of the vascular system is a median anterior vessel-like prolongation of the heart, ruming on the dorsal side to the brain ; this may be called the aorta 
cephalica. It is perhaps the remains of an originally long tubular heart which reached as far as the anterior region of the body, and which ceased to develop ostia.

The heart lies in all Arachnoidea in the abdomen, or in that part of the body which corresponds with the abdomen.

Scorpionidæ (Fig. 370, $A$ ).--The extended tubular heart of the Seorpion lies in the pre-abdomen. It is $\mathbf{8}$ chambered, and has 8 pairs of lateral openings. From the posterior end of eaeh eliamber a pair of lateral arteries direrges. The heart is continued posteriorly into an aorta of the post-abdomen, and anteriorly into an

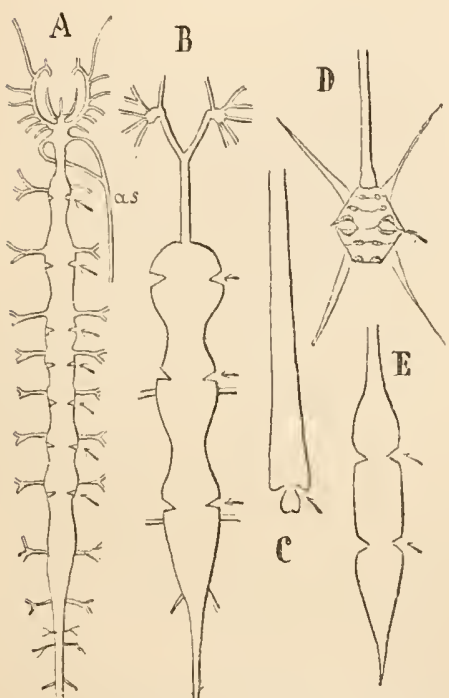

FrG. 370.-The hearts of various Arachnoidea. A, Scorpion (after Newport). $D$, Araneid. $C$, Obisium silvaticum, juv. (Pseudoscorpionid) (after Winkler). D, Gamasus fucorum, larra (after Winkler). $E$, Young Phalangid (after Winkler).

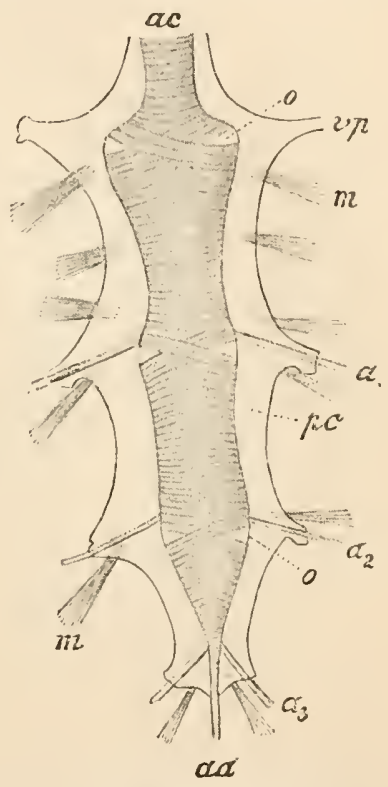

Fic. 371.-Heart of a Spider (l'holcus phalangoitles) (after Schimkewitsch). ac, Aorta cephalica; 0 , ostia of the heart; $v_{p}$, origin of the vena pulmonalis; $a_{1}, \alpha_{2 .}, a_{3}$, lateral arteries of the heart; $\alpha a$, aorta or arteria abominalis; $m$, alary muscles, attachel to the pericardium; pe, perieardinn.

aorta cephalica which runs through the eephalo-thorax. From the posterior aorta several lateral pairs of arteries arise. Immediately in front of the most anterior pair of ostia, and thus at the root of the aorta eephaliea, a lateral artery is likewise given off on eaeh side. A little further forward there are two more lateral arteries ruming downwards, and embraeing the esophagus, so forming an osophageal ring. From this resophageal ring arises a medio-ventral longitudinal vessel running baekwards; this lies above the ventral ehord, and is ealled the supraneural vessel. In front of the ressels forming the esophageal ring the aorta eephaliea gives off numerous other arteries, principally to the 6 pairs of extremities.

All the arteries alparently open into a laeunar system of the borly, through which the blood flows in special eurrents, those of the pre-abdomen bathing the book-leaf 
trachere, again returning to the pericardium, and thence into the heart. This portion of the anatomy of the circulatory system, however, requires fresh investigation.

The circulatory system of the Scorpionide shows considerable similarity with that of the Xiphosura, which is increased by the occurrence of an cesophageal ring and a medio-ventral longitudinal vessel. It must, however, be particularly noticed that a medio-ventral longitudinal vessel (subncural vessel) occurs also in many Crustacec (Malacostrace), which further, in the Isopoda, is connected with the anterior end of the cephalic aorta by means of an cesophageal ring. In Pcripatus also a nedio-ventral vessel is said to have been observed.

Araneidæ (Figs, $370 \mathrm{~B}, 371$ ).-After the Scorpionidce the Araneidce possess, as far as we know, the most richly developed vascular system. The heart, which runs along the dorsal side of the abdomen, is enclosed in a sac-like pericardium, which is itself again, as it appears, surrounded by a blood sinus. The heart has only 3 (in Mygalc 4 ?) pairs of openings, and is continued anteriorly into an aorta cephalica and posteriorly into a short aorta or arteria posterior, and sends off laterally 3 pairs of inconsiderable arteries which soon open into the lacunar system of the body. The arteria posterior opens into a blood sinus placed near the anus. The aorta cephalica runs further forward into the cephalo-thorax, soon dividing into 2 lateral trunks, which bend downwards, and after a slort course break up into several arteries which run to the eyes and extremities. All these arteries open into blood lacune or blood sinuses. In this definitely arranger system of lacunæ and sinuses the blood flows through the body in definite dircetions. The greater portion of it finally collects on the ventral side in the anterior part of the abdomen, here takes an upward direction, and thus round the book-leaf trachee, and then again finally enters the pericardium, whence it returns to the heart chiefly through the most anterior pair of ostia. From the book-leaf trachere (lungs) to the pericardium the blood flows through a special vein, formed by a continuation of the pericardial wall. Since, however, the pericardium itsclf is only a part of the coelone, this vein also cannot be regarded as a genuine blood vessel, but only as a more sharply demarcated canal-like part of the coelome, i.e. of the general lacunar system.

In the Pseudoscorpionidæ (Fig. 370, C), Phalangidæ $(E)$, Cyphophthalmidæ and Acarina $(D)$ the vascular system is reduced to the heart and the aorta cephalica. The heart itself, placed in the anterior part of the abdomen, becomes shorter and more compact. The number of its pairs of ostia diminishes, till finally there is only 1 pair (Acarina, and Obisium among the Pseudoscorpionidee). This reduction probably is caused by the anterior part of the heart losing its ostia, becoming narrow and passing into the aorta cephalica, while only the posterior cardial chambers with their pairs of ostia remain as a sac-like organ of propulsion.

The heart of the Pscudoscorpionida lies in the 3 or 4 anterior abdominal segments, and in Obisium is said to have only 1 pair of ostia, in Chornes, however, 4 pairs. The heart of the Phalangida and Cyphophthalmide has 2 pairs of ostia. Among the Acarina a heart has so far been found only in the Gamaside and in Ixodes. It is probable, indeed almost certain, that many other Acarina have no heart, and in gcneral no special blood-vascular system. The same is the case in the Linguatulide.

In the other Arachnoidea the blood-vascular system has either not yet been investigated or else not sufficiently investigated for a comparative study.

\section{The Respiratory Organs.}

The respiratory organs of the Arachnoidea are tracheæ, whose 1 to 4 pairs of outer apertures or stigmata almost always lie ventrally 
and anteriorly in the abdomen. Two sharply distinguished forms of tracheæ occur: tubular tracheæ and book-leaf tracheæ. The former essentially agree with the trachere already known to us in the Protrucheate and Antennute. The latter, which are also called lungs, lung tracheæ, lung sacs, or leaf tracheæ, have till now only been met with in the Arachnoidea.

Tubular tracheæ appear in three modified forms, between which, however, intermediate stages occur. (1) The principal trunk arising from the stigma is branched like a tree in the body, as in the Insecte and most Myriapoda. Separate tracheal trees are connected together by anastomoses. A spiral thread becomes differentiated in the chitinous cuticle of the tracher. Such branched tree-like tracher are found in the Solpugidce, C'yphophthulmidce (Fig. 372, $s_{1}$ ), Phalangide, a few Pseudoscor. pionidee, and a few Acarina (Gumaside, Ixodes).

(2) The principal trunk arising from the stigma generally divides only once into 2 chief branches. On each of these principal branches, at irregular intervals, are attached tufts of long finer unbranched tracheal tubules. Only one such tracheal tuft is sometimes

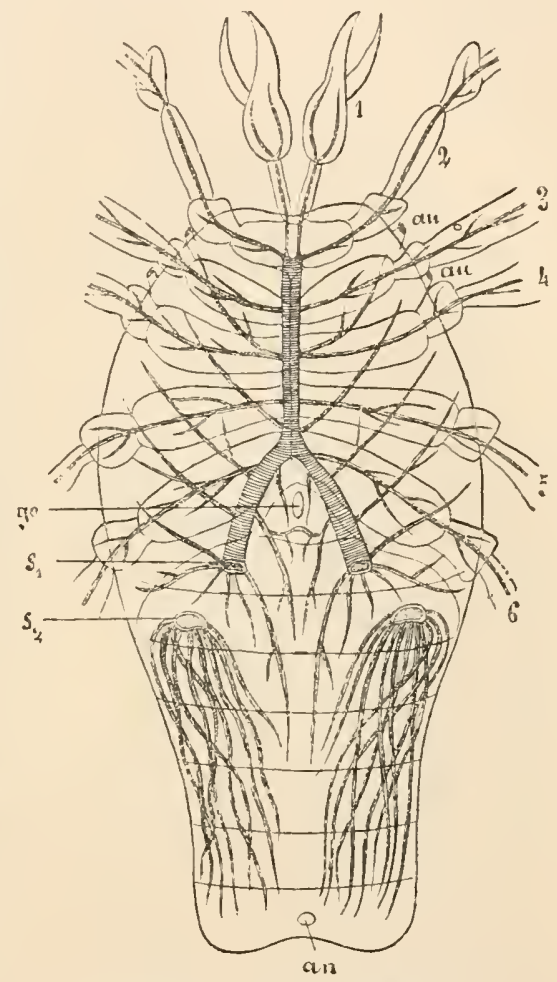

Fig. 372,-Diagranmatic representation of the tracheal system of Gibbocellum Sudeticum (after Stecker). 1-6, 1st to 6th pair of limbs, only the first (cheliceræ) drawn fully; au, eyes; go, genital aperture; $s_{1}$, anterior pair of stignata (for the tree-like trachea); $s_{2}$, posterior pair of stigmata for the tufted tracheæ; an, anus. found lying at the end of the principal trunk. Such tracheæ are found in many Araneide, many Pseudoscorpionida, and in most of those Acarine which are as a rule provided with tracher. This second tracheal form, and especially the modification of it last mentioned, leads over to the third form.

(3) A common tracheal trunk, arising from the stigma, is wanting. The separate tubules of the tracheal tuft branch directly from the stigma. We are the more justified in tracing back this third form to a shortening and later disappearance of the common tracheal trunk, since the posterior tracheal tufts of a few Pseudoscorpionidie (Chernes cimicoides) still rise from the end of a short tube. Such simple tufted

vOL. I 
trachere are found in a few Pseudoscorpionicle and a few Cyphophthulmide (Gibbocellum, Fig. 372, $s_{2}$ ). They show much similarity with the trachea of the Scutigera (p. 479). True spiral threads are not found in the second and third forms of tubular trachex.

Book-leaf tracheæ (tracheal lungs, lung sacs, Figs. 373

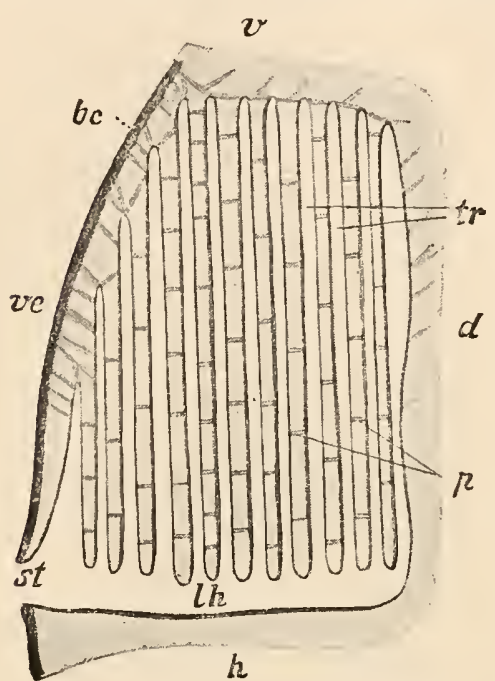

Fig. 373.-Longitudinal section through a book - leaf trachea of an Araneid, diagram. matic, after MacLeod. $v$, Anterior ; $h$, posterior ; ve, ventral side of the book-leaf trachea ; $d$, dorsal side; $b c$, integument of the ventral body wall of the abdomen; st, stigmatic aper. ture ; $t h$, air-or tracheal cavity ; $t r$, the spaces between the tracheal lamellæ; $p$, transverse supports between the trachex.

and 374 ). The stigma leads into a sac filled with air, into which there project from the anterior wall numerous leaves arranged like those of a book. They are, however, also attached by their side erges to the lateral walls of the sac, so that the latter may be compared with a letter-case divided by many partition walls into numerous compartments ; the walls of the sac are internally lined with a chitinous cuticle, a continuation of the outer chitinous integument of the body ; this is also continued on to the leaves, so that these consist of two somewhat closely contiguous lamellie connected by (muscular ?) trabeculæ or transverse supports. Between the two lamellæ of a leaf the blood enters from the colome and the respiratory process takes place through the lamellæ.

The most plausible view of the morphological signification of these lung saes seems still to be that they are modified tracheal tufts. If we imagine that in a tracheal tuft which opens outwardly by means of a short tracheal trunk the separate tubules standing close together, mutually flatten each other ont into hollow plates, and that these hollow plates become arranged in a row, we have before us a so-called book-leaf trachea or tracheal lung. The seprarate very narrow spaces lying between the leaves of the air sac would thus corresjond with the himina of the flattened trachere.

Ribbon-like flattened trachere are in fact to be found in the Araneidce. Compare further the fignres of the tracheal tufts of Scutigerc, p. 479, which greatly facilitate a comprehension of the view here given of the rise of book-leaf trachex.

Another view as to the morphological significance of the book-leaf trachere of the Arachnoidea has been put forward by those who hold that the Arachnoidea and especially the Scorpionidce are nearly related to the Xiphosura. According to this view the leaves or partition walls which project into the lung sac answer to the branchial leaves of the abdominal feet of Limulus, which have sunk below the body surface. The 4 pairs of book-leaf tracher in the Scorpion would thus represent rudiments of the 4 pairs of abdominal feet, i.e. of their branchial appendages. In comparison with the view first given, this view seems to us artificial and unsupported by comprative anatomy and ontogeny. 
The Scorpionide, Pedipalpi, and the tetrapneumonic Araneide (Mygalide) have only book-leaf traches. In the dipneumonic Araneide book-leaf and tubular trachere exist simultaneously.

\section{Number and Position of the Stigmata.}

The Scorpionide possess 4 prairs of book-leaf trachex and 4 pairs of stigmata, lying laterally on the ventral side of the $3 d$ to the 8 th abdominal segments (Fig. 362, p. 517).

The Pedipalpi have 2 pairs of book-leaf trachere with 2 pairs of stigmata on the ventral side of the 2d and $3 d$ abdominal segments (Fig. 364, p. 519).

Among the Araneide the arrangements are different in the Tetrepneumones and the Dipneumones. The Tetrapneumones (Mygalide) have 2 pairs of book-leaf trachere and 2 pairs of stigmata (Fig. 374, $f t, s)$ lying on the ventral side of the base of the abdomen. The Dimeumones have only one pair of book-leaf tracheæ, corresponding with the anterior pair of the Tetrapneumones. Besides these, however, they have, as the equivalent of the second pair of book-leaf trachere of the Tetrapneumones - tubular tracher, which generally open through an unpaired stigma in the shape of a transverse fissure placed far back on the abdomen. This unpaired stigma no doubt arises from a posteriorly placed pair of stigmata, which have united. This supposition is supported by the fact that in some Araneidee (Dysdera, Segestria, Argyroneta) two separate more anteriorly placed stigmata for the tubular trachee occur (behind the pair for the book-leaf tracheæ), and also by the circumstance that in a few cases (Dietyna) the tracheal trunks which open through the unpaired stigma are distinctly recog. nisable as double.

The Solmugidee have tubular trachere with tree-like ramifications, opening through 3 pairs of

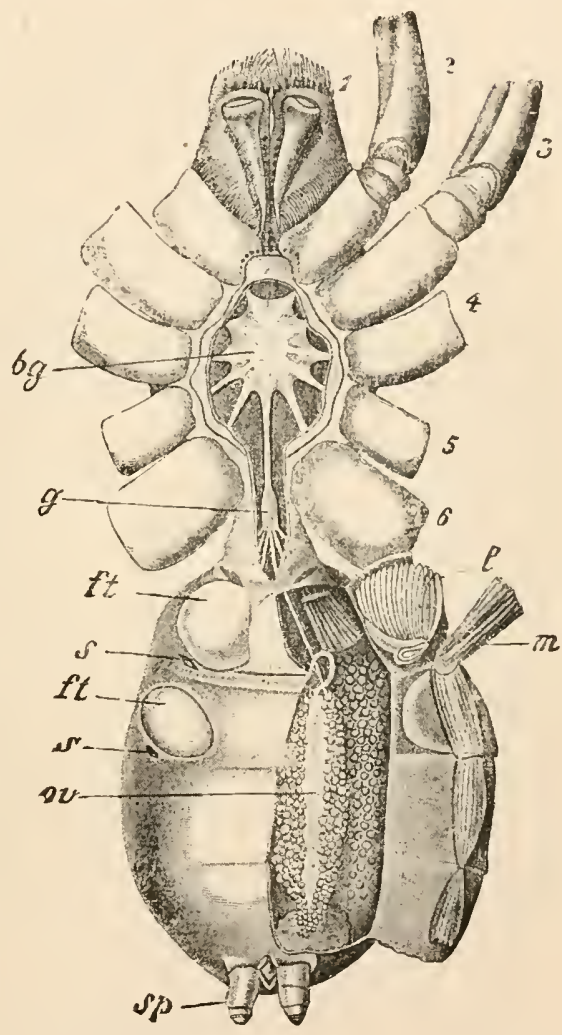

Fig. 374.-Mygale, from the rentral side. The rentral wall of the cephalo-thorax remored to show the large cephalo-thoracic ganglion $(b g)$ and the 2 l small ganglion at the base of the abdomen. The ventral wall of the abdomen on the left side opened out. $m$, Ventral inuscles of the abiomen; $l$, lamellæ of the book-leaf trachere; $f$, book-leaf trachea; $s$, stigmata of the same; ov, ovary ; $s p$, spinuing mammille; ; $1-6$, 1st to 6 th pairs of extrenities. 2-6, not completely drawn (Règne animal).

stigmata, the first pair lying in the first thoracic segment, the second and third pairs in the second and third abdominal segments. The position of the first pair of stigmata in the thorax deserves to be specially noted. 
The Pseudosconpionide have tubular trachere with 2 pairs of stigmata, which lie in the $2 d$ and $3 d$ abdominal segments. In Cheiridium there is only one pair of stigmata, which has perhaps arisen by the fusing of the two pairs found in other Pseudoscorpionide.

The ramified tracher of the Phalangide are said to open through a single pair of stigmata, lying ventrally at the anterior end of the abdomen, which is closely applied along its whole breadth to the cephalo-thorax.

Among the Cyphophthalmide, Cyphophthalmus is said to have only one pair of stigmata on the under side of the first abdominal segment. Gibbocellum (Fig. 372), on the contrary, has 2 pairs of stigmata lying laterally and ventrally in the $2 d$ and $3 \mathrm{~d}$ abdominal segments. The anterior pair of stigmata leads into richly branched trachee, whose two principal trunks unite into an unplaired median trunk in the cephalo-thorax. The posterior pair of stigmata lead into tufted trachere. Each stigma is covered by a plate pierced like a sieve, and each pore in this plate represents the aperture of a tracheal tubule.

In many Acarinu, especially in the parasitic and marine Acarina, tracher are wanting. When they are present they open out through one pair of stigmata, which are placed very unusually. This pair of stigmata generally lies near the coxal joints of the last pair of extremities, but often much further forward. It occasionally lies on the dorsal side, and sometimes above the base of the cheliceræ. This arrangement is not at present understood. In certain Acarina short tubes or sacs connected with apertures in the outer chitinous integument have been considered as the rudiments of tracher.

The Linguatulide are devoid of tracher. The Microthclyphonida also are said to have no special respiratory organs. If this be established, it must not be considered in the Acaride the original arrangement.

The Tartaride are said to possess lateral apertures supposed to be stigmatic in the $2 \mathrm{~d}, 3 \mathrm{~d}$, and 4 th ventral rings, thus having 6 in all.

A review of the position of the respiratory organs and their apertures in the various divisions of the Arachnoidea shows us that not only do several abdominal segments possess stigmata, but that these may occur, as is shown by the example of the Solmugide, in the thorax also. Leaving out of consideration the anterior position of the stigmata in certain Acarina, which are a very one-sidedly developed Arachnoid group, and evidently, excepting the Linguatulida, the furthest removed from the racial form, we are justified in assuming that the, to us, unknown racial form of the Arachnoidea possessed a larger number of stigmata $^{1}$ and of trachere connected with them than any Arachnoid form now living. This presupposes that the book-leaf tracheæ are modified tubular tracheæ.

\section{Sexual Organs.}

In all Arachnoidea the sexes are separate. The sexual organs lie in the abdomen. The testes and ovaries are either paired or single. The paired condition must be the more primitive. The ovaries in very many Arachnoidea appear as tubes beset with spherules or sacs, and so have a grape-like appearance. The eggs arise only in the sacs, which may be called egg-follicles, and they thence enter the ovarian tube, which serves only as a duct.

With very rare exceptions the ducts of the sexual organs are paired. These unite in their terminal portion, and open externally

1 See footnote on page 516 . 
through an unpaired rentral genital aperture at the anterior end of the abdomen. Several organs, chiefly accessory, are connected with the terminal portion of the ducts, viz. receptacula seminis, vesicula seminales, glands, male and female copulatory organs. The anatomical structure of the sexual apparatus in the different Arachnoidea varies greatly in detail. The review which follows is incomplete, and only takes into account the better known forms.

Scorpionidæ. Female Apparatus (Fig. 375, A).-Three longitudinal tubes, beset with spherical ovarian follicles, lie in the pre-abdomen, one median and two lateral. The median tube is comected with the lateral by 5 transverse anastomoses, also beset

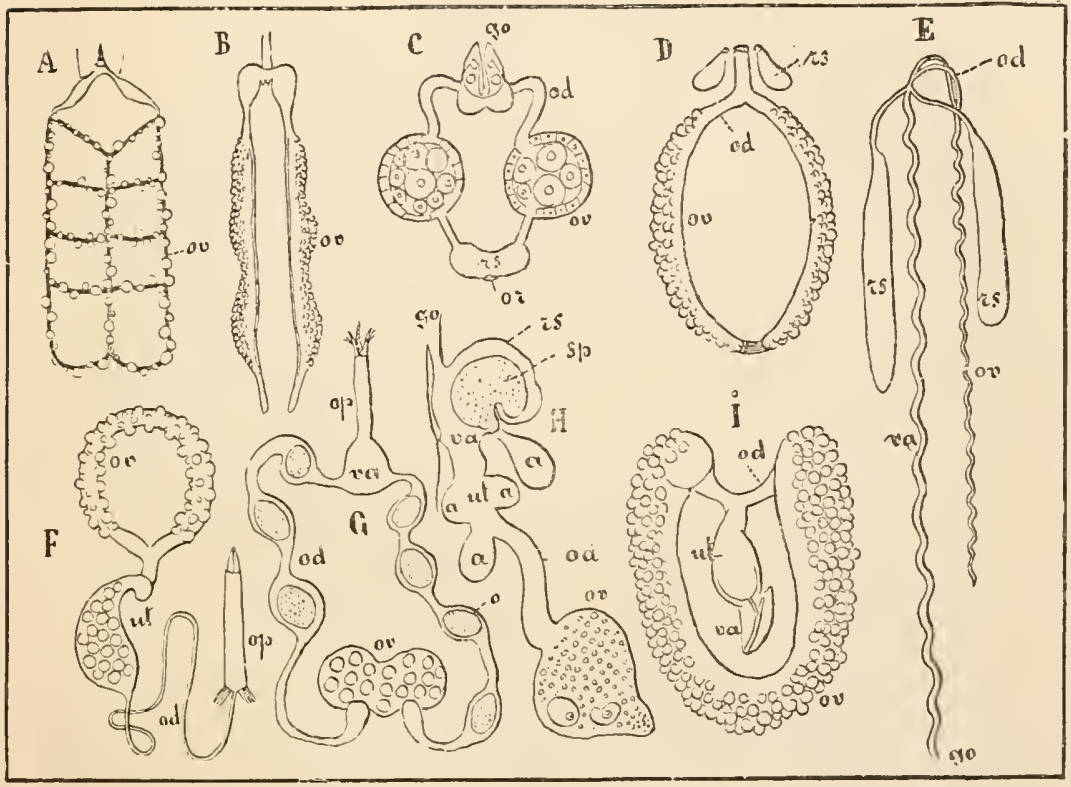

Fig. 375. - Female sexual apparatus of various Arachnoidea. Most of the figures are somewhat diagrammatic. A, Scorpio occitanus (after Blanchard). $B$, Galeodes barbarus (after L. Dufour). $\quad C$, Trichodactylus anonymus (Acarid) female sexual organs of the nymph (after Nalepa). $D$, An Araneid. E, Pentastoma tænioides (after R. Leuckart). F, Phalangium opilio (after Gegenbauer). G. Cepheus tegeocranus (oribatid) (after Michael). H. Gamasus crassipes (Acarid) (after Winkler). I, Trombidium fuliginosum (after Henking). ov, ovaries; od, oviduct; go, genital aperture; $r s$, receptaculum seminis ; or (in $C$ ), onter aperture of the same; $v($, vagina (in $E$ also the uterus); op, ovipositor ; $\alpha$, glanclular appendages.

with ovarian follicles, so that the ovigerous portion of the sexual apparatus forms a network of 8 meshes. From the anterior end of this there arises on each side an oviduct, which at once swells into a rather long tube (receptaculum seminis, or vagina?) The two tubes converge towards the ventral middle line, where they emerge on the first abdominal ring, in front of the combs, through an aperture which is corered by 2 valves. The Scorpionide are viviparous. The embryos derelop in the ovarial tubes, which function as uteri.

Male Apparatus (Fig. 376, $A$ ). - The tubular testes are distinctly paired. There 
are on each side two testicle tubes connected together by anastomoses. These two tubes unite anteriorly to form a sperm duct, which, joining the duct from the other side, opens outwardly at the place where, in the female, the genital aperture lies. Paired accessory organs are connected with the ducts, viz. copulatory organs, seminal vesicles, and glands.

Pseudoscorpionidæ. - The ovary is an mplaired tube beset with follicles, which is continued into two oviducts entering a short vagina. Numerous unicellular, and 2 long tangled tubular glands are connected with the ragina.

The testes in Chernes and Obisium recall in their form the ovaries of the Scorpionidce. In Chelifer, on the contrary, we find a single median testicle tube. There are everywhere 2 sperm ducts, entering a common copulatory apparatus, with which are comnected glands similar to those in the female. The nupaired genital aperture lies rentrally in both sexes on the boundaries between the $2 \mathrm{~d}$ and $3 \mathrm{~d}$ abdominal segments.
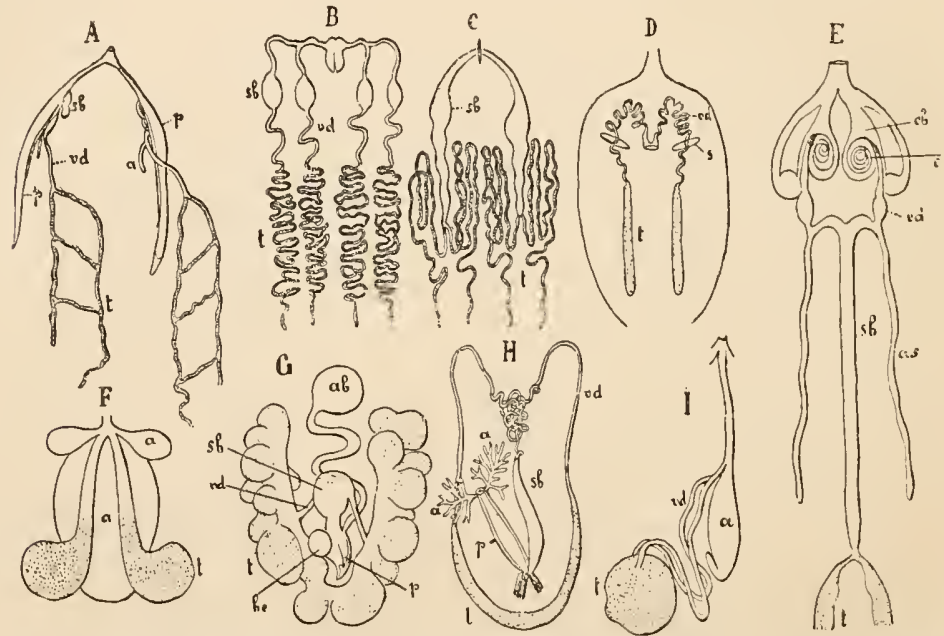

FIG. 376.-Male sexual apparatus of various Arachnoidea. Most of the figures are somewhat diagrammatic. A, Scorpio occitanus (after Blanchard). B, Galeodes barbarus. C, Galeodes nigripalpis (after Dufour). D, Philoica domestica (Araneid) (after Bertkau). E, Pentastoma tænioides, only the anterior end of the testes drawn (after Leuckart). F, Uropoda (Acarid) (after Winkler). $G$, Trombidium fuliginosum (Acarid) (after Henking). $H$, Phalangium opilio (after Krohn). I, Gamasus crassipes (Acarid) (after Winkler). The letters in all cases signify : $t$, testes (dotted); $v d$, vasa deferentia ; $s b$, seminal vesicle; $p$, penis; $a$, glandular appendages; $a s$, tubular appendages; $a b$, vesicular appendages ; $b c$, bursa expulsatoria ; $c$, cirrus ; $c b$, cirrus pouch.

Solpugidæ.-The female sexual apparatus (Fig. 375, $B$ ) consists of 2 long orarial tubes beset at their outer edges with numerous ovarian follicles, and placed in the abdomen. From each ovary there arises an oviduct. The 2 oviducts unite, their ends swelling. The external genital aperture is a longitudinal fissure on the ventral side of the first abdominal segment.

The male apparatus (Fig. $376, B, C$ ) consists of 2 thin and very long winding testicle tubes on each side of the abdomen, and quite separate from each other. These testicle tubes are continued into sperm ducts. The 2 sperm ducts of one side unite after a longer or shorter course into one duct, which, joining that from the other side, opens externally through a common aperture, which lies ventrally on the first abdominal segment. The ducts have either 4 or 2 swellings, regarded as seminal 
resicles; if there are 4 they lie in the course of the 4 sprem ducts, if 2 in the course of the 2 common efferent ducts.

Pedipalpi. - The ovaries and testes are paired with paired ducts, and a common unpaired genital aperture on the ventral side of the first abdominal segment. The Phrynidce are viriparous.

Microthelyphonidæ.-The germ glands (the ovaries at least) are said to be unpaired. There arc probably 2 oviducts, which open outward by means of a common terminal piecc on the ventral side of the first abdominal segment.

Araneidæ. Female Appraratus (Fig. 375, D).-There are in the abdomen 2 wide tubes, beset with numerous ovarian follicles, and looking like a cluster of grapes. The free ends of the ovaries sometimes fuse in such a way as to give rise to an unpaired circular ovary. There are always two short oviducts, uniting to form a short terminal portion (vagina), which emerges through the unpaired median genital aperture at the base of the abdomen, on the rentral side, between or somewhat behind the anterior pair of stigmata. All female Arancide possess receptacula seminis. There is either one receptaculum, or two lateral receptacula, less frequently three, one median and two lateral. These receptacula, into which, during copulation, the semen is introduced, are entirely separate from the sexual apparatus in many Arancidce, and have separate outer apertures near the female genital apertures. In other's they are accessory organs of the ragina. In Epcira each of the two receptacula has 2 apertures - an outer one, placed on the genital plate near the sexual aperture, and an inner one leading into the vagina.

Male Apparatus (Fig. $376, D$ ).-Two testes lie as long tubes in the abdomen, and are continued as 2 long thin and often much coiled sperm ducts, these opening ontward by means of a short wide common duct through the male genital aperture, which lies between the 2 anterior stigmata. The transition from the testes into the rasa deferentia is often gradual, so that it is difficnlt to say where the former leave off and the latter begin. Occasionally the blind ends of the 2 testes are united by connective tissue.

In the male sexual apparatus of the Arancide a special copulatory organ is wanting. The pedipalps of the male function as copulatory organs, their terminal joints (Fig. 37\%) being transformed in a peculiar manner. The inner side of this terminal joint carries an outgrowtl, through which runs a spirally coiled canal emerging at the pointed end. This canal is filled by the malc with sperm from the genital aperture. When copulation takes place the point of the outgrowth of the predipalp is introduced into the receptaculum seminis of the female, and the semen discharger from the spiral canal into the receptaculum.

Phalangidæ (Fig. 375, F, Fig. 376, $I$ ). -Both the ovaries and testes are here un-

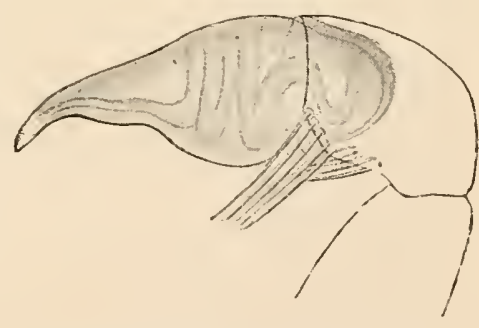

F\&. 37T.-Last joint of the pedipalp of Filistata testacea Latr. (after Bertkau).

paired. Each germ gland is a semicircular tube which, by analogy with the arrangement described in the Arancidce, may well be consiclered to have arisen by the fusing of the blind ends of originally paired germ glands. The ovarian tube is superficially beset with ovarian follicles. The 2 ends of the germ glands are continued into 2 ducts (sperm ducts in the male, oviducts in the female), and these unite to form a common duct which enters the copulatory apparatus. This, in the male, is a rod-like penis, in the female, a long cylindrical oripositor. Both the penis and the ovipositor are enclosed in special sheaths, and they can, together with their sheaths, be protruded and evaginated. The 2 vasa deferentia are very much coiled 
shortly before entering the common duct. Before the latter enters the penis, its wall becomes strongly muscular. This muscular portion of the duct evidently serves as a propelling organ for driving the semen out of the penis. A pair of accessory glands enters the end of the penis sheath.

In the female the common efferent duct has 2 divisions, the proximal division being enlarged into a uterus, which at maturity is filled with eggs, the narrow and long distal portion being a vagina which is continued into the ovipositor. The vagina has 3 lateral sacs, which are regarded as receptacula seminis. Accessory glands enter the end of the sheath of the ovipositor.

The genital aperture in both sexes lies ventrally, on the boundary between the cephalo-thorax and the abdomen.

It often occurs in the male Phalangidce that eggs develop on the surface of the testes; these apparently do not leave the body, but are reabsorbed.

Cyphophthalmidæ. - Here also the genital aperture lies ventrally at the base of the abdomen (on the first abdominal segment). The male has a long penis, the female a long ovipositor.

Acarina (Fig. 375, $C, G, H, I$, Fig. 376, F, G, I).-Great variety here prevails in the structure of the sexual organs. The following are 2 extreme cases. In the first there are 2 separate symmetrically-placed germ glands and 2 separate ducts, opening outwards through a common unpaired copulatory organ. We here see the more original arrangement. The other extreme is rare. It is found in the female of the Gamasidce (Fig. $375, H$ ), where a single unpaired ovary is continued into a single nupaired duct, which opens outwards through the copulatory organ. Transition forms between these 2 extremes are very commonly found. The 2 germ glands fuse in various ways to form one, which sometimes still shows traces of its originally double character ; the ducts, however, remain separate to a greater or smaller extent.

Accessory organs, glands, receptacula seminis are often connected with the ducts. The unpaired terminal portion of the ducts nearly always leads to the outer sexual apparatus, which in the male is the penis, and in the female may be developed as an ovipositor. There are often found near the genital apertures adaptations (e.g. suckers) which assist in copulation. The sexual organs are by no means limited in position to the posterior part of the body, on the contrary, the fact that they oftenirun far forward shows the extent to which the concentration of the whole body and the obliteration of the boundary between the cephalo-thorax and the abdomen have taken place. The aperture of these organs often lies far forward also, in some cases as far forward as between the most anterior pair of legs. It has been observed in the Tyroglypha (Trichodactylus anonymus) that the genital aperture which in the adult female lies between the $2 d$ pair of legs, in the last larval stage (before the last moult) still lies between the last pair. This observation also throws light on the anterior position of the stigmata in many mites, which must be attributed to displacenent.

As in the Arancidce, so also in ccrtain Acaridce there occur in the females receptacula seminis with apertures separate from the rest of the sexual apparatus. Trichodactylus thus has a receptaculum at the posterior end of the body, opening outward through a post-anal aperture. The penis is introduced into this aperture during copulation. The receptaculum is comnected by 2 short tubes with the 2 ovaries. This arrangement and that found in Epeira recall to a certain extent the well-known arrangement in the Trematoda and Cestoda, where the female sexual apparatus is connected with the exterior not only by means of the usual genital aperture, but by Laurer's duct as well. In Trichodactylus the receptaculum arises independently by an invagination of the integument, and becomes connected with the ovaries only secondarily.

Some Acarina are vivinarons, others ovoriviparous, i.e. the eggs develop to a 
certain extent within the mother body, so that the young is hatcherl soon after the laying of the egg. Ilost Acarina, however, are oviparous. The eggs or cmbryos collect often in great numbers in the expanded oviducts, which then function as uteri.

Linguatulidæ. Female Apparatus (Figs. 375 E, 378). - The ovary is a long unpaired tube, beset with ovarian follicles, which runs through the body over the intestine in a longitudinal direction. It is continued anteriorly into 2 oviducts, which surround the œsophagus, and under it enter the anterior end of the unpaired ragina. This serves at the same time as uterus, the first embryonic development of the eggs taking place in it. The vagina is an musually long tube which runs backward with many windings, accompanying the intestine, and is often filled with several hundreds of thousands of eggs and embryos ; it opens outward through a female genital aperture close to the anus. The ducts of 2 long receptacula seminis, whieh lie at the 2 sides of the mid-gut, enter the most anterior end of the vagina at the point where the oriducts join it.

Male Apparatus (Fig. 376, E). - The testes are paired or umpaired tubes placed like the ovary. The testis or testes are continued anteriorly into an unpaired efferent division, which has been regarded as a seminal vesicle. This vesicula seminalis divides anteriorly into 2 canals, the vasa deferentia, which encircle the cesophagus. Each vas deferens ends in a male copulatory apparatus. The male genital aperture eommon to the 2 copulatory apparati lies, in contradistinction to that of the female, in the anterior portion of the hody, between the $2 \mathrm{~d}$ pair of hooks. Corresponding with the recertacula seminis of the female there are in the male 2 blind tuhes rumning backward, thesc are apparently organs for propelling the semen, and enter the 2 sperm ducts. The end of each sperm duct enters a very long chitinous cirrus, which at a time of rest is rolled up in a speeial sae.

\section{Ontogeny.}

We can only bring forward a few facts concerning the ontogeny of the Arachnoidea, chiefly sueh as are of most importance from the point of view of eomparative anatomy.

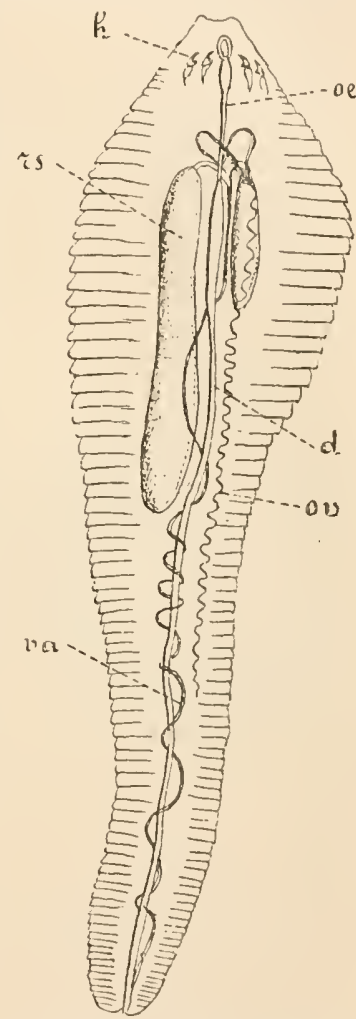

FIg, 37S.-Female of Pentas. tomum tænioides at the time of copulation, with the viscera (after Leuckart). h, Hooks; oe, asophagus; $r s$, receptacula seminis, one of which is still empty; $d$, gut; ov, ovary ; $v a$, vagina.

1. The segmentation is in the main that of the centro- or mesolecithal eggs. A blastoderm is formed covering the jolk, in which, however, meroeytes remain. The formation of the germ layers and of the rudiments of the most important organs proceeds, as in other Arthropoda, from a blastoderm plate, which may be ealled the embryonie rudiment. In the Scorpionida, however, the egg seems to be meroblastieally telolecithal, and the furrowing takes a corresponding course, so that no blastoderm enveloping the yolk on all sides is formed, but a germ disc is developed at one pole of the egg. 
2. Embryonic envelopes have till now only been found in the Scorpionide. The embryonic envelope here, as in the Insecta, consists of 2 membranes, the outer repre-

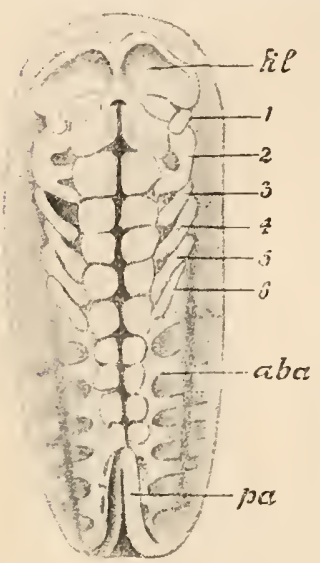

Flc.379.-Embryo of a Scor. pion, spread out flat, from the ventral side (after Metschnikoff). $k i l$, Frontal lobes; 1 , cheliceræ; 2, pedipalps ; $3 \cdot 6$, the 4 pairs of legs; $a b a$, rudi. ments of the abrominal limbs; pa, post abdomen.

\section{,} senting the serosa, the inmer the amnion of the Hcxapoda.

3. The formation of segments in the embryonic rudiments takes place as a rule from before backward, so that new segments are continually formed from the terminal segment behind those already developed. Fre'juently, however, the segment bearing the cheliceræ, and sometimes that bearing the pedipalps, appear only after the formation of a few of the subsequent segments.

4. The rudiments of the extremities seem in various Arachnoidea to have different orders of succession. The permanent extremities, with the exception of the chelicerre, which begin to form later, often develop simultaneously. In the Pseuloscarpionidec the rudiments of the extremities are even said to be recognisable before the marking off of the segments on the embryouic rudiments.

5. In all Arachnoidea, except the Linguatulida, the body is, in its embryonic condition, more richly segmented than in the adult animal. The cephalothoracic region especially shows embryonic metamerism. This region consists at certain embryonic stages of a cephalic or frontal lobe, in which the stomodxum and the definitive oral aperture form, and of 6 subsequent and thus post-oral segments, the 1st being that of the chelicerr, the $2 d$ that of the pedipalps, while the 4 others are the segments of the 4 following pairs of extremities. In the abdomen also, even when there is no metamerism in the adult animal, segmentation is to be recognised in the embryo. The number of the embryonic abdominal segments in the varions divisions of the Arachnoilea, however, differs greatly.

It is a specially important fact that the segment bearing the cheliceræ is in the embryo post-oral. No extremities develop on the frontal lobe, where, in the Crustacca, Protrachcata, and Antennata, the antemne form. ${ }^{I}$ From this fact it follows that there is no corresponclence between the chelicere of the Arachnoidea and the antenure of the Antennata.

The appearance of rudimentary abdominal limbs in the embryos of many Arachnoidea has aheady been mentioned; some of these rudiments disappear later, some, however, are retained (c.g. the combs of the Scorpion, the spinning mamnille of the Arancide $)$.

6. What has been sail about the relation of the embryonic metamerism of the body to the definitive metamerism of the same is also true of the nervous system. Investigations show that in the Scorpionidee and Arancidce a pair of ganglia forms in each embryonic segment. The embryonic pair of ganglia of the frontal lobe is the rndiment of the supra-cesophageal ganglion. In the first post-oral segment a special ganglion for the cheliceræ is developed, which only secondarily joins the supracesophageal ganglion, forming with it the brain. In the Antennata and Protrachcata, on the contrary, the antenne are from the very first imnervated from the preoral supra-cesophageal ganglion. Each of the following embryonic segments except the terminal segment in like mamner possesses 1 pair of ganglia. The more or less 
concentrated form of the nervons system of the adult animal arises in conseruence of the fusing of pairs of ganglia which were separate in the embryo. The whole central nerrous system arises in a manner similar to that in other Arthropodu.

7. The Mesoderm of the Arachnoidea at a certain embryonic stage is developed just as in the Anmelata, Protracheata, Antennata, and perhaps also the Crustacca, in the form of 2 lateral segmented streaks or bands with segmental cavities.

8. The fore- and hind-guts develop in the well-known way as invaginations of the ectoderm (stomodreum and proctodeum). Opinions still differ as to the manner of formation of the tube of the mid-gut.

8. The first rndiments of the lungs (book-leaf trachere) apprear as invaginations of the ectoderm, and thus in the same way as the trachere in the Antennata.

10. Most Arachnoidea when born or hatched from the egg resemble the adult. As far as we know, a post-embryonic metamorphosis occurs only in the Pscudoscorpionidec and Acarince. The former are hatehed in a rery imprerfect condition, bnt

B

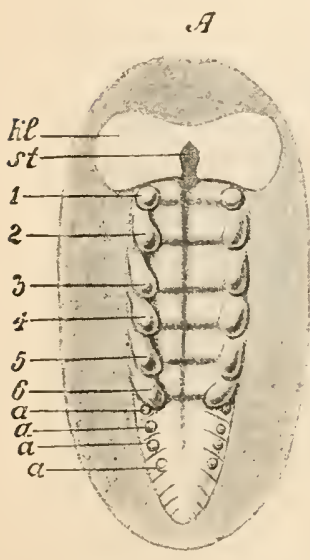

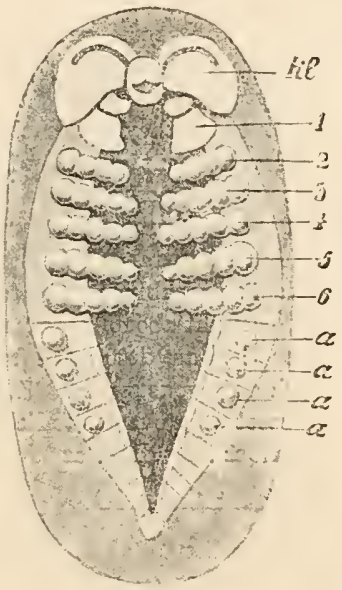

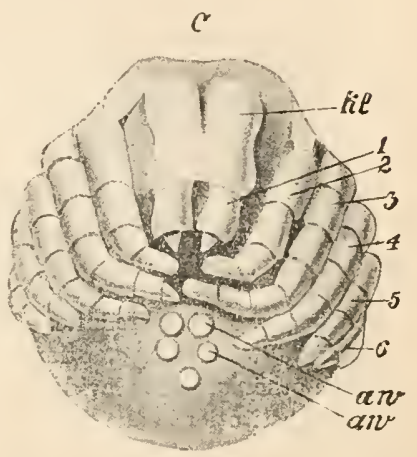

Fig. 3S0.-A, $E, C$, Embryos of Agelena labyrinthica at three stages of derelopment; in $A$ and $B$ supposed to be spread out flat, in $C$ in the natural form from the ventral side ; $7 l$, frontal lobes ; st, stomodæum; $1-6,1$ st to 6 th pairs of extremities (of the cephalo-thorax); viz, 1, the cheliceræ; 2 , the pedipalps ; $3 \cdot 6$, legs; $a$, rudiments of abdominal limbs; $\alpha w$ in $C$ spinning mammilla (after Balfour).

remain for some time (parasitically) attached to the body of the mother, who earries the eggs about with her. The young larve of the Acarina (Fig. 361, 1). 514) are still devoid of the last pair of extremities, i.e. of the 4 th pair of legs. The metamorphosis in the Acurina is often very complicated, and is accompanied by many monlts. Sometimes several pupal and larval stages occur. In such cases the metamorphosis is accompanied by the same inner processes as in the Insecta with complete metamorphosis, i.e. by the breaking up and disappearance of larval organs, and by the formation of the definitive organs ont of imaginal portions of the larva. The development and life-history of the Lingualulide were briefly described in the systematic review. The ontogeny of this gronp yields no data for deciding their systematic position.

\section{Phylogeny.}

The Arachnoidea form a sharply demarcated natural division of the Arthropode. Leaving the Linguatulide ont of consideration, there can be no doubt as to the 
relationship of the various orders united in this class. There is, further, no doubt that those Arachnoidea whose bodies are most richly segmented have best preserved the original character. These are the Scorpionide, on account of the rich segmentation of their abdomen and abdominal nervous system, and the Solpregider, on accomnt of the segmentation of that part of the body which answers to the cephalo-thorax of other Arachnoidea; this cephalo-thorax consists of an anterior section and three subsequent segments, which may be comprared with the head and three anterior trunk segments of the Antennata. For such a comparison, however, further data as to the structure and development of the Solpugidce are needer.

The Acarina, with their highly concentrated organisation, are evidently the furthest removed from the racial form of the Arachnoidea. The other divisions in various points take intermediatc positions, and may be used as examples of progressive concentration.

It is by no means proved that the Linguatulide belong to the Arachnoidea. We are not even in a position strictly to prove that they are Arthropoda. It is, in any case, quite possible that the Linguatulide are mite-like animals greatly modified by parasitism, but they might just as well be degenerate descendants of other Arthropoda. Definite data are wanting for deciding whether the want of a respiratory and bloodvascular system is original, or has only arisen secondarily through parasitism. The presence of 2 pairs of hooks does not prove that they are Arachnoidea or indeed Arthropodc at all. The history of their development also affords us no assistance. The position of the female genital aperture at the posterior end of the body is unusual in the Arachnoidea, The diverticula of the mid-gut so common among the Arachnoidea are wanting here. The reduction of the central nervous system to an osophageal ling with several cesophageal ganglia is probably connected with the reduction of sensory organs, extrenities (?), etc., brought about by parasitism, but this does not help to decide the question whether they are descended from Arachnoidea and not from other animals provider with snch a nervous system. There finally remains only the constitution of the ovarial tubes beset with ovarian follicles, which specially recall the Arachnoid arrangement, and opinions may differ as to the value of this point of agreement.

The question as to the systematic position of the Arachnoid class in the Arthroporlan system is still a matter of discussion. There are two views on this subject. According to one of these views the Arachnoidea are nearly related to the Xiphosura and fossil Gigantostrued ; these three would then together form a third subphylum of the Arthropoda, distinct both from the Crustacea and the Antennata. According to the other view the Arachnoidea are racially connected with the Antcnnata, and form with these and the Protracheata the subphylum of the Tracheata. At present we prefer the latter view, and consider the Arachnoidea as Trachcata which have lost their antennæ, ${ }^{1}$ while the first postoral pair of limbs, homologous with the mandibles of the Antennata, has been pushed forward, so that in all adult Arachnoidea they are inserted in front of the mouth. The cephalo-thorax of the Arachnoidea would then correspond with the fused head and thorax (3 anterior trunk segments) of the Antennata, and we thus perhaps find in the segmentation of the cephalo-thorax in the Solpugidce a primitive arrangement. If this supposition should prove correct, then the comparison of the other organs presents no very great difficulties. In judging of the systematic position of the Arachnoidea, their relationship to the Antennate is strongly supported by the facts that the Arachnoidea possess both Malpighian vessels and tracheæ, which are wanting in the Crustaceans as in the Xiphosura.

In the Antennata, the mandibles and the 2 pairs of limbs of the head which 
follow them are either not at all or very little like legs, they are changed into mouth parts. In the Arachnoidea, the appendages which lrobably correspond with them (the chelicere, the pedipalps, and the 1st pair of legs) have preserved far better the character of long-jointed extremities. Now, since we can find no justification in comparative anatomy or ontogeny for deriving long many-jointed extremities from abbreviated and specialised mouth-parts adapted for chewing, sucking, etc., but are, on the contrary, distinctly justificd in assuming that the opposite process is the usual one, we conclude that the racial form of the Arachnoidea branched off from the racial form of the Antennata very early, at a time when the limbs lying directly belind the mouth were not yet changed into specialised mouth-parts. The Arcehnoiden (Cheliecrota) on the one hand, and the Antennata on the other, would thus represent two branches diverging early from the Tracheate trunk. The Protracheata cannot, it is true, be placed at the root of this trunk, but may still in many points of their organisation nuch more faithfully retain the primitive condition than clo the Arachnoidea and Antenncte, and may thus to a certain extent represcnt an offshoot from the root.

The above statements must make the relationship of the Arachoidea and especially of the Scorpionicke with the Xiphosura and Gigantostrace aplyear at present doubtful. At the same time it cannot be denied that the limbs of the cephalothorax in the Arachnoidea show a remarkable agreement with those of the Xiphosurce and Gigantostraea, a much greater agreement than with the corresponding limbs of the Antennata. The want of preoral limbs comparable with the antemne is also a point of agreement not to be underestimated. ${ }^{1}$ But we may possibly have here only a phenomenon of convergence. The agreement in the rest of the organisation, leaving out of account characteristics common to all Aithopoda, appears to us not so great as to justify a nearer relationship based upon it. Even if the occurrence of rudimentary abdominal limbs forces us to assume that the ancestors of the Arachnoidea possessed abdominal limbs, the same is true of the Hexapoda also, the Myriapoda still possessing limbs on all the trumk segments.

The comparison of the book-leaf trachee with the book-like gills of the Xiphosure seems far-fetched compared with their derivation from the tufted tracher. The assumption that the tubular trachex in the Arachmoida have arisen independently of those of the Protracheata and Antennata can only be resorted to as a makeshift. Malpiglian vessels are wanting in the Xiphosura. The sexual organs may emerge at very different regions of the body in the Antennata, as was seen as early as in the Mryriapoda, and therefore no very great weight should be attached to the circunstance that their position is almost similar in the Arachnoidea and the Xiphosura. The prescnce of coxal glands, which emerge in the Arachnoidea and Xiphosura on the third pair of legs, does not bear much upon this question, since, on the one hand, coxal glands may occur on other pairs of legs as well in the Arachnoidea, and on the other, these glands are very widely distributed anong the Protracheate and Antemata (esprecially Hyriapoda), and apparently were originally found in all the pairs of legs, as is still the case in the Protrachectu.

In any case further investigations as to the relations betreen the Arachnoidea and the Xiphosura cannot but be fruitful, and may throw much light upon the as yet by no means solved problem of the relationship of the two grouls.

The Pantopoda (Pyenogonidce) are also often considered as related to the Araclnoidea, a vicw whieh was arrived at originally in consequence of the great sinilarity in alpearance of the two groups. This view had, however, to be abandoned when their organisations were more closely comprared ( $c f$. 1. 424). 


\section{Review of the most important Literature.}

\section{Anatomy.}

Ph. Bertkau. Ueber den Generationsapparat der Araneiden. Archivf. Naturgeseh. 41 Jahrg.

The same. Beiträge zur Kenntniss der Sinnesorgane der Spinnen. Areh. f. mikr. Anatomie. $27 \mathrm{Bd}$.

The same. Ueber die Respirationsorgane der Araneen. Areh. $f$. Naturg. $38 \mathrm{Bd}$. 1872.

The same. Ueber das Cribrcllum und Calamistrum. Ein Beitrag zur Histiologie, Biologie und Systematik der Spinnen. Archiv für Naturgeschichte. 48 Jahrg. 1882.

The same. Ueber den Bau und die Funktion der sogen. Leber bei den Spinnen. Arch. f. mikr. Anat. $23 \mathrm{Bd} .1884$.

The same. Ueber den I'erdaungsapparat der Spinnen. Arch.f. mikr. Anatomic. $24 \mathrm{Bd} .1885$.

Edouard Claparède. Etudes sur la cireulation du sang chez les Aranécs du genre Lyjose. Hémoires Soc. Physique ct d'Histoire natur. Geneva. $17 \mathrm{Bd} .1863$.

The same. Studien an Acariden. Zeitsehr. f. wiss. Zool. 18 Bd. 1867-1868.

G. Cuvier. Le Riène animal. Nouv. Edition. Paris, 1849. Insectes, Arachnides, Crustacées von Audonin, Blanchard, etc.

L. Dufour. Histoire anatomique et physiologique des Scorpions. Mém. Acad. Sciene. Savants étrangers. XIV. 1856.

The same. Anatomic, Physiologie et Histoire naturclle des Galéodes. Mémoires de l'Acad. d. Seiences. Paris. Savants étrangers. XVII. 1858.

Hugo Eisig. Monographie der Capitelliden des Golfes von Neapel. Berlin, 1887. (Contains the morphological significance of the coxal glands, spinning glands, etc. of the Arachnoidea.)

Batt. Grassi. I. Progenitori dei Miriapodi e degli Insetti. V. Intomo ad un nuovo aracnide artrogastro. Boll. Societì entomol. italiana. XVIII. 1886.

Hermann Henking. Beiträge zur Anatomie, Entwicklungsgeschichte und Biologie von Trombidium fuliginosum. Zcitsehr. für. wiss. Zool. 37 Bd. 1882.

W. E. Hoyle. On a new Specics of Pentastomum (P. protelis), from the Mesentery of Proteles cristatus. Transact. Roy. Society, Edinburgh. Vol. XXXII. 1883.

G. Joseph. Cyphophthalmus duricarius. Berliner Entom. Zeitschr. 1868.

E. Ray Lankester. Limulus an Arachnid. Quart. Journ. Microse. Seience. N.S. Vol. XXI. 1881.

E. Ray Lankester and A. G. Bourne. The minute structure of the lateral and of the central eyes of Scorpio and of Limulus. Quart. Journ. Hierose. Science. N.S. Vol. XXIII. 1883.

Rud. Leuckart. Ueber den Bau und die Bedeutung der sog. Lungen bei den Arachniden. Zeitsehr. f. wiss. Zool. 1 Bd. 1849.

The same. Bau und Entwickclungsyeschichte der Pentastomen. Leipzig and Heidelberg. 1860.

J. MacLeod. La structure des trachées et la circulation péritrachéenne. Brussels. 1880.

The same. Recherches sur la structure et la signification de l'appareil respiratoire des Arachnides. Arch. Biolog. Tome V. 1884.

A. Menge. Die Shecrenspinnen. Sehriften der naturf. Gesellsch. zu Danzig. 1855. Albert D. Michael. British Oribatidec. Ray Society. London, 1884.

Nalepa. Die Anatomic der Tyroglyphen. I. Abth. Sitzber. math.-naturwiss. Classe. 
Akademie Wissensch. Wien. $90 \mathrm{Bd}$. 1585. II. Abth. Ibid. $92 \mathrm{Bd}$. I. Abth. 1886.

Newport. On the structure, relations, and development of the nerrous and cireulatory systems in Myriapoda and macrourous Arachnida. Philos. Transuct. I. 1843.

R. Rössler. Beiträge zur Anatomie der Phalangiden. Zeitschr. f. wiss. Zool. 36 Bd. 1882.

Robert von Schaub. Ueber die Anatomie von Hydrodoma. Ein Beitrag zur Kenntniss der Hydrachniden. Sitzber. Alial. Wiss. Wien. math-naturw. Classe. 97 Bd. 1888 .

Wladimir Shimkewitsch. Étude sur l'anatomie de l'Épeire. Annales Scienc. natur. $6^{0}$. Tome 17. 1884.

Anton Stecker. Anatomisches und Histiologisches über Gibbocellum, eine neue Arachmide. Arch.f. Naturgesch. 42 Jahrg. 1876.

Alfred Tulk. Upon the anatomy of Phalangium Opitio. Ann. Magaz. Nat. Hist. Vol. XII. 1843.

Bernh. Weissenborn. Beitrigge zur Phylogenie der Arachniden. Jenaische Zeitschr. f. Naturwissensch. 20 Bd. N. F. 13.1885 (with Bibliograplry).

Willibald Winkler. Das Herz der Acarinen nebst vergleichenden Bemerkungen über das Herz der Phalangiden und Chernetiden. Arb. Zool. Inst. Unirer's. Wien. 7 Bd. 1886.

The same. Anatomie der Gamasiden. Arbeit. Zool. Inst. Vinirersität Wien. ; Bd. 1888.

Other authors: De Graaf, Loman, Krohn, Henking, Horn, Dahl, MacLeod, Ehlers, Karpelles, Stecker, Oeffinger, Croneberg, Pelseneer, Bertkau, Lohmam, Kramer, Haller, Menge, Parker, Pagenstecher, O. P. Cambridge, Ray Lankester, Gulland, Meckel, Plateau, Abendroth, P. J. van Berreden, Blanchard, Brandt, Gerrais, Mégrin, Grube, J. van der Hoeven (on Phrymıs), Leydig, Nicolet Lucas, Kittary, Dugès, Treviranus, Hutton, Hasselt, Foch, Blanc.

On Acarina many works of Kramer and Haller.

\section{Ontogeny.}

F. M. Balfour. Notes on the development of the Araneina. Quart. Joum. Nicr. Science. Vol. XX. 1880.

Edouard Claparède. Recherches sur l'érolution des araignées. Natuurk. I'erhandl. Provinciaal Ltrechtsch genootschap van Kunsten en Wetensch. Deel I. Utrecht 1862.

William Locy. Observations on the development of Agelena neria. Bullet. Hus. Comp. Zool. Havard Coll. Cambridge. Vol. XII. 1886.

El. Metschnikoff. Embryologie des Scorpions. Zeitschr. f. uissensch. Zoologie. 21 Bd. 1870.

The same. Entwicklungsgeschichte von Chelifer. Zeitschr.f. wissensch. Zoologic. 21 Bd. 1870.

W. Schimkewitsch. Etude sur le déreloppement des Araignées. Arch. Biol. Tome 6. 1887.

Other authors: Rathke, Balbiani, Barrois, Herold, Ludwig, P. J. van Beneden, Claparède, Henking, Kowalersky and Schulgin, Morin, Jaworowski (in reference to note on 1. 516). 


\section{Appendage to the Race of the Arthropoda.}

\section{The Tardigrada, or Bear Animalcule.}

The body of these small animals, which does not exceed $1 \mathrm{~mm}$. in length, is cylindrical or a long oval ; it is outwardly unsegmented, and carries 4 pairs of short truncated appendages armed with claws, and not marked off from the body loy joints. The last pair of these appendages lies at the posterior end of the body. The most anterior portion of the body is either narrowed like a proboscis, or marked off

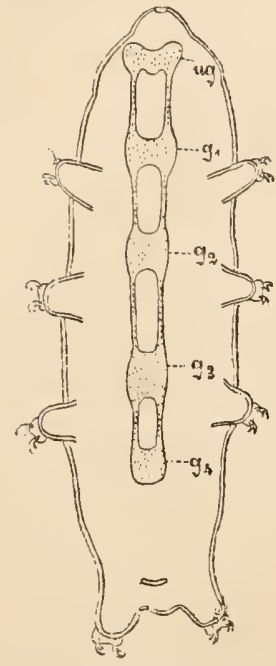

F1G. 381.-Macrobiotus Hufelandii. Outlines of the body and ventral chord. The supra-œsopliageal ganclion is not represented. $v g$, Infra-œsophageal ganglion; $g_{1}, g_{2}, g_{3}, g_{4}$, the 4 following ganglia (after Plate).

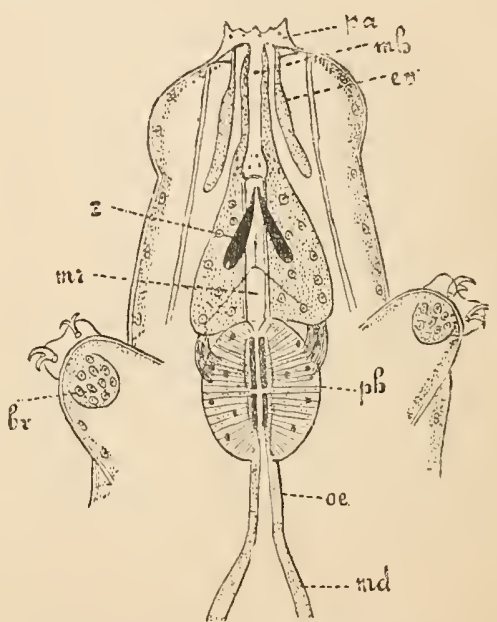

Fig. 3S2.- Head of Doyeria simplex, from the ventral side. The nervous system not drawn. $p a$, Oral papillse; $m h$, oral cavity ; $e v$, lyspodermal thickenings near the mouth (glands?); $z$, teeth; $m \imath$, oral tube; $p h$, pharynx; oc, cesophagus; $m d$, mid-gut or stomach intestine; $b v$, hypodernal thickenings (leg glands? coxal glands?) in the feet (after Plate).

like a head. The body is covered by a probably chitinous euticle, which is thrown off from time to time (ecdysis). 'The mouth lies at the anterior, and the anus at the posterior end of the body. In the straight digestive tract which passes through the colome the 3 wellknown regions, the fore-gut, mid-gut, and hind-gut (rectum) may be distinguished. The oral aperture, which is surrounded by papillæ, and in some cases by setæ, also leads into an oral cavity, into which project the pointed and sometimes calcified ends of 2 teeth. Two pear-shaped or tube-like glands (salivary glands? poison glands?) enter the oral cavity. The oral cavity is followed by a generally narrow oral tube, which swells out at its posterior end into a muscular, spherical, or eggo-shaped œesophageal bulb (pharynx). Between the mid-gut (stomach) 
and the oesophageal bulb an osophagus is intercalated. Two blind tubes enter the rectum, no doubt corresponding with the Malpighian vessels of the Trucheuta.

The sexes are separate; the germ glands umpaired, and sacshaped. In both sexes they enter the hind-gut, which thus becomes a cloaca. Special circulatory and respiratory organs are wanting. The nervous system consists of a brain, an infra-nesophageal ganglion which is connected with the brain by two oesophageal commissures, and 4 other rentral ganglia, which are connected by longitudinal commissures placed far apart from one another. There are two eye spots in the head, lying on two small gąnglia comnected by nerves with the brain. The musculature is richly developed. Tarious dorsal, ventral, and lateral longitudinal muscles run under the integument. Special muscles serve for moving the legs. All the muscles are smooth.

The systematic position of the Tardigrada is uncertain. The three related facts that they possess accessory organs of the hind-gut comparable with the Malpighian vessels, tubelike oral glands, and truncated fect provided with claws, make it not improbable that they belong to the Arthropoda, and especially to the Tracheata. The want of oral limbs, the structure of the nervous system, and the manner of emergenee of the sexual organs, stand in the way of a eomparison of the Tardigrada with the Acarina. Although we may agree with the view that they are somehow related to the Tracheata, or to the ances-

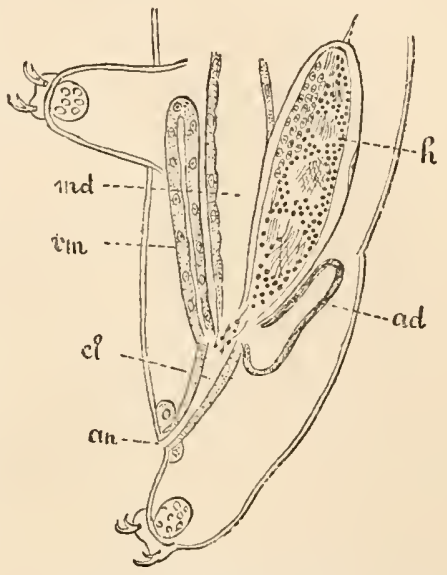

Fig. 3\$3.-Posterior portion of the body of Macrobiotus Hufelandii \& , from the side. $h$, Testis; $a d$, accessory gland of the male sexual apparatus ; $c l$, cloaca ; an, anus; vm, excretory tube (Malpighian vessel); $m d$, mid-gut (after Plate). tors of the Tracheata, we cannot in any case assume that they, in any way, resemble the primitive arrangements. The want of a blood-vascular system, the unpaired germ glands, the reduced and abbreviated condition of the whole body, the absence of nephridia and of eoxal glands (?), rather make the Tardigrada appear as a onesidedly developed lateral branch.

Most of the Tardigrada live among moss and lichens, a very few in fresh or salt vater. They can stand desiccation, and remain apparently dead for a long time, réviving again when wetted. Echiniscus, Macrobiotus, Milnesium, Doyeria.

\section{Literature.}

Ludwig H. Plate. Bciträge zur Naturgesehiehte der Tardigraden. . Zool. Jahrbüeher von Spengel, Abth. für Anatomie und Ontogenie. $3 \mathrm{Bd}$. 18s8. In this treatis there is a bibliography up to 1888 . 



\section{IN D E X}

Numbers in Italics give Systematic Position. Numbers in Black Type refer to Figures.

A BDOMINALIA, 292

Abyla, 70

Acantharia, 6

Aconthia, 440

Acanthin, 16

Acanthocephala, 180

Acanthodrilus, 181

Acanthometra, 6

Acanthocystis, 6

Acarina, 510

Accessory intestine (Vermes), 206

Acheta campestris, sexual organs, 486

Achromatin, 35

Achtheres, 291

Acidaspis, 415

Acineta, 11

Accela, 134

Acone eyes (Insecta), 470

Acontia, 83

A cotylea, 133

A crospedc, 71

Acridiidde, 439

Acridium tertaricum, 474

Acronyctides, 443

Actinaria, 71

Actinia, 71

Actinocephalus, 9

Actinophrys, 6

Actinophrys sol, 6

Actinosphorium, 6

Actinotrocha, 272

Aculeata, 44:

Adamsia, 71

Adradii, 74

EEga, 295

Eigineta, 69

Eginopsis, 69

Elosoma, 181

Equorea Forskalea, 68; auditory vesicles,

\section{5}

Eschna, 439 ; sexual organs, 485

Agalma, \%o

Agulmopsis, 113
Agelena, 510

" labyrinthica, embryo, 539,

Aglantha digitalis, 69

Agnostus, 415

Agrion, 439

Arotide, 442

Alary muscles, 475

Alcippidee, 292

Aleyonaria, 70 ; gemmation, 107

Alcyonella, 184

Alcyonium, 70

Alcyonidium, 184

Alcyopidae, 182

Aletes, 510

Aletia, 463

Alima type of larva, 393

Allantonema mirabile, 200

Alloiocoelc, 134

Allolobophora, 181

Allurus, 181

Alma nilotica, 246

Alpheus, 298

Alternation of generations (Protozoa), 21 ; (Cnidaria), 115; (Vermes), 267 ; (Antennata), 502

Alydus, 440

Amalthoidar, 90

Ametabole, 491

Ammothea, 424

Amnion, 434, 493

A moeba, 4

$$
\text { ", polypodia, 3, } 12
$$

Amoebince, if

Amphiasters, 35

Amphiglene, 234

Amphilina, 134

Amplinomida, 182

Amphipoda, 296 ; circulatory system, 362

Amphiporus, 17S

$$
\text { , Moseleyi, } 220
$$

Amphipneustic tracheal system, 4 S2

Amphistoma, 134

A mphithö̈ penicillata, thoracic limbs, 318 
Amphitivitc, $18 ?$

Inacheta, 181

Analges, 510

Anceille, 295

Anchorella, 291

Anchylostoma, 180

Androctonus, 509

Anemonia, 71

Anguillula aceti, $17 \mathrm{~S}$

Anilocra, 295 ; pleopoda, 324

Anisopoda, 293

Anisospore, 20

Annulate (Amnelida), 180 ; diagram of pharynx, 202, 203; section, 237

Anomura, .998

Anonymus, 133

Antennate, 438-508

Anthea cereus, 50

Anthemodes, 70

Anthomedusce, 69

Anthophore, 492

Anthozoa, ro

Antipatharia, $\approx 1$

A phaniptera, 441

A phanoncura, 181

Aphida, 440

Aphis pelargonii, tracheal system, 481

A phroditea, $18 \%$

Aphrophora, 441

Apiclo, 442

Apis melifica, anatomy, 462, 463 ; sexual organs, 487

Aplysina, 62

Apoda, 992

Apolemia, $\% 0$

A pneustic tracheal system, 481

Apsendes, 293 ; anditory hair, 356 ; thoracic limbs, 318

A psendes Latrcillii nervous system, 346

Apterygota, 439

Apus, 28S; section, 315 ; larvæ, 383

,, longicaudatus, trunk feet, 316

,, lucasanus, mandibles, 311

Arachnoidea, 509-543

Arcncidce, 510 ; book-leaf tracheæ, 530 ; sexual organs, $\mathbf{5 3 3}$

Arcclla, 4

$$
\text { , vulgaris, } 3
$$

Archoostraca, 293

Archenteron, 37

Archiannelida, 181

Archigetes, 134

Arenicolide, 182

Argas, 510

Argiope, 185 ; larva, 273

Argulide, 291

Argulus, 291

, Corrcgoni nervous system, 346

, foliaceus, 291

Argyroneta, 510

Ariciidae, 18?

Arthrobranchiæ, 328

Arthropoda, 287-545
Arthrostraca, 293; thoracic limbs, 318

Articulate, 287

A saphus, 415

A scandra, 60

Ascarile, 180 ; section, 194

Ascaris lumbricoiles, 180 ; genital apparatus, 255

, nigrovenosa, 179

Ascones, 6?

Asellide, 295 ; thoracic limbs, 318

A sellus aquaticus, enteric canal, 340 ; geni-

tal apparatus, 374 ; nervous system, 346

A silidu, 443

Aspidiotus, 440

Aspidogaster, 143

A splencha, 185

Astacide, 298

Astacus furviatilis, 298, 298, 299; 21

antennæ, 310 ; antennules, 308 ; anterior

maxille, 312 ; cephalo-thorax, 326 ; for-

ceps, 335 ; gills, 327 ; mandibles, 311 ;

muscles, 334 ; nervous system, 346 ;

ontogeny, 399-406 ; pleopoda, 324 ; pos-

terior maxillæ, 313 ; sections, 338, 365 ;

segments, 333 ; sexual organs, 375 ;

thoracic feet, 323

Asterias glacialis, eggs, 31, 33

Asterope, 182

Astrea, 71

Astroides, 71

Atax, 510

Atructonema, 200

Atractosoma, 439

Attus, 510

Atypus, 510

Aulactinium, $\%$

Aulosphere, 7

actinastrum, 7

1 ulostomum, 181

A uralia, 70

A urelia aurita, 72 ; development of, 130

A uronecta, 70

Auropliore, 70

Autolytus, 182

Avicularia, 510

Avicularia, 267

Axolotl, 119

Axopodia, 14

BACILLUS, 439

Baetis binoculatus, segment, 483

Balanide, 299

Balanoglossus, 119

Balantidium, 9

Balanus, 29\%

Hameri, 303
,$\quad$ perforatus, trunk feet, 316
,$\quad$ tintinabulum, 304

Bdellida, 510

Belinurus, 417

Bcroida, 7\%

Bibionide, 443

Biogenesis, 118 
Bipalium, 133

Biryus, 299

", latro, sections, 328, 367

Bittrecus, 441

Blastoccel, 123

Blastoderm, 126

Blastomeres, 121-131

Blastopore, 57, 123

Blastula, 36, 57

Blatta, mouth parts, 446

, orientalis, nervous system, $: 468$

Blattido, 439

Bombycide, 442

Bombycina, $44^{2}$

Bombylliide, 443

Bonellia, 182 ; egg segmentation, 124

Bopyride, 295

Boreomysis scyphops, 321

Boreus, 441

Borlasia, $17 \mathrm{~S}$

Bostrychidoe, 4 '1

Bothriocephalus latus, 134; scolex, 164 punctatus, 15.4

Bougainvillca ramosu, 6S, 67, 104

Brochionus, 185

Brachiopoda, 184, 263

Brachoniloe, 442

Brachycera, 443

Brachydesmus, 438

Brachyurc, 299 ; development, 396

Bract, 112

Branchellion, 181

Branchial formula, Astacus, 329 ; Cancer pegurus, 329

Branchiata, $98 y$

Branchiobdella, 181

Branchiomma, 247

Branchiopode, $2 S S$

Branchiostegite, 307

Branchipus, 2SS ; mandibles, 311 ; section of eye, 354 ; tactile liair, 356 ; ontogeny, $39 \mathrm{~S}$

Branchiura, 991

stagnalis, 191

Breula, $44^{3}$

Brood capsule, 316 ; care of, 379 : carity, 380 ; chamber, 434 ; lamellæ, 321,378 ; plate, 319 ; pouch, 318

Bronteus, 415

Bryozoc, 183

Bugula, 184

Bunodes, $41 \%$

Buprestide, 443

Buthus, 509 , occinatus, anatomy, 517

Cenogenesis, 118

Calanella mediterranea, 353

Calappa, 293

Calcaria, 60

Calceoli, 356

Calcispongice, 60
Caligus, 291

Cullienassa, 99S

Cullianira, aboral pole and sensory horly, 97 ; development, 131

Calliaxis, gills of larva, 322

Callizona grubei, eye of, 230

Calopteryx, 439

Calyconceta, $\approx 0$

Crilymene, 415

Calymna, 6

Calyptopis larva, 389

C'ampanaria, 68

C'ampanularia geniculata, $6 S$

Campanulina tenuis, $6 S$

Campoder, 439

$$
\text { ,, staphylinus, } 444
$$

Campylaspis nodulosa, mandibles 311

Cancer, 300

Cuncrion miser, 379

Cannopilus, 7

Cannorhiza, \%?

$$
\text { , connexa, } 85
$$

Cannostome, 72

Cantharida, 441

Canthocamptus, 291

Capitellido, 181

Capitibranchiata, 18?

Camia nigre, larva and imago, 456

Caprella acutifions, 295

Caprollide, 296

Capsus, 440

Carabidee, 443

Carebus auratus, digestive al'paratus, 461

Curcinus, 300

Carchesium, 11

Caridido. 298

Carina, 304

Carinella, 1 s

Carmarina hastete, 69

Caryophyllows, 13 '

Camyophyllia, ry 1

Cassiopee, ry

Catallacta, 11

Cathammal plates, 74 , 78

Catometope, 300

reculomyia, 502

Cellepore, 184

Cellulose, 16

Centrotus, 441

Cephalodiscus, 184

Cephalogaster, 341

Cephalo-thorax, 302

C'epheus tegiocranus, sexual organs, 533

Cerambycida, 4 千 1

Ceraspongia, 6?, 61

Ceratiocaride, 293

Ceratium $S$, , Tripus. 9

Coratopsyllus, $4: 1$

Cercaria, 169

Corebratulus, 1\%S

Cerianthus, $\% 1$

Cestille, ris 
Cestoda, 134

Cestoplana, 133

Cetochilus, 291 ; development of, 385

, septentrionalis, 385 ; ontogeny, 398

Cetonia auruta, sexual organs, 485

Chcetogaster diaphanus, anterior part of body, 221

Chatogastrida, 181

Chotognatha, 185

Chaetopoda, 181

Chatozone, 253

Chalaza, 30

Challengeria, 7

Charybileidoe, n2

Cheirurus, 415 ," Quenstedtii, 414

Cheliceræ (Xiphosura), 417 ; (Arachnoidea), 515

Chelicerota, 509

Chelifcr, 509

,, Bravaisii $\mathbf{5 1 3}$

Chermes, 440

Chernctidoe, 509

Chilaria, 417

Chilodon, 9

Chilognatha, 438

Chilomonas, 8 , Paramocium, 8

Chilopoda, 438

Chilostomatc, 264

Chironomus plumosus, nervous system, 466 Chirodropus, 72

Chlö, 439 ; segment, 383

Chlorcemida, 1S?

Chloragogen cells, 213

Choanoflagellata, $S$

Chondracanthus, 291

Chondrosia, 61

Chordeumidce, 438

Chordotonal ligament, 472 ; organs, 472, 473

Chorion 28

Chromatin, 35

Chrysaora, 101

Chrysomelidee, 441

Chrysope, 441

Chthonius, 509

Cicada, 441

Cicindelidce, 442

Ciliata, 9

Cilioflagellata, 8

Cirolana, 295 , spinipes, posterior maxillie, 313

Cirratulidoe, 182

Cirri, 188

Cirripedia, 291

Cistelidoe, 441

Citigrada, 510

Cladocera, 289

Cladocora, ${ }_{1} 1$

Cladocoryne, 90

Cladonema radiatum, 68
Clathria, 61

Clathrulina, 6

Clausocalanus, 291

Clepsidrina, 9 mastigophorus, 290

Clepsine, 181

Clistonustus, 266

Clitellio, 181

Clitellum, 192

Cloen dimidiatum, segments of larva, 457

Clubiona, 510

Cnidaria, 66-132

Cnidoblast, 39

Coccida, 440

Coccinellida, 441

Colenterata, 58-132

Coloblastula, 123

Coelogastrula, 123

Coloplana Mecznikowi, 136

Coloplanula, 126

Conurus, 172

, cerebralis, 135

Coleoptera, 441

Collembola, 439

Collosendeis gigas, 424

Collosphcera, 6

Collozoum, 6

Columella, 99

Complementary males (Cirripedia), 305 ; (Myzostonida), 266

Conchoderma, 202

Conilera cylindracea, 361

Conocephalites, 415

Conopidoe, 443

Convoluta, 134 ; pharyngeal apparatus, 139

Copepoda, 290

Corals (Anthozoa), 70 ; section, 76

Cordilophora lacustris, 68 ; stinging cells, 81

Corethra, imaginal discs, 499

Coreus, 4.40

Corixa, 440

Corizus, 440

Cormidium, 70, 112, 113

Cornutclla, 7

Coronula, 293

Corophium, 296

, longicorne, thoracic limbs, 318

Corrodentia, 440

Cortina, 7

," typus, 7

Corycaus, 291

Coryclalis, 441

Cosside, 44\%

Cotylea, 133

Cotylorhiza, 72

Crab's eyes (gastroliths), 337

Crambessa, 72

Crangon, 298

Crania, 185

Craspedota, 67, 69, 73 ; diagram, 73 ; formation of, 105 
Crayfish, see Astacus fluviatilis

Crevettina, 236

Cribrellum, 522

Criodrilida, 181

Cristatella, 184

Crustacca, 2S8-413

Cryptoniscidoe, 296

Cryptopentamert, 441

Cryptophyalus, 292

Cryptops, 438

Cryptotetrama, 441

Ctenaria ctenophora, 68,80

Cteniza, 510

Ctenodrilus, 181 ,, monostylus, 267 , pardalis, 267

Ctenophora, ry?; adhesive cells, 81 ; development, 131 ; segmentation of egg, 125 ; sensory body, 79,96 ; swimming plates, 79,81

Ctcnoplana Kouvelevskii, 136, 137

Cubomedusa, 72

Cuculliedce, 443

Culex, mouth parts, 450

Culicide, 443

Culiciformes, 443

Cumacca, 297

Cunina, 69

, lativcntris, tentaculocysts, 95

Curculionidae, 441

Cyomida, 296

Cyanea, 72

Cyclometopa, 299

Cycloporus, 133

Cyclops, 291

, coronatus, posterior maxille, 313

,, serrulata, antennules, 308

,, signatus, $2 \mathrm{~d}$ antennx, 310

"tenuicornis, mandibles, 311

Cyclostomata, 264

Cydippilce, 79

Cylicobdclla, 259

Cylindrostome, 156

Cymothoa ostroides, sexual organs, 381

Cymothoidea, 295

Cynipida, 449

Cyphonantes, 271

Cyphophthalmide, 509

Cypridince, 290

$\begin{array}{ll}, & \text { mediterranea, } 289 \\ , & \text { mcssinensis, posterior maxillæ, } \\ & 313 \\ & \text { stcllifera, anterior maxillæ, } 312\end{array}$

Cypris, 290

stclliferu, anterior maxillæ, 312

Cypris larva, 387, 386, 388

Cyrtopice larva, 389

Cysticercus, 171

,, cellulosa, 135, 172

Cystoflagcllata, 8

fasciolaris, 185

pisiformis, 135

Cystonecta, 70

Cythera, 290
C'ytherd viridis, anterior maxille, 312

Cytod, 2

DAYAIS, 463

archippus, anatomy, 488

Daphinia, 290

, pulex, antemnules, 308

,, similis, 289 ; anterior maxillæ,

Duphnide, $2 S 9$

312 ; trunk feet, 316

Dasybranchus, 181

Decapoda, 298

Decticus, 439

Delamination, 126

Dcmodicidac, 510

Dendrobcena, 181

Dendrocolum, 133

Dendrocometes, 11

Dendrometrida, 442

Dermaleichida, 510

Demaptera, 439

Dero, 181

Dcsor's larva, 275

Deutomerit, 9,16

Deutoplasm, 26

Diastylis, 297

,, stygia, 295 ; thoracic feet, 319 pleopoda, 324

Dictyastrum, 6

Jictyna, 510

Dicyemide, $5 S$

Dicyema, 59

Difflugia, 4

,, pyriformis, 3

Digenetic Trematoda, 134

Dimorphism, sexual (Vermes), 265; (Crustacea), 376 ; (Antennata), 490

Dinoflagellata, 8

Dinophilus, 185

$$
\begin{array}{ll}
,, & \text { apatris, } 265 \\
,, & \text { gyrociliatus, } 246 \\
,, & \text { vorticoides, } 265
\end{array}
$$

Jiopatra, 1S?

Diphyes, 7o

Liplopoda, 4.38

Diplo:oon, 134

Jipneumones, 510

Jiptera, 443; mouth parts, 450

Discalia, 70

Discocclis, 120

Discodrilide, 181 ; segmentation of egg, 125

Discogastrula, 128

Discomedusa, $\approx \mathcal{O}$

Disconantha, 70

Iisconecta, 70

Discophora, 180

Discoplanula, 128

Distoma, 134

,, divergens, water-vascular system, 153

hematobium, 154

heoaticum 134; life-history 169 
Distome isostomum, 134; intestinal and nervous system, 143

,, lanccolatum, 134 ; sexual organs, 158

Dochmius duodenalis, 180

Dorippe, 290

Doropygus porcicauda, trunk feet, 316

Dorsobranchiata, 1S.

Doyeria simplcx, head, 544

Drassus, 510

Drepanophorus, $1 \% \mathrm{~S}$ ,, Lankasterii, nervous sys-

Dromia, 299 tem, 216

Dwarf males (Cirripedia), 305 ; (Crustacea generally), 377

Dysderide, 510

Dysmorphosa carnca, $6 S$

Dytiscicle, 442

Dytiscus, section through ocellus, $\mathbf{4 7 0}$

Earthworm, see Lumbricus

Ecurdines, 185

Ecdysis, 458

Echinococcus, 172

Echinodera, 186

$$
\text { veterinorum, } 135
$$

Echinoderm, 119

Echinorhynchus, 180 ; genital orgaus, 257 ; organisation, 258

Echiurido, 182 gigas, 180

Echiurus, enteric canal, vascular system, and nephridia, 207; nervous system, 223

Ectoparasitica, 134

Ectoplasm, 13

Ectoprocta, 184

Ectosare, 13

Edriophthalmata, 293

Edwardsia, 71

Eggs, animal, 25; partlogenetic, 32 ; segmentation, 121-131; summer (Crustacea), 376,382 ; types of, 27-32 ; winter (Crustacea), 376, 382

Elaterida, 442

Elytra (Vermes), 189 ; (Antennata), 441

Embida, 439

Embole, 123

Empida, 443

Empis stercored, nervous system, 466

Enchytraidce, 181

Encystation, 16

Endite, 315

Endomychider, 441

Endoparasitica, 134

Encloplasm, 13

Endopodite, 307

Endosarc, 13

Enoplida, $17 \mathcal{S}$

Entomostraca, $2 S S$

Entoniscus, 296

Entoprocta, 184
Epcira, 510

Ephemericte, 439 ; sexual organs, 485 ; Iarva, 483

Ephippigera, 463

Ephippium, 380

Ephyre, \%?

Epibole, 124

Epimerit, 9, 16

Epipodite, 315

Epistylis, 11

Equitide, 442

Erichthus Iarva, 393, 394

Eriphio, 300

Errantia, 18?

Erscea, ro, 113

Eschara, 184

Estheria, $2 S S$

Eucharis, 7?

Eucone eyes, 470

Eucope campanulata, 6S, 74, 102

Eucopepoda, 290

Eucopic australis, posterior maxillæ, 313

Eudendrium ramosum, 68

Eudorina, $\mathcal{S}$

Eudoxia, 70, 113

Eudrilus, 181

Euglena, $S$

Eulimnadia Agassizii, 21 antennx, 310

Eunice limosa, 188

tearana, $2 \mathrm{~d}$ anteumx, 310

Eunicida, 182

Eupagurus, 298

Euphausia pellucida, 2d antennæ, 310 ; anterior maxillæ, 312 ; nervous system, 346 ; pleopoda, 325

Euphausille, $29 S$; larval history, $3 \$ 9$; larvæ, 390

Euphrosyne, 182

Euplectella, 61

Euplotes, 9

Eupomatus uncinatus, egg segmentation, 123 ; Iarva, 269

Euprepiade, 442

Eurylepta, 133

Eurypteride, 415

Euscorpius, 509

$$
, \quad \text { italicus, eje, } \mathbf{5 2 1}
$$

Euspongia officinalis, $6 \Omega$

Eustrongylas gigas, 180

Evadne, 290

Evaniadce, 442

Exorgone, 18?

Exopodite, 307

Exotheca, 99

Exumbrella, 73

Exuvia, 458

Eye-spots (Cnidaria), 75, $97 ;$ (Protozoa), 18 ; $\mathrm{x}$-shaped (Crustacea), 352 ; (Pla. todes), 169

FABRICIA, 234

Facet-ejes, 470

Falces, 515 
Fat-body (Crustacea), 370; (Antennata), 477

Filaria medinensis, $1 \% 9$

Filariule, 178

Filistata testacea Latr., pedipalp, 535

Finn, 135, 166, 171, 172

"Fish trap" apparatus (Pantopoda), 422 ; (Antennata), 451

Flabellum, ${ }_{1}$

Flagellate, 7

Flame-cell, 152

Floscularia, 185

Flustra, 184

Forficula auricularia, sexual organs, 485

Forficulide, 439

Formicide, 442

Forskalice, ro

Fossoria, 442

Fredericella, 184

Fricia, 9

Fulyore, 441

Fungia, ry 1

Fingicolae, 443

Funiculus, 215

Furcilia larva, 389

GALATEID.E, 299

Guleodes, 509

, barbarus, sexual organs, 533, 534

, Lastaguei, 511

, nigripalpis, sexual organs, 534

Galleria, 463

Gallicolee, 443

Gamasida, 510

Gamasus, nerrous system, 520 ; digestive apparatus, $\mathbf{5 2 4}$

, crassipes, sexual organs, 533, 534 fucorum, larva, 514; heart, 527

Gametes, 20

Gammarus, 296

Gasterostomum, 162

Gastræa theory, 56

Gestroidce, 58-60

Gastroblasta Raffoclii, $6 S$

Gastroliths, 337

Gastrophysema, $5 \mathcal{S}$

Gastrotricha, 186

Gastrula, 37, 57, 118

Gastrulation, 120-131

Gebia, 298

Gecarcinus, 300

Gemmulx, 65

Geacores, 440

Gcolesmus, 133

Geodia, 61

Gcometrina, 443

Geonemertes palaensis, 199

Geophilide, 438

Gephyrea, 190

Gercrdia, 71 ; horn skeleton of, 99, 100

Germaria, 25, 155

Germinal disc, 128 ; spot, 26 ; resicle, 25

Geryonia, segmentation of egg, 126
Geryonin proboscidulis, 69

Giant nerve tulues (Crustacea), 351 ; Termes), $2 \cdot 22$

Gibbocellum, 509

,, Sudcticum, 529

Gigantostrace, $415,410^{\circ}$

Glands, 40

, anal (Protr.), 431

,2 antennal (Crust.), 36s, 369

, cement (Antem.), 48T; (Crust.), 369 ; (Pantop.), 424

,, coxal (Arach.), 52:; (Protr.), 432 ; (Xipl. ), 420

granular, 160

green (Decapoda), $36 \mathrm{~s}$

look (Caprella), 331

,, Krohn's (Arach.), 522

, $\quad \operatorname{leg}$ (Antemn.), 459 ; (C'rust.), 330 ; (Protr.), 432

Morren's (Oligochrta), 200

oil (Arach.), 522

pertipalp (Arach.), 522

, pharyngeal (Oligochæta), 202

,, poison (Antemn.), 459 ; (Araneidre), 522 ; (Temes), 199

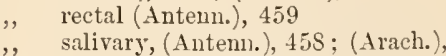
525 ; (Crust.), 336 ; (Platoles), 140 ; (Protr.), 429; (Termes), 202

,, septal (Oligochrta), 202

,, sliell (Crust.), 368, 369; (Plat. odes), $15 \mathrm{~s}$

,, slime (Antenn.), 48T; (Protr.), 432

, spinning (Antemn.), 45S ; (Araneicle), 522 ; (Termes), 192

stigmatic (Arach.), 522

, stink (Antem.), 459; (Aracl..), 522

, ventral (Crust.), 330

, wax (Antem.), 459

Globigerina, 4

Glomeride, 438

Glomeris maryinata, sexual organs, 486

Glyceride, 18:

Glyptonotus, 348

Guathobdcllider, 181

Gnathochilarium, 447

Guathophausia, 349

Ginathostomata, 311

Gonades, 102

Gonangia, 68

Gonochorism, 24

Gonophore, 105, 106. 111

Conyleptus, 509

Gordiide, 180

Gordius, 256

, aquaticus, 150

,, Prestii, 236

Gorgonia, ro

Grafilla, 1.34

Grapsus, 300 
Gregarina, $S$

Gromia, 4

,, ovifomis, $\mathbf{5}$

Griyllidce, 439

Gryllotalpa, 439

Gunda seymentata, 133

tryge, 296

(rynacophorus hamatobius, 134

Gyrator, 157

Gyrodactylus, 134

II.ENATOPINUS, .440

IIcemopis aulastomum, 181

Halcearidee, 510

Halesus, 441

Halichondrina, 61

Haliphysema, $5 \mathcal{S}$

Haliscara, 61

Halistemma, 70

lobularis, section, 65

II Illa, 1SP

IIulobutes, 440

Halocypris, 290

Halycryptus, 183

Halteres, 473

Haplosyllis, 1S2

Harpes, 415

$$
\text { spongicola, } 266
$$

Heliconiida, 442

Heliozoa, 6

Hemerobius, 441

Hemiaspida, 416

Hemimetabole, 491

Hemiptcra, 440; mouth parts, 451

Henicops, 438

Hermaphroditism, 24

Hermellicia, 18?

protandrous, 65

Hermione, 189

IIesionida, 182

Hesperida, 442

Heterogeny, 171

Heteromera, 441

Heteroptera, 440

Heterotricha, 9

Hexacorallia, $\approx 1$

Hexactinellider, 61

Hexapoda, 438

Himantarium, 438

Hippidee, 299

Hippolyte, 357

Hippopodius, $\% 0$

IIirudinea, 180 ; eye, 232 ; section, 249

II irudo medicinalis, 181 ; genital organs,

258 ; intestinal canal, 206 ; nerrous system, 218, 219, 220

II istriobclella, 181

Holometabole, 491

Holopneustic tracheal system, 480

Holotrichu, 9

Homarus, 238

Homoptera, 441

Honey-bee, see Apis
Honey-stomach, 461

Hoplonemertina, $17 S$

Hormiphera, 72

,, plumosa, 79

Hornera, 184

Hyalonema, 61

Hyaloplasm, 26, 49

Hyalosphenia, 4

," lata, 3

Hydatina, 185

,, senta, 245

IIydra, 67; neuromuscular cells, 46

Hydrachnide, 510

Hydride, 67

Hydracorallia, 67

Hydrocores, 440

Hyclrodoma, 510

Hydromedusce, 67

Hydrometra, 440

Hydrophitida, $44 ?$

Hydrophilus, embryos, 455 ; development, $494,495,497,498$

Hydropolyp, $6 G$; diagram, $\mathbf{7 3}$

Hydropsyche, 441

Hydrozoa, 66

Hydrula, 66

Hymenocaris, 293

Hymenoptera, 422 ; mouth parts of larva, 449

Hyperina, 296

Hypotricha, 9

IAPIX, 439

Ibla, .99?

Ichneumonida, 442

Ichthydium, 186

Idotheide, 295

Ilia, 299

Imago, 490

Imperforata, 4

Inachus, 299

Infusoria, 9

Ingluvies, 461

Insecta, 438

Interarticular (intersegmental) membranes, 300

Interradia, 74

Interseptal spaces, 88

Intima, 336

Intraseptal spaces, 88

Iolanthe acanthronotus, $2 \mathrm{~d}$ antennæ, 310

Isis, 70

Isopoda, 294; circulatory system, 360

Isospore, 20

Isopteryx apicalis, chordotonal organ, $\mathbf{4 7 3}$

Isotoma, 439

Iulida, 439

Iulus Sabulosus, sensory organs, 474

Ixodidae, 510

KARYOKINESIS, 35

Fientiogonidce, 292

Kentrogon larva 387, 386 
Kiphobetemnon, ro

$$
\text { ," Lcuckurtii, } 71
$$

LABIDURA, 439

Lacenularia, 185

Lacinia, externa, 312, 313 ; interna, 312 , 313

Lambrus, 299

Lemellicornia, 44 ?

Lämodipoda, 236

Langia, 17s

Lanice, $18 ?$

$$
\text { ,, conchilega, } 241
$$

Latomedia Caliculata, 68

Laterigrada, 510

Laurer's canal, 159

Lecanium, 440

Ledra, 441

Leiobunum, 509

Lemnisci, 248

Leiosoma, 510

Lepadide, 292 ; organisation, 303

Lepas antifcra, 303

$$
\text { ,, fasciculata, Cypris-like larva, }
$$
388

Lepidoptera, 44.

$$
\text { pectinata, pupa, } 388
$$

Lepisma, 439

Leptidee, 443

Leptochclia, 293

Leptodiscus, $\mathcal{S}$

Leptodora, 290

Leptomedusa, 68

Leptoplana, 133 ; sexual organs, 156

Leptostraca, 292 ; pleopoda, 324

Lermcea, 291

" branchialis, posterior maxillæ, 313

Lernceascus, 291

Lernceocera, 291

$$
\text { , nematoxys, } \mathbf{3 7 7}
$$

,, $\quad \operatorname{csocin} a, 380$

Lernceopodide, 316

Lernanthropus, 291; genital organs, 372

Leucandra, 60

Leucocytes, 500

Lerecones, 63

Libellulide, 439

Lichas, 415

Ligula, 134

Limnadia, 2SS ; nervons system, 346

Limneeus truncatulus, 169

Limnobiidce, 443

Limnocythere incisa, posterior maxillæ, 313 ; trunk feet, 316

Limnodrilus, 181

Limnophitus, 441

Limulidae, 421; section of eye, 419

Limulus moluccanus, 421 ,, polyphemus, 421, 418 ; trilobite stage, 421 ; section, 419

Lineus, $17 \mathrm{~S}$

Linguatulide, 510
Lingula, 185 ; embryo, 273

Linyphia, 510

Liotheum, 440

Liparida, 442

Listrophorus, 510

Lithobiida, 438

Lithobius forficulatus, 464 validus, 447

Lithodes, 299

Lituola, 4

Livia, 440

Lizusa octocilia, 68

Lobate, 72

Locusta viridissima, tibia of fore leg, 473

Locustide, 439

Lopadorhynchus, 250

Lophogaster typicus, thoracic feet, 321

Lophogastride, 298

Lophophore, 183

Lophopus, 184; anterior body, 184

Loricato, 410

Loxosoma, 184

Lucemaria, 11

Lucifer, 298; mandibles, 311

Lumbricilce, 181

Lumbriculider, 181

Lumbricus, 181; embryo, 276 ; germ streaks, 278, 279 ; section, 250

Lycanida, 44 ?

Lycosidee, 510

Lygeres, 440

Lympl gills, 246

Lynceres, 290

Lysianassa, 296

,, producta, pleopoda, 324

,, umbo, vosterior maxillæ, 313

Lysopetalide, 438

Lysiopetalum carinatum, gnatlochilarium, 447

Lysiosquilla maculata, posterior maxillæ, 313

MACIILIS, 439

, maritima, nervous system, 465 ;

tracheal system, 481 ; ventral shield, 454

Macroblella, sensory organ, 232

Macrobiotus Hufclandii, hinder body, 545 ; outline, 544

Macrolepidoptera, month parts, 448

Macromeres, 122-131

Macronucleus, 9, $1 \mathrm{~S}$

Hacrorhynchus, 134

Macrospores, 20 croccus, proboscis, 151

Macrostoma, 134

I Iacrotoma, 439

Macrura, 298

Halreporaria, 71 ; diagram of strncture, 98 
Mandrina, $\sim 1$

Magosphera, 11 ; planula, 11

Muja, .299; Zocea of, 396

, squinado, nervous system, 346

Mala interna and exterua, $446^{\circ}$

Malacobdellina, 178

Mulacodermatu, 442

Malacostraca, 292; pleopopa, 324

Nallophage, 440

Malpighian vessels, 460, 462 ; (Arachn.), 525 ; (Tardigr.), 545

Mantide, 439

Mantispa, 4.41

Margelis ramosa, 6S, 67

Marginal lobes, 71,92 ; vesicles, 75

Mastigophora, 7

Mastobrenchus, 253

Mecostethus, 439

Meduse, 67, ry

Megalopa, larva, 396

Megaloptera, 441

Melicerta, 185

Meloida, 441

Melolontha valgaris, sexual organs, 486

Melophargus, 443 ,, ovimus, sexual organs, 486

Mermecophila, 439

Mermis nigrcscens, 179

Mermithide, $1 \% 3$

Merocytes, 126

Merostoma, 415

Mesenterial filaments, 75,83

Mesostoma, 134; intestinal and nervous system, 142 ; pharyngeal apparatus, 139

," Ehrenbergii, sexual organs, 158

Mesothorax, 441

Meta, 510

Metagenesis, 115

Mctonauplius larva, 389

Metapneustic tracheal system, 482

Netathorax, 444

Metazoa, 4; divisions of, 57

Microlepidoptera, 443

Micromeres, 122-131

Micrommata, 510

Microuncleus, 9, 18

Wieropteryx, 44:

Micropyle, 28

Microspores, 20

Hierostoma, 13 ' , lincare, 166

Mierothelyphonide, 509

Miliola, 4, 5

Millepora, 67

Miris, 440

Misicle, 237

IVitrocoma, 94

Woine, 290

Monas, $S$

, rectirostris, ontogeny, 397

Monera, 2, 4
Moniligaster, 181

Honocystidu, 9

Monogenetic Trematoda, 134

Monostomum, 134

Monothalamia, 16

Monotus, 134

Ionozod, 134

Miiller's larva, 168

Munnopsis typica, antennules, 308

Muscidu, 443; development, 500, 501

Mygale, 510 ; auatomy, 531

, comentaria, digestive apparatus, 524

Myoblasts, 49

Myophrises, 15

Myrianide, 182

Myriapoda, 438

Wyrmeleon, 441

Myside, 237 ; antennal gland, 369

Mysis flexuosa, thoracic feet, 321

,, relicta, 349

, larva, 29S, 392

Mysodopsis, 365

Nystacides, 441

Myxicala, 1S?

Myxilla, 61

Ifyxodiction, 4

Myxopodia, 14

Myzostoma, nervous system, 224 ; section, 263

Myzostomide, 182

cirriferum, organisation, 262

NAIINA, 131

Niidomorpha, 181

Tais, 181

,, barbata, 267

Varcomeduswe, 69

Tassella, 7

Nassellaria, 7

Nancoris, 440

Nauplius, 307, 386, 390

Nausithoё, 7尺, 77 ; sensory bodies, 96. 116

Nebalia, 293 ; antemules, 308 ; mandibles, 311 ; olfactory tubes, 356 ; pleopoda, 324; thoracic foot, 317

," Geoffroyi, 293

Nebalide, 293

Icbaliopsis, 29?

Nectophore, 110,112

Nemathelmia, $17 \mathrm{~S}$

Nematocysts, 39, 81

Nematodu, $17 S$; diagram of nerrous system, 218

Temertes, $17 \mathrm{~S}$

Yemertina, 17S; anterior end of body, 217 ; diagram of proboscis, 198 ; iutestiual canal and genital organs, 205 ; larva, 274; nepliridial and circulatory system, 235 ; section through body, 192 Nemocera, 443 
Nemura, 440

Nepa, 4.40

Nephelis, 181; vascular system, 249

Nephridia, 235; as ducts for sexual products, 243 ; excretory organs, 243 ; permanent, 239; phylogenetic origin of, 247 ; provisional or embryonic, 23i, 238

Nephroblasts, 279

Nephrops, 298

Nephthys, 1S? "scolopendroides, 251; section, 252

Noreide, $18 \Omega$

Nereis cultrifera, 239

Nerocila, 295

Neural plate, 167

Neurilemma, 52

Neuroblasts, 278

Neurochord (Vermes), 222 ; (Crustacea), 351

Neuroptera, 4'41

Nicoletia, 439

Noctiluca, 8 ", miliaris, 9

Noctuiformes, 443

Noctuina, 44?

Non-Calcarea, 60

Notodelphys, 291; trunk feet, 316 ," agilis, anterior maxillæ, 312 ,, Almannii, mandibles, 311

Notodontidae, 442

Notomastus, 181

Notommata, 185

Votonecta, 440

Notopoda, 993

Notopygos, 18\%

Nucleus, 1

Nieda, re

Nycteribia, 443

Nymphalide, $44^{2}$

Nymphon, 424 ," hispidum, 423

OBELLA gcnjculata, $6 S$

Obisinem, 509

Ocellata, 97

$$
\text { silvaticum, heart, } \mathbf{5 2 7}
$$

Ocelli, 469

Ocneria, mouth parts, 448

Octocorallia, 70

Ocypoda, 300

Odonata, 439

Odontoblasts, 45

Ecanthres, 454

Edemerida, 441

Edipoda, 439; sexual organs, 485

Estridce, 443

Olenus, 415

Oligocheta, 181 ; nephridia, 240

Oligocledus, 146

Olindias Mülleri, 69

Olynthus, 60, 62
Ommatidium, 353, 471

Ocecia, 264

Ootype, 159

Oniscide, 295

Onychophora, 4:37

Operculum, 417

Opheliacee, 181

Ophivside, 442

Ophryelium, 11

opisthotrema, 162

Orbitelarice, 510

Orchestic, 2916

$$
\text { , caimana, } 294
$$

Oribatide, 510

Orthe:ia, 463

Orthonectille, 58

Orthopteru, 439 ; sexual organs of larva 485

Oscurella, 61

Osculosa, 7

$$
\text { lobularis, section, } 65
$$

Osteoblasts, 45

Ostia, 358

Ostracoda, 930

Oxycephalus, 236

Oxyrhynche, 293

Oxystomata, 299

Oxytricha, 9

Oxyuris vermicularis, 180

PACHYDRILCS, 181

Pædogenesis, 502

I'cryuride, 298

I'alemon, 298

,, Squilla, eyes, 354

Palaonemertina, $1 \% S$

Palingenia, 439

Palingenesis, 118

Palinuride, 298

Palinurus, 298

Pallene, 424

Phyllosoma of, 395

Palpons, 112

Paludicella, 184

Pandorina, 8

Panorpate, 441

Pentopoda, 422-425

Paradesmes gracilis, 459

Puradoxides, 415

Paragnatha, 315

Paramecium, 9

Paranébalia, 293 aurelia, 17

$$
\begin{aligned}
& \text { " longipes, anterior maxillæ, } \\
& \quad 312 \text {; posterior maxillæ, } \\
& 313
\end{aligned}
$$

Parapodia, 188

Parasitism, 172

Parthenogenesis (Vermes), 266 ; (Insecta), 501,502

Parthenogonidia, 21

Pauropoda, 438

Pedicellina, 1S4; larva, 271 
Pcliculide, 440

Pedipalpi, 509

Pedipalps (Arachn.), 515

Pedunculata, 292

Pegantha, 69

Pelagia noctiluca, 72

Peltogaster, 292

Penceus, 298 ; posterior maxillæ of larva,

313 ; older larvæ, 392

Penella, 291

Pennatula, ro

Pentamera, 441

Pentestomido, 510

Pentastomum, 510

,, clenticulatum, 511

, $\quad$ twnioides, 510 ; nervous sys-

tem, 520 ; sexual organs,

533, 534, 537

Pentatoma, 440 ; mouth parts, 451

Perforata, 4

Perichata, 181

Pericolpa, 7\%

$$
\text { mirabilis, } 240
$$

Peridininem, 8

Peripatus, 437

", capensis, 437 ; anatomy, $\mathbf{4 3 0}$; anterior body, 429

", Edwardsii, 437; embryo, 435 ; head, 427 ; nephridia, 431; section of segment, 428 ; sexual organs, 436

, Leuckartii, 437

," Nove Zecilandice, 437, 427

Periphylla, 7\%

Periplanata, 439

Peripneustic tracheal system, 482

Peritricha, 11

Perlaria, 440

Peromeduse, $7_{1}$

Peronia, 69

Perradii, 74

Phacelli, 78, 85

Phacops, 415

Phwodaria, 7

Phæodium, 7

Phagocytes, 500

Phalangide, 509 ; heart, 527

Phalangium opitio, sexual organs, 533, 534

Phalansterium, $s$

Phascolion, 244

Phascolosoma, 183

Phasmide, 439

Phialidium variabile, 68

Philodromus, 510

Philoica domestica, sexual organs, 534

Philopterns, 440

Pholcus, 510

,, phalangoides, heart, $\mathbf{5 2 7}$

Phoronide, 183

Phoronis, 183; larva, 272

Phoxichitidium, 424

Phractaspis, 6

,, prototypus, 6
Phreatothrix, 240

Phrcoryctide, 181

Phronima, 296

Phryganea, 441

P'hrynus, 509

Phthivius, 440

Phylactolcemata, 184

Phyllacanthidee, water-vascular system, 153

Phyllium, 439

Phyllobothrinem, 134

Phyllobranchix, 328

Phyllodocida, 182

Phyllopoda, 288

Phyllosoma larva, 395

Phylloxera, 440

Physalia, 70

Physemaria, 58

Physonecta, 70

Physophora, $\% 0$

Physopoda, 440

Phytometridee, 442

Phytophthires, 440

Phytoptide, 510

Pilema, $\gamma_{2}$

Pitidium larva, 274, 275

Pilumnus, 300

Pinnoteres, 300

Pisa, 299

Piscicola, 240

Plagiostoma, 134

Plakina, 61

Planaria, 133 ; ovary, 29

Planocera, 133 ; pharynx, 139 ; intestinal and nervous system, 141

Planula, 129, 130

Platodes, 133-172

Platycleis, 439

Platyscelus, 296

Plecoptera, 440

Pleon, 301

Pleopoda, 315, 322

Pleura, 414

Pleurobranchiæ, 328, 327

Plenrochata, 181

Plumatella, 184

Plumnlarie, 68 repens, 208

Plusiada, 44 ?

Pneumatophore, 70, 108

Podobranchix, 328, 327

Podoconus, 7

Podocoryne curnea, GS

Podophrya, 11 ,, gemmipara, 11

Podophthalmata, 296

Podura, 439

Pocilopoda, 417

Polar bodies, 31

Polia, 178

Pollicipes, 292

Polychata, 181

Polycladide, 133

Polycystida, 9 
Polycyttaria, $G$

Polydesmider, 4 is

Polydesmus complanatus, anterior body; 452 ; larva, 503

Polygoutius, 181

Polymuia, 182

Polymorphism (Insecta), 490

Polynce, 182

Polyophthatmus, 181

Polyphemus, 990

Polystomum, 134

Polythalamia, 16

Polyxenide, 438

Polyzoa, 134

Polyzonide, 438

Pontobdella, 181

Pontonia, 29S

Porcellanidu, 999

Porcellio, 295

Porifera, 60-66

Porpalia, 70

Porpita, \%o

Portunus, 300, 378

, monadis, embryo, 379

,Wegulopa, larva, 396

Pranizida, 295

Praya, 70

, galea, 111, 113

Priapulidee, 183

Probosciclca, 139, 157

Proctodæum, 269

Proetus, 415

Proglottides, 164

Promesostoma, 157

Pronucleus, 32

Prorhynchus, 134

Prosopygia, 182

Prosthiostomum, 133 ; pharyngeal apparatus, 139

Protamceba, 4

Protella, 996

Proteolepadida, 292

Prothorax, 444

Protista, 4

Proto, 206

Protodrilus, 181

Protomerit, 9, 16

Protomyza, 4

Protoplasm, 1

Protopodite, 307

Protosponsia, 8

Protozoa, 4-23 II cueckelii, 8

Protozoce larva, 390, 391, 392

Protracheata, 427-437

Protula, 182

Provortex, 157

Proxenctes, 156

Pscimmoryctes, 181

Pselaphida, 44?

Pseudocalanus clongatus, $2 \mathrm{~d}$ antennæ, 310

Pseudocerida, 150
Pseudoneuroptera, $44^{3}$

Psendophana, 441

Pseudopodia, 4, 14

Pseudoscorpionider, 509

Psocida, 440

Psychide, 443

Psygmobicinchus, 280

Psyltide, 440

Psyllopsis fraxinicola, enteric canal, $\$ 63$

Pterobuanchia, 183

Pteromalido, 443

Pterophovide, 442

Pteryyota, 439

Ptcrygotus, 416

osiliensis, 416

Pupipara, 443

Pycnogonida, 4:2

Pygidium, 414

Pyralida, 443

Pyrrhocoris, 440 ; mouth parts, 451

QLADRLLA, 4

,, symmetrica, 3

RADIOLARIA, 6

Ranatre, 440

Raphilia, 441

Rathke's organ, 342

Reclia, 169

Reduriis, 440

Reniera, 61

Reticulım, 151

Retinacula, 200

Retinophora, 471

Retitelavia, 510

Rhabdites, 135

Rhabdit is nigrovenosa, 1is

Rhabdocolidw, 133

Rhabdom, 354

Rhablomere, 470

Rhabdopleuta, 184

Rhachis, 414

Rhipiphórida, 441

Rhizocephalu, 292

Rhisophysa, ro

Rhizopoda, 4

Rhizostome, *2

Rhodatia, $\%$

Rhopalia, 71, 95, 96

Rhopalocera, 44:

Rhopaloncma velatum, 69 ; tentacles, 95

Rhopalura, $5 \mathrm{~S}$

,, Giardii, 59

Rhynchelmis, 181

Rhynchobulelicler, $1 S 1$

Rihymchocola, 17s

Rhynchodeum, 197

Rhynchonclla, 185

Rhynchoter, 440 pittucer, 191

Rhynchothorcex, 421

Rotatice, 4 
Rotalia Ficyeri, 5

Rotatoria, 185

Rotifer $\ell$, diagram, 185

Rugosa, 70

SABELLA, 1S?

Subellaria, 189

,, alvcolata, nervous and nephridial system, 221

Saccocirrus, 181

Sacculina, 29,2

, carcini, 305 ; development, 386; section, $\mathbf{3 7 3}$; larval stages, $\mathbf{3 8 6}$

, extcrne, 387

, interno, 387

Sagitta, 185 ; development, 281 ; section, 197

, bipunctata, head of, $\mathbf{2 2 7}$

, heicutera, 227 ; eye, 231

Salpingoeca, $S$

Sultutoria, 439

Sulticus, 510

Saltigrada, 510

Sao, 415

Supphirina, 291

,, Edwardsii, nervous system,

Sarcodictyum, 15

Sarcodima, 4

Sarcolenma, 4\$

Sarcomatrix, 15

Sareophaga camaria, nervous system, 466

Sarcopsylla, 441

Sarcoptide, 510

Sarcosepta, 99

Sarsia siphonophora, 110

," tululosa, $6 S$

Satumida, 442

Satyridce, 442

Stculpellum, 992

Schistoccphalus, 134

Schizonemertina, 178

Schizoncura, 440

Schizopoda, $29 \%$; thoracic feet, 321 ; larva, 392

Schultzia, 156

Scolex, 138, 164

Scolopendrclla, 438 ; heart, 476

Scolopendride, 438

immaculata, 444 ; posterior body, 453

Scolopophore, 471

Scorpio, embryo, 538; nervous system, 519; digestive tract, 524: heart, $\mathbf{5 2 7}$

Africenus, $\mathbf{5 1 2}$

, accitanus, sexual organs, 533, 534

Scorpionidee, 509

Scuta, 304

Scutigerc coleoptera, trachæ, $\mathbf{4 7 9}$

Scutigeride, 438
Scyllarıs, 29S ; development, 395

Scyphistoma, $\% 2$

Scyphomed ust, 71

Scyphopolyp or Scyphulu, ro; development, 130

Scyphozod, ro

Sedenturia, 18?

Scgestria, 510

Segmental organs, sce Nephridia

Segmentation, 120-129; nucleus, 33

Seison, 185

Semostome, r?

Sensory body of Ctenophora, 79, 96

sergestes, 998

Serictery, 458

Serpulida, 18?

Sertulariu, $6 S$

Sesiada, 442

Sialicle, 441

Sicla, 290

Silphide, 442

Siphonantha, ro, 108-114, 109

Siphonaptera, 441

Siphonophora, 69

Siphonostoma, 182

Sipunculacer, 183

Sipunculide, 183

Sipunculus, 183 ; anatomy, 208 ; diagram of muscles, 195 ; larva, 270

Siriella, 897 ,, gracilis, pleopoda, 324

Sitaris, 492

Thompsonii, pleopoda, 324

Sklerosepta, 99

Sminthurus, 439

Solcnopharynx, 157

Solmaris, 69

Solpugide, 509

Spadella, 185

Sphceromide, 295

Spharozoum, 6

Spharerula bombi, 179

Sphingina, 442

Spicules, 64

Spiculispongice, 61

Spionide, 1S2

Spirifer, 185

Spirographis, 1S2

Spirostomum, 9

Spongetia, 62

Spongilla, 61

Spongin, 63

Spongioplasm, 26, 49

Sporocysts, 169

Spumellaria, 6

Squame, 309

Squilla, 295, 296 ; thoracic feet of larva, 320 ; circulatory system of larva, 363 mantis, genital organs, $\mathbf{3 7 5}$

Staphylinide, 442

Statoblasts, 264

Stauridium cladonema, 68 
Stauromedusa, 71

Stcnobothras, 439

Stenorhynchus, 299

Stcnostoma, 134; water-vascular system, 153

Stentor, 9

, Roeselii, 10

Stcphalia, 70

$$
\text { , corona, } 110
$$

Stcphanoceros, 185

Stephanosphira, 8

Sternaspida, 182

Sterrogastrula, 124

Sterroplaunla, 127

Stichocotyle, 143

Stigmata (Protozoa), 18 ; (Antennata), $426-478$

Stomatopoda, 297 ; larvæ, 393, 394

Stomodæum, 167, 269

Stratiomyido, 443

Strepsiptera, 490

Strobila, Monolisc, 107 ; Polydisc, 107

Strobilation, 116

Strombidinm, 11

Stylaria, 181

Stylaster, 67y

Stylochoplana, 162

Stylochns, 162

Stylodritus, 181

Stylonichia, 9 ,, mytilus, 10

Stylorhynchus, 9

Stylostomum, 133 longicollis, 9

Sinberites, 61

Subradii, 74

Subumbrella, 73

Suctoria, 11

Sycandra, 60

$$
\text { , } \quad \text { ciliata, } 63
$$

Sycones, 62, 66

Syllide, 182

Syllis, 189

," ramosa, 267

Sympathetic nervous system (Antenn.), 468; (Arachr.), 520; (Crust.), 350 ; Protrach.), 430 ; (Vermes), 220

Symphyla, 438

Syncoryne Sarsii, $6 S$

Syncytia, 41

Syrphidee, 443

TABANID.E, 443

Tabanns, mouth parts, 450

Tenia, 134 bovinus, nervous system, 466

, conurus, 135

, erassicollis, 135

, cucumerina, 135

, Echinococcus, 135

, saginata, 134; proglottis, 159 ; (mediocanellata) sexual organs, 159 scolices, 164

VOL. I
Tenia serrata, 135 ; nervous system of scolex, 147

,, solium, 135 ; proglottis, 159 ; scolex, 164; Finn 172

Tænioles, 75, 78

Talitrus, 296'

Tanais, 293

Tarantula, 510

Tardigrada, 544, 545

Tartaride 509

Tegenaria, 510

Telphnsa, 299

Telson, 322

Tenebrionida, 441

Tentuculata, ry2

Tentaculocyst, 69, 95

Tenthredinide, 443

Tenthredo, mouth parts of larva, 449

Terebcllidw, $18 ?$

Terebrantia, 442

Tercbratula, 185

", vitrea, 226

Terga, 304

Termitida, 440

Tesser $\alpha, 71$

Testicardines, 185

Tethya, 61

Tctracorallia, 70

Tetranychida, 510

Tetraphyllide, 162

Tetrapneumones, 510

Tetrarhynchus, 134

Tetrastemma. 178

Tettigonia, 441

Tettix, 439

Thalassema, 182

Thalassicolla, 6

Thalassoplancta, 6

Thamnotrizon, 439

brevispicula, 6

Theca, 68, 99

Thecidium, 185

Thelyphonida, 509

Thelyphonus caudatus, nervous system, 519

Therevide, 443

Theridium, 510

Thoracostraca, 296

Thrips, 440

Thysanoessa gregaria, thoracic feet, 321

Thysanopoda, 298

Thysanoptera, 440

Thysanozoon, 133

Thysanura, 439

Tineido, 443

Tintinnus, 11

Tipnlaria, 443

Tomopterida, 18?

Tortricida, 442

Tracheæ, 477 ; structure, 478

$$
\text { ,, book-leaf, } 530
$$

, tubular, 529

Tracheal gills, 457, 482, 483 
Tracheal lungs, 530

Tracheata, $2 S \%$

Trachelius, 9

Trachomedusu, 69

Travisia, 181

Trebius candatus, $2 \mathrm{~d}$ antenmæ, 310

Trematoda, 134

Tricenophorus, 134

Trichina spiralis, 179, 179

Trichobranchiæ, 328

Trichocephalus disper, 179

Trichocyst, 13, 17

Trichodactylus anonymus, sexual organs, 533

Trichodectes, 440

Trichodina, 11

Trichoplax alherens, $5 S, 60$

Trichoptera, 441

Trichotrachelida, 179

Triclalide, 133; intestinal and nervous systems, 142 ; sexual organs, 156

Trigonoporus, 133

Trilobita, 414, 415 ; restored trunk segment, 414

Trinucleus, 415

Tristomum, 134

Trochosu singoriensis, 516

Troctes, 440

Trombidiide, 510

Trombidium fuliginosum, sexual organs, 533

Tuberella, 61

Tubicinella, 992

Tubificider, 181

Tubipora, 70

Tubitelaria, 510

Tubularia larynx, 68

Turbellaria, 133 ; pharyngeal apparatus, 139 ; excretory cell, 152

Tylenchus scundens, 178

Tympanal organ, 473

Typhlosolis, 206

Tyroglyphide, 510

UROCERIDA, 442

Urochata, 181
Uropoda, 510 ; sexual organs, 534

Uropoda, 389

Urospora, 9

Urostyla, 9

Uterus bell, 257

VACUOLEs, contractile, 17 ; noncontractile, 14

Velarium, 92

T'elella, \%o, 114

Velum, 75, 90

Termes, $177-286$

Versutrida, 101

I'esiculata, 94

Vespide, 44,

Vibracularia, 267

Vitellaria, 26, 155

Volvox, $s$

,, globatur, 21

Tortex, 134

Vorticella, 11

,, microstoma, 10

Vorticeros, 134

W ALDIEIMIA, 185 , flavescens, 196

Water-vascular system, 136

TANтHO, 300

Testoleberis aurantia, mandibles, 311

Tiphosura, 417-421

Iylophaga, 442

Tylophayide, 443

Iysticus, 510

YUNGIA, 183

ZILLA, 510

Zocea larva, 298, 391, 392, 396

Zoanthus, 71

Zoophyta, 58-132

Zona radiata, 28

Zyganide, 440

Zygote, 20

THE END 


\section{MESSRS. MACMILLAN AND C0.'S WORKS FOR BIOLOGICAL STUDENTS.}

By the late Professor F. M. Balfour, F.R.S.

A TREATISE ON COMPARATIVE EMBRYOLOGY. By F. II. BALFour, F.R.S., Fellow and Lecturer of Trinity College, Cambridge. Illustrated. $2 \mathrm{~d}$ Ed., reprinted withont alteration from the 1st Ed. 2 vols. 8vo. Vol. I. 18s. Vol II. 21s.

By Dr. G. H. T. EIMER AND J. T. CUNNINGHAM.

ORGANIC EVOLUTION AS THE RESULT OF THE INHERITANCE OF ACQUIRED CHARACTERS ACCORDING TO THE LAWS OF ORGANIC GRoWTH. By Dr. G. H. Theodor Ermer. Translated by J. T. Conningham, F.R.S.E., late Fellow of University College, Oxford. 8vo. 12s. 6d.

\section{- By W. FEARNLEY.}

A MANUAL OF ELEMENTARY PRACTICAL Histology. By Wildiha Fearnley. Illustrated. Cr. 8vo, $7 \mathrm{~s}$. 6d.

BY W. H. FLOWER., F.R.S. AND DR. HANS GADOW.

AN INTRODUCTION TO THE OSTEOLOGY OF THE MAMAIALIA. By W. H. FLower, F.R.S., Director of the Natural History Departments of the British Mnseum. Illustrated. 3d El. Revised with the assistance of Hans Gadow, Ph.D., Lecturer on the Advanced Morphology of Vertebrates in the University of Cambridge. Cr. 8vo. 10s. 6d.

BX MICHAEL FOSTER, M.D.

Professor of Pliysiology in the University of Cambridge.

PRIMER OF PHYSIOLOGY. Illustrated. $18 \mathrm{mo}$. Is.

A TEXT-BOOK OF PHYSIOLOGY. Illustrated. 6th Ed., largely revised. 8vo. Part I., comprising Book I. Blood-The Tissues of Movement, The Vascular Mechanism. 10s. 6d. Part II., comprising Book II. The Tissues of Chemical Action, with their respective Mechanisms-Nntrition. 10s.6d. Part III. The Central Nervous System. 7s, 6d. [Fort IF. in the Press.

By Professors michael Foster and F. M. BALFOUR.

THE Elements OF EMBRYologY. By Professor Michael Foster, M.D., and the late F. M. BALFour, F.R.S., Professor of Aninial Morphology in the University of Cambridge. 2d Ed., revised. Edited by A. SEDGwick, M. A., Fellow and Assistant Lectnrer of Trinity College, Cambridge, and W. HeAPE, M.A. late Demonstrator in the Morphological Laboratory of the University of Cambridge. Illustrated. Cr. 8vo, 10s, 6d.

By Professor michaEl Foster and J. N. LANGLEY.

A COURSE OF ELEMENTARY PRACTICAL PHYSIOLOGY AND histologY. By Professor Michael Foster, M.D., and J. N. Langlex, F.R.S., Fellow of Trinity College, Cambridge. 6th Ed, Cr, 8vo. 7s. 6u.

$$
\text { BY A. GAMGEE, F.R.S. }
$$

A TEXT-BOOK OF THE PHYSIOLOGICAL CHEMISTRY OF THE ANIMAL BODY. Including an Acconnt of the Chemical changes occurring in Disease. By A. GAMGEE, M.D., F.R.S. Illustrated. 8vo. Vol. I. 18s.

By Professor G. B. HOWES.

AN ATLAS OF PRACTICAL ELEMENTARY BIOLOGY. By G. B. Howes, Assistant Professor of Zoology, Normal School of Science and Royal School of Mines. With a Preface by Professor T. H. Huxlex, F.R.S. 4to. 14s.

By Professors WIEDERSHEIM AND W. N. PARKER.

ELEMENTS OF THE COMPARATIVE ANATOMY OF VERTEBRATES. By Professor R. Wiedersheim. Adapted by W. Newton Parker, Professor of Biology in the University College of South Wales and Mommouthshire. With Additions. Illnstrated. 8vo. 12s. 6d. 


\section{MIESSRS. MACMILLAN AND CO.'S WORKS FOR BIOLOGICAL STUDENTS}

By Professor T. H. HUXLEY, F.R.S.

INTRODUCTORY PRIMER OF SCIENCE. 18mo. Is.

LESSONS IN ELEMENTARY PHYSIOLOGY. Illustrated. Feap. 8 vo. $4 \mathrm{~s} .6 \mathrm{~d}$.

QUESTIONS ON HUXLEY'S PHYSIOLOGY. By T. Alcock, M.D. 18 mo. 1s. $6 \mathrm{~d}$.

By Professors HUXley and MaRTin.

A · COURSE OF PRACTICAL INSTRUCTION IN ELEMENTARY BIOLOGY. By Professor T. H. Huxley, F.R.S., assisted by H. N. Martin, F.R.S., Professor of Biology in the Johns Hopkins University, U.S.A. New Ed., revised and extended by G. B. Howes and D. H. Scotr, Ph,D., Assistant Professors, Normal Selrool of Science and Royal School of Mines. With a Preface by T. H. Huxley, F.R.S. Cr. 8vo. 10s. 6d.

BY E. KLEIN, F.R.S.

Lecturer on General Anatomy and-Physiology in the Medical School of St. Bartholonew's Hospital, Professor of Bacteriology at the College of State Medicine, London.

MICRO-ORGANISMS AND DISEASE. An Introduction into the Study of Specific Micro-organisms. Illustrated. 3d Ed., revised. Cr. 8vo. 6s.

THE BACTERIA IN ASIATIC CHOLERA. Cr. 8vo. $5 \mathrm{~s}$.

BY E. PAY LANKESTER, F.R.S.

Linacre Professor of Human and Comparative Anatomy in the University of Oxford.

A TEXT-BOOK OF ZOOLOGY. 8vo.

[In preparation.

THE ADVANCEMENT OF SCIENCE. Occasional Essays and Addresses. 8 vo. 10s. $6 \mathrm{~d}$.

BY ST. GEORGE MIVART, F.R.S.

LESSONS IN ELEMENTARY ANATOMY. By St. George Mivart, F.R.S. Lecturer on Comparative Anatomy at St. Mary's Hospital, Illustrated. Fcap. 8vo. 6s. 6d.

BY T. JEFFERY PARKER, F.R.S.

Professor of Biology in the University of Otago, New Zealand.

A COURSE OF INSTRUCTION IN ZOOTOMY (VERTEBRATA). Illustrated. Cr. 8vo. 8s. 6 d.

LESSONS IN ELEMENTARY BIOLOGY. IHustrated. Cr. 8vo. 10s. 6d.

By Professor W. K. PARKER and G. T. BETTANy.

THE MORPHOLOGY OF THE SKULL. By Professor W. K. Parker, F.R.S., and G. T. Bettany. Illustrated. Cr. 8vo. 10s. $6 \mathrm{~d}$.

BY G. J. ROMANES, F.R.S.

THE SCIENTIFIC EVIDENCES OF ORGANIC EVOLUTION. By George J. Romanes, F.R.S., Zoological Secretary of the Limnean Society. Cr. Svo. 2s. $6 \mathrm{~d}$.

BY ADAM SEDGWICK, F.R.S.

A SUPPLEMENT TO F. M. BALFOUR'S TREATISE ON EMBRY. OLOGY. By AdAM SEDGwick, F.R.S., Fellow and Lecturer of Trinity College, Cambridge. Illustrated. 8 vo. [In preparation. BY R. W. SHUFELD'T.

THE MYOLOGY OF THE RAVEN (Corvus corax sinuatus). A guide to the Study of the Muscular System in Birds. By R. W. ShuFELDT. Illustrated. 8vo. 13s. net.

BY A. R. WALLACE, F.R.S.

DARWINISM : An Exposition of the Theory of Natural Selection, with some of its Applications. By Alfred Russel Wallace, LL.D., F.R.S. 3d. Ed. Cr. 8vo. 9s.

MACMILLAN AND CO., LONDON. 



